.. 
LIBRARY

UNIVEF: M OF

CALIF O OATA

SAN DHECO 
Stm bnoors:

$\times 67008$ 
Digitized by the Internet Archive in 2007 with funding from Microsoft Corporation 




\section{ENGLISH SYNONYMES}




\section{Books ON ENGLISH}

CRABB'S SYNONYMES (Centennial Edition)

A GUIDE TO GOOD ENGLISH

By Robert Palfrey Utter

EVERY-DAY WORDS AND THEIR USES

By Robert Palfrey Utter

STANDARD PRONUNCIATION IN ENGLISH

Thomas R. Lounsbury

ENGLISH SPELLING AND SPELLING REFORM

Thomas R. Lounsbury

THE STANDARD OF USAGE IN ENGLISH

Thomas R. Lounsbury

EVERYBODY'S WRITING-DESK BOOK

HARPER \& BROTHERS, NEW YORK

Eatablished 1817 


\section{CENTENNIAL EDITION}

\section{R A B B'S}

\section{ENGLISH SYNONYMES}

B Y

GEORGE CRABB, A. M.

REVISED AND ENLARGED BY THE ADDITION OF MODERN TERMS AND DEFINITIONS ARRANGED

ALPHABETICALLY WITH COMPLETE CROSS

REFERENCES THROUGHOUT

WITH AN INTRODUCTION

BY

JOHN H. FINLEY, LL.D.

COMMISSIONER OF EDUCATION

STATE OF NEW YORK

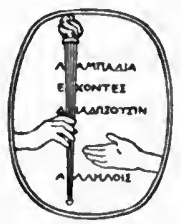

HARPER \& BROTHERS PUBLISHERS NEW YORK AND LONDON 


\section{Crabi's Synonymes}

Copyright, I917, by Harper \& Brothers

Printed in the United States of America

M-T 


\section{INTRODUCTION}

IT is a happy conceit that has suggested the celebration of a philologist's centenary by assembling in a new edition the words which his patient and critical labor has helped the century to hold in clear, accurate memory or keep in definitive daily use. The name "Crabb" is so closely and exclusively associated with his book of "synonymes" that it has itself become as a synonym for the title. "The man "Crabb" has, for those living a hundred years after him, no personality, no corporeal existence apart. He is, to most or all of us, his "Book of English Synonymes" which was his enduring work and is his epitaph.

An able newspaper editor said to me some months ago that he had no use for a book of synonyms, because, as he added, there are no words of identical meaning. If synonyms were words which had always exactly the same meaning, there would be no need for such a book. It is the differences, unseen by the undiscerning, the ignorant, or the careless, between words that are of similar import, that gave Crabb his meticulous labor and a life beyond his years. If synonyms were "equinyms" (that is, words of equal meaning) the English vocabulary might be shortened by hundreds or thousands of words, except for reasons of euphony or cherished associations. As it is, I suppose there are no equal words save those adopted for exchange purposes or carried over because of affection from other languages. A condition of exactitude in speech is a discernment of the differences between words nearly equal but so similar as to be called "synonyms." A book or catalogue of such discernment of differences might well be called the "Troy measure" of words, the measure which in weighing substances is employed in measuring those whose slightest differences are precious in value or potent in consequence.

As far back as the writing of the Book of Leviticus (and doubtless still farther back) were men enjoined to righteousness in measurements, whether of judgment, meteyard, or weight. "Just balances, just weights, a just ephah, a just hin shall ye have." Governments have by statute established, and by commissioners or bureaus maintained, standards for measuring the things we eat, drink, and wear, the land we live upon, and the light we burn. 
A false weight or meter is "an abomination," not only to the Lord, but also to men in organized society.

And so must false words be, especially in a democracy. We have fought for free speech. Having that, we have greater need of accurate speech-speech that will say what one means to say when one desires to tell the truth, the whole truth, and nothing but the truth. For there be three classes of men who do not tell the truth, except by accident: first, those who do not know it; second, those who wish not to tell it; and third, those who do not know how to tell it. Those who do not know the meanings of words are in the third category even if they escape the other two. They have no accurate measure for giving or receiving those intangible things of the mind's exchange or the spirit's commerce. They are as one who has not gotten beyond the "avoirdupois" table, or as one who has but a peck measure in an apothecary shop.

How many live in abject verbal poverty, when the riches of the race are within their reach! Many persons, especially women, have but one adjective of favorable appraisal and but one of unfavorable comment; and many a man's vocabulary is like that of Caliban, who boasted that, after all of Prospero's pains to teach him, the "profit on't" was that he knew "how to eurse." This state of poverty or elemental profanity would not be so woeful or pitiable a state, if one living in it did not thereby fall into poverty of thought, for one is able to rise toward the ultimate truth only as one can define clearly to one's self at least what one has discerned; and can carry others toward it only as one has the words of accurate expression. To such the lexicographer offers his "meteyards" and his "steelyards," and Crabb his "balances" that jump at a hair's difference.

I find a protest rising here such as came to Dr. Samuel Johnson (whom Crabb in his conseientiousness would not consult, going rather to the originals), for I recall somewhere to have read that once he said, "I am not so lost in lexicography as to forget that words are the daughters of earth and things the sons of heaven." But my answer would remind the protesting that it is chiefly through the "daughters of earth"-words - that the "sons of heaven"things-become human; for the word in one form or another is the flesh become spirit.

There comes often to me the remark of the Captain in the crucifixion scene of "The Terrible Meek." The soldier looking up at the figure on the cross, barely discernible in the darkness, had said, "It's hard that one should come to this just for the usin' of a few words." And the Captain answered: "Words, words; there is great power in words. All the things that ever get done in the world, good or bad, are done by words."

And inestimable bad is done not only by putting good words te 


\section{INTRODUCTION}

a purposely bad use, but by using good words with a good purpose inaccurately, whether from ignorance, chronic slovenliness, or occasional carelessness.

So I am constrained to join in this celebration of Crabb's centennial (though I cannot do so as a critical philologist), because of what he has done to help keep from debasement our old English coin as medium of intellectual exchange.

There has recently come into my possession a very small pewter vessel known as a "stoup," officially stamped as a gill measure. It bears the marks of much service, and was no doubt of practical value a century or more ago. It is said to have belonged to Robert Burns, and is precious because of that assumed association. I have been thinking, however, that the words in which his thoughts were measured are infinitely more precious to the race than all the stoups he used as a gauger. And from this illustration I rise again to the thought that infinitely more valuable to our progress as individuals and as a people are the word measures by which we receive and give with accuracy what the race's experiences have deposited in language, spoken and written.

Long life to Crabb and to that for which his name is as a synonym!

John H. Finley. 


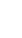




\section{PREFACE TO THE CENTENNIAL EDITION 1916}

ONe hundred years ago George Crabb, an English philologist, then thirty-eight years old, published the first edition of his "English Synonymes Explained." This edition was arranged on the alphabetical plan. In a later one he adopted the classification plan, as being "more scientifick," but in a subsequent one he reverted to the alphabetical as being less perplexing to readers.

It is an exceptional tribute to Crabb's scholarship that during an entire century his masterful work has continued to hold the regard of the English-speaking world, and that to-day it is consulted with probably more appreciation than ever before.

Crabb found the study of words a fascinating diversion, and, familiar as any one may be with the general run of them, but little association is required to discover that they are very illusive creatures in a large family that is divided into four groups of progenies-viz., synonyms, or words of similar meaning; antonyms, their opposites in meaning; homonyms, those alike in spelling but different in meaning; and homophonous ones, that differ in spelling and meaning but are alike in sound. Crabb confined himself to an exposition of the first group, and it was his purpose in explaining the most common members to indicate clearly the various meanings of words that bear a family resemblance by familiar comparisons, apposite historical allusions, and homely reflections.

It has been claimed by eminent philologists that every language the world has ever known has contributed to the formation of what is to-day called the English language. Single roots, meaning specific things, through local application, have been changed into idioms meaning other, though somewhat related, things. Then both roots and idioms have been adopted into more widely diffused forms, such as Hebrew, Greek, and Latin, and thence again into the specifically modern languages. Practically each new incorporation has undergone some change either in form or signification until, when a migratory word has found a lodgment in the English language, its appearance and meaning differ more or less from those of the primitive stock. It is this transmigration of words 
from language to language, losing some force here and gaining a new force there, that has given so many of them a variety of meanings, according to local usage and to other words with which they have become associated. Hence the large educational value of Crabb's synonymic explanations.

In the studious treatment of his subject, Crabb's work differs greatly from others, which, in the main, give only the generic, or key, words and some others that have a like significance. It will be observed that in many instances the author indicated the different shades of meaning of a single key ,word by separate paragraphs following the main application. This was to clarify the import of such words as Fair with its synonyms, as applied to the sky or weather, Fair with its synonyms, as applied to a person's conduct, reputation, and qualities, and Fair with its synonyms, as applied to an exhibition.

In this Centennial Edition of Crabb's most enduring work nothing has been eliminated from the master's explanations of his chosen words, and his style of presentation has been followed as closely as intervening conditions would permit. The entire body of the original words and explanations has been supplemented by a large number of words with their applications that have grown into the language within recent years, besides many that came to have a deeper significance than before because of the great European War.

And probably the most noteworthy feature of this edition is the exceedingly copious cross-references throughout the body of the work, binding closely related words together and so facilitating the location of a particular word that may be wanted without the tedious searching of a cumbersome index. 


\section{INTRODUCTION TO THE FIRST EDITION}

1816

IT may seem surprising that the English, who have employed their talents successfully in every branch of literature, and in none more than in that of philology, should yet have fallen below other nations in the study of their synonymes. It cannot, however, be denied that, while the French and Germans have had several considerable works on the subject, we have not a single writer who has treated it in a scientific manner adequate to its importance: not that I wish by this remark to depreciate the labors of those who have preceded me, but simply to assign it as a reason why I have now been induced to come forward with an attempt to fill up what is considered a chasm in English literature.

In the prosecution of my undertaking, I have profited by everything which has been written in any language upon the subject; and although I always pursued my own train of thought, yet whenever I met with anything deserving of notice I adopted it, and referred it to the author in a note. I had not proceeded far before I found it necessary to restrict myself in the choice of my materials, and accordingly laid it down is a rule not to compare any words together which were sufficiently distinguished from each other by striking features in their signification, such as abandon and quit, which require a comparison with others, though not necessarily with themselves; for the same reason I was obliged to limit myself, as a rule, to one authority for each word, unless where the case seemed to require further exemplification. But, notwithstanding all my care in this respect, I was compelled to curtail much of what I had written, for fear of increasing the volume to an inconvenient size.

Although a work of this description does not afford much scope for system and arrangement, yet I laid down to myself the plan of arranging the words according to the extent or universality of their acceptation, placing those first which had the most general sense and application, and the rest in order. By this plan I found myself greatly aided in analyzing their differences, and I trust that the reader will thereby be equally benefited. ...

For the sentiments scattered through this work I offer no 
apology, although I am aware that they will not fall in with the views of many who may be competent to decide on its litcrary merits. I write not to please or displease any description of persons; but I trust that what I have written according to the dictates of my mind will meet the approbation of those whose good opinion I am most solicitous to obtain. Should any object to the introduction of morality in a work of science, I beg them to consider that a writer whose business it was to mark the nice shades of distinction between words closely allied could not do justice to his subject without entering into all the relations of society, and showing, from the acknowledged sense of many moral and religious terms, what has been the general sense of mankind on many of the most important questions which have agitated the world. My first object certainly has been to assist the philological inquirer in ascertaining the force and comprehension of the English language; yet I should have thought my work but half completed had I made it a mere register of verbal distinctions. While others seize every opportunity unblushingly to avow and zealously to propagate opinions destructive of good order, it would ill become any individual of contrary sentiments to shrink from stating his convictions when called upon, as he seems to be, by an occasion like that which has now offered itself. As to the rest, I throw myself on the indulgence of the public, with the assurance that, having used every endeavor to deserve their approbation, I shall not make an appeal to their candor in vain. 
ENGLISH SYNONYMES 


\section{ENGLISH SYNONYMES}

A

ABACK, BaCKWARD, BeHIND, Rearward, Retrograde, Surprise. $A b a c k$, in Anglo-Saxon, on bace, at or on the back, is applied both to persons and localities. A person goes aback, backward, or rearward, or he retrogrades when in a movement opposite to forward or going ahead, and he goes behind when he passes from the front to the rear, and also when he fails to maintain a set gait in a movement or a course in a study. An object is behind or to the rearward of another object according as it is placed or becomes situated. In navigation, a sail is aback when pressed against a mast. A person surprised, taken unawares, or suddenly astonished, confused, or perplexed, is said to be taken aback.

abaft, Aft, Behind, Rearward, Astern. These words abound in nautical language, and, in relation to a given point forward or ahead of something on shipboard, imply localities. Abaft, from $a$ (on) and AngloSaxon be-ceftan (itself a combination of be (by) and aftan, an adverb meaning behind or back), is the opposite of afore. The original stem of the word appears in the phrase fore and aft.

ABANDON, DEsert, Forsake, ReLinguish. The idea of leaving or separating one's self from an object is common to these terms, which vary in the circumstances of the action. Abandon, from Old French $a$ bandon (proscription, control, ban), meant originally to put under a public ban, to proscribe utterly. Desert, from Late Latin deserto, is derived from the privative de and the verb sero, meaning bind or join, the root of which also appears in the noun series. It therefore signified the breaking of ties, the severing of one's connection with something. Forsake, compounded of the prefix for and the Anglo-Saxon sacan, to strive, meant to strive against, to take the opposite side, hence to repudiate. Abandoning is a violation of the most sacred ties, and exposes the object to every misery; desertion is a breach of honor and fidelity; it deprives a person of the assistance or the countenance which he has a right to expect; by forsaking, the kindly feelings are hurt and the social ties are broken. A bad mother abandons her offspring; a soldier deserts his comrades; a man forsakes his companions.

Things as well as rersons may be abandoned, deserted, or forsaken; things only are relinquished. To abandon may be an act of necessity or discretion, as a captain abandons a vessel when it is no longer safe to remain in it. Desertion is often a dereliction of duty, as to desert one's post; and often an indifferent action, particularly in the sense of leaving any place which has had one's care and attention bestowed upon it, as people desert a village, or any particular country where they have been established. Forsaking is an indifferent action, and implies simply the leaving something to which one has been attached in one form or another; a person forsakes a certain house which he has been accustomed to frequent; birds forsake their nests when they find them to have been discovered. To relinquish is an act of prudence or imprudence; men often inadvertently relinquish the fairest prospects in order to follow some favorite scheme which terminates in their ruin.

We may desert or forsake a place, but the former comprehends more than the latter; a place that is deserted is left by all, and left entirely. A place may be 
forsaken by individuals or to a partial extent.

Abandon, Resign, Renounce, Abdicate. -The idea of giving up is common to these terms, which signification, though analogous to the former, admits, however, of this distinction, that in the one case we separate ourselves from an object, in the other we send or cast it from us. Abandon (see above). Resign, from re and signo, signifies to sign away or back from one's self. Renounce, in Latin renuntio, from nuntiare, to tell or declare, is to declare off from a thing. Abdicate, from $a b$, from, and dicere, to speak, signifies likewise to call or cry off from a thing.

We abandon and resign by giving up to another; we renounce by sending away from ourselves; we abandon a thing by transferring it to another; in this manner a debtor abandons his goods to his creditors; we resign a thing by transferring our possession of it to another; in this manner we resign a place to a friend; we renounce a thing by simply ceasing to hold it; in this manner we renounce a claim or a profession. As to renounce, signified originally to give up by word of mouth, and to resign to give up by signature, the former is consequently a less formal action than the latter; we may renounce by implication; we resign in direct terms; we renounce the pleasures of the world when we do not seek to enjoy them; we resign a pleasure, a profit, or advantage, of which we expressly give up the enjoyment. To $a b-$ dicate is a species of informal resignation. A monarch abdicates his throne who simply declares his will to cease to reign; but a minister resigns his office when he gives up the seals by which he held it. We abandon nothing but that over which we have had an entire control; we abdicate nothing but that which we have held by a certain right, but we may resign or renounce that which may be in our possession only by an act of violence; a usurper cannot be said properly to abandon his people or abdicate a throne, but he may resign his power or renounce his pretensions to a throne.

To abandon and resign are likewise used in a reflective sense; the former in the bad sense, to denote the giving up the understanding to the passion, or the giving up one's self, mind and body, to bad practices; the latter in the good sense, to denote the giving up one's will and desires to one's circumstances or whatever is appointed. The soldiers of Hannibal abandoned themselves to pleasure at Capua. A patient man resigns himself to his fate, however severe that may be. When resign is taken in the bad sense, it is not so complete a giving up of one's self as abandonment, which implies a yielding to a passion.

See also WaIve.

ABANDONED. See Profligate.

abase, Humble, Degrade, Disgrace, Humiliate, Depress, Lower, Reduce, Debase. To abase expresses the strongest degree of self-humiliation; like the French abaisser, it signifies literally to bring down or make low, abaisser being compounded of the intensive syllable $a$ or $a d$, and baisser, from Low Latin bassare, to make low. The root appears in the Latin basis, Greek $\beta a$ ors, the lowest part of the column, from the root $\beta \dot{\alpha}$, to go, hence, in some cases, to stand, the basis being that on which the rest of the column stands. It implies the laying aside all the high pretensions which distinguish us from our fellow-creatures-the descending to a state comparatively low and mean. To humble, in French humilier, from the Latin humilis, humble, and humus, the ground, naturally marks a prostration to the ground, and figuratively a lowering of the thoughts and feelings. According to the principles of Christianity whoever abaseth himself shall be exalted, and according to the same principles whoever reflects on his own littleness and unworthiness will daily humble himself before his Maker. The abasement consists in the greatest possible dejection of spirit which, if marked by an outward act, will lead to the utmost prostration of the body; humbling, in comparison with abasement, is an ordinary sentiment.

Abase and humble have regard to persons considered absolutely, degrade and disgrace to their relative situation. To degrade (see Disparage) signifies to descend from one rank (Latin gradus, rank, English grade) to another. It 
supposes elevation either in outward circumstances or in public opinion. To disgrace, compounded of the privative dis and grace, or favor, properly implies to put out of favor, which is always attended with circumstances of more or less ignominy. To abase and humble one's self may be meritorious acts as suited to the infirmity and fallibility of human nature, but to degrade or disgrace one's self is always a culpable act. The penitent man humbles himself, the contrite man abases himself, the man of rank degrades himself by a too familiar deportment with his inferiors, he disgraces himself by his vices. The great and good man may also be abased and humbled without being degraded or disgraced; his glory follows him in his abasement or humiliation, his greatness protects him from degradation, and his virtue shields him from disgrace.

To degrade has most regard to the external rank and condition, disgrace to the moral estimation and character. Whatever is low and mean is degrading for those who are not of mean condition; whatever is immoral is disgraceful to all, but most so to those who ought to know better. It is degrading to a nobleman to associate with prize-fighters and jockeys, it is disgraceful for him to countenance a violation of the laws which he is bound to protect. The higher the rank of the individual, the greater is his degradation; the higher his previous character, or the more sacred his office, the greater his disgrace if his acts be inconsistent with its duties.

Persons may sometimes be degraded and disgraced at the will of others, but with a similar distinction of the words. He who is not treated with the outward honor and respect he deserves is degraded; he who is not regarded with the same kindness as before is disgraced.

These terms may be employed with a similar distinction in regard to things, and in that case they are comparable with debase. To debase, from the intensive syllable de and base. signifying to make base, is applied to whatever may lose its purity or excellence.

To humiliate a person implies the doing by another or the occurrence of something that produces mortification, vexation, chagrin, etc. To depress, in relation to a person, is to dispirit, discourage, cast down? debilitate; in rolation to material objects, it is to press or thrust down, to flatten, from above or vertically; in relation to commerce, it is to bring about a diminution or dullness in trade. To lower is to lessen, bring down, change from a high price (or note in music) to a lesser one, to sink, to rebate. A person lowers himself in another's estimation by a wrongful or unfriendly act. To reduce is to bring into a lower state, to shorten, to condense, to abbreviate (see ABATE). A person is degraded or disgraced by being reduced from one station to a lower one.

ABASH, Confound, Confuse. Abash, Old French esbahir, an onomatopotic word formed from the interjection $b a h$ of astonishment, meant originally to amaze, astound, but it has been partly confused with the word abase and is sometimes used as an intensive of it. Confound and confuse are derived from different parts of the same Latin verb confundo and its participle confusus. Confundo is compounded of con and fundo, to pour together. To confound and confuse then signify properly to melt together or into one mass what ought to be distinct; and figuratively, to derange the thoughts so that they seem melted together.

Abash expresses more than confound, and confound more than confuse. Abash has regard to the spirit which is greatly abased and lowered, confound has regard to the faculties which are benumbed and crippled; confuse has regard to the feelings and ideas which are deranged and perplexed. The haughty man is abashed when he is humbled in the eyes of others; the wicked man is confounded when his villainy is suddenly detected; a modest person may be confused in the presence of his superiors.

$A b a s h$ is always taken in a bad sense; neither the scorn of fools, nor the taunts of the oppressor, will abash him who has a conscience void of offence toward God and man. To be confounded is not always the consequence of guilt; superstition and ignorance are liable to be confounded by extraordinary phenomena; and Providence sometimes thinks fit to confound the wisdom of 
the wisest by signs and wonders, far above the reach of human comprehension. Confusion is at the best an infirmity more or less excusable according to the nature of the cause: a steady mind and a clear head are not easily confused; but persons of quick sensibility cannot always preserve a perfect collection of thought in trying situations; and those who have any consciousness of guilt, and are not very hardened, will be soon thrown into confusion by close interrogatories.

To Shame, Mortify, Disconcert, Discompose, Dishearten, Bewilder.-These words signify a something done by a person or an occurrence that unpleasantly affects another person. You may shame a person by exposing an act of crime, dishonor, impropriety, or breach of modesty or decorum on his part, and the person may bring the painful sensation of shame upon himself by his own premeditated or incautious action. The acts that shame a person may also mortify him, and in addition actions of himself or others that cause in him a sense of humiliation, vexation, chagrin, or guilt, may also do so. Various substances mortify when their vital functions are destroyed, the root of the word being derived from the Latin mors, mortis, death. Gangrene produces mortification of the flesh. Some acts of penance or austerities, imposed as a punishment, are said to mortify the body. To disconcert and discompose are closely allied to confound and confuse, specifically meaning to disturb one's composure or selfpossession. To dishearten is to do that toward another that will disappoint, discourage, depress, dispirit him; also an untoward occurrence that produces the same effect. To bewilder (Eng. prefix be, and Prov. Eng. wildern, a wilderness; Ger. verwildern, to render wild) implies a stronger action than either to confound or to confuse, for it involves in addition to those distractions a sense of extreme perplexity, helplessness, stupefaction, such as would possess a person lost in a wilderness and not knowing which way to turn to get out.

ABATE, Lessen, Diminish, DeCREASE. Abate, from the French abattre, signified originally to beat down, in the active sense; to come down, in the neuter sense. Diminish, from the Latin de and minuere, to lessen, and minus. less, expresses, like the verb lessen, the sense of either making less or becoming less. Decrease is compounded of the privative $d e$ and Latin crescere, to grow, signifying to grow less.

Abate, lessen, and diminish agree in the sense of becoming less and of making less; decrease implies only becoming less. Abate respects only vigor of action, and applies to that which is strong or violent, as a fever abates, pain, anger, etc.: abate; lessen and diminish are applied to size, quantity, and number, but lessen is much seldomer used intransitively than dimin$i s h$; things are rarely said to lessen of themselves, but to diminish. The passion of an angry man ought to be allowed to abate before any appeal is made to his understanding. Objects apparently diminish as they recede from the view.

Abate, transitively taken, signifies to bring down -i.e., to make less in height or degree by means of force or a particular effort, as to abate pride or to abate miscry; lessen and diminish, the former in the familiar, the latter in the grave style, signify to make less in quantity or magnitude by an ordinary process, as the size of a room is lessened, the credit of a person is diminished. We may lessen the number of our evils by not dwelling upon them; nothing $d i$ minishes the lustre of great deeds more than cruelty.

To decrease is to fall off; a retreating army will decrease rapidly when, exposed to all the privations and hardships attendant on forced marches, it is compelled to fight for its safety; some things decrease so gradually that it is some time before they are observed to be diminished.

The decrease is the process, the diminution is the result; as a decrease in the taxes causes a diminution in the revenue. The term decrease is peculiarly applicable to material objects which can grow less, diminution is applicable to objects generally which may become or be actually less from any cause.

To Remit, Rebate, Deduct, Decline, Slacken, Subside, Suppress, Subdue, 
Allow, Mitigate, Alleviate, Quell, Calm. -Remit, rebate, deduct, and allow are terms especially common in business transactions. A statement of an account is remitted, or sent, by the seller to the purchaser, and a specified discount or reduction in the amount of monev called for in the statement is remitted, rebated, deducted, or allowed by the seller for a cash payment within a designated period of time. To decline, slacken, subside signify a decrease, a slowing-up, a settling. Stocks, bonds, commodities decline in prices from time to time for various reasons; a person's hea th declines as it becomes less vigorous than usual; winds, storms, and tides slacken as they diminish in severity and flow; and storms, disturbances, excitements, anxieties, alarms, fevers, and various physical conditions subside as their causes are brought under control or climinated. Suppress, quell, and subdue are suggestive of riots and their ending; the crushing, overpowering, conquering of discordant or dangerous elements and conditions; all implying the use of force against force. Subdue is the rather stronger term of the trio, for while a disturbance may be suppressed or quclled, the resulting condition is not necessarily a finality, as the disturbance is liable to break out anew, whereas the elements of a disturbance that are subdued are presumably forced into submission.

A harsh legal sentence is mitigated when its severity is reduced in consideration of extenuating circumstances; sickness and untoward conditions are alleviated when made less painful or threatening. Calm stands for the most benevolent and inspiring condition in human life and nature, being indicative of peace, quiet, tranquillity, serenity, safety. A person, the ocean, the weather, the stock-markets, and countless activities are calm when undisturbed.

ABATEMENT. See Denuction. ABBREVIATE. Sce ABRIDGE.

ABDICATE. See ABANDon.

ABERRATION. See HalldCINATION.

ABETTOR, Accessony, AccoMplice, Confederate. Abettor, or one that abets, gives aid and encourage- ment by counsel, promises, or rewards. An accessory, or one added and annexed, takes an active, though subordinate, part. An accomplice, not related to accomplish, implies the principal in any plot, who takes a leading part and brings it to perfection. Abettors propose, accessories assist, accomplices execute. The abctior and accessory, or the abettor and accomplice, may be one and the same person; but not so the accessory and accomplice. In every deep-laid scheme there must be abcttors to set it on foot, accessories to co-operate, and accomplices to put it into execution; in the Gunpowder Plot there were many secret abcttors, some noblemen who were accessories, and Guy Fawkes the principal accomplice. Accomplice, like the other terms, may be applied to other objects besides criminal offences. A confederate assists in an undertaking, and may do so openly or secretly, actively or passively. In criminal matters a confederate is equally guilty with a principal.

ABHOR, Detest, Abominate, LoATHE. These terms equally denote a sentiment of aversion. Abhor, in Latin abhorreo, compounded of $a b$, from, and herrere, to stiffen with horror, signifies to star: from with a strong emotion of $\mathrm{h}$ rror. Detest, in Latin delestor, compounded of de, from or against, and testor, I bear witness, signifies to condemn with indignation. Abominate, in Latin abominatus, participle of abominor, compounded of $a b$, from or against, and ominor, to fear something as being of ill omen, signifies to hold in religious abhorrence, to detest in the highest possible degree. Loathe, Anglo-Saxon lathian, is associated with the very common Anglo-Saxon adjective lath, hatcful, and is allied with the German verb leiden, to suffer. It suggests a fecling of intense and even painful physical repulsion.

What we abhor is repugnant to our moral feelings; what we detest is opposed to our moral principles; what we abominate does violence to our religious and moral sentiments; what we loathe offends our physical taste. We abhor what is base and ungenerous, we detest hypocrisy; we abominate profanation and open impiety; we loathe food when we are sick. 
In the moral acceptance loathe is a strong figure of speech to mark the abhorrence and disgust which the sight or thought of offensive objects produces.

ABIDE, Sojourn, Dwell, Live, Reside, Inhabit. Abide, in AngloSaxon abidan, signifies to await, to expect. Sojourn, in French séjourner, from $s u b$ and diurnus, in the daytime, signifies to pass the day-that is, a certain portion of one's time-in a place. Dwell is from a Teutonic root meaning to wander, to lead astray, to tarry. This was the meaning of the Anglo-Saxon dwellan; the present meaning of the word is a peculiar development in English paralleled only by some uses of the word in the Scandinavian tongues. At the present it implies a stay in a place by way of residence, which is expressed in common discourse by the word live, for passing one's life. Reside, from the Latin re and sedere, to sit down, conveys the full idea of a settlement. Inhabit, from the Latin habito, a frequentative of habeo, signifies to have or occupy for a permanency.

The length of stay implied in these terms is marked by a certain gradation. Abide denotes the shortest stay; to sojourn is of longer continuance; dwell comprehends the idea of perpetuity in a given place, but reside and inhabit are partial and local-we dwell only in one spot, but we may reside at or inhabit many places. These words have likewise a reference to the state of societv. Abide and sojourn relate more properly to the wandering habits of men in a primitive state of, society. Dwell, as implying a stay under a cover, is universal in its application; for we may $d w e l l$ either in a palace, a house, a cottage, or any shelter. Live, reside, and inhabit are confined to a civilized state of society; the former applying to the abodes of the inferior orders, the latter to those of the higher classes. The word inhabit is never used but in connection with the place inhabited.

The Fasterners abode with one another, sojourned in a country, and dwelt in tents. The angels abode with Lot that night; Abram sojourned in the land of Canaan; the Israelites dwelt in the land of Goshen. Savages either dwell in the cavities which nature has formed for them, or in some rude structure erected for a temporary purpose; but as men increase in cultivation they build places for themselves which they can inhabit; the poor have their cottages in which they can live; the wealthy provide themselves with superb buildings in which they reside.

ABILITY, CApacity. Ability, in French habilité, Latin habilitas, comes from able, habile, habilis, and habeo, to have, because possession and power are inseparable. Capacity, in French capacité, Latin capacitas, from capax and capio, to receive, marks the abstract quality of being able to receive or hold. Ability is to capacity as the genus to the species. Ability comprehends the power of doing in general, without specifying the quality or degree; capacily is a particular kind of ability. Ability may be either physical or mental; capacity, when said of persons, is mental only. Ability respects action, capacity respects thought. Ability always supposes something able to be done; capacity is a mental endowment, and always supposes something ready to receive or hold.

Ability is no wise limited in its extent; it may be small or great; capacity of itself always implies a positive and superior degree of power, although it may be modified by epithets to denote different degrees; a boy of capacity will have the advantage over his school-fellows, particularly if he be classed with those of a dull capacity.

Abilities, when used in the plural only, is confined to the signification of mental endowments, and comprehends the operations of thought in general; capacity, on the other hand, is that peculiar endowment, that enlargement of understanding, that exalts the possessor above the rest of mankind. Many men have the abilities for managing the concerns of others who would not have the capacity for conducting a concern of their own. We should not judge highly of that man's abilities who could only mar the plans of others, but had no capacity for conceiving and proposing anything better in their stead.

Ability, Faculty, Talent. - These terms all agree in denoting a power. Ability is, as in the preceding case, the 
general term. Facully, in Latin facultas, changed from facilitas and facere, to do, signifying an ability to do; and talent, in Latin talentum, a Greek coin exceeding one hundred pounds sterling, and employed figuratively, as in Matthew 25, 15, for a gift, possession, or power-denote definite kinds of power.

Ability relates to human power generally, by which a man is enabled to act; it may vary in degree and quality with times, persons, and circumstances; health, strength, and fortune are abilities; faculty is a gift of nature directed to a certain end and following a certain rule. An ability may be acquired, and consequently is properly applied to individuals, an ability to spcak extempore or an ability to write; but a faculty belongs to the species, as a faculty of speech or of hearing, etc.

Ability being in general the power of doing, may be applied in its unqualified sense to the whole species, without any distinction. Faculty is always taken in a restricted sense, although applied to the species. Faculty and talent are both gifts of nature, but a faculty is supposed to be given in an equal degree to all, a talent in an unequal degree; as the facully of seeing, the talent of mimicry, the talent for music; a faculty may be impaired by age, disease, or other circumstances; a talent is improved by exercise.

As all these terms may be applied to different objects, they are aptly enough used in the plural to denote so many distinct powers: abilities denote all our powers generally, corporeal and mental, but more especially the latter; faculties relate to the ordinary powers of body and mind, as when we speak of a person's retaining or losing his faculties; talents relate to the particular gifts or powers which may serve a beneficial purpose, as to employ one's talents usefully.

Ability, Dexterity, Address.-Ability is, as before observed, a general term, without any qualification. Dexterity, from dexter, the right hand, signifying mechanical or manual facility, and address, signifying a mode of address, are particular terms. Ability may be used to denote any degree, as to do according to the best of one's ability; and it may be qualified to denote a small degree of ability. Dexterity and address are positive degrees of ability.

Ability is, however, frequently taken in a restricted sense for a positive degree of ability, which brings it still nearer to the two other terms, from which it differs only in the application; ability in this case refers to intellectual endowment generally, dexterity relates to a particular power or facility of executing, and address to a particular mode or manner of addressing one's self on particular occasions. Ability shows itself in the most important transactions and the general conduct in the highest stations, as a minister of state displays his ability; dexterity and address are employed occasionally, the former in removing difficulties and escaping dangers, the latter in improving advantages and accommodating tempers; the former in directing the course of things, the latter in managing of men.

Able, Capable, Capacious. - These epithets, from which the preceding abstract nouns are derived, have distinctions peculiar to themselves. Able and capable are applied to ordinary actions, but not always indifferently, the one for the other: able is said of the abilities generally, as a child is able or not able to walk; capable is said of one's ability to do particular things, as to be capable of performing a great journey. Able is said of that which one can do, as to be able to write or read; capable is said of that which either a person or a thing can take, receive, or hold; a person is capable of an office, or capable of great things; a thing is capable of improvement. Able may be added to a noun by way of epithet when it denotes a positive degree of ability, as an able commander, an able financier. Capable may be used absolutely to express a mental power.

Capable and capacious, though derived from the same verb capio, to take or receive, are distinguished from each other in respect to the powers or properties of the objects to which they are applied, capable being said of powers generally, capacious only of the property of having amplitude of space or a power to take in or compre- 
hend; and men are capable of thought or reason, of life or death, etc.; a hall may be said to be capacious, or, figuratively, a man has a capacious mind.

ABIOGENIC, LifEless, Só́trceLESS. Abiogenic is a recently coined word that has no real synonyms; abiogenic, the adjective of abiogenesis, a compound of the Greek $\alpha$, without, $\beta_{\text {tós, }}$ life, and $\gamma_{\varepsilon}^{\prime} \nu \varepsilon \sigma \varsigma$, origin, invented by Huxley, signifies, literally, spontaneous generation, the opposite of sexual generation and biogenesis (which see). Abiogenic pertains to the production of life or living beings under certain physical conditions without the intervention of antecedent living forms, Huxley having propounded the theory that living matter can be produced from that which in itself is not living matter. Hence, it is claimed, as the basis of abiogenesis, that certain material objects may be developed from other objects that in themselves are lifeless and, as far as known, sourceless.

Biologists at one time held the view that some of the lower animals or plants, or the primordial of one or the other, or both, of the animal and vegetable kingdoms may have sprung from lifeless matter without the intervention of any previously existing parent. On the demonstration that alleged instances of such spontaneous generation were unfounded, the early view was discarded till Haeckel and other evolutionists revived it and Huxley gave it a name.

aBjURE, Recant, Retract, ReCALL, RevoKe. Abjure, in Latin $a b$ juro, is compounded of the privative $a b$ and juro, swear, signifying to swear to the contrary, or give up with an oath. Recant, in Latin recanto, is compounded of the privative $r e$ and canto, to sing or declare, signifying to unsay, to contradict by a counter declaration. Retract, in Latin retractus, participle of retraho, is compounded of re, back, and traho, to draw, signifying to draw back what has been let go. Revoke and recall have the same original sense as recant, with this difference only, that the word call, which is expressed also by voke, or in Latin voco, implies an action more suited to a multitude than the word canto, to sing, which may pass in solitude. We $a b-$ jure a religion, we recant a doctrine, we retract a promise, we revoke a command, we recall an expression, and, where the initiative, referendum, and recall prevail, an incompetent or unfaithful official.

What has been solemnly professed is renounced by abjuration; what has been publicly maintained as a settled point of belief is as publicly given up by recanting; what has been pledged so as to gain credit is contradicted by retracting; what has been pronounced by an act of authority is rendered null by revocation; what has been misspoken through inadvertence or mistake is rectified by recalling the words.

Although Archbishop Cranmer recanted the principles of the Reformation, yet he soon after recalled his words, and died boldly for his faith. Henry IV. of France abjured Calvinism, but he did not retract the promise which he had made to the Calvinists of his protection. Louis XIV. drove many of his best subjects from France by revoking the Edict of Nantes. Interest but too often leads men to abjure their faith; the fear of shame or punishment leads them to recant their opinions; the want of principle dictates the retracting of one's promise; reasons of state occasion the revoking of decrees; a love of precision commonly induces a speaker or writer to recall a false expression.

ABOLISH, Abrogate, Repeal, Revoke, ANNUL, CANCEL. Abolish, in French abolir, Latin abolere, to grow less, is compounded of $a b$, away, and olere, to grow. Abrogate, in French abroger, Latin abrogatus, participle of $a b r o g o$, compounded of $a b$, away, and rogare, to ask, signifies to ask away, or to ask that a thing may be done away; in allusion to the custom of the Romans, among whom no law was valid unless the consent of the people was obtained by asking, and in like manner no law was unmade without asking their consent. Repeal, in French rappeller, from the Latin words $r e$ and appello, signifies literally to call back or unsay what has been said, which is in like manner the original meaning of re- 
voke. Annul, in French annuller, comes from Latin nullus, ne-ullus, not any, signifying to reduce to nothing. Cancel, in French canceller, comes from the Latin cancello, cut crosswise, signifying to strike out crosswise-that is, to cross out.

The word abolish conveys the idea of putting a total end to a thing, and is applied properly 'to those things which have been long in existence and firmly established: an abolition may be effected either by an act of power, as to abol$i s h$ an institution or an order of men, and the like. Or it may be a gradual act, or effected by indirect means, as to abolish a custom, practice, etc.

All the other terms have respect to the partial acts of men, in undoing that which they have done. Laws are either repealed or abrogated, but repealing is a term of modern use, applied to the acts of public councils or assemblies, where laws are made or unmade by the consent or open deelaration of numbers. Abrogate is a term of less definite import; to abrogate a law is to render it null by any act of the legislature; thus. the making of a new law may abrogate the old one.

Revoking is an act of individual authority - edicts are revoked; annulling is an act of discretion, as official proceedings or private contracts are annulled; cancelling is a species of annulling, as in the case of cancelling deeds, bonds, obligations, etc. None can abrogate but those who have the power to make. Any one who has the power to give his word may also revoke it, if he see reason so to do. Any one who can bind himself or others, by any deed or instrument, may annul or render this null and void, provided it be done for a reasonable cause, and in the proper manner. As cancelling serves to blot out or obliterate what has been written, it may be applied to what is blotted out of the memory. It is a voluntary resignation of right or demand which one person has upon another.

ABOMINABLE, Detestable, ExeCRABLE. The primitive idea of these terms, agreeable to their derivation (for which 'see aBOMINATE, MaLEDICTION, and DETEST), is that of badness in the highest degree; conveying by themselves the strongest signification, and excluding the necessity for every other modifying epithet.

The abominable thing excites aversion; the detestable thing, hatred and revulsion; the execrable thing, indignation and horror.

These sentiments are expressed against what is abominable by strong ejaculations, against what is detestable by animadversion and reprobation, and against what is execrable by imprecations and anathemas.

In the ordinary acceptation of these terms, they serve to mark a degree of excess in a very bad thing; abominable expressing less than detestable, and that less than execrable. This gradation is sufficiently illustrated in the following example. Dionysius, the tyrant, having been informed that a very aged woman prayed to the gods every day for his preservation, and wondering that any of his subjects should be so interested for his safety, inquired of this woman respecting the motives of her conduct, to which she replied, "In my infancy I lived under an abominable prince, whose death I desired; but when he perished, he was succeeded by a detestable tyrant worse than himself. I offered up my vows for his death also, which were in like manner answered; but we have since. had a worse tyrant than he. This execrable monster is yourself, whose life I have prayed for, lest, if it be possible, you should be succeeded by one even more wicked."

The exaggeration conveyed by these expressions has given rise to their abuse in vulgar discourse, where they are often employed indifferently to serve the humor of the speaker.

ABOMINATE. See ABhor.

ABORIGINAL. See First.

ABORTION. See FaILURE.

ABOVE, OVER, UPON, BeYoNd. When an object is above another, it exceeds it in height; when it is over another, it extends along its superior surface; when it is upon another, it comes in contact with its superior surface; when it is beyond another, it lies at a greater distance. Trees frequently grow above a wall, and sometimes the branches hang over the wall, or rest upon it, but they seldom stretch much beyond it. 
In the figurative sense, the first is mostly employed to convey the idea of superiority; the second, of authority; the third, of immediate influence; and the fourth, of extent. Every one should be above falsehood, but particularly those who are set over others, who may have an influence on their minds beyond all calculation.

ABRIDGe, Abbreviate, Curtail, Contract. Abridge, in French abréger, Latin abbreviare, is compounded of the intensive syllabl $3 a b$ and breviare, from brevis, short, signifying to make short. Abridge and abbreviate, by derivation, have therefore exactly the same meaning, though they are used in different connections. We abbreviate a word; we abridge a book. Curtail, in French court, short, and tailler, to cut, signifies to diminish in length by cutting. Contract, in Latin contractus, participle of contraho, is compounded of con and traho, signifying to draw close together.

By abridging, in the figurative as well as the literal sense, the quantity is diminished; by curtailing, the measure or number is reduced; by contracting, the compass is reduced. Privileges are abridged, pleasures curtailed, and powers contracted. It is ungenerous to abridge the liberty of any one, or curtail him of his advantages, while he makes no improper use of them; otherwise it is advisable, in order to contract his means of doing mischief.

See also Deprive.

Abridgment, Compendium, Epitome, Digest, Summary, Abstract.-The first four terms are applied to a distinct work, the two latter to parts of a work.

An abridgment is the reduction of a work into a smaller compass. A compendium is a general and concise view of any science, as geography or astronomy. An epitome is a compressed view of all the substantial parts of a thing, or, in other words, the whole of any matter brought into a small compass. A digest is any materials digested in order. A summary comprehends the heads and subdivisions of a work. An abstract includes a brief but comprehensive view of any particular proceeding. Abridgments often surpass the originals in values when they are made with judgment. Compendiums are fit- ted for young persons to commit to memory on commencing the study of any science. There is perhaps not a better epitome than that of the Universal History by Bossuet, nor a better digest than that of the laws made by order of Justinian. Systematic writers give occasional summaries of what they have been treating upon. It is necessary to make abstracts of deeds or judicial proceedings. Epitome and abstract are taken for other objects, which contain within a small compass the essence of a thing.

ABROAD. See OUT.

ABROGATE. See ABolish.

ABRUPT, RUGGED, ROUGH. $A b$ rupt, in Latin abruptus, participle of abrumpere, to break off, signifies the state of being broken off. Rugged is a Scandinavian word signifying hairy, hence unshaven, rough. Rough, from Anglo-Saxon ruh, hairy, rough, had the same meaning and development.

These words mark different degrees of unevenness. "What is abrupt has greater cavities and protuberances than what is rugged; what is rugged has greater irregularities than what is rough. In the natural sense abrupt is opposed to what is unbroken, rugged to what is even, and rough to what is smooth. A precipice is abrupt, a path is rugged, a plank is rough. The abruptness of a body is generally occasioned by a violent concussion and separation of its parts; ruggedness arises from natural, but less violent, causes; roughness is mostly a natural property, although sometimes produced by friction.

In the figurative or extended application, the distinction is equally clear. Words and manners are abrupt when they are sudden and unconnected; the temper is rugged which is exposed to frequent ebullitions of angry humor; actions are rough when performed with violence and incaution. An abrupt behavior is the consequence of an agitated mind; a rugged disposition is inherent in the character; a rough deportment arises from an undisciplined state of feeling. An habitual steadiness and coolness of reflection is best fitted to prevent or correct any abruptness of manner; a cultivation of the 
Christian temper cannot fail of smoothing down all ruggedness of humor; an intercourse with polished society will inevitably refine down all roughness of behavior.

See also Stdden.

abscond, Steal Away, Secrete ONE'S SELF. Abscond, in Latin $a b$ scondo, is compounded of $a b s$ and condo, signifying to hide from the view, which is the original meaning of the other words; to abscond is to remove one's self for the sake of not being discovered by those with whom we are acquainted. To steal away is to get away so as to elude observation. To secrete one's self is to get into a place of secrecy without being perceived. Dishonest men abscond, thieves steal away when they dread detection, and fugitives secrete themselves. Those who abscond will have frequent occasion to steal away, and still more frequent occasion to secrete themselves.

abSENT, Abstracted, Abstract, Diverted, Distracted. Absent, in French absent, Latin absens, comes from $a b$, from, and sum, to be, signifying away or at a distance from all objects. Abstracted, or abstract, in French abstrait, Latin abstractus, participle of abstraho, or abs, from, and traho, to draw, signifies drawn or separated from all objects. Diverted, in French divertir, Latin diverto, compounded of dis, asunder, and vertere, to turn, signifies turned aside from the object that is present. Distracted, of course, implies drawn asunder by different objects.

A want of proper attention is implied in all these terms, but in different degrees and under different circumstances. Absence of mind is either a state or a habit; a man may be occasionally absent. Or a man may contract an habitual absence, either from profound study, or from any other less commendable cause. $A b$ straction denotes a state, and, for the most part, a temporary state.

The term absent simply implies not present with one's mind, not observant of present objects, but it does not necessarily imply thinking of anything; a man man be absent who is thinking of nothing.

Abstracted, on the other hand, denotes deep thought of something not present. Abstract may in poetry be used in the sense of abstracted.

Absent and abstracted denote an exclusion of present objects; diverted and distracted, a misapplied attention to present objects, or to such objects as do not demand attention. An absent man never has his body and mind in the same place; the abstracted man is lost in thinking; a man who is easily diverted seeks to take an interest in every passing object; a distracted man is unable to think properly of anything: it may be good to be sometimes diverted. It is bad at any time to be distracted, particularly when it arises from passion.

ABSOLUTe, Despotic, Arbitrary, Tyrannical. Absolute, in Latin $a b$ solutus, participle of absolvo, signifies absolved or set at liberty from all restraint as it regards persons; unconditional, unlimited, as it regards things. Despotic, from despot, in Greek $\delta \varepsilon \sigma \pi \delta$ r $\eta s$, a master or lord (the same root appears in the word potent), implies being like a lord, uncontrolled. Arbitrary, in French arbitraire, from the Latin arbitror, act as an umpire, decide, implies independence of judgment and will. Tyrannical signifies being like a tyrant. Absolute power is independent of and superior to all other power: an absolute monarch is uncontrolled not only by men, but things; he is above all law except what emanates from himself. When this absolute porer is assigned to any one according to the constitution of a government, it is despotic. Despotic power is therefore something less than absolute power; a prince is absolute of himself; he is despotic by the consent of others. In the early ages of society monarchs were absolute, and among the Eastern nations they still retain the absolute form of "government, though much limited by established usage. In the more civilized stages of society the power of despots has been considerably restrieted by prescribed laws, in so much that despotism is now classed among the regular forms of government.

Absolute is a term of a general application in the sense of absolved or freed from all control or limit; in this sense God is said to be absolute. Sometimes it is applied either to the power 
itself or to the exercise of power, as absolute rule or dominion; despotic is likewise applied to the exercise of the power as well as the power itself, as despotic sway; arbitrary and tyrannical are used only in this last application: the latter is always taken in a bad sense, the former sometimes in an indifferent sense. With arbitrariness is associated the idea of caprice and selfishness. With tyranny is associated the idea of oppression and injustice. Among the Greeks the word ripavyos, a tyrant, implied no more than what we now understand by despot, or, more properly, one who gained the supreme power in a republic; but from the natural abuse of such power, it has acquired the sigmification now attached to it, namely, of exercising power to the injury of another. If absolute power come into the hands of any one man or body of men, it is fair to expect that it will be used arbitrarily. In despotic governments the tyrannical proceedings of the subordinate officers are often more intolerable than those of the prince.

ABSOLUTION. See Forgive.

ABSOLVE, ACQUiT. Absolve, in Latin absolvo, is compounded of $a b$, from, and solvere, to loose, signifying to loose from that with which one is bound. Acquit, in French acquitter, is compounded of the intensive syllable $a c$ or $a d$, and quit, quitter, from Latin quietus, quiet, signifying to make easy by the removal of a charge.

These terms imply the setting free from guilt or its consequences. Absolving may sometimes be applied to offences against the laws of man, but more frequently to offences against God; acquitting applies solely to offences against man. The conscience is released by absolution; the body, goods, or reputation are set free by an $a c$ quittal.

\section{See also Forgrve.}

Absolve, Acquit, Clear.-Absolve in this case, as distinguished from the former article, is extended to all matters affecting the conscience generally. Acquit and clear, in the sense of making clear or free from, are applied to everything which may call for blame, or the imputation of what is not right. A person may be absolved from his oath, acquitted or pronounced quit of every charge, and cleared from every imputation.

ABSORB, Swallow Up, Ingulf, Engross, ImbiBe. Absorb, French $a b-$ sorber, Latin absorbeo, is compounded of $a b$ and sorbeo, to sup up, in distinction from swallow $u p$-the former denoting a gradual consumption; the latter, a sudden envelopment of the whole object. The excessive heat of the sun $a b$ sorbs all the nutritious fluids of bodies, animal and vegetable. The gamingtable is a vortex in which the principle of every man is surallowed up with his estate. Ingulf, compounded of in and gulf, signifies to be enclosed in a great gulf, which is a strong figurative representation for being swallowed up. As it applies to grand and sublime objects, it is used only in the higher style.

Engross, which is compounded of the French words en gros, whole, signifies to purchase wholesale, so as to swallow up the profits of others. In the moral application therefore it is very analogous to absorb. The mind is absorbed in the contemplation of any subject when all its powers are so bent upon it as not to admit distraction. The mind is engrossed by any subject when the thoughts of it force themselves upon its contemplation to the exclusion of others which should engage the attention.

Absorb conveys the idea not only of taking from something, but also of taking to itself; engross conveys the idea of taking to itself, to the exclusion of others; a certain subject absorbs the faculties, and, metaphorically, the root s of plants absorb moisture; a person engrosses the conversation so that others cannot take part in it.

$A b s o r b$, and imbibe, from in and bibo, to drink, both imply the taking in by a gradual process; but the former includes the idea of being taken in so as to be lost, the latter that of being taken in so as to form a part of that by which it is received. So in the improper application, an idea $a b s o r b s$ the mind, and the mind imbibes the idea.

See also Monopolize.

ABSORBABle. See Assimilable.

ABSTAIN, Forbear, Refrais. Abstain, in French abstenir, Latin abstineo, is compounded of $a b$ or $a b s$, from, 
and tenere, to keep, signifying to keep one's self from a thing. Forbear is compounded of the preposition for, or from, and the verb to bear or carry, signifying to carry or take one's self from a thing. Refrain, in French refréner, Latin refrano, is compounded of re, back, and fronum, a bridle, signifying to keep back as it were by a bridle, to bridle in.

All these terms imply the omission to do anything, but vary in the circumstances and in the motives for the omission. To abstain is the general term, to forbear and refrain are particular modes of abstaining. Abstaining is an act that may require no self-denial, nor oppose any inclination; forbearing and refraining both imply a certain degree of opposition to the will or inclination, the latter much more than the former. We abstain from doing indifferent things from motives of convenience, as to abstain from speaking upon a particular subject, or we $a b$ stain from important matters from a sense of duty, as "to abstain from the appearance of evil." We forbear from prudence or duty to do that which we have motives for doing; as we forbear to do an injury though in return for an injury. We refrain, from the same motives, from doing that which we are strongly inclined or impelled to do, as to refrain from expressing the feelings of the moment.

These words are often coupled with a negative, to show the inability of the agent to omit doing a thing, as when it is said, "I cannot abstain from the gratification," or "I cannot forbear mentioning," etc., or "she was so affected that she could not refrain" from tears.

Abstaining as a religious duty is mostly said of indulgences as to food or otherwise which are prohibited; as it is the part of the Mohammedan faith to abstain from wine; forbearing is mostly said of that which concerns others. Every one is too liable to offend, not to have motives for forbearing to deal harshly with the offences of others; for being patient, indulgent, long-suffering.

Abstinence, Fast, Abstinent, Sober, Abstemious, Temperate.-Abstinence is a general term, applicable to any ob- ject from which we abstain; fast is a species of abstinence, namely, an abstaining from food. The general term is likewise used in the particular sense, to imply a partial abstinence from particular food; but fast signifies an abstinence from food altogether.

Abstinent respects everything that acts on the senses, and in a limited sense applies particularly to solid food. Sober, from the Latin sobrius, compounded of so or se, expressing separation (cf. se in separation) and ebrius, drunk, implies an abstinence from excessive drinking. 'Abstemious, from the Latin abstemius, compounded of $a b s$ and temetum, wine, implies the abstaining from wine or strong liquor in general. Temperate, in Latin temperatus, participle of tempero, to moderate or regulate, implies a well-regulated abstinence in all manner of sensual indulgence.

The first of the last four terms is generic, the rest specific. We may be abstinent without being sober, sober without being abstemious, and all together without being temperate. An abstinent man does not eat or drink as much as he could enjoy; a sober man may drink much without being affected; an abstemious man drinks nothing strong; a temperate man enjoys all in a due proportion. A particular passion may cause us to be abstinent either partially or totally; sobriety may often depend upon the strength of the constitution, or be prescribed by prudence: necessity may dictate abstemiousness, but nothing short of a well-disciplined mind will enable us to be temperate.

aBstract, Separate, DistinGUISH. Abstract, see ABRIDGE; ABSENT. Separate, in Latin separatus, participle of separo, is compounded of se, apart, and parare, to dispose, signifying to put things asunder, or at a distance from each other. Distinguish, in French distinguer, Latin distinguo, is compounded of the separative preposition dis and a root which appears in the Greek ori $\gamma \gamma \omega$, prick, and in the English sting, stick, etc. It may signify the giving of different marks to things, by which they may be known from each other.

Abstract, as compared with the other terms, is used in the moral sense only; 
separate mostly in a physical sense: distinguish either in a moral or physical sense; we abstract what we wish to regard particularly and individually; we separate what we wish not to be united; we distinguish what we wish not to confound. The mind performs the office of abstraction for itself; separating and distinguishing are exerted on external objects. Arrangements, place, time, and circumstances serve to separate: the ideas formed of things, the outward marks attached to them, the qualities attributed to them, serve to distinguish. By the operation of $a b$ straction the mind creates for itself a multitude of new ideas; in the act of separation bodies are removed from each other by distance of place; in the act of distinguishing objects are discovered to be similar or dissimilar. Qualities are abstracted from the subjects in which they are inherent; countries are separated by mountains or seas; their inhabitants are distinguished by their dress, language, or manners. The mind is never less abstracted from one's friends than when separated from them by immense oceans; it requires a keen eye to distinguish objects that bear a great resemblance to each other. Volatile persons easily abstract their minds from the most solemn scenes to fix them on trifling objects that pass before them: an unsocial temper leads some men to separate themselves from all their companions: an absurd ambition leads others to distinguish themselves by their eccentricities.

See also ABridGMENT.

Abstracted, Abstract, Abstraction, Alienation, Estrangement.-Abstracted, as in the former case (see ABsent), is properly applied to persons or things personal. Abstract, which is but a contraction of the former, is most commonly used to denote the qualities of things. A person is said to be $a b$ stracted who is in a state of abstraction; or a person may lead an abstracted life or course of life, or follow an abstracted theory, when the mind is altogether abstracted from external or sensible objects; a thing is said to be abstract which is formed by the operation of abstraction or abstracted thinking, as an abstract idea, which is abstracted or separated by the mind from the ob- jects to which they belong or inhere; whiteness is an abstract idea, because it is conceived in the mind abstracted from snow, a wall, or any other substance that is white.

Abstraction expresses the state of being abstracted as to one's mind or person from any object generally. Alienation, the state of being alienated as to one's affections from others. Estrangement, the state of being a stranger is unknown to others. Abstraction expresses less than alienation or estrangement; it is simply the abstaining to take a part with others in any matter, as an abstraction from the world, its cares, pursuits, and pleasures. Alienation and estrangement both suppose an altered state of mind toward any object; alienation is where the heart and affections become alien or strange to that on which they have been or ought to be fixed; estrangement is where the person becomes distant from that with which one has been or ought to be intimate. One is said to be abstracted from the thing, but alienated or estranged from the person or the thing.

See also ABsent.

ABSURD. See FARCICAL; IrraTIONAL.

\section{ABUNDANT. See Plenttrut.}

ABUSE, Misuse, Abuse, in Latin abusus, participle of abutor, compounded of $a b$, from, and utor, to use, signifies to use away or wear away with using; in distinction from misuse, which signifies to use amiss.

Everything is abused which receives any sort of injury; it is misused if not used at all, or turned to a wrong use. Young people are too prone to abuse books for want of setting a proper value on their contents; they do not always avoid misusing them in their riper years, when they read for amusement only instead of improvement. Money is abused when it is clipped or its value any way lessened; it is misused when it is spent in excess and debauchery.

Abuse, Invective.-Abuse is here taken in the metaphorical application for illtreatment of persons by the use of harsh words. Invective, from the Latin inveho, signifies to bear upon or, in mod- 
ern slang, to "sail into." Harsh and unseemly censure is the idea common to these terms; but the former is employed more properly against the person, the latter against the thing. Abuse is addressed to the individual, and mostly by word of mouth; invective is communicated mostly by writing. Abuse is dictated by anger, which throws off all constraint and violates all decency; invective is dictated by party spirit, or an intemperate warmth of feeling in matters of opinion. Abuse is always resorted to by the vulgar in their private quarrels; invective is the ebullition of zeal and ill-nature in public concerns. The more rude and ignorant the man, the more liable he is to indulge in abuse; the more restless and opinionated the partisans, whether in religion or politics, the more ready he is to deal in invective.

ABUSIVE. See Reproachrol.

ABUTTING. See Salient.

ABYSS. See Gulf.

ACADEMic, Classic, Scholastic, Pedantic. These words all refer to formal learning, but there is a difference in their origin and their application. Academic is derived from Greek $a x a \delta \eta \mu \dot{\varepsilon}^{\prime} \iota a$, the name of the garden or grove where Plato taught. It referred at first to Plato's school, and then became a general designation. Academic, therefore, means according to the methods of the schools, and is sometimes used in a good sense with reference to the life of the scholar in the universities, and sometimes in a derogatory sense to characterize that which merely originates in books, and is unrelated to practical experience. Classic, from Latin classis, meant originally of the highest class, and referred especially to the works of the Greek and Latin authors as being the highest types of literature. It is usually contrasted with modern and natural, as academic is contrasted with practical. In a general way, therefore, it is associated with the idea conveyed in academic, though not strictly synonymous with it. Scholastic, Latin scholasticus (from Greek $\sigma \chi_{0} \lambda_{a} \dot{c}_{\varepsilon \varepsilon \nu}$, to devote one's leisure to learning, from $\sigma \chi_{0} \lambda i$, leisure), refers especially to the scholars of the Middle Ages, called the scholastic. philosophers. It means characterized by the methods of the schools, with special reference to logical procedure and minute analysis. Pedantic, from Italian pedante, a schoolmaster or ped-

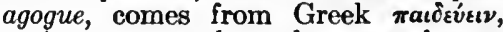
to instruct youth, and means characteristic of the schoolmaster. It is used in a derogatory sense to characterize barren learning.

ACADEMY. See School.

ACCEDE. See Agree.

ACCELERATE. See Hasten.

ACCENT. See Stress.

ACCEPT. See Take.

ACCEPTABLE, Gratefol, WeICOME. Acceptable signifies worthy to be accepted. Grateful, from the Latin gratus, pleasing, signifies altogether pleasing; it is that which recommends itself. The acceptable is a relative good; the grateful is positive; the former depends upon our external condition, the latter on our feelings and taste; a gift is acceptable to a poor man, which would be refused by one less needy than himself; harmonious sounds are always grateful to a musical ear.

Welcome signifies come well or in season for us. Acceptable and welcome both apply to external circumstances, and are therefore relatively employed; but the former is confined to such things as are offered for our choice, the latter refers to whatever happens according to our wishes; we may not always accept that which is acceptable, but we shall never reject that which is welcome; it is an insult to offer anything by way of a gift to another which is not acceptable; it is a grateful task to be the bearer of welcome intelligence to our friends.

Acceptance, Acceptation. - Though both derived from the verb accept, these terms have this difference, that the former is employed to express the active sense of the verb, the latter the passive sense. Acceptance is the act of accepting, acceptation the state of being accepted, as the acceptance of a favor lays a person under an obligation. A book, or whatever else is offered to us, may be worthy of our acceptance or not; a word acquires its acceptation from the manner in which it is generally accepted by the learned.

ACCESS. See APPROACH. 
ACCESSION. See InCrease.

ACCESSORY. See ABETTOR.

ACCIDENT, Chance. Accident, in Latin accidens, from $a d$ and cadens, falling, and chance (in French chance, also connected with cadens), both signify falling out (cf. English befall)-i. e., without any design; but the former, by the force of the $a c$ or $a d$, signifies falling out at a given time, or under given circumstances; chance, on the other hand, signifies falling out without any qualification or restriction. Both may be employed to denote either the manner or cause of things happening, or the things themselves that so happen; in the first sense, accident and chance may be used indifferently in the colloquial expressions to happen by chance or by accident, but otherwise accident is used only in respect to particular events as, it was pure accident; but chance is employed to denote a hidden senseless cause of things, as opposed to a positive intelligent cause. Atheists ascribe all things to chance; whatever happens by secondary causes hidden from our view we are accustomed to ascribe to chance, which is only a mode of confessing our ignorance as to how it happens.

When taken for the thing that happens, accident is said ordinarily of things that have been; chance of things that are to be. That is an accident which is done without intention; that is a chance which cannot be brought about by the use of means. It is an accident when a house falls; it is a chance when and how it may fall. Accidents cannot be prevented; chances cannot be calculated upon. Accidents may sometimes be remedied; chances can never be controlled. Accidents give rise to sorrow; thcy mostly occasion mischief: chances give rise to hope; they often produce disappointment; it is wise to dwell upon neither.

Sometimes chance is used without reference to time for any fortuitous event, and in that case it is more expressive than the word accident. The term accident may likewise sometimes be taken for what may happen in the future.

See also Event.

Accident, Contingency, Casualty, Accidental, Incidental, Casual, Contingent.
-Accident (see above). Contingency, in French contingence, Latin contingens, participle of contingo, compounded of con, together, and tangere, to touch one another, signifies the falling out or happening together, or the thing that happens in conjunction with another. Casualty, in French casualité, from the Latin casualis, and cado, to fall or happen, signifies the thing that happens in the course of events.

All these words imply whatever takes place independently of our intentions. Accidents express more than contingencies; the former comprehend events with their causes and consequences; the latter respect collateral actions, or circumstances appended to events; casualties have regard simply to circumstances. Accidents are frequently occasioned by carelessness, and contingencies by trivial mistakes; but casualties are altogether indepcndent of ourselves. The overturning of a carriage is an accident; our situation in a carriage at the time is a contingency, which may occasion us to be more or less hurt; the passing of any one at the time is a casualty. We are all exposed to the most calamitous accidents, and our happiness or misery depends upon a thousand contingencies; the best-concerted schemes may be thwarted by casualties, which no human foresight can prevent.

Accidental, see under Accident. Incidental, from incident, in Latin incidens and incido, or in, on, and cadere, to fall upon, signifies belonging to a thing by chance. Casual, see CASUALTY above. Contingent, see ContinGENCY above.

Accidental is opposed to what is designed or planned; incidental to what is premeditated; casual to what is constant and regular; contingent to what is definite and fixed. A meeting may be accidental, an expression incidental, a look, expression, etc., casual, an expense or circumstance contingent. We do not expect what is accidental; we do not suspect or guard against what is incidental; we do not heed what is casual; we are not prepared for what is contingent. Many of the most fortunate and important occurrences in our lives are accidental; many remarks, seemingly incidental, do in reality concea' 
a settled intent; a casual remark in the course of conversation will sometimes make a stronger impression on the minds of children than the most eloquent and impressive discourse or repeated counsel; in the prosecution of any plan we ought to be prepared for the numerous contingencies which we may meet with to interfere with our arrangements.

aCClamation. See Applause.

aCClimate. See Naturalize.

ACCOMMODATE. See Fit.

ACCOMMODATOR, AssisTANT, HELPER. Accommodator, from the Latin accommodatus or accommodo, that from ad, to, and commodo, to adapt, signifies, literally, one who accommodates another, who adapts himself or herself to the wishes of another. While the accommodation may be rendered in any desired direction, the term accommodator has recently taken on a new application, ard now implies a man or woman who makes a business of hiring out by the hour or day to render whatever assistance or help a housewife may require.

Assistant (for the derivation see assist urider HELP) has a less specialized meaning. It designates any one whose office it is to aid another in his work - assistant secretary, assistant editor, assistant to the president, etc. Helper is more colloquial and informal. We speak of the helpers in any regularly organized business office as assistants, but an assistant in certain household duties is often called a "mother's helper," and country people speak of their "hired help" rather than of their "hired assistants."

ACCOMPANIMENT, COMPANION, Concomitant. Accompaniment is properly a collective term to express what goes in company, and is applied only to things; companion, which also signifies what is in the company, is applied either to persons or to things. Concomitant, from the intensive syllable con and comes, a companion, implies what is attached to an object, or goes in its train, and is applied only to things.

When said in relation to things, $a c-$ companiment implies a necessary connection, companion an incidental connection; the former is as a part to a whole, the latter is as one whole to an- other; the accompaniment belongs to the thing accompanied, inasmuch as it serves to render it more or less complete; the companion belongs to the thing accompanied, inasmuch as they correspond: in this manner singing is an accompaniment to instrumental music; subordinate ceremonies are the accompaniments in any solemn service; but a picture may be the companion of another picture from their fitness to stand together. A concomitant is as much of an appendage as the accompaniment, but it is applied only to moral objects; thus morality is a concomitant to religion.

ACCOMPANY, AtTend, Escort. Accompany, Old French companie, Low Latin companiem, is compounded of con, with, and panis, bread, and signifies the breaking of bread together, hence friendly intercourse and society. Accompany is compounded of $a d$, to, and companiem, and hence means to give one's society to another. Attend, in French attendre, compounded of ad and tendere, to tend or incline toward, signifies to direct one's notice or care toward any object. Escort, in French escorter, from the Latin $e x$ and corrigo (set right or correct), meant to guide in the right direction, and referred especially to the band of armed attendants delegated to guide a traveler through a dangerous country.

We accompany those with whom we wish to go; we attend those whom we wish to serve; we escort those whom we are called upon to protect or guard. We accompany our equals, we attend our superiors, and escort superiors or inferiors. The desire of pleasing or being pleased actuates in the first case; the desire of serving or being served, in the second case; the fear of danger or the desire of security, in the last place. One is said to have a numerous company, a crowd of attendants, and a strong escort; but otherwise one person only may accompany or attend, though several are wanting for an escort. Friends accompany each other in their excursions; a servant attends his master on a journey; a strong escort is necessary in traveling through unfrequented and dangerous roads.

Accompany and attend may likewise be said of things as well as persons. 
In this case the former is applied to what goes with an object so as to form a part of it; the latter to that which follows an object as a dependent upon it. Pride is often accompanied by meanness, and attended with much inconvenience to the possessor.

ACCOMPLICE. See

Confederate.

ACCOMPLISH, EFFECT, ExecUTE, AcHIEve. Accomplish, in French accomplir, is compounded of the intensive syllable $a c$ or ad, and complir, in Latin compleo, fill to the top, signifying to finish entirely. Effect, in Latin effectus, participle of efficio, compounded of $e x$, out of or up, and facere, to make, signifies to make until nothing remains to be done. (Compare the colloquial phrase "How did you make out with it?") Execute, in Latin executus, participle of exsequor, compounded of ex and sequor, follow, signifies to carry through to the end. (Compare the business slang "follow-up methods," etc.) Achieve, in French achever, from the phrase venir a chef, Latin ad caput venire, come to a head, expresses the same meaning by another and, to us also, a familiar metaphor.

To accomplish is properly a mode of effecting, namely, to effect completely, or to the utmost extent proposed; to accomplish an object, therefore, signifies more than simply to effect a purpose, both as to the thing aimed at and the means employed in bringing it about. Extraordinary means are requisite for accomplishing, and ordinary means for effecting. To accomplish is properly said of that which a person sets before himself; but to effect, execute, and achieve do not relate to the views of the person acting, but to the thing brought about. To effect expresses less than execute or achieve; whatever is brought about or into effect is effected; what is executed is complicated in its nature, as to execute a design or project; what is achieved is grand, as to achieve an enterprise. Practical abilities are requisite for effecting, skill for executing, spirit and talent for achieving. Some persons are always striving to attain an end without even accomplishing what they propose. It is the part of wisdom to suit the means to the end when we have any scheme to effect. Those who are readiest in forming projects are not always the fittest for carrying them into execution. That ardor of character which impels to the achievement of arduous undertakings belongs but to very few. We should never give up what we have the least chance of accomplishing, if it be worth the labor; nor pursue any plan which affords us no prospect of effecting what we wish; nor undertake what we do not feel ourselves competent to execute, particularly when there is anything extraordinary to achieve.

See also Fulfil.

Accomplished, Perfect, Accomplishment, Perfection.-These epithets express an assemblage of all the qualities suitable to the subject; and mark the qualification in the highest degree. Accomplished refers only to the artificial refinements of the mind; perfect is said of things in general, whether natural or artificial, mental or corporeal.

An acquaintance with modern languages and the ornamental branches of the arts and sciences constitutes a person accomplished; the highest possible degree of skill in any art constitutes a man a perfect artist.

An accomplishment is acquired; but a perfection is either acquired or natural. See also Qualification.

ACCORD. See Agree; TAlly.

ACCORDANCE. See Melody.

ACCORDANT. See Consonant.

ACCORDINGLY. See Therefore.

ACCOST, Salute, Address, Greet, HaIl, Welcome. Accost, in French accoster, is compounded of ad, and the Latin costa, a rib or side, signifying to come by the side of a person. Salute, in Latin saluto, from salus, health, signifies to bid good-speed. Address, in French adresser, compounded of ad and dresser, from the Low Latin drictus, a contracted form of directus, straight, signifies to direct one's discourse to a person.

See also under ABILTty.

To accost and salute are said of persons on their first meeting; address may be said of those who direct their discourse to others at any time. The leading idea of accost is that of speaking to a person on coming up to him; salute is to notice a person, which may be by 
words or otherwise; that of address is to direct one's words to the individual, which may either be personally or by writing. Accosting is an act of familiarity not warranted by anything but an intimate acquaintance, or for purposes of business; saluting is an aet of courtesy between friends which cannot be dispensed with; addressing is a matter of convenience or discretion.

Greet, Anglo-Saxon gretan, to visit or address, implies a verbal and friendly salute between equals, conveying a good and kind wish. Hail, from heal and health, denotes a wish for the health and long life of the person addressed, which was a customary form of address among the Eastern nations on approaching their sovereign; the word is now used to denote a similar expression on solemn occasions, particularly by the poets. Welcome denotes an expression of good wishes and kind regards on a person's first arrival; it is therefore confined to strangers or those who have been absent for a time. See also under ACCEPTABLE.

ACcount, Reckoning, Bill. Account, compounded of ad and count, signifies to count to a person; an account is the thing so counted. Reckoning, from the verb to reckon, signifies the thing reckoned up. Bill, Low Latin billa, is derived from Latin bulla, a sealed writing fastened with a bulla or a round seal like a knob, knob being the original meaning of the word. (The same root appears in the words bulletin, Papal bull, billet-doux, etc.) These words, which are very similar in signification, may frequently be substituted for one another.

Account is the generic, the others the specific terms; a reckoning and bill is an account, though not always vice versa; account expresses the details, with the sum of them counted up; reckoning implies the register and notation of the things to be reckoned up; bill denotes the details, with their particular charges. An account should be correct, containing neither more nor less than is proper; a reckoning should be explicit, leaving nothing unnoticed as to dates and names; a bill should be fair. We speak of keeping an account, of coming to a reckoning, of sending in a bill. Customers have an account with their tradespeople; masters have a reckoning with their workpeople; tradesmen send in their bills at stated periods.

Account, from the extensive use of the term, is applicable to everything that is noted down, the particulars of which are considered worthy of notice, individually or collectively: merchants keep their accounts; an account is taken at the Custom-House of all that goes in and out of the kingdom; an account is taken of all transactions, of the weather, of natural phenomena, and whatever is remarkable. Reckoning, as a particular term, is more partial in its use; it is mostly confined to the dealings of men with one another; in which sense it is superseded by the preceding term, and now serves to express only an explanatory enumeration, which may be either verbal or written. Bill, as implying something charged or engaged, is used not only in a mercantile, but a legal sense; hence, we speak of a bill of lading, a bill of parcels, a bill of exchange, a bill of indictment, or a bill in Parliament, Congress, or a Legislature. See also Reckon; SaKe.

Account, Narrative, Description.Account is the most general of these terms; whatever is noted as worthy of remark is an account. Narrative, from narrate, in Latin narratus, from narus or gnarus, knowing, signifies the thing made known. Description, from describe, in Latin describo, from de, down, and scribere, to write, signifies the thing written down.

Account has no reference to the person giving the account; a narrative must have a narrator; a description must have a describer. An account may come from one or several quarters, or no specified quarter; but a narrative and description bespeak themselves as the production of some individual. $A c$ counts from the armies are anxiously looked for in time of war; he suddenly broke off his narrative; his book is full of descriptions.

An account may be given of political events, domestic occurrences, or natural phenomena, but more particularly of matters of temporary and immediate interest; it may be true or false; a narrative is mostly personal, respecting the proceedings, accidents, or adventures of individuals; it may be real or ficti- 
tious; a description does not so much embrace occurrences as local circumstances, properties, and characteristics; it is either correct or otherwise.

ACCOUNTABLE, See ANswerABLE.

ACCUMUlate. See Absorb; ACQuire; Collect; Gain; Gather; Heap.

ACCURATe, Exact, Precise. Accurate, in French accurate, Latin accuratus, participle of accuro, compounded of the intensive ad and curare, to take care of, signifies done with great care. Exact, in French exacte, Latin exactus, participle of exigere, to finish or complete, denotes the quality of completeness, the absence of defect. Precise, in French précis, Latin pracisus, participle of procidere, to cut by rule after the manner of carpenters, signifies the quality of doing by rule.

Accurate refers to the care bestowed upon any matter to make it what it ought to be; exact and precise simply denote the quality of the thing, the former implying completeness, the latter nicety as to the manner of executing anything. From this difference in their meaning arises a difference in their application; a painting, on examination or on observation, is more properly said to be accurate; a model, figure, or measure, to be exact; a line, a rule, or a form, to be precise.

These epithets rise in sense upon each other, exact signifying more than accurate, and precise a greater degree of minuteness than either. With this distinction they may be applied to the same or similar objects: a description or view may be accurate and exact, but in the former case it is only just as far as it goes, in the latter it is fuller of particulars and details.

In denoting moral qualities or habits, accuracy may be applied to whatever men attempt to do; exactness to matters of economy, prudence, and duty; precision, in regard to manners, modes, and forms. Accuracy is indispensable in either business or science, but particularly in commercial and legal transactions; exactness is requisite in the payment of debts and the observance of all obligations. Some men may be very accurate in their particular line who are not very exact in fulfilling their engage- ments. In some cases, where great results may flow from trifling causes, the greatest precision becomes requisite; we may, however, be too precise when we dwell on unimportant particulars or adhere too tenaciously to forms and modes, but we never can be too accurate or exact; hence the epithet precise is sometimes taken for affectedly exact. A man may be precise in his dress who is not remarkable either for accuracy or exactness in his general conduct. A time or a period is said to be exact, an hour, a moment, or instant, precise; an expression accurate; the meaning of a word precise.

ACCUSATION. See Complaint.

ACCUSE, Charge, Impeach, ArRAIGN. Accuse, in Latin accuso, compounded of ad and causa, a cause or trial, signifies to bring to trial. Charge, like cargo, is derived from Low Latin carrico, to load a car (Latin carrus). Impeach, in French empêcher, to hinder or disturb, compounded of in and pes, the foot, significs to entangle the feet in anything. Arraign, Old French aranier, areisnier, from Latin ad and ratio, reason, meant to reason against, to bring a formal charge against another.

The idea of asserting something to the prejudice of another is common to these terms; but accuse is said of acts, charge of moral qualities constituting the character: we accuse a person of murder; we charge him with dishonesty. Accuse is properly a formal action; charge is an informal action: criminals are accused, and their accusation is proved in a court of judicature to be true or false; any person may be charged, and the charge may be either substantiated or refuted in the judgment of a third person.

Impeach and arraign are both species of accusing; the former in application to statesmen and state concerns, the latter in regard to the general conduct or principles; with this difference, that he who impeaches only asserts the guilt, but does not determine it; but those who arraign also take upon themselves to decide: statesmen are impeached for misdemeanors in the administration of government: kings arraign governors of provinces and subordinate princes, and in this manner kings are sometimes 
arraigned before mock tribunals: our Saviour was arraigned before Pilate; and creatures in the madness of presumption arraign their Creator.

Accuse, Censure.-Accuse, see above. Censure, in French censure, in Latin censura, is derived from censor, a Roman magistrate who took cognizance of the morals and manners of the citizens, as also of the domestic arrangements of the city. It signifies not only the office of censor, but, in an extended sense, the act of blaming or punishing offenders against morality, which formed a prominent feature in his office.

To accuse is only to assert that which is prejudicial to another; to censure is to take the fault for granted. We accuse only to make known the offence, to provoke inquiry; we censure in order to inflict a punishment. An accusation may be false or true; a censure mild or severe. It is extremely wrong to accuse another without sufficient grounds; but still worse to censure him without the most substantial grounds. Every one is at liberty to accuse another of offences which he knows him for a certainty to have committed; but none can censure who are not authorized by their age or station.

ACHIEVE. See Accomplish.

ACHIEVEMENT. See DEED.

ACKNOWLEDGE, OWN, ConFEss, Avow. The first of these terms, compounded of $a$ and knowledge, implies to bring to knowledge, to make known. Own is a familiar figure, signifying to take to one's self, to make one's own; it is a common substitute for confess. Confess, in French confesser, Latin confessus, participle of confiteor, compounded of con, together, and fateor, I speak, signifies to impart to any one. Avow, in French avouer, Latin advovco, signifies to vow or protest to any one.

These words all denote the making known to others what relates to one's self, or that in which one has taken a part; acknowledge is used in this general sense in a diversity of applications; the other terms are partially employed, and with various modifications in their meaning. Acknowledge and own are employed either in matters of indifference or those which are blameworthy; con- fess mostly in such matters as are criminal or in a high degree culpable. A person acknowledges that he was present, or owns that he assisted another, he confesses a theft, or confesses his guilt, or a sinner confesses his sins. To acknowledge and own, when applied to culpable matters, may either have respect to particular transactions or general characteristics, as to acknowledge or own the fact, to acknowledge or own one's weakness, fallibility, incapacity, etc.; to confess is mostly said of particular transactions, as to confess the crime laid to one's charge. To acknowledge, being a voluntary act, may be either by words or actions, or tacitly without any outward expression; confessing, on the other hand, being mostly called for in consequence of an interrogatory or the neccssities of the party, must always be by express words.

To acknowledge and own also signify to admit that a thing belongs to one, but the former denotes only a general relationship, the latter a special ownership; with this distinction we may speak of acknowledging or owning a son; but we may likewise acknowledge many things which we cannot properly own, as to acknowledge a woman as one's wife, or any particular person as a prince, or any particular state as independent.

To acknowledge, own, and confess are all used in the sense of expressing one's mind or what passes in one's mind, in which application they are comparable with avow. In this ease to acknovledge is most properly applied to matters of opinion, own to matters of feeling, although they may in many such cases be indifferently employed.

To acknowledge is to declare in a general manner one's assent to anything: to confess is to declare in a solemn manner one's assent to matters of faith; to avow is to declare the motives or reasons of one's actions, particularly such as might with more propriety be concealed; as to acknowledge the justness of a remark, to confess the faith, to avow one's motives, contempt, scorn, etc. Sce also Recognize.

ACME. See ZENITH.

ACQUAINT. See INForM.

ACQUAINTANCE. FAMILIARITY, 
INTIMACY. Acquaintance, from acquaint, is derived from the Old 'French acointer (Latin ad and cognitus, from the verb cognosco which is cognate with the English know and has the same meaning); it signifies being known to another. Familiarity comes from familiar, in Latin familiaris and familia (from famulus, a servant), signifying known as one of the household. Intimacy, from Latin intimus, innermost, signifies known to the innermost recesses of the heart. These terms mark different degrees of closeness in the social intercourse; acquaintance expressing less than familiarity, and that less than intimacy.

Acquaintance springs from occasional intercourse; familiarity is produced by a daily intercourse, which wears off all constraint and banishes all ceremony; intimacy arises not merely from frequent intercourse, but unreserved communication. An acquaintance will be occasionally a guest; but one that is on terms of familiarity has easy access to our table; and an intimate likewise lays claim to a share, at least, of our confidence. An acquaintance with a person affords but little opportunity for knowing his character: familiarity puts us in the way of seeing his foibles, rather than his virtues; but intimacy enables us to appreciate his worth.

A simple acquaintance is the most desirable footing on which to stand with all persons, however deserving. If it have not the pleasures of familiarity or intimacy, it can claim the privilege of being exempted from their pains. "Too much familiarity," according to the old proverb, "breeds contempt." The unlicensed freedom which commonly attends familiarity affords but too ample scope for the indulgence of the selfish and unamiable passions. Intimacies begun in love often end in hatred, as ill-chosen friends commonly become the bitterest enemies. A man may have a thousand acquaintances, and not one whom he should make his intimate.

These terms may be applied to things as well as persons, in which case they bear a similar analogy. An acquaintance with a subject is opposed to entire ignorance upon it; familiarity with it is the consequence of frequent repetition; and intimacy of a steady and thorough research. In our intercourse with the world we become daily acquainted with fresh subjects to engage our attention. Some men have by extraordinary diligence acquired a considerable familiarity with more than one language and science; but few, if any, can boast of having possessed an intimate acquaintance with all the particulars of even one language or science. When we can translate the authors of any foreign language, we may claim an acquaintance with it; when we can speak or write it freely, we may be said to be familiar with it; but an intimate acquaintance comprehends a thorough critical intimacy with all the niceties and subtleties of its structure.

\section{ACQUIESCE. See Agree.}

ACQUIRE, OBTAIN, GaIN, WIN, EARN. Acquire, Old French acquérir, Latin acquiro, is compounded of ad, to, and quarere, to seek, signifying to seek or get for one's self. Obtain, in French obtenir, Latin obtineo, is compounded of $o b$, near, and tenere, to hold, signifying to lay hold or secure within one's reach. Gain comes from French gagne, from a Teutonic root signifying a pasture, hence something to be desired among shepherd-people, hence success, profit. Win comes from Anglo-Saxon winnan, to fight or struggle, hence to succeed in a struggle. Earn comes from AngloSaxon earnian, allied to German ernte, a harvest.

The idea of getting is common to these terms, but the circumstances of the action vary. We acquire by our own efforts; we obtain by the efforts of others as well as ourselves; we gain or win by striving; we earn by labor. Talents and industry are requisite for acquiring; what we acquire comes gradually to us in consequence of the regular exercise of our abilities; in this manner, knowledge, honor, and reputation are acquired. Things are $o b$ tained by all means, honest or dishonest; whatever comes into our possession agreeable to our wishes is obtained; favors and requests are always obtained. Fortune assists in both gaining and winning; but particularly in the latter case; a subsistence, a superiority, a victory, or battle, is gained; a game or a prize in the lottery is won. A good 
constitution and full employment are all that is necessary for earning a livelihood. Fortunes are acquired after a course of years; they are obtained by inheritance, or gained in trade.

What is acquired is solid, and produces lasting benefit; what is obtained may often be injurious to one's health, one's interest, or one's morals: what is gained or won is often only a partial advantage, and transitory in its nature; it is gained or won only to be lost; what is earned serves sometimes only to supply the necessity of the moment; it is hardly got and quickly spent. Scholars acquire learning, obtain rewards, gain applause, and win prizes, which are often hardly earned by the loss of health.

Acquire, Attain.-To acquire is a progressive and permanent action. To attain, in Latin attingo, compounded of ad and tango, touch, signifies to touch the goal, to reach the end, and represents a perfect and finished action. We always go on acquiring; but we stop when we have attained. What is acquired is something got into one's possession; what is attained is the point arrived at. We acquire a language; we attain to a certain degree of perfection. By abilities and perseverance we may acquire a considerable fluency in speaking several languages; but we can scarcely expect to attain to the perfection of a native in any foreign language. Ordinary powers coupled with diligence will enable a person to acquire whatever is useful; but we cannot attain to superiority without extraordinary talents and determined perseverance. Acquirements are always serviceable; attainments always creditable.

Acquirement, Acquisition.-Two abstract nouns, from the same verb, denoting the thing acquired. Acquirement implies the thing acquired for and by ourselves; acquisition, that which is acquired for the benefit of one's self or another. People can expect to make but slender acquirements without a considerable share of industry; and without them they will be no acquisition to the community to which they have attached themselves. Acquirement rather the exertions employed; $a c$ quisition the benefit or gain accruing. To learn a language is an acquirement; to gain a class or a degree, an acquisition. The acquirements of literature far exceed in value the acquisitions of fortune.

ACQUIT. See ABsolve.

ACRIMONY, TARTNESS, ASPERITY, HARSHNESS. These epithets are figuratively employed to denote sharpness of feeling corresponding to the quality in natural bodies. Acrimony, in Latin acrimonia, from acer, sharp, is the characteristic of garlic, mustard, and pepper, that is, a biting sharpness. Tartness, from tart, AngloSaxon teart, sharp, from teran, tear, is associated with the idea of tearing as bitter is associated with that of biting. Asperity is derived from the Latin asper, a word of uncertain etymology signifying rough. Harshness is the substantive corresponding to harsh, a Scandinavian word signifying rank, unpleasant to the taste, and denotes especially the sharp, rough taste of unripe fruit.

A quick sense produces acrimony; it is too frequent among disputants, who embitter each other's feelings. An acute sensibility, coupled with quickness of intellect, produces tartness; it is too frequent among females. Acrimony is a transient feeling that discovers itself by the words; tartness is an habitual irritability that mingles itself with the tone and looks. An acrimonious reply frequently gives rise to much ill-will; a tart reply is often treated with indifference, as indicative of the natural temper, rather than of any unfriendly feeling.

Asperity and harshness respect one's conduct to inferiors; the latter expresses a strong degree of the former. A sperity is opposed to mildness and forbearance; harshness to kindness. A reproof is conveyed with asperity, when the words and looks convey strong displeasure; a treatment is harsh when it wounds the feclings and does violence to the affections. Mistresses sometimes chide their servants with asperity; parents sometimes deal harshly with their children.

ACT, Do, MAKE. Act, in Latin actus, participle of ago, Greek ă $\gamma \omega$, drive 
or impel, signifies literally to move or put in motion. Do, in German thun,

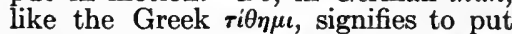
or put in order, to bring to pass. Make, Anglo-Saxon macian, corresponds to German machen, and is allied to match.

All these terms imply to exert a power in a given form and manner: act, which is the general term, conveys this general idea without any further qualification; the other terms convey this idea with modifications. We always act when we do, but we do not always do when we act. To act is applied either to persons or things, as a spring or a lock acts; to do applies in this sense to persons only. To act is also mostly intransitive or reflective, as to act well or ill in this or that manner; to do is always transitive, as to do right or wrong, to do one's duty.

One may either act a part or do one's part, which are essentially different things; to act a part is either really or fictitiously to act in any part; but to do our part is to do that which is allotted to us as our part or duty.

To do and to make, in regard to persons, are both used in the sense of voluntarily exerting a power to bring a thing to pass; but do applies to the ordinary business of life or what is done by a given rule, as to do a work, to do justice; make applies to that which is done by a particular contrivance? or for a particular purpose, as to make a pen or a table, etc. What is done once may have been done before, and may be done again; but what is made is at once brought into existence, and, if it be made again, it can only be by imitation.

To do and to make, as applied to things, signify to cause; but the former is used only in the expressions to do good or harm, the latter is ordinarily used, to make room, to make a thing easy, etc.

Act, Work, Operate.-To act is to exert a simple power, or by simple means, as a wire acts. Work, Anglo-Saxon wyrcan, like the German wirken, etc., is to exert complex powers, or exert power by a gradual process. A machine works, but each of its parts is said to act; so beer works, and bread works; acting may be accompanied with no particular effect or change in the body that acts, but that which works mostly undergoes a change and also produces changes, as medicine, which works in the system. Sometimes act as well as work is taken in the sense of exerting a power upon other bodies and producing changes, as the sun acts on the plants.

To work and operate both imply to $a c t$, or exert a power in order to bring about some end or purpose; but operate is applied to matters of a general nature in science or morals, as a measure operates, or words may operate on the mind, or reasons may operate on the understanding. To work is mostly applied to familiar matters and particular objects, as the hand works, the head works, the brain works; operate is always intransitive.

As nouns, action implies either the act of acting or the thing done; work, the act or state of working, or what results from the work, as to go to work or be at work, the work of one's hands; operation, either to the act of operating, as the operation of thought or the operation of vegetation, or the mode of operating, as the operations of time are various. 4

See also DeaL.

Act, Action, Deed.-The words act, action, and deed, though derived from the preceding verbs, have an obvious distinction in their meaning. Act, in French acte, Latin actum, denotes the thing done. Action, in French action, Latin actio, signifies doing. Act is a single exercise of power, as an act of the will or an act of the mind, the act of walking, speaking, and the like; action a continued exercise of power, or a state of exercising power, as to be in action, as opposed to rest; the action of walking is agreeable in fine weather.

When these words are taken in the sense of the thing done, they admit of a similar distinction. An act is the single thing done, or what is done by a single effort, as that is your act or his act; an action may consist of more acts than one, or embrace the causes and consequences of the action, as a bold action, to judge of actions, etc.

Hence it is that the term act is more proper than action where it is so defined as to imply what is single and simple, as an act of authority, an act of government, an act of folly, and the like; but otherwise the word action is to be pre- 
ferred where the moral conduct or character is in question. We may enumerate particular acts of a man's life, as illustritive of certain traits in his character, or certain circumstances in his life; but to speak at large of his actions would be to describe his character.

Act and deed are both employed for what is done; but act refers to the power exerted, and deed to the work performed; as a voluntary or involuntary act, a good or bad deed.

$A c t$ is mostly employed either in an abstract or familiar application; deed is employed for whatever men do in the business of life, particularly in those things which are extraordinary.

Acts are either public or private, of individuals or of bodies, as acts of government; acts of Parliament; deeds are always private, or what is done by men individually.

$A c t s$ are in their proper sense informal; but deeds may sometimes be formal instruments: when you speak of a thing as a man's act and deed, this is not tautology; it is his act as far as he and no one else acts in it, it is his deed as far as it is that which is done completely or is accomplished.

Action, Gesture, Gesticulation, Posture, Attitude.-Action, see derivation in preceding group of words; also BATTLE. Gesture, Low Latin gestura, Latin gestus, participle of gero, carry, signifies the manner of carrying one's body. Gesticulation, in Latin gesticulatio, comes from gesticulor, to make many gestures. Posture, in French posture, Latin positura, a position, comes from positus, participle of pono, signifying the manner of placing one's self. Attitude, in French attitude, Italian attitudine, is a doublet of aptitude, signifying a propriety in the disposition of one's body.

All these terms are applied to the state of the body; the three former indicating a state of motion, the two latter a state of rest. Action respects the movements of the body in general; gesture is an action indicative of some particular state of mind; gesticulation is a species of artificial gesture. Raising the arm is an action; bowing is a gesture. Actions may be ungraceful; gestures indecent. A suitable action some- times gives great force to the words that are uttered; gestures often supply the place of language between people of different nations. Actions characterize a man as vulgar or well-bred; gestures mark the temper of the mind. There are many actions which it is the object of education to prevent from growing into habits; savages express the vehement passions of the mind by vehement gestures on every occasion, even in their amusements. An extravagant or unnatural gesture is termed a gesticulation; a sycophant, who wishes to cringe into favor with the great, deals largely in gesticulation to mark his devotion; a buffoon who attempts to imitate the gestures of another will use gesticulation; and the monkey who apes the actions of human beings does so by means of gesticulations.

Posture and attitude both imply a mode of placing the body, but the posture is either natural or assumed; the attitude is always assumed or represented: natural postures are those in which the body places itself for its own conveniences, as sitting, standing, or lying postures.

A posture, when assumed, may be distorted or ridiculous, to suit the humor of the party, as mountebanks put themselves into ridiculous postures; or they may be artfully contrived to improve the carriage of the body, as the postures of a dancing-master; and, in graver matters, a person may put himself in a pasture of defence.

An attitude is assumed in order to display some grace of the body, or some affection or purpose of the mind, as to stand in a graceful attitude, to represent any one in the attitude of prayer.

These terms may be applied to things personified, with precisely the same distinction. They may also be applied figuratively to other objects besides the body, as an army assumes a menacing attitude, a critical posture of affairs.

Action, Agency.-Action is the effect; agency the cause. Action is inherent in the subject; agency is something exterior; it is, in fact, putting a thing into action: in this manner the whole world is in action through the agency of the Divine Being.

ACTIVE, Diligent, Industrious, Assiduous, Laborious. Active, from 
the verb to act, implies a propensity to act, to be doing something without regard to the nature of the object. Diligent, in French dilligent, Latin diligens, participle of diligo, to choose or like, implies an attachment to an object, and consequent attention to it. Industrious, in French industrieux, Latin industrius, from indu, for in, and struere, to build, make, or do, signifies an inward or thorough inclination to be engaged in some serious work. Assiduous, in Latin assiduus, is compounded of ad and siduus, from sedere, to sit, signifying to sit close to a thing. Laborious, in French laborieux, Latin laboriosus, from labor, signifies the inclination to labor.

We are active if we are only ready to exert our powers, whether to any end or not; we are diligent when we are active for some specific end; we are industrious when no time is left unemployed in some serious pursuit; we are assiduous if we do not leave a thing until it is finished; we are laborious when the bodily or mental powers are regularly employed in some hard labor. A man may be active without being diligent, since he may employ himself in what is of no importance; but he can scarcely be diligent without being active, since diligence supposes some degree of activity in one's application to a useful object. A man may be diligent without being industrious, for he may diligently employ himself about a particular favorite object without employing himself constantly in the same way; and he may be industrious without being diligent, since diligence implies a free exercise of the mental as well as corporeal powers; but industry applies principally to manual labor. Activity and diligence are, therefore, commonly the property of lively or strong minds, but industry may be associated with moderate talents. A man may be diligent without being assiduous; but he cannot be assiduous without being diligent, for assiduity is a sort of persevering diligence. A man may be industrious without being laborious, but not vice versa; for laboriousness is a severer kind of industry.

Active, Brisk, Agile, Nimble.-Active, see preceding group. Brisk is of ob- scure origin, possibly Celtic. Agile, in Latin agilis, comes from the same verb as active, signifying a fitness, a readiness to act or move. Nimble comes from Anglo-Saxon niman (German nehmen), to take, implying a capacity "to take hold," to "catch on," as we say to-day. Compare the name $N y m$, in Henry $V$, signifying thief.

Activity respects one's transactions; briskness one's sports: men are active in carrying on business; children are brisk in their play. Agility refers to the light and easy carriage of the body in springing; nimbleness to its quick and gliding movements in running. A ropedancer is agile; a female moves nimbly. Activity results from ardor of mind; briskness from vivacity of feeling: agility is produced by corporeal vigor and habitual strong exertion; nimbleness results from an habitual effort to move lightly.

See also Kinetic.

Active, Busy, Officious.-Active, same as in the preceding groups. Busy, Anglo-Saxon bysig, signifies to be actively engaged in some work. Officious, in French officieux, Latin officiosus, from officium, duty or service, signifies a propensity to perform some service or office.

Active respects the habit or disposition of the mind; busy and officious, either the disposition of the mind, or the employment of the moment: the former regards every species of employment; the latter only particular kinds of employment. An active person is ever ready to be employed; a person is busy when he is actually employed in any object; he is officious when he is employed for others. Active is always taken in a good, or at least an indifferent sense; it is opposed to lazy: busy, as it respects occupation, is mostly in a good sense; it is opposed to being at leisure; as it respects disposition, it is always in a bad sense; officious is seldom taken in a good sense; it implies being busy without diseretion. To an active disposition nothing is more irksome than inaction; but it is not concerned to inquire into the utility of the action. It is better for a person to be busy than quite unemployed; but a busy person will employ himself about the concerns of others when he has 
none of his own sufficiently important to engage his attention; an officious person is as unfortunate as he is troublesome; when he strives to serve he has the misfortune to annoy.

ACTOR, AGENT. These terms vary according to the different senses of the verb from which they are drawn. Actor is used for one who either acts a part, or who represents the actions and characters of others, whether real or feigned.

Agent is, in the general sense, an active or acting being, one possessing and exerting the faculty of action, as a free agent, a moral agent. The agent is properly opposed to the patient in the physical world. Agent is also taken generally for whatever puts in motion.

Actor, Player, Performer.-The actor and player both perform on a stage; but the former is said in relation to the part that is acted, the latter to the profession that is followed. We may be actors occasionally, without being players professionally, but we may be players without deserving the name of actors. Those who personate characters for their amusement are actors, but not players; those who do the same for a livelihood are players as well as actors; hence we speak of a company of players, not actors. So, likewise, in the figurative sense, whoever acts a part real or fictitious, that is, on the stage of life, or the stage of a theatre, is an actor; but he only is a player who performs the fictitious part; hence the former is taken in a bad or good sense, according to circumstances.

The player is always taken in a less favorable sense, from the artificiality which attaches to his profession.

Performer signifies, in its most general sense, one that performs any act or part; but in a limited sense, one who performs a part in a public exhibition, whether as a singer, actor, dancer, or otherwise.

aCtual, Real, Positive. Actwal, in French actuel, Latin actualis, from actio, a deed, signifies belonging to the thing done. Real, in French réel, Latin realis, from res, signifies belonging to the thing as it is. Positive, in French positif, Iatin positivus, from pono, place or fix, signifies the state or quality of being fixed, established.
What is actual has proof of its existence within itself, and may be exposed to the eye; what is real may be satisfactorily proved to exist; and what is positive precludes the necessity of a proof. Actual is opposed to the supposititious, conceived or reported; real to the feigned, imaginary; positive to the uncertain, doubtful. Whatever is the condition of a thing for the time being is the actual condition; sorrows are real which flow from a substantial cause; proofs are positive which leave the mind in no uncertainty. The actual state of a nation is not to be ascertained by individual instances of poverty, or the reverse; there are but few, if any, real objects of compassion among common beggars; many positive facts have been related of the deception which they have practised. By an actual survey of human life, we are alone enabled to form just opinions of mankind; it is but too frequent for men to disguise their real sentiments, although it is not always possible to obtain positive evidence of their insincerity.

See also OBjective.

ACTUATE, IMPEL, INDUCE. Actuate, from the Latin actum, an action, implies to call into action. Impel, in Latin impello, is compounded of in, toward, and pellere, to drive, signifying to drive toward an object. Induce, in Latin induco, is compounded of in, in, and ducere, to lead, signifying to lead into an object.

One is actuated by motives, impelled by passions, and induced by reason or inclination. Whatever actuates is the result of reflection; it is a steady and fixed principle: whatever impels is momentary and vehement, and of ten precludes reflection: whatever induces is not vehement, though often momentary. One seldom repents of the thing to which one is actuated; as the principle, whether good or bad, is not liable to change: but we may frequently be impclled to measures which cause serious repentance: the thing to which we are induced is seldom of suff.cient importance to call for repentance.

aCUTe, Keen, Shrewd, Sharp. Acute, in French aigu, Latin acutus, associated with acus, a nẹecile, signifies the quality of sharpness and pointed- 
ness peculiar to a needle. Keen in Anglo-Saxon cene, is related to the German kühn, bold, and signified originally energy and activity of spirit, hence quickness of mind. Shrewd, from the verb shrewen, to curse, beshrew, is from Anglo-Saxon screawa, a shrewmouse, whose bite was venomous, and is allied to the word shrew, a scolding woman. It meant malicious, cunning, sharp, in the double sense-sharp of temper, and sharp of mind and tongue -hence the modern significance.

In the natural sense, a fitness to pierce is predominant in the word acute; and that of cutting, or a fitness for cutting, in the word keen. The same difference is observable in their figurative acceptation. An acute understanding is quick at discovering truth in the midst of falsehood; it fixes itself on a single point with wonderful celerity: a keen understanding cuts or removes away the artificial veil under which the truth lies hidden from the view: a shrewd understanding is rather quicker at discovering new truths than at distinguishing truth from falsehood. Acuteness is requisite in speculative and abstruse discussions; keenness in penetrating characters and springs of action; shrewdness in eliciting remarks and new ideas. The acute man detects errors, and the keen man falsehoods; the shrewd man exposes follies. Arguments may be acute, reproaches keen, and replies or retorts shrewd. A polemic, or a lawyer, must be acute, a satirist keen, and a wit shrewd.

Sharp primarily signifies a thin edge or fine point; also artful, crafty, subtle. A pain, ache, or retort in conversation may be distressingly sharp. An unscrupulous person is often guilty of sharp practice in dealing with others.

See also Sharp.

ACUTENesS. See Gumption; PenETRATION.

ADAGE. See Axiom.

ADAPT. See Fit.

ADD, Join, Unite, Coalesce. $A d d$, in Latin addo, compounded of ad and $d o$, to give or put, signifies to put one thing to another. Join, in French joindre, and Latin jungo, is in all probability connected with, if not derived from, the Greek, $\xi \varepsilon \tilde{v} \gamma \omega$, to yoke, that is, to set one thing in juxtaposition with another. Unite, from the Latin unus, one, signifies to make into one. Coalesce, in Latin coalesco, from con, together, and alescere, to grow, signifies to grow together.

We add by putting a part to any body so as to form a whole; we join by attaching two whole bodies to each other; we unite by putting two bodies to or into one another, so that they may become one body; things coalesce when their parts mingle together so as to form one substance. Additions may be made to whatever admits of becoming greater in size or quantity; a wing may be added to a building, or a house may be added to a row of houses; junctions may be made of any two bodies which can touch each other in any part; thus two houses may be joined, or two countries, lands, kingdoms, etc., may be joined; unions may be formed of any things which admit of being made into one so as to lose their individuality; as, if two houses be made into one, they may be said to be united; things may be said to coalesce, the minutest parts of which will readily fall into one another; a coalition is properly a complete union, and is applied to the natural process of bodies. Adding is opposed to subtracting or diminishing, joining to separating, uniting to dividing, and coalescing to falling asunder.

They preserve this distinction in their moral application. One virtue or perfection may be added to another; persons join in matrimony, trade, or other particular act; they unite in families, in mind, or modes of living; qualities may be joined with others in the same substance, without any necessary connection between them; they are united when they belong to or are intimately connected with each other; nations coalesce when they adopt the same language, laws, and manners; parties coalesce when they lay aside their differences and unite.

See also INCREASE.

ADDICT, Devote, Apply. $A d$ dict, from addico, or ad and dico, to speak or declare in favor of a thing, signifies generally to apply one's self to it. Devote, from the Latin devoveo, or $d e$, on account or behalf of, and voveo, 
to vow, signifies to make a solemn vow or resolution for a thing. Apply, in French appliquer, and Latin applico, from $a p$ or $a d$ and plico, signifies to knit or join one's self to a thing.

To addict is to indulge one's self in any particular practice; to devote is to direct one's powers and means to any particular pursuit; to apply is to employ one's time or attention about any object. Men are addicted to learning; they devote their talents to the acquirement of any art or science; they apply their minds to the investigation of a subject.

Addict is seldomer used in a good than in a bad sense; devote is mostly employed in a good sense; apply in an indifferent sense. We are addicted to a thing from an irresistible passion or propensity; we are devoted to a thing from a strong, but settled, attachment to it; we apply to a thing from a sense of its utility. We addict ourselves to study by yielding to our passion for it; we devite ourselves to the service of our king and country by employing all our powers to their benefit; we apply to business by giving it all the time and attention that it requires.

ADDITION. See INCREASE.

ADDRESS, APPLY. For the derivation of these words see Accost and ADDicT.

An address is immediately directed from one party to the other, either personally or by writing; an application may be made through the medium of a third person. An address may be made for an indifferent purpose or without any express object; but an application is always occasioned by some serious circumstance. We address those to whom we speak or write; but we apply to those to whom we wish to communicate some objeet of personal interest. An address, thercfore, may be made without an application; and an application may be made by means of an address. An address may be rude or civil; an application may be frequent or urgent. It is impertinent to address any one with whom we are not acquainted, unless we have any reason for making an application to him. It is a privilege of the British Constitution that the subject may address the monarch, and apply for a redress of grievances. A court is addressed by a suitor or counsel on his behalf; it is applied to by means of legal forms for the redress of grievances. We cannot pass through the streets of the metropolis without being continually addressed by beggars, who apply for the relief of artificial more than of real wants. Men in power are always exposed to be publicly addressed by persons who wish to obtrude their opinions upon them, and to have perpetual applications from those who solicit favors.

See also Ability; Accost; DirecTION.

Address, Speech, Harangue, Oration. -Addrcss, see preceding terms for derivation. Speech, from Anglo-Saxon spoec, the substantive corresponding to speak, signifies the thing spoken. Harangue, Old French harangue, comes from Old High German hrinc, whence ring, rank, etc., are derived, and signified an address to a circle or ring of listeners. Oration, from the Latin oro, to beg or entreat, signifies that which is said by way of entreaty.

All these terms denote a set form of words directed or supposed to be directed to some person: an address in this sense is always written, but the rest are really spoken, or supposed to be so; a speech is in general that which is addressed in a formal manner to one person or more; a harangue is a noisy, tumultuous speech addressed to many; an oration is a solemn speech for any purpose. Addresses are frequently sent up to the throne by public bodies. Spceches in Parliament, like harangues at clections, are often little better than the crude effusions of party spirit. The orations of Demosthenes and Cicero, which have been so justly admired, received a polish from the correcting hand of their authors before they were communicated to the public.

ADDUCE, Allege, Assign, ADVANCE. Adduce, in Latin adducere, compoundled of ad and ducere, to lead, signifies to bring forward proofs or evidence in support of some statement or proposition already made. Allege, in French alléguer, in Latin allegare, compounded of ad and legare, from the stem lex, legis, law, signified to send with legal dispatehes, hence to affirm authoritatively. Assign, in French 
assigner, Latin assigno, compounded of as or ad and signo, to sign or mark out, signifies to set apart for a purpose. Advance, Middle English avancen, from French avant, Low Latin $a b$ (from) and ante (before), written abante, signified to come from the front ranks, to proceed from the front ranks forward.

An argument is adduced; a fact or a charge is alleged; a reason is assigned; a position or an opinion is advanced. What is adduced tends to corroborate or invalidate; what is alleged tends to criminate or exculpate; what is assigned tends to justify or support; what is advanced tends to explain and illustrate. Whoever discusses disputed points must have arguments to adduce in favor of his principles; censures should not be passed where nothing improper can be alleged; a conduct is absurd for which no reason can be assigned; those who advance what they cannot maintain expose their ignorance as much as their folly. We may controvert what is adduced or advanced; we may deny what is alleged, and question what is assigned. The reasoner adduces facts in proof of what he has advanced; the accuser alleges circumstances in support of his charge; the philosophical investigator assigns causes for particular phenomena.

ADEQUATE. See Proportionate. 'ADHERE, ATtach, AdHesion, AdHERENCE. Adhere, from the French adhérer, Latin adharo, is compound 'of $a d$ and horo, to stick close to. Attach, in French attacher, is compounded of ad and a root which is found in the English word tack, meaning peg or small nail, so that to attach was to fasten with a tack.

A thing is adherent by the union which nature produces; it is attached by arbitrary ties which keep it close to another thing. Glutinous bodies are apt to adhere to everything they touch; a smaller building is sometimes attached to a larger by a passage, or some other mode of communication. What adheres to a thing is closely joined to its outward surface; but what is attached may be fastened to it by the intervention of a third body. There is a universal adhesion in all the particles of matter one to another; the sails of a vessel are attached to a mast by means of ropes; or bodies are attached by bare locality, or being in the same enclosure.

In the improper and figurative application, things adhere from a fitness of their natures. Things are attached to each other by politicial ties.

Adherence and attachment are both applied to persons in a moral sense; the former as it respects matters of principle, the latter as it respects matters of inclination or interest. Adherence is always marked by a particular line of conduct; but attachment may exist without any particular expression. A person adheres to a prince or a community so long as he follows the one or co-operates with the other; he is attached to a person whenever the feeling or relation is created.

In the same manner, a person adheres to matters of opinion, by professing his belief; he is attached to objects from habit or private motives.

Adhesion and adherence are both derived from the verb adhere, one expressing the proper or figurative sense, and the other the moral sense or acceptation. There is a power of adhesion in all glutinous bodies, a disposition for adherence in steady minds.

See also STICK.

ADHERENT. See Follower.

ADJACENT, Adjorning, Contiguous. Adjacent, in Latin adjiciens, participle of adjicio, is compounded of $a d$ and jacio, to lie near. Adjoining, as the word implies, signifies being joined together. Contiguous, Latin contiguus, comes from contingo, or con and tango, signifying to touch close.

What is adjacent may be separated altogether by the intervention of some third object; what is adjoining must touch in some part; and what is contiguous must be fitted to touch entirely on one side. Lands are adjacent to a house or a town; fields are adjoining to each other; and houses contiguous to each other.

ADJECTIVE. See Epithet.

ADJOINING. See AdJACENT.

ADJOURN. See Prorogue.

ADJUST. See Counterpoise; Fit. ADMINISTER. See Minister. ADMINISTRATION. See GovERNMENT. 
ADMIRE. See Wonder.

ADMISSION. See ADMIT.

ADMIT, Recerve. Admit, in French admettre, Iatin admitto, compounded of $a d$ and mitto, signifies to send or suffer to pass to. Receive, in French recevoir, Latin recipio, compounded of re and capio, signifies to take back or to one's self.

To admit is a general term, the sense of which depends upon what follows; to receive has a complete sense in itself: we cannot speak of admitting without associating with it an idea of the object to which one is admitted; but receive includes no relative idea of the receiver or the received. Admitting is an act of relative import; receiving is always a positive measure: a person may be admitted into a house, who is not prevented from entering; he is received only by the actual consent of some individual. We may be admitted in various capacities; we are received only as guests, friends, or inmates. Persons are admitted to the tables, and into the familiarity or confidence of others; they are hospitably received by those who wish to be their entertainers.

When applied to unconscious agents, the distinction is similar: rays of light are admitted into a room, or ideas into the mind, when they are suffered to enter at pleasure; but things receive each other for specific purposes, according to the laws of nature.

We admit willingly or reluctantly; we receive politely or rudely. Foreign ambassadors are admitted to an audience, and received at court. It is necessary to be cautious not to admit any one into our society who may not be an agreeable and suitable companion; but still more necessary not to receive any one into our houses whose character may reflect disgrace on ourselves. Whoever is admitted as a member of any community should consider himself as bound to conform to its regulations; whoever is received into the service of another should study to make himself valued and esteemed. A winning address and agreeable manners gain a person admittance into the most refined circles; the talent for affording amusement procures a person a good reception among the mass of mankind.
Admit, Allow, Permit, Suffer, Tolerate.-Admit, see key word preceding. Allow, in French allower, from Latin allaudare, from laus, laudis, praise, signified to give approving consent. Compare laudatory, laudable, etc. Permit, in French permettre, Latin permitto, is compounded of per, through or away, and mitto, to send or let go, signifying to let go its way. Suffer, in French souffir, Latin suffero, is compounded of $s u b$ and fero (cognate with English bear), signifying to bear with. Tolerate, in Latin toleratus, participle of tolero, sustain, signifies to bear or bear with.

To admit is an involuntary or negative act; to allow is voluntary and positive: we admit by simply not refusing or preventing; we allow by positively granting or complying with; we admil that which concerns ourselves or is done toward ourselves; we allow that which is for the convenience of others, or what they wish to do: one admits the freedoms or familiarities of those who choose to offer them; one allows an indulgence to a child. To permit is very nearly allied to allow, both in sense and application, with this difference, tha prrmit is more formal and po:itive, bei $g$ employed in respect to more important matters; as a father permits his son to travel; one man permits another to use his name. To suffer and tolerate are nearly allied to admit, but both are mere passive acts, and relate to matters which are more objectionable and serious: what is admitted may be at most but inconvenient; what is suffered may be burdensome to the sufferer, if not morally wrong; what is tolerated is bad in itself, and suffered only because it cannot be prevented: a parent frequently suffers in his children what he condemns in others; there are some evils in society which the magistrate finds it ncedful to tolerate.

A well-regulated society will be careful not to admit of any deviation from good order, which may afterward become injurious as a practice: it frequently happens that what has been allowed from indiscretion is afterward claimed as a right: no earthly power can permit that which is prohibited by the rlivine law: when abuses are 
suffered to creep in and to take deep root in any established institution, it is difficult to bring about a reform without endangering the existence of the whole; when abuses, therefore, are not very grievous, it is wiser to tolerate them than run the risk of producing a greater evil.

Admit, Allow, Grant.-These terms are here compared only in regard to matters of speculation; and in this case they rise in sense, allow being more voluntary and positive than admit, and grant more so than allow. What is admitted is that which it is either not easy or possible for a person to deny; certain facts are admitted which are too clearly proved to be disputed; what is allowed is that which is agreed to from the conviction or feelings of the party allowing; it is said mostly of that in which the interests as well as the opinions of men are concerned; he allows that it would be good, but thinks that it is not practicable; what is granted is agreed upon as true, and is said most properly of abstract or self-evident truths, as to grant that two and two make four, or to take that for granted which is the point in dispute.

Admittance, Admission.-These words differ according to the different acceptations of the primitive from which they are both derived; the former being taken in the proper sense or familiar style, and the latter in the figurative sense or in the grave style. The admittance to public places of entertainment is, on particular occasions, difficult. The admission of irregularities, however trifling in the commencement, is mostly attended with serious consequences.

Admittance is properly confined to the receiving a person or a thing into a given place; admission includes in itself the idea not only of receiving, but also the purpose of receiving. Whoever is admitted, or has the liberty of entering any place, whether with or without an object, has admittance; but a person has admission to places of trust, or into offices and the like.

See also Approach.

ADMITTANCE. See Admit.

ADMONISH, ADvise. Admonish, in Latin admoneo, is compounded of the intensive $a d$ and monere, to advise, signifying to put seriously in mind. $A d$ vise is compounded of the Latin $a d$ and visus, participle of videre, to see, signifying to make to see or to show.

Admonish mostly regards the past; advise respects the future. We admonish a person on the errors he has committed, by representing to him the extent and consequences of his offence; we advise a person as to his future conduct, by giving him rules and instructions. Those who are most liable to transgress require to be admonished; those who are most inexperienced require to be advised. Admonition serves to put people on their guard against evil; advise to direct them in the choice of good.

Admonition, Warning, Caution.-Admonition (see ADMoNIsH). Warning, from Anglo-Saxon warnian, is allied with the words wary, ward, guard, etc., and hence it meant to tell another to beware, to be on his guard. Caution, from caveo, beware, signifies the making beware. A guarding against evil is common to these terms; but admonition expressed more than warking, and that more than caution.

An admonition respects the moral conduct; it comprehends reasoning and remonstrance: warning and caution respect the personal interest or safety; the former comprehends a strong, forcible representation of the evil to be dreaded; the latter a simple apprisal of a future contingency. Admonition may therefore frequently comprehend warning; and warning may comprehend caution, though not vice versa. We admonish a person against the commission of any offence; we warn him against danger; we caution him against any misfortune. Admonitions and warnings are given by those who are superior in age and station; cautions by any who are previously in possession of information. Parents give admonitions; ministers of the gospel give warnings; indifferent persons give cautions. It is necessary to admonish those who have once offended to $a b-$ stain from a similar offence; it is necessary to warn those of the consequences of $\sin$ who seem determined to persevere in a wicked course; it is necessary to caution those against any false 
step who are going in a strange path. Admonitions should be given with mildness and gravity; warnings with impressive force and warmth; cautions with clearness and precision. The young require frequent admonitions; the ignorant and self-deluded solemn warnings; the inexperienced timely cautions. Admonitions ought to be listened to with sorrowful attention; warnings should make a deep and lasting impression; cautions should be borne in mind; but admonitions are too often rejected, warnings despised, and cautions slighted.

Admonitions are given by persons only; warnings and cautions are given by things as well as persons. The young are admonished by the old; the death of friends serves as a warning to the survivors; the unfortunate accidents of the careless serve as a caution to others to avoid the like error.

ADOPT. See Espouse; NatuRALIZE.

ADORE, WORSHIP. Adore, in French adorer, Latin adoro-that is, ad and orare, to pray to. Worship, in Anglo-Saxon weorthscype, is contracted from worthship, implying either the object that is worth, or the worth itself: whence it has been employed to designate the action of doing suitable homage to the object which has worth, and, by a just distinction, of paying homage to our Maker by religious rites.

Adoration is the service of the heart toward a Superior Being, in which we acknowledge our dependence and obedience by petition and thanksgiving; worship consists in the outward form of showing reverence to some supposed superior being. Adoration can with propriety be paid only to the one true God; but worship is offered by heathen to stocks and stones. We may adore our Maker at all times and in all places, whenever the heart is lifted up toward Him; but we worship Him only at stated times and according to certain rules. Outward signs are but secondary in the act of adoration; and in divine worship there is often nothing existing but the outward form. We may adore without worshipping; but we ought not to worship without adoring.

Adore, Reverence, Venerate, Revere.Adore, sce key word preceding. Reverence, in Latin reverentia, reverence or awe, implies to show reverence, from revereor, to stand in awe of; from vereor, I fear, allied with English wary. Venerate, in Latin veneratus, participle of veneror, is allied to venus, love, from a root wan signifying to love or win. Revere has the same etymology as reverence.

Adoration has been before considered only in relation to our Maker; it may, however, be employed in an improper and extended application to express in the strongest possible manner the devotion of the mind toward sensible objects. Good princes are frequently said to be adored by their subjects.

Reverence is equally engendered by the contemplation of superiority, whether of the Supreme Being as our Creator, or of any earthly being as our parent: it differs, however, from adoration, inasmuch as it has a mixture of fear, arising from the consciousness of weakness and dependence, or of obligations for favors received. Adoration in this case, as in the former, requires no external form; it is properly the homage of the mind: reverencing our Maker is also an inward sentiment; but reverencing our parents, who are invested with a sacred character, includes in it an outward expression of our sentiments by our deportment toward them.

As sentiments of the mind, there is this distinction between reverence and veneration, that the latter has none of the feeling of fear which forms a part of the former. The contemplation of a sacred edifice which combines grandeur with solemnity will awaken reverence; the contemplation of any place rendered sacred by its antiquity awakens veneration.

Between the verbs to revere and to reverence there is but a small shade of difference in the sense: the former denotes a sentiment of the mind only; the latter the expression of that sentiment, as well as the sentiment itself. Hence we say with more propriety, to revere, not to reverence, a name or memory of any one, etc.

ADORN, Decorate, Embellish. Adorn, in Latin, adorno, is compounded of the intensive syllable ad and orno, in Greek wpaios beautiful, signifying to dispose for the purpose of ornament. Decorate, in Latin decoratus, 
participle of decoro, from decus, an ornament, signifies to make beautiful by the addition of something extraneous. Embellish, in French embellir, is compounded of the intensive syllable $\mathrm{em}$ or in and bellir or bel, in Latin bellus, handsome, signifying to make handsome.

We adorn by giving the best external appearance to a thing; we decorate by annexing something to improve its appearance; we embellish by giving a finishing stroke to a thing that is well executed, or adding to the beauty of a thing. Females adorn their persons by the choice and disposal of their dress; or gentlemen adorn their estates by giving them the appearance of tasteful cultivation: a head-dress is decorated with flowers, or a room with paintings: fine writing is embellished by suitable flourishes.

Adorn and embellish are figuratively employed; decorate only in the proper sense. Inanimate objects may be adorned, or the mind is adorned by particular virtues which are implanted in it; a narrative is embellished by the introduction of some striking incidents.

See also Garnish; Ornate.

ADROIT. See Clever.

ADROITNESS. See KNACK.

adUlate, Flatter, Compliment. Adulate, in Latin adulatus, participle of adulor, signified to wag the tail as a dog does, to fawn like a dog. Flatter, Old French flater, to stroke, to soothe, signified to calm with caressing words. Compliment, like comply, is derived through the Italian complimento, civility, from the Latin compleo, fill entirely, hence to fulfil expectations, to please.

We adulate by discovering in our actions as well as words an entire sub-. serviency: we flatter directly by words expressive of admiration; indirectly by actions which convey the same sentiments: we compliment by fair language or respectful civilities. An adulatory address is couched in terms of feigned devotion to the object; a flattering address is filled with the fictitious perfections of the object; a complimentary address is suited to the station of the individual and the occasion which gives rise to it. Courtiers are guilty of adulation; lovers are addicted to flattery; people of fashion in- dulge themselves in a profusion of compliments.

Adulation can never be practised without falsehood; its means are hypocrisy and lying, its motive servile fear, its end private interest: flattery always exceeds the truth; it is extravagant praise dictated by an overweening partiality, or, what is more frequent, by a disingenuous temper: compliments are not incompatible with sincerity, unless they are dictated from a mere compliance with the prescribed rules of politeness or the momentary desire of pleasing. Adulation may be fulsome, flattery gross, compliments unmeaning. Adulation inspires a person with an immoderate conceit of his own importance; flattery makes him in love with himself; compliments make him in good-humor with himself.

ADVANCE, Proceed. Advance (see ADDOCE). Proceed, in Latin procedo, signifies to go forward.

To advance is to go toward some point; to proceed is to go onward in a certain course. The same distinction is preserved between them in their figurative acceptation. A person advances in the world who succeeds in his transactions and raises himself in society; he proceeds in his business when he carries it on as he has done beforé. We advance by proceeding, and we proceed in order to advance. Some people pass their lives in the same situation without advancing; some are always doing without proceeding. Those who make considerable progress in learning stand the fairest chance of advancing to dignity and honor. See also ADdUCE; Encourage; Go; Progress.

ADVANTAGE, BENEFIT, UTILITY. Advantage, French avantage, for the derivation of which see advance under ADDOCE, signifies that which advances one's interests, improves one's condition. Benefit, in French bienfait, Latin benefactum, compounded of bene, well, and factum, done, signifies done or made to one's wishes. Utility, in French utilité, Latin utilitas, and utilis, useful, from utor, to use, signifies the quality of being able to be used.

Advantage respects external or extrinsic circumstances of profit, honor, and convenience; benefit respects the consequences of actions and events; 
utility respects the good which can be drawn from the use of any object. A large house or a particular situation may have its advantages; suitable exercise is attended with benefit; sun-dials have their utility in ascertaining the hour precisely by the sun. Things are sold to advantage; persons ride or walk for the benefit of their health; they purchase articles for their utility. A good education has always its advantages, although every one cannot derive the same benefit from the cultivation of his talents, as all have not the happy art of employing their acquirements to the right objects; riches are of no utility unless rightly employed. It is of great advantage to young people to form good connections on their entrance into life; it is no less beneficial to their morals to be under the guidance of the aged and experienced, from whom they may draw many useful directions for their future conduct.

See also Goop.

Advantage, Profit. - Advantage, see above. Profit, in French profit, Latin profectus, participle of proficio, compounded of pro and facio, signifies to make an advance.

The idea common to these terms is of some good received by a person. Advantage is general; it respects everything which can contribute to the wishes, wants, and comforts of life; profit in its proper sense is applied to pecuniary.advantage. Situations have their advantages; trade has its profits. Advantage may be applied either to the good derived from a thing, as the advantage of dress - that is, the advantage derived from dress-or to the thing from which the good is derived, as, dress is an advantage to the person.

Profit is always taken for that good which is derived from a thing.

Advantage implies something annexed to or coming to a thing accidentally; or it may be what a man esteems to be an advantage; profit is that which is real, substantial, and permanent.

ADVENTURE. See EVENT.

ADVENTUROUS. See ENTERPRISING; FOOLHARDY.

ADVERSARY. See ENEMY.

ADVERSE, Contrary, Opposite. Adverse, in French adverse, Latin adversus, participle of adverto, compound- ed of $a d$ and verto, signifies turning toward or against. Contrary, in French contraire, Latin contrarius, comes from contra, against. Opposite, in Latin oppositus, participle of oppono, is compounded of $o b$ and pono, signifying placed in the way.

Adverse respects the feelings and interests of persons; contrary regards their plans and purposes; opposite respects the situation and relative nature of things. Fortune is adverse; an event turns out contrary to what was expected; sentiments are opposite to each other. Circumstances are sometimes so adverse as to baffle the best concerted plans; facts often prove directly contrary to the representations given of them; people with opposite characters cannot be expected to act together with pleasure to either party.

Adverse, Inimical, Hostile, Repugnant.-Adverse, see above. Inimical, from the Latin in amicus, not friendly, and hostile from Latin hostis, an enemy (allied to English guest, a stranger), signify belonging to an enemy. Repugnant, in Latin repugnans, from repugno, or re and pugnare, to fight against, signifies warring with.

Adverse may be applied to either persons or things; inimical and hostile to persons or things personal; repugnant to things only. A person is adverse, or a thing is adverse to an object; a person, or what is personal, is either inimical or hostile to an object; one thing is repugnant to another. We are adverse to a proposition, or circumstances are adverse to our advancement; partisans are inimical to the proceedings of government, and hostile to the possessors of power. In respect to persons, adverse denotes merely the relation of being opposed; inimical, the spirit of the individual in private matters; and hostile, the situation, conduct, and temper of individuals or bodies in public matters. Those who are adverse to any undertaking are not likely to use their endeavors to insure success; traders will be inimical to the introduction of anything that threatens to be injurious to their trade; some persons are hostile to establishments in religion.

In respect to things, what is adverse acts to the hindrance or disadvantage 
of the thing to which it is opposed; as adverse minds, adverse circumstances. Sickness is adverse to the improvement of youth; what is inimical acts directly to injury, as writings which are inimical to religion, a spirit inimical to learning; what is repugnant is in a state of positive opposition or contrariety, as slavery is repugnant to the mild spirit of Christianity.

Adverse, Averse. - Adverse (see above), signifying turned against or over against, denotes simply opposition of situation. Averse, from $a$ and versus. signifying turned from or away from, denotes an active removal or separation from. Adverse is therefore as applicable to inanimate as to animate objects; averse only to animate objects. When applied to conscious agents, adverse refers to matters of opinion and sentiment; averse to matters of feeling. One is adverse to that which he thinks wrong; he is averse to that which opposes his inclinations, habits, or interests.

Adversity, Distress.-Adversity signifies adverse circumstances. Distress, from the Latin distringo, compounded of dis, asunder, and stringo, I pull, signified tearing to pieces, hence the state of a mind disorganized by grief or fear.

Adversity respects external circumstances, distress regards either external circumstances or inward feelings. $A d$ versity is opposed to prosperity; distress to ease. Adversity is a general condition; distress a particular state. Distress is properly the highest degree of adversity. When a man's affairs go altogether adverse to his wishes and hopes, when accidents deprive him of his possessions or blast his prospects, he is said to be in adversity; but when in addition to this he is reduced to a state of want, deprived of friends and all prospect of relief, his situation is that of real distress. Adversity is trying, distress is overwhelming. Every man is liable to adversity, although few are reduced to distress but by their own fault.

ADVERTISE, Publish. Advertise, from the Latin adverto, compounded of ad and verto, to turn to, signifies to turn the attention to a thing. Publish, in Latin publico-that is, facere publicum - signifies to make public.
Advertise denotes the means, and publish the end. To advertise is to direct the public attention to any event by means of a printed circular; publish is to make known either by oral or printed communication. We publish by advertising, but we do not always advertise when we publish. Mercantile and civil transactions are conducted by means of advertisements. Extraordinary circumstances are speedily published in a neighborhood by circulating from mouth to mouth. See also ANNounce.

ADVICE, Counsel, Instruction. Advice (see ADMONISH). Counsel, in French conseil, Latin consilium, comes from consilio (compounded of con and a root which probably meant to sit), signified to come together to talk over something; and in an extended sense implies deliberation, or the thing deliberated upon, determined, and prescribed. Instruction, in French instruction, Latin instructio, building, signified to build up from within, and is used in this literal sense by Milton: "Instruct me, for Thou knowest," meaning "Enter into me and build up my spirit from within."

The end of all the actions implied by these words is the communication of knowledge, and all of them include the accessory idea of superiority, either of age, station, knowledge, or talent. $A d$ vice flows from superior professional knowledge, or an acquaintance with things in general; counsel regards superior wisdom, or a superior acquaintance with moral principles and practice; instruction respects superior local knowledge in particular transactions. A medical man gives advice to his patient; a father gives counsel to his children; a counsellor gives advice to his client in points of law; he receives instructions from him in matters of fact. Advice should be prudent and cautious; counsel sage and deliberative; instructions clear and positive. Advice is given on all the concerns of life, important or otherwise; counsel is employed for grave and weighty matters; instruction is used on official occasions. Men of business are best able to give advice in mercantile transactions. In all measures that involve our future happiness, it is prudent to take the counsel of those who are more experienced than ourselves. 
An ambassador must not act without instructions from his court. See also INFORMATION.

ADVISE. See ADmoNish.

ADVOCATE. See Defender. AERIAL NAVIGATION.

See

AERoNaUtics.

AERIAL NAVIGATOR. See AEroNAUT.

AERIAL PILOT. See Aeronatt.

AERONAUT, AERIal Navigator, Aerial Pilot, Aviator, Balloonist. Aeronaut, in French aéronaute, from Latin aer, the air, and nauta, a sailor, as a general term, any one who navigates the air. Aerial navigator and aerial pilot are terms used to distinguish the one who guides an aircraft from the crew having other duties. Aviator is applied to any one engaged in aerial flights, but is more akin to aerial navigator. Balloonist, strictly an aviator who makes ascensions in a balloon or a lighter-than-air craft, usually an elongated or spherical bag inflated with gas - the original flying-machine.

AERONAUTICS, Aerostatics, Aerostation, Aviation, Ballooning. Aeronautics, in French aéronautique, the science or art which treats of aerial navigation. Aerostatic, in German aerostatik, in French aérostatique, "standing in the air," and aérostation both relate to air at rest and specifically to the suspension and control of flying-craft in the air. Aviation, from the Latin avis, a bird, applies both to the science of aerial flight in general and particularly to the use of machines capable of rising and maintaining themselves in the air without the aid of gas or rarefied air. Balloon, allied to ball, meant originally a large spherical bag, and ballooning differs from aviation as here defined in that it applies to a machine deriving its ascending and sustaining power from gas or rarefied air contained in a huge bag. A captive balloon is one used for observation purposes over a limited area, and is attached by a rope or cable to a holding object on the ground. It was formerly used for scouting in warfare, but has given way to other forms of aircraft.

AEROPlane. See Aircraft.

AFFABLE, Courteous. Affable, in Latin affabilis, from af or ad, to, and fari, to speak, signifies ready to speak or be spoken with, and is particularly applied to persons in a higher condition; princes and nobles are commonly said to be affable when they converse freely with those not in the same condition.

Affability is properly confined to verbal communications; but courteousness, from the word court, signifying after the manner of a court or courtier, refers to actions and manners; affability flows from the natural temper; courteousness from good breeding, or the acquired temper.

AFFAIR, Business, CoNcern. Affair, in French affaire, is formed from the phrase $\dot{a}$ faire, corresponding to English do, etc., in such phrases as "much ado," "a great to do," etc. Business, from busy (sec Active), signifies the thing that makes or interests a person or with which he is busy or occupied. Concern, in French concerner, Latin concerno, compounded of con and cernere, to sift, cognate with

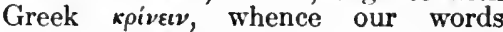
critic, criticism, are derived, signifies the sifting out of things that belong together.

An affair is what happens; a business is what busies; a concern is what is felt. An affair is general; it respects one, many, or all: every business and concern is.an affair, though not vice versa. Business and concern are personal; business is that which engages the attention; concern is that which interests the feelings, prospects, and condition, advantageously or otherwise. An affair is important; a business is serious; a concern momentous. The usurpation of power is an affair which interests a nation; the adjusting a difference is a business most suited to the ministers of religion; to make one's peace with one's Maker is the concern of every individual. Affairs are administered; business is transacted; concerns are managed. The affairs of the world are administered by a Divine Providence. Those who are in the practice of the law require peculiar talents to fit them for transacting the complicated business which perpetually offers itself. Some men are so involved in the affairs of this world as to forget the concerns of the next, which ought to be nearest and dearest to them. 
AFFECT, Concern. Affect, in French affecter, Latin affectum, participle of afficio, compounded of ad and facere, to do or act, signifies to act upon. Concern, for derivation see under AfFair.

Things affect us which produce any change in our outward circumstances; they concern us if connected with our circumstances in any shape. Whatever affects must concern; but all that concerns does not affect. The price of corn affects the interest of the seller; and therefore it concerns him to keep it up, without regard to the public good or injury. Things affect either persons or things; but they concern persons only. Rain affects the hay or corn; and these matters concern every one more or less.

Affect and concern have an analogous meaning likewise when taken for the influence on the mind. We are affected by things when our affections only are awakened by them: we are concerned when our understanding and wishes are engaged. We may be affected either with joy or sorrow: we are concerned only in a painful manner. People of tender sensibility are easily affected: irritable people are concerned about trifles. It is natural for every one to be affected at the recital of misfortunes; but there are people of so cold and selfish a character as not to be concerned about anything which does not immediately affect their own persons or property.

AFFECT, Assume. Affect, in this sense, derives its origin immediately from the Latin affecto, desire eagerly, signifying to aim at or aspire after. Assume, in Latin assumo, compounded of ad and sumere, to take, signifies to take to one's self.

To affect is to use forced efforts to appear to have that which one has not; to assume is to appropriate to one's self that which one has no right to have. One affects to have fine feelings, and assumes great importance. Affectation springs from the desire of appearing better than we really are; assumption from the thinking ourselves better than we really are. We affect the virtues which we have not; we assume the character which does not belong to us. An affected person is always thinking of others; an assuming person thinks only of himself. The affected man strives to gain applause by appearing to be what he is not; the assuming man demands respect upon the ground of what he supposes himself to be. Hypocrisy is often the companion of affectation, self-conceit always that of assumption.

To affect is always taken in a bad sense; but to assume may be sometimes an indifferent action at least, if not justifiable. Men always affect that which is supposed to please others, in order to gain their applause; but they sometimes assume a name or an authority which is no more than their just right.

Affect, Pretend.-Affect, see above. Pretend, in Latin pretendo-that is, pro and tendo-signifies to hold or stretch one thing before another by way of a blind.

These terms are synonymous only in the bad sense of setting forth to others what is not real: we affect by putting on a false air; we pretend by making a false declaration. Art is employed in affecting; assurance and self - complacency in pretending. A person affects not to hear what it is convenient for him not to answer; he pretends to have forgotten what it is convenient for him not to recollect. One affects the manners of a gentleman, and pretends to gentility of birth. One affects the character and habits of a scholar; one pretends to learning. To affect the qualities which we have not spoils those which we have; to pretend to attainments which we have not made obliges us to have recourse to falsehoods in order to escape detection. See also ThriLl.

Affected, Disposed.-Affected signifies moved or acted upon by any particular circumstance, as to be affected at any spectacle. Disposed, from dispose, to settle or put in order, signifies settled or determined as to one's purpose; as disposed to do a good turn.

Affected likewise signifies to be affected with a particular sentiment, which brings it nearer to the sense of disposed in denoting a state of mind, but disposed in this case implies a settled if not an habitual temper, $a f$ fection a temporary and partial state: 
subjects are either well or ill affected to their government; people are either well or ill disposed as regards their moral character or principles.

See also NAMBY-PAMBY.

AFFECTING. See Moving.

AFFECTION, Love. Affection, from the verb affect, denotes the state of being kindly affected toward a person. Love, German liebe, like the English lief, German lieb, dear or pleasing, is connected with the Latin libet, it is pleasing, signifying the state of holding. a person dear.

These two words are comparable, inasmuch as they denote a sentiment toward any object: they differ both in the nature of the object and the nature of the sentiment. Affection is private or confined to one or more particular individuals; love is either general or particular: it either embraces all objects capable of awakening the sentiment, or it is confined to particular objects: in the former case love expresses the sentiment of the Divine Being toward all His creatures, and also that of man to the rest of his fellow-crcatures.

When applied to particular objects, love is a much warmer sentiment than affection. The latter subsists between persons of the same sex, the former in a particular manner between persons of a different sex. Affection is a tender and durable sentiment, a chastened feeling under the control of the understanding which promises no more pleasure than it gives; love is an ardent sentiment which, as between the sexes, has all the characteristics of a passion, being exclusive, restless, and fluctuating. Love may subsist before marriage, but it must terminate in affection in order to insure happiness after marriage.

Between the words affection and love there is this further distinction, that the former did not always imply a kindly or favorable sentiment; there may be an ill as well as a good affection: the affections of a people to a government may be various; the affection of a prince may change from favor to disfavor toward a subject.

See also ATtachment.

Affectionate, Kind, Fond.-Affectionate, from affection (see above), denotes the quality of having affection. Kind, from the word kind, kindred or family, denotes the quality or feeling engendered by the family tie. Fond is the past participle of Middle English fonnen, to be weak, to act like a fool.

Affectionate characterizes the feeling; kind has mostly a reference to the action: affectionate is directed to a particular object; kind to objects generally. Relations are affectionate to one another, persons may be kind to any one, even to mere strangers.

So toward animals generally we may be kind, and toward favorite animals affectionate.

As epithets, these words observe the same distinction; a mother or a child is affectionate, a master kind; looks, or whatever serve to express affection, are said most appropriately to be affectionate; offices, or any actions prompted by the general sentiment of kindness, are called kind.

Affectionate and kind are always taken in the good sense for a proper sentiment; fondness is an excess of liking for any object, which, whether it be a person or a thing, is more or less reprehensible; children are always fond of whatever affords them pleasure or of whoever gives them indulgences.

AFFinItY. See Alliance; KrnDRED.

AFFIRM, Asseverate, Assure, Vouch, Aver, Protest. Affirm, in French affirmer, Latin affirmo, compounded of ad and firmo, strengthen, signifies to give strength to what has been said. Asseverate, in Latin asseveratus, participle of assevero, compounded of ad and severus, signifies to make a serious statement. Assure, in French assurer, is compounded of the intensive syllable as or ad and securus (English secure), safe, signif ying to make sure. Vouch is probably changed from vow. Aver, in French averer, is compounded of the intensive syllable $a$ or ad and verus, true, signifying to bear testimony to the truth. Protest, in French protester, Latin protcsto, is compounded of pro and testor, to call to witness as to what we think about a thing. All these terms indicate an expression of a person's conviction.

In one sense, to affirm is to declare that a thing is, in opposition to denying or declaring that it is not; in the 
sense here chosen, it signifies to declare a thing as a fact on our credit. To asseverate is to declare it with confidence. To vouch is to rest the truth of another's declaration on our own responsibility. To aver is to express the truth of a declaration unequivocally. To protest is to declare a thing solemnly, and with strong marks of sincerity. Affirmations are made of the past and present; a person affirms what he has seen and what he sees. Asseverations are strong affirmations, made in cases of doubt to remove every impression disadvantageous to one's sincerity. Assurances are made of the past, present, and future; they mark the conviction of the speaker as to what has been, or is, and his intentions as to what shall be; they are appeals to the estimation which another has in one's word. Vouching is an act for another; it is the supporting of another's assurance by our own. Averring is employed in matters of fact; we aver as to the accuracy of details; we aver on positive knowledge that sets aside all question. Protestations are stronger than either asseverations or assurances, they are accompanied with every act, look, or gesture that can tend to impress conviction on another.

Affirmations are employed in giving evidence, whether accompanied with an oath or not; liars deal much in asseverations and protestations. People asseverate in order to produce a conviction of their veracity; they protest in order to obtain a belief of their innocence; they aver where they expect to be believed. Assurances are altogether personal; they are always made to satisfy some one of what they wish to know and believe. We ought to be sparing of our assurances of regard for another. Whenever we affirm anything on the authority of another, we ought to be particularly cautious not to vouch for its veracity if it be not unquestionable.

See also Swear.

Affirm, Assert.-Affirm (see above). Assert, in Latin assertus, participle of assero, compounded of ad and sero, to connect, signifies to connect words into a proposition. To affirm is said of facts; to assert, of opinions; we jaffirm what we know; we assert what we believe. Whoever affirms what he does not know to be true is guilty of falsehood; whoever asserts what he cannot prove to be true is guilty of folly. We contradict an affirmation; we confute an assertion.

AFFix, Subjoin, Attach, Annex. Affix, in Latin affixus, participle of affigo, compounded of af or ad and figo, to fix, signifies to fix to a thing. Subjoin comes from Latin $s u b$, under, and jungere, to join, and means to join to the lower or farther extremity of a body. Attach (see ADHERE), to adhere. Annex, in Latin annexus, participle of annecto, compounded of $a n$ or ad and necto, to knit, signifies to knit or tie to a thing.

To affix is to put anything as an essential to any whole; to subjoin is to put anything as a subordinate part to a whole: in the former case, the part to which it is put is not specified; in the latter, the syllable $s u b$ specifies the extremity as the part: to attach is to make one person or thing adhere to another by a particular tie, mostly in the moral sense; to annex is to bring things into a general connection with each other. A title is affixed to a book; a few lines are subjoined to a letter by way of postscript; we attach blame to a person; a certain territory is annexed to a kingdom. Letters are affixed to words in order to modify their sense, or names are affixed to ideas; it is necessary to subjoin remarks to what requires illustration; we are apt from prejudice or particular circumstances to attach disgrace to certain professions which are not only useful, but important; papers are annexed by way of appendix to some important transaction.

AFFliCT, Distress, Trodble. $A f$ flict, in Latin affictus, participle of affligo, compounded of ad, to, and figere, to dash, signifies to strike to the ground. For distress see ADVErsity. Trouble signifies to cause a tumult, from the Latin turba, Greek rí $\beta \eta \eta$, a tumult.

When these terms relate to outward circumstances, the first expresses more than the second, and the second more than the third. People are afflicted with grievous maladies. The mariner is distressed for want of water in the midst of 
the wide ocean; or an embarrassed tradesman is distressed for money to maintain his credit. The mechanic is troubled for want of proper tools, or the head of a family for want of good domestics.

When they respect the inward feelings afflict conveys the idea of deep sorrow; distress that of sorrow mixed with anxiety; trouble that of pain in a smaller degree. The death of a parent afflicts; the misfortunes of our family and friends distress; crosses in trade and domestic inconveniences trouble. In the season of affliction prayer affords the best consolation and surest support. The assistance and sympathy of friends serve to relieve distress. We may often help ourselves out of our troubles, and remove the evil by patience and perseverance. Afflictions may be turned to benefits if they lead a man to turn inwardly into himself and examine the state of his heart and conscience in the sight of his Maker. The distresses of human life often serve only to enhance the value of our pleasures when we regain them. Among the troubles with which we are daily assailed, many of them are too trifling for us to be troubled by them.

Affiction, Grief, Sorrow.-Afliction (see AFFLICT). Grief, Old French grief, comes from Latin gravus, heavy, burdensome, sad. Sorrow, in German sorge, etc., originally signified care, as well as sorrow.

All these words mark a state of suffering which differs either in the degree or the cause, or in both. Affliction is much stronger than grief; it lies deeper in the soul, and arises from a more powerful cause; the loss of what is most dear, the continued sickness of our friends, or a reverse of fortune, will all cause affiction; the misfortunes of others, the failure of our favorite schemes, the troubles of our country, will occasion us grief. Sorrow is less than grief; it arises from the untoward circumstances which perpetually arise in life. A disappointment, the loss of a game, our own mistake, or the negligence of others causes sorrow. Affliction lies too deep to be vehement; it discovers itself by no striking marks in the exterior; it is lasting, and does not cease when the external causes cease to act; grief may be violent, and discover itself by loud and indecorous signs; it is transitory, and ceases even before the cause which gave birth to it: sorrow discovers itself by a simple expression; it is still more transient than grief, not existing beyond the moment in which it is produced. A person of a tender mind is afficted at the remembrance of his sins; he is grieved at the consciousness of his fallibility and proneness to error; he is sorry for the faults which he has committed. Affiction is allayed: grief subsides: sorrow is soothed.

AFFLUENCE. See Riches.

AFFORD, YIELD, Produce. Afford, Anglo-Saxon geforthian ( $a$ being a corruption of ge, pronounced ye, a verbal prefix, added to forth, the present English forth), meant to cause to come forth, to promote, etc. Yield, German gelten, in Anglo-Saxon gildan, gieldan, means to give the value of something. Produce, in Latin produco, compounded of pro, forth, and ducere, to bring, signifies to bring out or into existence.

With afford is associated the idea of communicating a part or property of some substance to a person, by way of supply to his wants: meat affords nourishment to those who make use of it; the sun affords light and heat to all living creatures.

To yield is the natural operation of any substance to give up or impart the parts or properties inherent in it; it is the natural surrender which an object makes of itself: trees yield fruit; the seed yields grain; some sorts of grain do not yield much in particular soils, and in an extended application trees may be said to yield a shade.

Produce conveys the idea of one thing causing another to exist, or to spring out of it; it is a species of creation, the formation of a new substance: the earth produces a variety of fruits; confined air will produce an explosion.

In the moral application they are similarly distinguished: nothing affords so great a scope for ridicule as the follies of fashion; nothing yields so much satisfaction as religion; nothing produces so much mischief as the vice of drunkenness.

See also Gıve.

Afford, Spare.-Afford (sce above). 
Spare, in German sparen, Latin parco, signifies laying aside for some particular use.

The idea of deducting from one's property with convenience is common to these terms; but afford respects solely expenses which are no more than commensurate with our income; spare is said of things in general, which we may part with without any sensible diminution of our comfort. There are few so destitute that they cannot afford something for the relief of others who are more destitute. He who has two things of a kind may easily spare one.

AFFRAY. See QUARREL.

AFFRONT, INSULT, OUTRAGe. Affront, in French affronte, from the Latin ad and frons, the forehead, signifies flying in the face of a person. Insult, in French insulte, comes from the Latin insulto, meaning literally "to jump on." The former of these actions marks defiance, the latter scorn and triumph. Outrage is compounded of the French adverb outre and the suffix rage, and signifies to go beyond bounds.

An affront is a mark of reproach shown in the presence of others; it piques and mortifies: an insult is an attack made with insolence; it irritates and provokes: an outrage combines all that is offensive; it wounds and injures. An intentional breach of politeness is an affront; if coupled with any external indication of hostility, it is an insult; if it break forth into personal violence, it is an outrage. Captious people construe every innocent freedom into an affront. When people are in a state of animosity they seek opportunities of offering one another insults. Intoxication or violent passion impels men to the commission of outrages.

See also OFFENCE.

afraid, Fearful, Timorous, TimID. Afraid is changed from afeard, signifying in a state of fear. Fearful, as the words of which it is compounded imply, signifies full of fear. Timorous and timid come from the Latin timidus, fearful, timor, fear, and timere, to fear.

The first of these epithets denotes a temporary state, the last three a habit of the mind. Afraid may be used either in a physical or moral application, either as it relates to ourselves only or to others; fearful and timorous are applied only physically and personally; timid is mostly used in a moral sense. It is the character of the fearful or timorous person to be afraid of what he imagines would hurt himself; it is not necessary for the prospect of danger to exist in order to awaken fear in such a disposition; it is the characteristic of the timid person to be afraid of offending or meeting with something painful from others; a person of such a disposition is prevented from following the dictates of his own mind. Between fearful and timorous there is little distinction, either in sense or application, except that we say fearful of a thing, not timorous of a thing.

AFTER, BEHIND. After respects order; behind respects position. One runs after a person, or stands behind his chair. After is used either figuratively or literally; behind is used only literally. Men hunt after amusements; misfortunes come after one another; a garden lies behind a house; a thing is concealed behind a bush.

aGe. See Generation; Thme.

AGED. See Elderly; Gloaming. AGENCY. See ACT.

AGENT. See Actor; Factor.

AGGravate, Irritate, Provoke, Exasperate, Tantalize. Aggravate, in Latin aggravatus, participle of $a g$ gravo, compounded of the intensive syllable ad and gravo, make heavy, signifies to make very heavy. Irritate, in Latin irritatus, participle of irrito, snarl, is a word of uncertain origin. It may be a frequentative of irrire, to snarl like a dog, which is possibly an imitative word. Provoke, in French provoquer, Latin provaco, compounded of pro, forth, and voco, call, signifies to challenge or defy. Exasperate, Latin exasperatus, participle of exaspero, is compounded of the intensive syllable $e x$ and asper, rough, signifying to make things exceedingly rough. Tantalize, in French tantaliser, Greek

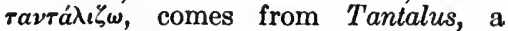
king of Phrygia, who, having offended the gods, was destined, by way of punishment, to stand up to his chin in water, with a tree of fair fruit hanging over his head, both of which, as he attempted to allay his hunger and thirst, fled from his touch. 
All these words, except the first, refer to the feelings of the mind, and in familiar discourse that also bears the same signification, but otherwise respects the outward circumstances. The crime of robbery is aggravated by any circumstances of cruelty; whatever comes across the feelings irritates; whatever awakens anger provokes; whatever heightens this anger extraordinarily exasperates; whatever raises hopes in order to frustrate them tantalizes. An appearance of unconcern for the offence and its consequences aggravates the guilt of the offender; a grating, harsh sound irritates, if long continued and often repeated; angry words provoke, particularly when spoken with an air of defiance: when to this are added bitter taunts and multiplied provocations, they exasperate; the weather, by its frequent changes, tantalizes those who depend upon it for amusement. Wicked people aggravate their transgression by violence; susceptible and nervous people are most easily irritated; proud people are quickly provoked; hot and fiery people are soonest exasperated; those who wish for much, and wish for it eagerly, are oftenest tantalized.

See also Heighten.

AGGRESSOR, Assailant. Aggressor, from the Latin aggressus, participle of aggredior, compounded of ag or ad and gradi, to step, signifies one stepping up to, falling upon, or attacking. Assailant comes from assail, in French assaillir, compounded of $a d$ and the Latin salio, to leap upon, and signifies one leaping upon or attacking any one vehemently. Compare the origin of insult.

The characteristic idea of aggression is that of one person going up to another in a hostile manner, and by a natural extension of the sense commencing an attack: the characteristic idea of assailing is that of one committing an act of violence upon another. An aggressor offers to do some injury either by word or deed; an assailant actually commits some violence: the former commences a dispute; the latter carries it on with a vehement and direct attack. An aggressor is blamable for giving rise to quarrels: an assailant is culpable for the mischief he does. Were there no aygressors, there would be no disputes; were there no assailants, those disputes would not be serious. An aggressor may be an assailant, or an assailant may be an aggressor, but they are as frequently distinct.

AGILE. See Active.

agitation, Trepidation, Tre: MOR, EMOTION. Agitation, in Latin agitatio, from agito, a frequentative of ago, act, signifies the state of being agitated or put into action. Trepidation, in Latin trepidatio, from trepidare, to tremble, signifies the condition of trembling in all one's limbs from head to foot. Tremor, from the Latin tremor, signifies originally the same state of trembling. Emotion, in Latin emotio, from emotus, participle of emoveo, compounded of $e$, out of, and movere, to move, signifies the state of being moved out of rest or put in motion.

Agitation is a violent action backward and forward and in different ways. It may be applied either to the body or the mind; the body may be agitated or thrown into violent and irregular motion, either by external action upon it, or by the operations of grief, terror, or any other passion; the mind is agitated when the thoughts or the feelings are put into any violent or irregular motion. Trepidation, like the former, is an irregular motion of the body, but differs both in the manner and cause of the motion; trepidation is the hurried trembling motion of the limbs in performing their functions, whence we speak of doing a thing with trepidation, or that there is a trepidation in a person's manner: in all cases it arises from a sentiment of fear or alarm.

Agitation and trepidation may be both applied to bodies of men as well as individuals, with a similar distinction.

Tremor is a trembling motion of the body, differing from the two former either in the force or the causes of the action: it is not violent nor confined to any particular part, like trepidation, and may, like agitation, arise either from physical or mental causes. There may be a tremor in the whole body, or a tremor in the voice, and the like.

Emotion refers solely to the move- 
ments of the mind, and is therefore to be compared only with agitation. Emotion is the movement of a single feeling, varying with the object that awakens it; there may be emotions of pleasure as well as of pain; agitation may be the movement of one or many feelings; but those always of the painful kind. Emotions may be strong, but not violent: agitation will always be more or less violent.

AGONY. See Distress; Pain.

AGREE, ACCede, Consent, ComPLY, ACQUiesce. Agree, from the Old French phrase $a$ gre, at pleasure, from Latin gratia, signifies to be in a pleasant relation to another, to like something. Accede, in Latin accedo, $a c$ or $a d$ and cedo, go or come, signifies to come toward another. Consent, from consentio, or con, cum, with, together, and sentio, think or feel, signifies to think or feel in unison. Com$p l y$, in French complaire, Latin compleo (for derivation see CoMplimenT), signifies to fulfil all expectations, to satisfy the demands of another. Acquiesce, in Latin acquiesco, or $a c$, ad, to or with, and quiesco, be quiet, signifies rest contented with.

All of these terms denote the falling in of any one or more persons in any matter that comes before their notice. Agree expresses this general idea without any qualifications; all the other terms express different modes of agreeing. All may agree in the same thing, or one may agree to that which is proposed; acceding, complying, and acquiescing are the acts of persons individually; consenting is properly the act of numbers, but it is also the act of individuals; one accedes to, complies with, or acquiesces in a thing. Agreeing is often a casual act not brought about by the parties themselves; the other terms denote positive acts, varying in the motives and circumstances. We accede by becoming a party to a thing: those who accede are on equal terms; one objects to that to which one does not accede; we consent to a thing by authorizing it, we comply with a thing by allowing it; those who consent or comply are not on equal terms with those in whose favor the consent is given or compliance made; consenting is an act of authority, complying an act of good nature or weakness; one refuses that to which one does not consent, or with which one does not comply; to acquiesce is quietly to admit; it is a passive act, dictated by prudence or duty; one opposes that in which one does not acquiesce.

To agree is to be of the same mind in matters of opinion or feeling; it is well for those who act together to be able to agree.

The term agree is, however, commonly used in regard to acting, as well as thinking, in the ordinary transactions of life.

To accede and the other terms are with very few exceptions employed in practical matters, but sometimes otherwise; to accede is mostly said in regard to that which is in a special manner proposed, if not recommended; as a private individual accedes to a proposition; a plenipotentiary accedes to a treaty.

To consent, as far as it is a universal act, is applied to moral objects; as customs are introduced by the consent of the community; but as the act of one or more individuals, it is applied to such practical matters as interest the parties for themselves or others; the parliament consents to the measures of the ministry; a parent consents to the marriage of a child. Equals consent to that in which they have a common interest.

Complying is used in the sense of yielding to the requests, demands, or wishes of another for the sake of conformity, and sometimes in the general sense of yielding to the wishes of the community.

To acquiesce is applied in the sense of yielding or agreeing to that which is decided upon by others. In this sense we acquiesce in the dispensations of Providence.

Agree, Accord, Suit.-Agree is here used in application to things only. Accord, in French accord, from the Latin cors, cordis, heart, signifies literally "heart to heart," in hearty agreement. Suit, from the Latin secutus, participle of sequor, follow, signifies to be in a line, in the order a thing ought to be.

An agreement between two things requires an entire sameness; an accord- 
ance supposes a considerable resemblance; a suitableness implies an aptitude to coalesce. Opinions agree, feelings accord, and tempers suit. Two statements agree which are in all respects alike; that accords with our feelings which produces pleasurable sensations; that suits our taste which we wish to adopt, or, in adopting, gives us pleasure. Where there is no agreement in the essentials of any two accounts, their authenticity may be greatly questioned: if a representation of anything accords with what has been stated from other quarters, it serves to corroborate it: it is advisable that the ages and stations as well as tempers of the parties should be suitable who look forward for happiness in a matrimonial connection.

Agree, Coincide, Concur.-Agree is here taken in its application to both persons and things. It is as before the general term. Coincide, from the Latin con, together, and incido, fall, means literally "to fall in with." Concur, from con, together, and curro, run, implying a running in the samc course, an acting together on the same principles, or modes of agreeing.

In respect to persons, they agree either in their general or particular opinions; they coincide and concur only in particular opinions. A person coincides in opinion with another in regard to speculative matters, but concurs with another in regard to practical matters; to coincide is only to meet at the same point, but to concur is to go together in the same road or in the same course of conduct.

In respect to things, they agree in one, many, or every point, as the accounts of different persons, times, modes, and circumstances agree; things coincide or meet at one point, as where two circumstances fall out at the same time; this is a coincidence; things concur if they have the same tendency or lead to the same point; several circumstances must sometimes concur to bring about any particular event. The coincidence is mostly accidental, the concurrence depends upon the nature of things.

See also Tally.

agreeable, Pleasant, PleasING. The first two of these epithets approach so near in sense and application that they can with propriety be used indifferently, the one for the other; yet there is an occasional difference which may be clearly defined. The agreeable is that which agrees with or suits the character, temper, and feelings of a person; the pleasant that which pleases; the pleasing that which is adapted to please. Agreeable expresses a feeling less vivid than pleasant; people of the soberest and gravest character may talk of passing agreeable hours, or enjoying agreeable society, if those hours were passed agreeably to their turn of mind, or that society suited their taste; but the young and the gay will prefer pleasant society, where vivacity and mirth prevail, suitable to the tone of their spirits. A man is agreeable who by a soft and easy address contributes to the amusement of others; a man is pleasant who to this softness adds affability and communicativeness. Pleasing marks a sentiment less vivid and distinctive than either. A pleasing voice has something in it which we like; an agreeable voice strikes with positive pleasure upon the ear. A pleasing countenance denotes tranquillity and contentment; it satisfies us when we view it: a pleasant countenance bespeaks happiness; it gratifies the beholder, and invites him to look upon it.

See also Conformable.

AGREement, Contract, Covenant, Compact, Bargain. Agreement signifies what is agreed to. Contract, in French contrat, from the Latin contractus, participle of contraho, draw close together or bind, signifies the thing thus contracted or bound. Covenant, in Old French covenant, from the present participle of convenio, meet together, signifies the point at which several meet, that is, the thing agreed upon by many. Compact, in Latin compactus, participle of compingo, bind close, signifies the thing to which people bind themselves close. Bargain comes from Late Latin barcaniare, to change about. Its remote origin is unknown.

An agreement is general, and applies to transactions of every description, but particularly such as are made between single individuals, in cases where 
the other terms are not so applicable; a contract is a binding agreement between individuals; a simple agreement may be verbal, but a contract must be written and legally executed: covenant, in the technical sense, is an agreement by deed, but in the general sense a solemn agreement; a compact is an agreement among numbers; a covenant may be a national and public transaction; a compact respects individuals as members of a community, or communities with each other who are compacted together: a bargain, in its proper sense, is an agreement solely in matters of trade, but applies figuratively in the same sense to other objects. The simple consent of parties constitutes an agreement; certain solemnities are necessary to make a contract or covenant valid; a tacit sense of mutual obligation in all the parties gives virtue to a compact; an assent to stipulated terms of sale may form a bargain.

Friends make an agreement to meet at a certain time; two tradesmen enter into a contract to carry on a joint trade; and if it be under hand and seal, the stipulations therein contained are technically called covenants; in the Society of Freemasons, every individual is bound to secrecy by a solemn compact; the trading part of the community are continually striking bargains.

AGRICULTURIST. See FARMER.

AID. See Help; UpHOLd.

AIDING. See AUXILIARY.

AIM, Object, End, VIew. Aim is mostly derived from the Latin cestimare, to put a value on, signifying the thing valued, consequently the particular point to which one's efforts are directed, which is held always in view, and to the attainment of which everything is made to bend. Object, from the Latin objectus, participle of $o b$ and jacio, throw in the way, is more vague; it signifies the thing that lies before us; we pursue it by taking the necessary means to obtain it; it becomes the fruit of our labor. End, Anglo-Saxon ende, a Teutonic word meaning termination, is still more general, signifying the thing that ends one's wishes and endeavors; it is the result not only of action, but of combined action; it is the consummation of a scheme; we must take the proper measures to arrive at it.
The aim is that which the person has in his own mind: it depends upon the character of the individual whether it be good or bad, attainable or otherwise; the object lies in the thing; it is a matter of choice, it depends upon accident as well as design, whether it be worthy or unworthy; the end is that which follows or terminates any course or proceeding; it depends upon the means taken whether the end is arrived at or not. It is the aim of the Christian to live peaceably; it is a mark of dulness or folly to act without an object; it is sophistry to suppose that the end will justify the means.

Aim and view, from video, to see or look at, are both acts of the mind, but the aim is that which the mind particularly sets before itself as a thing to be obtained; the view is, generally speaking, whatever the mind sets before itself, whether by way of opinion or motive; a person's views may be interested or disinterested, correct or false. The aim is practical in its operations; the view is a matter rather of contemplation than of practice.

See also Endeavor; Tendency; TENor.

Aim, Point, Level.-Aim, signifying to take aim, is to direct one's aim toward a point. Point, Latin punctum, from pungere, to prick (compare pungent), signifies to direct the sharp end or point of an implement toward something. Level comes from Old French livel, from Latin libella, a diminutive of libra, a balance, and signified an instrument for determining that a thing is horizontal. Level, from the adjective level, signifies to put one thing on a level or in a line with another.

Aim expresses more than the other two words, inasmuch as it denotes a direction toward some minute point in an object, and the others imply direction toward the whole objects themselves. We aim at a bird; we point a cannon against a wall; we level a cannon at a wall. Pointing is of course used with most propriety in reference to instruments that have points; it is likewise a less decisive action than either aiming or leveling. A stick or a finger may be pointed at a person, merely out of derision; but a blow is leveled or aimed with an express 
intent of committing an act of violence.

The same analogy is kept up in their figurative application. The shafts of ridicule are but too often aimed with little effect against the follies of fashion: remarks which seem merely to point at others, without being expressly addressed to them, have always a bad tendency; it has hitherto been the fate of infidels to level their battery of sneers, declamation, and sophistry against the Christian religion, only to strengthen the conviction of its sublime truths in the minds of mankind at large.

Aim, Aspire.-Aim includes efforts as well as views, in obtaining an object. Aspire, from as or ad, to or after, and spiro, breathe, comprehends views, wishes, and hopes to obtain an object.

We aim at a ccrtain proposed point by endeavoring to gain it; we aspire after that which we think ourselves entitled to, and flatter ourselves with gaining. Many men aim at riches and honor: it is the lot of but few to aspire to a throne. We aim at what is attainable by ordinary efforts; we aspire after what is great and unusual, and of ten improper.

AIR, Manner. Air, Latin aer, Greek án $\rho$, signifies the atmosphere; and thence, figuratively, the enveloping atmosphere of a personality created by appearance, manner, etc. Manner, Old French maniere, allied to the verb manier, to handle, from Latin manus, hand, signifies the way of handling something, hence a way of doing.

Air lies in the whole person; manner is confined to the action or the movement of a single limb. A man has the air of a common person; it discovers itself in all his manners. An air strikes at the first glance, whether the person be in motion or at rest; the manner can only be seen when the person is in action; it develops itself on closer observation. Some people have an air about them which displeases; but their manners afterward win upon those who have a further intercourse with them. An air is indicative of a state of mind; it may result either from a natural or habitual mode of thinking: a manner is indicative of the education; it is produced by external circumstances. An air is noble or simple, it marks an ele- vation or simplicity of character: a manner is rude, rustic, or awkward, for want of culture, good society, and good example. We assume an air, and affect a manner.

See also Appearance.

Air, Mien, Look.-Air (see above). Mien is a word of unknown origin, possibly Celtic, adopted into English from the French. Look signifies properly a mode of looking or appearing (for derivation see Look).

The exterior of a person is comprehended in the sense of all these words. Air depends not only on the countenance, but the stature, carriage, and action: mien respects the whole outward appearance, not excepting the dress: look depends altogether on the face and its changes. Air marks any settled state of the mind: mien denotes any state of the outward circumstances: look any individual movement of the mind. We may judge by a person's air that he has a confident and fearless mind; we may judge by his sorrowful mien that he has substantial cause for sorrow; and by sorrowful looks that he has some partial or temporary cause for sorrow. We talk of doing anything with a particular air; of having a mien; of giving a look. An innocent man will answer his accusers with an air of composure; a person's whole mien sometimes bespeaks his wretched condition; a look is sometimes given to one who acts in concert by way of intimation.

AIRCRAFT, Aeroplane, Balloon, Biplane, Dirigible, Flying-Machine, Gyroplane, Helicopter, HYDROplane, Monoplane, Multiplane, OrNithopter, TaUbe, Triplane, ZePPELIN.

Aircraft is a compound of French air, Greek án $\rho$, from a root signifying to blow, meaning the lower atmosphere, and craft, a nautical term for vessel.

The European war which began in 1914 gave a new impetus to the designing and construction of aircraft as an offensive weapon. From the mechanism originally built for pleasure or scientific research there was speedily developed a variety of apparatus that in operation startled and shocked the world, especially those acroplanes and the Zeppelins that were constructed to 
drop bombs on an enemy's territory and to carry rifled cannon with.which to fight similar hostile craft.

An aeroplane is a heavier-than-air flying-machine with one or more planes or sustaining surfaces; a balloon is a lighter - than - air construction, elongated or spherical in shape, made of silk or other fabric, and inflated with gas; a biplane is an aeroplane with two sustaining surfaces; a dirigible is a balloon made to travel in any direction by means of a propeller operated by a motor; a flying-machine is the common but indefinite name of any form of aircraft; a gyroplane is a machine combining the features of an aeroplane and a helicopter; a helicopter is a machine that derives its ascending power from a fan wheel; a hydroplane is an aeroplane with a body that enables it to alight on or rise from a water surface; a monoplane is a machine with a single sustaining surface; a multiplane is a machine with two or more sustaining surfaces; an ornithopter is a machine with movable or flapping planes; a Taube is a German bomb-dropping aeroplane; a triplane is an aeroplane with three sustaining surfaces; a Zeppelin is a German dirigible and passenger-carrying apparatus constructed on the balloon principle, and used in the European war as a raiding bomb-dropper.

ALACRITY. See Alertness.

AlARM, Terror, Fright, CoNSTERNATION. Alarm is probably derived through French from the Italian all' arme, to arms, Latin ad illa arma, or Low Latin ad illas armas, to the arms. Terror, in Latin terror, comes from terreo, to cause to tremble. Fright, Anglo-Saxon fyrhto, allied to German fürchten, is a widely distributed Germanic word from a root signifying fear. Consternation, in Latin, consternatus, from consterno, strew, scatter on the ground, expresses the mixed emotion of terror and amazement which confounds.

Alarm springs from any sudden signal that announces the approach of danger. Terror springs from any event or phenomenon that may serve as a prognostic of some catastrophe. It supposes a less distinct view of danger than alarm, and affords room to the imagination, which commonly magnifies objects. Alarm therefore makes us run to our defence, and terror disarms us. Fright is a less vivid emotion than either, as it arises from the simple appearance of danger. It is more personal than either alarm or terror; for we may be alarmed or terrified for others, but we are mostly frightened for ourselves. Consternation is stronger than either terror or affright; it springs from the view of some very serious evil, and commonly affects many. Alarm affects the feelings, terror the understanding, and fright the senses; consternation seizes the whole mind and benumbs the faculties. Cries alarm; horrid spectacles terrify; a tumult frightens; a sudden calamity fills with consternation. One is filled with alarm, seized with terror, overwhelmed with fright or consternation. We are alarmed for what we apprehend; we are terrified by what we imagine; we are frightened by what we see; consternation may be produced by what we learn.

ALERTNESS, Alacrity. Alertness, from ales, a wing, designates corporeal activity or readiness for action. Alacrity, from acer, sharp, brisk, designates mental activity. We proceed with alertness when the body is in its full vigor; we proceed with alacrity when the mind is in full pursuit of an object. ALIEN. See STranger.

alienate. See Transfer; Wean. alienation. See Abstraction. ALIKE. See Equal.

ALL, Whole. All is a Germanic word signifying everything. Whole, Anglo-Saxon hal, allied to German heil, and Greek $\kappa a \lambda o ́ s$, excellent, beautiful, and the English words hale, health, wholesome, etc., signified to be sound, well, without fault or blemish, hence complete, entire.

All respects a number of individuals; whole respects a single body with its components: we have not all, if we have not the whole number; we have not the whole, if we have not all the parts of which it is composed. It is not within the limits of human capacity to take more than a partial survey of all the interesting objects which the whole globe contains. When applied to spiritual objects in a general sense, all is preferred to whole; but 
when the object is specific, whole is preferable: thus we say, all hope was lost; but, our whole hope rested in this.

All, Every, Each.-All is collective; every single or individual; each, distributive. All and every are universal in their signification; each is restrictive: the former are used in speaking of great numbers; the latter is applicable to small numbers. All men are not born with the same talent, either in degree or kind; but every man has a talent peculiar to himself; a parent divides his property among his children, and gives to each his due share.

allay, Soothe, Appease, Mitigate, Assuage. To allay, Middle English aleggen, is properly no more than a French doublet of the word alleviate, derived from Latin ad and levis, light; hence it means to lighten a burden. Soothe, from Anglo-Saxon soth, true, which appears in the phrases "in sooth," "forsooth," etc., means to assent to something as being true, hence to humor. Appease, in French apaiser, is compounded of ad and pax, peace, signifying to quiet. Mitigate, from mitis, meek, gentle, signifies to make gentle or easy to bear. Assuage, from Old French $a$ (Latin $a d$ ) and suavis, sweet, pleasant, cognate with the English sweet (compare the adjective suave), means literally to sweeten.

All these terms indicate a lessening of something painful. In a physical sense an irritating poin is allayed; a wounded part is soothed by affording ease and comfort. Extreme heat or thirst is allayed; extreme hunger is appeased; a punishment or sentence is mitigated.

In a moral sense one allays what is fervid and vehement; one soothes what is distressed or irritated; one appeases what is tumultuous and boisterous; one mitigates the pains of others, or what is rigorous and severe; one assuages grief or afflictions. Nothing is so calculated to allay the fervor of a distempered imagination as prayer and religious meditation: religion has everything in it which can soothe a wounded conscience by presenting it with the hope of pardon, that can appease the angry passions by giving us a sense of our own sinfulness and need of God's pardon, and that can assuage the bit- terest griefs by affording us the brightest prospects of future bliss.

See also QUELL.

ALLEGE. See Adduce.

Allegory. See Figure; ParABLE.

Alleviate, Relieve. For the derivation of alleviate see AlLAY. Relieve, from the Latin relevo, is compounded of re and levo, lift up, signifying to take away or remove.

A pain is alleviated by making it less burdensome; a necessity is relieved by supplying what is wanted. Alleviate respects our internal feelings only; relieve, our external circumstances. That alleviates which affords ease and comfort; that relieves which removes the pain. It is no alleviation of sorrow to a feeling mind to reflect that others undergo the same suffering; a change of position is a considerable relief to an invalid, wearied with confinement. Condolence and sympathy tend greatly to alleviate the sufferings of our fellowcreatures; it is an essential part of the Christian's duty to relieve the wants of his indigent neighbor.

See also Abate.

ALliance, League, ConfederACY. Alliance, in French alliance, from the Latin alligo, to tie to (compare ligament), signifies the state of being tied. League, in French ligue. comes from the same verb, ligo, bind. Confederacy or confederation, in Latin confederatio, from con and foedus, an agreement, signifies a joining together under a certain pledge.

All these terms agree in expressing the union between two or more persons or bodics, but they differ in the nature of the union and the motive for entering into it. Alliance is the most general term, the other two are rather particular terms; an alliance may be entered into either on public grounds as between states, or on private grounds as between families or individuals; a league or confederacy is entered into upon public grounds or for common interests, as a league between nations or states, and a confederacy between smaller powers or between individuals. Alliances are formed for the mutual conveniences of partics, as between states to promote commerce; leagues and confederacies are entered into most- 
ly for purposes of self-defence or common safety against the attacks of a common enemy; but a league is mostly a solemn act between two or more states and for general purposes of safety; and may, therefore, be both defensive and offensive; a confederacy is mostly the temporary act of several uniting in a season of actual danger to resist a common adversary.

Alliance, as regards persons, is always taken in a good sense, and as between families or individuals is mostly matrimonial. League and confederacy are frequently taken in a bad sense; we may speak of a wicked league or an unnatural league between persons of opposite characters for their own private purposes, or a league between beasts for savage purposes; there may be a confederacy between persons to resist a lawful demand or to forward any evil design.

Alliance, Affinity. - Alliance (see above). Affinity, in Latin affinitas, from ad and finis, a border, signifies a contiguity of borders.

An alliance is a union artificially formed between persons; an affinity is a relation which flows from that act as far as the alliance is matrimonial; the affinity is properly that which results from it; when an alliance is formed between persons of different scxes, this necessarily creates an affinity between the relatives of the two parties.

As respects things, alliance is used figuratively in the same sense to denote their union by an artificial tie; as an alliance between church and state; affinity in this case implies a relation between things by reason of their agreement or resemblance to each other; as an affinity of sounds or an affinity of languages.

ALL-KNOWING. See OMniscient.

ALlot, Appoint, Destine. Allot is a hybrid word compounded of the Latin ad and the English word lot, a portion. Appoint, in French appointer, from ad and pungo, participle punctus, signifies to point out or set out in a particular manner for a particular purpose. Destine, in French destiner, Latin destino, compounded of de and a verb from the root sta, to stand, signifies to place apart for a particular object.
The idea of setting apart or selecting is common to these terms; but allot is used only for things, appoint and destine for persons or things. A space of ground is allotted for cultivation, a person is appointed as steward or governor; a youth is destined for a particular profession. Allotments and appointments are made for immediate purposes, destinations for a future purpose; time may be either allotted, appointed, or destined; but allot respects indefinite portions of time, as to allot a portion of one's time to religious meditations; appoint respects any particularly defined portion of time, as to appoint an hour of meeting; destine implies a future time purposely fixed, as the destined hour arrived. A space may be allotted, because space may be divided into portions; a particular place is appointed for a particular immediate object, or it is destined by some previous determination; as a person appoints the place where a house shall be built; he destines a house for a particular purpose.

See also Distribute.

allow, Grant, Bestow. Allow (see Aвate; Admit). Grant, Old French graunter or creanter, to assure, from Latin stem credent, from credere, to trust, is allied on the one hand to the word guarantee, on the other to such words as credible, credulous, credence, etc. Bestow is compounded of the prefix be and the Anglo-Saxon stow, a place, from the root sta, whence stand is also derived, and which is closely allied to the English verb stow. Hence to bestow signifies to dispose according to one's wishes and convenience.

That is allowed which may be expected, if not directly required; that is granted which is desired, if not directly asked for; that is bestowed which is wanted as a matter of necessity. What is allowed is a gift sometimes stipulated as to time and quantity, but frequently depends upon the will of the giver; what is granted is sometimes perfectly gratuitous on the part of the giver, but, when granted, is not always to be taken back; what is bestowed is occasional, altogether depending on circumstances and disposition of both giver and receiver. Many of the poor are allowed a small sum weekly 
from the parish. It is as improper to grant a person more than he asks, as it is to ask a person for more than he can grant. Alms are very ill bestowed which only serve to encourage beggary and idleness. A grant comprehends in it something more important than an allowance, and passes between persons in a higher station; what is bestowed is of less value than either. A father allows his son a yearly sum for his casual expenses, or a master allows his servant a maintenance; kings grant pensions to their officers; governments grant subsidies to one another; relief is bestowed on the indigent.

In a figurative application, things are allowed either out of courtesy or complaisance; they are granted by way of favor or indulgence; they are bestowed either from necessity or urgent reasons: merit is allowed; a request is granted; attention or applause is bestowed.

See also ADMrT; Consent.

Allowance, Stipend, Salary, Wages, Hire, Pay.-All these terms denote a stated sum paid according to certain stipulations. Allowance, from allow (see ADMIT), signifies the thing allowed. Stipend, in Latin stipendium, from stips, a piece of money, signifies money paid. Salary, in French salaire, Latin salarium, comes from sal, salt, and meant salt-money, money for salt. (Compare the word pin-money for a similar method of designation.) Wages, Old French gage, Low Latin vadium, signifies something paid for labor. Hire expresses the sum for which one is hired, and pay the sum that is to be paid.

An allowance is gratuitous; it ceases at the pleasure of the donor; all the rest are the requital for some supposed service; they cease with the engagement made between the parties. A stipend is more fixed and permanent than a salary; and that than wages, hire, or pay; a stipend depends upon the fulfilling of an engagement, rather than on the will of an individual; a salary is a matter of contract between the giver and receiver, and may be increased or diminished at will. An allowance may be given in any form, or at any stated times; a stipend and salary are paid yearly, or at even portions of a year; wages, hire, and pay are estimated by days, weeks, or months, as well as years. An allowance may be made by, with, and to persons of all ranks; a stipend and salary are assignable only to persons of respectability; wages are given to laborers, hire to servants, pay to soldiers or such as are employed under government.

ALL-SEEING. See OMINISCIENT.

ALLUDE, Refer, HiNT, Suggest. Allude, in Latin alludo, is compounded of $a d$ and ludo, sport. It means to say anything in a cursory manner. Refer, in Latin refero, signifies to bring back - that is, to bring back a person's recollection to any subject by mentioning it. Hint, a verb formed from the noun hint, which is a contraction of the participle of a verb hinten, hinted, is allied to the words hit, hurt, etc., and originally meant taken, touched. To hint is to touch upon something. Suggest, in Latin suggestus, participle of suggero, is compounded of $s u b$ and gero, bring under or near, and signifies to bring forward in an indirect or casual manner.

To allude is not so direct as to refer, but it is more clear and positive than either hint or suggest. We allude to a circumstance by introducing it into one's discourse; we hint at a person's intentions by darkly insinuating what may possibly happen; we suggest an idea by some poetical expressions relative to it. There are frequent allusions in the Bible to the customs and manners of the East. It is necessary to refer to certain passages of a work when we do not expressly copy them. It is sometimes better to be entirely silent upon a subject than to hint at what cannot be fully explained. Many improvements have owed their origin to some ideas casually suggested in the course of conversation.

Allude and refer are always said with regard to things that have positively happened, and mostly such as are indifferent; hint and suggest have mostly a personal relation to things that are precarious. The whole drift of a discourse is sometimes unintelligible for want of knowing what is alluded to; although many persons and incidents are referred to with their proper names and dates. It is the part of the slan- 
derer to hint at things discreditable to another when he does not dare to speak openly; and to suggest doubts of his veracity when he cannot positively charge him with falsehood.

See also Glance.

ALLURE, Tempt, Seduce, Entice, Decoy. Allure, from the Old French à leurre, a word of possibly Germanic origin, signifying bait, meant to draw to a bait. Tempt, in French tenter, Latin tento, a frequentative of the verb tendere, to stretch, meant to draw out one's will, hence to try the strength of, hence to test. Seduce, in French séduire, Latin seduco, is compounded of se, apart, and duco, lead, signifying to lead any one aside. Entice comes from Old French enticier, based on titio, a firebrand. Decoy, from de and Old French coi, earlier coit, from Latin quietus, quiet, still, meant to render still or tame. (Compare the adjective coy.) But it is also influenced by provincial English coy, fróm Latin cavea (whence English cage), a trap for catching wild ducks.

We are allured by the appearances of things; we are tempted by the words of persons as well as the appearances of things; we are enticed by persuasions; we are seduced or decoyed by the influence and false arts of others. To allure and tempt are used either in a good or bad sense: entice sometimes in an indifferent, but mostly in a bad sense; seduce and decoy are always in a bad sense. The weather may allure us out-of-doors: the love of pleasures may allure us into indulgences that afterward cause repentance. We are sometimes tempted upon very fair grounds to undertake what turns out unfortunately in the end: our passions are our bitterest enemies; the devil uses them as instruments to tempt us to sin. When the wicked entice us to do evil, we should turn a deaf ear to their flattering representations: those who know what is right, and are determined to practise it, will not suffer themselves to be enticed into any irregularities. Young men are frequently seduced by the company they keep. Children are decoyed away by the evil-minded, who wish to get them into their possession. The country has its allurements for the contemplative mind; the metropolis is full of temptations. Those who have any evil project to execute will omit no enticement in order to seduce the young and inexperienced from their duty. The practice of decoying children or ignorant people into places of confinement was formerly more frequent than at present.

Allure does not imply such a powerful influence as tempt; what allures draws by gentle means; it lies in the nature of the thing that affects: what tempts acts by direct and continued efforts; it presents motives to the mind in order to produce decision; it tries the power of resistance. Entice supposes such a decisive influence on the mind as produces a determination to act; in which respect it differs from the two former terms. Allure and tempt produce actions on the mind, not necessarily followed by any result; for we may be allured or tempted to do a thing, without necessarily doing the thing; but we cannot be enticed unless we are led to take some step. Seduce and decoy have reference to the outward action, as well as the inward movements of the mind which give rise to them; they indicate a drawing aside of the person as well as the mind; it is a misleading by false representation. Prospects are alluring, offers are tempting, words are enticing, charms are seductive.

See also Atrract; Tweedle.

ALL-WISE. See OMNISCIENT.

ALLY, Confederate. Although derived from the preceding terms (see Alliance), these are used only in part of their acceptations. An ally is one who forms an alliance in the political sense; a confederate is one who forms confederacies in general, but more particularly when such confederacies are unauthorized. William Tell had some few particular friends who were his confederates; but we should use the word with more propriety in its worst sense, for an associate in a rebellious faction, as in speaking of any bandit and his confederates.

almanac. See Calendar.

ALONE, Solitary, LoNely. Alone, in Middle English often written as two words, al one, signifies altogether one, or single; that is, by one's self. Soli- 
tary, in' French solitaire, Latin solitarius, from solus, alone, signifies the quality of being alone. Lonely is a derivative of lone, which is a contraction of all one. Alone marks the state of a person; solitary the quality of a person or thing; lonely has more melancholy connotations than solitary, and may be used to indicate the state of mind of one dwelling alone. A person walks alone, or takes a solitary walk in a lonely place. Whoever likes to be much alone is of a solitary turn; wherever we can be most and of tenest alone, that is a solitary or lonely place; people who are forced to dwell alone may be of ten lonely.

ALSO, Likewise, Too. Also, compounded of all and so, signifies literally all in the same manner. Likewise, compounded of like and wise, or manner, signifies in like manner. Too, a variation of the numeral twa, signifies what may be added or joined to another thing from its similarity.

These adverbial expressions obviously convey the same idea of including or classing certain objects together upon a supposed ground of affinity. Also is a more general term, and has a more comprehensive meaning, as it implies a sameness in the whole; likewise is more specific and limited in its acceptation; too is still more limited than either, and refers only to a single object. "He also was among the number," may convey the idea of totality both as respects the person and the event; "he writes likewise a very fine hand," conveys the idea of similar perfection in his writing as in other qualifications; "he said so, too," signifies he said so in addition to the others; "he said it likewise," would imply that he said the same thing or in the same manner.

AlTER. See Change.

ALTERCATION. See DifferENCE.

ALTERNATE. See Successive.

ALTISCOPE. See Periscope.

always, At all Times, Ever. Always, compounded of all and ways, is the same as, under all circumstances, through all the ways of life, that is, uninterruptedly. At all times means without distinction of time. Ever implies for a perpetuity, without end. man must be always virtuous, that is, whether in adversity or prosperity; and at all times virtuous, that is, in his going out and coming in, his rising up and his lying down, by day and by night; he will then be ever happy, that is, in this life and the life to come.

See also Aye.

AMASS. See Heap.

AMAZE. See Wonder.

AMBASSADOR, ENyoy, PleniPOTENTIARY, DEPUTY. Ambassador is derived through French from Low Latin ambactus, by way of Italian. A mbactus is derived from an Old Gaulish (Celtic) root meaning servant, which also appears in the Anglo-Saxon ombiht, a servant. Envoy, Old French envoyer, to send, from Latin inde, and via, way, meant one sent on a mission. (Compare Vorage.) Plenipotentiary, from the Latin plenus and potens, signifies one invested with full powers. Deputy (for etymology see depute under AssigN) meant one deputed, one assigned to a particular mission.

Ambassadors, envoys, and plenipotentiaries speak and act in the name of their sovereigns, with this difference, that the first is invested with the highest authority, acting in all cases as the representative; the second appears only as a simple authorized minister acting for another, but not always representing him: the third is a species of envoy used by courts only on the occasion of concluding peace or making treaties: deputies are not deputed by sovereigns, although they may be deputed to sovereigns; they have no power to act or speak but in the name of some subordinate community or particular body. The functions of the first three belong to the minister, those of the latter to the agent.

An ambassador is a resident in a country during a state of peace; he must maintain the dignity of his court by a suitable degree of splendor: an envoy may be a resident, but he is more commonly employed on particular occasions; address in negotiating forms is an essential in his character: a plenipotentiary is not so much connected with the court immediately as with persons in the same capacity with himA self; he requires to have integrity, 
coolness, penetration, loyalty, and patriotism. A deputy has little or no responsibility, and still less intercourse with those to whom he is deputed; he needs no more talent than is sufficient to maintain the respectability of his own character and that of the body to which he belongs.

AMBIGUOUS, EQUIVOCAL. $\mathrm{Am}$ biguous, in Latin ambiguus, from ambigo, compounded of ambo, both, and agere, to act, signifies acting both ways or having two meanings. Equivocal, in French équivoque, Latin equivocus, composed of axquus and vox, signifies a word to be applied equally to two or more different objects.

An ambiguity arises from a too general form of expression, which leaves the sense of the author indeterminate; an equivocation lies in the power of particular terms used, which admit of a double interpretation, or an application to two different things: the ambiguity leaves us in entire incertitude as to what is meant; the equivocation misleads us in the use of a term in the sense which we do not suspect.

The ambiguity may be unintentional, arising from the nature both of the words and the things; or it may be employed to withhold information respecting our views; the equivocation is always intentional, and may be employed for purposes of fraud. The históries of heathen nations are full of confusion and ambiguity; the heathen oracles are mostly veiled by some equivocation; of this we have a remarkable instance in the oracle of the Persian mule, by which Crœsus was misled.

AMENABLE. See ANswerable.

AMEND, Correct, EMENd, IMprove, Mend, Better. Amend and emend, in Latin emendo, from menda, the fault of a transcriber, signifies to remove faults generally. Mend, which is a contraction of amend, is similar in sense, but different in application. Correct, from cum and regere, to regulate, signifies to set right in a particular manner. Improve, from probus, good, signifies to make good, as better signifies to make better.

To amend, emend, correct, and mend imply the removing of an evil; improve and better, the increase of good.
Amend, emend, and correct, are all applied to works of the understanding, with this distinction, that amend signifies to remove faults or defects generally, either by adding, taking away, or altering, as to amend a law, to amend a passage in a book; this is the work of the author, or some one acting for him: to emend is to remove particular faults in any literary work by the alteration of letters or single words; this is the work of the critic: to correct is to remove gross faults, as to correct the press.

Amend and correct may be applied to moral objects with a similar distinction.

Mend is employed in respect to any works in the sense of putting that right which either is or has become faulty. It is a term in ordinary use, but may be employed in the higher style.

To improve is said either of persons or things which are made better; as to improve the mind, morals, etc.: to better is mostly applied to the outward condition on familiar occasions.

\section{AMENDS. See Compensation;} Restoration.

AMIABLe, Lovely, Beloved. A miable, in Latin amabilis, from amare to love, signifies fit to be loved. Lovely, compounded of love and ly, or like, signifies like that which we love, fit to produce love. Beloved signifies having or receiving love.

The two first express the fitness of an object to awaken the sentiment of love: the former by spiritual qualities, the latter by personal attractions. One is amiable from the qualities of the heart.

So also it is said of things personified. One has a lovely person, or is lovely in one's person. It may be applied to the attractions of other objects besides those of the person.

Beloved denotes the state of being loved, or being the object of love, which may arise from being amiable or lovely, or from other causes. Both persons and things may be beloved.

AMICABLE, FriendLy. Amicable, from amicus, a friend, signifies able or fit for a friend. Friendly signifies like $a$ friend. The word amicus likewise comes from amo, to love, and friend from Anglo-Saxon freogan, to love. Amicable and friendly, therefore, both 
denote the tender sentiment of goodwill which all men ought to bear one to another; but amicable rather implies a negative sentiment, a freedom from discordance; and friendly a positive feeling of regard, the absence of indifference. We make an amicable accommodation, and a friendly visit. It is a happy thing when people who have been at variance can amicably adjust all their disputes. Nothing adds more to the charms of society than a friendly correspondence. Amicable is always said of persons who have been in connection with each other; friendly may be applied to those who are perfect strangers. Neighbors must always endeavor to live amicably with each other. Travelers should always endeavor to keep up a friendly intercourse with the inhabitants wherever they come.

The abstract terms of the preceding qualities admit of no variation but in the signification of friendship, which marks an individual feeling only. To live amicably, or in amity with all men, is a point of Christian duty, but we cannot live in friendship with all men, since friendship must be confined to a few: so nations may be in amity, though not on terms of friendship with each other.

AMMUNITION, Munitions. These words have been somewhat modified in application since the beginning of the European war. Ammunition was originally merely an army corruption of munition, from Latin munitio (from munire, to fortif $y$ with a wall). During the war, however, the word munitions, used in the plural, has been widely used to designate all the materials for shooting employed in warfare; ammunition has merely kept its meaning of material with which to load a gun which it had before the war, and in popular speech has been largely supplanted by the more general word munitions.

AMNESIA, Bewilderment, ForGETFULNESS. Amnesia comes from the Greek á $\mu \nu \eta \sigma i a$, and implies the loss of memory for words. The victim is apt to be an apparently aimless wanderer on the streets, and on being accosted appears to be in a high state of bewilderment, anxiety, perplexity.
While the affliction is in an acute stage the victim is unable to recall his or her name, place of residence, occupation, or present intentions.

Properly speaking, the word has no genuine synonym. Bewilderment and forgetfulness are general words which may be used to describe the state of mind of one afflicted by amnesia.

AMOROUS, LOVING, Fond. Amorous, from amor, and the ending, ous, which designates abundance, signifies full of love. Loving signifies the act of loving, that is, continually loving. Fond (for derivation see under affectionate) signifies an extreme or foolish attachment.

These epithets are all used to mark the excess or distortion of a tender sentiment. Amorous is taken in a criminal sense, loving and fond in a contemptuous sense; an indiscriminate and dishonorable attachment to the fair sex characterizes the amorous man; an overweening and childish attachment to any object marks the loving and fond person. Loving is less dishonorable than fond: men may be loving; children and brutes may be fond. Those who have not a wellregulated affection for each other will be loving by fits and starts; children and animals who have no control over their appetites will be apt to be fond of those who indulge them. An amorous temper should be suppressed; a loving temper should be regulated; a fond temper should be checked.

When taken generally, loving and fond may be used in a good or indifferent sense.

AMORTIZEMENT, AMORTIZATION. The term amortizement, in French amortissement, is derived from amortize, in French amortir, to extinguish, from Latin mortis, death, meaning in a general sense to make dead or render useless.

While amortization specifically means the right of alienating lands in mortmain, the term has of late come into vogue as synonymous with amortizement, especially in European countries burdened with debt.

Thus we read that certain revenues, or parts thereof, of a country have been assigned to the amortization or amortizement of the national debt, 
meaning a payment on account, or the extinction (payment in full), liquidation (partial or full payment), reduction (partial payment), or redemption (full payment) of outstanding obligations.

AMPLE, - Spacious, Capacious. Ample is in French ample, Latin amplus, large, full. Spacious, in French spacieux, from Latin spatium, allied to Greek $\sigma \pi a ́ \varepsilon \iota \nu$, to draw out, English span-all from a root spa, to spread or draw out. Capacious, in Latin capax, from capio, to hold, signifies the quality of being able to hold.

These epithets convey the analogous ideas of extent in quantity and extent in space. Ample is figuratively employed for whatever is extended in quantity; spacious is literally used for whatever is extended in space; capacious is literally and figuratively.employed to express extension in both quantity and space. Stores are ample, room is ample, an allowance is ample; a room, a house, or a garden is spacious; a vessel or hollow of any kind is capacious; the soul, the mind, and the heart are capacious. Ample is opposed to scanty, spacious to narrow, capacious to small. What is ample suffices and satisfies; it imposes no constraint: what is spacious is free and open; it does not confine: what is capacious readily receives and contains; it is liberal and generous. Although sciences, arts, philosophy, and languages afford to the mass of mankind ample scope for the exercise of their mental powers without recurring to mysterious or fanciful researches, yet this world is hardly spacious enough for the range of the intellectual faculties: the capacious minds of some are no less capable of containing than they are disposed for receiving whatever spiritual good is offered them.

See also Plentiful.

AMUSE, Divert, Entertain. To amuse, to cause to muse or wonder at, is derived from French $d$ and muser (English verb muse), Italian musare, to gape idly about, from muso, a snout, a face. "The image is that of a dog snuffling idly about, and musing which way to take" (Skeat). Cf. muzzle. Divert, in French divertir, Latin diverto, is compounded of $d i$, apart, and vertere, to turn aside, signifying to turn the mind aside from an object. Entertain, in French entretenir, compounded of entre, Latin inter, and tenir, Latin tenere, to keep, signifies to keep the mind fixed on a thing.

We amuse or entertain by engaging the attention on some present occupation, we divert by drawing the attention from a present object; all this proceeds by means of that pleasure which the object produces, which in the first case is less vivid than in the second, and in the second case is less durable than in the third. Whatever amuses serves to kill time, to lull the faculties and banish reflection; it may be solitary, sedentary, and lifeless; whatever diverts causes mirth and provokes laughter; it will be active, lively, and tumultuous: whatever entertains acts on the senses and awakens the understanding; it must be rational, and is mostly social. The bare act of walking and changing place may amuse; the tricks of animals divert; conversation entertains. We sit down to a card-table to be amused; we go to a comedy or pantomime to be diverted; we go to a tragedy to be entertained. Children are amused with looking at pictures; ignorant people are $d i$ verted with shows; intelligent people are entertained with reading. The dullest and most vacant minds may be amused; the most volatile are diverted; the most reflective are entertained; the Emperor Domitian amused himself with killing flies; the Emperor Nero diverted himself with appearing before his subjects in the characters of the gladiator and charioteer; Socrates entertained himself by discoursing on the day of his execution with his friends on the immortality of the soul.

Amuse, Beguile.-As amuse denotes the occupation of the mind, so beguile, compounded of the English prefix be and Old French guile (English wile), (for the derivation of which see that key-word), signifying to overreach with guile, expresses an effect or consequence of amusement. When amuse and beguile express any species of deception, the former indicates what is effected by persons, and the latter that which is effected by things. The first is a fraud upon the understanding; the second is a fraud upon the memory and con- 
sciousness. We are amused by a false story; our misfortunes are beguiled by the charms of fine music or fine scenery. To suffer one's self to be amused is an act of weakness; to be beguiled is a relief and a privilege. Credulous people are easily amused by any idle tale, and thus prevented from penetrating the designs of the artful; weary travelers beguile the tedium of the journey by lively conversation.

Amusement, Entertainment, Diversion, Sport, Recreation, Pastime.-Amusement signifies here that which serves to amuse. Entertainment, that which serves to entertain. Diversion, that which serves to divert. Sport, that which serves to give sport. Recreation, that which serves to recreate, from recreatus, participle of recreo, or re and creo, means to create or make alive again, and was originally used of a recovery from illness. Pastime is that which serves to pass time.

The first four of these terms are either applied to objects which specifically serve the purposes of pleasure, or to such objects as may accidentally serve these purposes; the last two terms are employed only in the latter sense. The distinction between the first three terms is very similar in this as in the preceding case. Amusement is a general term, which comprehends little more than the common idea of pleasure, whether small or great; $e n$ tertainment is a species of amusement which is always more or less of an intellectual nature; diversions and sports are a species of amusements more adapted to the young and the active, particularly the latter: the theatre or the concert is an amusement; fairs and public exhibitions are diversions; games of racing or cricket, hunting, shooting, and the like, are sports.

Recreation and pastime are terms of relative import: the former is of use for those who labor; the latter for those who are idle. A recreation must partake more or less of the nature of an amusement, but it is an occupation which owes its pleasure to the relaxation of the mind from severe exertion: in this manner gardening may be a recreation to one who studies; company is recreation to a man of business: the pastime is the amusement of the leisure hour; it may be alternately a diversion, a sport, or a simple amusement, as circumstances require.

ANATHEMA. See Malediction.

ANATHEMATIZE. See ExcomMUNICATE.

ANCESTORS. See Forefathers. ANCIENT. See OLD.

ANCIENTLY. See Formerly. ANECDOTE, STORY. An anecdote has but little incident and no plot; a story (which, like Latin historia, English history, is derived from Greek ioropia, which originally referred to something learned by inquiry, being a derivative from a verb signifying to know) may have many incidents and an important catastrophe annexed to it: anecdotes are related of individuals, some of which are of a trifling nature, and others characteristic; stories are generally told to young pcople of ghosts and visions, which are calculated to act on their fears. An anecdote is pleasing and pretty; a story is frightful or melancholy; an anecdote always consists of some matter of fact; a story is sometimes founded on that which is real. Anecdotes are related of some distinguished persons, displaying their charaeters or the eircumstances of their lives: stories from life, however striking and wonderful, will seldom impress so powerfully as those which are drawn from the world of spirits: anecdotes serve to amuse men, stories to amuse children.

Anecdotes, Memoirs, Chronicles, Annals.-Anecdote, Greek av'śóoros, meant literally unpublished, not given out, from íx (ex) and $\delta i \delta \omega \mu$, give. $M e$ moirs, in French mémoires, from the word memory, signifies what serves to help the memory. Chronicle, in French chronique, from the Greek xpónos, time, signifies an account of the times. Annals, from the French annales, from the Latin annus, signifies a detail of what passes in the year.

All these terms mark a species of narrative, more or less connected, that may serve as materials for a regular history. Anecdotes consist of personal or detaehed circumstances of a public or private nature, involving one subjeet or more. Anecdotes may be either moral or political, literary or biographical; they may serve as character- 
istics of any individual, or of any particular nation or age. Memoirs may include anecdotes, as far as they are connected with the leading subject on which they treat: memoirs are rather connected than complete; they are a partial narrative respecting an individual, comprehending matter of a public or private nature; they serve as memorials of what ought not to be forgotten, and lay the foundation either for a history or a life.

Chronicles and annals are altogether of a public nature; and approach the nearest to regular and genuine history. Chronicles register the events as they pass; annals digest them into order, as they occur in the course of successive years. Chronicles are minute as to the exact point of time; annals only preserve a general order within the period of a year. Chronicles detail the events of small as well as large communities, as of particular districts and cities; annals detail only the events of nations. Chronicles include domestic incidents, or such things as concern individuals; the word annals, in its proper sense, relates only to such things as affect the great body of the public, but it is frequently employed in an improper sense. Chronicles may be confined to simple matter of fact; annals may enter into the causes and consequences of events.

ANGER, Resentment, Wrath, Ire, INDignation. Anger comes from the Latin angere, Greek ä $\gamma \chi \varepsilon \iota \nu$, to strangle, Icelandic angr, grief, sorrow, Danish anger, compunction, etc., from which our words anxious, anxiety, etc., are also derived, and refers to the physical sensations accompanying anger or grief. Resentment, in French ressentiment, from resentir, is compounded of $r e$ and sentir, signifying to feel again, over and over, or for a continuance. Wrath, Anglo-Saxon wrath, English wroth, angry, and ire, Latin ira, are less obviously metaphorical than the preceding, the original roots in both cases having, apparently, the meaning of the present words. Indignation, in French indignation, in Latin indignatio, from indignor, to think or feel unworthy, marks the strong feeling which base conduct or unworthy treatment awakens in the mind.
An impatient agitation against any one who acts contrary to our inclinations or opinions is the characteristic of all these terms. Resentment is less vivid than anger, and anger than wrath, ire, or indignation. Anger is a sudden sentiment of displeasure; resentment is a continued anger; wrath is a heightened sentiment of anger, which is poetically expressed by the word ire. Anger may be either a selfish or a disinterested passion, it may be provoked by injuries done to ourselves, or injustice done to others: in this latter sense of strong displeasure God is angry with sinners, and good men may to a certain degree be angry with those under their control who act improperly. Resentment is a brooding sentiment altogether arising from a sense of personal injury; it is associated with a dislike of the offender, as much as the offence, and is diminished only by the infliction of pain in return; in its rise, progress, and effects, it is alike opposed to the Christian spirit. Wrath and ire are the sentiment of a superior toward an inferior, and when provoked by personal injuries discovers itself by haughtiness and a vindictive temper: as a sentiment of displeasure, wrath is unjustifiable between man and man; but the wrath of God may be provoked by the persevering impenitence of sinners; the ire of a heathen god, according to the gross views of pagans, was but the wrath of man associated with greater power: it was altogether unconnected with moral displeasure. Indignation is a sentiment awakened by the unworthy and atrocious conduct of others; as it is exempt from personality, it is not irreconcilable with the temper of a Christian: a warmth of constitution sometimes gives rise to sallies of anger; but depravity of heart breeds resentment; unbending pride is a great source of wrath; but indignation may flow from a high sense of honor and virtue.

See also Displeasure.

Anger, Choler, Rage, Fury.-Anger (see above). Choler, in French colere,

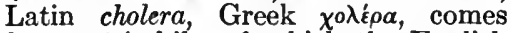
from $\chi 0 \lambda \dot{\eta}$, bile, of which the English word gall is a cognate, because the overflowing of bile was supposed to be the physical accompaniment of anger. 
Rage, in French rage, from Latin rabies, madness, and rabio, to rave like a madman, signifies madness, hence the loss of self-control in extreme anger. Compare the use of mad for angry among children. Fury, derived through French from Latin furia, is from a root signifying to rage, which refers especially to violent physical expression of anger, because one is carried or hurried away by the emotion of fury.

These words have a progressive force in their significance. Choler expresses something more sudden and virulent than anger; rage is a vehement ebullition of anger; and fury is an excess of rage. Anger may be so stifled as not to discover itself by any outward symptoms; choler is discoverable by the paleness of the visage; rage breaks forth into extravagant expressions and violent distortions; fury takes away the use of the understanding. Anger is an infirmity incident to human nature; it ought, however, to be suppressed on all occasions: choler is a malady too physical to be always corrected by reflection: rage and fury are distempers of the soul, which nothing but religion and the grace of God can cure.

ANGLE. Sce Corner.

ANGRY, Passionate, Hasty. $A n$ gry signifies either having anger, or prone to anger. Passionate signifies prone to passion. Hasty signifies prone to excess of haste from intemperate feeling.

Angry denotes either a particular state or a habit of the mind; passionate expresses a habit of the mind; hastiness is mostly a temporary feeling. An angry man is in a state of anger; a passionate man is habitually prone to be passionate. The angry has less that is vehement and impetuous in it than the passionate; the hasty has something less vehement, but more sudden and abrupt in it than either. The angry man is not always easily provoked, nor ready to retaliate; but he often retains his anger until the cause is removed: the passionate man is quickly roused, eager to repay the offence, and speedily appeased by the infliction of pain of which he afterward probably repents: the hasty man is very soon offended. but not ready to offend in return; his angry sentiment spends itself in angry words.

See also Splenetic.

ANGUISH. See Distress; Pain. ANIMADVERSION, CRITICISM, Stricture. Animadversion, in Latin animadversio, from animadvertere, that is vertere animum ad, signifies to turn the mind to a thing. Criticism, in French critique, Latin criticus, Greek

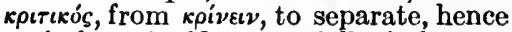
to judge, signifies especially judgment founded on analysis. Stricture, Latin strictura, comes from the verb stringere, to draw tight, to urge, and signifies in Latin the exertion of pressure, oppression, etc. (Compare strict, stringent.)

Animadversion includes censure and reproof; criticism implies scrutiny and judgment, whether for or against; and stricture comprehends a partial investigation mingled with censure. We animadvert on a person's opinions by contradicting or correeting them; we criticise a person's works by minutely and rationally exposing their imperfections and beauties; we pass strictures on public measures by descanting on them cursorily and censuring them partially. Animadversions are too personal to be impartial, consequently they are seldom just; they are mostly resorted to by those who want to build up one system on the ruins of another: criticism is one of the most important and honorable departments of literature; a critic ought justly to weigh the merits and demerits of authors, but of the two his office is rather to blame than to praise; much less injury will accrue to the cause of literature from the severity than from the laxity of criticism; strictures are mostly the vehicles of party spleen; like most ephemeral productions, they are too superficial to be entitled to serious notice.

See also Censure.

ANIMAL, BRUTE, Beast. animal, Latin animal, from anima, life, which is derived from a root signifying to breathe, indicates a living thing-i. $e$., one that breathes. Brute, Latin brutus, heavy, dull, was originally used as an adjective with beast, "a brute beast," and hence developed into a substantive. Beast, French bête, from Latin bestia, signified the lower animals, as distinguished from man. 
Animal is the generic, brute and beast are the specific terms. The animal is the thing that lives and moves. If animal be considered as thinking, willing, reflecting, and acting, it is confined in its signification to the human species; if it be regarded as limited in all the functions which mark intelligence and will, if it be divested of speech and reason, it belongs to the brute; if animal be considered, moreover, as to its appetites, independent of reason, of its destination, and consequent dependence on its mental powers, it descends to the beast. Man and brute are opposed. To man an immortal soul is assigned; but we are not authorized by Scripture to extend this dignity to the brutes. "The brutes that perish" is the ordinary mode of distinguishing that part of the animal creation from the superior order of terrestrial beings who are destined to exist in a future world. Animal, when applied to man individually, is a term of reproaeh; the epithets brute and beast are still stronger terms of reproach, the perversion of the rational faculty being at all times more shocking and disgraceful than the absence of it by nature.

ANIMATE, inspire, Enliven, Cheer, Exhilarate. Animate, in Latin animatus, from animus, the mind, and anima, the soul or vital principle, signifies in the proper sense to give life, and in the moral sense to give spirit. The connection between the idea of breathing and that of life found in animate (see derivation of animal above) is more obvious in the word inspire, from in and spirare, breathe into. Enliven means literally to put life into. Cheer, Old French chere, is derived from Low Latin cara, a face, Greek кáoa, the head (compare cerebrum, the brain, cerebral, etc.) The original meaning is seen in the phrase "be of good cheer," literally put "a good face on the matter." It began to signify especially a glad face, and thence developed the verb to gladden, cheer. Exhilarate, in Latin exhilaratus, participle of exhilaro, from hilaris, Greek iגăpós, joyful, signifies to make glad.

Animate and inspire imply the communication of the vital or mental spark; enliven, cheer, and exhilarate signify ac- tions on the mind or body. To be animated in its physical sense is simply to receive the first spark of animal life in however small a degree; for there are animated beings in the world possessing the vital power in an infinite variety of degrees and forms: to be animated in the moral sense is to receive the smallest portion of the sentient or thinking faculty, which is equally varied in thinking beings; the term animation, therefore, taken absolutely, never conveys the idea of receiving any strong degree of either physical or moral feeling. To inspire, on the contrary, expresses the communication of a strong moral sentiment or passion; hence, to animate with courage is a less forcible expression than to inspire with courage: we likewise speak of inspiring with emulation or a thirst for knowledge; not of animating with emulation or a thirst for knowledge. To enliven respects the mind; cheer relates to the heart; exhilarate regards the spirits, both animal and mental; they all denote an action on the frame by the communication of pleasurable emotions: the mind is enlivened by contemplating the scenes of nature; the imagination is enlivened by reading poetry; the benevolent heart is cheered by witnessing the happiness of others; the spirits are exhilarated by the convivialities of social life: conversation enlivens society; the conversation of a kind and considerate friend cheers the drooping spirits in the moments of trouble; unexpected good news is apt to exhilarate the spirits.

See also Cheer; Encourage;
Hearten.
Animation, Life, Vivacity, Spirit.Animation and life do not differ either in sense or application, but the latter is more in familiar use. They express either the particular or general state of the mind. Vivacity and spirit express only the habitual nature and state of the feelings.

A person of no animation is divested of the distinguishing characteristic of his nature, which is mind; a person of no vivacity is a dull companion; a person of no spirit is unfit to associate with others. A person with animation takes an interest in everything: a vivacious man catches at everything 
that is pleasant and interesting: a spirited man enters into plans, makes great exertions, and disregards difficulties. A speaker may address his audience with more or less animation, according to the disposition in which he finds it: a man of a vivacious temper diffuses his vivacity into all his words and actions: a man of spirit suits his measures to the exigency of his circumstances.

\section{ANIMOSITY. See ENMITY.}

ANNALS. See ANecDotes.

ANNEX. See AFFix.

ANNOTATION. See REMARK.

ANNOUNCe, Proclaim, Publish. Announce, in Latin annuncio, is compounded of an or ad and nuncio, to tell to any one in a particular manner. Proclaim, in Latin proclamo, is compounded of pro and clamo, to cry before, or cry aloud. Publish, in Latin publico, from publicus and populus, signifies to make public or known to the people at large.

The characteristic sense of these words is the making of a thing known to numbers of individuals: a thing is announced in a formal manner to many or few; it is proclaimed to a neighborhood, and published to the world. We announce an event that is expected and just at hand; we proclaim an event that requires to be known by all the parties interested; we publish what is supposed likely to interest all who know it. Announcements are made verbally, or by some well-known signal; proclamations are made verbally and accompanied by some appointed signal; publications are ordinarily made through the press, or by oral communication from one individual to another. The arrival of a distinguished person is announced by the ringing of the bells; the proclamation of peace by a herald is accompanied with certain ceremonies calculated to excite notice; the publication of news is the office of the journalist.

See also Advertise.

ANNOY. See Hector; InconvenIENCE; IVORRY.

ANNUL. See Abolish.

ANSWER, REPLY, REJOINDER, RESPoNse. Answer, Anglo-Saxon ands- warian, compounded of and (corresponding to Latin ante, Greek ávrı) and swerian, to swear, means to swear in response to something, to take one's oath concerning the other side of the question. Reply comes from the French répliquer, Latin replico, unfold, signifying to unfold or enlarge upon by way of explanation. Rejoin is compounded of $r e$ and jungere, to join, signifying to join or add in return. Response, in Latin responsus, participle of respondeo, compounded of re and spondeo, promise (compare sponsor), signifies to promise in return, to give sanction to in return.

Under all these terms is included the idea of using words in return for other words, or returning $\approx$ sound for a sound. An answer is given to a question; a reply is made to an assertion; a rejoinder is made to a reply; a response is made in accordance with the words of another. We answer either for the purpose of affirmation, information, or contradiction; we always reply or rejoin, in order to explain or confute; responses are made by way of assent or confirmation. It is impolite not to answer when we are addressed; arguments are maintained by the alternate replies and rejoinders of two parties; but such arguments seldom tend to the pleasure and improvement of socicty: the responses in the Liturgy are peculiarly calculated to keep alive the attention of those who take part in the devotion.

An answer may be either spoken or written," or delivered in any manner; reply and rejoinder are used in personal discourse only; a response may be said or sung, or delivered in a formal manner.

Animals as well as men may give answers or make responses, though not replies or rejoinders.

Answerable, Responsible, Accountable, Amenable.-Answerable, from answer, signifies ready or able to answer for. Responsible, from respondeo, to answer, has a similar meaning in its original sense. Accountable, from account, signifies able or ready to give an account. Amenable, from the French amener, to lead, signifies liable to be led or bound.

Betwcen answerable and responsible 
there is a close alliance in the sense, but some difference in the application. A person is answerable generally in respect to what he undertakes to pay or take charge of; he is answerable for his own debts, or for the debts of others to which he has made himself liable; he may also be answerable for things left in his charge: responsible is applied to higher matters of trust or duty; as an officer is responsible for the conduct of the men who are under him; so to hold a responsible position under government; and in an extended sense to be morally responsible - that is, responsible to society as a moral agent.

Answerable and responsible convey the idea of a pledge given for the performance of some act, or the fulfilment of some engagement, a breach of which subjects the defaulter to loss, punishment, or disgrace: accountable implies simply giving an account or explanation of one's proceedings. The two former have respect to the obligations only: the accountability results from the relation of the parties; a person is accountable to his employer for the manner in which he has conducted any business intrusted to him; a child is accountable to his parents for all his actions while he is under their control; and we are all accountable to the Great Judge of all. To be amenable is to be accountable as far as laws and regulations bind a person; one is amenable to the laws of society, or he is amenable to the rules of the house in which he is only an inmate.

See also Correspondent.

ANTAGONIST. See Enemy.

ANTECEDENT, PreCEding, Foregoing, Previous, Anterior, Prior, Former. Antecedent, in Latin antecedens - that is, ante and cedens, going before. Preceding, in Latin precedens, going before. Foregoing, literally going before. Previous is in Latin provius, that is, proe and via, in the way before. Anterior, the comparative of the Latin in ante, before. Prior, in Latin prior, comparative of primus, first. Former, in English the comparative of first.

Antecedent, preceding, foregoing, previous are employed for what goes or happens before: anterior, prior, former, for what is or exists before. Antecedent marks priority of order, place, and position, with this peculiar circumstance, that it denotes the relation of influence, dependence, and connection established between two objects: thus, in logic the premises are called the antecedent, and the conclusion the consequent; in theology or politics, the antecedent is any decree or resolution which influences another decree or action; in mathematics it is that term from which any induetion ean be drawn to another; in grammar, the antecedent is that which requires a particular regimen from its subsequent. Antecedent and preceding both denote priority of time, or the order of events; but the former in a more vague and indeterminate manner than the latter. A preceding event is that which happens immediately before the one of which we are speaking; whereas antecedent may have events of circumstances intervening. An antecedent proposition may be separated from its consequent by other propositions; but a preceding proposition is closely followed by another. In this sense antecedent is opposed to posterior; preceding to succeeding.

Preceding respects simply the succession of tir 'es and things; but previous denotes the succession of actions and events, with the collateral idea of their connection with an influence upon each other: we speak of the preceding day, or the preceding chapter, merely as the day or ehapter that goes before; but when we spiak of a previous engagement or a previous inquiry, it supposes an engagement preparatory to something that is to follow: previous is opposed to subsequent: foregoing is employed to mark the order of things narrated or stated; as when we speak of the foregoing statement, the foregoing objections, or the foregoing calculation, etc.: foregoing is opposed to following.

Anterior, prior, and former have all a relative sense, and are used for things that are more before than others: anterior is a technical term to denote forwardness in place or time, but more commonly the former, as in anatomy; the anterior or fore part of the skull, in contradistinction to the posterior part; so likewise the anterior or fore front of a building, in opposition to the back 
front: prior is used in the sense of to do away by speaking. Defend, in previous when speaking comparatively French défendre, is compounded of of two or more things when it implies de and fendo, signifying to keep or anticipation; a prior claim invalidates ward off. Justify, in French justifier, the one that is set up; a prior engage- Latin justifico, is compounded of jusment prevents the forming of any tus and facio, signifying to do justice, other that is proposed: former is em- or to put right. Exculpate, in Latin ployed either with regard to times, as former times, in contradistinction to later periods, or with regard to propositions, when the former or first thing mentioned is opposed to the latter or last mentioned.

ANTHRAX, Malignant pustule, Splenic fever, Carbuncle. Anthrax, Greek $\boldsymbol{a} \nu \theta \rho a \xi$, a carbuncle or coal (compare anthracite), is the name for a disease attacking animals, and characterized by the appearance of malignant boils, or carbuncles. The various synonymes refer to the characteristics of the disease, but do not differ in application. Splenic fever refers to the enlargement of the spleen, caused by the disease. Malignant pustule refers especially to the inflammation and breaking of the boils. Carbuncle in itself does not indicate the disease as it is now known; it is the early name applied to boils in the skin.

The disease was long believed to affect the lower animals only, but late in 1915 several persons in the United States were attacked by it, some with fatal results. The Department of Agriculture placed at the disposal of the attending physicians a remedy it had been using with marked success among cattle, and in one case this proved effective, while in others the application was too late.

ANTICIPATE. See Prevent.

ANTIPATHY. See Aversion.

ANTIQUE. See Old.

ANXIETY. See Care; Distress;

WORRY.

ANY. See Some.

APARTMENTS. See LodgINGS.

APATHY. See INDIFFERENCE.

APE. See IMITATE.

APERTURE. See OPENING.

APEX. See ZeNITH.

APHORISM. See ANXIous.

APOLOGIZE, DEFEND, JUSTIFY, Exculpate, Excuse, Plead. Apologize, from the Greek ámoגoyia, and

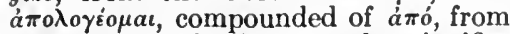
or away, and $\lambda_{\varepsilon}^{\prime} \gamma \omega$, speak, signifies exculpatus, participle of exculpo, compounded of ex and culpa, signifies to get out of a fault. Excuse, in French excuser, Latin excuso, compounded of $e x$ and causa, signifies to get out of any charge, causa being a legal term, found in the phrases "to plead one's cause," "make out a case," etc. Plead, in French plaider, is derived from placere, to please, like the words plea, please, placate, etc.

There is always some imperfection supposed or real which gives rise to an apology; with regard to persons it presupposes a consciousness of impropriety, if not of guilt; we apologize for an error by acknowledging ourselves guilty of it: a defence presupposes a consciousness of innocence more or less; we defend ourselves against a charge by proving its fallacy: a justification is founded on the conviction not only of entire innocence, but of strict propriety; we justify our conduct against any imputation by proving that it was blameless; exculpation rests on the conviction of innocence with regard to the fact: we exculpate ourselves from all blame by proving that we took no part in the transaction: excuse and plea are not grounded on any idea of innocence; they are rather appeals for favor resting on some collateral circumstance which serves to extenuate; a plea is frequently an idle or unfounded excuse, a frivolous attempt to lessen displeasure; we excuse ourselves for a neglect by alleging indisposition; we plead for forgiveness by solicitation and entreaty.

An apology mostly respects the conduct of individuals with regard to each other as equals; it is a voluntary act, springing out of a regard to decorum or the good opinion of others. To avoid misunderstandings it is necessary to a pologize for any omission that wears the appearance of neglect. A defence respects matters of higher importance; the violations of laws or public morals? judicial questions decided in a court 
or matters of opinion which are offered to the decision of the public; no one defends himself but he whose conduct or opinions are called in question. A justification is applicable to all moral cases in common life, whether of a serious nature or otherwise: it is the act of individuals toward each other according to their different stations: no one can demand a justification from another without a sufficient authority, and no one will attempt to justify himself to another whose authority he does not acknowledge: men justify themselves either on principles of honor or from the less creditable motive of concealing their imperfections from the observation and censure of others. An exculpation is the act of an inferior; it respects the violations of duty toward the superior; it is dictated by necessity, and seldom the offspring of any higher motive than the desire to screen one's self from punishment: exculpation regards offences only of commission; excuse is employed for those of omission as well as commission: we excuse ourselves oftener for what we have not done than for what we have done: it is the act of persons in all stations, and arises from various motives, dishonorable or otherwise: a person may often have substantial reasons to excuse himself from doing a thing or for not having done it; an excuse may likewise sometimes be the refuge of idleness and selfishness. To plead is properly a judicial act, and extended in its sense to the ordinary concerns of life; it is mostly employed for the benefit of others rather than ourselves.

Excuse and plea, which are mostly employed in an unfavorable sense, are to apology, defence, and exculpation as the means to an end: an apology is lame when, instead of an honest confession of an unintentional error, an idle attempt is made at justification; a defence is poor when it does not contain sufficient to invalidate the charge; a justification is nugatory when it applies to conduct altogether wrong; an excuse or a plea is frivolous or idle which turns upon some falsehood, misrepresentation, or irrelevant point.

APOPHTHEGM or APothegm. 'See AxIoM.
APOSTATE. See Recreant.

APPALL. See Dismay.

APPAREL, AtTire, Array. Apparel comes from Old French apareiller, from Latin ad, to, and Medieval Latin pariculus, from par, equal, meaning to put together things that are alike, to arrange, hence to arrange the dress. Attire comes from Old French atirier, from ad, to, and Old French tire or tiere, a row (compare our word tier), possibly of Teutonic origin; it means to place in rows, hence to arrange. Array comes from Latin ad and Teutonic rede, ready; and meant at first to get ready.

These terms are all applicable to dress or exterior decoration. Apparel is the dress of every one; attire is the dress of the great; array is the dress of particular persons on particular occasions: it is the first ebject of every man to provide himself with apparel suitable to his station; but the desire of shining forth in gaudy attire is the property of little minds: in festivals and solemn occasions it may be proper for those who are to be conspicuous to set themselves out with a comely array. A pparel and attire respect the quality and fashion of the thing; but array has regard to the disposition of the things with their neatness and decorum: $a p$ parel may be costly or mean; attire may be gay or shabby; but array will never be otherwise than neat or comely.

APPARENT, Visible, Clear, Plain, Obviods, Evident, Manifest. Apparent, in Latin apparens, participle of appareo, to appear, signifies the quality of appearing. Visible, in Latin visibilis, from visus, participle of video, to see, signifies capable of being seen. Clear is in French clair, German, Swedish, etc., klar, Latin clarus. Plain, in Latin planus, even, signifies what is so smooth and unencumbered that it can be seen. Obvious in Latin obvius, compounded of $o b$ and via, signifies the quality of lying in one's way or before one's eyes. Evident, in French évident, Latin evidens, means something clearly seen or known, from $e$ or $e x$, out, and video, see. The intensive force of $e$ in this case is similar to that of the prepositions or adverb in English phrases like "see one's way out" of 
difficulty, "to see through" something, etc. Manifest, in French manifeste, Latin manifcstus, compounded of manus, the hand, and festus, possibly from fendo, to strike, signifies the quality of being so near that it can be laid hold of by the hand.

These words agree in expressing various degrees in the capability of seeing; but visible is the only one used purely in a physical sense; apparent, clear, plain, and obvious are used physically and morally; evident and manifest solely in a moral acceptation. That which is simply an object of sight is visible; that which presents itself to our view in any form, real or otherwise, is apparent; the stars themselves are visible to us; but their size is apparent.

Visible is applied to that which merely admits of being seen; apparent and the other terms denote not only what is to be seen, but what is easily to be seen: they are all applied as epithets to objects of mental discernment; what is apparent strikes the view; what is clear is to be seen in all its parts and in its proper colors: it is opposed to that which is obscure; what is plain is seen by a plain understanding: it requires no deep reflection or severe study; it is opposed to what is intricate: what is obvious presents itself readily to the mind of every one; it is seen at the first glance, and is opposed to that which is abstruse: what is evident is seen forcibly, and leaves no hesitation on the mind; it is opposed to that which is dubious; manifest is a greater degree of the evident; it strikes on the understanding and forces conviction; it is opposed to that which is dark. A thing is apparent upon the face of it: a case is clear; it is decided on immediately: a truth is plain; it is involved in no perplexity; it is not multifarious in its bearings: a falsehood is plain; it admits of no question: a reason is obvious; it flows out of the nature of the case: a proof is evident; it requires no discussion, there is nothing in it that clashes or contradicts; the guilt or innocence of a person is cvident when everything serves to strengthen the conclusion: a contradiction or absurdity is manifest which is felt by all as soon as it is perceived.

APPARITION. See VISION.
APPEAR. See Look; See; Seem; TraNSPIRE.

APPEARANCE, AIR, Aspect. $\quad A p-$ pearance signifies the thing that appears or the manner of appearing. Air (see AIR). Aspect, in Latin aspectus, from aspicio, from ad (to) and specere, look, cognate with English spy, signifies the thing that is looked upon or seen.

Appearance is the generic, the rest are specific terms." The whols external form, figure, or colors, whatever is visible to the eye, is its appearance; air is a particular appearance of any object as far as it is indicative of its quality or condition; an air of wretchedness or poverty: aspect is the partial appearance of a body as it presents one of its sides to view; a gloomy or cheerful aspect. It is not safe to judge of either persons or things altogether by appearances; the appearance and reality are often at variance: the appearance of the sun is that of a moving body, but astronomers assert that it has no motion round the earth: there are particular towns, habitations, or rooms which have always an air of comfort, or the contrary: this is a sort of appearance the most to be relied on: politicians of a certain stamp are always busy in judging for the future from the aspect of affairs; but their predictions, like those of astrologers who judge from the aspect of the heavens, frequently turn out to the discredit of the prophet.

Sec also Air; SHow.

APPEASE, CALM, Pacify, QUIET, STILL. For derivation of appease see Allay. Calm comes from Late Latin cauma, the heat of the sun, Greek $\kappa a \bar{v} \mu a$, modified by Latin calere, to grow hot, and signified rest during the day. Pacify, in Latin pacifico, compounded of pax and facio, signifies to make peaceable. Quiet, in French quiet, Latin quietus, from quies, rest, signifies to put to rest. Still, from Anglo-Saxon stillan, to remain in a stall, is allied with the German stellen, to place, sind signifies to stop all movement, to place at rest.

To appease is to remove great agitation; to calm is to bring into a tranquil state. The wind is appeased, the sea is calmed. With regard to persons, it is 
necessary to appease those who are in transports of passion, and to $\mathrm{calm}$ those who are in trouble, anxiety, or apprehension. Appease respects matters of force or violence, calm those of inquietude and distress: one is appeased by a submissive behavior, and calmed by the removal of danger. Pacify corresponds to appease, and quiet to calm; in sense they are the same, but in application they differ; appease and calm are used only in reference to objects of importance; pacify and quiet to those of a more familiar nature: the uneasy humors of a child are pacified or its groundless fears are quieted. Still is a loftier expression than any of the former terms; serving mostly for the grave or poetic style: it is an onomatopæia for restraining or putting to silence that which is noisy and boisterous.

\section{See also Allay; Mollify.}

APPELlation. See Name.

APPLAUD. See PraIse.

APPLAUSE, ACclamation. $A p$ plause, from the Latin applaudo, signifies, literally, to clap or stamp the feet to a thing. Acclamation, from acclamo, signifies a crying out to a thing.

These terms express a public demonstration; the former by means of a noise with the hands or feet; the latter by means of shouts and cries: the former being employed as a testimony of approbation; the latter as a sanction, or an indication of respect. An actor looks for applause; a speaker looks for acclamation. What a man does calls forth applause, but the person himself is mostly received with acclamations. At the hustings popular speeches meet with applause, and favorite members are greeted with loud acclamations.

APPLICATION. See ATtend.

APPLY. See ADded; ADDress.

APPOINT, Order, Prescribe, OrDAIN. Appoint (see Allot). Order, in French ordre, Latin ordino, to arrange, dispose, ordo, order, signifies to place in regular position. Prescribe, in Latin prescribo, compounded of proe, before, and scribere, to write, signifies to draw a line for a person. Ordain is a variation of order.

To appoint is either the act of an equal or superior: we appoint a meet- ing with any one at a given time and place; a king appoints his ministers. To order is the act of one invested with partial authority: a customer orders a commodity from his tradesman: a master gives his orders to his servant. To prescribe is the act of one who is superior by virtue of his knowledge: a physician prescribes for his patient. To ordain is an act emanating from the highest authority: kings and councils ordain; but their ordinances must be conformable to what is ordained by the Divine Being. Appointments are made for the convenience of individuals or communities; but they may be altered or annulled at the pleasure of the contracting parties. Orders are dictated by the superior only, but they presuppose a discretionary obligation on the part of the individual to whom they are given. Prescriptions are binding on none but such as voluntarily admit their authority; but ordinances leave no choice to those on whom they are imposed to accept or reject them: the ordinances of man are not less binding than those of God, so long as they do not expressly contradict the divine law.

A ppointments are'kept, orders executed or obeyed, prescriptions followed, ordinances submitted to. It is a point of politeness or honor, if not of direct moral obligation, to keep the appointments which we have made. Interest will lead men to execute the orders which they receive in the course of business: duty obliges them to obey the orders of their superiors. It is a nice matter to prescribe to another without hurting his pride; this principle leads men often to regard the counsels of their best friends as prescriptions; with children it is an unquestionable duty to follow the prescriptions of those whose age, station, or experience authorizes them to prescribe. God has ordained all things for our good; it rests with ourselves to submit to His ordinances and be happy. See also Constitute.

APPORTION. See Distribute.

APPRAISE, APPRECIATE, EsTIMATE, Esteem. Appraise and appreciate, both from appretio and appretiatus, participle of apprecio, compounded of $a d$ and pretium, a price, signify to set 
a price or value on a thing. Estimate comes from estimatus, participle of estimo, to value. To esteem is a variation of estimate.

Appraise and appreciate are used in th precisely the same sense for setting a value on anything according to relative circumstanees; but the one is used in the proper, and the other in the figurative sense: a sworn appraiser appraises goods according to the condition of the articles and their salable property; the characters of men are appreciated by others when their good and bad qualities are justly put in a balance.

To estimate a thing is to get the sum of its value by calculation; to esteem anything is to judge its actual and intrinsic value. Estimate is used either in a proper or a figurative acceptation; esteem only in a moral sense: the expense of 'an undertaking, losses by fire, gains by trade, are estimated at a certain sum; the estimate may be too high or too low: the moral worth of men is often estimated above or below the reality, according to the particular bias of the estimator; but there are individuals of such an unquestionable worth that they need only to be known in order to be esteemed.

\section{APPRECIATE. See ApPraise.}

APPREHEND, CoNCEIVE, SUPPOSE, IMAGINE. To apprehend, from the Latin $a d$ and prehendo, I lay hold of, signifies to take. Conceive, from the Latin con and capio, to take togetherthat is, to put together in the mind. Suppose, from the Latin suppono, to put one thing in the place of another. Imagine, from imago, to have an image or figure of anything in the mind.

To apprehend is simply to take an idea into the mind; thus we may $a p$ prehend any object that we hear or see: to conceive is to form an idea in the mind, as to conceive the idea of doing anything, to conceive a design.

A pprehending is the first effort of the thinking faculty: conceiving is the act of a more matured understanding; the former belongs to children as well as grown persons, the latter more properly to grown persons. Apprehending is performed by the help of the senses; we may be quick or dull of apprehension. Conceiving is performed by re- flection and combination: we may conseive properly or improperly.

That of which we can have no sensible impression is not to be apprehended, that which is above the reach of our thought is not to be conceived.

To apprehend and to conceive are applied only to reality, to suppose and imagine are applied to things which may exist only in the imagination; but the former being drawn from that which is real may be probable or improbable according to circumstances; the latter being the peculiar act of the imagination, more commonly exists in the imagination only.

These terms are all employed to denote one's opinion or belief in regard to ordinary matters with a like distinction. Apprehend expresses the weakest kind of belief, the having the least idea of the presence of a thing.

A man is said to conceive that on which he forms a direct opinion.

What one supposes may admit of a doubt; it is frequently only conjectural.

What one imagines may be altogether improbable or impossible, and that which cannot be imagined may be too improbable to admit of being believed.

Apprehend, Fear, Dread.-Apprehend signifies to have an idea of danger in one's mind, without necessarily implying any sentiment of fear. Fear, Anglo-Saxon for, a sudden peril or danger, referred originally to the peril of travelling, and is allied to faran, modern fare, meaning to travel. Dread, Anglo-Saxon dradan, to be afraid, expresses the highest degree of fear.

What is possible may be apprehended; we may apprehend a change in the weather, or that an accident will take place by the way. What is probable may be feared; we may fear the consequences of a person's resentment. Not only the evil which is nigh, but that which is exceeding great, produces dread.

Apprehend is said only of things. Fear and dread are also applied to persons with the like distinction: fear is a salutary sentiment; it is the sentiment of a child toward a parent or instructor: dread, as toward a fellowcreature, is produced by harshness and 
oppression, but in regard to our Maker is produced by the consciousness of guilt.

APPREHENSION. See WorRY.

APPRISE. See INFORM.

APPRISED. See Aware.

APPROACH, Access, Admittance. Approach, Old French aprochier, from Latin prope, near, signifies near tothat is, coming near to. Access, in Latin accessus, from $a c$ or $a d$, and cedere, to go, is, properly, going to. $A d$ mittance (see ADMIT).

Approach signifies the coming near or toward an object, and consequently is an unfinished act, but access and admittance are finished acts; access is the coming to - that is, as close to an object as is needful; and admittance is the coming into any place or into the presence or society of any person. A pproach expresses simply the act of drawing near, but access and admittance comprehend, in their signification, the liberty and power of coming to or into: an approach may be quick or slow, an access easy or difficult, an admittance free or exclusive.

Approach may sometimes be taken for a road or way of approach, which brings it nearer in sense to the other terms, as the approaches to a bridge or a town.

Access is used only in its proper sense for the act of persons; approach and admittance are employed figuratively, as the approach of winter, age, etc., or the approach to immortality, in the sense of coming near to it in similitude, the admittance of immoral thoughts in to the mind.

Approach, Approximate.-Approach (see preceding use). A pproximate, compound of $a p$ and proximus, to come nearest or next, signifies either to draw near or bring near. To approach is intransitive only; a person approaches an object. To approximate is both transitive and intransitive; a person approximates two objects to each other.

To approach denotes simply the moving of an object toward another, but to approximate denotes the gradual moving of two objects toward each other: that which approaches may come into immediate conjunction; but bodies may approximate for some time before they form a junction, or may never form a junction. An equivocation $a p$ proaches to a lie. Minds approximate by long intercourse.

APPROBATION. See AsseNT; CoNSENT.

APPROPRIATE, USURP, ARROgate, Assume, Ascribe. Appropriate, in French approprier, compounded of ad and propriatus, participle of propriare, an old verb, and proprius, proper or own (compare proper), signifies to make one's own. Usurp, in French usurper, Latin usurpo, from usu rapere, to seize for one's own use, signifies to make use of as one's own. Arrogate, in Latin arrogatus, participle of arrogo, signifies to ask or claim for one's self. Assume, in French assumer, Latin assumo, compounded of as or ad and sumo, to take, signifies to take to one's self. Ascribe, in Latin ascribo, compounded of $a d$ and scribo, write, signifies here to write down to one's own account.

The idea of taking something to one's self by an act of one's own is common to all these terms. To appropriate is to take to one's self with or without right; to usurp is to take to one's self by violence or in violation of right. Appropriating is applied in its proper sense to goods in possession; usurping is properly applied to power, titles, rights. Individuals appropriate whatever comes to their hands which they use as their own; they usurp power when they exercise the functions of government without a legitimate sanction.

These words may be applied in the same sense to moral or spiritual objects. Arrogate, assume, and ascribe denote the taking to one's self, but do not, like appropriate and usurp, imply taking from another. Arrogate is a more violent action than assume, and assume than ascribe. Arrogate and assume are employed either in the proper or figurative sense, ascribe only in the figurative sense. We arrogate distinctions, honors, titles; we assume names, rights, and privileges. In the moral sense we arrogate pre-eminence, assume importance, ascribe merit. To arrogate is a species of moral usurpation; it is always accompained with haughtiness and contempt for others: that is arrogated to one's self to which one has not the smallest title: an arrogant temper is 
one of the most odious features in the human character; it is a compound of folly and insolence. To assume is a species of moral appropriation; its objects are of a less serious nature than those of arrogating, and it does less violence to moral propriety: we may assume in trifles, we arrogate only in important matters. To ascribe is of tener an act of vanity than of injustice: many men may be entitled to the merit which they ascribe to themselves; but by this very act they lessen the merit of their best actions.

Arrogating as an action, or arrogance as a disposition, is always taken in a bad sense: the former is always dictated by the most preposterous pride; the latter is associated with every unworthy quality. Assumption as an action varies in its character according to circumstances; it may be either good, bad, or indifferent: it is justifiable in certain exigencies to assume a command where there is no one else able to direct; it is often a matter of indifference what name a person assumes who does so only in conformity to the will of another; but it is always bad to assume a name as a mask to impose upon others. As a disposition assumption is always bad, but still not to the same degree as arrogance. An arrogant man renders himself intolerable to society: an assuming man makes himself offensive: arrogance is the characteristic of men; assumption is peculiar to youths: an arrogant man can be humbled only by silent contempt; an assuming youth must be checked by the voice of authority.

See also Monopolize; Nab; $\mathrm{Pe}-$ CULIAR.

APPROVE. See RatiFy.

APPROXIMATE. See APPROACH.

APT. See Fit; READY.

APTITUDE. See KNACK.

ARBITER. See JUDGE.

ARBITRARY. See ABSOLUTE.

ARBITRATE, Adjust, Decide, Determine, Mediate, Setrle. Arbitrate (for derivation see JUDGE) means to decide as an outsider, an impartial judge. Adjust (not derived from justice, but from ad and juxta, next to) meant originally to put side by side, to put something into a proper relation to something else. Decide is derived from $d e$ and coedere, to cut, and means to cut off, hence to end. Determine comes from Latin de and terminare, from terminus, limit, and meant to decide the limits of something. Medrate, from Latin medius, middle, meant to act as a go-between. Settle meant to cause to rest, from Anglo-Saxon setl, seat (compare the noun settle, a seat). It received the special sense of to establish peace between two combatants, from an association with the Anglo-Saxon saht, the end of a suit, allied to the verb sacan, to contend, which appears in forsake. Of these terms mediate and arbitrate refer especially to the difficulties that arise betwcen states or between other organized groups of individuals. To mediate involves an action prior to arbitration, for it is based upon a tender of the "good offices" of a neutral nation to others in a dispute or war. In case it is accepted the mediating nation may become the arbitrator or the dispute may be submitted to another form of arbitration-that is, final decision concerning the justice of the case by an impartial court. For an analysis of the difference between decide and determine see the article on decide. Decide and determine refer to purely intellectual operations. One may decide or determine the rights of a case without proceeding to adjust the difficulties or to settle the disturbance. Adjust and settle inply active participation. Adjust and settle differ mainly in the eonnotations suggested by their derivations. We adjust matters where the trouble is due to a lack of mutual understanding between two conflicting parties. We settle a disturbance where conflieting claims eannot be adjusted by superior force or authority.

ARBITRATOR. See Judge; PACIFIST.

ARCHITECT, BUILDER. Archilect, from architecture, in Latin architectus,

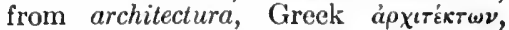
compounded of a $\rho \chi 0 \%$, the chief, and T'x $\chi \nu \eta$, art or contrivance, signifies the chief of contrivers. Builder, from the verb to build, denotes the person coneerned in buildings, who causes the structure of houses, either by his money or his personal service. 
An architect is an artist, employed only to form the plans for large buildings; a builder is a simple tradesman, or even workman, who builds common dwelling-houses.

ARCHIVE. See RECORD.

ARDENT. See Hot; Sanguine.

ARDOR. See Fervor; Zeal.

ARDUOUS. See Hard.

aRgue, Dispute, Debate. Argue comes from Latin arguere, to make clear. Dispute, in French disputer, Latin disputo, compounded of dis and puto, signifies to think differently; in an extended sense, to assert a different opinion. Debate, in French débattre, compounded of the intensive syllable de and battre, to beat or fight, signifies to contend for and against.

To argue is to defend one's self; to dispute, to oppose another; to debate, to dispute in a formal manner. To argue on a subject is to explain the reasons or proofs in support of an assertion; to argue with a person is to defend a position against him: to dispute a thing is to advance objections against a position; to dispute with a person is to start objections against his positions, to attempt to refute them: a debate is a disputation held by many. To argue does not necessarily suppose a conviction on the part of the arguer that what he defends is true, nor a real difference of opinion in his opponent; for some men have such an itching propensity for an argument that they will attempt to prove what nobody denies: to dispute always supposes an opposition to some person, but not a sincere opposition to the thing; for we may dispute that which we do not deny, for the sake of holding a dispute with one who is of different sentiments: to debate presupposes a multitude of clashing or opposing opinions. Men of many words argue for the sake of talking: men of ready tongues dispute for the sake of victory: in parliament men often debate for the sake of opposing the ruling party, or from any other motive than the love of truth.

Argue, Evince, Prove.-Argue (see above). Evince, in Latin evinco, compounded of vinco, to prove, or make out, and $e$, forth, signifies to bring to light, to make to appear clear. Prove, in French prouver, in Latin probo, from probus, good, signifies to make good or to make to appear good.

These terms in general convey the idea of evidence, but with gradations: argue denotes the smallest, and prove the highest degree. To argue is to serve as an indication amounting to probability; to evince denotes an indication so clear as to remove doubt; to prove marks an evidence so positive as to produce conviction. It argues a want of candor in any man to conceal circumstances in his statement which are in any wise calculated to affect the subject in question: the tenor of a person's conversation may evince the refinement of his mind and the purity of his taste: when we see men sacrificing their peace of mind and even their integrity of character to ambition it proves to us how important it is even in early life to check this natural and in some measure laudable, but still insinuating and dangerous, passion.

Argument, Reason, Proof.-Argument, from argue, signifies either the thing that argues, or that which is brought forward in arguing. Reason, in French raison, Latin ratio, from ratus, participle of reor, think, signifies the faculty of mind which draws conclusions. Proof, like prove, is derived ultimately from Latin probus, good, excellent, and means that which tests and reveals the excellence of samething.

An argument serves for defence; a reason for justification; a proof for conviction. Arguments are adduced in support of a hypothesis or proposition; reasons are assigned in matters of belief and practice; proofs are collected to ascertain a fact.

Arguments are either strong or weak; reasons solid or futile; proofs clear and positive, or vague and indefinite. We confute an argument, overpower a reason, and invalidate a proof. Whoever wished to defend Christianity will be in no want of arguments; the believer need never be at a loss to give a reason for the hope that is in him; but throughout the whole of Divine Revelation there is no circumstance that is substantiated with such irrefragable proofs as the resurrection of our Saviour.

ARISE, or Rise, Mount, Ascend, Climb, Scale. Arise or rise, derived 
from a root signifying to move, found in river, rivulet, etc., nreans specifically to move in an upward direction. $A s-$ cend is derived from ad, to, and scandere, to climb, from a root found in scandal (originally a stumbling-block), and means to climb to something. Climb means to ascend by grasping, and is derived from a Germanic root signifying to grasp, found in clip, cleave, clamber, etc. Scale is derived from Latin scala (from the same root found in ascend), that by which one ascends, and means to rise by a ladder.

The idea of going upward is common to all these terms; arise is used only in the sense of simply getting up, but rise is employed to express a continued motion upward: a person arises from his seat or his bed; a bird rises in the air; the silver of the barometer rises; the first three of these terms convey a gradation in their sense; to arise or rise denotes a motion to a less elevated height than to mount, and to mount that which is less elevated than ascend; a person rises from his seat, mounts a hill, and ascends a mountain. Arise and rise are intransitive only; the rest are likewise transitive: we rise from a point, we mount and ascend to a point, or we mount and ascend something: an air-balloon rises when it first leaves the ground; it mounts higher and higher until it is out of sight; but if it ascends too high it endangers the life of the aërial adventurer. Climb and scale express a species of rising: to climb is to rise step by step by clinging to a certain body; to scale is to rise by an escalade, or species of ladder, employed in mounting the walls of fortified towns: trees and mountains are climbed; walls are scaled.

Arise or Rise, Proceed, Issue, Spring, Flow, Emanate-To arise (see above). Proceed, in Latin procedo, that is, pro and cedere, to go, signifies to go forth. Issue is French issue, participle of $i s s i r$ (from ex, out of, and ire, to go. Spring, in German springen, signifies to leap forth. Flow, Anglo-Saxon flowan, is derived from a Germanic root allied to the Latin pluit, it rains, and the Greek $\pi \lambda \omega \varepsilon \iota \nu$, to float. It has no connection with the Latin fluere, to flow. Emanate, in Latin emanatus, participle of emano, from ex, out, and manare, to flow, means to flow out.

The idea of one object coming out of another is expressed by all these terms, but they differ in the circumstances of the action. What comes up out of a body and rises into existence is said to arise, as the mist which arises out of the sea: what comes forth as an effect, or comes forth in a particular manner, is said to proceed; thus the light proceeds from a certain quarter of the heavens, or from a certain part of a house: what comes out from a small aperture is said to issue; thus perspiration issues through the pores of the skin; water issues sometimes from the sides of rocks; what comes out in a sudden or quick manner, or comes from some remote source, is said to spring; thus blood springs from an artery which is pricked; water springs up out of the earth: what comes out in quantities or in a stream is said to flow; thus blood flows from a wound: to emanate is a species of flowing by a natural operation, when bodies send forth, or seem to send forth, particles of their own composition from themselves; thus light emanates from the sun.

This distinction in the signification of these terms is kept up in their moral acceptation, where the idea of one thing originating from another is common to them all; but in this case arise is a general term, which simply implies the coming into existence; proceed conveys also the idea of a progressive movement into existencc. Every object, therefore, may be said to arise out of whatever produces it; but it proceeds from it only when it is gradually produced: evils are continually arising in human society for which there is no specific remedy: in complicated disorders it is not always possible to say precisely from what the complaint of the patient proceeds. Issue is scldom used but in application to sensible objects: yet we may say, in conformity to the original meaning, that words issue from the mouth: the idea of the distant source or origin is kept up in the moral application of the term spring, when we say that actions spring from a generous or corrupt principle: the idea of a quantity and a stream is preserved in the moral use of the terms 
flow and emanate; but the former may be said of that which is not inherent in the body; the latter respects that only which forms a component part of the body: God is the spring whence all our blessings flow; all authority emanates from God, who is the supreme source of all things; theologians, when speaking of God, say that the Son emanates from the Father, and the Holy Ghost from the Father and the Son, and that grace flows upon us incessantly from the inexhaustible treasures of Divine mercy.

ARMISTICE. See TRUCE.

ARMS, Wrapons. Arms, from the Latin arma, literally fittings, equipments, from the root signifying to join or fashion found in art, arm (a part of the human body), etc., is now properly used for instruments of offence, and never otherwise except by a poetic license of arms for armor; but weapon, from a widespread Germanic root, may be used either for an instrument of offence or defence. We say fire-arms, but not fire-weapons; and weapons offensive or defensive, not arms offensive or defensive. Arms, likewise, agreeably to its origin, is employed for that only which is purposely made to be an instrument of offence; weapon, according to its extended and indefinite application, is employed for whatever may be accidentally used for this purpose: guns and swords are always arms; stones, brick-bats, and pitchforks, and also the tongue or words, may be occasionally weapons.

ARMY, Host. An army is an organized body of armed men; a host, from hostis, an enemy, is properly a body of bostile men. An army is a limited body; a host may be unlimited, and is therefore generally conside: $\mathrm{d}$ a very large body.

The word army applies only to that which has been formed by the rules of art for purposes of war: host has been extended in its application not only to bodies, whether of men or angels, that were assembled for purposes of offence, but also in the figurative sense to whatever rises up to assail.

ARRAIGN. See Accuse.

ARRange. See Class; Dispose. ARRAY. SEe APPAREL.
ARRIVE. See Come.

ARROGANCE, Presumption. Arrogance, in French arrogance, Latin arrogantia, signifies the disposition to arrogate (see Appropriate). Presumption, from presume, Latin prosumo, compounded of proe, before, and sumere, itself compounded from sub and emere, to buy, and meaning to put or take, signifies the disposition to put one's self forward.

Arrogance is the act of the great; presumption that of the little: the arrogant man takes upon himself to be above others; the presumptuous man strives to be on a level with those who are above him. Arrogance is commonly coupled with haughtiness; presumption with meanness: men arrogantly demand as a right the homage which has perhaps before been voluntarily granted; the creature presumptuously arraigns the conduct of the Creator, and murmurs against the dispensations of His providence.

See also Assumption; Haughtiness.

ARROGATE. See ApPropriate.

ART, Cunning, Deceit. Art, in Latin ars, from a root $a r$, to join (see arms), allied to Greek äprıos, fit, exact, signifies literally the "putting of two and two together." Cunning is derived from Anglo-Saxon cunnan, to know, and therefore corresponds exactly to the colloquial adjective knowing, in such phrases as "a knowing look," "a knowing child," etc. Deceit, in Latin deceptum, participle of decipio, or de and capio, signifies to take by surprise or unawares.

Art implies a disposition of the mind to use circumvention or artificial means to attain an end: cunning marks the disposition to practise disguise in the prosecution of a plan: deceit leads to the practice of dissimulation and gross falsehood, for the sake of gratifying a desire. Art is the property of a lively mind; cunning, of a thoughtful and knowing mind; deceit, of an ignorant, low, and weak mind. Art is practised often in self-defence; as a practice, therefore, it is even sometimes justifiable, although not as a disposition: cunning has always self in view; the cunning man seeks his gratification without regard to others; deceit is often practised to the express injury of an- 
other: the deceitful man adopts base means for base ends. Animals practise art when opposed to their superiors in strength; but they are not artful, as they have not that versatility of power which they can habitually exercise to their own advantage like human beings; animals may be cunning, inasmuch as they can by contrivance and concealment seek to obtain the object of their desire, but no animal is deceitful except man; the wickedest and stupidest of men have the power and the will of deceiving and practising falsehood upon others which is unknown to the brutes.

See also Business.

Artful, Artificial, Fictitious.-Artful, compounded of art and full, marks the quality of being full of art. Artificial, in Latin artificialis, from ars and facio, to do, signifies done with art. Fictitious, in Latin fictitius, from fingere to feign (compare article on feign), signifies the quality of being feigned.

Artful respects what is done with art or design; artificial what is done by the exercise of workmanship; fictitious what is made out of the mind. Artful and artificial are used either for natural or moral objects; fictitious always for those that are moral: artful is opposite to what is artless, artificial to what is natural, fictitious to what is real: the ringlets of a lady's hair are disposed in an artful manner; the hair itself may be artificial; a tale is artful which is told in a way to gain credit; manners are artificial which do not seem to suit the person adopting them; a story is fictitious which has no foundation whatever in truth and is the invention of the narrator. Children sometimes tell their stories so artfully as to impose on the most penetrating and experienced. Those who have no character of their own are induced to take an artificial character in order to put themselves on a level with their associates. Beggars deal in fictitious tales of distress in order to excite compassion.

See also Scheming.

ARTiCle, Condition, Term. $A r$ ticle, in French article, Latin articulus, a joint or a part of a member. Condition is usually believed to be derived from the Latin condere, to build. Skeat deelares that this is incorrect. The Latin conditio is derived from con and a root found in dicere, to speak, meaning to point out. Term is derived from Latin terminus, Greek ré $\rho \mu \alpha$, from the root meaning to cross over.

These words agree in their application to matters of compact, or understanding between man and man. Article and condition are used in both numbers: terms only in the plural in this sense: the former may be used for any point individually; the latter for all the points collectively: article is employed for all matters which are drawn out in specific articles or points; as the articles of an indenture, of a capitulation, or an agreement. Condition respects any point that is admitted as a ground of obligation or engagement: it is used for the general transactions of men, in which they reciprocally bind themselves to return certain equivalents. The word terms is employed in regard to mercantile transactions; as the terms of any bargain, the terms of any agreement, the terms on which anything is bought or sold. Articles are mostly voluntary; they are admitted by mutual agreement: conditions are frequently compulsory, sometimes hard; they are submitted to from poliey or necessity; terms are dictated by interest or equity; they are fair or unfair according to the temper of the parties; they are submitted or agreed to.

ARTICULATE. Sce UTter.

ARTIFICE, Trick, Finesse, StraTAGEM. Artifice, from French artifice, Latin artifex, an artificer, and artem facio, to execute an art, signifies the performance of an art. Trick is derived from Dutch and originally meant a clever contrivanee. Finesse, a word directly imported from France, with all the meaning attached to it which is characteristic of the nation itself, means properly fineness; the word fin in French is derived from Latin finitus, meaning well finished. Stratagem, in French stratageme, from the Greek

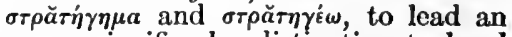
army, signifies by distinction to head them in carrying on any scheme.

All these terms denote the exercise of an art calculated to mislead others. Artifice is the generic term, the rest are 
specific: the former has likewise a particular use and acceptation distinct from the others; it expresses a ready display of art for the purpose of extricating one's self from a difficulty, or securing to one's self an advantage. Trick includes in it more of design to gain something for one's self, or to act secretly to the inconvenience of others: it is rather a cheat on the senses than the understanding. Finesse is a species of artifice in which art and cunning are combined in the management of a cause: it is a mixture of invention, falsehood, and concealment. Stratagem is a display of art in plotting and contriving, a disguised mode of obtaining an end. Females who are not guarded by fixed principles of virtue and uprightness are apt to practise artifices upon their husbands. Men without honor, or an honorable means of living, are apt to practise various tricks to impose upon others to their own advantage: every trade, therefore, is said to have its tricks; and professions are not entirely clear from this stigma, which has been brought upon them by unworthy members. Diplomatic persons have most frequent recourse to finesse. Military operations are sometimes considerably forwarded by well-concerted and well-timed stratagems to surprise the enemy.

An artifice may be perfectly innocent when it serves to afford a friend an unexpected pleasure. A trick is childish which only serves to deceive or amuse children. Stratagems are allowable not in war only; the writer of a novel or a play may sometimes adopt a successful stratagem to cause the reader a surprise. Finesse is never justifiable; it carries with it too much of concealment and disingenuousness to be practised but for selfish and unworthy purposes.

ARTIFICER. See Artist.

ARTIfICIAL. See Artful; TheATRICAL.

ARTISAN. See ARTist.

ARTIST, Artisan, Artificer, MeCHANIC. Artist is the practicer of the fine arts (for derivation see ART); artisan the practicer of the vulgar arts. Artificer comes from ars and facio, one who does or makes according to art. Mechanic, from Greek $\mu \eta \chi \alpha \nu \iota \kappa \eta$, machine, a device, signifies one who works with machines.

The artist ranks higher than the artisan, the former requires intellectual refinement, the latter nothing but to know the common practice of art. The musician, painter, and sculptor are artists; the carpenter, the sign-painter, and the blacksmith are artisans. The artificer is an intermediate term between the artist and the artisan; manufacturers are artificers; and, in an extended sense, any one who makes a thing by his contrivance is an artificer. The mechanic is that species of artisan who works at arts purely mechanical, in distinction from those which contribute to the completion and embellishment of any objects; on this ground a shoemaker is a mechanic, but a common painter is a simple artisan.

ARTLESS. See NaÏve.

AS. See Both.

ASCEND. See Arise.

ASCENDANCY. See Influence.

ASCetic, Austere, Rigid, Stern. Ascetic in French ascétique, from ä $\sigma \kappa \hat{\varepsilon} \boldsymbol{\imath} \nu$, to work, exercise, applied, literally, to the practice of an art, hence to an athlete, and, by extension, to the discipline practised by an athlete. In the schools of the stoics, the term that implied this discipline practised by the wrestlers was employed to designate the practice of mastering the desires and passions or of severe virtue, and in this sense it passed into the language of the early Christians: on this basis the modern meaning of a person unduly rigid or austere was derived.

Austere is derived from Latin austerus, harsh, sour, tart, from Greek

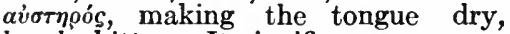
harsh, bitter. It signifies a manner, a temperament, and does not so distinctly imply the mastering of the physical appetites as does the word ascetic. Similarly stern, from AngloSaxon styrne, of harsh mind, refers to a kind of temper. Austerity suggests both the habits of life indicated in asceticism and the kind of nature suggested by sternness. A man may be stern and, at the same time, be the opposite of ascetic. Rigid, from Latin rigidus (whence rigorous is also derived 
by way of French), comes from the Latin rigere, to be stiff or straight. It refers both to the property of physical things and, figuratively, to a certain habit of mind or of life. Stern refers to a kind of emotional temperament; rigid suggests an intellectual habit, an unbending mind, whence certain characteristics of temper and habits of living might develop.

ASCRIBE, IMPUTE, ATTRIBUTE. To ascribe signifies here generally to write or set down in one's own mind to a person (see Appropriate) - that is, to assign anything in one's estimate as the possession or the property of another, as to ascribe honor or power. To impute, from im or in and puto, think, is to form an estimate of a person; as to impute a thing to a person's folly. To attribute, from ad and tribuo, bestow, is to assign a thing as a cause; as to attribute the loss of a vessel to the violence of the storm.

What is ascribed and imputed is mostly of a personal nature, either to honor or dishonor; ascribe more frequently for the former, impute for the latter. In the doxology of the church ritual, all honor, might, majesty, dominion, and power are ascribed to the three persons in the Holy Trinity; men of right minds cannot bear the slightest impulation on their honor, nor virtuous women the slightest imputation on their chastity.

Ascribe may, however, sometimes be employed in an unfavorable sense, and impute in a favorable sense. We may ascribe imperfection as well as perfection, and impute good as well as bad motives.

To ascribe may also denote to assign a cause, which brings it nearer in sense to attribute; but the former always refers to some characteristic of the person, and the latter, although applied to personal qualities, conveys no personal reflection.

To ascribe is always to assign to some individual person; but to attribute may either refer to no persons, or to none individually. Milton ascribes the first use of artillery to the devil: the Letters of Junius have been ascribed successively to many as the author; the death of many persons may be attributed to intemperance.
ASEPTIC, Germless, Non-PUTreFYING. Aseptic, a compound of the Greek $\ddot{a} \sigma \eta \pi \tau o \zeta$ (from $\dot{\alpha}$ privative and $\sigma \eta \pi \tau \iota k o ́ s$, putrefying) and the English suffix $i c$, signifies that which is not liable to putrefaction, or that which is germless or free from septic matter, or any substance that produces or promotes putrefaction; in the substantive form, asepsis, the absence of toxinous or pathogenic bacteria which poison the blood. From the original Greek term we have septicomia, an acute disease resembling pyæmia in its general characteristics, supposed to be caused by the introduction into the blood of putrid matter from the surface of a wound or ulcer, the putrefaction now being known, through the antiseptic researches of Pasteur and Lister, to be a fermentative change due to the presence of certain micro-organisms in the blood.

Antiseptic surgery is the operation of introducing antiseptic solutions into a wound whence the poisonous matter has been carried into the blood, or where the wound has not been promptly treated by antisepsis, or the exclusion of microbes or bacteria from wounds and open sores.

ASK, BEG, Request. Ask, in AngloSaxon ascian, is derived from a Germanic root signifying to wish. $\mathrm{Beg}$ is derived, by a somewhat complicated process, from a frequentative of bid, and meant to bid often, to ask again and again. Request, in Latin requisitus, participle of requiro, is compounded of $r e$ and quorere, to seek or look after, with indications of desire to possess.

The expression of a wish to some one to have something is the common idea comprehended in these terms. As this is the simple signification of $a s k$, it is the generic term; the other two are specific; we ask in begging and requesting, but not vice versa. Asking is peculiar to no rank or station; in consequence of our mutual dependence on each other, it is requisite for every man to ask something of another: the master asks of the servant, the servant asks of the master; the parent asks of the child, the child asks of the parent. Begging marks a degree of dependence which is peculiar to inferiors in station; we ask for matters of indifference; we beg 
that which we think is of importance: a child asks a favor of his parent; a poor man begs the assistance of one who is able to afford it: that is asked for which is easily granted; that is begged which is with difficulty obtained. To ask, therefore, requires no effort, but to beg is to ask with importunity: those who by merely asking find themselves unable to obtain what they wish, will have recourse to begging. As ask sometimes implies a demand, and beg a vehemence of desire or strong degree of necessity, politeness has adopted another phrase, which conveys neither the imperiousness of the one nor the urgency of the other; this is the word request. Asking carries with it an air of superiority; begging that of submission; requesting has the air of independence and equality. Asking borders too neariy on an infringement of personal liberty; begging imposes a constraint by making an appeal to the feelings; requests leave the liberty of granting or refusing unencumbered. It is the character of impertinent people to ask without considering the circumstances and situation of the person asked; they seem ready to take without permission that which is asked, if it be not granted: selfish and greedy people beg with importunity, and in a tone that admits of no refusal; men of good breeding tender their requests with moderation and discretion; they request nothing but what they are certain can be conveniently complied with.

Ask is altogether excluded from polite life, although beg is not. We may beg a person's acceptance of anything; we may beg him to favor or honor us with his company; but we can never talk of asking a person's acceptance, or asking him to do us an honor. Beg in such cases indicates a condescension which is sometimes not unbecoming, but on ordinary occasions request is with more propriety substituted in its place.

Ask, or Ask For, Claim, Demand.Ask (see above). Claim, in Old French claimer, Latin clamo, to cry after, signifies to express an imperious wish for. Demand, in French demander, is derived from Old French de and mander, to order from the hands of another (from manus, hand), and hence to ask for that which has been intrusted.

$A s k$, in the sense of $3 e g$, is confined to the expression of wishes on the part of the asker, without involving any obligation on the part of the person asked; all granted in this case is voluntary, or complied with as a favor; but ask for, in the sense here taken, is involuntary, and springs from the forms and distinctions of society. Ask is here, as before, generic or specific; claim and demand are specific: in its specific sense it conveys a less peremptory sense than either claim or demand. To ask for denotes simply the expressed wish to have what is considered as due; to claim is to assert a right or to make it known; to demand is to insist on having, without the liberty of a refusal. Asking respects obligation in general, great or small; claim respects obligations of importance. Asking for supposes a right not questionable; claim supposes a right hitherto unacknowledged; demand supposes either a disputed right or the absence of all right, and the simple determination to have: a tradesman asks for what is owed to him as circumstances may require; a person claims the property he has lost; people are sometimes pleased to make demands the legality of which cannot be proved. What is lent must be asked for when it is wanted; whatever has been lost and is found must be recovered by a claim; whatever a selfish person wants he strives to obtain by a demand, whether just or unjust.

Ask, Inquire, Question, Interrogate.Ask (see above). Inquire, Latin inquiro, compounded of in and quoro, signifies to search after. Question, in French questionner, signifies to put a question, from the Latin quastio and quaro, to seek or search, to look into. Interrogate, Latin interrogatus, participle of interrogo, compounded of inter and rogo, signifies to ask.

We perform all these actions in order to get information: but we ask for general purposes of convenience; we inquire from motives of curiosity; we question and interrogate from motives of discretion. To ask respects simply one thing; to inquire respects one or many subjects; to question and interrogate is to ask repeatedly, and in the 
fatter case more authoritatively than in the former. Indifferent people ask of each other whatever they wish to know: learners inquire the reasons of things which are new to them: masters question their servants, or parents their children, when they wish to ascertain the real state of any case: magistrates interrogate criminals when they are brought before them. It is very uncivil not to answer whatever is asked even by the meanest person: it is proper to satisfy every inquiry, so as to remove doubt: questions are sometimes so impertinent that they cannot with propriety be answered: interrogations from unauthorized persons are little better than insults.

ASKEW. See Wry.

ASPECT. See Appearance.

ASPERITY. See ACRIMONY.

ASPERSe, Detract, Defame, Slander, Calomniate. Asperse, in Latin aspersus, participle of aspergere, to sprinkle, allied to English sprinkle, signifies in a moral sense to stain with spots. Detract, in Latin detractus, participle of detraho, compounded of de and traho, to draw from, signifies to take from another that which is his due, or which he desires to retain; particularly to take from the merit of an action. Defame, in Latin defamo, compounded of the privative de and fama, from root fari, to speak, meaning reputation-that which others say about us - signifies to deprive of reputation. Slander, Middle English scla?$d r e$, is a doublet of scandal (see DisCREDIT), derived from Greek through Latin and French. Calumniate is derived from Latin calumnia, from caluere, to deceive.

All these terms denote an effort made to injure the character or estimation by some representation. Asperse and detract mark an indirect representation; defame, slander, and calumniate, a positive assertion. To asperse is to $\mathrm{fix}$ a moral stain on a character; to detract is to lessen its merits and excellences. Aspersions always imply something bad, real or supposed; detractions are always founded on some supposed good in the object that is detracted; to defame is openly to advance some serious charge against the character; to slan$d e r$ is to expose the faults of another in his absence; to calumniate is to communicate secretly, or otherwise, false circumstances to the injury of another. If I speak slightingly of my neighbor, and insinuate anything against the purity of his principles or the rectitude of his conduct, I asperse him: if he be a charitable man, and I ascribe his charities to a selfish motive, or otherwise take away from the merit of his conduct, I am guilty of detraction; if I publish anything openly that injures his 'reputation, I am a defamer; if I communicate to others the reports that are in circulation to his disadvantage, I am a slanderer; if I fabricate anything myself and spread it abroad, I am a calumniator.

ASPHYXIA, SyNCOPE, SUFFocaTION. Asphyxia, in French asphyxie, is from Latin asphyxia, Greek á $\sigma \phi v \boldsymbol{\zeta}_{i a}$ the latter a compound of $a$, without, and $\sigma \phi \dot{v} \xi$ sc, the pulse, signifies, literally, a pulseless condition, the temporary or permanent cessation of the motions or throbbings of the heart, as in hanging, drowning, and suffocation, due to an interruption of the passage of the blood in the body which keeps it from its connection with the atmospherc by respiration, and so prevents a sufficiently free exchange of carbonic acid for oxygen. In its mild form we have syncope, from $\sigma v \gamma$ and кó $\pi \tau \varepsilon \nu$, to cut. This is a fainting brought on by a sudden fright, illness, or a more than ordinarily disturbing spectacle. In its most severe or fatal form it becomes suffocation, the effect of a stoppage of respiration.

The usual treatment of asphyxia has recently been supplemented, with marked success, by the invention of the pulmotor, an apparatus designed to resuscitate victims of poisoning by gases and noxious fumes, electric shocks, suspended animation from any cause, drowning, attempted suicide, collapse in narcosis, and other mishaps, by forcing oxygen into the lungs. Many of the large gas companies now keep pulmotors on hand to send out in cases of accidental or intentional asphyxiation by illuminating gas.

ASPIRE. See AIM.

ASSAIL. See ATrack.

ASSAILANT. See Aggressor. 
ASSASSINATE. See Kill.

ASSAULT. See ATTACK.

ASSAY. See Test.

ASSEMBLAGE. See Assembly.

ASSEMBLE, Muster, Collect. Assemble is derived through French from Low Latin assimulare, from ad, to, and simul, together, from a root which also appears in similar, same, etc. Muster comes from Latin monstrari, to show, and means specifically a review of troops. Collect is derived from Latin con, together, and legere, to gather, from the root which also appears in college, colleague, etc.

Assemble is said of persons only; muster and collect of persons or things. To assemble is to bring together by a call or invitation; to muster is to bring together by an act of authority, or a particular effort, into one point of view at one time and from one quarter; to collect is to bring together at different times and from different quarters: the parliament is assembled; soldiers are mustered every day in order to ascertain their numbers; an army is collected in preparation for war; a king assembles his council in order to consult with them on public measures; a general musters his forces before he undertakes an expedition, and collects more troops if he finds himself too weak.

Collect is used for everything which can be brought together in numbers; muster is used figuratively for bringing together, for an immediate purpose, whatever is in one's possession: books, coins, curiosities, and the like are collected; a person's resources, his strength, courage, resolution, etc., are mustered; some persons have a pleasure in collecting all the pieces of antiquity which fall in their way; on a trying occasion it is necessary to muster all the fortitude of which we are master.

Assemble, Convene, Convoke.-Assemble (see above). Convene, in Latin convenio, signifies to come or bring together. Convoke, in Latin convoco, signifies to call together.

The idea of collecting many persons into one place, for a specific purpose, is common to all these terms. Assemble conveys this sense without any addition; convene and convoke include likewise some collateral idea: people arc assembled, therefore, whenever they are convened or convoked, but not vice versa. Assembling is mostly by the wish of one; convening by that of several: a crowd is assembled by an individual in the streets; a meeting is convened at the desire of a certain number of persons: people are assembled either on public or private business; they are always convened on a public occasion. A king assembles his parliament; a particular individual assembles his friends; the inhabitants of a district are convened. There is nothing imperative on the part of those that assemble or convene, and nothing binding on those assembled or convened; one assembles or convenes by invitation or request; one attends to the notice or not, at pleasure. Convoke, on the other hand, is an act of authority; it is the call of one who has the authority to give the call; it is heeded by those who feel themselves bound to attend.

Assembly, Assemblage, Group, Collection.-Assembly, assemblage, are collective terms derived from the verb assemble. Group comes through French from Italian groppo, which among painters signifies an assemblage of figures in one place. Collection expresses the act of collecting, or the body collected. Assembly respects persons only; assemblage, things only; group and collection, persons or things: an assembly is any number either brought together or coming together of themselves; an assemblage is any number of things standing together; a group is come together by accident or put together by design; a collection is mostly put or brought together by design. A general alarm will cause an assembly to disperse; an agreeable assemblage of rural objects, whether in nature or in representation, constitutes a landscape: a painting will sometimes consist only of a group of figures; but if they be well chosen it will sometimes produce a wonderful effect: a collection of evilminded persons ought to be immediately dispersed by the authority of the magistrate. In a large assembly you may sometimes observe a singular assemblage of characters, countenances, and figures: when people come together in great numbers on any occasion, they will often form themselves 
into distinct groups; the collection of scarce books and curious editions has become a passion, which is ridiculed under the title of Bibliomania.

Assembly, Company, Meeting, Congregation, Parliament, Diet, Congress, Convention, Synod, Convocation, Council.-An assembly (see Assembly) is simply the assembling together of any number of persons: this idea is common to all the rest of these terms, which differ in the object, mode, and other collateral circumstances of the action. Company, a body linked together (see AccompaNY), is an assembly for purposes of amusement. Meeting, : body met together, is an assembly for general purposes of business. Congregation, a body flocked or gathered together, from the Latin grex, a flock, is an assembly brought together from congeniality of sentiment and community of purpose. Parliament is derived through French parler, and a suffix from Latin parabola, Greek $\pi \alpha \rho \alpha \beta o \lambda \dot{\eta}$, a speech in which two things are compared. (Compare parable.) Diet, from Greek diatia, a mode of life, has the same etymology as the word diet applied to the mode of life in respect to food. The peculiar sense in which it is here used is due to a confusion of it in the popular mind with the Latin dies, day, especially a day set apart for public business; and so it came to mean an assembly which conducted public business. Congress, from the Latin congredior, to march in a body, is an assembly coming together in a formal manner from distant parts for special purposes. Convention, from the Latin convenio, come together, is an assembly coming together in an informal and promiscuous manner from a neighboring quarter. Synod, in Greek

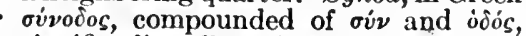
signifies literally going the same road, and has bcen employed to signify an assembly for consultation on matters of religion. Convocation is an assembly convoked for an especial purpose. Council is an assembly for consultation either on civil or on ecclesiastical affairs.

An assembly is, in its restricted sense, public, and under certain regulations; a company is private, and confined to friends and acquaintances; a meeting is either public or privatc; a congrega- tion is always public. Meetings are held by all who have any common concern to arrange; congregations consist of those who pursue the same objects particularly in matters of religion, although extended in its application to other matters: all these different kinds of assemblies are formed by individuals in their private capacity; the other terms designate assemblies that come together for national purposes, with the exception of the word convention, which may be either domestic or political. A parliament and diet are popular assemblies under a monarchical form of government; congress and convention are assemblies under a republican government: of the first description is the parliament of England, the diets of Prussia and Finland assembled by the reigning prince to deliberate on the affairs of the nation. Of the latter description is the congress of the United States of America and the national convention of France; but there is this difference observable between a congress and a convention, that the former eonsists of deputies or delegates from higher authorities - that is, from independent governments already established; but a convention is a self-constituted assembly, which has no power but what it assumes to itself. A synod and convocation are in religious matters what a diet and convention are in civil matters: the former exists only under an episeopal form of government; the latter may exist under any form of church discipline, even where the authority lies in the whole body of the ministry. A council is more important than all other species of assembly; it consists of persons invested with the highest authority, who, in their consultations, do not so much transact ordinary concerns as arrange the forms and fashions of things. Religious councils used to determine matters of faith and discipline; political councils frame laws and determine the fate of empires.

assent, Consent, Approbation, Concurrence. Assent, in Latin assentio, is compounded of as or ad and sentio, to think, signifying to bring one's mind or judgmert to a thing. Consent (sce ACcEDE). Approbation, in Latin approbatio, is compounded of ad 
and probo, to prove, signifying to make a thing out good. Concurrence (see Agree).

Assent respects matters of judgment; consent respects matters of conduct. We assent to what we admit to be true; we consent to what we allow to be done. Assent may be given to anything, whether positively proposed by another or not, but consent supposes that what is consented to is proposed by some other person. Some men give their hasty assent to propositions which they do not fully understand, and their hasty consent to measures which are very injudicious. It is the part of the true believer not merely to assent to the Christian doctrines, but to make them the rule of his life: those who consent to a bad action are partakers in the guilt of it.

Assent and consent may sometimes be both applied to matters of judgment or abstract propositions, but in that case assent is the act of an individual, consent is the act of many individuals: one assents to that which is offered to his notice; some things are admitted by the common consent of mankind.

Approbation is a species of assent, concurrence of consent. To approve is not merely to assent to a thing as right, but to determine upon it positively to be so; the word assent is applied therefore most properly to speculative matters, or matters of inference or deduction; approbation to practical matters or matters of conduct, as to give one's assent to a proposition in Euclid, to express one's approbation of a particular measure.

Concurrence is properly the consent of many: consent may pass between two individuals, namely, the party proposing and the party to whom the thing is proposed; but concurrence is always given by numbers: consent may be given by a party who has no personal interest in the thing consented to; concurrence is given by those who have a common interest in the thing proposed: consent therefore passes between persons individually, concurrence between communities or between men collectively.

Assent is given by equals or inferiors; it is opposed to contradiction or denial: consent is given by superiors, or those who have the power of preventing; it is opposed to refusal: approbation is given by equals or superiors, or those who have the power to withhold it; it is opposed to disapprobation: concurrence is given by equals; it is opposed to opposition or rejection.

ASSERT, MaINTaIN, Vindicate. Assert (see AfFirm). Maintain, in French maintenir, from the Latin manus and teneo, signifies to hold by the hand-that is, closely and firmly. Vindicate, in Latin vindicatus, participle of vindico (vin, a root signifying to wish, to claim, allied to venerate, Venus, etc., and dicere), signifies to express a wish or claim for ourselves or others.

To assert is to declare a thing as our own; to maintain is to abide by what we have so declared; to vindicate is to stand up for that which concerns ourselves or others. We assert anything to be true; we maintain it by adducing proofs, facts, or arguments; we vindicate our own conduct or that of another when it is called in question. We assert boldly or impudently; we maintain steadily or obstinately; we vindicate resolutely or insolently. A right or claim is asserted which is avowed to belong to any one; it is maintained when attempts are made to prove its justice or regain its possession; the cause of the asserter or maintainer is vindicated by another. Innocence is asserted by a positive declaration; it is maintained by repeated assertions and the support of testimony; it is vindicated through the interference of another. The most guilty persons do not hesitate to assert their innocence with the hope of inspiring credit; and some will persist in maintaining it even after their guilt has been pronounced; but the really innocent man will never want a friend to vindicate him when his honor or his reputation is at stake. Assertions which are made hastily and inconsiderately are seldom long maintained without exposing a person to ridicule; those who attempt to vindicate a bad cause expose themselves to as much reproach as if the cause were their own.

ASSESSMENT. See TAX. ASSEVERATE. See AFFIRM. ASSIDUOUS. See Active. 
ASSIGN. See Adduce; DistribUTE.

ASSIGNEE, Administrator. signee, in French assigné, from the Latin assigno ( $a d$, to, and signum, seal), signifies one to whom something is formally given over, either in trust or for his own use and enjoyment. An assignee in deed is one appointed by a person; an assignee in law is one appointed by a court or other competent authority; an assignee in bankruptcy is one to whom a bankrupt's estate is assigned and in whom it is vested for the benefit of his creditors.

The last is the most familiar application of the term. In his capacity as an administrator of another person's property (from Latin ad and ministrare, to serve, administer signifying public service applied in this case to a specific function) an assignee, after accepting the trust, is not at liberty to assign the property back again to the assignor. It is his duty to act as a faithful trustee for all concerned. $\mathrm{He}$ is to take immediate possession of all the property and effects and valuable interests of every kind of the insolvent, and demand and take any necessary steps to collect all outstanding debts. If he sells property of the insolvent he cannot buy it himself. Acting in the discharge of the ordinary duties of an administrator, an assignee is personally liable only for want of ordinary skill and care. See administer under Minister for further definition of the function of administrator in general.

ASSIMILABLE, ABSORBABLE, CONformable, Convertible. Assimilable, in French the same form, from assimilate, derived from ad and similis, to make like, signifies that which is capable of being made like another thing, or changed into its own substance. As an adjective, it implies that which may be made in some particulars to resemble another thing; and as a substantive, that which is capable of being so changed.

In the sense of mixing together, or merging, either of persons or substances, we have the main act of bringing some one or some thing into conformity or agreement with other persons or things, of converting, changing, or incorporating some one or some thing with others. A substance may be readily absorbable (from $a b$ and

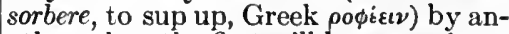
other when the first will be so conformable to the second that both become one substance, and each of the two separately is convertible into a single substance as if individually homogeneous.

Persons of like temperament and taste are assimilable in association with others of like qualities; citizens are made conformable to the law by penalties for being otherwise; sound securities are readily convertible into cash when desired; certain kinds of food and drink are assimilable, or capable of being united or mixed in the stomach without causing distress.

Hence, in all of these terms we have the sense of a complete and agreeable union of separate things in a single body, because each constituent in itself possesses the qualities of the others.

ASSIST. See Help.

ASSISTANT. See Accommodator; Coadjutor.

ASSISTING. See Auxiliary.

ASSOCIATE, Companion. Associate, in Latin associatus, participle of associo, is derived from ad and socius, a companion, literally a follower (allied to sequor, I follow). - Companion, from company (for derivation see AccomPANY), signifies one that bears company.

Associates are habitually together: companions are only occasionally in company. As our habits are formed from our associates, we ought to be particular in our choice of them: as our companions contribute much to our enjoyments, we ought to choose such as are suitable to ourselves. Many men may be admitted as companions who would not altogether be fit as associates.

An associate may take part with us in some business, and share with us in the labor: a companion takes part with us in some concern, and shares with us in the pleasure or the pain.

Association, Society, Company, Partnership.-All these terms denote a union of several persons into one body. Association is general, the rest are specific. Whenever we habitually or frequently meet together for some common object, it is an association. Asso- 
ciations are therefore political, religious, commercial, and literary. A society is an association for some specific purpose, moral or religious, civil or political. A company is an association of many for the purpose of trade. A partnership is an association of a few for the same object.

Whenever association is used in distinction from the others, it denotes that which is partial in its object and temporary in its duration. It is founded on unity of sentiment as well as unity of object; but it is mostly unorganized, and kept together only by the spirit which gives rise to it. A society requires nothing but unity of object which is permanent in its nature; it is well organized, and commonly set on foot to promote the cause of humanity, literature, or religion. No country can boast such numerous and excellent societies, whether of a charitable, a religious, or a literary description, as England. Companies are brought together for the purpose of interest, and are dissolved when that object ceases to exist: their duration depends on the contingencies of profit and loss. The South Sea Company, which was founded on an idle speculation, was formed for the ruin of many, and dispersed almost as soon as it was formed. Partnerships are altogether of an individual and private nature. As they are without organization and system, they are more precarious than any other association. Their duration depends not only on the chances of trade, but the compatibility of individuals to cooperate in a close point of union. They are often begun rashly and end ruinously.

Association, Combination.-Association (see the preceding). Combination, from the Latin combino, or con and binus, signifies tying two into one.

An association is something less binding than a combination; associations are formed for purposes of convenience; combinations are formed to serve either the interests or passions of men. The word association is therefore always taken in a good or an indifferent sense; combination in an indifferent or bad sense. An association is public; it embraces all classes of men: a combination is often private, and includes only a particular deseription of persons. Associations are formed for some general purpose; combinations are frequently formed for particular purposes which respect the interest of the few to the injury of many. Associations are formed by good citizens; combinations by discontented mechanics, or low persons in general.

When used for things, association is a natural action; combination an arbitrary action. Things associate of themselves, but combinations are formed either by design or accident. Nothing will associate but what harmonizes; things the most opposite in their nature may be combined together. We associate persons with places, or events with names; discordant properties are combined in the same body. With the name of one's birthplace are associated pleasurable recollections; virtue and vice are so combined in the same character as to form a contrast. The association of ideas is a remarkable phenomenon of the human mind, but it can never be admitted as solving any difficulty respecting the structure and composition of the soul; the combination of letters forms syllables, and that of syllables forms words.

ASSUAGE. See Allay.

ASSUME. See AFFECT; APPROPRIATE.

ASSUMPtion, Prestumption, ArROGANCE. Assumption, the act of assuming (see Appropriate). Presumption, from presume, in Latin prosumo, from pro, before, and sumo, to take, signifies to take beforehand, to take for granted. Arrogance (see APPRoPRIATE).

Assumption is a person's taking upon himself to act a part which does not belong to him. Presumption is the taking a place which does not belong to him. Assumption has to do with one's general conduct; presumption relates to matters of right and precedence. A person may be guilty of assumption by giving commands when he ought to receive them, or by speaking when he ought to be silent: he is guilty of presumption in taking a seat which is not fit for him. Assumption arises from self-conceit and self-suf- 
ficiency, presumption from self-importance. Assumption and presumption both denote a taking to one's self merely, arrogance claiming from others. A person is guilty of assumption and presumption for his own gratification only, without any direct intentional offence to others; but a man cannot be arrogant, be guilty of arrogance, without direct offence to others. The arrogant man exacts deference and homage from others; his demands are as extravagant as his mode of making them is' offensive. Children are apt to be assuming, low people to be presuming; persons among the higher orders, inflated with pride and bad passions, are apt to be arrogant.

ASSURANCE, CONFIDENCE. Assurance implies either the act of making another sure (see AFFiRis), or of being sure one's self. Confidence implies simply the act of the mind in confiding, which is equivalent to a feeling.

Assurance, as an action, is to confidence as the means to the end. We give a person an assurance in order to inspire him with confidence. Assurance and confudence, as a sentiment in ourselves, may respect either that which is external of us, or that which belongs to ourselves; in the first case they are both taken in an indifferent sense: but the feeling of assurance is much stronger than that of confidence, and applies to objects that interest the feelings; whereas confidence applies only to such objects as exercise the understanding: thus we have an assurance of a life to come; an assurance of a blessed immortality: we have a confidence in a person's integrity.

As respects ourselves exclusively, assurance is employed to designate either an occasional feeling or a habit of the mind; confidence, an occasional feeling mostly; assurance, therefore, in this sense, may be used indifferently, but in general it has a bad acceptation: confidence has an indifferent or a good sense.

Assurance is a self-possession of the mind, arising from the convietion that all in ourselves is right; confudence is that self-possession only in particular cases, and grounded on the reliance we have in our abilities or our char- acter. The man of assurance never loses himself under any circumstances, however trying; he is calm and easy when another is abashed and confounded: the man who has confidence will generally have it in cases that warrant him to trust to himself. A liar utters falsehoods with an air of assurance, in order the more effectually to gain belief; conscious innocence enables a person to speak with confidence when interrogated. Assurance shows itself in the behavior, confidence in the conduct. Young people are apt to assert everything with a tone of assurance; no man should undertake anything without a confidence in himself.

Assurance, Impudence. - Assurance (see above). Impudence literally implies shamelessness, from in, a negative prefix, and pudere, to feel shame. They are so closely allied to each other that assurance is distinguished from impudence more in the manner than the spirit; for impudence has a grossness attached to it which does not belong to assurance. Vulgar people are impudent, because they have assurance to break through all the forms of society; but those who are more cultivated will have their assurance controlled by its decencies and refinements.

ASSURE. See AFFirm.

ASTERN. See ABAFT.

ASTONISH. See WoNdER.

ASTRONOMY, ASTROLOGY. Astronomy is compounded of the Greek ã $\sigma \rho 0 \nu$, cognate with English star, and vónos, law, and signifies the laws of the stars, or a knowledge of their laws.

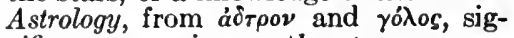
nifies a reasoning on the stars.

The astronomer studies the course and movement of the stars; the astrologer reasons on their influence. The former observes the state of the heavens, marks the order of time, the eclipses, and the revolutions which arise out of the established laws of motion in the immense universe: the latter predicts events, draws horoscopes, and announces all the vicissitudes of rain and snow, heat and cold, etc. The astronomer calculates and seldom errs, as his calculations are built on fixed rulcs and actual observations; the astrologer deals in conjectures, and his 
imagination often deceives him. The astronomer explains what he knows, and merits the esteem of the learned; the astrologer hazards what he thinks, and seeks to please.

ASYlum, Refuge, Shelter, ReTREAT. Asylum, in Latin asylum, in Greek ä $\sigma v \lambda o \nu$, compounded of $\alpha$, privative, and $\sigma \dot{v} \lambda \eta$, plunder, signifies a place exempt from plunder. Refuge, in Latin refugium, from refugio, to fly away, signifies the place one may fly away to. Shelter is a corruption of Middle English sheld-trume, Anglo-Saxon scildtruma, shield-troop, a band of armed men protecting something, and hence a protection in general. Retreat, in French retraite, Latin retractus, from retraho, or re and traho, to draw back, signifies the place that is situated behind or in the background.

Asylum, refuge, and shelter all denote a place of safety; but the former is fixed, the two latter are occasional: the retreat is a place of tranquillity rather than of safety. An asylum is chosen by him who has no home, a refuge by him who is apprehensive of danger: the French emigrants found a refuge in England, but very few will make it an asylum. The inclemencies of the weather make us seek a shelter. The fatigues and toils of life make us seek a retreat. It is the part of a Christian to afford an asylum to the helpless orphan and widow. The terrified passenger takes refuge in the first house he comes to, when assailed by an evil-disposed mob. The vessel shattered in a storm takes shetter in the nearest haven. The man of business, wearied with the anxieties and cares of the world, disengages himself from the whole, and seeks a retreat suited to his circumstances.

ATOMIC, INAPPRECIABLE, MIrute, Sirall. Atomic, in Freneh atomique, is in English a compound of atom and the suffix $i c$; atom, Latin

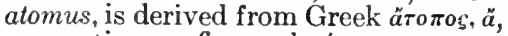
a negative prefix, and $\tau^{\prime} \mu \nu \varepsilon \omega \nu$, to cut, and signifies that which cannot be cut, a particle of matter which cannot be made smaller. Inappreciable is compounded of in, a negative prefix, and $a d$ and pretium, price, and signifies something too small to evaluate, too small to notice at all. MFinute is derived from the past participle of minuere, to make small, whence minor, diminish, etc., are also derived. Small is a Teutonic word meaning in most Germanic languages what it means in English.

Of these terms atomic is the most absolute and emphatic, and small the least so. Small is used relatively. We speak of a small man or a small army, though the man is gigantic compared with a mosquito, and the army may be many times the size of groups of people which at other times we call large. We mean that the man is small compared with other men, etc. The use of small is generally influenced by some specific standard of comparison. Minute suggests extreme smallness, but is not so absolute a term as atomic. A minute object is small compared with most of the things that we know, but it may nevertheless contain many atoms. Inappreciable is a relative term, but it differs from small in emphasizing the relation of the object to the mind perceiving it. While the degree of smallness indicated in the word inappreciable may vary with the circumstances, the fluctuation is not so great as in the word small, because the capacity of the mind to notice and appreciate remains fairly stable, and hence inappreciable has much the same meaning for one person as for another.

ATONE, Expiate. Atone, or at one, signifies to be at peace or good friends. Expiate, in Latin expiatus, participle of expio, compounded of ex and pio, signifies to put out or cancel by an act of piety.

Both these terms express a satisfaetion for an offence; but atone is general, expiate is particular. We may atone for a fault by any species of suffering; we expiate a crime only by suffering a legal punishment. A woman often sufficiently atones for her violation of chastity by the misery she brings on herself; there are too many unfortunate wretches in England who expiate their crimes on the gallows.

Neither atonement nor expiation always necessarily requires punishment. or even suffering from the offender. The nature of the atonement depends on the nature of the offence or will of the 
individual who is offended; expiations are frequently made by means of performing certain religious rites or acts of piety. Offences between man and man are sometimes atoned for by an acknowledgment of error; but offences toward God require an expiatory sacrifice, which our Saviour has been pleased to make of himself, that we, through him, might become partakers of eternal life. Expiation, therefore, in the religious sense, is to atonement as the means to the end: atonement is often obtained by an expiation, but there may be expiations where there is no atonement.

ATROCIOUS. See Diabolic; HeINous.

ATTACH., See Adhere; Affix.

ATTACHE, Assistant, INForMaNT. Attaché, though a purely French term, has been adopted in the vocabulary of practically all modern nations, implying, literally, a person attached to a thing or other person, and, specifically, one attached to an embassy. In the diplomatic world, an attache is much less than an ambassador, and much more than a routine clerk. One may be an ordinary attaché who gathers information for his superior, a military attache, who is usually an officer in the army of his own country, or a naval atlaché, one holding a naval office at home.

Assistant (see HeLP) and informant (see INFORM) are more general terms which may be specialized to refer to the functions of an attaché in assisting the work of his superiors, and informing them concerning conditions in the country where he serves.

In peaceful days the post of an attaché is a very pleasant one: in wartimes it may be a very difficult and unpleasant one, as, in carrying out instructions of his superior and secretly gaining some desired information, an attaché may become seriously involved with the authorities of the country to which he is assigned, though immune from arrest or other legal proceeding. In December, 1915, the United States Government demanded the recall of the military and naval attachés of the German embassy at Washington, because of their activities in fomenting local troubles during the Eu- ropean war. Both officers declared they had acted under orders, as they were bound to do.

ATTACHED. See ON.

ATTACHMENT, AFFECTION, INCLINATION. Attachment respects persons and things: affection regards persons only: inclination, denoting the act of inclining, has respect to things mostly, but may be applied to objects generally.

Attachment, as it regards persons, is not so powerful or solid as affection. Children are attached to those who will minister to their gratifications; they have an affection for their nearest and dearest relatives. Attachment is sometimes a tender sentiment between persons of different sexes; affection is an affair of the heart without distinction of sex. The passing attachments of young pcople are seldom entitled to serious notice; although sometimes they may ripen by a long intercourse into a laudable and steady affection. Nothing is so delightful as to see affection among brothers and sisters.

Attachment is a something more powerful and positive than inclination; the latter is a rising sentiment, a mere leaning of the mind toward an object; the former is a feeling already fixed so as to create a tie; an altachment is formed, an inclination arises in the mind of itself.

In respect to things, attachment and inclination admit of a similar distinction. We strive to obtain that to which we are attached, but a simple inclination rarely produces any effort for possession. Little minds are always betraying their attachment to trifles. It is the character of indifference not to show an inclination to anything. Interest, similarity of character, or habit gives rise to attachment; a natural warmth of temper gives birth to various inclinations. Suppress the first inclination to gaming, lest it grow into an attachment.

ATTACK, Assail, Assault, ENcouNTEr. Attack is a doublet of attach, derived from the same original word. (See AdHere.) Assail, assault, in French assaillir, Latin assilio, assaltum, compounded of ad and salio, signify to leap upon. Encounter, in Old French encontrer, compounded of en 
or in and contre, in Latin contra, against, signifies to run or come against.

Attack is the generic, the rest are specific terms. To attack is to make an approach in order to do some violence to the person; to assail or assault is to make a sudden and vehement attack; to encounter is to meet the attack of another. One attacks by simply offering violence without necessarily producing an effect; one assails by means of missile weapons; one assaults by direct personal violence; one encounters by opposing violence to violence. Men and animals attack or encounter; men only, in the literal sense, assail or assault. Animals attack each other with the weapons nature has bestowed upon them: those who provoke a multitude may expect to have their houses or windows assailed with stones, and their persons assaulted; it is ridiculous to attempt to encounter those who are superior in strength and prowess.

They are all used figuratively. Men attack with reproaches or censures; they assail with abuse; they are assaulted by temptations; they encounter opposition and difficulties. A fever attacks; horrid shrieks assail the ear; dangers are encountered. The reputations of men in public life are often wantonly attacked; they are assailed in every direction by the murmurs and complaints of the discontented; they often encounter the obstacles which party spirit throws in the way, without reaping any solid advantage to themselves.

Attack, Assault, Encounter, Onset, Charge.-Attack, assault, encounter, denote the act of attacking, assaulting, encountering. Onset signifies a setting on or to, a commencing. Charge (see ACCUSE) signifies pressing upon.

An attack and assault may be made upon an unresisting object; encounter, onset, and charge require at least two opposing parties. An attack may be slight or indirect; an assault must always be direct, and mostly vigorous. An attack upon a town need not be attended with any injury to the walls or inhabitants; but an assault is commonly conducted so as to effect its capture. Attacks are made by robbers upon the person or property of another; assaults upon the person only. encounter generally respects an informal casual meeting between single individuals; onset and charge a regular attack between contending armies: onset is employed for the commencement of the battle; charge for an attack from a particular quarter. When knighterrantry was in vogue, encounters were perpetually taking place between the knights, which were sometimes fierce and bloody. Armies that make impetuous onsets are not always prepared to withstand a continued attack with perseverance and steadiness. A furious and well-directed charge from the cavalry will sometimes decide the fortune of the day.

See also IMPUGN.

ATTAIN. See AcQUire.

ATTAINT, Corrupt, Stain, TArNT. Attaint and taint are commonly confused in the popular mind, but, etymologically, they have nothing to do with each other. Attaint is the past participle of the verb attain, used in a technical sense in law. To attain meant to convict, to attain the end sought in a legal trial.

Under an act of the British parliament known as the Act of Attainder, an attainder is a decree involving the loss of civil rights and estate of one guilty of the crime of treason or other capital offence, and a Bill of Attainder is the designation of the foregoing act. Hence, in the popular mind, it was natural that attaint should be associated with taint (from Latin tingere, to color, whence tint is derived), and with stain (from distingere, literally to discolor), because the conviction by the court involved disgrace, or the staining and tainting of the character and reputation.

The Constitution of the United States declares that (1) "No bill of attainder or ex post facto laws shall be passed"; (2) "No state shall ... pass any bill of attainder, ex post facto law, or law impairing the obligation of contracts"; and (3) "... but no attainder of treason shall work corruption of blood or forfeiture except during the life of the person attained."

Corrupt, as used in the phrase corruption of blood, implies that the blood of a person who has been attainted or is under an attainder has been legally corrupted, tainted, or stained by the 
disgrace. In old English law a jury that brought in a false verdict was liable to be attainted by another jury, and in case of conviction the members were pronounced infamous, their goods were forfeited, their families turned out of doors, and their houses razed. The later practice set aside verdicts and granted new trials, and an act of parliament put an end to the system of attaints.

a'T'TEMPT, Trial, ENdeavor, EFForT, Essay. Attempt, in French attenter, Latin attento, from ad and tento, signifies to try at a thing. Trial, from French trier, try, comes from Late Latin tritare, to pound small; thence developing the meaning of culling, picking out. Endeavor, compounded of $e n$ and the French devoir, to owe, signifies to try according to one's duty. Effort, from Latin ex and fortem (accusative), strength, signifies the putting forth of strength. Essay comes from Latin exagium, a trial of weight, from $e x$, out, and agere, to drive or move; it is the same word as assay.

To attempt is to set about a thing with a view of effecting it; to try is to set about a thing with a view of seeing the result. An attempt respects the action with its object; a trial is the exercise of power. We always act when we attempt: we use the senses and the understanding when we try. We attempt by trying, but we may try without attempting; when a thief attempts to break into a house, he first tries the locks and fastenings, to see where he can most easily gain admittance. Men attempt to remove evils; they try experiments. Attempts are perpetually made by quacks to recommend some scheme of their own to the notice of the public, which are often nothing more than trials of skill to sce who can most effectually impose on the credulity of mankind. Spirited people make attempts; persevering people make trials; players at tempt to perform different parts, and try to gain applause. An endeavor is a continued attempt. Attempts may be fruitless; trials may be vain; endeavors, though unavailing, may be well meant. Many attempts are made which exceed the abilities of the attempter; attempts at imitation expose the imitator to ridicule when they do not succeed; trials are made in matters of speculation, the results of which are uncertain; endeavors are made in the moral concerns of life. People attempt to write books; they try various methods; and endeavor to obtain a livelihood.

An effort is to an attempt as a means to an end; it is the act of calling forth those powers which are required in an attempt. Great attempts frequently require great efforts, either of body or mind.

An essay is an imperfect attempt, or attempt to do something which cannot be done without difficulty. It is applied either to corporeal or intellectual matters.

Whence treatises which serve as attempts to illustrate any point in morals are termed essays.

Attempt, Undertaking, Enterprise.Attempt signifies the thing attempted. Undertaking, from undertake, or take in hand, signifies the thing taken in hand. Enterprise, from the Old French enterpris, participle of entreprendre, to undertake, has the same original sense.

The idea of something set about to be completed is common to all these terms. An attempt is less complicated than an undertaking; and that less arduous than an enterprise. Attempts are the common exertions of power for obtaining an object; an undertaking involves in it many parts and particulars which require thought and judgment: an enterprise has more that is hazardous and dangerous in it; it requires resolution. Attempts are frequently made on the lives and property of individuals; undertakings are formed for private purposes; enterprises are commenced for some great national object. Nothing can be effected without making the attempt; attempts are therefore often idle and unsuccessful when they are made by persons of little discretion, who are eager to do something without knowing how to direct their powers: undertakings are of a more serious nature, and involve a man's serious interests; if begun without adequate means of bringing them to a conclusion, they too frequently bring ruin by their failure on those who are concerned in them: enterprises require personal sacrifices rather than those of interest; he who does not combine 
great resolution and perseverance with considerable bodily powers will be illfitted to take part in grand enterprises.

atTend, Mind, Regard, Heed, Notice. Attend, in French attendre, Latin attendo, compounded of $a d$ and tendere, to stretch, signifies to stretch or bend the mind to a thing. Mind comes from Anglo-Saxon munan, to think. Regard, in French regarder, compounded of re and garder, a word of German origin meaning to watch over, signifies to look upon again or with attention. Heed, Anglo-Saxon hedan, is allied to German hüten, to guard. Notice, from the Latin notitia, knowledge, signifies to bring to the knowledge of, or bring to one's mind.

The idea of fixing the mind on an object is common to all these terms. As this is the characteristic of attention, attend is the generic, the rest are specific terms. We attend in minding, regarding, heeding, and noticing, and also in many cases in which these words are not employed. To mind is to attend to a thing, so that it may not be forgotten; to regard is to look on a thing as of importance; to heed is to attend to a thing from a principle of caution; to notice is to think on that which strikes the senses. We attend to a speaker when we hear and understand his words; we mind what is said when we bear it in mind; wa regard what is said by dwelling and reflecting on it; heed is given to whatever awakens a sense of danger; notice is taken of what passes outwardly. Children should always attend when spoken to, and mind what is said to them; they should regard the counsels of their parents, so as to make them the rule of their conduct, and heed their warnings so as to avoid the evil; they should notice what passes before them, so as to apply it to some useful purpose. It is a part of politeness to attend to every minute circumstance which affects the comfort and convenience of those with whom we associate: men who are actuated by any passion seldom pay any regard to the dictates of conscience, nor heed the unfavorable impressions which their conduct makes on others, for in fact they seldom think what is said of them to be worth their notice.

See also Accompany.
Attend, Wait On.-Attend is here employed in the improper sense for the devotion of the person to an object. To wait on is the same as to wait for the wishes of another. They may be either partial and temporary acts or permanent acts; in either case attend has a higher signification than wait on. Attendance is for the purpose of discharging some duty, as a physician attends his patient; a member attends in parliament; waiting on is either a matter of courtesy between equals, as one gentleman waits on another to whom he wishes to show a mark of respect; or a matter of business, as a tradesman waits on his customers to take orders.

In the sense of being permanently about the person of any one, to attend is to bear company or be in readiness to serve; to wait c.) is actually to perform some service. A nurse attends a patient in order to afford him assistance as occasion requires; the servant waits on him to perform the menial duties. Attendants about the great are always near the person; but men and women in waiting are always at call. People of rank and fashion have a crowd of attendants; those of the middle classes have only those who wait on them.

Attend, Hearken, Listen.-Attend (see above). Hearken comes from Anglo-Saxon heorcnian, to listen to, but is not directly allied to hear. Listen comes from Anglo-Saxon hlystan, to hear.

Attend is a mental action; hearken, both corporeal and mental; listen simply corporeal. To attend is to have the mind engaged on what we hear; to hearken and listen are to strive to hear. People attend when they are addressed; they hearken to what is said by others; they listen to what passes between others. It is always proper to attend, and mostly of importance to hearken, but frequently improper to listen. The mind that is occupied with another object cannot attend; we are not disposed to hearken when the thing does not appear interesting; curiosity often impels to listening to what does not concern the listener.

Listen is sometimes used figuratively in the sense of hearkening with the de- 
sire to profit by it; it is necessary at all times to listen to the dictates of reason.

Attention, Application, Study.These terms indicate a direction of the thoughts to an object, but differing in the degree of steadiness and force. Attention marks the simple bending of the mind. Application (see ADDress) marks an envelopment or engagement of the powers; a bringing them into a state of close contact. Study, from the Latin studeo, to desire eagerly, marks a degree of application that arises from a strong desire of attaining the object.

Attention is the first requisite for making a progress in the acquirement of knowledge; it may be given in various degrees, and it rewards according to the proportion in which it is given: a divided attention is, however, more hurtful than otherwise; it retards the progress of the learner, while it injures his mind by improper exercise. Application is requisite for the attainment of perfection in any pursuit; it cannot be partial or variable, like attention; it must be the constant exercise of power or the regular and uniform use of means for the attainment of an end: youth is the period for application, when the powers of body and mind are in full vigor; no degree of it in afterlife will supply its deficiency in younger years. Study is that species of application which is most purely intellectual in its nature; it is the exercise of the mind for itself and in itself, its native effort to arrive at maturity; it embraces both attention and application. The student altends to all he hears and sees; applies what he has learned to the acquirement of what he wishes to learn, and digests the whole by the exercise of reflection: as nothing is thoroughly understood or properly reduced to practice without study, the professional man must choose this road in order to reach the summit of excellence.

See also Heed.

Attentive, Careful.-Attentive marks a readiness to attend. Careful signifies full of care (see CARE, Solicitude).

These epithets denote a fixedness of mind: we are attentive in order to understand and improve: we are careful to avoid mistakes. An attentive scholar profits by what is told him in learning his task: a careful scholar performs his exercises correctly. Attention respects matters of judgment; care relates to mechanical action: we listen attentively; we read or write carefully. A servant must be attentive to the orders that are given him, and careful not to injure his master's property. A translator must be altentive; a transcriber careful. A tradesman ought to be attentive to the wishes of his customers, and careful in keeping his accounts.

atTENDANT. See Chaperon.

ATTIRE. See Apparel.

ATTITUDE. See Act.

ATTRACT, Allure, Invite, ENGAGE. Attract, in Latin attractum, participle of attraho, compounded of ad, to, and traho, signifies to draw toward. Allure (see AlluRe). Invite, in French inviter, Latin invitare, means to ask or request, the stem being allied to vitus in invitus, unwilling. Engage, compounded of $e n$ or in and the French gage, a pledge (from a Teutonic root), signifies to bind as by a pledge.

That is attractive which draws the thoughts toward itself; that is alluring which awakens desire; that is inviting which offers persuasion; that is engaging which takes possession of the mind. The attention is attracted; the senses are allured; the understanding is invited; the whole mind is engaged. A particular sound attracts the ear; the prospect of gratification allures; we are invited by the advantages which offer; we are engaged by those which already accrue. The person of a female is attractive; female beauty involuntarily draws all eyes toward itself; it awakens admiration: the pleasures of society are alluring; they create in the receiver an eager desire for still further enjoyment; but when too eagerly pursued they vanish in the pursuit, and leave the mind a prey to listless uncasiness: fine weather is inviling; it seems to persuade the reluctant to partake of its refreshments: the manners of a person are engaging; they not only occupy the attention, but they lay hold of the affections.

Attractions, Allurements, Charms.Attraction signifies the thing that attracts. Allurement signifies the thing that allures. Charm, from the Latin 
carmen, a verse, signifies whatever acts by an irresistible influence, like poetry.

Besides the synonymous idea which distinguishes these words, they are remarkable for the common property of being used only in the plural when denoting the thing that attracts, allures, and charms, as applied to female endowments or the influence of persons on the heart: it seems that in attractions there is something natural; in allurements something artificial; in charms something moral and intellectual. Attractions and charms are always taken in a good sense; allurements mostly in a bad sense: attractions lead or draw; allurements win or entice; charms seduce or captivate. The human heart is always exposed to the power of female atractions; it is guarded with difficulty against the allurements of a coquette; it is incapable of resisting the united charms of body and mind.

When applied to other objects, an attraction springs from something remarkable and striking; it lies in the exterior aspect, and awakens an interest toward itself; a charm acts by a, sceret, all-powerful, and irresistible impulse on the soul; it springs from an accordance of the object with the affections of the heart; it takes hold of the imagination, and awakens an enthusiasm peculiar to itself: an allurement acts on the senses; it flatters the passions; it enslaves the imagination. The metropolis has its attractions for the gay; music has its charms for every one; fashionable society has too many allurements for youth, which are not easily withstood. ITY.

ATTRIBUTE. See Ascribe; Qual-

AUDACITY, EFFrontery, HardiHOOD or HARDINESs, Boldness. Audacity, from audacious, in French audacieux, Latin audax and audere, to dare, signifies literally the quality of daring. Effrontery, through French from $e f$, for $e x$, out, and frons, a face, signifies putting out the forehead. Hardihood or hardiness, from hardy or hard, signifies a capacity to endure or stand the brunt of difficulties, opposition, or shame. Bold comes from Anglo-Saxon bald.

The idea of disregarding what others regard is common to all these terms.
Audacity expresses more than effrontery; the first has something of vehemence, of defiance in it; the latter that of cool unconcern: hardihood expresses less than boldness; the first has more of determination, and the second more of spirit and enterprise. Audacity and effrontery are always taken in a bad sense; hardihood, in an indifferent, if not a bad sense; boldness, in a good, bad, or indifferent sense. Audacity marks haughtiness and temerity; effrontery the want of all modesty, a total shamelessness; hardihood indicates a firm resolution to meet consequences; boldness; a spirit and courage to commence action. An audacious man speaks with a lofty tone, without respect and without reflection; his haughty demeanor makes him forget what is due to his superiors. Effrontery discovers itself by an insolent air, a total unconcern for the opinions of those present, and a disregard of all the forms of civil society. A hardy man speaks with a resolute tone, which seems to brave the utmost evil that can result from what he says. A bold man speaks without reserve, undaunted by the quality, rank, or haughtiness of those whom he addresses. It requires audacity to assert false claims or vindicate a lawless conduct in the presence of accusers and judges; it requires effrontery to ask a favor of the man whom one has basely injured, or to assume a placid, unconcerned air in the presence of those by whom one has been convicted of flagrant atrocities; it requires hardihood to assert as a positive fact what is dubious, boldness to maintain the truth in spite of every danger with which one is threatened.

AUGMENTATION. See INCREASE. AUGur, Presage, Forebode, BeToken, Pontend. Augur, in French augurer, Latin augurium, comes from avis, a bird, as an augury was originally, and at all times principally, drawn from the song, the flight, or other actions of birds. Presage, in French présage, from the Latin pre and sagio, to be instinctively wise, signifies to be thus wise about what is to come. Forebode is compounded of fore and the Anglo-Saxon bodian, to declare, signifying to pronounce on futurity. Betoken signifies to serve as a token, 
from Anglo-Saxon tacen (from a root found also in teach). Portend, in Latin portendo, compounded of por, for, and tendo, signifies to set or show forth.

Augur signifies either to serve or make use of as an augury; to forebode, and presage, is to form a conclusion in one's own mind: to betoken or portend is to serve as a sign. Persons or things augur; persons only forebode or presage; things only betoken or portend. Auguring is a calculation of some future event, in which the imagination seems to be as much concerned as the understanding: presaging is rather a conclusion or deduction of what may be from what it is; it lies in the understanding more than in the imagination: foreboding lies altogether in the imagination. Things are said to betoken which present natural signs; those are said to portend which present extraordinary or supernatural signs. It augurs ill for the prosperity of a country or a state when its wealth has increased so as to take away the ordinary stimulus to industry and to introduce an inordinate love of pleasure. We presage the future greatness of a man from the indications which he gives of possessing an elevated character. A distempered mind is apt to forebode every ill from the most trivial circumstances. We see with pleasure those actions in a child which betoken an ingenuous temper: a mariner sees with pain the darkness of the sky which portends a storm; the moralist augurs no good to the morals of a nation from the lax discipline which prevails in the education of youth; he presages the loss of independence to the minds of men in whom proper principles of subordination have not been early engendered. Men sometimes forebode the misfortunes which happen to them, but they oftener forebode evils which never come.

AUGUST. See Magisterial; SUPERB.

AUSPICIOUS, Propitious. Auspicious, from the Latin auspicium and auspex, compounded of avis and spicio; to behold, signifies favorable according to the inspection of birds. Propitious is probably also a term in augury, meaning "flying forward," from pro, forward, and petere, to seek, originally to fly.
Auspicious is said only of things; propitious is said only of persons or things personified. Those things are auspicious which are casual or only indicative of good; persons are propitious to the wishes of others who listen to their requests and contribute to their satisfaction. A journey is undertaken under auspicious circumstances where everything incidental, as weather, society, and the like, bid fair to afford pleasure; it is undertaken under propitious circumstances when everything favors the attainment of the object for which it was begun. Whoever has any request to make ought to seize the auspicious moment when the person of whom it is asked is in a pleasant frame of mind; a poet in his invocation requests the muse to be propitious to him, or the lover conjures his mistress to be propitious to his vows.

See also Opportune.

AUSTERE, Rigid, Severe, Rigorous, Stern. For the derivations of austere, rigid, rigorous, and stern see Ascetic. Severe comes from Latin severus, serious, grave.

Austere applies to ourselves as well as to others; rigid applies to ourselves only; severe, rigorous, stern, apply to others only. We are austere in our manner of living; rigid in our mode of thinking; austere, severe, rigorous, and stern in our mode of dealing with others. Effeminacy is opposed to austerity, pliability to rigidity. The austere man mortifies himself; the rigid man binds himself to a rule: the manners of a man are austere when he refuses to take part in any social enjoyments; his probity is rigid-that is, inaccessible to the allurements of gain or the urgency of necessity: an austere life consists not only in the privation of every pleasure, but in the infliction of every pain; rigid justice is unbiased, no less by the fear of loss than by the desire of gain: the present age affords no example of austerity, but too many of its opposite extreme, effeminacy: and the rigidity of former times, in modes of thinking, has been succeeded by a culpable laxity.

Austere, when taken with relation to others, is said of the behavior; severe of the conduct: a parent is austere in 
his looks, his manner, and his words to his child; he is severe in the restraints he imposes and the punishments he inflicts; an austere master speaks but to command, and commands so as to be obeyed; a severe master punishes every fault and punishes in an undue measure; an austere temper is never softened; the countenance of such a one never relaxes into a smile, nor is he pleased to witness smiles: a severe temper is ready to catch at the imperfections of others and to wound the offender: a judge should be a rigid administrator of justice between man and man, and severe in the punishment of offences as occasion requires; but never austere toward those who appear before him; austerity of manner would ill become him who sits as a protector of either the innocent or the injured. Riyor is a species of great severity, namely, in the infliction of punishment: toward enormous offenders, or on particular occasions where an example is requisite, rigor may be adopted, but otherwise it marks a cruel temper. A man is austere in his manners, severe in his remarks, and rigorous in his discipline. Austerity, rigidity, and severity may be habitual; rigor and sternness are occasional. Sternness is a species of severity more in manner than in direct action; a commander may issue his commands sternly, or a despot may issue his stern decrees.

See also Ascetic; Severe.

AUTHOR. See WrITER.

AUTHORITATIVE. See

COMMAND; ORACULAR.

AUTHORITy. See Influence; Power.

AUTHORIZE. See Commission.

AUTOCRACY, Oligarchy, ARIsTOCRACY. Autocracy corresponds most nearly to words listed under ABsolute, which see. Autocracy, from Greek

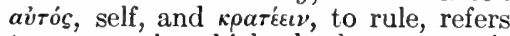
to a state in which absolute power is in the hands of one man or a small group of men. Oligarchy is a form of autocracy in which the power is in the hands of a few- of a council of men or a group of nobles. It is derived

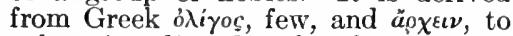
rule. An oligarchy, therefore, is generally an autocracy, but an autocracy is not always an oligarchy; at least nominally it is not, but practically it generally is, because the power even of an absolute monarch really resides in the group of his advisers. An aristocracy is an oligarchy in which the few are also the best men, from Greek âpırтos, best. While the Greeks held an ideal of a state in which the power was in the hands of the wisest and the noblest, as a matter of fact there was, in practice, little difference between an aristocracy and an oligarchy, the "best" men being the self-assertive and the powerful who could get the government into their hands, with special reference to those of noble birth.

As adjectives autocratic corresponds very nearly to absolute (which see), and has the same synonymes - despotic, tyrannical, etc. Autocratic generally has reference to the assertion of the right to hold absolute rule, in action, speech, or manner; despotic and tyrannical to the actual exercise of that selfappointed right to the oppression of another. Aristocratic, like autocratic, is a more general word than oligarchical. Oligarchical means characteristic of an oligarch, one of a small group of autocratic rulers; aristocratic refers in general to the characteristics of men of hereditary importance in a state whose qualities of personality and gifts of fortune entitle them to a position of dignity. It is generally used in a good sense, while oligarchical is somewhat derogatory.

AUTOMOBILE, AUto, CAR, MACHINE, Motor. These words do not differ in meaning or application; the only difference is the extent and dignity of their usage as designations for exactly the same thing. Automobile is the regular word; the rest are more or less colloquial substitutes. Automobile is a French word formed by adding Greek aúro, self, to French mobile, to indicate a self-moving vehicle, one propelled by its own machinery. Auto is a somewhat inelegant abbreviation usually frowned on in polite society in favor of car or machine, general words which have been given this special application. Motor, in America, is usually employed as a verb meaning to ride in an automobile; in England, however, motor-car is the common term for automobile. 
AUXILIARY, ANCILLARY, SUbSIDIARY. Auxiliary comes from Latin auxilium, help, from augere, to increase. Ancillary comes from Latin ancilla, a handmaid, and means literally serving in the capacity of a handmaid. Subsidiary comes from Latin subsidium, a body of troops in reserve, from Latin sub, under, in reserve, and sedere, to sit. All these words mean aiding or assisting, and there is very little difference in their application. What there is is mainly that suggested by the derivation. Auxiliary does not suggest the degree of subordination implied in ancillary and subsidiary. Subsidiary and ancillary differ slightly in the relation of the implied help to the person or object to be helped, ancillary suggesting merely subordinate aid, subsidiary aid held in reserve.

AVAIL. See SigNify; Utility.

AVARICE. See Covetousness.

AVARICIOUS, Miserly, ParsimoNious, Niggardly. Avaricious, from Latin avarus, and avere, to desire, signifies desiring money, from a love of it. Miserly signifies like a miser, or miserable man; for none are so miserable as the lovers of money. Parsimonious, from the Latin parcere, to spare or save, signifies, literally, saving. Niggardly is a Scandinavian word signifying stingy.

The avaricious man and the miser are one and the same character, with this exception, that the miser carries his passion for money to a still greater excess. An avaricious man shows his love of money in his ordinary dealings, but the miser lives upon it, and suffers every privation rather than part with it. An avaricious man may sometimes be indulgent to himself and generous to others; the miser is dead to everything but the treasure which he has amassed. Parsimonious and niggardly are the subordinate characteristics of avarice. The avaricious man indulges his passion for money by parsimonythat is, by saving out of himself, or by niggardly ways in his dealings with others. He who spends a farthing on himself where others with the same means spend a shilling does it from parsimony: he who looks to every farthing in the bargains he makes gets the name of a niggard. Avarice sometimes cloaks itself under the name of prudence: it is, as Goldsmith says, often the only virtue which is left a man at the age of seventy-two. The miser is his own greatest enemy, and no man's friend; his ill-gotten wealth is generally a curse to him by whom it is inherited. A man is sometimes rendered parsimonious by circumstances; but he who first saves from necessity too often ends with saving from inclination. The niggard is an object of contempt, and sometimes hatred; every one fears to lose by a man who strives to gain from all.

See also Greedy.

AVENGE, Revenge, Vindicate. Avenge, revenge, and vindicate all spring from the same source, namely, the Latin vindicare, from vindex, a claimant, signifying to pronounce justice or put justice in force.

The idea common to these terms is that of taking up some one's cause. To avenge is to punish in behalf of another; to revenge is to punish for one's self; to vindicate is to defend another. The wrongs of a person are avenged or revenged; his rights are vindicated. The act of avenging, though attended with the infliction of pain, is oftentimes an act of humanity, and always an act of justice; none are the sufferers but such as merit it for their oppression; while those are benefited who are dependent for support: this is the act of God Himself, Who always avenges the oppressed who look up to Him for support; and it ought to be the act of all His creatures who are invested with the power of punishing offenders and protecting the helpless. Revenge is the basest of all actions, and the spirit of revenge the most diametrically opposed to the Christian principles of forgiving injuries and returning good for evil; it is gratified only with inflicting pain without any prospect of advantage. Vindication is an act of generosity and humanity; it is the production of good without the infliction of pain: the claims of the widow and orphan call for vindication from those who have the time, talent, or ability to take their cause into their own hands: England can boast of many noble vindicators of the rights of humanity, not excepting those which concern the brute creation. 
AVER. See AFFirm.

AVERSE, UNWILliNG, BaCKWARD, Loath, Reluctant. Averse, in Latin aversus, participle of avertere, compounded of vertere, to turn, and $a$, from, signifies the state of having the mind turned from a thing. Unwilling literally signifies not willing. Backward signifies having the will in a backward direction. Loath, from Anglo-Saxon lath, hateful, hostile, has developed a somewhat milder meaning. Reluctant, from the Latin re against, and luctare, to struggle, signifies struggling with the will against a thing.

Averse is positive, it marks an actual sentiment of dislike; unwilling is negative, it marks the absence of the will; backward is a sentiment between the two, it marks a leaning of the will against a thing; loath and reluctant mark strong feelings of aversion. Aversion is an habitual sentiment; unwillingness and backwardness are mostly occasional; loath and reluctant always occasional. Aversion must be conquered; unwillingness must be removed; backwardness must be counteracted or urged forward; loathing and reluctance must be overpowered. One who is averse to study will never have recourse to books; but a child may be unwilling or backward to attend to his lessons from partial motives, which the authority of the parent or master may correct; he who is loath to receive instruction will always remain ignorant; he who is reluctant in doing his duty will always do it as a task. A miser is averse to nothing so much as to parting with his money: he is even unwilling to provide himself with necessaries, but he is not backward in disposing of his money when he has the prospect of getting more; friends are loath to part who have had many years' enjoyment in each other's society; we are reluctant in giving unpleasant advice. Lazy people are averse to labor; those who are not paid are unwilling to work; and those who are paid less than others are backward in giving their services: every one is loath to give up a favorite pursuit, and when compelled to it by circumstances they do it with reluctance.

See also Adverse.

Aversion, Antipathy, Dislike, Hatred,
Repugnance. - Aversion denotes the quality of being averse. Antipathy, in French antipathie, Latin antipathia, Greek $\dot{\alpha} \nu \tau \iota \pi \dot{\alpha} \theta \varepsilon \iota a$, compounded of ád against, and $\pi \alpha \theta \bar{\varepsilon} \nu$, to suffer, to feel, feeling, signifies here a natural feeling against an object. Dislike, compounded of the privative dis and like, signifies not to like or be attached to. Hatred comes from Anglo-Saxon hatian, to hate. Repugnance, in French répugnance, Latin repugnantia and repugnare, compounded of re, against, and pugnare, to fight, signifies the resistance of the feelings to an object.

A version is in its most general sense the generic term to these and many other similar expressions, in which case it is opposed to attachment, the former denoting an alienation of the mind from an object; the latter a knitting or binding of the mind to objects: it has, however, more commonly a partial acceptation, in which it is justly comparable with the-above words. The first four are used indifferently for persons and things, the last for things. Aversion and antipathy seem to be less dependent on the will, and to have their origin in the temperament or natural taste, particularly the latter, which springs from causes that are not always visible; it lies in the physical organization. Antipathy is, in fact, a natural aversion opposed to sympathy: dislike and hatred are, on the contrary, voluntary, and seem to have their root in the angry passions of the heart; the former is less deep-rooted than the latter, and is commonly awakened by slighter causes: repugnance is not an habitual and lasting sentiment, like the rest; it is a transitory but strong dislike to anything. People of a quiet temper have an aversion to disputing or argumentation; those of a gloomy temper have an aversion to society; antipathies mostly discover themselves in early life, and as soon as the object comes within the view of the person affected: men of different sentiments in religion or politics, if not of amiable tempers, are apt to contract dislikes to each other by frequent irritation in discourse: when men of malignant tempers come in collision, nothing but a deadly hatred can ensue from their repeated and complicated aggressions 
toward each other; any one who is under the influence of a misplaced pride is apt to feel a repugnance to acknowledge himself in error.

aviation. See Aeronadtics.

AVIATOR. See AEronaUt.

AVIDITY. GREediness, EagerNESS are terms expressive of a strong desire. Avidity, in Latin aviditas, from avere, to desire, expresses very strong desire. Greediness comes from AngloSaxon gradig, greedy. Eagerness, through French from the Latin acer, sharp, signifies acuteness of feeling.

Avidity is in mental desires what greediness is in animal appetites: eagerness is not so vehement, but more impatient than avidity or greediness. Avidity and greediness respect simply the desire of possessing; eagerness the general desire of attaining an object. An opportunity is seized with avidity; the miser grasps at money with greediness, or the glutton devours with greediness; a person runs with eagerness in order to get to the place of destination: a soldier fights with eagerness in order to conquer; a lover looks with eager impatience for a letter from the object of his affection. Avidity is employed in the adverbial form to qualify an action: we seize with avidity; greediness marks the abstract quality or habit of the mind; greediness is the characteristic of low and brutal minds: eagerness denotes the transitory state of feeling; a person discovers his eagerness in his looks.

AVOCATION. See Business.

AVOId, Eschew, Shun, Elude. Avoid comes from Old French esvuidier, to empty out, from French $e s$, Latin $e x$, and vuide, voide, empty, a word of unknown origin. Eschew comes through French from Old High German sciuhan to frighten. Shun comes from Anglo-Saxon scunian, to shun or avoid, whence schooner is derived. Elude, in French éluder, Latin eludo, compounded of $e$, out, and ludere, to play, to trick, signifies to get one's self out of a thing by a trick.

Avoid is both generic and specific; we avoid in eschewing or shunning, or we avoid without eschewing or shunning. Various contrivances are requisite for avoiding; eschewing and shunning consist only of going out of the way, of not coming in contact; eluding, as its derivation denotes, has more of artifice in it than any of the former. We avoid a troublesome visitor under real or feigned pretences of ill-health, prior engagement, and the like; we eschew evil company by not going into any but what we know to be good; we shun the sight of an offensive object by turning into another road; we elude a punishment by getting out of the way of those who have the power of inflicting it. Prudence enables us to avoid many of the evils to which we are daily exposed: nothing but a fixed principle of religion can enable a man to eschew the temptations to evil which lie in his path: fear will lead us to shun a madman whom it is not in our power to bind: a want of all principle leads a man to elude his creditors whom he wishes to defraud. We speak of avoiding a danger and shunning a danger; but to avoid it is in general not to fall into it; to shun it is with care to keep out of the way of it.

AVOW. See ACKNOWLEDGe; Swear. AWAIT. See WaIT.

AWAKeN, Excite, Provoke, ROUSE, STIR UP. To awaken is to make awake or alive. Excite, in Latin excito, compounded of the intensive syllable $e x$, and citare, to arouse, means to arouse very much. Provoke (see AgGravate). To rouse is to cause to rise. Stir comes from Anglo-Saxon styrian, to move, which may be allied to storm. To excite and provoke convey the idea of producing something: rouse and stir up that of only calling into action that which previously exists; to awaken is used in either sense. To awaken is a gentler action than to excite, and this is gentler than to provoke. We awaken by a simple effort; we excite by repeated efforts or forcible means; we provoke by words, looks, or actions. The tender feelings are awakened; affections, or the passions in general, are excited; the angry passions are commonly provoked. $\mathrm{Ob}$ jects of distress awaken a sentiment of pity; competition among scholars $e x-$ cites a spirit of emulation; taunting words provoke anger. Awaken is applied only to the individual and what passes within him; excite is applicable to the outward circumstances of one 
or many; provoke is applicable to the conduct or temper of one or many. The attention is awakened by interesting sounds that strike upon the ear; the conscience is awakened by the voice of the preacher, or by passing events: a commotion, a tumult, or a rebellion is excited among the people by the active efforts of individuals; laughter or contempt is provoked by preposterous conduct.

To awaken is in the moral, as in the physical sense, to call into consciousness from a state of unconsciousness; to rouse is forcibly to bring into action that which is in a state of inaction; and stir $u p$ is to bring into a state of agitation or commotion. We are awakened from an ordinary state by ordinary means; we are roused from an extraordinary state by extraordinary means; we are stirred up from an ordinary to an extraordinary state. The mind of a child is awakened by the action on its senses as soon as it is born; there are some persons who are not roused from their stupor by anything but the most awful events; and there are others whose passions, particularly of anger, are stirred $u p$ by trifling circumstances. The conscience is sometimes awakened for a time, but the sinner is not roused to a sense of his danger, or to any exertions for his own safety, until an intemperate zeal is stirred $u p$ in him by means of enthusiastic preaching, in which case the vulgar proverb is verified, that the remedy is as bad as the disease. Death is a scene calculated to awaken some feeling in the most obdurate breast: the tears and sighs of the afflicted excite a sentiment of commiseration; the most equitable administration of justice may excite murmurs among the discontented; a harsh and unreasonable reproof will provoke a reply: oppression and tyranny mostly rouse the sufferers to a sense of their injuries; nothing is so calculated to stir up the rebellious spirits of men as the harangues of political demagogues.

AWARE, ON ONe's GUARd, ApPRISED, Conscious. Aware is a corruption of Anglo-Saxon gewar, from Anglo-Saxon ge, a common prefix, and wor, cautious, modern English wary. Guard comes through Old French from a Teutonic word cognate with English ward, and meant to watch, hence guard. Apprise is derived through French appris, the past participle of apprendre, from Latin ad, to, and prehendere, to take. Conscious, in Latin conscius, compounded of con and scire, to know, signifies knowing within one's self.

The idea of having the expectation or knowledge of a thing is common to all these terms. We are aware of a thing when we calculate upon it; we are on our guard against it when we are prepared for it; we are apprised of that of which we have had an intimation, and are conscious of that in which we have ourselves been concerned. To be aware, and on one's guard, respect the future; to be apprised, either the past or present; to be conscious, only the past. Experience enables a man to be aware of consequences; prudence and caution dictate to him the necessity of being on his guard against evils. Whoever is fully aware of the precarious tenure by which he holds all his goods in this world will be on his guard to prevent any calamities, as far as depends upon the use of means in his control. We are apprised. of events, or what passes outwardly, through the medium of external circumstances; we are conscious only through the medium of ourselves, or what passes within.

aWe, Reverence, Dread. Awe is a Scandinavian word allied to Gothic agis, fear, anguish. Reverence comes from Latin $r e$, intensive, and vereri, to fear, allied to English wary. Dread comes from drædan, in Anglo-Saxon ondrcedan, to fear.

Awe and reverence both denote a strong sentiment of respect, mingled with some emotions of fear; but the former marks the much stronger sentiment of the two: dread is an unmingled sentiment of fear for one's personal security. Awe may be awakened by the help of the senses and understanding; reverence by that of the understanding only; and dread principally by that of the imagination. Sublime, sacred, and solemn objects awaken awe; they cause the beholder to stop and consider whether he is worthy to approach them any nearer; they rivet his mind and body to a spot, and make him cautious 
lest by his presence he should contaminate that which is hallowed: exalted and noble objects produce reverence; they lead to every outward mark of obeisance and humiliation which it is possible for him to express; terrific objects excite dread; they cause a shuddering of the animal frame, and a revulsion of the mind which is attended with nothing but pain. When the creature places himself in the presence of the Creator-when he contemplates the immeasurable distance which separates himself, a frail and finite mortal, from his infinitely perfect Maker-he approaches with awe; even the sanctuary where he is accustomed thus to bow before the Almighty acquires the power of awakening the same emotions in his mind. Age, wisdom, and virtue, when combined in one person, are never approached without reverence; the possessor has a dignity in himself that checks the haughtiness of the arrogant, that silences the petulance of pride and self-conceit, that stills the noise and giddy mirth of the young, and communicates to all around a sobriety of mien and aspect. A grievous offender is seldom without dread; his guilty conscience pictures everything as the instrument of vengeance, and every person as pronouncing his merited sentence. The solemn stiliness of the tomb will inspire awe, even in the breast of him who has no dread of death. Children should be early taught to have a certain degree of reverence for the Bible as a book, in distinction from all other books.

AWKWARD, ClumsY. Awkward is composed of an English suffix ward, added to a Scandinavian word, and originally signified transversely or " in a backhanded manner." Clumsy comes through Middle English clumsed, benumbed, from the Scandinavianclumsy being therefore the manner or action characteristic of benumbed hands.

These epithets denote what is contrary to rule and order, in form or manner. Awkward respects outward deportment; clumsy the shape and make of the object: a person has an awkward gait, is clumsy in his whole person. A wkwardness is the consequence of bad education; clumsiness is mostly a natu- ral defect. Young recruits are awkward in marching and clumsy in their manual exercise.

They may be both employed figuratively in the same sense, and sometimes in relation to the same objects: when speaking of awkward contrivances, or clumsy contrivances, the latter expresses the idea more strongly than the former.

Awkward, Cross, Untowoard, Crooked, Froward, Perverse.-Awkward (see above). Cross, from the noun cross, implies the quality of being transverse, hence contrary, like the arms of a cross. Untoward signifies the reverse of toward. Crooked signifies the quality of resembling a crook, a Scandinavian word meaning hook, angle, etc. Froward is composed of an English suffix added to a Scandinavian wordfro for English from - and means in the contrary direction. Perverse, Latin perversus, participle of perverto, compounded of per and verto, signifies turned aside.

Awkward, cross, untoward, and crooked are used as epithets in relation to the events of life or the disposition of the mind; froward and perverse respect only the disposition of the mind. Awkward circumstances are apt to embarrass; cross circumstances to pain; crooked and untoward circumstances to defeat. What is crooked springs from a perverted judgment; what is untoward is independent of human control. In our intercourse with the world there are always little awkward incidents arising which a person's good sense and good nature will enable him to pass over without disturbing the harmony of society. It is the lot of every one in his passage through life to meet with cross accidents that are calculated to ruffle the temper, but he proves himself to be the wisest whose serenity is not so easily disturbed. A crooked policy obstructs the prosperity of individuals, as well as of states. Many men are destined to meet with severe trials in the frustration of their dearest hopes, by numberless untoward events which call forth the exercise of patience; in this case the Christian can prove to himself and others the infinite value of his faith and doctrine. 
When used with regard to the disposition of the mind, awkward expresses less than froward, and froward less than perverse. Awkwardness is an habitual frailty of temper; it includes certain weaknesses and particularities, pertinaciously adhered to: crossness is a partial irritation resulting from the state of the humors, physical and mental. Frowardness and perversity lie in the will: a froward temper is capricious; it wills or wills not to please itself without regard to others. Perversity lies deeper; taking root in the heart, it assumes the shape of malignity; a perverse temper is really wicked; it likes or dislikes by the rule of contradiction to another's will. Untowardness lies in the principles; it runs counter to the wishes and counsels of another. An awkward temper is connected with selfsufficiency; it shelters itself under the sanction of what is apparently reasonable; it requires management and indulgence in dealing with it. Crossness and frowardness are peculiar to children; indiscriminate indulgence of the rising will engenders those diseases of the mind which, if fostered too long in the breast, become incorrigible by anything but a powerful sense of religion. Perversity is, however, but too commonly the result of a vicious habit, which embitters the happiness of all who have the misfortune of coming in collision with it. Untowardness is also another fruit of these evil tempers. A froward child becomes an untoward youth, who turns a deaf ear to all the admonitions of an afflicted parent.

AWRY. See Bent.

AXIOM, MAXIM, APHORISM, APOPHTHEGM (old form; modern APOTHEGM), Saying, Adage, Proverb, Byword, SAw. Axiom, in French axiome, Latin axioma, comes from the Greek $\dot{\alpha} \xi i \omega \pi a$, worth, signifying the thing valued. Maxim, in French maxime, in Latin maxima for maxima sentiarum, the most important opinion. Aphorism,

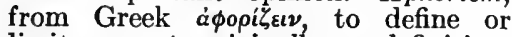
limit, meant originally a definition. Apothegm, in Greek ámó $\phi \varepsilon \gamma \mu \alpha$, from $\dot{a} \pi \dot{o}$, from, and $\phi \theta^{\prime} \gamma \gamma \varepsilon \sigma \theta \alpha a_{h}$ to utter, to speak pointedly, signifies a pointed saying. Saying signifies literally what is szid-that is, said habitually. Adage, in Latin adagium, comes from Latin ad, to, to the point, and a stem signifying to say. Proverb, in French proverbe, Latin proverbium, compounded of pro, publicly, and verbum, a saying, signifies a common saying. Byword signifies a word by-the-by, or by-the-way, in the course of conversation. Saw comes from Anglo-Saxon sagu, a saying, from the verb to say in its older form.

A given sentiment conveyed in a specific sentence, or form of expression, is the common idea included in the signifcation of these terms. The axiom is a truth of the first value; a self-evident proposition which is the basis of other truths. A maxim is a truth of the first moral importance for all practical purposes. An aphorism is a truth set apart for its pointedness and excellence. Apothegm is, in respect to the ancients, what saying is in regard to the moderns; it is a pointed sentiment pronounced by an individual and adopted by others. Adage and proverb are vulgar sayings, the former among the ancients, the latter among the moderns. The byword is a casual saying originating in some local circumstance. The saw, which is a barbarous corruption of saying, is the saying formerly current among the ignorant.

Axioms are in science what maxims are in morals; self-evidence is an essential characteristic in both; the axiom presents itself in so simple and undeniable a form to the understanding as to exclude doubt and the necessity for reasoning. The maxim, though not so definite in its expression as the axiom, is at the same time equally parallel to the mind of man, and of such general application that it is acknowledged by all moral agents who are susceptible of moral truth; it comes home to the common sense of all mankind. "Things that are equal to one and the same thing are equal to each other"- "Two bodies cannot occupy the same space at the same time," are axioms in mathematics and metaphysics. "Virtue is the true source of happiness"-"The happiness of man is the end of civil government," are axioms in ethics and politics. "To err is human, to forgive divine" - "When our vices leave us, we flatter ourselves that we leave them," are among the number of maxims. Be- 
tween axioms and maxims there is this obvious difference to be observed: that the former are unchangeable both in matter and manner and admit of little or no increase in number; but the latter may vary with the circumstances of human life, and admit of considerable extension.

An aphorism is a speculative principle either in science or morals, which is presented in a few words to the understanding; it is the substance of a doctrine, and many aphorisms may contain the abstract of a science. Of this description are the aphorisms of Hippocrates, and those of Lavater in physiognomy.

Sayings and apothegms differ from the preceding, inasmuch as they always carry the mind back to the person speaking; there is always one who says when there is a saying or an apothegm, and both acquire a value as much from the person who utters them as from the thing that is uttered: when Leonidas was asked why brave men prefer honor to life, his answer became an apothegm; namely, that " they hold life by fortune, and honor by virtue": of this description are the apothegms comprised by Plutarch, the sayings of Franklin's Poor Richard, or those of Dr. Johnson: they are happy effusions of the mind which men are fond of treasuring.

The adage and proverb are habitual as well as general sayings, not repeated as the sayings of one, but of all; not adopted for the sake of the person, but for the sake of the thing; and they have been used in all ages for the purpose of conveying the sense of mankind on ordinary subjects. The adage of former times is the proverb of the present time: if there be any difference between them, it lies in this, that the former are the fruit of knowledge and long experience, the latter of vulgar observations; the adage is therefore more refined than the proverb. Adversity is our best teacher, according to the Greek adage, "What hurts us instructs us." "Old birds are not to be caught with chaff" is a vulgar proverb.

Bywords rarely contain any important sentiment; they mostly consist of familiar similes, nicknames, and the like, as the Cambridge, byword of "Hobson's choice," signifying that or none: the name of Nazarene was a byword among the Jews for a Christian. A saw is vulgar in form and vulgar in matter: it is the partial saying of particular neighborhoods, originating in ignorance and superstition: of this description are the sayings which attribute particular properties to animals or to plants, termed old women's sayings.

AYE, AY. Aye and $a y$ are words frequently confused - so of ten confused, indeed, that the distinction between them is not clearly maintained even in good writing; but the distinction exists. Aye, pronounced like $I$, seems to have been originally a different form from ay; it means yes, and is still used in poetry and in old-fashioned and humble colloquial speech, for yesas well as in the parliamentary procedure of voting. $A y$, which rhymes with day, gay, etc., from a Teutonic root meaning age, eternity, means ever, always, and continually. It should not be spelled or pronounced like aye. 


\section{B}

BabBle, Chatter, Chat, Prattle, Prate. Babble is allied to German bappeln, Dutch babbelen, French babiller, etc. The suffix le is frequentative, and the verb means to keep on saying $b a$, $b a$, syllables imitative of a child trying to talk. Chatter and chat are imitative words. Prate, allied to Dutch prat, talk, Low German praten, etc., is possibly an imitative word. Prattle is the frequentative of prate and means to keep on prating.

All these terms mark a superfluous or improper use of speech: babble and chatter are onomatopceias drawn from the noise or action of speaking; babbling denotes rapidity of speech, which renders it unintelligible; hence the term is applied to all who make use of many words to no purpose: chatter is an imitation of the noise of speech properly applied to magpies or parrots, and figuratively to a corresponding vicious mode of speech in human beings. The vice of babbling is most commonly attached to men, that of chattering to women: the babbler talks much to impress others with his selfimportance; the chatterer is actuated by self-conceit and a desire to display her volubility: the former cares not whether he is understood; the latter cares not if she be but heard. Chatting is both harmless and respectable; the winter's fireside invites neighbors to assemble and chat away many an hour which might otherwise hang heavy on hand, or be spent less inoffensively; chatting is the practice of adults; prattling and prating that of children, the one innocently, the other impertinently; the prattling of babes has an interest for every feeling mind, but for parents it is one of their highest enjoyments; prating, on the contrary, is the consequence of ignorance and childish assumption: a prattler has all the unaffected gayety of an uncontaminated mind; a prater is forward, obtrusive, and ridiculous.

BACCALAUREATE, BACHELOR. Baccalaureate is a term of uncertain derivation. Baccalaureate and bachelor are derived from the same Latin word, baccalaureus, the one directly, the other through the medium of French. Baccalaureus meant "cowherd," from bacca, cow; thence it became the term applied to any young man. Bachelor in the Middle Ages signified a young knight, one not old enough to display his own banner, and still fighting under the standard of another. In modern times it has been specialized to mean, on the one hand, an unmarried man, on the other, the recipient of the first degree at a university - the degree of Bachelor of Arts. The term baccalaureate has been similarly specialized to refer to the type of academic initiation into mature life that corresponds in modern times to the military initiation of the young bachelor at arms. Baccalaureate refers to the ceremony of receiving the bachelor's degree, and, in America, it refers especially to the farewell sermon preached to students on the Sunday preceding their graduation, which is called the baccalaureate sermon.

BACK, BaCKWARD, BeHIND. Back and backward are used only as adverbs: behind, either as an adverb or a preposition-to go back or backward, to go behind, or behind the wall. Back denotes the situation of being and the direction of going; backward simply the manner of going; a person stands back who does not wish to be in the way; he goes backward when he does not wish to turn his back to an object. Back marks simply the situation of a place, behind the situation of one object with regard to another: a person stands back who stands in the back part of any place; he stands behind who has any one in front of him: the back is opposed to the front, behind to before.

See also Aback; AfT; AVErse.

BACKSLIDER. See RECREANT.

BAD, WICKED, Evil. Bad is formed from Anglo-Saxon boddel, a hermaphrodite, an effeminate man, hence a worthless fellow-thence bad, worthless. Wicked, Anglo-Saxon wikke, evil, is derived from the substantive wikke, 
a witch. Wicked means bewitched, possessed of an evil spirit. Bad respects moral and physical qualities in general; wicked, only moral qualities. Evil, Anglo-Saxon yfel, comes from a widely distributed Germanic root, the ultimate origin of which is unknown. Evil, in its full extent, comprehends both badness and wickedness.

Whatever offends the taste and sentiments of a rational being is bad; food is bad when it disagrees with the constitution; the air is bad which has anything in it disagreeable to the senses or hurtful to the body; books are bad which only inflame the imagination or the passions. Whatever is wicked offends the moral principles of a rational agent: any violation of the law is wicked, as law is the support of human society; an act of injustice or cruelty is wicked, as it opposes the will of God and the feelings of humanity. Evil is either moral or natural, and may be applied to every object that is contrary to good; but the term is employed only for that which is in the highest degree bad or wicked.

When used in relation to persons, both refer to the morals, but bad is more general than wicked; a bad man is one who is generally wanting in the performance of his duty; a wicked man is one who is chargeable with actual violations of the law, human or divine; such a one has an evil mind. A bad character is the consequence of immoral conduct; but no man has the character of being wicked who has not been guilty of some known and flagrant vices: the inclinations of the best are evil at certain times.

BADGE. See MARK.

BADLY, ILL. Badly means in the manner of bad (sce above). IIl is a Scandinavian word, not a contraction of the word which appears in AngloSaxon as $y f e l$, in Modern English as evil.

These terms are both employed to modify the actions or qualities of things, but badly is always annexed to the action, and ill to the quality: as to do anything badly, the thing is badly done, an ill-judged scheme, an ill-contrived measure, an ill-disposed person.

BAFFle, Defeat, Disconcert, Confound. Baffle is a Scotch word of doubtful origin meaning originally to disgrace or vilify. Compare French beffler, and Middle High German beffen, to scold. It may be of imitative origin, like the slang biff, meaning to slap. Defeat, in French défait, participle of défaire, is derived from dis, apart, and facere, to do, and signifies to undo. Disconcert is compounded of the privative dis and concert, signifying to throw out of concert or harmony, to put into disorder. Confound, in French confondre, is compounded of con and fundere, to pour, and signifies to melt or mix together in general disorder.

When applied to the derangement of the mind or rational faculties, baffle and defeat respect the powers of argument; disconcert and confound, the thoughts and feelings: baffle expresses less than defeat; disconcert less than confound; a person is baffled in argument who is for the time discomposed and silenced by the superior address of his opponent; he is defeated in argument if his opponent has altogether the advantage of him in strength of reasoning and justness of sentiment: a person is disconcerted who loses his presence of mind for a moment, or has his feelings any way discomposed; he is confounded when the powers of thought and consciousness become torpid or vanish. A superior command of language or a particular degree of effrontery will frequently enable a person to baffle one who is advocating the cause of truth: ignorance of the subject, or a want of ability, may occasion a man to be defeated by his adversary, even when he is supporting a good cause: assurance is requisite to prevent any one from being disconcerted who is suddenly detected in any disgraceful proceedings: hardened effrontery sometimes keeps the daring villain from being confounded by any events, however awful.

When applied to the derangement of plans, baffle expresses less than defeat, defeat less than confound, and disconcert less than all. Obstinacy, perseverance, skill, or art baffles; superior force defeats; awkward circumstances disconcert; the visitation of God confounds. When wicked men strive to obtain their ends, it is a happy thing if their adversaries have sufficient skill and address to baffle all their arts, and sufficient power to defeat all their projects; but 
sometimes when our best endeavors fail in our own behalf, the devices of men are confounded by the interposition of Heaven. It frequently happens, even in the common transactions of life, that the best schemes are disconcerted by the trivial casualties of wind and weather. The obstinacy of a disorder may baffle the skill of the physician; the imprudence of the patient may defeat the object of his prescriptions; the unexpected arrival of a superior may disconcert the unauthorized plan of those who are subordinate; the miraculous destruction of his army confounded the project of the king of Assyria.

BALANCE. See Counterpoise; PoIse.

BALDERDASH. See Twaddle.

BALL. See Globe.

BALLOON. See Aircraft.

BALLOONIST. See AEronatt.

BAN, Curse, Denounce, Forbid, Pronibit. These terms represent various types and degrees of social and spiritual ostracism. Ban, in Anglo-Saxon bannan, is a Germanic word which has entered most of the Romance languages and appears in the word abandon, derived in English from a French phrase. In ancient German law a ban was a sentence of outlawry pronounced against one who had escaped from justice or refused to submit to trial; the ban of the empire was a penalty imposed on refractory princes and even on cities, in Germany. Ban implies a formal forbidding or prohibiting. To curse, Anglo-Saxon cursian, is to attempt to cut souls off from all sources of spiritual life and health. It is a spiritual ban, as it were, and corresponds in the world of the spirit to the political outlawry suggested by the word ban. Denounce, from Latin de, fully, and nuntiare, to make a formal statement, suggests a public criticism or accusation which might lead to a ban, but which, in itself, does not imply that the person denounced is forbidden to enjoy any of his natural rights or prohibited from doing what he pleases. Forbidden, Anglo-Saxon forbeodan, from for, a privative prefix, and beodan, to bid, means to bid a person not to do some- thing. It does not imply formal and public action, as does the word ban. Prohibit, from Latin prohibere, pro and habere, means to keep another from doing something, and implies an exertion of some force besides the purely verbal one expended in forbidding. It does not imply formal and public action.

band, Compant, Crew, Gang. Crew, is from crue, a shortened form of accrue, a reinforcement, from Old French accroistre, to increase, from Latin accrescere. Gang, from AngloSaxon gangen, to go, signifies a group of individuals who go together.

All these terms denote a small association for a particular object: a band is an association where men are bound together by some strong obligation, whether taken in a good or bad sense, as a band of soldiers, a band of robbers. A company marks an association for convenience, without any particular obligation, as a company of travellers, a company of strolling players. Crew marks an association collected together by some external power, or by coincidence of plan and motive: in the former case it is used for a ship's crew; in the latter and bad sense of the word it is employed for any number of evil-minded persons met together from different quarters and cooperating for some bad purpose. Gang is used in a bad sense for an association of thieves, murderers, and depredators in general; or in a technical sense for those who work together.

See also Chain.

BANe, Pest, Ruin. Bane is derived from Anglo-Saxon bana, a murderer, from a root found in Icelandic bani, death, Gothic banja, a wound, Greek фóvos, murder, etc. Pest, from Latin pestis, originally meant a deadly disease. Ruin, Latin ruina, is derived from ruere, to fall down. Milton uses ruin with special reference to its etymology to mean something rushing down, falling headlong.

These terms borrow their figurative signification from three of the greatest evils in the world: namely, poison, plague, and destruction. Bane is said of things only; pest of persons only: whatever produces a deadly corruption is the bane; whoever is as obnoxious as 
the plague is a pest; luxury is the bane of civil society; gaming is the bane of all youth; sycophants are the pests of society. Ruin comprehends more than either bane or pest, these latter being comparatively partial mischiefs, but ruin extends to every part of that which it affects.

BANISH, ExILE, Expel. Banish, in French bannair, German bannen, signifies to put out of a community by a ban or civil interdict, which was formerly either ecclesiastical or civil. Exile, in French exiler, from the Latin exilium, hanishment, and exul, an exile, compounded of extra and solum, the soil, signifies to put away from one's native soil or country. Expel, in Latin expello, compounded of $e x$ and pellere, to drive, signifies to drive out.

The idea of exclusion, or of a coercive removal from a place, is common to these terms: banishment includes the removal from any place, or the prohibition of access to any place, where one has been or whither one is in the habit of going; exile signifies the removal from one's home; to exile, therefore, is to banish, but to banish is not always to exile; the Tarquins were banished from Rome never to return; Coriolanus was exiled, or driven from his home. Banishment follows from a decree of justice; exile either by the necessity of circumstances or an order of authority: banishment is a disgraceful punishment inflicted by tribunals upon delinquents; exile is a disgrace incurred without dishonor: exile removes us from our country; banishment drives us from it ignominiously: it was the custom in Russia to banish offenders to Siberia; Ovid was exiled by an order of Augustus. Banishment is an action, a compulsory exercise of power over another, which must be submitted to; exile is a state into which we may go voluntarily; many Romans chose to go into exile rather than await the judgment of the people, by whom they might have bcen banished. Banishment and expulsion both mark a disgraceful and coercive exclusion, but banishment is authoritative; it is a public act of government: expulsion is simply coercive; it is the act of a private individual or a small community. Banishment always supposes a removal to a distant spot, to another land; expulsion never reaches beyond a particular house or society: expulsion from the university, or any public school, is the necessary consequence of discovering a refractory temper or a propensity to insubordination.

Banishment and expulsion are likewise used in a figurative sense, although exile is not: in this sense, banishment marks a distant and entire removal; expulsion a violent removal: we banish that which it is not prudent to retain; we expel that which is noxious. Hopes are banished from the mind when every prospect of success has disappeared; fears are banished when they are altogether groundless; envy, hatred, and every evil passion should be expelled from the mind as disturbers of its peace: harmony and good-humor are best promoted by banishing from conversation all subjects of difference in religion and politics; good morals require that every unseemly word should be expelled.

See also Proscribe.

BANKRUPTCY. See InsolveNCY. BANQUET. See FEAST.

BANTER. See DERIDE.

BAR. See TribuNal.

BARBAROUS. See CrUEl.

BARE, NAKED, UNCOVERED. Bare and naked are both Anglo-Saxon words -the one being in Anglo-Saxon bar, the other nacod. For the derivation of uncover see Cover.

Bare marks the condition of being without a particular covering; naked that of being without any covering; bare is therefore often substituted for naked, to a certain degree: we speak of bareheaded, barefoot, to expose the bare arm; but a figure is naked, or the body is naked.

When applied to other objects, bare conveys the idea of a particular want; naked of a general want: as the bare ground, bare walls, a bare house, where the idca of want in a certain particular is strongly conveyed; but naked walls, naked fields, a naked appearance, denote the absence of covering that is usual or general: bare in this sense is frequently followed by the object that is wanted; naked is mostly employed as an adjunct: a tree is bare of lcaves: this constitutes it a naked tree.

They preserve the same analogy in their figurative application: a bare 
sufficiency is that which scarcely suffices; the naked truth is that which has nothing about it to intercept the view of it from the mind.

Naked and uncovered bear a strong resemblance to each other; to be naked is, in fact, to have the body uncovered, but many things are uncovered which are not naked; nothing is said to be naked but what in the nature of things, or according to the usages of men, ought to be covered; everything is uncovered from which the covering is removed. According to our natural sentiments of decency or our acquired sentiments of propriety, we expect to see the naked body covered with clothing: the naked tree covered with leaves; the naked walls covered with paper or paint; and the naked country covered with verdure or habitations: on the other hand, plants are left uncovered to receive the benefit of the sun or rain; furniture or articles of use or necessity are left uncovered to suit the convenience of the user; or a person may be uncovered, in the sense of bareheaded, on certain occasions; so in the moral application, what is naked is without the ordinary or necessary appendage; what is uncovered is simply without any covering.

Bare, Scanty, Destitute-Bare (see above). Scanty is derived from scant, a Scandinavian word, from a root found in Icelandic skamt, short, brief, and in the somewhat colloquial verb scamp, in the phrase "to scamp work," etc. Destitute, in Latin destitutus, participle of destituo, compounded of de, privative, and statuo, appoint or provide for, signifies unprovided for or wanting.

All these terms denote the absence or privation of some necessary. Bare and scanty have a relative sense: bare respects what serves for ourselves; scanty that which is provided by others. A subsistence is bare; a supply is scanty. An imprudent person will estimate as a bare competence what would supply an economist with superfluities. A hungry person will consider as a scanty allowance what would more than suffice for a moderate eater.

Bare is said of those things which belong to our corporeal sustenance; destitute is said generally of what- ever one wants. A person is bare of clothes or money; he is destitute of friends, of resources, or of comforts. Bare, Mere.-Bare (see above). Mere is derived from Latin merus, pure, unmixed, used especially of wine.

Bare is used in a positive sense; mere, negatively. The bare recital of some events brings tears. The mere circumstances of receiving favors ought not to bind any person to the opinions of another. The bare idea of being in the company of a murderer is apt to awaken horror in the mind. The mere attendance at a place of worship is the smallest part of a Christian's duty.

BAREFACED. See Glaring.'

BARGaIN. See AgreEMent; BuY. BARTER. See Change; EXCHANGE.

BASE, Vile, Mean. For the origin of base see ABAsE. Vile is derived from Latin vilis, of small price, cheap, worthless. Mean, Anglo-Saxon mene, usually found in gemone, German gemein, instead of in its simple form, signifies common; hence low, ordinary, of little value, etc.

Base is a stronger term than vile, and vile than mean. Base marks a high degree of moral turpitude: vile and mean denote in different degrees the want of all that can be valued or esteemed. What is base excites our abhorrence, what is vile provokes disgust, what is mean awakens contempt. Base is opposed to magnanimous, vile to noble, mean to generous. Ingratitude is base; it does violence to the best affections of our nature: flattery is vile; it violates truth in the grossest manner for the lowest purposes of gain: compliances are mean which are derogatory to the rank, dignity, or responsibility of the individual. The more elevated a person's rank, the greater is his baseness who abuses his influence to the injury of those who repose confidence in him. The lower the rank of the individual and the more atrocious his conduct, the viler is his character. The more respectable the station of the person and the more extended his wealth, the greater is his meanness when he descends to practices fitted only for his inferiors. The schoolmaster of Falerii was guilty of the basest treachery in surrendering his helpless 
charge to the enemy: the Roman general, therefore, with true nobleness of mind, treated him as a vile malefactor. Sycophants are in the habit of practising every mean artifice to obtain favor.

BASHFUL. See Modest.

BASIS. See Foundation.

BATTLE, Combat, Engagement, Action. Battle, in French bataille, comes from the Latin batuere, to beat, signifying a beating. Combat signifies literally a battle, one with the other, from con, with, and batuere. Engagement signified binding with a pledge, fighting under a pledge to defend some one or some cause, from French en and gage, a pledge - a word of Teutonic origin. Action signifies the state of acting and being acted upon by the way of fighting.

Battle is a general term; combat, engagement, and action are particular terms, having a modified signification. Battle, as an act of fighting, may be applied to what takes place either between bodies or individuals, as the battles between the Carthaginians and the Romans, or between Cæsar and Pompey; combal applies only to what takes place between individuals, as the combat between the Horatii and the Curiatii. Battle is taken for that which is premeditated and prepared, as battles between armies always are; combats are frequently accidental, if not unexpected, as the combats of Hercules or the combat between Menelaus and Paris.

Battle and combat are taken for the act of fighting generally; engagement and action are seldom used in any other acceptation. Battle in this case is taken without any qualification of time, circumstances, or manner, as armed for battle, wager of battle, and the like; combat refers to the act of individuals fighting with one another: to challenge to single combat; the combat was obstinate and bloody: engagement and action, which are properly abstract and general terms to denote engaging and acting, but here limited to the act of fighting, have always a reference to something actually passing or described as passing, and are therefore confined to descriptions, as in describing what passes during the engagement or action, or the number of engagements or actions, in which an individual is present or takes a part. It is reported of the German women that whenever their husbands went to battle they used to go into the thickest of the combat to carry them provisions or dress their wounds; and that sometimes they would take part in the engagement.

BE, Exist, Subsist. $B e$, with its inflections, is to be traced through the Northern languages to an original Aryan root signifying to live, to exist. Exist, in French exister, Latin existo, compounded of $e$ or $e x$ and sisto, signifies to "stand out" against the fortunes of life, hence simply to live, to keep on living. From this derivation of the latter verb arises the distinction in the use of the two words. The former is applicable either to the accidents of things or to the substances of things themselves; the latter only to substances or things that stand or exist of themselves. We say of qualities, of forms, of actions, of arrangement, of movement, and of every different relation, whether real, ideal, or qualificative, that they are; we say of matter, of spirit, of body, and of all substances, that they exist. Man is man, and will be man under all circumstances and changes of life: he exists under every known climate and variety of heat or cold in the atmosphere.

Being and existence as nouns have this further distinction, that the former is employed not only to designate the abstract action of being, but is metaphorically employed for the sensible object that is; the latter is confined altogether to the abstract sense. Hence we speak of human beings; beings animate or inanimate; the Supreme Being: but of the existence of a God; existence of innumerable worlds; the existence of evil.

Being may in some cases be indifferently employed for existence, particularly in the grave style: when speaking of animate objects, as the being of a God; our frail being; and when qualified in a compound form is preferable, as our well-being.

Subsist is properly a species of $e x$ isting; from the Latin prepositive sub, 
signifying for a time, it denotes temporary or partial existence. Everything exists by the creative and preservative power of the Almighty; that which subsists depends for its existence upon the chances and changes of life. To exist, therefore, designates simply the event of being or existing; to subsist conveys the accessory ideas of the mode and duration of existing. Man exists while the vital or spiritual part of him remains; he subsists by what he obtains to support life. Friendships exist in the world, notwithstanding the prevalence of selfishness; but they cannot subsist for any length of time between individuals in whom this base temper prevails.

Be, Become, Grow.-Be (see above). Become signifies to come to be-that is, to be in course of time. Grow comes from Anglo-Saxon growan, to produce green shoots, and is allied to green.

$\mathrm{Be}$ is positive; become is relative: a person $i s$ what he $i s$ without regard to what he was; he becomes that which he was not before. We judge of a man by what he $i s$, but we cannot judge of him as to what he will become; this year he is immoral and irreligious, but by the force of reflection on himself he may become the contrary in another year. To become includes no idea of the mode or circumstance of its becoming; to grow is to become by a gradual process: a man may become a good man from a vicious one, in consequence of a sudden action on his mind; but he grows in wisdom and virtue by means of an increase in knowledge and experience.

BEAM. See Gleair; Ray.

BEAR, YIELD. Bear, Anglo-Saxon beran, is allied to Latin ferre, Greek $\phi \dot{\varepsilon} \rho \varepsilon \iota v$, to carry, hence to bring forth that which has been carried and nourished within a living organism or a life-giving substance. Yield (see AFFORD).

Bear conveys the idea of creating within itself; yield, that of giving from itself. Animals bear their young, inanimate objects yield their produce. An apple-tree bears apples; the earth yields fruits. Bear marks properly the natural power of bringing forth something of its own kind; yield is said of the result or quantum brought forth: shrubs bear leaves, flowers, or berries, according to their natural properties; flowers yield seeds plentifully or otherwise, as they are favored by circumstances.

Bear, Carry, Convey, Transport.Carry comes immediately from Latin carrus, a four-wheeled vehicle, and hence meant to bear about in a car. Convey is derived from con, with, and via, way, and means to bear with one on the way. Transport, in French transporter, Latin transporto, compounded of trans, over, and portare, to carry, signifies to carry to a distance.

To bear is simply to take the weight of any substance upon one's self, or to have the object about one: to carry is to remove a body from the spot where it was: we always bear in carrying, but we do not always carry when we bear. Both may be applied to things as well as persons: whatever receives the weight of anything bears it; whatever is caused to move with anything carries it. That which cannot be easily borne must be burdensome to carry; in extremely hot weather it is sometimes irksome to bear the weight even of one's clothing: Virgil praises the pious Eneas for having carried his father on his shoulders in order to save him from the sacking of Troy. Weak people or weak things are not fit to bear heavy burdens: lazy people prefer to be carried rather than to carry anything.

To bear is said either of persons or inanimate things; to carry, in its proper application, is said of persons only.

To bear supposes the bearer for the most part to be stationary, but it may be applied to one who is in motion, as the bearer of a letter. In poetry it is mostly used in such connection for carry.

To carry always supposes the carrier to be in motion, and that which is carried may either be about his person or resting on something, as to carry a thing in one's hand, or to carry it in a basket.

Bear and carry preserve this distinction in their figurative or moral application; bear is applied to that which for the most part remains with the person or thing bearing; carry to that which passes by means of the person; thus to bear or carry a name: 
to bear a name is to have it without regard to time or place; to carry a name is to carry it down to posterity. So to bear a burden, to carry weight, authority, conviction, etc.; to bear a stamp, to carry a mark to one's grave.

Convey and transport are species of carrying. Carry in its particular sense is employed either for personal exertions or actions performed by the help of other means; convey and transport are employed for such actions as are performed not by immediate personal intervention or exertion: a porter carries goods on his knot (i. e., shoulderpad); goods are conveyed in a wagon; they are transported in a vessel. Convey expresses simply the mode of removing; transport annexes to this the idea of the place and the distance. Merchants get the goods conveyed into their warehouses which they have had transported from distant countries. Pedestrians take no more with them than what they can conveniently carry; could armies do the same, one of the greatest obstacles to the indulgence of human ambition would be removed; for many an incursion into a peaceful country is defeated for the want of means to convey provisions sufficient for such numbers; and when mountains or deserts are to be traversed, another great difficulty presents itself in the transportation of artillery.

Bear, Suffer, Endure, Support.To bear (see above). Suffer, in Latin suffero, compounded of sub, under, and ferre, to bear, signifies to "bear up under" - an expression frequently heard in English, which, like several others cited in this book, literally translates the Latin word. Endure, from Latin durus, hard, lasting, aignifies to harden one's self under trouble. Support, from sub and portare, to carry, has the same meaning as suffer, as far as its etymology is concerned.

The idea of receiving the weight or pressure of any object is common to these terms, which differ only in the circumstances of the action. To bear is the general term taken in the proper sense without any qualification; the other terms denote different modes of bearing. To bear may be said of that which is not painful, as to bear a burden, in the indifferent sense; so like- wise the term to support, as to support a person who is falling; but for the most part these, as well as the other two terms, are taken in the bad sense. In this case to bear and to suffer are both involuntary acts as far as they relate to evils imposed upon us without our will; but bear is also voluntary, inasmuch as it denotes the manner of receiving the evil, so as to diminish the sense of it; and suffer is purely passive and involuntary. We are born to suffer-hence the necessity for us to learn to bear all the numerous and diversified evils which to us are obnoxious.

To bear is applied either to ordinary or extraordinary evils, and is either a temporary or a permanent act of the resolution; to endure is applied only to great evils requiring strong and lasting resolution: we bear disappointments and crosses; we endure hunger, cold, tortures, and provocations. The first object of education should be to accustom children to bear contradictions and crosses, that they may afterward be enabled to endure every trial.

To bear and endure signify to receive becomingly the weight of what befalls ourselves; to support signifies to bear either our own or another's evils, for we may either support ourselves or be supported by others, but in this former case we bear not so much from the resolution to bear as from the motives which are presented to the mind; a person supports himself in the hour of trial by the condolence of friends, but still more by the power of religion.

The words suffer and endure are said only of persons and personal matters: to bear and support are said also of things; the former in respect to things of any weight, large or small; the latter in respect to things of great weight, as the beams are cut according to the weight they have to bear; a building is supported by pillars.

Sec also Brook; Undergo; WaFt.

BEAST. Sec ANimal.

BEAT, Strike, Hit. Beat is derived from Anglo-Saxon beatan, from a Teutonic root signifying to push. The resemblance to Latin batuere, French battre, is merely accidental. Strike is derived from a Teutonic root meaning to give blows to. Hit is a 
Scandinavian word meaning to light on, to attain to, hence to strike, and is allied to hint. For a similar relation between the idea of lighting upon and striking see the slang expression " $\mathrm{He}$ lit into me."

To beat is to redouble blows; to strike is to give one single blow; but the bare touching in consequence of an effort constitutes hitting. We never beat but with design, nor hit without an aim, but we may strike by accident. Beating was formerly resorted to as almost the only mode of punishment. He who brandishes a stick heedlessly may strike another to his serious injury. Hitting is the object of the marksman.

Beat, Defeat, Overpower, Rout, Overthrow.-Beat is here figuratively employed in the sense of the former section. Defeat, from the French défaire, implies to undo, and overpower to have the power over any one. To rout is derived from rupta, broken, from Latin rumpere, to break, and overthrow, to throw over or upside down.

Beat respects personal contests between individuals or parties; defeat, rout, overpower, and overthrow are employed mostly for contests between numbers. A general is beaten in important engagements; he is defeated and may be routed in partial attacks; he is overpowered by numbers, and overthrown in set engagements. To beat is an indefinite term expressive of no particular degree: the being beaten may be attended with greater or less damage. To be defeated is a specific disadvantage, it is a failure in a particular object of more or less importance. To be overpowered is a positive loss; it is a loss of the power of acting, which may be of longer or shorter duration; to be routed is a temporary disadvantage; a rout alters the route or course of proceeding, but does not disable: to be overthrown is the greatest of all mischiefs, and is applicable only to great armies and great concerns: an overthrow commonly decides a contest. Beat is a term which reflects more or liess dishonor on the general or the army, or on both: defeat is an indifferent term; the best generals may sometimes be defeated by circumstances which are above human control; over- powering is coupled with no particular honor to the winner nor disgrace to the loser; superior power is oftener the result of good fortune than of skill. The bravest and finest troops may be overpowered in cases which exceed human power: a rout is always disgraceful, particularly to the army; it always arises from want of firmness: an overthrow is fatal rather than dishonorable; it excites pity rather than contempt.

BEATIFICATION, CanoNization. These acts emanate from the pontifical authority, by which the Pope declares a person, whose life had been exemplary and accompanied with miracles, as entitled to enjoy eternal happiness after his death, and determines in consequence the sort of worship which should be paid to him. In the act of beatification (beare, to make blessed) the Pope pronounces only as a private person, and uses his own authority only in granting to certain persons, or to a religious order, the privilege of paying a particular worship to a beatified object. In the act of canonization, the Pope speaks as a judge after a judicial examination on the state, and decides the sort of worship which ought to be paid by the whole church.

\section{BEAU. See Gallant.}

BEAUTIFUl, Frne, Handsome, PRETTY. Beautiful, or full of beauty, in French beauté, comes from beau, belle, in Latin bellus, fair. Fine is derived from finitus, the past participle of finire, to finish, and meant finished, polished, finely wrought, hence, on the one hand, delicate, small; on the other hand, impressive, comely, the very opposite of delicate. Handsome originally meant dexterous, handy, and hence well formed, comely, good-looking. Pretty comes from Anglo-Saxon protig, deceitful, tricky, etc.; its ultimate origin and meaning are uncertain. It may have developed its present meaning through the same psychological process that has turned words like cunning, cute, etc., into endearing descriptive epithets.

Of these epithets, which denote what is pleasing to the eye, beautiful conveys the strongest meaning; it marks the possession of that in its fullest extent of which the other terms denote the possession in part only. Fineness, 
handsomeness, and prettiness are to beauty as parts to a whole. When taken in relation to persons, a woman is beautiful who in feature and complexion possesses a grand assemblage of graces; a woman is fine who with a striking figure unites shape and symmetry; a woman is handsome who has good features, and pretty if with symmetry of feature be united delicacy. The beautiful is determined by fixed rules; it admits of no excess or defect; it comprehends regularity, proportion, and a due distribution of color, and every particular which can engage the attention: the fine must be coupled with a certain grandeur of figure; it is incompatible with that which is small; a little woman can never be fine; the handsome is a general assemblage of what is agreeable; it is marked by no particular characteristic but the absence of all deformity: prettiness is always coupled with simplicity; it is incompatible with that which is large; a tall woman. with masculine features cannot be pretty. Beauty is peculiarly a female perfection; in the male sex it is rather a defect; a man can scarcely be beautiful without losing his manly characteristicsboldness and energy of mind, strength and robustness of limb; but though a man may not be beautiful or pretty, he may be fine or handsome.

When said in relation to other objects, beautiful, fine, pretty have a strong analogy. With respect to the objects of nature, the beautiful is displayed in the works of creation, and wherever it appears it is marked by elegance, variety, harmony, proportion, but, above all, that softness which is peculiar to female beauty; the fine, on the contrary, is associated with the grand, and the pretty with the simple: the sky presents either a beautiful aspect or a fine aspect, but not a pretty aspect. A rural scene is beautiful when it unites richness and diversity of natural objects with superior cultivation; it is fine when it presents the bolder and more impressive features of nature, consisting of rocks and mountains; it is pretty when, divested of all that is extraordinary, it presents a smiling view of nature in the gay attire of shrubs, and many-colored flowers, and verdant meadows, and luxuriant fields.

Beautiful, fine, and pretty are applied indifferently to works of nature and art; handsome mostly to those of art only: a becutiful picture, a fine drawing, a pretty cap, and handsome furniture.

In the moral application beautiful sentiments have much in them to interest the affections as well as the understanding; they make a vivid impression: fine sentiments mark an elevated mind and a loftiness of conception; they occupy the understanding and afford scope for reflection; they make a strong impression: pretty ideas are but pleasing associations or combinations that only amuse for the time being, without producing any lasting impression. We may speak of a beautiful poem, although not a beautiful tragedy; but a fine tragedy, and a pretty comedy. Imagery may be beautiful and fine, but seldom pretty.

Handsome conveys the idea not only of that which is agreeable in appearance, but also that which is agreeable to the understanding and the moral feelings from its fitness and propriety; it is therefore applied with this collateral meaning to moral circumstances and actions, as a handsome present, a handsome apology.

BECOME. See $\mathrm{BE}$.

BECOMING, DeCent, SeemLy, Fit, Surtable. Becoming comes from Anglo-Saxon becuman, to arrive, happen; hence to happen to fit. Decent, in French décent, in Latin decens, participle of deccre, to beseem, is allied to decus, an ornament, honor, fame, etc. Seemly is derived from a root which appears in same, similar, etc., and $l y$, meaning like; it means literally "same like," just like, hence suitable, fitting, etc. Fit is a Scandinavian word meaning to knit together, to draw laces together, etc. Suitable, from suit, signifies able to suit; and suit, in French suite, Latin secuta, comes from sequor, to follow, signifying to follow.

What is becoming respects the manner of being in society such as it ought; as to person, time, and place. Decency regarde the manner of displaying one's self so as to be approved and respected. Seemliness is very similar in sense to de- 
cency, but is confined to such things as immediately strike the observer. Fitness and suitableness relate to the disposition, arrangement, and order of either being or doing, according to persons, things, or circumstances. The becoming consists of an exterior that is pleasing to the view: decency involves moral propriety; it is regulated by the fixed rules of good-breeding: seemliness is decency in the minor morals or in one's behavior; fitness is regulated by local circumstances, and suitableness by the established customs and usages of society. The dress of a woman is becoming that renders her person more agreeable to the eye; it is decent if it in no wise offends modesty; it is unseemly if it in any wise violates propriety; it is fit if it be what the occasion requires; it is suitable if it be according to the rank and character of the wearer. What is becoming varies for every individual; the age, the complexion, the stature, and the habits of the person must be consulted in order to obtain th? appearance which is becoming; what becomes a young female, or one of fair complexion, may not become one who is further advanced in life, or who has dark features: decency and seemliness are one and the same for all; all civilized nations have drawn the exact line between the decent and the indecent, although fashion or false principles may sometimes draw persons aside from this line: fitness varies with the seasons, or the circumstances of persons; what is fit for the winter is unfit for the summer, or what is fit for dry weather is unfit for wet; what is fit for town is not fit for the country; what is fit for a healthy person is not fit for one that is infirm: suitableness accommodates itself to the external circumstances and conditions of persons; the house, the furniture, the equipage of a prince must be suitable to his rank; the retinue of an ambassador must be suitable to the character which he has to maintain, and to the wealth, dignity, and importance of the nation whose monarch he represents. Gravity becomes a judge or a clergyman at all times: an unassuming tone is becoming in a child when he addresses his superiors. Decency requires a more than ordinary gravity when we are in the house of mourning or prayer; it is indecent for a child, on the commission of a fault, to affect a careless unconcern in the presence of those whom he has offended. Seemliness is an essential part of good manners; to be loud or disputative in company is unseemly. There is a fitness or unfiness in persons for one another's society: education fits a person for the society of the noble, the wealthy, the polite, and the learned. There is a suitableness in people's tempers for one another; such a suitability is particularly requisite for those who are destined to live together: selfish people, with opposite tastes and habits, can never be suitable companions.

Becoming, Comely, Graceful. - Becoming (see preceding). Comely, or come like, signifies coming or appearing as one would have it. Graceful signifies full of grace.

These epithets are employed to mark in general what is agreeable to the eye. Becoming denotes less than comely, and this less than graceful; nothing can be comely or graceful which is unbecoming; although many things are becoming which are neither comely nor graceful. Becoming respects the decorations of the person and the exterior deportment; comely respects natural embellishments; graceful, natural or artificial accomplishments: manner is becoming; figure is comely; air, figure, or attitude is graceful.

Becoming is a relative term depending on the circumstances and condition of the person: what is unbecoming in one case may not be so in another, and what is becoming in one person may not be so in another: what is graceful is so absolutely and at all times, although it may not be seen and acknowledged without the aid of cultivation.

BEDEW. See SPRINKLE.

BEG, Desire. $\quad B e g$ (see Ask). Desire, Latin desidero, is probably allied to sidus, sideris, star, which also appears in consider. To desire, from de, from, and sidus, star, may mean to be turned away from the light of the stars.

To beg marks the wish; to desire, the will and determination. Beg is the act of an inferior, or one in a subordinate condition; desire is the act of a su- 
perior: we beg a thing as a favor; we desire it as a right: children beg their parents to grant them an indulgence; parents desire their children to attend to their business.

Beg, Beseech, Solicit, Entreat, Supplicate, Implure, Crave.-Beg (see above). Beseech, compounded of be and seken, seek, is an intensive verb, signifying to seek strongly. Solicit, in French soliciter, Latin solicito, is probably compounded of sollus and citus, aroused, signifying to rouse altogether. Entreat, compounded of en or in and treat, in French traiter, Latin tracto, to manage, signifies to act upon. Supplicate, in Latin supplicatus, participle of supplico, compounded of $s u b$ and plicare, to fold, signifies to bend the body down; in token of submission or distress, in order to awaken notice. Implore, in French implorer, Latin imploro, compounded of in and plorare, to weep or lament, signifies to act upon by weeping. Crave, from Anglo-Saxon crafian, to demand, means to long for earnestly.

All these terms denote a species of asking varied as to the person, the object, and the manner; the first four do not mark such a state of dependence in the agent as the last three: to beg denotes a state of want; to beseech, entreat, and solicit, a state of urgent necessity; supplicate and implore, a state of abject distress; crave, the lowest state of physical want: one begs with importunity; beseeches with earnestness; entreats by the force of reasoning and strong representation: one solicits by virtue of one's interests, supplicates by a humble address; implores by every mark of dejection and humiliation. Begging is the act of the poor when they need assistance: beseeching and entreating are resorted to by friends and equals when they want to influence or persuade, but beseeching is more urgent, entreating morc argumentative: solicitations are employed to obtain favors, which have more respect to the circumstances than the rank of the solicitor: supplicating and imploring are resorted to by sufferers for the relief of their misery, and are addressed to those who have the power of averting or increasing the calamity: craving is the consequence of longing; it marks an earnestness of supplication, an abject state of suffering dependence. Those who are too idle to work commonly have recourse to begging; a kind parent will sometimes rather beseech an undutiful child to lay aside his wicked courses than plunge him deeper into guilt by an ill-timed exercise of authority; when we are entreated to do an act of civility, it is a mark of unkindness to be heedless to the wishes of our friends; gentlemen in office are perpetually exposed to the solicitations of their friends, to procure for themselves, or their connections, places of trust and emolument; a slave supplicates his master for pardon when he has offended, and implores his mercy to mitigate, if not to remit, the punishment; a poor wretch, suffering with hunger, craves a morsel of bread.

BEGIN, Commence, ENTER Upon. Begin, in German beginnen, is compounded of be and ginnen, signifying to do a thing first. Commence is derived through French from Low Latin cominitiare, from con, and in, into, and ire, to go, meaning to initiate, to enter upon something. Enter, in Latin intro, within, signifies, with the proposition upon, to go into a thing.

Begin and commence are so strictly allied in signification that it is not easy to discover the difference in their application, although a minute difference does exist. To begin respects the order of time; to commence, the exertion of setting about a thing: whoever begins a dispute is termed the aggressor; no one should commence a dispute unless he can calculate the consequences, and. as this is impracticable, it is better never to commence disputes. Begin is opposed to end; commence to complete: a person begins a thing with a view of ending it; he commences a thing with a view of completing it. To begin is either transitive or intransitive; to commence is mostly transitive: a speaker begins by apologizing; he commences his speech with an apology: happiness frequently ends where prosperity begins; whoever commences any undertaking, without estimating his own power, must not expect to succeed. To begin is used either for things or persons; to commence for persons only: all things have their beginning; in order 
to effect anything, we must make a commencement; a word begins with a particular letter, or a line begins with a particular word; a person commences his career. Lastly, begin is more colloquial than commence; thus we say, to begin the work, to commence the operation: to begin one's play; to commence the pursuit: to begin to write; to commence the letter.

To commence and enter upon are as closely allied in sense as the former words; they differ principally in application: to commence seems rather to denote the making an experiment; to enter upon, that of first doing what has not been tried before; we commence an undertaking; we enter upon an employment: speculating people are very ready to commence schemes; considerate people are always averse to entering upon any office until they feel themselves fully adequate to discharge its duties.

BEGINNING. See ORIGIN.

BEGUILE. See Amuse.

BEHAVE. See DEAL.

BEHAVIOR, Conduct, Carriage, Deportment, Demeanor. Behavior, from Anglo-Saxon behabban, composed of the prefix be and the verb which now appears as have, signifies to have one's self, or have self-possession. Conduct, in Latin conductus, participle of conduco, compounded of con and ducere, to lead along, signifies, literally, leading one's self along, acting as a guide to one's self. Carriage, the abstract of carry (see BEAR), signifies the act of carrying one's body, or one's self. Deportment from Latin de, from, and portare, to carry, means, literally, what is expressed in our colloquial expression, "He carried it off well." Demeanor is a coined word from Middle English demenen, to demean or behave, which comes through Old French from Late Latin minare, to drive cattle, to conduct, signifying to conduct others, then to conduct one's self, to control or guard one's own action.

Behavior respects corporeal or mental actions; conduct, mental actions; carriage, deportment, and demeanor are different species of behauior. Behavior respects all actions exposed to the notice of others; conduct, the general line of a person's moral proceedings: we speak of a person's behavior at table or in company, in a ball-room, in the street, or in public; of his conduct in the management of his private concerns, in the direction of his family, or in his different relations with his fellow-creatures. Behavior applies to the minor morals of society; conduct, to those of the first moment: in our intercourse with others we may adopt a civil or polite, a rude or boisterous behavior; in our serious transactions we may adopt a peaceable, discreet, or prudent, a rash, dangerous, or mischievous conduct. The behavior of young people in society is of particular importance; it should, above all things, be marked with propriety in the presence of superiors and elders: the youth who does not learn betimes a seemly behavior in company will scarcely know how to conduct himself judiciously on any future occasion.

Carriage respects simply the manner of carrying the body; deportment includes both the action and the carriage of the body in performing the action: demeanor respects only the moral character or tendency of the action; deportment is said only of those exterior actions that have an immediate reference to others; demeanor, of the general behavior as it relates to the circumstances and situation of the individual: the carriage is that part of behavior which is of the first importance to attend to in young persons. A carriage should neither be haughty nor servile; to be graceful, it ought to have a due mixture of dignity and condescension: the deportment of a man should be suited to his station; a humble deportment is becoming in inferiors; a stately and forbidding $d e$ portment is very unbecoming in superiors: the demeanor of a man should be suited to his situation; the suitable demeanor of a judge on the bench, or of a clergyman in the pulpit, or when performing his clerical functions, adds much to the dignity and solemnity of the office itself. The carriage marks the birth and education: an awkward carriage stamps a man as vulgar: a graceful carriage evinces refinement and culture. The deportment marks either the habitual or the existing temper of 
the mind: whoever is really impressed with the solemnity and importance of public worship will evince his impressions by a gravity of deportment: the demeanor is most commonly used to denote the present temper of the mind; as a modest demeanor is particularly suitable for one who is in the presence of the person whom he has offended.

BEHIND. See ABack; ABafT; AFTER.

BEHOLD. See LooK.

BEHOLDER. See LOOKER-ON.

BELIEF, Credit, Trust, Faith. In belief the be stands for an earlier $g e$ which appears in the German glauben, originally ge-lauben, to believe. The root is the same as that which appears in the adjective lief, dear, and the Latin libel, it pleases, and, in this case, signifies the pleasure or assent of the mind. Credit is derived from the Latin credere, to believe, which also gives rise to the words credulous, credible, creed, etc. Trust is a Germanic word (German trost, consolation), from a root whence true, truth, trow, etc., are derived, meaning protection, confidence, consolation, etc. Faith, Old French $f e i$, is derived from Latin fidem (accusative), Greek riorıs, faith, from $\pi \dot{\varepsilon} \theta \varepsilon \iota \nu$, to persuade.

Belief is the generic term, the others are specific; we believe when we credit and trust, but not always vice versa. Belief rests on no particular person or thing; but credit and trust rest on the authority of one or more individuals. Everything is the subject of belief which produces one's assent: the events of human life are credited upon the authority of the narrator: the words, promises, or the integrity of individuals are trusted; the power of persons and the virtue of things are objects of faith. Belief and credit are particular actions or sentiments: trust and faith are permanent dispositions of the mind. Things are entitled to our belief; persons are entitled to our credit; but people repose a trust in others, or have a faith in others. Our belief or unbelief is not always regulated by our reasoning faculties or the truth of things: we often believe, from presumption, ignorance, or passion, things to be true which are very false. With the bulk of mankind assurance goes further than anything else in obtaining credit; gross falsehoods, pronounced with confidence, will be credited sooner than plain truths told in an unvarnished style. There are no disappointments more severe than those which we feel on finding that we have trusted to men of base principles. Ignorant people have commonly a more implicit faith in any nostrum recommended to them by persons of their own class than in the prescriptions of professional men regularly educated.

Belief, trust, and faith have a religious application, which credit has not. $B e-$ lief is simply an act of the understanding; trusi and faith are active moving principles of the mind. Belief does not extend beyond an assent of the mind to any given proposition; trust and faith impel to action. Belief is to trust and faith as cause to effect: there may be belief without either trust or faith; but there can be no trust or faith without belief; we believe that there is a God who is the creator and preserver of all His creatures; we therefore trust in Him for His protection of ourselves: we believe that Jesus Christ died for the sins of men; we have, therefore, faith in his redeeming grace to save us from our sins. Belief is common to all religions: trust is peculiar to the believers in Divine revelation: faith is employed by distinction for the Christian faith. Belief is purely speculative; and trust and faith are operative: the former operates on the mind, the latter on the outward conduct. Trust in God serves to dispel all anxious concern about the future. Theorists substitute belief for faith; enthusiasts mistake passion for faith. True faith must be grounded on a right belief and accompanied with a right practice.

BELIEVE. See Think.

BELOVED. See AMIABLe.

BELOW. See UNDER.

BELT. See ZoNE.

BEMOAN. See BEWAIL.

BENCH. See Tribunal.

BEND, BENT. Bend and bent are both derived from a root found in the English bind, Anglo-Saxon bindan, Icelandic benda, to stretch, strain. Bend means to strain a bow by fastening the band or string, hence to curve it (Skeat). Both abstract nouns from 
the verb to bend; the one to express its proper, and the other its moral application: a stick has a bend; the mind has a bent. A bend in anything that should be straight is a defect; a bent of the inclination that is not sanctioned by religion is detrimental to a person's moral character and peace of mind. For a vicious bend in a natural body there are various remedies; but nothing will cure a corrupt bent of the will except religion.

TURN.

See also Deflect; Knuckle; Lean;

BENEATH. See UNDER.

BENEFACTION, Donation. Benefaction, from the Latin benefacio, signifies the thing well done, or done for the good of others. Donation, from dono, to give or present, signifies the sum presented.

Both these terms denote an act of charity, but the former comprehends more than the latter: a benefaction comprehends acts of personal service in general toward the indigent; donation respects simply the act of giving and the thing given. Benefactions are for private use; donations are for public service. A benefactor to the poor does not confine himself to the distribution of money; he enters into all their necessities, consults their individual cases, and suits his benefactions to their exigencies; his influence, his counsel, his purse, and his property are employed for their good: his donations form the smallest part of the good. which he does.

Beneficent, Bountiful or Bounteous, Munificent, Generous, Liberal.-Beneficent comes from benefacio (see above). Bountiful signifies full of bounty or goodness, from the French bonté, Latin bonitas. Munificent, in Latin munificus, from munus, present, gift, and facio, signifies the disposition to make presents. Generous, from Latin generosus, meant originally of high blood, of noble extraction, and consequently of a noble character. Liberal, in French libéral, Latin liberalis, from liber, free, signifies the quality of being like a freeman in distinction from a bondman, and, by a natural association, being of a free disposition, ready to communicate.

Beneficent respects everything done for the good of others: bounty, munificence, and generosity are species of beneficence; liberality is a qualification of all. The first two denote modes of action: the last three either modes of action or modes of sentiment. The sincere well-wisher to his fellow-creatures is beneficent according to his means; he is bountiful in previding for the comfort and happiness of others; he is munificent in dispensing favors; he is generous in imparting his property; he is liberal in all he does. Beneficence and bounty are characteristics of the Deity as well as of His creatures: munificence, generosity, and liberality are mere human qualities. Beneficence and bounty cre the peculiar characteristics of the Dity: with Fim the will and the act of doing good are commensuratc only with His power; He was beneficent to us as our Creator, and continues His beneficencs to us by His daily preservation and protection; to some, however, He has been more bountiful than to others, by providing them with an unequal share of the good things of this life. The beneficence of man is regulated by the bounty of Providence: to whom much is given, from him much will be required. Instructed by His word, and illumined by that spark of benevolence which was infused into their souls with the breath of life, good men are ready to believe that they are but stewards of all God's gifts, holden for the use of such as are less bountifully provided. They will desire, as far as their powers extend, to imitate this feature of the Deity by bettering with their beneficent counsel and assistance the condition of all who require it and by gladdening the hearts of many with their bountiful provisions.

Princes are munificent, friends are generous, patrons liberal. Munificence is measured by the quality and quantity of the thing bestowed; generosity by the extent of the sacrifice made; liberality by the warmth and freedom of the spirit discovered. A monarch displays his munificence in the presents which he sends by his ambassadors to another monarch. A generous man will waive his claims, however powerful they may be, when the accommodation or relief of another is in question. A liberal spirit does not stop to inquire 
the reason for giving, but gives when the occasion offers. Munificence may spring either from ostentation or a becoming sense of dignity; generosity may spring either from a generous temper or an easy unconcern about property; liberality of conduct is dictated by nothing but a warm heart and an expanded mind. Munificence is confined simply to giving, but we may be generous in assisting, and liberal in rewarding.

BENEFIT, Favor, Kindness, CrvILITY. - Benefit signifies here that which is done to benefit (see Advantage). Favor, in French faveur, Latin favor and favere, to bear good-will, signifies the act flowing from good-will. Kindness signifies an action that is kind (see AfFectionate). Civility signifies that which is civil.

The idea of an action gratuitously performed for the advantage of another is common to these terms. Benefits and favors are granted by superiors; kindnesses and civilities pass between equals. Benefits serve to relieve actual wants: the power of conferring and the necessity of receiving them constitute the relative difference in station between the giver and the receiver: favors tend to promote the interest or convenience; the power of giving and the advantage of receiving are dependent on local circumstances, more than on difference of station. Kindnesses and civilities serve to afford mutual accommodation by a reciprocity of kind offices on the many and various occasions which offer in human life: they are not so important as either benefits or favors, but they carry a charm with them which is not possessed by the former. Kindnesses are more endearing than civilities, and pass mostly between those who are known to each other: civilities may pass between strangers. Benefits tend to draw those closer to one another who by station of life are set at the greatest distance from each other: affection is engendered in him who benefits, and devoted attachment in him who is benefited: favors increase obligation beyond its due limits; if they are not asked and granted with discretion, they may produce servility on the one hand and haughtiness on the other.
Kindnesses are the offspring and parent of affection; they convert our multiplied wants into so many enjoyments: civilities are the sweets which we gather on the way as we pass along the journey of life.

Benefit, Service, Good Office.-Benefit (see above). Service (see Advantage). Office, in French office, Latin officium, duty, from officio, perhaps from opi (opus), work, and facere, to do, signifies the doing of one's work, the fulfilling of a duty or obligation.

These terms, like the former, agree in denoting some action performed for the good of another, but they differ in the principle on which the action is performed. A benefit is perfectly gratuitous, it produces an obligation; a service is not altogether gratuitous; it is that at least which may be expected, though it cannot be demanded: a good office is between the two; it is in part gratuitous, and in part such as one may reasonably expect. Benefits flow from superiors, or those who are in a situation to do good, and service from inferiors or equals: but good offices are performed by equals only. Princes confer benefits on their subjects; subjects perform services for their princes; neighbors do good offices for one another. Benefits are sometimes the reward of services; good offices produce a return from the receiver. Benefits consist of such things as serve to relieve the difficulties or advance the interests of the receiver: services consist in those acts which tend to lessen the trouble, or increase the ease and convenience, of the person served: good offices consist in the employ of one's credit, influence, and mediation for the advantage of another; it is a species of voluntary service. It is a great benefit to assist an embarrassed tradesman out of his difficulty: it is a great service for a soldier to save the life of his commander, or for a friend to open the eyes of another to see his danger: it is a good office for any one to interpose his mediation to settle disputes and heal divisions. It is possible to be loaded with bcnefits so as to affect one's independence of character. Services are sometimes a source of dissatisfaction and disappointment when they do not meet with the remuneration or re- 
turn which they are supposed to deserve. Good offices tend to nothing but the increase of good-will. Those who perform them are too independent to expect a return, and those who receive them are too sensible of their value not to seek an opportunity for making a return. Politically, they are tendered by a neutral nation to another or others in time of trouble.

See also Advantage; Good.

BENEVOLENCE, BENEFICENCE. Benevolence is literally well willing. Beneficence is literally well doing. The former consists of intention, the latter of action: the former is the cause, the latter the result. Benevolence may exist without beneficence, but beneficence always supposes benevolence; a man is not said to be beneficent who does good from sinister views. The benevolent man enjoys but half his happiness if he cannot be beneficent; yet there will still remain to him an ample store of enjoyment in the contemplation of others' happiness; that man who is gratified only with that happiness which he himself is the instrument of producing is not entitled to the name of benevolent. As benevolence is an affair of the heart, and beneficence of the outward conduct, the former is confined to no station, no rank, no degree of education or power: the poor may be benevolent as well as the rich, the unlearned as the learned, the weak as well as the strong: the latter, on the contrary, is controlled by outward circumstances, and is therefore principally confined to the rich, the powerful, the wise, and the learned.

Benevolence, Benignity, Humanity, Kindness, Tenderness.-Benevolence (see above). Benignity, in Latin benignitas, from bene and gigno, beget, signifies the quality or disposition for producing good. Humanity, in French humanité, Latin humanitas, from humanus and homo, man signifies the quality of belonging to a man, or having what is common to man. Kindness, from kind (see Afrectionate). Tenderness, from tender, is in Latin tener, allied to tenuis, thin-hence soft, gentle, mild, etc.

Benevolence lies in the will, benignity in the disposition or frame of mind; humanity lies in the heart; kindness and tenderness in the affections: benev- olence indicates a general good-will to all mankind; benignity particular goodness or kindness of disposition; humanity is a general tone of feeling; kindness and tenderness are particular modes of feeling. Benevolence consists in the wish or intention to do good; it is confined to no station or object: the benevolent man may be rich or poor, and his benevolence will be exerted wherever there is an opportunity of doing good; benignity is mostly associated with the power of doing good, and is actually exerted or displayed in the actions or looks. Benevolence in its fullest sense is the sum of moral excellence, and comprehends every other virtue; when taken in this acceptation, benignity, humanity, kindness, and tenderness are but modes of benevolence. Benevolence and benignity tend to the communicating of happiness; humanity is concerned in the removal of evil. Benevolence is common to the Creator and His creatures; it differs only in degree; the former has the knowledge and power as well as the will to do good; man often has the will to do good, without having the power to carry it into effect. Benignity is ascribed to the stars, to Heaven, or to princes; ignorant and superstitious people are apt to ascribe their good fortune to the benign influence of the stars rather than to the gracious dispensations of Providence. Humanity belongs to man only; it is his peculiar characteristic, and ought at all times to be his boast; when he throws off this, his distinguishing badge, he loses everything valuable in him; it is a virtue that is indispensable in his present suffering condition: humanity is as universal in its application as benevolence; wherever there is distress, $h u$ manity flies to its relief. Kindness and tenderness are partial modes of affection, confined to those who know or are related to one another; we are kind to friends and acquaintances, tender toward those who are near and dear: kindness is a mode of affection most fitted for social beings; it is what every one can show, and every one is pleased to receive: tenderness is a state of feeling that is occasionally acceptable: the young and the weak demand tenderness from those who stand in the closest con. 
nection with them, but this feeling may be carried to an excess, so as to injure the object on which it is fixed.

BENIGNITY. See Benevolence. BENT, Curved, Crooked, Awry. For bent see the derivation of bend. Curved is derived from Latin curvus, allied to circus, and means bent so as to form the arc of a circle. Awry is derived from Anglo-Saxon urigian, to turn, whence wriggle is also derived. Crooked (see Awkward).

Bent is here the generic term, all the rest are but modes of the bent; what is bent is opposed to that which is straight; things may therefore be bent to any degree, but when curved they are bent only to a small degree; when crooked they are bent to a great degree: a stick is bent any way; it is curved by being bent one specific way; it is crooked by being bent different ways. Things may be bent by accident or design; they are curved by design or according to some rule; they are crooked by accident or in violation of some rule: a stick is bent by the force of the hand; a line is curved so as to make a mathematical figure; it is crooked so as to lose all figure: awry marks a species of crookedness, but crooked is applied as an epithet, and awry is employed to characterize the action; hence we speak of a crooked thing and of sitting or standing awry.

Bent, Bias, Inclination, Prepossession.-Bent (see above). Bias, in French biais, at first signified a slope; its origin is unknown. Inclination, in -French inclination, Latin inclinatio, from inclino, Greek $\kappa \lambda i \nu \omega$, signifies a leaning toward. Prepossession, compounded of pre and possession, signifies the taking possession of the mind previously or beforehand.

All these terms denote a proponderating influence on the mind. Bent is applied to the will, affection, and power in general: bias solely to the judgment: inclination and prepossession, to the state of the feelings. The bent includes the general state of the mind, and the object on which it fixes a regard: bias, the particular influential power which sways the judging faculty: the one is absolutely considered with regard to itself; the other relatively to its results and the object it acts upon. Bent is sometimes, with regard to bias, as cause is to effect; we may frequently trace in the particular bent of a person's likes and dislikes the principal bias which determines his opinions. Inclination is a faint kind of bent; prepossession is a weak species of bias; an inclination is a state of something - namely, a state of the feelings: prepossession is an actual something-namely, the thing that prepossesses.

We may discover the bent of a person's mind in his gay or serious moments, in his occupations, and in his pleasures; in some persons it is so strong that scarcely an action passes which is not more or less influenced by it, and even the exterior of a man will be under its control; in all disputed matters the support of a party will operate more or less to bias the minds of men for or against particular men or particular measures; when we are attached to the part that espouses the cause of religion and good order, this bias is in some measure commendable and salutary; a mind without inclination would be a blank, and where inclination is there is the groundwork for prepossession. Strong minds will be strongly bent and labor under a strong bias; but there is no mind so weak and powerless as not to have its inclinations, and none so perfect as to be without its prepossessions; the mind that has virtuous inclinations will be prepossessed in favor of everything that leans to virtue's side: it were well for mankind were this the only prepossession; but in the present mixture of truth and error it is necessary to guard against prepossessions as dangerous anticipations of the judgment: if their object be not perfectly pure, or their force be not qualified by the restrictive powers of the judgment, much evil springs from their abuse.

See also Bend; TURn.

BENUMBED. See NuMB.

BEQUEATH. See Devise.

BEREAVE, Deprive, Strip. Bereave, in Anglo-Saxon bereafian, is compounded of the verbal prefix be and a root found also in rob, rove, etc., which suggests the idea of taking by violence. Deprive, compounded of de and prive, French priver, Latin privo, from privus, private, signifies to cause a thing to be 
no longer a man's own. Strip is a Germanic word meaning to tear off, to make bare.

To bereave expresses more than deprive, but less than strip, which denotes a total and violent bereavement; one is bereaved of children, deprived of pleasures, and stripped of property: we are bereaved of that on which we set most value; the act of bereaving does violence to our inclination: we are deprived of the ordinary comforts and conveniences of life; they cease to be ours: we are stripped of the things which we most want; we are thereby rendered, as it were, naked. Deprivations are preparatory to bereavements; if we cannot bear the one patiently, we may expect to sink under the other: common prudence should teach us to look with unconcern on our deprivations: Christian faith should enable us to consider every bereavement as a step to perfection; that when stripped of all worldly goods we may be invested with, those more exalted and lasting honors which await the faithful disciple of Christ.

Bereave and deprive are applied only to persons, strip may be figuratively applied to things.

BESEECH. See BEG.

BESET. See BEsIEge.

BESIDES, Moreover. Besidesthat is, by the side, next to-marks simply the connection which subsists between what goes before and what follows. Moreover-that is, more than all else-marks the addition of something particular to what has already been said. Thus, in enumerating the good qualities of an individual, we may say "he is, besides, of a peaceable disposition." On concluding any subject of question, we may introduce a further cause by a moreover. "Moreover, we must not forget the claims of those who will suffer by such a change."

Besides, Except.-Besides, which is here taken as a preposition, expresses the idea of addition. Except expresses that of exclusion. There were many there besides ourselves; no one except ourselves will be admitted.

BESIEGE, BESET, ENCOMPASS, INVEST. Besiege, a compound of the Anglo-Saxon be by, and the Old French siege, a seat, signifies, as a transitive, to surround any place with soldiers, as a city or town, in order to take possession of it by force; literally; to sit down before a place with the view of capturing it; and, figuratively, to surround a person or place, as excited depositors making a run on a bank, a crowd pressing the gate-keepers at a game of baseball or football between favorite players.

To beset a person or place is to surround him or it with or without hostile intent, to press upon him or it on all sides, and, as applied to a city or fortification, to entangle it with obstructions, to prevent those within from escaping. To encompass, from Latin cum, with, and passus, pace or step, whence compass, a route that comes together and joins itself-a circular object-means to encircle, like a body of troops between hostile forces or placed about an objective point, so as to cut off means of communication, relief, or retreat; and to invest is to blockade, beleaguer, take possession of the outskirts of a place or army with forces, so as to intercept succor by men or provisions.

These terms are all used here in a military sense, and indicate movements intended to force the surrender of an army, a fortification, a strategic point, or a city by, literally, sitting down and waiting. For applications to other purposes see the articles on INVEST and Surround.

BESPEAK, Betoken, Engage, SoLICIT. Bespeak, a compound of the Anglo-Saxon be, by, and sprecan, to speak, German besprechen, signifies to speak for or on behalf of a person or thing beforehand, in advance, as to engage an article ahead of the time when it will be wanted. For the derivation of engage see engagement under BATTLE, engage always being suggestive of a pledge, however it is used. To betoken is to point out something in the future that is likely to occur from things or conditions known now, to foreshow a result from present indications, to predict or prognosticate, as indications tonight betoken a fair day to-morrow.

We engage now to buy or do a thing or go somewhere at a future time, pledge or bind a future undertaking by a contract or oath, promise or assume now an obligation for a future trans- 
action, and we solicit to-day a favor, benefit, or other advantage from another that we expect to obtain some other day when it is needed. For the derivation of solicit see BEG.

Give.

BESTOW. See Allow; Confer;

BETIMES. See Soon.

BETOKEN. See AUgur; Bespeak.

BETROTH. See Espouse.

BETTER. See AMEND.

BEWAIL, Bemoan, Lament. For the derivation of bewail see wail. Bemoan is derived from the verbal prefix be and Anglo-Saxon monan, to mean, intend. Moan in Middle English means both a communication and a complaint; its significance is no doubt influenced by the accidental effect of the sound, which makes it seem like an onomatopœetic word. Lament is formed with the suffix mentum from the base la, meaning to utter a cry (Latin lamentum).

All these terms mark an expression of pain by some external sign. Bewail is not so strong as bemoan, but stronger than lament; bewail and bemoan are expressions of unrestrained grief or anguish: a wretehed mother bewails the loss of her child; a person in deep distress bemoans his hard fate: lamentation may arise from simple sorrow or even imaginary grievances: a sensualist laments the disappointment of some expected gratification. Bewail and bemoan are always indecorous if not sinful expressions of grief which are inconsistent with the profession of a Christian; they are common among the uneultivated, who have not a proper principle to restrain the intemperance of their feelings. There is nothing temporal which is so dear to any one that he ought to bewail its loss; nor any condition of things so distressing or desperate as to make a man bemoan his lot. Lamentations are sometimes allowable; the miseries of others, or our own infirmities and sins, may justly be lamented.

BEWILDER. See ABASH.

BEWILDERMENT. See Amnesia. BEWITCHED. See SPELlBoUND.

BEYOND. See Above; OUT; YonDER.

bias, Prepossession, Prudence. Bias, prepossession (see Bent). Prej- udice, in French préjudice, Latin prajudicium, compounded of pra, before, and judicium, judgment, signifies a judgment beforehand - that is, before examination.

Bias marks the state of the mind, as leaning to this or that side, so as to determine one's feelings or opinions generally; prepossession denotes the previous occupation of the mind with some particular idea or feeling, so as to preclude the admission of any other; prejudice is a prejudging or predetermining a matter without knowing its merits. We may be biased for or against; we are always prepossessed in favor and mostly prejudiced against; the feelings have mostly to do with the bias and prepossession, and the understanding or judgment with the prejudice. Bias and prepossession suppose a something real, whether good or otherwise, which determines the inclination of the mind, but prejudice supposes a something unreal or false, which misleads the judgment: bias and prepossession may therefore be taken in an indifferent, if not a good sense; prejudice always in a bad sense: interest or personal affection may bias, but not so as to pervert either the integrity or judgment; prepossessions may be formed of persons at first sight, but they may be harmless, even although they may not be perfectly correct; prejudices prevent the right exercise of the understanding, and consequently favor the cause of falsehood, as when a person has a prejudice against another, which leads him to misinterpret his actions.

See also BENT.

BICKER, Contend, Dispute, QUARREL. Bicker is derived from a Celtic source, and is probably allied to peck and the word beak, that with which a bird pecks. Bikere in Middle English meant a skirmish. In Scottish speech it means to fight by throwing stones, to indulge in strife or contention by word of mouth. Contend is derived from Latin contendere, from con, against, and tendere, to stretch; it means to stretch against, to exert one's strength against.

To contend is to strive physically or verbally with another, to vie with or against another, to engage in more or less protracted disputes, to take part 
in a debate by opposing another in speech, to support an opinion or statement against another. To dispute is to attempt to maintain by argument an opinion different from one that has been advanced by another, to call in question or deny the correctness or justness of any statement or conclusion. For a critical comparison of the cognate terms contend, contest, and dispute sce the article on the former term.

A quarrel, in French querelle, an altercation, from the Latin querela, a complaint, is, literally, an angry dispute, an open variance between parties, a ground or reason of dispute, something that gives right to angry reprisal. It is the result of a breach of friendship or concord between persons or nations, a falling out or disagreement between parties, and may lead to a war between nations, or a judicial settlement of the questions in dispute, or a common brawl or petty fight between individuals. The term quarrel is further considered in connection with difference, dispute, and altercation in the article on Difference.

BID. See Call; Offer.

BIG. See Great.

BIGot. See Devotee.

BIKE. See Cycle.

BILL. See Account.

BILlow. See Wave.

BIND, TIE. Bind is a Germanic word, allied to bundle, bend, etc. Tie is a Germanic word from the root also found in tug, so that to tie is to tug or draw things tightly together.

The species of fastening denoted by these two words differ both in manner and degree. Binding is performed by circumvolution round a body; tying, by involution within itself. Some bodies are bound without being tied; others are tied without being bound: a wounded leg is bound, but not tied; a string is tied, but not bound; a ribbon may sometimes be bound round the head, and tied under the chin. Binding, therefore, serves to keep several things in a compact form together: tying may serve to prevent one single body separating from another: a criminal is bound hand and foot; he is tied to a stake. Binding and tying likewise differ in degree; binding serves to produce adhesion in all the parts of a body; tying only to produce contact in a single part: thus, when the hair is bound, it is almost enclosed in an envelope: when it is tied with a string, the ends are left to hang loose.

A similar distinction is preserved in the figurative use of the terms. A bond of union is applicable to a large body with many component parts; a tie of affection marks an adhesion between individual minds.

Bind, Oblige, Engage.-Bind (see above). Oblige, in French obliger, Latin obligo, compounded of $o b$, to, and ligo, signifies to tie up. Engage, in French engager, compounded of $e n$ or in and gage, a pledge, signifies to bind by means of a pledge.

Bind is more forcible and coercive than oblige; oblige than engage. We are bound by an oath, obliged by circumstances, and engaged by promises.

Conscience binds, prudence or necessity obliges, honor and principle engage. A parent is bound no less by the law of his conscience than by those of the community to which he belongs to provide for his helpless offspring. Politeness obliges men of the world to preserve a friendly exterior toward those for whom they have no regard. When we are engaged in the service of our king and country, we cannot shrink from our duty without exposing ourselves to the infamy of all the world. We bind a man by a fear of what may befall him; we oblige him by some immediate urgent motive; we engage him by alluring offers and the prospect of gain. A debtor is bound to pay by virtue of a written instrument in law; he is obliged to pay in consequence of the importunate demands of the creditor; he is engaged to pay in consequence of a promise given. A bond is the strictest deed in law; an obligation binds under pain of a pecuniary loss; an engagement is mostly verbal, and rests entirely on the rectitude of the parties.

See also RATiFx.

BIPLANE. See Aircraft.

BISHOPRIC, DIOCEse. Bishopric is derived from bishop, and the AngloSaxon rice, meaning dominion, realm.

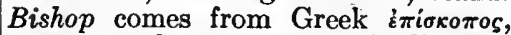
overseer, whence episcopal is directly, 
taken over into English. Diocese, in

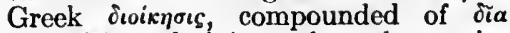
and oixé $\omega$, administer throughout, signifies the district within which a government is administered.

Both these words describe the extent of an episcopal jurisdiction; the first with relation to the person who officiates, the second with relation to the charge. There may, therefore, be a bishopric either where there are many dioceses or no diocese; but according to the import of the term, there is properly no diocese where there is no bishopric. When the jurisdiction is merely titular, as in countries where the Catholic religion is not recognized, it is a bishopric, but not a diocese. On the other hand, the bishopric of Rome, or that of an archbishop, comprehends all the dioceses of the subordinate bishops. Hence it arises that when we speak of the ecclesiastical distribution of a country, we term the divisions bishoprics; but when we speak of the actual office, we term it a diocese. England is divided into a certain number of bishoprics, not dioceses. Every bishop visits his diocese, not his bishopric, at stated intervals.

BITE. See NIP.

Blame, Censure, Condemn, RePROVE, REPROACH, UpBraId. Blame, Old French blasmer, is derived from Latin blasphemare, Greek $\beta \lambda \alpha \sigma \phi \eta \mu \varepsilon^{2} y$, to speak ill, whence the word blaspheme, to speak ill of things sacred, is directly taken. Censure (see Accose). Condemn, in Latin condemno, from con and damnum, loss or damage, signifies literally to inflict a penalty or to punish by a sentence. Reprove, from the Latin reprobo, signifies the contrary of probo, approve. Reproach, derived through French, from Latin repropriare and proprius, near, signifies to cast back upon or against another. Upbraid comes from Anglo-Saxon $u p$ and bregdan, to braid or weave, and also to pull, draw. The original sense of upbraid was probably to lay hands on, hence to attack, to lay to some one's charge.

The expression of an unfavorable opinion of a person or thing is the common idea in the signification of these terms. To blame is simply to ascribe a fault to; to censure is to express disapprobation: the former is less personal than the latter. The thing more than the person is blamed; the person more than the thing is censured. The action or conduct of a person in any particular may be blamed, without reflecting on the individual; but the person is directly censured for that which is faulty in himself.

Venial or unquestionable faults, or even things that are in themselves amiable, may be the subject of blame, but positive faults are the subject of censure. A person may be blamed for his good-nature and censured for his negligence.

Persons are blamed in general or qualified terms, but are censured in terms more or less harsh.

Condemn, like blame, though said of personal matters, has more reference to the thing than the person: but that which is condemned is of a more serious nature, and produces a stronger and more unfavorable expression of displeasure or disapprobation, than that which is blamed.

Blame and condemn do not necessarily require to be expressed in words, but censure must always be conveyed in direct terms.

Reprove is even more personal than censure. A reproof passes from one individual to another, or to a certain number of individuals; censure may be public or general.

Censure is frequently provoked by ill-nature or some worse feeling, or dictated by ignorance, as the censures of the vulgar.

Reproaching and upbraiding are as much the acts of individuals as reproving, but the former denote the expression of personal feelings, and may be just or unjust; the latter is presumed to be divested of all personal feelings.

Reproaches are frequently dictated by resentment or self-interest, upbraidings by contempt or wounded feelings.

Blame, condemn, reproach, and upbraid are applied to ourselves with the same distinction.

Reproof and censure are most properly addressed to others: in the following example, censure, as applied to one's self, is not so suitable as blame or condemn.

See also Find Fault. 
Blameless, Irreproachable, Unblemished, Unspotted, or Spotless.-Blameless signifies literally void of blame. Irreproachable, that is, not able to be reproached. Unblemished, that is, without blemish. Unspotted, that is, without spot (see Blemish).

Blameless is less than irreproachable; what is blameless is simply free from blame, but that which is irreproachable cannot be blamed, or have any reproach attached to it. It is good to say of a man that he leads a blameless life, but it is a high encomium to say that he leads an irreproachable life: the former is but the negative praise of one who is known only for his harmlessness; the latter is the positive commendation of a man who is well known for his integrity in the different relations of society.

Unblemished and unspotted are applicable to many objects besides that of personal conduct; and when applied to this, their original meaning sufficiently points out their use in distinction from the former two. We may say of a man that he has an irreproachable or an unblemished reputation, and unspotted or spotless purity of life.

BLASPHEME. See Swear.

BLAZE. See Flame.

BLemish, Stain, Spot, Speck, Flaw. Blemish is derived through French, possibly from Icelandic blamen, the livid color of a wound, cognate with English blue. Stain comes from Old French desteindre, from Latin dis, apart, and tingere, to color, and means to discolor. Spot means literally a thing spat out, hence a wet blot. Speck has a similar origin. Flaw is a Scandinavian word and originally signified a crack or break.

In the proper sense blemish is the generic, the rest specific: a stain, a spot, speck, and flaw are blemishes, but there are likewise many blemishes which are neither stains, spots, specks, nor flaws. Whatever takes off from the seemliness of appearance is a blemish. In works of art the slightest dimness of color or want of proportion is a blemish. A stain or spot sufficiently characterizes itself as that which is superfluous and out of its place. A speck is a small spot; and a flaw, which is confined to hard substances, mostly con- sists of a faulty indenture on the outer surface. A blemish tarnishes; a stain spoils; a spost. speck, or flaw disfigures. A blemish is rectified, a stain wiped out, a spot or speck removed.

All these terms are employed figuratively. Even an imputation of what is improper in our moral conduct is a blemish on our reputation: the failings of a good man are so many spots or specks in the bright hemisphere of his virtue: there are some vices which affix a stain on the character of nations, as well as of the individuals who are guilty of them. In proportion to the excellence or purity of a thing, so is any flaw the more easily to be discerned.

Blemish, Defect, Fault.-Blemish (see above). Defect is derived from the past participle of deficere, Latin, from de and facere, and means undone, something not made or made in the wrong way. Fault, French faillir, is derived from Latin fallere, to deceive, and signifies that which is wanting in truth and propriety.

Blemish respects the exterior of an object: defect consists in the want of some specific propriety in an object; fault conveys the idea not only of something wrong, but also of its relation to the author. There is a blemish in fine china; a defect in the springs of a clock; and a fault in the contrivance. An accident may cause a blemish in a fine painting; the course of nature may occasion a defect in a person's speech; but the carelessness of the workman is evinced by the faults in the workmanship. A blemish may be easier remedied than a defect is corrected or a fault repaired.

BLEND. See MIX.

BLIND. See ClOAK.

BLOCKADE. See Surround. BLOCKHEAD. See NiNNY.

BLONDE, Golden, Flaxen, Fair, XaNTHous. All these words indicate a type of fair hair and coloring opposed to brunette or dark. Blonde, a word of unknown origin which appears in Medieval Latin and French, signified "a colour midway between golden and light chestnut" (Littré). Golden signifies of the color of gold; flaxen of the color of flax, which is lighter than gold and not so bright. Fair is extended 
from its meaning of beautiful to indicate the coloring considered most beautiful- $-i$. $e$, the blonde coloring, and is, next to blonde, the word most generally applied to signify, not the hair alone, but the whole coloring. Xanthous, Greek, Kav日ós, yellow is the ethnological term indicating the blonde races.

\section{BLOODTHIRSTY. See SANGUI-} NARY.

\section{BLOODY. See Sanguinary.}

BLot, Expunge, Rase, or Erase, Efface, Cancel, Obliterate. Blot, signifying a spot, is derived from old French blotte, a clot of earth, probably of Teutonic origin. Expunge, in Latin expungo, compounded of ex and pungere, to prick, signifies to put out by pricking with any sharp instrument. Erase, in Latin erasus, participle of erado-that is, $e$ and rado found in abrade, to scratch out. Efface, from $e x$, out, and facies, face, means to remove the face of something. Cancel, in French canceller, Latin cancello, from cancelli, lattice-work, signifies to strike out with cross-lines. Obliterate, in Latin obliteratus, participle of oblitero, compounded of $o b$ and litera, letter, signifies to cover over letters.

All these terms obviously refer to characters that are impressed on bodies; the first three apply in the proper sense only to that which is written with the hand, and bespeak the manner in which the action is performed. Letters are blotted out, so that they cannot be seen again; they are expunged, so as to signify that they cannot stand for anything; they are erased, so that the space may be reoccupied with writing. The last three are extended in their application to other characters formed on other substances: efface is general, and does not designate either the manner or the object: inscriptions on stone may be effaced, which are rubbed off so as not to be visible: cancel is principally confined to written or printed characters; they are cancelled by striking through them with the pen; in this manner leaves or pages of a book are cancelled which are no longer to be reckoned: obliterate is said of all characters, but without defining the mode in which they are put out; letters are obliterated which are in any way made illegible. Efface applies to images, or the representations of things; in this manner the likeness of a person may be effaced from a statue; cancel respects the subject which is written or printed; obliterate respects the single letters which constitute words. Efface is the consequence of some direct action on the thing which is effaced; in this manner writing may be effaced from a wall by the action of the elements: cancel is the act of a person, and always the fruit of design: obliterate is the fruit of accident and circumstances in general; time itself may obliterate characters on a wall or on paper.

The metaphorical use of these terms is easily deducible from the preceding explanation; what is figuratively described as written in a book may be said to be blotted; thus our sins are blotted out of the book by the atoning blood of Christ: when the contents of a book are in part rejected, they are aptly described as being expunged; in this manner the freethinking sects $e x-$ punge everything from the Bible which does not suit their purpose, or they expunge from their creed what does not humor their passions. When the memory is represented as having characters impressed, they are said to be erased when they are, as it were, directly taken out and occupied by others; in this manner, the recollection of what a child has learned is easily erased by play; and with equal propriety sorrows may be said to efface the recollection of a person's image from the mind. From the idea of striking out or cancelling a debt in an account-book, a debt of gratitude, or an obligation, is said to be cancelled. As the lineaments of the face eorresponded to written characters, we may say that all traces of his former greatness are obliterated.

BLOW, STroke. Blow is a word of obscure history from a Teutonic root meaning to strikc. Stroke, from the word strike, is a substantive allied to the verb strike, and denotes the act of striking.

Blow is used abstractedly to denote the effect of violence; stroke is employed relatively to the person producing that effect. A blow may be 
received by the carelessness of the receiver or by a pure accident; but strokes are dealt out according to the design of the giver. Children are always in the way of getting blows in the course of their play, and of receiving strokes by way of chastisement. A blow may be given with the hand, or with any flat substance; a stroke is rather a long-drawn blow given with a long instrument, like a stick. Blows may be given with the flat part of a sword, and strokes with a stick.

Blow is seldom used but in the proper sense; stroke sometimes figuratively, as a stroke of death or a stroke of fortune.

See also KNock.

BLUNDER. See Error.

BLUNT. See Obtuse.

BLUSTER. See Gasconade.

BOAST. See GLORY.

BODILY. See Corporal.

Body, Corpse, Carcass.

Body, Anglo-Saxon bodig, is derived from the root meaning to bind, and signifies that which confines the life or spirit. It is here taken in the special sense of dead body. Corpse, from Latin corpus, body, represents the same kind of specialization-the general word for body being limited to the body in a single state. Carcass has been introduced through French from Italian carcassa, a kind of shell, the dead body being an empty shell. The word is ultimately derived from Persian.

$B o d y$ is applicable either to men or brutes, corpse to men only, and carcass to brutes only, unless when taken in a contemptuous sense. When speaking of any particular person who is deceased, we should use the simple term body; the body was suffered to lie too long unburied: when designating its condition as lifeless, the term corpse is preferable: he was taken up as a corpse; when designating the body as a lifeless lump separated from the soul, it may be characterized (though contemptuously) as a carcass; the fowls devour the carcass.

BOISTEROUS. See Violent.

BOLD, FEARLESS, INTREPID, UNdaunted. Bold (see Audacity). Fearless signifies without fear (see APpreHEND). Intrepid, compounded of in, privative, and trepidus, trembling, marks the total absence of fear. Un- daunted is the opposite of daunted, daunt being derived from the Latin verb domitare, to tame, allied to English tame.

Boldness is a positive characteristic of the spirit; fearlessness is a negative state of the mind, that is, simply an absence of fear. A person may be bold through fearlessness, but he may be fearless without being bold; he may be fearless where there is no apprehension of danger or no cause for apprehension, but he is bold only when he is conscious or apprehensive of danger, and prepared to encounter it. A man may be fearless in a state of inaction; he is bold only in action, or when in a frame of mind for action.

Intrepidity is properly a mode of fearlessness, undauntedness a mode of boldness in the highest degree, displayed only on extraordinary occasions; he is intrepid who has no fear where the most fearless might tremble; he is undaunted whose spirit is unabated by that which would make the stoutest heart yield. Intrepidity may be shown either in the bare contemplation of dangers or in the actual encountering of dangers in opposing resistance to force.

Undauntedness is the opposing actual resistance to a force which is calculated to strike with awe.
See also
DARING;
Stalwart; STRENUOUS.

BOLDNESS. See AUdacity.

BOMBASTIC. See High-FLOWN; TURGID.

BONDAGE. See SERVITUdE; Thraldom.

BOOTY, Spoll, Prey. Booty comes through Old French butin, from Low German, signifying prey. Spoil is derived from Latin spolium, meaning skin stripped off, referring to the stripping off of the dress of a slain warrior. Prey is derived from Latin procda, that which is taken or carried off.

Booty and spoil are used as military terms in attacks on an enemy, prey in cases of particular violence. The soldier gets his booty, the combatant his spoils, the carnivorous animal his prey. Booty respects what is of personal service to the captor: spoils, whatever 
serves to designate his triumph; prey includes whatever gratifies the appetite and is to be consumed. When a town is taken, soldiers are too busy in the work of destruction and mischief to carry away much booty; in every battle the arms and personal property of the slain enemy are the lawful spoils of the victor; the hawk pounces on his prey and carries it up to his nest. Greediness stimulates to take booty; ambition produces an eagerness for spoils; a ferocious appetite impels to a search for prey. Among the ancients the prisoners of war who were made slaves constituted a part of their booty; and even in later periods such a capture was good booty when ransom was paid for those who could liberate themselves. Among some savages the head or limb of an enemy constituted part of their spoils. Among cannibals the prisoners of war are the prey of the conquerors.

Booty and prey are often used in an extended and figurative sense. Plunderers obtain a rich booty; the diligent bee returns loaded with his booty. It is necessary that animals should become a prey to man, in order that man may not become a prey to them; everything in nature becomes a prey to another thing, which in its turn falls a prey to something else. All is changed but order. Man is a prey to the diseases of his body or his mind, and after death to the worms.

BORDER, EDGE, RIM or BRIM, Brink, Margin, Verge. Border, in French bord or bordure, Teutonic bord, is probably connected with bret, board, signifying a strip in shape like a board. Edge comes from Anglo-Saxon $e c g$, border; and rim from Anglo-Saxon rima, which has the same meaning. Brim is a Middle English word which does not appear in Anglo-Saxon, though it has Teutonic parallels. Brink comes from the Scandinavian. Margin is derived from Latin margo, a border or brink, cognate with English mark, a boundary. Verge, French verge, from Latin virga, at first signified a rod, wand, or hoop; from the sense of rod it came to mean hoop (a bent rod-bent to form a circle), a ring, hence rim or edge.

Of these terms, border is the least definite point; edge the most so; rim and brink are species of edpe; marain and verge are species of border. A border is a stripe, an edge is a line. The border lies at a certain distance from the edge; the edge is the exterior termination of the surface of any substance. Whatever is wide enough to admit of any space round its circumference may have a border, whatever comes to a narrow extended surface has an edge. Many things may have both a border and an edge; of this description are caps, gowns, carpets, and the like; others have a border, but no edge, as lands; and others have an edge, but no border, as a knife or a table. A rim is the edge of any vessel; and brim is the exterior edge of a cup; a brink is the edge of any precipice or deep place; a margin is the border of a book or a piece of water; a verge is the extreme border of a place.

Border, Boundary, Frontier, Confine, Precinct.-Border (see above). Boundary, from Old French bonne, a limit, Low Latin bodina, i.3 derived from a Celtic word signifying limit, and is allied to bourne. Frontier, French frontiere, from the Latin frons, a forehead, signifies the fore part, or the commencement of anything. Confine, in Latin confinis, compounded of con or cum and finis, an end, signifies an end next to an end. Precinct, in Latin procinctum, participle of pracingothat is, proe and cingere, to enclosesignifies any enclosed place.

Border, boundary, frontier, and confines are all applied to countries or tracts of land: the border is the outer edge or tract of land that runs along a country; it is mostly applied to countries running on a line with each other, as the borders of England and Scotland; the boundary is that which bounds or limits, as the boundaries of countries or provinces; the frontier is that which lies in the front or forms the entrance into a country, as the frontiers of Germany or the frontiers of France; the confines are the parts lying contiguous to others, as the confines of different states or provinces. The term border is employed in describing those parts which form the borders, as to dwell on the borders, or to run along the borders. The term boundary is used in speaking of the extent or limits of places; it belongs to 
the science of geography to describe the boundaries of countries. The frontiers are mostly spoken of in relation to military matters, as to pass the frontiers, to fortify frontier towns, to guard the frontiers, or in respect to one's passage from one country to another, as to be stopped at the frontiers. The term confines, like that of borders, is mostly in respect to two places; the border is mostly a line, but the confines may be a point: we therefore speak of going along the borders, but meeting on the confines.

The term border may be extended in its application to any space, and boundary to any limit. Confines is also figuratively applied to any space included within the confines, as the confines of the grave; precinct is properly any space which is encircled by something that serves as a girdle, as to be within the precincts of a court--that is, within the space which belongs to or is under the control of a court.

BORE. See Penetrate.

BOTCH. See Bungle.

BOTH, PaIr, Twain, Two. Both is a Scandinavian word-a compound of two words. Bo, meaning two, corresponds to bo in Latin xmbo, both, and Greek $\tilde{a} \mu \phi \omega$. The $t i$ originally stood for the definite article, as in Gothic ba tho skipa, "the two ships." Pair is derived from Latin par, equal, a pair being two equal things that belong together, or that form one single whole. The difference between two and twain was originally one of gender only. All of these words signify two, but there is a difference in their meaning corresponding to the difference in their derivation. Two is the general term; it merely conveys the idea of number. Twain was originally merely another form of two; it is now a poetic word, a trifle more specific than two, perhaps. Both contains the idea of the definite article or the demonstrative. It suggests two specific ideas, consciously comprehended in one general statement. To say that there are two books on the table suggests merely the general idea of number. To say that both books are on the table suggests that there are two particular books, distinguished in the mind of the speaker from all other books, and deliberately combined, as it were, in the general idea indicated in the verb. Pair suggests two objects, equal or alike, comprehended in one general idea-two separate and similar things which, taken together, make one whole, such as a pair of gloves, a pair of skates.

BoUnd, Limit, Confine, CircumSCRIBE, REsTrICT, Limit, from the Latin limes, a landmark, signifies to draw a line which is to be the exterior line or limit. Confine signifies to bring within confines. Circumscribe, in Latin circumscribo, is compounded of circum and scribo, to write roundthat is, to describe a line round. Restrict, in Latin restrictum, participle of restringo, compounded of $r e$ and stringo, signifies to keep fast back.

The first four of these terms are employed in the proper sense of parting off certain spaces. Bound applies to the natural or political divisions of the earth: countries are bounded by mountains and sea; kingdoms are often bounded by each other; Spain is bounded on one side by Portugal, on the other side by the Mediterranean, and on a third side by the Pyrenees. Limit applies to any artificial boundary: as landmarks in fields serve to show the limits of one man's ground from another's; so may walls, palings, hedges, or any other visible sign, be converted into a limit, to distinguish one spot from another, and in this manner a field is said to be limited, because it has limits assigned to it. To confine is to bring the limits close together; to part off one space absolutely from another: in this manner we confine a garden by means of walls. To circumscribe is literally to surround: in this manner a circle may circumscribe a square: there is this difference, however, between confine and circumscribe, that the former may not only show the limits, but may also prevent egress and ingress; whereas the latter, which is only a line, is but a simple mark that limits.

From the proper acceptation of these terms, we may easily perceive the ground on which their improper acceptation rests: to bound is an action suited to the nature of things, or to some given rule; in this manner our 
views are bounded by the objects which intercept our sight.

Or we bound our desires according to the principles of propriety.

To limit, confine, and circumscribe all convey the idea of an action more or less involuntary, and controlled either by circumstances or by persons. To limit is an affair of discretion or necessity; we limit our expenses because we are limited by circumstances.

Things may be limited to one or many points or objects.

Confine conveys the same idea to a still stronger degree: what is confined is not only brought within a limit, but is kept to that limit, which it cannot pass; in this manner a person confines himself to a diet which he finds absolutely necessary for his health, or he is confined in the size of his house, in the choice of his situation, or in other circumstances equally uncontrollable; hence the term confined expresses also the idea of the limits being made narrow as well as impassable or unchangeable. Therefore to confine is properly to bring within narrow limits; it is applied either to space or to the movements of the body or the mind.

To circumscribe is to limit arbitrarily, or to bring within improper or inconvenient limits.

Sometimes circumscribing is a matter of necessity resulting from circumstances, as a person is circumscribed in his means of doing good who cannot do all the good he wishes.

To restrict is to exercise a stronger degree of control, or to impose a harder necessity, than either of the other terms: a person is restricted by his physician to a certain portion of food in the day.

BOUNDARY. See BORDER; BOUNDS; TERM.

BOUNDLESS, UNBOUNDED, UNLIMITED, INFINITE. Boundless, or without bounds, is applied to objects which admit of no bounds to be made or conceived by us. Unbounded, or not bounded, is applied to that which might be bounded. Unlimited, or not limited, applies to that which might be limited. Infinite, or not finite, applies to that which in its nature admits of no bounds.

The ocean is a boundless object so long as no bounds to it have been discovered; desires are often unbounded which ought always to be bounded; power is sometimes unlimited which would be better limited; nothing is infinite but that Being from whom all finite beings procecd.

BOUNDS, Boundary. Bounds and boundary, from the verb bound, signify the line which sets a bound or marks the extent to which any spot of ground reaches.

Bounds is employed to designate the whole space, including the outer line that confines: boundary comprehends only this outer line. Bounds are made for a local purpose; boundary for a political purpose: the master of a school prescribes the bounds beyond which the scholar is not to go; the parishes throughout England have their boundaries, which are distinguished by marks; fields have likewise their boundaries, which are commonly marked out by a hedge or a ditch. Bounds are temporary and changeable; boundaries permanent and fixed: whoever has the authority of prescribing bounds for others may in like manner contract or extend them at pleasure; the boundaries of places are seldom altered but in consequence of great political changes.

In the figurative sense bound or bounds is even more frequently used than boundary; we speak of setting bounds or keeping within bounds, but to know a boundary: it is necessary occasionally to set bounds to the inordinate appetites of the best disposed children, who cannot be expected to know the cxact boundary for indulgence.

BOUNTEOUS. See Beneficent.

BOUNTIFUL. See Beneficent.

BRACE. See CoUple.

BRAG. See Gasconade.

BRAVE, Gallant. Brave, French brave, originally signified fine, proud, inclined to be a braggart; then valiant, allied to Italian bravo. The origin is unknown. Gallant, Old French galant, is a participle of galer, to make merry, allied to Italian and Spanish gala, which appears in the expression "gala day," "gala attire." The early meaning of dashing, spirited, bold, associated with this word is now obsolete 
in French, but survives in English together with the common French meaning-courteous, courtly, etc.

These epithets, whether applied to the person or the action, are alike honorable; but the latter is a much stronger expression than the former. Gallantry is extraordinary bravery, or bravery on extraordinary occasions: the brave man goes willingly where he is commanded; the gallant man leads on with vigor to the attack. Bravery is common to vast numbers and whole nations; gallantry is peculiar to individuals or particular bodies: the brave man bravely defends the post assigned him; the gallant man volunteers his services in cases of peculiar danger: a man may feel ashamed in not being considered brave; he feels a pride in being looked upon as gallant. To call a hero brave adds little or nothing to his character; but to entitle him gallant adds a lustre to the glory he has acquired.

See also STALWART.

Brave, Defy, Dare, Challenge.-Brave, from the epithet brave, signifies to act the part of a fearless man. Defy, in French défier, from Late Latin diffidare, from Latin dis, apart, and fides, faith, means to renounce faith. Dare, AngloSaxon ic dearr, 1 dare, is allied to Greek $\theta a \rho \sigma \widehat{\varepsilon} \nu$, to be bold. Challenge, Middle English chalenge, was often used in the sense of claim; it is derived from Latin calumnia, a false accusation, whence the word calumny is also derived. A challenge meant an invitation to defend one's honor against an accusation by fighting.

To brave is with bravery to resist or meet the force of any opposing power: as the sailor braves the tempestuous ocean, or, in the bad sense, a man braves the scorn and reproach of the world; so things personified may brave.

To defy is to hold cheap that which opposes itself as it respects persons; there is often much insolent resistance in defiance, as a man defies the threats of his superior.

In respect to things it denotes a resolution to bear whatever may be inflicted.

To dare and to challenge have more of provocation than resistance in them; he who dares and challenges provokes or calls on another to do something. To dare is an informal act, performed either by words or deeds; as to dare a person to come out, to dare him to leave his place of retreat: to challenge is a formal act, performed by words; as to challenge another to fight, or to engage in any contest.

Daring may sometimes be performed by actions, and braving sometimes by words; so that by the poets they are occasionally used one for the other.

Bravery, Courage, Valor.-Bravery denotes the abstract quality of brave. Courage, in French courage, comes from coeur, in Latin cor, the heart, which is the seat of courage. Valor, in French valeur, Latin valor, from valere, to be strong, signifies by distinction strength of mind.

Bravery lies in the blood; courage lies in the mind; the latter depends on the reason, the former on the physical temperament: the first is a species of instinct; the second is a virtue: a man is brave in proportion as he is without thought; he has courage in proportion as he reasons or reflects. Bravery is of utility only in the hour of attack or contest; courage is of service at all times and under all circumstances: bravery is of avail in overcoming the obstacle of the moment; courage seeks to avert the distant evil that may possibly arrive. Bravery is a thing of the moment-that is or is not, as circumstances may favor; it varies with the time and season: courage exists at all times and on all occasions. The brave man who fearlessly rushes to the mouth of the cannon may tremble at his own shadow as he passes through a churchyard or turn pale at the sight of blood: the courageous man smiles at imaginary dangers, and prepares to meet those that are real. It is as possible for a man to have courage without bravery as to have bravery without courage. Cicero showed no marks of personal bravery as a commander, but he displayed his courage when he laid open the treasonable purposes of Catiline to the whole senate, and charged him to his face with the crimes of which he knew him to be guilty.

Valor is a higher quality than either bravery or courage, and seems to partake of the grand characteristics of both; it 
combines the fire of bravery with the determination and firmness of courage: bravery is most fitted for the soldier and all who receive orders; courage is most adapted for the general and all who give command; valor for the leader and framer of enterprises and all who carry great projects into execution: bravery requires to be guided; courage is equally fitted to command or obey; valor directs and executes. Bravery has most relation to danger; courage and valor include in them a particular reference to action: the brave man exposes himself; the courageous man advances to the scene of action which is before him; the valiant man seeks for occasions to act. The three hundred Spartans who defended the Straits of Thermopylæ were brave. Socrates drinking the hemlock, Regulus returning to Carthage, Titus tearing himself from the arms of the weeping Berenice, Alfred the Great going into the camp of the Danes, were courageous. Hercules destroying monsters, Perseus delivering Andromeda, Achilles running to the ramparts of Troy, and the knights of more modern date who have gone in quest of extraordinary adventures, are all entitled to the peculiar appellation of valiant.

\section{BRAWNY. See Herculean.}

BREACH, Break, Gap, Chasm. Breach and break are both derived from the same verb break (see BREAK), to denote what arises from being broken, in the figurative sense of the verb itself. Gap is a Scandinavian word allied to gape, signifying that which gapes or stands open. Chasm (Latin chasma, a gulf, which is a transliteration of Greek $\chi \alpha \dot{\alpha} \mu a$, a yawning cleft, allied to $\chi^{a o s}$, , chaos) has a similar meaning.

The idea of an opening is common to these terms, but they differ in the nature of the opening. A breach and a gap are the consequence of a violent removal which destroys the connection; a break and a chasm may arise from the absence of that which would form a connection. A breach in a wall is made by means of cannon; gaps in fences are commonly the effect of some violent effort to pass through; a break is made in a page of printing by leaving off in the middle of a line; a chasm is left in writing when any words in the sentence are omitted. A breach and a chasm always imply a larger opening than a break or gap. A gap may be made in a knife; a breach is always made in the walls of a building or fortification: the clouds sometimes separate so as to leave small breaks; the ground is sometimes so convulsed by earthquakes as to leave frightful chasms.

Breach, chasm, and gap are figuratively applied to other objects with the same distinction; as a breach of friendship or of domestic harmony; a gap in nature or time; and a chasm in our enjoyments.

BREAK, RACK, REND, TEAR. Break, Anglo-Saxon brecan, is a Germanic word signifying to crack with a noise. Rack is a variant of wrack, allied to Anglo-Saxon urecan (Modern English wreck), to drive, urge: it refers especially to something driven ashore, hence to anything broken in pieces, like a ship crushed on the rocks in a storm. Rend, Northern French renne, to tear apart, has few cognates outside of English. Tear comes from Anglo-Saxon teran, to rend.

The forcible division of any substance is the common characteristic of these terms. Break is the generic term, the rest are specific: everything racked, rent, or torn is broken, but not vice versa. Break has, however, a specific meaning, in which it is comparable with the others. Breaking requires less violence than either of the others. brittle things may be broken with the slightest touch, but nothing can be racked without intentional violence of an extraordinary kind. Glass is quickly broken; a table is racked. Hard substances only are broken or racked; but everything of a soft texture and composition may be rent or torn. Breaking is performed by means of a blow; racking by that of a violent concussion or straining; but rending and tearing are the consequences of a pull or a sudden snatch. Anything of wood or stone is broken; anything of a complicated structure, with hinges and joints, is racked; cloth is rent, paper is torn. Rend is sometimes used for what is done by design; a tear is always faulty. Cloth is sometimes rent rather than cut 
when it is wanted to be divided; but when it is torn it is injured. To tear is also used in the sense not only of dividing by violence that which ought to remain whole, but by separating one object from another; as to tear anything off or out, etc.

In the moral or figurative application, break denotes in general a division or separation more or less violent of that which ought to be united or bound; as to break a tie, to break an engagement or promise. To rack is a continued action; as to rack the feelings, to place them in a violent state of tension. To rend is figuratively applied in the same sense as in the proper application, to denote a sudden division of what has been before whole; as to rend the heart, to have it pierced or divided, as it were, with grief; so likewise to rend the air with shouts. To tear is metaphorically separating objects from one another which are united; as to tear one's self from the company of a friend.

Break, Bruise, Squeeze, Pound, Crush. -Break (see above). Bruise, AngloSaxon brysan in the compound to-brysan, to bruise, is also found in Old French bruiser, to break. It may be a Celtic word. Squeeze, Late Middle English queisan, is derived from ex, and Anglo-Saxon cwiesan, to crush. Pound, from Anglo-Saxon punian, to pound, is allied to Dutch puin, rubbish, hash, or "a cyment of stones," and Low German pun, chips of stones. Crush, Old French crusir, to crack or break, is derived from a Teutonic root signifying to gnash with the teeth.

Break always implies the separation of the component parts of a body; bruise denotes simply the destroying the continuity of the parts. Hard, brittle substances, as glass, are broken; soft, pulpy substances, as flesh or fruits, are bruised. The operation of bruising is performed either by a violent blow or by pressure; that of squeezing by compression only. Metals, particularly lead and silver, may be bruised; fruits may be either bruised or squeezed. In this latter sense bruise applies to the harder substances, or indicates a violent compression; squeeze is used for soft substances or a gentle compression. The kernels of nuts are bruised; oranges or apples are squeezed. To pound is properly to bruise in a mortar, so as to produce a separation of parts; to crush is the most violent and destructive of all operations, which amounts to the total dispersion of all the parts of a body. What is broken may be made whole again; what is bruised or squeezed may be restored to its former tone and consistency; what is pounded is only reduced to smaller parts for convenience; but what is crushed is destroyed. When the wheel of a carriage passes over any body that yields to its weight, it crushes it to powder.

In the figurative sense, crush marks a total annihilation: if a conspiracy be not crushed in the bud, it will prove fatal to the power which has suffered it to grow.

Break, Burst, Crack, Split.-Break (see preceding). Burst, Anglo-Saxon berstan, is a Teutonic word signifying to break asunder. Crack, Anglo-Saxon cracian, to crack, is apparently an imitative word representing a sudden breaking asunder. Split is apparently borrowed from Middle Dutch splitten; it signifies a form of breaking.

Break is the general term, denoting any separation or coming apart with more or less force; the rest are particular modes, varied either in the circumstances of the action or the object acted upon. To break does not specify any particular manner or form of action; what is broken may be broken in two or more pieces, broken short or lengthwise, and the like: to burst is to break suadenly and with violence, frequently also with noise.

Everything that is exposed to external violence, particularly hard substances, are said to be broken; but hollow bodies, or such as are exposed to tension, are properly said to burst.

In the sense of making way or opening the same distinction is preserved.

To crack and split are modes of breaking lengthwise: the former in application to hard or brittle objects, as clay, or the things made of clay; the latter in application to wood, or that which is made of wood. Breaking frequently causes an entire separation of the component parts so as to destroy the things; cracking and splitting are but partial separations. 
BREAKER. See Wave.

BREED, ENGENDER. Breed signifies to produce or cherish a brood, a Teutonic word from a root meaning heat or warmth, breed being suggestive of fostering warmth. Engender, from Latin in, in, and generare, from gener, stem of genus, race, means to produce a race.

These terms are properly employed for the act of procreation. To breed is to bring into existence by a slow operation: to engender is to be the author or prime cause of existence. So, in the metaphorical sense, frequent quarrels are apt to breed hatred and animosity: the leveling and inconsistent ronduct of the higher classes in the present age serves to engender a spirit of insubordination and assumption in the inferior order. Whatever breeds acts gradually; whatever engenders produces immediately as cause and effect. Uncleanliness breeds diseases of the body; want of occupation breeds those of the mind; playing at chance games engenders a love of money.

See also RACE.

\section{BREEDING. See Eddcation.}

BREEZE, Gale, Blast, Gust, Storm, Tempest, Hurricane. All these words express the action of the wind, in different degrees and under different circumstances. Breeze, in Italian brezza, is in all probability an onomatopœia for that kind of wind peculiar to Southern climates. Gale is a Scandinavian word possibly allied to Danish gal, furious, and derived from the root found in Modern English yell. Blast, Anglo-Saxon bloest, signifies a blowing. Gust is allied to the verb gush, signifying a wind which gushes out, a sudden blast. Storm is a Germanic word from the root whence stir is also derived, and signifies a great stirring up of the elements. Tempest, in Latin tempestas, or tempus, a time or season, describes that season or sort of weather which is most remarkable, but at the same time most frequent, in Southern climates. IIurricane has been introduced by the Spaniards into European languages from the Caribbee Islands, where it describes that species of tempestuous wind most frequent in tropical climates.

A breeze is gentle; a gale is brisk, but steady; we have breezes in a calm summer's day; the mariner has favorable gales, which keep the sails on the stretch. A blast is impetuous: the exhalations of a trumpet, the breath of bellows, the sweep of a violent wind, are blasts. A gust is sudden and vehement; gusts of wind are sometimes so violent as to sweep everything before them while they last. Storm, tempest, and hurricane include other particulars besides wind. A storm throws the whole atmosphere into commotion; it is a war of the elements, in which wind, rain, hail, and the like conspire to disturb the heavens. Tempest is a species of storm which has also thunder and lightning to add to the confusion. Hurricane is a species of storm which exceeds all the rest in violence and duration.

Gust, storm, and tempest, which are applied figuratively, preserve their distinction in this sense. The passions are exposed to gusts and storms, to sudden bursts, or violent and continued agitations; the soul is exposed to tempests when agitated with violent and contending emotions.

BRIEF. See Laconic; Short.

BRIGHT. See Clear; Orient.

BRIGHTNESS, LUSTRE, SPLENDOR, Brilliancy. Brightness, from AngloSaxon beorht, shining, is allied to Greek фoorós, white. Lustre is derived from Late Latin lustrum, a window, Italian lustro, "a lustre, a glasse, a shining" (Florio), which comes ultimately from Latin lucere, to shine. Splendor, in French splendeur, is derived from Latin splendor, from splendere, to shine. Brilliancy, from French briller, to shine, comes from the Latin of the Middle Ages beryllus, a crystal.

Brightness is the generic, the rest are specific terms: there cannot be lustre, splendor, and brilliancy without brightness; but there may be brightness where these do not exist. These terms rise in sense; lustre rises on brightness, splendor on lustre, and brilliancy on splendor. Brightness and lustre are applied properly to natural lights; splendor and brilliancy have been more commonly applied to that which is artificial or unusual: there is always more or less brightness in the sun or moon; there is an occasional lustre in all the heavenly bodies when they shine in 
their unclouded brightness; there is splendor in the eruptions of flame from a volcano or an immense conflagration; there is brilliancy in a collection of diamonds. There may be both splendor and brilliancy in an illumination: the splendor arises from the mass and richness of light; the brilliancy from the variety and brightness of the lights and colors. Brightness may be obscured, lustre may be tarnished, splendor and brilliancy diminished.

The analogy is closely preserved in the figurative application. Brightness attaches to the moral character of men in ordinary cases, lustre attaches to extraordinary instances of virtue and greatness, splendor and brilliancy attach to the achievements of men. Our Saviour is strikingly represented to us as the brightness of his Father's glory and the express image of $\mathrm{His}$ person. The humanity of the English in the hour of conquest adds a lustre to their victories, which are either splendid or brilliant, according to the number and nature of the circumstances which render them remarkable.

BRILLIANCY. See BRIGHTNESS; RADIANCE.

BRILLIANT. See Gorgeous.

BRIM. See Bor.dER.

BRING, Fltch, Carry. Bring, Anglo-Saxo: bringan, is a widely distributed Germanic word. Fetch, AngloSaxon feccan, to fetch, is allied to fat, a pace, a step, and Latin pes, a foot; and meant to go to get something. Carry (see BEar; CARRY).

To bring is simply to take with one's self from the place where one is; to fetch is to go first to a place and then bring a thing; to fetch, therefore, is a species of bringing; whatever is near at hand is brought; whatever is at a distance must be fetched: the porter at an inn brings a parcel, a servant who is sent for it fetches it. Bring always respects motion toward the place in which the speaker resides; fetch, a motion both to and from; carry, always a motion directly from the place or at a distance from the place. A servant brings the parcel home which his master has sent him to fetch; he carries a parcel from home. A carrier carries parcels to and from a place, but he does not bring parcels to and from any place. Bring is an action performed at the option of the agent; fetch and carry are mostly done at the command of another. Hence the old proverb, "He who will fetch will carry," to mark the character of the gossip and tale-bearer, who reports what he hears from two persons in order to please both parties.

BRINK. See Border.

BRISK. See ACTION.

BRITTLE. See Fragile.

BROAD. See Large.

BROIL. See QuarRel.

BROOK, Bear, ENDURe, Stand. Brook is derived from Anglo-Saxon brucan, to enjoy. For the derivations of bear and endure, see BEAR. For the derivation of stand see that key-word. The term applies generally to the attitude of a person toward others. We bear with the company or actions of another whom we may dislike, from the impulse of politeness or policy, with conditions that are uncongenial because they are forced upon us or are unavoidable by us; we endure, or put up with, people, conditions, and objects because we are obliged to do so, or because it would not be convenient or prudent for us to do otherwise: and for similar reasons we permit or allow things to be said or done that are distasteful. The term stand, colloquially, has a very intimate relation to brook, as we say we will brook no delay, interference, postponement, and the like, in matters that concern us closely, implying that we will not stand, permit, or put up with any such actions.

BRUISE. See BREAK.

BRUTAL. See Heartless.

BRUTE. See ANIMAL.

BUD. See Germ; Sprout.

BUFFOON. See Fool.

BUILD, ERect, Construct. Build, Anglo-Saxon byldan, is allied to bold, a house, Icelandic bol, a house, etc., and signifies the making of a house. Erect, in French ériger, Latin erectus, participle of erigere, means to set up straight. Construct, in Latin constructus, participle of construo, compounded of con, together, and struere, to pile or put, signifies to build by piling stones one on top of another, etc.

The word build by distinction expresses the purpose of the action; erect 
indicates the mode of the action; construct indicates contrivance in the action. What is built is employed for the purpose of receiving, retaining, or confining; what is erected is placed in an elevated situation; what is constructed is put together with ingenuity. All that is built may be said to be erected or constructed; but all that is erected or constructed is not said to be built; likewise what is erected is mostly constructed, though not vice versa. We build from necessity; we erect for ornament; we construct for utility and convenience. Houses are built, monuments erected, machines are constructed.

See also Found.

BUILDER. See ARCHITECT.

BULK. See Size.

BULKX, Massive. Bulky denotes having bulk, from a root signifying to swell, which appears in bowl, bulge, belly, etc. It is a Scandinavian word. Massive, in French massif, from mass, signifies having a mass or being like a mass, which is in the German masse, Latin massa, Greek $\mu \tilde{a} \zeta \alpha$, dough, from $\mu \alpha \dot{\sigma} \sigma \varepsilon t \nu$, to knead, signifying made into a solid substance.

Whatever is bulky has a prominence of figure; what is massive has compactness of matter. The bulky, therefore, though larger in size, is not so weighty as the massive. Hollow bodies frequently have bulk; none but solid bodies can be massive. A vessel is bulky in its form; lead, silver, and gold are massive.

BULLY. See Hector.

BUNGLE, Botch, Mrsmanage, SpoIL. Bungle, a word of imitative origin, signifies in ordinary language to do anything clumsily, to mismanage, or execute badly an affair through ignorance, clumsiness, or awkwardness. Botch, a word of imitative origin allied to paich, a piece of work, means to put together carelessly, as a patch on anything, or a part of any work so finished that it looks worse than the rest or unbecoming to it. Spoil means to render useless, to disfigure beyond recognition, to mar, damage, or ruin anything, or by careless work to cause an object to deteriorate in appearance or value.

BUOYANT. See Sangunne.

BURDEN. See Freight; Weight.
BURDENSOME. See Heavy.

BURIAL, INTERMENT, SEPUlture. Burial, allied to bury, Anglo-Saxon byrigan, is derived from beorgan, to hide, and means to hide in the ground. Interment, from inter, compounded of in, and terra, signifies the putting into the ground. Sepulture, in French sépulture, Latin sepultura, is derived from sepelire, to bury.

Under burial is comprehended simply the purpose of the action; under interment and sepulture, the manner as well as the motive of the action. We bury in order to conceal; interment and sepulture are accompanied with religious ceremonies. Bury is confined to no object or place; we bury whatever we deposit in the earth, and wherever we please; but interment and sepulture respect only the bodies of the deceased when deposited in a sacred place. Burial requires that the object be concealed under ground; interment may be used for depositing in vaults. Selfmurderers were formerly buried in the highways; Christians in general are buried in the churchyard; but the kings of England were formerly interred in Westminster Abbey. Burial is a term in familiar use; interment serves frequently as a more elegant expression; sepulture is an abstract term confined to particular cases, as in speaking of the rites and privileges of sepulture.

BURIAL-GROUND. See NECROPOLIS.

BURLESQUE. See Caricature; Travesty; Wit.

BURNING. See Hot.

BURST. See Break.

BUSINESS, Occupation, EMployMent, Engagement, Avocation. Business signifies that which makes busy (see ACTIVE). Occupation, from Latin occupare, compounded of $o b$, near, and capere, to take, signifies that which serves or takes possession of a person or thing to the exclusion of other things. Employment, in French emploi, is derived from Latin implico (whence implicate), signifying to enfold, employment being that which enfolds one, shuts one off from other activities; compare the phrase "wrapped up in his work" for a similar metaphor. Engagement (see ATTRACT). Avocation, in Latin avocatio, from a, away, and 
vocare, to call, signifies the thing that calls off from another thing.

Business occupies all a person's thoughts as well as his time and powers; occupation and employment occupy only his time and strength: the first is mostly regular, it is the object of our choice; the second is casual, it depends on the will of another. Engagement is a partial employment, avocation a particular engagement: an engagement prevents us from doing anything else; an avocation calls off or prevents us from doing what we wish. Every tradesman has a business, on the diligent prosecution of which depends his success in life; every mechanic has his daily occupation, by which he maintains his family; every laborer has an employment which is fixed for him. Business and occupation always suppose a serious object. Business is something more urgent and important than occupation: a man of independent fortune has no occasion to pursue business, but as a rational agent he will not be contented to be without an occupation.

Employment, engagement, and avocation leave the object undefined. An employment may be a mere diversion of the thought and a wasting of the hours in some idle pursuit; a child may have its employment, which may be its play in distinction from its business: an engagement may have no higher object than that of pleasure; the idlest people have often the most engagements; the gratification of curiosity and the love of social pleasure supply them with an abundance of engagements. Avocations have seldom a direct trifling object, although it may sometimes be of a subordinate nature, and generally irrelevant: numerous avocations are not desirable; every man should have a fixed pursuit, as the business of his life, to which the principal part of his time should be devoted: avocations, therefore, of a serious nature are apt to divide the time and attention to a hurtful degree.

A person who is busy has much to attend to, and attends to it closely: a person who is occupied has a full share of business without any pressure; he is opposed to one who is idle: a person who is employed has the present mo- ment filled up; he is not in a state of inaction: the person who is engaged is not at liberty to be otherwise employed; his time is not his own; he is opposed to one at leisure.

Business, Trade, Profession, Art.Business (see above). Trade signifies that which employs the time by way of trade. Profession signifies that which one professes to do. Art signifies that which is followed in the way of the arts.

These words are synonymous in the sense of a calling for the purpose of a livelihood: business is general, trade and profession are particular; all trade is business, but all business is not trade. Buying and selling of merchandise is inseparable from trade; but the exercise of one's knowledge and experience for purposes of gain constitutes a business: when learning or particular skill is required, it is a profession; and when there is a peculiar exercise of art, it is an art; every shopkeeper and retail dealer carries on a trade; brokers, manufacturers, bankers, and others carry on business; clergymen, medical or military men follow a profession; musicians and painters follow an art.

Business, Office, Duty.-Business (see above). Office (see Benefit). Duty signifies what is due or owing one, based on. French du, Latin debitum, participle of debere, to owe.

Business is that which engages the time, talents, and interest of a man; it is what a man proposes to himself: office is that which a man is called upon to do for another; it is consequently prescribed by others: duty is that which duty prescribes: one follows business, fills or discharges an office, and performs or discharges a duty. As business is the concern of the individual, and duty is his duty, these terms properly apply to private matters as the business or duties of life: office, on the other hand, being that which is done for the benefit or by the direction of others, is properly applied to public matters.

But the terms may be so qualified that the former may be applied to public, and the latter to private matters.

Business and office are frequently applied to that part which a man is called to perform; in which sense busi- 
ness and office come still nearer to the term duty; what belongs to a person to do or see done, that is properly his business: a person is bound, either by the nature of his engagements or by private and personal engagements or private and personal motives, to perform a service for another, as the office of a prime minister, the office of a friend; that is his office. Duly in this application expresses a stronger obligation than either of the other terms; where the service is enjoined by law, or commanded by the person, that is a duty, as the clerical duties, the duty of a soldier.

See also Affarr.

BUSTLE, TUMdLT, Uproar. Bustle is a Scandinavian word, a frequentative of the Norwegian busta, to be violent, and related to Icelandic bustla, to splash about like a fish, and to English boast, boisterous, etc. Tumult, Latin tumultus, is derived from Latin tumere, to swell, surge up, whence tumor is also derived. Uproar is derived from Dutch op, up, and roeren, to excite, stir, move, and signified originally a stirring up; but its meaning has been influenced by its similarity to English roar.

Bustle has most of hurry in it; tumult most of disorder and confusion; uproar most of noise: the hurried movements of one, or many, cause a bustle; the disorderly struggles of many constitute a tumult; the loud elevation of many opposing voices produces an uproar. Buslle is frequently not the effect of design, but the natural consequence of many persons coming together; tumult commonly arises from a general effervescence in the minds of a multitude; uproar is the consequence either of general anger or mirth. A crowded street will always be in a bustle; contested elections are always accompanied with a great tumult; drinking-parties make a considerable uproar, in the indulgence of their intemperate mirth.

BUSY. See Active.

BUT, EXCEPT. As a conjunction but implies something more to supply, unless, yet, nevertheless, than, and otherwise than, and is used where a second sentence or clause is in opposition to the one precrding it, to arrest an inference which the first sentence or clause would otlerwise have sug- gested. As an adverb, it implies only; as a proposition, technically, a term of separation or exclusion, it signifies excepting; as an interjection it expresses surprise or dissent; as a substantive, a hindrance or impediment, also the outer room of a house of two or more apartments where the inner room is entered from the other. In logic, but is the connecting word which introduces the minor term of a syllogism; in mathematics, it denotes what is assumed or proved.

As a conjunction but is a synonyme of yet. Yet denotes a stronger degree of opposition than but. As a preposition but is a synonyme of except. There is little difference in meaning between the two prepositions. Except is somewhat clearer and more emphatic, and may be used to introduce not merely a noun but a noun clause.

BUTCHERY. See Carnage.

BUTT. See Mark.

BUY, Purchase, Bargain, CheapEN. Buy is derived from Anglo-Saxon bycgan, to buy. Purchase comes from Old French pour (Latin pro) and chacer, to chase, and signifies to hunt for eagerly. Bargain is derived from Late Latin barcaniare, to change about, to chaffer; its remoter origin is unknown. Cheapen, from Anglo-Saxon ceap, price, meant to price, and then to seek to obtain for a small price.

Buy and purchase have a strong resemblance to each other, both in sense and application; but the latter is a term of more refinement than the former: buy may always be substituted for purchase without impropriety; but purchase would be sometimes ridiculous in the familiar application of buy: the necessaries of life are bought; luxuries are purchased. The characteristic idea of buying is that of expending money according to a certain rule and for a particular purpose; that of purchasing is the procuring the thing by any means; some things, therefore, may more properly be said to be purchased than bought, as to purchase friends, ease, and the like.

Buying implies simply the exchange of one's money for a commodity; bargaining and cheapening have likewise respect to the price: to bargain is to make a specific agreement as to the 
price; to cheapen is not only to lower come lost to sight and, in a sense, to the price asked, but to deal in such memory. From this we have the familthings as are cheap: trade is supported by buyers; bargainers and cheapeners are not acceptable customers: mean people are prone to bargaining, poor people are obliged to cheapen.

BYGONE, PAST. Bygone, a compound of the English by, near, from, after, and gone, departed, moved, as an adjective implies gone by, passed or past, and as a substantive, things that have disappeared, passed away, beiar phrase let bygones be bygones, implying let the past be forgotten, doubtless from the old form, byganes suld be byganes, the past should not be brought up against one. As an adjective bygone does not really differ in meaning from past. But past is a prosaic word; it merely indicates a fact or a condition. Bygone has a pensive, poetic, slightly archaic quality.

BYWORD. See AxIOM. 
CABAL. See Combination. CAjOlE. See Coax.

CALAMITOUS. See INFELICITOUS. Calamity, Disaster, Misfortune, Mischance, Mishap. Calamity comes from Latin calamitas, misfortune; its ultimate origin is unknown. Disaster, in French désastre, is compounded of the privative des or dis and astre, in Latin astrum, a star, signifying what comes from the adverse influence of the stars. .Misfortune, mischance, and mishap naturally express what comes amiss by fortune or chance.

The idea of a painful event is common to all these terms, but they differ in the degree of impatience. A calami$t y$ is a great disaster or misfortune; a misfortune, a great mischance or mishap: whatever is attended with destruction is a calamity; whatever is accompanied with a loss of property, or the deprivation of health, is a misfortune; whatever diminishes the beauty or utility of objects is a mischance or mishap: the devastation of a country by hurricanes or earthquakes, and the desolation of its inhabitants by famine or plague, are great calamities; the overturning of a carriage, and the fracture of a limb, are disasters; losses in trade are misfortunes; the spoiling of a book is, to a greater or less extent, a mischance or mishap. A calamity seldom arises from the direct agency of man; the elements, or the natural course of things, are mostly concerned in producing this source of misery to men; the rest may be ascribed to chance, as distinguished from design: disasters mostly arise from some specific known cause, either the carelessness of persons or the unfitness of things for their use; as they generally serve to derange some preconcerted scheme or undertaking, they seem as if they were produced by some secret influence: misfortune is frequently assignable to no specific cause; it is the bad fortune of an individual; a link in the chain of his destiny; an evil independent of himself, as distinguished from a fault: mischance and mishap are misfortunes of comparatively so trivial a nature that it would not be worth while to inquire into their cause or to dwell upon their consequences. A calamity is dreadful, a disaster melancholy, a misfortune grievous or heavy, a mischance or mishap slight or trivial.

Calculate, Reckon, Compute, CounT. Calculate, in Latin calculatus, participle of calculo, comes from calculus, Greek кádı the Greeks gave their votes, and the Romans made out their accounts, by little stones; hence it denotes the action itself of reckoning. Reckon is derived from Anglo-Saxon gerecnian, to explain, from reccan to rule, order, direct, and refers to an orderly process of thought - to the directing and ordering of one's thoughts or plans. Compute, in French computer, Latin computo, compounded of com and puto, signifies to put together in one's mind. Count, in French compter, is but a contraction of computer.

These words indicate the means by which we arrive at a certain result in regard to quantity. To calculate is the generic term; the rest denote modes of calculating: to calculate denotes any numerical operation in general, but is particularly applicable to the abstract science of figures; the astronomer calculates the motions of the heavenly bodies; the mathematician makes algebraic calculations: to reckon is to enumerate and set down things in detail; reckoning is applicable to the ordinary business of life: tradesmen keep their accounts by reckoning; children learn to reckon by various simple processes. Calculation is therefore the science, reckoning the practical art of enumerating.

To compute is to come at the result by calculation; it is a sort of numerical estimate drawn from different sources: historians and chronologists compute the times of particular events by comparing them with those of other known events. An almanac is made by calculation, computation, and reckoning. The rising and setting of the heavenly 
bodies are calculated; from given astronomical tables is computed the moment on which any celestial phenomenon may return; and by reckoning are determined the days on which holidays, or other periodical events, fall.

To count is as much as to take account of, and when used as a mode of calculation it signifies the same as to reckon one by one; as to count one by one, to count the hours or minutes.

These words are all employed in application to moral objects, to denote the estimate which the mind takes of things. To calculate is to look to future events and their probable consequences; we calculate on a gain, on an undertaking, or any enterprise: to compute is to look to that which is past and what results from any past event, as to compute a loss, or the amount of any mischief done: to reckon is either to look at that which is present, and to set an estimate upon it; as to reckon a thing cheap; or to look to that which is future as something desirable, as to reckon on a promised pleasure. To count is to look on the thing that is present, and to set a value upon it according to circumstances, as to count a thing for nothing. A spirit of calculation arises from the cupidity engendered by trade; it narrows the mind to the mere prospect of accumulation and self-interest. Computations are inaccurate that are not founded upon exact numerical calculations. Inconsiderate people are apt to reckon on things that are very uncertain, and then lay up to themselves a store of disappointments. Those who have experienced the instability of human affairs will never calculate on an hour's enjoyment beyond the moment of existence. It is difficult to compute the loss which an army sustains upon being defeated, especially if it be obliged to make a long retreat. Those who know the human heart will never reckon on the assistance of professed friends in the hour of adversity. Men often count their lives as nothing in the prosecution of a favorite scheme.

CALENDAR, Almanac, EphemERIS. Calendar, Latin calendarium, was originally an account book kept by money-changers, so called because in- terest was due on the first of the month, which was termed the Calendar. Almanac is a word of unknown origin which appears in Latin in the thirteenth century, and shortly after that in most of the Romance languages. It may be derived from an Arabic root signifying

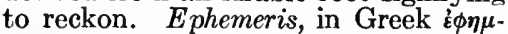

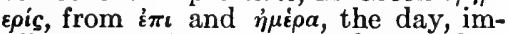
plies that which happens by the day. These terms denote a date-book, but the calendar is a book which registers events under every month: the almanac is a book which registers times, or the divisions of the year: and an ephemeris is a book which registers the planetary movements every day. An almanac may be a calendar and an ephemeris may be both an almanac and a calendar; but every almanac is not a calendar, nor every calendar an almanac. The Gardener's Calendar is not an almanac, and the sheet almanacs are seldom calendars: likewise the Nautical Ephemeris may serve as an almanac, although not as a calendar.

CALL, Cry, Exclaim. Call is a word of Scandinavian origin, and signifies simply the raising of the voice. Cry, French crier, Italian gridare, is derived from Latin quiritare, to shriek or lament, originally signifying to implore the aid of the Quirites, or Roman citizens. Exclaim is derived from the Latin ex and clamare, to cry out; both denote a raising the voice louder than a simple call. Call is used on all ordinary occasions in order to draw a person to a spot, or for any other purpose, when one wishes to be heard; to cry is to call loudly on particular occasions: a call draws attention; a cry awakens alarm.

To cry is for general purposes of convenience, as the cry of the hunter, or the cries of persons to or among numbers; to exclaim is an expression of some particular feeling.

See also Alarm; NAME.

Call, Invite, Bid, Summon.-Call, in its abstract and original sense, signifies simply to give an expression of the voice. Bid is derived from AngloSaxon beodan, to command. Invite comes from Latin invitus, unwilling, the unwilling person being one who must be especially requested or invited to do something. Summon is derived 
from Latin submoneo, from $s u b$ and monere, to warn, and signifies to give special notice.

The idea of signifying one's wish to another to do anything is included in all these terms. In the act of calling, any sounds may be used; we may call by simply raising the voice; inviting may be a direct or indirect act; we may invite by looks or signs as well as by words, by writing as well as by speaking.

To bid and summon require the express use of words; the former is always directly addressed to the person, the latter may be conveyed by an indirect channel.

As the action of calling requires no articulate sounds, it may be properly applied to animals; as sheep call their young.

So likewise to inanimate objects when made to sound by way of signal or for the purpose of calling.

So likewise invite may be said not only of unconscious, but spiritual agents.

Calling is the act of persons of all ranks, superiors, inferiors, or equals; it may therefore be either a command, a demand, or a simple request. Parents and children, masters and servants, call to each other as the occasion requires.

Bidding is always the act of a superior by way of command or entreaty.

Inviting is an act of courtesy or kindness between equals.

To summon is an act of authority, as to summon witnesses.

When these words are employed in the sense of causing any one to come to a place, call and summon are most nearly allied, as are also bid and invite. In this case to call is an act of discretion on ordinary occasions, and performed in an ordinary manner; as to call a meeting, to call together, to call home: to summon is a formal act, and more or less imperative according to the occasion; as to summon a jury.

Bidding and inviting, though acts of kindness, are distinguished as before according to the condition of the person; bid is properly the act of a superior, and invite of an equal, or one entitled to the courtesies of life.

These terms may all be used in the figurative application with a similar distinction in sense. Things personified may be said to call, summon, bid, invite.

Things personified may also be said to be called, invited, bidden, or summoned.

CALling. See Vocation.

CALlous. See Hard.

CAlM, Composed, Collected. Calm (see APPEASE). Composed, from the verb compose, marks the state $\alpha$ being composed; and collected, from collect, the state of being collected.

These terms agree in expressing a state; but calm respects the state of the feelings, composed the state of the thoughts and feelings, and collected the state of the thoughts more particularly. Calmness is peculiarly requisite in seasons of distress, and amidst scenes of horror: composure, in moments of trial, disorder, and tumult: collectedness, in moments of danger. Calmness is the companion of fortitude; no one whose spirits are easily disturbed can have strength to bear misfortune: composure is an attendant upon clearness of understanding; no one can express himself with perspicuity whose thoughts are any way deranged: collectedness is requisite for a determined promptitude of action; no one can be expected to act promptly who cannot think fixedly. It would argue a want of all feeling to be calm on some occasions, when the best affections of our nature are put to a severe trial. Composedness of mind associated with the detection of guilt evinces a hardened conscience and an insensibility to shame. Collectedness of mind has contributed in no small degree to the preservation of some persons' lives in moments of the most imminent peril. See also Abate; Peace; Quell; UNROFFLED.

Calm, Placid, Serene.-Calm (see above). Placid, in Latin placidus, from placeo, please, signifies the state of being pleased, or free from uneasincss. Serene is derived from Latin serenus, bright, clear.

Calm and serene are applied to the elements; placid only to the mind. Calmness respects only the state of the winds, serenity that of the air and heavens; the weather is calm when it is free from agitation: it is serene when 
free from noise and vapor. Calm respects the total absence of all perturbation; placid, the ease and contentment of the mind; serene, clearness and composure of the mind.

As in the natural world a particular agitation of the wind is succeeded by a calm, so in the mind of man, when an unusual effervescence has been produced, it commonly subsides into a calm; placidity and serenity have more that is even and regular in them; they are positively what they are. Calm is a temporary state of the feelings; placid and serene are habits of the mind. We speak of a calm state, but a placid and serene temper. Placidity is more of a natural gift; serenity is acquired: people with not very ardent desires or warmth of feeling will evince placidity; they are pleased with all that passes inwardly or outwardly: nothing contributes so much to serenity of mind as a pervading sense of God's good providence, which checks all impatience, softens down every asperity of humor, and gives a steady current to the feelings.

CALUMNIATE. See Asperse.

CAMOUflaGe, Disguise, Mask. Camouflage is a bit of trench slang which bids fair to become a naturalized English word. It is said to have been originally applied to the actor's make-up, and is derived through French camoufler, to disguise, from Latin caput, head, and Low Latin muffulare, to muffle. It referred to the covering of the head or disguising of the features in such a way as to escape recognition. It is now applied to the art of concealing or disguising guns, trenches, etc., in such a way that they appear to the enemy to be innocuous features of the natural scenery.

In meaning camouflage does not really differ from disguise; in most instances disguise may be substituted for it. But it is a much fresher and more picturesque term, and carries with it a definite suggestion of the romance and adventure of warfare. Mask is a word which also has the fundamental meaning of disguise, and suggests an image similar to that originally implied by camouflage. But it has not the vividness and timeliness of the new word
CAN, May. Can, in the Northern languages können, etc., is derived, most probably, from kennen, to know, from the natural intimacy which subsists between knowledge and power. May is in German mögen, to desire or wish, its present meaning having developed from the connections between wishing and complying with a wish. Can denotes possibility, may liberty and probability: he who has sound limbs can walk; but he may not walk in places which are prohibited.

CANCEL. See Abolish; Blot.

CANDID, Open, Sincere. Candid, Latin candidus, from candere, to shine, signifies to be pure as truth itself. Open, Anglo-Saxon ofen, is possibly allied to $u p$, and may have signified the lifting up of the tent door. Sincere comes from Latin sincerus, pure, unaffected.

Candor arises from a conscious purity of intentions; openness, from a warmth of feeling and love of communication; sincerity, from a love of truth.

Candor obliges us to acknowledge even that which may make against ourselves; it is disinterested: openness impels us to utter whatever passes in the mind; it is unguarded: sincerity prevents us from speaking what we do not think; it is positive. A candid man will have no reserve when openness is necessary; an open man cannot maintain a reserve at any time; a sincere man will maintain a reserve only as far as it is consistent with truth. Candor wins much upon those who come in connection with it; it removes misunderstandings and obviates differences; the want of it occasions suspicion and discontent. Openness gains as many enemies as friends; it requires to be well regulated not to be offensive; there is no mind so pure and disciplined that all the thoughts and feelings which it gives birth to may or ought to be made public. Sincerity is an indispensable virtue; the want of it is always mischievous, frequently fatal.

See also Frank.

CANONIZATION. See BeatificaTION.

CAPABLE. See Able. 
CApacious. See Able; Ample.

CAPACITY, Capaciousness. Capacity (see ABILITY) is the abstract of capax, receiving or apt to hold; it is therefore applied to the contents of hollow bodies. Capaciousness (see AMple) is the abstract of capacious, and is therefore applied to the plane surface comprehended within a given space. Hence we speak of the capacity of a vessel, and the capaciousness of a room.

Capacity is an indefinite term designating the property of being fit.to hold or receive, as applied to bodies generally; but capaciousness denotes a fulness of this property as belonging to a particular object in a great degree. Measuring the capacity of vessels belongs to the science of mensuration: the capaciousness of a room is to be observed by the eye. They are marked by the same distinction in their moral application: men are born with various capacities; some are remarkable for the capaciousness of their minds.

CAPRICE. See HuMOR.

CAPRICIOUS, See FANCIFUL; HuMORSOME.

Captious, Cross, Peevish, Petulant, Fretrul. Captious is derived from Latin captio, a sophistical argument, from capere, to hold. Cross, after the noun cross, Latin crux, signifies a temper which is contrary to the wishes of others. Peevish is a word of imitative origin; the leading idea seems to have been to make a whining cry. Fret, Anglo-Saxon fretan, from fra, from, and etan, eat, signifies to eat away, hence a wearing and gnawing grief or anger. Petulant, Latin petulans, comes from the root found in petere, to seek, to fly toward, and signified originally a dissatisfied temper, one which was continually seeking something not in its possession.

All these terms indicate an unamiable working and expression of temper. Captious marks a readiness to be offended or come across the wishes of others; peevish expresses a strong degree of crossness; fretful, a complaining impatience; petulant, a quick or sudden impatience. Captiousness is the consequence of misplaced pride; crossness, of ill-humor; peevishness and fretfulness. of a painful irritability; petu- lance is either the result of a naturally hasty temper or of a sudden irritability: adults are most prone to be captious; they have frequently a self-importance which is in perpetual danger of being offended: an undisciplined temper, whether in young or old, will manifest itself on certain occasions by cross looks and words toward those with whom they come in connection: spoiled children are most apt to be peevish; they are seldom thwarted in any of their unreasonable desires without venting their ill-humor by an irritating and offending action: sickly children are mostly liable to fretfulness, their unpleasant feelings vent themselves in a mixture of crying, complaints, and crossness: the young and ignorant are most apt to be petulant when contradicted.

\section{See also Crnical.}

CAPtivate. See Charm; EnSLAVE.

CAPTIVITy. See Confinement.

CAPTURe, Seizure, Prize. Capture, Latin captura, from captus, participle of capere, to take, signifies either the act of taking or the thing taken, but mostly the former. Seizure, in French saisir, comes from Late Latin sacire, to put, to place. Prize, French prise, the thing taken, from Latin prehendere, to take, signifies only the thing taken.

Capture and seizure differ in the mode: a capture is made by force of arms; a seizure by direct and personal force. The capture of a town or an island requires an army; the seizure of property is effected by the exertions of an individual.

A seizure always requires some force, but a capture may be effected without force on unresisting objects. Merchant vessels are captured; contraband goods are seized, or there may be an unlawful seizure of another's property.

Capture and seizure relate to the act of taking as well as the thing taken: prize relates only to the thing taken, and its value to the captor. There are many captures made at sea which never become prizes; the term prize is therefore applied to whatever valuable comes into our possession by our own efforts.

CARBUNCle. See Anthrax. 
CARCASS. See Body.

CARDINAL, ChIEF, LeadiNG, MAIN. Cardinal, in Latin cardinalis, from cardo, a hinge, French cardinal, principal. The implication of a hinge in the term is said to have been derived from a letter erroneously attributed to Pope Anacletus I., in the first century, in which the apostolic chair was declared "the hinge and head of all the Churches and, as a door is controlled by its hinge, so all Churches are governed by this Holy Chair."

For the difference between chief and main see Chief. Cardinal differs from these two words mainly in the image that it suggests. Chief and main indicate objects, people, or ideas that are prominent by reason of position or size; cardinal indicates something that is important by reason of its relation to something else.

CARE, Solicitude, ANXIETy. Care, Anglo-Saxon caru, anxiety, is allied to Old Saxon kara, sorrow, Old High German chara, a lament. Solicitude, from the same root as solicit, meant originally the state of being aroused or stirred up. Anxiety, from Latin angere (whence anger is also derived), to suffocate or torment, signifies a state of mental discomfort caused by uncertainty.

These terms express the application of the mind to any object. Care is the most indefinite of the three; it may be accompanied with pain or not, according to the nature of the object or the intensity of the application: solicitude and anxiety are accompanied with a positive degree of pain, the latter still more than the former. When care is employed in the discharge of any office, it may be without any feeling, but it is always accompanied with active exertions, as the care which a subordinate takes of a child. Solicitude and anxiety lie together in the mind, unaccompanied with any other action: solicitude has desire, mixed with fear; anxiety has distress for the present, mixed with fear for the future.

Care is inseparable from the business of life; there is nothing which is done but what requires care for it to be well done: solicitude and anxiety are produced by the events and circumstances of life, with this difference, that, as solicitude has so much of desire in it, it is more under our control or may be more easily restrained than anxiety, which is forced upon us.

Care by its intensity and duration, and anxiety by its violence, may produce injurious effects; as worn out with care, overwhelmed with anxiety.

Solicitude is awakened only by ordinary events, and never rises to excess: there may be a solicitude to please, or a tender solicitude for the health of a person.

See also Heal.

Care, Concern, Regard.-Care (see above). Concern (see AffaIr) and regard, from Latin re, back, and French garder, to look at (from an Old High German root signifying to watch, or guard, found in wary, ward, etc., meaning to look back upon or look at attentively), are nearly allied to each other in denoting the application of the mind to any object.

Care, as in the former article, is either coupled with active exertions or is employed in the right doing of things; we take care to do a thing, or we bestow care upon a thing: concern and regard both lie in the mind, but in the former case the feelings as well as the thoughts, and in the latter case the thoughts only, have a part. Concern is particularly applied to that which awakens a painful interest in the mind, as to express or show a concern for another's troubles or distress; regard is applied to that which one values sufficiently to bestow one's thoughts upon.

Care and concern are also used to denote the object of caring or concerning, but regard is only employed for the action of regarding. The care is that which requires care to be bestowed upon it; concern is that in which one is concerned, or has a share or interest.

Care, Charge, Management.-Care (see above). Charge, in French charge, is derived from Late Latin carricare, to load a car, whence cargo is also derived. It is figuratively employed in the sense of a burden. Management, in French ménagement, is ultimately derived from Latin manus, hand, and signifies the doing or directing of something with the hand. 
Care will include both charge and management; but, in the strict sense, it comprehends personal labor: charge involves responsibility: management includes regulation and order. A gardener has the care of a garden; a nurse has the charge of children; a steward has the management of a farm: we must always act in order to take care; we must look in order to take charge; we must always think in order to manage. Care is employed generally in all matters, high and low, which require mental application or active exertion; charge, in matters of trust and confidence; management, in matters of business and experience: the servant has the care of the cattle; an instructor has the charge of youth; a clerk has the management of a business.

Careful, Cautious, Provident.-Careful, or full of care, that is, having care, is the general term. Cautious, that is, having caution, and provident, that is, literally foreseeing, are modes of the careful. To be cautious is to be careful in guarding against danger; to be provident is to be careful in preventing straits and difficulties. One is careful either in doing or in omitting to do: one is cautious in abstaining from doing, as to be careful in writing, or in the disposition of things; to be cautious not to offend, not to say anything.

When the terms careful and cautious are applied to what is to be avoided, the former is used in ordinary cases, where the difficulty of avoiding the evil is not great; the latter on extraordinary occasions, where the danger of falling into the evil is great.

The term careful is applied for the most part to present matters, but provident only to that which is future. One is careful of his money or his books, but provident toward a time of need.

These words are all employed to denote a habit of the mind or a characteristic of the person with a similar distinction, except that caution, being properly a virtue of the occasion, becomes excessive if it be always employed whether it be necessary or not. See also AtTention.

CARELESS. See Indolent; NegLIGENT.

CARESS, FoNDle. terms mark a species of endearment. Caress, like cherish, and the French cherir and cher, comes from the Latin carus, dear, signifying the expression of a tender sentiment. Fondle, from fond (for derivation see under AFFEcTION), is a frequentative verb, signifying to become fond of, or express one's fondness for.

We caress by words or actions; we fondle by actions only: caresses are not always unsuitable; but fondling, which is the extreme of caressing, is not less unfit for the one who receives than for the one who gives: animals caress each other, as the natural mode of indicating their affection; fondling, which is the expression of perverted feeling, is peculiar to human beings, who alone abuse the faculties with which they are endowed.

CARICATURE, BURLESqUe, Exaggeration, Parody. Caricature, in Italian caricatura, a satirical picture, from caricare, to load, Low Latin carrico, load, from carrus, a cart, signifies, literally, a picture that is overloaded with exaggeration, and, specifically, a twisted or distorted resemblance to a person or object, a figure, drawing, or description of a person or thing in which defects or peculiarities are greatly exaggerated in order to make the subject appear ludicrous. Burlesque is derived from Latin burre, trifles, Italian burlesco, ludicrous, and signifies a trifling or ludicrous representation. Exaggeration, from Latin $e x$, an intensive prefix, and agger, heap, means a heaping up, hence a heightening by over - statement, over - coloring, etc. Parody, parodia, from Greek rapwdia ( $\pi \alpha \rho \dot{a}$, besides, and $\dot{\omega} \delta \eta^{\prime}$, song, English ode), signified a song sung in imitation of another. All of these terms signify a humorous imitation, but they differ somewhat in their usual applications. Caricature generally refers to a humorous imitation of a person; burlesque to the imitation of an action or an occasion; and parody to the imitation of a literary productionof words either spoken or written. Caricature and burlesque are almost interchangeable, however. Exaggeration is a more general word. It signifies a humorous imitation which depends for its effect upon the heightening of cer- 
tain features. An exaggeration may not be a caricature or a burlesque, though caricatures and burlesques usually depend upon exaggeration for the creation of the humorous effect.

CARGo. See Freight.

CARNAGE, Slaughter, MasSACRE, BUTCHERY. Carnage, from the Latin caro, carnis, flesh, implies properly a collection of dead flesh; that is, the reducing to the state of dead flesh. Slaughter, from slay, is the act of taking away life. Massacre, in French massacre, comes from old French maçacre, shambles, slaughterhouse, the origin of which is unknown. Butchery, OId French bochier, signified originally the killing of goats, from Old French boc, a goat, German bock, English buck.

Carnage respects the number of dead bodies made; it may be said either of men or animals, but more commonly of the former: slaughter respects the act of taking away life, and the circumstances of the agent: massacre and butchery respect the circumstances of the objects who are the sufferers of the action; the last three are said of human beings only. Carnage is the consequence of any impetuous attack from a powerful enemy; soldiers who get into a besieged town, or a wolf that breaks into a sheepfold, commonly make a dreadful carnage: slaughter is the consequence of warfare; in battles the slaughter will be very considerable where both parties defend themselves pertinaciously: a massacre is the consequence of secret and personal resentment between bodies of people; it is always a stain upon the nation by whom it is practised, as it cannot be effected without a violent breach of confidence and a direct act of treachcry; of this description was the massacre of the Danes by the original Britons: butchery is the general accompaniment of a nuassacre; defenceless women and children are commonly butchered by the savage furies who are most active in this work of blood.

CAROUSAL. See Feast.

CARP. See Censure.

CARRIAGE, Gait, Walk. Carriage, from the verb to carry (see BEAR), signifies the act of carrying in general, but here that of carrying the body.
Gait, allied to go, signifies the manner of going. Walk signifies the manner of walking.

Carriage is here the most general term; it respects the manner of carrying the body, whether in a state of motion or rest: gait is the mode of carrying the limbs and body whenever we move: walk is the manner of carrying the body when we move forward to walk. A person's carriage is somewhat natural to him; it is of ten an indication of character, but admits of great change by education; we may always distinguish a man as high or low, either in mind or station, by his carriage; gait is artificial; we may contract a certain gait by habit; the gait is therefore often taken for a bad habit of going, as when a person has a limping gait or an unsteady gait: walk is less definite than either, as it is applicable to the ordinary movements of men; there is a good, a bad, or an indifferent walk; but it is not a matter of indifference which of these kinds of walk we have; it is the great art of the dancing-master to give a good walk.

See also BeHavior.

CARRY. See Bear; Bring.

CASE, CaUSE. Case, in Latin casus, from cadere, to fall, happen, signifies the thing falling out. Cause, in French cause, comes from Latin causa, a cause.

The case is matter of fact; the cause is matter of question: a case involves circumstances and consequences; a cause involves reasons and arguments: a case is something to be learned; a cause is something to be decided. A case needs only to be stated; a cause must be defended: a cause may include cases, but not vice versa: in all causes that are to be tried there are many legal cases that must be cited: whoever is interested in the cause of humanity will not be heedless of those cases of distress which are perpetually presenting themselves.

See also Situation.

CASH. See Money.

CAST, Throw, Hurd. Cast is a Scandinavian word signifying to throw. Throw, Anglo-Saxon thrawan, originally meant to twist. Hurl is a Scandinavian word of imitative origin.

These terms all express the idea of sending one object from another. To 
cast is often a negative act, to throw is always positive. We cast off clothes by simply ceasing to wear them, but we throw off clothes by removing them from the person with an actual effort. Hence the word cast is most aptly applied when the manner of the action is left undefined, and the word throw when it is intended to be expressly defined; as to cast anchor, which may either be done by simply letting it down or by sending it forth from one with force: so to cast seed into the ground may be simply to let it fall in, or to cast anything into a box; but to throw anything into the sea, or to throw seed into the ground, implies a specific act done in a specific manner.

For the same reason casting is applied to what is done by a process of nature, as animals cast their young, or cast their coats, or to what is acted on by unconscious agents; as a ship or a person is cast on a shore.

Throwing is not merely an act of direct purpose, but frequently of a violent or offensive purpose; as to throw stones or dust at a person, to throw down the gauntlet.

So to cast a glance may be simply to direct the eye to an object, but to throw an angry look is the result of anger.

The word cast, from the generality of its meaning, is properly employed in the higher style of writing, and in reference to higher subjects: when throw is used in respect to any but familiar subjects, it is taken figuratively; as to throw a veil over a matter, to throw light upon a subject.

When applied to similar objects, they preserve the same distinction; throwing requires a greater effort or more violence than casting, as to cast away prejudices, to throw off habits, etc.

To hurl is a violent species of throw ing, employed only on extraordinary occasions. Sometimes it denotes the vehemence of the agent: but still oftener the magnitude of the object or the extremity of the occasion. The giants, who made war against heaven, are feigned to have been hurled by the thunderbolts of Jupiter down to the earth.

Cast, Turn, Description. - Cast, from the verb to cast (see above), signifies that which is cast, and here, by an ex- tension of the sense, the form in which it is cast. Turn, from the verb to turn, signifies also the act of turning or the manner of being turned. Description signifies the act of describing, or the thing which is to be described.

What is cast is artificial; what turns is natural: the former is the act of some foreign agent; the latter is the act of the subject itself: hence cast, as applicable to persons, respects that which they are made by circumstances; turn, that which they are by themselves: thus there are religious castes in India, that is, men cast in a certain form of religion; and men of a particular moral cast, that is, such as are cast in a particular mould as respects their thinking and acting: so in like manner men of a particular turn, that is, as respects their inclinations and tastes.

The cast is that which marks a man to others; the turn is that which may be known only to a man's self; the description is that by which he is described or made known to others.

CASUAL. See Accidental; OcCASIONAL.

CASUAlty. See Accident.

CATALOGUE. See List.

CATEGORICAL, UNQUALIFIED, Positive. Categorical is derived from Greek кarayopia, an accusation, and is in logic an unconditional statement, one which does not depend upon a hypothesis or any modifying qualification. Hence the word has been extended to mean in general an unqualified or positive statement. These two adjectives, though synonymous here, have different original meanings. Unqualified comes from Latin qualis, how much, and means not questioning or indicating how much-not modified in accordance with any possible standard of measurement. Positive, from positus, the past participle of ponere, means placed, ready to stand, unmovable.

CaUCUS, Private Meeting. In this case caucus represents a species of the genus indicated in the words private meeting. Caucus is a purely American term, possibly of American Indian origin, from the Algonkin kawo-kaw-asu, a counsellor. It has, strictly speaking, no real synonymes. The term applies chiefly to political gatherings, or pri- 
vate meetings of representatives of a party, faction, or interest, called to consider a situation and to plan a programme for action.

A caucus by different political parties is generally held prior to an election, at which candidates for office are selected and arrangements perfected for the ensuing campaign. Members of the Congress, of State legislatures, of municipal bodies, and even of smaller organizations, meet in caucus prior to the opening sessions, or when deemed necessary, at any time during a session. Members who are entitled to attend a caucus and, from dissatisfaction or other cause fail to do so, are said to bolt the caucus - that is, they won't be bound to any action on which the caucus has decided.

Cause, Reason, Motive. Cause is supposed to signify originally the same as case; it means, however, now, by distinction, the case or thing happening before another as its cause. Reason, in French raison, Latin ratio, from ratus, participle of reor, to think, signifies the thing thought, estimated, or valued in the mind. Motive, in French motif, from the Latin motus, participle of movere, to move, signifies the thing that brings into action.

Cause respects the order and connection of things; reason, the movements and operations of the mind; motives, the movements of the mind and body. Cause is properly the generic term; reason and motive are specific: every reason or motive is a cause, but every cause is not a reason or motive. Cause is said of all inanimate objects; reason and motive, of rational agents: whatever happens in the world happens from some cause mediate or immediate; the primary or first cause of all is God: whatever opinions men hold, they ought to be able to assign a substantial reason for them; and for whatever they do, they ought to have a sufficient motive.

As the cause gives birth to the effect, so does the reason give birth to the conclusion, and the motive gives birth to the action. Between cause and effect there is a necessary connection: whatever in the natural world is capable of giving birth to another thing is an adequate cause; but in the moral world there is not a necessary connection between reasons and their results, or motives and their actions; the state of the agent's mind is not always such as to be acted upon according to the nature of things: every adequate reason will not be followed by its natural conclusion, for every man will not believe who has reasons to believe, nor yield to the reasons that would lead to a right belief; and every motive will not be accompanied with its corresponding action, for every man will not act who has a motive for acting, nor act in the manner in which his motives ought to dictate.

Cause, Occasion, Create.-To cause, from the substantive cause, naturally signifies to be the cause of. Occasion, from the noun occasion, signifies to be the occasion of. Create is, in Latin, creatus, participle of creare, to make.

What is caused seems to follow naturally; what is occasioned follows incidentally; or what occasions may be incidental, but necessary: what is created receives its existence arbitrarily. A wound causes pain; accidents occasion delay; busybodies create mischief. The misfortunes of children cause great affliction to their parents; business occasions a person's late attendance at a place; disputes and misunderstandings create animosity and ill-will. The cause of a person's misfortune may often be traced to his own misconduct: the improper behavior of one person may occasion another to ask for an explanation: jealousies are created in the minds of relatives by an unnecessary reserve and distance.

CAUTion. See Admonish; CaVEAT.

CaUtious, Wary, Circomspect. For cautious see CAREFUL. Wary, Anglo-Saxon wor, is allied to ward, guard, etc., and to the Greek óáw, I see. Circumspect, from circumspicio, look about, signifies literally looking on all sides. The idea of using great care for the preventing of evil is common to these terms, but they vary in the degree and object of the care. Cautious expresses less than wary: we must be cautious on all occasions where there is danger, but we must be wary where there is great danger. A tradesman must be cautious in his dealings 
with all men, but he must be wary when he has to deal with designing men.

Cautious and wary are used in reference to practical matters, or the common matters of business, where the senses or bodily powers are more exercised than the mind: circumspect is used in reference to matters of theory or contemplation, when the mind is principally employed. A traveler must be cautious in passing along a road that is not familiar to him; he must be wary in passing over slippery and dangerous places. A man must be circumspect when he transacts business of particular importance and delicacy. Hence it is that cautious and wary may be said of the brute creation; circumspect only of rational beings.

CaVEat, Caution, Warning. Caveat, in Latin the same form, implying let him beware, from cavere, to beware, signifies, in law, a judicial warning or caution, an intimation to stay proceedings, an intimation or notice by a party interested in an approaching procedure to the proper officer, to prevent the latter from taking any action without an intimation or notice being given to the said party to enable him to appear and object. A caveat is commonly filed with the proper officer against the probating of a will by an interested party to enable him to contest it or file objections against its probate. Until the caveat is withdrawn by the person who filed it, the probating process is halted.

Hence caveat represents a species of the genus indicated in caution (from the same Latin verb, caveo), and warning (allied to wary). Of these two words warning is a stronger word than caution. We caution others against something which may prove annoying or inconvenient; we warn them against something really dangerous.

CAVIL. See Censure.

CAVITy. See Opening.

CEAse, Leave Off, Discontinue. Cease, in French cesser, Latin cessare, a frequentative of cedere, to yield, signifies to give up or put an end to. Leave, from Anglo-Saxon leaf, permission, is derived from the same root found in the adjective lief, dear or pleasing. Discontinue, with the priva- tive dis, expresses the opposite of continue.

To cease is neuter; to leave off and discontinue are active: we cease from doing a thing; we leave off or discontinue a thing. Cease is used either for particular actions or general habits: leave off more usually and properly for particular actions; discontinue for general habits. A restless, spoiled child never ceases crying until it has obtained what it wants; it is a mark of impatience not to cease lamenting when one is in pain. A laborer leaves off his work at any given hour. A delicate person discontinues his visits when they are found not to be agreeable. It should be our first endeavor to cease to do evil. It is never good to leave off working while there is anything to do and time to do it in. The discontinuing a good practice without adequate grounds evinces great instability of character.

\section{CEDE. See Give Up.}

CELEBRATE, Commemorate. Celebrate, in Latin celebratus, participle of celebrare, from celeber, populous, signifies to gather a big assembly for some festive purpose. Commemorate, in Latin commemoratus, participle of commemoro, compounded of com or cum and memoro, to keep in mind, signifies to keep in the memory of a number.

Commemorate is a species of celebrating; we always commemorate when we celebrate, but not vice versa. Everything is celebrated which is distinguished by ang marks of attention, without regard to the time of the event, whether present or past; but nothing is commemorated but what has been past. A marriage or a birthday is celebrated; the anniversary of any national event is commemorated. Celebrating is not limited to any species of events or circumstanees; whatever interests any number of persons is celebrated: commemorating is confined to whatever is thought of sufficient impurtance to be borne in mind, whether of a public or private nature. The election of a favorite member is celebrated by those who have contributed to his success: a remarkable preservation, whether national or individual, sometimes demands some signal act of commemoration.

Celebrating is a festive as well as so- 
cial act; it may be sometimes serious, but it is mostly mingled with more or less of gayety and mirth: commemorating is a solemn act; it may be sometimes festive and social, but it is always mingled with what is serious, and may be altogether solitary; it is suited to the occasion, and calculated to revive in the mind suitable impressions of what is just. The birthday of our sovereign is always celebrated by his people with such marks of honor and congratulation as are due from subjects to a prince: the providential escape of our nation from destruction by the Gunpowder Plot is annually commemorated by a public act of devotion, as also by popular demonstrations of joy. The Jews celebrate their feast of the Passover: as Christians, we commemorate the sufferings and death of our Saviour by partaking of the Lord's Supper.

CELEBRATED. See Famous.

CELERITY. See QUICKNESS.

CELESTIAL, Heavenly. Celestial and heavenly derive their difference in signification from their different origin: they both literally imply belonging to heaven; but the former, from the Latin calum, signifies belonging to the heaven of heathens; the latter, which has its origin among believers in the true God, has acquired a superior sense, in regard to heaven as the habitation of the Almighty. This distinction is pretty faithfully observed in their application: celestial is applied mostly in the natural sense of the heavens; heavenly is employed more commonly in a spiritual sense. Hence we speak of the celestial globe as distinguished from the terrestrial; of the celestial bodies; of Olympus, as the celestial abode of Jupiter; of the celestial deities.

But, on the other hand, of the heavenly habitation, of heavenly joys or bliss, of heavenly spirits, and the like.

See also Ethereal.

CEMETERY. See NECROPOLIS.

CENSOR, CrITIC, Examiner, INsPECTOR. These terms all signify an official whose duty it is to see documents, publications, public performances, etc., and to pass judgment upon them. But examiner and inspector emphasize the act of seeing; censor and critic that of judging.
Examiner (for the derivation of examine see Discuss) is a stronger word than inspector. Examine means to inspect with particular care, with the intention of passing a judgment. Similarly critic is a milder and more general term than censor (from Latin censere, to rate). To censor is not merely to judge, but to abolish that which proves to be contrary to the censor's judgment. These terms differ also in their applications. Censor is applied particularly to the examining and judging of literary material-letters and cables in time of war, books, newspapers, etc.-and of artistic public productions. A rigorous censorship of mail, etc., was maintained in all belligerent countries during the European war. The term inspector is applied to various public officials whose duty it is to detect any violation of the laws-health-inspectors, milk-inspectors, customs-inspectors, etc. The terms critic and examiner are less frequently used to refer to public officials.

CENSURE, ANimadvert, Criticise. Censure (see Accuse). Animadvert and criticise (see ANIMADVERSION).

To censure expresses less than to animadvert or criticise; one may always censure when one animadverts or criticises. To censure and animadvert are both personal, the one direct, the other indirect; criticism is directed to things, and not to persons only. Censuring consists in finding some fault, real or supposed: it refers mostly to the conduct of individuals. Animadvert consists in suggesting some error or impropriety; it refers mostly to matters of opinion and dispute; criticism consists in minutely examining the intrinsic characteristics and appreciating the merits of each individually or the whole collectively; it refers to matters of science and learning. To censure requires no more than simple assertion; its justice or propriety often rests on the authority of the individual: animadversions require to be accompanied with reasons; those who animadvert on the proceedings or opinions of others must state some grounds for their objections. Criticism is altogether argumentative and illustrative; it takes nothing for granted, it analyzes and decomposes, it compares and combines 
it asserts and supports the assertions. The office of the censurer is the easiest and least honorable of the three; it may be assumed by ignorance and impertinence, it may be performed for the purpose of indulging an angry or imperious temper. The task of animadverting is delicate; it may be resorted to for the indulgence of an overweening self-conceit. The office of a critic is both arduous and honorable; it cannot be filled by any one incompetent for the charge without exposing his arrogance and folly to merited contempt.

See also Blame; Lash.

Censure, Carp, Cavil.-Censure (see above). Carp, a Scandinavian word, appears in Middle English with the meaning of to talk (in Icelandic it meant to boast). The present sinister sense is apparently due to a confusion with Latin carpere, to pluck. Cavil, in French caviller, Latin cavillor, from cavilla, a taunt, and cavus, hollow, signifies to be unsound or unsubstantial in speech.

To censure respects positive errors; to carp and cavil have regard to what is trivial or imaginary: the former is employed for errors in persons; the latter for supposed defects in things. Censures are frequently necessary from those who have the authority to use them; a good father will censure his children when their conduct is censurable. Carping and cavilling are resorted to only to indulge ill-nature or selfconceit: whoever owes another a grudge will be most disposed to carp at all he does, in order to lessen him in the esteem of others: those who contend more for victory than truth will be apt to cavil when they are at a loss for fair argument: party politicians carp at the measures of administration; infidels cavil at the evidences of Christianity, because they are determined to disbelieve.

CEREMONIAL. See Formal. CEREMONIOUS. See ForMal; THEATRICAL.

CEREMONY. See ETIQUETTE; ForM.

CerTaIN, Sure, Secure. Certain, in French certain, Latin certus, comes from cernere, to discriminate. Sure and secure are variations of the same word, in French sar, German sicher, Latin securus; this is compounded of se (sine), apart, and cura, care, signifying without care, requiring no care.

Certain and sure have regard to a person's convictions; secure to his interests or condition: one is certain from actual knowledge or from a belief in others; one is sure from a reliance upon others; one is secure when free from danger. We can be certain of nothing future but death; we may be sure that God will fulfil His promises in His own way; we may be secure against any loss or mischief if we use proper precautions.

In respect to things the distinction is similar: facts, principles, and rules are certain which are certainly known and admitted: rules, methods, guides, etc., are sure which guard against error and may be depended upon; a place may be secure which serves to secure or preserve with certainty from mischief or danger.

\section{See also Infallible; Tangible.}

\section{CERTAINLY. See Are.}

CESSATION, STOP, INTERMission. Cessation, from the verb to cease, marks the condition of leaving off. Stop, from to stop, marks that of being stopped or prevented from going on. Rest, from to rest, marks the state of being quiet; and intermission, from intermit, marks that of ceasing occasionally.

To cease respects the course of things; whatever does not go on has ceased; things cease of themselves: stop respects some external action or influence; nothing stops but what is supposed to be stopped or hindered by another: rest is a species of cessation that regards labor or excrtion; whatever does not move or exert itself is at rest: intermission is a species of cessation only for a time or at certain intervals. That which ceases or stops is supposed to be at an end; rest or intermission supposes a renewal. A cessation of hostilities is at all times desirable; to put a stop to evil practices is sometimes the most difficult and dangerous of all undertakings: rest after fatigue is indispensable, for labor without intermission exhausts the frame. The rain ceases, a person or a ball stops running, the laborer rests from his toil, a fever is intermittent. 
There is nothing in the world which does not cease to exist at one point or another: death stops every one sooner or later in his career: whoever is vexed with the cares of getting riches will find no rest for his mind or body; he will labor without intermission oftentimes only to heap troubles on himself.

\section{CHAFE. See Rub.}

CHAGRIN. See Vexation.

ChaIN, Fetrer, Band, Shackle. Chain, in French chaîne, Latin catena, signifies that which takes or holds. Fetter, Anglo-Saxon fetor, meant a shackle for the foot, and is allied to the word foot, feet. Band, from bind, signifies that which binds. Shackle, Anglo-Saxon sceacul, bond, fetter, was originally a loose band which shook when the captive moved, shackle being from the same root as shake.

All these terms designate the instrument by which animals or men are confined. Chain is general and indefinite; all the rest are species of chains: but there are many chains which do not come under the other names; a chain is indefinite as to its make; it is made generally of iron rings, but of different sizes and shapes: fetters are larger; they consist of many stout chains: bands are in general anything which confines the body or the limbs; they may be either chains or even cords: shackle is that species of chain which goes on the legs to confine them; malefactors of the worst order have fetters on different parts of their bodies, and shackles on their legs.

These terms may all be used figuratively. The substantive chain is applied generally to whatever confines like a chain, and the verb to chain signifies to confine as with a chain: thus the mind is chained to rules, according to the opinions of the freethinkers, when men adhere strictly to rule and order: the noun fetter is seldom used except in the proper sense, but the verb to fetter signifies to control or prevent the proper exercise of the mind, as to be fettered by systems. $B a n d$, in the figurative sense, is applied, particularly in poetry, to everything which is supposed to serve the purpose of a band; thus love is said to have its silken bands. Shackle, whether as a substantive or a verb, retains the idea of impeding the progress of a person, not in his body only, but also in his mind and in his moral conduct; thus a man who commences life with a borrowed capital is shackled in his commercial concerns by the interest he has to pay and the obligations he has to discharge.

\section{Challenge. See Brave.}

CHAMPION. See Combatant.

ChanCE, Fortune, Fate. Chance (see AccIDENT) is here considered as the cause of what falls out. Fortune, in French fortune, Latin fortuna, comes from fors, chance, allied to ferre, to bear -fortune being that which is brought to one, borne in upon the sufferer. Fate, in Latin fatum, from fatum, participle of fari, to speak or decree, signifies that which is decreed, or the power of decreeing.

These terms have served at all times as cloaks for human ignorance; and before mankind was favored by the light of Divine Revelation they had an imaginary importance which has now happily vanished. Believers in Divine Providence no longer conceive the events of the world as left to themselves, or as under the control of any unintelligent or unconscious agent, but ascribe the whole to an overruling mind, which, though invisible to the bodily eye, is clearly to be traced by the intellectual eye wherever we turn ourselves. In conformity, however, to the preconceived notions attached to these words, we now employ them in regard to the agency of secondary causes. But how far a Christian may use them, without disparagement to the majesty of the Divine Being, it is not so much my business to inquire as to define their ordinary acceptation. In this ordinary sense chance is the generic, fortune and fate are specific terms: chance applies to all things, personal or otherwise; fortune and fate are mostly said of that which is personal. Chance neither forms, orders, nor designs; neither knowledge nor intention is attributed to it; its events are uncertain and variable: fortune forms plans and designs, but without choice; we attribute to it an intention without 
discernment; it is said to be blind: fate forms plans and chains of causes; intention, knowledge, and power are attributed to it; its views are fixed, its results decisive. A person goes as chance directs him when he has no express object to determine his choice one way or other; his fortune favors him if without any expectation he gets the thing he wishes; his fate wills it if he reaches the desired point contrary to what he intended. Men's success in their undertakings depends oftener on chance than on their ability; we are ever ready to ascribe to ourselves what we owe to our good fortune; it is the fate of some men to fail in everything they undertake. When speaking of trivial matters this language is unquestionably innocent, and any objection to its use must spring from an overscrupulous conscience. If I suffer my horse to direct me in the road I take to London, I may fairly attribute it to chance if I take the right instead of the left; and if in consequence I meet with an agreeable companion by the way, I shall not hesitate to call it my good fortune; and if, in spite of any previous intention to the contrary, I should be led to take the same road repeatedly, and as often meet with an agreeable companion, I shall immediately say that it is my fate to meet with an agreeable companion whenever I go to London.

See also HAppen.

Chance, Probability. - Chance (see above). Probability, in French probabilité, Latin probabilitas, from probabrilis and probare, to prove, signifies the quality of being able to be proved or made good.

These terms are both employed in forming an estimate of future events; but the chance is either for or against, the probability is always for a thing. Chance is but a degree of probability; there may in this latter case be a chance where there is no probability. A chance affords a possibility; many chances are requisite to constitute a probability. What has been once may, under similar circumstances, be again; for that there is a chance; what has fallen to one man may fall to another; so far he has a chance in his favor; but in all the chances of life there will be no prob- ability of success where a man does not unite industry with integrity. Chance cannot be calculated upon; it is apt to produce disappointment; probability justifies hope; it is sanctioned by experience.

Chance, Hazard. - Chance (see above). Hazard comes from Spanish $a z a r$, an unlucky throw at dice, possibly allied to Arabian al zahr, but the ultimate origin is doubtful.

Both these terms are employed to mark the course of future events, which is not discernible by the human eye. With the Deity there is neither chance nor hazard; His plans are the result of omniscience: but the designs and actions of men are all dependent on chance or hazard. Chance may be favorable or unfavorable, more commonly the former: hazard is always unfavorable; it is properly a species of chance. There is a chance either of gaining or losing; there is a hazard of losing. In most speculations the chance of succeeding scarcely outweighs the hazard of losing.

CHANGE, Alter, VARY. Change, in French changer, is probably derived from the Middle Latin cambio, exchange, signifying to take one thing for another. Alter, from the Latin alter, another, signifies to make a thing otherwise. Vary, in Latin vario, make various, from varius, doubtful.

We change a thing by putting another in its place; we alter a thing by making it different from what it was before; we vary it by altering it in different manners and at different times. We change our clothes whenever we put on others: the tailor alters clothes which are found not to fit; and he varies the fashion of making them whenever he makes new. A man changes his habits, alters his conduct, and varies his manner of speaking and thinking, according to circumstances. A thing is changed without altering its kind; it is altered without destroying its identity; and it is varied without destroying the similarity. We change our habitation, but it still remains a habitation; we alter our house, but it still remains the same house; we vary the manner of painting and decoration, but it may strongly resemble the manner in which it has been before executed. 
Change, Exchange, Barter, Substitute. -Change (see preceding). Exchange is compounded of $e$ or $e x$ and changer, signifying to change in the place of another. Barter is supposed to come from the French barater, to cheat or beguile, the ultimate origin of which is doubtful. Substitute, in French substitut, Latin substitutus, from $s u b$, instead of, and statuere, to place, signifies to place one thing in the room of another.

The idea of putting one person or thing in the place of another is common to all these terms, which varies in the manner and the object. Change is the generic, the rest are specific terms: whatever is exchanged, bartered, or substituted is changed, but not vice versa. To change in respect to persons is to take one for another, without regard to whether they are alike or different, as a king changes his ministers; to exchange is to take one person in return for another who is in like condition, as prisoners are exchanged in time of war.

In respect to things, to change is to take anything new or fresh, whether alike or different. Clothes may be changed, or books may be changed, or things may be changed for others quite different; to exchange is to take one thing for another, that is, either of the same kind or equivalent in value, as to exchange one commodity for another, one house, or one piece of land, for another. To change may often be the result of caprice, but to exchange is always an act either of discretion or necessity.

To barter is a species of exchanging, namely, the giving of any commodity for others of the same or a different kind; it is confined properly to what passes by way of commerce, as, in dealing with savages, to barter toys or knives for provisions.

To substitute is to put one person in the place of another for the purpose of doing any service or filling any office, as to substitute one for another who has been drawn for the militia.

In the moral application these terms bear the same analogy to each other, with this difference, that the word barter is taken in a bad sense. A person changes his opinions; but a proneness to such changes evinces a want of firmness in the character. A good king at his death exchanges a temporal for an eternal crown. The mercenary trader barters his conscience for paltry pelf. Men of dogmatical tempers substitute assertion for proof, and abuse for argument.

Change, Variation, Vicissitude.Change and variation (see preceding). Vicissitude, in French vicissitude, Latin vicissitudo, from vicissim, by turns, signifies changing alternately.

Change is, both to vicissitude and variation, as the genus to the species. Every variation or vicissitude is a change, but every change is not a variation or vicissitude. Change consists simply in ceasing to be the same: variation consists in being different at different times; vicissitude, in being alternately or reciprocally different and the same. All created things are liable to change; old things pass away, all things become new: the humors of men, like the elements, are exposed to perpetual variations: human affairs, like the seasons, are subject to frequent vicissitudes. Changes in societies or families are seldom attended with any good effect. Variations in the state of the atmosphere are indicated by the barometer or thermometer. Vicissitudes of a painful nature are less dangerous than those which elevate men to an unusual state of grandeur. By the former they are brought to a sense of themselves, by the latter they are carried beyond themselves.

Changeable, Mutable, Variable, Inconstant, Fickle, Versatile.-Changeable, ready to change. Mutable, from the Latin mutare, to change, is the same as changeable. Variable means liable to vary. Inconstant, compounded of the privative in and constant, in Latin constans, from con and stare, to stand together or remain the same, signifies not remaining the same for any long continuance. Fickle, Anglo-Saxon ficol, is allied to facne, deceitful, and facen, fraud. Versatile, in Latin versatilis, from verto, to turn, signifies easy to be turned.

Changeable is said of persons or things; mutable is said of things only: human beings are changeable, human affairs are mutable.

Changeable respects the sentiments 
and opinions of the mind; variable, the state of the feelings; inconstant, the affections; fickle, the inclinations and attachments; versatile, the application of the talents. A changeable person rejects what he has once embraced in order to take up something new; a variable person likes and dislikes alternately the same thing; an inconstant person likes nothing long; a fickle person likes many things successively or at the same time; a versatile person has a talent for whatever he likes. Changeableness arises from a want of fixed principles; variableness, from a predominance of humor; inconstancy, from a selfish and unfeeling temper; fickleness, from a lightness of mind; versatility, from a flexibility of mind. Men are the most changeable and inconstant; women are the most variable and fickle: the former offend from an indifference for objects in general or a diminished attachment for any object in particular; the latter from an excessive warmth of feeling that is easily biassed and ready to seize new objects. People who are changeable in their views and plans are particularly unfit for the government of a state; those who are variable in their humors are unsuitable as masters; people of an inconstant character ought to be shunned as lovers; those of a fickle disposition ought not to be chosen as friends.

Changeable, variable, inconstant, and fickle, as applied to persons, are taken in the bad sense; but versatility is a natural gift which may be employed advantageously.

CHANNEL. See Trench.

CHAPERON, Attendant, Guide. Of these terms attendant is the general word: guide and chaperon indicate particular kinds of attendants. For the meaning and derivation of attendant see Accompany. A chaperon, French chaperon, Italian capperone, the wearer of a hooded cape, signifies a woman who accompanies a young girl in public places to guide her, and protect her from annoyance. The term guide is applied to attendants whose function it is to point out the way to otherssuch as mountain-guides, guides in large museums or public galleries, etc.
CHARACTER, LETTER. Character comes from the Greek $\chi$ ă,axтíp, signifying an impression or mark, from $\chi$ ă is derived from Latin littera, a letter.

Character is to letter as the genus to the species: every letter is a character; but every character is not a letter. Character is any written or printed mark that serves to designate something; a letter is a species of character which is the constituent part of a word. Shorthand and hieroglyphics consist of characters, but not of letters. Character is employed figuratively, but letter is not. A grateful person has the favors which are conferred upon him written in indelible characters upon his heart.

Character, Reputation. - From the natural sense of a stamp or mark. Character (see above) is figuratively employed for the moral mark which distinguishes one man from another. Reputation, from the French réputer, Latin reputare, to think, signifies what is thought of a person.

Character lies in the man; it is the mark of what he is; it shows itself on all occasions: reputation depends upon others; it is what they think of him. A character is given particularly: a reputation is formed generally. Individuals give a character of another from personal knowledge: public opinion constitutes the reputation. Character has always some foundation; it is a positive description of something: reputation has more of conjecture in it; its source is hearsay. It is possible for a man to have a fair reputation who has not in reality a good character, although men of really good character are not likely to have a bad reputation.

CHARACTERIZE. See Name.

CHARGE. See Accuse; Attack; Care; Cost; Office.

CHARM, ENChaNT, Fascinate, ENrapture, Captivate. Charm (see AtTraction). Enchant, French enchanter, is derived from Latin in, in, and cantare, to sing, whence incantation is also derived. It signified to sing to another until the music entered into the hearer, as it were, and had some magical or hypnotic effect upon his soul. Fascinate is derived from Latin fascinum, a spell. Enrapture, com- 
pounded of en and rapture, signifies to put into a rapture; and rapture, from the Latin rapio, to seize or carry away signifies the state of being carried away; whence to enrapture signifies to put into that state. Captivate, in Latin captivatus, participle of captivo, from capere, to take, signifies to take, as it were, prisoner.

To charm expresses a less powerful effect than to enchant; a charm is simply a magical verse used by magicians and sorcerers: incantation or enchantment is the use not only of verses, but of any mysterious ceremonies, to produce a given effect. To charm and enchant in this sense denotes an operation by means of words or motions; to fascinate denotes an operation by means of the eyes or tongue: the two former are less powerful acts than the latter: the superstitious have always had recourse to charms or enchantments, for the purpose of allaying the passions of love or hatred; the Greeks believed that the malignant influence passed by fascination from the eyes or tongues of envious persons, which infected the ambient air, and through that medium penetrated and corrupted the bodies of animals and other things. Charms and enchantments are performed by persons; fascinations are performed by animals: the former have always some supposed good in view; the latter have always a mischievous tendency: there are persons who pretend to charm away the toothache, or other pains of the body: some serpents are said to have a fascinating power in their eyes by which they can kill the animals on which they have fixed them.

To charm, enchant, and fascinate are taken in the improper sense to denote moral as well as natural operations; enrapture and captivate have a moral application only, in reference to those things which act more on the imagination or the moral feelings than on the senses. To charm in this case is to act as a charm; to enchant, to act by enchantment; and to fascinate, to act by the power of fascination; all which, as in the former case, denote a secret or involuntary influence. To enrapture and captivate, on the other hand, denote a direct but irresistible influence. To charm, enchant, and enrapture, when applied to the same objects, rise in their sense; to enchant expresses a stronger effect than to charm, and to enrapture than to enchant. Music ordinarily charms, delightful music charms a delicate ear: the finest music only is calculated to enrapture, or the finest ears to be enraptured.

Beauty or fine scenery may in the same manner charm, enchant, or enrapture, according to the circumstances of the case.

To fascinate and captivate are, according to their original import, oftener used in a bad sense than a good one: we may sometimes speak indifferently of fascinating manners or a captivating address; but for the most part what fascinates and captivates acts on the passions to the injury of the understanding: a bad woman may have more power to fascinate than a modest woman, and flowery language may captivate when plain speech would not be heeded.

See also Grace; Pleasure.

CHARMED. See Spellbound. CHARMING. See Delightful. CHARMS. See AtTractions.

CHASE. See HuNT.

CHASM. See Breach.

CHASTEN, Chastise. Chasten, chastise, both come through the French chatier, from the Latin castigare, to make pure.

Chasten has most regard to the end, chastise to the means; the former is an act of the Deity, the latter a human action: God chastens His faithful people, to cleanse them from their transgressions; parents chastise their children, to prevent the repetition of faults: afflictions are the means which God adopts for chastening those whom He wishes to make more obedient to his will; stripes are the means by which offenders are chastised.

CHASTITY, Continence. Chasti$t y$, in French chastité, Latin castitas, comes from castus, pure, and the Hebrew kedish, sacred. Continence, in French continence, Latin continentia, from continens and contineo, signifies the act of keeping one's self within bounds.

These two terms are equally employed in relation to the pleasures of sense: both are virtues, but sufficiently distinct in their characteristics. 
Chastity prescribes rules for the indulgence of these pleasures; continence altogether interdicts their use. Chastity extends its views to whatever may bear the smallest relation to the object which it proposes to regulate; it controls the thoughts, words, looks, attitudes, food, dress, company, and, in short, the whole mode of living: continence simply confines itself to the privation of the pleasures themselves; it is possible, therefore, to be chaste without being continent, and continent without being chaste. Chastity is suited to all times, ages, and conditions; continence belongs only to a state of celibacy; the Christian religion enjoins chastity as a positive duty on all its followers; the Romish religion enjoins continence on its clerical members.

See also Virtuous.

ChatTels. See Goods.

CHATTER. See BABBLE; JABBER. CHEAPEN. See BUY.

Cheat, Defraud, Trick. Cheat comes from escheat, Middle English eschete, Old French eschete, rent, that which falls to the landlord, from $e x$, out, and cadere, to fall. As Skeat says, the lords of the manor or the escheaters "were often cheats in our sense, hence the verb." Defraud, from de and fraud, is either to practise fraud or get from a person by fraud. Trick, Norman French trigue, is probably influenced by Dutch trik, a pull, a stroke, a touch; the development of meaning is a little uncertain.

These terms convey the idea of practising deception, but in different ways. One cheats by direct and gross falsehood or artifice; one defrauds by a settled plan or contrivance; one tricks by a sudden invention. Cheating and tricking are resorted to in the common dealings of men; both may be equally low in their ends, but not equally base in their means. Tricking requires ingenuity, which is not wanted in the practice of cheating. Defrauding applies to the more serious concerns of life, and for the most part involves a breach of confidence, as to defraud one's creditors.

Cheating has respect to the delusion practised on the person, and may therefore be applied to whatever produces the delusion. Defrauding re- spects the thing wrongfully got, and may therefore be applied to persons, animals, or things which may suffer from fraud: as to defraud the state, the revenue, or animals of their food. Tricking properly passes only between men in their dealings with one another.

See also JJGgre.

CHECK, Curb, Control. All these terms express a species of restraining. Check and curb derive their meaning from natural objects. To check, in French checé (from the Persian word for king found in shah, king), in reference to the movement in the game of chess by which the king is prevented moving, implies generally to impede the course. Curb, from Latin curvare, to bend, refers to the binding of the horse's neck by pulling on the bit. To check is properly applied to bodies in motion, but curb may be applied to those which are at rest or in motion: a horse with a tender mouth is easily checked with a touch of the bridle; a young horse requires to be curbed.

To check and to curb have also a moral application; to control, contracted from counter-roll, or to keep one roll or account against another, has only a moral application. To check is, as before, an act of much less restraint than to curb. Every feeling, however good, may sometimes require to be checked; the passions, or will, require to be curbed.

To check is applied to individual acts, frequently to the act or circumstance of the moment, as to check the forwardness of youth; to curb and control, to the general conduct; the former in respect to bodies of men as well as individuals; the latter in respect to individuals, as to curb a people by laws, to control youth until they are enabled to act for themselves.

The act of checking is applied to one's self; a person may check himself when he is going to speak: to curb and control are properly applied to the acts of others.

Check, Chide, Reprimand, Reprove, Rebuke.-Check (see above). Chide is a word peculiar to English. It is not found in any other language. Reprimand is derived from the gerundive of 
Latin reprimere, to repress, and so indicates something that ought to be repressed, hence the attempt to repress it by an expression of opinion. $R e-$ prove, in French réprouver, Latin reprobo, is compounded of the privative syllable re and probo, signifying to find the contrary of good, that is, to find bad, to blame. Rebuke is derived from Old French busche, a log, and meant originally to lop, to cut back.

The idea of expressing one's disapprobation of a person's conduct is common to all these terms. A person is checked that he may not continue to do what is offensive; he is chidden for what he has done, that he may not repeat it: impertinent and forward people require to be checked, that they may not become intolerable; thoughtless people are chidden when they give hurtful proofs of their carelessness. People are checked by actions and looks as well as words; they are chidden by words only: a timid person is easily checked: the want even of due encouragement will serve to damp his resolution: the young are perpetually falling into irregularities which require to be chidden.

To chide marks a stronger degree of displeasure than reprimand, and reprimand than reprove or rebuke; a person may chide or reprimand in anger, he reproves and rebukes with coolness: great offences call forth chidings; omissions or mistakes occasion or require a reprimand: irregularities of conduct give rise to reproof; and improprieties of behavior demand rebuke. Chiding and reprimanding are employed for offences against the individual, and in cases where the greatest disparity exists in the station of the parties; a child is chidden by his parent; a servant is reprimanded by his master. Reproving and rebuking have less to do with the relation or station of the parties than with the nature of the offence: wisdom, age, and experience, or a spiritual mission, give authority to reprove or rebuke those whose conduct has violated any law, human or divine: the prophet Nathan reproved King David for his heinous offences against his Maker; our Saviour rebuked Peter for his presumptuous mode of speech. See also Snub.
Check, Stop.-Check, as before, signifies to impede the course of a body in motion, that is, to cause it to move slowly; to stop (see Cessation) is to cause it not to move at all: the growth of a plant is checked when it does not grow so fast as usual; its growth is stopped when it ceases altogether to grow: the water of a river is stopped by a dam; the rapidity of its course is checked by the intervention of rocks and sands.

These words admit of a similar distinction when applied to the conduct or condition of men and things: if an evil be checked, it is diminished in extent; if it be stopped, it is altogether put an end to; so a person may be checked in his career, or stopped in his career, with the like distinction.

CHEER, Encourage, Comfort. Cheer (see Animate). Encourage, compounded of en and courage, signifies to inspire with courage. Comfort is compounded of com or cum, and fortis, strong, signifying to invigorate or strengthen.

To cheer regards the spirits; to encourage, the resolution: the sad require to be cheered; the timid to be encouraged. Mirthful company is suited to cheer those who labor under any depression; the prospect of success encourages those who have any object to obtain.

To cheer and comfort have both regard to the spirits, but the latter differs in degree and manner: to cheer expresses more than to comfort, the former signifying to produce a lively sentiment, the latter to lessen or remove a painful one: we are cheered in the moments of despondency, whether from real or imaginary causes; we are comforted in the hour of distress.

Cheering may be effected either by the direct effort of others or by anything passing outward or inward; a discourse or voice cheers, a prospect or a reflection cheers: comforting is often properly effected by external objects, whether personal or otherwise. Cheering is purely a mental operation, but comforting may act on the body as well as on the mind.

See also Animate; Hearten.

Cheerful, Merry, Sprightly, Gay.Cheerful signifies full of cheer, or of 
that which cheers. Merry, AngloSaxon myrge, meant originally "lasting a short time," fragile, evanescent; hence that which makes the time pass quickly. Sprightly should be spelled spritely, from sprite, Old French esprit, a spirit (Latin spiritus), or the spirit. It signifies full of life, animated. Sprightly is contracted from spiritedly. Gay is from Old High German wahi, fine, beautiful.

Cheerful marks an unruffled flow of spirits; with mirth there is more of tumult and noise; with sprightliness there is more buoyancy; gayety comprehends mirth and indulgence. A cheerful person smiles; a merry person laughs; a sprightly person dances; a gay person takes his pleasure. The cheerful countenance is permanently so; it marks the contentment of the heart and its freedom from pain: the merry face will often look sad; a trifle will turn mirth into sorrow: the sprightliness of youth is often succeeded by the listlessness of bodily infirmity or the gloom of despondency: gayety is as transitory as the pleasures upon which it subsists; it is often followed by sullenness and discontent. Cheerfulness is a habitual state of the mind; mirth is an occasional elevation of the spirits; sprightliness lies in the temperature and flow of the blood; gayety depends altogether on external circumstances. Religion is the best promoter of cheerfulness; it makes its possessor pleased with himself and all around him; company and wine are but too often the only promoters of mirth; youth and health will naturally be attended with sprightliness; a succession of pleasures, ar exemption from care, and the banishment of thought will keep gayety alive.

Sprightliness and mirth are seldom employed but in the proper sense as respects persons; but cheerful and gay are extended to different objects which affect the senses or the mind: cheerful objects are such as cheer the spirits; gay objects please or delight the senses; as a cheerful prospect, a cheerful room, gay attire, a gay scene, gay colors, etc.

See also Glad; Optimistic; SanGUINE.

CHERISH. See Foster; Nourish.
CHICANeRY, Pettifoggery. Chicanery and pettifoggery are both words of obscure origin meaning the abuse of legal forms-trickery, sophistry, and subterfuge in conducting a case. Pettifoggery comes from pettifogger, a legal practitioner of inferior status who gets up or conducts petty cases. Apart from this suggestion of particular attorneys of rascally practices in the development of the word pettifoggery, instead of the general habit of quibbling and cavilling in law-courts suggested in chicanery, there is really no difference between the words, and they can be used interchangeably. Chicane was applied long ago to the game of pall-mall, then to a dispute arising in that game, and latterly to sharp practice, especially in law-suits.

\section{CHIDE. See Check.}

ChIEF, Principal, Main. Chief, in French chef, from the Latin caput, the head, signifies belonging to the uppermost part. Principal, in French principal, Latin principalis, comes from princeps, a chief or prince, signifying belonging to a prince. Main, from the Scandinavian, Icelandic megn, strong, signifies to a great degree.

Chief respects order and rank; principal has regard to importance and respectability; main, to degree or quantity. We speak of a chief clerk; a commander in chief; the chief person in a city; but the principal people in a city; the principal circumstances in a narrative, and the main object. The chief cities, as mentioned by geographers, are those which are classed in the first rank; the principal cities generally include those which are the most considerable for wealth and population; these, however, are not always technically comprehended under the name of chief cities: the main end of men's exertions is the acquirement of wealth.

See also Cardinal.

Chief, Leader, Chieftain, Head.Chief and chieftain signify him who is chief. Leader, from to lead, and head, from the head, sufficiently designate their own signification.

Chief respects precedency in civil matters; leader regards the direction of enterprises: chieftain is a species of leader; and head is the superior in general concerns. Among savages the 
chief of every tribe is a despotic prince within his own district, acting or directing in particular cases. Factions and parties in a state, like savage tribes, must have their leaders, to whom they are blindly devoted and by whom they are instigated to every desperate proceeding. Robbers have their chieftains, who plan and direct everything, having an unlimited power over the band. The heads of families were, in the primitive ages, the chiefs, who in conjunction regulated the affairs of state. Chiefs have a permanent power, which may descend by inheritance, to branches of the same families: leaders and chieftains have a deputed power with which they are invested as the time and occasion require: heads have a natural power springing out of the nature of their birth, rank, talents, and situation; it is not hereditary, but successive. Chiefs ought to have superiority of birth combined with talents for ruling; leaders and chieftains require a bold and enterprising spirit; heads should have talents for directing.

See also Supreme.

CHIEFLY. See Especially.

CHILDISH. InfantiNe. Childish is in the manner of an infant.

What children do is frequently simple or foolish; what infants do is commonly pretty and engaging; therefore childish is taken in the bad, and infantine in the good sense. Childish manners are very offensive in those who have ceased, according to their years, to be children; the infantine actions of some children evince a simplicity of character.

CHILL, CoLD. Chill and cold are but variations of the same word, in German kalt, etc.

Chill expresses less than cold; that is to say, it expresses a degree of cold. The weather is often chilly in summer, but it is cold in winter. We speak of taking the chill off water when the cold is in part removed; and of a chill running through the frame when the cold begins to penetrate the frame that is in a state of warmth.

CHIMERICAL. See Utopian.

CHOICE. See Option.

CHOKE. See Suffocate.

CHOLER. See ANGER.

CHOOSE, Prefer. Choose, Anglo-
Saxon ceossan, is allied to Latin gustare,

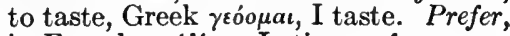
in French prćférer, Latin prafero, compounded of proe and ferre, to take before, signifies to take one thing rather than another.

To choose is to prefer as the genus to the species: we always choose in preferring, but we do not always prefer in choosing. To choose is to take one thing from among others; to prefer is to take one thing before or rather than another. We sometimes choose from the bare necessity of choosing; but we never prefer without making a positive and voluntary choice.

When we choose from a specific motive, the acts of choosing and preferring differ in the nature of the motive. The former is absolute, the latter relative. We choose a thing for what it is, or what we esteem it to be of itself; we prefer a thing for what it has, or what we suppose it has, superior to another. Utility or convenience are grounds for choosing; comparative merit occasions the preference: we choose something that is good, and are contented with it until we see something better which we prefer. We calculate and pause in choosing; we decide in preferring; the judgment determines in making the choice; the will or the affections determine in giving the preference. We choose things from an estimate of their merits or their fitness for the purpose proposed; we prefer them from their accordance with our tastes, habits, and pursuits. Books are chosen by those who wish to read; romances and works of fiction are preferred by general readers; learned works by the scholar. One who wants instruction chooses a master, but he will mostly prefer a teacher whom he knows to a perfect stranger. Our choice is good or bad according to our knowledge; our preference is just or unjust according as it is sanctioned by reason or otherwise. Our choice may be directed by our own experience or that of others; our preference must be guided by our own feelings. We make our choice; we give our preference: the first is the settled purpose of the mind, it fixes on the object; the latter is the inclining of the will, it yields to the object.

Choosing must be employed in all 
the important concerns of life; preferring is admissible in subordinate matters only. There is but one thing that is right, and that ought to be chosen when it is discovered: there are many indifferent things that may suit our tastes and inclinations; these we are at liberty to prefer. But to prefer what we ought not to choose is to make our reason bend to our will. The path of life should be chosen; but the path to be taken in a walk may be preferred. It is advisable for a youth in the choice of a profession to consult what he prefers, as he has the greatest chance of succeeding when he can combine his pleasure with his duty. A friend should be chosen: a companion may be preferred. A wife should be chosen; but unfortunately lovers are most apt to give a preference in a matter where a good or bad choice may determine one's happiness or misery for life. A wise prince is careful in the choice of his ministers; but a weak prince has mostly favorites whom he prefers.

Choose, Pick, Select.-To choose is here, as in the foregoing article, a general and indefinite term, signifying to take one out of two or more. To pick is allied to peck. In Middle English pikken, to pick, and pekken, to peck, are equivalent words. They are derived from pic, a sharp point, and signify to take anything up with a beak or a pointed thing; hence to take things one by one. Select, in Latin selectus, from seligo, or se, apart, and lego, to gather, signifies properly to set apart. We may choose whatever comes in our way without regard to the number of the objects to be chosen from, but we pick or select out of a number only; as to pick or select books from a library: we may pick one or many out of a number, but we mostly select a number. Choosing is not always an act of particular design or discrimination; but to pick and select signify to choose with care, the latter with still greater care than the former. What is picked and selected is always the best of its kind; but the former is commonly something of a physical nature, the latter of a moral or intellectual description. Soldiers are sometimes picked to form a particular regiment; pieces are selecled in prose or verse for gencral purposes.
Choose, Elect.-Choose (see above). Elect, in Latin electus, participle of eligo, is compounded of $e$ and lego, signifying to gather or take out from.

Both these terms are employed in regard to persons appointed to an office; the former in a general, the latter in a particular sense. Choosing is the act either of one man or of many; election is always that of a number; it is performed by the concurrence of many voices. A prince chooses his ministers; the constituents elect members of parliament. A person is chosen to serve the office of sheriff; he is elected by the corporation to be mayor. Choosing is an act of authority; it binds the person chosen: election is a voluntary act; the elected has the power of refusal. People are obliged to serve in some offices when they are chosen, although they would gladly be exempt. The circumstances of being elected is an honor after which they eagerly aspire, and for the attainment of which they risk their property and use the most strenuous exertions.

To elect may sometimes be extended in its application to persons or things for general purposes, which brings it nearer to the word choose; but election in this case signifies the choosing one out of two or more specific objects; as where one has several friends and makes his election of one to be his constant companion, or a person makes his election where he has several alternatives set before him.

CHRONICLES. See ANECDOTES. CHURCH. See TeMple.

CIPHER. See ZERo.

CIRCle, Sphere, Orb, Globe. Circle comes from Latin circulus, a diminutive of circus, a ring. Sphere is derived from Latin sphcra, a transliteration of Greek roaipa, a ball. Orb is derived from Latin orbis, a round disk or ring. Globe comes from Latin globus, a ball.

Rotundity of figure is the common idea expressed by these terms; but the circle is that figure which is represented on a plane superficies; the others are figures represented by solids. We draw a circle by means of compasses; the sphere is a round body, conceived 
to be formed according to the rules of geometry by the circumvolution of a circle round about its diameter; hence the whole frame of the world is denominated a sphere. An orb is any body which describes a circle; hence the heavenly bodies are termed orbs: a globe is any solid body the surface of which is in every part equidistant from the centre; of this description is the terrestrial globe.

A circle may be applied in the improper sense to any round figure which is formed or supposed to be formed by circumscribing a space; simple rotundity constitutes a circle: in this manner a circle may be formed by real objects, as persons, or by moral objects, as pleasures. To the idea of circle is annexed that of extent around, in the signification of a sphere, as a sphere of activity, whether applied in the philosophical sense to natural bodies or in the moral sense to men. Hollowness, as well as rotundity, belongs to an $o r b$; hence we speak of the orb of a wheel. Of a globe, solidity is the peculiar characteristic; hence any ball, like the ball of the earth, may be represented as a globe.

CIRCUIT, Tour, Round. Circuit, in French circuit, Latin circuitus, participle of circumeo, signifies either the act of going round or the extent gone. Tour is derived from Latin tornum (acc.), Greek rópvos, a lathe. Round comes from Latin rotundus, indicating the motion of a wheel, from rota, wheel.

A circuit is made for a specific end of a serious kind; a tour is always made for pleasure; a round, like a circuit, is employed in matters of business, but of a more familiar and ordinary kind. A judge goes his circuit at particular periods of time: gentlemen, in times of peace, consider it as an essential part of their education to make what is termed the grand tour: tradesmen have certain rounds, which they take on certain days. We speak of making the circuit of a place; of taking a tour in a given country; and going a particular round. A circuit is wide or narrow; a tour and a round are great or little. A circuit is prescribed as to extent; a tour is optional; a round is prescribed or otherwise.

Circuit is seldom used but in specific sense; tour is seldom employed but in regard to travelling; round may be taken figuratively, as when we speak of going one's round of pleasure.

CIRCUlate. See Spread.

CIRCUMSCRIBE, INCLOSE. Circumscribe, from the Latin circum, about, and scribere, to write, marks simply the surrounding with a line. Inclose, from the Latin inclusus, participle of includo, based on in and claudere, to shut, marks a, species of confinement.

The extent of any place is drawn out to the eye by a circumscription; its extent is limited to a given point by an inclosure. A garden is circumscribed by any ditch, line, or posts that serve as its boundaries; it is inclosed by wall or fence. An inclosure may serve to circumscribe; but that which circumscribes is frequently imaginary, and will not serve to inclose.

See also Bound.

CIRCUMSPECT. See CaUtious. CIRCUMSTANCE, Situation. Circumstance, in Latin circumstantia, from circum and sto, signifies what stands about a thing, or belongs to it as its accident. Situation, in French situation, comes from the Latin situs, a place.

Circumstance is to situation as a part to a whole: many circumstances constitute a situation: a situation is an aggregate of circumstances. A person is said to be in circumstances of af. fluence who has an abundance of every. thing essential for his comfort; he is in an easy situation when nothing exists to create uneasiness. Circumstance respects that which externally affects us; situation is employed both for the outward circumstances and the inward feelings. The success of any undertaking depends greatly on the circumstances under which it is begun; the particular situation of a person's mind will give a cast to his words or actions. Circumstances are critical, a situation is dangerous.

Circumstance, Incident, Fact.-Circumstance is, as before, a general term. Incident, in Latin incidens, participle of incido, or in and cadere, to fall, signifying what falls upon or to another thing, and fact, in Latin factus, parti- 
ciple of facere, to do, signifying the thing done, are species of circumstances. Incident is what happens; fact is what is done; circumstance is not only what happens and is done, but whatever is or belongs to a thing. To everything are annexed circumstances, either of time, place, age, color, or other collateral appendages, which changes its nature. Everything that moves and operates is exposed to incidents; effects are produced, results follow, and changes are brought about; these are incidents: whatever moves and operates does, and what it produces is done or is the fact: when the artificer performs any work of art, it depends not only on his skill, but on the excellence of his tools, the time he employs, the particular frame of his mind, the place where he works, with a variety of other circumstances, whether he will succeed in producing anything masterly. Newspapers abound with the various incidents which occur in the animal or the vegetable world, some of which are surprising and singular; they likewise contain a number of facts which serve to present a melancholy picture of human depravity.

Circumstance is as often employed with regard to the operations or properties of things, in which case it is most analogous to incident and fact; it may then be employed for the whole affair, or any part of it whatever that can be distinctly considered. Incidents and facts either are circumstances or have circumstances belonging to them. A remarkably abundant crop in any particular part of a field is for the agriculturist a singular circumstance or incident; this may be rendered more surprising if associated with unusual sterility in other parts of the same field. A robbery may either be a fact or a circumstance; its atrocity may be aggravated by the murder of the injured parties, the savageness of the perpetrators, and a variety of circumstances. Circumstance comprehends in its signification whatever may be said or thought of anything; incident carries with it the idea of whatever may befall or be said to befall anything; fact includes in it nothing but what really is or is done. A narrative, therefore, may contain many circum- stances and incidents without any fact, when what is related is either fictitious or not positively known to have happened: it is necessary for a novel or play to contain much incident, but not facts, in order to render it interesting; history should contain nothing but facts, as authenticity is its chief merit.

Circumstantial, Particular, Minute.Circumstantial, from circumstance, signifies consisting of circumstances. Particular cemes from Latin particula, a double diminutive of partem (acc.), part; hence a very little part. Minute, in French minute, Latin minutus, participle of minuere, to diminish, signifies diminished or reduced to a very small point.

Circumstantial expresses less than particular, and that less than minute. A circumstantial account contains all leading events; a particular account includes every event and movement, however trivial; a minute account omits nothing as to person, time, place, figure, form, and every other trivial circumstance connected with the events. A narrative may be circumstantial, particular, or minute; an inquiry, investigation, or description may be minute. An event or occurrence may be particular, a circumstance or particular may be minute.

CITE, Quote. Cite is derived from Latin citare, a frequentative of ciere, to arouse (compare excite, incite, etc.). As applied to persons it means to arouse, to summon; it was figuratively applied to things in a similar sense. To cite a passage in a book or an instance in history meant to summon it to bear witness. Quote is derived from Latin quotare, to mark off into chapters or verses for reference, from quotus, how much (compare quota); from the significance to mark off it came to mean the repeating of the words marked off.

To cite is employed for persons or things; to quote for things only: authors are cited, passages from their works are quoted: we cite only by authority; we quote for general purposes of convenience. Historians ought to cite their authority in order to strengthen their evidence and inspire confidencc; controversialists must ouote 
the objectionable passages in those works which they wish to confute: it is prudent to cite no one whose authority is questionable; it is superfluous to quote anything that can be easily perused in the original.

Cite, Summon.-The idea of calling a person authoritatively to appear is common to these terms. Cite is used in a general sense, summon in a particular and technical sense: a person may be cited to appear before his superior; he is summoned to appear before a court: the station of the individual gives authority to the act of citing; the law itself gives authority to that of summoning. When cite is used in a legal sense, it is mostly employed for witnesses, and summon for every occasion: a person is cited to give evidence; he is summoned to answer a charge. Cite is seldomer used in the legal sense than in that of calling by name, in which general acceptation it is employed with regard to authors, as specified in the preceding article, and in some few other connections: the legal is the ordinary sense of summon; it may, however, be extended in its application to a military summons of a fortified town, or to any call for which there may be occasion; as when we speak of the summons which is given to attend the death-bed of a friend; or, figuratively, death is said to summon mortals from this world.

CIVIL, Polite. Civil, in French civil, Latin civilis, from civis, a citizen, signifies belonging to or becoming a citizen. Polite, in French poli, Latin politus, participle of polire, to polish, signifies properly polished.

These two epithets are employed to denote different modes of acting in social intercourse: polite expresses more than civil; it is possible to be civil without being polite: politeness supposes civility and something in addition. Civility is confined to no rank, age, condition, or country; all have an opportunity with equal propriety of being civil, but not so with politeness; that requires a certain degree of equality, at least the equality of education; it would be contradictory for masters and servants, rich and poor, learned and unlearned, to be polite to one another. Civility is a Christian duty; there are times when every man ought to be civil to his neighbor: politeness is rather a voluntary devotion of ourselves to others: among the inferior orders civility is indispensable; an uncivil person in a subordinate station is an obnoxious member of society: among the higher orders politeness is often a substitute; and, where the form and spirit are combined, it supersedes the necessity of civility: politeness is the sweetener of human society; it gives a charm to everything that is said and done. Civility is contented with pleasing when the occasion offers: politeness seeks the opportunity to please; it prevents the necessity of asking by anticipating the wishes; it is full of delicate attentions, and is an active benevolence in the minor concerns of life. Civil is therefore most properly applied to what passes from and to persons of inferior condition; as the peasantry are very civil.

Or it may be applied to the ordinary transactions of life without distinction of rank.

Polite is applied to those who are in a condition to have good-breeding.

Civility is rather a negative than a positive quality, implying the absence of rudeness. Politeness requires positive and peculiar properties of the head and heart, natural and acquired. To be civil, therefore, is the least that any one can be to another if he do not wish to offend; but politeness, where it is real, is as strong an indication of kindness in the outward behavior as the occasion calls for.

The term civil may be applied figuratively, but politeness is a characteristic of real persons only.

See also Temporal.

Civil, Obliging, Complaisant.-Civil is more general than obliging, which signifies ready to oblige. One is always civil when one is obliging, but not always obliging when one is civil. Civil applies to words or manner as well as to the action; obliging, to the action only. As civil is indefinite in its meaning, so it is indiscriminate in its application; obliging, on the other hand, is confined to what passes between particular persons or under particular circumstances. Strangers may be civil, and persons may frequently 
be civil who from their situation may be expected to be otherwise; one friend is obliging to another.

Civil and obliging both imply a desire to do a kindness; but complaisant, which is a variation of complacent, from complaceo, to be highly pleased, signifies the desire of receiving pleasure, which is a refined mode of doing a kindness.

Civility, lying very much in the manner, may be put on, and complaisance, implying a concern to please by being pleased, may be bad if it lead one to consult the humors of others to the sacrifice of duty or propriety.

CIVILITY. See BENEFIT.

CIVIlization. See Cultivation. Claim. See Ask; Pretension; RIGHT.

CLAMOR. See NoISE.

CLAMOROUS. See Lotd.

ClaNDESTINe, Secret. Clandestine, in Latin clandestinus, comes from clam, secretly. Secret, in French secret, Latin secretus, participle of secernere, to separate, signifies remote from observation.

Clandestine expresses more than secret. To do a thing clandestinely is to elude observation; to do a thing secretly is to do it without the knowledge of any one: what is clandestine is unallowed, which is not necessarily the case with what is secret. With the clandestine must be a mixture of art; with secrecy caution and management are requisite: a clandestine marriage is effected by a studied plan to escape notice; a secret marriage is conducted by the forbearance of all communication; conspirators have many clandestine proceedings and secret meetings: an unfaithful servant clandestinely conveys away his master's property from his premises; a thief secretly takes a purse from the pocket of a bystander.

Clasp, Hug, Embrace. Clasp is a word confined to English. It first appears in the fourteenth century; it means to fasten by two interlocking parts. Hug may be a Scandinavian word related to Icelandic hugga, to soothe; hugna, to please. Embrace, in French embrasser, is compounded of en and bras, arm, Latin brachia, arms, signifying to take or lock in one's arms.
All these terms are employed to express the act of inclosing another in one's arms: clasp marks this action when it is performed with the warmth of true affection; $h u g$ is a ludicrous sort of clasping, which is the consequence of ignorance or extravagant feeling; embrace is simply a mode of ordinary salutation: a parent will clasp his long-lost child in his arms on their re-meeting; a peasant in the excess of his raptures would throw his body, as well as his arms, over the object of his joy, and stifle with hugging him whom he meant to embrace; in the Continental parts of Europe embracing between males, as well as females, is universal on meeting after a long absence, or on taking leave for a length of time; embraces are sometimes given in England between near relatives, but in no other case.

Clasp and embrace may be applied to other objects besides persons in the same sense.

Class, Order, Rank, Degree. Class is derived from Latin classis, a faction, a division, a fleet. Order, Latin ordo, is allied to Latin ordiri, to begin, from oriri, to rise. Rank, old French reng, comes from Old High German hrinc, a ring of men. Degree, in French degré, comes from the Latin gradus, a stop.

Class is more general than order; degree is more specific than rank. Class and order are said of the persons who are distinguished; rank and degree of the distinction itself: men belong to a certain class or order; they hold a certain rank; they are of a certain degree: among the Romans all the citizens were distinctly divided into classes according to their property; but in the modern constitution of society classes are distinguished from one another on general, moral, or civil grounds; there are reputable or disreputable classes; the laboring class, the class of merchants, mechanics, etc.; order has a more particular signification; it is founded upon some positive civil privilege or distinction: the general orders are divided into higher, low$\mathrm{er}$, and middle, arising from the unequal distribution of wealth and power; the particular orders are those of the nobility, of the clergy, of freemasonry, 
and the like: rank distinguishes one individual from another; it is peculiarly applied to the nobility and the gentry, although every man in the community holds a certain rank in relation to those who are above or below him: degree, like rank, is applicable to the individuál, but only in particular cases; literary and scientific degrees are conferred upon superior merit in different departments of science; there are likewise degrees in the same rank, whence we speak of men of high and low degree.

Class, Arrange, Range.-To class, from the noun class, signifies to put in a class. Arrange and range both come from the Old French rangier, from reng, Old High German hrinc, a ring, a row-arrange being formed by the addition of Latin ad (to) to the French verb.

The general qualities and attributes of things are to be considered in classing; their fitness to stand by each other must be considered in arranging; their capacity for forming a line is the only thing to be attended to in ranging. Classification serves the purposes either of public policy or science; arranging is a matter of convenience to the individual himself; ranging is a matter of convenience for others: men are classed into different bodies according to some certain standard of property, power, education, occupation, etc.; furniture is arranged in a room according as it answers in color, shade, convenience of situation, etc.; men are ranged in order whenever they make a procession. All these words require more or less exercise of the intellectual faculty, but classing is a more abstract and comprehensive act than either arranging or ranging. All objects, external or internal, may admit of classification, according to their similitudes and differences; but arranging and ranging are particular acts employed in regard to familiar objects, and the order in which they ought to be placed. Ideas are classed by the logician into simple and complex, abstract and concrete; an individual arranges his own ideas in his mind: words are classed by the grammarian into different parts of speech: words are arranged by the writer in a sentence, so as to be suit- able. To arrange is a more complex proceeding than simply to range; a merchant or tradesman arranges his affairs when they are got into confusion, but a shopkeeper ranges his goods in such manner as best to set them out to view.

These words are applied figuratively in the same sense.

ClASSIC. See Academic.

Clean, Cleajury, Pure. Clean and cleanly come from Anglo-Saxon cloene, pure, bright, which in German developed the special sense of littleGerman klein. Pure, in French pur, Latin purus.

Clean expresses a freedom from dirt or soil; cleanly the disposition or habit of being clean. A person who keeps himself clean is cleanly; a cleanly servant takes care to keep other things clean. Clean is employed either in the proper or the figurative sense; pure, mostly in the moral sense: the hands should be clean; the heart should be pure; it is the first requisite of good writing that it should be clean; it is of the first importance for the morals of youth to be kept pure.

CLEANSE, See SATCTIFY.

CLEAR, LUCID, Bright, Vivid. Clear, see Absolve. Lucid, in Latin lucidus, from lucere, to shine, and lux, light, signifies having light." Bright, see Brightness. Vivid, Latin vividus, from vivere, to live, signifies being in a state of life.

These epithets mark a gradation in their sense; the idea of light is common to them, but clear expresses less than lucid, lucid than bright, and bright less than vivid; a mere freedom from stain or dulness constitutes the clearness; the return of light, and consequent removal of darkness, constitutes lucidity; brightness supposes a certain strength of light; vividness a freshness combined with the strength, and even a degree of brilliancy: a sky is clear that is divested of clouds: the atmosphere is lucid in the day, but not in the night; the sun shines bright when it is unobstructed by anything in the atmosphere; lightning sometimes presents a vivid redness, and sometimes a vivid paleness: the light of the stars may be clear, and sometimes bright, but never vivid; the light of the sun is 
rather bright than clear or vivid; the light of the moon is either clear, bright, or vivid. These epithets may with equal propriety be applied to color as well as to light: a clear color is unmixed with any other; a bright color has something striking and strong in it; a vivid color something lively and fresh in it.

In their moral application they preserve a similar distinction: a conscience is said to be clear when it is free from every stain or spot; a deranged understanding may have lucid intervals; a bright intellect throws light on everything around it; a vivid imagination glows with every inage that nature presents.

See also Apparent; Diaphanots; EUPhonious; Falr.

Clearly, Distinctly. - That is seen clearly of which one has a clear view independent of anything else; that is seen distinctly which is seen so as to distinguish it from other objects. We see the moon clearly whenever it shines, but we cannot see the spots in the moon distinctly without the help of glasses. What we see distinctly must be seen clearly, but a thing may be seen clearly without being seen distinctly. A want of light, or the intervention of other objects, prevents us from seeing clearly; distance, or a defect in the sight, prevents us from seeing distinctly. Old men often see clearly, but not distinctly; they perceive large or luminous objects at a distance, but they cannot distinguish such small objects as the characters of a book without the help of convex glasses; short-sighted persons, on the contrary, see near objects distinctly, but they have no clear vision of distant ones, unless they are viewed through concave glasses.

Clearness, Perspicuity. - Clearness, from clear, is here used figuratively to mark the degree of light by which one sees things distinctly. Perspicuity, in French perspicuiié, Latin perspicuitas, from perspicuus and perspicere, to look through, signifies the quality of being able to be seen through.

These epithets denote qualities equally requisite to render a discourse intelligible, but each has its peculiar character. Clearness respects our ideas and springs from the distinction of the things themselves that are discussed: perspicuity respects the mode of expressing the ideas, and springs from the good qualities of style. It requires a clear head to be able to see a subject in all its bearings and relations; to distinguish all the niceties and shades of difference between things that bear a strong resemblance, and to separate it from all irrelevant objects that intermingle themselves with it. But whatever may be our clearness of conception, it is requisite, if we would communicate our conceptions to others, that we should observe a purity in our mode of diction, that we should be particular in the choice of our terms, careful in the disposition of them, and accurate in the construction of our sentences; 'that is perspicuity which, as it is the first, so, according to Quintilian, it is the most important part of composition.

Clearness of intellect is a natural gift; perspicuity is an acquired art: although intimately connected with each other, yet it is possible to have clearness without perspicuity, and perspicuity without clearness. People of quick capacities will have clcar ideas on the subjects that offer themselves to their notice, but for want of education they may often use improper or ambiguous phrases; or by errors of construction render their phraseology the reverse of perspicuous: on the other hand, it is in the power of some to express themselves perspicuously on subjects far above their comprehension, from a certain facility which they acquire of catching up suitable modes of expression. The study of the classics and mathematics is most fitted for the improvement of clearness; the study of grammar, and the observance of good models, will serve most effectually for the acquirement of perspicuity.

Cleave. See Stick.

CLEFT. Sce JAGgen.

CLEMENCY, LENITY, MeRCY. Clemency is in Latin clementia, signifying mildness. Lenity is in Latin lenitas, from lenis, soft. Mercy is derived trom Latin merces, pay, which has developed into words of curiously diverse meanings - mercenary, merchant, French merci, thanks, etc. In this connection 
it signifies that which brings a reward in heaven, and is influenced by the Latin misericordia, pitiful of heart.

All these terms agree in denoting the disposition or act of forbearing to inflict pain by the exercise of power. Clemency and lenity are employed only toward offenders; mercy toward all who are in trouble, whether from their own fault or any other cause. Clemency lies in the disposition; lenity and mercy, in the act; the former as respects superiors in general, the latter in regard to those who are invested with civil power: a monarch displays his clemency by showing mercy; a master shows lenity by not inflicting punishment where it is deserved. Clemency is arbitrary on the part of the dispenser, flowing from his will, independent of the object on whom it is bestowed: lenity and mercy are discretionary, they always have regard to the object and the nature of the offence or misfortunes; lenity, therefore, often serves the purposes of discipline, and mercy those of justice, by forgiveness instead of punishment; but clemency sometimes defeats its end by forbearing to punish where it is needful. A mild master, who shows clemency to a faithless servant by not bringing him to justice, often throws a worthless wretch upon the public to commit more atrocious depredations. A well-timed lenity sometimes recalls an offender to himself, and brings him back to good order. Upon this principle the English constitution has wisely left in the hands of the monarch the discretionary power of showing mercy in all cases that do not demand the utmost rigor of the law.

Clergyman, Parson, Priest, Minister. Clergyman is derived from Latin clericus, from Greek $x \lambda$ poikós, $\kappa \lambda \eta \overline{\rho o s}$, a lot); in Late Greek it signifies the consecrated members of a Christian society, whose lot or portion "is in the Lord." Parson is derived from Latin persona, a person of rank, and meant a person of rank in a Christian society. Priest comes from the Greek $\pi \rho \varepsilon \sigma \beta \dot{r} \tau \varepsilon \rho o s$, signifying an elder who holds the sacerdotal office. Minister, in Latin minister, a servant, from minor, less or inferior, signifies literally one who performs a subordinate. office.
It acquired a special significance because of the Christian emphasis upon humility. The Pope called himself the "servant of the servants of Jesus Christ."

The word clergyman applies to such as are regularly bred according to the forms of the national religion, and applies to none else. In this sense we speak of the English, the French, and Scotch clergy without distinction. A parson is a species of clergyman who ranks the highest in the three orders of inferior clergy, that is, parson, vicar, and curate; the parson being a technical term for the rector, or he who holds the living: in its technical sense it has now acquired a definite use, but in general conversation it is become almost a nickname. The word clergyman is always substituted for parson in polite society. When priest respects the Christian religion it is a species of clergyman, that is, one who is ordained to officiate at the altar in distinction from the deacon, who is only an assistant to the priest. But the term priest has likewise an extended meaning in reference to such as hold the sacerdotal character in any form of religion, as the priests of the Jews, or those of the Greeks, Romans, Indians, and the like. A minister is one who actually or habitually officiates. Clergymen are therefore not always strictly ministers, nor are all ministers clergymen. If a clergyman delegates his functions altogether he is not a minister; nor is he who presides over a dissenting congregation a clergyman. In the former case, however, it would be invidious to deprive the clergyman of the name of minister of the Gospel, but in the latter case it is a misuse of the term clergyman to apply it to any minister who does not officiate according to the form of an established religion.

Clever, Skilful, Expert, DexTerous, Adroit. Clever, Middle English cliver, ready to seize, is allied to Middle English cliver, a claw. Skilful comes from skill, a Scandinavian word which meant originally intelligent, discerning. Expert, in French expert, Latin expertus, participle of experior, to search or try, signifies searched and tried. Dexterous, in Latin dexter, sig- 
nifies the quality of doing rightly, as with the right hand. Adroit is derived from the French phrase $a$ droit, from Latin $a d$ (to) and directum, right, justice, ultimately from regere, to order or rule.

Cleverness is mental power employed in the ordinary concerns of life: a person is clever in business. Skill is both a mental and corporeal power, exerted in mechanical operations and practical sciences: a physician, a lawyer, or an artist is skilful: one may have a skill in divination, or a skill in painting. Expertness and dexterity require more corporeal than mental power exerted in minor arts and amusements: one is expert at throwing the quoit: dexterous in the management of horses. Adroitness is altogether a corporeal talent, employed only as occasion may require: one is adroit at eluding the blows aimed by an adversary. Cleverness is rather a natural gift; skill is cleverness improved by practice and extended knowledge; expertness is the effect of long practice; dexterity arises from habit combined with agility; adroitness is a species of dexterity arising from a natural agility. A person is clever at drawing who shows a taste for it, and executes it well without much instruction: he is skilful in drawing if he understands it both in theory and practice; he is expert in the use of the bow if he can use it with expedition and effect; he is dexterous at any game when he goes through the mancuvres with celcrity and an unerring hand; he is adroit if, by a quick, sudden, and welldirected movement of his body, he effects the object he has in view.

\section{CLEVERNESS. See GUMption.}

Climacteric, Critical, DaNGERous. These words all suggest a time of suspense, when some misfortune may be about to fall. Of the three words climacteric is the most specific. Climacteric, from the Greek $\kappa \lambda \bar{i} \mu \alpha \kappa \tau \dot{\rho} \rho$, a round or step of a ladder, pertains to one of the supposed critical and dangerous steps or periods in human life, in which some great change is by some believed to take place in the human constitution. The numbers 7 and 9 are thought by many to mark the years of age when such steps or periods are reached, and when dangerous attacks of siekness may be expected. The most critical period of all, according to belief, and known as the grand climacteric, is within the $63 d$ year, that is $7 \times 9$, of a man's life, when his constitution is said to decline rapidly, involving him in critical illness till the year has passed and old age begins.

Critical (see Critical) and dangerous (see DaNGer) are less limited in their application. Dangerous is a stronger word than critical. Critical suggests the possibility of misfortune; dangerous the probability.

\section{CLIMB. See ARISE.}

CloAK, Mask, Blind, Veil. These are figurative terms, expressive of different modes of intentionally keeping something from the view of others. They are borrowed from those familiar objects which serve similar purposes in common life. Cloak and mask express figuratively and properly more than blind or veil. The two former keep the whole object out of sight; the two latter only partially intercept the view. In this figurative sense they are all employed for a bad purpose. The cloak, the mask, and the blind serve to deceive others; the veil serves to deccive one's self. The whole or any part of a character may be concealed by a blind; a part, though not the whole, may be concealed by a mask. A blind is not only employed to conceal the character, but the conduct or proceedings. We carry a cloak and a mask about with us; but a blind is something external. The cloak, as the external garment, is the most convenient of all coverings for entirely keeping concealed what we do not wish to be seen; a good outward deportment serves as a cloak to conceal a bad character. A mask hides only the face; a mask, therefore, serves to conceal only as much as words and looks can effect. A blind is intended to shut out the light and prevent observation; whatever, therefore, conceals the real truth, and prevents suspicion by a false exterior, is a blind. A veil prevents a person from seeing as well as being seen; whatever, therefore, obscures the mental sight acts as a veil to the mind's eye. Religion is unfortunately the object which may serve to cloak the worst of purposes and the worst of characters: its importance in 
the eyes of all men makes it the most effectual passport to their countenance and sanction; and its external observances render it the most convenient mode of presenting a false profession to the eyes of the world: those, therefore, who set an undue value on the ceremonial part of religion do but encourage this most heinous of all sins, by suffering themselves to be imposed upon by a cloak of religious hypocrisy. False friends always wear a mask; they cover a malignant heart under the smiles and endearments of friendship. Illicit traders mostly make use of some blind to facilitate the carrying on their nefarious practices. Am*ng the various arts resorted to in the metropolis by the needy and profligate, none is so bad as that which is made to be a blind for the practice of debauchery. Prejudice and passion are the ordinary veils which obscure the judgment and prevent it from distinguishing the truth.

ClOG, Load, Encumber. Clog in Middle English means the wooden sole of a shoe; hence a hindrance. For the derivation of load see Freight. Encumber is from French encombrer, Latin in and Late Latin combrus, an obstacle.

Clog is figuratively employed for whatever impedes the motion or action of a thing, drawn from the familiar object which is used to impede the motion of animals: load is used for whatever occasions an excess of weight or materials. A wheel is clogged, or a machine is clogged; a fire may be loaded with coals, or a picture with coloring. The stomach and memory may be either clogged or loaded: in the former case by the introduction of improper food, and in the second case by the introduction of an improper quantity. A memory that is clogged becomes confused, and confounds one thing with another; that which is loaded loses the impression of one object by the introduction of another. Clog and encumber have the common signification of interrupting or troubling by means of something irrelevant. Whatever is clogged has scarcely the liberty of moving at all; whatever is encumbered moves and acts, but with difficulty. When the roots of plants are clogged with mould, or any improper substance, their growth is almest stopped; weeds and noxious plants are encumbrances in the ground where flowers should grow.

Cloister, Convent, Monastery. Cloister, Latin claustrum, means literally an enclosure, and signifies a certain close place in a convent, or an enclosure of houses for canons, or, in general, a religious house. Convent, from the Latin conventus, a meeting, and convenire, to come together, signifies a religious assembly. Monastery, in French monastère, signifies a habitation for monks, from the Greek $\mu$ óvoc, alone.

The proper idea of cloister is that of seclusion; the proper idea of convent is that of community; the proper idea of a monastery is that of solitude. One is shut up in a cloister, put into a convent, and retires to a monastery. Whoever wishes to take an absolute leave of the world shuts himself up in a cloister; whoever wishes to attach himself to a community that has renounced all commerce with the world goes into a convent; whoever wishes to shun all human intercourse retires to a monastery. In the cloister our liberty is sacrificed; in the convent our worldly habits are renounced, and, those of a regular religious community being adopted, we submit to the yoke of established orders: in a monastery we impose a sort of voluntary exile upon ourselves; we live with the view of living only to God. In the ancient and true monasteries the members divided their time between contemplation and labor; but as population increased and towns multiplied monasteries were, properly speaking, succeeded by convents. In ordinary discourse cloister is employed in an absolute and indefinite manner: we speak of the cloister to designate a monastic state; as entering a cloister; burying one's self in a cloister; penances and mortifications are practised in a cloister. It is not the same thing when we speak of the cloister of the Benedictines and of their monastery; or the cloister of the Capuchins and their convent.

ClOSE, Compact. Close is from the French clos, and Latin clausus, the participle of claudere, to shut. Compact 
is derived from Latin compactus, cum, together, and pangere, to fasten, to fit, and signifies fitted, close, form.

Proximity is expressed by both these terms; the former in a general and the latter in a restricted sense. Two bodies may be close to each other, but a body is compact with regard to itself. Contact is not essential to constitute closeness; but a perfect adhesion of all the parts of a body is essential to produce compactness. Lines are close to each other that are separated but by a small space; things are rolled together in a compact form that are brought within the smallest possible space.

Close, Near, Nigh. - Close (see above). Near is the comparative of nigh.

Close is more definite than near: houses stand close to each other which are almost joined; men stand close when they touch each other; objects are near which are within sight; persons are near each other when they can converse together. Near and nigh, which are but variations of each other in etymology, admit of little or no difference in their use; the former, however, is the most general. People live near each other who are in the same street; they live close to each other when their houses are adjoining. Close is annexed as an adjective; near is employed only as an adverb or preposition. We speak of close ranks or close lines; but not near ranks or near lines.

See also End; Sequel.

Close, Shut.-Close (see above). Shut, Anglo-Saxon scyttan, meant originally to fasten a door with a bolt, and is allied to shoot. We still say "shoot the bolt" (Skeat).

To close signifies simply to put close together; shut to stop or prevent admittance; closing is therefore a partial shutting, and shutting a complete closing; as to close a door or window is to put it partially to, as distinguished from shutting it, $i$. e., shutting it close. The eyes are shut by closing the eyelids, and the mouth is shut by closing the lips; and by the figure of metonymy to close may therefore often be substituted for shut: as to close the eyes, to close the mouth, particularly in poetry.
There is, hewever, a further distinction between these two words: to close properly denotes the bringing anything close, and may, therefore, be applied to any opening or cavity which may thus be filled up or covered over for a permanency; as to close a wound, to close the entrance to any place; but shutting implies merely an occasional stoppage of an entrance by that which is movable: whatever is shut may be opened in this sense; not only a door, a book, or a box may be shut, but also the ears may be shut. In familiar language it is usual to speak of closing a scene, for putting an end to it; but in poetry the term shut may without impropriety be used in the same sense.

See also Blockade.

Close, Conclude, Finish.-To close is to bring toward an end; to conclude, from con and claudere, to shut, $i$. e., to shut together, signifies to bring actually to an end; finish, in Latin finio and finis, an end, signifies also literally to bring to an end. The idea of putting an end to a thing is common to these terms, but they differ in the circumstances of the action. To close is the most indefinite of the three. We may close at any point by simply ceasing to have any more to do with it; but we conclude in a definite and positive manner. Want of time may compel us to close a letter before we have said all we wish to say; a letter is commonly concluded with expressions of kindness or courtesy. Whatever admits of being discontinued is properly said to be closed; as to close a procession, entertainment, and the like.

Whatever is brought to the last or the desired point is properly said to be concluded; as to conclude a speech, a narrative, a business, and the like.

To conclude is to bring to an end by determination; to finish is to bring to an end by completion: what is settled by arrangement and deliberation is properly concluded; what is begun on a certain plan is said to be finished.

ClOWN. See Countryman.

CLOY. See SATISFY.

CLUE. See Key.

CLUMSY. See Awrward.

CLUTCH. See NAn.

COADJUTOR, Assistant. Coadju- 
tor, compounded of von and adjutor, a helper, signifies a fellow-laborer. Assistant signifies properly one that assists or takes a part.

A coadjutor is more noble than an assistant: the latter is mostly in a subordinate station, but the former is an equal; the latter performs menial offices in the minor concerns of life, and a subordinate part at all times; the former labors conjointly in some concern of common interest and great importance. An assistant is engaged for a compensation; a coadjutor is a voluntary fellow-laborer. In every public concern where the purposes of charity or religion are to be promoted coadjutors often effect more than the original promoters: in the medical and scholastic professions assistants are indispensable to relieve the pressure of business. Coadjutors ought to be zealous and unanimous; assistants ought to be assiduous and faithful.

COALESCE. See ADD.

COALITION. See Union.

COARSE, Rough, RUDE. was formerly course, and developed as an adjective from the phrase in course, to denote anything of ordinary character. Rough comes from Anglo-Saxon ruh, rough, hairy. Rude is derived from Latin rudis, raw, rough.

These epithets are equally applied to what is not polished by art. In the proper sense coarse refers to the composition and materials of bodies, as coarse bread, coarse meat, coarse cloth; rough respects the surface of bodies, as rough wood and rough skin; rude respects the make or fashion of things, as a rude bark, a rude utensil. Coarse is opposed to fine, rough to smooth, rude to polished.

In the figurative application they are distinguished in a similar manner: coarse language is used by persons of naturally coarse feeling; rough language, by those whose tempers are either naturally or occasionally rough; rude language, by those who are ignorant of any better.

See also Gross.

Coax, Wheedle, Cajole, Fawn. Coax is a comparatively recent word of uncertain origin. Dr. Johnson, 1755-73, describes it as "a low word." The original meaning seems to have been to make a cokes of, from cokes, a simpleton, a dupe. Wheedle may be derived from Anglo-Saxon woedlian, to beg, originally to be poor, from wodl, poverty. Cajole meant formerly to chatter like a jay. It may be of imitative origin. Fawn is derived from Anglo-Saxon fahnian, to rejoice, from fagen, fain, glad, and means to rejoice servilely, hence to cringe.

The idea of using mean arts to turn people to one's selfish purposes is common to all these terms: coax has something childish in it; wheedle and cajole that which is knavish; fawn that which is servile. The act of coaxing consists of urgent entreaty and whining supplication; the act of wheedling consists of smooth and winning entreaty; cajoling consists mostly of trickery and stratagem, disguised under a soft address and insinuating manners; the act of fawning consists of supplicant grimace and antics, such as characterize the little animal from which it derives its name: children coax their parents in order to obtain their wishes; the greedy and covetous wheedle those of any easy temper; knaves cajole the simple and unsuspecting; parasites fawn upon those who have the power to contribute to their gratifications: coaxing is mostly resorted to by inferiors toward those on whom they are dependent; wheedling and cajoling are low practices confined to the baser sort of men with one another; fawning, though not less mean and disgraceful than the above-mentioned vices, is commonly practised only in the higher walks, where men of base character, though not mean education, come in connection with the great.

COERCE, Restrain. Coerce, in Latin coerceo, that is, con and arceo, from arca, a chest, signifies to drive into conformity, with the under meaning of enclosing. Restrain is a variation of restrict (see BIND).

Coercion is a species of restraint: we always restrain or intend to restrain when we coerce; but we do not always coerce when we restrain; coercion always comprehends the idea of force; restraint, that of simply keeping under or back: coercion is always an external application; restraint either external or internal: a person is coerced by others 
only; he may be restrained by himself as well as others. Coercion acts by a direct application: it opposes force to resistance: restraint acts indirectly to the prevention of an act: the law restrains all men in their actions more or less; it coerces those who attempt to violate it; the unruly will is coerced; the improper will is restrained. Coercion is exercised; restraint is imposed: punishment, threats, or any actual exercise of authority, coerces; fear, shame, or a remonstrance from others, restrains.

COEval, Contemporary. Coeval, from the Latin avum, an age, signifies of the same age. Contemporary, from tempus, signifies of the same time.

An age is a specifically long space of time; a time is indefinite; hence the application of the terms to things in the first case and to persons in the second: the dispersion of mankind and the confusion of languages were coeval with the building of the tower of Babel; Addison was contemporary with Swift and Pope.

COGENT, Forcible, Strong. $\mathrm{Co}$ gent, from the Latin cogere, to compel; and forcible, from the verb to force (see CoMPEL), have equally the sense of acting by force. Strong is here figuratively employed for that species of strength which is connected with the mind (for derivation see STroNG).

Cogency applies to reasons individually considered; force and strength, to modes of reasoning or expression: cogent reasons impel to decisive conduct; strong conviction is produced by forcible reasoning conveyed in strong language: changes of any kind are so scldom attended with benefit to society that a legislator will be cautious not to adopt them without the most cogent reasons; the important truths of Christianity cannot be presented from the pulpit too forcibly to the minds of men. Accuracy and strength are seldom associated in the same mind; those who accustom themselves to strong language are not very scrupulous about the correctness of their assertions.

COINCIDE. See Agree; Tally. COLD. See Chill; CoOl.

COlleague, Partier. lega, compounded of ligare, to bind, signifies united in the same work. Partner, from Latin partem (acc.), part, whence our word part is derived, signifies one having a part or share.

Colleague is more noble than partner: men in the highest offices are colleagues; tradesmen, mechanics, and subordinate persons are partners: every Roman consul had a colleague; every workman had commonly a partner. Colleague is used only with regard to community of office; partner is most generally used with regard to community of interest: whenever two persons are employed to act together on the same business they stand in the relation of colleagues to each other; whenever two persons unite their endeavors either in trade or in games, or the business of life, they are denominated partners: ministers, judges, commissioners, and plenipotentiaries are colleagues; bankers, chess-players, card-players, and the like, have partners.

Collect. See Assemble; GarNER.

COlleCted. See Calm.

COLlection. See Assembly. COlloquY. See Conversation. COlOR, Dye, Tinge, Stain. To color, in Latin color, signifies to put color on or give color to a thing. To dye, in Anglo-Saxon deagian, signifies to imbue with a color. To tinge, in Latin tingo, and Greek T'́ $\gamma \gamma \varepsilon \iota \nu$, to sprinkle, signifies to touch lightly with a color. Stain, in French déteindre, comes from Latin dis, apart, and tingere, color, signifies to put a color on in a bad manner, or give a bad color.

To color, which is the most indefinite of these terms, is employed technically for putting a color on a thing; as to color a drawing.

But to color, in the general sense of giving color, may be applied to physical objects; as to color the cheeks. More commonly, however, to moral objects, as to color a description with the introduction of strong figures, strong facts, or strong descriptions, etc.

To dye is a process of art, as in the dyeing of cloth, but the term is applied to objects generally in the sense of imbuing with any substance so as to change the color. 
To tinge may be applied to ordinary objects; as to tinge a painting with blue by way of intermixing colors; but it is most appropriately used in poetry.

To stain is used in its proper sense when applied to common objects; as to stain a painting by putting blue instead of red, or to stain anything by giving it an unnatural color.

Whence it has also a moral application in the sense of taking away the purity from a thing; as to stain the reputation or character.

Color, Hue, Tint.-Hue and tint, from tinge, are but modes of color; the former of which expresses a faint or blended color; the latter a shade of color. Between the colors of black and brown, as of all other leading colors, there are various hues and tints, by the due intermixture of which natural objects are rendered beautiful.

Colorable, Specious, Ostensible, Plausible, Feasible.-Colorable, from to color or tinge, expresses the quality of being able to give a fair appearance. Specious, from the Latin species, appearance, from the root spec, to see, signifies the quality of looking as it ought. Ostensible, from the Latin ostendere, to stretch before the eyes, signifies the quality of being able or fit to be shown or seen. Plausible, from plaudo, to clap or make a noise, signifies something deserving of applause or approval. Feasible, from the French faire, and Latin facere, to do, signifies literally doable, and denotes seemingly practicable.

The first three of these words are figures of speech drawn from what naturally pleases the eye; plausible is drawn from what pleases the ear: feasible takes its signification from what meets the judgment or conviction. What is colorable has an aspect or face upon it that lulls suspicion and affords satisfaction; what is specious has a fair outside when contrasted with that which it may possibly conceal; what is ostensible is that which presents such an appearance as may serve for an indication of something real: what is plausible is that which meets the understanding merely through the ear; that which is feasible recommends itself from its intrinsic value rather than from any representation given of it. A pretence is colorable when it has the color of truth impressed upon it; it is specious when its fallacy is easily discernible through the thin guise it wears; a motive is ostensible which is the one soonest to be discovered; an excuse is plausible when the well-connected narrative of the maker impresses a belief of its justice: a plan is feasible which recommends itself as fit to be put in execution.

COMBAT, OpPose. Combat, from the French combattre, from Latin con, together, and batuere, to beat, to fight together, is used figuratively in the same sense with regard to matters of opinion. Oppose, through French opposer, from Latin $o b$ and Late Latin pansare, for pono, to place one's self in the way, signifies to set one's self against another.

Combat is properly a species of opposing; one always opposes in combating, though not vice versa. To combat is used in regard to speculative matters; oppose in regard to private and personal concerns. A person's positions are combated, his interests or his measures are opposed. The Christian combats the erroneous doctrines of the infidel with no other weapon than that of argument: the sophist opposes Christianity with ridicule and misrepresentation. The most laudable use to which knowledge can be converted is to combat error wherever it presents itself; but there are too many, particularly in the present day, who employ the little pittance of knowledge which they have collected to no better purpose than to oppose everything that is good, and excite the same spirit of opposition in others.

See also Battle; Conflict.

COMBatant, Champion. Combatant, from to combat, marks any one that engages in a combat. Champion, French champion, signifies originally a soldier or fighter, from the Latin campus, a field, especially a field of battle.

A combatant fights for himself and for victory; a champion fights either for another or in another's cause. The word combatant has always relation to some actual engagement; champion may be employed for one ready to be engaged or in the habit of being en- 
Igaged. The combatants in the Olympic games used to contend for a prize; the Roman gladiators were combatants who fought for their lives: when knighterrantry was in fashion there were champions of all descriptions, champions in behalf of distressed females, champions in behalf of the injured and oppressed, or champions in behalf of aggrieved princes. The mere act of fighting constitutes a combatant; the act of standing up in another's defence at a personal risk constitutes the champion. Animals have their combats, and consequently are combatants; but they are seldom champions. There may be champions for causes as well as persons, and for bad as well as good causes; as champions for liberty, for infidelity, and for Christianity.

Combination, Cabal, Plot, Conspiracy. Combination (see Association). Cabal, in French cabale, comes from the Hebrew kabala, signifying a secret science pretended to by the Jewish rabbi, whence it is applied to any association that has a pretended secret. Plot, in French complot, is a word of unknown origin. Plot in the sense of plan may have developed from plot, a small portion, to plot being to lay out in portions; from this familiar significance of the word may have developed its sinister meaning. Conspiracy, in French conspiration, from con and spirare, to breathe together, signifies the having one spirit.

An association for a bad purpose is the idea common to all these terms, and peculiar to combination. A combination may be either secret or open, but secrecy forms a necessary part in the signification of the other terms; a cabal is secret as to its end; a plot and conspiracy are secret both as to the means and the end. Combination is the close adherence of many for their mutual defence in obtaining their demands or resisting the claims of others. A cabal is the intrigue of a party or faction, formed by cunning practices in order to give a turn to the course of things to their own advantage: the natural and ruling idea in cabal is that of assembling a number and manœuvring secretly with address. A plot is a clandestine union of some persons for the purpose of mischief: the ruling idea in a plot is that of a complicated enterprise formed in secret, by two or more persons. A conspiracy is a general intelligence among persons united to effect some serious change: the ruling and natural idea in this word is that of unanimity and concert in the prosecution of a plan.

Combination, Cabal, Junto.- A special term applied to a combination or cabal for political purposes is found in the word junto, from Spanish junta (Latin jungere, to join), signifying a secret council or assembly, a select body of men combined secretly to effect some political aim. The form junta refers specifically to the Grand Council of the State of Spain, and was adopted in 1895 by the Cuban insurgents to designate the representation of their cause in foreign countries. The form junto is applicable to any secret gathering of men of a political character. It does not have the sinister significance of cabal, but, like cabal, it adds the idea of secrecy to that of combination.

See also Association.

Combine. See Connect; Merge. COMBINED. See SYNTHETIC.

COME, Arrive. Come is general; arrive is particular.

Persons or things come; persons only, or what is personified, arrives. To come specifies neither time nor manner; arrival is employed with regard to some particular period or circumstance. The coming of our Saviour was predicted by the prophets; the arrival of a messenger is expected at a certain hour. We know that evils must come, but we do wisely not to meet them by anticipation; the arrival of a vessel in the haven, after a long and dangerous voyage, is a circumstance of general interest in the neighborhood where it happens.

COMELY. See Becoming.

COMFORT, Pleasure. Comfort (see Chenr). Pleasure, from to please, signifies what pleases.

Comfort describes a state of quiet enjoyment, a freedom from trouble, pain, or disquiet. It is applied also to the relief or strength afforded in time of weakness, oppression, or danger. The grand feature in comfort is substantiality; in that of pleasure is 
warmth. Pleasure is quickly succeeded by pain; it is the lot of humanity that to every pleasure there should be an alloy: comfort is that portion of pleasure which seems to lie exempt from this disadvantage; it is the most durable sort of pleasure. Comfort must be sought for at home; pleasure is pursued abroad: comfort depends upon a thousand nameless trifles which daily arise; it is the relief of a pain, the heightening of a gratification, the supply of a want, or the removal of an inconvenience. Pleasure is the companion of luxury and abundance: it dwells in the palaces of the rich and the abodes of the voluptuary. Comfort is less than pleasure in the detail; it is more than pleasure in the aggregate.

See also Cheer; Console; Hearten.

\section{COMICAL. See Ladghable.}

COMMAND, ORDER, INJUNCTION, PreCePt. Command is compounded of con, together, and mandare, or dare in manus, to give into the hand, signifying to give or appoint as a task. Order, in the extended sense of regularity, implies what is done in the way of order or for the sake of regularity. Injunction comes from in and jungo, which signifies literally to join or bring close to; figuratively, to impress on the mind. Enjoin is derived from the same Latin word. Precept, in French précepte, Latin prcceptum, participle of prcecipio, compounded of proe and capere, to take before, signifies the thing proposed to the mind.

A command is an exercise of power or authority; it is imperative and must be obeyed: an order serves to direct; it is instructive and must be executed.

Command is properly the act of a superior or of one possessing power: order has more respect to the office than to the person. A sovereign issues his commands: orders may be given by a subordinate or by a body; as orders in council, or orders of a court.

A command may be divine or given from heaven; an order or injunction is given by men only.

Order is applied to the common concerns of life; injunction and precept to the moral conduct or duties of men. Injunction imposes a duty by virtue of the authority which enjoins: the precept lays down or teaches such duties as already exist.

\section{See also PraIse.}

COMMANDING, IMPERATIVE, IMPerioys, AUthoritative. Commanding signifies having the force of a command (see above). Imperative, from Latin imperare, is derived from Latin $i n$, and parare, to prepare, hence to order, arrange, command. Imperious, also from imperare, signifies in the way of, or like a command. Authoritative signifies having authority, or in the way of authority (for the derivation of which see INFLUENCE).

Commanding is either good or bad, according to circumstances; a commanding voice is necessary for one who has to command; but a commanding air is offensive when it is affected: $i m$ perative is applied to things, and used in an indifferent sense; imperious is used for persons or things in the bad sense: any direction is imperative which comes in the shape of a command, and circumstances are likewise imperative which act with the force of a command: persons are imperious who exercise their power oppressively; in this manner underlings in office are $i m-$ perious; necessity is imperious when it leaves us no choice in our conduct. Authoritative is mostly applied to persons or things personal in the good sense only; magistrates are called upon to assume an authoritative air when they meet with any resistance.

COMMEMORATE. See CeleBRATE.

COMMENCE. See Begin.

COMMENDABLE. See Laddable. COMMENSURATE. See ProporTIONATE.

COMMENT. See REMARK.

COMMENTARY. See REMARK.

COMMERCE. See INTERCOURSE;

Trade.

COMMERCIAL. See Mercantile. COMMISERATION. See SYMPaTHY.

COMMISSION, AUTHORIZE, EMPower. Commission, from Latin cum, with, and mittere, to send, signifies the act of sending some one with authority, or putting into the hands of another. To authorize signifies to give authority; to empower, to put in possession of power. 
The idea of transferring some business to another is common to these terms; the circumstances under which this is performed constitute the difference. We commission in ordinary cases; we authorize and empower in extraordinary cases. We commission in matters where our own will and convenience are concerned; we authorize in matters where our personal authority is requisite; and we empower in matters where the authority of the law is required. A commission is given by the bare communication of one's wishes; we authorize by a positive and formal declaration to that intent; we empower by the transfer of some legal document. A person is commissioned to make a purchase; he is authorized to communicate what has been confided to him; he is empowered to receive money. Commissioning passes mostly between equals; the performance of commissions is an act of civility; authorizing and empowering are as often directed to inferiors; they are frequently acts of justice and neecssity. Friends give one another commissions; servants and subordinate persons are sometimes authorized to act in the name of their employers; magistrates empower the officers of justice to apprehend individuals or enter houses. We are commissioned by persons only; we are authorized sometimes by circumstances; we are empowered by law.

COMMIT. See Consign; PerPETUATE.

COMMODIOUS, Convenient. Commodious, from the Latin commodus, or con and modus, according to the measure and degree required. Convenient, from the Latin conveniens, participle of con and venire, to come together, signifies that which comes together with something else as it ought.

The commodious is a species of the convenient, namcly, that which men contrive for their convenience. Commodious is therefore mostly applied to that which contributes to the bodily ease and comfort, convenient to whatever suits the purposes of men in their various transactions: a house, a chair, or a place is commodions; a time, an opportunity, a season, or the arrival of a person is convenient.

What is commodious is rendered so by design; what is convenient is 80 from the nature of the thing: in this sense arguments may be termed commodious which favor a person's ruling propensity or passion.

COMMODITY, Goods, MERchaNDISE, WARE. These terms agree in expressing articles of trade under various circumstances. Commodity, in Latin commoditas, signifies in its abstract sense convenience, and in an extended application anything that is convenient or fit for use. This being also salable, the word has been applied to things that are sold. Goods, from Anglo-Saxon god, fit, which denotes the thing that is good, has derived its use from the same analogy in its sense. Merchandise, from Latin merx, pay, Greek $\mu a ́ \rho \pi \tau є \iota \nu$, to seize, signifies salable things. (Compare the derivation of mercy under the key-word Clemency.) Ware, Anglo-Saxon waru, originally meant valuables, being allied to waru, signifying protection, guard, custody, etc.

Commodity is employed only for articles of the first necessity; it is the source of comfort and object of industry: goods is applied to everything belonging to tradesmen for which there is a stipulated value; they are sold retail, and are the proper objects of trade: merchandise applies to what belongs to merchants; it is the object of commerce: wares are manufactured, and may be either goods or merchandise; a country has its commodities, a shopkeeper his goods, a merchant his merchandise, a manufacturer his wares.

COMMON, Vulgar, OrdiNary, Mean. Common, in French commun, Latin communis, from con and munus, the joint office or property of many, has regard to the multitude of objects. Vulgar, in French vulgaire, Latin oulgaris, from vulgus, the people, has regard to the number and quality of the persons. Ordinary, in French ordinaire, Latin ordinarius, from ordo, the order or regular practice, has regard to the repetition or disposition of things. Mean is derived from AngloSaxon mone, which usually appears in the word gemane, common (German gemein); its meaning has been influenced by Latin medius, moderate, and by the English mean, the middle 
place, derived from that Latin word. Familiar use renders things common, vnlgar, and ordinary; but what is mean is so of itself: the common, vulgar, and ordinary are therefore frequently, though not always, mean; and, on the contrary, what is mean is not always common, vulgar, or ordinary; consequently in the primitive sense of these words the first three are not strictly synonymous with the last: monsters are common in Africa; vulgar reports are little to be relied on; it is an ordinary practice for men to make light of their word.

In the figurative sense in which they convey the idea of low value they are synonymous with mean; what is to be seen, heard, and enjoyed by everybody is common and naturally of little value, since the worth of objects frequently depends upon their scarcity and the difficulty of obtaining them. What is peculiar to common people is vulgar and consequently worse than common; it is supposed to belong to those who are ignorant and depraved in taste as well as in morals: what is done and seen ordinarily may be done and seen easily; it requires no abilities or mental acquirements; it has nothing striking in it, it excites no interest: what is mean is even below that which is ordinary; there is something defective in it. Common is opposed to rare and refined; vulgar, to polite and cultivated; ordinary, to the distinguished; mean, to the noble: a common mind busies itself with common objects; vulgar habits are easily contracted from a slight intercourse with vulgar people; an ordinary person is seldom associated with elevation of character; and a mean appearance is a certain mark of a degraded condition if not of a degraded mind.

See also Public.

Commonly, Generally, Frequently, Usually. - Commonly, in the form of common (see above). Generally, from general, and the Latin genus, the kind, respects a whole body in distinction to an individual. Frequently, from frequent, Latin frequens, is derived from a lost Latin verb, frequere, to cram, and signifies, properly, in a crowding manner. Usually, from Latin usualis, from usus, use, signifies according to use or custom.
What is commonly done is an action common to all; what is generally done is the action of the greatest part; what is frequently done is either the action of many or an action many times repeated by the same person; what is usually done is done regularly by one or many. Commonly is opposed to rarely; generally and frequently, to occasionally or seldom; usually, to casually: men commonly judge of others by themselves; those who judge by the mere exterior are generally deceived; but notwithstanding every precaution one is frequently exposed to gross frauds; a man of business usually repairs to his counting-house every day at a certain hour.

COMMON - CARRIER, SHIPPER, Transporter. Common-carrier is one of two conspicuous legal and commercial terms applied to a person or company engaged in the business of carrying goods from one place to another for the general public and for pay; the other term being private-carrier, one who carries only for a particular customer and not for the general public, and who incurs no responsibility beyond that of ordinary diligence.

A common-carrier by land may be a railroad corporation, express company, stage-coach proprietor, a truckman, teamster, or porter, and a commoncarrier by water may be a steamship company, the master or owner of other ships and vessels engaged in transportation of goods, a lighterman, canalboatman, ferryman, and others employed in like manner.

A shipper is one who puts goods on board the ship; and is extended to refer to any one whose business it is to put goods on some means of conveyance for transportation to another place. The transporter (from Latin trans, across, and portare, to carry) is, strictly speaking, the person who carries the goods from one spot to another. A common-carrier in America is a public transporter, and as such is bound by strict legal obligations defined by the Interstate Commerce Commission.

COMMONWEALTH. See State. COMMOTION,Disturbance. Commotion, compounded of cum, together, 
and movere, signifying properly a motion of several together, expresses more than disturbance, which denotes the 'state of being disturbed (see TROUBLE). When applied to physical objects, commotion denotes the violent motion of several objects or of the several parts of any individual thing; disturbance denotes any motion or noise which puts a thing out of its natural state. We speak of the commotion of the elements, or the stillness of the night being disturbed by the rustling of the leaves.

In respect to men or animals, commotion and disturbance may be either inward or outward with a like distinction in their signification. A commotion supposes a motion of all the feelings; a disturbance of the mind may amount to no more than an interruption of the quiet to an indefinite degree.

So in regard to external circumstances: a commotion in public is occasioned by extraordinary circumstances, and is accompanied with unusual bustle and movement; whatever interrupts the peace of a neighborhood is a disturbance: political events occasion a commotion; drunkenness is a common cause of disturbances in the streets or in families.

COMMUNICATE, IMPART. To communicate, from the Latin communis, common, signifies to make common, or give a joint possession or enjoyment: to impart, from in and part, signifies to give in part or make partaker. Both these words denote the giving some part of what one has in his power or possession; but the former is more general and indefinite in its signification and application than the latter. A thing may be communicated directly or indirectly, and to any number of persons; as to communicate intelligence by signal or otherwise. Impart is a direct action that passes between individuals; as to impart instruction.

What is communicated may be a matter of interest to the person communicating or otherwise; but what is imparted is commonly and properly that which interests both parties. A man may communicate the secrets of another as well as his own; he imparts his sentiments and feelings to a friend.

Communion, Converse.-Communion, from commune and common, signifies the act of making common. Converse, from Latin con and versari, to dwell, from vertere, to turn, signifies the intercourse of those dwelling together.

Both these terms imply a communication between minds; but the former may take place without corporeal agency, the latter never does; spirits hold communion with one another; people hold converse. For the same reason a man may hold communion with himself; he holds converse always with another.

See also Lord's SUPPer.

COMMUNISM. See Socialism.

COMMUNITY, SocIETY. Both these terms are employed for a body of rational beings. Community, from communitas and communis, common, signifies abstractly the state of being common, and in an extended sense those who are in a state of common possession. Society, in Latin societas, from socius, a companion, signifies the state of being companions, or those who are in that state.

Community in anything constitutes a community; a common interest, a common language, a common government, is the basis of that community which is formed by any number of individuals; the coming together of many and keeping together under given laws and for given purposes constitutes a society; societies are either public or private, according to the purpose: friends form societies for pleasure, indifferent persons form societies for business. The term community is therefore appropriately applied to indefinite numbers, and society in cases where the number is restricted by the nature of the union.

The term community may likewise be applied to a small body, and in some cases be indifferently used for society; but as it always retains its generality of meaning, the term society is more proper where the idea of a close union, a tie, or obligation is to be expressed; as, every member of the community is equally interested; every member of the society is bound to contribute.

See also Public.

COMMUTE. See Exchange.

COMPACT. See AGrEement; Close.

COMPANION. See ACcompant- 
COMPANY. See Assembly; Association; Band; Society; Troop.

COMPARISON, Contrast. Comparison, Latin comparo, or con, together, and par, equal, signifies the putting together of equals. Contrast, in French contraster, Latin contrasto, or contra, against, and stare, to stand, signifies the placing one thing opposite to another.

Likeness in the quality and difference in the degree are requisite for a comparison; likeness in the degree and opposition in the quality are requisite for a contrast: things of the same color are compared; those of an opposite color are contrasted: a comparison is made between two shades of red: a contrast between black and white. Comparison is of a practical utility, it serves to ascertain the true relation of objects; contrast is of utility among poets, it serves to heighten the effect of opposite qualities: things are large or small by comparison; they are magnified or diminished in one's mind by contrast: the value of a coin is best learned by comparing it with another of the same metal; the generosity of one person is most strongly felt when contrasted with the meanness of another.

See also Simur.

COMPASSION. See Pity; SrmpaTHY.

COMPATIBLe, Consistent. Compatible, compounded of com or cum, with, and pati, to suffer, signifies a fitness to be suffered together. Consistent, in Latin consistens, participle of consisto, compounded of con and sistere, to cause to stand, to please, signifies the fitness to be placed together.

Compatibility has principally a reference to plans and measures; consistency, to character, conduct, and station. Everything is compatible with a plan which does not interrupt its prosecution; everything is consistent with a person's station by which it is neither degraded nor elevated. It is not compatible with the good discipline of a school to allow of foreign interference; it is not consistent with the elevated and dignified character of a clergyman to engage in the ordinary pursuits of other men.

COMpel, Force, Oblige, Necessitate. All these terms denote the application of force either on the body or the mind in order to influence the conduct. To compel, from the Latin con and pello, drive, signifying to drive to a specific point, denotes rather moral than physical force; but to force, from Latin fors, strong, signifying to effect by force, is properly applied to the use of physical force or a violent degree of moral force. A man may be compelled to walk if he have no means of riding; he may be forced to go at the will of another.

These terms may, therefore, be applied to the same objects to denote different degrees of force.

Compel expresses a direct and powerful force on the will which leaves no choice. Oblige, from ob and ligare, to bind, signifying to bind or keep down to a particular point, expresses only an indirect influence, which may be resisted or yielded at discretion; we are compelled to do that which is repugnant to our will and our feelings; that which one is obliged to do may have the assent of the judgment if not of the will. Wants compel men to do many things which are inconsistent with their station and painful to their feelings. Honor and religion oblige men scrupulously to observe their word one to another.

Compel, force, and oblige are mostly the acts of persons in the proper sense. Necessitate, which signifies to lay under a necessity, is properly the act of things. We are necessitated by circumstances, or by anything which puts it out of our power to do otherwise.

Compel, Impel, Constrain, Restrain. -To compel and impel are both derived from the verb pello, to drive; the former, by the force of the preposition com, is to drive to any particular action or for a given purpose; but the latter, from the preposition $i m$ or in, into, is to force into action generally. A person, therefore, is compelled by outward circumstances, but he is impelled from within: he is compelled by another to go farther than he wished, he is impelled by curiosity to go farther than he intended. Constrain and restrain are from stringere, to bind or oblige. The former, by force of the con or com, to force in a particular manner or for a particular purpose; the latter 
by the re, back or again, is to keep back from anything. To constrain, like to compel, is to force to act; to restrain, to prevent from acting. Constrain and compel differ only in the degree of force used, constrain signifying a less degree of force than compel. A person who is compelled has no choice whatever left to him; but when he is only constrained he may do it or not at discretion.

Constraint is put on the actions or movements of the body only, restraint on the movements of both body and mind: a person who is in a state of constraint shows his want of freedom in the awkwardness of his movements; he who is in a state of restraint may be unable to move at all. Constraint arises from that which is inherent in the person, restraint is imposed upon him.

See also Constraint.

COMPENDIUM. See MENT.

COMPENSATION, Amends, Satisfaction, Recompense, Remuneration, Requital, Reward. All these terms imply some return or equivalent for something else, good or bad. Compensation, from cum and pendere, to weigh, signifies literally what is weighed with or against something else, hence paid for another thing. Amends, from amend, signifies that which amends or makes good. Satisfaction, that which satisfies or makes up something wanted. Recompense, from pensum, participle of pendo, that which pays back. Remuneration, from munus, a gift or reward, that which is given back by way of reward. Requital, from to quit, that which acquits in return. The first three of these terms denote a return or equivalent for something amiss or wanting; the last three a return for some good.

A compensation is a return for a loss or damage sustained; justice requires that it should be equal in value, although not alike in kind.

Amends is a return for anything that is faulty in ourselves or toward others. A person may make amends for idleness at one time by double portion of diligence at another.

A man may make another amends for any hardship done to him by showing him some extra favor another way.
Satisfaction is that which satisfies the individual requiring it; it is given for personal injuries, and may be made either by a slight return or otherwise, according to the disposition of the person to be satisfied. As regards man and man, affronts are often unreal, and the satisfaction demanded is still oftener absurd and unchristian-like. As regards man and his Maker, satisfaction is for our offences, which Divine Justice demands and Divine Mercy accepts.

Compensation and amends may both denote a simple equivalent without any reference to that which is personal. A compensation in this case may be an advantage one way to counterbalance a disadvantage another way. Or it may be the putting one desirable thing of equal value in the place of another. An amends supplies a defect by something superabundant in another part. Compensation is sometimes taken for a payment or some indefinite return for a service or good done: this brings it nearer in sense to the words recompense and remuneration, with this difference, that the compensation is given for bodily labor, or inferior services; recompense and remuneration, for that which is done by persons in a superior condition. The time and strength of a poor man ought not to be used without his receiving a compensation.

A recompense is a voluntary return for a voluntary service; it is made from a generous feeling, and derives its value not so much from the magnitude of the service or return as from the intentions of the parties toward each other; and it is received not so much as a matter of right as of courtesy: there are a thousand acts of civility performed by others which may be entitled to some recompense.

Remuneration is not so voluntary as recompense, but it is equally indefinite, being estimated rather according to the condition of the person and the dignity of the service than its positive worth. Authors often receive a remuneration for their works according to the reputation they have previously acquired, and not according to the real merit of the work.

Requital is the return of a kindness, the making it is an act of gratitude. 
Reward, from ward, and the German währen, to see, signifies properly a looking back upon-i.e., a return that has respect to something else. A reward conveys no idea of an obligation on the part of the person making it; whoever rewards acts optionally. It is the conduct which produces the reward, and consequently this term, unlike all the others, denotes a return for either good or evil. Whatever accrues to a man and the consequences of his conduct, be it good or bad, is a reward. The reward of industry is ease and content.

When a deceiver is caught in his own snare, he meets with the reward which should always attend deceit.

A compensation, recompense, requital, and reward may be a bad as well as a good return. That which ill supplies the thing wanted is a bad compensation; honor is but a poor compensation for the loss of health.

That which does not answer one's expectations is a bad recompense; there are many things which people pursue with much eagerness that do not recompense the trouble bestowed upon them.

When evil is returned for good, that is a bad requital, and, as a proof of ingratitude, wounds the feelings. Those who befriend the wicked may expect to be ill requited.

A reward may be a bad return when it is inadequate to the merits of the person.

COMPETENT, FitTed, Qualified. Competent, from con, together, and petere, to seek, signifies suitable (literally, seeking that which belongs to one). Fitted, from fit (see Becoming). Qualified, participle of qualify, from the Latin qualis, how much, and facere, to make, signifies made as much as it ought to be, measured up to a standard.

Competency mostly respects the mental endowments and attainments; fitness, the disposition and character; qualification the artificial acquirements or natural qualities. A person is competent to undertake an office; fitted or qualified to fill a situation. Familiarity with any subject aided by strong mental endowments gives competency: suitable habits and temper constitute the fitness: acquaintance with the business to be done, and expertness in the mode of performing it, constitute the qualification: none should pretend to give their opinions on serious subjects who are not competent judges; none but lawyers are competent to decide in cases of law; none but medical men are competent to prescribe medicines: none but divines of sound learning, as well as piety, to determine on doctrinal questions: men of sedentary and studious habits, with a serious temper, are most fitted to be clergymen: and those who have the most learning and acquaintance with the Holy Scriptures are the best qualified for the important and sacred office of instructing the people. Many are qualified for managing the concerns of others who would not be competent to manage a concern for themselves. Many who are fitted, from their turn of mind, for any particular charge may be unfortunately incompetent for want of the requisite qualifications.

COMPETITION, EMULATION, RIVALRY. Competition, from the Latin competo, compounded of con and peto, signifies to sue or seek together, to seek for the same object. Emulation comes from Latin amulus, which means striving to be equal. Rivalry, from the Latin rivus, the bank of a stream, signifies the undivided or common enjoyment of any stream, which in olden times was a natural source of discord and led to rivalry

Competition is properly an act, emulation is a feeling or temper of mind which incites to action, and emulation, therefore, frequently furnishes the motive for competition; the bare action of seeking the same object constitutes the competition; the desire of excelling is the principal characteristic in emulation. Competition, therefore, applies to matters either of interest or honor where more than one person strive to gain a particular object, as competition for the purchase of a commodity or for a prize. Emulation is confined to matters that admit of superiority and distinction.

Rivalry resembles emulation as far as it has most respect to the feeling, and competition as far as it has respect to the action. But competition and emulation'have for the most part a laudable 
object, and proceed in the attainment of it by honest means; rivalry has always a selfish object, and is often but little scrupulous in the choice of the means: a competitor may be unfair, but a rival is very rarely generous. There are competitors for office, or competitors at public games, and rivals for the favor of others.

When emulation degenerates into a desire for petty distinctions it is akin to rivalry.

Competitors must always come in close collision, as they seek for the same individual thing; but rivals may act at a distance, as they only work toward the same point: there may be rivalry between states which vie with one another in greatness or power, but there cannot properly be competition.

COMPLAIN, LAMENT, REgReT. Complain, French complaindre or plaindre, Latin plango, to beat the breast as a sign of grief. Lament (see BeWAIL). Regret comes through French from Latin $r e$ and a Scandinavian verb found in Anglo-Saxon gratan, to bewail.

Complaint marks most of dissatisfaction; lamentation, most of grief; regret, most of pain. Complaint is expressed verbally; lamentation, either by words or signs; regret may be felt without being expressed. Complaint is made of personal grievances; lamentation and regret may be made on account of others as well as ourselves. We complain of our ill health, of our inconveniences, or of troublesome circumstances; we lament our inability to serve another; we regret the absence of one whom we love. Selfish people have the most to complain of, as they demand most of others and are most liable to be disappointed; anxious people are the most liable to lament, as they feel everything strongly; the best-regulated mind may have occasion to regret some circumstances which give pain to the tender affections of the heart.

We may complain without any cause, and lament beyond what the eause requires; but regret is always founded on some real cause, and never exceeds in measure.

Complain, Murmur, Repine-Complain (see above). Murmur is a word of imitative origin, from Latin murmur, Sanskrit marmara, the rustling sound of the wind; hence a low complaining. Repine is compounded of re and pine, from Anglo-Saxon pin, pain, Latin

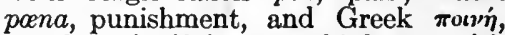
penalty, signifying to think on with pain.

The idea of expressing displeasure or dissatisfaction of what is done by others is common to these terms. Complaint is not so loud as murmuring, but more so than repining. We complain or murmur by some audible method; we may repine secretly. Complaints are always addressed to some one; murmurs and repinings are often addressed only to one's self. Complaints are made of whatever creates uneasiness, without regard to the source from which they flow; murmurings are a species of complaints made only of that which is done by others for our inconvenience; when used in relation to persons, complaint is the act of a superior, or of one who has a right to express his dissatisfaction; murmuring, that of an inferior, or one who is subject to another. When the conduct of another offends, it calls for complaint; when a superior aggrieves by the imposition of what is burdensome, it occasions murmuring on the part of the aggrieved.

Complain and murmur may sometimes signify to be dissatisfied simply, without implying any direct expression which brings them nearer to the word repine; in this case complain expresses a less violent dissatisfaction than murmur, and both more than repine, which implies what is deep-seated. With this distinction they may all be employed to denote the dissatisfaction produced by events that inevitably happen. Men may be said to complain, murmur, or repine at their lot.

Complaint, Accusation.-Complaint (see prcceding term). Accusation (see ACCUSE). Both these terms are employed in regard to the conduct of others, but a complaint is mostly made in matters that personally affect the complainant; an accusation is made of matters in general, but especially those of a moral nature. A complaint is made for the sake of obtaining redress; an accusation is made for the sake of ascertaining a fact or bringing to punishment. A complaint may be frivolous, an accusation false. People 
in subordinate stations should be careful to give no cause for complaint: the most guarded conduct will not protect any person from the unjust accusations of the malevolent.

COMPlaisance, Deference, Condescension. Complaisance, from the present participle of French complaire (Latin complacere, please), signifiesthe act of complying with, or pleasing others. Deference, in French déférence, from the Latin defero, to bear down, marks the inclination to defer, or acquiesce in the sentiments of another in preference to one's own. Condescension, from Latin con, with, and descendere, to descend, means the descending from one's own height to comply with the wishes of others.

The necessities, the conveniences, the accommodations and allurements of society, of familiarity, and of intimacy lead to complaisance: it makes sacrifices to the wishes, tastes, comforts, enjoyments, and personal feelings of others. Age, rank, dignity, and personal merit call for deference: it enjoins compliance with respect to our opinions, judgments, pretensions, and designs. The infirmities, the wants, the defects and foibles of others call for condescension: it relaxes the rigor of authority and removes the distinction of rank or station. Complaisance is the act of an equal; deference, that of an inferior; condescension, that of a superior. Complaisance is due from one well-bred person to another; deference is due to all superiors in age, knowledge, or station whom one approaches; condescension is due from all superiors to such as are dependent on them for comfort and enjoyment. All these qualities spring from a refinement of humanity; but complaisance has most of genuine kindness in its nature; deference, most of respectful submission; condescension, most of easy indulgence.

COMPLAISANT. See Civil; CourTEOUS.

COMPlete, Perfect, Finished. Complete, in French complet, Latin completus, participle of complere, to fill up, signifies the quality of being filled, or having all that is necessary. Perfect, in Latin perfectus, participle of perficere, from per, through, and facere, to do, signifies the state of being done thor- oughly. Finished, from finish (see Close), marks the state of being finished.

That is complete which has no deficiency: that is perfect which has positive excellence; and that is finished which has no omission in it. That to which anything can be added is incomplete; when it can be improved, it is imperfect; when more labor ought to be bestowed upon it, it is unfinished. A thing is complete in all its parts; perfect as to the beauty and design of the construction; and finished as it comes from the hand of the workman and answers his intention. A set of books is not complete when a volume is wanting: there is nothing in the proper sense perfect which is the work of man, but the term is used relatively for whatever makes the greatest approach to perfection: a finished performance evinces care and diligence on the part of the workman. These terms admit of the same distinction when applied to moral or intellectual objects.

See also Wrole.

Complete, Finish, Terminate.-We complete, that is, make complete, what is undertaken by continuing to labor at. it. We finish what is begun in a state of forwardness by putting the last hand to it. We terminate what ought not to last by bringing it to a close, from terminus, a term, a boundary, signifying to set bounds to a thing.

The characteristic idea of completing is that of making a thing altogether what it ought to be; that of finishing the doing all that is intended to be done toward a thing; and that of terminating, simply putting an end to a thing. Completing has properly relation to permanent works only, whether mechanical or intellectual; we desire a thing to be completed from a curiosity to see it in its entire state. To finish is employed for passing occupations; we wish a thing finished from an anxiety to proceed to something else, or a dislike to the thing in which we are engaged. Terminating respects space or time: a view may be terminated, a life may be terminated, or that to which one may put a term, as to terminate a dispute. Light minds undertake many things 
without completing any. Children and unsteady people set about many things without finishing any. Litigious people terminate one dispute only to commence another.

COMPLETELY. See QUITE.

COMPLETION. See ConsUmmaTION.

COMPLEX. See CoMPoUnd.

COMPLEXITY, CoMPLICATION, INTRICACY. Complexity and complication, in French complication, compounded of con, with, and plectere, to plait, allied to plicare, to twine, signifies a plaiting together of two different things-an interweaving. Intricacy, Latin intricatio and intrico, compounded of in and tricoe, perplexities, signifies a state of entanglement.

Complexity expresses the abstract quality or state; complication the act: they both convey less than intricacy; intricate is that which is very complicated. Complexity arises from a multitude of objects and the nature of these objects; complication, from an involvement of objects; and intricacy, from a winding and confused involution. What is complex must be decomposed; what is complicated must be developed; what is intricate must be unraveled. A proposition is complex, affairs are complicated; the law is intricate. The complexity of a subject often deters young persons from application to their business. There is nothing embarrasses a physician more than a complication of disorders, where the remedy for one impedes the cure for the other. Some affairs are involved in such a degrec of intricacy as to exhaust the patience and perseverance of the most laborious.

COMPLIMENT. See AdULATE.

COMPLY, Conform; Yield, SUbMrT. Comply (see AGres). Conform, compounded of con and formare, signifies to put into the same form. Yield (see AGReE). Submit, in Latin submitto, compounded of sub, under, and mittere, to send, signifies to put under, that is to say, to put one's self under another person. Compliance and conformity are voluntary; yielding and submission are involuntary. Compliance is an act of the inclination; conformity an act of the judgment: compliance is altogether optional; we com- ply with a thing or not, at pleasure; conformity is binding on the conscience; it relates to matters in which there is a right and a wrong. Compliance with the fashions and customs of those we live with is a natural propensity of the human mind that may be mostly indulged without impropriety; conformity in religious matters, though not to be enforced by human law, is not on that account less binding on the consciences of every member of the community; the violation of this duty on trivial grounds-involves in it that of more than one breach of the moral law.

Compliance and conformity are produced by no external action on the mind; they flow spontaneously from the will and understanding: yielding is altogether the result of foreign agency. We comply with a wish as soon as it is known; it accords with our feelings so to do: we yield to the entreaties of others; it is the effect of persuasion, a constraint upon or at least a direction of the inclination. We conform to the regulations of a community, it is a matter of discretion; we yield to the superior judgment of another, we have no choice or alternative. We comply cheerfully; we conform willingly; we yield reluctantly. A cheerful compliance with the requests of a friend is the sincerest proof of friendship: the wisest and most learned of men have ever been the readiest to conform to the general sense of the community in which they live: the harmony of social life is frequently disturbed by the reluctance which men have to yield to one another.

To yield is to give way to another, either with one's will, judgment, or outward conduct; submission is the giving up of one's self altogether; it is the substitution of another's will for one's own. Yielding is partial; we may yield in one case or in one action, though not in another: submission is general; it includes a system of conduct.

We yield when we do not resist; this may sometimes be the act of a superior: we submit only by adopting the measures and conduct proposed to us; this always is the act of an inferior. Yielding may be produced by means more or less gentle, by enticing or insinuat- 
ing arts, or by the force of argument; submission is made only to power or positive force: one yields after a struggle; one submits without resistance: we yield to ourselves or others; we submit to others only: it is a weakness to yield either to the suggestions of others or our own inclinations to do that which our judgments condemn; it is a folly to submit to the caprice of any one where there is not a moral obligation: it is obstinacy not to yield when one's adversary has the advantage; it is sinful not to submit to constituted authorities.

See also Agres.

Compliant, Yielding, Submissive.These epithets from the preceding verbs serve to designate a propensity to the respective actions, which may be excessive or otherwise. A compliant temper complies with every wish of another, good or bad: a yielding temper leans to every opinion, right or wrong; a submissive temper submits to every demand, just or unjust. A complaint person may want command of feeling; a yielding person may want fixedness of principle; a submissive person may want resolution: a too complaint disposition will be imposed upon by the selfish and unreasonable; a too yielding disposition is most unfit for commanding; a too submissive disposition exposes a person to the exactions of tyranny.

COMPOSE, SETTLE. Compose is derived through French from Greek

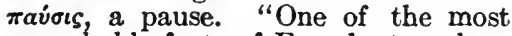
remarkable facts of French etymology is the extraordinary substitution whereby Late Latin pausare, from Greek, coming to mean to cause to rest, usurped the place of Latin ponere, with which it had no etymological connection at all; so that the compounds of pausare (compausare, French composer, for example) usurped the place of the compounds of Latin ponere, like componere, throughout" (Skeat). Settle is derived from Anglo-Saxon setlan, to fix, from setl, a seat, Modern English settle, a seat.

We compose that which has been disjointed and separated by bringing it together again; we settle that which has been disturbed and put in motion by making it rest: we compose our thoughts when they have been deranged and thrown into confusion: we settle our mind when it has been fluctuating and distracted by contending desires; the mind must be composed before we can think justly; it must be settled before we can act consistently.

Differences are composed where there are jarring and discord; it is effected by conciliation, differences are settled when they are brought to a final arrangement by consultation or otherwise. In this manner a person may be said to compose himself, his thoughts, his dress, and the like; to settle matters, points, questions, etc. It is a good thing to compose differences between friends; it is not always easy to settle questions where either party is obstinate.

See also Compound; Form.

Composed, Sedate.-Composed signifies the state or quality of being in order, or free from confusion or perturbation; it is applied either to the mind or to the air, manner, or carriage. Sedate, in Latin sedatus, from Latin sedare, to make calm, causative of sedere, to sit (compare sedative), signifies properly the quality of being settled (see Compose), $i$. e., free from irregular motion, and is applied either to the carriage or the temper. Composed is opposite to ruffled or hurried, and is a temporary state; sedate is opposed to buoyant or volatile, and is a permanent habit of the mind or body. A person may be composed or his carriage may be composed in moments of excitement. Young people are rarely sedate.

See also Calm; Synthetic.

COMPOUND, COMPLEX.

Compound comes from the present of componere, to place together. Complex (see COMPLEXITY).

The compound consists of similar and whole bodies put together; the complex consists of various parts linked together: adhesion is sufficient to constitute a compound; involution is requisite for the complex; we distinguish the whole that forms the compound; we separate the parts that form the complex; what is compound may consist only of two; what is complex consists always of several. Compound and complex are both commonly opposed 
to the simple; but the former may be opposed to the single, and the latter to the simple: words are compounded, sentences are complex.

Compound,Compose.-Compound and compose (see Compose). Compound is used in the physical sense only; compose in the proper or the moral sense; words are compounded by making two or more into one; sentences are composed by putting words together so as to make sense: a medicine is compounded of many ingredients; society is composed of various classes.

COMPREHEND. See CoMPRISE; CoNCEIVE.

COMPREHENSIVE, EXTENSIVE. Comprehensive, from comprehend, in Latin comprchendo, from con, together, and prehendere, to take, signifies the quality of putting together. Extensive, from extend, in Latin extendo, or ex and tendere, to stretch out, signifies the quality of reaching to a distance.

Comprehensive respects quantity, $e x$ tensive regards space: that is comprehensive which extends into a wide field: a comprehensive view of a subject includes all branches of it; an extensive view of a subject enters into minute details: the comprehensive is associated with the concise; the extensive with the diffuse: it requires a capacious mind to take a comprehensive survey of any subject; it is possible for a superficial thinker to enter very extensively into some parts, while he passes over others. Comprehensive is employed only with regard to intellectual objects; extensive is used both in the proper or the improper sense: the signification of a word is comprehensive, or the powers of the mind are comprchensive: a plain is extensive, or a field of inquiry is extensive.

COMPRISE, COMPREHEND, EMbrace, Contain, Include. Comprise, through the French compris, participle of comprendre, comes from the same source as comprehend. Embrace (see Clasp). Contain, in French contenir, Latin contineo, compounded of con and tenco, signifies to hold together within one place. Include, in Latin includo, compounded of in and cludo or claudo, signifies to shut in or within a given space.

Comprise, comprehend, and embrace have regard to the aggregate value, quantity, or extent; include, to the individual things which form the whole; contain, either to the aggregate or to the individual, being in fact a term of more ordinary application than any of the others. Comprise and contain are used either in the proper or the figurative sense; comprehend, embrace, and include in the figurative sense only: a stock comprises a variety of articles; a library comprises a variety of books; the whole is comprised within a small compass; rules comprehend a number of particulars; laws comprehend a number of cases; countries comprehend a certain number of districts or divisions; terms comprehend a certain meaning: a discourse embraces a variety of topics; a plan, project, scheme, or system embraces a variety of objects; a house contains one, two, or more persons; a city contains a number of houses; a book contains much useful matter; a society contains very many individuals; it includes none but of a certain class; or it includes some of every class.

COMPULSION. See Constraint. COMPUNCTION. See REPENTANCE.

COMPUTE. See Calculate; EsTIMATE.

CONCEAL, Dissemble, Disguise. Conceal is compounded of Latin con and celare, to hide. Dissemble, in French dissimuler, compounded of dis, negative prefix, and similis, like, signifies to make a thing appear unlike what it is. Disguise, in French déguiser, compounded of the privative dis or de and guise, in Old High German wise, a manner or fashion, signifies to take a form opposite to the reality.

To conceal is simply to abstain from making known what we wish to keep secret; to dissemble and disguise signify to conceal by assuming some false appearance: we conceal facts; we dissemble feelings; we disguise sentiments. Caution only is requisite in concealing: it may be effected by simple silence: art and address must be employed in dissembling; it mingles falsehood with all its proceedings; labor and cunning are requisite in disguising; it has nothing but falsehood in all its movements. The concealer watches over 
himself that he may not be betrayed into any indiscreet communication; the dissembler has an eye to others, so as to prevent them from discovering the state of his heart; disguise assumes altogether a different face from reality, and rests secure under this shelter. It is sufficient to conceal from those who either cannot or will not see; it is necessary to dissemble with those who can see without being shown; but it is necessary to disguise from those who are anxious to discover and use every means to penetrate the veil that intercepts their sight.

Conceal, Hide, Secrete.-Conceal (see above). Hide, Anglo-Saxon hydan, is allied to Greek $\kappa \varepsilon \dot{v} \theta \varepsilon \imath v$, to cover or put out of sight. Secrete, in Latin secretus, participle of secerno, or se, apart, and cernere, to separate, means to take away and hide in a place apart.

Concealing has simply the idea of not letting come to observation; hiding, that of putting under cover; secreting, that of setting at a distance or in unfrequented places: whatever is not seen is concealed, but whatever is hidden or secreted is intentionally put out of sight: a person conceals himself behind a hedge; he hides his treasures in the earth; he secretes what he has stolen under his cloak. Conceal is more general than either hide or secrete: all things are concealed which are hidden or secreted, but they are not always hidden or secreted when they are concealed: both mental and corporeal objects are concealed; corporeal objects mostly, and sometimes mental ones, are hidden; corporeal objects only are secreted: we conceal in the mind whatever we do not make known: that is hidden which may not be discovered or cannot be discerned; that is secreted which may not be seen. Facts are concealed, truths are hidden, goods are secreted. Children should never attempt to conceal from their parents or teachers any error they have committed when called upon for an acknowledgment; we are told in Scripture, for our consolation, that nothing is hidden which shall not be revealed; people seldom wish to secrete anything but with the intention of concealing it from those who have a right to demand it back.
Concealment, Secrecy.-Concealment is itself an action; secrecy, from secret, is the quality of an action: concealment may respect the state of things; secrecy the conduct of persons; things may be concealed so as to be known to no one; but secrecy supposes some person to whom the thing concealed is known. Concealment has to do with what concerns others; secrecy, with that which concerns ourselves: what is concealed is kept from the observation of others; what is secret is known only to ourselves: there may frequently be concealment without secrecy, although there cannot be secrecy without concealment: concealment is frequently practised to the detriment of others; secrecy is always adopted for our own advantage or gratification: concealment is essential in the commission of crimes; secrecy in the execution of schemes: many crimes are committed with impunity when the perpetrators are protected by concealment; the best - concerted plans are often frustrated for want of observing secrecy.

See also Camouflage.

CONCEDE. See Grve UP.

CONCEIT, FANCY. Conceit comes immediately from the Latin conceptus, participle of concipere, from con, together, and capere, take, and means to take and put together, to conceive or form in the mind. Fancy, in French phantasie. Latin phantasia, Greek

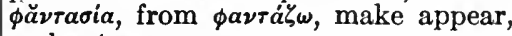
and $\phi c i v \omega$, appear.

These terms equally express the working of the imagination in its distorted state; but conceit denotes a much greater degree of distortion than fancy: our conceits are preposterous; what we fancy is unreal or only apparent. Conceit applies only to internal objects: it is mental in the operation and the result; it is a species of invention: fancy is applied to external objects, or whatever acts on the senses: nervous people are subject to strange conceits; timid people fancy they hear sounds or see objects in the dark which awaken terror. Those who are apt to conceit oftener conceit that which is painful than otherwise; conceiting either that they are always in danger of dying, or that all the world is their enemy. 
There are, however, insane people who conceit themselves to be kings and queens: and some, indeed, who are not called insane, who conceit themselves very learned while they know nothing, or very wise and clever while they are exposing themselves to perpetual ridicule for their folly, or very handsome while the world calls them plain, cr very peaceable while they are always quarrelling with their neighbors, or very humble while they are tenaciously stickling for their own: it would be well if such conceits afforded a harmless pleasure to their authors, but unfortunately they only render them more offensive and disgusting than they would otherwise be. Those who are apt to fancy never fancy anything to please themselves; they fancy that things are too long or too short, too thick or too thin, too cold or too hot, with a thousand other fancies equally trivial in their nature, thereby proving that the slightest aberration of the mind is a serious evil, and productive of evil.

When taken in reference to intellectual objects, conceit is always in a bad sense; but fancy may be employed in a good sense.

See also PrIDE.

CONCEITED. See Opinionated.

CONCEIVE, UNDERstaNd, CoMPREHENd. Conceive has the same derivation as conceit. Understand signifies to stand under, or near to the mind. Comprehend, in Latin comprehendo, compounded of con, together, and prehendere, to sieze, signifies to seize or embrace within the mind.

These terms indicate the intellectual operations of forming ideas, that is, ideas of the complex kind, in distinction from the simple ideas formed by the act of perception. Conception is the simplest operation of the three; when we conceive we may have but one idea; when we understand or comprehend we have all the ideas which the subject is capable of presenting. We cannot understand or comprehend without conceiving; but we may often conceive that which we neither understand nor comprehend. That which we cannot conceive is to us nothing; but the conception of it gives it an existence, at least in our minds; but understanding and comprehending is not essential to the belief of a thing's existence. So long as we have reasons sufficient to conceive a thing as possible or probable, it is not necessary either to understand or comprehend it in order to authorize our belief. The mysteries of our holy religion are objects of conception, but not of comprehension. We conceive that a thing may be done without understanding how it is done; we conceive that a thing may exist without comprehending the nature of its existence. We conceive clearly, understand fully, comprehend minutely.

Conceiving is a species of invention; it is the fruit of the mind's operation within itself. Understanding and comprehension arc employed solely on external objects; we understand and comprehend that which actually exists before us and presents itself to our observation. Conceiving is the office of the imagination as well as the judgment; understanding and comprehension are the officc of the reasoning faculties exclusively.

Conceiving is employed with regard to matters of taste, to arrangements, designs, and projects; understanding is employed on familiar objects which present themselves in the ordinary discourse and business of men; comprehending respects principles, lessons, and speculative knowledge in general. The artist conceives a design, and he who will execute it must understand it; the poet conceives that which is grand and sublime, and he who will enjoy the perusal of his conceptions must have refinement of mind, and capacity to comprehend, the grand and sublime. The builder conceives plans, the scholar understands languages, the metaphysician attempts to explain many things which are not to be comprehended.

See also APPREHEND.

Conception, Notion. - Conception, from conceive, signifies the thing conceived. Notion, in French notion, Latin notio, from notus, the participle of noscere, to know, signifies the thing known.

Conception is the mind's own work, what it pictures to itself from the exercise of its own powers; notion is the representation of objects as they are drawn from observation. Conceptions 
are the fruit of the understanding and imagination; notions are the result of experience and information. Conceptions are formed; notions are entertained. Conceptions are either grand or mean, gross or sublime; either clear or indistinct, crude or distinct; notions are either true or false, just or absurd. Intellectual culture serves to elevate men's conceptions; the extension of knowledge serves to correct and refine their notions.

Some heathen philosophers had an indistinct conception of the Deity, whose attributes and character are unfolded to us in His revelation: the ignorant have often false notions of their duty and obligations to their superiors. The unenlightened express their gross and crude conceptions of a Superior Being by some material and visible object: the vulgar notion of ghosts and spirits is not entirely banished from the most cultivated parts of any country.

See also Perception.

CONCERN. See AfFatr; AfFect; Care; INTEREST.

CONCERT, Contrive, Manage. Concert is derived from Latin concertare, from con, together, and certare, to strive, and signified to strive together, to vie. Contrive comes from Old French controver, to find together. Manage, in French ménager, comes from Latin manus, hand, and means to control with the hand.

There is a secret understanding in concerting; invention in contriving; execution in managing. There is mostly contrivance and managing in concerting; but there is not always concerting in contrivance or management. Measures are concerted; schemes are contrived; affairs are managed. Two parties at least are requisite in concerting, one is sufficient for contriving and managing. Concerting is always employed in all secret transactions; contrivance and management are used indifferently. Robbers who have determined on any scheme of plunder concert together the means of carrying their project into execution; they contrive various devices to elude the vigilance of the police; they manage everything in the dark. Those who are debarred the opportunity of seeing one another unrestrainedly concert measures for meeting privately. The ingenuity of a person is frequently displayed in the contrivances by which he strives to help himself out of his troubles. Whenever there are many parties interested in a concern, it is never so well managed as when it is in the hands of one individual suitably qualified.

CONCILIATE, Reconcile. Conciliate, in Latin conciliatus, and reconcile, in Latin reconcilio, both come from conciliare, to bring together, whence council is also derived, and denote an achieving of unity and harmony.

Conciliate and reconcile are both employed in the sense of uniting men's affections, but under different circumstances. The conciliator gets the goodwill and affections for himself; the reconciler unites the affections of two persons to each other. The conciliator may either gain new affections or regain those which are lost; the reconciler always either renews affections which have been once lost or fixes them where they ought to be fixed. The best means of conciliating esteem is by reconciling all that are at variance. Conciliate is mostly employed for men in public stations; reconcile is indifferently employed for those in public or private stations. Men in power have sometimes the happy opportunity of conciliating the good-will of those who are most averse to their authority, and thus reconciling them to measures which would otherwise be odious. Kindness and condescension serve to conciliate; a friendly influence, or a well-timed exercise of authority, is often successfully exerted in reconciling.

Conciliate is mostly employed in the sense of bringing persons into unison with each other who have been at variance; but reconcile may be employed to denote the bringing a person into unison or acquiescence with that which would be naturally disagreeable.

CONCISE. See Laconic; Short.

CONCLUDE. See Close; DeCIDE.

CONCLUSION, INFERENCE, DeDUCTION. Conclusion, from Latin concludere, compounded of con, together, and claudere, close, signifies the closing 
up of all arguments and reasoning. Inference, from infer, in Latin infero, signifies what is brought in. Deduction, from Latin deducere, compounded of de, from, and ducere, lead, to bring out, signifies the bringing or drawing one conclusion from another.

A conclusion is full and decisive; an inference is partial and indecisive: a conclusion leaves the mind in no doubt or hesitation; it puts a stop to all further reasoning: inferences are special conclusions from particular circumstances; they serve as links in the chain of reasoning. Conclusion in the technical sense is the concluding proposition of a syllogism, drawn from the two others, which are called the premises.

Conclusions are drawn from real facts; inferences are drawn from the appearances of things; deductions only from arguments or assertions. Conclusions are practical, inferences ratiocinative, deductions are final. We conclude from a person's conduct or declarations what he intends to do or leave undone; ' we infer from the appearance of the clouds or the thickness of the atmosphere that there will be a heavy fall of rain or snow; we deduce, from a combination of facts, inferences, and assertions, that a story is fabricated. Hasty conclusions betray a want of judgment or of firmness of mind: contrary inferences are frequently drawn from the same circumstances to serve the purpose of party and support a favorite position; the deductions in such cases are not unfrequently true when the inferences are false.

Conclusive, Decisive, Convincing.Conclusive applies either to practical or argumentative matters; decisive, to what is practical only; convincing, to what is argumentative only. It is necessary to be conclusive when we deliberate, and decisive when we command. What is conclusive puts an end to all discussions and determines the judgment; what is decisive puts an end to all wavering and determines the will. Negotiators have sometimes an interest in not speaking conclusively; commanders can never retain their authority without speaking decisively. Conclusive, when compared to convinc- ing, is general; the latter is particular: an argument is convincing, a chain of reasoning conclusive. There may be much that is convincing where there is nothing conclusive: a proof may be convincing of a particular circumstance, but conclusive evidence will bear upon the main question.

See also FinaL.

CONCOMITANT. See AccomPANIMENT.

CONCORD, HARMONY. Concord, in French concorde, Latin concordia, is compounded from con, together, and cors, heart, having the same heart and mind. Harmony, in French harmonie,

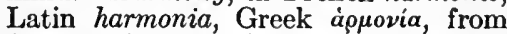
á $\rho$ ós, a joining, signifies the state of fitting or suiting.

The idea of union is common to both these terms, but under different circumstances. Concord is generally employed for the union of wills and affections; harmony respects the aptitude of minds to coalesce. There may be concord without harmony, and harmony without concord. Persons may live in concord who are at a distance from one another; but harmony is mostly employed for those who are in close connection and obliged to cooperate. Concord should never be broken by relations under any circumstances; harmony is indispensable in all members of a family that dwell together. Interest will sometimes stand in the way of brotherly concord; a love of rule and a dogmatical temper will sometimes disturb the harmony of a family.

These terms are both applied to music, the one in a particular, the other in a general sense; there is concord between two or more single sounds, and harmony in any number or aggregate of sounds.

Harmony may be used in the sense of adaptation to things generally.

See also Uniox.

CONCUR. See AGREE.

CONCURRENCE. See Assent. CONCUSSION. See SHOCK.

CONDEMN. See Blame; Proscribe; Reprobate; Sentence.

CONDESCENSION. See CoMPLAISANCE.

CONDition, Station. Condition, 
in French condition, Latin conditio, from con, together, and dicere, to talk, signifies the agreement arrived at as a result of talking a matter over-something granted as a prerequisite to granting something else. Station, in French station, Latin statio, from stare, to stand, signifies a standing place or point.

Condition has most relation to circumstances, education, birth, and the like; station refers rather to the rank, occupation, or mode of life which is marked out. Riches suddenly acquired are calculated to make a man forget his original condition and to render him negligent of the duties of his station. The condition of men in reality is often so different from what it appears that it is extremely difficult to form an estimate of what they are or what they have been. It is the folly of the present day that every man is unwilling to keep the station which has been assigned to him by Providence: the rage for equality destroys every just distinction in society; the low aspire to be, in appearance at least, equal with their superiors; and those in elevated stations do not hesitate to put themselves on a level with their inferiors.

See also Article; Estate; SituaTION.

CONDITIONAL. See ProVISIONAL.

CONDOLENCE. See Sympathy.

CONDUCE, Contribute. Conduce, Latin conduco, compounded of con and duco, signifies to bring together for one end. Contribute, in Latin contributus, participle of contribuo, compounded of con and tribuere, to divide and assign, signifies to bestow for the same end.

To conduce signifies to serve the full purpose; to contribute signifies only to serve a secondary purpose: the former is always taken in a good sense, the latter in a bad or good sense. Exercise conduces to the health; it contributes to give vigor to the frame. Nothing conduces more to the well-being of any community than a spirit of subordination among all ranks and classes. A want of firmness and vigilance in the government or magistrates contributes greatlv to the spread of disaffection and rebellion. Schemes of ambition never conduce to tranquillity of mind. A single failure may contribute sometimes to involve a person in perpetual trouble.

CONDUCT, Manage, Direct. Conduct, in Latin conductus, participle of conduco, signifies to lead in some particular manner or for some special purpose. To manage (see Care; Charge). To direct, in Latin directus, participle of dirigo, or dis, apart, and regere, to rule, signifies to regulate distinctly or put each in its right place.

Conducting requires most wisdom and knowledge; managing most action; direction most authority. A lawyer conducts the cause intrusted to him; a steward manages the mercantile concerns for his employer; a superintendent directs the movements of all the subordinate agents. Conducting is always applied to affairs of the first importance: management is a term of familiar use to characterize a familiar employment: direction makes up in authority what it wants in importance; it falls but little short of the word conduct. A conductor conceives, plans, arranges, and disposes; a manager acts or executes; a director commands.

It is necessary to conduct with wisdom; to manage with diligence, attention, and skill; to direct with promptitude, precision, and clearness. A minister of state requires peculiar talents to conduct with success the various and complicated concerns which are connected with his office; he must exercise much skill in managing the various characters and clashing interests with which he becomes connected; and possess much influence to direct the multiplied operations by which the grand machine of government is kept in motion. When a general undertakes to conduct a campaign, he will intrust the management of minor concerns to persons on whom he can rely; but he will direct in person whatever is likely to have any serious influence on his success.

See also Behavior; Lead.

CONFEDERACY. See Allitance.

CONFEDERATE,

ACCOMPLICE.

Confederate (see ALIY) and accomplice (see ABETTOR) both imply a partner in 
some proceeding, $\mathrm{bu}_{\mathrm{i},}$ they differ as to the nature of the proceeding: in the former case it may be lawful or unlawful; in the latter unlawful only. In this latter sense a confederate is a partner in a plot or secret association: an accomplice is a partner in some active violation of the laws. Guy Fawkes retained his resolution, till the last extremity, not to reveal the names of his confederates: it is the common refuge of all robbers and desperate characters to betray their accomplices in order to screen themselves from punishment.

CONFER, Bestow. Confer, in French conférer, Latin confero, compounded of con and fero, signifies to bring something toward a person or place it upon him. Bestow is compounded of be, a verbal prefix, and Anglo-Saxon stow, a place, and signifies to put in a place. Conferring is an act of authority; bestowing that of charity or generosity. Princes and men in power confer; people in a private station bestow. Honors, dignities, privileges, and rank are the things conferred; favors, kindnesses, and pecuniary relief are the things bestowed. Merit, favor, interest, caprice, or intrigue give rise to conferring; necessity, solicitation, and private affection lead to bestowing.

In the moral application, what is conferred or bestowed is presumed to be deserved, but with the distinction that the one is gratuitous, the other involuntary.

CONFERENCE. See CoNversaTION.

CONFESS. See AckNowledge.

CONFIDE, Trust. Confide, in Latin confido (or cum, with, and fidere, to trust), signifying to be united by trust with another, is to trust (see BELIEF) as the species to the genus: we always trust when we confide, but not vice versa. Confidence is an extraordinary trust, but trust is always ordinary unless the term be otherwise qualified. Confidence involves communication of a man's mind to another, but trust is confined to matters of action.

Confidence may be sometimes limited in its application, as confidence in the integrity or seerecy of a man; but trust is in its signification limited to matters of personal interest. A breach of trust evinces a want of that common principle which keeps human society together; but a breach of confidence betrays a more than ordinary share of baseness and depravity.

Confident, Dogmatical, Positive.Confident, from confide, marks the temper of confiding in one's self. Dogmati-

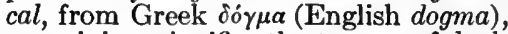
an opinion, signifies the temper of dealing in unqualified assertions. Positive, in Latin positivus, from positus, signifies fixed to a point.

The first two of these words denote an habitual or permanent state of mind; the last either a partial or an habitual temper. There is much of confidence in dogmatism and positivity, but it expresses more than either. Confidence implies a general reliance on one's abilities in whatever we undertake; dogmatism implies a reliance on the truth of our opinions; positivity, a reliance on the truth of our assertions. A confident man is always ready to act, as he is sure of succeeding; a dogmatical man is always ready to speak, as he is sure of being heard; a positive man is determined to maintain what he has asserted, as he is convinced that he has made no mistake. Confidence is opposed to diffidence; dogmatism, to scepticism; positivity, to hesitation. A confident man mostly fails for want of using the necessary means to insure success; a dogmatical man is mostly in error, because he substitutes his own partial opinions for such as are established; a positive man is mostly deceived, because he trusts more to his own senses and memory than he ought. Self-knowledge is the most effectual cure for self-confidence; an acquaintance with men and things tends to lessen dogmatism; the experience of one's self having been deceived, and the observation that others are perpetually liable to be deceived, ought to check the folly of being positive as to any event or circumstance that is past. Confidence is oftener expressed by actions than words; dogmatism and positivity always by words; the former denotes only the temper of the speaker, but the latter may influence the temper of others; a positive assertion may not only denote the state of the person's mind who makes it, but also may serve to make another positive.

See also SANGUINE. 
CONFINE. See BORDER; BodNd; INTERN.

CONFINED. See Contracted.

CONFINEMENT, IMPRISONMENT, Captivity. Confinement (see Bound) Imprisonment, compounded of Latin in and prensionem (acc.), a seizure French prison, from pris, participle of prendre, Latin prehendere, to take, signifies the act or state of being taken or laid hold of. Captivity, in French captivité, Latin captivitas, from capere, to take, signifies likewise the state of being, or being kept, in possession by another.

Confinement is the generic, the other two are specific terms. Confinement and imprisonment both imply the abridgment of one's personal freedom, but the former specifies no cause, which the latter does. We may be confined in a room by ill health or confined in any place by way of punishment; but we are never imprisoned but in some specific place appointed for the confinement of offenders, and always for some supposed offence. We are captives by the rights of war when we fall into the hands of the enemy. Confinement does not specify the degree or manner as the other terms do; it may even extend to the restricting the body of its free movements; while $i m$ prisonment simply confines the person within a certain extent of ground or the walls of a prison; and captivity leaves a person at liberty to range within a whole country or district.

Confinement is so general a term as to be applied to animals and even inanimate objects; imprisonment and captivity are applied in the proper sense to persons only, but they admit of a figurative application. Poor stray animals, which are found trespassing on unlawful ground, are doomed to a wretched confinement, rendered still more hard and intolerable by the want of food: the confinement of plants within too narrow a space will stop their growth for want of air. There is many a poor captive in a cage who, like Sterne's starling, would say, if it could, "I want to get out."

CONFIRM, Corroborate. To confirm, in Latin confirmo, or con and firmare, to make firm, signifies to make firm in a special manner. Corroborate, from Latin robur, strength, whence our adjective robust is derived, signifies to give additional strength.

The idea of strengthening is common to these terms, but under different circumstances; confirm is used generally, corroborate only in particular instances. What confirms serves to confirm the mind; what corroborates gives weight to the thing. An opinion or a story is confirmed; an evidence or the representation of a person is corroborated. What confirms removes all doubt; what corroborates only gives more strength than the thing had before. When the truth of a thing is confirmed, nothing more is necessary: the testimony of a person may be so little credited that it may want much corroboration.

Confirm, Establish. - Confirm (see above). Establish, from Latin stabilis, English stable, from stare, to stand, signifies to make stable, or able to stand.

The idea of strengthening is common to these as to the former terms, but with a different application: to confirm is applied to what is partial, if not temporary; to establish to that which is permanent and of importance, as to confirm a report, to establish a reputation, to confirm a treaty or alliance, to establish a trade or government.

So in respect to the mind and its operations: a belief, opinion, suspicion, or resolution is confirmed; principles, faith, hopes, etc., are established.

See also RATIFY.

CONFlict, Combat, Contest. Confict, in Latin conflictus, participle of confligo, compounded of con and fligere, to flip or strike, signifies to strike against each other. Combat (see BatTLE). Contest, in French contester, Latin contestor, compounded of con and testor, from testes, a witness (compare English testify), signifies to call or set witness against witness.

A striving for the mastery is the common idea in the signification of these terms, which is varied in the manner and spirit of the action. A conflict has more of violence in it than a combat, and a combat than a contest. A conflict supposes a violent collision, a meeting of force against force; a combat supposes a contending together in fighting or battle. A conflict may be the unpremeditated meeting of one or more 
persons in a violent or hostile manner; a combat is frequently a concerted engagement between two or more particular individuals, as a sudden and violent conflict ensued upon their coming up; they engaged in single combat.

Conflict is applied to whatever comes in violent collision, whether animate or inanimate, as the conflicts of wild beasts or of the elements; combat is applied to animals as well as men, particularly where there is a trial of skill or strength, as the combats of the gladiators either with one another or with beasts; contest is applied only to men.

Confict and contest are properly applied to moral objects, and combat sometimes figuratively so, and all with a like distinction; violent passions produce conflicts in the mind; there may be a combat between reason and any particular passion; there may be a contest for honors as well as posts of honor; reason will seldom come off victorious in the combat with ambition.

CONFORM. See COMPLY.

CONFORMABLE, Agreeable, SutTaBle. Conformable signifies able to conform (see Comply), that is, having a sameness of form. Agreeable signifies the quality of being able to agree. Suitable signifies able to suit (see AGres).

Conformable is employed for matters of obligation; agreeable, for matters of choice; suitable, for matters of propriety and discretion: what is conformable accords with some prescribed form or given rule of others; what is agreeable accords with the feelings, tempers, or judgments of ourselves or others; what is suitable accords with outward circumstances: it is the business of those who act for others to act conformably to their directions; it is the part of a friend to act agreeably to the wishes of a friend; it is the part of every man to act suitably to his station. The decisions of a judge must be strictly conformable to the letter of the law; he is seldom at liberty to consult general views of equity: the decision of a partisan is always agreeable to the temper of his party: the style of a writer should be suitable to his subject.

See also Assimilable.

CONFORMATION. See ForM.

CONFOUND, CoNfuse. Confound

13 and confuse are both derived from different parts of the same verb, namely, confundo, and its participle confusus, signifying to pour or mix together without design that which ought to be distinct.

Confound has an active sense; confuse a neuter or reflective sense: a person confounds one thing with another; objects become confused, or a person confuses himself: it is a common error among ignorant people to confound names, and among children to have their ideas confused on commencing a new study. The present age is distinguished by nothing so much as by confounding all distinctions, which is a great source of confusion in men's intereourse with one another, both in public and private life.

Confuse is sometimes used transitively in the sense of causing confusion, as to confuse an account; but in this case it is as much distinguished from confound as in the other case. A person confounds one account with the other when he takes them to be both the same; but he confuses any particular account when he mingles different items under one head or brings the same item under different heads.

See also Abash; Baffle; Mrx.

CONFRONT, FACE. Confront, from the Latin frons, a forehead, implies to set face to face; and face. from Latin facies, English face, signifies to set the face toward any object. The former of these terms is always employed for two or more persons with regard to one another; the latter for a single individual with regard to objects in general. Witnesses are confronted; a person faces danger, or faces an enemy: when people give contrary evidence, it is sometimes necessary, in extra-judicial matters, to confront them in order to arrive at the truth; the best evidence which a man can give of his courage is to evince his readiness for facing his enemy whenever the occasion requires.

CONFUSE. See Abash; ConFOUND.

CONFUSED. See Indistinct.

CONFUSION, Disorder. Confusion signifies the state of being confounded or confused (see Confound). 
Disorder, compounded of dis, privative, and Latin ordo, English order, signifies the reverse of order.

Confusion is to disorder as the species to the genus: confusion supposes the absence of all order; disorder the derangement of order where it exists, or is supposed to exist: there is always disorder in confusion, but not always confusion in disorder. The greater the multitude the more they are liable to fall into confusion if they do not act in perfect concert, as in the case of a routed army or a tumultuous mob.

Where there is the greatest order, the smallest circumstance is apt to produce disorder, the consequences of which will be more or less serious.

See also Jemble.

CONFUTe, Refute, Disprove, Oppugn. Confute and refute, in Latin confuto and refuto, are compounded of con, against, re privative, and a verb stem futa, which is probably from the same root as Latin fundere, to pour out, overthrow, and is allied to English futile, Latin futilis, etc. Disprove, compounded of dis, privative, and probare, to prove, signifies to prove the contrary. Oppugn comes from Latin oppugnare, to fight against.

To confute respects what is argumentative; refute, what is practical and personal; disprove, whatever is represented or related; oppugn, what is held or maintained. An argument is confuted by proving its fallacy; a charge is refuted by proving the innocence of the party charged; an assertion is disproved by proving that it is incorrect; a doctrine is oppugned by a course of reasoning. Paradoxes may be easily refuted; calumnies may be easily refuted; the marvellous and incredible stories of travellers may be easily disproved; heresies and sceptical notions ought to be oppugned. The pernicious doctrines of sceptics, though often confuted, are as often advanced with the same degree of assurance by the freethinking, and I might say the unthinking, few who imbibe their spirit: it is the employment of libellists to deal out their malicious aspersions against the objects of their malignity in a manner so loose and indirect as to preclude the possibility of refutation: it would be a fruitless and unthank- ful task to attempt to disprove all the statements which are circulated in a common newspaper. It is the duty of the ministers of the Gospel to oppugn all doctrines that militate against the established faith of Christians.

CONGRATULATE. See FeliciTATE.

CONGREgATION. See AssemBLE.

CONGRESS. See Assemble.

CONJECTURE, SUPPosition, SURMISE. Conjecture, in French conjecture, Latin conjectura, from con, together, and jacere, to throw, signifies the thing put together or framed in the mind without design or foundation. Supposition, in French supposition, from Latin supponere, compounded of $s u b$, in place of, and ponere, to place, signifies to put one's thoughts in place of reality. Surmise is compounded of Old French sur, "Latin super, above, and mettre (Latin mittere), to put; it very nearly corresponds in its original meaning to the modern slang "put it over."

All these terms convey an idea of something in the mind independent of the reality; but conjecture is founded less on rational inference than supposition; and surmise less than either: any circumstance, however trivial, may give rise to a conjecture; some reasons are requisite to produce a supposition; a particular state of feeling or train of thinking may of itself create a surmise. Although the same epithets are generally applicable to all these terms, yet we may with propriety say that a conjecture is idle, a supposition false, a surmise fanciful. Conjectures are employed on events, their causes, consequences, and contingencies: supposition, on speculative points; surmise, on personal concerns. The secret measures of government give rise to various conjectures: all the suppositions which are formed respecting comets seem at present to fall short of the truth: the behavior of a person will of ten occasion a surmise respecting his intentions and proceedings, let them be ever so disguised. Antiquarians and etymologists deal much in conjectures; they have ample scope afforded them for asserting 
what can be neither proved nor denied: religionists are pleased to build many suppositions of a doctrinal nature on the Scriptures, or, more properly, on their own partial and forced interpretations of the Scriptures: it is the part of prudence, as well as justice, not to express any surmises which we may entertain, either as to the character or conduct of others, which may not redound to their credit.

See also Guess.

CONJUNCTURE, CRISIS. Conjuncture, in Latin conjunctura, from con, together, and jungere, to join, signifies the joining together of circumstances. Crisis, in Latin crisis, Greek koiбı,

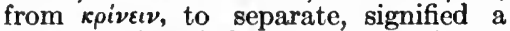
judgment founded upon analysis; hence simply a judgment, or anything which decides, or turns the scale.

Both these terms are employed to express a period of time marked by the state of affairs. A conjuncture is a joining or combination of corresponding circumstances tending toward the same end: a crisis is the high-wrought state of any affair which immediately precedes a change: a conjuncture may be favorable, a crisis alarming. An able statesman seizes the conjuncture which promises to suit his purpose, for the introduction of a favorite measure: the abilities, firmness, and perseverance of Alfred the Great, at one important crisis of his reign, saved England from destruction.

CONJURE. See JUgGle.

CONNECT, CoMbine, Unite. Connect, Latin connecto, compounded of con and netc, signifies to knit together. Combine (see Association). Unite (see ADD).

The idea of being put together is common to these terms, but with different degrees of proximity. Connected is more remote than combined, and this than united. What is connected and combined remains distinct, but what is united loses all individuality. Things the most dissimilar may be connected or combined; things of the same kind only can be united. Things or persons are connected more or less remotely by some common property or cireumstance that serves as a tie; they are combined by a species of juncture; they are united by a coalition: houses are connected by means of a common passage; the armies of two nations are combined; two armies of the same nation are united. Trade, marriage, or general intercourse ereate a connection between individuals; co-operation and similarity of tendency are grounds for combination; entire accordance leads to a union. It is dangerous to be connected with the wicked in any way; our reputation, if not our morals, must be the sufferers thereby. The most obnoxious members of society are those in whom wealth, talents, influence, and a lawless ambition are combined. United is an epithet that should apply to nations and families; the same obedience to laws should regulate every man who lives under the same government; the same heart should animate every breast; the same spirit should dictate every action of every member in the community who has a common interest in the preservation of the whole.

Connection, Relation. - Connection (see above). Relation, from relate, in Latin relatus, participle of refero, to bring back, signifies carrying back to some point.

These words are applied to two or more things to denote the manner in which they stand in regard to one another. A connection denotes that which binds two objects, or the situation of being so bound by some tie; but relation denotes the situation of two or more objects in regard to one another, yet without defining what it is; a connection is therefore a species of relation, but a relation may be something which does not amount to a connection. Families are connected with each other by the ties of blood or marriage; persons are connected with each other in the way of trade or business; objects stand in a certain relation to each other, as persons stand in the relation of giver and reeeiver; or of debtor and creditor; there is a connection between Church and State, or between morality and religion; men stand in the relation of creatures to their Creator.

The word relation is sometimes taken in a limited sense for one connected by family ties, which denotes something nearer in that case than connection; as when speaking of a man's relations, 
or of a person being related to another, or to leave one's property to one's relations.

\section{See also Intercoúrse.}

CONQUER, VANQUish, SUbdue, Overcome, Surmount. Conquer, in French conquérir, Latin conquiro, compounded of con and quarere, to search after diligently, signifies in an extended sense to obtain by searching. Vanquish is in French vaincre, Latin vincere. Subdue, Latin subdere, signifies to give or put under. Overcome signifies to come over or get the mastery over one. Surmount, in French surmonter, compounded of sur (Latin super), above, and monter (from Latin montem, hill), to climb a hill, or simply to climb, signifies to rise above any one. The leading idea in the word conquer is that of getting; the leading idea in vanquish and subdue is that of getting the better of, the former partially, the latter thoroughly, so as to prevent any future resistance: a country is conquered; an enemy is vanquished; in the field of battle a people is subdued.

Conquer may sometimes also signify to get the better of, but in that case it does not define the mode or extent of the action; we may conquer another in any contest and in any manner; but we vanquish and subdue persons only by force, and mostly by force of arms.

When overcome is applied to persons it has precisely the same indefinite and general meaning as conquer.

But overcome, as well as conquer, subdue, and vanquish, are applied also to moral objects, and surmount has for the most part no other application. To conquer is said of the person himself, his likes, dislikes, and feelings generally; subdue of what relates either to the person himself or some other person, as to subdue the will or the passions. What is conquered makes less resistance and requires less force than what is subdued. It is likewise not so thoroughly subjugated or destroyed. We may conquer an aversion at one time which may return at another time; if the will be subdued in childhood, it will not prevail in riper years.

To vanquish is applied figuratively to particular objects as in the proper sense.

To overcome is applied to objections, scruples, prejudices, difficulties, and the like; surmount, to difficulties, obstacles, impediments, etc. What is overcome requires less exertion than that which is surmounted. We may overcome by patience or forbearance; but determination, or the application of more or less force, is necessary in surmounting obstacles.

Conqueror, Victor. - These terms, though derived from the preceding verbs, have, notwithstanding, characteristics peculiar to themselves. A conqueror is always supposed to add something to his possessions; a victor gains nothing but the superiority: there is no conquest where there is not something gotten; there is no victory where there is no contest: all conquerors are not victors, nor all victors conquerors: those who take possession of other men's lands by force of arms make a conquest; those who excel in any trial of skill are the victors. Monarchs when they wage a successful war are mostly conquerors; combatants who compel their adversaries to yield are victors.

CONQUEST. See TRIUMPH

CONSANGUINITY. See KINDRED.

CONSCIENTIOUS. ScRUPUlOUS. Conscientious, ultimately from Latin con, intensive prefix, and scire, to know, signifies the possession of moral intelligence, the perception of right and wrong. Scrupulous, from scruple, signifies the quality of having scruples. Scruple, in Latin scrupulus, signifies a little hard stone, which in walking gives pain.

Conscientious is to scrupulous as a whole to a part. A conscientious man is so altogether; a scrupulous man may have only particular scruples: the one is therefore always taken in a good sense; and the other at least in an indifferent, if not a bad sense. A conscientious man does nothing to offend his conscience; but a scrupulous man has often his scruples on trifling or minor points; the Pharisees were scrupulous without being conscientious: we must therefore strive to be conscientious without being over-scrupulous.

CONSCIENTIOUSLY. See EthICAL.

CONSCIOUS. See Aware; Feel. CONSECRATE. See Dedicate; SANCTIFY. 
Consent, Permit, Allow. Consent (see AGree). Permit and allow (see Admit).

The idea of determining the conduct of others by some authorized act of one's own is common to these terms, but under various circumstances. They express either the act of an equal or a superior. As the act of an equal we consent to that in which we have a common interest with others: we permit or allow swhat is for the accommodation of others: we allow by abstaining to oppose; we permit by a direct expression of our will; contracts are formed by the consent of the parties who are interested. The proprietor of an estate permits his friends to sport on his grounds; he allows of a passage through his premises. It is sometimes prudent to consent, complaisant to permit, good-natured or weak to allow.

Consent respects matters of serious importance; permit and allow regard those of an indifferent nature: a parent consents to the establishment of his children; he permits them to read certain books; he allows them to converse with him familiarly. We must pause before we give our consent; it is an express sanction to the conduct of others; it involves our own judgment and the future interests of those who are under our control. This is not always so necessary in permitting and allowing; they are partial actions, which require no more than the bare exercise of authority, and involve no other consequence than the temporary pleasure of the parties concerned. Public measures are permitted and allowed, but never consented to. The law permits or allows; or the person who is authorized permits or allows. Permit in this case retains its positive sense; allow, its negative sense, as before. Government permits individuals to fit out privateers in time of war: when magistrates are not vigilant, many things will be done which are not allowed. A judge is not permitted to pass any sentence but what is strictly conformable to law: every man who is accused is allowed to plead his own cause, or intrust it to another, as he thinks fit.

These terms are similarly distinguished in the moral application.

See also Assent.
CONSEquenCE, EFfect, Result, Isșue, Event. Consequence, in French conséquence, Latin consequentia, from consequor, follow, signifies that which follows in connection with something else. Effect is the thing effected (see Accomplished). Result, in French résulte, Latin resulto, or resultus and resilire, to rebound, signifies that which springs or bounds back from another thing. Issue is that which issues or flows out (see ARISE). Event, in Latin eventus, participle of evenio, from $e$, forth, and venire, to come, is that which comes forth.

All these terms are employed to denote that which follows something else; they vary according to the different circumstances under which they follow, or the manner of their following. A consequence is that which follows of itself, without any qualification or restriction; an effect is that which is effected or produced, or which follows from the connection between the thing effecting, as a cause, and the thing effected. In the nature of things causes will have effects, and for every effect there will be a cause, although it may not be visible. Consequences, on the other hand, are either casual or natural; they are not always to be calculated upon. Effect applies to physical or moral objects; consequences to moral objects only: diseases are the effects of intemperance; the loss of character is the general consequence of an irregular life.

Consequences follow either from the actions of men or from things where there is no direct ageney or design; results follow from the actions or efforts of men: consequences are good or bad; results are favorable or unfavorable. We endeavor to avert consequences and to produce results. Not to foresee the consequences which are foreseen by others evinces a more than ordinary share of indiscretion and infatuation. To calculate on a favorable result from an ill-judged or ill-executed enterprise only proves a consistent blindness in the projector.

A conscquence may be particular or follow from a part; a result is general, following from a whole: there may be many consequences from the same thing, and but one result only. 
As results follow from actions or $e f-$ forts, there is this further distinction; that in regard to intellectual operations results may be drawn by the act of the mind, as the results of reasoning or calculation.

Consequences may be intermediate or final; issue and event are always final: the former is that which flows from particular efforts; the latter from complicated undertakings where chance may interpose to bring about that which happens; hence we speak of the issue of a negotiation or a battle, and the event of a war. The fate of a nation sometimes hangs on the issue of a battle. The measures of government are often unjustly praised or blamed according to the event.

See also IMPORTANCE.

CONSEQUENTLY. See NaTURALLY; THEREFORE.

CONSERVE. See Husband.

CONSIDER, REFLECT. Consider is derived from Latin con, together, and sidus, star, signifying to contemplate the stars, then simply to contemplate or think. Reflect, in Latin reflecto, compounded of re and flecto, bend, signifies to turn back or upon itself.

The operation of thought is expressed by these two words, but it varies in the circumstances of the action. Consideration is employed for practical purposes; reflection for matters of speculation or moral improvement. Common objects call for consideration; the workings of the mind itself, or objects purely spiritual, occupy reflection. It is necessary to consider what is proper to be done before we take any step; it is consistent with our natures, as rational beings, to reflect on what we are, what we ought to be, and what we snall be. Without consideration we shall naturally commit the most flagrant errors; without reflection we shall never understand our duty to our Maker, our neighbor, and ourselves.

Consider, Regard.-To consider signifies to take a view of a thing in the mind which is the result of thought. To regard (see CARE) is properly to look back upon or to look at with concern. There is more caution or thought in considering, more personal interest in regarding. To consider is to bear in mind all that prudence or propriety suggests; to regard is to bear in mind all that our wishes or interests suggest. It is most usual to consider the means or matters in detail, and to regard the end or object at large: a man will consider whether a thing is good or bad, proper or improper, out of the regard which he has for his reputation, his honor, his conscience, and the like. Where he has no consideration he cannot possibly have a regard, but he may have a regard where considerations are not necessary. A want of consideration as to the circumstances and capacity of another may lead one to form a wrong judgment of his conduct. A want of regard for the person himself may lead one to be regardless of his comfort and convenience.

So, in application to things not expressly connected with one's interests or inclinations, to consider is to look at things simply as they are; to regard is to look at them with a certain degree of interest.

Consideration, Reason.-Consideration, or that which enters into a person's consideration, has a reference to the person considering. Reason (see CAUSE), or that which influences the reason, is taken absolutely. Considerations are therefore, for the most part, partial, as affecting particular interests, or dependent on particular circumstances. Reasons, on the contrary, may be general, and vary according to the subject.

The consideration influences particular actions; the reason determines a line of conduct: no consideration of profits should induce a person to forfeit his word; the reasons which men assign for their conduct are often as absurd as they are false.

In matters of argument, the consideration is that which one offers to the consideration of another; the reason is that which lies in the nature of the thing.

CONSIGN, Commit, Intrust. Consign, in French consigner, Latin consigno, compounded of con and signare, to seal, signifies to seal for a specific purpose, also to deposit. Commit, in French commettre, Latin committo, compounded of con, together, and mittere, to send or put, signifies to put into a 
person's hands. Intrust signifies to put in trust.

The idea of transferring from one's self to the care of another is common to these terms, differing in the nature and object of the action. To consign is a more formal act, a more absolute giving from ourselves to another, than to commit: a merchant consigns his goods to another to dispose of them for his advantage; he commits the management of his business to his clerk: a child is consigned to another, for him to take the whole charge of his education, maintenance, and the like; but when he is committed to the charge of another, it is mostly with limitations.

To intrust refers to the degree of trust or confidence which is reposed in the individual; a child may be intrusted to the care of a servant for a short time; a person may be intrusted with the property or secrets of another; or individuals may be intrusted with power.

In the figurative application, to consign is to deliver over so as to become the property of another thing; to commit is to give over for the purpose of taking charge of. Death consigns many to an untimely grave; a writer commits his thoughts to the press.

Consign may thus be used in the sense of assign, and commit in the sense of trusting at all hazards.

CONSISTENT. See Compatible; Consonant.

CONSOle, Solace, Comfort. Console and solace are derived from the same source, in French consoler, Latin consolari, to comfort. Comfort (see Comfort).

Console and solace denote the rclieving of pain; comfort marks the communication of positive pleasure. We console others with words; we console or solace ourselves with reflections; we comfort by words or deeds. Console is used on more important occasions than solace. We console our friends when they meet with afflictions; we solace ourselves when we meet with disasters; we comfort those who stand in need of comfort. The greatest consolation which we can enjoy on the death of our friends is derived from the hope that they have exchanged a state of imperfection and sorrow for one that is full of pure and unmixed felicity. It is no small solace to us, in the midst of all our troubles, to consider that they are not so bad that they might not have been worse. The comforts which a person enjoys may be considerably enhanced by the comparison with what he has formerly suffered.

CONSONANT, ACCORDANT, CONsisTENT. Consonant, from the Latin consonans, participle of con, together, and sonare, to sound, signifies to sound, or be, in unison or harmony. Accordant, from accord, signifies the quality of according (for derivation see accord under the key-word AGree). Consistent, from the Latin consistens, participle of consisto, from con, together, and sistere, to place, signifies the quality of being able to stand in unison together.

Consonant is employed in matters of representation; accordant, in matters of opinion or sentiment; consistent, in matters of conduct. A particular passage is consonant with the whole tenor of the Scriptures; a particular account is accordant with all one hears and sees on a subject; a person's conduct is not always consistent with his station. Consonant is opposed to dissonant; accordant, to discordant; consistent, to inconsistent. Consonance is not so positive a thing as either accordance or consistency, which respects real events, circumstances, and actions. Consonance may serve to prove the truth of a thing, but dissonance does not prove its falsehood until it amounts to direct discordance or inconsistency. There is a dissonance in the accounts given by the four Evangelists of our Saviour, which serves to prove the absence of all collusion and imposture, since there is neither discordance nor inconsistency in what they have related or omitted. CONSPICUOUS. See DistiNguished; Prominent.

CONSPIRACY. See Combination. CONSTANCY, StabilitT, Steadiness, Firmess. Constancy, in French constance, Latin constantia, from constans and consto, compounded of con and stare, to stand by or close to a thing, signifies the quality of adhering to the thing that has been once chosen. Stability, in French stabilité, Latin stabilitas, from stabilis and stare, to stand, 
signifies the quality of being able to stand. Steadiness, the quality of being steady, is derived from Anglo-Saxon stede, a place, found in words like homestead, instead, etc. Steady signifies standing in one place. Firm comes from Latin firmus, unmoved.

Constancy respects the affections; stability, the opinions; steadiness, the action or the motives of action; firmness, the purpose or resolution. Constancy prevents from changing, and furnishes the mind with resources against weariness or disgust of the same object; it preserves and supports an attachment under every change of circumstances; stability prevents from varying; it bears up the mind against the movements of levity or curiosity, which a diversity of objects might produce; steadiness prevents from deviating; it enables the mind to bear up against the influence of humor, which temperament or outward circumstances might produce; it fixes on one course, and keeps to it: firmness prevents from yielding; it gives the mind strength against all the attacks to which it may be exposed; it makes a resistance, and comes off triumphant. Constancy among lovers and friends is the favorite theme of poets; the word has, however, afforded but few originals from which they could copy their pictures: they have mostly described what is desirable rather than what is real. Stability of character is essential for those who are to command, for how can they govern others who cannot govern their own thoughts? Steadiness of deportment is a great recommendation to those who have to obey: how can any one perform his part well who suffers himself to be perpetually interrupted? Firmness of character is indispensable in the support of principles: there are many occasions in which this part of a man's character is likely to be put to a severe test. Constancy is opposed to fickleness; stability, to changeableness; steadiness, to flightiness; firmness, to pliancy.

CONSTANT. See

DURABLE; UNSWERVING.

CONSternation. See Alarm. CONSTituent. See ElementARY.

CONStitute, Appoint, Depute.
Constitute, in Latin constitutus, participle of constituto, that is, con, together, and statuo, place, signifies here to put or place for a specific purpose. Appoint (see Appoint). Depute, in French députer, Latin deputo, compounded of de, from, and putare, to esteem or assign, signifies to assign a certain office to a person.

The act of choosing some person or persons for an office is comprehended under all these terms: constitute is a more solemn act than appoint, and this than depute: to constitute is the act of a body; to appoint and depute, either of a body or an individual: a community constitutes any one their leader; a monarch appoints his ministers; an assembly deputes some of its members. To constitute implies the act of making as well as choosing; the office as well as the person is new: in appointing, the person, but not the office, is new. A person may be constituted arbiter or judge as circumstances may require; a successor is appointed, but not constituted.

Whoever is constituted is invested with supreme authority derived from the highest sources of power; whoever is appointed derives his authority from the authority of others, and has consequently but limited power: no individual can appoint another with authority equal to his own: whoever is deputed has private and not public authority; his office is partial, often confined to the particular transaction of an individual, or a body of individuals. According to the Romish religion, the Pope is constituted supreme head of the Christian Church throughout the whole world; governors are appointed to distant provinces; persons are deputed to present petitions or make representations to government.

See also Form.

CONSTitution. See Frame.

CONSTRAIN. See CoMpel.

CONSTRAINT, CoMpUlsion. Constraint, from constrain, Latin constringo, compounded of con, together, and stringere, to draw tight, signifies the act of straining or tying together. Compulsion signifies the act of compelling. (See CoMpel.)

There is much of binding in con- 
straint; of violence in compulsion: constraint prevents from acting agreeably to the will; compulsion forces to act contrary to the will: a soldier in the ranks moves with much constraint, and is often subject to much compulsion to make him move as is desired. Constraint may arise from outward circumstances; compulsion is always produced by some active agent: the forms of civil society lay a proper constraint upon the behavior of men, so as to render them agreeable to one another; the arm of the civil power must ever be ready to compel those who will not submit without compulsion: in the moments of relaxation, the actions of children should be as free from constraint as possible; those who know and wish to do what is right will always be ready to discharge their duty without compulsion.

Constraint, Restraint. - Constraint (see above). Restraint (see CoERcE).

Constraint respects the movements of the body only; restraint, those of the mind and the outward actions: when they both refer to the outward actions, we say a person's behavior is constrained; his feelings are restrained: he is constrained to act or not to act, or to act in a certain manner; he is restrained from acting at all, or he may be restrained from feeling: the conduct is constrained by certain prescribed rules, by discipline and order; it is restrained by particular motives: whoever learns a mechanical exercise is constrained to move his body in a certain direction; the fear of detection often restrains persons from the commission of vices more than any sense of their enormity.

CONSTRUCT. See BUILD.

CONSUlt, Deliberate. Consult, in French consulter, Latin consulto, is a frequentative of consulo, signifying to counsel together (see ADvice). The root of consulo is uncertain; it may be allied to sedere, to sit. Deliberate, in French délibérer, Latin delibero, compounded of de and libra, a balance, signifies to weigh as in a balance.

Consultations always require two persons at least; deliberations may be carried on either with a man's self or with numbers: an individual may consult with one or many; assemblies commonly deliberate: advice and informa- tion are given and received in consullations; doubts, difficulties, and objections are started and removed in deliberations. We communicate and hear when we consult; we pause and hesitate when we deliberate: those who have to co-operate must frequently consult together; those who have serious measures to decide upon must coolly deliberate.

CONSUME. See Destroy.

CONSUMMATION, Completion. Consummation, Latin consummatio, compounded of con, together, and summa, the top, the sum, from supmus (superlative of words whose comparative is super, above), signifying the very top, means the summing or winding up of the whole-the putting a final period to any concern. Completion signifies either the act of completing or the state of being completed (see CoMPLETE).

The arrival at a conclusion is comprehended in both these terms, but they differ principally in application; wishes are consummated; plans are completed: we often flatter ourselves that the completion of all our plans will be the consummation of all our wishes, and thus expose ourselves to grievous disappointments

As epithets, consummate and complete admit of a similar distinction. Consummate is said of that which rises absolutely to the highest possible degree, as consummate wisdom, or consummate felicity: complete is said of that which is so relatively; a thing may be complete which fully answers the purpose.

CONSUMPTION. See Decay.

CONTACT, Touch. Contact, in Latin contactus, participle of contingo, compounded of con and tangere, to touch together, is distinguished from the simple word touch (derived through French toucher from a Teutonic root allied with Anglo-Saxon teon, to pull or draw, and Latin ducere, to lead), not so much in sense as in grammatical construction; the former expressing a state, and referring to two bodies actually in that state; the latter, on the other hand, implying the abstract act of touching: we speak of things coming or being in contact, but not of the contact instead of the touch of a 
thing: the poison which comes from the poison-tree is so powerful in its nature that it is not necessary to come in contact with it in order to feel its baneful influence; some insects are armed with stings so inconceivably sharp that the smallest touch possible is sufficient to produce a puncture in the flesh.

CONTAGION, INFECTION. Both these terms imply the power of communicating something bad, but contagion, from the Latin con, and tag, from tango, to come in contact, proceeds from a simple touch; and infection, from the Latin inficio, or in, in, and facere, to make, proceeds by receiving something inwardly or having it infused. We consider contagion as to the manner of spreading from one body to another; we consider infection as to the act of its working itself into the system. Whatever acts by contagion acts immediately by direct personal contact; whatever acts by infection acts gradually and indirectly, or through the medium of a third body, as clothes, or the air when infected. The word contagion is, therefore, properly applied only to particular diseases, but infection may be applied to every disease which is communicable from one subject to another. Whatever, therefore, is contagious is also infectious, but not vice versa.

So, in application to other things besides diseases, contagion is employed to denote that species of communication which is effected by a direct action on the senses.

Infection is employed to denote the communication which takes place by the gradual process of being infected with anything.

So, in the moral application, whatever is outward acts by contagion, as to shun the contagion of bad example or bad manners. Whatever acts inwardly acts by infection, as to shun the infection of bad principles.

Contagious, Epidemical, Pestilential. - Contagious signifies having or causing contagion. Epidemical, in Latin

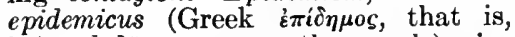
$\dot{\varepsilon} \pi i$ and $\delta \tilde{\eta} \mu o s$, among the people), signifies universally spread. Pestilential, from the Latin pestis, the plague, signifies having the plague, or a similar disorder.
The contagious applies to that which is capable of being caught, and ought not, therefore, to be touched; the epidemical, to that which is already caught or circulated, and requires, therefore, to be stopped; the pestilential, to that which may breed an evil, and is, therefore, to be removed: diseases are contagious or epidemical; the air or breath is pestilential.

They may all be applied morally or figuratively in the same sense. We endeavor to shun a contagious disorder, that it may not come near us; we endeavor to purify a pestilential air, that it may not be inhaled to our injury; we endeavor to provide against epidemical disorders, that they may not spread any farther. Vicious example is contagious; certain follies or vices of fashion are epidemical in almost every age; the breath of infidelity is pestilential.

CONTAIN, Hold. Contain (see CoMprise). Hold is derived from Anglo-Saxon healdan, which appears in some form in most of the Teutonic languages with the significance that it now has in English.

These terms agree in sense, but differ in application; the former is by comparison noble, the latter is ignoble in its use: hold is employed only for the material contents of hollow bodies; contain is employed for moral or spiritual contents: in familiar discourse a cask is said to hold, but in more polished language it is said to contain a certain number of gallons. A coach holds or contains a given number of persons; a room holds a given quantity of furniture; a house or city contains its inhabitants.

CONTAMinate, Defile, PolLUTe, TaInt, Corrupt. Contaminate has the same derivation as contagion; it comes from Latin contaminare, from the prefix con, together, and the root tag, touch. Defile is compounded of Latin de, from, and Anglo-Saxon fylan, to make foul, from ful, Modern English foul. Pollute is derived from Latin pol, allied to Old Latin por, toward, and luere, to wash, allied to lave, and meant originally to wash over, like a flooded river. Taint, in French teint, participle of teindre, in Latin tingere, to dye or stain. Corrupt, 
in Latin corruptus, participle of corrumpo, compounded of con, together, and rumpere, to break, signifies to break to pieces.

Contaminate is not so strong an expression as defile or pollute; but it is stronger than taint: these terms are used in the sense of injuring purity: corrupt has the idea of destroying it. Whatever is impure contaminates; what is gross and vile in the natural sense defiles, and in the moral sense pollutes; what is contagious or infectious corrupts; and what is corrupted may taint other things. Improper conversation or reading contaminates the mind of youth; lewdness and obscenity defile the body and pollute the mind; loose company corrupts the morals; the coming in contaet with a corrupted body is sufficient to give a taint. If young people be admitted to a promiscuous intercourse with society, they must unavoidably witness objects that are calculated to contaminate their thoughts, if not their inclinations. They are thrown in the way of seeing the lips of females defiled with the grossest indecencies, and hearing or seeing things which cannot be heard or seen without polluting the soul: it cannot be surprising if after this their principles are found to be corrupted before they have reached the age of maturity.

CONTEMn, Despise, Scorn, DisDAIN. Contemn comes from Latin contemnere, compounded of con, intensive prefix, and temnere, to despisc. Despise, in Latin despicio, compounded of de, from, and specere, to look, signifies to look down upon, which is a strong mark of contempt. Scorn, from Old French escorner, meant originally to deprive of horns (Latin ex, from, and cornu, horn), hence to humiliate or dishonor. It has been influenced by the Old High German scernon, to deride. Disdain is compounded of dis, privative, and Old French degnier, from Latin digmare, to think worthy; accordingly it means to think unworthy.

The above elucidations sufficiently evince the feeling toward others which gives birth to all these actions. But the feeling of contempt is not quite so strong as that of despising, nor that of despising so strong as those of scorning and disdaining, the latter of which expresses the strongest sentiment of all. Persons are contemned for their moral qualities; they are despised on account of their outward circumstances, their characters, or their endowments. Superiors may be contemned; inferiors only, or those who degrade themselves, are despised. Contempt, as applied to persons, is not incompatible with a Christian temper when justly provoked by their character; but despising is distinctly forbidden and seldom warranted. Yet it is not so much our business to contemn others as to contemn that which is contemptible; but we are not equally at liberty to despise the person, or anything belonging to the person, of another. Whatever springs from the free-will of another may be a subject of contempt, but the casualties of fortune or the gifts of Providence, which are alike independent of personal merit, should never expose a person to be despised. We may, however, contemn a person for his impotent malice, or despise him for his meanness.

Persons are not scorned or disdained, but they may be treated with scorn or disdain; they are both improper expressions of contempt or despite: scorn marks the sentiment of a little, vain mind: disdain of a haughty and perverted one. A beautiful woman looks with scorn on her whom she despises for the want of this natural gift. The wealthy man treats with disdain him whom he despises for his poverty.

In speaking of things independently of others, or as immediately connected with ourselves, all these terms may be sometimes employed in a good or an indifferent sense. When we contemn a mean action, and scorn to conceal by falsehood what we are called upon to acknowledge, we act the part of the gentleman as well as the Christian; but it is inconsistent with our infirm and dependent condition that we should feel inelined to despise anything that falls in our way; much less are we at liberty to disdain to do anything which our station requires; we ought to think nothing unworthy of us, nothing degrading to us, but that which is inconsistent with the will of God: there are, however, too many 
who affect to despise small favors as not reaching their fancied deserts, and others who disdain to receive any favors at all, from mistaken notions about dependence and obligation.

CONTEMPLATE, Meditate, Muse. Contemplate, from Latin contemplari, was used at first of the observations and meditations of the augurs, and was derived from templum, English temple, the consecrated place open to the sky, where the augurs made their observations. Meditate, in Latin meditatus, participle of meditor, from Greek $\mu \dot{\varepsilon} \delta o \mu \alpha \iota, I$ attend to, meant to devote the thoughts to something. For the derivation of muse see Audse.

Different species of reflection are marked by these terms. We contemplate what is present or before our eyes; we meditate on what is past or absent. The heavens and all the works of the Creator are objects of contemplation; the ways of Providence are fit subjects for meditation. One muses on events or circumstances which have been just passing.

We may contemplate and meditate for the future, but never muse. In this case the two former terms have the sense of contriving or purposing: what is contemplated to be done is thought of more indistinctly than when it is meditated to be done: many things are bad in contemplation which are never seriously meditated upon: between contemplating and meditating there is oftener a greater distance than between meditating and executing.

Meditating is a permanent and serious action; musing is partial and unimportant: meditation is a religious duty, it cannot be neglected without injury to a person's spiritual improvement; musing is a temporary employment of the mind on the ordinary concerns of life, as they happen to excite an interest for the time. Contemplative and musing, as epithets, have a strong analogy to each other. Contemplative is a habit of the mind; musing is a particular state of the mind. A person may have a contemplative turn, or be in a musing mood.

CONTEMPORANEOUS. See SynCHRONOUS.

CONTEMPORARY. See Coeval. CONTEMPTIBLE. ous. These terms are very frequently, though very erroneously, confounded in common discourse. Contemptible is applied to the thing deserving contempt; contemptuous, to that which is expressive of contempt. Persons, or what is done by persons, may be either contemptible or contemptuous. A production is contemptible; a sneer or look is contemptuous.

Contemptible, Despicable, Pitiful.Contemptible is not so strong as despicable or pitiful. A person may be contemptible for his vanity or weakness; but he is despicable for his servility and baseness of character; he is pitiful for his want of manliness and becoming spirit. A lie is at all times contemptible; it is despicable when it is told for purposes of gain or private interest; it is pitiful when accompanied with indications of unmanly fear. It is contemptible to take credit to one's self for the good action one had not performed; it is despicable to charge another with the faults which we ourselves have committed; it is pitiful to offend others, and then attempt to screen ourselves from their resentment under any shelter which offers. It is contemptible for a man in a superior station to borrow of his inferiors; it is despicable in him to forfeit his word; it is pitiful in him to attempt to conceal anything by artifice.

Contemptuous, Scornful, Disdainful. - These epithets rise in sense by a regular gradation. Contemptuous is general, and applied to whatever can express contempt: scornful and disdainful are particular; they apply only to outward marks: one is contemptuous who is scornful or disdainful, but not vice versa. Words, actions, and looks are contemptuous: looks, sneers, and gestures are scornful and disdainful. Contemptuous expressions are always unjustifiable; whatever may be the contempt which a person's conduct deserves, it is unbecoming in another to give him any indications of the sentiment he feels. Scornful and disdainful smiles are resorted to by the weakest or the worst of mankind.

CONTEND, Contest, Dispute. Contend, from tendo, stretch, and contra, against, signifies to strive against. Contest, from con, against, and testor, 
from testis, a witness, signifying to call to witness against; and dispute, from dis and puto, signifying to think diversely, are modes of contending.

To contend is simply to exert a force against a force; to contest is to struggle together for an object.

To contend and contest may be both applied to that which is claimed and striven for; but contending is the act of the individual without reference to others, where success depends upon personal efforts or prowess, as when one contends at games. To contest is to set up rival pretensions to be determined by the suffrage of others, as to contest an election, to contest a prize.

Opinions may likewise be both contended and contested, with this distinction, that to contend is to maintain any opinion; to contest is to maintain different opinions: the person is said to contend and the thing to be contested.

To dispute, according to its original meaning, applies to opinions only, and is distinguished from contend in this, that the latter signifies to maintain one's own opinion, and the former to call in question the opinion of another.

In respect to matters of personal interest, contend and dispute are employed with a like distinction, the former to denote striving for something desired by one's self, the latter to call in question something relating to others, as to contend for a victory, to dispute a person's right; and when the idea of striving for a thing in dispute is to be expressed, this word may be employed indifferently with contend for, as to dispute or contend for a prize.

Contention, contest, and dispute, as nouns, admit of a further distinction. Contention is always of a personal nature, whether as regards interests or opinions, and is always accompanied with more or less ill feeling.

Contests may be as personal as contentions, but the objects in a contest being higher, and the contesting parties coming less into direct collision, there is less ill feeling produced.

As differences of opinion have a tendency to create ill feeling, disputes are rarely conducted without acrimony; but sometimes there may be dispuics for that which is honorable, where there is no personal animosity. See also Bicker; Strive.

CONTENTION. See Dissension; STRIFE.

CONTENTMENT, Satisfaction. Contentment, in French contentement, from content, in Latin contentus, participle of contenere, to contain or hold, signifies the keeping one's self to a thing. Satisfaction, in Latin satisfactio, compounded of satis, enough, and facere, to do, signifies the making or having enough.

Contentment lies in ourselves: satisfaction is derived from external objects. One is contented when one wishes for no more: one is satisfied when one has obtained all one wishes. The contented man has always enough; the satisfied man has only enough for the time being. The contented man will not be dissatisfied; but he who looks for satisfaction will never be contented. Contentment is the absence of pain; satisfaction is positive pleasure. Contentment is accompanied with the enjoyment of what one has; satisfaction is often quickly followed with the alloy of wanting more. A contented man can never be miserable; a satisfied man can scarcely be long happy. Contentment is a permanent and habitual state of mind; it is the restriction of all our thoughts, views, and desires within the compass of present possession and enjoyment: satisfaction is a partial and turbulent state of the feelings, which awakens rather than deadens desire. Contentment is suited to our present condition; it accommodates itself to the vicissitudes of human life; satisfaction belongs to no created being; one satisfied desire engenders another that demands satisfaction. Contentment is within the reach of the poor man, to whom it is a continual feast; but satisfaction has never been procured by wealth, however enormous, or ambition, however boundless and successful. We should therefore look for the contented man where there are the fewest means of being satisfied. Our duty bids us be contenied; our desires ask to be salisfied: but our duty is associated with our happiness; our desires are the sources of our misery.

When taken in a partial applieation 
to particular objects, there are cases in which we ought not to be contented, and where we may with propriety look for permanent satisfaction. We cannot be contented to do less than our duty requires; we may justly be satisfied with the consciousness of having done our duty.

CONTEST. See Conflict; CoNTEND.

CONTIGUOUS. See ADJACENT.

CONTINENCE. See Chastity.

CONTINGENCY. See ACCIDENT. CONTINGENT. See Accidental; Provisional.

Continual, Perpetual, Constant. Continual, in French continuel, Latin continuus, from continere, to hold or keep together, signifies keeping together without intermission. Perpetual, in French perpétuel, Latin perpetualis, from perpeto, compounded of per, meaning thoroughly, and petere, to seek, to seek thoroughly, signifies going on everywhere and at all times. Constant (see Constancy).

What is continual admits of no interruption: what is perpetual admits of no termination. There may be an end to that which is continual, and there may be intervals in that which is perpetual. Rains are continual in the tropical climates at certain seasons: complaints among the lower orders are perpetual, but they are frequently without foundation. There is a continual passing and repassing in the streets of the metropolis during the day; the world and all that it contains are subject to perpctual change.

Constant, like continual, admits of no interruption, and it also admits of no change; what is continual may not always continue in the same state, but what is constant remains in the same state: continual is therefore applied to that which is expected to cease, and constant to that which ought to last. A nervous person may fancy he hears continual noises. It will be the constant endeavor of a peaceable man to live peaceably.

Continual may sometimes have a moral application; as when we say, contentment is a continual feast; to have a continual enjoyment in anything: constant is properly applied to moral objects.
Continual, Continued. - Continual and continued both mark length of duration, but the former admits of a certain degree of interruption, which the latter does not. What is continual may have frequent pauses; what is continued ceases only to terminate. Rains are continual which are frequently repeated; so noises in a tumultuous street are continual: the bass in music is said to be continued; the mirth of a drunken party is one continued noise. Continual interruptions abate the vigor of application and create disgust: in countries situated near the poles, there is one continued darkness for the space of five or six months, during which time the inhabitants are obliged to leave the place.

Continual respects the duration of actions only; continued is likewise applied to the extent or course of things: rumors are continual; talking, walking, running, and the like, are continual; but a line, a series, a scene, or a stream of water is continued.

Continuance, Continuation, Duration. -Continuance, from the intransitive verb to continue, denotes the state of continuing or being carried on further. Continuation, from the transitive verb continue, denotes the act of continuing or carrying on further. The continuance is said of that which itself continues; the continuation, of that which is continued by some other agency: as the continuance of the rain; the continuation of a history, work, line, etc.

As the species is said to be continued, the word continuation is most properly applied in this case.

Continuance and duration are both employed for the time of continuing; things may be of long continuance or of long duration; but continuance is used only with regard to the action; duration with regard to the thing and its existence. Whatever is occasionally done, and soon to be ended, is not for a continuance; whatever is made, and soon destroyed, is not of long duration: there are many excellent institutions in England which promise to be of no less continuance than utility. Duration is with us a relative term; things are of long or short duration by comparison: the duration of the world, and all sublunary objects, is nothing in regard to eternity. 
Continuation, Continuity.-Continuation signifies either the act of continuing, as to undertake the continuation or continuing of a history; or the thing continued; as to read the continuation of a history-that is, the history continued.

Continuity denotes the quality of bodies holding together without interruption; there are bodies of so little continuity that they will crumble to pieces on the slightest touch.

Continue, Remain, Stay.-Continue (see Contindal). Remain, in Latin remaneo, is compounded of re, behind, and manere, to stay, and signifies to stay bchind. Stay is derived through French from Middle Dutch stade, which is allied to English stead, in steadfast, steady, etc., signifying place; it means to remain in one place.

The idea of keeping to an object is common to these terms. To continue is associated with a state of action; to remain, with a state of rest: we are said to continue to speak, walk, or do anything, to continue in action or motion; to remain stationary, or in a position.

So likewise in application to the outward condition or the state of mind, continue denotes that which is active and positive; remain, that which is quiescent and tranquil; to continue in a course or in a belief; to continue steadfast: to remain in doubt.

The same distinction exists between these words when things are the subjects: a war continues; a stone remains in the place where it is put.

Continue is frequently taken absolutely for continuing in action; remain, from the particle $r e$, has a relative signification to something else: the sickness or the rain continues; I will use my utmost endeavors as long as health remains.

Continue and remain are used in respect of place; stay is used in that of connection only. Continue is indefinite in its application and signification; as to continue in town or in the country: to remain is an involuntary act; as a soldier remains at his post, or a person remains in prison: stay is a voluntary act; as to stay at a friend's or with a friend.

Continue, Persevere, Persist, Pursue,
Prosecute-Continue (see above). Persevere, in French persévérer, Latin perseverare, compounded of per, through, and severus, strict and steady, signifies to be steady throughout or to the end. Persist, in French persister, Latin persisto, is compounded of per, through, and sistere, to put, and corresponds to the modern phrase "to put it through." Pursue and prosecute, in French poursuivre, come from the Latin prosequor and its participle prosecutus, signifying to follow after or keep on with.

The idea of not setting aside is common to these terms, which is the sense of continue without any qualification; the other terms, which are all species of continuing, include likewise some collateral idea which distinguishes them from the first, as well as from one another. Continue is comparable with persevere and persist in the neuter sense, with pursue and prosecute in the active sense. To continue is simply to do as one has done hitherto; to persevere is to continue without wishing to change or from a positive desire to attain an object; to persist is to continue from a determination or will not to cease. The act of continuing, therefore, specifies no characteristic of the agent; that of persevering or persisting marks a direct temper of mind; the former is always used in a good sense, the latter in an indifferent or bad sense. We continue from habit or casualty; we persevere from reflection and the exercise of our judgment; we persist from attachment. It is not the most exalted virtue to continue in a good course merely because "we have bcen in the habit of so doing: what is done from habit merely, without any fixed principle, is always exposed to change from the influence of passion or cvil counsel; there is real virtue in the act of perseverance, without which many of our best intentions would remain unfulfilled and our best plans would be defeated: those who do not persevere can do no essential good; and those who do persevere often effect what has appeared to be impracticable; of this truth the discoverer of Amcrica is a remarkable proof, who, in spite of every mortification, rebuff, and disappointment, persevered in calling the attention of monarchs to his project, 
until he at length obtained the assistance requisite for effecting the discovery of a new world.

The Romans have not observed this distinction between perseverare and persistere; for they say, "In errore perseverare:" CiCERo. "Ad ultimum perseverare:" LIVY. "In eadem impudentiâ persistere:" Lrvy. "In proposito persistere:" Cicero. Probably in imitation of them, examples are to be found in English writers of the use of persevere in the bad sense, and of persist in the good sense; but the distinction is now invariably observed. Persevere is employed only in matters of some moment, in things of sufficient importance to demand a steady purpose of the mind; persist may be employed in that which is trifling, if not bad: a learner perseveres in his studies, in order to arrive at the necessary degree of improvement; a child persists in making a request until he has obtained the object of his desire: there is always wisdom in perseverance, even though unsuccessful; there is mostly folly, caprice, or obstinacy in persistence: how different the man who perseveres in the cultivation of his talents from him who only persists in maintaining falsehoods or supporting errors!

Continue, when compared with persevere or persist, is always coupled with modes of action: but in comparison with pursue or prosecute, it is always followed by some object: we continue to do, persevere or persist in doing something: but we continue, pursue, or prosecute some object which we wish to bring to perfection by additional labor. Continue is equally indefinite as in the former case; pursue and prosecute both comprehend collateral ideas respecting the disposition of the agent and the nature of the object: to continue is to go on with a thing as it has been begun; to pursue and prosecute is to continue by some prescribed rule, or in some particular manner: a work is continued; a plan, measure, or line of conduct is pursued; an undertaking or a design is prosecuted: we may continue the work of another in order to supply a deficiency: we may pursue a plan that emanates either from ourselves or another; we prosecute our own work only in order to obtain some peculiar object: continue, therefore, expresses less than pursue, and this less than prosecute: the history of England has been continued down to the present period by different writers; Smollett has pursued the same plan as Hume in the continuation of his history; Captain Cook prosecuted his work of discovery in three several voyages. To continue is itself altogether an indifferent action; to pursue and prosecute are commendable actions; the latter still more than the former: it is a mark of great instability not to continue anything that we begin; it betrays a great want of prudence and discernment not to pursue some plan on every occasion which requires method; it is the characteristic of a persevering mind to prosecute whatever it has deemed worthy to enter upon.

CONTINUITY. See ContinuaTION.

CONTRABAND, Forbidden, ProHIBITED. Contraband is derived through Spanish and Italian from Latin contra, against, and Italian bando, Late Latin bannum, a word of Teutonic origin found in abandon, ban, etc. It means literally a ban against something, and refers to a special kind of forbidding or prohibiting. McCulloch, in the "Commercial Dictionary," gives the following succinct definition of the perplexing phrase contraband of war:

"When two nations are engaged in war, if there be any foreign article or articles necessary for the defence or subsistence of either of them, and without which it would be difficult for it to carry on the contest, the other may legitimately exert every means in its power to prevent its opponent being supplied with such article or articles."

Such goods are called contraband of war. After forbidding the importation of such goods by a legal proclamation, a nation may use every means to prohibit the enemy from obtaining the contraband articles. For a further definition of the difference between forbid and prohibit see BAN and ForBID.

CONTRACT. See Abridge; AgreeMENT.

CONTRACTED, CoNFINED, NARnow. These words agree in denoting 
a limited space; but contracted, from contraho, draw together, signifying drawn into a smaller compass than it might otherwise be in, and confined (see BoUND), signifying brought within unusually small bounds, are said of that which is made or becomes so by circumstances. Narrow comes from Anglo-Saxon nearu, closely drawn. A limb is said to be contracted which is drawn up by disease; a situation is confined which has not the necessary or usual degree of open space; a road or a room is narrow.

These terms are figuratively applied to moral objects with the same distinction: the mind is contracted by education or habit; a person's views are confined by reason of his ignorance; people have for the most part a temper narrow by nature.

CONTRADICT, DenY, Oppose. Contradict, from the Latin contra, against, and dictum, speech, signifies a speech against a specch. Deny is derived from Latin de and negare, to say "no," from the negative particle ne, and significs to say "no." Oppose comes from Latin $o b$, in the way of, and French poser (see Compose), and signifies to place in the way of.

To contradict, as the origin of the word sufficiently denotes, is to set up one assertion against another, but it does not necessarily imply an intentional act. The contradiction may lie in the force of the terms, whence logicians call those propositions contradictory which in all their terms are directly opposed to each other: as, "All men are liars"; "No men are liars." A person may contradict himself, or two witnesses may contradict each other who have had no communication.

To deny is to assert the falsehood of another's asscrtion, and is therefore a direct and personal act; as to deny any one's statement.

Contradictions may be given at the pleasure or for the convenience of the parties; denials are made in support either of truth or falsehood, in matters of fact or matters of opinion.

One contradicts in direct terms by asserting something contrary; one denies by advancing arguments or suggesting doubts or diffieulties. These terms may therefore both be used in reference to disputations. We may deny the truth of a position by contradicting the assertions that are advanced in its support.

Contradiction and denial are commonly performed by words only; opposition, by any kind of action or mode of expression. We may therefore sometimes oppose by contradiction, although not properly by denial; contradicting and opposing being both voluntary acts, denying frequently a matter of necessity or for self-defence.

CONTRARY. See Adverse; HeteROGENEOUS.

CONTRAST. See CoMparison.

CONTRIBUTE. See CoNDUCE;

MiNister.

CONTRIBUTION. See Tax.

CONTRITION. See RePENTANCE. CONTRIVE, Devise, Invent. Contrive in Old French controver, compounded of Latin con, together, and a stressed stem of Old French trover, to find, signifies to find out by putting together. Devise, compounded of de and Latin visus, seen, signifies to show or present to the mind. Invent, in Latin inventus, participle of invenire, compounded of in, in, and venire, to come, signifies to come or bring into the mind.

Contriving requires less exercise of the thoughts than devising: we contrive on familiar and common occasions; we devise in seasons of difficulty and trial. A contrivance is simple and obvious to a plain understanding: a device is complex and far-fetched; it requires a ready conception and a degree of art. Contrivances serve to supply a deficiency or increase a convenience; devices are employed to extricate from danger, to remove an evil, or forward a scheme: the history of Robinson Crusoe derives considerable interest from the rclation of the various contrivances by which he provided himself with the first articles of necessity and comfort; the history of robbers and adventurers is full of the various devices by which they endeavor to carry on their projects of plunder or elude the vigilance of their pursuers.

To contrive and devise do not express so much as to invent: we contrive and 
devise in small matters; we invent in those of greater moment. Contriving and devising respect the manner of doing things; inventing comprehends the action and the thing itself; the former are but the new fashioning of things that already exist; the latter is, as it were, the creation of something new: to contrive and devise are intentional actions, the result of a specific effort; invention naturally arises from the exertion of an inherent power: we require thought and combination to contrive or devise; ingenuity is the faculty which is exerted in inventing. A device is often employed for bad and fraudulent purposes: contrivances mostly serve the innocent purposes of life; inventions are mostly good, unless they are stories invented, which are always false.

See also Concert.

CONTRIVING. See Scheming.

CONTROL. See CHECK.

CONTROVERT, Dispute. Controvert, compounded of the Latin contra, against, and vertere, to turn, signifies to turn against another in discourse, or direct one's self against another. Dispute (see ARGUE).

To controvert has regard to speculative points; to dispute respects matters of fact: there is more of opposition in controversy; more of doubt in disputing: a sophist controverts; a sceptic disputes: the plainest and sublimest truths of the Gospel have been all controverted in their turn by the self-sufficient inquirer: the authenticity of the Bible itself has been disputed by some few individuals: the existence of a God by still fewer. Controversy is worse than an unprofitable task; instead of eliciting truth, it does but expose the failings of the parties engaged: disputing is not so personal, and consequently not so objectionable: we never controvert any point without seriously and decidedly intending to oppose the notions of another; we may sometimes dispute a point for the sake of friendly argument or the desire of information: theologians and politicians are the greatest controversialists: it is the business of men in general to dispute whatever ought not to be taken for granted.

CONTUMACIOUS. See NATE.
CONTUMACY, Rebellion. Contumacy, from the Latin contumax, compounded of contra, against, and tumere, to swell, signifies the swelling one's self up by way of resistance. Rebellion, in Latin rebellio, compounded of $r e$, in return, and bellum, war, signifies carrying on war against those to whom we owe, and have before paid, a lawful subjection.

Resistance to lawful authority is the common idea included in the signification of both these terms, but contumacy does not express so much as rebellion: the contumacious resist only occasionally; the rebel resists systematically: the contumacious stand only on certain points, and oppose the individual; the rebel sets himself up against the authority itself: the contumacious thwart and contradict, they never resort to open violence: the rebel acts only by main force; contumacy shelters itself under the plea of equity and justice; rebellion sets all law and order at defiance.

CONTUMELY. See REPROACH.

CONVENE. See Assembi.e. .

CONVENIENT, SUITABle. Convenient (see Commodous). Suitable (see Conformable).

Convenient regards the circumstances of the individual; suitable respects the established opinions of mankind, and is closely connected with moral propriety: nothing is convenient which does not favor one's purpose: nothing is suitable which does not suit the person, place, and thing: whoever has anything to ask of another must take a convenient opportunity in order to insure success; his address on such an occasion would be very unsuitable if he affected to claim as a right what he ought to solicit as a favor.

CONVENT. See Cloister.

CONVENTION, Agreement, ComPaCT, Treaty. Convention, in French the same form, from Latin con, together, and venire, to come, in the diplomatic sense in which it is here used signifies literally an agreement as distinguished from an assembly of a political character. In international disputes or warfare it has frequently been the custom for the disputants to seek a peaceable solution of the trouble between them, the first step 
being a meeting of mutual delegates to ascertain what demands and concessions are likely to be made.

This meeting may formulate terms, which are usually of a tentative character, and afterward plenipotentiaries are appointed to negotiate a formal agreement, compact, and sometimes a treaty itself. The final engagement becomes effective only on its ratification by each disputant. The plenipotentiaries, instructed on general lines by their respective governments, give and take, and their agreement is almost always accepted as binding by their governments.

See also Assembly.

CONVERSABLE. See Facetiods. CONVERSANT, FaMiliar. Conversant, from con, together, and versari, to dwell, signifies dwelling together, hence familiar with, consequently becoming acquainted. Familiar, from the Latin familiaris, to be of the same family, signifies the closest connection.

An acquaintance with things is implied in both these terms, but the latter expresses something more particular than the former. A person is conversant in matters that come frequently before his notice; he is familiar with such as form the daily routine of his business: one who is not a professed lawyer may be conversant with the questions of law which occur on ordinary occasions; but one who is skilled in his profession will be familiar with all cases which may possibly be employed in support of a cause: it is advisable to be conversant with the ways of the world; but to be familiar with the greater part of them would not redound to one's credit or advantage.

Conversation, Dialogue, Conference, Colloquy. - Conversation denotes the act of holding converse (see Communion). Dialogue, in French dialogue, Latin dialogus, Greek diáxoyos, compounded of

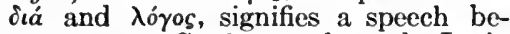
tween two. Conference, from the Latin con, together, and ferre, to bring, signifies consulting together on subjects. Colloquy, in Latin colloquium, from con, together, and loquor, speak, signifies the art of talking together.

A conversation is always something actually held between two or more persons; a dialogue is mostly fictitious, and written as if spoken: any number of persons may take part in a conversation, but a dialogue always refers to the two persons who are expressly engaged: a conversation may be desultory; a dialogue is formal, in which there will always be reply and rejoinder: a conversation may be carried on by any signs besides words, which are addressed personally to the individual present; a dialogue must always consist of express words: a prince holds frequent conversations with his ministers on affairs of state; Cicero wrote dialogues on the nature of the gods, and many later writers have adopted the dialogue form as a vehicle for conveying their sentiments: a conference is a species of conversation; a colloquy is a species of dialogue: a conversation is indefinite as to the subject or the parties engaged in it: a conference is confined to particular subjects and descriptions of persons: a conversation is mostly occasional: a conference is always specifically appointed: a conversation is mostly on indifferent matters; a conference is mostly on national or public concerns: we have a conversation as friends; we have a conference as ministers of state. The dialogue naturally limits the number to two; the colloquy is indefinite as to number: there may be dialogues, therefore, which are not colloquies; but every colloquy may be denominated a dialogue.

CONVERSE See Commonion; SPEAK.

CONVERT, Proselyte. Convert, from the Latin converto, signifies changed to something in conformity with the views of another. Proselyte, from the Greek $\pi \rho$ ós, to, and $\ddot{\eta} \lambda v \theta o \nu$, second aorist of texopat, I come, signifies come over to the side of another.

Convert is more extensive in its sense and application than prosclyte: convert in its full sense includes every change of opinion, without respect to the subject; proselyte, in its original application, denoted changes only from one religious belief to another: there are many converts to particular doctrines of Christianity, and prosclytes from the Pagan, Jewish, or Mohammedan to the Christian faith; but the word proselyte has since acquired an application which distinguishes it from convert. 
Conversion is a more voluntary act than proselytism; it emanates entirely from the mind of the agent, independently of foreign influence; it extends not merely to the abstract or speculative opinions of the individual, but to the whole current of his feelings and spring of his actions: it is the conversion of the heart and soul. Proselytism is an outward act, which need not extend beyond the conformity of one's words and actions to a certain rule: convert is therefore always taken in a good sense; it bears on the face of it the stamp of sincerity: proselyte is a term of more ambiguous meaning; the proselyte is often the creature and tool of a party: there may be many proselytes where there are no converts. The conversion of a sinner is the work of God's grace, either by His special interposition or by the ordinary influence of His Holy Word on the heart: partisans are always anxious to make proselytes to their own party.

CONVERTIBLE. See Assimilate. CONVEY. See Bear; WaFT.

CONVICT, Detect. Convict, from the Latin convictus, participle of convinco, I make manifest, signifies to make guilt clear. Detect, from the Latin detectus, participle of detego, compounded of the privative de and tegere, to cover, signifies to uncover or lay open guilt.

A person is convicted by means of evidence; he is detected by means of ocular demonstration. One is convicted of having been the perpetrator of some evil deed; one is detected in the very act of committing the deed. Whatever serves to prove the guilt of another is said to convict, whether the conviction be by others or by one's self: a man may be convicted in his own mind, as well as in the opinion of others, before a public tribunal or by private individuals; detection is confined to the act of the individual, which is laid open to others.

See also Criminal.

Convict, Convince, Persuade.-To convict is to satisfy a person of another's guilt or error. To convince is to satisfy the person himself of the truth or falsehood of a thing.

A person may be convicted of heresy, if it be proved to the satisfaction of others; he may be convinced that the opinion which he has held is heretical. So a person may be convicted who is involuntarily convinced of his error, but he is convinced if he is made sensible of his error without any force on his own mind. One is convicted only of that which is false or bad, but one is convinced of that which is true as well as that which is false. The noun conviction is used in both the senses of convict and convince.

What convinces binds; what persuades attracts. We are convinced by arguments; it is the understanding which determines: we are persuaded by entreaties and personal influence; it is the imagination or will which decides. Our conviction respects solely matters of belief or faith; our persuasion respects matters of belief or practice: we are convinced that a thing is true or false; we are persuaded that it is either right or wrong, advantageous or the contrary. A person will have half effected a thing who is convinced that it is in his power to effect it; he will be easily persuaded to do that which favors his own interests.

Conviction respects our most important duties; persuasion is applied to matters of indifference, or of temporary personal interest. The first step to true repentance is a thorough conviction of the enormity of sin. The cure of people's maladies is sometimes promoted to a surprising degree by their persuasion of the efficacy of the remedy.

As conviction is the effect of substantial evidence, it is solid and permanent in its nature; it cannot be so easily changed and deceived: persuasion, depending on our feelings, is influenced by external objects, and exposed to various changes; it may vary both in the degree and in the object. Conviction answers in our minds to positive certainty; persuasion answers to probability. We ought to be convinced of the propriety of avoiding everything which can interfere with the good order of society; we may be persuaded of the truth of a person's narrative or not, according to the representation made to us; we may be persuaded to pursue any study or lay it aside.

CONVINCING. See Conclusive.

CONVIVIAL, Social. Convivial, in 
Latin convivialis, from con, together, and vivere, to live, signifies being entertained together. Social, from socius, a companion, signifies pertaining to company.

The prominent idea in convivial is that of sensual indulgence; the prominent idea in social is that of enjoyment from an intercourse with society. Convivial is a species of the social, it is the social in matters of festivity. What is convivial is social, but what is social is something more; the former is excelled by the latter as much as the body is excelled by the mind. We speak of convivial meetings, convivial enjoyments, or the convivial board; but social intercourse, social pleasure, social amusements, and the like.

CONVOCATION. See Asś́mble.

CONVOKE. See Assemble.

COOL, Cold, Frigid. In the natural sense, cool is simply the absence of warmth; cold and frigid are positively contrary to warmth; the former in regard to objects in general, the latter to moral objects: in the figurative sense the analogy is strictly preserved. Cool is used as it respects the passions and the affections; cold only with regard to the affections; frigid only in regard to the inclinations. With regard to the passions, cool designates a freedom from agitation, which is a desirable quality. Coolness in a time of danger, and coolness in an argument, are alike commendable. As cool and cold respect the affections, the cool is opposed to the friendly, the cold to the warmhearted, the frigid to the animated; the former is but a degree of the latter. A reception is said to be cool, an embrace to be cold, a sentiment frigid. Coolness is an enemy to social enjoyments; coldness is an enemy to affection; frigidity destroys all force of character. Coolness is engendered by circumstances; it supposes the previous existence of warmth; coldness lies often in the temperament, or is engendered by habit; it is always something vicious; frigidity is occasional, and is always a defect. Trifling differences produce coolness sometimes between the best friends: trade sometimes engenders a cold, calculating temper in some minds: those who are remarkable for apathy will often express themselves with frigid indifference on the most important subjects.

See also Dispassionate.

COPIOUS. See Plentiful.

COPIOUSLY. See LARGELY.

COPY, Transcribe. Copy is derived from the Latin copia, abundance, and signifies to create an abundance of some article by duplicating it or copying. Transcribe, in Latin transcribo, that is, trans, over, and scribere, to write, signifies literally to write over from something else, to make to pass over in writing from one paper or substance to the other.

To copy respects the matter; to transcribe respects simply the act of writing. What is copied must be taken immediately from the original, with which it must exactly correspond; what is transcribed may be taken from the copy, but not necessarily in an entire state. Things are copied for the sake of getting the contents; they are often transcribed for the sake of clearness and fair writing. A copier should be very exact; a transcriber should be a good writer. Lawyers copy deeds, and have them afterward frequently transcribed as occasion requires.

See also SuITable.

Copy, Model, Pattern, Specimen.Copy, from the verb to copy, marks either the thing from which we copy or the thing copied. Model, in French modèle, Latin modulus, a little mode or measure, signifies the thing that serves as a measure or that is made after a measure. Pattern, which is a variation of patron, from the Latin patronus, whence English patron is derived, signifies the thing that directs. Specimen, in Latin specimen, from specere, to behold, signifies what is looked at for the purpose of forming one's judgment by it.

A copy and a model imply either that which is copied or taken from something, as when we speak of a copy in distinction from an original, and of making a model of anything.

Or they imply that from which anything is copied or taken, as to follow a copy, to choose a model.

The term copy is applied to that which is delineated, as writings or pictures, which must be taken faithfully and literally; the model, to that 
which may be represented in wood or stone, and which serves as a guide.

In application to other objects, a copy may be either that which is made or done in imitation, or it may be that which is imitated.

A model is that which may be used as a guide or rule.

Pattern and specimen serve, like the model, to guide or regulate, but differ in the nature of the objects; the pattern regards solely the outward form or color of anything that is made or manufactured, as the pattern of a carpet; a person fixes on having a thing according to a certain pattern; the specimen is any portion of a material which serves to show the quality of that of which it forms a part, as the specimen of a printed work; the value of things is estimated by the specimen.

In the moral application pattern respects the whole conduct or behavior which may deserve imitation; specimen only the detached parts by which a judgment may be formed of the whole: the female who devotes her whole time and attention to the management of her family and the education of her offspring is a pattern to those of her sex who depute the whole concern to others. A person gives but an unfortunate specimen of his boasted sincerity who is found guilty of an evasion.

COQUETTE, Flirt, Jilt. Coquette is in French the feminine form of coquet, a little cock, and signified a proud and strutting little creature, hence a woman who seeks admiration and attention. Flirt is an imitative word which originally meant to jerk lightly away, hence to tease, mock, gibe. Jilt is a diminutive of Jill, a girl's name, contracted from Latin Juliana, and frequently found in old rhymes and proverbs - "Every Jack must have his Jill," "Jack and Jill went up the hill," etc. Of these words the more recent term, firt, has partly replaced the older words, coquette and jilt. Flirt is a more vulgar term than coquette. There is something of a fine lady in the coquette. The flirt uses the natural arts of an ordinary girl; the coquette is the product of a refined and sophisticated society. The coquette has more daintiness and apparently more reserve than the firt, but she may be more heartless and less innocent. Jilt is a word which formerly was much more commonly employed than at present; now it survives mainly in the verb to jilt, to break one's engagement. The older distinction between coquette and jilt is expressed by Crabb as follows: Coquetry is contented with employing little arts to excite notice; jilting extends to the violation of truth and honor, in order to awaken a passion which it afterward disappoints. Vanity is the mainspring by which coquettes and jilts are impelled to action; but the former indulges her propensity mostly at her own expense only, while the latter does no less injury to the peace of others than she does to her own reputation. The coquette makes a traffic of her own charms by seeking a multitude of admirers; the jilt sports with the sacred passion of love, and barters it for the gratification of any selfish propensity. Coquetry is a fault which should be guarded against by every female as a snare to her own happiness; jilting is a vice which cannot be practised without some depravity of the heart.

CORDIAL. See Hearty.

CORNER, ANgle. Corner comes from Latin cornu, signifying a horn or projection. Angle, in Latin angulus, comes in all probability from ä $\boldsymbol{y}_{\kappa v \lambda o s,}$ the elbow.

Corner properly implies the outer extreme point of any solid body; angle, on the contrary, the inner extremity produced by the meeting of two right lines or plane surfaces. When speaking, therefore, of solid bodies, corner and angle may be both employed; but in regard to simple right lines, or plane surfaces, the word angle only is applicable; in the former case a corner is produced by the meeting of the different parts of a body, whether inwardly or outwardly: but an angle is produced by the meeting of two bodies; inwardly one house has many corners; two houses, or two walls at least, are requisite to make an angle.

CORPORAL, Corporeal, Bodily. Corporal, corporeal, and bodily, as their origin bespeaks, have all relation to the same object, the body; but the two former are employed to signify relating or appertaining to the body, 
the latter to denote containing or forming part of the body. Hence we say corporal punishment, bodily vigor or strength, corporeal substances; the Godhead bodily, the corporeal frame, bodily exertion. Corporal is only employed for the animal frame in its proper sense; corporeal is used for animal substance in an extended sense; hence we speak of corporal sufferance and corporeal agents. Corporeal is distinguished from spiritual; bodily from mental. It is impossible to represent spiritual beings any other way than under a corporeal form; bodily pains, however severe, are frequently overpowered by mental pleasures.

Corporeal, Material. - Corporeal is properly a species of material; whatever is corporeal is material, but not vice versâ. Corporeal respects animated bodies; material is used for everything which can act on the senses, animate or inanimate. The world contains corporeal beings, and consists of material substances.

See also TANGible.

Corpulent, Stout, Lusty.-Corpulent, from corpus, the body, signifies having fulness of body. Stout, Anglo-Saxon stolt, is allied to German stolz, proud, and possibly to Latin stultus, foolhardy; it signifies strength and self-assertion resulting from a large physical frame; hence, in some cases, the large physique itself. Lusty, in German, etc., lustig, merry, cheerful, implies here a vigorous state of body.

Corpulent respects the fleshy state of the body; stout respects also the state of the muscles and bones: corpulence is therefore an incidental property; stoutness is a natural property: corpulence may come upon us according to circumstances; stoutness is the natural make of the body which is born with us. Corpulence and lustiness are both occasioned by the state of the health; but the former may arise from disease, the latter is always the consequence of good health: corpulence consists of an undue proportion of fat; lustiness consists of a due and full proportion of all the solids in the body.

CORRECT, RECTIFY, REFORM. Correct (see AMEND) is more definite in its meaning, and more general in its application, than rectify, which, from rectus and facio, signifies simply to make right or as it should be.

To correct is an act of necessity or discretion; to rectify, an act of discretion only. What is corrected is substantially faulty; what is rectified may be faulty by accident or from inadvertence. Faults in the execution are corrected; mistakes are rectified.

To reform, from re, again, and formare, to form, signifies to form again, or put into a new form; it expresses, therefore, more than correct, which removes that which is faulty in a thing without altering the thing itself. Correction may produce only a partial change, but what is reformed assumes a new form and becomes a new thing.

They are employed also in respect to public matters with a like distinction: abuses are corrected, the state is reformed.

Correct, Accurate-Correct is equivalent to corrected, or set to rights. Accurate, from Latin ad, to, and cura, care, signifies done with care, or by the application of care. Correct applies to that which is done according to rules which either a man prescribes to himself or are prescribed for him; accurate, to that which is done by application of the mind or attention to an object: the result in both cases will be nearly the same-namely, that the thing will be as it ought or is intended to be, but there is a shade of difference in the meaning and application. What is done by the exercise of the judgment is said to be correct, as a correct style, a correct writer, a correct way of thinking; what is done by the effort of the individual is more properly accurate, as accurate observations, an accurate survey, and the like.

When applied to the same objects, correct is negative, it is opposed to incorrect or faulty; accurate is positive, it is opposed to inaccurate or loose: it is sufficient to be free from fault to be correct; it must contain every minute particular to be accurate: information is correct which contains nothing but facts; it is accurate when it contains all the details of dates, persons, and circumstances given accurately.

Correction, Discipline, Punishment.As correction and discipline have commonly required punishment to render 
them efficacious, custom has affixed to them a strong resemblance in their application, although they are distinguished from each other by obvious marks of difference. The prominent idea in correction is that of making right what has been wrong. In discipline, from the Latin disciplina and discere, to learn, the leading idea is that of instructing or regulating. In punishment, from the Latin punio, and the Greek $\pi \circ \imath \eta^{\prime}$, penalty, the leading idea is that of inflicting pain as a penalty for wrong-doing.

We remove an evil by correction; we prevent it by discipline. Correction extends no further than to the correcting of particular faults; but discipline serves to train, guide, and instruct generally.

When correction and discipline are taken in the sense of punishment, they mean punishment for the purpose of correction and discipline: punishment, on the other hand, means the infliction of pain as the consequence of any particular conduct. Correction and discipline are personal acts, and mostly acts of authority. A parent inflicts correction, a master exercises discipline: punishment may either be inflicted by persons or result from things: the want of proper discipline may be punished by insubordination.

CORRECTNESS. See Justness.

CORRESPOND. See TALLY.

CORRESPONDENT, ANSWERable, Suitable. Correspondent, from Latin cum, together, and respondere, to answer, signifies to answer in unison or in uniformity. Answerable and suitable, from answer and suit, mark the quality or capacity of answering or suiting. Correspondent supposes a greater agreement than answerable, and answerable requires a greater agreement than suitable. Things that correspond must be alike in size, shape, color, and in every minute particular; those that answer must be fitted for the same purpose; those that suit must have nothing disproportionate or discordant. In the artificial dispositions of furniture, or all matters of art and ornament, it is of considerable importance to have some things made to correspond, so that they be placed in suitable directions to answer to each other.
In the moral application, actions are said not to correspond with professions; the success of an undertaking does not answer the expectations; particular measures do not suit the purpose of individuals. It ill corresponds with a profession of friendship to refuse assistance to a friend in the time of need; wild schemes undertaken without thought will never answer the expectations of the projectors; it never suits the purpose of the selfish and greedy to contribute to the relief of the necessitous.

CORROBORATE. See CONFIRM; RATIFY.

CORRUPT. See AtTaInt; Contaminate; Debauch; Rot.

CORRUPTION. See DePravity.

COSMOS, EARTH, UNIVERSE, WorLD. These words all indicate the world in which we live, but they differ considerably in their application and connotations. Cosmos, from Greek кó $\sigma \mu \mathrm{os}$, order, ornament, was so called by Pythagoras or his disciples from its "perfect order and arrangement." Cosmos corresponds very nearly to universe (from Latin unus, and vertere, meaning turned into one, combined into a whole), with the additional suggestion of harmonious system. Universe refers to the whole infinite extent of life and form; cosmos to the whole orderly scheme of things as they are. World and earth are Anglo-Saxon terms. World, from wer, man, and eld, age, meant originally a lifetime, a course of life, and age; and referred to the whole of the present creation, which was thought of as having been brought into existence at a particular time, and doomed to extinction at some future time. It is a more extensive word than earth, but less extensive than universe or cosmos. Earth, AngloSaxon eorth, signifies the ground under our feet-as distinguished from the heavens above - and now refers to the particular globe on which we live.

Cost, Expense, Price, Charge. Cost is derived through Old French coster, from Latin con, together, and stare, to stand, and signified, literally, to support, and, in an extended sense, what is given for support. Expense is compounded of ex and Latin pensus, participle of pendere, to weigh, signifying 
the thing paid or given out. Price, from the Latin pretium, price, signifies the thing given for what is bought. Charge, from Latin carricare, to load a car, signifies the thing laid on as a burden in return for something received.

The cost is what a thing costs, or what is to be laid out for it; the expense is that which a person actually lays out; the price is that which a thing may fetch or which it may be worth; the charge is that which a person or thing is charged with. As a cost commonly comprehends an expense, the terms are on various occasions used indifferently for each other: we speak of counting the cost or counting the expense of doing anything; at a great cost or at a great expense: on the other hand, of doing a thing to one's cost, of growing wise at other people's expense. The cost and the price have respect to the thing and its supposed value; the expense and the charge depend on the option of the persons. The cost of a thing must precede the price, and the expense must succeed the charge: we can never set a price on anything until we have ascertained what it has cost us; nor can we know or defray the expense until the charge be made. There may, however, frequently be a price where there is no cost, and vice versâ: there may also be an expense where there is no charge; but there cannot be a charge without an expense: what costs nothing sometimes fetches a high price, and other things cannot obtain a price equal to the first cost. Expenses vary with modes of living and men's desires; whoever wants much, or wants that which is not easily obtained, will have many expenses to defray; when the charges are exorbitant, the expenses must necessarily bear a proportion.

Between the epithets costly and expensive there is the same distinction. Whatever is costly is naturally expensive, but not vice versâ. Articles of furniture, of luxury, or indulgence are costly, either from their variety or their intrinsic value; everything is expensive which is attended with much expense, whether of little or great value. Jewels are costly; travelling is expensive. The costly treasures of the East are imported into Europe for the gratification of those who cannot be contented with the produce of their native soil: those who indulge themselves in such expensive pleasures often lay up in store for themselves much sorrow and repentance in the time to come.

In the moral acceptation, the attainment of an object is said to cost much pains; a thing is persisted in at the $e x$ pense of health, of honor, or of life. The sacrifice of a man's quiet is the price which he must pay for the gratification of his ambition.

COSTLy. See Valdable.

COUNCIL. See Assemble.

COUNSEL. See ADVICE.

COUNT. See Calculate; Reckon. COUNTENANCE, Sanction, SUPPORT. Countenance comes from Latin con, together, and tenere, to hold together, to control, referring to the personal demeanor, hence to the face. To countenance means to keep in countenance. Sanction, in French sanction, Latin sanctio, from sanctus, sacred, signifies to ratify a decree or ordinance; in an extended sense, to make anything binding. Support, in French supporter, Latin supporto, compounded of sub and porto, to bear, signifies to bear from underneath, to bear up.

Persons are countenanced; things are sanctioned; persons or things are supported: persons are countenanced in their proceedings by the apparent approbation of others; measures are sanctioned by the consent or approbation of others who have due authority; measures or persons are supported by every means which may forward the object. There is most of encouragement in countenancing; it consists of some outward demonstration of regard or good-will toward the person: there is most of authority in sanctioning; it is the lending of a name, an authority, or an influence, in order to strengthen and confirm the thing: there is most of assistance and co-operation in support; it is the employment of means to an end. Superiors only can countenance or sanction; persons in all conditions may support: those who countenance evil-doers give a sanction to their evil deeds; those who support either an individual or a cause ought to be satisfied that they are entitled to support.

See also Face. 
COUNTERFEIT. See Imitate; SPURIOUS.

COUNTERPoISE, Balance, PoIse, WeIGH. These terms all indicate methods of weighing. Counterpoise is derived from Latin contra, against, and pensare, to weigh, and signifies to weigh one thing against another. Poise is derived from pensare, also; it signifies to weigh, and refers especially to the adjusting of one part of a balance to the other. Balance comes through Italian from bilanx, Latin, from bis, double, and lanx, a dish or platter, and refers to a pair of scales with two plates suspended from a cross-bar. Weigh, Anglo-Saxon wegan, to carry or bear, meant at first to move in any direction; then to lift up, then to lift up two things, balancing one against the other. Hence these words have practically the same meaning, but differ in the vividness with which they suggest the actual performance of weighing-balance and counterpoise being more suggestive in this respect than poise and weigh. The substantives corresponding to these words have figurative meanings which differ somewhat more vividly. Poise and balance are both applied to a kind of self-control, which enables its possessor to remain quiet and reasonable, and uninfluenced either by outward events or violent emotion. Poise, in this sense, is a general attribute; balance is applied to specific cases in which poise has been displayed. We say that a lady has poise, meaning that she is almost uniformly unruffled and self-controlled-that she resembles a pair of scales in which the weight on one side exactly corresponds to the weight on the other. We say that a man kept his balance, when we mean that in a particular instance he did not let himself be absolutely controlled by only one feeling or one consideration. Weight has a figurative meaning of another sort; it corresponds to heaviness, and signifies that which weighs heavily. A man of weight is a man who can bring much force or influence to bear upon a situation.

COUNTRY. See LAND.

COUNTRYMan, Peasant, Swain, Hind, Rustic, Clown. Countryman, that is, a man of the country, or one belonging to the country, is the general term-applicable to all inhabiting the country, in distinction from a townsman. Peasant, from Old French pais (French pays), the country, signified originally the inhabitant of a pagus (Latin) village-pagus being the word whence pagan is also derived. Peasant is employed in the same sense for any countryman among the inhabitants of the Continent, and is in consequence used in poetry or the grave style for a countryman. Swain, in Anglo-Saxon swan, signified literally a swineherd, but it has acquired, from its use in poetry, the higher signification of a shepherd, or husbandman. Hind is derived from Anglo-Saxon hina, a domestic, and hiwen, a family; compare the relation of Latin famulus, servant, to the word family. It signified a servant in the household. Rustic, from rus, the country, signifies one born and bred in the country. Clown is a Scandinavian word meaning a clumsy, boorish fellow, allied to clump.

All these terms are employed as epithets to persons, and principally to such as live in the country: the terms countryman and peasant are taken in an indifferent sense, and may comprehend persons of different descriptions; they designate nothing more than habitual residence in the country: the other terms are employed for the lower orders of countrymen, but with collateral ideas favorable or unfavorable annexed to them: swain, hind, both convey the idea of innocence in a humble station, and are therefore always employed in poetry in a good sense: the rustic and clown both convey the idea of that uncouth rudeness and ignorance which is in reality found among the lowest orders of countrymen.

COUPle, Pair, Brace. Couple comes from Latin con, together, and Old Latin apere, to join, preserved in aptus, English apt. It signifies things joined together; and as two things are with most convenience bound together, it has by custom been confined to this number. Pair, in French paire, Latin par, equal, signifies things that are equal, which can with propriety be said only of two things with regard to each other. Brace, from the French bras, arm, signifies things locked to- 
gether after the manner of the folded arms, which on that account are confined to the number of two.

From the above illustration of these terms, it is clear that the number of two, which is included in all of them, is, with regard to the first, entirely arbitrary; that with regard to the second it arises from the nature of the junction; and with regard to the third it arises altogether from the nature of the objects; couples and braces are made by coupling and bracing; pairs are either so of themselves or are made so by others: couples and braces always require a junction in order to make them complete; pairs require similarity only to make them what they are: couples are joined by a forcign tie; even the being in company is sufficient to make a couple; braces are produced by a close junction, or what is supposed to be so, which requires them to go together. Couple is applied to objects generally.

Pair is applied to things that naturally go in pairs.

Brace is applied to particular things, either themselves joined together or serving to join others together; as birds that are shot and are usually linked together are termed a brace; whence in poctry the term is applied to animals or other objects in a close state of junction.

Couple is applied to persons of different sex who arc bound to each other by the ties of affection or by the marriage tie.

Pair is also applied to persons similarly situated, but refers more to the moral tie from similarity of feeling: whence the newly married couple is in ordinary discourse called the happy pair.

Pair is applied to persons in no other connection, and brace never except in the burlesque style.

COURAGE, Fortitude, Resoletion. Courage (see Bravery). Fortitude, in French fortitude, Latin fortitudo, is the abstract noun from fortis, strong. Resolution, from Latin re, again, and solvere, $\backslash$ to loose, signifies to divide something into its component parts; hence to decide; and marks the act of resolving, or the state of being resolved.
Courage respectś action, fortitude respects passion: a man has courage to meet danger, and fortitude to endure pain. Courage is that power of the mind which bears up against the evil that is in prospect; fortitude is that power which endures the pain that is felt: the man of courage goes with the same coolness to the mouth of the cannon as the man of fortitude undergoes the amputation of a limb. Horatius Cocles displayed his courage in defending a bridge against the whole army of the Etruscans: Caius Mutius displayed no less fortitude when be thrust his hand into the fire in the presence of King Porsena, and awed him as much by his language as his action.

Courage seems to be more of a manly virtue; fortitude is more distinguishable as a feminine virtue: the former is at least most adapted to the male sex who are called upon to act, and the latter to the females, who are obliged to endure: a man without courage would be as ill prepared to discharge his duty in his intercourse with the world as a woman without fortitude would be to support herself under the complicated trials of body and mind with which she is liable to be assailed.

Resolution is a minor species of courage, or it is courage in the minor concerns of life: courage comprehends under it a spirit to advance; resolution simply marks the will not to recede: we require courage to bear down all the obstacles which oppose themselves to us; we require resolution not to yicld to the first difficulties llat offcr.

COURSE, Race, Passage. Course, from currere, to run, signifies either the act of running or the space run over. Race comes from Scandinavian ras, a running, and signifies the same act. Passage, Latin passus, a step, signifies cither the act of stepping, or the space passed over.

Course and race as acts imply the act of walking or running; passage, the act of passing or going generally: as swift in the course, to win the race, to be lost in the passage. The course in this case may be the act of one alone; the race is always the act of one in competition with others.

In the sense of the space gone over, 
course is to be compared with passage in the proper application, and with race in the improper. The course is the direction taken or chosen by any object, and applies to persons or things personified; as a person pursues a course.

Passage is the way either through or over an object, and applies only to inanimate objects.

Course, in the moral application, signifies the direction taken in the business of life; as to pursue a right or wrong course.

The race is that course of life which a person is supposed to run with others toward a certain object. It is used mostly in the spiritual sense.

See also Route; Series; Way.

COURT. See Homage; Tribunal.

COURTEOUS, COMPLA I SANT, Codrtuy. Courteous, from court, denotes properly belonging to a court, and, by a natural extension of the sense, suitable to a court. Complaisant (see Complaisance).

Courteous in one respect comprehends in it more than complaisant; it includes the manner as well as the action; it is, properly speaking, polished complaisance: on the other hand, complaisance includes more of the disposition in it than courteousness; it has less of the polish, but more of the reality of kindness. Courteousness displays itself in the address and manners; complaisance, in direct good offices: courteousness is practised between strangers; complaisance, among friends.

See also AfFable; WELL-Bred.

Courtly, though derived from the same word as courteous, is in some degree opposed to it in point of sense; it denotes a likeness to a court, but not a likeness which is favorable: courtly is to courteous as the form to the reality; the courtly consists of the exterior only, the latter of the exterior combined with the spirit; the former, therefore, seems to convey the idea of insincerity when contrasted with the latter, which must necessarily suppose the contrary: a courtly demeanor, or a courtier-like demeanor, may be suitable on certain occasions; but a courteous demeanor is always desirable.

Courtly may likewise be employed in relation to things, as belonging to a court; but courteous has always respect to persons: we may speak of a courtly style, or courtly grandeur; but we always speak of courteous behavior, courteous language, and the like.

COVENANT. See Agremant.

COVER, Hide. Cover, in French couvrir, Italian coprire, Latin cooperio, is compounded of con, intensive, and operio, to conceal, and signifies to conceal thoroughly. Hide (see CoNCEAL).

Cover is to hide as the means to the end: we commonly hide by covering; but we may easily cover without hiding, as also hide without covering. The ruling idea in the word cover is that of throwing or putting something over a body: in the word hide is that of keeping carefully to one's self, from the observation of others. In most civilized countries it is common to cover the head: in the Eastern countries females commonly wear veils to hide the face.

Cover sometimes, particularly in the moral application, signifies to conceal; but in that case it denotes the manner of concealing, namely, by overspreading; but hide denotes either the intention or desire to conceal or the concealing what ought not to be seen.

Cover, Shelter, Screen.-Cover properly denotes what serves as a cover, in the literal sense of the verb from which it is derived (see above). Shelter comes from Anglo-Saxon scildtruma, literally shield-troop, a band of men with shields set to guard a place; hence any protection. Screen is derived through French from Teutonic schranne, a railing or a grate.

Cover is literally applied to many particular things which are employed in covering; but in the general sense which makes it analogous to the other terms it includes the idea of concealing: shelter comprehends that of protecting from some immediate or impending evil: screen includes that of warding off some trouble. A cover always supposes something which can extend over the whole surface of a body; a shelter or a screen may merely interpose to a sufficient extent to serve the intended purpose. Military operations are sometimes carried on under cover of the 
night; a bay is a convenient shelter for vessels against the violence of the winds; a chair may be used as a screen to prevent the violent action of the heat or the external air.

In the moral sense, a fair reputation is sometimes made the cover for the commission of gross irregularities in secret. When a person feels himself unable to withstand the attacks of his enemies, he seeks a shelter under the sanction and authority of a great name. Bad men sometimes use wealth and power to scrcen them from the punishment which is due to their offences.

COVERING. See TEgUMENT.

COVET. See Desire.

COVETOUSNESS, C U P I I I T Y, Avarice. Covetousness, from covet, and Latin cupere, to desire, signifies having a desire. Cupidity is a more immediate derivative from the Latin, signifying the same thing. Avarice (see AvARICIOUS).

All these terms are employed to express an illicit desire after objects of gratification; but covetousness is applied to property in general, or to whatever is valuable; cupidity and avarice, only to money or possessions. A child may display its covetousness in regard to the playthings which fall in its way; a man shows his cupidity in regard to the gains that fall in his way; we should, therefore, be careful to check a covetous disposition in early life, lest it show itself in the more hateful character of cupidity in advanced years. Covetousness is the natural disposition for having or getting; cupidity is the acquired disposition. As the love of appropriation is an innate characteristic in man, that of accumulating or wanting to accumulate, which constitutes covetousness, will show itself, in some persons, among the first indications of character: where the prospect of amassing great wealth is set before a man, as in the case of a governor of a distant province, it will evince great virtue in him if his cupidity be not excited. The covetous man seeks to add to what he has; the avaricious man only strives to retain what he has: the covetous man sacrifices others to indulge himself; the avaricious man will sometimes sacrifice himself to indulge others; for generosity, which is op- posed to covetousness, is sometimes associated with avarice.

COWARD. See RECREANT.

COWER. See QUAIL.

CRACK. See BREAK.

CRAFTY. See CUNNING.

CRAVE. See Beg; Yearn.

CREATE. See Cause; Make.

CREDIT, FAVOR, INFLUENCE. Credit, from the Latin creditus, participle of credere, to believe or trust, marks the state of being believed or trusted. Favor, from the Latin favere, to befriend or please, marks an agreeable or pleasant state of feeling toward an object. Influence, in French influence, Latin influentia, from in, in, and fluere, to flow, marks the state or power of acting upon any object so as to direct or move it.

These terms mark the state we stand in with regard to others as flowing out of their sentiments toward ourselves: credit arises out of esteem: favor, out of good-will or affection; influence, out of either credit or favor, or external circumstances: credit depends altogether on personal merit, real or supposed; favor may depend on the caprice of him who bestows it. The credit which we have with others is marked by their confidence in our judgment; by their disposition to submit to our decisions; by their reliance on our veracity or assent to our opinions: the favor we have with others is marked by their readiness to comply with our wishes, their subserviency to our views, attachment to our society: men of talent are ambitious to gain credit with their sovereigns by the superiority of their counsel: weak men or men of ordinary powers are contented with being the favorites of princes and enjoying their patronage and protection. Credit redounds to the honor of the individual, and stimulates him to noble exertions; it is beneficial in its results to all mankind, individually or collectively: favor redounds to the personal advantage, the selfish gratification of the individual; it is apt to inflame pride and provoke jealousy.

Credit and favor are the gifts of others; influence is a possession which we derive from circumstances: there will always be influence where there is credit or favor, but it may exist inde- 
pendently of either: we have credit and favor for ourselves; we exert influence over others: credit and favor serve one's own purposes; influence is employed in directing others: weak people easily give their credit, or bestow their favor, by which an influence is gained over them to bend them to the will of others; the influence itself may be good or bad, according to the views of the person by whom it is exerted.

See also Belief; Name.

CREED. See FAITH.

CREMATION, InCINERATION. Cremation, in Latin crematio through crematus from cremare, to burn, and incineration, in Low Latin incineratio from incinerare, to reduce to ashes, both refer to the method of disposing of the dead by burning, instead of earth burial. Cremation is the more common term in the United States.

CREW. See BAND.

CRIME, Vice, Sin. Crime, in

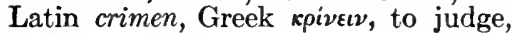
signifies a sentence, or punishment; and also the cause of the sentence or punishment, in which latter sense it is here taken. Vice, in Latin vitium, a blemish, signifies that which destroys the perfection of something. Sin, Anglo-Saxon synn, is allied to one form of the verb to be (Latin sum, sunt, etc.). "Language regards the guilty man as the man who it was" (CURTIUS).

A crime is a social offence; a vice is a personal offence: every action which does injury to others, either individually or collectively, is a crime; that which does injury to ourselves is a vice. Crime consists in a violation of human laws; vice, in a violation of the moral law; $\sin$, in a violation of the divine law: sin, therefore, comprehends both crime and vice; but there are many sins which are not crimes nor vices: crimes are tried before a human court, and punished agreeably to the sentence of the judge; vices and sins are brought before the tribunal of the conscience; the former are punished in this world, the latter will be punished in the world to come, by the sentence of the Almighty: treason is one of the most atrocious crimes; drunkenness one of the most dreadful vices; religious hypocrisy one of the most heinous sins.
Crime, Misdemeanor - Crime (see above). Misdemeanor signifies literally a wrong demeanor.

The former of these terms is to the latter as the genus to the species: a misdemeanor is in the technical sense a minor crime. Housebreaking is under all circumstances a crime; but shoplifting or pilfering amounts only to a misdemeanor. Corporal punishments are most commonly annexed to crimes; pecuniary punishments frequently to misdemeanors. In the vulgar use of these terms, misdemeanor is moreover distinguished from crime by not always signifying a violation of public law, but only of private morals; in which sense the former term implies what is done against the state, and the latter that which offends individuals or small communities.

Criminal, Guilty.-Criminal, from crime, signifies belonging or relating to a crime. Guilty, from guilt (in AngloSaxon gylt, a trespass and a fine for trespass, possibly allied to geldan, to pay, whence our word yield is derived), signifies having guilt.

Criminal respects the character of the offence; guilty respects the fact of committing the offence. The criminality of a person is estimated by all the circumstances of his conduct which present themselves to observation; his guilt requires to be proved by evidence. The criminality is not a matter of inquiry, but of judgment; the guilt is often doubtful, if not positively concealed. The higher the rank of a person the greater his criminality if he does not observe an upright and irreproachable conduct: where a number of individuals are concerned in any unlawful proceeding, the difficulty of attaching the guilt to the real offender is greatly increased.

Criminal may be applied as an epithet either to the person or that which is personal: guilty is properly applied only to the person: a person, or his actions, looks, thought, intentions, may be criminal: the person himself is guilty of whatever he actually commits. What is criminal is against good morals; but a person may be guilty of trivial errors in indifferent matters.

Criminal, Culprit, Malefactor, Felon, Convict.-All these terms are employed 
for a public offender; but the first conveys no more than this general idea; while the others comprehend some accessory idea in their signification. Criminal is a general term, and the rest are properly species of criminals. Culprit comes from Anglo-French cul (for Latin culpa, fault) and prest, ready to prove it, signifying that the clerk of the crcwn was ready to prove the indictment. Malefactor, compounded of the Latin terms male and factor, signifies an evil-doer-that is, one who does evil, in distinction from him who does good. Felon is derived from Late Latin felonem (accusative), a traitor, allied to fell, meaning cruel, dire. Convict, in Latin convictus, participle of convinco, to convince or prove, signifies one proved or found guilty.

When we wish to speak in general of those who by offences against the laws or regulations of society have exposed themselves to punishment, we denominate them criminals: when we consider them as already brought before a tribunal, we call them culprits: when we consider them in regard to the moral turpitude of their character, as the promoters of evil rather than of good, we entitle them malefactors: when we consider them as offending by the grosser violations of the law, they are termed felons: when we consider them as already under the sentence of the law, we denominate them convicts. The punishments inflicted on criminals vary according to the nature of their crimes and the spirit of the laws by which they are judged: a guilty conscience will give a man the air of a culprit in the presence of those who have no authority to be either his accusers or judges; it gratified the malice of the Jews to cause our blessed Saviour to be crucified between two malefactors: it is an imnortant regulation in the internal economy of a prison to have felons kept distinct from one another, particularly if their crimes are of an atrocious nature: it has not unfrequently happened that, when the sentence of the law has placed convicts in the lowest state of degradation, their characters have undergone so entire a reformation as to enable them to attain a higher pitch of elevation than they had ever enjoyed before.
CRINGE. See KNuckle.

CRISIS. See ConJunctore.

CRITERION, StandaRd. Criterion,

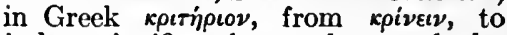
judge, signifies the mark or rule by which one may judge. Standard signified originally an ensign, a flag fixed on a large standing-pole, and is derived from extendere, to extend, though influenced by the verb stand. The pole bearing the flag came to indicate a standard of measurement, symbolizing the ideals of the people whom it represented, and the action expected of them.

The criterion is employed only in matters of judgment; the standard is used in the ordinary concerns of life. The former serves for determining the characters and qualities of things; the latter for defining quantity and measure. The language and manners of a person are the best criterion for forming an estimate of his station and education. In order to produce a uniformity in the mercantile transactions of mankind one with another, it is the custom of governments to fix a certain standard for the regulation of coins, weights, and measures.

The word standard may likewise be used figuratively in the same sense. The Bible is a standard of excellence, both in morals and religion, which cannot be too closely followed. It is impossible to have the same standard in the arts and sciences, because all our performances fall short of perfection and will admit of improvement.

See also Shibboleth; Test.

CRITICAL, Crucial, Important, VITAL. These words all suggest a state of uncertainty, or something necessary to decide the welfare or success of a person or a project. Critical, from the

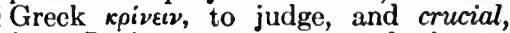
from Latin crux, a cross, referring to the cross placed at the fork in a road to point the way, have a similar meaning. A critical moment is a moment in which the decision hangs in the balance. A crucial instance is the instance on which the decision depends. The use of crucial is partly influenced by its relation to crux, which also suggests an instrument of torture - so that the word has a certain intensity of meaning that critical does not have. It has also a 
more limited and specific application. Important, from in, in, and portare, to bring, is a more general word. It signifies, literally, "bringing in" much, having weighty results; it does not suggest the making of a decision. Vital (from vita, life) means essential to the life of something.

See also Censor; Chimacteric.

CRITICISE. See Censure.

CRITICISM. See ANimadversion.

CROOKED. See AwKWARD; BENT; WrY.

CROSS. See AwKwaRd; CAPTIOUS; QUERULOUS.

CROTCHET. See VAGARY.

CROWD. See MULTITUDE.

CRUCIAL. See Critical.

CRUEL, INHUMAN, BARBAROUS, Brutal, Savage. Cruel, from the Latin crudelis and crudus, raw, rough, or untutored; inhuman, compounded of the privative in and human, signif ying not human; barbarous, from the Greek $\beta a ́ \rho \beta a ̆ \rho o s$, foreigner, in imitation of the sound of a strange language-" bar"-all these mark a degree of bad feeling which is uncontrolled by culture or refinement. Brutal, signifying like the brute (see ANIMAL), and savage, from Old French salvage, from Latin silva, woods, signifying a dweller in the woods-these mark a still stronger degree of this bad passion.

Cruel is the most familiar and the least powerful epithet of all these terms; it designates the ordinary propensity which, if not overpowered by a better principle, will invariably show itself by the desire of inflicting positive pain on others, or abridging their comfort: inhuman and barbarous are higher degrees of cruelty; brutal and savage rise so much in degree above the rest as almost to partake of another nature. A child gives early symptoms of his natural cruelty by his ill-treatment of animals; but we do not speak of his inhumanity, because this is a term confined to men, and more properly to their treatment of their own species, although extended in its sense to their treatment of the brutes: barbarity is but too common among children and persons of riper years. A person is cruel who neglects the creature he should protect and take care of: he is inhuman if he withhold from him the common marks of tenderness or kindness which are to be expected from one human being to another; he is barbarous if he find amusement in inflicting pain; he is brutal or savage according to the circumstances of aggravation which accompany the act of torturing.

See also Hard-HEarted; HeartLESS.

CRUSH. See Break; Overwhelm; QUELL.

CRUTCH. See Staff.

CRY, WEEP. An outward indication of pain is expressed by both these terms, but cry (see CALL) comprehends an audible expression accompanied with tears or otherwise. Weep, AngloSaxon wepan, signified originally to make an outcry; it now refers to the silent shedding of tears. Crying arises from an impatience in suffering corporeal pains; children and weak people commonly cry: weeping is occasioned by mental grief; the wisest and best of men will not disdain sometimes to weep. Crying is as selfish as it is weak; it serves to relieve the pain of the individual to the annoyance of the hearer; weeping, when called forth by others sorrows, is an infirmity which no man could wish to be without: as an expression of generous sympathy, it affords essential relief to the sufferer.

Cry, Scream, Shriek.-To cry indicates the utterance of an articulate or an inarticulate sound. Scream is a Scandinavian word meaning to cry aloud. Shriek is an imitative word, like screech, which tries to represent by its sound a certain kind of cry. Crying is an ordinary mode of loud utterance resorted to on common occasions; one cries in order to be heard: screaming is an intemperate mode of crying, resorted to from an impatient desire to be heard or from a vehemence of feeling. People scream to deaf people from the mistaken idea of making themselves heard; whereas a distinct articulation will always be more efficacious. It is frequently necessary to cry when we cannot render ourselves audible by any other means; but it is never necessary nor proper to scream. Shriek may be compared with cry and scream as expressions of pain; in this case to shriek is more than to cry, and less than to scream. They both signify to cry 
with a violent effort. We may cry from the slightest pain or inconvenience; but one shrieks or screams only on occasions of great agony, either eorporeal or mental. A child cries when it has hurt its finger; it shrieks in the moment of terror at the sight of a frightful object, or screams until some one comes to its assistance.

See also W AIL.

CUFF. See KNOCK.

CULPABLE, FAULTY. Culpable, in Latin culpabilis, comes from culpa, a fault or blame, signifying worthy of blame, fit to be blamed. Faulty, from fault, is ultimately derived from Latin fallere, to deceive.

We are culpable from the commission of one fault; we are faulty from the number of faults: culpable is a relative term; faulty is absolute: we are culpable with regard to a superior whose intentions we have not fulfilled; we are faulty whenever we commit any faults. A master pronounces his servant as culpable for not having attended to his commands; an indifferent person pronounces another as faulty whose faults have come under his notice. It is possible, therefore, to be faulty without being culpable, but not vice versa.

CULPRIT. See Criminal.

CULTIVATED. See Well-Bred.

CULtivation, Culture, Crvilization, Refinement. Cultivation is derived from Latin cultus, from colere, to till, and denotes the act of cultivating, or state of being cultivated. Culture, from cultus, signifies the state only of being cultivated. Civilization signifies the act of civilizing, or state of being civilized, from civis, a citizen, one who lives with others on comfortable terms in a eity or state. Refinement denotes the act of refining, or the state of being refined.

Cultivation is with more propriety applied to the thing that grows; culture to that in which it grows. The cultivation of flowers will not repay the labor unless the soil be prepared by proper culture. In the same manner, when speaking figuratively, we say the cultivation of any art or seience: the cultivation of one's taste or inclination may be said to contribute to one's own skill or the perfection of the thing itself; but the mind requires culture pre- viously to this particular exertion of the powers.

Civilization is the first stage of cul tivation; refinement is the last; we civilize savages by divesting them of their rudeness and giving them a knowledge of such arts as are requisite for civil society; we cultivate people in general by calling forth their powers into aetion and independent exertion; we refine them by the introduction of the liberal arts. The introduction of Christianity has been the best means of civilizing the rudest nations. The cultivation of the mind in serious pursuits tends to refine the sentiments without debilitating the character; but the cultivation of the liberal arts may be pursued to a vicious extent, so as to introduce an excessive refinement of feeling that is incompatible with real manliness.

Cultivation, Tillage, Husbandry.Cultivation has a much more comprehensive meaning than either tillage or husbandry. Tillage comes from AngloSaxon tilian, to labor, from til, beneficial, and signifies to make land useful. It is a mode of cultivation that extends no further than the preparation of the ground for the reception of the seed; cultivation includes the whole process by which the produce of the earth is brought to maturity. We may till without cultivating; but we eannot cultivate, as far as respects the soil, without tillage. Husbandry (see HusBAND) is more extensive in its meaning than tillage, but not so extensive as cultivation. Tillage respects the act only of tilling the ground; husbandry is employed for the office of cultivating for domestic purposes. A cultivator is a general term, defined only by the object that is cultivated, as the cultivator of the grape or the olive; a tiller is a laborer in the soil that performs the office for another: a husbandman is a humble species of cultivator who himself performs the whole office of cultivating the ground for domestic purposes.

CULTURE. See Cultivation.

CUNNING, Crafty, Subtle, Sly, Wily. Cunning (see ART). Crafty signifies having craft, from Anglo-Saxon craft, German kraft, meaning power or energy, hence, specifically, power of mind; henee, in a still more specific 
sense, a particular kind of skill. (Compare the development of keen, from Anglo-Saxon cene, German kuhn, bold.) Subtle, in French subtil, and Latin subtilis, thin, from sub and tela, a thread drawn to be fine; hence in the figurative sense in which it is here taken, fine or acute in thought. Sly is a Scandinavian word originally meaning handy, dexterous, possibly allied to slay. Wily, full of wiles, may be derived from Anglo-Saxon wiglian, to practise sorcery.

All these epithets agree in expressing an aptitude to employ peculiar and secret means to the attainment of an end; they differ principally in the secrecy of the means or the degree of circumvention that is employed. The cunning man shows his dexterity simply in concealing; this requires little more than reservedness and taciturnity: the crafty man goes further; he shapes his words and actions so as to lull suspicion; hence it is that a child may be cunning, but an old man will be crafty: a subtle man has more acuteness of invention than either, and all his schemes are hidden by a veil that is impenetrable to common observation: the cunning man looks only to the concealment of an immediate object; the crafty and subtle man has a remote object to conceal: thus men are cunning in their ordinary concerns; politicians are crafty or subtle: but the former are more so as to the end, and the latter as to the means. A man is cunning and crafty by deeds; he is subtle mostly by means of words alone, or words and actions combined. Slyness is a vulgar kind of cunning; the sly man goes cautiously and silently to work. Wiliness is a species of cunning or craft, applicable only to cases of attack or defence.

See also ART.

CUPIDITY. See Covetousness.

CURB. See CHECK.

CURE, Heal, Remedy. Cure, in Latin curo, signifies to take care of, that is, by distinction, to take care of that which requires particular care, in order to remove an evil. Heal signifies to make whole that which is unsound. Remedy, in Latin remedium, is compounded of re and medere, to heal. The particle re is here an intensive.
To cure is employed for what is out of order; to heal, for that which is broken: diseases are cured, wounds are healed; the former is a complex, the latter is a simple process. Whatever requires to be cured is wrong in the system; it requires many and various applications internally and externally: whatever requires to be healed is occasioned externally by violence, and requires external applications. In a state of refinement men have the greatest number of disorders to be cured; in a savage state there is more occasion for the healing art.

Cure is used as properly in the moral as the natural sense; heal in the moral sense is altogether figurative. The disorders of the mind are cured with greater difficulty than those of the body. The breaches which have been made in the affections of relatives toward each other can be healed by nothing but a Christian spirit of forbearance and forgiveness.

To remedy, in the sense of applying remedies, has a moral application, in which it accords most with cure. Evils are either cured or remedied, but the former are of a much more serious nature than the latter. The evils in society require to be cured; an omission, a deficiency, or a mischief requires to be remedied. When bad habits become inveterate, they are put out of the reach of cure. It is an exercise for the ingenuity of man to attempt to remedy the various troubles and inconveniences which are daily occurring.

Cure, Remedy.-Cure denotes either the act of curing or the thing that cures. Remedy is mostly employed for the thing that remedies. In the former sense the remedy is to the cure as the means to the end; a cure is performed by the application of a remedy. That is incurable for which no remedy can be found; but a cure is sometimes performed without the application of any specific remedy. The cure is complete when the evil is entirely removed; the remedy is sure which by proper application never fails of effecting the cure. The cure of disorders depends upon the skill of the physician and the state of the patient; the efficacy of remedies depends upon their suitable choice and application: but a cure may be de- 
feated, or a remedy made of no avail, by a variety of circumstances independent of either.

A cure is sometimes employed for the thing that cures, which brings it nearer in sense to the word remedy, the former being applied to great matters, the latter to small. Quacks always hold forth their nostrums as infallible cures, not for one, but for every sort of disorder; experience has, however, fatally proved that the remedy in most cases is worse than the disease.

CURING. See SANITART.

CURIOUS, Inquisitive, PRYING. Curious, in French curieux, Latin curiosus, from cura, care, signifying full of eare. Inquisitive, in Latin inquisitus, from inquirere, to inquire or search into, signifies a disposition to investigate thoroughly. Prying, from pry, is derived from Old French prier, to pillage, from Late Latin predare, to prey upon, hence to search out prey, or simply to search out.

The disposition to interest one's self in matters not of immediate coneern is the idea common to all these terms. Curiosity is directed to all objects that can gratify the inclination, taste, or understanding; inquisitiveness, to such things only as satisfy the understanding. The curious person interests himself in all the works of nature and art; he is curious to try effeets and examine causes: the inquisitive person endeavors to add to his store of knowledge. Curiosity employs every means which falls in its way in order to procure gratification; the curious man uses his own powers or those of others to serve his purpose: inquisitiveness is indulged only by means of verbal inquiry; the inquisitive person collects all from others. A traveller is curious who examines everything for himself; he is inquisitive when he minutely questions others. Inquisitiveness is therefore to curiosity as a means to an end; whoever is curious will naturally be inquisitive, but he who is inquisitive may be so either from curiosity or from other motives.

Curious and inquisitive may both be used in a bad sense; prying is never used otherwise than in a bad sense. Inquisitive, as in the former case, is a mode of curiosity, and prying is a species of eager curiosity. A curious person takes unallowed means of learning that which he ought not to wish to know; an inquisitive person puts many impertinent and troublesome questions: a prying temper is unceasing in its endeavors to get acquainted with the secrets of others. Curiosity is a fault most frequent among females; inquisitiveness is most general among children; a prying temper belongs only to people of low eharacter. A well-disciplined mind ehecks the first risings of idle curiosity: children should be taught early to suppress an inquisitive temper, which may so easily become burdensome to others: those who are of a prying temper are insensible to everything but the desire of unveiling what lies hidden; such a disposition is often engendered by the unlicensed indulgence of curiosity in early life, which becomes a sort of passion in riper years.

CURRENT. See STREAM.

CURSE. See Ban; Malediction; SWEAR.

CURSORY, Hasty, Slight, DesULTORY. Cursory, from the Latin curro, signifies run over or done in running. Hasty signifies done in haste, from Anglo-Saxon host, violence. Slight meant originally even or flat; then plain, smooth, simple, trivial. Desultory, from desilo, to leap, signifies leaped over.

Cursory ineludes both hasty and slight; it includes hasty inasmuch as it expresses a quick motion; it includes slight inasmuch as it conveys the idea of a partial aetion: a view may be either cursory or hasty, as the former is taken by design, the latter from earelessness: a view may be either cursory or slight; but the former is not so imperfect as the latter: an author will take a cursory view of those points which are not necessarily connected with his subject; an author who takes a hasty view of a subject will mislead by his errors; he who takes a slight view will disappoint by the shallowness of his information. Between cursory and desultory there is the same difference as between running and leaping: we run in a line, but we leap from one part to another; so remarks that are cursory have still more or less eonnec- 
tion, but remarks that are desultory are without any coherence.

CURTAIL. See Abridge.

CURVED. See BENT.

CUSTODY. See KEEPING.

CUSTOM, HaBIT. Custom, in

French coutume, from Latin consuetudinem, based on Latin consuetum, participle of consuescere, to accustom. Habit, in French habit, Latin habitudo, from habere, to have, marks the state of having or holding.

Custom is a frequent repetition of the same act; habit, the effect of such repetition: the custom of rising early in the morning is conducive to the health, and may in a short time become such a habit as to render it no less agreeable than it is useful. Custom supposes an act of the will; habit implies an involuntary movement: custom is followed; a habit is acquired.

Custom is applicable to bodies of men; habit is confined to the individual; every nation has customs peculiar to itself; and every individual has habits peculiar to his age, station, and circumstances.

Customary and habitual, the epithets derived from these words admit of a similar distinction: the customary action is that which is repeated after the manner of a custom; the habitual action is that which is done by the force of habit.

See also TAx; Usage.

Custom, Fashion, Manner, Practice.Customs, fashions, and manners are all employed for communities of men; custom respects established and general modes of action: fashion, in French façon, from factio, a making or doing, regards partial and transitory modes of making or doing things: manner, in the limited sense in which it is here taken, signifies the manner or mode of men's living or behaving in their social intercourse.

Custom is authoritative; it stands in the place of law and regulates the conduct of men in the most important concerns of life: fashion is arbitrary and capricious, it decides in matters of trifling import: manners are rational; they are the expressions of moral feelings. Customs have most force in a simple state of society; fashions rule most where luxury has made the great- est progress; manners are most distinguishable in a civilized state of society. Customs are in their nature as unchangeable as fashions are variable; manners depend on cultivation and collateral circumstances; customs die away or are abolished; fashions pass away and new ones take their place; manners are altered either for the better or the worse.

Practice, in Latin practica, Greek $\pi \rho \alpha \kappa \tau \iota k \dot{n}$, from $\pi \rho a ́ \sigma \sigma \varepsilon \iota \nu$, to do, signifies actual doing or the thing done, that is, by distinction, the regularly doing, or the thing regularly done, in which sense it is most analogous to custom; but the former simply conveys the idea of actual performance; the latter includes also the accessory idea of repetition at stated periods: a practice may be defined as frequent or unfrequent, regular or irregular; but a custom does not require to be qualified by any such epithets: it may be the practice of a person to do acts of charity, as the occasion requires; but, when he uniformly does a particular act of charity at any given period of the year, it is properly denominated his custom.

Both practice and custom are general or particular, but the former is absolute, the latter relative: a practice may be adopted by a number of persons without reference to one another; but a custom is always followed either by imitation or prescription: the practice of gaming has always been followed by the vicious part of society; but it is to be hoped for the honor of man that it will never become a custom.

CUT. See NIP; Trench.

CUTTING. See Trenchant.

CYCle, Bicycle, Tricycle, HyDROCYCLE, MOTORCYCLE, TANDEM, SoCIABLE. Cycle, from the Greek kúkios, a circle, in the sense of a vehicle, is a shortened term for a variety of constructions, outgrowths of the old French velocipede and dandy-horse of two and three wheels.

The bicycle and tricycle, as their names denote, are supplied with two and three wheels respectively; the hydrocycle is an adaptation for use on a water surface; the motorcycle is a bicycle propelled by an electric motor or other contrivance instead of by 
pedals on the front wheel, a form of having a more or less fancy rear seat cycle much used by the police; a for a second person, a form also used tandem has two whtels farther sepa- for light delivery vehicles. rated than the ordinary bicycle, with Bike is a new slang term given by seats for two persons, one in the rear both professional and amateur wheelof the driver; and the sociable is one of men to their machines.

several names applied to a tricycle CYNICAL. See Misanthropical. 
DaBBLE, Dip, Splash. Dabble exactly agrees in form and sense with Dutch dabbelen. Dip comes from Anglo-Saxon dyppan. Splash is formed by adding $s$, French $e s$, Latin $e x$, to plash (from a Teutonic root meaning to strike) for added emphasis. Dip means to immerse in water and then to withdraw the immersed object quickly-indicating a light, decided, comparatively noiseless action. Splash means to dip in such a way as to fling the water about and make considerable noise. Dabble means to keep dipping lightly, making each time a little splash. It indicates a purposeless action; dip indicates an action not lacking in purpose, but in continuity and endurance.

DAILY, Diurnal. Daily, from day and like, signifies after the manner or in the time of the day, day being derived from a Teutonic root signifying to burn, day being the bright, hot time, as opposed to night. Diurnal, from dies, day, signifies belonging to the day.

Daily is the colloquial term which is applicable to whatever passes in the day-time; diurnal is the scientific term, which applies to what passes within or belongs to the astronomical day: the physician makes daily visits to his patients; the earth is said by astronomers to have a diurnal motion on its own axis.

DAINTY, Delicacy. These terms, which are in vogue among epicures, have some shades of difference not altogether undeserving of notice. Dainty, through French from Latin dignitatem, worthy, is applied to that which is of worth or value- of course only to such things as have a superior value in the estimation of epicures, and consequently conveys a more positive meaning than delicacy; inasmuch as a dainty may be that which is extremely delicate, a delicacy is sometimes a species of dainty; but there are many delicacies which are altogether suited to the most delicate appetite that are neither costly nor rare, two qualities which are almost inseparable from a dainty: those who indulge themselves freely in dainties and delicacies scarcely know what it is to eat with an appetite; but those who are temperate in their use of the enjoyments of life will be enabled to derive pleasure from ordinary food.

DALLY, Toy. Dally comes from Old French dalier, to converse, to pass one's time in light social converse. Toy is derived from Dutch tuig, tools, utensils. A toy is a device to give amusement, a plaything for children, especially. To toy is to treat as a plaything - as a matter of no consequence; to amuse one's self as with a game. Dally and toy have substantially the same meaning, indicating frivolous or playful self-indulgence. Such difference as there is is that suggested by their derivation-dally emphasizing a certain lightness and frivolousness, toy a more positive playing with something. Both words are used to refer to amorous caresses with the slight difference in meaning above suggested. Dally means also to delay, to put off by trifling, and toy a purposeless handling, as when we say "He toyed with his watch-chain."

DAMAGE. See INJURY; Loss; SCATHE.

DAMPNESS. See MoIstURE.

DAMSEL. See VIRGIN.

DANGer, Peril, Hazard. Danger, Old French dongier, from Late Latin dominum, power, from Late Latin domnus, lord-one who has absolute authority. Peril is derived from Latin periculum, from the verb periri, to try, Greek $\pi \widehat{\varepsilon} \hat{\imath} \rho$, an attempt. Hazard (see ChANCE).

The idea of chance or uncertainty is common to all these terms; but the two former may sometimes be foreseen and calculated upon; the latter is purely contingent. Dangers are far and near, ordinary and extraordinary: they meet us if we do not go in search of them; perils are always distant and extraordinary: we must go out of our course to expose ourselves to them; in the quiet walk of life, as in the most 
busy and tumultuous, it is the lot of man to be surrounded by danger; the mariner, and the traveller who goes in search of unknown countries, put themselves in the way of undergoing perils both by sea and land.

Danger and peril are applied to positive evils; hazard respects the possibilities of good as well as of evil. When we are involved in danger we are in a situation to lose what we wish to retain; when we run the hazard of a battle we may either win or lose.

The same distinction exists between the epithets that are derived from these terms.

It is dangerous for a youth to act without the advice of his friends; it is perilous for a traveler to explore the wilds of Africa; it is hazardous for a merchant to speculate in time of war: experiments in matters of policy or government are always dangerous; a journey through deserts that are infested with beasts of prey is perilous; a military expedition conducted with inadequate means is hazardous.

DANGEROUS. See Climacteric. DARE. See Brave.

DARING, BoLD. Daring signifies having the spirit to dare. Bold (see AUdACITY).

These terms may both be taken in a bad sense, but daring much oftener than bold; in either case daring expresses much more than bold: he who is daring provokes resistance and courts danger; but the bold man is contented to overcome the resistance that is offered to him: a man may be bold in the use of words only, he must be daring in actions: he is bold in the defence of truth; he is daring in military enterprise.

See also Stalwart.

DARK, Obscure, Dim, Mysterious. Dark, Anglo-Saxon deorc, is connected with Old High German tarchanjan, to hide. Obscure comes from Latin obscurus, from $o b$, over, and scurus, covered. Dim comes from AngloSaxon dim, and is allied to Swedish dimma, a fog or haze.

Darkness expresses more than obscurity; the former denotes the total privation of light; the latter only the diminution of light. Dark is opposed to light; obscure to bright; what is dark is altogether hidden; what is obscure is not to be seen distinctly or without an effort.

Darkness may be used either in a natural or moral sense; obscurity only in the latter; in which case the former conveys a more unfavorable idea: darkness serves to cover that which ought not to be hidden; obscurity intercepts our view of that which we would wish to see: the former is the consequence of design; the latter of neglect or accident: the letter sent by the conspirator in the gunpowder plot to his friend was dark; all passages in ancient writers which allude to circumstances no longer known must necessarily be obscure; a corner may be said to be dark or obscure, but the former is used literally and the latter figuratively; the owl is obliged from the weakness of its visual organs to seek the darkest corners in the daytime; men of distorted minds often seek obscure corners only from disappointed ambition.

Dim expresses a degree of darkness, but it is employed more in relation to the person seeing than to the object seen. The eyes are said to grow dim, or the sight dim. The light is said to be dim by which things are but dimly seen. Mysterious denotes a species of the dark, in relation to the actions of men; where a veil is intentionally thrown over any object so as to render it as incomprehensible as that which is sacred. Dark is an epithet taken always in the bad sense, but mysterious is always in an indifferent sense. We are told in the Sacred Writings that men love darkness rather than light, because their deeds are evil. Whatever, therefore, is dark in the ways of men is naturally presumed to be evil: but things may be mysterious in the events of human life without the express intention of an individual to render them so. The speeches of an assassin and conspirator will be dark; any intricate affair, which involves the characters and conduct of men may be mysterious. The same distinction exists between these terms whon applied to the ways of Providence, which are said to be sometimes dark, inasmuch as they present a cloudy aspect; and mostly mysterious, inasmuch as they are past finding out. 
DART. See Shoot.

DASH. See SALLY.

DASTARD. See RECREANT.

DATE. See Trme.

DAUB. See SMEAR.

DaUnT. See Dismax; Overawe.

DAY OF REST. See SabBath.

DAZZLING. See Gorgeous.

DEAD. See LiFELESSS.

DEADLy, Mortal, Fatal. Deadly or dead-like signifies like death itself in its effects. Mortal, in Latin mortalis, signifies belonging to death . Fatal, in Latin fatalis, signifies according to fate.

Deadly is applied to what is productive of death; mortal to what terminates in or is liable to death; fatal applies not only to death, but everything which may be of great mischief. A poison is deadly; a wound or a wounded part is mortal; a step in walking, or a step in one's conduct, may be fatal. Things only are deadly; creatures are mortal. Hatred is deadly; whatever has life is mortal. There may be remedies sometimes to counteract that which is deadly; but that which is mortal is past all cure; and that which is fatal cannot be retrieved.

DEAL, Quantity, Portion. Deal, Anglo-Saxon doel, a part, and German theil, from doelen, theilen, etc., to divide, signifies literally the thing divided or taken off. Quantity, in Latin quantitas, comes from quantus, signifying how much. Portion comes from Latin portio, allied to parare, to prepare, signifying a part prepared.

Deal always denotes something great, and cannot be coupled with any epithet that does not express much: quantity is a term of relative import; it either marks indefinitely the how much or so much of a thing, or may be defined by some epithet to express much or little: portion is of itself altogether indefinite, and admits of being qualified by any epithet to express much or little: deal is a term confined to familiar use, and sometimes substituted for quantity, and sometimes for portion. It is common to speak of a deal or a quantity of paper, a great deal or a great quantity of money; likewise of a great deal or a great portion of pleasure, a great deal or a great portion of wealth: and in some cases deal is more usual than either quantity or portion, as a deal of heat, a deal of rain, a deal of frost, a deal of noise, and the like; but it is admissible only in the familiar style.

Portion is employed only for part of that which is detached from the whole; quantity may sometimes be employed for a number of wholes. We may speak of a large or a small quantity of books; a large or a small quantity of plants or herbs; but a large or small portion of food, a large or small portion of color.

Deal, Act, Behave, Trade.-In an extended sense, deal relates to a business transaction, and also implies to behave well or ill, to act or practise, and one's conduct or behavior toward others. In business concerns a deal may be an ordinary buying and selling of a commodity, more generally a bargain resulting from dickering between interested parties, a trade or exchange of one commodity for another, or a transaction more or less discreditable to those engaged in it.

As applied to persons, we have political deals, the trading of supposed or actual influence for votes, the disposition of a public measure according to the wishes of certain interested parties, as opposed to the authors and promoters of the measure, the sidetracking, pigeonholing, or defeat of a legislative bill as payment for services rendered in other directions, and the like. We say deal gently with the erring, meaning to act kindly toward them; that was an unfriendly deal, a questionable, unfortunate, or indiscreet transaction; to deal with, to trade with or be a customer of another: to deal by, to treat well or ill; to deal out, to distribute or give in small quantities, doles; to deal the cards, to give each player the proper number; and a great deal, meaning very much, a large quantity.

DEALING. See Trade.

DEARTH. See ScARCITY.

DEATH, Departure, Decease, Demise, Passing Over. Death signifies the act of dying. Departure signifies the act of departing. Decease, from the Latin de, away, and cedere, to go, signifies the act of going away. Demise, from demittere, to lay down, signifies literally resigning possession. 
Death is a generai or a particular term; it marks, in the abstract sense, the extinction of life, and is applicable to men or animals, to one or many. Departure, decease, and demise are particular expressions suited only to the condition of human beings. We speak of death in reference to what happens before or at the time; we speak of the death of men generally, or of the death of individuals; we speak of the circumstances of death, its causes and effects. Departure is a Christian term which carries with it an idea of a passage from one life to another. Death of itself has always something terrific in it; but the Gospel has divested it of its terrors: the hour of departure, therefore, for a Christian, is often the happiest period of his mortal existence.

Decease presents only the idea of leaving life to the survivors. It is either a technical term in law for death or it is used in common discourse for the falling off from the number of the living. Property is in perpetual occupancy; at the decease of one possessor it passes into the hands of another.

Demise signifies properly a putting off, and in this acceptation the putting off of mortality; it is therefore appropriately used for princes, to denote that they at the same time put off or resign an earthly crown.

As an epithet, dead is used collectively; departed is used with a noun only; deceased, generally without a noun, to denote one or more, according to the connection. There is a respect due to the dead which cannot be violated without offence to the living. It is a pleasant reflection to conceive of $d e$ parted spirits as taking an interest in the concerns of those whom they have left. All the marks on the body of the deceased indicated that he had met with his death by some violence.

Passing over is the term used by Christian Scientists for dying.

DEBAR. See DEPRIVE.

DEBASE. See Abase.

DEBATE, Deliberate. These terms equally mark the acts of pausing or withholding the decision, whether applicable to one or many. To debate (see Argue) supposes always a contrariety of opinion; to deliberate (sce Consult) supposes simply the weigh- ing or estimating the value of the opinion that is offered. Where many persons have the liberty of offering their opinions, it is natural to expect that there will be debating; when any subject offers that is complicated and questionable, it calls for mature deliberation. It is lamentable when passion gets such an ascendancy in the mind of any one as to make him debate which course of conduct he shall pursue between virtue and vice; the want of deliberation, whether in private or public transactions, is a more fruitful source of mischief than almost any other.

DEBAUCH, Seduce, Pollute. These words all indicate the act of enticing or corrupting, or both. $D e-$ bauch comes from French débaucher, to mar, seduce, mislead, probably of Teutonic origin. Seduce comes from Latin se, apart, and ducere, to lead, and means to lead astray, to entice into reprehensible action. Pollute comes from Old Latin por or pol, toward, and luere, to wash, referring to the overflowing of a river; hence it came to mean to defile-as the washing over of the turbid flood destroys the cleanness and beauty of the shores. Debauch is the strongest of these three words and the most specific in its application. It includes the idea of seducing or leading astray and of polluting, and connotes unrestrained sensual indulgence. Debauch has always a moral application; pollute may have either a moral or physical application. Seduce suggests trickery and persuasion in attaining an unhallowed end; debauch suggests violence and moral ruin.

DEBILITATE. See WEAkEN.

DEBILITY, INFIRMITY, IMBECILITY. Debility comes from Latin debilis, weak. Infirmity, in Latin infirmitas, from infirmus, or in, privative, and firmus, strong, signifies the absence of strength. Imbecility comes from Latin imbecilius, weak.

All these terms denote a species of weakness, but the former two, particularly the first, respect that which is either physical or mental. Debility is constitutional or otherwise; imbecility is always constitutional; infirmity is accidental, and results from sickness 
or a decay of the frame. Debility may be either general or local; infirmity is always local; imbecility always general. Debility prevents the active performance of the ordinary functions of nature; it is a deficiency in the muscular power of the body: infirmity is a partial want of power which interferes with, but does not necessarily destroy, the activity: imbecility lies in the whole frame, and renders it almost entirely powerless. Young people are frequently troubled with debilities in their ankles or legs, of which they are never cured. Old age is most exposed to infirmities; but there is no age at which human beings are exempt from infirmity of some kind or another. The imbecility natural to youth, both in body and mind, would make them willing to rest on the strength of their elders if they were not too often misled by a mischievous confidence in their own strength.

DEBT, Due. Debt and due, in French $d \hat{u}$, are both derived from the Latin debere, to owe. Debt is used only as a substantive; due either as a substantive or an adjective. As a substantive, debt is commonly applied to that which is owing from the person spoken of; due is always applied to that which is owing to the person: to pay one's debts, and receive one's due. So in the moral application to pay the debt of nature, that is, what is due or owing to nature; to give every man his due.

DECAY, Decline, Consumption. Decay, in French déchoir, from the Latin decado, signifies literally to fall off or away. Decline, from the Latin declino, or de, away, and clino, a root meaning to lean, signifies to turn away or lean aside. The direction expressed by both these actions is very similar; it is a downward movement, but decay expresses more than decline. What is decayed is fallen or gone; what declines leads toward a fall, or is going; when applied, therefore, to the same objects, a decline is properly the commencement of a decay. The health may experience a decline at any period of life from a variety of causes, but it naturally experiences a decay in old age.

Consumption, in general, implies rapid decay. By decay things lose their perfection, their greatness, and their consistency; by decline they lose their strength, their vigor, and their lustre; by consumption they lose their existence. Decay brings to ruin; decline leads to an end or expiration. There are some things to which decay is peculiar, and some things to which decline is peculiar, and other things to which both decay and decline belong. The corruption to which material substances are particularly exposed is termed decay: the close of life, when health and strength begin to fall away, is termed the decline: the decay of states in the moral world takes place by the same process as the decay of fabrics in the natural world; the decline of empires, from their state of elevation and splendor, is a natural figure drawn from the decline of the setting sun. Consumption is seldom applied to anything but animal bodies except figuratively.

See also Degenerate; Perish.

DECEASE. See DEATH.

DECEIT, DECEPTION. Deceit and deception are both associated with the verb deceive, from, decipere, to take away, and both imply the act of deceiving; with this difference, that the deceit is practised frrm an expressly bad motive, but deception may be from either bad or indifferent motives. A person is therefore said to be guilty of déceit who has sought to deceiveanother for his own purposes; but deceptions may be practised in a diversity of ways, and from a diversity of motives.

Deceit is always a personal act, and if there be an habitual propensity to deceiving, the deceit is then a characteristic of the person; a deceiver is full of deceit. Deception frequently denotes the state of being deceived; it is the effect of any agency, whether from accident or from design. Deceit is applied to cases where the understanding is intentionally deceived; but there may be a deception on the senses as well as on the understanding.

Deceitful and deceptive are employed with this distinction: a person is said to be deceitful, and a thing deceptive. See also SopHIsTrY.

Deceit, Duplicity, Double-dealing.Deceit (see above). Duplicity signifies 
doubleness in dealing, the same as double-dealing. The former two may be applied either to habitual or particular actions, the latter only to particular actions. There may be much deceit or duplicity in a person's character or in his proceedings; there is double-dealing only where dealing goes forward. The deceit may be more or less veiled; the duplicity lies very deep, and is always studied whenever it is put into practice. Duplicity, in reference to actions, is mostly employed for a course of conduct; double-dealing is but another term for duplicity on particular occasions. Children of reserved characters are frequently prone to deceit, which grows into consummate duplicity in riper years: the wealthy are often exposed to much duplicity when they choose their favorites among the low and ignorant.

Deceit, Fraud, Guile.-Deceit is allied to fraud in reference to actions; to guile in reference to the character.

Deceit is here, as in the preceding article, indeterminate when compared with fraud, which is a specific mode of deceiving; deceit is practised only in private transactions; fraud is practised toward bodies as well as individuals, in public as well as private: a child practises deceit toward its parents; frauds are practised upon government, on the public at large, or on tradesmen: deceit involves the violation of moral law, fraud that of the criminal law. A servant may deceive his master as to the time of his coming or going, but he defrauds him of his property if he obtains it by any false means.

Deceit as a characteristic is indefinite in magnitude; guile marks a strong degree of moral turpitude in the individual. The former is displayed in petty concerns; the latter, which contaminates the whole character, displays itself in inextricable windings and turnings that are suggested in a peculiar manner by the author of all evil. Deceitful is an epithet commonly and lightly applied to persons in general; but guileless is applied to characters which are the most diametrically opposed to, and at the greatest possible distance from, that which is false.

See also ART.

DECEITFUL. See Fallacious.
DECEIVe, Delude, Impose Upon. Deceive, in French décevoir, Latin decipere, compounded of de, privative, and capere, to take, signifies to take wrong. Delude, in Latin deludo, compounded of $d e$ and ludere, signifies to play upon or to mislead by a trick. Impose comes from Latin in, on, and French poser, from Latin pausare.

Falsehood is the leading feature in all these terms; they vary, however, in the circumstances of the action. To deceive is the most general of the three; it signifies simply to produce a false conviction; the other terms are properly species of deceiving, including accessory ideas. Deception may be practised in various degrees; deluding is always something positive, and considerable in degree. Every false impression produced by external objects, whether in trifles or important matters, is a deception; but delusion is confined to errors in matters of opinion. We may be deceived in the color or the distance of an object: we are deluded in what regards our principles or moral conduct.

A deception does not always suppose a fault on the part of the person deceived, but a delusion does. A person is sometimes deceived in cases where deception is unavoidable; he is deluded through a voluntary blindness of the understanding: artful people are sometimes capable of deceiving so as not even to excite suspicion; their plausible tales justify the credit that is given to them: when the ignorant enter into nice questions of politics or religion, it is their ordinary fate to be deluded.

Deception is practised by an individual on himself or others; a delusion is commonly practised on one's self; an imposition is always practised on another. Men deceive others from a variety of motives; they always $\mathrm{im}$ pose upon them for purposes of gain or the gratification of ambition. Men deceive themselves with false pretexts and false confidence; they delude themselves with vain hopes and wishes.

Deceiver, Impostor. - Between the words deceiver and impostor there is a similar distinction. A deceiver is any one who practises any sort of deception; but an impostor is a deceiver who 
studiously deceives by putting on a false appearance. The deceiver practises deception on individuals or the public; the impostor most commonly on the public at large. The false friend and the faithless lover are deceivers; the assumed nobleman who practises frauds under his disguise, and the pretended prince who lays claim to a crown to which he was never born, are impostors.

DECENCY, Decorom. Though decency and decorum are both derived from the same word (see Becoming), they have acquired a distinction in their sense and application. Decency respects a man's conduct; decorum his behavior: a person conducts himself with decency: he behaves with decorum. Indecency is a vice; it is the violation of public or private morals: indecorum is a fault; it offends the feelings of those who witness it. Nothing but a depraved mind can lead to indecent practices; indiscretion and thoughtlessness may sometimes give rise to that which is indecorous. Decency enjoins upon all relatives, according to the proximity of their relationship, to show certain marks of respect to the memory of the dead: regard for the feelings of others enjoins a certain outward decorum upon every one who attends a funeral.

DECENT. See Becoming.

DECEPTION. See Deceit.

DECide, Determine, Conclude. Decide, from the Latin decido, compounded of de, from, and caedere, to cut, signifies to cut off or cut short a business. For the derivation of determine see Arbitrate. Conclude (see Close).

The idea of bringing a thing to an end is common in the signification of all these words; but to decide expresses more promptitude than to determine: we may decide instantaneously, but we must take more or less time to determine; we may decide any single point either by an act of external force or by a sudden act of the mind; but, in determining any question, its extent, limits, and every circumstance must be taken into consideration; determining is therefore an act of deliberation. To decide is an act of greater authority: a parent decides for a child, but subordinates sometimes determine in the absence of their employers. Points of law are decided by the judge, points of fact are determined by the jury. To decide is therefore properly applied to all matters of dispute where more or less power or force is required to bring it to an end; to determine, to all matters of conduct which may more easily be brought to an end.

To determine and decide are applied to practical matters; to conclude to speculative as well as practical matters, as to decide the fate of persons, to determine anything that interests one, to conclude that a thing is right or wrong, just or unjust, and the like.

In respect to practical matters, to determine is either said of that which is subordinate or it is a partial act of the mind; to conclude is said of the grand result; it is a complete act of the mind. Many things may be determined on which are either never put into execution or remain long unexecuted; but that which is concluded on is mostly followed by immediate action. To conclude is properly to come to a final determination.

Decided, Determined, Resolute.-A man who is decided remains in no doubt: he who is determined is uninfluenced by the doubts or questions of others: he who is resolute (see DETERMINED) is uninfluenced by the consequences of his actions. A decided character is at all times essential for a prince or a minister, but particularly so in an unsettled period; a determined character is essential for a commander or any one who has to exercise authority; a resolute character is essential for one who is engaged in dangerous enterprises. Pericles was a man of a decided temper, which was well fitted to direct the affairs of government in a season of turbulence and disquietude: Titus Manlius Torquatus displayed himself to be a man of a determined character when he put to death his victorious son for a breach of military discipline. Brutus, the murderer of Cæsar, was a man of a resolute temper.

Decided, Decisive. - Decided marks that which is actually decided: decisive, that which appertains to decision. 
Decided is employed for persons or things; decisive only for things. A person's aversion or attachment is decided; a sentence, a judgment, or a victory is decisive. A man of a decided character always adopts decisive measures. It is right to be decidedly averse to everything which is immoral: we should be cautious not to pronounce decisively on any point where we are not perfectly clear and well grounded in our opinion. In every popular commotion it is the duty of a good subject to take a decided part in favor of law and order: such is the nature of law that if it were not decisive it would be of no value.

Decision; Judgment, Sentence.-Decision signifies literally the act of deciding, or the thing decided upon. Judgment signifies the act of judging or determining in general. Sentence, in Latin sententia, from sentire, to think, signifies the opinion held or maintained.

These terms, though very different in their original meaning, are now employed so that the two latter are species of the former: a final conclusion of any business is comprehended in them all; but decision conveys none of the collateral ideas which are expressed by judgment and sentence: a decision has no respect to the agent; it may be said of one or many; it may be the decision of the court, of the nation, of the public, of a particular body of men, or of a private individual; but a judgment is given in a public court or among private individuals: a sentence is passed in a court of law or at the bar of the public. A decision specifies none of the circumstances of the action: it may be a legal or an arbitrary decision; it may be a decision according to one's caprice or after mature deliberation: a judgment is always passed either in a court of law, and consequently by virtue of authority, or it is passed by an individual by the authority of his own judgment: a sentence is passed either by the authority of law or at the discretion of an individual or of the public.

A decision is given; it is that which decides, and, by putting an end to all dispute and doubt, enables a person to act. A judoment is formed; it re- spects the guilt or innocence, the moral excellence or defects, of a person or thing; it enables a person to think. A sentence is pronounced or passed; it respects all matters generally, and determines what are the sentiments of those by whom it is pronounced. Some points are of so complicated a nature that no decision can be given upon them; some are of so high a nature that they can be decided only by the highest authority; men are forbidden by the Christian religion to be severe in their judgments upon one another; the works of an author must sometimes await the sentence of impartial posterity before their value can be duly appreciated.

DECISIVE. See Conclusive; DECIDED.

DECLAIM, INveigh. Declaim, in Latin declamo, that is, de and clamo, signifies literally to cry aloud in a set form of words. Inveigh (see ABUSE; INVECTIVE).

The sense in which these words agree is that of using the language of displeasure against any person or thing: declaim is used generally, inveigh particularly: public men and public measures are subjects for the declaimer; private individuals afford subjects for inveighing against: the former is under the influence of particular opinions or prejudices; the latter is the fruit of personal resentment or displeasure: politicians declaim against the conduct of those in power or the state of the nation; they inveigh against individuals who have offended them. A declaimer is noisy; he is a man of words; he makes long and loud speeches: an inveigher is virulent and personal; he enters into private details, and often indulges his malignant feelings under an affected regard for morality.

DEClare, Publish, Proclaim. Declare, in Latin declaro, compounded of de and clarus, clear, signifies literally to make clear or show plainly to a person. Publish (see ANwounce). Proclaim, in Latin proclamo, compounded of pro and clamo, signifies to cry before or in the ears of others.

The idea of making known is common to all these terms: this is simply the signification of dcclare, but the other two include accessory ideas. The word declare does not express any 
particular mode or circumstance of making known, as is implied by the others: we may declare publicly or privately; we publish and proclaim only in a public manner: we may declare by word of mouth or by writing; we publish or proclaim by any means that will render the thing most generally known. In declaring, the leading idea is that of speaking out that which passes in the mind; in publishing, the leading idea is that of making public or common; in proclaiming, the leading idea is that of crying aloud; we may, therefore, often declare by publishing and proclaiming: a declaration is a personal act; it concerns the person declaring, or him to whom it is declared; its truth or falsehood depends upon the veracity of the speaker: a publication is of general interest; the truth or falsehood of it does not always rest with the publisher: a proclamation is altogether a public act, in which no one's veracity is implicated. Facts and opinions are declared; events and circumstances are published; the measures of government are proclaimed: it is folly for a man to declare anything to be true which he is not certain to be so, and wickedness in him to declare that to be true which he knows to be false: whoever publishes all he hears will be in great danger of publishing many falsehoods; whatever is proclaimed is supposed to be of sufficient importance to deserve the notice of all who may hear or read.

A declaration is always a personal act, whether relating to public or private matters: a publication and a proclamation may be both indirect actions made by any channel the fittest to make a wide communication. In cases of war or peace, princes are expected to declare themselves on one side or the other; in the political world intelligence is quickly published through the medium of the public papers; in private life domestic occurrences are published with equal celerity through the medium of tale-bearers; proclaiming is not confined to political matters: whatever is made known after the manner of a proclamation is said to be proclaimed: joyful news is proclaimed, and where private matters which ought not to be known are published to the world peo- ple are said to proclaim their own shame.

See also Discover; Express; ProFESS.

DECLINE. See Decay; DegenerATE; REFUSE.

DECORATE. See Adorn; GarNISH.

DECORATED. See Ornate.

DECORUM. See Decency; ETIQUETTE.

DECOY. See Allure; Tweedle.

DECREASE. See Abate.

DECREe, Edict, Proclamation. Decree, in French décret, Latin decretus, from decernere, to give judgment or pass sentence, signifies the sentence or resolution that is passed. Edict, in Latin edictus, from edico, to say out, signifies the thing spoken out or sent forth. Proclamation (see DEclare).

A decree is a more solemn and deliberative act than an edict; on the other hand, an edict is more authoritative than a decree. A decree is the decision of one or many; an edict speaks the will of an individual: councils and senates, as well as princes, make decrees; despotic rulers issue edicts. Decrees are passed for the regulation of public and private matters; they are made known as occasion requires, but are not always public; edicts and proclamations contain the commands of the sovereign authority, and are directly addressed by the prince to his people. An edict is peculiar to a despotic government; a proclamation is common to a monarchical and aristocratic form of government: the ukase in Russia was a species of edict, by which the emperor made known his will to his people; the king of England communicates to his subjects the determinations of himself and his council by means of a proclamation.

The term decree is applied figuratively; the other terms are used, for the most part, in their proper sense only. See also OrdinaNCE.

DECRY. See Disparage.

DEDICATE, Devote, Consecrate, Hallow. Dedicate, in Latin dedicatus, participle from de and dicare, signifies to set apart by a promise. Devote, in Latin devotus, participle from devoveo, signifies to vow for an express purpose. Consecrate, in Latin consecratus, from 
consecro, or con and sacrare, signifies to make sacred by a special act. Hallow, from Anglo-Saxon halig, holy, signifies to make holy.

There is something more solemn in the act of dedicating than in that of devoting; but less so than in that of consecrating. To dedicate and devote may be employed in both temporal and spiritual matters; to consecrate and hallow only in the spiritual sense: we may dedicate or devote anything that is at our disposal to the service of some object; but the former is employed mostly in regard to superiors, and the latter to persons without distinction of rank: we dedicate a house to the service of God; or we devote our time to the benefit of our friends or the relief of the poor: we may dedicate or devote ourselves to an object; but the former always implies a solemn setting apart springing from a sense of duty; the latter an entire application of one's self from zeal and affection; in this manner he who dedicates himself to God abstracts himself from every object which is not immediately connected with the service of God; he who devotes himself to the ministry pursues it as the first object of his attention and regard. To consecrate is a species of formal dedication by virtue of a religious observance; it is applicable mostly to places and things connected with religious works: hallow is a species of informal consecration applied to the same objects: the church is consecrated; particular days are hallowed.

DEDUCE. Sce DERIVE.

DEDUCT, SuBTraCT. Deduct, from the Latin deductus, participle of deducere, to lead away, and subtract, from subtractum, participle of subtrahere, to draw away, have both the sense of taking from, but the former is used in a general, and the latter in a technical sense. He who makes an estimate is obliged to deduct; he who makes a calculation is obliged to subtract. The tradesman deducts what has been paid from what remains due; the accountant subtracts small sums from the gross amount.

Deduction, Abatement. - Both these words imply a taking off from something, but the deduction is made at the discretion of the person deducting; while the abatement is made for the convenience or at the desire of the person for whom it is made. A person may make a deduction in an account for various reasons, but he makes an abatement in a demand when it is objected to as excessive; so an abatement may be made in a calculation when it is supposed to be higher than it ought to be.

\section{See also Conclusion.}

DEED, EXploit, ACHIEvement, Feat. Deed, allied to do, expresses the thing done. Exploit, in French exploit, was most probably changed from explicatus, signifying the thing unfolded or displayed. Achievement comes from French à chef, to a head, meaning something brought to a head or finished. Feat, in French fait, Latin factum, from facio, signifies the thing done.

The first three words rise progressively on one another: deeds, compared with the others, is employed for that which is ordinary or extraordinary; $e x-$ ploit and achievement are used only for the extraordinary; the latter in a higher sense than the former. Deeds must always be characterized as good or bad, magnanimous or atrocious, and the like, except in poetry, when the term becomes elevated.

Exploit and achievement do not necessarily require such epithets; they are always taken in the proper sense for something great. Exploit, when compared with achievement, is a term used in plain prose; it designates not so much what is great as what is real: achievement is most adapted to poctry and romance; an exploit is properly a single act, and refers to the cfforts of the individual performing it; an achievement may involve many acts and circumstances; in the execution it refers us to the point gained, as also to the difficulties of gaining it. An exploit marks only personal bravery in action; an achievement denotes elevation of character in every respect, grandeur of design, promptitude in exceution, and valor in action. An exploit may be executed by the design and at the will of another; a common soldier or an army may perform exploits. An achievement is designed and executed by the achiever: Hercules is distin- 
guished for his achievements; and in the same manner we speak of the achievements of knights-errant or of great commanders.

Feat approaches nearest to exploit in signification; the former marks skill, and the latter resolution. The feats of chivalry displayed in jousts and tournaments were in former times as much esteemed as warlike exploits.

Exploit and feat are often used in derision, to mark the absence of skill or bravery in the actions of individuals. The soldier who affects to be foremost in situations where there is no danger cannot be more properly derided than by terming his action an exploit; he who prides himself on the display of skill in the performance of a paltry trick may be laughed at for having performed a feat. The same words may also be applied in an indifferent sense to familiar objects, as the exploits of a freebooter, or feats of horsemanship.

See also ACT.

DEEM. See Think.

DEFACE, Disfigure, Deform. Deface, disfigure, and deform signify literally to spoil the face, figure, and form. Deface expresses more than either deform or disfigure. To deface is an act of destruction; it is the actual destruction of that which has before existed: to disfigure is either an act of destruction or an erroneous execution, which takes away the figure: to $d s$ form is altogether an imperfect execution, which renders the form what it should not be. A thing is defaced by design; it is disfigured either by design or accident; it is deformed either by an error or by the nature of the thing. Persons only deface; persons or things disfigure; things are most commonly deformed of themselves. That may be defaced, the face or external surface of which may be injured or destroyed; that may be disfigured or deformed, the figure or form of which is imperfect or may be rendered imperfect. A fine painting or piece of writing is defaced which is torn or besmeared with dirt: a fine building is disfigured by any want of symmetry in its parts: a building is deformed that is made contrary to all form. A statue may be defaced, disfigured, and deformed: it is defaced when any violence is done to the face or any outward part of the body; it is disfigured by the loss of a limb; it is deformed if made contrary to the perfect form of the person or thing to be represented. Inanimate objects are mostly defaced or disfigured, but seldom deformed; animate objects are either disfigured or deformed, but seldomer defaced. A person may disfigure himself by his dress; he is deformed by the hand of nature.

DEFAME. See Asperse.

DEFEAT, Foil, Disappoint, Frustrate. Defeat (see Beat). Foil comes from Late Latin fullare, to full cloth, a method of cleaning. It originally meant to trample on, then to defeat by less obvious physical action. Frustrate, in Latin frustratus, from frustra, vain, signifies to make vain. Disappoint, from the privative dis and the verb appoint, signifies literally to do away with what has been appointed.

Defeat and foil are both applied to matters of enterprise; but that may be defeated which is only planned, and that is foiled which is in the act of being executed. What is rejected is defeated: what is aimed at or purposed is frustrated: what is calculated on is disappointed. The best concerted schemes may sometimes be easily defeated: where art is employed against simplicity, the latter may be easily foiled: when we aim at what is above our reach, we must be frustrated in our endeavors: when our expectations are extravagant, it seems to follow, of course, that they will be disappointed. Design or accident may tend to defeat, design only to foil, accident only to frustrate or disappoint. The superior force of the enemy, or a combination of untoward events which are above the control of the commander, will serve to defeat the best concerted plans of the best generals: men of upright minds can seldom foil the deep-laid schemes of knaves: when we see the perversity of men is liable to frustrate the kind intentions of others in their behalf, it is wiser to leave them to their folly: the cross accidents of human life are a fruitful source of disappointment to those who suffer themselves to be affected by them.

See also BAFFLE. 
DEFECT. See Blemish; ImperFECTION.

DEFECTION, Revolt. Defection, from the Latin de, negative, and facere, to do, signifies literally an undoing. Revolt comes from French re and the verb volvere, to roll, meaning to roll back, to overturn, to turn against.

Defection is a general, revolt a specific term, that is, it denotes a speeies of defection. Defection is applicable to any person or thing to which we are bound by any obligation; revolt is applicable only to the government to which one is bound. There may be a defection from religion, or any cause that is held sacred: a revolt is only against a monarch or the supreme authority.

Defection does not designate the mode of the action; it may be quietly made or otherwise: a revolt is an act of violence, and always attended with violence. The defection may be the act of one; a revolt is properly the act of many. A general may be guilty of a defection who leaves the party to which he has hitherto adhered; a nation or a community may commit an act of revolt by shaking off the authority under which they have lived. A defection, being mostly the act of an individual, or one part of a community against the whole, is mostly a culpable act; but a revolt may be a justifiable measure when one nation revolts against another, under whose power it has been brought by force of arms: the Roman people were guilty of a defection when they left the senate and retired to Mount Aventine; the Germans frequently attempted to recover their liberty by revolting against the Romans.

DEFECTIVE, Deficient. Defective expresses the quality or property of having a defect (see BLEMISH); deficient is employed with regard to the thing itself that is wanting. A book may be defective in consequence of some leaves being deficient; a child may de defective because of some mental deficiency. A deficiency is therefore often what constitutes a defect. Many things, however, may be defective without having any deficiency, and vice versâ. Whatever is misshapen, and fails either in beauty or utility, is defective; that which is wanted to make a thing complete is deficient. It is a defect in the eye when it is so constructed that things are not seen at their proper distances; there is a deficiency in a tradesman's accounts when one side falls short of the other. That which is defective is most likely to be permanent; but a deficiency may be only occasional and easily rectified.

DEFEND, Protect, Vindicate. Defend (see Apologize). Protect, in Latin protectum, participle of protegere, compounded of pro, bcfore, and tegere, to cover, signifies to put anything before a person as a covering. Vindicate (See ASSERT).

Defend is a general term; it defines nothing with regard to the degree and manner of the action: protect is a particular and positive term, expressing an action of some considerable importance. Persons may defend others without distinction of rank or station: none but superiors or persons having power can protect others. Defence is an occasional action; protection is a permanent action. A person may be defended in any particular case of actual danger or difficulty; he is protected from what may happen as well as what does happen. Defence respects the evil that threatens; protection involves the supply of necessities and the affording comforts.

Defence requires some active exertion either of body or mind; protection may consist only of the extension of power in behalf of any particular individual. A defence is successful or unsuccessful; a protection, weak or strong. A soldier defends his country; a counsellor defends his client; a prince protects his subjects.

In a figurative and extended sense things may either defend or protect with a similar distinction: a coat defends us from the inclemencies of the weather; houses are a protection not only against the changes of the seasons, but also against the violence of men.

To vindicate is a species of defence only in the moral sense of the word. Acts of importance are defended: those of trifling import are commonly vindicated. Cicero defended Milo against the charge of murder, in which he was implicated by the death of Clodius; a 
child or a servant vindicates himself when any blame is attached to him. Defence is employed either in matters of opinion or conduct; vindicate only in matters of conduct. Some opinions are too absurd to be openly defended; he who vindicates the conduct of another should be fully satisfied of the innocence of the person whom he defends.

See also Espouse; Garnish; GUard.

Defendant, Defender. - The defendant defends himself; the defender defends another. We are defendants when any charge is brought against us which we wish to refute: we are defenders when we undertake to rebut or refute the charge brought against any person or thing.

Defender, Advocate, Pleader.-A defender exerts himself in favor of one who wants support: an advocate, from the Latin $a d$, to, and vocare, to call, signifies one who is called to speak in favor of another; he exerts himself in favor of any cause that offers: a pleader, from plea or excuse, signifies him who pleads in behalf of one who is accused or in distress. A defender attempts to keep off a threatened injury by rebutting the attack of another: an advocate states that which is to the advantage of the person or thing advocated; a pleader throws in pleas and extenuations; he blends entreaty with argument. Oppressed or accused persons and disputed opinions require defenders; that which falls in with the humors of men will always have advocates; the unfortunate and the guilty require pleaders.

An official, known as the public defender, has been appointed recently in a number of cities in the United States, to defend in courts persons unable to pay lawyers' fees.

The term pleader is used sometimes like that of defender, in the general sense. Valeria and Volumnia, the mother and wife of Coriolanus, were powerful and successful pleaders in behalf of the Roman republic.

Defensible, Defensive.-Defensible is employed for the thing that is to be defended; defensive, for the thing that defends. An opinion or a line of conduct is defensible; a weapon or a military operation is defensive. The defensible is opposed to the indefensible; and the defensive to the offensive. It is the height of folly to attempt to defend that which is indefensible; it is sometimes prudent to act on the defensive when we are not in a condition to commence the offensive.

DEFER. See Delay.

DEFERENCE. See SANCE.

DEFICIENT. See Defective; FaIL. DEFILE. See Contaminate.

DEFINITE, Positive. Definite, in Latin definitum, participle of definire, compounded of de and finis, signifies that which is bounded by a line or limit. Positive, in Latin positivus, from ponere, to place, signifies that which is placed or fixed.

Definite signifies that which is defined, or has the limits drawn or marked out; positive that which is placed or fixed in a particular manner: definite is said of things as they present themselves or are presented to the mind, as a definite idea, a definite proposal; positive is said of a person's temper of mind; a person is positive as to his opinions, or an assurance is positive which serves to make one positive. In respect to a man's self, his views ought to be definite to prevent him from being misled, but he ought not to be positive in matters that admit of doubt. In respect to others, the more definite the instructions which are given the less danger there is of mistake; the more positive the information communicated the greater the reliance which is placed upon it.

DEFINITION, Explanation. A definition is properly a species of explanation. The former is used scientifically, the latter on ordinary occasions; the former is confined to words, the latter is employed for words or things. A definition is correct or precise; an explanation is general or ample. The definition of a word defines or limits the extent of its signification; it is the rule for the scholar in the use of any word: the explanation of a word may include both definition and illustration: the former admits of no more words than will include the leading features in the meaning of any term; the latter admits of an unlimited scope for diffuseness on the part of the explainer. 
DEFLECT, BEND, D I VERGE, Swerve. Deflect is the Latin term; bend, the Anglo-Saxon word. Bend, Anglo-Saxon bendan, allied to band, bind, etc., means to curve as a bow is curved when the string is fastened. Deflect, from de, from, and flectere, to bend, means to bend from the straight course, especially to turn to one side. Diverge, from Latin dis, apart, and vergere, to bend, is the intransitive corresponding to the transitive deflect. We deflect another's course; we diverge from that which we have marked out for ourselves. Bend is a more general word than deflect or diverge. It indicates the physical act of bending, and suggests any kind of departure from the condition of straightness. Deflect suggests a turning from a straight line contrary to all apparent intention or purpose. Swerve, Anglo-Saxon sweorfan, suggests a very sudden turning, a jerky and unpremeditated movement, emphasizing the idea of action contrary to apparent purpose, barely suggested in deflect. All these words may be used either with the physical or with a moral application.

DEFORM. See DeFACE.

DEFORMED. See WRY.

DEFRAUD. See Cheat.

DEFY. See Brave.

DEGENERATE, Deteriorate. Degenerate signifies to fall from race or kind, to lose ancestral quality, from Latin degenerare, compounded of $d e$, from, and the stem of genus, race. Deteriorate comes from Latin deteriorare, to grow worse, from the comparative of an obsolete adjective connected with de, down. Both these words mean to grow worse, but degenerate adds to the idea contained in deteriorate a definite indication that the deterioration is a departure from the standard of the individual's race or natural endowment. It is therefore more specific in its implications.

DEGRADE. See ABase; DisParage; Humble.

DEGREE. See Class.

DEITY, Divinity. Deity, from deus, a god, signifies a divine person. Divinity, from divinus, signifies the divine essence or power; the deities of the heathens had little of divinity in them; the divinity of our Saviour is a fundamental article in the Christian faith.

DEJECTION, Depression, MeLANCHOLY. Dejection, from dejicere, to cast down, and depression, from deprimere, to press or sink down, have both regard to the state of the animal spirits. Melancholy, from the Greek $\mu \varepsilon \lambda a \gamma \times o \lambda i a$, black bile, originally referred to the state of the humors in general, or of the particular humor called the bile.

Dejection and depression are occasional, and depend on outward circumstances; melancholy is permanent, and lies in the constitution. Depression is but a degree of dejection: slight circumstances may occasion a depression; distressing events occasion a dejection: the death of a near and dear relative may be expected to produce dejection in persons of the greatest equanimity; lively tempers are most liable to depressions; melancholy is a disease which nothing but clear views of religion can possibly correct.

Delay, Defer, Postpone, Procrastinate, Prolong, Protract, ReTARD. Delay, compounded of de and lay, signifies to lay or keep back. Defer, compounded of de and ferre, to bring, signifies to put off. Postpone, compounded of post and the Latin ponere, to place, signifies to place behind or after. Procrastinate, from pro, for, and cras, to-morrow, signifies to put off until to-morrow. Prolong signifies to lengthen out the time, and protract to draw out the time. Retard, from re, intensive, and tardum, slow, to make a thing go slowly.

To delay is simply not to commence action; to defer and postpone are to fix its commencement at a more distant period: we may delay a thing for days, hours, and minutes; we defer or postpone it for months or weeks. Delays mostly arise from the fault of the person delaying; they are seldom reasonable or advantageous: deferring and postponing are discretionary acts, which are justified by the circumstances; indolent people are most prone to delay; when a plan is not maturely digested, it is prudent to defer its execution until everything is in an entire state of preparation. Procrastination is a culpable delay arising solely from 
the fault of the procrastinator: it is the part of a dilatory man to procrastinate that which it is both his interest and duty to perform.

We delay the execution of a thing; we prolong or protract the continuation of a thing; we retard the termination of a thing: we may delay answering a letter, prolong a contest, protract a lawsuit, and retard a publication.

Delay, Laches, Moratorium.-Laches and moratorium are two special applications of the idea of delay. They are not synonymous with each other at all, but they are connected through the general idea expressed in the key-word. Laches is a legal term (from Latin laxus, loose), signifying inexcusable delay in meeting the terms of a contract, or taking up and paying a promissory note. Moratorium, on the other hand, signifies a delay granted by a government, corporation, or other large body to persons to delay making payment of their obligations beyond the time of their maturity.

Delegate, Depute; Delegate, Depoty. Delegate, in Latin delegatus, from delegare, signifies to send on a mission; depute comes from deputare, to assign a business to. To delegate is applied to the power or office which is given; depute to the person employed. Parents delegate their office to the instructor; persons are deputed to act for others.

As nouns, delegate and deputy are applied only to persons. The delegate is the person commissioned, who is bound to act according to his commission; the deputy is the person deputed, who acts in the place of another, but may act according to his own discretion or otherwise, as circumstances require. A delegate is mostly chosen in public matters and on particular occasions: as delegates sent from a besieged town to the camp of the besiegers; deputies are those who are deputed to act officially and regularly for others, as deputies sent to any public assembly.

DELIBERATE. See Consent; Debate; Thoughtful.

DELICACY. See DAINTY.

DELICATE. See Fine.

DELight. See Pleasure.

DELIGHTFUL, Charming. lightful is applied either to material or spiritual objects; charming, mostly to objects of sense. When they both denote the pleasure of the sense, delightful is not so strong an expression as charming: but the latter rises to a degree that carries the senses away captive. Of music we should rather say that it was charming than delightful, as it acts on the senses in so powerful a manner; on the other hand, we should with more propriety speak of a delightful employment to relieve distress, or a delightful spectacle to see a family living together in love and harmony.

DELINEATE, Sкetch. Delineate, in Latin delineatus, participle of delineare, from de, down, and linea, line, means literally to put down lines on paper. Sketch, Dutch and Italian schizzo, a first rough draft, comes from Latin schedium, a thing made hastily, from Greek $\sigma \chi^{\varepsilon} \delta \iota \sigma^{\prime}$, hastily.

Both these terms are properly employed in the art of drawing, and figuratively applied to moral subjects to express a species of descriptions: a delineation expresses something more than a sketch; the former conveying not merely the general outlines or more prominent features, but also as much of the details as would serve to form a whole; the latter, however, seldom contains more than some broad touches by which an imperfect idea of the subject is conveyed. A delineation, therefore, may be charactérized as accurate, and a sketch as hasty or imperfect: an attentive observer who has passed some years in a country may be enabled to give an accurate delineation of the laws, customs, manners, and character of its inhabitants; a traveller who merely passes through can give only a hasty sketch from what passes before his eyes.

DELINQUENT. See OFFENDER.

DELIVER, Rescue, Save. Deliver, in French délivrer, from the Latin de, and liberare, from liber, free, signifies to make free. Rescue comes from Late Latin rescutere, from re, again, and excutere, to drive. Save signifies literally to make safe, from Latin salvus, safe.

The idea of taking or keeping from De- any evil is common to these terms; but 
to deliver and rescue signify most properly to take, and save to keep from evil. To deliver is a general term, not defining either the mode or object of the action. One may be delivered from any evil, whether great or small, and in any manner: to rescue is to deliver from a great impending danger or immediate evil; as to rescue from the hands of robbers or from the jaws of a wild beast.

One is delivered mostly by some active effort; but we may be saved either by active or passive means. A person is delivered from the hands of an enemy by force or stratagem: he saves his life by flying.

See also Fill; Give Up.

Deliverance, Delivery.-Both words are drawn from the same verb (see above) to express its different senses of taking from or giving to: the former denotes the taking something from one's self; the latter implies giving something to another. To wish for a deliverance from that which is hurtful or painful is to a certain extent justifiable: the careful delivery of property into the hands of the owner will be the first object of concern with a faithful agent.

See also Salvation.

DELUDE. See Deceive.

DELUGE. See Overflow.

DELUSION, Illusion. Both these words, being derived from the Latin ludere, to play, are applied to such matters as act upon the imagination; but delude, by the force of the preposition de, signifies to carry away from the right line, to cause to deviate into error; while illude, from the preposition $i l$, im, in or upon, signifies simply to act on the imagination. The former is therefore taken in a bad sense, but the latter in an indifferent sense. A deranged person falls into different kinds of delusions: as when he fancies himself poor while he is very rich, or that every one who comes in his way is looking at him, or having evil designs against him, and the like; but there may be optical illusions, when an object is made to appear brighter or larger than it really is.

See also Fallacy; Halldcination.

DEMAND, Require. Demand (see Ask). Require, in Latin requiro, compounded of $r e$, again, and quarere, to seek, signifies to seek for or to seek to get back.

We demand that which is owing and ought to be given; we require that which we wish and expect to have done. A demand is more positive than a requisition; the former properly admits of no question; the latter is liable to be both questioned and refused: the creditor makes a demand on the debtor; the master requires a certain portion of duty from his servant: it is unjust to demand of a person what he has no right to give; it is unreasonable to require of him what it is not in his power to do. A thing is commonly demanded in express words; it is required by implication: a person demands admittance when it is not voluntarily granted; he requires respectful deportment from those who are subordinate to him.

In the figurative application the same sense is preserved: things of urgency and moment demand immediate attention; difficult matters require a steady attention.

See also Ask.

DEMEANOR. See BeHAVIOR.

\section{DEMISE. See DeatrH.}

DEMOLISH, Raze, Dismantle, Destroy. The throwing down what has been built up is the common idea included in all these terms. Demolish, from the Latin demolior, and moles, a mass or structure, signifies to decompound what has been fabricated into a mass. Raze, like erase (see Blot), signifies the making smooth or even with the ground. Dismantle, in French démanteler, signifies to deprive a thing of its mantle or guard. Destroy, from the Latin destruo, compounded of the privative de and struo, to build, signifies properly to pull down.

A fabric is demolished by scattering all its component parts; it is mostly an unlicensed act of caprice; it is razed by way of punishment, as a mark of public vengeance; a fortress is dismantled from motives of prudence, in order to render it defenceless; places are destroyed by various means and from various motives, that they may not exist any longer. Individuals may demolish; public authority causes an edifice to be razed with the ground; a general orders towers to be dismantled and fortifications to be destroyed. 
DEMON. See Devil.

DEMONSTRATE. See Prove.

DEMONSTRATIVE. See CateGORICAL.

DEMUR, Hesitate, Pause. Demur, in French demeurer, Latin demorari, signifies to keep back. Hesitate, in Latin hasitatum, participle of hoesito, a frequentative from horeo, signifies to stick or remain a long time back. Pause, in Latin pausa, from the Greek $\pi a v i \omega$, cease, signifies to make a stand.

The idea of stopping is common to these terms, to which signification is added some distinct collateral idea for each: we demur from doubt or difficulty; we hesitate from an undecided state of mind; we pause from circumstances. Demurring is a matter of prudence, it is always grounded on some reason; hesitating is rather a matter of feeling and is oftener faulty than otherwise: when a proposition appears to be unjust, we demur in supporting it, on the ground of its injustice; when a request of a dubious nature is made to us, we hesitate in complying with it: prudent people are most apt to demur; but people of a wavering temper are apt to hesitate: demurring may be often unnecessary, but it is seldom injurious; hesitating is mostly injurious when it is not necessary. Demurring and hesitating are both employed as acts of the mind; pausing is an external action: we demur and hesitate in determining; we pause in speaking or doing anything.

Demur, Doubt, Hesitation, Objection. - Demur (see above). Doubt, in Latin dubito, from duo, two, and itus, past participle of ire, to go, signifies to go two ways. Hesitation (see above). Objection, from objicio, or $o b$, in the way, and jacere, to throw, to throw in the way, signifies what is thrown in the way so as to stop our progress.

Demurs often occur in matters of deliberation; doubt in regard to matters of fact; hesitation in matters of ordinary conduct; and objections in matters of common consideration. Artabanes made many demurs to the proposed invasion of Greece by Xerxes.

Doubts have been suggested respecting the veracity of Herodotus as a historian.
It is not proper to ask that which cannot be granted without hesitation; and it is not the part of an amiable disposition to make a hesitation in complying with a reasonable request.

There are but few things which we either attempt to do or recommend to others that are not liable to some kind of an objection.

A demur stops the adjustment of any plan or the determination of any question.

A doubt interrupts the progress of the mind in coming to a state of satisfaction and certainty.

The last two words are both applied to abstract questions, or such as are of general interest. Hesitation and objection are more individual and private in their nature. Hesitation lies mostly in the state of the will; objection is rather the offspring of the understanding. A hesitation interferes with the action; an objection affects the measure or the mode of action.

DENOMINATION. See NAME.

DENOTE, SIGNIFY. Denote, in Latin denoto or noto, from notum, participle of nosco, signifies to cause to know. Signify, from the Latin signum, a sign, and facere, to make, is to become or be made a sign or guide for the understanding.

Denote is employed with regard to things and their characters; signify, with regard to the thoughts or movements. A letter or character may be made to denote any number, as words are made to signify the intentions and wishes of the person. Among the ancient Egyptians hieroglyphics were very much employed to denote certain moral qualities; in many cases looks or actions will signify more than words. Devices and emblems of different descriptions, drawn either from fabulous history or the natural world, are likewise now employed to denote particular circumstances or qualities: the cornucopia denotes plenty; the beehive denotes industry; the dove denotes meekness, and the lamb gentleness: he who will not take the trouble to signify his wishes otherwise than by nods or signs must expect to be frequently misunderstood.

DENOUNCE. See BAN; ExcommUNicate; Proscribe. 
DENSE. See Thick.

DENTICULATED. See JAgged.

DENY, REFuse. Deny, in Latin $d e$, from, and negare, to say no, from: ne, not, signifies to cay no to a thing. Refuse, in Latin refusus, from re and fundere, to pour or cast, signifies to throw off from one.

To deny respects matters of fact or knowledge; to refuse, matters of wish or request. We deny what immediately relates to ourselves; we refuse what relates to another. We deny as to the past; we refuse as to the future: we deny our participation in that which has been; we refuse our participation in that which may be: to deny must always be expressly verbal; a refusal may sometimes be signified by actions or looks as well as words. A denial affects our veracity; a refusal affects our good-nature.

But to deny signifies in this case simply to withhold; and refuse signifies to cast off from one, which is a more positive act: to deny one's self a pleasure is simply to abstain from it; but to refuse one's food is to cast it from one with a positive indisposition. What is denied may be denied by circumstances or by Providence; and it may be denied to one, many, or all; but what is refused is refused by and to particular individuais.

\section{See also Contradict; Disavow.}

DEPART. See Go.

DEPARTED, See BYgone.

DEPARTURE. See Death; Exit.

DEPENDENCE, RELIANCE. Dependence, from depend, from Latin de, from, and pendere, to hang, signifies, literally, to rest one's weight by hanging from that which is held. Rely, compounded of $r e$ and lie, signifies likewise to rest one's weight by lying or hanging back from the object held.

Dependence is the general term; reliance is a species of dependence: we depend either on persons or things; we rely on persons only: dependence serves for that which is immediate or remote; reliance serves for the future only. We depend upon a person for that which we are obliged to receive or led to expect from him: we rely upon a person for that which he has given us reason to expect from him. Dependence is an outward condition or the state of ex- ternal circumstances; reliance is a state of the feelings with regard to others. We depend upon God for all that we have or shall have; we rely upon the word of man for that which he has promised to perform. We may depend upon a person's coming from a variety of causes; but we rely upon it only in reference to his avowed intention.

DEPICT. See Paint.

DEPLORE, LAMENT. De plore comes from Latin deplorare, from de, intensive, and plorare, to weep. Lament, see Bewall.

Deplore is a much stronger expression than lament; the former calls forth tears from the bitterness of the heart; the latter excites a cry from the warmth of feeling. Deploring indicates despair; to lament marks only pain or distress. Among the poor we have deplorable instances of poverty, ignorance, vice, and wretchedness combined; among the higher classes we have often lamentable instances of extravagance and consequent ruin. A field of battle or a city overthrown by an earthquake is a spectacle truly deplorable: it is lamentable to see beggars putting on all the disguises of wretchedness in order to obtain by deceit what they might earn by honest industry. The condition of a dying man suffering under the agonies of an awakened conscience is deplorable; the situation of the relative or friend who witnesses the agony, without being able to afford consolation to the sufferer, is truly lamentable.

See also WarL.

DEPONENT, EvideNCE, WrTNESS. Deponent, from deponere, to lay down or set forth, signifies he who declares or substantiates anything. The evidence, from evident, is that which makes evident; and the witness, from the AngloSaxon witan, to know, signifies he who makes known.

All these words are properly applied to judicial proceedings, where the $d e-$ ponent deposes generally to facts either in causes or otherwise: the evidence consists either of persons or things, which are brought before the court for the purpose of making a doubtful matter clear; the witness is always a person who bears witness to any fact for or against another. 
Evidence is applied to moral objects, in the proper sense, and witness in the figurative application.

DEPORTMENT. See BEHAVIOR.

DEPOSE. See Swear.

DEPOSIT, Pledge, Security. Deposit is a general term, from the Latin depositus, participle of deponere, signifying to lay down, or put into the hands of another. Pledge comes through French from Old Low German plegan, to promise. Security, the substantive corresponding to secure, comes from Latin se, privative, and cura, care, signifying free from care.

The term deposit has most regard to the confidence we place in another; pledge has most regard to the security we give for ourselves; security is a species of pledge. A deposit is always voluntarily placed in the hands of an indifferent person; a pledge and security are required from the parties who are interested. A person may make a deposit for purposes of charity or convenience; he gives a pledge or security for a temporary accommodation or the relief of a necessity. Money is deposited in the hands of a friend in order to execute a commission: a pledge is given as an equivalent for that which has been received: a security is given by way of security for the performance of some agreement. A deposit must consist of something movable, as money, papers, or jewels, which can be deposited or placed in the hands of another. It may sometimes serve as a pledge or security where it is intended to bind the party depositing to anything. A pledge may, properly speaking, be anything which serves to pledge or bind a person by motives of interest, affection, or honor; it may consist of anything which is given to another for that purpose. A security is whatever makes a person secure against a loss, and in the ordinary acceptation consists of any instrument or written document which legally binds a person. In this sense, the person who binds himself for another becomes a security.

These words are all applied in this sense to moral objects.

See also Garner.

DEPRAVITY, Depravation, CorRUPTION. Depravity, from the Latin pravitas and pravus, crooked or not straight, marks the quality of being crooked. Depravation, in Latin depravatio, signifies a making crooked, or not as it should be. Corruption, in Latin corruptio, corrumpo, from rumpere, to break, marks the disunion and decomposition of the parts of anything.

All these terms are applied to objects which are contrary to the order of Providence, but the term depravity characterizes the thing as it is; the terms depravation and corruption designate the making or causing it to be so; depravity, therefore, excludes the idea of any cause; depravation always carries us to the cause or external agency: hence we may speak of depravity as natural, but we speak of depravation as the result of circumstance: there is a depravity in man which nothing but the grace of God can correct; the introduction of obscenity on the stage tends greatly to the depravation of morals; bad company tends to the corruption of a young man's morals.

Depravity or depravation implies crookedness or a distortion from the regular course; corruption implies a dissolution, as it were, in the component parts of bodies. Cicero says ( $2 \mathrm{De}$ Finibus) that depravity is applicable only to the mind and heart; but we say a depraved taste, and depraved humors in regard to the body. A depraved taste loathes common food, and longs for that which is unnatural and hurtful. Corruption is the natural process by which material substances are disorganized. In the figurative application of these terms they preserve the same signification. Depravity is characterized by being directly opposed to order and an established system of things; corruption marks the vitiation or spoiling of things, and the ferment that leads to destruction. $D e-$ pravity turns things out of their ordinary course; corruption destroys their essential qualities. Depravity is a vicious state of things, in which all is deranged and perverted: corruption is a vicious state of things, in which all is sullied and polluted. That which is depraved loses its proper manner of acting and existing; that which is corrupted loses its virtue and essence.

That is a depraved state of morals in 
which the gross vices are openly practised in defiance of all decorum: that is a corrupt state of society in which vice has secretly insinuated itself into all the principles and habits of men, and concealed its deformity under the fair semblance of virtue and honor. The manners of savages are most likely to be depraved; those of civilized nations to be corrupt, when luxury and refinement are risen to an excessive pitch. Cannibal nations present us with the pieture of human depravity; the Roman nation, during the time of the emperors, affords us an example of almost universal corruption.

From the above observations it is clear that depravity is best applied to those objects to which common usage has annexed the epithets of right, regular, fine, etc.; and corruption, to those which may be characterized by the epithets of sound, pure, innocent, or good. Hence we prefer to say depravity of mind and corruption of heart; depravity of principle and corruption of sentiment or feeling: a depraved character; a corrupt example; a corrupt influence.

In reference to the arts or belles-lettres we say either depravity or corruption of taste, because taste has its rules, is liable to be disordered, is or is not conformable to natural order, is regular or irregular; and, on the other hand, it may be so intermingled with sentiments and feelings foreign to its own native purity as to give it justly the title of corrupt. The last thing worthy of notice respecting the two words depravity and corruption is that the former is used for man in his moral capacity, but the latter for man in a political capacity: hence we speak of human deparvity, but the corruption of government.

DEPRECIATE. See Disparage.

DEPREDATION, ROBBERY. Depredation, in Latin depradatio, from proda, a prey, conveys the idea of taking by way of prey. $R o b$ is allied to Anglo-Saxon reaf, the root found in bereave, and robe, i. e., that stripped from the slain; it signified to strip, despoil, take away. Both these words denote the taking what belongs to another, but differ in the circumstances of the action. Depredation is not so lawless an act as robbery; it may be excused, if not justified, by the laws of war or the hostile situation of parties to each other. The borderers on the confines of England and Scotland used to commit depredations on each other. Robbery is in direct violation of every law, it is committed only by those who set all laws at defiance. Depredations may be committed in any manner short of direet violence; those who commit depredations do so mostly in the absence of those on whom they are committed: robberies are commonly committed on the persons, and mostly accompanied with violence. Depredation taken absolutely refers us to that which the depredator gains or gets to himself by the act; robbery refers us to that which the person loses who is robbed: the one goes away loaded with his plunder, the other goes away stripped of that which is most valuable to him.

In the extended application of these words this distinction is kept up: birds commit depredations on cornfields, bees rob flowers of their honey.

DEPRESSED. See HYPOCHONDRIACAL.

DEPRESSION. See DEJECTION.

DEPRIVATION. See Spoliation.

DEPRIVE, Debar, Abridge. Deprive, from de, from, and Latin privus, one's own, signifies to make not one's own what one has or expects to have. Debar, from de and bar, signifies to prevent by means of a bar. Abridge (see ABRIDGE).

Deprive conveys the idea of either taking away that which one has or withholding that which one may have; debar conveys the idea only of withholding; abridge conveys that also of taking away. Depriving is a coercive measure; debar and abridge are merely acts of authority. We are deprived of that which is of the first necessity; we are debarred of privileges, enjoyments, opportunities, etc.; we are abridged of comforts, pleasures, conveniences, etc. Criminals are deprived of their liberty; their friends are in extraordinary cases debarred the privilege of seeing them; thus men are often abridged of their comforts in consequence of their own faults. Deprivations and debarring sometimes arise from things as well as persons; abridging is always the voluntary act of conscious agents. Religion 
teaches men to be resigned under the severest deprivations; it is painful to be debarred the society of those we love, or to abridge others of any advantage which they have been in the habit of enjoying.

When used as reflective verbs they preserve the same analogy in their signification. An extravagant person deprives himself of the power of doing good. A person may debar himself of any pleasure from particular motives of prudence. A miser abridges himself of every enjoyment in order to gratify his ruling passion.

See also Bereave.

DEPTH, Profundity. Depth comes from Anglo-Saxon deop, and contains the same root as that found in dip, dive, etc. Profundity, from profound, in Latin profundus, compounded of pro, far, and fundus, the bottom, signifies remoteness from the lower surface of anything.

These terms do not differ merely in their derivation; but depth is indefinite in its signification; and profundity is a positive and considerable degree of depth. Moreover, the word depth is applied to objects in general; profundity is confined in its application to moral objects: thus we speak of the depth of the sea, or the depth of a person's learning, but his profundity of thought.

DEPUTE. See Constitution; Delegate.

DEPUTY. See Ambassador.

DERANGE. See Disorder.

DERANGEMENT, INSANITY, LUnacy, Madness, Mania. Derangement, from the verb to derange, implies the first stage of disordered intellect. Insanity, or unsoundness, from in, negative, and Latin sanus, whole, implies positive disease, which is more or less permanent. Lunacy is a violent sort of insanity, which was supposed to be influenced by the moon, and is derived from Latin luna, the moon. Cf. Shakespeare's "moon-struck calf. "Madness, allied to Anglo-Saxon gemoedan, to drive mad, from a root meaning severely injured, and mania, Latin mania,

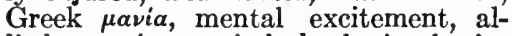
lied to $\mu$ évos, mind, both imply insanity in its most furious and confirmed stage. Deranged persons may sometimes be perfectly sensible about everything but particular subjects. Insane persons are sometimes entirely restored. Lunatics have their lucid intervals, and maniacs their intervals of repose. Derangement may sometimes be applied to the temporary confusion of a disturbed mind which is not in full possession of all its faculties: madness may sometimes be the result of violently inflamed passions: and mania may be applied to any vehement attachment which takes possession of the mind.

DERIDE, Mock, RIDICULE, RALLY, BANTER. Deride and ridicule are both derived from Latin ridere, to smile at. Mock comes from Late Latin muccare, to blow the nose (compare mucus), indicating a scoffing, coarse gesture. Rally is allied to rail, perhaps; its real origin is unknown. The origin of banter is also obscure.

Strong expressions of contempt are designated by all these terms. Derision and mockery evince themselves by the outward actions in general; ridicule consists more in words than actions; rallying and bantering almost entirely in words. Deride is not so strong a term as mock, but much stronger than ridicule. There is always a mixture of hostility in derision and mockery, but ridicule is frequently unaccompanied with any personal feeling of displeasure. Derision is often deep, not loud; it discovers itself in suppressed laughter, contemptuous sneers or gesticulations, and cutting expressions: mockery is mostly noisy and outrageous; it breaks forth in insulting buffoonery and is sometimes accompanied with personal violence: the former consists of real but contemptuous laughter; the latter often of affected laughter and grimace. Derision and mockery are always personal; ridicule may be directed to things as well as persons. Derision and mockery are a direct attack on the individual, the latter still more so than the former; ridicule is as often used in writing as in personal intercourse.

Rally and banter, like derision and mockery, are altogether personal acts, in which application they are very analogous to ridicule. Ridicule is the most general term of the three; we often rally and banter by ridiculing. There 
is more exposure in ridiculing, reproof in rallying, and provocation in bantering. A person may be ridiculed on account of his eccentricities; he is rallied for his defects; he is bantered for accidental circumstances: the former two actions are often justified by some substantial reason; the last is an action as puerile as it is unjust, it is a contemptible species of mockery. Self-conceit and extravagant follies are oftentimes best corrected by goodnatured ridicule; a man may deserve sometimes to be rallied for his want of resolution; those who are of an illnatured turn of mind will banter others for their misfortunes, or their personal defects, rather than not say something to their annoyance.

Derive, Trace, Deduce. Derive, from the Latin de and rivus, a river, signifies to draw, after the manner of water, from a source. Trace, Middle French tracer, is drawn ultimately from Latin tractus, the past participle of trahere, to draw or drag; and originally signified the mark left by drawing something across the surface, or the act of making such a mark. Deduce, in Latin de, from, and ducere, to lead, signifies to bring from.

The idea of drawing one thing from another is included in all the actions designated by these terms. The act of deriving is immediate and direct; that of tracing a gradual process; that of deducting a ratiocinative process. We discover causes and sources by derivation; we discover the course, progress, and commencement of things by tracing; we discover the grounds and reasons of things by deduction. A person derives his name from a given source; he traces his family up to a given period; principles or powers are deduced from circumstances or observations. The Trojans derived the name of their city from Tros, a king of Phrygia; they traced the line of their kings up to Dardanus.

DEROGate. See Disparage.

DESCRIBE. See Relate.

DESCRIPTION. See ACCOUNT; Cast.

DESCRY. See FIND.

DESECRATING. See SACrILE-
Desert, Merit, Worth. Desert, from deserve, in Latin deservio, signifies to do service or to be serviceable. Merit, in Latin meritus, participle of mereor, comes from the Greek $\mu$ epos, a share, because he who merils anything has a right to share in it. Worth, in German werth, seems to come from a root found in Latin vereri, to respect.

Desert is taken for that which is good or bad; merit for that which is good only. We deserve praise or blame: we merit a reward. Desert consists in the action, work, or service performed; merit has regard to the character of the agent or the nature of the action. A person does not deserve a recompense until he has performed some service; he does not merit approbation if he have not done his part well. Deserve is a term of ordinary import; merit applies to objects of greater moment: the former includes matters of personal and physical gratification; the latter those altogether of an intellectual nature. Criminals cannot always be punished according to their deserts; a noble mind is not contented with barely obtaining, it seeks to merit what it obtains.

The idea of value, whicn is prominent in the signification of the term merit, renders it closely allied to that of worth. Merit is that on which mankind set a value; it is sought for on account of the honor or advantages it brings: worth is that which is absolutely valuable; it must be sought for on its own account.

From these words are derived the epithets deserved and merited, in relation to what we receive from others; and deserving, meritorious, worthy, and worth, in regard to what we possess in ourselves: a treatment is deserved or undeserved; reproofs are merited or unmerited: the harsh treatment of a master is easier to be borne when it is undeserved than when it is deserved; the reproaches of a friend are very severe when unmerited.

A laborer is deserving on account of his industry; an artist is merilorious on account of his professional abilities; a citizen is worthy on account of his benevolence and uprightness. The first person deserves to be well paid and encouraged; the second merits the applause which is bestowed on him; the Grous. 
third is worthy of confidence and esteem from all men. Between worthy and worth there is this difference, that the former is said of intrinsic and moral qualities, the latter of extrinsic ones: a worthy man possesses that which calls for the esteem of others; but a man is worth the property which he can call his own: so in like manner a subject may be worthy the attention of a writer, or a thing may not be worth the while to consider.

See also Abandon; Solitary.

DEsign, Purpose, Intend, Mean. Design, from the Latin de, down, and signare, to make a sign, signifies to mark out as with a pen or pencil. Purpose, like propose, comes through French from the Latin pro and pansare, signifying to set before one's mind as an object of pursuit. Intend, in Latin in, to, and tendere, to stretch, signifies the bending of the mind toward an object. Mean, in Anglo-Saxon monen, German meinen, is probably connected with the word mind, signifying to have in the mind.

Design and purpose are terms of higher import than intend and mean, which are in familiar use; the latter still more so than the former. A design embraces many objects; a purpose consists of only one: the former supposes something studied and methodical, it requires reflection; the latter supposes something fixed and determinate, it requires resolution. A design is attainable; a purpose is steady. We speak of the design as it regards the thing conceived; we speak of the purpose as it regards the temper of the person. Men of a sanguine or aspiring character are apt to form designs which cannot be carried into execution; whoever wishes to keep true to his purpose must not listen to many counsellors.

A purpose is the thing proposed or set before the mind; an intention is the thing to which the mind bends or inclines: purpose and intend differ, therefore, both in the nature of the action and the object; we purpose seriously; we intend vaguely: we set about that which we purpose; we may delay that which we have only intended: the execution of nne's purpose rests mostly with one's self; the fulfilment of an intention depends upon circumstances: a man of a resolute temper is not to be diverted from his purpose by trifling objects: we may be disappointed in our intentions by a variety of unforeseen but uncontrollable events. Purpose is always applied to some proximate or definite object; intend, to that which is indefinite or remote. Mean, which is a term altogether of colloquial use, differs but little from intend, except that it is used for matters requiring but little thought; to mean is simply to have in the mind, to intend is to stretch with the mind to a thing.

Design and purpose are taken sometimes in the abstract sense; intend and mean, always in connection with the agent who intends or means: we see a design in the whole creation which leads us to reflect on the wisdom and goodness of the Creator; whenever we see anything done, we are led to inquire the purpose for which it is done; or are desirous of knowing the intention of the person in so doing: things are said to be done with a design, in opposition to that which happens by chance; they are said to be done for a purpose in reference to the immediate purpose which is expected to result from them. Design, when not expressly qualified by a contrary epithet, is used in a bad sense in connection with a particular agent; purpose, intention, and meaning, taken absolutely, have an indifferent sense: a designing person is full of latent and interested designs; there is nothing so good that it may not be made to serve the purposes of those who are bad; the intentions of a man must always be taken into the account when we are forming an estimate of his actions: ignorant people frequently mean much better than they do.

Design, Plan, Scheme, Project.-Design (see preceding). Plan, in French plan, comes from Latin planus, smooth or even, signifying a drawing on a flat surface, a preliminary drawing of something to be constructed. Scheme, in Latin schema, Greek $\sigma \chi \dot{\eta} \mu \alpha$, a form or figure, signifies the thing drawn out in the mind. Project, in Latin projectus, from projicio, compounded of pro and jacio, signifies to cast or put forth something, hence to propose.

Arrangement is the idea common to those terms: the design includes the 
thing that is to be brought about; the plan includes the means by which it is to be brought about: a design was formed in the time of James I. for overturning the government of the country; the plan by which this was to have been realized consisted in placing gunpowder under the Parliament House and blowing up the assembly. A design is to be estimated according to its intrinsic worth; a plan is to be estimated according to its relative value, or fitness for the design: a design is noble or wicked, a plan is practicable; every founder of a charitable institution may be supposed to have a good design; but he may adopt an erroneous plan for obtaining the end proposed.

Scheme and project respect both the end and the means, which makes them analogous to design and plan: the design stimulates to action; the plan determines the mode of action; the scheme and project consist most in speculation: the design and plan are equally practical, and suited to the ordinary and immediate circumstances of life; the scheme and project are contrived or conceived for extraordinary or rare occasions: no man takes any step without a design; a general forms the plan of his campaign; adventurous men are always forming schemes for gaining money; ambitious monarchs are full of projects for increasing their dominions. Scheme and project differ principally in the magnitude of the objects to which they are applied, the former being much less vast and extensive than the latter: a scheme may be formed by an individual for attaining any trifling advantage; projects are mostly conceived in matters of great moment involving deep interests.

DESIGNATE. See Name.

DESIGNING. See Scheming.

DESIRE, Wish, LoNg For, HANKer After, Cover. Desire, in Latin desidero, is a word of obscure origin; it may be allied to sidus, star, like consider, which see. Wish is derived from a Germanic root which is derived from the Aryan root whence the word win, and Latin ven, in Venus, venerate, etc., are also drawn. Long comes from Anglo-Saxon langian, to crave or desire. Hanker signifies to hang on an object with one's mind. Covet (see Covetous).
Desire is imperious, it demands gratification; wish is less vehement, it consists of a strong inclination; longing is an impatient and continued species of desire; hankering is a desire for that which is set out of one's reach; coveting is a desire for that which belongs to another, or what it is in his power to grant: we desire or long for that which is near at hand or within view; we wish for and covet that which is more remote or less distinctly seen; we hanker after that which has been once enjoyed: a discontented person wishes for more than he has; he who is in a strange land longs to see his native country; vicious men hanker after the pleasures which are denied them; ambitious men covet honors, avaricious men covet riches. Desires ought to be moderated, wishes to be limited, longings, hankerings, and covetings to be suppressed: uncontrolled desires become the greatest torments; unbounded wishes are the bane of all happiness; ardent longings are mostly irrational and not entitled to indulgence; coveting is expressly prohibited by the Divine law.

Desire, as it regards others, is not less imperative than when it respects ourselves; it lays an obligation on the person to whom it is expressed: a wish is gentle and unassuming; it appeals to the good-nature of another: we act by the desire of a superior or of one who has a right to ask; we act according to the wishes of an equal, or of one who can only request: the desire of a parent will amount to a command in the mind of a dutiful child: his wishes will be anticipated by the warmth of affection.

See also Beg; YearN.

DESIST, Leave Off. Desist, from the Latin desistere, signifies to take one's self off. Desist is applied to actions good, indifferent, or offensive to some person; leave off, to actions that are indifferent; the former is voluntary or involuntary, the latter voluntary: we are frequently obliged to desist; but we leave off at our option: it is prudent to desist from using our endeavors when we find them ineffectual; it is natural for a person to leave off when he sees no further occasion to continue his labor: he who annoys another 
must be made to desist; he who does not wish to offend will leave off when requested.

\section{DESOLATE. See Solitary.}

DESOlation. See Ravags.

DESPAIR, DESPERATION, DESPONDENCY. Despair, desperation, from the French désespoir, compounded of the privative de and the Latin spes, hope, signifies the absence or the annihilation of all hope. Despondency, from despond, in Latin despondeo, compounded of the privative de and spondere, to promise, signifies literally to deprive in a solemn manner, or cut off from every gleam of hope.

Despair is a state of mind produced by the view of external circumstances; desperation and despondency may be the fruit of the imagination; the former, therefore, always rests on some ground, the latter are sometimes ideal: despair lies mostly in reflection; desperation and despondency in the feelings: the former marks a state of vehement and impatient feeling, the latter that of fallen and mournful feeling. $D e-$ spair is of ten the forerunner of desperation and despondency, but it is not necessarily accompanied with effects so powerful: the strongest mind may have occasion to despair when circumstances warrant the sentiment; men of an impetuous character are apt to run into a state of desperation; a weak mind full of morbid sensibility is most liable to fall into despondency. Despair interrupts or checks exertion; desperation impels greater exertions; despondency unfits for exertion: when a physician despairs of making a cure, he lays aside the application of remedies; when a soldier sees nothing but death or disgrace before him, he is driven to desperation, and redoubles his efforts; when a tradesman sees before him nothing but failure for the present and want for the future he may sink into despondency: despair is justifiable as far as it is a rational calculation into futurity from present appearances; desperation may arise from extraordinary circumstances or the action of strong passions; in the former case it is unavoidable, and may serve to rescue from great distress; in the latter case it is mostly attended with fatal consequences: despondoncy is a disease of the mind, which nothing but a firm trust in the goodness of Providence can obviate.

Desperate, Hopeless.-Desperate (see above) is applicable to persons or things; hopeless to things only: a person makes a desperate effort; he undertakes a hopeless task. Desperate, when applied to things, expresses more than hopeless; the latter marks the absence of hope as to the attainment of good, the former marks the absence of hope as to the removal of an evil: a person who is in a desperate condition is overwhelmed with actual trouble for the present and the prospect of its continuance for the future; he whose case is hopeless is without the prospect of effecting the end he has in view: gamesters are frequently brought into desperate situations when bereft of everything that might possibly serve to lighten the burdens of their misfortunes: it is a hopeless undertaking to endeavor to reclaim men who have plunged themselves deep into the labyrinths of vice.

See also Deter.

DESPICABLE. See ContempTIBLE.

DESPISE. See ConTEMN.

DESPOIL. See SACK.

DESPONDENCY. See Despair.

DESPONDING. See Pessimistic.

DESPOTIC. See Absolute.

DESTINE. See ALLOT.

DESTINY, Fate, Lot, Doom. Destiny, from destine (see ApPoINT) signifies either the power that destines or the thing destined. Fate (see ChaNcE). Lot, Anglo-Saxon hlot, signifies a ticket, die, or any other thing by which the casual distribution of things is determined; and, in an extended sense, it expresses the portion thus assigned by chance. Doom comes from a Teutonic root meaning that which is put up or set up-irrevocably decreed and established.

All these terms are employed with regard to human events which are not under one's control: among the heathens destiny and fate were considered as deities, who each in his way could direct human affairs and were both superior even to Jupiter himself: the Destinies, or Parcæ, as they were 
termed, presided only over life and death; but Fate was employed in ruling the general affairs of men. Since revelation has instructed mankind in the nature and attributes of the true God, those blind powers are now not acknowledged to exist in the overruling providence of an all-wise and an all-good Being; the terms destiny and fate, therefore, have now only a relative sense as to what happens without the will or control of man.

Destiny is used in regard to one's station and walk in life; fate, in regard to what one suffers; lot, in regard to what one gets or possesses; and doom to the final destiny which terminates unhappily and depends mostly upon the will of another: destiny is marked out; fate is fixed; a lot is assigned; a doom is passed. It is the destiny of some men to be always changing their plan of life; it is but too frequently the fate of authors to labor for the benefit of mankind and to reap nothing for themselves but poverty and neglect; it is the lot of but very few to enjoy what they themselves consider a competency; a man sometimes seals his own doom by his imprudence or vices.

Destiny, Destination.-Both destiny and destination are used for the thing destined; but the former is said in relation to a man's important concerns, the latter only of particular circumstances; in which sense it may likewise be employed for the act of destining. Destiny is the point or line marked out in the walk of life; destination is the place fixed upon in particular: as every man has his peculiar destiny, so every traveller has his particular destination. Destiny is altogether set above human control; no man can determine, though he may influence, the destiny of another: destination is, however, the specific act of an individual, either for himself or another: we leave the destiny of a man to develop itself; but we may inquire about his own destination or that of his children: it is a consoling reflection that the destinies of short-sighted mortals like ourselves are in the hands of One who both can and will overrule them to our advantage if we place full reliance in Him; in the destination of children for their several professions or callings, it is of importance to consult their particular turn of mind as well as inclination.

DESTITUTE. See Bare; ForSAKEN.

DESTROY, Consume, Waste. Destroy, in Latin destruo, from de, privative, and struere, to build, is to undo that which has been built or done. Consume, in French consumer, Latin consumo, $i$. e., con or cum, together, and sumere, to take, signifies to take away altogether. Waste comes from Latin vastus, desolate, English waste, and signifies to make desolate.

To destroy is to reduce to nothing that which has been artificially raised or formed; as to destroy a town or a house: to consume is to use up; as to consume food, or to consume articles of manufacture: to destroy is an immediate act mostly of violence; consume is a gradual and natural process, as oil is consumed in a lamp.

To destroy is always taken in the bad sense for putting an end to that which one wishes to preserve; consume is also taken in a similar sense, but with the above distinction as to the mode of the action: as a hurricane destroys the crops; rust consumes iron: to waste is to consume by a misuse; as to waste provisions by throwing them away or suffering them to spoil; or to fall away or lose its substance, as the body wastes from disease.

In the figurative application they are used with precisely the same distinction: happiness or peace is destroyed; time is consumed in an indifferent sense; time or strength is wasted in the bad sense.

See also Demolish.

DESTROYER. Sce UNDERSEACRAFT.

DESTRUCTION, RoIn. Destruction, from destroy, and the Latin destruo, signifies literally to unbuild that which is raised up. Ruin, from the Latin ruere, to fall, signifies that which is fallen into pieces.

Destruction is an act of immediate violence; ruin is a gradual process; a thing is destroyed by some external action upon it; a thing falls to ruin of itself: we witness destruction wherever war or the adverse elements rage; we 
witness ruin whenever the works of man are exposed to the effects of time; nevertheless, if destruction be more forcible and rapid, ruin is, on the other hand, more sure and complete: what is destroyed may be rebuilt or replaced; but what is ruined is mostly lost forever, it is past recovery: when houses or towns are destroyed, fresh ones rise up in their place; but when commerce is ruined it seldom returns to its old course. Destruction admits of various degrees; ruin is something positive and general. The property of a man may be destroyed to a greater or less extent without necessarily involving his ruin. The ruin of a whole family is oftentimes the consequence of destruction by fire. Health is destroyed by violent exercises or some other active cause; it is ruined by a course of imprudent conduct. The happiness of a family is destroyed by broils and discord; the morals of a young man are ruined by a continued intercourse with vicious companions.

Both words are used figuratively with the same distinction. The destruction of both body and soul is the consequence of sin; the ruin of a man, whether in his temporal or spiritual concerns, is inevitable if he follow the dictates of misguided passion.

Destructive, Ruinous, Pernicious.Destructive signifies producing destruction. Ruinous signifies either having or causing ruin. Pernicious, from the Latin pernicies, or per, intensive, and stem neci of nex, slaughter, signifies causing violent and total dissolution.

Destructive and ruinous, as the epithets of the preceding terms, have a similar distinction in their sense and application; fire and sword are destructive things; a poison is destructive: consequences are ruinous; a condition or state is ruinous; intestine commotions are ruinous to the prosperity of a state. Pernicious approaches nearer to destructive than to ruinous; both the former imply a tendency to produce dissolution, which may be more or less gradual; but the latter refers us to the result itself, to the dissolution as already having taken place: hence we speak of the instrument or cause as being $d e-$ structive or pernicious, and the action, event, or result as ruinous: destructive is applied in the most extended sense to every object which has been created or supposed to be so; pernicious is applicable only to such objects as act only in a limited way: sin is equally destructive to both body and soul; certain food is pernicious to the body; certain books are pernicious to the mind.

See also Spolitation.

DESULTORY. See CURSORY.

DETACH. See Segregate; SepaRATE; WEAN.

DETAIN. See Hold.

DETECT, Discover. Detect, from the Latin de, privative, and tegere, to cover, and discover, from the privative dis and cover, both originally signify to deprive of a covering; see Cover.

Detect is always taken in a bad sense: discover in an indifferent sense. A person is detected in what he wishes to conceal; a person or a thing is discovered that has unintentionally lain concealed. Thieves are detected in picking pockets; a lost child is discovered in a wood or in some place of security. Detection is the act of the moment; it relates to that which is passing: a discovery is either a gradual or an immediate act, and may be made of that which has long since passed. A plot is detected by any one who communicates what he has seen and heard; many murders have been discovered after a lapse of years by ways the most extraordinary.

\section{See also Convict.}

DETER, Discourage, Dishearten. Deter, in Latin deterreo, compounded of de and terrere, signifies to frighten away from a thing. Discourage and dishearten, by the privative dis, signify to deprive of courage or heart. One is deterred from commencing anything; one is discouraged or disheartened from proceeding. A variety of motives may deter any one from an undertaking; but a person is discouraged or disheartened mostly by the want of success or the hopelessness of the case. The prudent and the fearful are alike easily to be deterred; impatient people are most apt to be discouraged; fainthearted people are easily disheartened. The foolhardy and the obdurate are the least easily deterred from their object; the persevering will not suffer themselves to be discouraged by particular failures; the resolute and self- 
confident will not be disheartened by trifling difficulties.

DETERIORATE. See Degenerate.

DETERMINE, RESOLVE. To determine (see DECIDE) is more especially an act of the judgment; to resolve (see Courage) is an act of the will: we determine how or what we shall do; this requires examination and choice: we resolve that we will do what we have determined upon; this requires a firm spirit. Our determinations should be prudent, that they may not cause repentance; our resolutions should bc fixed, in order to prevent variation. There can be no co-operation with a man who is undetermined; it will be dangerous to co-operate with a man who is irresolute. In the ordinary concerns of life we have frequent occasions to determine without resolving; in the discharge of our moral duties, or the performance of any office, we have occasion to resolve without determining. A master determines to dismiss his servant; the servant resolves on becoming more diligent. Personal convenience or necessity gives rise to the determination; a sense of duty, honor, fidelity, and the like gives birth to the resolution. A traveller determines to take a certain route; a learner resolves to conquer every difficulty in the acquirement of learning. Humor or change of circumstances occasions a person to alter his determination; timidity, fear, or defect in principle occasions the resolution to waver. Children are not capable of determining; and their best resolutions fall before the gratification of the moment.

In matters of knowledge, to determine is to fix the mind, or to cause it to rest in a certain opinion; to resolve is to lay open what is obscure, to clear the mind from doubt and hesitation. We determine points of question; we resolve difficulties. It is more difficult to determine in matters of rank or precedence than in cases where the solid and real interests of men are concerned; it is the business of the teacher to resolve the difficulties which are proposed by the scholar. Every point is not proved which is determined, nor is every difficulty resolved which is answered.

See also Decide; Fix.
ING.

DETERMINED. See UNSwERY-

DETEST. See Abhon; Hate

DETESTABLE. See Abominable. DETRACT. See Asperse; DISPARAGE.

DETRIMENT. See Disadvantage; Loss.

DEVASTATE. See SAck.

DEVASTATION. See Ravage.

DEVELOP. See UNFOLD.

DEVELOPMENT. Sec Evolution.

DEVIATE, WANDER, Swerve, Stray. Deviate, from devious, and the Latin de viâ, signifies, literally, to run out of the way. Wander is a frequentative of wend and is connected with Anglo-Saxon windan, to wind; it meant originally to keep winding in and out-indicating a purposeless going. For the derivation of swerve see Deflect. Stray comes from Old French estraier, to wander out into the streets, from Latin strata, street, whence our word street is derived.

Deviate always supposes a direct path which is departed from; wander includes no such idea. The act of deviating is commonly faulty, that of wandering is different: they may frequently exchange significations; the former being justifiable by necessity, and the latter arising from an unsteadiness of mind. Deviate is mostly used in the moral acceptation; wander may be used in either sense. A person deviates from any plan or rule laid down; he wanders from the subject in which he is engaged. As no rule can be laid down which will not admit of an exception, it is impossible but the wisest will find it necessary in their moral conduct to deviate occasionally; yet every wanton deviation from an established practice evinces a culpable temper on the part of the deviator. Those who wander into the regions of metaphysics are in great danger of losing themselves; it is with them as with most wanderers, that they spend their time at best but idly.

See also Digress.

DEVIL, Demon. Devil, in AngloSaxon deofal, French diable, etc., is connected with the Greek diáßoגos, from $\delta_{\imath} a \beta a \lambda \lambda_{\varepsilon \iota \nu}$, to traduce, literally to throw something at another (cf. the slang phrase to "sling mud" for mean- 
ing to slander). It signifies properly a calumniator, and is always taken in the bad sense for the spirit which incites to evil and tempts men through the medium of their evil passion. Demon, in Latin domon, Greek $\delta a i \mu \omega \nu$, a being of divine nature, is taken either in a bad sense or good sense for the power that acts within us and controls our actions. Since the devil is represented as the father of all wickedness, associations have been connected with the name that render its pronunciation in familiar discourse offensive to the chastened ear; it is therefore used in the grave style only.

Among Jews and Christians the term demon is always taken in a bad sense for an evil spirit generally; but the Greeks and Romans understood by the word domon any genius or spirit, but particularly the good spirit or guardian angel who was supposed to accompany a man from his birth. Socrates professed to be always under the direction of such a damon, who is alluded to very much by the ancients in their writings and on their medals; hence it is that in figurative language the word may still be used in a good sense.

In general, the word is taken for an evil spirit, as the demon of discord.

DEvise, Bequeath. Devise, compounded of de and visus, participle of videre, to see or show, signifies to point out specifically. Bequeath comes from Anglo-Saxon becwethan, from cwethan, to say (whence quoth), and means to give over to a person by saying or by word of mouth.

In the technical sense, to devise is to give lands by a will duly attested according to law; to bequeath is to give personality after one's death by a less formal instrument; whence the term bequeath may also be used figuratively, as to bequeath one's name to posterity.

DEVOID. See EMPTX.

DEVOTE. See AdDict: Dedicate; SANCTIFY.

DEVOTEE. See Enthusiast.

DEVOUT. See HoLY.

DEXTERITY. See AbILITY; KNaCK. DEXTERous. See Clever.

DIABOLIC, Devilish, Fiendish, Satanic. These words all mean resembling the devil or the powers of evil, and differ very little in meaning. Devilish and diabolical both come ultimately from Greek ò $\_\alpha ́ \beta o \lambda o s$, devil, literally slanderer, hater. Fiendish comes from Anglo-Saxon feond, an enemy, from feogan, to hate. Satanic comes originally from the Hebrew designation of the "Prince of the Powers of Darkness," which meant "Adversary." All the words signify the highest degree of wickedness and maliciousness, characteristic of the opponent of all good. Though devilish and diabolical have the same derivation, devilish has been so largely and carelessly used in colloquial speech to signify anything unpleasant that it has somewhat lost its force and dignity; diabolical expresses more definitely the idea of resemblance to the devil with special reference to malicious skill and ingenuity. Fiendish has the same meaning with special emphasis on malignity and cruelty. Satanic means characteristic of Satan, the prince of devils, and sometimes has special reference to size and daring in malignant action, or to Satan's distinguishing characteristic of pride. However, the words are really well-nigh interchangeable.

DIALECT. See LANGUAGE.

Dialogue. See Conversation.

diaphanous, Clear, Pellucid, Transldcent. Diaphanous, in French

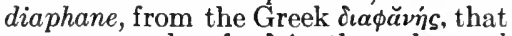
a compound of $\delta \dot{\alpha} \alpha$, through, and

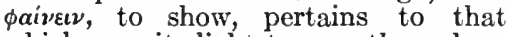
which permits light to pass through or has the quality of transmitting light. Clear and pellucid apply to substances, as air and water, when free from anything that would obstruct a view through them; but diaphanous implies a translucent quality in distinction from a transparent one. A substance is translucent that permits rays of light to pass through it without rendering the form or color of objects on the other side distinguishable; hence so nearly opaque that objects are scarcely, if at all, visible through it; while transparent applies to a substance that can be seen through clearly or allows light to pass through without diminution. A diaphanous substance, therefore, is translucent or only partially transparent.

Translucency implies that property of 
certain minerals, as well as other substances, which permits light to pass through them, but in a subdued degree. Diaphanous has been of late especially applied to semi-transparent textures such as lace and chiffon. There is nothing in the history of the word to support such a limitation of its meaning, but this is its most frequent application. A veil is diaphanous; a piece of smoked glass for viewing the sun and spectacles worn by people motoring or exposed to strong light are translucent; window-glass is transparent.

dictate, Prescribe.

Dictate, from the Latin dictatus and dictum, a word, signifies to make a word for another; and prescribe literally signifies to write down for another (see APPOINT), in which sense the former of these terms is used technically for a principal who gets his secretary to write down his words as he utters them; and the latter for a physician who writes down for his patient what he wishes him to take as a remedy.

They are used figuratively for a species of counsel given by a superior; to dictate is, however, a greater exercise of authority than to prescribe. To dictate amounts even to more than to command; it signifies commanding with a tone of unwarrantable authority, or still of tener a species of commanding by those who have no right to command; it is therefore mostly taken in a bad sense. To prescribe partakes altogether of the nature of counsel, and nothing of command; it serves as a rule to the person prescribed, and is justified by the superior wisdom and knowledge of the person prescribing; it is therefore always taken in an indifferent or a good sense. He who dictates speaks with an adventitious authority; he who prescribes has the sanction of reason. To dictate implies an entire subserviency in the person dictated to; to prescribe carries its own weight with it in the nature of the thing prescribed. Upstarts are ready to dictate even to their superiors on every occasion that offers; modest people are often fearful of giving advice lest they should be suspected of prescribing.

Dictate, Suggestion.-Dictate signifies the thing dictated, and has an imperative sense, as in the former case. Suggestion signifies the thing suggested, and eonveys the idea of its being proposed secretly or in a gentle manner.

These terms are both applied with this distinction to acts of the mind. When conscience, reason, or passion presents anything forcibly to the mind, it is called a dictate; when anything enters the mind in a casual manner, it is ealled a suggestion. The dictate is obeyed or yielded to; the suggestion is followed or listened to. It is the part of a Christian at all times to obey the dictales of reason. He who yields to the dictates of passion renounces the character of a rational being. It is the eharacteristic of a weak mind to follow the suggestions of envy.

Dictate is employed only for what passes inwardly; suggestion may be used for any action on the mind by external objects. No man will err essentially in the ordinary affairs of life who is guided by the dictates of plain sense. It is the lot of sinful mortals to be drawn to evil by the suggestions of Satan as well as their own evil inelinations.

Diction, Style, Phrase, PhraseoloGy. Diction, from the Latin dictio, saying, is put for the mode of expressing ourselves. Style comes from the Latin slylus, the bodkin with which the Latins wrote and corrected what they had written on their waxen tablets; whence the word has been used for the manner of writing in general. Phrase,

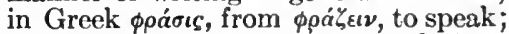

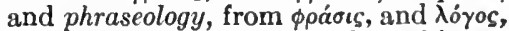
both signify the manner of speaking.

Diction expresses much less than style: the former is applicable to the first efforts of learners in composition; the latter only to the original productions of a matured mind. Errors in grammar, false construction, a confused disposition of words, or an improper application of them constitutes bad diction; but the niceties, the elegancies, the peculiarities, and the beauties of composition which mark the genius and talent of the writer are what is comprehended under the name of style. Diction is a general term, applicable alike to a single sentence or a connected composition; style 
is used in regard to a regular piece of composition. As diction is a term of inferior import, it is of course mostly confined to ordinary subjects, and style to the productions of authors. We should speak of a person's diction in his private correspondence, but of his style in his literary works. Diction requires only to be pure and clear; style may likewise be terse, polished, elegant, florid, poetic, sober, and the like.

Diction is said mostly in regard to what is written; phrase and phraseology are said as often of what is spoken as what is written; as that a person has adopted a strange phrase or phraseology. The former respects single words; the latter comprehends a succession of phrases.

DICTIONARY, ENCYCLOPEDIA. Dictionary, Late Latin dictionarium, from the Latin dictum, a saying or word, is a register of words. Encyclo-

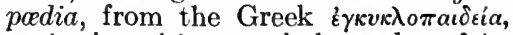

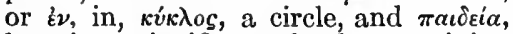
learning, signifies a book containing the whole circle of knowledge.

The definition of words, with their various changes, modifications, uses, acceptations, and applications, are the proper subjects of a dictionary; the nature and properties of things, with their construction, uses, powers, etc., are the proper subjects of an encyclopodia. A general acquaintance with all arts and sciences as far as respects the use of technical terms, and a perfect acquaintance with the classical writers in the language, are essential for the composition of a dictionary; an entire acquaintance with all the minutiæ of every art and science is requisite for the composition of an encyclopoedia. A single individual may qualify himself for the task of writing a dictionary; but the universality and diversity of knowledge contained in an encyclopoedia render it necessarily the work of many. The term dictionary has been extended in its application to any work alphabetically arranged, as biographical, medical, botanical dictionarics, and the like, but still preserving this distinction, that a dictionary always contains only a general or partial illustration of the subject proposed, while an encyclopadia embraces the whole circuit of science.
Dictionary, Lexicon, Vocabulary, Glossary, Nomenclature.-Dictionary is a general term; lexicon, from $\lambda \dot{c}$ ' $\varepsilon \iota \nu$, to say; vocabulary, from vox, a word; glossary, from gloss, to explain, from $\gamma \lambda \bar{\omega} \sigma \sigma \alpha$, the tongue; and nomenclature, from nomen, are all species of the dictionary.

Lexicon is a species of dictionary appropriately applied to the dead languages. A Greek or Hebrew lexicon is distinguished from a dictionary of the French or English language. A vocabulary is a partial kind of dictionary, which may comprehend a simple list of words, with or without explanation, arranged in order or otherwise. A glossary is an explanatory vocabulary, which commonly serves to explain the obsolete terms employed in any old author. A nomenclature is literally a list of names, and in particular a reference to proper names.

DIDACTIC, Pedagogic. Didactic, in Greek $\delta \imath \delta a \kappa r \iota \kappa o ́ s$, from $\delta \imath \delta a ́ \sigma \kappa \varepsilon \imath \nu$, to teach, cognate with the Latin doceo, in French didactique, signifies, specifically, whatever pertains to teaching, conveying instruction, or containing precepts or rules. In the plural and substantive form the term implies the science of teaching, the best methods of systematic instruction. Didactic poetry is a kind which aims, or seems to aim, at instruction, making pleasure entirely subservient to this. The "Georgics" of Virgil have been the model according to which such poems have generally been composed. Pedagogic has in recent years become a more conspicuous term than didactic, because of the great advance in educational methods. The term is from

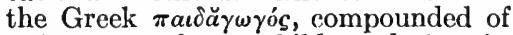

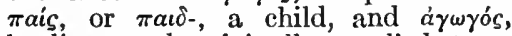
learing, and originally applied to a slave who led his master's children to school and places of amusement while they were too young to go alone, and, in exceptional instances, such pedagogues acted also as teachers. Latterly the term pedagogue came to be used in contempt or ridicule to designate a pedant or a supercilious instructor.

Now pedagogy, the science of teaching, has become conspicuous among the learned arts, and has its special colleges with degree-granting privileges, 
besides the many state and municipal normal schools.

DIE, Expire, Pass Over. Die is a Scandinavian word from a Teutonic base whence dead, death, etc., are also derived. Expire, from ex, out, and spirare, to breathe, means giving up the breath of life.

There are beings, such as trees and plants, which are said to live, although they have not breath; these die, but do not expire; there are other beings which absorb and emit air, but do not live; such as the flame of a lamp which does not dic, but it expires. By a natural metaphor, the time of being is put for the life of objects; and hence we speak of the date expiring, the term expiring, and the like; and as life is applied figuratively to moral objects, so may death to objects not having physical life.

To pass over is the Christian Science equivalent for to die.

See also Perish.

DIET. See Assembly; Food.

DIFFER, VARY, Disagree, Dissent. Differ, in Latin differo, or dis, apart, and ferre, to bear, signifies to make into two. Vary (see Change). Disagree is literally not to agree. Dissent, in Latin dissentio, or dis and sentire, to think or feel, signifies to think or feel apart or differently.

Differ, vary, and disagree are applicable either to persons or things; dissent to persons only. First as to persons: to differ is the most general and indefinite term, the rest are but modes of difference: we may differ from any cause, or in any degree, we vary only in small matters: thus persons may differ or vary in their statements. There must be two at least to differ, and there may be an indefinite number: one may vary, or an indefinite number may vary; thus two or more may differ in an account which they give; one person may vary at different times in the account which he gives. To differ may be either in fact or matters of speculation; to disagree, mostly in matters of practice or personal interest; to dissent, mostly in matters of speculation or opinion. Philosophers may differ in accounting for any phenomenon; politicians may differ as to the conduct of public affairs; people may disagree who have to act to- gether; a person may dissent from any opinion which is off ered or prescribed.

Differences may occasion discordant feeling or otherwise, according to the nature of the difference. Differences in regard to claims or matters of interest are rarely unaccompanied with some asperity. Disagreements, variances, and dissensions are always accompanied with more or less ill-humor or ill-feeling. Disagreements between those who ought to agree and to co-operate are mostly occasioned by opposing passions; variance is said of whatever disturbs the harmony of those who ought to live in love and harmony. Dissensions arise not merely from diversity of opinion, but also from diversity of interest, and always produce much acrimony of feeling. They arise mostly among bodies of men.

In regard to things, differ is said of two things with respect to each other; vary of one thing in respect to itself: thus two tempers differ from each other, and a person's temper varies from time to time. Things differ in their essences, they vary in their accidents; thus the genera and species of things differ from each other, and the individuals of each species vary: differ is said of everything promiscuously, but disagree is only said of such things as might agree; thus two trees differ from each other by the course of things, but two numbers disagree which are intended to agree.

Difference, Variety, Diversity, Medley.-Difference signifies the cause or the act of differing. Variety, from various or vary, in Latin varius, different, signifies a continual difference. Diversity, in Latin diversitas, comes from diverto, compounded of dis, apart, and vertere, to turn, and signifies to turn asunder. Medley has the same derivation as middle, for which see intermeddle under INTERCEDE.

Difference and varicty scem to lie in the things themselves; diversity and medley are created either by accident or design; a difference may lie in two objects only; a variety cannot exist without an assemblage: a difference is discovered by means of a comparison which the mind forms of objects to prevent confusion; variety strikes on the mind and pleases the imagination with many agreeable images; it is opposed 
to dull uniformity: the acute observer traces differences, however minute, in the objects of his research, and by this means is enabled to class them under their general or particular heads; nature affords such an infinite variety in everything which exists that if we do not perceive it the fault is in ourselves.

Diversity arises from an assemblage of objects naturally contrasted; a medley is produced by an assemblage of objects so ill suited as to produce a ludicrous effect. Diversity exists in the tastes or opinions of men; a medley is produced by the concurrence of such tastes or opinions as can in no wise coalesce. A diversity of sounds heard at a suitable distance in the stillness of the evening will have an agreeable effect on the ear; a medley of noises, whether heard near or at a distance, must always be harsh and offensive.

Difference, Distinction. - Difference lies in the thing; distinction is the act of the person: the former is, therefore, to the latter as the cause to the effect; the distinction rests on the difference: those are equally bad logicians who make a distinction without a difference, or who make no distinction where there is a difference.

Sometimes distinction is put for the ground of distinction, which brings it nearer in sense to difference, in which case the former is a species of the latter: a difference is either external or internal: a distinction is always external, the former lies in the thing, the latter is designedly made: we have differences in character and distinctions in dress; the difference between profession and practice, though very considerable, is often lost sight of by the professors of Christianity; in the sight of God there is no rank or distinction that will screen a man from the consequences of unrepented sins.

Difference, Dispute, Altercation, Quarrel.-Difference (see DrFFer). Dispute (see ARGUE). Altercation, in Latin altercatio, from alter, the other of two people, signifies to dispute in turns, first one speaking and then the othersuggesting also a decided difference of opinion. Quarrel, in French querelle, from the Latin queri, to complain, signifies having a complaint against another.
All these terms are here taken in the general sense of a difference on some personal question; the term difference is here as general and indefinite as in the former case: a difference, as distinguished from the others, is generally of a less serious and personal kind; a dispute consists not only of angry words, but much ill blood and unkind offices; an altercation is a wordy dispute, in which difference of opinion is drawn out into a multitude of words on all sides; quarrel is the most serious of all differences, which leads to every species of violence; a difference may sometimes arise from a misunderstanding, which may be easily rectified; differences seldom grow to disputes but by the fault of both parties; altercations arise mostly from pertinacious adherence to, and obstinate defence of, one's opinions; quarrels mostly spring from injuries real or supposed: differences subsist between men in an individual or public capacity; they may be carried on in a direct or indirect manner; disputes and altercations are mostly conducted in a direct manner between individuals; quarrels may arise between nations or individuals, and be carried on by acts of offence directly or indirectly.

Different, Distinct, Separate-Different (see Differ). Distinct, in Latin distinctus, participle of distinguo, and separate (see ABSTRACT for both).

Difference is opposed to similitude; there is no difference between objects absolutely alike: distinctness is opposed to identity; there can be no distinction where there is only one and the same being: separation is opposed to unity; there can be no separation between objects that coalesce or adhere: things may be different and not distinct, or distinct and not different: different is said altogether of the internal properties of things; distinct is said of things as objects of vision, or as they appear either to the eye or to the mind: when two or more things are seen only as one they may be different, but they are not distinct; but whatever is seen as two or more things, each complete in itself, is distinct, although it may not be different: two roads are said to be different which run in different directions, but they may not be distinct when seen on a map: on the other hand, 
two roads are said to be distinct when they are observed as two roads to run in the same direction, but they need not in any particular to be different: two stars of different magnitudes may, in certain directions, appear as one, in which case they are different but not distinct; two books on the same subject, and by the same author, but not written in continuation of each other, are distinct books, but not different.

What is separate must in its nature be generally distinct; but everything is not separate which is distinct: when houses are separate they are obviously distinct; but they may frequently be distinct when they are not positively separated: the distinct is marked out by some external sign which determines its beginning and its end; the separate is that which is set apart and to be seen by itself: distinct is a term used only in determining the singularity or plurality of objects; the separate only in regard to their proximity to or distance from each other: we speak of having a distinct household, but of living in separate apartments; of dividing one's subject into distinct heads, or of making things into separate parccls: the body and soul are different, inasmuch as they have different properties; they are distinct, inasmuch as they have marks by which they may be distinguished, and at death they will be separate.

Different, Several, Divers, Sundry, Various.-All these terms are employed to mark a number, but different is the most indefinite of all these terms, as its office is rather to define the quality than the number, and is equally applicable to few and many; it is opposed to singularity, but the other terms are employed positively to express many. Several, from to sever, signifies split or made into many; they may be either different or alike: there may be several different things, or several things alike; but we need not say several divers things, for the word divers signifies properly many different. Sundry, from Anglo-Saxon adverb sundor, apart, signifies many things scattered or at a distance, whether as it regards time or space. Various expresses not only a greater number, but a greatcr diversity than all the rest.
The same thing often affects different persons differently: an individual may be affected several times in the same way; or particular persons may be affected at sundry times and in divers manners; the ways in which men are affected are so various as not to admit of enumeration; it is not so much to understand different languages as to understand several different languages; divers modes have been suggested and tried for the good education of youth, but most are of too theoretical a nature to admit of being reduced successfully to practice; an incorrect writer omits sundry articles that belong to a statement; we need not wonder at the misery which is introduced into families by extravagance and luxury when we notice the infinitely various allurements for spending money which are held out to the young and the thoughtless.

Different, Unlike.-Different is positive, unlike is negative: we look at what is different, and draw a comparison; but that which is unlike needs no comparison: a thing is said to be different from every other thing, or unlike to anything seen before; which latter mode of expression obviously conveys less to the mind than the former.

Difficult. See Hard; HercuLEAN; KNOTTY.

DIFFICULTIES, EMBARRASS MENTS, Troubles. These terms are all applicable to a person's concerns in life; but difficulties relate to the difficulty of conducting a business; embarrassments relatc to the confusion attending a state of debt; and trouble to the pain which is the natural consequence of not fulfilling engagements or answering demands. Of the three, the term difficulties expresses the least, and that of troubles the most. A young man on his entrance into the world will unavoidably experience difficulties if not provided with ample means in the outset. But let his means be ever so ample, if he have not prudence and talents fitted for business he will hardly keep himself free from embarrassments, which are the greatest troubles that can arise to disturb the peace of a man's mind.

Difficulty, Obstacle, Impediment.- 
Difficulty, in Latin difficultas, and difficilis, compounded of the privative dis and facilis, easy, from facere, to do, signifies not easy to be done. Obstacle, in Latin obstaculum, from $o b$, in the way, and stare, to stand, signifies the thing that stands in the way between a person and the object he has in view. Impediment, in Latin impedimentum, from impedio, compounded of in, in, and pedes, feet, signifies something that entangles the feet.

All these terms include in their signification that which interferes either with the actions or views of men: the difficulty lies most in the nature and circumstances of the thing itself; the obstacle and impediment consist of that which is external or foreign: a difficulty interferes with the completion of any work; an obstacle interferes with the attainment of any end; an impediment interrupts the progress and prevents the execution of one's wishes: a difficulty embarrasses, it suspenos the powers of acting or deciding; an $o b$ stacle opposes itself, it is properly met in the way, and intervenes between us and our object; an impediment shackles and puts a stop to our proceedings: we speak of encountering a difficulty, surmounting an obstacle, and removing an impediment: the disposition of the mind often occasions more difficulties in negotiations than the subjects themselves; the eloquence of Demosthenes was the greatest obstacle which Philip of Macedon experienced in his political career; ignorance of the language is the greatest impediment which a foreigner experiences in the pursuit of any object out of his own country.

See also OBjection.

DIFFIDENCE. See Distrust.

DIFFIDENT. See Modest.

DIFFUSE, Prolrx. Both mark defects of style opposed to brevity. Diffuse, in Latin diffusus, participle of diffundere, to pour out or spread wide, marks the quality of being extended in space. Prolix comes from Latin pro, beyond, and liquere, to flow (whence liquid, liquor, etc.), and means flowing beyond bounds, overflowing.

The diffuse is properly opposed to the precise; the prolix to the concise or laconic. A diffuse writer is fond of amplification, he abounds in epithets, tropes, figures, and illustrations; the prolix writer is fond of circumlocution, minute details, and trifling particulars. Diffuseness is a fault only in degree and according to circumstances; prolixity is a positive fault at all times. The former leads to the use of words unnecessarily; the latter to the use of phrases, as well as words, that are altogether useless: the diffuse style has too much of repetition: the prolix style abounds in tautology. Diff useness often arises from an exuberance of imagination; prolixity from the want of imagination; on the other hand, the former may be coupled with great superficiality and the latter with great solidity. Modern writers have fallen into the error of diffuseness. Lord Clarendon and many English writers preceding him are chargeable with prolixity.

See also Spread.

DIGEST. See Abridgment; DisPOSE.

DigNIFIED. See Magisterial.

DIGNITY. See Honor; Pride.

DIGRESS, Deviate. Both in the original and the accepted sense, these words express going out of the ordinary course; but digress is used only in particular, and deviate in general cases. We digress only in a narrative, whether written or spoken; we deviate in actions as well as in words, in our conduct as well as in writings. Digress is mostly taken in a good or indifferent sense, deviate in an indifferent or bad sense. Although frequent digressions are faulty, yet occasionally it is necessary to digress for the purpose of explanation; every deviation is bad which is not sanctioned by the necessity of circumstances.

DILATE, Expand. Dilate, in Latin dilato, from dis, apart, and latus, wide, that is, to make very wide. Expand, in Latin expando, compounded of ex and pandere, to spread, to appear or show, signifying to set forth or lay open to view by spreading out.

The idea of drawing anything out so as to occupy a greater space is common to these terms in opposition to contracting. A bladder dilates on the admission of air, or the heart dilates with joy; knowledge expands the mind, or a person's views expand with circumstances. 
DILATORY. See Slow.

DILIGENT, Expeditious, Prompt. All these terms mark the quality of quickness in a commendable degree. Diligent, from diligere, to love, marks the interest one takes in doing something; he is diligent who loses no time, who keeps close to the work from inclination. Expeditious comes from the Latin expedio, from ex, out, and pes, pedis, foot, which meant originally to get one's foot out, to set off with speed. $\mathrm{He}$ who is expeditious applies himself to no other thing that offers; he finishes everything in its turn. Prompt, from the Latin promo, to draw out or make ready, marks one's desire to get ready; he is prompt who sets about a thing without delay, so as to make it ready. Idleness, dilatoriness, and slowness are the three defects opposed to these three qualities. The diligent man goes to his work willingly, and applies to it assiduously; the expeditious man gets it finished quickly; the prompt man sets about it readily and gets it finished immediately. It is necessary to be diligent in the concerns which belong to us, to be expeditious in any business that requires to be terminated, to be prompt in the execution of orders that are given to us.

See also Active; Sedulous.

DIM. See DARK.

DIMINISH. See Abate.

DIMINUTIVE. See Litrle.

DIOCESE. See BISHOPRIC.

DIP. See DabBle.

DIPLOMACY. See TACT.

DiRECT, Regulate, Dispose. We direct for the instruction of individuals; we regulate for the good order or convenience of many.

To direct is personal, it supposes authority; to regulate is general, it supposes superior information. An officer directs the movements of his men in military operations; the steward or master of the ceremonies regulates the whole concerns of an entertainment: the director is often a man in power; the regulator is always the man of business; the latter is frequently employed to act under the former.

To direct is always used with regard to others; to regulate, frequently with regard to ourselves. One person di- rects another according to his betten judgment: he regulates his own conduct by principles or circumstances.

But sometimes the word direct is taken in the sense of giving a direction to an object, and it is then distinguished from regulate, which signifies to determine the measure and other circumstances.

To dispose, from Latin dis, and French poser, for derivation of which see Compose, signifying to put apart for a particular purpose, supposes superior power like direct, and superior wisdom like regulate; whence the term has been applied to the Almighty, who is styled the Supreme Disposer of events, and by the poets to the heathen deities.

See also Conduct; Straight.

Direction, Address, Superscription.Direction marks that which directs. Address is that which addresses. Superscription, from super, above, and scribere, to write, signifies that which is written over.

Although these terms may be used promiscuously for one another, yet they have a peculiarity of signification by which their proper use is defined: a direction may serve to direct to places as well as to persons: an address is never used but in direct application to the person: a superscription has more respect to the thing than the person. A direction may be written or verbal; an address in this sense is always written; a superscription must not only be written, but either on or over some other thing: a direction is given to such as go in search of persons and places; it ought to be clear and particular: an address is put either on a card and a letter or in a book; it ought to be suitable to the station and situation of the person addressed: a superscription is placed at the head of other writings, or over tombs and pillars; it ought to be appropriate.

Direction, Order. - Direction (sce Direct). Order (see Command).

Direction contains most of instruction in it; order, most of authority. Directions should be followed, orders obeyed. It is necessary to direct those who are unable to act for themselves: it is necessary to order those whose 
business it is to execute the orders. Directions given to servants and children must be clear, simple, and precise; orders to tradespeople may be particular or general. Directions extend to the moral conduct of others, as well as the ordinary concerns of life; orders are confined to the personal convenience of the individual. A parent directs a child as to his behavior in company, or as to his conduct when he enters life; a teacher directs his pupil in the choice of books, or in the distribution of his studies: the master gives orders to his attendants to be in waiting for him at a certain hour; or he gives orders to his tradesmen to provide what is necessary.

See also KEY.

Directly, Immediately, Instantly, Instantaneously.-Directly signifies in a direct or straight manner. Immediately signifies without any medium or intervention. Instantly and instantaneously, from instant, signifies in an instant.

Directly is most applicable to the actions of men; immediately and instant$l y$ to either actions or events. Directly refers to the interruptions which may intentionally delay the commencement of any work; immediately in general refers to the space of time that intervenes. A diligent person goes $d i$ rectly to his work; he suffers nothing to draw him aside: good news is immediately spread abroad upon its arrival; nothing intervenes to retard it. Immediately and instantly, or instantaneously, both mark a quick succession of events, but the latter in a much stronger degree than the former. Immediately is negative; it expresses simply that nothing intervenes; instantly is positive, signifying the very existing moment in which the thing happens. A person who is of a willing disposition goes or runs immediately to the assistance of another; but the ardor of affection impels him to fly instantly to his relief, as he sees the danger. A surgeon does not proceed directly to dress a wound: he first examines it in order to ascertain its nature: men of lively minds immediately see the source of their own errors: people of delicate feelings are instantly alive to the slightest breach of decorum. A course of proceeding is direct, the consequences are immediate, and the effects instantaneous.

DIRIGIBLE. See Aircraft.

DIRTY. See SQUALID.

DISABILITY. See INABILITY.

DISADVANTAGE, InJURY, Hurt, Detriment, Prejudice. Disadvantage implies the absence of an advantage, which see. Injury, in Latin injuria, from in, not, and jus, juris, right, properly signifies what is contrary to right or justice, but extends in its sense to every loss or deficiency which is occasioned. Hurt, Middle English hurten, from Old French hurter, meant to strike or dash against, hence to injure. Detriment, in Latin detrimentum, from detritum and deterrere, to wear away, signifies the effect of being worn out. Prejudice, in the improper sense of the word (see Bias), implies the ill which is supposed to result from prejudice.

Disadvantage is rather the absence of a good; injury is a positive evil: the want of education may frequently be a disadvantage to a person by retarding his advancement; the ill word of another may be an injury by depriving him of friends. Disadvantage, therefore, is applied to such things as are of of an adventitious nature: the injury, to that which is of essential importance.

Hurt, detriment, and prejudice are all species of injuries. Injury, in general, implies whatever ill befalls an object by the external action of other objects, whether taken in relation to physical or moral evil, to persons or to things; hurt is that species of injury which is produced by more direct violence; too close an application to study is injurious to the health; reading by an improper light is hurtful to the eyes; so in a moral sense, the light reading which a circulating library supplies is often injurious to the morals of young people; all violent affections are hurtful to the mind.

Detriment and prejudice are species of injury which affect only the outward circumstances of a person or thing, the former implying what may lessen the value of an object, the latter what may lower it in the esteem of others. Whatever affects the stability 
of a merchant's credit is highly detrimental to his interests: whatever is prejudicial to the character of a man should not be made the subject of indiscriminate conversation.

DISAFFECTION, Disloyalty. Disaffection is general: disloyalty is particular; it is a species of disaffection. Men are disaffected to the government, disloyal to their prince. Disaffection may be said with regard to any form of government; disloyalty, only with regard to monarchy. Although both terms are commonly employed in a bad sense, yet the former does not always convey the unfavorable meaning which is attached to the latter. A man may have reasons to think himself justified in disaffection, but he will never attempt to offer anything in justification of disloyalty. A usurped government will have many disaffected subjects with whom it must deal leniently; the best king may have disloyal subjects, upon whom he must exercise the rigor of the law. Many were disaffected to the usurpation of Oliver Cromwell, because they would not be disloyal to their king.

\section{DISAGREE. See DifFer.}

DISAPPEAR, VANish. To disappear signifies not to appear (see AIR). Vanish, in French évanouir, Latin evaneo or evanesco, compounded of $e$ and vanescere, to become empty, from vanus, empty, signifies to go out of sight.

To disappear comprebends no particular mode of action; to vanish includes in it the idea of a rapid motion. A thing disappears either gradually or suddenly; it vanishes on a sudden; it disappears in the ordinary course of things; it vanishes by an unusual effort, a supernatural or a magic power. Any object that recedes or moves away will soon disappear; in fairy tales things are made to vanish the instant they are beheld. To disappear is often a temporary action; to vanish generally conveys the idea of being permanently lost to the sight. The stars appear and disappear in the firmament; lightning vanishes with a rapidity that is unequalled.

DISAPPOINT. See DefEat.

DISAPPROBATION. See DisPLEASURE.
DISAPPROVE, DisLIKE. To disapprove is not to approve, or to think not good. To dislike is not to like, or to find unlike or unsuitable to one's wishes.

Disapprove is an act of the judgment; dislike is an act of the will or the affection. To approve or disapprove is peculiarly the part of a superior, or one who determines the conduct of others; to dislike is altogether a personal act, in which the feelings of the individual are consulted. It is a misuse of the judgment to disapprove where we need only dislike; it is a perversion of the judgment to disapprove because we dislike.

DISASTER. See CaLamity.

DISAVOW, DenY, Disown. To disavow, from dis and avow (see AcKNOWLEDGE), is to avow that a thing is not: deny is to assert that a thing is not: disown, from dis and own, is to assert that a person or thing is not one's own or does not belong to one. A disavowal is a general declaration; a denial is a particular assertion; the former is made voluntarily and unasked for, the latter is always in direct answer to a charge: \&we disavow in matters of general interest where truth only is concerned; we deny in matters of personal interest where the character or feelings are implicated. What is disavowed is generally in support of truth; what is denied may often be in direct violation of truth: an honest mind will always disavow whatever has bcen erroneously attributed to it; a timid person sometimes denies what he knows to be true from a fear of the consequences.

Deny is said of things that concern others as well as ourselves; disown only of things in which one is personally concerned or supposed to be so. Denial is employed for events or indifferent matters; disowning extends to whatever one ean own or possess: a person denies that there is any truth in the assertion of another; he disowns all participation in any affair. Our veracity or judgment is often the only thing implicated in the denial: our guilt or innocence, honor or dishonor, is implicated in what we disown.

DISAVOWED. See Neutral. DISBELIEF, UnBelief. Disbelief 
properly implies the believing that a thing is not, or refusing to believe that it is. Unbelief expresses properly a believing the contrary of what one has believed before: disbelief is most applicable to the ordinary events of life; unbelief to serious matters of opinion: our disbelief of the idle tales which are told by beggars is justified by the frequent detection of their falsehood; our Saviour had compassion on Thomas for his unbelief, and gave him such evidences of His identity as dissipated every doubt.

DISCARD. See Dismiss.

DISCERN. See Perceive.

Discernment, Penetration, Discrimination, Judgment. Discernment expresses the power of discerning (see Perceive). Penetration denotes the act or power of penetrating, from penetrate, in Latin penetratus, participle of penetrare, from penitus, within, and penus, the inner part of a sanctuary, signifying to see into the interior. Discrimination denotes the act or power of discriminating, from discriminate, in Latin discriminatus, participle of discrimino, to make a difference. Judgment denotes the power of judging, from judge, in Latin judico, compounded of jus, right, and dicere, signifying to pronounce right.

The first three of these terms do not express different powers, but different modes of the same power; namely, the power of seeing intellectually, or exerting the intellectual sight. Discernment is not so powerful a mode of intellectual vision as penetration; the former is a cominon faculty, the latter is a higher degree of the same faculty; it is the power of seeing quickly, and seeing in spite of all that intercepts the sight and keeps the object out of view: a man of common discernment discerns characters which are not concealed by any particular disguise; a man of penetration is not to be deceived by any artifice, however thoroughly cloaked or secured, even from suspicion. Discernment and penetration serve for the discovery of individual things by their outward marks; discrimination is employed in the discovery of differences between two or more objects; the former consists of simple observation, the latter combines also comparison: dis- cernment and penetration are great aids toward discrimination; he who can discern the springs of human action or penetrate the views of men will be most fitted for discriminating between the characters of different men.

Although judgment derives much assistance from the three former operations, it is a totally distinct power: these only discover the things that are acting on external objects by seeing them: the judgment is creative; it produces by deduction from that which passes inwardly. Discernment and the others are speculative; they are directed to that which is to be known, and are confined to present objects; they serve to discover truth and falsehood, perfections and defects, motives and pretexts: the judgment is practical; it is directed to that which is to be done, and extends its views to the future; it marks the relations and connections of things; it foresees their consequences and effects.

Of discernment, we say that it is clear; it serves to remove all obscurity and confusion: of penetration we say that it is acute; it pierces every veil which falsehood draws before truth, and prevents us from being deceived: of discrimination we say that it is nice; it renders our ideas accurate and serves to prevent us from confounding objects; of judgment we say that it is solid or sound; it renders the conduct prudent and prevents us from committing mistakes or involving ourselves in embarrassments.

When the question is to estimate the real qualities of either persons or things, we exercise discernment; when it is required to lay open that which art or cunning has concealed, we must exercise penetration; when the question is to determine the proportions and degrees of qualities in persons or things, we must use discrimination; when called upon to take any step or act any part, we must employ judgment. Discernment is more or less indispensable for every man in private or public stations; he who has the most promiscuous dealings with men has the greatest need of it: penetration is of peculiar importance for princes and statesmen: discrimination is of great utility for all who have to determine 
the characters and merits of others: judgment is an absolute requisite for all to whom the execution or management of concerns is intrusted.

See also Gumption.

DISCHARGE. See Dismiss.

DISCIPLE. See Scholar.

DISCLAIM, Disown. Disclaim and disown are both personal acts respecting the individual who is the agent; to disclaim is to throw off a claim, as to disown (see Disavow) is not to admit as one's own; as claim, from the Latin clamo, signifies to declare with a loud tone what we want as our own; so to disclaim is, with an equally loud or positive tone, to give up a claim: this is a more positive act than to disown, which may be performed by insinuation or by the mere abstaining to own. He who feels himself disgraced by the actions that are done by his nation or his family will be ready to disclaim the very name which he bears in common with the offending party; an absurd pride sometimes impels men to disown their relationship to those who are beneath them in external rank and condition: an honest mind will disclaim all right to praise which it feels not to belong to itself; the fear of ridicule sometimes makes a man disown that which would redound to his honor.

DISClOSE. See Publish; UNCOVER; UNVEIL.

DISCOMPOSE. See Abash; DisORDER.

DISCONCERT. See ABAsh; BAFFLE; DISORDER; SNUB.

Discontinue. See Cease.

DISCORD, STRIFE. Discord comes from Latin dis, apart, and the stem cord, heart, signifying a lack of harmony between two people, but now it is consciously used as a metaphor in which it derives its signification from the harshness produced in music by the clashing of two strings which do not suit with each other; whence, in the moral sense, the chords of the mind which come into an unsuitable collision produce a discord. Strife comes from the word strive, to denote the action of striving, that is, in any angry manner (see CoNTEND); where there is strife there must be discord; but there may be discord without strife; discord consists most in the feeling; strife consists most in the outward action. Discord evinces itself in various ways; by looks, words, or actions: strife displays itself in words or acts of violence. Discord is fatal to the happiness of families; strife is the greatest enemy to peace between neighbors; discord arose between the goddesses on the apple being thrown into the assembly; Homer commences his poem with the strife that took place between Agamemnon and Achilles. Discord may arise from mere difference of opinion; strife is in general occasioned by some matter of personal interest; discord in the councils of a nation is the almost certain forerunner of its ruin; the common principles of politencss forbid strife among persons of good breeding.

See also Dissension.

\section{DISCOURAGE. See Deter.}

DISCOURSE. See SPEAK.

DISCOVER, Manifest, Declare. The idea of making known is conveyed by all these terms; but discover, which signifies simply to take off the covering from anything, expresses less than manifest (see APPARENT), and that than declare (sec Declare): we discover by any means direct or indirect; we manifest by unquestionable marks; we declare by express words: talents and dispositions discover themselves; particular ieelings and sentiments manifest themselves; facts, opinions, and sentiments are declared; children early discover a turn for some particular art or science; a person manifests his regard for another by unequivocal proofs of kindness; a person of an open disposition is apt to declare his sentiments without disguise.

Animals or unconscious agents may be said to discover, as things discover symptoms of decay; but persons only, or things personified, manifest or declare; cruelty may be manifested by actions; the works of the creation $d e-$ clare the wisdom of the Creator.

See also Detect; Find; Spy; UNCOVER.

DISCREDIT, DISGRACE, ReProACH, Scandal. Discredit signifies the loss of crcdit; disgrace, the loss of grace, favor, or esteem; reproach stands for the thing that deserves to be rcproached, 
and scandal comes from Greek $\sigma \kappa a ́ v \delta a \lambda o v$, Latin scandalum, a stumbling-block, from the root found in ascend, signifying to step or jump. The conduct of men in their various relations with one another may give rise to the unfavorable sentiment which is expressed in common by these terms. Things are said to reflect discredit or disgrace, or to bring reproach or scandal on the individual. These terms seem to rise in sense one upon the other: disgrace is a stronger term than discredit, reproach than disgrace, and scandal than reproach.

Discredit interferes with a man's credit or respectability; disgrace marks him out as an object of unfavorable distinction; reproach makes him a subject of reproachful conversation; scandal makes him an object of offence or even abhorrence. As regularity in hours, regularity in habits or modes of living, regularity in payments, are a credit to a family, so is any deviation from this order to its discredit: as moral rectitude, kindness, charity, and benevolence serve to insure the good-will and esteem of men, so do instances of unfair dealing, cruelty, inhumanity, and an unfeeling temper tend to the disgrace of the offender: as a life of distinguished virtue or particular instances of moral excellence may cause a man to be spoken of in strong terms of commendation, so will flagrant atrocities or a course of immorality cause his name and himself to be the general subject of reproach: as the profession of a Christian with a consistent practice is the greatest ornament which a man can put on, so is the profession with an inconsistent practice the greatest deformity that can be witnessed; it is calculated to bring a scandal on religion itself in the eyes of those who do not know and feel its intrinsic excellences.

Discredit and disgrace are negative qualities, and apply properly to the outward and adventitious circumstances of a person; but reproach and scandal are something positive and have respect to the moral character. A man may bring discredit or disgrace upon himself by trivial or indifferent things; but reproach or scandal follows only the violation of some positive law, moral or divine.
The term reproach is also taken for the object of reproach, and scandal for the object of scandal.

See also Disgrace.

DISCRETION. See JUdGMENT. DISCRIMINATE. See DistinGUISH.

DISCRIMINATION. See DiscerNMENT.

DISCUSS, Examne. Discuss, in Latin discussus, participle of discutio, from dis, apart, and quatere, to shake, signifies to shake asunder or to separate thoroughly so as to see the whole composition. Examine, in Latin examino, comes from examen, the middle beam, or thread, by which the poise of the balance is held, because the judgment holds the balance in examining.

The intellectual operation expressed by these terms is applied to objects that cannot be immediately discerned or understcod, but they vary both in mode and degree. Discussion is altogether carried on by verbal and personal communication; examination proceeds by reading, reflection, and observation; we often examine, therefore, by discussion, which is properly one mode of examination; a discussion is always carried on by two or more persons; an examination may be carried on by one only: politics are a frequent though not always a pleasant subject of discussion in social meetings; complicated questions cannot be too thoroughly examined.

DisDain. See Contemn; HadghTINESS.

DISDAINFUL. See Contempteous.

DISEASE. See Disorder.

DISEASED. See Srck.

Disengage, Disentangle, ExTRICATE. Disengage signifies to make free from an engagement. Disentangle is to get rid of an entanglement. Extricate, in Latin extricatus, from ex and trica, difficulties, impediments. As to engage signifies simply to bind, and entangle signifies to bind in an involved manner (for derivation and meaning see Embarrass), to disentangle is naturally applied to matters of greater difficulty and perplexity than to disengage; and as the term extricate 
includes the idea of that which would hold fast and keep within a tight involvement, it is employed with respect to matters of the greatest possible embarrassment and intricacy: we may be disengaged from an oath; disentangled from pecuniary difficulties; extricated from a perplexity; it is not right to expect to be disengaged from all the duties which attach to men as members of society; he who enters into metaphysical disquisitions must not expect to be soon disentangled: when a general has committed himself by coming into too close a contact with a very superior force, he sometimes may be able to extricate himself from his awkward situation by his generalship.

Disentangle. See Disengage. DISFIGURE. See DEFACE.

DISGRACE. See Abase; DisCREDIT; DISHONOR.

\section{DISGUISE. See Conceal.}

DISGUST, Loathing, Nausea. Disgust, from dis and gustare, to taste, from Latin gustus, the taste, denotes the aversion of the taste to an object. Loathing (see ABHOR). Nausea, in Latin nausea, from the Greck vavis, a ship, properly denotes seasickness.

Disgust is less than loathing, and that than nausea. When applied to sensible objects, we are disgusted with dirt; we loathe the smell of food if we have a sickly appetite; we nauseate medicine: and when applied metaphorically we are disgusted with affectation; we loathe the endearments of those who are offensive; we nauseate all the enjoyments of life after having made an intemperate use of them and discovered their inanity.

\section{See also DisLike.}

DISHEARTEN. See Abash; DeTER.

DISHONEST, KNavish. Dishonest marks the contrary to honest; knavish marks the likeness to a knave, from Anglo-Saxon cnapa, a boy, German knabe, a boy, a boy-servant; hence some one as mischievous and unreliable as boy-servants were likely to be. Dishonest characterizes simply the mode of action;.knavish characterizes the agent as well as the action: what is dishonest violates the established laws of man; what is knavish supposes peculiar art and design in the accomplishment. It is dishonest to take anything from another which does not belong to one's self; it is knavish to get it by fraud or artifice, or by imposing on the confidence of another. We may prevent dishonest practices by ordinary means of security; but we must not trust ourselves in the company of knavish people if we do not wish to be overreached.

DISHONOR, Disgrace, Shame. Dishonor signifies what does away honor. Disgrace (see Degrade). Shame signifies what produces shame. Dishonor deprives a person of those outward marks of honor which men look for according to their rank and station, or it is the state of being dishonored or less thought of and esteemed than one wishes. Disgrace deprives a man of the favor and kindness which he has heretofore received from others, or it is the state of being positively cast off by those who have before favored him or by whom he ought to be looked upon with favor. It is the fault of the individual that causes the disgrace. Shame expresses more than disgrace; it is occasioned by direct moral turpitude or that of which one ought to be ashamed. The fear of dishonor acts as a laudable stimulus to the discharge of one's duty; the fear of disgrace or shame serves to prevent the commission of vices or crimes. A soldier feels it a dishonor not to be placed at the post of danger, but he is not always sufficiently alive to the disgrace of being punished, nor is he deterred from his irregularities by the open shame to which he is sometimes put in the presence of his fellowsoldiers.

As epithets they likewise rise in sense and are distinguished by other characteristics: a dishonorable action is that which violates the principles of honor; a disgraceful action is that which reflects disgrace; a shameful action is that of which one ought to be fully ashamed: it is very dishonorable for a man not to keep his word; very disgraceful for a gentleman to associate with those who are his inferiors in station and education; very shameful for him to use his rank and influence over the lower orders only to mislead them from their duty. The sense of 
what is dishonorable is to the superior what the sense of the disgraceful is to the inferior, but the sense of what is shameful is independent of rank or station, and forms a part of that moral sense which is inherent in the breast of every rational creature. Whoever, therefore, cherishes in himself a lively sense of what is dishonorable or disgraceful is tolerably secure of never committing anything that is shameful.

See also Disgrace.

DISINClination. See Dislike.

DISJOIN. See SEParate.

DISJOINT, Dismember. Disjoint signifies to separate at the joint. Dismember signifies to separate the members.

The terms here spoken of derive their distinct meaning and application from the signification of the words joint and member. A limb of the body may be disjointed if it be so put out of the joint that it cannot act; but the body itself is dismembered when the different limbs or parts are separated from one another.

So in the metaphorical sense our ideas are said to be disjointed when they are so thrown out of their order that they do not fall in with one another: and kingdoms are said to be dismembered where any part or parts are separated from the rest.

Dislike, Displeasure, DissatisFaction, Distaste, Disgust. Dislike (see Aversion). Displeasure signifies the opposite to pleasure. Dissatisfaction is the opposite to satisfaction. Distaste is the opposite to an agreeable taste.

Dislike and dissatisfaction denote the feeling or sentiment produced either by persons or things: displeasure, that produced by persons only: distaste and disgust, that produced by things only. In regard to persons, dislike is the sentiment of equals and persons unconnected; displeasure and dissatisfaction, of superiors, or such as stand in some particular relation to one another. Strangers may feel a dislike upon seeing each other: parents or masters may feel displeasure or dissatisfaction: the former sentiment is occasioned by supposed faults in the moral conduct of the child or servant; the latter by supposed defective services. I dislike a person for his assumption or loquacity;
I am displeased with him for his carelessness, and dissatisfied with his labor. Displeasure is awakened by whatever is done amiss: dissatisfaction is caused by what happens amiss or contrary to our expectation. Accordingly, the word dissatisfaction is not confined to persons of a particular rank, but to the nature of the connection which subsists between them. Whoever does not receive what he thinks himself entitled to from another is dissatisfied. A servant may be dissatisfied with the treatment he meets with from his master; and may be said, therefore, to express dissatisfaction, though not displeasure.

In regard to things, dislike is a casual feeling not arising from any specific cause. A dissatisfaction is connected with our desires and expectations: we dislike the performance of an actor from one or many causes, or from no apparent cause; but we are dissatisfied with his performance if it fall short of what we were led to expect. In order to lessen the number of our dislikes we ought to endeavor not to dislike without a cause; and in order to lessen our dissatisfaction we ought to be moderate in our expectation.

Dislike, distaste, and disgust rise on one another in their signification. Distaste expresses more than dislike, and disgust more than distaste. Dislike is a partial feeling, quickly produced and quickly subsiding; distaste is a settled feeling, gradually produced and permanent in its duration: disgust is either transitory or otherwise; momentarily or gradually produced, but stronger than either of the two others. Caprice has a great share in our likes and dislikes: disiaste depends upon the changes to which the constitution physically and mentally is exposed: disgust owes its origin to the nature of things and their natural operation on the minds of men. A child likes and dislikes his playthings without any apparent cause for the change of sentiment: after a long illness a person will frequently take a distaste to the food or the amusements which before afforded him much pleasure: what is indecent or filthy is a natural object of disgust to every person whose mind is not depraved. It is good to suppress un- 
founded dislikes; it is difficult to overcome a strong distaste; it is advisable to divert our attention from objects calculated to ereate disgust.

See also Aversion; Disapprove.

Dislike, Disinclination.-Dislike (see above). Disinclination is the reverse of inclination (see ATTACHMENT). Dislike applies to what one has or does; disinclination only to what one does: we dislike the thing we have, or dislike to do a thing; but we are disinclined only to do a thing. They express a similar feeling that differs in degree. Disinclination is but a small degree of dislike; dislike marks something contrary; disinclination does not amount to more than the absence of an inelination. None but a disobliging temper has a dislike to comply with reasonable requests; but the most obliging disposition may have an occasional disinclination to comply with a particular request.

DISLOYALTY. See Disaffection. DISMAL. See DULL.

Dismantle. See Demolish.

DISMAY, DaUnT, Appal. Dismay comes from the Old French participle form, dismayé, of a verb compounded from Latin dis, privative, and Old High German magan, might or power. Daunt eomes from Latin domare to tame, English tame being probably the same word originally. Appal, compounded of the intensive ad and pallere, to grow pale, signifies to make pale with fear.

The effeet of fear on the spirit is strongly expressed by all these terms; but dismay expresses less than daunt, and this than appall. We are dismayed by alarming cireumstanees; we are daunted by terrifying; we are appalled by horrid circumstances. A severe defeat will dismay so as to lessen the foree of resistance: the fiery glare from the eyes of a ferocious beast will daunt him who was venturing to approaeh: the sight of an apparition will appall the stoutest heart.

\section{DISMEMBER. See DisJoINT}

DISMISS, Discharge, Discard. Dismiss, in Latin dismissus, participle of dimitto, compounded of dis, away, and mittere, to send, signifies to send away. Discharge signifies to release from a charge. Discard, in Spanish descartar, compounded of des and cartar, signifies to lay cards out or aside, to cast them off.

The idea of removing to a distance is included in all these terms, but with various collateral eireumstances. Dismiss is the general term; discharge and discard are modes of dismissing: dismiss is applicable to persons of all stations, but used more particularly for the higher orders: discharge, on the other hand, is confined to those in a subordinate station. A elerk is dismissed; a menial servant is discharged: an officer is dismissed; a soldier is discharged.

Neither dismiss nor discharge defines the motive of the action; they are used indifferently for that which is voluntary or the contrary: discard, on the contrary, always marks a dismissal that is not agreeable to the party discarded. A person may request to be dismissed or discharged, but never to be discarded. The dismissal or discharge frees a person from the obligation or necessity of performing a certain duty; the discarding throws him out of a desirable rank or station.

They are all applied to things in the moral sense: we are said to dismiss our fears, to discharge a duty, and to discard a sentiment from the mind.

DISORDER, Derange, DisconCERT, Discompose. Disorder signifies to put out of order. Derange, from de and range or rank, signifies to put out of the rank in which it was placea. Disconcert, to put out of the coneert or harmony. Discompose, to put out of a state of composure.

All these terms express the idea of putting out of order; but the latter three vary as to the mode or object of the action. The term disorder is used in a perfeetly indefinite form, and might be applied to any objeet. As everything may be in order, so may everything be disordered; yet it is seldom used except in regard to such things as have been in a natural order. Derange and disconcert are employed in speaking of such things as have been put into an artifieial order. To derange is to disorder that which has been systematically arranged or put in a certain range; and to disconcert is to disorder that which has been put 
together by concert or contrivance: thus the body may be disordered; a man's affairs or papers deranged; a scheme disconcerted. To discompose is a species of derangement in regard to trivial matters: thus a tucker, a frill, or a cap may be discomposed. The slightest change of diet will disorder people of tender constitutions: misfortunes are apt to derange the affairs of the most prosperous: the unexpected return of a master to his home disconcerts the schemes which have been formed by the domestics: those who are particular as to their appearance are careful not to have any part of their dress discomposed.

When applied to the mind, disorder and derange are said of the intellect; disconcert and discompose of the ideas or spirits, the former denoting a permanent state, the latter a temporary or transient state. The mind is said to be disordered when the faculty of ratiocination is in any degree interrupted; the intellect is said to be deranged when it is brought into a positive state of incapacity for action: persons are sometimes disordered in their minds for a time by particular occurrences who do not become actually deranged; a person is said to be disconcerted who suddenly loses his collectedness of thinking: he is said to be discomposed who loses his regularity of feeling. A sense of shame is the most apt to disconcert: the more irritable the temper the more easily one is discomposed.

See also JuMble.

Disorder, Disease, Distemper, Malady. -Disorder signifies the state of being out of order. Disease signifies the state of being ill at ease, from old French des, privative, and aise, ease. Distemper signifies the state of being out of temper or out of a due temperament. Malady is derived from the Latin male habitus, badly settled, in a bad condition.

All these terms agree in their application to the state of the animal body. Disorder is, as before, the general term, and the other specific. In this general sense disorder is altogether indefinite; but in its restricted sense it expresses less than all the rest: it is the mere commencement of a disease: disease is also more general than the other terms, for it comprehends every serious and permanent disorder in the animal economy, and is therefore of universal application. The disorder is slight, partial, and transitory: the disease is deep-rooted and permanent. The disorder may lie in the extremities: the disease lies in the humors and the vital parts. Occasional headaches, colds, and what is merely cutaneous are termed disorders; fevers, dropsies, and the like are diseases. Distemper is used for such particularly as throw the animal frame most completely out of its temper or course, and is consequently applied properly to virulent disorders, such as the smallpox. Malady has less of a technical sense than the other terms; it refers more to the suffering than to the state of the body. There may be many maladies where there is no disease; but diseases are themselves in general maladies. Our maladies are frequently born with us, but our diseases may come upon us at any time of life. Blindness is in itself a malady and may be produced by a disease in the eye. Our disorders are frequently cured by abstaining from those things which caused them; the whole science of medicine consists in finding out suitable remedies for our diseases; our maladies may be lessened with patience, althcugh they cannot always be alleviated or removed by art.

The terms disorder, disease, and distemper may be applied with a similar distinction to the mind as well as the body. The disorders are either of a temporary or a permanent nature, but, unless specified to the contrary, are understood to be temporary: diseases consist in vicious habits: our distempers arise from the violent operations of passion; our maladies lie in the injuries which the affections occasion. Any perturbation in the mind is a disorder: avarice is a disease: melancholy is a distemper as far as it throws the mind out of its bias; it is a malady as far as it occasions suffering.

DISORDERED. See TOPSY-TURVY. DISORDERLY. See Irregular.

DISOWN. See Disavow; Disclaim. Disparage, Detract, Traduce, Depreciate, Degrade, Decry. Dis- 
parage, compounded of $d i s$ and Late Latin paraticum, from par, equal, signifies to make a thing unequal or below what it ought to be. Detract (see Asperse). Traduce, from Latin trans, across, and ducere, to lead, signifies to carry from one to another that which is unfavorable. Depreciate, from the Latin pretium, a price, signifies to bring down the price. Degrade (see ABASE). Decry signifies literally to cry down.

The idea of lowering the value of an object is common to all these words, which differ in the circumstances and object of the action. Disparagement is the most indefinite in the manner: detract and traduce are specific in the forms by which an object is lowered: disparagement respects the mental endowments and qualifications: detract and traduce are said of the moral character, the former, however, in a less specific manner than the latter. We disparage a man's performance by speaking slightingly of it: we detract from the merits of a person by ascribing his success to chance; we traduce him by handing about tales that are unfavorable to his reputation: thus authors are apt to disparage the writings of their rivals; or a soldier may detract from the skill of his commander, or he may traduce him by relating scandalous reports.

To disparage, detract, and traduce can be applied only to persons or that which is personal; depreciate, degrade, and decry, to whatever is an object of esteem; we depreciate and degrade, therefore, things as well as persons, and decry things: to depreciate is, however, not so strong a term as to degrade, for the language which is employed to depreciate will be mild compared with that used for degrading: we may depreciate an object by implication or in indirect terms, but harsh and unseemly epithets are employed for degrading: thus a man may be said to depreciate human nature who does not represent it as capable of its true elevation; he degrades it who sinks it below the scale of rationality. We may depreciate or degrade an individual, a language, and the like; we decry measures and principles: the former two are an act of an individual; the latter is properly the act of many. Some men have such perverted notions that they are always depreciating whatever is esteemed excellent in the world: they whose interests have stifled all feelings of humanity have degraded the poor Africans in order to justify the enslaving of them: political partisans commonly decry the measures of one party in order to exalt those of another.

Disparage, Derogate, Degrade-Disparage (see above). Derogate, in Latin derogatus, from de, from, away, and rogare, to ask, meaning to "ask away," to repeal in part, signifies to take from a thing that which is claimed. Degrade (see Abase).

Disparage is here employed, not as the act of persons, but of things, in which case it is allied to derogate, but retains its indefinite and general sense as before: circumstances may disparage the performances of a writer, or they may derogate from the honors and dignities of an individual: it would be a high disparagement to an author to have it known that he had been guilty of plagiarism; it derogates from the dignity of a magistrate to take part in popular measures. To degrade is here, as in the former case, a much stronger expression than the other two: whatever disparages or derogates does but take away a part from the value: but whatever degrades a thing sinks it many degrees in the estimation of those in whose eyes it is degraded; in this manner religion is degraded by the low arts of its enthusiastic prof essors: whatever tends to the disparagement of learning or knowledge does injury to the cause of truth; whatever derogates from the dignity of a man in any office is apt to degrade the office itself.

DISPARITY, INEQUALITY. Disparity, from dis, negative, and par. equal, means to be unequal. Inequality, from the Latin in, negative, and aquus, even, signifies having no regularity.

Disparity applies to two objects which should meet or stand in coalition with each other: inequality is applieable to those who are compared with each other: the disparity of age, situation, and cireumstances is to be con. sidered with regard to persons entering into a matrimonial connection: the inequality in the portion of labor 
which is to be performed by two persons is a ground for the inequality of their recompense: there is a great inequality in the chance of success where there is a disparity of acquirements in rival candidates: the disparity between David and Goliath was such as to render the success of the former more strikingly miraculous; the inequality in the conditions of men is not attended with a corresponding inequality in their happiness.

DISPASSIONATE, CoOL. Dispassionate is taken negatively, it marks merely the absence of passion; cool is taken positively, it marks an entire freedom from passion.

Those who are prone to be passionate must learn to be dispassionate; those who are of a cool temperament will not suffer their passions to be roused. Dispassionate solely respects angry or irritable sentiments; cool respects any perturbed feeling: when we meet with an angry disputant it is necessary to be dispassionate in order to avoid quarrels; in the moment of danger our safety often depends upon our coolness.

DISPEL, Disperse. Dispel, from the Latin pellere, to drive, signifies to drive away. Disperse comes from Latin $d i s$, apart, and spargere, to scatter, and means to scatter in all directions.

Dispel is a more forcible action than to disperse: we destroy the existence of a thing by dispelling it; we merely destroy the junction or cohesion of a body by dispersing it; the sun dispels the clouds and darkness; the wind disperses the clouds or a surgeon disperses a tumor.

DISPENSE, Distribute. Dispense, from dis, asunder, and pendere, to weigh, to weigh out money, to bestow, signifies to bestow in different directions; and distribute, from the Latin tribuere, to assign, signifies the same thing. Dispense is an indiscriminate action; distribute is a particularizing action: we dispense to all; we distribute to each individually: nature dispenses her gifts bountifully to all the inhabitants of the earth; a parent distributes among his children different tokens of his parental tenderness. Dispense is an indirect action that has no immediate reference to the receiver; distribute is a direct and personal action communicated by the giver to the receiver: Providence dispenses His favors to those who put a sincere trust in Him; a prince distributes marks of his favor and preference among his courtiers.

Disperse. See Dispel; Spread.

DISPLAY. See SHow.

DISPLEASE, OFFEND, VeX. Displease (see DisLIKE) naturally marks the contrary of pleasing. Offend, from Latin $o b$, against, and fendere, to strike, means, literally, to strike against. Vex, in Latin vexo, is a frequentative of vehere, to carry (whence vehicle), signifying literally to toss up and down.

These words express the painful sentiment which is felt by the supposed impropriety of another's conduct. Displease is not always applied to that which personally concerns ourselves; although offend and vex have always more or less of what is personal in them: a superior may be displeased with one who is under his charge for improper behavior toward persons in general; he will be offended with him for disrespectful behavior toward himself or neglect of his interests: circumstances as well as actions serve to displease; a supposed intention or design is requisite in order to offend; we may be displeased with a person or at a thing; one is mostly offended with the person; a child may be displeased at not having any particular liberty or indulgence granted to him; he may be offended with his playfellow for an act of incivility or unkindness.

Displease respects mostly the inward state of feeling; offend and vex have most regard to the outward cause which provokes the feeling: a humorsome person may be displeased without any apparent cause, but a captious person will at least have some avowed trifle for which he is offended. Vex expresses more than offend; it marks, in fact, frequent efforts to offend, or the act of offending under aggravated circumstances: we often unintentionally displease or offend, but he who vexes has mostly that object in view in so doing: any instance of neglect displeases; any marked instance of neglect offends; any aggravated instance of neglect vexes. The feeling of displeasure is more perceptible and vivid than that of offence, 
but it is less durable: the feeling of vexation is as transitory as that of displeasure, but stronger than either. Displeasure and vexation betray themselves by an angry word or look; offence discovers itself in the whole conduct: our displeasure is unjustifiable when it exceeds the measure of another's fault; it is a mark of great weakness to take offence at trifles; persons of the greatest irritability are exposed to the most frequent vexations.

These terms may all be applied to the acts of unconscious agents on the mind.

As epithets they admit of a similar distinction: it is very displeasing to parents not to meet with the most respectful attentions from children when they give them counsel; and such conduct on the part of children is highly offensive to God: when we meet with an affensive object we do most wisely to turn away from it: when we are troubled with vexatious affairs our best and only remedy is patience.

Displeasure, Anger, Disapprobation. -Displeasure (see DisLike). Anger (for derivation see ANGER). Disapprobation is the reverse of approbation (see Assent).

Between displeasure and anger there is a difference in the degree, the cause, and the consequence of the feeling: displeasure is always a softened and gentle feeling; anger is always a harsh feeling, and sometimes rises to vehemence and madness. Displeasure is always produced by some adequate cause, real or supposed; but anger may be provoked by every or any cause, according to the temper of the individual: displeasure is mostly satisfied with a simple, verbal expression; but anger, unless kept down with great force, always seeks to return evil for evil. Displeasure and disapprobation are to be compared, inasmuch as they respect the conduct of those who are under the direction of others: displeasure is an act of the will, it is an angry sentiment; disapprobation is an act of the judgment, it is an opposite opinion: any mark of self-will in a child is calculated to excite displeasure; a mistaken choice in matrimony may produce disapprobation in the parent.

Displeasure is always produced by that which is already come to pass; disapprobation may be felt upon that which is to take place; a master feels displeasure at the carelessness of his servant; a parent expresses his disapprobation of his son's proposal to leave his situation; it is sometimes prudent to check our displeasure, and mostly prudent to express our disapprobation; the former cannot be expressed without inflicting pain; the latter cannot be withheld when required without the danger of misleading.

See also Dislike.

DISPOSAL, Disposition. These words derive their different meanings from the verb to dispose, to which they owe their common origin. Disposal is a personal act; it depends upon the will of the individual: disposition is an act of the judgment; it depends upon the nature of the things. The removal of a thing from one's self is involved in a disposal; the good order of the things is comprehended in their disposition. The disposal of property is in the hands of the rightful owner; the success of a battle often depends upon the right disposition of an army.

Dispose, Arrange, Digest.-Dispose, in French disposer, from Latin dis, apart. and French poser, is derived from Greek $\pi a \bar{v} \sigma \varsigma$, a pause, not from Latin ponere (see Compose). Arrange (see Class). Digest, in Latin digestus, participle of digero, or dis, apart, and gerere, past participle gestus, to earry, signifies to gather apart with design.

The idea of a systematic laying apart is common to all, and proper to the word dispose. We dispose when we arrange and digest; but we do not always arrange and digest when we dispose; they differ in the eircumstances and object of the action. There is less thought employed in disposing than in arranging and digesting; we may dispose ordinary matters by simply assigning a place to each; in this manner trees are disposed in a row, but we arrange and digest by an intellectual effort; in the first ease by putting those together which ought to go together, and in the latter ease by both separating that which is dissimilar and bringing together that which is similar; in this manner books are arranged in a library according to their size or their 
subject; the materials for a literary production are digested, or the laws of the land are digested. What is not wanted should be neatly disposed in a suitable place: nothing contributes so much to beauty and convenience as the arrangement of everything according to the way and manner in which they should follow; when writings are involved in great intricacy and confusion, it is difficult to digest them.

In an extended and moral application of these words we speak of a person's time, talent, and the like being disposed to a good purpose; of a man's ideas being properly arranged, and of being digested into form. On the disposition of a man's time and property will depend in a great measure his success in life; on the arrangement of accounts greatly depends his facility in conducting business; on the habit of digesting our thoughts depends in a great measure correctness of thinking.

See also Direct; Place.

Disposition, Temper. - Disposition, from dispose, signifies here the state of being disposed. Temper, like temperament, from the Latin temperare, to temper or manage, signifies the thing modelled or formed.

These terms are both applied to the mind and its bias; but disposition respects the whole frame and texture of the mind; temper respects only the bias or tone of the feelings.

Disposition is permanent and settled; temper may be transitory and fluctuating. The disposition comprehends the springs and motives of actions; the temper influences the action of the moment: it is possible and not infrequent to have a good disposition with a bad temper, and vice versâ.

A good disposition makes a man a useful member of society, but not always a good companion; a good temper renders him acceptable to all and peaceable with all, but essentially useful to none: a good disposition will go far toward correcting the errors of temper; but where there is a bad disposition there are no hopes of amendment. The disposition is properly said to be natural, the temper is rather acquired or formed by circumstances.

If the temper be taken for what is natural, it implies either the physical temperament or that frame of mind which results from or is influenced by it.

Disposition, Inclination. - Disposition in the former section is taken for the general frame of the mind; in the present case for its particular frame. Inclination (see ATTACHMENT).

Disposition is more positive than inclination. We may always expect a man to do that which he is disposed to do; but we cannot always calculate upon his executing that to which he is merely inclined. We indulge a disposition; we yield to an inclination. The disposition comprehends the whole state of the mind at the time; an inclination is particular, referring always to a particular object. After the performance of a serious duty, no one is expected to be in a disposition for laughter or merriment: it is becoming to suppress our inclination to laughter in the presence of those who wish to be serious; we should be careful not to enter into controversy with one who shows a disposition to be unfriendly. When a young person discovers any inclination to study, there are hopes of his improvement.

DISPOSED. See AFFECTED.

DISPROVE. See CONFUTE.

DISPUTE. See Argue; Bicker; Contend; Controvert; Difference.

DISQUISITION. See ToPIC.

DISREgARD, Neglect, Slight. Disregard signifies properly not to regard. Neglect, in Latin neglectus, participle of negligo, is compounded of nec, not, and legare, to gather or choose out, signifying not to choose, to pay no attention to. Slight comes from an Old Low German word which originally meant flat, smooth, and developed in English through a series of meanings, smooth, simple, etc., into the meaning of trivial, unimportant. The verb slight means to treat as if of no importance.

We disregard the warnings, the words, or opinions of others; we neglect their injunctions or their precepts. To disregard results from the settled purpose of the mind; to neglect, from a temporary forgetfulness or oversight. What is disregarded is seen and passed over; what is neglected is generally not 
thought of at the time required. What is disregarded does not strike the mind at all; what is neglected enters the mind only when it is before the eye: what we disregard is not esteemed; what we neglect is of ten esteemed, but not sufficiently to be remembered or practised: a child disregards the prudent counsels of a parent; he neglects to use the remedies which have been prescribed to him.

Disregard and neglect are frequently not personal acts; they respect the thing more than the person; slight is altogether an intentional act toward an individual or toward any object which one has heretofore esteemed or ought to esteem.

DisSATISFACTION. See Dislike.

DISSATISFYING: See UNSATISFACTORY.

\section{Dissemble. See CoNceal.}

DISSEMINATE. See Spread,

DISSENSION, CoNTENTION, DisCORD. Dissension marks either the act or the state of dissenting. Contention marks the act of contending. Discord (see Contention).

A collision of opinions produces dissension; a collision of interests produces contention; a collision of humors produces discord. A love of one's own opinion, combined with a disregard for the opinion of others, gives rise to dissension; selfishness is the main cause of contention, and an ungoverned temper that of discord.

Dissension is peculiar to bodies or communities of men; contention is applicable mostly, and discord always, to individuals. A Christian temper of conformity to the general will of those with whom one is in connection would do away with dissension; a limitation of one's desire to that which is attainable by legitimate means would put a stop to contention; a correction of one's impatient and irritable humor would check the progress of discord. Dissension tends not only to alienate the minds of men from one another, but to dissolve the bonds of society; contention is accompanied by anger, ill-will, envy, and many evil passions; discord interrupts the progress of the kind affections, and bars all tender intercourse.
DISSENT. See Differ.

DISSENTER. See Heretic.

DISSERTATION. See EsSay.

DisSimilar. See Heterogeneous.

Dissimulation. See SimulaTION.

DISSIPATE. See SPEND.

DISSOLUTE. See LoOSE.

DISTANT, FAR, REMOTE. Distant is employed as an adjunct or otherwise; far is used only as an adverb. We speak of distant objects, or objects being distant; but we speak of things only as being far. Distant, in Latin distans, compounded of dis, apart, and the participle stans, standing, from the verb stare, to stand, means standing apart, and is employed only for bodies at rest. Far comes from a Germanic and ultimately an Aryan root meaning beyond, found in Greek $\pi \dot{\varepsilon} \rho \alpha \nu$, beyond; and is employed for bodies either stationary or otherwise; hence we say a thing is distant, or it goes, runs, or flies far. Distant is used to designate great space; far only that which is ordinary: astronomers estimate that the sun is ninety-four millions of miles distant from the earth; a person lives not very far off, or a person is far from the spot. Distant is used absolutely to express an intervening space. Remote, in Latin remotus, participle of removere, to move back or away, rather expresses the relative idea of being gone out of sight. A person is said to live in a distant country, or in a remote corner of any country.

They bear a similar analogy in the figurative application; when we speak of a remote idea it designates that which is less liable to strike the mind than a distant idea. A distant relationship between individuals is never altogether lost sight of; when the connection between objects is very remote it easily escapes observation.

DISTASTE. See Dislike.

DISTEMPER. See Disorder.

Distinc'T. See Categorical;

DIFFERENT.

DISTINCTION. See Difference;

FASHION.

DISTINCTLY. See Clear.

DISTINGUISH, Discriminate. To distinguish (see Arstract) is the gen- 
eral, to discriminate (see DiscernMENT) is the particular term: the former is an indefinite, the latter a definite action. To discriminate is in fact to distinguish specifically; hence we speak of a distinction as true or false, but of a discrimination as nice. We distinguish things as to their divisibility or unity; we discriminate them as to their inherent properties; we distinguish things that are alike or unlike, in order to separate or collect them; we discriminate those that are different, for the purpose of separating one from the other: we distinguish by means of the senses as well as the understanding; we discriminate by the understanding only: we distinguish things by their color or we distinguish moral objects by their truth or falsehood; we discriminate the characters of men or we discriminate their merits according to circumstances.

See also Abstract; Perceive; SigNALIZE.

Distinguish, Conspicuous, Noted, Eminent, Illustrious. - Distinguished signifies having a mark of distinction by which a thing is to be distinguished (see ABstract). Conspicuous, in Latin conspicuus, from con, intensive, and spicere, to see, signifies easily to be seen. Noted comes from notus, known, well known. Eminent, in Latin eminens, from emineo, or $e$ and a stem min, signifying to project, found in English prominent, means projecting out. Illustrious is a badly coined word from the root of lux, light, meaning full of light, shining out.

The idea of an object having something attached to it to excite notice is common to all these terms. Distinguished in its general sense expresses little more than this idea; the rest are but modes of the distinguished. A thing is distinguished in proportion as it is distinct or separate from others; it is conspicuous in proportion as it is easily seen; it is noted in proportion as it is widely known. In this sense a rank is distinguished; a situation is conspicuous; a place is noted. Persons are distinguished by external marks or by characteristic qualities; persons or things are conspicuous mostly from some external mark; persons or things are noted mostly by collateral circum- stances. A man may be distinguished by his decorations, or he may be distinguished by his manly air, or by his abilities: a person is conspicuous by the gaudiness of his dress; a house is conspicuous that stands on a hill: a person is noted for having performed a wonderful cure; a place is noted for its fine waters.

We may be distinguished for things good, bad, or indifferent: we may be conspicuous for our singularities or that which orly attracts vulgar notice: we may be noted for that which is bad, and mostly for that which is the subject of vulgar discourse: we can be eminent and illustrious only for that which is really good and praiseworthy; the former applies, however, mostly to those things whioh set a man high in the circle of his acquaintance; the latter to that which makes him shine before the world. A man of distinguished talent will be apt to excite envy if he be not also distinguished for his private virtue: affection is never better pleased than when it can place itself in such a conspicuous situation as to draw all eyes upon itself: lovers of fame are sometimes contented to render themselves noted for their vices or absurdities: nothing is more gratifying to a man than to render himself eminent for his professional skill: it is the lot of but few to be illustrious, and those few are very seldom to be envied.

In an extended and moral application these terms may be employed as epithets to heighten the character of an object: valor may be said to be distinguished, piety eminent, and a name illustrious.

DISTORT. See TurN.

DISTORTED. See WRY.

DISTRACTED. See ABsENT.

DISTRESS, ANXIETY, ANGOISH, Agony. Distress (see Adversity). Anxiety is allied to Latin angustus, narrow, and angere, to choke, from a root found also in anger. Agony, in French agonie, Latin agonia, Greek á $\gamma \omega \nu i a$, a struggle, signifies a severe struggle with pain and suffering.

Distress is the pain felt when in a strait from which we see no means of extricating ourselves; anxiety is that pain which one feels on the prospect of an evil. Distress always depends uoon 
some outward cause; anxiety often lies in the imagination. Distress is produced by the present but not always immediate evil; anxiety respects that which is future; anguish arises from the reflection on the evil that is past; agony springs from witnessing that which is immediate or before the eye.

Distress is not peculiar to any age; where there is a consciousness of good and evil, pain and pleasure, distress will inevitably exist from some circumstance or another. Anxiety, anguish, and agony belong to riper years: infancy and childhood are deemed the happy periods of human existence because they are exempt from the anxieties attendant on every one who has a station to fill and duties to discharge. Anguish and agony are species of distress, of the severer kind, which spring altogether from the maturity of reflection and the full consciousness of evil. A child is in distress when it loses its mother, and the mother is also in distress when she misses her child. The station of a parent is, indeed, that which is most productive, not only of distress, but of anxiety, anguish, and agony: the mother has her peculiar anxieties for her child while rearing it in its infant state: the father has his anxiety for its welfare on its entrance into the world: they both suffer the deepest anguish when their child disappoints their dearest hopes by running a career of vice; not unfrequently they are doomed to suffer the agony of seeing a child encircled in flames from which he cannot be snatched, or sinking into a watery grave from which he cannot be rescued.

See also Afruict.

Distress, Harass, Perplex.-Distress (see above). Harass, in French harasser, is possibly derived from Old French harer, to set a dog on, from an Old High German word to call out. Perplex, in Latin perplexus, participle of perplector, compounded of plectere, to plait, with the prefix per, through, meaning to braid in and out, hence to make something difficult to unravel or to understand.

A person is distressed either in his outward circumstances or his feelings; he is harassed mentally or corporeally; he is perplexed in his understanding more than in his feelings: a deprivation distresses; provocations and hostile measures harass; stratagems and ambiguous measures perplex: a besieged town is distressed by the cutting off its resources of water and provisions; the besieged are harassed by perpetual attacks; the besiegers are perplexed in all their manœuvres and plans by the countermanœuvres and contrivances of their opponents: a tale of woe distresses; continual alarms and incessant labor harass; unexpected obstacles and inextricable difficulties perplex.

DISTRIBUTE, Allot, Assign, ApPORTION. Distribute, in Latin distributus, participle of distribuo, from dis, apart, and tribuere, to bestow, signifies to portion out to several. Allot (for derivation see ALLOT). Assign, in French assigner, Latin assigno, from $a d$, to, and signare, to set 9 , seal to, signifies, by signing or marking, to set out for a particular purpose. A pportion, from $a d$, to, and portio, a part prepared, signifies to give by way of portion for a particular purpose.

The idea of giving to several is common to these terms; this is the proper signification of distribute; but to that of the other terms is annexed some qualification. Distributing is always applied to a number of individuals, but allotting, assigning, or apportioning is the giving either to one or several: a sum of money is distributed among a number of poor people; it is allotted, assigned, or apportioned to a particular individual, or to each individual out of a number. Distribute is said properly of that which is divided, or divisible into any number of parts, as bread is distributed in loaves, or money is distributed in the way of shillings; allotted is applied to that which is divisible into lots, and apportion to that which is formed into certain proportional parts or portions, as to allot land, to give a lot of land; to apportion a sum of money - that is, to give it in certain proportions. Assign is applied to any distinct whole, not considered either as divided or divisible, as to assign a house, place, etc. To distribute is to give promiscuously, without reference to the nature of objects or the purpose for which they are given; things may be distributed to the worthy 
or the unworthy, to those who want it or those who do not, at the will of the distributor or otherwise. To allot is tc give according to the lots into which the thing is divided for a given purpose, as to allot land to each cottager; to assign is to set apart something that is suited to the person or adapted for the object proposed, as a prize is assigned to the most meritorious; a house is assigned for the reception of the houseless wanderer; to apportion is to give in a certain proportion according to a certain rule, as to apportion rent to different houses according to their size and value.

So in the figurative or moral application, the goods or ills of life are distributed by a wise Providence, but of ten in ways or for purposes that are hidden from our view.

Particular portions of that which is desirable, or the contrary, is allotted to each according to the circumstances of the case.

Offices, duties, properties, and the like are assigned according as they really are or are supposed to be suitable.

Labor, happiness, misery, or anything of which only parts can be had, may be apportioned.

See also Dispense; Divide.

DISTRICT, REgION, TraCT, QUARTER. District is derived from the past participle of the verb distringere, from dis, apart, and stringere, to pull. It means to pull asunder, to vex, hence to force or rule; a district was a section in which a lord has power to enforce justice. Region, in Latin regio, from regere, to rule, signifies a portion that is within rule. Tract, in Latin tractus, from trahere, to draw, signifies a part drawn out. Quarter, from Latin quartus, signifies literally a fourth part.

These terms are all applied to portions of country, the former two comprehending divisions marked out on political grounds; the latter a geographical or an indefinite division: district is smaller than a region; the former refers only to part of a country, the latter frequently applies to a whole country: a quarter is indefinite, and may be applied either to a quarter of the world or a particular neighborhood: a tract is the smallest portion of all, and comprehends frequently no more than what may fall within the compass of the eye. We consider a district only with relation to government; every magistrate acts within a certain district: we speak of a region when considering the circumstances of climate, or the natural properties which distinguish different parts of the earth; as the regions of heat and cold: we speak of the quarter simply to designate a point of the compass; as a person lives in a certain quarter of the town that is north or south, east or west, etc.; and so also, in an extended application, we say to meet with opposition in an unexpected quarter: we speak of a tract to designate the land that runs on in a line; as a mountainous tract.

DISTRUST, Suspicion, DiffiDENCE. Distrust signifies not putting trust in (see Belief). Suspicion, from the Latin suspicio, or sub and specere, signifies looking at askance, or with a wry mind. Diffidence, from the Latin diffido or disfido, signifies having no faith.

Distrust is said of either ourselves or others; suspicion is said only of others; diffidence only of ourselves: to be distrustful of a person is to impute no good to him; to be suspicious of a person is to impute positive evil to him: he who is distrustful of another's honor or prudence will abstain from giving him his confidence; he who is suspicious of another's honesty will be cautious to have no dealings with him.

Distrust is a particular state of feeling having a specific object; suspicion is an habitual state of feeling, and has indefinite objects.

As regards one's self, a person may distrust his own powers for the execution of a particular office, or a distrust of himself in company; he has a general diffidence, or he is naturally diffident.

DISTURB, INTERRUPT. Disturb (see Commotion). Interrupt, from the Latin inter, between, and rumpere, to break, signifies to break in between so as to stop the progress.

We may be disturbed either inwardly or outwardly; we are interrupted only outwardly: our minds may be disturbed by disquieting reflections, or we may be disturbed in our rest or in our business by unseemly noises; but we 
can be interrupted only in our business or pursuits: the disturbance, therefore, depends upon the character of the person; what disturbs one man will not disturb another: an interruption is, however, something positive: what interrupts one person will interrupt another: the smallest noises may disturb one who is in bad health; illness or the visits of friends will interrupt a person in any of his business.

The same distinction exists between these words when applied to things as to persons: whatever is put out of its order or proper condition is disturbed; thus water which is put into motion from a state of rest is disturbed: whatever is stopped in the evenness or regularity of its course is interrupted; thus water which is turned out of its ordinary channel is interrupted.

See also Trouble; Worry.

DISTURBANCE. See Commotion.

DITCH. See TrEnch.

DIURNAL. See DaILY.

DIVE. See Plunge.

DIVERGE. See Deflect.

DIVERS. See Different.

DIVERSION. See AMUSement.

DIVERSITY. See Difference.

DIVERT. See AMUSE.

DIVERTED. See AbSENT.

Divide, Separate, Part. comes from Latin dis, apart, and lost verb meaning to separate. Separate (see ABstract). Part signifies to make into parts.

That is said to be divided which has been or is conceived to be a whole, that is separated which might be joined: an army may be divided into two or three divisions or portions: the divisions are frequently separated in their march. Things may be divided by anything which distinguishes the parts from one another; they are separated by disjunction of space only.

Things may be mentally divided, but they are separated only corporeally: the minds of men are often most divided when in person they are least separated.

To part has an intermediate sense between divide and separate; to divide is properly to make any whole into two parts; to part is to destroy the cohesion of two or more wholes when joined together: a loaf is divided when it is cut into two or more pieces; two loaves are parted. Sometimes things are both divided and parted in order to be distributed; in this case the distinction is the same; solid things, or what is in a mass, is divided; but things which do not lose their integrity are parted: an estate is divided; goods or effects are parted.

As disjunction is the common idea attached to both separate and part, they are frequently used in relation to the same objects; things are mostly said to be parted which are made to be apart for any temporary purpose or by any means, however slight or trivial; thus rooms may be parted by a partition; that is said to be separated which is intended to be kept permanently separate, or which ought not to be joined; thus fields are separated by hedges.

With regard to persons, part designates the actual leaving of the person; separate is used in general for that which lessens the society; the former is often casual, temporary, or partial; the latter is positive and serious; the parting is momentary; the separation may be longer or shorter: two friends part in the streets after a casual meeting; two persons separate on the road who had set out to travel together; men and their wives often part without coming to a positive separation: some couples are separated from each other in every respect but that of being directly parted; the moment of parting between friends is often more painful than the separation which afterward ensues.

Divide, Distribute, Share. - Divide (see above). Distribute, in Latin distributus, from distribucre, or dis and tribuere, signifies to bestow apart. Share, allied to the word shear, and the German scheeren, signified originally to cut.

The act of diriding does not extend beyond the thing divided; that of distributing and sharing comprehends also the purpose of the action: we divide the thing; we distribule to the person: we may divide, therefore, without distributing; or we may divide in order to distribute: thus we divide our land into distinct fields for our private convenience; or we divide a sum of money 
into so many parts, in order to distribute it among a given number of persons: on the other hand, we may distribute without dividing; for money, books, fruit, and many other things may be distributed which require no division.

To share is to make into parts, the same as divide, and it is to give those parts to some persons, the same as distribute; but the person who shares takes a part himself; he who distributes gives it all to others; a loaf is divided in order to be eaten, bread is distributed in loaves among the poor; the loaf is shared by a poor man with his poorer neighbor, or the profits of a business are shared by the partners.

To share may imply either to give or to receive; to distribute implies giving only: we share our own with another, or another shares what we have; but we distribute our own to others.

DIVINE. See Ecclesiastic; GodLIKE; GUESS; Holy.

DIVINITY. See Deity.

DIVISION. See PART.

DIVORCE, Separation. Divorce, in French the same form, from the Latin divortium, compounded of dis, apart, and vertere, to turn, means the legal dissolution of the marriage contract, with a complete severance of all mutual claims and the right to remarry. A separation, often called a legal separation or a judicial separation, is a separation countenanced or required by a court of law, but not implying a complete severance of the marriage tie or the right to remarry. Divorce is often used, in a figurative sense, to refer to any disunion of things which have been closely united, and separation, of course, has also a wider application. See Separate.

DIVUlge. See Publish.

DO. See ACT.

DOCile, Tractable, Ductile. Docile, in Latin docilis, from docere, to teach, means ready to be taught. Tractable, from tractare, the frequentative of trahere, to draw, denotes the readiness to be drawn. One is docile as a scholar; one is tractable as a child or a servant. Where anything is to be learned, docility is necessary; where anything is to be done at the call of another, tractability is required. Duc- tility, from duco, to lead, signifies aptness to be led, and is applied to the mind or its powers, which yield readily to impressions.

Animals may be said to be docile and tractable with a like distinction; inanimate objects, as metals, etc., may be ductile.

DOCTRINe, Precept, Principle. Doctrine, in French doctrine, Latin doctrina, from docere, to teach, signifies the thing taught; precept, from the Latin pro, before, and capere, to take, signifies the thing placed before one as a guide to conduct. Principle comes from French principe, Latin principium, the beginning of things, their first or original component parts.

A doctrine requires a teacher; a precept requires a superior with authority; a principle requires only a maintainer or holder. A doctrine is always framed by some one; a precept is enjoined or laid down by some one; a principle lies in the thing itself. A doctrine is composed of principles; a precept rests upon principles or doctrines. Pythagoras taught the doctrine of metempsychosis, and enjoined many precepts on his disciples for the regulation of their conduct, particularly that they should abstain from eating animal food and be only silent hearers for the first five years of their scholarship: the former of these rules depended upon the preceding doctrine of the soul's transmigration to the bodies of animals; the latter rested on that simple principle of education, the entire devotion of the scholar to the master. We are said to believe in doctrines, to obey precepts, to imbibe or hold principles. Doctrine is that which constitutes our faith; precepts are that which directs the practice: both are the subjects of rational assent, and suited only to the matured understanding: principles are often admitted without examination, and imbibed as frequently from observation and circumstances as from any direct personal efforts; children as well as men acquire principles.

Doctrine, Dogma, Tenet.-A doctrine originates with an individual. Dogma,

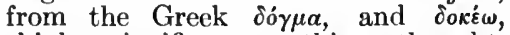
think, signifies something thought, admitted, or taken for granted; this lies with a body or number of individ- 
uals. Tenet, from the Latin tenet, he holds, signifies the thing held or maintained, and is a species of principle specifically maintained in matters of opinion by persons in general. A doctrine rests on the authority of the individual by whom it is framed; the dogma, on the authority of the body by whom it is maintained; a tenet rests on its own intrinsic merits. Many of the doctrines of our blessed Saviour are held by faith in him; they are subjects of persuasion by the exercise of our rational powers; the dogmas of the Romish Church are admitted by none but such as admit its authority: every sect has its peculiar tenets.

DOGMA. See Doctrine.

DOGMATICAL. See Confident; Oracular.

DOLEFul. See Piteods.

DOMESTIC. See Servant.

DOMICILE, Habitation, Home House, Residence. These words all signify a dwelling-place, but they differ in their application and in the dignity of their usage. Domicile, from Latin domus, home, is the Latin term corresponding to the native English home, Anglo-Saxon ham. Home is the familiar and homely word, carrying with it all the emotional and imaginative connotations of the intimate communal life of those bound together by ties of birth and affection. Domicile is the corresponding intellectual and "learned" word, meaning more than the mere externals of home indicated in habitation or residence, for instance, but emptied of all emotional content, and sometimes employed, like many Latin words in English, with a slightly humorous assumption of dignity. Domicile is also used as a verb meaning "to make one's self at home." Habitation, from Latin habitare, a frequentative of habere, to have, means simply a dwelling-place. House also signifies a dwelling-place, but it is a more specific term than habitation, indicating a certain kind of permanent shelter, built for warmth and comfort. A house is a habitation; but a habitation is not necessarily a house. Tents, dug-outs, caves, etc., may be habitations. Many people have a sentimental habit of substituting home for the word house, when they mean merely the structure that may contain a home. "We have bought a new home," they say, meaning merely that they have bought a new house to contain the old home. A house is the outside shell of a home. Residence is used to indicate a house of some pretension and stateliness. We speak of a spacious residence, a handsome residence, etc. It may also be extended to refer simply in a general way to one's dwelling-place, as when we speak of residence in the city, etc., not referring to any specific habitation, but merely the general idea of living or dwelling.

DOMINEERING. See IMPERIoUs. DOMINION. See EMPIRe; Power; TERRITORY.

DONATION. See Benefaction; GiFT,

DOOM. See Destiny; Sentence. DOUBT, QUESTION. Doubt, in French douter, Latin dubito, from duo, two, and ire, past participle itus, to go, signifies a state in which the mind is going in two directions, as it were, or does not know which direction to take. Question, in Latin quastio, from quœerere, to inquire, signifies to make a question.

Both these terms express the act of the mind in staying its decision. Doubt lies altogether in the mind; it is a less active feeling than question: by the former we merely suspend deeision; by the latter we actually demand proofs in order to assist us in deciding. We may doubt in silence: we eannot question without expressing it, directly or indireetly. He who suggests doubts does it with caution: he who makes a question throws in difficulties with a degree of confidenee. Doubts insinuate themselves on the part of the doubter; questions are always made with an express design. We doubt in matters of general interest, on abstruse as well as common subjects: we question mostly in ordinary matters that are of a personal interest: we doubt the truth of a position; we question the veraeity of an author. When the practicability of any plan is questioned, it is unnecessary to enter any further into its merits.

The doubt is frequently confined to the individual; the question frequently respects others. We doubt whether we 
shall be able to succeed; we question another's right to interfere: we doubt whether a thing will answer the end proposed; we question the utility of any one making the attempt. There are many doubtful cases in medicine, where the physician is at a loss to decide; there are many questionable measures proposed by those who are in or out of power which demand consideration. $\mathbf{A}$ disposition to doubt everything is more inimical to the cause of truth than the readiness to believe everything; a disposition to question whatever is said or done by others is much more calculated to give offence than to prevent deception.

See also Demur.

Doubt, Suspense. - Doubt respects that which we should believe; suspense that which we wish to know or ascertain. We are in doubt for the want of evidence; we are in suspense for the want of certainty. Doubt interrupts our progress in the attainment of truth; suspense impedes us in the attainment of our objects: the former is connected principally with the understanding; the latter acts altogether upon the hopes. We have our doubts about things that have no regard to time; we are in suspense about what is to happen in the future. Those are the least inclined to doubt who have the most thorough knowledge of a subject; those are the least exposed to the unpleasant feeling of suspense who confine their wishes to the present.

See also QUANDARY.

Doubtful, Dubious, Uncertain, Precarious. - The doubtful admits of doubt; the dubious creates doubt or suspense. The doubtful is said of things in which we are required to have an opinion; the dubious respects events and things that must speak for themselves. In doubt$f u l$ cases it is advisable for a judge to lean to the side of mercy; while the issue of a contest is dubious, all judgment of the parties, or of the case, must be carefully avoided.

Doubtful and dubious have always a relation to the person forming the opinion on the subject in question; uncertain and precarious are epithets which designate the qualities of the things themselves. Whatever is uncertain may from that very circum- stance be doubtful or dubious to those who attempt to determine upon them; but they may be designated for their uncertainty, without any regard to the opinions which they may give rise to. A person's coming may be doubtful or uncertain, the length of his stay is oftener described as uncertain than as doubtful. The doubtful is opposed to that on which we form a positive conclusion, the uncertain to that which is definite or prescribed. The efficacy of any medicine is doubtful; the manner of its operation may be uncertain. While our knowledge is limited, we must expect to meet with many things that are doubtful; as everything in the world is exposed to change, and all that is future is entirely above our control, we must naturally expect to find everything uncertain but what we see passing before us.

Precarious, from the Latin precarius, and precare, to pray, signifies granted to entreaty, depending on the will or humor of another, whence it is applicable to whatever is obtained from others. Precarious is the highest species of uncertainty, applied to such things as depend on future casualties in opposition to that which is fixed and determined by design. The weather is uncertain; the subsistence of a person who has no stated income or source of living must be precarious. It is uncertain what day a thing may take place until it is determined; there is nothing more precarious than what depends upon the favors of princes.

DOWNFALL. See FaLL.

DOZE. See SleEP.

DRAIN. See SPEND.

DRAMATIC. See Theatrical.

DRAW, Drag, HaUl or Hale, Pull, Pluck, Tug. Draw comes from Anglo-Saxon dragan, German tragen, to draw, and drag is the Scandinavian form of the same word. Haul or hale comes through French from an Old High German word signifying to require or get. Pull comes from AngloSaxon-pullian, to pull or pluck. Pluck is a Teutonic word which may possibly be borrowed from Late Latin piluccare, Italian piluccare, from pilus, hair (English pile), meaning to pluck out hairs. Tug is a Scandinavian word; compare Icelandic $t o g$, a rope to pull by. 
Draw expresses here the idea common to the first three terms, namely, of putting a body in motion from behind one's self or toward one's self; to drag is to draw a thing with violence, or to draw that which makes resistance; to haul is to drag it with still greater violence. We draw a cart; we drag a body along the ground; or haul a vessel to the shore. To pull signifies only an effort to draw without the idea of motion: horses pull very long sometimes before they can draw a heavily laden cart uphill. To pluck is to pull with a sudden twitch, in order to separate; thus feathers are plucked from animals. To tug is to pull with violence; thus men tug at the oar.

In the moral application of the words we may be said to be drawn by anything which can act on the mind to bring us near to an object; we are dragged only by means of force; we pull a thing toward us by a direct effort. To haul, pluck, and tug are seldom used but in physical application.

DREAD. See APPrehend; Awe.

DREADFUL. See Fearful; ForMIDABLE.

DREAM, Revery. Dream is a word of uncertain origin apparently unrelated to the Anglo-Saxon dream, which meant joy, and allied to Old Norse drauge, a ghost, the radical meaning being a deceptive appearance, an illusion. Compare German trïgen, to deceive. Revery, in French réverie, like the English rave and the Latin rabies, madness, originally signified something wandering or incoherent.

Dreams and reveries are alike opposed to the reality; and have their origin in the imagination; but the former commonly passes in sleep, and the latter when awake; the dream may and does commonly arise when the imagination is in a sound state; the revery is the fruit of a heated imagination: dreams come in the course of nature; reveries are the consequence of a peculiar ferment.

When the term dream is applied to the act of one that is awake it admits of another distinction from revery. They both designate what is confounded, but the dream is less extravagant than the revery. Ambitious men please themselves with dreams of future greatness; enthusiasts debase the purity of the Christian religion by blending their own wild reveries with the doctrines of the Gospel. He who indulges himself in idle dreams lays up a store of disappointment for himself when he recovers his recollection, and finds that it is nothing but a dream: a love of singularity operating on an ardent mind will too often lead men to indulge in strange reveries.

DREGS, Sediment, Dross, Scum, Refuse. Dregs is a Scandinavian word; it is the plural form of a word which in Middle English means mire. Sediment, from sedere, to sit, signifies that which settles at the bottom. Dross is a Germanic word; compare German drusen, meaning husks of grapes. Scum comes from a Scandinavian word meaning froth or foam, and referred especially to the scum thrown off from metals in the process of melting. Refuse comes from Latin re, away, and fundere, to pour, signifying that which is poured out, thrown away.

All these terms designate the worthless part of any body; but dregs is taken in a worse sense than sediment, for the dregs is that which is altogether of no value; but the sediment may sometimes form a necessary part of the body. The dregs are mostly a sediment in liquors, but many things are a sediment which are not dregs. After the dregs are taken away, there will frequently remain a sediment; the dregs are commonly the corrupt part which separates from compound liquids, as wine or beer; the sediment consists of the heavy particles which belong to all simple liquids, not excepting water itself. The dregs and sediment separate of themselves, but the scum and dross are forced out by a process; the former from liquids, and the latter from solid bodies rendered liquid or otherwise. Dross is applied to solid bodies in the same sense as scum, being that which remains after the purifying. as the dross of corn after threshing and cleaning. Refuse, as its derivation implies, is always said of that which is intentionally separated to be thrown away, and agrees with the former terms only inasmuch as they express what is worthless. With this distinction 
they are figuratively applied to moral objects.

DRENCH. See SoAK.

DRIFT. See Tendency; Tenor.

DROLL. See Farcical; Ladghable.

DROOP. See FALL.

DROSS. See Dregs.

DROWSE. See Sleep.

DRUDGE. See Servant.

DRUMMER, COMMERCIAI-TRAVELler, Salesman, Solicitor. Drummer is a pure Americanism, supposed to have been derived from the old custom of having a man beat a drum to attract people to a circus, fair, show, recruiting-place, and the like, and signifies, literally one who drums up or summons people for a special purpose. Its general application is to a person employed by a manufacturer or merchant to solicit or "drum up trade," to secure new customers, to open up new lines of business. The professional drummer is not regarded in the same light as a salesman. The latter may be a graduated drummer, but his business is more particularly to keep in touch with the customers he has secured for his employer, ascertain the condition or amount of their stock of commodities he is interested in, and make such sales as he can.

The commercial-traveller and the salesman are quite similar in quality, but with this difference: the former travels extensively and at regular seasons to meet his customers at their places of business, and the latter usually remains at the home house to meet the customers from other cities who come to his house for purchases, though he, too, may travel. Again, a salesman may be an ordinary employee in a retail store who waits on and sells to ordinary patrons. The drummer and solicitor are also quite similar in quality, as both seek orders for goods from any one likely to buy, whether regular customers or strangers.

DUbious. See Doubtrul.

DUCTILE. See. Docile.

DUll, Gloomy, Sad, Dismal. Dull comes from Anglo-Saxon dol, foolish, German toll, mad. Gloomy is in Middle English gloumen, to lower, and is allied to Norwegian glyma, an overcast sky; compare the adjective glum. Sad, Anglo-Saxon sad, meant originally sated; hence tired, dispirited, grieved. Dismal comes from Latin diesmali, bad days, unlucky days.

When applied to natural objects, dull and gloomy denote the want of necessary light or life: in this sense metals are more or less dull according as they are stained with dirt: the weather is either dull or gloomy in different degrees, that is, dull when the sun is obscured by clouds, and gloomy when the atmosphere is darkened by fogs or thick clouds. Dismal denotes not merely the want of that which is necessary, but also the presence of that which is repugnant to the senses; as a glare of light or a sound may be dismal. A room is dull, gloomy, or dismal, according to circumstances: it is dull if the usual quantity of light and sound be wanting; it is gloomy if the darkness and stillness be very considerable; it is dismal if it have only light enough to show its wretchedness; in this sense a dungeon is a dismal abode. Sad is not applied so much to sensible as moral objects, in which sense the distressing events of human life, as the loss of a parent or a child, is justly denominated sad.

In regard to the frame of mind which is designated by these terms, it will be easily perceived from the above explanation. As slight circumstances produce dulness, any change, however small, in the usual flow of spirits may be termed dull. Gloom weighs heavy on the mind, and gives a turn to the reflections and the imagination: desponding thoughts of futurity will spread a gloom over every other object. Sad indicates a wounded state of the heart, feelings of unmixed pain.

See also Obtuse; Stupid.

DUMB. See Silent.

DUNCE. See NiNNY.

DUPLICITY. See Deceit.

DURable, Lasting, Permanent. Durable is said of things that are intended to remain a shorter time than that which is lasting; and permanent expresses less than durable. Durable, from the Latin durus, hard, respects the texture of bodies and marks their capacity to hold out. Lasting is the participle of the verb last from the 
Anglo-Saxon lastan, to observe, perform, originally to follow in the track of, from last, a foot-track (found in the shoemaker's term-last of a shoe). It is applicable to that which is of the longest duration. Permanent, from the Latin per, through, and manere, to remain, signifies remaining to the end.

Durable is naturally said of material substances, and lasting of those which are spiritual, although in ordinary discourse sometimes they exchange offices: permanent applies more to the affairs of men. That which perishes quickly is not durable; that which ceases quickly is not lasting; that which is only for a time is not permanent. Stone is more durable than iron, and iron than wood: in the feudal times animosities between families used to be lasting; a clerk has not a permanent situation in an office.

Durable, Constant. - Durability lies in the thing. Constancy lies in the person. What is durable is so from its inherent property; what is constant is so by the power of the mind. No durable connections can be formed where avarice or lust prevails.

DURATION, Trme. In the philosophical sense, according to Locke, time is that mode of duration which is formed in the mind by its own power of observing and measuring the passing objects. In the vulgar sense, in which duration is synonymous with time, it stands for the time of duration, and is more particularly applicable to the objects which are said to last; time being employed in general for whatever passes in the world.

Duration comprehends the beginning and end of any portion of time, that is, the how long of a thing; time is employed more frequently for the particular portion itself, namely, the time when: we mark the duration of a sound from the time of its commencement to the time that it ceases; the duration of a prince's reign is an object of particular concern to his subjects if he be either very good or the reverse; the time in which he reigns is marked by extraordinary events: the historian computes the duration of reigns and of events in order to determine the antiquity of a nation; he fixes the exact time when each person begins to reign and when he dies, in order to determine the number of years that each reigned.

\section{See also Continuance.}

DUTIABLE. See Ethical.

DUTIFUL, OBEDIENT, RespectFul. Dutiful signifies full of a sense of duty or full of what belongs to duty. Obedient signifies ready to obey. Respectful signifies literally full of respect.

The obedient and respectful are but modes of the dutiful: we may be dutiful without being either obedient or respectful; but we are so far dutiful as we are either obedient or respectful. Duty denotes what is due from one being to another: it is independent of all circumstances: obedience and respect are relative duties depending upon the character and station of individuals: as we owe to no one so much as to our parents, we are said to be dutiful to no earthly being besides; and in order to deserve the name of dutiful a child, during the period of his childhood, ought to make a parent's will to be his law, and at no future period ought that will ever to be an object of indifference: we may be obedient and respectful to others besides our parents, although to them obedience and respect are in the highest degree and in the first case due; yet servants are enjoined to be obedient to their masters, wives to their husbands, and subjects to their king. Respectful is a term of still greater latitude than either; for as the characters of men as much as their stations demand respect, there is a respectful deportment due toward every superior.

Duty, Obligation.-Duty, as we see in the preceding section, consists altogether of what is right or due from one being to another. Obligation, from the Latin obligo, to bind, signifies the bond or necessity which lies in the thing.

All duty depends upon moral obligation which subsists between man and man or man and his Maker; in this abstract sense, therefore, there can be no duty without a previous obligation, and where there is an obligation it involves a duty; but in the vulgar acceptation, duty is applicable to the conduct of men in their various relations; obligation only to particular circum- 
stances or modes of action: we have duties to perform as parents and children, as husbands and wives; as rulers and subjects, as neighbors and citizens: the debtor is under an obligation to discharge a debt; and he who had promised is under an obligation to fulfil his promise: a conscientious man, therefore, never loses sight of the obligations which he has at different times to discharge. The duty is not so peremptory as the obligation; the obligation is not so lasting as the duty: our affections impel us to the discharge of duty; interest or necessity impels us to the discharge of an obligation: it may therefore sometimes happen that the man whom a sense of duty cannot actuate to do that which is right will not be able to withstand the obligation under which he has laid himself.

See also Business; TaX. DWELL. See AbIDE. DYE. See ColOR. 
EACH. See AlL.

EAGER, EArNest, Serious. Eager (see Avidity.) Earnest, Anglo-Saxon eornest, meaning earnestness, comes from a root found in Greek ő $\rho v v \mu$, to excite, and in Icelandic arnbrick, implying intensity of spirit; not the same as pledge (see below). Serious, Latin serius, grave, earnest, may possibly be allied to German schwer, heavy.

Eager is used to qualify the desires or passions; earnest, to qualify the wishes or sentiments; the former has either a physical or moral application, the latter altogether a moral application: a child is eager to get a plaything; a hungry person is eager to get food; a covetous man is eager to seize whatever comes within his grasp: a person is earnest in solicitation, earnest in exhortation, earnest in devotion. Eagerness is mostly faulty; it cannot be too early restrained in children. Whence this term is with particular propriety applied to brutes.

Earnestness is always taken in the good sense for the inward conviction of the mind, accompanied with the warmth of the heart in a good cause. A person is said to be earnest, or in earnest; a person or thing is said to be serious: the former characterizes the temper of the mind, the latter characterizes the object itself. In regard to persons, in which alone they are to be compared, earnest expresses more than serious; the former is opposed to lukewarmness, the latter to unconcernedness: we are earnest as to our wishes or our persuasions; we are serious as to our intentions: the earnestness with which we address another depends upon the force of our conviction; the seriousness with which we address them depends upon our sincerity and the nature of the subject: the preacher earnestly exhorts his hearers to lay aside their sins; he seriously admonishes those who are guilty of irregularities.

Earnest, Pledge. - In the proper sense, the earnest, compounded of Old French erres, arres, from Latin arrha and a diminutive, is given as a token of our being in earnest in the promise we have made; the pledge, in all probability from plico, to fold or implicate, signifies a security by which we are engaged to indemnify for a loss. When a contract is only verbally formed, it is usual to give earnest; whenever money is advanced, it is common to give a pledge.

In the figurative application the terms bear the same analogy: a man of genius sometimes, though not always, gives an earnest in youth of his future greatness; children are the dearest pledges of affection between parents.

EAGERNESS. See AVIDITT.

EARLY. See Soon.

EARN. See ACQUIRE.

EARNESTNESS. See UNCTION.

EARTH. See Cosmos.

EASE, Quiet, Rest, Repose. Ease comes from the French aise, a word of unknown origin. Quiet is derived from Latin quietus, quiet. Rest comes from Anglo-Saxon rest, originally, perhaps, a halting-place. Repose comes from Latin re, back, and French poser, to place, from Late Latin pausare, allied to pause; it means to place one's self backward in an easy posture.

The idea of a motionless state is common to all these terms: ease and quiet respect action on the body; rest and repose respect the action of the body: we are easy or quiet when freed from any external agency that is painful; we have rest or repose when the body is no longer in motion. Ease denotes an exemption from any painful agency in general; quiet denotes an exemption from that in particular which noise, disturbance, or the violence of others may cause: we are casy or at ease when the body is in a posture agreeable to itself, or when no circumjacent object presses unequally upon it; we are quiet when there is an agrecable 
stillness around: our ease may be disturbed either by internal or external causes; our quiet is most commonly disturbed by external objects.

Rest simply denotes the cessation of motion; repose is that species of rest which is agreeable after labor: we rest as circumstances require; in this sense, our Creator is said to have rested from the work of creation: repose is a circumstance of necessity; the weary seek repose; there is no human being to whom it is not sometimes indispensable. We may rest in a standing posture; we can repose only in a lying position: the dove which Noah first sent out could not find rest for the sole of its foot; soldiers who are hotly pursued by an enemy have no time or opportunity to take repose: the night is the time for rest; the pillow is the place for repose.

Rest may be as properly applied to things as to persons; repose is figuratively applied to things.

Ease, Easiness, Facility, Lightness.Ease denotes either the abstract state of a person or quality of a thing; easiness, from easy, signifying having ease, denotes simply an abstract quality which serves to characterize the thing; a person enjoys ease, or he has an easiness of disposition.

Ease is said of that which is borne, or that which is done; easiness and facility, from the Latin facilis, easy, from facere, to do, most commonly of that which is done; the former in application to the thing as before, the latter either to the person or the thing: we speak of the easiness of the task, but of a person's facility in doing it: we judge of the easiness of a thing by comparing it with others more difficult; we judge of a person's facility by comparing him with others who are less skilful.

Ease and lightness are both said of what is to be borne; the former in a general, the latter in a particular sense. Whatever presses in any form is not easy; that which presses by excess of weight is not light: a coat may be easy from its make; it can be light only from its texture. A work is easy which requires no particular effort either of body or of mind from any one performing it; a work is light as far as it requires no bodily effort, or not more than what the individual can easily make who has to perform it.

The same distinction exists between their derivatives, to ease, facilitate, and lighten; to ease is to make easy or free from pain, as to ease a person of his labor; to facilitate is to render a thing more practicable or less difficult, as to facilitate a person's progress; to lighten is to take off an excessive weight, as to lighten a person's burdens.

Easy, Ready.-Easy signifies here a freedom from obstruction in ourselves. Ready is derived from rade, which meant literally equipped for riding, prepared for a raid - all these words coming from the same root.

Easy marks the freedom of being done; ready, the disposition or willingness to do; the former refers mostly to the thing or the manner, the latter to the person; the thing is easy to be done: the person is ready to do it; it is easy to make professions of friendship in the ardor of the moment; but every one is not ready to act up to them when it interferes with his convenience or interest. As epithets, both are opposed to difficult, but agreeably to the above explanation of the terms; the former denotes a freedom from such difficulties or obstacles as lie in the nature of the thing itself; the latter an exemption from such as lie in the temper and character of the person; hence we say a person is easy of access whose situation, rank, employments, or circumstances do not prevent him from admitting others to his presence; he is ready to hear when he himself throws no obstacles in the way, when he lends a willing ear to what is said. So likewise a task is said to be easy; a person's wit, or a person's reply, to be ready.

EASTERN. See OrIENT.

EBULlition, EFFERVESCENCE, Fermentation, Ferment. These technical terms have a strong resemblance in their signification, but they are not strictly synonymous; they have strong characteristic differences. Ebullition, from the Latin ebullitio and ebullio, compounded of $e$ and bullire, to bubble, boil, marks the commotion of a liquid acted upon by fire, and in chemistry it is said of two substances which, 
by penetrating each other, occasion bubbles to rise up. Effervescence, from the Latin effervescentia, and effervescere, to grow hot, marks the commotion which is excited in liquors by a combination of substances, such as of acids, which are mixed and commonly produce heat. Ferment, or fermentation, from the Latin fermentatio and fermentum or fervimentum, from fervere, to grow hot, marks the internal movement which is excited in a liquid of itself, by which its components undergo such a change or decomposition as to form a new body.

Ebullition is a more violent action than effervescence; ferment and fermentation are more gradual and permanent than either. Water is exposed to ebullition when acted upon by any powerful degree of external heat; iron in aqua-fortis occasions effervescence; beer and wine undergo a ferment or fermentation before they reach a state of perfection. These terms are applied figuratively to moral objects. The passions are exposed to ebullitions; the heart and affections to effervescence when powerfully awakened by particular objects. The minds or spirits, particularly of numbers, may be in a ferment or fermentation. If the angry humors of an irascible temper be not restrained in early life, they but too frequently break forth in the most dreadful ebullitions in maturer years; religious zeal, when not constrained by the sober exercise of judgment and corrected by sound knowledge, is an unhappy effervescence that injures the cause which it espouses and often proves fatal to the individual by whom it is indulged: the ferment produced by public measures may often endanger the public peace.

ECCENTRIC. See Erratic; ParTICULAR.

ECClesiastic, Divine, TheoLOGIAN. An ecclesiastic derives his title from the office which he bears in the ecclesia, or church; a divine and theologian, from his pursuit after or engagement in divine or theological matters. An ecclesiastic is connected with an episcopacy; a divine or theologian is unconnected with any form of church government. An ecclesiastic need not in his own person perform any office, although he fills a station; a divine not only fills a station, but actually performs the office of teaching; a theologian neither fills any particular station nor discharges any specific duty, but merely follows the pursuit of studying theology. An ecclesiastic is not always a divine, nor a divine an ecclesiastic; a divine is always more or less a theologian, but every theologian is not a divine. Among the Roman Catholics all monks, and in the Church of England the various dignitaries who perform the episcopal functions, are entitled ecclesiastics. There are but few denominations of Christians who have not appointed teachers who are called divines. Professors or writers on theology are peculiarly denominated theologians.

ECLIPSE, Obscure. Eclipse, from Greek $\dot{\varepsilon} \kappa$, out, and $\lambda \varepsilon i \pi \varepsilon \nu$, to leave, means the leaving out or vanishing of light. Obscure, from the adjective obscure (see DARK), significs to cause the intervention of a shadow.

In the natural as well as the moral application eclipse is taken in a particular and relative signification; obscure is used in a general sense. Heavenly bodies are eclipsed by the intervention of other bodies between them and the beholder; things are in general $o b$ scured which are in any way rendered less striking or visible. To eclipse is thercfore a species of obscuring: that is always obscured which is eclipsed; but everything is not eclipsed which is obscured. So, figuratively, real merit is eclipsed by the intervention of superior merit; it is often obscured by an ungracious exterior in the possessor or by his unfortunate circumstances.

ECONOMICAL, Saving, Sparixg, Thrifty, Penurious, Niggardly. The idea of not spending is common to all these terms; but cconomical signifies not spending unnecessarily or unwisely. Saving is kecping and laying by with care; sparing is keeping out of that which ought to be spent; thrifty or thriving is accumulating by means of saving; penurious is suffering as from penury by means of saving; niggardly, after the manner of a niggard, nigh or close person, is not spending or letting go but in the smallest possible quantities. To be economical 
is a virtue in those who have but narrow means; all the other epithets, however, are employed in a sense more or less unfavorable; he who is saving when young will be avaricious when old; he who is sparing will generally be sparing out of the comforts of others; he who is thrifty commonly adds the desire of getting with that of saving; he who is penurious wants nothing to make him a complete miser; he who is niggardly in his dealings will be mostly avaricious in his character.

Economy, Frugality, Parsimony.Economy, from the Greek oikovopia, the management of a house, is derived from Greek oícos, house, and v'́ $\mu \varepsilon \iota \nu$, to deal out. Frugality, from the Latin fruges, fruits, means subsisting on the fruits of the earth, hence temperance. Parsimony (see Avaricrous) implies simply forbearing to spend, which is in fact the common idea included in these terms; but the economical man spares expense according to circumstances; he adapts his expenditure to his means and renders it by contrivance as effectual to his purpose as possible; the frugal man spares expense on himself or on his indulgences; he may, however, be liberal to others while he is frugal toward himself as well as others; he has no other object than saving. By economy a man may make a limited income turn to the best account for himself and his family; by frugality he may with a limited income be enabled to lay by money; by parsimony he may be enabled to accumulate great sums out of a narrow income; hence it is that we recommend a plan for being economical; we recommend a diet for being frugal; we condemn a habit or a character for being parsimonious.

Economy, Management. - Economy has a more comprehensive meaning than management; for it includes the system of science and of legislation as well as that of domestic arrangements: as the economy of agriculture; the internal economy of a government; political, civil, or religious economy: or the economy of one's household. Management, on the contrary, is an action that is very seldom abstracted from its agent, and is always taken in a partial sense, namely, as a part of economy. The internal economy of a family depends principally on the prudent management of the female: the economy of every well-regulated community requires that all the members should keep their station and preserve a strict subordination; the management of particular branches of this economy should belong to particular individuals.

ECONOMIZE. See Husband.

ECSTASY, Rapture, Transport. There is a strong resemblance in the meaning and application of these words. They all express an extraordinary elevation of the spirits or an excessive tension of the mind. Ecstasy marks a passive state, from the Greek

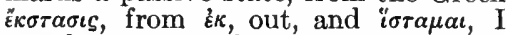
stand, means to be out of one's self, out of one's mind. Rapture, from the Latin rapere, to seize or carry away; and transport, from trans and portare, to carry beyond one's self, rather designate an active state, a violent impulse with which it hurries itself forward. Ecstasy and rapture are always pleasurable, or arise from pleasurable causes; transport respects either pleasurable or painful feelings: joy occasions ecstasies or raptures; joy and anger have their transports. An ecstasy benumbs the faculties; it will take away the power of speech and often of thought; it is commonly occasioned by sudden and unexpected events: rapture, on the other hand, often invigorates the powers and calls them into action; it frequently arises from deep thought: the former is common to all persons of ardent feelings, but more particularly to children, ignorant people, or to such as have not their feelings under control; rapture, on the contrary, is applicable to persons with superior minds and to circumstances of peculiar importance. Transports are sudden bursts of passion which, from their vehemence, may lead to intemperate actions: a reprieve from the sentence of death will produce an ecstasy or delight in the pardoned criminal. Religious contemplation is calculated to produce holy raptures in a mind strongly imbued with pious zeal: in transports of rage men have committed enormities which have cost them bitter tears of repentance ever after: youth is the period in which transports of delight are mostly felt. 
EDGE. See Border.

EDICT. See Decree; Ordinance. EDIFICE, Structure, Fabric. Edifice, in Latin œdificium, from adifico, or oedes, a house, and facere, to make, signifies properly the house made. Structure, from the Latin structura, and struere, to heap together, signifies the raising a thing or the thing raised. Fabric comes from Latin faber, a workman, from a base signifying skill, and means something made by skill.

Edifice in its proper sense is always applied to a building; structure and fabric are either employed as abstract actions or the results and fruits of actions: in the former case they are applied to many objects besides buildings, structure referring to the act of raising or setting up together, fabric to that of framing or contriving. As edifice bespeaks the thing itself, it requires no modification, since it conveys of itsclf the idea of something superior: the word structure must always be qualified; it is employed only to designate the mode of action; fabric is itself a species of epithet, it designates the object as something contrived by the power of art or by design. Edifices dedicated to the service of religion have in all ages been held sacred: it is the business of the architect to estimate the merits or demerits of any structure; when we take a survey of the vast fabric of the universe, the mind becomes bewildered with contemplating the infinite power of its Divine author.

When employed in the abstract sense of actions, structure is limited to objects of magnitude, or such as consist of complicated parts: fabric is extended to everything in which art cr contrivance is requisite; hence we may speak of the structure of vessels, and the fabric of cloth, ironware, or the fabric of states, the universe, etc.

EDUCATION, I N S T R U C TION, BREEDING. Instruction and breeding are to education as parts to a whole: instruction respects the communication of knowledge, and breeding respects the manners or outward conduct; but education comprehends not only both these, but the formation of the mind, the regulation of the heart, and the establishment of the principles: good instruction makes one wiser; good breeding makes one more polished and agreeable; good education makes one really good. A want of education will always be to the injury, if not to the ruin, of the sufferer: a want of instruction is of more or less inconvenience, according to circumstances; a want of breeding only unfits a man for the society of the cultivated. Education belongs to the period of childhood and youth; instruction may be given at different ages; good-breeding is best learned in the early part of life.

EFFACE. See BLot.

EFFECT, Produce, Perform. The latter two are in reality included in the former; what is effected is both produced and performed; but what is produced or performed is not always effected. To effect, in Latin effectus, participle of efficio, compounded of ex, out, and facere, to make, signifies to make out anything. To produce, from the Latin pro, forth, and ducere, to draw, signifies literally to draw forth. To perform, Old French parfournir, from Latin per, through, and Old High German frumjan, to provide, French fournir, English furnish, significs to do or provide everything necessary.

To produce signifies to bring something forth or into existence; to perform to do something to the end: to effect is to produce an effeet by performing; whatever is effected is the consequence of a specific design; it always requires, therefore, a rat ıonal agent to effect: what is produced nay follow incidentally, or arise from the action of an irrational agent or an inanimate object; what is performed is done by speeific efforts; it is, therefore, like effect, the consequence of design, and requires a rational agent. To cffect respeets both the end and the means by which it is brought about; to produce respects the end only; to perform the means only. No person ought to calculate on effecting a reformation in the morals of men without the aid of religion; changes both in individuals and communities are often produced by trifles.

To effect is said of that which emanates from the mind of the agent himself; to perform, of that which is marked 
out by rule or prescribed by another. We effect a purpose, we perform a part, a duty, or office. A true Christian is always happy when he can effect a reconciliation between parties who are at variance: it is a laudable ambition to strive to perform one's part creditably in society.

See also Accompursh; CoNse-
QUENCE.

Effective, Efficient, Effectual, Efficacious.-Effective signifies capable of effecting; efficient signifies, literally, effecting; effectual and efficacious signify having the effect, or possessing the power to effect. Effective and efficient are used only in regard to physical objects: an army or a revenue is effective that can be employed to effect any object: a cause is efficient that is adequate to produce an effect.

Effectual and efficacious are said of operations and intellectual objects: an end or result is effectual; the means are efficacious: a remedy or cure is effectual that is in reality effected; a medicine is efficacious that effects a cure. No effectual stop can be put to the vices of the lower orders while they have a vicious example from their superiors: a seasonable exercise of severity on an offender is often very efficacious in quelling a spirit of insubordination. When a thing is not found effectual, it is requisite to have recourse to further measures; that which has been proved to be inefficacious should never be adopted.

EFFECTS. See Goods.

EFFEMINATE. See Female.

EFFERVESCENCE. See EBuLLITION.

EFFICACIOUS. See EFFECT.

EFFIGY. See LiknNess.

EFFORT. See ATTEMPT; ENDEAVOR.

EFFRONTERY. See AUDACITY.

EFFUSION, EJaCULATION. Effu. sion signifies the thing poured out, from $e x$, out, and fundere, to pour, and ejaculation, the thing ejaculated or thrown out, from $e x$, out, and iacere, to throw, both indicating a species of verbal expression; the former either by utterance or in writing; the latter only by utterance. The effusion is not so vehement or sudden as the ejaculation; the ejaculation is not so ample or dif- fuse as the effusion; effusion is seldom taken in a good sense; ejaculation rarely otherwise. An effusion commonly flows from a heated imagination uncorrected by the judgment; it is, therefore, in general not only incoherent, but extravagant and senseless: an ejaculation is produced by the warmth of the moment, but never without reference to some particular circumstance. Enthusiasts are full of extravagant effusions; contrite sinners will often express their penitence in pious ejaculations.

EGOISTICAL. See MisanthropICAL; OPINIONATED.

EJACULATION. See EfFusion.

ELATED. See SANGUINE.

ELDER. See SENIOR.

ELDERLY, AGED, OLD. These three words rise by gradation in their sense; aged denotes a greater degree of age than elderly, and old still more than either. The elderly man has passed the meridian of life; the aged man is fast approaching the term of our existence; the old man has already reached this term or has exceeded it. In conformity, however, to the vulgar prepossession against age and its concomitant infirmities, the term elderly or aged is always more respectful than old, which latter word is often used by way of reproach, and can seldom be used free from such an association unless qualified by an epithet of praise, as good or venerable.

ELECT. See Choose.

ELECTRIC, MAGNETIC. Electric comes from Latin electrum, Greek

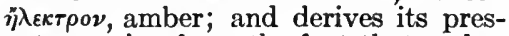
ent meaning from the fact that amber developed electricity when excited by friction. Magnetic referred to a similar property observed in the magnesian stone, so called because it was found in large quantities in magnesia. This stone had the power to attract iron and steel. Both words originally referred to the attractive power associated with certain substances under certain conditions. But, as the science of electricity has developed, magnetic has been associated with the properties of the magnet and electric with a force or current existent or generated under certain conditions. When used figuratively electric refers to the swift and 
thrilling quality of electricity, magnetic to a quality of attractiveness associated with the mysterious thrill of electrical force.

ELEGANT. See SUPERB.

ELEMENTARY, CoNSTITUENT, Primary, Rudimentary. Elementary is the adjective corresponding to element, Latin elementum, a word whose etymology and primary meaning are uncertain, but which is used to indicate one of the simple substances of which all material bodies are compounded. Constituent, from Latin con, together, and statuere, to set up, indicates that which when joined to something else goes to make up a complex whole. But it does not indicate a simple or uncompounded substance, as does elementary. Primary, from Latin primus, first, means the first elements, the things absolutely necessary to form a contemplated whole; but it does not definiteiy suggest the combination of substances as does constituent. Rudimentary, from Latin rudimentum, from rudis, rough, indicates the first rude state of things. These words, therefore, all mean characteristic of that which is necessary to the formation of a complex whole; but they differ in the emphasis upon the character of the thing indicated, and its relation to a larger whole.

\section{ELEVATE. See LiFT.}

ELIGIBLE, Preferable. Eligible, or fit to be elected, and preferable, fit to be preferred, serve as epithets in the sense of choose and prefer (see Choose; Prefer); what is eligible is desirable in itself, what is preferable is more desirable than another. There may be many eligible situations, out of which perhaps there is but one preferable. Of persons, however, we say rather that they are eligible to an office than preferable.

ELOCUTION, Eloquence, OraTORY, RHETORIC. Elocution and eloquence are derived from the same Latin verb, eloqui, from $e x$, out, and loqui, to speak, to speak out. Oratory, from orare, to implore, signifies the art of making a set speech.

Elocution consists in the manner of delivery; eloquence in the matter that is delivered. We employ elocution in repeating the words of another; we employ eloquence to express our own thoughts and feelings. Elocution is requisite for an actor; eloquence for a speaker.

Eloquence lies in the person: it is a natural gift: oratory lies in the mode of expression; it is an acquired art. Rhetoric is properly the theory of that art of which oratory is the practice. But the term rhetoric may be sometimes employed in an improper sense for the display of oratory or scientific speaking. Eloquence speaks one's own feelings; it comes from the heart and speaks to the heart: oratory is an imitative art; it describes what is felt by another. Rhetoric is either in the technical sense the science of oratory, or oratory reduced to rule, or, in the vulgar acceptation, it is the affectation of oratory.

\section{ELUCidate. See Explain.}

ELUDE. See Escape.

EMANATE. See Arise.

EMANCIPATE, ENFRANCHISE, UNSHACKLE. Emancipate comes from Latin emancipare, e manibus capere, to take out of the hands of, and referred to the provision made in Roman law for freeing a child or a wife from the pow $r$ of the father or husband. It also referred to the freeing of slaves. Enfranchise comes from Old French franchise, privileged liberty, and referred especially to the admitting of a slave or a serf to personal freedom. The two words have therefore almost exactly the same meaning, but enfranchise has also been given the special significance of to admit to the full rights of a citizen, especially to grant the right to vote. Hence when we speak of the emancipation of the negro slaves, we refer to the decree of the President delivering them from the power of their masters. When we speak of their enfranchisement, we refer to the passing of the amendment to the Constitution of the United States granting them the right to vote. Unshackle is a figurative word from shackle (see CHAIN), meaning to deliver from shackles, and may be used to mean either emancipate or enfranchise or free in a still larger sense. See FrEE.

EMBARGO, BAN, Prohibition. Embargo, Spanish embargo, from barra, a bar, means a prohibiting order, for- 
bidding the ships of a foreign power to enter or leave the ports of a country or native ships to proceed there, generally issued in anticipation of war. It also indicates a suspension of commerce by municipal law. Ban is an older term of Germanic origin signifying a formal edict-a call to arms, an announcement of intention to marry, or an ecclesiastical excommunication. Prohibition (for derivation see BAN) is used in a special sense to refer to the forbidding of the sale of alcoholic liquor by the law of a community. It refers to a special embargo on alcoholic drink.

See also INTERN.

EMBARRASS, Perplex, ENTaNGLE. Embarrass (see DifficulTY) respects a person's manners or circumstances, perplex (see Distress), his views and conduct; entangle (see DisENGAGE) is said of particular circumstances. Embarrassments depend altogether on ourselves; the want of prudence and presence of mind is the common cause; perplexities depend on extraneous circumstances as well as ourselves; extensive dealings with others are mostly attended with perplexities; entanglements arise mostly from the evil designs of others. That embarrasses which interrupts the even course or progress of one's actions: that perplexes which interferes with one's decisions: that entangles which binds a person in his actions. Pecuniary difficulties embarrass, or contending feelings produce embarrassment; contrary counsels or interests perplex; the artifices of cunning entangle. Steadiness of mind prevents embarrassment in the outward behavior. Firmness of character is requisite in the midst of perplexities; caution must be employed to guard against entanglements.

EMBARRASSMENT. See QUANDARY.

EMBARRASSMENTS. See DifFICULTIES.

EMBELLISH. See Adorn; GarNISH.

EMBLEM. See FiguRE.

EMBOLDEN. See Encodrage.

EMBRACE. See Clasp; CoMprise.

EMBRYO, FoETUS. Embryo, in French embryon, Greek $\tilde{\varepsilon} \mu \beta \rho v o \nu$, from $\beta \rho v i \varepsilon \nu$, to swell out or germinate, sig- nifies the thing germinated. Fotus, Latin fœetus, comes from an obsolete Latin verb signifying to generate or produce, and signifies the thing cherished. Both words refer to what is formed in the womb of the mother; but embryo properly implies the first-fruit of conception, and the foetus that which is arrived to a maturity of formation. Anatomists tell us that the embryo in the human subject assumes the character of the foetus about the fortysecond day after conception.

Foetus is applicable only in its proper sense to animated beings: embryo has a figurative application to plants and fruits when they remain in a confused and imperfect state, and also a moral application to plans, or whatever is roughly conceived in the mind.

See also Germ.

EMEND. See AMEND.

EMERGE. See RISE.

EMERGENCE. See EXIGENCY.

EMINENT. See Distinguished.

EMISSARY, SPY. Emissary, in Latin emissarius, from emittere, to send forth, signifies one sent out. Spy is a shortened form of espy, which comes through French espier, from Old High German spehon, German spähen, to spy.

Both these words designate a person sent out by a body on some public concern among their enemies; but they differ in their office according to the etymology of the words. The emissary is by distinction sent forth; he is sent so as to mix with the people to whom he goes, to be in all places, and to associate with every one individually as may serve his purpose; the spy, on the other hand, takes his station wherever he can best perceive what is passing; he keeps himself at a distance from all but such as may particularly aid him in the object of his search. Although the offices of emissary and spy are neither of them honorable, yet that of the former is more disgraceful than that of the latter. The emissary is generally employed by those who have some illegitimate object to pursue; spies, on the other hand, are employed by all regular governments in a time of warfare. Nations that are at war sometimes send emissaries into the states of the enemy to excite civil commo- 
tions. At Sparta, the trade of a spy was not so vile as it has been generally esteemed; it was considered as a selfdevotion for the public good, and formed a part of their education.

These terms are applied to other objects figuratively.

See also SPY.

eMIT, Exhale, Evaporate. Emit, from the Latin emittere, expresses properly the act of sending out: exhale, from halitus, the breath, and evaporate, from vapor, vapor or steam, are both modes of emitting.

Emit is used to express a more positive effort to send out; exhale and evaporate designate the natural and progressive process of things; volcanoes emit fire and lava; the earth exhales the damps, or flowers exhale perfumes; liquids evaporate. Animals may emit by an act of volition; things exhale or evaporate by an external action upon them; they exhale that which is foreign to them; they evaporate that which constitutes a part of their substance. The skunk emits such a stench from itself when pursued as to keep its pursuers at a distance from itself: bogs and fens exhale their moisture when acted upon by the heat: water evaporates by means of steam when put into a state of ebullition.

See also Transpire.

EMOLUMENT. See GaIN.

EMOTION. See Agitation.

EMPHASIS. See STrEss.

EMPIRE, KingDOM, REPUBLIC. Although the first two words obviously refer to two species of states, where the princes assume the title of either emperor or king, yet the difference between them is not limited to this distinction.

The word empire carries with it the idea of a statc that is vast and composed of many different people; that of kingdom marks a state more limited in extent and united in its composition. In kingdoms there is a uniformity of fundamental laws, the difference in regard to particular laws or modes of jurisprudence being merely variations from custom, which do not affect the unity of political administration. From this uniformity, indced, in the functions of government, we may trace the origin of the words king and kingdom, since there is but one prince or sovereign ruler, although there may be many employed in the administration. With empires it is different: one part is sometimes governed by fundamental laws very different from those by which another part of the same empire is governed, which diversity destroys the. unity of government and makes the union of the state to consist in the submission of certain chiefs in the commands of a superior general or chief. From this very right of commanding, then, it is evident that the words empire and emperor derive their origin; and hence it is that there may be many princes or sovereigns, and kingdoms, in the same empire. Rome, therefore, was first a kingdom while it was formed of only one people: it acquired the name of empire as soon as other nations were brought into subjection to it and became members of it, not by losing the distinctive character as nations, but by submitting themselves to the supreme command of their conquerors. For the same reason the German empire was so denominated because it consisted of several states independent of one another, yet all subject to one ruler or emperor; so likewise the Russian empire, the Ottoman empire, and the former Mogul empire, which were composed of different nations: and, on the other hand, the kingdom of Spain and of England, both of which, though divided into different provinces, were, nevertheless, onc people, having but one rulcr. While France, however, included many distinct countries within its jurisdiction, it properly assumed the name of an empire, and, with Portugal later, took the name of republic; and England, having by a legislative act united to itself a country distinct both in its laws and customs, has likewise, with equal propriety, been denominated the British empire.

The term republic applies both to countries as vast as the United States, Brazil, and Mexico, as several in Europe, and also to smaller ones, as those in Central and South America and some parts of Europe; and the term represents the form of government, the supreme authority being chosen or delegated by the people instead of bcing hereditary in a single family. 
Empire, Reign, Dominion.-In the preceding article empire has been considered as a species of state: in the present case it conveys the idea of power or an exercise of sovereignty. In this sense it is allied to the word reign, which, from the verb to reign, signifies the act of reigning; and to the word dominion, which, from the Latin dominus, a lord, signifies either the power or the exercise of the power of a lord.

As empire signifies command, or the power exercised in commanding, it properly refers to the country or people commanded; and as reign signifies the act of reigning, it refers to the individual who reigns. If we speak of an extended empire, it has regard to the space over which it extends; if of an extended reign, it has regard either to the country reigned over or to the length of time that a prince reigns.

From this distinction of the terms the epithets vast, united, dismemberized, and the like are most appropriately applied to empire; the epithets peaceful, warlike, glorious, prosperous, and the like, to reign. Empire and reign are properly applied to civil government or the exercise of regular power; dominion signifies either the act of ruling by a sovereign or a private individual, or the power exercised in ruling, which may be either regular or irregular; a sovereign may have dominion over many nations by force of arms; he holds his reign by force of law.

If empire and reign be extended in their application to other objects, it is figurative; thus a female may be said to hold her empire among her admirers, or fashions may be said to have their reign. Dominion may be applied in the proper sense to the power which man exercises over the brutes or inanimate objects, and figuratively to the power of the passions.

In countries under the republican form of government the entire body of citizens constitute the sovereignty. They choose the Congress, which is the highest lawmaking authority, and elect the President, who is the chief executive of the laws,

EMPIRICAL, EXPERIMENTAL, HYPothetical, Provisional, Tentative. All these words mean "not yet estab- lished as an absolute fact, but serving as a working basis" for further discovery. But the failure to establish as an absolute fact or law is indicated under somewhat different conditions. Empirical, from Greek $\dot{k} \nu$, on, in, and $\pi \varepsilon i \rho \alpha$, trial, experience, refers to knowledge gained simply from observation and experience, not based on any thorough study of cause and effect or even on scientific experiment. Experimental, on the other hand, coming from Latin experiri, to make a thorough trial of, means the process of discovering laws or facts through systematized observation; experimental simply suggests an incomplete process of discovery. Hypothetical, from Greek $\dot{v} \pi o^{\prime}$, under, and $\theta^{\prime} \sigma \iota \varsigma$, a placing; it is the adjective corresponding to hypothesis. A hypothesis is a formulation of a possible law which has not yet been fully demonstrated by experience. That which is experimental may be as yet unformulated; that which is hypothetical may be formulated, but not yet proved by experiment. Provisional, from pro, forward, and videre, to see, means taken as truth or right until a better way can be discovered; it is a formulation of a principle or method of action with the distinct expectation that it will be superseded; and is intended to serve as a means to an end. Tentative, from Latin tentare, to try, also means experimental, but it refers to informal rather than formal and systematic experiment, and partly suggests the meaning of provisional. That which is tentative is tried as an experiment till something better can be discovered.

EMPLOY, UsE. Employ, from the Latin in, in, and plicare, to fold, signifies to implicate or apply for any special purpose. Use, from the Latin usus, past participal of utor, signifies to enjoy or derive benefit from.

Employ expresses less than use; it is in fact a species of partial using: we always employ when we use; but we do not always use when we employ. We employ whatever we take into our service or make subservient to our convenience for a time; we use whatever we entirely devote to our purpose. Whatever is employed by one person may, in its turn, be employed by an- 
other, or at different times be employed by the same person; but what is used is frequently consumed or rendered unfit for a similar use. What we employ may frequently belong to another; but what one uses is supposed to be his exclusive property. On this ground we may speak of employing persons as well as things: but we speak of using things only, and not persons, except in the most degrading sense. Persons, time, strength, and power are employed; houses, furniture, and all materials, of which either necessities or conveniences are composed, are used. It is a part of wisdom to employ well the short portion of time which is allotted to us in this sublunary state, and to use the things of this world so as not to abuse them. No one is exculpated from the guilt of an immoral action 'by suffering himself to be employed as an instrument to serve the purposes of another: we ought to use our utmost endeavors to abstain from all connections with such as wish to implicate us in their guilty practices.

EMPLOYMENT. See Business; Vocation.

EMPOWER. See CoMmission.

EMPTY, VaCaNT, VoId, Devoid. Empty is in Anglo-Saxon cemta, cmetta, meaning leisure. Void and devoid come from Old French voide, of unknown origin, meaning empty.

Empty is the term in most general use; vacant, void, and devoid are employed in particular cases; empty and vacant have either a proper or an improper application; void or devoid only a moral acceptation. Empty, in the natural sense, marks an absence of that which is substantial, or adapted for filling: vacant designates or marks the absence of that which should occupy or make use of a thing. That which is hollow may be empty: that which respects an even space may be vacant. $\mathrm{A}$ house is empty which has no inhabitants; a seat is vacant which is without an occupant; a room is empty which is without furniture; a space on paper is vacant which is free from writing.

In their figurative application empty and vacant have a similar analogy: the empty is opposed to that which is substantial: the vacant to that which is or ought to be occupied; a dream is said to be empty, or a title empty; a stare is said to be vacant, or an hour vacant.

Void and devoid are used in the same sense as vacant, as qualifying epithets, but not prefixed as adjectives, and always followed by some object; thus we speak of a creature as void of reason, and of an individual as devoid of common sense.

See also Holnow.

EMULATION. See CoMpetition.

ENCHANT. See CharM.

ENCHANTED. See Spellbodnd.

ENCIRCLE. See SURround.

ENCOMIUM, EUlogy, PANegYric. Encomium comes from Greek $\dot{t} v$, in, and $\kappa \hat{\omega} \rho o s$, revelry, and signifies a set form of verses used on festive occasions for the purposes of praise. Eulogy, in

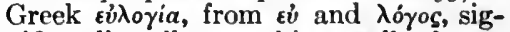
nifies, literally, speaking well of any one. Panegyric, in Greek $\pi a v \eta \gamma v \rho c v^{2}$, from $\pi \dot{\alpha} \nu$, the whole, and $\alpha$ yopi, an assembly, signifies that which is spoken before an assembly, a solemn oration.

The idea of praise is common to all these terms; but the first seems more properly applied to the thing, or the unconscious object; the second to persons in general, their characters and actions; the third to the person of some particular individual: thus we bestow encomiums upon any work of art or production of genius, without reference to the performer; we bestow eulogies on the exploits of a hero, who is of another age or country; but we write panegyrics either in a direct address or in direct reference to the person who is panegyrized: the encomium is produced by merit, real or supposed; the eulogy may spring from admiration of the person eulogized; the panegyric may be mere flattery, resulting from servile dependenee: great encomiums have been paid by all persons to the constitution of England; our naval and military heroes have received the eulogies of many besides their own countrymen; authors of no mean reputation have condescended to deal out their panegyrics pretty freely, in dedications to their patrons.

ENCOMPASS. See Brsiege.

ENCOUNTER. See ATTACK.

ENCOURAGE, ANIMATE, INCITE, Impel, UrGe, Stimdlate, INVesti- 
gate. Encourage (see Cheer). Animate (see ANIMATE). Incite, from the Latin citare, to stir up, signifies to put into motion toward an object. Impel (see ActuATE). Urge comes from Latin urgere, to drive. Stimulate, from the Latin stimulus, a spur or goad, and instigate, from the Latin stigo, signify literally to goad. The idea of actuating or calling into action is common to these terms, which vary in the circumstances of the action.

Encouragement acts as a persuasive: animate, as an impelling or enlivening cause: those who are weak require to be encouraged; those who are strong become stronger by being animated: the former require to have their difficulties removed, their powers renovated, their doubts and fears dispelled; the latter may have their hopes increased, their prospects brightened, and their powers invigorated; we are encouraged not to give up or slacken in our exertions; we are animated to increase our efforts: the sinner is encouraged by offers of pardon, through the merits of a Redeemer, to turn from his sinful ways; the Christian is animated by the prospect of a blissful eternity, to go on from perfection to perfection.

What encourages and animates acts by the finer feelings of our nature; what incites acts through the medium of our desires: we are encouraged by kindness; we are animated by the hope of reward: we are incited by the desire of distinction.

What impels, urges, stimulates, and instigates acts forcibly, be the cause internal or external: we are impelled and stimulated mostly by what is internal; we are urged and instigated by both the internal and the external, but. particularly the latter: we are impelled by motives; we are stimulated by appetites and passions; we are urged and instigated by the representations of others: a benevolent man is impelled by motives of humanity to relieve the wretched; an ardent mind is stimulated by ambition to great efforts; we are urged by entreaties to spare those who are in our power; one is instigated by malicious representations to take revenge on a supposed enemy.

We may be impelled and urged, though not properly stimulated or in- stigated, by circumstances; in this case the former two differ only in the degree of force in the impelling cause: less constraint is laid on the will when we are impelled than when we are urged, which leaves no alternative or choice: a monarch is sometimes impelled by the state of the nation to make a peace less advantageous than he would otherwise do; he is urged by his desperate condition to throw himself upon the mercy of the enemy: a man is impelled by the mere necessity of choosing to take one road in preference to another; he is urged by his pecuniary embarrassments to raise money at a great loss.

We may be impelled, urged, and stimulated to that which is bad; we are never instigated to that which is good; we may be impelled by curiosity to pry into that which does not concern us; we may be urged by the entreaties of those we are connected with to take steps of which we afterward repent; we may be stimulated by a desire of revenge to many foul deeds; but those who are not hardened in vice requirc the instigation of persons more abandoned than themselves before they will commit any desperate act of wickedness.

Encouragement and incitement are the abstract nouns either for the act of encouraging or inciting, or the thing that encourages or incites: the encouragement of laudable undertakings is itself laudable; a single word or look may be an encouragement: the incitement of passion is at all times dangerous, but particularly in youth; money is said to be an incitement to evil. Incentive, which is another derivative from incite, has a higher application for things that incite than the word incitement; the latter being mostly applied to sensible, and the former to spiritual objects: savory food is an incitement to sensualists to indulge in gross acts of intemperance: a religious man wants no incentives to virtues; his own breast furnishes him with those of the noblest kind. Impulse is the derivative from impel, which denotes the act of impelling; stimulus, which is the root of the word stimulate, naturally designates the instrument, namely, the spur or goad, with which one is stimulated: hence, we 
speak of acting by a blind impulse, or wanting a stimulus to exertion.

See also Hearten.

Encourage, Advance, Promote, Prefer, Forward.-To encourage (see above). Advance (see ADvance). Promote, from the Latin pro, forward, and movere, to move, signifies to move forward. Prefer, from the Latin profero, from pro, before, and ferre, to carry, signifies to set up before others. To forward is to put forward.

The idea of exerting an influence to the advantage of an object is included in the signification of all these terms, which differ in the circumstances and mode of the action: to encourage, advance, and promote are applicable to both persons and things; prefer, to persons only; forward, to things only.

First as to persons, encourage is partial as to the end, and indefinite as to the means: we may encourage a person in anything, however trivial, and by any means; thus we may encourage a child in his rudeness by not checking him; or we may encourage an artist or man of letters in some great national work; but to advance, promote, and prefer are more general in their end and specific in the means; a person may advance himself, or may be advanced by others; he is promoted and preferred only by others: a person's advancement may be the fruit of his industry, or result from the efforts of his friends; promotion and preferment are the work of one's friends; the former in regard to offices in general, the latter mostly in regard to ecclesiastical situations: it is the duty of every one to encourage, to the utmost of his power, those among the poor who strive to obtain an honest livelihood; it is every man's duty to advance himself in life by every legitimate means; it is the duty and the pleasure of every good man in the state to promote those who show themselves deserving of promotion; it is the duty of a minister to accept of preferment when it offers, but it is not his duty to be solicitous for it.

When taken in regard to things, encourage is used in an improper or figurative acceptation; the rest are applied properly: if we encourage an undertaking, we give courage to the undertaker; but when we speak of advancing a cause, or promoting an interest, or forwarding a purpose, these terms properly convey the idea of keeping things alive or in a motion toward some desired end: to advance is, however, generally used in relation to whatever admits of extension and aggrandizement; promote is applied to whatever admits of being brought to a point of maturity or perfection; forward is but a partial term, employed in the sense of promote in regard to particular objects: thus we advance religion or learning; we promote an art or an invention; we forward a plan.

Encourage, Embolden.-To encourage is to give courage, and to embolden to make bold, the former impelling to action in general, the latter to that which is more difficult or dangerous: we are encouraged to persevere; the resolution is thereby confirmed: we are emboldened to begin; the spirit of enterprise is roused. Success encourages; the chance of escaping danger $\mathrm{em}$ boldens.

ENCROACH, INTRENCH, INTRUdE, INVADE, INFRINGE. Encroach comes through Old French en crochier, from French en (Latin in), and Middle Dutch kroke, hook (corresponding to English (rook), and means literally to hook in. Intrench, from Latin in and trencare for truncare, to cut, from truncus, the trunk of a tree, signifies to cut into another's territory. Intrude comes from Latin in, and trudere, to thrust, meaning, literally, in the slang phrase, "to butt in." Invade, from in, in, and vadere, to go, signifies to march in upon. Infringe, from the Latin infringo, compounded of in and frangere, to break, signifies to break in upon.

All these terms denote an unauthorized procedure; but the first two designate gentle or silent actions, the latter violent if not noisy actions. Eneroach is often an imperceptible action, performed with such art as to elude observation; it is, according to its derivation, an insensible ereeping into: intrench is, in fact, a species of encroachment, namely, that perceptible species which consists in exceeding the boundaries in marking out the ground or space.

In an extended and figurative application of the terms one is said to 
encroach on a person or on a person's time, etc.; to intrench on the sphere or privilege of another.

Intrude and invade designate an unauthorized entry, the former in violation of right, equity, or good manners, the latter in violation of public law: the former is more commonly applied to individuals; the latter to nations or large communities: unbidden guests intrude themselves sometimes into families to their no small annoyance; an army never invades a country without doing some mischief.

They are figuratively applied to other objects: intrude, in the sense of going in without being invited, as unwelcome thoughts intrude themselves into the mind: invade, in the sense of going in by force, as sounds invade the ear.

To invade and infringe are both violent acts; but there is more violation of good faith in infringing than in invading, as the infringement of a treaty. A privilege may be either invaded or infringed; but to invade in this sense is applied to any privilege, however obtained; but infringe properly applies to that which persons hold under some grant, compact, or law.

ENCUMBER. See Clog.

ENCYCLOPAEDIA. See DiCTIONARY.

END, Terminate, Close. To end is either to come to an end or put an end to. To terminate, either to come to a term or set a term to. To close, to come or bring to a close. To end is indefinite in its meaning and general in its application; terminate and close are modes of ending: to terminate is to end finally; to close, to end gradually. Whatever is begun will end, and it may end in any way; but what terminates is that which has been designedly brought to an end; a string, a line, a verse, etc., may end, but a road is said properly to terminate.

Things may end abruptly or at once, but they close by a process or by bringing the parts or points together; a scene may close, or several lines may close.

Any period of time, as a day, a life, may end or close.

See also Arm; SAKe.

End, Extremity.-Both these words imply the last of those parts which constitute a thing; but the end designates that part generally; the extremity marks the particular point. The extremity is from the Latin extremus, the very last $e n d$, that which is outermost. Hence end may be said of that which bounds anything, but extremity of that which extends farthest from us: we may speak of the ends of that which is circular in its form, or of that which has no specific form; but we speak of the extremities of that only which is supposed to project lengthwise. The end is opposed to the beginning; the $e x-$ tremity to the centre or point from which we reckon. When a man is said to go to the end of a journey or the end of the world, the expression is in both cases indefinite and general: but when he is said to go to the extremities of the earth or the extremities of a kingdom, the idea of relative distance is manifestly implied. He who goes to the end of a path may possibly have a little farther to go in order to reach the extremity. In the figurative application, end and extremity differ so widely as not to admit of any just comparison.

ENDEAVOR, Aim, Strive, StroGGLE. To endeavor is general in its object, aim is particular; we endeavor to do whatever we set about; we aim at doing something which we have set before ourselves as a desirable object. To strive is to endeavor earnestly; to struggle is to strive earnestly. An endeavor springs from a sense of duty (from French en devoir, on duty); we endeavor to do that which is right and avoid that which is wrong: aiming is the fruit of an aspiring temper; the object aimed at is always something superior either in reality or in imagination, and calls for particular exertion: striving is the consequence of an ardent desire; the thing striven for is always conceived to be of importance: struggling is the effect of necessity; it is proportioned to the difficulty of attainment and the resistance which is opposed to it; the thing struggled for is indispensably necessary. Those only who endeavor to discharge their duty to God and their fellow-creatures can expect real tranquillity of mind. Whoever aims at the acquirement of great wealth 
or much power opens the door for much misery to himself. As our passions are acknowledged to be our greatest enemies when they obtain the ascendency, we should always strive to keep them under our control. There are some men who struggle through life to obtain a mere competence, and yet die without succeeding in their object.

Endeavor, Effort, Exertion.-Endeavor (see ATTEMPT and above). Effort comes from Latin ex, out, and fortis, strong, and means to bring force to bear upon. Exertion is derived from Latin ex, out, and serere, to join, or put, meaning to put forth the strength and apply it to something.

The idea of calling our powers into action is common to these terms; endeavor expresses little more than this common idea, being a term of general import: effort and exertion are particular modes of endeavor; the former being a special strong endeavor, the latter a continued strong endeavor. An endeavor is called forth by ordinary circumstances; effort and exertion, by those which are extraordinary. An endeavor flows out of the condition of our being and constitution; as rational and responsible agents we must make daily endeavors to fit ourselves for a hereafter; as willing and necessitous agents we use our endeavors to obtain such things as are agreeable or needful for us: when a particular emergency arises we make a great effort. An endeavor may call forth one or many powers; an effort calls forth but one power: the endeavor to please in socicty is laudable if it do not lead to vicious compliances; it is a laudable effort of fortitude to suppress our complaints in the moment of suffering.

The exertion is as indefinite as the endeavor is to the means, but, like the effort, is definite as to the object: when a serious object is to be obtained, suitable exertions must be madc. The endeavor is mostly applied to individuals, but the exertion may frequently be the combined endeavors of numbers.

ENDLESS. See ETERNAL.

ENDOW. See INVEST.

ENDOWMENT. See GIFT.

ENDURANCE. See Patience.
ENDURE. See Bear; Brook; TolERATE; UNDERGO.

ENEMY, Foe, Adversary, OpPoNent, ANTAGonist. Enemy, in Latin inimicus, compound of in, privative, and amicus, a friend, signifies one that is unfriendly. Foe comes from AngloSaxon fah, hostile. Adversary, in Latin adversarius from adversus, against, signifies one that takes part against another; adversarius in Latin was particularly applied to those who contested a point in law with another. Opponent, in Latin opponens, participle of opponere, from $o b$, in the way of, and ponere, to place, signifies one pitted against another. Antagonist, in Greek

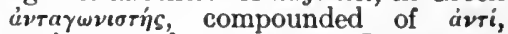

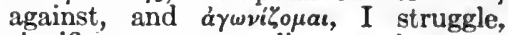
signifies one struggling against another.

An enemy is not so formidable as a foe; the former may be reconciled, but the latter always retains a deadly hate. An enemy may be so in spirit, in action, or in relation; a foe is always so in spirit, if not in action likewise: a man may be an enemy to himself, though not a foe. Those who are national or political enemies are often private friends, but a foe is never anything but a foe. A single act may create an enemy, but continued warfare creates a foe.

Enemies are either public or private, collective or personal; in the latter sense the word enemy is most analogous in signification to that of adversary, opponent, antagonist. The term enemy is always taken in a larger sense than the other terms: a private enemy is never inactive; he seeks to do misehief from the desire of so doing. An adversary, opponent, and antagonist may be so simply from the relation which they stand in to others: the adversary is one who is adverse either in his claims, his opinions, his purposes, or his endeavors; he is active against others only as far as his interests and views requirc. An opponent is one who stands or acts in opposition to another: an opponent opposes the opinions, principles, conduct, and writings of others. An adversary is always personal, and sets himself up immediately against another; but an opponent has nothing to do with the person, but with the thing that emanates from or is connected 
with the person. A man can have no adversaries except while he is living, but he may have opponents after he is dead; partisans are always opponents to each other. An antagonist is a particular species of opponent either in combat or in action; it is personal or otherwise, according to circumstances: there may be antagonists who contend for victory without any feeling of animosity; such were the Horatii and Curiatii among the Romans: or they may engage in a personal and bloody conflict, as the gladiators who fought for their lives: in this sense wild beasts are antagonists when they engage in battle; there are also literary antagonists who are directly pitted against each other: as Scaliger and Petavius among the French; Boyle and Bentley among the English.

Enemy and foe are figuratively applied to moral objects, the first in a general, the second in a particular sense: our passions are our enemies when indulged: envy is a foe to happiness. The word antagonist may also be applied metaphorically to other objects.

ENERGY, ForCe, VIgor. Energy comes from Greek 'vं $\rho$ ' $i \nu$, in, and $\tilde{c}^{\prime}$ yov, work, meaning work put into something. Force (see ComPEL). Vigor, from the Latin vigere, to flourish, signifies' unimpaired power, or that which belongs to a subject in a sound or flourishing state.

With energy is connected the idea of activity; with force, that of capability; with vigor, that of health. Energy lies only in the mind; force and vigor are the property of either body or mind. Knowledge and freedom combine to produce energy of character; force is a gift of nature that may be increased by exercise: vigor, both bodily and mental, is an ordinary accompaniment of youth, but is not always denied to old age.

ENERVATE. See Weaken.

ENFEEBLE. See Weaken.

ENFRANCHISE. See EMANCIPaTION. BiND.

ENGAGE. See ATtract; Bespeak;

ENGAGEMENT. Business; Promise.
ENGENDER. See Breed.

ENGRAVE. See IMPRINT.

ENGRAVING. See Picture.

ENGROSS. See ABSORB; MonopOLIZE.

enigma, Paradox, Ridple. All these words indicate something puzzling, hard to understand or solve, but the character of the implied intellectual difficulty varies. Enigma comes from Greek åı $\nu$ l $\gamma \mu \alpha$, meaning an obscure speech, and referred to a short composition in prose or verse in which something was described by intentionally obscure metaphors, in order to afford an exercise for the ingenuity of the reader in guessing what was meant. Riddle, Anglo-Saxon radels, is the native English term for exactly the same sort of thing. A paradox, from Greek $\pi a \rho a ́$, contrary to, and $\delta \dot{c}^{\xi} a$, opinion, is a statement contrary to received opinion, a statement which on the face of it seems self-contradictory, absurd, or at variance with common sense, though it may be essentially true. An enigma, therefore, is not a paradox, but a paradox, not being intelligible, may seem like an enigma. Between enigma and riddle there is no essential difference. Enigma, being the Greek term and the learned word, less clearly suggests its exact character to the popular mind than the familiar native term riddle. Accordingly it is at once more vague and more dignified. Paradox has an essentially different meaning from enigma and riddle, but it is included because it shares with them the general implication of obscurity-something puzzling to the mind, difficult to solve.

ENJOYMENT, Fruition, GratiFICATION. Enjoyment, from enjoy, to have the joy or pleasure, signifies either the act of enjoying or the pleasure itself derived from that act. Fruition, from frui, to enjoy, is employed only for the act of enjoying; we speak either of the enjoyment of any pleasure or of the enjoyment as a pleasure: we speak of those pleasures which are received from the fruition, in distinction from those which are had in expectation. Enjoyment is either corporeal or spiritual, as the enjoyment of music or the enjoyment of study: but the fruition of eating or any other sensible, or at 
least external, object: hope intervenes between the desire and the fruition.

Gratification, from the verb to gratify, to make grateful or pleasant, signifies either the act of giving pleasure or the pleasure received. Enjoyment springs from every object which is capable of yielding pleasure; by distinction, however, and in the latter sense, from moral and rational objects: but gratification, which is a species of enjoyment, is obtained through the mediu of the senses. Enjoyment is not so vivid as gratification: gratification is not so permanent as enjoyment. Domestic life has its peculiar enjoyments; brilliant spectacles afford gratification. Our capacity for enjoyment depends upon our intellectual endowments; our gratification depends upon the tone of our feelings and the nature of our desires.

ENLARGE, INCREASE, Extend. Enlarge signifies literally to make large or wide, and is applied to dimension and extent. Increase, from the Latin increscere, from in, in, and crescere, to grow, means to grow from within, and is applicable to quantity, signifying to become greater in size by natural development. Extend, in Latin extendo, or ex, out, and tendere, to stretch, signifies to stretch out, that is, to make greater in space. We speak of enlarging a house, a room, premises, or boundaries; of increasing an army or property, capital, expense, etc.; of extending the boundaries of an empirc. We say the hole or cavity enlarges, the head or bulk enlarges; the number increases, the swelling, inflammation, and the like increase: so likewise in the figurative sense, the views, the prospects, the powers, the ideas, and the mind are enlarged; pain, pleasure, hope, fear, anger, or kindness is increased; views, prospects, connections, and the like arc extended.

ENLIGHTEN. See Illuminate.

ENLIST. See ENroll.

ENLIVEN. See Animate.

ENMITY, ANinosity, Hostility. Enmity lies in the heart; it is deep and malignant. Animosity, from animus, a spirit, lies in the passions; it is fierce and vindictive: hostility, from hostis, a political enemy, lies in the action; it is mischicvous and destructive.
Enmity is something permanent; animosity is partial and transitory: in the feudal ages, when the darkness and ignorance of the times prevented the mild influence of Christianity, enmities between particular families were handed down as an inheritance from father to son; in free states party spirit engenders greater animosities than private disputes.

Enmity is altogether personal; hostil ity respects public or private measures. Enmity often lies concealed in the heart and does not betray itself by any open act of hostility.

See also Hatred.

ENORMOUS, HUGE, IMMENSE, VAST. Enormous, from $e$ and norma, a rule, signifies out of rule or order. Huge comes from Anglo-French ahoge, the origin of which is unknown. Immense, in Latin immensus, compounded of in, privative, and mensus, measured, signifies not to be measured. Vast, in French vaste, Latin vastus, waste, signifies characteristic of a great open space, of a waste or wilderness.

Enormous and huge are peculiarly applicable to magnitude; immense and vast to extent, quantity, and number. Enormous expresses more than huge, as immense expresses more than vast: what is enormous exceeds in a very great degree all ordinary bounds; what is huge is great only in the superlative degrec. The enormous is always out of proportion; the huge is relatively extraordinary in its dimensions. Some animals may be made enormously fat by a particular mode of feeding: to one who has seen nothing but level ground common hills will appear to be huge mountains. The immense is that which exceeds all ealeulation: the vast comprehends only a very great or unusual excess. The distance between the earth and sun may be said to be immense: the distance between the poles is vast.

Of all these terms huge is the only one confined to the proper application and in the proper sense of size: the rest arc employed with regard to moral objects. We speak only of a huge animal, a huge monster, a huge mass, a huge size, a huge bulk, and the like; but we speak of an enormous waste, an immense difference, and a vast number. 
Enormous, Prodigious, Monstrous.Enormous (see above). Prodigious comes from prodigy, in Latin prodigium, signifying, literally, breaking out in excess or extravagance. Monstrous, from monster, in Latin monstrum, and monstro, show or make visible, signifies remarkable, or exciting notice.

The enormous contradicts our rules of estimating and calculating; the prodigious raises our minds beyond their ordinary standard of thinking: the monstrous contradicts nature and the course of things. What is enormous excites our surprise or amazement: what is prodigious excites our astonishment: what is monstrous does violence tc our senses and understanding. There is something enormous in the present scale upon which property, whether public or private, is amassed and expended: the works of the ancients in general, but the Egyptian pyramids in particular, are objects of admiration, on account of the prodigious labor which was bestowed on them: ignorance and superstition have always been active in producing monstrous images for the worship of its blind votaries.

ENOUGH, SUFFicient. Enough, Anglo-Saxon genoh, German genug, probably comes from a root signifying to attain to. Sufficient, in Latin sufficiens, participle of sufficio, compounded of sub and facere, to make, signifies made or suited to the purpose.

He has enough whose desires are satisfied; he has sufficient whose wants are supplied. We may therefore frequently have sufficieney when we have not enough. A greedy man is commonly in this case, who has never enough, although he has more than a sufficiency. Enough is said only of physical objects of desire: sufficient is employed in a moral application for that which serves the purpose. Children and animals never have enough food, nor the miser enough money: it is requisite to allow sufficient time for everything that is to be done, if we wish it to be done well.

ENRAPTURE. See Chari.

ENROLL, ENLIST or LIST, REgISTER, REcord. Enroll, compounded of French en, Latin in, and role, from rotula, a little wheel, signifies to place in a roll, that is, in a roll of paper or a book. Enlist is compounded of French en and liste from Old High German lista, a border or strip, signif ying a long strip of paper on which names were written; the verb meaning to put on a list. Register comes from Latin re, back, and gestum, past participle of gerere, to carry, and means a thing carried back, a memorandum brought back; the verb means to write the memorandum. Record, in Latin recorder, compounded of re, back or again, and cors, the heart, signifies to bring back to the heart or call to mind by a memorandum.

Enroll and enlist respect persons only; register respects persons and things: record respects things only. Enroll is generally applied to the act of inserting names in an orderly manner into any book; enlist is a species of enrolling applicable only to the military. The enrolment is an act of authority; the enlisting is the voluntary act of an individual. Among the Romans it was the office of the censor to enroll the names of all the citizens, in order to ascertain their number and estimate their property: in modern times soldiers are mostly raised by means of enlisting.

In the moral application of the terms, to enroll is to assign a certain place or rank; to enlist is to put one's self under a leader or attach one's self to a party. Hercules was enrolled among the gods; the common people are always ready to enlist on the side of anarchy and rebellion.

To enroll and register both imply writing down in a book; but the former is a less formal act than the latter. The insertion of the bare name or designation in a certain order is enough to constitute an enrolment; but registering comprehends the birth, family, and other collateral circumstances of the individual. The object of registering likewise differs from that of enrolling: what is registered serves for future purposes and is of permanent utility to society in general; but what is enrolled of ten serves only a particular or temporary end. Thus in numbering the people it is necessary simply to enroll their names; but when in addition to this it was necessary, as among the Romans, to ascertain their rank in the state, everything connected with their 
property, their family, and their conneetion required to be registered; so in like manner, in more modern times, it has been found necessary for the good government of the state to register the births, marriages, and deaths of every citizen: it is manifest, therefore, that what is registered, as far as respects persons, may be said to be enrolled; but what is enrolled is not always registered. Persons only, or things personal, are enrolled, and that properly for public purposes only; but things as well as persons are registered for private as well as public purposes.

To register in its proper sense is to place in writing; to record is to make a memorial of anything, either by writing, printing, engraving, or otherwise: registering is for some specific and immediate purpose; as to register deerees or other proceedings in a court: recording is for general and oftentimes remote purposes: to record events in history.

In an extended and figurative application, things may be said to be registered in the memory; or events recorded in history. We have a right to believe that the actions of good men are registered in heaven; the particular sayings and actions of princes are recorded in history, and handed down to the latest posterity.

ENSAMPLE. See Example.

ENSLAVE, Captivate. To enslave is to bring into a state of slavery. To captivate is to make a captive.

There is as much difference between these terms as between slavery and captivity: he who is a slave is fettered both body and mind; he who is a captive is only constrained as to his body: hence to enslave is always taken in the bad sense; captivate, in a good or bad sense: enslave is employed literally or figuratively; captivate only figuratively: we may be enslaved by persons or by our gross passions; we are captivated by the charms or beauty of an objeet.

ENSUE. See Follow.

ENTANGLE. See Embarrass; INSNARE.

ENTER. See BEGIN.

ENTERPRISE. See ATTEMPT.

ENTERPRISING, ADVENTUROUS. These terms mark a disposition to engage in that whieh is extraordinary and hazardous; but enterprising. from en- terprise (see АттEмPT), is connected with the understanding; and adventurous, from adventure (from Latin ad, to, and venire, to come, meaning a eoming to, an attempt or trial), is a characteristic of the passions. The enterprising eharacter conceives great projects, and pursues objects that are difficult to be obtained; the adventurous character is contented with seeking that which is new and placing himself in dangerous and unusual situations. An enterprising spirit belongs to the commander of an army or the ruler of a nation; an adventurous disposition is suitable to men of low degree. Peter the Great possessed, in a peculiar manner, an enterprising genius; Robinson Crusoe was a man of an adventurous turn. Enterprising characterizes persons only, but adventurous is also applied to things, to signify containing adventures; hence a journey, or a voyage, or a history may be denominated adventurous.

ENTERTAIN. See AMUse.

ENTERTAINMENT. See AMUSEMENT; FEAST.

ENTHUSIaSt, Fanatic, VisionARY, DEVOTEE. The enthusiast, fanatic, and visionary have disordered imaginations; but the enthusiast is only affected inwardly with an extraordinary fervor, the fanatic and visionary betray that fervor by some outward mark; the former by singularities of conduet, the latter by singularities of doetrine. Fanatics and visionaries are therefore always more or less enthusiasts; but enthusiasts are not always fanatics or

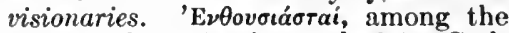
Greeks, from $\dot{\varepsilon} \nu$, in, and $\theta \varepsilon o ́ c$, God, signified those supposed to have, or pretending to have, divine inspiration. Fanatici were so ealled among the Latins from fana (temples), in which they spent an extraordinary portion of

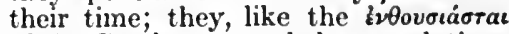
of the Greeks, pretended to revelations and inspirations, during the influence of which they indulged themselves in many extravagant trieks, cutting themselves with knives, and distorting themselves with every speeies of antic, gesture, and grimace.

In the modern acceptation of these terms the fanatic is one who fancies himself inspired, and, rejeeting the use of his understanding, falls into every 
kind of extravagance; it is mostly applied to a man's religious conduct and belief, but may be applied to any extravagant conduct founded on false principles.

An enthusiast is one who is under the influence of any particular fervor of mind, more especially where it is a religious fervor.

There may be enthusiasm in other matters, where it is less mischievous. There may be enthusiasts in the cause of humanity, or in the love of one's country, or in any other matter in which the affections may be called into exercise.

The visionary is properly one that sees or professes to see visions, and is mostly applied to those who pretend to supernatural visions, but it may be employed in respect to any one who indulges in fantastical theories.

A devotee is one who is extravagantly and, it may be, superstitiously devoted to a cause. The word expresses exaggerated interest, and, so far, is synonymous with the other terms, but it does not suggest disordered imagination, as does fanatic.

ENTHUSIASTIC. See Sanguine.

entice. See Allure; Persuade; Tweedle.

ENTIRE. See Whole.

ENTIRELY. See QUITE.

ENTITLE. See NAME.

ENTRAP. See InsNare.

ENTREAT. See BEG.

ENTREATy. See Prayer.

ENVIOUS. See INVIDIOUS.

ENVIRON. See Surround.

ENVOY. See Ambassador.

ENVY. See Jealousy.

EPHEMERAL. See Evanescent. EPHEMERIS. See CALENDAR.

EPICURE. See Sensualist.

EPIDEMICAL. See Contagious.

EPITHET, Adjectrve. Epithet is the technical term of the rhetorician; adjective that of the grammarian. The same word is an epithet as it qualifies the sense; it is an adjective as it is a part of speech: thus, in the phrase "Alexander the Great," great is an epithet, inasmuch as it designates Alexander in distinction from all other persons: it is an adjective as it expresses a quality in distinction from the noun Alexander, which denotes a thing.

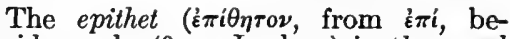

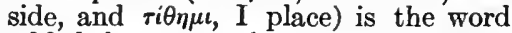
added by way of ornament to the diction; the adjective, from adjectivum, is the word added to the noun as its appendage, and made subservient to it in all its inflections. When we are estimating the merits of any one's style or composition, we should speak of the cpithets he uses; when we are talking of words, their dependencies and relations, we should speak of adjectives: an epithet is either gentle or harsh, an adjective is either a noun or a pronoun adjective. All adjectives are epithets, but all epithets are not adjectives; thus, in Virgil's Pater Aneas, the pater is an epithet, but not an adjective.

EPOCHA. See Time.

EQUAL, Even, Equable, like or Alike, UNIForm. Equal, in Latin aqualis, comes from aquus. Even is in Anglo-Saxon efen. Equable, in Latin equabilis, signifies susceptible of equality. Like, Anglo-Saxon lic, comes from a Teutonic base meaning resembling in form. Uniform, compounded of unus, one, and forma, form, bespeaks its own meaning.

All these epithets are opposed to difference. Equal is said of degree, quantity, number, and dimensions, as equal in years; of an equal age; an equal height: even is said of the surface and position of bodies; a board is made even with another board; the floor or the ground is even: like is said of accidental qualities in things, as alike in color or in feature: uniform is said of things only as to their fitness to correspond; those which are unlike in color, shape, or make are not uniform, and cannot be made to match as pairs: equable is used only in the moral acceptation, in which all the others are likewise employed.

As moral qualities admit of degree, they admit of equality: justice is dealt out in equal portions to the rich and the poor; God looks with an equal eye on all mankind. As the natural path is rendered uneven by high and low ground, so the evenness of the temper, in the figurative sense, is destroyed by changes of humor, by elevations and depressions of the spirits; and the equability of life, from prosperous to adverse. 
Even and equable are applied to the same object in regard to itself, as an even path or equable course; like or alike is applied to two or more objeets in regard to one another, as two persons are alike in disposition, taste, opinions, ete.; uniform is said, either of one objeet in regard to itself, as to be uniform in eonduct, or of many objects in regard to one another, as modes are uniform.

EQUIP. See FIr.

EQUITABLE. See FAIr.

EQUITY. See JUSTICE.

EQUIVOCAL. See AMbiguots.

EQUIVOCATE. See Evade.

EQUIVOCATION. See SoPHISTRY.

ERA. See TIME.

ERADICATE, Extirpate, ExterMINATE. To eradicate, from radix, the root, is to get out by the root: extirpate, from ex and stirps, the stem, is to get out the stock, to destroy it thoroughly. In the natural sense we may eradicate noxious weeds whenever we pull them from the ground; but we ean never extirpate all noxious weeds, as they always disseminate their seeds and spring up afresh. These words are seldomer used in the physical than in the moral sense; where the former is applied to such objeets as are eonceived to be plueked up by the roots, as habits, vices, abuses, evils; and the latter to whatever is united or supposed to be united into a race or family, and is destroyed root and branch. Youth is the season when vicious habits may be thoroughly eradicated; by the universal deluge the whole human race was $e x$ tirpated with the exception of Noah and his family.

Exterminate, in Latin exterminatus, participle of extermino, from ex or extra and terminus, boundary, signifies to expel beyond the boundary (of life), that is, out of existence. It is used only in regard to sueh things as have life, and designates a violent and immediate action: extirpate, on the other hand, may designate a progressive aetion: the former may be said of individuals, but the latter is employed in the collective sense only. Plague, pestilence, famine, extirpate: the sword exterminates.
ERASE. See BLot.

ERECT. See BuILd; InstituTE; LIFT.

ERRAND. See Message.

ERRATIC, ECCENTRIC. Erratic eomes from French erratique, Latin erraticus, prone to wander, from errare, to wander. Eccentric comes through

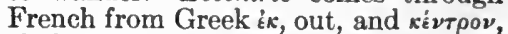
cirele, meaning not concentric with another circle, or, in astronomy, moving in an orbit deviating more or less from a center. These words have similar meanings. Both were astronomical terms; both indicate motion deviating from a fixed course; and both have been employed, in a figurative sense, to indicate that which does not correspond to a set .standard. Erratic, however, refers to a more active departure from a fixed course than does eccentric. The eccentric person does not do as others do; the erratic person fails to do as others do, but acts in a particularly irregular and jerky and unsystematic fashion.

ERROR, Mistake, BLUNDER. Error, in French erreur, Latin error, from errare, to wander, marks the act of wandering, as applied to the rational faculty. A mistake is a taking amiss or wrong, and is derived from the Seandinavian. Blunder is a Seandinavian word formed as a frequentative from Ieelandic blunda, to doze or slumber, allied to blind.

Error in its universal sense is the general term, since every deviation from what is right in rational agents is termed error, which is strictly opposed to truth; error is the lot of humanity; into whatever we attempt to do or think error will be sure to ereep: the term, therefore, is of unlimited use; the very mention of it reminds us of our condition: we have errors of judgment, errors of ealculation, errors of the head, and errors of the heart. The other terms designate modes of error, which mostly refer to the eommon concerns of life: mistake is an error of choiee; blunder an error of action: children and eareless people are most apt to make mistakes; ignorant, conceited, and stupid people eommonly commit blunders: a mistake must be rectified: in commercial transactions it may be of serious consequence: a blunder must be 
set right; but blunderers are not always to be set right; and blunders are frequently so ridiculous as only to excite laughter.

See also Sophistry.

Error, Fault.-Error respects the act; fault, from Latin fallere, to deceive, English fail, respects the agent: an error may lie in the judgment or in the conduct; but a fault lies in the will or intention: the errors of youth must be treated with indulgence; but their faults must on all accounts be corrected: error is said of that which is individual and partial; fault is said likewise of that which is habitual: it is an error to use intemperate language at any time; it is a fault in the temper of some persons that they cannot restrain their anger.

See also LAPSE.

ERST. See ONCE.

ERUDITION. See KNowlEDGE.

ERUPTION, EXPLOSION. Eruption, from $e$, out, and rumpere, to break, signifies the breaking forth, that is, the coming into view, by a sudden bursting; explosion, from ex, out, and plaudere, to clap, meant to drive off the stage by clapping; and now signifies bursting out with a noise: hence of flames there will be properly an eruption, but of gunpowder an explosion: volcanoes have their eruptions at certain intervals, which are sometimes attended with explosions: on this account eruptions are applied to the human body for whatever comes out as the effects of humor, and may be applied in the same manner to any indications of humor in the mind; explosions are also applied to the agitations of the mind which burst out.

ESCAPE, Elude, Evade. Escape means literally to slip out from under one's cape, from French es, out, Latin ex, and cappa, cape. Elude (see ÁvorD). Evade, from the Latin evado, compounded of $e$, out, and vadere, to go, signifies to go or get out of a thing.

The idea of being disengaged from that which is not agreeable is comprehended in the sense of all these terms; but escape designates no means by which this is effected; elude and evade define the means, namely, the efforts which are used by one's self: we are simply disengaged when we' escape, but we disengage ourselves when we elude and evade: we escape from danger; we elude search: our escapes are often providential and often narrow; our success in eluding depends on our skill: there are many bad men who escape punishment by the mistake of a word; there are many who escape detection by the art with which they elude observation and inquiry.

Elude and evade both imply the practice of art on trying occasions; but the former is employed to denote a more ready and dexterous exercise of art than the latter; the former consists mostly of that which is done by a trick, the latter consists of words as well as actions: a thief eludes those who are in pursuit of him by dexterous modes of concealment; he evades the interrogatories of the judge by equivocating replies. One is said to elude a punishment and to evade a law.

ESCORT. See AccompaNY.

ESPECIALLY, PARTICULARLY, Principally, Chiefly. Especially and particularly are exclusive or superlative in their import; they refer to one object out of many that is superior to all; principally and chiefly are comparative in their import; they designate in general the superiority of some objects over others. Especially is a term of stronger import than particularly, and principally expresses something less general than chiefly: we ought to have God before our eyes at all times, but especially in those moments when we present ourselves before Him in prayer: the heat is very oppressive in all countries under the torrid zone, but particularly in the deserts of Arabia, where there is a want of shade and moisture: it is principally among the higher and lower orders of society that we find vices of every description to be prevalent; robberies happen chiefly by night.

ESPOUSE, BETroth. Espouse, in old French espouser, modern French épouser, a spouse or wife, from the Latin sponso, to betroth, that from spondere, to promise, old Spanish esposar, Italian sposare, has two very different significations. In the present and more common one the term implies to promise, or engage in marriage, usually by a written contract, sometimes by word 
of mouth with or without witnesses, and espousal implies the act of contracting a man and woman to each other in marriage.

Betroth, a compound of the English $b e$ and the Old English troth, truth, signifies the act of plighting or pledging one's troth, a token of faith, truth, or earnest intention: in this application a pledge or agreement of marriage. To espouse is to wed; to betroth is to give a pledge that the man and woman will wed. A father or sponsor gives a woman to a man to be his spouse, or wife, and a bridegroom takes the woman as his spouse.

Espouse is also used figuratively, meaning to make one's own entirely, as in the phrase to espouse a cause.

ESPY. See FIND.

essay, Treatise, Tract, DisserTATION. All these words are employed by authors to characterize compositions varying in their form and contents. Essay, which signifies a trial or attempt, is here used to designate in a specific manner an author's attempt to illustrate any point: it is most commonly applied to small detached pieces, which contain only the general thoughts of a writer on any given subject, and afford room for amplification into details also: though, by Locke, in his "Essay on the Understanding," Beattie, in his "Essay on Truth," and other authors, it is modestly used for their connected and finished endeavors to elucidate a doctrine. A treatise is more systematic than an essay; it treats on the subject in a methodical form, and conveys the idea of something labored, scientific, and instructive. A tract is only a species of a small treatise, drawn up upon particular occasions, and published in a separate form; they are both derived from the Latin tractus, participle of traho, draw, manage, or handle. Dissertation, from Latin disserere, compounded of dis, apart, and serere, to join, means the taking up of a subject part by part, suggesting a thorough and exhaustive analysis.

Essays are either moral, political, philosophical, or literary: they are the crude attempts of the youth to digest his own thoughts or they are the more mature attempts of the man to communicate his thoughts to others: of the former description are the prize essays in schools; and of the latter are the innumerable essays which have been published on every subject since the time of Bacon to the present day: treatises are mostly written on ethical, political, or speculative subjects such as F.nelon's, Milton's, or Locke's treatise on education; De Lolme's treatise on the constitution of England; Colquhoun's treatise on the police: dissertations are employed on disputed points of literature, as Bentley's dissertation upon the epistles of Phalaris; De Pauw's dissertations on the Egyptians and Chinese: tracts are ephemeral productions, mostly on political and religious subjects, which seldom survive the occasion which gave them birth; of this description are the pamphlets which daily issue from the press, for or against the measures of government or the public measures of any particular party.

See also ATTEMPT.

ESSENTIAL. See Necessary.

ESTABLISH. See ConfrRM; Fix; INSTITUTE.

estate, Property, Rank. Estate, Old French estat, from Latin status, meant originally condition in general or a good condition, with special reference to worldly prosperity. Out of its original sense it developed several different meanings, characterized in each case, however, by a certain formality and legal stiffness in its application. In one sense estate is a synonyme of property, from Latin proprius, one's own, meaning that which is one's own. Property is the general and familiar term applied to all that one owns; estate a legal term applied to the interest that any one has in lands, tenements, or other effects. Again property may indicate a piece of land owned by an individual or a corporation; estate that same piece of land if it is sufficiently large and sumptuously developed. We speak of the farmer's property; the rich man's estate.

Estate, Rank. - Estate is also a synonyme of rank (see Class), from which it differs in suggesting not merely a division into ranks, but something of its original reference to worldly condition; as well as in being a somewhat more formal and specific word 
with distinctly French associations. In Great Britain the estates of the realm mean the lords spiritual, the lords temporal, and the commons-the first two being represented in the House of Lords, the last in the House of Commons.

ESTEEM, RESPECT, Regard. Esteem (see APPRAISE). Respect, from the Latin respicere, signifies to look back upon, to look upon with attention. Regard (see ATTEND).

A favorable sentiment toward particular objects is included in the meaning of all these terms. Esteem and respect flow from the understanding; regard springs from the heart as well as the head: esteem is produced by intrinsic worth; respect by extrinsic qualities; regard is affection blended with esteem: it is in the power of every man, independently of all collateral circumstances, to acquire the esteem of others; but respect and regard are within the reach of a limited number only: the high and the low, the rich and the poor, the equal and the unequal are each, in their turn, the objects of esteem; those only are objects of respect who have some mark of distinction or superiority of either birth, talent, acquirements, or the like; regard subsists only between friends, or those who stand in close connection with one another: industry and sobriety excite our esteem for one man, charity and benevolence our esteem for another; superior learning or abilities excite our respect for another; a long acquaintance or a reciprocity of kind offices excites a mutual regard.

See also VALUE.

eSTIMATE, Compute, Rate. Estimate (see ApPraISE). Compute (see Calculate). Rate, in Latin ratus, participle of reor, to think, signifies to weigh in the mind.

All these terms mark the mental operations by which the sum, amount, or value of things is obtained: to estimate is to obtain the aggregate sum in one's mind, either by an immediate or a progressive act; to compute is to obtain the sum by the gradual process of putting together items; to rate is to fix the relative value in one's mind by deduction and comparison; a builder estimates the expense of building a house on a given plan; a proprietor of houses computes the probable diminution in the value of his property in consequence of wear and tear; the surveyor rates the present value of lands or houses.

In the moral acceptation they bear the same analogy to each other: some men are apt to estimate the adventitious privileges of birth or rank too high; it would be a useful occupation for men to compute the loss they sustain by the idle waste of time, on the one hand, and its necessarily unprofitable consumption, on the other: he who rates his abilities too high is in danger of despising the means which are essential to secure success; and he who rates them too low is apt to neglect the means, from despair of success.

ESTRANGEMENT. See ABstracTION.

E'TERNAL, Endless, EverlastING. The eternal is set above time, the endless lies within time; it is therefore by a strong figure that we apply eternal to anything sublunary; although endless may with propriety be applied to that which is heavenly; that is properly eternal which has neither beginning nor end; that is endless which has a beginning but no end: God is, therefore, an eternal, but not an endless being: there is an eternal state of happiness or misery which awaits all men, according to their deeds in this life; but their joys or sorrows may be endless as regards the present life. That which is endless has no cessation; that which is everlasting has neither interruption nor cessation: the endless may be said of existing things; the everlasting naturally extends itself into futurity: hence we speak of endless disputes, an endless warfare; an everlasting memorial, an everlasting crown of glory.

ethereal, Celestral, HeavenLY, Spiritual. Ethereal, derived from the same source as ether, viz., the Greek ai $\theta \dot{n} \rho$, the sky, from ai $\theta \omega$, to light up, cognate with the Latin astas, summer, or cestus, heat, in Italian etere, implies, literally, that which pertains to, or is formed of, ether, the fluid that is believed to pervade all space beyond the atmosphere of the earth, and, figuratively, the high heavens or home of the gods. Ethereal, in chem- 
istry, applies to whatever contains ether, but in ordinary language it has a strong poetical and religious significance.

Celestial specifically implies that which pertains to the sky or heavens, and, commonly, that which is exquisite or supremely excellent or which relates to the empire or people of China. Whatever is heavenly pertains to or resembles heaven, the firmament or sky, the abode of God and the blessed, and implies the state or condition of absolute bliss. Because of the general religious and the mythological belief that heaven is the abode of the redeemed and the gods who controlled the destinies of mankind, the term has come to designate the spiritual or incorporeal part of humanity, the state of being pure, holy, and heavenly-minded.

ETHICAL, Moral. Moral, from Latin mos, moris, meaning custom, was Cicero's translation of the Greek $\dot{\eta} \theta$ cós, indicating habitual conduct. Both words, therefore, were meant to refer to a habit of right action habitual with the individual and sanctioned by the custom of the society in which he lived. But ethical has come to refer to the principles of right in the abstract, with reference to the individual character and its complete development in aecordance with general human laws; moral refers to action as affecting the community and sanctioned by social and religious law. Ethical has philosophical connotations; moral practical and religious ones. When we speak of something as being ethically right, we suggest that we are going back to first principles and judging it as a matter of abstract right and wrong. When we speak of something as morally wrong, we are thinking especially of the act in relation to society and social judgments.

etiquetTe, Ceremony, Decorum, Fashion, Manners. Etiquette, in Old French estiquet, a little note, from the German stichen, to stick, is really a doublet of ticket, and signifies, literally, a ticket on which the forms to be observed on particular occasions were inscribed. Originally, the term was applied to a little piece of paper or note stuck up on the gate of a court. On state or very formal occasions it was customary to send small tickets to invited guests, informing them concerning the parts they were expected to take in the ceremony. From this practice the present meaning of the term doubtless arose, and the word came to signify the forms that should be observed in the ceremonial intercourses of life.

Of the words included in this article as synonymes of etiquette, manners is the most general, for the derivation and definition of which see Mavners. It means simply ways of doing things. Decorum (see Decency) means manners, with special reference to that which is suitable and graceful. Fashion (see FASHION) signifies manners with special reference to the habits that happen to prevail in socicty at the minute. Etiquette indieates the manners that prevail in formal society considered as a well-defined system, in which every detail of conduct is regulated. Ceremony is the etiquelle of particular formal occasions, with special reference to external dignity and form (see Form).

EUGENICS, BREEDINA. There is no real synonyme for eugenics, but the general word breeding, which it has partly replaced, may serve the purpose. Eugenics, from Greek $\varepsilon \tilde{v}$, well, and y'vos, race, means the science of produeing a good race of human beings, and all that pertains thereto. Breeding (see BreED) means simply the production of animals or plants, but it has been specialized among raisers of stock, etc., to refer to the production of a good stock or particular kinds of stock, and hence as applied to the development of the lower orders of being it has much the same meaning as eugenics.

\section{EULOGY. See Encomium.}

EUPHONIOUS, HARNONIOUS. Euphonious, from Greek $\varepsilon \dot{v}$, well, and фoví, a sound, meaning a pleasant sound, and harmonious (see MELODY), both mean "agreeable to the ear," but harmonious is a more positive word than euphonious. Harmonious suggests the presence of sounds whose combination is delightful; cuphonious the absence of all sounds which might be unpleasant. Euphonious refers especially" to the juxtaposition of sounds in speaking: 
harmonious to the juxtaposition of musical sounds, in singing, playing, etc.

EUTHANASIA, EASY DEATH. Euthanasia, from Greek $\varepsilon \hat{v}$, well, and távaros, death, being a technical word, has no exact synonymes except phrases like easy death, painless death, which are simply translations of the Greek term into familiar English. It refers to an easy or painless death, especially one attained through the administration of a drug by a physician in cases of mortal and painful illness.

EVAde, Equivocate, Prevaricate. Evade (see Escape). Equivocate (see AMBIGUIT). Prevaricate comes from Latin prevaricari, from proe, especially, very, and varus, crooked, and originally meant to say something very crooked, to tell a lie.

These words designate an artful mode of escaping the scrutiny of an inquirer: we evade by artfully turning the subject or calling off the attention of the inquirer; we equivocate by the use of equivocal expressions; we prevaricate by the use of loose and indefinite expressions; we avoid giving satisfaction by evading; we give a false satisfaction by equivocating: we give dissatisfaction by prevaricating. Evading is not so mean a practice as equivocating: it may be sometimes prudent to evade a question which we do not wish to answer; but equivocations are employed for the purposes of falsehood and interest: prevarications are still meaner; and are resorted to mostly by criminals in order to escape detection.

Evasion, Shift, Subterfuge.-Evasion is here taken only in the bad sense; shift and subterfuge are modes of evasion: the former signifies that gross kind of evasion by which one attempts to shift off an obligation from one's self; the subterfuge, from subter, under, and fugio, to fly, is a mode of evasion in which one has recourse to some screen or shelter. The evasion, in distinction from the others, is resorted to for the gratification of pride or obstinacy: whoever wishes to maintain a bad cause must have recourse to evasions; candid minds despise all evasions; the shift is the trick of a knave, it always serves a paltry, low purpose; he who has not courage to turn open thief will use any shifts rather than not get money dishonestly: the subterfuge is the refuge of one's fears; it is not resorted to from the hope of gain, but from the fear of a loss; not for purposes of interest, but for those of character; he who wants to justify himself in a bad cause has recourse to subterfuge.

EVANESCENT,Ephemeral, Transitory. These words all indicate that which endures for only a little space, but there is some difference in the image conveyed in each word. Evanescent, from Latin $e$, away, and vanescere, about to vanish, means about to vanish away. Ephemeral, from Greek $\dot{\varepsilon} \pi i$ and $\dot{\eta} \mu \dot{\varepsilon} \rho \alpha$, for a day, means enduring but for a day. Transitory, from Latin trans, beyond, and itus, the past participle of ire, to go, means about to pass beyond our sight. Ephemeral indicates that which by its very nature cannot endure; transitory that which, as a matter of fact but not of necessity, is not enduring. Evanescent indicates a higher degree of transitoriness suggesting that which is disappearing into thin air, as it were, before our very eyes.

EVANGELICAL, Gospel, ORTHoDox. Gospel, used as an adjective, is

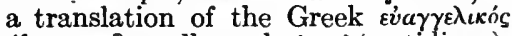
(from $\varepsilon \dot{v}$, well, and $\dot{\alpha} \gamma \gamma \varepsilon \lambda i a$, tidings), into Anglo-Saxon god, good, and spell, story or tale. Both referred specifically to the original documents of the Christian faith, the biographies of Christ, and the message therein delivered. But, as in the case of many other similar pairs of words, the Greek has been specialized to refer to particular sects and tenets. Evangelical means like the original gospel, and has been adopted by certain sects, to characterize their attempts to carry out the precepts of the New Testament more literally. Gospel perfection means the standard of perfection enjoined in the Christian gospel; evangelical teaching may refer to the teaching of the New Testament or to the particular teaching of the evangelical sects. Orthodox, from Greek

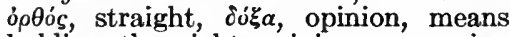
holding the right opinion concerning matters of Christian faith, and refers to matters of intellectual belief, rather than the active practice or emotional 
faith suggested in evangelical. It also refers to the whole body of Christian teaching founded upon the gospel rather than to the gospel itself.

eVen, Smooth, Level, Plain. Even (see Equal). Smooth, AngloSaxon smethe, comes from a Teutonic base signifying creamy. Level, Late Latin libella, from libra, balance, was originally simply the name of a carpenter's instrument for determining that a thing is horizontal. Plain (see Apparent).

Even and smooth are both opposed to roughness; but that which is even is free only from great roughness or irregularities; that which is smooth is free from every degree of roughness, however small: a board is even which has no knots or holes; it is not smooth unless its surface be an entire plane: the ground is said to be even, but not smooth; the sky is smooth, but not even. Even is to level, when applied to the ground, what smooth is to even; the even is free from protuberances and depressions on its exterior surface; the level is free from rises or falls: a path is said to be even; a meadow is level: ice may be level, though it is not even; a walk up the side of a hill may be even, although the hill itself is the reverse of a level: the even is said of that which unites and forms one uninterrupted surface; but the level is said of things which are at a distance from each other, and are discovered by the eye to be in a parallel line; hence the floor of a room is even with regard to itself; it is level with that of another room. Evenness respects the surface of bodies; plainness respects their direction and freedom from external obstructions: a path is even which has no indentures or footmarks; a path is plain which is not stopped up or interrupted by wood, water, or any other thing intervening.

When applied figuratively, these words preserve their analogy: an even temper is secured from all violent changes of humor; a smooth speech is divested of everything which can ruffle the temper of others; but the former is always taken in a good sense, and the latter mostly in a bad sense, as evincing an illicit design or a purpose to deceive: a plain speech, on the other hand, is divested of everything obscure or figurative, and is consequently a speech free from disguise and easy to be understood.

Even and level are applied to conduct or condition, the former as regards ourselves, the latter as regards others: he who adopts an even course of conduct is in no danger of putting himself upon a level with those who are otherwise his inferiors.

\section{EVENING. See Glonming.}

EVENT, INCIDENT, ACcident, Adventure, Occurrence. Event, in Latin eventus, participle of evenire, to come out, signifies that which falls out or turns up. Incident, in Latin incidens, from incidere, signifies that which falls in or forms a collateral part of anything. Accident (for derivation see ACCIDENT). Adventure, from the Latin advenire, to come to, signifies what comes to or befalls one. Occurrence, from the Latin $o b$, in the way, and currere, to learn, signifies that which runs or comes in the way.

These terms are expressive of what passes in the world, which is the sole signification of the term event; while to that of the other terms are annexed some accessory ideas: an incident is a personal event; an accident, an accidental event which happens by the way; an adventure, an extraordinary event; an occurrence, an ordinary or domestic event: event, in its ordinary and limited acceptation, excludes the idea of chance; accident excludes that of design; incident, adventure, and occurrence are applicable in both cases.

Events affect nations and communities as well as individuals; incidents and adventures affect particular individuals; accidents and occurrences affect persons or things particularly or generally, individually or collectively: the making of peace, the loss of a battle, and the death of a prince are national events; the forming a new acquaintance and the revival of an old one are incidents that have an interest for the parties concerned; an escape from shipwreck, an encounter with wild beasts or savages, are adventures which individuals are pleased to relate and others to hear; a fire, the fall of a house, the breaking of a limb, are accidents or 
occurrences; a robbery and the death of individuals are properly occurrences which afford subject for a newspaper and excite an interest in the reader.

Event, when used for individuals, is always of greater importance than an incident. The settlement of a young person in life, the adoption of an employment, or the taking a wife, are events, but not incidents; while, on the other hand, the setting out on a journey or the return, the purchase of a house, and the despatch of a vessel are characterized as incidents, and not events.

It is further to be observed that accident, event, and occurrence are said only of that which is supposed really to happen: incidents and adventures are often fictitious; in this case the incident cannot be too important, nor the adventure too marvellous. History records the events of nations; plays require to be full of incident in order to render them interesting; romances and novels derive most of their charms from the extravagance of the adventures which they describe; periodical works supply the public with information respecting daily occurrences.

See also Consequence.

EVER. See Always.

EVERLASTING. See EternaL.

EVERY. See ALL.

EVERYWHERE. See UBIQUITOUS.

EVIDENCE. See DEPONENT; Proof.

EVIDENT. See Apparent.

EVIL or Ill, Misfortune, Harm, Mischief. Evil, in its full sense, comprehends every quality which is not good, and consequently the other terms express only modifications of evil. The word is, however, more limited in its application than its meaning, and admits, therefore, of a just comparison with the other words here mentioned. They are all taken in the sense of evils produced by some external cause, or evils inherent in the object and arising out of it. The evil, or, in its contracted form, the $i l l$, befalls a person; the misfortune comes upon him; the harm, originally Anglo-Saxon hearm, is taken, or one receives the harm; mischief is compounded of French mes,
Latin minus, lacking in, less, and chef, Latin caput, head, and means foolishness, something lacking in sense and wit, hence something harmful or annoying to others.

Evil, in its limited application, is taken for evils of the greatest magnitude; it is that which is evil without any mitigation or qualification of circumstances. The misfortune is a minor evil; it depends upon the opinion and circumstances of the individual; what is a misfortune in one respect may be the contrary in another respect. An untimely death, the fracture or loss of a limb, are denominated evils; the loss of a vessel, the overturning of a carriage, and the like are misfortunes, inasmuch as they tend to the diminution of property; but as all the casualties of life may produce various consequences, it may sometimes happen that that which seems to have come upon us by our ill fortune turns out ultimately of the greatest benefit; in this respect, therefore, misfortune is but a partial evil: of evil it is likewise observable that it has no respect to the sufferer as a moral agent; but misfortune is used in regard to such things as are controllable or otherwise by human foresight. The evil which befalls a man is opposed only to the good which he in general experiences; but the misfortune is opposed to the good fortune or the prudence of the individual. Sickness is an evil, let it be endured or caused by whatever circumstances it may; it is a misfortune for an individual to come in the way of having this evil brought on himself: his own relative condition in the scale of being is here referred to.

Harm and mischief are species of minor evils, the former of which is much less specific than the latter both in the nature and cause of the evil. A person takes harm from circumstances that are not known; the mischief is done to him from some positive and immediate circumstance. He who takes cold takes harm, the cause of which, however, may not be known or suspected: a fall from a horse is attended with mischief if it occasion a fracture or any evil to the body. Evil and misfortune respect persons only as the objects; harm and mischief are said 
of inanimate things as the object. A tender plant takes harm from being exposed to the cold air; mischief is done to it when its branches are violently broken off or its roots are laid bare.

See also BAD.

Evince. See Argue; Prove.

EVOLUTION, DevelopMent. Evolution, from Latin $e$, out, and volvere, to roll, unfold, and development, from de, down, and volvere, to roll, have originally the same meaning, but evolution has become a somewhat technical term referring to what in a more general way is indicated in development. Development refers to the orderly unfolding of plant or animal life or to the courses of history, evolution to this same orderly unfolding with specific reference to the doctrines and laws of development formulated by the natural scientists of the nineteenth century, especially Darwin, and extended from the field of natural science to all fields.

EXACT, ExTorT. Exact, in Latin exactus, participle of exigere, to drive out, signifies the exercise of simple force; but extort, from extortus, participle of extorquere, to wring out, marks the exercise of unusual force. In the application, therefore, to exact is to demand with force-it is commonly an act of injustice: to extort is to get with violence-it is an act of tyranny. The colleetor of the revenue exacts when he gets from the people more than he is authorized to taka: an arbitrary prince extorts from his conquered subjects whatever he can grasp at. In the figurative sense, deference, obedience, applause, and admiration are exacted: a confession, an acknowledgment, a discovery, and the like are extorted.

Exact, Nice, Particular, Punctual. Exact (see Accurate). Nice in Middle English means foolish or simple, from Old French nice, lazy, simple, Latin nescius, ignorant, compounded of ne, not, and scius, knowing. From the earlier meaning of simple the meaning of fastidious, careful in little things, developed. Particular means attentive to each little particle. Punctual, from the Latin punctum, a point, signifies keeping to a point.

Exact and nice are to be eompared in their application either to persons or to things: particular and punctual, only in application to persons. To be exact is to arrive at perfection; to be nice is to be free from faults; to be particular is to be nice in eertain particulars; to be punctual is to be exact in certain points. We are exact in our conduct or in what we do, nice and particular in our mode of doing it, punctual as to the time and season for doing it. It is necessary to be exact in our accounts; to be nice as an artist in the choice and distribution of colors; to be particular as a man of business, in the number and the details of merchandises that are to be delivered out; to be punctual in observing the hour of the day that has been fixed upon.

Exactness and punctuality are always taken in a good sense; they designate an attention to that which eannot be dispensed with: they form a part of one's duty: niceness and particularity are not always taken in the best sense; they designate an excessive attention to things of inferior importanee, to matters of taste and choiee. Early habits of method and regularity will make a man very exact in the performance of all his duties, and particularly punctual in his payments: an over-niceness in the observance of mechanical rules often supplies the want of genius; it is the mark of a contracted mind to amuse itself with particularities about dress, personal appearance, furniture, and the like.

When exact and nice are applied to things, the former expresses more than the latter; we speak of an exact resemblance and a nice distinetion. The exact point is that which we wish to reach; the nice point is that which it is difficult to keep.

EXAGgeration. See CaricaTURE.

\section{EXALT. See LiFT.}

EXAMINATION, SEARCH,INQUIRY, Research, Investigation, Scrutivy. Examination (see Discuss). Scarch comes from Old French cercher, Latin circare, to go around in a circle, to look everywhere. Inquiry (see Ask). Research is an intensive of scarch. Investigation, from the Latin vestigium, a track, signifies seeking by the tracks or footsteps. Scrutiny, from the Latin scrutor, to search, and scruta, broken 
pieces, signifies looking for among rubbish, to ransack.

Examination is the most general of these terms, which all agree in expressing an active effort to find out that which is unknown. An examination may be made without any particular effort, and may be made of things that are open to the observation, as to examine the face or features of a person, or anatomically to examine the body: a search is a close examination into matters that are hidden or less obvious: as to search the person or papers of one that is suspected, to search a house for stolen goods.

Examinations may be made by putting questions; an inquiry is always made in this manner. We may examine persons or things; we inquire of persons and into things: an examination of persons is always done for some specific and public purpose; one person inquires of another only for private purposes; a student is examined for the purpose of ascertaining his progress in learning; an offender is examined in order to ascertain his guilt; a person inquires as to the residence of another, or the road to be taken, and the like.

In the moral application of these terms, the examination is, as before, a general and indefinite action, which may either be confined simply to those matters which present themselves to the mind of the examiner or it may be extended to all points: the search is a laborious examination into that which is remote; the inquiry is extended to examination into that which is doubtful.

A research is a remote search; an investigation is a minute inquiry; a scrutiny is a strict examination. Learned men of inquisitive tempers make their researches into antiquity: magistrates investigate doubtful and mysterious affairs; physicians investigate the causes of diseases; men scrutinize the actions of those whom they hold in suspicion. Acuteness and penetration are peculiarly requisite in making researches, patience and perseverance are the necessary qualifications of the investigator; a quick discernment will essentially aid the scrutinizer.

Examine, Search, Explore.-Examine and search (see above for both). Explore, in Latin exploro, compounded of $e x$, out, and plorare, to flow, signifies to make to flow out, to look for something until it is found.

These words are here considered as they designate the looking upon places or objects, in order to get acquainted with them. To examine expresses a less effort than to search, and this expresses less than to explore. We examine objects that are near; we search those that are hidden or removed at a certain distance; we explore those that are unknown or very distant. The painter examines a landscape in order to take a sketch of it; the botanist searches after curious plants; the inquisitive traveller explores unknown regions. An author examines the books from which he intends to draw his authorities; the antiquarian searches every corner in which he hopes to find a monument of antiquity; the classic scholar explores the learning and wisdom of the ancients.

EXAMINE. See Assay; Discuss. EXAMINER. See Censor.

EXAMPLE, PATTERn, ENsample. Example, in Latin exemplum, from Latin ex, from, and emere, to take, means that from which something is to be imitated or taken. Pattern (see CoPY). Ensample is an Anglo-French corruption of Latin exemplum.

All these words are taken for that which ought to be followed: but the example must be followed generally; the pattern must be followed particularly, not only as to what, but how a thing is to be done: the former serves as a guide to the judgment; the latter to guide the actions. The example comprehends what is either to be followed or to be avoided; the pattern only that which is to be followed or copied: the ensample is a species of example, the word being employed only in the solemn style. The example may be presented either in the object itself or the description of it; the pattern displays itself most completely in the object itself; the ensample exists only in the description. Those who know what is right should set the example of practising it; and those who persist in doing wrong must be made an example to deter others from doing the same: every 
one, let his age and station be what it may, may afford a pattern of Christian virtue; the child may be a pattern to his playmates of diligence and dutifulness; the citizen may be a pattern to his fellow-citizens of sobriety, and conformity to the laws; the soldier may be a pattern of obedience to his comrades: our Saviour has left us an $e x$ ample of Christian perfection which we ought to. imitate, although we cannot copy it: the Scripture characters are drawn as ensamples for our learning.

Example, Precedent.-Example (see above). Precedent, from the Latin precedens, preceding, signifies by distinetion that preceding which is entitled to notice. Both these terms apply to that which may be followed or made a rule; but the example is commonly present or before our eyes; the precedent is properly something past; the example may derive its authority from the individual; the precedent acquires its sanction from time and common consent: we are led by the example, or we copy the example; we are guided or governed by the precedent. The former is a private and often a partial affair; the latter is a publie and often a national concern; we quote examples in literature and precedents in law.

Example, Instance.-Example refers in this case to the thing. Instance, from the Latin instans, standing on or in, signifies that which stands or serves as a resting-point.

The example is set forth by way of illustration or instruction; the instance is adduced by way of evidence or proof. Every instance may serve as an example, but every example is not an instance. The example consists of moral or intellectual objects; the instance consists of actions only, or of what serves as a proof. Rules are illustrated by examples; characters are illustrated by instances: the best mode of instructing children is by furnishing them with examples for every rule that is laid down; the Roman history furnishes us with many extraordinary instances of self-devotion for their country.

EXASPERATE. See Aggravate.

EXCEED, Excel, Surpass, TranSCEND, OUTDo. Exceed, from the Latin excedo, compounded of $e x$, out, and cedere, to pass, means to pass out of, or beyond, the line, and is the general term. Surpass, compounded of French sur, Latin super, beyond, and French passer, to pass, from Latin passus, step, is one species of exceeding. Excel, compounded of ex and cellere, to lift or move over, found only in compounds, is another species.

Exceed is applied mostly to things in the sense of going beyond in measure, degree, quantity, and quality; one thing exceeds another in magnitude, height, or any other dimensions; a person's success exceeds his expectations.

It is taken either in an indifferent or in a bad sense, particularly in regard to persons, as a person exceeds his instructions or excecds the due measure.

To excel and surpass signify to exceed, or be superior in that which is good. To excel may be used with reference to all persons generally, as a person strives to excel; to surpass is used in regard to particular objects, as to surpass another in any trial of skill.

When excel is used in respect of particular objects, it is more general in its sense than surpass: the Dutch and Italians formerly excelled the English in painting; one person may surpass another in bravery, or a thing may surpass one's expectations. Men excel in learning, arts, or arms; .competitors surpass one another in feats of agility.

The derivatives excessive and excellent have this obvious distinetion between them, that the former always signifies excceding in that which ought not to be exceeded; and the latter exceeding in that where it is honorable to exceed: he who is habitually excessive in any of his indulgenees must be insensible to the excellence of a temperate life.

Transcend, from trans, beyond, scandere, to elimb, signifies to climb beyond; and outdo-that is, to do out of the ordinary course, are particular modes of excelling or exceeding. The genius of Homer transcends that of almost every poet; Heliogabalus outdid every other emperor in extravagance.

EXCELLENCE, SUPERIORTY. Excellence is an absolute term; superiority 
is a relative term; many may have excellence in the same degree, but they must have superiority in different degrees; superiority is often superior excellence, but in many cases they are applied to different objects. There is a moral excellence attainable by all who have the will to strive after it; but there is an intellectual and physical superiority which is above the reach of our wishes and is granted to a few only.

EXCEPT. See Besides; But; UNLESS.

EXCEPTION. See ObJection.

EXCESS, SuperflutTy, ReduNDANCY. Excess is that which exceeds any measure; superfluity, from super, over, and fluere, to flow, and redundancy, from re, back, and unda, a wave, to stream back or over, signify an excess of a good measure. We may have an excess of heat or cold, wet or dry, when we have more than the ordinary quantity, but we have a superfluity of provisions when we have more than we want. Excess is applicable to any object, but superfluity and redundancy are species of excess, the former applicable in a particular manner to that which is an object of our desire, and redundancy to matters of expression or feeling. We may have an excess of prosperity or adversity, a superfluity of good things, and a redundancy of speech or words.

Excessive, Immoderate, Intemperate.The excessive is beyond measure; the immoderate, from modus, a mode or measure, is without measure; the intemperate, from tempus, a time or term, is that which is not kept within bounds.

Excessive designates excess in general; immoderate and intemperate designate excess in moral agents. The excessive lies simply in the thing which exceeds any given point: the immoderate lies in the passions which range to a boundless extent: the intemperate lies in the will which is under no control. Hence we speak of an excessive thirst physically considered, an immoderate ambition or lust of power, an intemperate indulgence, an intemperate warmth. Excessive admits of degrees; what is excessive may exceed in a greater or less degree: immoderate and intemperate mark a positively great degree of excess, the former still higher than the latter: immoderate is in fact the highest $\mathrm{cmn}$ ceivable degree of excess. The excessive use of anything will always be attended with some evil consequence: the $\mathrm{im}$ moderate use of wine will rapidly tend to the ruin of him who is guilty of the excess: the intemperate use of wine will proceed by a more gradual but not less sure process to his ruin.

See also Unreasonable.

EXCHANGE, Barter, Truck, Coumute. To exchange (see Change) is the general term signifying to take one for another, or put one thing in the place of another; the rest are but modes of exchanging. To barter is to exchange one article of trade for another, from Old French barater, to cheat, beguile, a word of doubtful origin, possibly Celtic. To truck is a familiar term to express a familiar action for exchanging one article of private property for another. Commute, from the Latin syllable cum, with, and mutare, to change, signifies an $e x-$ changing one mode of punishment for another, or one mode of payment for another: we may exchange one book for another; traders barter trinkets for gold-dust; coachmen or stablemen truck a whip for a handkerchief; government commutes the punishment of death for that of banishment.

Commute is now used, in a special sense, to refer to the travelling to and fro of people who dwell in the suburb of a city and do their business and find their pleasure within the city itself.

EXCITE, Incite, Provoke. To excite (see AWAKEN) is said more particularly of the inward feelings; incite (see ENCOURAGE) is said of the external actions; provoke (see AgGravate) is said of both. A person's passions are excited; he is incited by any particular passion to a course of conduct; a particular feeling is provoked, or he is provoked by some feeling to a particular step. Wit and conversation excite mirth; men are incited by a lust for gain to fraudulent practices; they are provoked by the opposition of others to intemperate language and intemperate measures. To excite is very frequently used in a physical acceptation; incite always, and provoke mostly, in a moral application. We speak of exciting hun- 
ger, thirst, or perspiration; of inciting to noble actions; of provoking impertinence, provoking scorn or resentment. When excite and provoke are applied to similar objects, the former designates a much stronger action than the latter. A thing may excite a smile, but it provokes laughter; it may excite displeasure, but it provokes anger; it may excite joy or sorrow, but it provokes to madness.

EXCITING. See Electric.

EXClaim. See Call.

EXCLUDE. See CoMprise; SegreGATE.

EXCLUDING. See But.

EXCLUSION. See LockoUT.

EXCOMMUNICATE, ANathemaTIZE. Excommunicate and anathematize are used in similar connections to refer to the denunciation of individuals by the Catholic Church, but they differ somewhat in meaning. Excommunicate, from Latin ex, out, and communis, common, means to banish from the common society and privileges of the church and the good graces and services of all Christian people. Anathematize, from Greek á $\nu a ́ \theta \eta \mu a$, means to denounce formally and publicly, and may refer to opinions and actions as well as individuals. It does not necessarily include, however, the formal act of excommunication. Both terms may be extended to refer to punishment by any society, or formal denunciation of any sort.

EXCORIATE. See SkIN.

EXCUlPate. See Apologize; EXONERATE.

EXCURSION, Ramble, ToUR, TrIP, JAUNT. Excursion signifies going out of one's course, from the Latin $e x$ and cursus, the course or prescribed path: a ramble is a going without any course or regular path (see ramble under WANDER). A tour is a circuitous course: a trip, Middle English trippen, from base trap, meaning tread, found in tramp, means as a verb to tread lightly, and, as a substantive, a pleasant walk or, at present, any journey; jaunt comes from Old French jaunts, meaning toil, exercise. To go abroad in a carriage is an idle excursion, or one taken for mere pleasure: travellers who are not contented with what is not to be scen from a highroad make frequent excursions into the interior of the country. Those who are fond of rural scenery, and pleased to follow the bent of their inclinations, make frequent rambles. Those who set out upon a sober scheme of enjoyment from travelling are satisfied with making the tour of some one country or more. Those who have not much time for pleasure take trips. Those who have no better means of spending their time make jaunts.

EXCUSE, Pardon. We excuse (see Apologize) a person or thing by exempting him from blame. We pardon (from Late Latin perdonare, to give entirely or freely) by remitting the punishment for the offence one has committed.

We excuse a small fault, we pardon a great fault; we excuse that which personally affects ourselves; we pardon that which offends against morals: we may excuse as equals: we can pardon only as superiors. We exercise goodnature in excusing: we exercise generosity or mercy in pardoning. Friends excuse one another for the unintentional omission of formalities; it is the prerogative of the king to pardon criminals whose offences will admit of pardon: the violation of good manners is inexcusable in those who are cultivated; falsehood is unpardonable even in a child.

See also Pretence.

EXECRABLE. See Abominable.

EXECRATION. See Malediction.

EXeCUTE, Fulfil, Perform. Execute (see Accoмplish), in Latin executus, participle of exsequi, compounded of $e x$, out, and sequi, to follow, is to follow up to the end. To fulfil is to fill up to the full of what is wanted. Perform comes from Old French parfournir, from Latin per, thoroughly, and Old French fournir, to furnish, Old High German frumjan, to provide; and meant to furnish eompletely, to earry through to the end.

To execute is more than to fulfil, and to fulfil than to perform. To execute is to bring about an end; it involves active measures and is peculiarly applicable to that which is extraordinary or that which requires particular spirit and talents; schemes of ambition are 
executed: to fulfil is to satisfy a moral obligation; it is applicable to those duties in which rectitude and equity are involved; we fulfil the duties of citizens: to perform is to carry through by simple action or labor; it is more particularly applicable to the ordinary and regular business of life; we perform a work or a task. One executes according to one's own intentions or those of others; the soldier executes the orders of his general; the merchant executes the commissions of his correspondent: one fulfils according to the wishes and expectations of one's self or others; it is the part of an honest man to enter into no engagements which he cannot fulfil; it is the part of a dutiful son, by diligence and assiduity, to endeavor to fulfil the expectations of an anxious parent: one performs, according to circumstances, what suits one's own convenience and purposes; every good man is anxious to perform his part in life with credit and advantage to himself and others.

\section{EXEMPT. See Free.}

exemption. See Privilege.

EXERCISE, PRACTICE. Exercise, in Latin exercere, from Latin ex, out, and arcere, to enclose, meant originally to drive out of an enclosure, to set at work: Practice, from the Greek $\pi \rho \alpha$ á $\sigma \varepsilon \iota \nu$, to do, signifies to perform a part.

These terms are equally applied to the actions and habits of men; but we exercise in that where the powers are called forth; we practice in that where frequency and habitude of action are requisite: we exercise an art; we practice a profession: we may both exercise and practice a virtue; but the former is that which the particular occurrence calls forth, and which seems to demand a peculiar effort of the mind; the latter is that which is done daily and ordinarily: thus we in a peculiar manner are said to exercise patience, fortitude, or forbearance; to practice charity, kindness, benevolence, and the like.

A similar distinction characterizes these words as nouns, the former applying solely to the powers of the body or mind, the latter solely to the mechanical operation: the health of the body and the vigor of the mind are alike impaired by the want of exercise; in every art practice is an indispensable requisite for acquiring perfection: the exercise of the memory is of the first importance in the education of children; constant practice in writing is almost the only means by which the art of penmanship is acquired.

EXERT, EXERCISE. The employment of some power or qualification that belongs to one's self is the common idea conveyed by these terms; but exert (see ENDEAVOR) may be used for what is internal or external of one's self; exercise (see above) only for that which forms an express part of one's self; hence we speak of exerting one's strength, or exerting one's voice, or exerting one's influence: of exercising one's limbs, exercising one's understanding, or exercising one's tongue. Exert is often used only for an individual act of calling forth into action; exercise always conveys the idea of repeated or continued exertion; thus a person who calls to another exerts his voice; he who speaks aloud for any length of time exercises his lungs.

EXERTION. See ENDEAVOR.

EXHALE. See EMIT.

EXHAUST. See Speed.

EXHIBIT. See Grve; Show.

EXHILARATE. See ANIMATE.

EXHORT, Persoade. Exhort, in Latin exhorter, compounded of $e x$, intensive, and hortari, to persuade, meant to persuade earnestly. Persuade (see Conviction).

Exhortation has more of impelling in it; persuasion, more of drawing: a superior exhorts; his words carry authority with them, and rouse to action: a friend and an equal persuades; he wins and draws by the agreeableness or kindness of his expressions. Exhortations are employed only in matters of duty or necessity; persuasions are employed in matters of pleasure or convenience.

EXIGENCY, EMERgency. Necessity is the idea which is common to the signification of these terms: exigency, from the Latin exigere, to force out, to demand, expresses what the case demands; and emergency, from emergere, to arise out of, denotes what rises out of the case.

The exigency is more common, but less pressing; the emergency is im- 
perious when it comes, but comes less frequently: a prudent traveller will never carry more money with him than what will supply the exigencies of his journey; and in case of an emergency will rather borrow of his friends than risk his property.

EXILE. See Banish; Proscribe.

EXIST, LIVE. Live, Anglo-Saxon libban, is the native English word corresponding to the Latin exist, for which see BE.

Existence is the property of all things in the universe; life, which is the inherent power of motion, is the particular property communicated by the Divine Being to some parts only of His creation: exist, therefore, is the general, and live the specific term: whatever lives, exists according to a certain mode; but many things exist without living: when we wish to speak of things in their most abstract relation, we say they exist; when we wish to characterize the form of existence we say they live.

Existence, in its proper sense, is the attribute which we commonly ascribe to the Divine Being, and it is that which is immediately communicable by Himself; life is that mode of existence which He has made to be communicable by other objects besides Himself: existence is taken only in its strict and proper sense, independent of all its attributes and appendages; but life is regarded in connection with the means by which it is supported, as animal life, or vegetable life. In like manner, when speaking of spiritual objects, exist retains its abstract sense, and live is employed to denote an active principle: animosities should never exist in the mind; and everything which is calculated to keep them alive should be kept at a distance.

EXIT, Departure. Both these words are metaphorically employed for death or a passage out of this life; the former is borrowed from the act of going off the stage; the latter from the act of setting off on a journey. Exit seems to convey the idea of volition; for we spcak of making our exit; departure designates simply the event; the hour of a man's departure is not made known to him. When we speak of an exit, we think only of the place left; when we speak of a departure, we think of the place gone to: the unbeliever may talk of his exit; the Christian most commonly speaks of his departure.

EXONERATE, EXCULPATE. Exonerate, from onus, a burden, signifies to take off the burden of a charge or of guilt; to exculpate, from culpa, a fault or blame, is to throw off the blame: the first is the act of another; the second is one's own act: we exonerale him upon whom a charge has lain, or who has the load of guilt; we exculpate ourselves when there is any danger of being blamed: circumstances may sometimes tend to exonerate; the explanation of some person is requisite to exculpate: in a case of dishonesty, the absence of an individual at the moment when the act was comnitted will altogether exonerate him from suspicion; it is fruitless for any one to attempt to exculpate himself from the charge of faithlessness who is detected in conniving at the dishonesty of others.

EXPAND. See Dilate; SPREad.

EXPECT. See IVAIT.

EXPECTATION. See Hope.

EXPEDIENT, Resource. The expedient is an artificial meaus; the resource is a natural means: a cunning man is fruitful in expedients; a fortunate man abounds in resources: Robinson Crusoe adopted every expedient in order to prolong his existence at a time when his resources were at the lowest ebb.

Expedient, Fit.-Expedient, from the Lat in cxpedire, present participial stem, expedient (compounder of $e x$, out, and pedem, foot, and meaning to take one's feet out, to be ready to start) supposes a certain degree of necessity from circumstances; fit for the purpose signifies simply an agreement with, or suitability to, the circumstances: what is expedient must be $f t$. because it is ealled for; what is fit need not be expedient, for it may not be required. The expediency of a thing depends altogether upon the outward circumstances; the fitness is determined by a moral rule: it is imprudent not to do that which is expedicnt; it is disgraceful to do that which is unfit: it is expedient for him who wishes to prepare for death occasionally to take an account of his life; it is not fit for him who is about 
to die to dwell with anxiety on the things of this life.

See also Necessary.

EXPEDITE. See Hasten.

EXPEDITIOUS. See Diligent.

EXPEL. Sec Banish; Proscribe.

EXPEND.. See SPEND.

EXPENSE. See Cost.

EXPERIENCE, EXPERIMENT, Trial, Proof, Test. Experience and experiment, from the Latin $e x$, intensive, and periri, to make a trial of, mean that which is learned through personal trial. Try comes from Old French trier: originally from Late Latin tritare, to rub, pulverize, separate, purify. Proof signifies either the act of proving, from the Latin probare, to make good, or the thing made good, proved to be good. Test comes from the Italian testa, a vessel in which metals are tried.

By all the actions implied in these terms we endeavor to arrive at a certainty respecting some unknown particular: experience is that which has been tried; an experiment is the thing to be tried; experience is certain, as it is a deduction from the past for the service of the present; the experiment is uncertain and serves a future purpose: experience is an unerring guide, which no man can desert without falling into error; experiments may fail, or be superseded by others more perfect.

Experience serves to lead us to moral truth; experiments aid us in ascertaining speculative truth: we profit by experience to rectify practice; we make experiments in theoretical inquiries: he, therefore, who makes experiments in matters of experience rejects a steady and definitive mode of coming at the truth of one that is variable and uncertain, and that, too, in matters of the first moment.

The experiment, trial, and proof have equally the character of uncertainty; but the experiment is employed only in matters of an intellectual nature; the trial is employed in matters of a personal nature, on physical as well as mental objects; the proof is employed in moral subjects: we make an experiment in order to know whether a thing be true or false; we make a trial in order to know whether it be capable or incapable, convenient or inconvenient, useful or the contrary; we put a thing to the proof in order to determine whether it be good or bad, real or unreal: experiments tend to confirm opinions; the philosopher doubts every position which cannot be demonstrated by repeated experiments; trials are of absolute necessity in directing our conduct, our taste, and our choice; we judge of our strength or skill by trials; we judge of the effect of colors by trials, and the like: the proof is the trial that proves; it determines the judgment in the knowledge of men and things; the proof of men's characters and merits is best made by observing their conduct. The test is the most decisive kind of proof, whence the phrase "to stand the test."

The proof and test may be taken for that which serves to prove, with the same distinction: to give proofs of sincerity; ridicule is not the test of truth. See also Test.

EXPERIMENTAL. See EMPIRICAL.

EXPERT. See Clever.

EXPIATE. See Atone.

EXPIRE. See DiE.

EXPLAIN, EXPOUND, INTERPRET. Explain signifies to make plain (see APPARENT). Expound, from the Latin expono, compounded of ex, out, and ponere, to place or set, signifies to set forth in detail. Interpret, in Latin interpres, an agent, a broker, is compounded of inter, between, and possibly pretium, price, indicating a gobetween in business and financial transactions; then a go-between in other affairs, especially between people speaking different languages.

To explain is the generic, the rest are specific: to expound and interpret are each modes of explaining. Single words or sentences are explained; a whole work, or considerable parts of it, are expounded; the sense of any writing or symbolical sign is interpreted. It is the business of the philologist to explain the meaning of words by a suitable definition; it is the business of the divine to expound Scripture; it is the business of the antiquarian to interpret the meaning of old inscriptions or of hieroglyphics. An explanation serves to assist the understanding to supply a 
deficiency, and remove obscurity; an exposition is an ample explanation, in which minute particulars are detailed and the connection of events in the narrative is kept up; it serves to assist the memory and awaken the attention: both the explanation and exposition are employed in clearing up the sense of things as they are, but the interpretation is more arbitrary; it of ten consists of affixing or giving a sense to things which they have not previously had; hence it is that the same passages in authors admit of different interpretations, according to the character or views of the commentator.

To explain and interpret are not confined to what is written or said, they are employed likewise with regard to the actions of men; exposition is, however, used only with regard to writings. The major part of the misunderstandings and animosities which arise among men might easily be obviated by a timely explanation; it is the characteristic of good-nature to interpret the looks and actions of men as favorably as possible. The explanation may sometimes flow out of circumstances; the interpretation is always the act of a voluntary and rational agent. The discovery of a plot or secret scheme will serve to explain the mysterious and strange conduct of such as were previously acquainted with it. According to an old proverb, "Silence gives consent"; for thus at least they are pleased to interpret it who are interested in the decision.

Explain, Illustrate, Elucidate.-Explain (see above). Illustrate, in Latin illustratus, participle of illustrare, to throw light on, signifies to make a thing bright, or easy to be surveyed and examined. Elucidate, in Latin elucidatus, participle of elucido, from lux, light, signifies to bring forth into the light.

To explain is simply to render intelligible; to illustrate and elucidate are to give additional clearness: everything requires to be explained to one who is ignorant of it; but the best informed will require to have abstruse subjects illustrated and obscure subjects elucidated. We always explain when we illustrate or elucidate, and we always elucidate when we illustrate, but not vice vers $\hat{A}$. We explain by reducing compounds to simples, and generals to particulars; we illustrate by means of examples, similes, and allegorical figures; we elucidate by commentaries or the statement of facts. Words are the common subject of explanation; moral truths require illustration; poetical allusions and dark passages in writers require elucidation.

Explanatory, Explicit, Express.-Explanatory signifies containing or belonging to explanation. Explicit, in Latin explicatus, from explicare, to unfold, signifies unfolded or laid open. Express, in Latin expressus, the past participle of exprimere, to press out, signifies the same as expressed or delivered in specific terms.

The explanatory is that which is superadded to clear up difficulties or obscurities. A letter is explanatory which contains an explanation of something preceding, in lieu of anything new. The explicit is that which of itself obviates every difficulty; an explicit letter, therefore, will leave nothing that requires explanation: the explicit admits of a free use of words; the express requires them to be unambiguous. A person ought to be explicit when he enters into an engagement; he ought to be express when he gives commands.

EXPLOIT. See DEED.

EXPLORE. See Examine; RumMAGE.

EXPLOSION. See ERUPTION.

EXPOSED. See SUBJECT; VuL NERABLE.

EXPOSTULATE, Remonstrate. Expostulate, from postulare, to demand, signifies to demand reasons for a thing. Remonstrate, from monstrare, to show, signifies to show reasons against a thing.

We expostulate in a tone of authority; we remonstrate in a tone of complaint. He who expostulales passes a censure and claims to be heard; he who remonstrates presents his case and requests to be heard. Expostulation may often be the precursor of violence; remonstrance mostly rests on the force of reason and representation: he who admits of expostulation from an inferior undermines his own authority; he who is deaf to the remonstrances of his friends is far gone in folly; the expostulation is mostly on matters of personal 
interest; the remonstrance may as often be made on matters of propriety. The Scythian ambassadors expostulated with Alexander against his invasion of their country; King Richard expostulated with Wat Tyler on the subject of his insurrection; Artabanes remonstrated with Xerxes on the folly of his projected invasion.

EXPOUND. See EXPLAIN.

EXPRESS, Declare, Signify, TesTIFY, UTTER. All these terms are taken in the sense of communicating to others. To express, from the Latin exprimere, or ex, out, and premere, to press, signifying to bring out by a particular effort, is the general term. To declare and the other terms are different modes of expressing, varying in the manner and circumstances of the action. To express is the simple aet of communication, resulting from our circumstances as social agents; to declare is to express clearly and openly. A person may express his opinions to an individual, but to declare is to make clear or known to several. We may express directly or indirectly; we declare directly and sometimes loudly.

Words, looks, gestures, or movements serve to express; actions and things may sometimes declare: sometimes we cannot express our contempt in so strong a manner as by preserving a perfect silence when we are required to speak; an act of hostility on the part of a nation is as much a declaration of war as if it were expressed in positive terms.

To express is to convey to another by any means that which passes in one's mind. To signify, from signum, a sign, and facere, to make, is to convey by some outward sign. To express is said generally of one's opinions and feclings; to signify is to make one's particular wishes known to an individual: we express mostly in positive terms; we may signify in any manner, either by looks or words.

Words may both express and signify: they express the commonly received meaning affixed to them; but they signify more or less according to circumstances or the intention of the speaker; the word "no" expresses simple negation, but it may be made to signify very differently by any one using it.
As epithets, expressive and significant admit of a similar distinetion: an expressive look is that which is fitted to express what is intended; a significant look is that which is calculated to signify the particular feeling of the individual.

To signify and testify, from testis, a witness, and facere, to make, like the word express, are employed in general for any, act of communication otherwise than by words; but express is used in a stronger sense than either of the former. The passions and strongest movements of the soul are expressed; the simple intentions or transitory feelings of the mind are signified or testified. A person expresses his joy by the sparkling of his eye and the vivacity of his countenance; he signifies his wish by a nod; he testifies his approbation by a smile. People of vivid sensibility must take care not to express all their feelings; those who expect a ready obedience from their inferiors must not adopt a haughty mode of signifying their will: nothing is more gratifying to an ingenuous mind than to testify its regard for merit, wherever it may discover itself.

Utter, from the preposition out, signifying to bring out, differs from express in this, that the latter respects the thing which is communicated, and the former the means of communication. We express from the heart; we utter with the lips: to express an uneharitable sentiment is a violation of Christian duty; to utter an unseemly word is a violation of good manners: those who say what they do not mean utter, but not express; those who show by their looks what is passing in their hearts express, but do not utter.

See also Explanatory.

EXPRESSION. See WORD.

EXPRESSIVE. See Significant.

EXPUNGE. See BLoT.

EXTEMPORANEOUS. See UNPREMEDITATED.

EXTEND, STretch, Reach. These words are nearly allied to one another in the sense of drawing out so as to enlarge the dimensions, particularly that of length. Extend, from ex, out, and tendere, to stretch, signifying to tend outward or away from an object, is the most gencral of these terms. 
Stretch comes from Anglo-Saxon strac, hard, rigid; stretch being to make stiff or hard, as in straining a string. Reach, Anglo-Saxon recan, conveys the idea of attaining a point or an object by stretching. Things may extend in any manner, either by simply passing over or occupying a certain space; as a piece of water extends into a country.

They may also be extended by adding to their dimensions; as to extend the garden beyond the house.

Things are stretched or extended lengthwise as far as they will admit of extension; as to stretch one's neck; to lie stretched on the ground.

Wherefore these words may be applied to the same objects with this distinction: to extend the arm or hand is simply to put it out; to stretch the arm is to extend it its full length.

A country is said to extend in its ordinary application, but it is only said figuratively to stretch when it seems to extend itself by an effort to its utmost length.

To extend is indefinite as to the distance; it may be shorter or longer, and requires, therefore, to be expressly defined: to reach is defined by the point arrived at, which may be either expressed or implied; as the road extends many miles; it will not reach so far, $i . e$., as the house or other objects implicd.

Persons extend things, as one extends a field, boundary, etc.; persons or things reach things; a person reaches a place; a sound reaches the ear.

In the moral and extended application they are distinguished in a similar manner: influence, power, observations, etc., may be extended in an indefinite manner as before, but they are said to be stretched when they are carried as far as they can be, and sometimes farther than is convenient.

One reaches a ccrtain age, or one reaches a goal; the understanding reaches an object of contemplation.

See also EnLarge.

EXTENSIVE. See CoMpreilensive.

EXTENT. Sce LiMiT.

EXTENUATE, Palliáte. Extenuate, from the Latin tenuis, thin, small, signifies literally to make small. Palliate, in Latin palliatus, participle of pallio, from pallium, a cloak, signifies to throw a cloak over a thing so that it may not be seen.

These terms are both applicable to the moral conduct, and express the act of lessening the guilt of any impropricty.

To extenuate is simply to lessen guilt without reference to the means; to palliate is to lessen it by means of art. To extenuate is rather the effect of circumstances: to palliate is the direct effort of an individual. Ignorance in the offender may serve as an extenuation of his guilt, although not of his offence: it is but a poor palliation of a man's guilt to say that his crimes have not been attended with the mischief which they were calculated to produce.

EXTERIOR. Sec OUTWARD.

EXTERMINATE. See ERADICATE. EXTERNAL. See ObJective; OUtWARD.

EXTINGUISHED. See OUT.

EXTIRPATE. Sec ERADICATE.

EXTOL. See Praise.

EXTORT. See EXACT.

EXTRANEOUS, Extrinsic, ForEIGN. Extraneous, from ex or extra, signifies out of the land, not belonging to it. Extrinsic, in Latin extrinsecus, compounded of extra and secus, beside, signifies outward, external. Foreign, from the Latin foris, out-of-doors, signifies not belonging to the household.

The extraneous is that which forms no necessary or natural part of anything: the extrinsic is that which forms a part or has a connection, but only in an indirect form; it is not an inherent or component part: the foreign is that. which forms no part whatever and has no kind of connection. A work is said to contain extraneous matter which contains much matter not necessarily belonging to, or illustrative of, the subject: a work is said to have $e x$ trinsic merit when it borrows its value from local circumstances, in distinction from the intrinsic merit, or that which lies in the contents.

Extraneous and extrinsic have a general and abstract sense, but foreign has a particular signification; they always pass over to some object either expressed or understood: hence we say extraneous idcas or extrinsic worth, but that a particular mode of acting is 
foreign to the general plan pursued. Anecdotes of private individuals would be extraneous matter in a general history: the respect and credit which men gain from their fellow-citizens by an adherence to rectitude is the extrinsic advantage of virtue; the peace of a good conscience and the favor of God are its intrinsic advantages: it is foreign to the purpose of one who-is making an abridgment of a work to enter into details in any particular part.

EXTRAORDINARY, REMARKABLE, are epithets both opposed to the ordinary; and in that sense the $e x$ traordinary is that which in its own nature is remarkable: but things, however, may be extraordinary which are not remarkable, and the contrary. The extraordinary is that which is out of the ordinary course, but it does not always excite remark, and is not, therefore, remarkable, as when we speak of an extraordinary loan, an extraordinary measure of government: on the other hand, when the extraordinary conveys the idea of what deserves notice, it expresses much more than remarkable. "There are but few extraordinary things; many things are remarkable: the remarkabie is eminent; the extraordinary is supereminent: the extraordinary excites our astonishment; the remarkable only awakens our interest and attention. The extraordinary is unexpected; the remarkable is sometimes looked for: every instance of sagacity and fidelity in a dog is remarkable, and some extraordinary instances have been related which would almost stagger our belief.

eXtravagant, Prodigal, LavISH, Profose. Extravagant, from extra and vagans, participle of vagari, to wander, signifies in general wandering from the line; and prodigal, from the Latin prodigus, from prod-, forth, and agere, to drive, signifies in general sending forth, or giving out in great quantities. Lavish, from Anglo-Saxon lafian, to wash, was probably borrowed from Latin lavare, to wash, at an early time, signifying to wash away in waste. Profuse, from the Latin profusus, participle of profundere, to pour forth, signifies pouring out freely.

The idea of using immoderately is implied in all these terms, but extrava- gant is the most general in its meaning and application. The extravagant man spends his money without reason; the prodigal man spends it in excesses: one may be extravagant with a small sum where it exceeds one's means; one can be prodigal only with large sums.

Extravagant and prodigal designate habitual as well as particular actions: lavish and profuse are properly applied to particular actions, the former to denote an expenditure more or less wasteful or superfluous, the latter to denote a full supply without any sort of scant. $\mathrm{He}$ who is lavish consumes without considering the value of what is spent; but profuseness may sometimes arise from an excess of liberality.

As extravagance has respect to the disorder of the mind, it may be employed with equal propriety to other objects; as to be extravagant in praises, requests, etc. As prodigal refers to excess in the measure of consumption, it may be applied to other objects than worldly possessions; as to be prodigal of one's time, treasure, strength, and whatever is near and dear to us. Lavish may be applied to any objects which may be dealt out without regard to their value; as to be lavish of one's compliments by scattering them indiscriminately. Profuse may be applied to whatever may be given in superabundance, but mostly in a good or indifferent sense.

\section{EXTREME. See UtTerMost.}

EXTREME UNCTION. See UNCTION.

EXTREMITY, EXTREME. Extrem$i t y$ is used in the proper or the improper sense; extreme, in the improper sense: we speak of the extremity of a line or an avenue, the extremity of distress, but the extreme of the fashion. In the moral sense, extremity is applicable to the outward circumstances; extreme, to the opinions and conduct of men: in matters of dispute between individuals it is a happy thing to guard against coming to extremities; it is the characteristic of volatile tempers to be always in extremes, either the extreme of joy or the extreme of sorrow.

See also END.

EXTRICATE. See Disengage.

EXTRINSIC. See Extraneous. 
EXUBERANT, LUXURIANT. Exu- be exuberance; plants are to be seen berant, from the Latin exuberans, or ex in their luxuriance only in seasons that and $u b e r$, udder, signifies very fruitful or superabundant: luxuriant, in Latin luxurians, from luxus, pomp, excess, signifies expanding with unrestrained freedom. These terms are both applied to vegetation in a flourishing state; but exuberance expresses the excess, and luxuriance the perfection: in a fertile soil, where plants are left unrestrainedly to themselves, there will are favorable to them.

In the moral application exuberance of intellect is often attended with a restless ambition that is incompatible both with the happiness and advancement of its possessor; luxuriance of imagination is one of the greatest gifts which a poet can boast of.

EXULtation. See Triumph. EYE. See LoOr. 
Fable, Tale, Novel, Romance. Fable, in Latin fabula, from fari, to speak or tell, and tale, from to tell, both designate a species of narration; novel, from the Italian novella, comes from Latin novellus, a diminutive of novus, new, and signifies news from real life, or simply something new in the way of a story; romance meant a tale in verse, embodying the adventures of some hero of chivalry, written in the vernacular-i.e., Italian or Old French -instead of Latin, and derives its name from Romanicus, Roman, the general designation of the various Latin dialects, French, Italian, etc., as opposed to classical Latin. Different species of composition are expressed by the above words: the fable is allegorical; its actions are natural, but its agents are imaginary: the tale is fictitious but not imaginary; both the agents and actions are drawn from the passing scenes of life. Gods and goddesses, animals and men, trees, vegetables, and inanimate objects in general may be made the agents of a fable; but of a tale, properly speaking, only men or supernatural spirits can be the agents: of the former description are the celebrated fables of Esop, and of the latter the tales of Marmontel, the tales of the Genii, the Chinese tales, etc.: fables are written for instruction, tales principally for amusement: fables consist mostly of only one incident or action, from which a novel may be drawn; tales, always of many which excite an interest for an individual.

The tale, when compared with the novel, is a simple kind of fiction, and consists of but few persons in the drama; while the novel, on the contrary, admits of every possible variety in characters; the tale is told without much art or contrivance to keep the reader in suspense, without any depth of plot or importance in the catastrophe; the novel affords the greatest scope for exciting an interest by the rapid succession of events, the involvements of interest, and the unravelling of its plot. If the novel awakens the attention, the romance rivets the whole mind and engages the affections; it presents nothing but what is extraordinary and calculated to fill the imagination; "of the former description, Cervantes, Le Sage, and Fielding have given us the best specimens; and of the latter we have the best modern specimens from the pen of Mrs. Radcliffe."

FABRIC. See EDIFICE.

FABRICATE. See INVENT.

FABRICATION. See Fiction.

FABULOUS. See LEgendary.

FACE, FroNt, figuratively designate the particular parts of bodies which bear some sort of resemblance to the human face or forehead. Face is applied to that part of bodies which serves as an index or rule and contains certain marks to direct the observer; front is employed for that part which is most prominent or foremost: hence we speak of the face of a wheel or clock, the face of a painting, or the face of nature: but the front of a house or building, and the front of a stage: hence, likewise, the propriety of the expressions, to put a good face on a thing, to show a bold front.

See also Confront.

Face, Countenance, Visage. - Face, in Latin facies, appearance, signifies that which first strikes the attention in the general appearance of another$i$. e., the face. Countenance, in French contenance, from the Latin continere, to control, meant method of acting or controlling one's self, gestures, demeanor-hence face. Visage, from visus, sight, look, signifies the particular form of the face as it presents itself to view; properly speaking, a kind of countenance. The face consists of a certain set of features; the countenance consists of the general aggregate of looks produced by the mind upon the features; the visage consists of the whole assemblage of features and looks in particular cases: the face is the work of nature; the countenance and visage are the work of the mind: the face re- 
mains the same, but the countenance and visage are changeable.

The face properly belongs to brutes as well as men, the countenance is the peculiar property of man, although sometimes applied to the brutes; the visage is peculiarly applicable to superior beings: the last term is employed only in the grave or lofty style.

FACETIOUS, CONVERSABLE, Pleasant, Jocular, Jocose.

All these epithets designate that companionable quality which consists in liveliness of speech. Facetious was in Latin facetus, signifying fine, witty, courteous. Conversable is literally able to hold a conversation. Pleasant (see AGREeABLE) signifies making ourselves pleasant with others, or them pleased with us. Jocular signifies after the manner of a joke, from joculus, a little joke; jocose, using or having jokes, from iocus, joke.

Facetious may be employed either for writing or for conversation; the rest only in conversation: the facetious man deals in that kind of discourse which may exeite laughter; a conversable man may instruet as well as amuse; the pleasant man says everything in a pleasant manner; his pleasantry even on the most delicate subject/is without offence: the person speaking is jocose; the thing said, or the manner of saying it, is jocular; it is not for any one to be always jocose, although sometimes one may assume a jocular air when we are not at liberty to be serious. A man is facetious from humor; he is conversable by means of information; he indulges himself in occasional pleasaniry, or allows himself to be jocose, in order to enliven conversation; a useful hint is sometimes conveyed in jocular terms.

FACILITY. Sce Ease.

FaCT. See Circumstance.

FACTION, Party. These two words equally suppose the union of many persons, and their opposition to certain views different from their own: but faction, from factio, making, denotes an activity and secret machination against those whose views are opposed; and party, from the verb to part or split, expresses only a division of opinion.

The term parly has of itself nothing odious; that of faction is always so: any man, without distinetion of rank, may have a parly either at court or in the army, in the eity or in literature, without being himself immediately implicated in raising it; but factions are always the result of active efforts: one may have a party for one's merit, from the number and ardor of one's friends; but a faction is raised by busy and turbulent spirits for their own purposes: Rome was torn by the intestine factions of Casar and Pompey. Faction is the demon of discord, armed with the power to do endless mischief, and intent alone on destroying whatever opposes its progress; woe to that state into which it has found an entrance: party spirit may show itself in noisy debate; but while it keeps within the legitimate bounds of opposition it is an evil that must be endured.

FACTIOUS, Seditious. Factions, in Latin factiosus, from facere, to do, signifies the same as busy or intermeddling; ready to take an active part in matters not of one's own immediate concern. Seditious, in Latin seditiosus, signifies prone to sedition (see INSURRECTION).

Factious is an epithet to characterize the tempers of men; seditious characterizes their conduct: the factious man attempts to raise himself into importance, he aims at authority, and secks to interfere in the measures of government; the seditious man attempts to exeite others, and to provoke their resistance to established authority: the first, wants to be a lawgiver; the second does not hesitate to be a law-breaker: the first wants to direct the state; the second, to overturn it: the factious man is mostly in possession of either power, rank, or fortune; the seditious man is seldom elevated in station or cireumstances above the mass of the people. The Roman tribunes were in general little better than factious demagogues, such, in fact, as abound in all republies; Wat Tyler was a seditious disturber of the peace. Factious is mostly applied to individuals; seditious is employed for bodies of men: hence we speak of a factious nobleman, a seditious multitude. 
FACTOR, Agent: Though both these terms, according to their origin, imply a maker or doer, yet, at present, they have a distinct signification; the word factor is used in a limited, and the word agent in a general sense: the factor only buys and sells on the account of others; the agent transacts every sort of business in general: merchants and manufacturers employ factors abroad to dispose of goods transmitted; lawyers are frequently employed as agents in the receipt and payment of money, the transfer of estates, and various other pecuniary concerns.

\section{FACULTY. See ABILITy.}

FAIL, FALl Short, Be Deficient. Fail, in French faillir, is derived from the Latin fallere, to deceive. To fail marks the result of actions or efforts; a person fails in his undertaking: fall short designates either the result of actions or the state of things; a person falls short in his calculation or in his account; the issue falls short of the expectation: to be deficient marks only the state or quality of objects; a person is deficient in good manners. People frequently fail in their best endeavors for want of knowing how to apply their abilities; when our expectations are immoderate, it is not surprising if our success falls short of our hopes and wishas: there is nothing in which people discover themselves to be more deficient than in keeping ordinary engagements. To fail and be deficient are both applicable to the characters of men; but the former is mostly employed for the moral conduct, the latter for the outward behavior; hence a man is said to fail in his duty, in the discharge of his obligations, in the performance of a promise, and the like: but to be deficient in politeness, in attention to his friends, in his address, in his manner of entering a room, and the like.

Failure, Failing.-Failure bespeaks the action or the result of the action; a failing is the habit or the habitual failure: the former is said of our undertakings, the latter of our moral character. Failure is opposed to success, a failing to a perfection. The merchant must be prepared for failures in his speculations; the statesman for failures in his projects, the result of which depends upon contingencies that are above human control. With our failings, however, it is somewhat different; we must never rest satisfied that we are without them, nor contented with the mere consciousness that we have them.

\section{See also IMPERFECTION.}

Failure, Miscarriage, Abortion.Failure has always a reference to the agent and his design; miscarriage, that is, the carrying or going wrong, is applicable to all sublunary concerns, without reference to any particular agent; abortion, from the Latin aboriri, to deviate from the rise, or to pass away before it comes to maturity, is in the proper sense applied to the process of animal nature, and in the figurative sense to the thoughts and designs which are conceived in the mind.

Failure is more definite in its signification and limited in its application; we speak of the failures of individuals, but of the miscarriages of nations or things: a failure reflects on the person so as to excite toward him some sentiment, either of compassion, displeasure, or the like; a miscarriage is considered mostly in relation to the course of human events: hence the failure of Xerxes's expedition reflected disgrace upon himself; but the miscarriage of military enterprises in general are attributable to the elements or some such untoward circumstance. The abortion, in its proper sense, is a species of miscarriage, and in application a species of failure, as it applies only to the designs of conscious agents; but it does not carry the mind back to the agent, for we speak of the abortion of a scheme with as little reference to the schemer as when we speak of the miscarriage of an expedition.

See also Insolvency.

FAILING. See FAIL; ImperfecTION.

FAINT, LANGUID, Faint comes from Latin fingere, to feign, Old French feint, pretended, hence weak; thence developed the general idea of weakness or unreality, to grow faint, or to faint meaning to be weak. Languid, in Latin languidus, from languere, is allied to

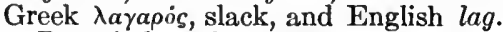
Faint is less than languid; faintness 
is, in fact, in the physical application, / well as himself, he wishes only for an the commencement of languor; we equal share of advantage; a man may may be faint for a short time, and if continued and extended through the limbs it becomes languor; thus we say, to speak with a faint tone, and have a languid frame. In the figurative application, to make a faint resistance, to move with a languid air, to form a faint idea, to make a languid effort.

FAIR, Clear. Fair, in AngloSaxon fager, beautiful, is allied to Gothic fagrs, fit. Clear (for derivation see Clear).

Fair is used in a positive sense, clear in a negative sense: there must be some brightness in what is fair; there must be no spots in what is clear. The weather is said to be fair which is not only free from what is disagreeable, but somewhat enlivened by the sun; it is clear when it is free from clouds or mists. A fair skin approaches to white; a clear skin is without spots or irregularities.

In the moral application, a fair fame speaks much in praise of a man; a clear reputation is free from faults. A fair statement contains everything that can be said pro and con; a clear statement is free from ambiguity or obscurity. Fairness is something desirable and inviting; clearness is an absolute requisite, it cannot be dispensed with.

See also Blonde.

Fair, Honest, Equitable, Reasonable. - Fair (see above). Honest, in Latin honestus, comes from honos, honor. Equitable signifies having equity, or according to equity, from Latin aquus, equal. Reasonable signifies having reason, or according to reason.

Fair is said of persons or things; honesty mostly characterizes the person, either as to his conduct or his principle. When fair and honest are both applied to the external conduct, the former expresses more than the latter: a man may be honest without being fair; he cannot be fair without being honest. Fairness enters into every minute circumstance connected with the interests of the parties, and weighs them alike for both; honesty is contented with a liberal conformity to the law, it consults the interest of one party; the fair dealer looks to his neighbor as be an honest dealer while he looks to no one's advantage but his own: the fair man always acts from a principle of right; the honest man may be so from a motive of fear.

When fair is employed as an epithet to qualify things, or to designate their nature, it approaches very near in signification to equitable and reasonable; they are all opposed to what is unjust: fair and equitable suppose two objects put in collision; reasonable is employed abstractly; what is fair and equitable is so in relation to all circumstances, what is reasonable is so of itself. An estimate is fair in which profit and loss, merit and demerit, with every collateral circumstance, is duly weighed; : a judgment is equitable which decides suitably and advantageously for both parties; a price is reasonable which does not exceed the limits of reason or propriety. A decision may be either fair or equitable; but the former is said mostly in regard to trifling matters, even in our games and amusements, and the latter in regard to the important rights of mankind. It is the business of the umpire to decide fairly between the combatants or the competitors for a prize; it is the business of the judge to decide equitably between men whose property is at issuc. A demand, a charge, a proposition, or an offer may be said to be either fair or reasonable; but the former term always bears a relation to what is right between man and man; the latter, to what is right in itself according to circumstances.

FAITH, Creed. Faith (see BELIEF) denotes either the principle of trusting or the thing trusted. Creed, from the Latin credere, to believe, denotes the thing believed.

These words are synonymous when taken for the thing trusted in or belicved; but they differ in this, that faith has always a reference to the principle in the mind; creed only respects the thing which is the object of faith: faith is the general and creed the particular term, for a creed is a set form of faith: hence we say to be of the same faith, or to adopt the same creed. The holy martyrs died for the faith 
as it is in Christ Jesus; every established form of religion will have its peculiar creed. The Church of England has adopted that creed which it considers as containing the purest principles of Christian faith.

Faith, Fidelity. - Though derived from the same source, they differ widely in meaning: faith here denotes a mode of action, namely, in acting true to the faith which others repose in us; fidelity, a disposition of the mind to adhere to that faith which others repose in us. We keep our faith, we show our fidelity. Faith is a public concern, it depends on promises; fidelity is a private or personal concern, it depends upon relationships and connections. $\mathrm{A}$ breach of faith is a crime that brings a stain on a nation, for faith ought to be kept even with an enemy. A broach of fidelity attaches disgrace to the individual, for fidelity is due from a subject to a prince, or from a servant to his master, or from married people one to another. No treaty can be made with him who will keep no faith; no confidence can be placed in him who discovers no fidelity.

Faithful, Trusty.-Faithful signifies full of faith or fidelity. Trusty signifies fit or worthy to be trusted.

Faithful respects the principle altogether; it is suited to all relations and stations, public and private; trusty includes not only the principle, but the mental qualifications in general; it applies to those in whom particular trust is to be placed. It is the part of a Christian to be faithful to all his engagements; it is a particular excellence in a servant to be trusty.

Faithful is applied in the improper sense to an unconscious agent; trusty may be applied with equal propriety to things as to persons. We may speak of a faithful saying or a faithful picture; a trusty sword or a trusty weapon.

In the United States the term trusty has of late come to apply to an inmate of an institution for the insane whose condition has so far improved that he or she is relieved of ordinary restraint and is permitted to go about the grounds and vicinity; to a prisoner whose conduct has won for him a relaxation of rules and permission to go beyond the prison walls without a guard; and to one committed to a correctional institution who is allowed similar privileges.

Faithless, Unfaithful. - Faithless is mostly employed to denote a breach of faith, and unfaithful to mark the want of fidelity. The former is positive; the latter is rather negative, implying a deficiency. A prince, a government, a people, or an individual is said to be faithless; a husband, a wife, a servant, or any individual, unfaithful. Mettus Fuffetius, the Alban Dictator, was faithless to the Roman people when he withheld his assistance in the battle and strove to go over to the enemy: a man is unfaithful to his employer who sees him injured by others without doing his utmost to prevent it. A woman is faithless to her husband who breaks the marriage vow; she is unfaithful to him when she does not discharge the duties of a wife to the best of her abilities.

Faithless, Perfidious, Treacherous.Faithless is the generic term, the rest are specific terms; a breach of good faith is expressed by them all, but faithless expresses no more: the others include accessory ideas in their signification. Perfidious, in Latin perfidiosus, signifies literally breaking through faith in a great degree, and now implies the addition of hostility to the breach of faith. Treacherous is derived from Old French trechier, to trick, Latin tricare, from tricoe, difficulties, wiles, and is allied to intricate, etc.

A faithless man is faithless only for his own interest; a perfidious man is expressly so to the injury of another. A friend is faithless who consults his own safety in time of need; he is perfidious if he profits by the confidence reposed in him to plot mischief against the one to whom he has made vows of friendship. Faithlessness does not suppose any particular efforts to deceive: it consists of merely violating that faith which the relation produces; perfidy is never so complete as when it has most effectually assumed the mask of sincerity.

Perfidy may lie in the will to do; treachery lies altogether in the thing done; one may therefore be perfidious 
without being treacherous. A friend is perfidious whenever he evinces his perfidy; but he is said to be treacherous only in the particular instance in which he betrays the confidence and interests of another. I detect a man's perfidy, or his perfidious aims, by the manner in which he attempts to draw my secrets from me; I am not made acquainted with his treachery until I discover that my confidence is betrayed and my secrets are divulged. On the other hand, we may be treacherous without being perfidious. Perfidy is an offence mostly between individuals; it is rather a breach of fidelity (see FAITH) than of faith; treachery, on the other hand, includes breaches of private or public faith. A servant may be both perfidious and treacherous to his master; a citizen may be treacherous, but not perfidious, toward his country. It is said that in the South Sea Islands, when a chief wants a human victim, their officers will sometimes invite their friends or relations to come to them, when they take the opportunity of suddenly falling upon them and despatching them; here is perfidy in the individual who acts this false part, and treachery in the act of betraying him who is murdered. When the school-master of Falerii delivered his scholars to Camillus, he was guilty of treachery in the act and of perfidy toward those who had reposed confidence in him. When Romulus ordered the Sabine women to be seized, it was an act of treachery, but not of perfidy; so, in like manner, when the daughter of Tarpeius opened the gates of the Roman citadel to the enemy.

FALL, Downfall, Ruin. comes from Anglo-Saxon feallan, possibly allied to Latin fallere, to deceive. Ruin (see Destruction).

Whether applied to physical objects or the condition of persons, fall expresses less than downfall, and this less than ruin. Fall applies to that which is erect; downfall, to that which is elevated: everything which is set up, although as trifling as a stick, may have a fall; but we speak of the downfall of the loftiest trees or the tallest spires. A fall may be attended with more or less mischief, or even with none at all; but downfall and ruin are accompanied with the dissolution of the bodies that fall. The higher a body is raised, and the greater the art that is employed in the structure, the completer the downfall; the greater the strueture the more extended the ruin. In the figurative application we may speak of the fall of man from a state of innocence, a state of ease, or a state of prosperity, or his downfall from greatness or high rank. He may recover from his fall, but his downfall is commonly followed by the entire ruin of his concerns, and often of himself. The fall of kingdoms and the downfall of empires must always be succeeded by their ruin as an inevitable result.

Fall, Drop, Droop, Sink, Tumble.Fall (see above). Drop and droop were originally the same word, drop being the Anglo-Saxon form, and droop the Scandinavian form. Sink comes from Anglo-Saxon sincan, to sink. Tumble is in Anglo-Saxon tumbian, meaning to turn heels over head, allied to Old High German tumon, to turn over and over, whence French tomber, to fall, is derived.

Fall is the generic, the rest specific terms: to drop is to fall suddenly, and mostly in the form of a drop; to droop is to drop in part; to sink is to fall gradually; to tumble is to fall awkwardly or contrary to the usual mode. In cataracts the water falls perpetually and in a mass: in rain it drops partially; in ponds the water sinks low. The head droops, but the body may fall or drop from a height, it may sink down to the earth, it may tumble by accident.

Fall, drop, and sink are extended in their applieation to moral or other objects; droop and tumble, in the physical sense. A person falls from a state of prosperity; words drop from the lips and sink into the heart. Corn, or the price of corn, falls; a subject drops; a person sinks into poverty or in the estimation of the world.

FALlacious, Deceitful, FraudvLENT. Fallacious comes from the Latin fallax and fallere, to deccive, signifying the property of misleading. Deceilful (see DEcerve). Fraudulent signifies after the manner of a fraud.

The fallacious has respect to falsehood in opinion; deceilful to that which is externally false: our hopes are often 
fallacious; the appearances of things are often deceitful. Fallacious, as characteristic of the mind, excludes the idea of design; deceitful excludes the idea of mistake; fraudulent is a gross species of the deceitful. It is a fallacious idea for any one to imagine that the faults of others can serve as any extenuation of his own; it is a deceitful mode of acting for any one to advise another to do that which he would not do himself; it is fraudulent to attempt to get money by means of a falsehood.

Fallacy, Delusion, Illusion. - The fallacy is that which has the tendency to deceive; the delusion is that which deludes; or the state of being deluded; the illusion is that which has the power of illuding or sporting with the mind, or the state of being so played upon. We endeavor to detect the fallacy which lies concealed in a proposition: we endeavor to remove the delusion to which the judgment has been exposed, and to dissipate the illusion to which the senses or fancy are liable.

In all the reasonings of freethinkers there are fallacies against which the ignorant cannot always be on their guard. The ignorant are perpetually exposed to delusions when they attempt to speculate on matters of opinion. The ideas of ghosts and apparitions are mostly attributable to the illusions of the senses and the imagination.

See also SopHISTRY.

FALL SHORT. See FAIL.

FALSEHOOD. See Fiction; UNTRUTH.

FALSITY. See UNTRUTh.

FALTER. See Hesitate.

FAME, Reputation, Renown. Fame (from Latin fari, to speak) is the most noisy and uncertain; it rests upon report: reputation (see CharACTER) is silent and solid; it lies more in the thoughts and is derived from observation. Renown, in French renommée, from Latin re, again, and nomen, name, meaning named again and again, signifies the reverberation of a name; it is as loud as fame, but more substantial and better founded: hence we say that a person's fame is gone abroad, his reputation is established, and he has got renown.

Fame may be applied to any object, good, bad, or indifferent; reputation is applied only to real eminence in some department; renown is employed only for extraordinary men and brilliant exploits. The fame of a quack may be spread among the ignorant multitude by means of a lucky cure; the reputation of a physician rests upon his tried skill and known experience; the renown of a gencral is proportioned to the magnitude of his achievements.

Fame, Report, Rumor, Hearsay.Fame has a reference to the thing which gives birth to it; it goes about of itself without any apparent instrumentality. Report (from re and portare, to carry back, or away from an object) has always a reference to the reporter. Rumor, in Latin rumor, from a root which signifies to make a humming noise, has a reference to the buzzing nature of words that are carried; it is therefore properly a buzzing report. Hearsay refers to the receiver of that which is said: it is limited, therefore, to a small number of speakers or reporters. Fame serves to form or establish a character either of a person or a thing; it will be good or bad, according to circumstances; the fame of our Saviour's miracles went abroad through the land; a report serves to communicate information of events; it may be more or less correct according to the veracity or authenticity of the reporter; reports of victories mostly precede the official confirmation: a rumor serves the purposes of fiction; it is more or less vague, according to the temper of the times and the nature of the events; every battle gives rise to a thousand rumors: the hearsay serves for information or instruction, and is seldom so incorrect as it is familiar.

FAMILIAR. See Conversant; FreE.

FAMILIARITY. See ACQUAINTANCE.

Family, House, Lineage, Race. Divisions of men, according to some rule of relationship or connection, is the common idea in these terms. Family is the most general in its import (from the Latin familia, a family, famulus, a servant). It is applicable to those who are bound together upon the principle of dependence. House figuratively denotes those who live in the 
same house (Anglo-Saxon hus, German haus, possibly from a root meaning to hide), and is commonly extended in its signification to all that passes under the same roof: hence we rather say that a woman manages her family; that a man rules his house. The family is considered as to its relationshipsthe number, union, condition, and quality of its members: the house is considered more as to what is transacted within its walls. We speak of a numerous family, a united or affectionate family; a mercantile house, and the House, meaning the members of the House of Parliament or House of Representatives, sometimes called the Lower House to distinguish it from the House of Lords or the Senate, familiarly called the Upper House. If a man cannot find happiness in the bosom of his family, he will seek for it in vain elsewhere; the credit of a house is to be kept up only by prompt payments.

In an extended application of these words they are made to designate the quality of the individual, in which case family bears the same familiar and indiscriminate sense as before: house is employed as a term of grandeur. When we consider the family in its domestic relations, in its habits, manners, connections, and circumstances, we speak of a genteel family, a respectable family, the royal family: but when we consider it with regard to its political and civil distinctions, its titles and its power, then we denominate it a house, as an illustrious house; the House of Bourbon, of Brunswick, or of Hanover; the imperial House of Austria. Any subject may belong to an ancient or noble family: princes are said to be descended from ancient houses. A man is said to be of family or of no family: we may say likewise that he is of a certain house; but to say that he is of no house would be superfluous. In republies there are families, but not houses, because there is no nobility; in China, likewise, where the private virtues only distinguish the individual or his family, the term house is altogether inapplicable.

Family includes in it every eircumstance of connection and relationship; lineage respects only consanguinity: family is employed mostly for those who are coeval; lineage is generally used for those who have gone before. When the Athenian general Iphicrates, son of a shoemaker, was reproached by Harmodius with his birth, he said, I had rather be the first than the last of my family: David was of the lineage of Abraham, and our Saviour was of the lineage of David. Race, from the Latin radix, a root, denotes the origin, or that which constitutes the original point of resemblance. A family supposes the elosest alliance; a race supposes no closer connection than what a common property creates. Family is confined to a comparatively small number; race is a term of extensive import, including all mankind, as the human race, or particular nations, as the race of South Sea Islanders; or a particular family, as the race of the Heraclides: from Hercules sprang a race of heroes.

famous, Celebrated, ReNowned, Illustrious. Famous signifies literally having fame or the cause of fame; it is applicable to that which causes a noise or sensation; to that which is talked of, written upon, discussed, and thought of ; to that which is reported of far and near; to that which is circulated among all ranks and orders of men. Celebrated signifies literally kept in the memory by a celebration or memorial, and is applicable to that which is praised and honored with solemnity. Renowned signifies literally possessed of a name, and is applicable to whatever extends the name or eauses the name to be of ten repeated. Illustrious signifies literally what has or gives a lustre: it is applicable to whatever confers dignity.

Famous is a term of indefinite import; it conveys of itself frequently neither honor nor dishonor, since it is employed indifferently as an epithet for things praiseworthy or otherwise; it is the only one of these terms which may be used in a bad sense. The others rise in a gradually good sense. The celebrated is founded upon merit, and the display of talent in the arts and seienees; it gains the subject respect: the renowned is founded upon the possession of rare or extraordinary qualities, upon successful exertions and 
an accordance with public opinion; it brings great honor or glory to the subject: the illustrious is founded upon those solid qualities which not only render one known, but distinguished; it insures regard and veneration. A person may be famous for his eccentricities; celebrated as an artist, a writer, or a player; renowned as a warrior or a statesman; illustrious as a prince, a statesman, or a senator. The Maid of Orleans, who was decried by the English and idolized by the French, is equally famous in both nations. There are celebrated authors whom to censure, even in that which is censurable, would endanger one's reputation. The renowned heroes of antiquity have, by the perusal of their exploits, given birth to a race of modern heroes not inferior to themselves. Princes may shine in their lifetime, but they cannot render themselves illustrious to posterity except by the monuments of goodness and wisdom which they leave after them.

FANATIC. See ENTHusiast.

FANCIFUL, Fantastical, Whimsical, Capricious. Fanciful signifies full of fancy (see CoNcEIT). Fantastical signifies belonging to the fantasy, which is the imme iate derivative from the Greek фavraria, Latin fantasia, a vision, from root meaning to shine. Whimsical signifies either like a whim or having a whim, from a Scandinavian word meaning freak. Capricious means having caprice.

Fanciful and fantastical are both employed for persons and things; whimsical and capricious are mostly employed for persons, or what is personal. Fanciful is said of that which is irregular in the taste or judgment; fantastical is said of that which violates all propriety as well as regularity: the former may consist of a simple deviation from rule; the latter is something extravagant. A person may, therefore, sometimes be advantageously fanciful, although he can never be fantastical but to his discredit. Lively minds will be fanciful in the choice of their dress, furniture, or equipage: the affectation of singularity frequently renders people fantastical in their manners as well as their dress.

Fanciful is said mostly in regard to errors of opinion or taste; it springs from an aberration of the mind: whimsical is a species of the fanciful in regard to one's likes or dislikes; capricious respects errors of temper or irregularities of feeling. The fanciful does not necessarily imply instability; but the capricious excludes the idea of fixedness. One is fanciful by attaching a reality to that which only passes in one's own mind; one is whimsical in the inventions of the fancy; one is capricious by acting and judging without rule or reason that which admits of both.

See also Utopian.

Fancy, Imagination. - From what has already been said the distinction between fancy and imagination, as operations of thought, will be obvious. Fancy, considered as a power, simply brings the object to the mind or makes it appear; but imagination, from image, in Latin imago, from the root found in imitari, English imitate, is a power which presents the images or likenesses of things. The fancy, therefore, only employs itself about things without regarding their nature; but the imagination aims at tracing a resemblance and getting a true copy. The fancy consequently forms combinations, either real or unreal, as chance may direct; but the imagination is seldomer led astray. The fancy is busy in dreams or when the mind is in a disordered state; but the imagination is supposed to act when the intellectual powers are in full play.

The fancy is employed on light and trivial objects which are present to the senses; the imagination soars above all vulgar objects and carries us from the world of matter into the world of spirits, from time present to the time to come.

A milliner or mantua-maker may employ her fancy in the decorations of a cap or gown; but the poet's imagination depicts everything grand, everything bold, and everything remote.

Although Mr. Addison has thought proper, for his convenience, to use the words fancy and imagination promiscuously when writing on this subject, yet the distinction, as above pointed out, has been observed both in familiar dis- 
course and in writing. We say that we fancy, not that we imagine, that we see or hear something; the pleasures of the imagination, not of the fancy.

See also Conceit; VAGary.

FANTASTIC. See QuIXotic.

FANTASTICAL. See Fanciful.

FAR. See Distant.

FARCICAL, Comic. Farcical, the adjective of farce (in French the same form, from farcer, to stuff, Latin farcio, Italian farso), signifies, literally, the stuffing in meat, and, in ordinary language, whatever pertains to a farce, anything stuffed with foreign matters, specifically a dramatic piece of a humorous character, full of exaggeration and drollery; hence, anything absurdly exaggerated.

Farce differs from comedy proper in degree, but not in kind. The aim of both is to excite mirth, but while the comedy does so by a comparatively faithful adherence to nature and truth, the farce takes much greater license and does not scruple to make use of any extravagance or improbability that may serve its purpose. At one time a farce was a petty show exhibited in the streets, then it was a short after-piece on the stage following a more serious performance, and latterly it supplied the entire performance.

FARE, Provision. Fare, from Anglo-Saxon faran, to go, signifies in general the condition or thing that comes to one or is provided for a journey. Provision, from provide, signifies the thing provided for one.

These terms are alike employed for the ordinary concerns of life, and may either be used in the limited sense for the food one procures or in general for whatever necessity or convenience is procured: to the term fare is annexed the idea of accident; provision includes that of design: a traveller on the Continent must frequently be contented with humble fare, unless he takes the precaution of carrying his provisions with him.

FARMER, HUSBANDMAN, AgricULT URIST. Farmer comes from AngloFrench ferme, Late Latin firma, from firmus, a fixed rent, a farmer being one who paid a fixed rent to a landlord; husbandman is one following husbandry, that is, the tillage of land by manual labor; the farmer, therefore, conducts the concern, and the husbandman labors under his direction: agriculturist, from the Latin ager, a field, and colere, to till, significs any one engaged in the art of cultivation. The farmer is always a practitioner; the agriculturist may be a mere theorist: the farmer follows husbandry solely as a means of living: the agriculturist follows it as a science; the former tills the land upon given admitted principles; the latter frames new principles or alters those that are established. Between the farmer and the agriculturist there is the same difference as between practice and theory: the former may be assisted by the latter so long as they can go hand in hand; but in the case of a collision the farmer will be of more service to himself and his country than the agriculturist; farming brings immediate profit from personal service; agriculture may only promise future, and consequently contingent, advantages.

Husbandman is now obsolete in prose, though it is still used in poetry.

FARRAGO. See Olio.

FARTHEST. See UtTERMost.

FASCINATE. See CharM.

FASCINATED. See Spellbound.

FASHION, Quality, Distinction. These epithets are employed promiscuously in colloquial discourse, but not with strict propriety: by men of fashion are understood such men as live in the fashinable world and keep the best company; by men of quality are understood men of rank or title; by men of distinction are understood men of honorable superiority, whether by wealth, office, or pre-eminence in society. Gentry and merchants, though not men of quality, may, by their mode of living, be men of fashion; and by the office they hold in the state they may likewise be men of distinction.

See also Custom; Etiquette; Fors; VOGUE.

FAst. See Abstinence.

FASTEN. Sec FIX.

FASTIDIOUS, Squeamish. Fastidious comes from Latin fastidium, loathing, pcrhaps from fastus, arrogance, and tadium, disgust, fastidium meaning arrogant disgust; squeamish 
is in Middle English skeymous, disdainful, from Anglo-French escoymous, delicate, nice as to food, from Greek $\sigma \chi \bar{\eta} \mu a$, English scheme, meaning form, air, mien, manners-hence literally full of airs; in a moral sense it signifies foolishly sickly, easily disgusted. Squeamish implies a stronger physical shrinking than fastidious. The fastidious man avoids or rejects what he does not like; a squeamish person reacts more obviously against it with a kind of nervous horror. Whoever examines his own imperfections will cease to be fastidious; whoever restrains humor and caprice will cease to be squeamish.

Fatal. See Deadly.

Fate. See Chance; Destiny.

FATIGUE, WEARINESS, LASSITUDE. Fatigue, from the Latin fatigare, possibly from a root meaning to yawn, is the Latin word corresponding to the English weariness. Weariness is the substantive corresponding to weary, Anglo-Saxon werig, from worian, to tramp about in a swampy place, from wor, swamp; hence the state of feeling produced by walking over swampy ground. Lassitude, from the Latin lassus, weary, marks a state without specifying a cause.

Fatigue is an exhaustion of the animal or mental powers; weariness is a wearing out the strength or breaking the spirits; lassitude is a general relaxation of the animal frame: the laborer experiences fatigue from the toils of the day; the man of business, who is harassed by the multiplicity and complexity of his concerns, suffers fatigue; and the student who labors to fit himself for a public exhibition of his acquirements is in like manner exposed to fatigue: weariness attends the traveller who takes a long or pathless journey; weariness is the lot of the petitioner who attends in the antechamber of a great man; the critic is doomed to suffer weariness who is obliged to drag through the shallow but voluminous writings of a dull author. Lassitude is the consequence of a distempered system, sometimes brought on by an excess of fatigue, sometimes by sickness, and frequently by the action of the external air.

FAULT. See Blemish; Error; IMPERFECTION; LAPSE.
FAULTLESS. See ORIENT; UnofFENDING.

Faulty. See Culpable.

FAVOR. See Benefit; Credit; GRACE.

FAVORABLE, Propitious. In a former paragraph (see AUSPICIOUs) I have shown propitious to be a species of the favorable, namely, the favorable as it springs from the design of an agent; what is propitious, therefore, is always favorable, but not vice versa: the favorable properly characterizes both persons and things; the propitious, in the proper sense, characterizes the person only: as applied to persons, an equal may be favorable; a superior only is propitious: the one may be favorable only in inclination; the latter is favorable also in granting timely assistance. Cato was favorable to Pompey; the gods were propitious to the Greeks: we may all wish to have our friends favorable to our projects; none but heathens expect to have a blind destiny propitious. In the improper sense, propitious may be applied to things with a similar distinction: whatever is well disposed to us, and seconds our endeavors, or serves our purpose, is favorable; whatever efficaciously protects us, speeds our exertions, and decides our success is propitious to us: on ordinary occasions, a wind is said to be favorable which carries us to the end of our voyage; but it is said to be propitious if the rapidity of our passage forwards any great purpose of our own.

See also Opportune.

FAWN. See Coax.

FEALTy. See Homage.

FEAR. See APPREHEND; WorRy.

FEARFUL, Dreadful, Frightful, Tremendous, Terrible, Terrific, Horrible, Horrid. Fearful here signifies full of that which causes fear (see AlarM); dreadful, full of what causes dread (see APPREHENSION); frightful, full of what causes fright (see AFraIn); tremendous, that which causes trembling; terrible or terrific, causing terror; horrible or horrid, causing horror. The application of these terms is easily to be discovered by these definitions: the first two affect the mind more than the senses; all the others affect the senses 
more than the mind: a contest is fearful when the issue is important but the event doubtful; the thought of death is dreadful to one who feels himself unprepared. The frightful is less than the tremendous, the tremendous than the terrible, the terrible than the horrible: shrieks may be frightful; thunder and lightning may be tremendous; the roaring of a lion is terrible; the glare of his eye terrific; the actual spectacle of killing is horrible or horrid. In their general application these terms are often employed promiscuously to characterize whatever produces very strong impressions: hence we may speak of a frigh's,l, dreadful, terrible, or horrid dream; or $f$ 'htful, dreadful, or terrible tempest; drec ful, terrible, or horrid consequences.

FEARLESS. See BoLd.

FEAsible. See Colorable.

Feast, Banquet, Carousal, EN TERTainment, Treat. As fecists, in the religious sense, being derived from festus, joyful, are always days of leisure and frequently of public rejoicing, this word has been applied to any social meal for the purposes of pleasure: this is the idea common to the signification of all these words, of which feast seems to be the most general; and for all of which it may frequently be substituted, although they have each a distinct application: feast conveys the idea merely of enjoyment: banquet is a splendid feast, attended with pomp and state; it is a term of noble use, particularly adapted to poetry and the high style: carousal, French carous, from the German garaus (from gar, entirely, and aus, out), means the emptying out of the glass, a drinking-bout; entertainment and treat convey the idea of hospitality.

Feast, entertainment, and treat are taken in a more extended sense, to express other pleasures besides those of the table: feast retains its signification of a vivid pleasure, such as voluptuaries derive from delicious viands; entertainment and treat retain the idea of being granted by way of courtesy: we speak of a thing as being a feast or high delight; and of a person contributing to one's entertainment, or giving one a treat. To a benevolent mind the spectacle of an afflicted man relieved and comforted is a feast; to a mind ardent in the pursuit of knowledge, an easy access to a well-stocked library is a continued feast: men of a happy temper give and receive entertainment with equal facility; they afford entertainment to their guests by the easy cheerfulness which they impart to everything around them; they in like manner derive entertainment from everything they see or hear or observe: a treat is given or received only on particular occasions; it depends on the relative circumstances and tastes of the giver and receiver; to one of a musical turn one may give a treat by inviting him to a musical party; and to one of an intelligent turn it will be equally a treat to be of the party which consists of the enlightened and conversable.

Feast, Festival, Holiday.-Feast, in Latin festum, or festus, changed most probably from fesize and ferize, which latter, in all probability, comes from the Greek iźpєıa, sacred, because these days were kept sacred or vacant from all secular labor: festival and holiday, as the words themselves denote, have precisely the same meaning in their original sense, with this difference, that the former derives its origin from heathenish superstition, the latter owes its rise to the establishment of Christianity in its reformed state.

A feast, in the Christian sense of the word, is applied to every day which is regarded as sacred and observed with particular solemnity, except Sundays; a holyday, or, according to its modern orthography, a holiday, is simply a day on which ordinary business is suspended: among the Roman Catholies there are many days which are kept holy, and consequently by them denominated feasts, which in the English reformed chureh are only observed as holidays, or days of exemption from public business; of this description are the saints' days, on which the public offices are shut: on the other hand, Christmas, Easter, and Whitsuntide are regarded in both churehes more as feasts than as holidays. There are, therefore, many feasts where there are no holidays, and many holidays where there are no feasts. 
A feast is altogether sacred; a holiday has frequently nothing sacred in it, not even in its cause; it may be a simple ordinary transaction, the act of an individual: a festival has always either a sacred or a serious object. A feast is kept by religious worship; a holiday is kept by idleness; a festival is kept by mirth and festivity: some feasts are festivals, as in the case of the carnival at Rome; some festivals are holidays, as in the case of weddings and public thanksgivings.

See also Saturnalia.

FEAT. See DEed.

FEEBLE. See Weak.

FEel, Be Sensible, Conscious. From the simple idea of a sense, the word feel has acquired the most extensive signification and application in our language, and may be employed indifferently for all the other terms, but not in all cases: to feel is said of the whole frame, inwardly and outwardly; it is the accompaniment of existence: to be sensible, from the Latin sentio, is said only of the senses. It is the property of all living creatures to feel pleasure and pain in a greater or less degree: those creatures which have not the sense of hearing will not be sensible of sounds. In the moral application, to feel is peculiarly the property or act of the heart; to be sensible is that of the understanding: an ingenuous mind feels pain when it is sensible of having committed an error: one may, however, feel as well as be sensible by means of the understanding: a person feels the value of another's service; is sensible of his kindness: one feels or is sensible of what passes outwardly; one is conscious only of what passes inwardly, from con or eum and scio, to know to one's self: we feel the force of another's remark; we are sensible of the evil which must spring from the practice of vice; we are conscious of having fallen short of our duty.

Feeling, Sense, Sensation.-Feeling, from Anglo-Saxon felan, is allied to Anglo-Saxon folm, the palm of the hand-the hand being that with which one feels. Sensation is taken only in a partichlar sense. Feeling and sense are either physical or moral properties; sensation is a particular aet of physical or moral fceling.
Feeling, physically considered, is but a mode of sense; anatomists reckon five senses, of which feeling is one: sense is the abstract faculty of perceiving through the medium of the sense, as to be deprived of sense when stunned by a blow; to be without sense when divested of the ordinary faculties. As. all creatures which have life have feeling, the expression, creatures without feeling, may be applied to inanimate objects; but in general the term feeling is taken for the sense of feeling.

Feeling, in its limited acceptation, is either a state of feeling or an act of feeling: sense is a mode of sense, $i$. $e$, a mode of perceiving through the medium of any particular organ of sense, or a state of perceiving particular objects. In this acceptation feeling is applied to moral as well as physical objects, sense, to intellectual as well as sensible objects: feeling has its seat in the heart, sense in the understanding; feeling is transitory and fluctuating, sense is permanent and regular. There are feelings of love, charity, compassion, etc.; there is a sense of justice, rectitude, propriety, etc.

As the sensation denotes a particular act of feeling, it differs from feeling only in application: the term feeling is most adapted to ordinary discourse on familiar matters; sensation, to the grave and scientific style: a child may talk of an unpleasant or pleasant feeling, a feeling of cold or hunger; the professional man talks of the sensation of giddiness, a gnawing sensation, and the like.

Feeling, Sensibility, Susceptibility.Feeling, in the present case, is taken for a positive characteristic, namely, the property of feeling in a strong de, gree; in this sense feeling expresses either a particular act or a habitual property of the mind. Sensibility is always taken in the sense of a habit. Traits of feeling in young people are happy omens in the estimation of the preceptor: an exquisite sensibility is not a desirable gift; it creates an infinite disproportion of pain. Feeling and sensibility are here taken as moral properties, which are awakened as much by the operations of the mind within itself as by external objects: susceptibility, from the Latin suscipere, 
and capere, to take, designates that property of the body or the mind which consists in being ready to be influenced by external objects; hence we speak of a person's susceptibility to take cold or his susceptibility to be affected with grief, joy, or any other passion: if an excess of sensibility be an evil, an excess of susceptibility is a still greater evil; it makes us slaves to every circumstance, however trivial, which comes under our notice.

FEIGN, Pretend. Feign, in Latin fingo or figo, meant originally to fashion with the hands. Pretend, in Latin pro, before, and tendere, to stretch, signifies properly to stretch before, that is, to put on the outside.

These words may be used for either doing or saying; they are both opposed to what is true, but they differ from the motives of the agent: to feign is taken in either a bad or an indifferent sense; to pretend, always in a bad sense: one feigns in order to gain some future end; a person feigns sickness in order to be excused from paying a disagreeable visit: one pretends in order to serve a present purpose; a child pretends to have lost his book who wishes to excuse himself for his idleness. To feign consists often of a line of conduct; to pretend consists mostly of words, sometimes coupled with assumed looks and manners: Ulysses feigned madness in order to escape from going to the Trojan war: according to Virgil, the Grecian Sinon pretended to be a deserter come over to the Trojan camp.

In matters of speculation, to feign is to invent by force of the imagination; to pretend is to set up by force of selfconceit or false opinion: it is feigned by the poets that Orpheus went down into hell and brought back Eurydice, his wife; infidel philosophers pretend to account for the most mysterious things in nature upon natural or, as they please to term it, rational principles.

See also INVENT; UNFEIGNED.

FElicitate, Congratulate. Felicitate, from the Latin felix, happy, signifies to make happy, and is applicable only to ourselves; congratulate from gratus, pleasant or agreeable, is to make agreeable, and is applicable to either ourselves or others: we felicitate ourselves on having escaped the danger; we congratulate others on their good fortune.

FELLOWSHIP, SocIETY. Both these terms are employed to denote a close intereourse; but fellowship is said of men as individuals, society of them collectively: we should be careful not to hold fellowship with any one of bad character, or to join the society of those who profess bad principles.

FElon. See Criminal.

FEMAle, Feminine, EFfeminate. Female is said of the sex itself, and feminine of the characteristics of the sex. Female is opposed to male, feminine to masculine.

In the female character we expect to find that which is feminine. The female dress, manners, and habits have engaged the attention of all essayists from the time of Addison to the present period. The feminine is natural to the female; the effeminate is unnatural to the male. A feminine air and voice, which is truly grateful to the observer in the one sex, is an odious mark of effeminacy in the other. Beauty and delicacy are feminine properties; robustness and vigor are masculine properties; the former, therefore, when discovered in a man, entitle him to the epithet effeminate.

FENCE, Guard, Security. Fence is a contraction of defence. Guard comes from Anglo-Saxon weardian, to wateh, allied to ward, wary, etc.; $g u$ is the French form corresponding to Germanic w-as in guise and wise, for example. Security implies that which secures or prevents injury, mischief, and loss. A fence, in the proper sense, is an inanimate object; a guard is a living agent; the former is of permanent utility, the latter acts to a partial extent: in the figurative sense they retain the same distinction. Modesty is a fence to a woman's virtue; the love of the subject is the monarch's greatest safeguard. There are prejudices which favor religion and subordination, and act as fences against the introduction of licentious principles into the juvenile or unenlightened mind; a proper sense of an overruling Providence will serve as a guard to prevent the admission of improper 
thoughts. The guard only stands at the entrance to prevent the ingress of evil: the security stops up all the avenues, it locks up with firmness. A guard serves to prevent the ingress of everything that may have an evil intention or tendency: the security rather secures the possession of what one has and prevents a loss. A king has a guard about his person to keep off all violence.

FERMENT. See Eb dLLITION; Fermentation.

FEROCIOUS, Fierce, SAvage. Ferocious and fierce are both derived from the Latin ferox, from ferus, wild. Savage (see CRUEL).

Ferocity marks the untamed character of a cruel disposition: fierceness has a greater mixture of pride and anger in it, the word fier in French being taken for haughtiness: savageness marks a more permanent, but not so violent, a sentiment of either cruelty or anger as the former two. Ferocity and fierceness are in common applied to the brutes to designate their natural tempers: savage is mostly employed to designate the natural tempers of man when uncontrolled by the force of reason and a sense of religion. Ferocity is the natural characteristic of wild beasts; it is a delight in blood that needs no outward stimulus to call it into action; but it displays itself most strikingly in the moment when the animal is going to grasp, or when in the act of devouring, its prey: fierceness may be provoked in many creatures, but it does not discover itself unless roused by some circumstance of aggravation; many animals become fierce by being shut up in cages and exposed to the view of spectators: savageness is as natural a temper in the uncivilized man as ferocity or fierceness in the brute; it does not wait for an enemy to attack, but is restless in search of some one whom it may make an enemy and have an opportunity of destroying. It is an easy transition for the savage to become the ferocious cannibal, glutting himself in the blood of his enemiss, or the fierce antagonist to one who sets himself up in opposition to him.

In an extended application of these terms, they bear the same relation to one another: the countenance may be either ferocious, fierce, or savage, according to circumstances. A robber who spends his life in the act of unlawfully shedding blood acquires a ferocity of countenance: a soldier who follows a predatory and desultory mode of warfare betrays the licentiousness of his calling and his undisciplined temper in the fierceness of his countenance; the tyrant whose enjoyment consists in inflicting misery on his dependants or subjects evinces the savageness of his temper by the savage joy with which he witnesses their groans and tortures.

Fertile, Fruitful, Prolific. Fertile, in Latin fertilis, from ferre, to bear, signifies capable of bearing or bringing to light. Fruitful signifies full of fruit, or containing within itself much fruit. Prolific is compounded of proles and facere, to make a progeny.

Fertile expresses in its proper sense the faculty of sending forth from itself that which is not of its own nature, and is peculiarly applicable to the ground which causes everything within itself to grow up. Fruitful expresses a state containing or possessing abundantly that which is of the same nature; it is, therefore, peculiarly applicable to trees, plants, vegetables, and whatever is said to bear fruit. Prolific expresses the faculty of generating; it conveys, therefore, the idea of what is creative, and is peculiarly applicable to animals. We may say that the ground is either fertile or fruitful, but not so properly prolific: we may speak of a female of any species being fruitful and prolific, but not fertile; we may speak of nature as being fruitful, but neither fertile nor prolific. A country is fertile as it respects the quality of the soil; it is fruitful as it respects the abundance of its produce: it is possible, therefore, for a country to be fruitful by the industry of its inhabitants which was not fertile by nature. An animal is said to be fruitful as it respects the number of young which it has; it is said to be prolific as it respects its generative power. Some women are more fruitful than others; but there are many animals more prolific than human creatures. 
In the figurative application they admit of a similar distinetion. A man is fertile in expedients who readily contrives upon the spur of the occasion; he is fruitful in resources who has them ready at his hand; his brain is prolific if it generates an abundance of new conceptions. A mind is fertile which has powers that admit of cultivation and expansion: an imagination is fruitful that is rich in stores of imagery; a genius is prolific that is rich in invention. Females are fertile in expedients and devices; ambition and avarice are the most fruitful sources of discord and misery in public and private life; novel-writers are the most prolific class of authors.

FERVOR, ARDOR. Fervor, from fervere, to boil, is not so violent a heat as ardor, from ardere, to burn. The affections are properly fervent; the passions are ardent: we are fervent in feeling, and ardent in acting; the fervor of devotion may be rational, but the ardor of zeal is mostly intemperate. The first martyr, Stephen, was filled with a holy fervor; St. Peter, in the ardor of his zeal, promised his Master to do more than he was able to perform.

See also Unction.

FESTIVAL. See Feast.

FESTIVITY, MIRTH. There is commonly mirth and festivity, but there may be frequently mirth without festivity. The festivity lies in the outward eircumstances, mirth in the temper of the mind. Festivity is rather the producer of mirth than the mirth itself. Festivity includes the social enjoyments of eating, drinking, dancing, cards, and other pleasures: mirth includes in it the buoyancy of spirits which is engendered by a participation in such pleasures.

FETCH. See Bring.

FETTER. See Chain.

FEUD. See QUARREL.

Fickle. See Changeable.

FICTION, Fabrication, FalseHOOD. Fiction is opposed to what is real; fabrication and falsehood to what is true. Fiction relates what may be, though not what is: fabrication and falsehood relate what is not as what is, and vice versâ. Fiction serves for amusement and instruction: fabrication and falsehood serve to mislead and deceive. Fiction and fabrication both require invention: falsehood consists of simple contradiction. The fables of Esop are fictions of the simplest kind, but yet such as require a peculiarly lively fancy and inventive genius to produce: the fabrication of a play, as the production of Shakespeare's pen, was once executed with sufficient skill to impose for a time upon the public credulity: a good memory is all that is necessary in order to avoid uttering falsehoods that can be easily contradieted and confuted. In an extended sense of the word fiction, it approaches still nearer to the sense of fabricate, when said of the fictions of the ancients, which were delivered as truth, although admitted now to be false: the motive of the narrator is what here constitutes the difference, namely, that in the former case he believes what he relates to be true, in the latter he knows it to be false. The heathen mythology consists prineipally of the fictions of the poets: newspapers commonly abound in fabrication.

Fabrication may sometimes be used in a good sense: in this case it denotes not the thing fabricated, but the act of fabricating.

As epithets, fictitious and false are very closely allied; for what is fictitious is false, though all that is false is not fictitious: the fictitious is that which has been feigned, or falsely made by some one; the false is simply that which is false by the nature of the thing; the fictitious account is therefore the invention of an individual, whose veracity is thereby impeached; but there may be many false accounts unintentionally. circulated.

Fictitious. See Artful.

FIDELITY. See FaITH.

FIENDISH. See Diabolic.

FIERCE. See Ferocious.

FIGURE, Metaphor, Allegory, Emblem, Symbor, Type. Figure, in Latin figura, from fingere, to fashion or shape, signifies anything painted or feigned by the mind. Metaphor, in

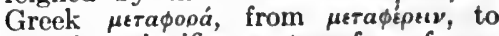
transfer, signifies a transfer of one object to another. Allegory, in Greek

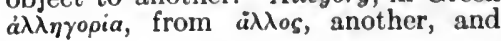


áyopévยเv, to relate, signifies the relation of something under a borrowed term. Emblem, in Greek $\tilde{\varepsilon} \mu \beta \lambda \eta \mu \alpha$, from $\dot{z} \mu \beta a \dot{\lambda} \lambda \varepsilon \varepsilon \nu$, to impress, signifies the thing stamped on as a mark. Sym-

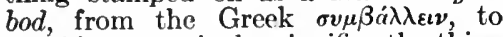
consider attentively, signifies the thing cast or conceived in the mind, from its analogy to represent something else.

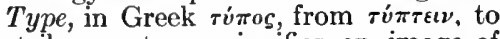
strike or stamp, signifies an image of something that is stamped on something else.

Likeness between two objects, by which one is made to represent the other, is the common idea in the signification of these terms. Figure is the most general of these terms, comprehending everything which is figured by means of the imagination; the rest are but modes of the figure. The figure. consists either in words or in things generally: we may have a figure in expression, a figure on paper, a figure on wood or stone, and the like. It is the business of the imagination to draw figures out of anything; the metaphor and allegory consist of a representation by means of words only: the figure, in this case, is any representation which the mind makes to itself of a resemblance between objects, which is properly a figure of thought, which when clothed in words is a figure of speech: the metaphor is a figure of speech of the simplest kind, by which a word acquires other meanings besides that which is originally affixed to it; as when the term head, which properly signifies a part of the body, is applied to the leader of an army. The allegory is a continued metaphor, where attributes, modes, and actions are applied to the objects thus figured, as in the allegory of sin and death in Milton.

The emblem is that sort of figure of thought by which we make corporeal objects to stand for moral properties; thus the dove is represented as the emblem of meekness, or the beehive is made the emblem of industry: the symbol is that species of emblem which is converted into a constituted sign among men; thus the olive and laurel are the symbols of peace, and have been recognized as such among barbarous as well as enlightened nations.
The type is that species of emblem by which one object is made to represent another mystically; it is, therefore, only employed in religious matters, particularly in relation to the coming, the office, and the death of our Saviour; in this manner the offering of Isaac is considered as a type of our Saviour's offering himself as an atoning sacrifice. See also ForM.

FINAL, CoNclusive. Final, in French final, Liatin finalis, from finis, the end, signifies having an end. Conclusive signifies shutting up, or coming to a conclusion.

Final designates simply the circumstance of being the last; conclusive the mode of finishing or coming to the last: a determination is final which is to be succeeded by no other; a reasoning is conclusive that puts a stop to further question. The final is arbitrary; it depends upon the will to make it so or not: the conclusive is relative; it depends upon the circumstances and the understanding: a person gives a final answer at option; but in order to make an answer conclusive it must be satisfactory to all parties. See also LAST.

FINAL WORD. See Ultimatum.

FIND, Find OUT, Discover, Espy, Descry. Find is in Anglo-Saxon findan, German finden, etc. Discover (see Detect). Espy comes through French from the Old High German spehon, to spy. Descry comes from Latin describere, from de, down, and scribere, to write, meaning to make a note of, hence to see and notice.

To find signifies simply to come within sight of a thing, which is the general idea attached to all these terms: they vary, however, either in the mode of the action or in the object. What we find may become visible to us by accident, but what we find out is the result of an effort. We may find anything as we pass along in the streets: but we find out mistakes in an account by carefully going over it, or we find out the difficulties which we meet with in learning by redoubling our diligence. What is found may have been lost to ourselves, but visible to others. What is discovered is always remote and unknown, and when discovered is something new. A piece of money may be 
found lying on the ground; but a mine is discovered underground. When Captain Cook discovered the islands in the South Sea, many plants and animals were found. What is not discoverable may be presumed not to exist; but that which is found may be only what has been lost. What has once been discovered cannot be discovered again; but what is found may be many times found. Find out and discover differ principally in the application, the former being applied to familiar, and the latter to seientific objects: scholars find out what they have to learn; men of research discover what escapes the notice of others.

To espy is a species of finding out, namely, to find out what is very secluded or retired; and descry is a species of discovering or observing at a distance or among a number of objects. An astronomer discovers fresh stars or planets; he finds out those on particular oceasions which had been already discovered. A person finds out by continued inquiry any place to which he had been wrongly directed: he espies an object which lies concealed in a corner or secret place; he descries a horseman coming down a hill. Find and discover may be employed with regard to objects, either of a corporeal or intellectual kind; espy and descry, only with regard to sensible objects of corporeal vision: find, for those that are either external or internal; discover, only for those that are external. The distinction between them is the same as before; we find by simple inquiry; we discover by reflection and study: we find or find out the motives which influence a person's conduct; we discover the reasons or causes of things: the finding serves the particular purpose of the finder; the discovery serves the purpose of science, by adding to the stock of general knowledge.

When find is used as a purely intellectual operation, it admits of a new view, in relation both to discover and to invent, as may be seen in the following article.

Find, Find Out, Discover, Invent.To find or find out is said of things which do not exist in the forms in which a person finds them: to discover is said of that which exists in an entire state: invent, from invenire, signif ying literally to come upon, is said of that which is newly made or modelled. The merit of finding or inventing consists in newly applying or modifying the materials which exist separately; the merit of discovering consists in removing the obstacles which prevent us from knowing the real nature of the thing: imagination and industry are requisite for finding or inventing; acuteness and penetration for discovering. Find is applicable to the operative arts, invent to the mechanical, discover to the speculative. We speak of finding modes for performing actions and effecting purposes: of inventing machines, instruments, and various matters of use or elegance; of discovering the operations and laws of nature. Many fruitless attempts have been made to find the longitude: men have not been so unsuccessful in finding out various arts for communicating their thoughts, commemorating the exploits of their nations, and supplying themselves with luxuries. Harvey discovered the circulation of the blood: the geometrician finds by reasoning the solution of any problem; or by investigating he finds out a clearer method of solving the same problem; or he invents an instrument by which the proof can be deduced from ocular demonstration.

Find Fault With, Blame, Object To.All these terms denote not simply feeling, but also expressing, dissatisfaction with some person or thing. To find fault with signifies here to point out a fault, either in some person or thing; to blame is said only of the person; object is applied to the thing only: we find fault with a person for his behavior; we find fault with our seat, our conveyance, and the like; we blame a person for his temerity or his improvidence; we object to a measure that is proposed. We find fault with or blame that which has been done; we object to that which has been or is to be done. Finding fault is a familiar action applied to matters of personal convenience or taste; blame and object to, particularly the latter, are applied to serious objects. Finding fault is often the fruit of a discontented temper; there are some whom nothing will 
please, and who are ever ready to find faull with whatever comes in their way: blame is a matter of discretion; we blame frequently in order to correct: objecting to is an affair either of caprice or discretion; some capriciously object to that which is proposed to them merely from a spirit of opposition; others object to a thing from substantial reasons.

FINE, Delicate, Nice. It is remarkable of the word fine (see BEAUTIFUL) that it is equally applicable to large and small objects: delicate, in Latin delicatus, from delicioe, delights, and delicere, to allure, is applied only to small objects. Fine, in the natural sense, denotes smallness in general. Delicate denotes a degree of fineness that is agreeable to the taste. Thread is said to be fine, as opposed to the coarse and thick; silk is said to be delicate when to fineness of texture it adds softness. The texture of a spider's web is remarkable for its fineness; that of the ermine's fur is remarkable for its delicacy. In writing, all up-strokes must be fine; but in superior writing they will be delicately fine. When applied to colors, the fine is coupled with the bold and strong; delicate, with what is faint, soft, and fair: black and red may be fine colors; white and pink delicate colors. The tulip is reckoned one of the finest flowers; the white moss-rose is a delicate flower. A fine painter delineates with boldness; but the artist who has a delicate taste throws delicate touches into the grandest delineations.

In their moral application these terms admit of the same distinction: the fine approaches either to the strong or to the weak; the delicate is a high degree of the fine; as a fine thought, which may be lofty; or fine feeling, which is acute and tender; and delicate feeling, which exceeds the former in fineness. The French use their word fin only in the latter sense, of acuteness, and apply it merely to the thoughts and designs of men, answering either to our word subtle, as un homme fin, or neat, as une satire fine.

Delicate is said of that which is agreeable to the sense and the taste; nice, to what is agreeable to the appetite: the former is a term of refinement, the latter of epicurism and sensual indulgence. The delicate affords pleasure only to those whose thoughts and desires are purified from what is gross; the nice affords pleasure to the young, the ignorant, and the sensual: thus delicate food, delicate colors, delicate shapes and forms, are always acceptable to the cultivated; a meal, a show, a color, and the like, which suits its appetite or meets its fancy, will be nice to a child.

When used in a moral application, nice, which is taken in a good sense, approaches nearer to the signification of delicate. A person may be said to have a delicate ear in music whose ear is offended with the smallest discordance; he may be said to have a nice taste or judgment in music who scientifically discriminates the beauties and defects of different pieces. A person is delicate in his choice who is guided by taste and feeling; he is nice in his choice who adheres to a strict rule. A point in question may be either delicate or nice; it is delicate as it is likely to touch the tender feelings of any party; it is nice as it involves contrary interests and becomes difficult of determination. There are delicacies of behavior which are learned by goodbreeding, but which minds of a refined cast are naturally alive to without any particular learning; there are niceties in the law which none but men of superior intellect can properly enter into and discriminate.

Fine, Mulct, Penalty, Forfeiture.Fine, from the Latin finis, the end or purpose, signifies, by an extended application, satisfaction by way of amends for an offence. $\quad$ Mulct, in Latin, mulcta, comes from mulcare, to injure. Penalty, in Latin pœnalitas, from pœna, a pain, signifies what gives pain by way of punishment. Forfeiture, from forfeit, comes through French from Late Latin foris factum, a trespass, from foris, beyond, and facere, to do, signifying an action beyond the bounds of law, hence a penalty for illegal action.

The fine and mulct are always pecuniary; a penalty may be pecuniary; a forfeiture consists of the deprivation of any right or property: the fine and mulct are imposed; the penalty is inflicted or incurred; the forfeiture is 
ineurred. The violation of a rule or law is attended with a fine or mulct, but the former is a term of general use; the latter is rather a teehnical term in law: a criminal offenee incurs a penalty; negligence of duty oecasions the forfeiture. A fine or mulct serves either as punishment to the offender or as an amends for the offenee: a penalty always infliets some kind of pain as a punishment on the offender: a forfeiture is attended with loss as a punishment to the delinquent. Among the Chinese all offenees are punished with fines or flogging: the Roman Catholies were formerly subjeet to penalties if deteeted in the performanee of their religious worship: societies subjeet their members to forfeitures for the violation of their laws.

Finical, Spruce, Foppish.-These epithets are applied to sueh as attempt at finery by improper means. The finical is insignifieantly fine; the spruce is laboriously and artfully fine; the foppish is fantastically and affeetedly fine. The finical is said mostly of manners and speech: the spruce is said of the dress; the foppish, of dress and manners.

A finical gentleman clips his words and serews his body into as small a compass as possible, to give himself the air of a delicate person: a spruce gentleman strives not to have a fold wrong in his frill or eravat, nor a hair of his head to lie amiss: a foppish gentleman seeks, by extravaganee in the cut of his clothes and by the tawdriness in their ornaments, to render himself distinguished for finery. A little mind, full of coneeit of itself, will lead a man to be finical: a vacant mind that is anxious to be pleasing will not objeet to the employment of rendering the person spruce: a giddy, vain mind, eager after applause, impels a man to every kind of foppery.

FINISH. See Close.

FINISHed. See Complete; Out. FINITE, Limited. Finite, from finis, an end, isthe natural property of things; and limited, from limes, a boundary, is the artificial property: the former is opposite only to the infinite; but the latter, whieh lies within the finite, is opposed to the unlimited or the infinite. This world is finite, and spaee infinite; the power of a prinee is limited. It is not in our power to extend the bounds of the finite, but the limited is mostly under our control. We are finite beings, and our eapacities are variously limited either by nature or eireumstanees.

FIRE, Heat, Warmth, Glow. In the proper sense these words are easily distinguished, but not so easily in the improper sense; and as the latter depends prineipally upon the former, it is not altogether useless to enter into some explanation of their physieal meaning.

Fire is with regard to heat as the cause to the effect; it is itself an inherent property in some material bodies, and when in aetion eommunieates heat: fire is pereeptible to us by the eye as well as the touch; heat is perceptible only by the touch; we distinguish fire by means of the flame it sends forth or by the ehanges whieh it produces upon other bodies; but we discover heat only by the sensations which it produces in ourselves.

Heat and warmth differ prineipally in degree, the latter being a gentle degree of the former. The term heat is, however, in its most extensive sense, applieable to that universal prineiple which pervades all nature, animate and inanimate, and seems to vivify the whole; it is this prineiple whieh appears either under the form of fire or under the more commonly eonceived form of heat, as it is generally understood and as I have here considered it. Heat in this limited sense is less aetive than fire and more active than warmth: the former is produced in bodies, either by the violent action of fire, as in the boiling of water, the melting of lead, or the violent friction of two hard bodies; the latter is produced by the simple expulsion of cold, as in the ease of feathers, wool, and other substanees which produce and retain warmth. Glow is a partial heat or warmth which exists, or is known to exist, mostly in the human frame; it is commonly produced in the body when it is in its most vigorous state and its nerves are firmly braced by the eold.

From the above analysis the figurative application of these terms, and the 
grounds upon which they are so employed, will be easily discerned. As fire is the strongest and most active principle in nature, which seizes everything within its reach with the greatest possible rapidity, genius is said to be possessed of fire, which flies with rapidity through all the regions of thought and forms the most lively images and combinations; but when fire is applied to the eye or the looks, it borrows its meaning from the external property of the flame, which is very aptly depicted in the eye or the looks of lively people. As heat is always excessive and mostly violent, those commotions and fermentations of the mind which flow from the agitation of the passions, particularly of the angry passions, are termed heat. As warmth is a gentle and grateful property, it has with most propricty been ascribed to the affections. As glow is a partial but vivid feeling of the body, so is friendship a strong but particular affection of the mind: hence the propriety of ascribing a glow to friendship. Age damps the fire of the poet. Disputants in the heat of the contest are apt to forget all the forms of good-breeding. A man of tender moral feelings speaks with warmth of a noble action, or takes a warm interest in the concerns of the innocent and the distressed. A youth in the full glow of friendship feels himself prepared to make any sacrifices in supporting the cause of his friend.

FIRM, Fixed, Solnd, Stable. Firm (see Constancy). Fixed denotes the state of being fixed. Solid, in Latin solidus, comes from solum, the ground, which is the most solid thing existing. Stable (see Constancy).

That is firm which is not easily shaken; that is fixed which is fastened to something else and not easily torn; that is solid which is able to bear, and does not easily give way; that is stable which is able to make a stand against resistance or the effects of time. A pillar which is firm on its base, fixed to a wall made of solid oak, is likely to be stable. A man stands firm in battle who does not flinch from the attack: he is fixed to a spot by the order of his commander.

In the moral sense, firmness is used only for the purpose, or such actions as depend on the purpose; fixed is used either for the mind or for outward circumstances; solid is applicable to things in general, in an absolute sense; stable is applicable to things in a relative sense. Decrees are more or less firm, according to the source from which they spring; none are firm, compared with those which arise from the will of the Almighty: laws are fixed in proportion as they are connected with a constitution in which it is difficult to innovate. That which is solid is so of its own nature, but does not admit of degrees: a solid reason has within itself an independent property, which cannot be increased or diminished. That which is stable is so by comparison with that which is of less duration: the characters of some men are more stable than those of others; youth will not have so stable a character as manhood. A friendship is firm when it does not depend upon the opinion of others; it is fixed when the choice is made and grounded in the mind; it is solid when it rests on the only solid basis of accordancy in virtue and religion; it is stable when it is not liable to decrease or die away with time.

See also Hard; Stalwart.

FIRMNESS. See Constancy.

FIRST, Aboriginal, Original, PriMARY. All these words signify holding the first place, but to the general idea of being simply number one in any counting which is indicated in first, aboriginal, original, and primary add certain subsidiary notions. Original, from Latin oriri, to rise, means the first to appear or arise, and refers to the beginning of something, considered with reference to that which follows after the beginning or develops out of it. When we speak of the first language spoken in England, we are thinking of this language simply as number one in a series; when we speak of the origina! language of the Aryan peoples, we are thinking of it with reference to the languages which followed after it or developed out of it. The difference is not of meaning, but of emphasis. Aboriginal, from the phrase $a b$ origine, meaning from the beginning, has the meaning of original specifically applied to the first tribes or peoples inhabiting a given 
land. Primary, from Latin primus, first, means first, not merely with respect to numbers, but with respect to relation. It differs from original in emphasizing, not the idea of the beginning, but the idea of the relation of the things designated as primary to something else of which they are considered a part.

See also Supreme.

FIT, Apt, Meet. Fit (see BecomING) is either an acquired or a natural property; apt, in Latin aptus, from the Old Latin apere, to fit or join together, is a natural property; meet, from AngloSaxon metan, signifying measured, is a moral quality. A house is fit for the accommodation of the family according to the plan of the builder; the young mind is apt to receive either good or bad impressions. Meet is a term of rare use, except in spiritual matters or in poetry: it is meet to offer our prayers to the Supreme Disposer of all things.

Fit, Equip, Prepare, Qualify.-To fit signifies to adopt means in order to make fit, and conveys the general sense of all the other terms; they differ principally in the means and circumstances of fitting: to equip is to fit out by furnishing the necessary materials: to prepare, from the Latin praparare, compounded of proe and parare, to get beforehand, is to take steps for the purpose of fitting in future: to qualify, from the Latin qualifacere, or qualis and facere, to make a thing as it should be, is to fit or furnish with any requisites.

To fit is employed for ordinary cases; to equip is employed only for expeditions: a house is fitted up for the residence of a family; a vessel is equipped with everything requisite for a voyage; to fit may be for an immediate or a remote purpose; to prepare is for a remote purpose; to fit does not define the means; to prepare requires for the most part labor, time, and expense. A persons fits himself for taking orders when he is at the university: he prepares for an examination by going over what he has already learned.

To fit is said of everything, both in a natural and a moral sense: to qualify is used only in a moral sense. Fit is employed mostly for acquirements which are gained by physical exertions; qualify for those which are gained by intellectual exertion: a youth fits himself for a mechanical business by working at it; a youth qualifies himself for a profession by following a particular course of studies.

See also Expedient; PreparedNESS; RIght.

Fit, Suit, Adapt, Accommodate, Adjust.-Fit signifies to make or be fit. Suit signifies to make or be suitable (see AGreE). Adapt, from aptus, fit, signifies to make fit for a speeific purpose. Accommodate signifies to make commodious. Adjust signifies to make a thing just as it is desired to be.

To $f i$, in the transitive sense, is to make of like proportions, so that one thing may join with another as it ought: as to fit one board to another; to fit clothes to the body: to suit is to make things agreeable to one another, and is mostly applied to moral objects: as to suit one's actions or language to the occasion.

Fit may likewise be figuratively applied to moral objects, in the sense of making one object fit for another, as to fil a person by his education for a particular walk of life; to fit the mind for the reception of truth.

In the transitive sense these words have precisely the same distinction: as the shoe fits, or fits the foot, which is made to the same size; things suit which agree in essential qualities or produce an agreeable effect when placed together; as furniture is made to suit.

In the moral sense, the fitness of things is what we term just, right, or decent: that which suits falls in with our ideas and feelings.

To adapt is a species of fitting; to accommodate is a species of suiting; both applied to the moral actions of conscious beings. Adaptation is an act of the judgment; accommodation is an act of the will; we adapt by an exercise of discretion; we accommodate by a management of the humors: an adaptation does not interfere with our interests; but an accommodation alway's supposes a sacrifice: we adapt our language to the understandings of our hearers; we accommodate ourselves to the humors of others. The mind of an infinitely wise Creator is clearly evinced in the world by the universal 
adaptation of means to their ends: a spirit of accommodation is not merely a characteristic of politeness: it is of sufficient importance to be ranked among the Christian duties.

Accommodate and adjust are both applied to the affairs of men which require to be kept, or put, in right order : but the former implies the keeping as well as putting in order; the latter simply the putting in order. Men accommodate each other, that is, make things commodious for one another; but they adjust things either for themselves or for others. Thus they accommodate one another in pecuniary matters; or they adjust the ceremonial of a visit. Accommodate likewise always supposes a certain sacrifice or yielding on the part of the person accommodating for the convenience of the person accommodated. On this ground we may say that a difference is either accommodated or adjusted; for it is accommodated, inasmuch as the parties yield to each other so as to make it commodious to both; it is adjusted, inasmuch as that which was wrong is set right.

FITTED. See CoMpeTENT.

Fix, Fasten, Stick. Fix is a generic term; fasten, i. e., to make fast, and stick, $i$. e., to make to stick, are but modes of fixing: we fix whatever we make to remain in a given situation; we fasten if we $f i x$ it firmly; we stick when we $f i x$ a thing by means of sticking. A post is fixed in the ground; it is fastened to a wall by a nail; it is stuck to another board by means of glue. Shelves are fixed: a horse is fastened to a gate; bills are stuck. What is fixed may be removed in various ways: what is fastened is removed by main force: what is stuck must be separated by contrivance.

See also Frrir.

Fix, Settle, Establish.-Fix, in Latin fixi, perfect of figo, signifies simply to make to keep its place. Settle, from Anglo-Saxon setl, seat, allied to sit, signifies to make to sit or be at rest. Establish, from the Latin stabilis, signifies to make stable.

Fix is the general and indefinite term: to settle and establish are to fix strongly. Fix and settle are applied either to material or spiritual objects, establish only to moral objects. A post may be fixed in the ground in any manner, but it requires time for it to settle. A person may either fix himself, settle himself, or establish himself: the first case refers simply to his taking up his abode or choosing a certain spot; the second refers to his permanency of stay; and the third to the business which he raises or renders permanent.

The same distinction exists between these words in their further application to the conduct of men. We may fix one or many points, important or unimportant-it is a mere act of the will; we settle many points of importanceit is an act of deliberation; thus we fix the day and hour of doing a thing; we settle the affairs of our family: so likewise to $f(x$ is properly the act of one; to settle may be the joint act of many; thus a parent fixes on a business for his child, or he settles the marriage contract with another parent.

To $f i x$ and settle are personal acts, and the objects are mostly of a private nature: but establish is an indirect action, and the object mostly of a public nature: thus we $f i x$ our opinions; we settle our minds; or we are instrumental in establishing laws, institutions, and the like. It is much to be lamented that any one should remain unsettled in his faith; and still more so, that the best form of faith is not universally established.

Fix, Determine, Settle, Limit.-To $f i x$ is here the general term; to determine (see Decide); to settle (see PRECEDING); to limit (see BouND), are here modes of fixing. They all denote the acts of conscious agents, but differ in the object and circumstances of the action; we may fix any object by any means and to any point; we may fix material objects or spiritual objects; we may fix either by means of our senses or our thoughts; but we can determine only by means of our thoughts. To $f i x$, in distinction from the rest, is said in regard to a single point or a line; but to determine is always said of one or more points or a whole: we $f x$ where a thing shall begin; but we determine where it shall begin and where it shall end, which way and how far it shall go, and the like: thus, we may fix our eye upon a star, or we $f i x$ our minds upon a particular branch 
of astronomy; but we determine the distance of the heavenly bodies, or the specific gravity of bodies, and the like, upon philosophical principles.

So in respect to other objects, to $f i x$ is a positive and immediate act; as to $f x$ the day, hour, or minute, etc.; to determine requires consideration; as to determine times and seasons, or modes of doing things, and the like.

Determine is to settle as a means to the end; we commonly determine all subordinate matters in order to settle a matter finally: thus, the determination of a single cause will serve to settle all other differences. The determination respects the act of the individual who fixes certain points and brings them to a term; the settlement respects simply the conclusion of the affair or the termination of all dispute and question.

To determine and limit both signify to fix boundaries; but to determine or fix a term to a thing respects such boundaries or terms as are formed by the nature of things: to limit is the act of a conscious agent; a question is determined by removing the doubt; the price is limited by law, or the command of the magistrate, or the agreement of the parties.

FIXED. See FIRM.

Flag, Droop, Languish, Pine. Flag comes from a Teutonic base found in Anglo-Saxon flacor, flying, roving, and Icelandic flaka, originally an imitative syllable found in flap, flicker, etc.; it means here to be weary after roving, to cease to rove, etc. Droop (see FALL). To languish is to become or continue languid (see FaINT). Pine, Middle English pinen, to suffer, more frequently to torment (from Anglo-Saxon pin, borrowed from Latin pona, pain, penalty), means to languish with suffering.

In the proper application nothing flags but that which can be distended and made to flutter by the wind, as the leaves of plants when they are in want of water or in a weakly condition; hence figuratively the spirits are said to flag: nothing is said to droop but that the head of which flags or drops; the snow-drop droops, and flowers will generally droop from excess of drought or heat: the spirits in the same manner are said to droop, which expresses more than to flag; the human body also droops when the strength fails: languish is a still stronger expression than droop, and is applicable principally to persons; some languish in sickness, some in prison, and some in a state of distress: to pine is to be in a state of wearing pain which is mostly of a mental nature; a child may pine when absent from all its friends and supposing itself deserted.

FLAGitious. See Heinous.

FLAGRANT. See HeINous.

Flame, Blaze, Flash, Flare, Glare. Flame, in Latin flamma, from the Greek $\phi \lambda \varepsilon \xi \epsilon t \nu$, to burn, signifies the luminous exhalation emitted from fire. Blaze, Anglo-Saxon bloese, torch, signifies a flame blown up, that is, an extended flame: flash comes from Middle English flaschen, to dash, Icelandic flas, a swift rushing, and refers to a sudden rush of light. Flare is only a variant of Swedish flasa, to burn violently. Flash and flare, which are but variations of flame, denote different species of flame; the former, a sudden flame, the second, a dazzling, unsteady flame. Glare, Anglo-Saxon glar, amber, is possibly allied to glass; it refers to a sharp and shining flight, a strong flame, that emits a strong light: a candle burns only by flame, paper commonly by a blaze, gunpowder by a flash, a torch by a flare, and a conflagration by a glare.

Flat, Level. Flat is a Scandinavian word of uncertain origin. Level, in all probability from libella and libra, a balance, signifies the evenness of a balance. Flat is said of a thing with regard to itself; it is opposed to the round or protuberant; level, as it respects another thing; it is opposed to the uneven: a country is flat which has no elevation; a country is level as contrasted with that which is mountainous, or a wall is level with the roof of a house when it rises to the height of the roof.

In the moral application they differ too widely to render comparison necessary.

See also INsipin.

FLATTER. See ADULATE.

FLATTERER, Srcophant, Parasite. Flalterer (see Adulate). Syco- 


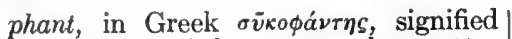
originally an informer on the matter of figs, but has now acquired the meaning of an obsequious and servile per-

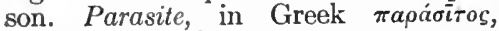
from $\pi \alpha \rho a ́$ and riros, corn or meat, originally referred to the priests who attended feasts, but it is now applied to a hanger-on at the tables of the great.

The flatterer is one who flatters by words; the sycophant and parasite is therefore always a flatterer, and something more, for the sycophant adopts every mean artifice by which he can ingratiate himself, and the parasite submits to every degradation and servile compliance by which he can obtain his base purpose. These terms differ more in the object than in the means, the former having general purposes of favor, and the latter particular and still lower purposes to answer. Courtiers may be sycophants in order to be well with their prince and obtain preferment; but they are seldom parasites, who are generally poor and in want of a meal.

FLAVOR. See TASTE.

FLAW. See Blemish.

FLAY. See Skin.

FLEETING. See Temporary.

FLEETNESS. See QuickNess.

Flexible, Pliable, Pliant, SupPLE. Flexible, in Latin flexibilis, from flectere, to bend, signifies able to be bent. Pliable signifies able to be plied or folded: pliant signifies literally plying, bending, or folding. Supple, in French souple, comes from Latin supplicem (accusative), in the old sense of bending under; compare supplicate.

Flexible is used in a natural or moral sense; pliable, in the familiar sensc only; pliant, in the higher and moral application only: what can be bent in any degree as a stick is flexible; what can be bent as wax, or folded like cloth, is pliable. Supple, whether in a proper or a figurative sense, is an excess of pliability; what can be bent backward and forward, like osier twig, is supple.

In the moral application, flexible is indefinite both in degree and application; it may be greater or less in point of degree; whercas pliant supposes a great degree of pliability, and supple- ness a great degree of pliancy or pliability; it applies likewise to the outward actions, to the temper, the resolution, or the principles; but pliancy is applied to the principles or the conduct dependent upon those principles; suppleness, to the outward actions and behavior only. A temper is flexible which yields to the entreaties of others; the person or character is pliant when it is formed or moulded easily at the will of another; a person is supple who makes his actions and his manners bend according to the varying humors of another: the first belongs to one in a superior station who yields to the wishes of the applicant; the latter two belong to equals or inferiors who yield to the influence of others. Flexibility is frequently a weakness, but never a vice; it always consults the taste of others, sometimes to its own inconvenience and often in opposition to its judgment; pliancy is often both a weakness and a vice: it always yields for its own pleasure, though not always in opposition to its sense of right and wrong: suppleness is always a vice, but never a weakness; it seeks its gratification to the injury of another by flattering his passions. Flexibility is opposed to firmness, pliancy to steadiness, suppleness to rigidity.

FLICKERING. See Lambent.

FLight. See Situation.

FLIGHTINESS. See LightNess.

FLIMSY. See Superficial.

FLOAT. See WAFT.

FLOATING. See UNFUNDED.

FLOURISH, Thrive, Prosper. Flourish, in French fleurir, florissant, Latin floresco, or floreo, from flos, a flower, is a figure of speech borrowed from the action of flowers which grow in full vigor and health. Thrive is a Scandinavian word from a root signifying to seize, meaning to seize for one's self, hence to prosper. Prosper, in Latin prosper, prosperus, compounded of pro and spes, hope, signifies to be agreeable to the hopes.

To flourish expresses the state of being that which is desirable: to thrive the process of becoming so. In the proper sense, flourish and thrive are applied to vegetation: the former to that which is full grown, the latter to 
that which is in the act of growing: the oldest trees are said to flourish which put forth their leaves and fruits in full vigor; young trees thrive when they increase rapidly toward their full growth.

Flourish and thrive are taken likewise in the moral sense; prosper is employed only in this sense; flourish is said either of individuals or of communities of men; thrive and prosper only of individuals. To flourish is to be in full possession of powers, physical, intellectual, and incidental: an author flourishes at a certain period; an institution flourishes; literature or trade flourishes; a nation flourishes. To thrive is to carry on one's concerns to the advantage of one's circumstances; it is a term of familiar use for those who gain by positive labor: the industrious tradesman thrives. To prosper is to be already in advantageous circumstances: men prosper who accumulate wealth agreeably to their wishes and beyond their expectations.

FLOW, Stream, Gush. For the derivation of flow see Arise. Stream is, in Anglo-Saxon, stream, from a root signifying to flow. Gush comes from a Teutonic root and is allied to Icelandic gjiota, to pour.

Flow is here the generic term: the other two are specific terms, expressing different modes: water may flow either in a large body or in a long, but narrow course; the stream, in a long, narrow course only: thus, waters flow in seas, rivers, rivulets, or in a small pond; they stream only out of spouts or small channels: they flow gently or otherwise; they stream gently; but they gush with violence: thus, the blood flows from a wound which comes from it in any manner; it streams from a wound when it runs, as it were, in a channel; it gushes from a wound when it runs with impetuosity and in as large quantities as the cavity admits.

See also Arise.

FLUCTUATE, WAVER. Fluctuate, in Latin fluctuatus, participle of fluctuare, from fluctus, a wave, signifies to move backward and forward like a wave. Waver comes from Anglo-Saxon wofre, restless, wandering; it is not, however, the same word as wave, which is allied to wag.
To fluctuate conveys the idea of strong agitation; to waver, that of constant motion backward and forward: when applied in the moral sense, to fluctuate designates the action of the spirits or the opinions; to waver is said only of the will or opinions: he who is alternately merry and sad in quick succession is said to be fluctuating; or he who has many opinions in quick succession is said to fluctuate; but he who cannot form an opinion or come to a resolution is said to waver.

See also WAG.

FLUENT. See Voluble.

FLUID, Liquid, Liquidate. Fluid, from fluere, to flow, signifies that which from its nature flows; liquid, from liquere, to be clear, signifies that which is melted. These words may be employed as epithets to the same objects; but they have a distinct office which they derive from their original meaning: when we wish to represent a thing as capable of passing along in a stream or current, we should denominate it a fluid; when we wish to represent it as passing from a congealed to a dissolved state, we should name it a liquid; water and air are both represented as fluids from their general property of flowing through certain spaces; but ice, when thawed, becomes a liquid and melts; melted lead is also termed a liquid: the humors of the animal body and the juices of trees are fluids; what we drink is a liquid, as opposed to what we eat, which is solid. We liquidate an obligation or debt when we settle it or pay it off.

FLUTTER. See Palpitate.

FLYING-MACHINE. See AIRCRAFT.

FOE. See Enemy.

FETUS. Sce EMbryo.

FOIBLE. See IMPERFECTION.

FOIL. See Defeat.

FOLKS. See People.

FOLLOW, SuCCEed, Exsue. Follow comes from Anglo-Saxon folgian. Succeed is compounded of Latin sub, next, and cedere, to go, meaning to go after. Ensue comes from French suivre, Latin sequi, to follow.

Follow and succeed are said of persons and things; ensue, of things only: follow, in respect of persons, denotes the 
going in order, in a trace or line; succeed denotes the going or being in the same place immediately after another: many persons may follow one another at the same time; but only one individual properly succeeds another. Follow is taken literally for the motion of the physical body in relation to another; succeed is taken in the moral sense for taking the place of another: people follow one another in a procession, or one follows another to the grave; a king succeeds to a throne, or a son succeeds to the inheritance of his father. To follow may also be to go in the same course, though not at the same time, as co follow a person to the grave in the sense of dying after him: to succeed is always to go in the place of another, whether living or dead, as one minister of state succeeds another, or a son sucreeds his father.

Persons may follow things, but things only succeed things: as to follow a rule or follow a course of conduct.

To follow, in relation to things, is said either simply of the order in which they go or of such as go by a connection between them; to succeed implies simply to take the place after another; to ensue is to follow by a necessary connection: as in a natural tempest one wave of the sea follows another in rapid succession, so in the moral tempest of political revolutions one mad convulsion is quickly succeeded by another: nothing can ensue from popular commotions but bloodshed and misery. Follow is used in general propositions; ensue is used in specific cases: sin and misery follow each other as cause and effect; quarrels too often ensue from the conversations of violent men who differ either in religion or politics.

Follow, Pursue.-The idea of going after any object in order to reach or obtain it is common to these terms, but under different circumstances: to follow a person is mostly with a friendly intention; to pursue (see CoNTINUE), with a hostile intention: a person follows his fellow-traveller whom he wishes to overtake; the officers of justice pursue the criminal whom they wish to apprehend; so likewise the huntsmen and hunters follow the dogs in the chase; the dogs pursue the hare.

In application to things, follow is taken more in the passive, and pursue more in the active sense: a man follows the plan of another, and pursues his own plan; he follows his inclinations, and pursues an object.

Follow, Imitate.-Follow (see above). Imitate is in Latin imitatus, participle of imitare, from a root also found in imago.

Both these terms denote the regulating our actions by something that offers itself to us or is set before us; but we follow that which is either internal or external; we imitate that only which is external: we either follow the dictates of our own minds or the suggestions of others; but we imitate the conduct of others: in regard to external objects, we follow either a rule or an example; but we imitate an example only: we follow the footsteps of our forefathers; we imitate their virtues and their perfections: it is advisable for young persons as closely as possible to follow the good example of those who are older and wiser than themselves; it is the bounden duty of every Christian to imitate the example of our blessed Saviour to the utmost of his power.

To follow and imitate may both be applied to that which is good or bad: the former to any action, but the latter only to the behavior or the mode of doing anything: we may follow a person in his career of virtue or vice; we imitate his gestures, tone of voice, and the like.

Follower, Adherent, Partisan.-A follower is one who follows a person generally; and adherent is one who adheres to his cause; a partisan is the follower of a party; the follower follows either the person, the interests, or the principles of any one; thus the retinue of a nobleman, or the friends of a statesman, or the friends of any man's opinions, may be styled his followers; but the adherent is that kind of follower who espouses the interests of another, as the adherents of Charles I.: a follower follows near or at a distance; but the adherent is always near at hand; the partisan hangs on or keeps at a certain distance; the follower follows from various motives; the adherent adheres from a personal motive; the partisan, from a partial motive: Charles I. had as 
many adherents as he had followers; the rebels had as many partisans as they had adherents.

FOLLY, Foolery. Folly is the abstract of foolish, and characterizes the thing; foolery, the abstract of fool, and characterizes the person: we may commit an act of folly without being chargeable with weakness or folly; but none are guilty of fooleries who are not themselves fools, either habitually or temporarily: young people are perpetually committing follies if not under proper control; fashionable people lay aside one foolery only to take up another.

FOND. See AFFEctionate; AMoROUS; INDULGENT.

FONDle. See Caress; Dally.

FOOD, Diet, Regimen. Food, Anglo-Saxon foda, signifying what one eats, comes from a root which appears in Latin panis, bread (English pantry), pasture, etc., $p$ in Latin corresponding to $f$ in the Teutonic languages, as in pater and father, pedem and foot. Diet,

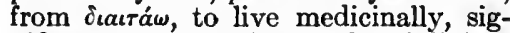
nifies any particular mode of living. Regimen, in Latin regimen, from rego, signifies a system or practice by rule.

All these terms refer to our living, or that by which we live: food is here the general term; the others are specific. Food specifies no circumstances; whatever is taken to maintain life is food: diet is properly prescribed or regular food: it is the hard lot of some among the poor to obtain with difficulty food and clothing for themselves and their families; an attention to the diet of children is an important branch of their early education. Food is an unqualified term applicable to either man or beast; diet is applied to man only, not merely to individuals in the limited sense, but to the species in the sense of their daily and regular food. Food has also a figurative application which diet has not.

Diet and regimen are both particular modes of living; but the former respects the quality of food, the latter the quantity as well as quality: diet is confined to modes of taking nourishment; regimen often respects the abstinence from food, bodily exercise, and whatever may conduce to health: diet is generally the consequence of an immediate prescription from a physician, and during the period of sickness; regimen commonly forms a regular part of a man's system of living: diet is in certain cases of such importance for the restoration of a patient that a single deviation may defeat the best medicine; it is the misfortune of some people to be troubled with diseases from which they cannot get any exemption but by observing a strict regimen.

FOOL, IDIOT, BUFFOON. Fool comes from Latin follis, a wind-bag, and folles, puffed cheeks. Idiot comes from the

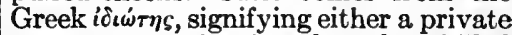
person or one that is rude and unskilled in the ways of the world. Buffoon comes from French bouffer, to puff.

The fool is either naturally or artificially a fool; the idiot is a natural fool; the buffoon is an artificial fool: whoever violates common sense in his actions is a fool; ' whoever is unable to act according to common sense is an idiot; whoever intentionally violates commonsense is a buffoon.

See also NinNy.

Foolhardy, Adventurous, Rash.-Foolhardy signifies having the hardihood of a fool. Adventurous signifies ready to venture. Rash comes from a Germanic root signifying quick, sudden.

Foolhardy expresses more than the adventurous, and adventurous than rash. The foolhardy man ventures in defiance of consequences: the adventurous man ventures from a love of the arduous and the bold; the rash man ventures for want of thought: courage and boldness become foolhardihood when they lead a person to run a fruitless risk; an adventurous spirit sometimes leads a man into unnecessary difficulties; but it is a necessary accompaniment of greatness. There is not so much design, but there is more violence and impetuosity in rashness than in foolhardihood: the former is the consequence of an ardent temper which will admit of correction by the influence of the judgment; but the latter comprehends the perversion of both the will and the judgment. An infidel is foolhardy, who risks his future salvation for the mere gratification of his pride; Alexander was an adventurous prince who delighted in enterprises in proportion as they presented difficulties; he was likewise a rash prince, as was 
evinced by his jumping into the river Cydnus while he was hot, and by his leaping over the wall of Oxydracæ and exposing himself singly to the attack of the enemy.

FOOLISH. See Irrational; SimPLE.

FOOTSTEP. See MARK.

FOPPISH. See FINICAL.

FORBEAR. See ABSTAIN.

FORBID, PROHIBIT, INTERDICT. The for in forbid, like the German ver, is negative, signifying to bid not to do. The pro in prohibit, and inter in interdict, have both a similarly negative sense: the former verb, from $h a-$ bere, to have, signifies to have or hold that a thing shall not be done, to restrain from doing; the latter, from dicere, to say, signifies to say that a thing shall not be done.

Forbid is the ordinary term; prohibit is the judicial term; interdict the moral term. To forbid is a direct and personal act; to prohibit is an indirect action that operates by means of extended influence: both imply the exercise of power or authority by any person; but the former is more applicable to the power of private persons, and the latter to the authority of government. A parent forbids his child marrying when he thinks proper: the government prohibits the use of spirituous liquors. Interdict is a species of forbidding applied to more serious concerns, as to interdict the use of any one strong drink. To forbid or interdict is opposed to command; to prohibit, to allow. As nothing is forbidden to Christians which is good and just in itself, so nothing is commanded that is hurtful and unjust. As no one is prohibited in our own country from writing that which can tend to the improvement of mankind, so on the other hand he is not allowed to indulge his private malignity by the publication of injurious personalities.

Forbid and interdict, as personal acts, are properly applicable to persons only, but by an improper application are extended to things; prohibit, however, in the general sense of restraining, is applied with equal propriety to things as to persons: shame forbids us doing a thing; law, authority, and the like, prohibit.

See also BAN.
FORCE, VIOLENCE. Both these terms imply an exertion of strength; but the former in a much less degree than the latter. Force (see CoMPEL) is ordinarily employed to supply the want of a proper will; violence, in Latin violentia, from vis, and the Greek, Bía, strength, is used to counteract an opposing will. The arms of justice must exercise force in order to bring offenders to a proper account; one nation exercises violence against another in the act of carrying on war. Force is mostly conformable to reason and equity; violence is always resorted to for the attainment of that which is unattainable by law. All who are invested with authority have occasion to use force at certain times to subdue the unruly will of those who should submit: violence and rapine are inseparable companions; a robber could not subsist by the latter without exercising the former.

In an extended and figurative application to things, these terms convey the same general idea of exerting strength. That is said to have force that acts with force; and that to have violence that acts with violence. A word, an expression, or a remark has force or is forcible; a disorder, a passion, a sentiment, has violence or is violent. Force is always something desirable; violence is always something hurtful. We ought to listen to arguments which have force in them; we endeavor to correct the violence of all angry passions.

See also Energy; Power; Strain.

FORCIBLE. See Cogent.

FOREBODE. See AUgur.

FORECAST. See Foresight.

FOREFATHERS, PROGENITORS, ANCEsTons. Forefathers signifies our fathers before us, and includes our immediate parents. Progenitors, from pro and gignere, to beget, signifies those begotten before us, exclusive of our immediate parents. Ancestors, contracted from antecessors, or those going before, is said of those from whom we are remotely descended. Forefathers is a partial and familiar term for the preceding branches of any family.

Progenitors is a higher term in the same sense applied to families of dis- 
tinction: we speak of the forefathers of a peasant, but the progenitors of a nobleman.

Forefathers and progenitors, but particularly the latter, are said mostly of individuals, and respect the regular line of succession in a family; ancestors is employed collectively as well as individually and regards simply the order of succession: we may speak of the ancestors of a nation as well as of any particular person.

FOREGo. See Give Up; WaIve.

FOREGOING. See ANTECEDENT.

FOREIGN. See Extraneous.

FOREIGNER. See STRANGER.

FORERUNNER, Precursor, MesSENGer, Harbinger. Forerunner and precursor signify literally the same thing, namely, one running before; but the term forerunner is properly applied only to one who runs before to any spot to communicate intelligence; and it is figuratively applied to things which in their nature, or from a natural connection, precede others; precursor is only employed in this figurative sense: thus imprudent speculations are said to be the forerunners of a man's ruin; the ferment which took place in men's minds was the precursor of the revolution.

Messenger signifies literally one bearing messages: and harbinger, from the Old French herberger, Old High German heri-berga, from heri, an army, and bergan, to shelter, signitied, one who provided a shelter for an army. Both terms are employed for persons: but the messenger states what has been or is; the harbinger announces what is to be. Our Saviour was the messenger of glad tidings to all mankind: the prophets were the harbingers of the Messiah. A messenger may be employed on different offices; a harbinger is a messenger who acts in a specific office. The angels are represented as messengers on different occasions. John the Baptist was the harbinger of our Saviour, who prepared the way of the Lord. They are both applied figuratively to other objects.

FORESIGHT, FORETHOdGHT, FOREcast, Premeditation. Foresight, from seeing before, and forethought, from thinking beforehand, denote the simple act of the mind in seeing a thing before it happens: forecast, from casting the thoughts onward, signifies coming at the knowledge of a thing beforehand by means of ealculation: premeditation, from meditate, signifies obtaining the same knowledge by force of meditating, reflecting deeply. Foresight and forethought are general and indefinite terms; we employ them on either ordinary or extraordinary occasions; but forethought is, of the two, the most familiar term; forecast and premeditation, mostly in the latter case: all business requires foresight; state concerns require forecast; foresight and forecast respect what is to happen; they are the operations of the mind in ealeulating futurity: premeditation respects what is to be said or done; it is a preparation of the thoughts and designs for action: by foresight and forecast we guard against evils and provide for contingencies; by premeditation we guard against errors of conduct. A man betrays his want of foresight who does not provide against losses in trade; he shows his want of forecast who does not provide against old age; he shows his want of premeditation who acts or speaks on the impulse of the moment: the man, therefore, who does a wicked act without premeditation lessens his guilt.

FOREST, Chase, PARK, are all habitations for animals of venery; but the forest is of the first magnitude and importance, it being a franchise and the property of the king; the chase and park may be either public or private property. The forest is so formed of wood, and covers such an extent of ground, that it may be the haunt of wild beasts; of this description are the forests in Germany: the chase is an indefinite and open space that is allotted expressly for the chase of particular animals, such as deer; the park is an enclosed space that serves for the preservation of domestic animals.

Foretell, Predict, Prophesy, Prognosticate. To foretell is compounded of fore and tell; predict comes from pre, before, and dicere, to say; prophesy, in French prophétiser, Latin prophetiso, Greek $\pi \rho \circ \phi \eta \eta \eta \bar{s}$, from $\pi \rho 0$, Latin pro, before, and $\phi \eta \mu i$, to speak, meaning to speak before the event, con- 
veys the same idea; prognosticate, from the Greek $\pi \rho 0 \gamma \cdot \gamma \nu \omega \sigma \kappa \varepsilon \iota \nu$, to know beforehand, to bode or imagine to one's self beforehand, denotes the action of feeling or knowing, rather than speaking of things to come.

Foretell is the most general in its sense and familiar in its application; we may foretell common events, although we cannot predict or prophesy anything important: to foretell is an ordinary gift; one foretells by a simple calculation or guess: to predict and prophesy are extraordinary gifts; one predicts by a supernatural power, real or supposed; one prophesies by means of inspiration. Men of discernment and experience easily foretell the events of undertakings which fall under their notice. The priests among the heathens, like the astrologers and conjurers of more modern times, pretended to predict events that affected nations and empires. The gift of prophecy was one among the number of the supernatural gifts communicated to the primitive Christians by the Holy Ghost.

Prediction, as a noun, is employed for both the verbs foretell and predict; it is, therefore, a term of less value than prophecy. We speak of a prediction being verified and a prophecy fulfilled: the predictions of almanacmakers respecting the weather are as seldom verified as the prophecies of visionaries and enthusiasts are fulfilled respecting the death of princes or the affairs of governments.

To prognosticate is an act of the understanding; it is guided by outward symptoms, as a rule; it is only stimulated, and not guided, by outward objects; a physician prognosticates the crisis of a disorder by the symptoms discoverable in the patient.

FORFEITURE. See FINE.

\section{FORGE. See INvent.}

FORGETFULNESS, O B L I I ION. Forgetfulness characterizes the person or that which is personal; oblivion, the state of the thing: the former refers to him who forgets, the latter to that which is forgotten: we blame a person for his forgelfulness; but we sometimes bury things in oblivion.

See also AMNesia.

FORGIVE, Absolve, Pardon, Re-
MIT. Forgive, Anglo-Saxon forgefan, compounded of the privative for and gifan, Modern English give, and pardon (see ExcuSE) both signify not to give the punishment that is due, to relax from the rigor of justice in demanding retribution. Forgive is the familiar term; pardon is adapted to the serious style. Individuals forgive one another personal offences; they pardon offences against law and morals: the former is an act of Christian charity: the latter an act of clemency: the former is an act that is confined to no condition; the latter is peculiarly the act of a superior. $\mathrm{He}$ who has the right of being offended has an opportunity of forgiving the offender; he who has the authority of punishing the offence may pardon.

Pardon, when compared with remission, is the consequence of offence; it respects principally the person offending; it depends upon him who is offended; it produces reconciliation when it is sincerely granted and sincerely demanded. Remission is the consequence of the crime; it has more particular regard to the punishment; it is granted by either the prince or the magistrates; it arrests the execution of justice. Remission, like pardon, is peculiarly applicable to the sinner with regard to his Maker. Absolution is taken in no other sense: it is the consequence of the fault or the sin, and properly concerns the state of the culprit; it properly loosens him from the tie with which he is bound; it is pronounced either by the civil judge or by the ecclesiastical minister; and it re-establishes the accused or the penitent in the rights of innocence.

FORGOTTEN. See BYgoNe.

FORLORN. See ForsakeN.

FORM, Figdre, Conformation. Form, in Latin forma, signifies properly the life within which gives shape and individuality to anything. Figure signifies the image feigned or conceived. Conformation, in French conformation, in Latin conformatio, from conform, signifies the image disposed or put together.

Form is the generic term; figure and conformation are special terms. The form is the work either of nature or art; it results from the arrangement of 
the parts: the figure is the work of design: it includes the general contour or outline: the conformation includes such a disposition of the parts of the body as is adapted for performing certain functions. Form is the property of every substance; and the artificial form approaches nearest to perfection as it is most natural; the figure is the fruit of the imagination; it is the representation of the actual form that belongs to things; it is more or less just as it approaches to the form of the thing itself: conformation is said only with regard to animal bodies; nature renders it more or less suitable according to the accidental concurrence of physical causes. The erect form of man is one of the distinguishing marks of his superiority over every other terrestrial being: the human figure when well painted is an object of admiration: the turn of the mind is doubtless influenced by the conformation of the organs. A person's form is said to be handsome or ugly, common or uncommon, his figure to be correct or incorrect; a conformation, to be good or bad. Heathens have worshipped the Deity under various forms: mathematical figures are the only true figures with which we are acquainted: the craniologist affects to judge of characters by the conformation of the skull.

Form and figure are used in a moral application, although conformation is not. We speak of adopting a form of faith, a form of words, a form of godliness; cutting a showy, a dismal, or ridiculous figure.

Form, Fashion, Mould, Shape--To form is to put into a form, which is here as before the generic term: to fashion is to put into a particular or distinct form; to mould is to put into a set form; to shape is to form simply as it respects the exterior. As everything respects a form when it receives existence, so to form conveys the idea of producing. When we wish to represent a thing as formed in any distinct or remarkable way, we may speak of it as fashioned. God formed man out of the dust of the ground; He fashioned him after His own image. When we wish to represent a thing as formed according to a precise rule, we should say it was moulded; thus the habits of a man are moulded at the will of a superior. When we wish to represent a thing as receiving the accidental qualities which distinguish it from others, we talk of shaping it: the potter shapes the clay; the milliner shapes a bonnet; a man shapes his actions to the humors of another.

See also Make.

Form, Compose, Constitute.-Form is a generic and indefinite term, signifying to give a form. To compose and constitute are modes of forming. These words may be employed either to designate modes of action or to characterize things. Things may be formed either by persons or things; they are composed and constituted only by conscious agents: thus persons form things, or things form one another: thus we form a circle, or the reflection of the light after rain forms a rainbow. Persons compose and constitute: thus a musician composes a piece of music, or men constitute laws.

To form, in regard to persons, is simply to put into a form; to compose is to put together into a form; and to constitute is to make to stand together in a form; to form, therefore, does not qualify the action: one forms a thing without defining how, whether at once or by degrees, whether with one or several materials; to compose and constitute are both modes of forming by the help of several materials, with device and contrivance; compose is said of that which only requires to be put together; constitute, of that to which a certain degree of stability must be given. God formed man, man forms a cup or a vessel; he composes a book; he constitutes offices, bodies, politic, and the like.

When employed to characterize things, form signifies simply to have a form, be it either simple or complex; compose and constitute are said only of those things which have complex forms; the former as respecting the material, the latter the essential parts of an object: thus we may say that an object forms a circle, or a semicircle, or the segment of a circle: a society is composed of individuals; but law and order constitute the essence of society: so letters and syllables compose 
a word; but sense is essential to constitute a word.

Form, Ceremony, Rite, Observance.Form (see above). Ceremony, in Latin ceremonia, signifies a formal celebration. Rite, Latin ritus, means a going, a way, a way of doing, from a root ri, meaning to flow, to move. Observance signifies the thing observed, from Latin observare, to heed, to observe.

All these terms are employed with regard to particular modes of action in civil society. Form is here, as in the preceding sections, the most general in its sense and application; ceremony, rite, and observance are particular kinds of form, suited to particular occasions. Form, in its distinct application, respects all determinate modes of acting and speaking that are adopted by society at large in every transaction of life; ceremony respects those forms of outward behavior which are made the expressions of respect and deference; rite and observance are applied to national ceremonies in matters of religion. A certain form is requisite for the sake of order, method, and decorum, in every social matter, whether in affairs of state, in a court of law, in a place of worship, or in the private intercourse of friends. So long as distinctions are admitted in society, and men are agreed to express their sentiments of regard and respect to one another, it will be necessary to preserve the ceremonies of politeness which have been established. Administering oaths by the magistrate is a necessary form in law; kissing the king's hand is a ceremony practiced at court.

As far as form, ceremonies, rites, and observances respect religion, the first is used in the most universal and unqualified sense in respect to religion generally or any particular form: the second may be said either of an individual or a community; the third only of a community; and the last, more properly, of an individual either in public or in private. There can be no religion without some form, but there may be different forms which are equally good. Every country has adopted certain rites founded upon its peculiar religious faith, and prescribed certain observances by which individuals can make a public profession of their faith: baptism is one rite of initiation into the Christian church; kneeling at prayer is a ceremony, prayer itself is an observance.

Formal, Ceremonious, Ceremonial.Formal and ceremonious, from form and ceremony, are either taken in an indifferent sense with respect to what contains form and ceremony, or in a bad sense, expressing the excess of form and ceremony. A person expects to have a formal dismissal before he considers himself as dismissed; people of fashion pay one another ceremonious visits, by way of keeping up a distant intercourse.

Ceremonial is employed in the sense of appertaining to prescribed ceremonies; and formal implies appertaining to prescribed forms in public matters, as formal communications from one government to another: it is the business of the church to regulate the ceremonial part of religion.

Ceremonious was formerly used in the same sense as ceremonial.

Formal, in the bad sense, is opposed to easy: ceremonious, to the cordial. A formal carriage prevents a person from indulging himself in the innocent familiarities of friendly intercourse; ceremonious carriage puts a stop to all hospitality and kindness. Princes, in their formal intercourse with one another, know nothing of the pleasures of society; ceremonious visitants give and receive entertainments without tasting any of the enjoyments which flow from the reciprocity of kind offices.

FORMER. See ANTECEDENT.

FORMERLY, IN TIMES PAST or Old Times, Days of Yore, Anciently or Ancient Times. Formerly supposes a less remote period than in times past: and that less remote than in days of yore and anciently. The first two may be said of what happens within the age of man; the last two are extended to many generations and ages. Any individual may use the word formerly with regard to himself: thus, we enjoyed our health better formerly than now. An old man may speak of times past, as when he says he does not enjoy himself as he did in times past. Old times, days of yore, and anciently are more applicable to nations than to individuals; and all these express differ- 
ent degrees of remoteness. With respect to our present period, the age of Queen Elizabeth may be called old times; the days of Alfred, and, still later, the days of yore: the earliest period in which Britain is mentioned may be termed ancient times.

\section{See also ONCE.}

FORMIDABLE, Dreadful, TerRIBLE, Shocking. Formidable is applied to that which is apt to excite fear (see Apprenend). Dreadful, to what is calculated to excite dread; terrible (see Alarm), to that which excites terror; and shocking (from Middle English shokken, to jolt) is applied to that which violently shakes or agitates (see Agitate). The formidable acts neither suddenly nor violently; the dreadful may act violently but not suddenly: thus the appearance of an army may be formidable; but that of a field of battle is dreadful. The terrible and shocking act both suddenly and violently; but the former acts both on the senses and on the imagination, the latter on the moral feelings: thus, the glare of a tiger's cye is terrible; the unexpected news of a friend's death is shocking.

FORSAKE. See ABANdon.

FORSAKEN, ForlorN, Destitute. To be forsaken is to be deprived of the company and assistance of those we have looked to; to be forlorn, AngloSaxon forloren (German verloren), past participle of forleosan, to lose entirely, signifying lost, is to be forsaken in time of difficulty, to be without a guide in an unknown road; to be destitule, from the Latin destitutus, from Latin de, away, and statuere, to place, meaning taken away from, is to be deprived of the first necessaries of life. To be forsaken is a partial situation; to be forlorn and destitute is a permanent condition. We may be forsaken by a fellow-traveller on the road; we are forlorn when we get into a deserted path with no one to direct us; we are destitute when we have no means of subsistence, nor the prospect of obtaining the means. It is particularly painful to be forsaken by the friend of our youth and the sharer of our fortunes; the orphan who is left to travel the road of life without counsellor or friend is, of all others, in the most forlorn condition; if to this be added poverty, his misery is aggravated by his becoming destitute.

FORSWEAR, Peruure, SUborn. Forswear is Anglo-Saxon; perjure is Latin; the prepositions for and per are both privative, and the words signify literally to swear contrary to the truth; this is, however, not their only distinction: to forswear is applied to all kinds of oaths; to perjure is employed only for such oaths as have been administered by the civil magistrate. A soldier forswears himself who breaks his oath of allegiance by desertion; and a subject forswears himself who takes an oath of allegiance to his sovereign which he afterward violates; a man perjures himself in a court of law who swears to the truth of that which he knows to be false. Forswear is used only in the proper sense: perjure may be used figuratively with regard to lover's vows; he who deserts his mistress to whom he has pledged his affections is a perjured man.

Forswear and perjure are the acts of individuals; suborn, from the Latin $s u b$, secretly, and ornare, to adorn, to enrich, meaning to enrich secretly, to bribe, and hence to make to forswear; a perjured man has all the guilt upon himself; but he who is suborned shares his guilt with the suborner.

FORTIFY. See Strengthen.

FORTITUdE. See Courage.

FORTUITOUS. Sec Fortunate.

FORTUNATE, LUCKY, FonTuITOUS, Prosperous, Successful. Fortunate signifies having fortune (see CHANCE). Lucky is the adjective corresponding to luck, which is not found in AngloSaxon, but is a late borrowing from Dutch and German. (Compare German Glück.) Fortuitous, from fors, chance, signifies according to chance. Prosperous (see Flourish). Successful signifies full of success, enabled to succeed.

The fortunate and lucky are both applied to that which happens without the control of man; but the latter, which is a collateral term, describes the capricious goddess Fortune in her most freakish humors, while fortunate represents her in her more sober mood: in other words, the fortunate is more according to the ordinary course of 
things; the lucky is something sudden, unaccountable, and singular: a circumstance is said to be fortunate which turns up suitably to our purpose; it is said to be lucky when it comes upon us unexpectedly, at the moment that it is wanted: hence we speak of a man as fortunate in his business and the ordinary concerns of life, but lucky in the lottery or in games of chance: a fortunate year will make up for the losses of the past year; a lucky hit may repair the ruined spendthrift's fortune, only to tempt him to still greater extravagances.

Fortunate and lucky are applied to particular circumstances of good fortune and luck, but fortuitous is employed only in matters of chance generally and indifferently.

Prosperous and successful seem to exclude the idea of what is fortuitous, although prosperity and success are both greatly aided by good fortune. Fortunate and lucky are applied as much to the removal of evil as to the attainment of good; prosperous and successful are concerned only in what is good, or esteemed as such: we may be fortunate in making our escape; we are prosperous in the acquirement of wealth. Fortunate is employed for single circumstances; prosperous only for a train of circumstances; a man may be fortunate in meeting with the approbation of a superior; he is prosperous in his business. Prosperity is extended to whatever is the object of our wishes in this world; success is that degree of prosperity which immediately attends our endeavors; wealth, honors, children, and all outward circumstances constitute prosperity; the attainment of any object constitutes success: the fortunate and lucky man can lay no claim to merit, because they preclude the idea of exertion; the prosperous and successful man may claim a share of merit proportioned to the exertion.

The epithet prosperous may be applied to those things which promote prosperity or ultimate success.

See also Happy.

FORTUNE. See Chance.

FORWARD. See Encourage; On; ONWARD.

FOSTER, Cherish, Harbor, INDULGE. To foster comes from Anglo-
Saxon fostor, nourishment, allied to foda, food; to cherish, through French from Latin carus, dear, is to hold affection; to harbor, from a harbor or haven, is to provide with a shelter and protection; to indulge comes from Latin indulgere, to be courteous to, of unknown origin. These terms are all employed here in the moral acceptation, to express the idea of giving nourishment to an object. To foster in the mind is to keep with care and positive endeavors; as when one fosters prejudices by encouraging everything which favors them: to cherish in the mind is to hold dear or set a value upon; as when one cherishes good sentiments by dwelling upon them with inward satisfaction: to harbor is to allow room in the mind, and is generally taken in the worst sense for giving admission to that which ought to be excluded; as when one harbors resentment by permitting it to have a resting-place in the heart: to indulge in the mind is to give the whole mind to it, to make it the ehief source of pleasure: as when one indulges an affection, by making the will and the outward conduct bend to its gratification.

\section{- FOUL. See Sodalid.}

FOUND, Ground, Rest, BUILd. Found, in French fonder, Latin fundo, comes from fundus, the ground, and, like the verb ground, properly signifies to make firm in the ground, to make the ground the support. To found implies the exercise of art and contrivance in making a support; to ground signifies to lay a thing so deep that it may not totter; it is merely in the moral sense that they are here considered, as the verb to ground with this signification is never used otherwise. Found is applied to outward circumstances; ground, to what passes inwardly: a man founds his charge against another upon certain facts that are come to his knowledge; he grounds his belief upon the most substantial evidence: a man should be cautious not to make any accusations which are not well founded, nor to indulge any expectations which are not well grounded: monarchs commonly found their claims to a throne upon the right of primogeniture; Christians ground their hopes of immortality on the word of God. 
To found and ground are said of things which demand the full exercise of the mental powers; to rest is an action of less importance: whatever is founded requires and has the utmost support; whatever is rested is more by the will of the individual: a man founds his reasoning upon some unequivocal fact; he rests his assertion upon mere hearsay. The words found, ground, and rest have always an immediate reference to the thing that supports; to build has an especial reference to that which is supported, to the superstructure that is raised: we should not say that a person founds an hypothesis without adding something, as observations, experiments, and the like, upon which it was founded; but we may speak of his simply building systems, supposing them to be the mere fruit of his distempered imagination; or we may say that a system of astronomy has been built upon the opinion of Copernicus respecting the motion of the earth.

See also Institute.

Foundation, Ground, Basis.-Foundation and ground derive their meaning and application from the preceding article: a report is said to be without any foundation which has taken its rise in mere conjecture or in some arbitrary cause independent of all fact; a man's suspicion is said to be without ground which is not supported by the shadow of external evidence: unfounded clamors are frequently raised against the measures of government; groundless jealousies frequently arise between families to disturb the harmony of their intercourse.

Foundation and basis may be compared with each other, either in the proper or the improper signification: both foundation and basis are the lowest parts of any structure; but the former lies under ground, the latter stands above: the foundation supports some large and artificially erected pile; the basis supports a simple pillar: hence we speak of the foundation of St. Paul's, and the base or basis of the Monument.

This distinction is likewise preserved in the moral application of the terms: disputes have too often their foundation in frivolous circumstances; trea- ties have commonly their basis in some acknowledged general principle; with governments that are at war pacific negotiations may be commenced on the basis of the uti possidetis.

FOUNTAIN. See SPRINa.

FOURIERISM. See SócialisM.

FRACTURE. See RUPTURE.

FRAGile, Frail, Brittle. Fragile and frail, in French frêle, both come from the Latin fragilis, signifying breakable; but the former is used in the proper sense only, and the latter more generally in the improper sense: man, corporeally considered, is a fragile creature, his frame is composed of fragile materials; mentally considered, he is a fragile creature, for he is liable to every sort of frailty.

Brittle comes from the Anglo-Saxon breotan, to break, and means breakable; but it conveys a stronger idea of this quality than fragile: the latter applies to whatever will break from the effects of time; brittle to that which will not bear a temporary violence: in this sense all the works of men are fragile, and, in fact, all sublunary things; but glass, stone, and ice are peculiarly denominated brittle.

FRAGRANCE. See Syell.

FraIl. See Fragile.

FRAILTY. See IMPERFECTION.

FRAME, Temper, Temperament, Constitution. Frame, Anglo-Saxon framian, to further, is allicd to from, the preposition, and means literally the outside of anything; it is also allied to fram, meaning strong, and German fromm, good; it is applied to man physically or mentally, as denoting that constituent portion of him which seems to hold the rest together; which by an extension of the metaphor is likewise put for the whole contents, the whole body, or the whole mind. Temper and temperament, in Latin temperamentum, from temperare, to govern or dispose, signify the particular modes of being disposed or organized. Constitution, from constitute or appoint, signifies the particular mode of being constituted or formed.

Frame, when applied to the body, is taken in its most universal sense: as when we speak of the frame being violently agitated, or the human frame being wonderfully constructed: when 
applied to the mind, it will admit either of a general or restricted signification. Temper, which is applicable only to the mind, is taken in the general or particular state of the individual. The frame comprehends either the whole body of mental powers or the particular disposition of those powers in individuals; the temper comprehends the general or particular state of feeling as well as thinking in the individual. The mental frame which receives any violent concussion is liable to derangement; it is necessary for those who govern to be well acquainted with the temper of those whom they govern. By reflection on the various attributes of the Divine Being, a man may easily bring his mind into a frame of devotion: by the indulgence of a fretful, repining temper, a man destroys his own peace of mind and offends his Maker.

Temperament and constitution mark the general state of the individual; the former comprehends a mixture of the physical and mental; the latter has a purely physical application. A man with a warm temperament owes his warmth of character to the rapid impetus of the blood; a man with a delicate constitution is exposed to great fluctuations in his health; the whole frame of a new-born infant is peculiarly tender. Men of fierce tempers are to be found in all nations; men of sanguine tempers are more frequent in warm climates; the constitutions of females are more tender than those of the male, and their frames are altogether more susceptible.

See also Invent.

FRANK, CANDID, INGeNuous, Free, Open, Plain. Frank, in French franc, Old. High German franko, a Frank, from a weapon, was originally the name of a Germanic tribe which gave its name to France; the word signified a free-born German, as distinguished from those whom the Germans conquered, and hence the liberal and fearless manners of the man who calls no man master. Candid (for derivation see $\mathbf{C}_{\mathrm{AN}}$ DID). Ingenuous comes from the Latin ingenuus, which signifies literally freeborn, as distinguished from the liberti, who were afterward made free: hence the term has been employed by a figure of speech to denote nobleness of birth or character. Free, Anglo-Saxon freo, originally meant dear, and was applied to the free-born children of a household, distinguished from the childslaves. Compare Latin liberi, free, which also meant children. Open (see Candid). Plain (see Apparent).

All these terms convey the idea of a readiness to communicate and be communicated with; they are all opposed to concealment, but under different circumstances. The frank man is under no constraint; his thoughts and feelings are both set at ease, and his lips are ever ready to give utterance to the dictates of his heart; he has no reserve: the candid man has nothing to conceal; he speaks without regard to self-interest or any partial motive; he speaks nothing but the truth: the ingenuous man throws off all disguise; he scorns all artifice and brings everything to light; he speaks the whole truth. Frankness is acceptable in the general transactions of society; it inspires confidence and invites communication: candor is of peculiar use in matters of dispute; it serves the purposes of equity and invites to conciliation: ingenwousness is most wanted where there is most to conceal; it courts favor and kindness by an acknowledgment of that which is against itself.

Frankness is associated with unpolished manners, and frequently appears in men of no rank or education; sailors have commonly a deal of frankness about them: candor is the companion of uprightness; it must be accompanied with some refinement, as it acts in cases where nice discriminations are made: ingenuousness is the companion of a noble and elevated spirit: it exists most frequently in the unsophisticated period of youth. Frankness displays itself in the outward behavior; we speak of a frank air and frank manner: candor displays itself in the language which we adopt and the sentiments we express; we speak of a candid statement, a candid reply: ingenuousness shows itself in all the words, looks, or actions; we speak of an ingenuous countenance, an ingenuous acknowledgment, an ingenuous answer.

Free, open, and plain have not so high an office as the first three; free and open may be taken either in a 
good, bad, or indifferent sense; but seldomer in the first than in the last two senses.

The frank, free, and open men all speak without constraint; but the frank man is not impertinent, like the free man, nor indiscreet, like the open man. The frank man speaks only of what concerns himself; the free man speaks of what concerns others: a frank man may confess his own faults or inadvertencies; the free man corrects those which he sees in another: the frank man opens his heart from the warmth of his nature; the free man opens his mind from the conceit of his temper, and the open man says all he knows and thinks, from the inconsiderate levity of his temper.

Plainness, the last quality to be here noticed, is a virtue which, though of the humbler order, is not to be despised: it is sometimes employed, like freedom, in the task of giving counsel; but it does not convey the idea of anything unauthorized either in matter or manner. A free counsellor is more ready to display his own superiority than to direct the wanderer in his way; he rather aggravates faults than instructs how to amend them; he seems more like a supercilious enemy than a friendly monitor: the plain man is free from these faults: he speaks plainly but truly; he gives no false coloring to his speech; it is not calculated to offend, and it may serve for improvement: it is the part of a true friend to be plain with another whom he sees in imminent danger. A free speaker is in danger of being hated; a plain dealer must at least be respected.

FRAUD. See Deceit.

FRAUDUlent. See Fallaciods. FRAY. See QUARREL.

FREAK, WHIM. Freak comes from Anglo-Saxon frec, meaning bold, rash. Whim is a Scandinavian word, allied to Icelandie hvima, to wander with the eyes, to be foolish. Freak has more of childishness and humor than boldness in it, a whim more of eccentricity than of childishness. Fancy and fortune are both said to have their freaks, as they both deviate most widely in their movements from all rule; but whims are at most but singular devia- tions of the mind from its ordinary and even course. Females are most liable to be seized with freaks, which are in their nature sudden and not to be caleulated upon: men are apt to indulge themselves in whims which are in their nature strange and often laughable. We should call it a freak for a female to put on the habit of a male, and so accoutred to sally forth into the streets: we term it a whim in a man who takes a resolution never to shave himself any more.

FREE, LIBERAL. In the section on Frank, free is considered only as it respects communication by words; in the present case it respects actions and sentiments. In all its acceptations, free is a term of dispraise, and liberal that of commendation. To be free signifies to act or think at will; to be liberal is to act according to the dictates of an enlarged heart and an enlightened mind. A clown or a fool may be free with his money, and may squander it away to please his humor or gratify his appetite; but the nobleman and the wise man will be liberal in rewarding merit, in encouraging industry, and in promoting whatever can contribute to the ornament, the prosperity, and improvement of his country.

A man who is free in his sentiments thinks as he pleases; the man who is liberal thinks according to the extent of his knowledge. The freethinking man is wise in his own conceit, he despises the opinions of others; the liberalminded thinks modestly on his own personal attainments, and builds upon the wisdom of others.

Free, Set Free, Deliver, Liberate.To free is properly to make free, in distinction from set free; the first is employed in what concerns ourselves, and the second in that which concerns another. A man frees himself from an engagement; he sets another free from his engagement: we free, or set ourselves free, from that which has been imposed upon us by ourselves or by circumstances; we are delivered or liberated from that which others have imposed upon us; the former from evils in general, the latter from the evil of confinement. I free myself from a burden; I set my own slave free from his slavery; I deliver another man's slave 
from a state of bondage; I liberate a man from prison. A man frees an estate from rent, service, taxes, and all encumbrances; a king sets his subjects free from certain imposts or tributes, he delivers them from a foreign yoke, or he liberates those who have been taken in war.

\section{See also Emancipate.}

Free, Familiar.-Free has already been considered as it respects words, actions and sentiments; in the present case it is coupled with familiarity, inasmuch as they respect the outward behavior or conduct in general of men one to another. To be free is to be disengaged from all the constraints which the ceremonies of social intercourse impose; to be familiar is to be upon the footing of a familiar, of a relative, or one of the same family.

Neither of these terms can be admitted as unexceptionable; freedom is authorized only by particular circumstances and within certain limitations; familiarity sometimes shelters itself under the sanction of long, close, and friendly intercourse. Free is a term of much more extensive import than familiar; a man may be free toward another in a thousand ways; but he is familiar toward him only in his manners and address. A man who is free makes free with everything as if it were his own; a familiar man only wants to share with another, and to stand upon an equal footing in his social intercourse. No man can be free without being in danger of infringing upon what belongs to another, nor familiar without being in danger of obtruding himself to the annoyance of others, or of degrading himself.

Free, Exempt.-Free (see preceding terms). Exempt, in Latin exemptus, from ex, out, and emere, to take, signifies set out or disengaged from anything.

The condition and not the conduct of men is here considered. Freedom is either accidental or intentional; the exemption is always intentional; we may be free from disorders, or free from troubles; we are exempt, that is, exempted by government, from serving in the militia. Free is applied to everything from which any one may wish to be free; but exempt, on the contrary, to those burdens which we should share with others: we may be free from imperfections, free from inconveniences, free from the interruptions of others, but exempt from any office or tax. We may likewise be said to be exempt from troubles when speaking of these as the dispensations of Providence to others.

Freedom, Liberty.-Freedom, the abstract noun of free, is taken in all the senses of the primitive. Liberty, from the Latin liber, free, is only taken in the sense of free from external constraint, from the action of power.

Freedom is personal and private; $l i b-$ erty is public. The freedom of the city is the privilege granted by the city to individuals; the liberties of the city are the immunities enjoyed by the city. By the same rule of distinction we speak of the freedom of the will, the freedom of manners, the freedom of conversation, or the freedom of debate: but the liberty of conscience, the liberty of the press, the liberty of the subject.

Freedom serves, moreover, to qualify the action; liberty is applied only to the agent; hence we say, to speak or think with freedom; but to have the liberty of speaking, thinking, or acting.

Freedom and liberty are likewise employed for the private conduct of individuals toward one another; but the former is used in a qualified good sense, the latter often in an unqualified bad sense. A freedom may sometimes be licensed or allowed; a liberty, if it be taken, may be something not agreeable or allowed. A freedom may be innocent and even pleasant; a liberty may do more or less violence to the decencies of life or the feelings of individuals. There are little freedoms which may pass between youth of different sexes, so as to heighten the pleasures of society; but a modest woman will be careful to guard against any freedoms which may admit of misinterpretation, and resent every liberty offered to her as an insult.

FREIGHT, BURDeN, Cargo, LadING, LOAD. Freight is a word which has come from Dutch or Low German through French into English; it originally signified the earnings or the hire of a ship. Cargo comes through Spanish from the Late Latin carricare, to 
load a car. Lading, from lade, is derived from Anglo-Saxon hladan, to heap, to heap together. Load comes from Anglo-Saxon lad, a way or journey, allied to Modern English lead, and signifies that which is carried on a journey. Burden, from bear, conveys the idea of weight which is borne by the vessel.

A captain speaks of the freight of his ship as that which is the object of his voyage, by which all who are interested in it are to make their profit; he speaks of the lading as the thing which is to fill the ship; the quantity and weight of the lading are to be taken into the consideration: he speaks of the cargo as that which goes with the ship, and belongs, as it were, to the ship; the amount of the cargo is that which is first thought of: he speaks of the burden as that which his vessel will bear; it is the property of the ship which is to be estimated. The shipbroker regulates the freight: the captain and the crew dispose of the lading: the agent sees to the procuring of the cargo: the ship-builder determines the burden: the carrier looks to the load which he has to carry.

\section{FRENZY. See MADNESS.}

FREQUENT, RESORT To, HaUNT. Frequent comes from French fréquent, in Latin frequens, erowded, signifying to come in numbers, or eome often to the same place. Resort comes from Late Latin resortere, from $r e$, again, and sors, a lot, and meant to go to a tribunal, to re-obtain by appeal. Haunt, from Old French hanter, is a word whose ultimate origin and meaning are disputed.

Frequent is more commonly used of an individual who goes often to a place; resort and haunt, of a number of individuals. A man is said to frequent a public place; but several persons may resort to a private place: men who are not fond of home frequent taverns; in the first ages of Christianity, while persecution raged, its professors used to resort to private plaees for purposes of worship.

Frequent and resort are indifferent actions; but haunt is always used in a bad sense. A man may frequent a theatre, a elub, or any other social meeting, innocent or otherwise; people from different quarters may resort to a fair, a chureh, or any other place where they wish to meet for a common purpose; but those who haunt any place go to it in privacy for some bad purpose.

FREQUENTLY. See Commonly; OFTEN.

FRESH. See New.

FRET. See RUB.

FRETFUL. See Captiods; QuerUlous; SPlenetic.

FRIENDLY. See AMICABLE.

FRIENDSHIP. See Love.

FRIGHT. See ALARM.

FRIGHTEN, Intimidate. Between frighten and intimidate there is the same difference as between fright (see ALARM) and fear (see APPREHEND): the danger that is near or before the eyes frightens; that which is seen at a distance intimidates: hence females are oftener frightened and men are oftener intimidated: noises will frighten; threats may intimidate: we may run away when we are frightened; we waver in our resolution when we are intimidated; we fear immediate bodily harm when we are frightened; we fear harm to our property as well as our persons when we are intimidated; frighten, therefore, is always applied to animals, but intimidate never.

See also Overawe.

Frightful. See Fearful.

FRIGID. See Cool.

FRIVOlOUS. See Trifling.

FROlic, Gambol, Prank. Frolic is a Dutch word, allied to German froh, merry. Gambol is derived through French from Italian gambata, a kick, Italian gamba, a leg (French jambe), from Late Latin gamba, a joint of the leg. Prank comes from Middle English pranken, to trim; compare prink, to arrange one's clothes before a mirror. The frolic is a merry, joyous entertainment; the gambol is a dancing, light entertainment; the prank is a freakish, wild entertainment. Laughing, singing, noise, and feasting constitute the frolic of the careless mind; it belongs to a company; conceit, levity, and trick, in movement, gesture, and contrivance, constitute the gambol; it belongs to the individual: adventure, eccentricity, and humor constitute the prank; it belongs to one or many. 
One has a frolic; one plays a gambol or a prank.

FRONT. See FACE.

FRONTIER. See BORDER.

FROWARD. See AWKWARD.

FRUGALITY. See Economy.

FRUITFUL. See Fertile.

FRUITION. See ENJOYMENT.

FRUITLESS. See VAIN.

FRUSTRATE. See Defeat.

FULFIL, AcComplish, REalize. To fulfil is literally to fill quite full, that is, to bring about full to the wishes of a person; accomplish is to bring to perfection, but without reference to the wishes of any one; to realize is to make real, namely, whatever has been aimed at. The application of these terms is evident from their explanations: the wishes, the expectations, the intentions and promises of an individual are appropriately said to be fulfilled; national projects, or undertakings, prophecies, and whatever is of general interest are said to be $a c$ complished: the fortune or the prospeets of an individual, or whatever results successfully from specific efforts, is said to be realized: the fulfilment of our wishes may be as much the effect of good fortune as of design; the accomplishment of projects mostly results from extraordinary exertion, as the $a c$ complishment of prophecies results from a miraculous exertion of power; the realization of hopes results more commonly from the slow process of moderate well-combined efforts than from anything extraordinary.

See also Execute; Keep.

FULL. See Quite.

FULLy. See Largely.

FULNESS, Plenitude. Although fulness is simply the Anglo-Saxon translation of Latin plenitude (from plenus, full), yet the latter is used either in the proper sense to express the state of objects that are full, or in the improper sense to express great quantity, which is the accompaniment of fulness; the former only in the higher style and in the improper sense: hence we say in the fulness of one's heart, in the fulness of one's joy, or the fulness of the Godhead bodily; but the plenitude of power.
FULSOME, Florid, RanK. All these words indicate an overgrowth, over-development, especially as applied figuratively to language or manners. Fulsome originally meant over full, indicating a fulness of growthanimal or vegetable growth-offensive to the taste. It is now almost obsolete except as applied figuratively to speech, to refer to exaggerated flattery or over-demonstrative affection. Florid, from florem (accusative), flower, means literally flowery, and is applied figuratively to speech, but it has different connotations; it refers simply to the elaborate and ornamental phraseology without the suggestion of flattery or demonstrativeness. Rank, AngloSaxon rank, strong, proud, like fulsome, applies to coarse, luxuriant growth, and by extension to a kind of speech-as when we say "rank flattery"-with an emphasis upon offensiveness.

FUNCTION. See OfFice.

FUNDED. See UNFUNDED.

FUNERAL, OBSEQUIES. Funeral is in Latin funus, a burial; the term funeral, therefore, denotes the ordinary solemnity which attends the consignment of a body to the grave. Obsequies, from Latin $o b$, near, and sequi, to follow, means literally following the corpse, and refers to funerals attended with more than ordinary solemnity.

We speak of the funeral as the last sad office which we perform for a friend; it is accompanied by nothing but by mourning and sorrow: we speak of obsequies as the greatest tribute of respect which can be paid to the person of one who was high in station or public esteem: the funeral, by its frequency, becomes so familiar an object that it passes by unheeded; obsequies which are performed over the remains of the great attract our notice from the pomp and grandeur with which they are conducted.

FURIOUS. See VIOLENT.

FURNISH. See Provide.

FURNITURE. See Goods.

FURROW. See TRENCH.

FURY. See Anger; Madness.

FUTILE. See TrifLING. 


\section{G}

GABBLE. See JABBER.

GAIN, Profit, Emolument, Lucre. Gain signifies in general what is gained (see AcQuire; Get). Profit (see ADVANTAGE). Emolument, from emoliri, from $e$, out, and moliri, to work, signifies to work out or get by working. Lucre is in Latin lucrum, gain.

Gain is here a general term, the other terms are specific: the gain is that which comes to a man; it is the fruit of his exertions, or agreeable to his wish: the profit is that which accrues from the thing. Thus, when applied to riches, that which increases a man's estate is his gains; that which flows out of his trade or occupation is his profits; that is, they are his gains upon dealing. Emolument is a species of gain from labor, or a collateral gain; of this description are a man's emoluments from an office: a man estimates his gains by what he receives in the year; he estimates his profits by what he receives on every article; he estimates his emoluments according to the nature of the service which he has to perform: the merchant talks of his gains, the retail dealer of his profits, the placeman of his emoluments.

Gain and profit are also taken in an abstract sense; lucre is never used otherwise; but the latter always conveys a bad meaning; it is, strictly speaking, unhallowed gain: an immoderate thirst for gain is the vice of men who are always calculating profit and loss; a thirst for lucre deadens every generous feeling of the mind.

Gain and profit may be extended to other objects, and sometimes opposed to each other; for as that which we gain is what we wish only, it is often the reverse of profitable.

GaIt. See Carriage.

GALL. Sec RUB.

Gallant, Bead, Spark. These words convey nothing respectful of the person to whom they are applied; but the first, as is evident from its deri- vation, has something in it to recommend it to attention above the others: as true valor is ever associated with a regard for the fair sex, a gallant man will always be a gallant when he can render a female any service; sometimes, however, his gallantries may be such as to do them harm rather than good: insignificance and effeminacy characterize the beau or fine gentleman; he is the woman's man-the humble servant to supply the place of a lackey: the spark has but a spark of -that fire which shows itself in impertinent puerilities; it is applicable to youth who are just broke loose from school or college and eager to display their manhood.

See also Brave.

GAMBOL. See Frolic.

GAME. See Play.

GaMesome. See Playful.

GANG. See BAND.

GAP. See BrEaCH.

Gape, Stare, Gaze. Gape is a Scandinavian word meaning to look with an open or wide mouth. Stare, Anglo-Saxon starian, is allied to sta, the root of stand, stalion, statue, etc.; and signifies to look with fixed eyes. Gaze, Middle English gasen, is a Scandinavian word meaning to look at earnestly.

Gape and stare are taken in a bad sense, the former indicating the astonishment of gross ignorance, the latter not only ignorance, but impertinence: gaze is taken always in a good sense, as indicating a laudable feeling of astonishment, pleasure, or curiosity: a clown gapes at the pictures of wild beasts which he sees at a fair; an impertinent fellow stares at every woman he looks at, and stares a modest woman out of countenance: a lover of the fine arts will gaze with admiration and delight at the productions of Raphael or Titian; when a person is stupefied by affright he gives a vacant stare: those who are filled with transport gaze on the object of their ecstasy.

GARNER, DEPosit, HoARd. Gar- 
ner comes from Latin granaria, a place in which the grain (granum) is gathered. Deposit is derived from depositus, the past participle of Latin deponere, to lay down. Hoard comes from Anglo-Saxon hord, from a root signifying to hide. These words have in common the general idea of gathering and stowing away, but they differ widely in their application. In one sense garner is synonymous with gather, which see. It signified originally to gather and put away the grain, and is used figuratively always with a distinct and poetic reminiscence of its original meaning. Deposit emphasizes not the gathering, but the putting away; it is given a special application nowadays in business. A deposit of money is a sum of money paid down against a debt that may be incurred, or simply the putting away of money in a bank. Hoard adds to the idea of gathering and stowing away the special suggestion of hiding secretly. A miser hoards his money; selfish people, in time of war, hoard foodstuffs, etc.

GARNISH, TrIM. Garnish, Old French garnis, comes from Old High German warnon, to defend one's self, to provide one's self with. It shares with trim the general idea of adorning by the addition of something external, especially of small and pretty decorations; but it has now a somewhat more limited application than trim. We speak of garnishing when we wish to refer especially to an ephemeral and perishable trimming. We garnish dishes served at the table, for instance; we may speak of garnishing a room with flowers. Trim is used in this connection, but it is extended to refer to all sorts of ornamental additions, including those of a more permanent nature - as trimming a hat, a dress, etc. It is a less dignified word than adorn and its synonymes (see ADORN), with which it has something in common.

GaRRULOUS. See Talkative.

GASCONADE. See VAUNT.

GASP. See Palpitate.

GATHER, CoLLECT. To gather is in Anglo-Saxon gaderian, to bring things together, from the root also found in together. To collect (see AsSEMBLE) annexes also the idea of bind- ing or forming into a whole; we gather that which is scattered in different parts: thus stones are gathered into a heap; vessels are collected so as to form a fleet. Gathering is a mere act of necessity or convenience; collecting is an act of design or choice: we gather apples from a tree, or a servant gathers books from off a table; the antiquarian collects coins, and the bibliomaniac collects rare books.

See also Garner.

GAUDY. See Showy.

GAUNT. See HAGGARD.

GAY. See Cheerful; ShowY.

GAYETY. See Glee.

GAZE, See GAPE.

GENDER, SEX. Gender, in Latin genus, signifies properly a genus, or kind. Sex comes from Latin sexus. "Was it originally 'division,' from secare, to cut?" (Skeat.) Gender is that distinction in words which marks the distinction of sex in things; there are, therefore, three genders, but only two sexes. By the inflections of words is denoted whether things are of this or that sex or of no sex. The genders, therefore, are divided in grammar into masculine, feminine, and neuter; and animals are divided into male and female sex.

GENERAL, Universal. The general is to the universal what the part is to the whole. What is general includes the greater part or number; what is universal includes every individual or part. The general rule admits of many exceptions; the universal rule admits of none. Human government has the general good for its object; the government of Providence is directed to universal good. General is opposed to particular, and universal to individual. A scientific writer will not content himself with general remarks when he has it in his power to enter into particulars; the universal complaint which we hear against men for their pride shows that in every individual it exists to a greater or less degree. It is a general opinion that women are not qualified for scientific pursuits, but many females have proved themselves honorable exceptions to this rule: it is a universal principle that children ought to honor their parents; the intention of the Creator in this respect is mani- 
fested in such a variety of forms as to admit of no question.

Sec also Public.

GENERALLY. See CommonLy.

GENERATION, AGE. Generation is said of the persons who live during any particular period; and age is said of the period itself.

Those who are born at the same time constitute the generation; that period of time which comprehends the age of man is the age: there may, therefore, be many generations spring up in the course of an age; a fresh generation is springing up every day, which in the course of an age pass away and are succeeded by fresh generations. We consider man in his generation as to the part which he has to perform. We consider the age in which we live as to the manners of men and the events of nations.

See also RACE.

GENEROUS. See BENEFICENT.

GENIUS. See Intellect; TASTe.

GENTEEL, Polite. Genteel, in French gentil, Latin gentilis, signifies literally one belonging to the same family, or the next akin to whom the estate would fall if there were no children; hence by an extended application it denoted to be of a good family. Polite (see Civin).

Gentility respects rank in life; politeness, the refinement of the mind and outward behavior. A genteel education is suited to the station of a gentleman; a polite education fits for polished society and conversation, and raises the individual among his equals. There may be gentility without politeness, and vice versá. A person may have genteel manners, a genteel carriage, a genteel mode of living as far as respects his general relation with society; but a polite behavior and a polite address, which may qualify him for every relation in society and enable him to shine in connection with all orders of men, is independent of either birth or wealth; it is in part a girt of nature, although it is to be acquired by art. His equipage, scrvants, house, and furniture may be such as to entitle a man to the name of genteel, although he is wanting in all the forms of real goodbreeding; while fortune may sometimes frown upon the polished gentleman, whose politeness is a recommendation to him wherever he goes.

gentile, Heatuen, Pagan. The Jews comprehended all strangers under the name of Goim, nations or gentiles: among the Greeks and Romans they were designated by the name of barbarians. By the name gentile was understood especially those who were not of the Jewish religion, including, in the end, even the Christians. Some learned men pretend that the Gentiles were so named from their having only a natural law, and such as they imposed on themselves, in opposition to the Jews and Christians, who have a positive revealed law to which they are obliged to submit. Heathen, Anglo-Saxon hoethen, meant originally a dweller on the heath; pagan comes from Latin pagus, village, and means a dweller in the village, because when Constantine banished idolaters from the towns they repaired to the villages, and secretly adhered to their religious worship, whence they were termed by the Christians of the fourth century Pagani, which was translated literally into the German heidener, a villager or worshipper in the ficld. Be this as it may, it is evident that the word pagan is in our language more applicable than heathen to the Greeks, the Romans, and the cultivated nations who practiced idolatry; and, on the other hand, heathen is more properly employed for rude and uncivilized people who worship false gods.

The Gentile does not expressly belicve in a Divine Revelation; but he either admits of the truth in part or is ready to rcceive it: the heathen adopts a positively false system that is opposed to the true faith: the pagan is a species of heathen, who obstinately persists in a worship which is merely the fruit of his own imagination. The heathens and pagans are Gentiles; but the Gentiles are not all either heathens or pagans. Confucius and Socrates, who rejected the plurality of gods, and the followers of Mohammed, who adore the true God, are, properly speaking, Gentiles. The worshippers of Jupiter, Juno, Minerva, and all the deities of the ancients are termed pagans. The worshippers of Fo, Brahma, Xaca, and all the deities of savage nations are termed heathens. 
The Gentiles were called to the true faith, and obeyed the call: many of the illustrious pagans would have doubtless done the same had they enjoyed the same privilege: there are to this day many heathens who reject this advantage, to pursue their own blind imaginations.

GENTLE, TAME. Gentleness lies rather in the natural disposition; tameness is the effect either of art or circumstances. Any unbroken horse may be gentle, but not tame; a horse that is broken in will be tame, but not always gentle. Gentle, as before observed (see Genteel), signifies literally well-born, and is opposed either to the fierce or the rude: tame is allied to Latin domare, to tame, whence daunt is also derived, and is opposed either to the wild or the spirited. Animals are in general said to be gentle who show a disposition to associate with man and conform to his will; they are said to be tame if, either by compulsion or habit, they are brought to mix with human society. Of the first description there are individuals in almost every species which are more or less entitled to the name of gentle; of the latter description are many species, as the dog, the sheep, the hen, and the like.

In the moral application, gentle is always employed in the good, and tame in the bad, sense: a gentle spirit needs no control, it amalgamates freely with the will of another: a tame spirit is without any will of its own; it is alive to nothing but submission; it is perfectly consistent with our natural liberty to have gentleness, but tameness is the accompaniment of slavery. The same distinction marks the use of these words when applied to the outward conduct or the language: gentle bespeaks something positively good; tame bespeaks the want of an essential good: the former is allied to the kind, the latter to the abject and mean qualities which naturally flow from the compression or destruction of energy and will in the agent. A gentle expression is devoid of all acrimony and serves to turn away wrath: a tame expression is devoid of all force or energy, and ill calculated to inspire the mind with any feeling whatever. In giving counsel to an irritable and conceited temper it is necessary to be gentle: tame expressions are nowhere such striking deformities as in a poem or an oration.

See also SoFT.

GENUINE. See INTRINSIC.

GERM, Bud, Embryo, Seed. These words all indicate the original or rudimentary state of a living organismeither animal or plant. Germ and seed represent the first beginnings, as it were, of life; embryo and bud, an early stage of development. Germ is a word of doubtful origin, probably allied to the root ger in gerere, to bear; it signifies that portion of an organic being which is capable of developing into the likeness of that from which it sprang. Seed, from Anglo-Saxon sawan, to sow, indicates that portion of a plant which is sown in the ground, and from which the new plant springs; it is the germ of the plant with a protective covering Embryo, Greek $\ddot{\mu} \mu \beta \rho v o \nu$, Greek $\dot{\varepsilon} \nu$ and $\beta \rho v i \nu$, neuter of the present participle of $\beta \rho v \varepsilon \varepsilon \nu$, to be full, to swell out. It refers to the first stage of new animal life. Bud, Middle English budde, is not found in Anglo-Saxon. It refers to the first stage of a new flower or the group of new leaves folded together in a hard little bundle, as it were.

GESTICULATION. See ACTION.

GESTURE. See ACTION.

Get, Gain, Obtain, Procure. To get signifies simply to cause to have or possess; it is generic, and the rest specific: to gain is to get the thing one wishes or that is for one's advantage: to obtain is to get the thing aimed at or striven after: to procure, from pro, for, and curare, to care, to care for, is to get the thing wanted or sought for.

Get is not only the most general in its sense, but in its application; it may be substituted in almost every case for the other terms, for we may say to get or gain a prize, to get or obtain a reward, to get or procure a book; and it is also employed in numberless familiar cases, where the other terms would be less suitable, for, what this word gains in familiarity it loses in dignity: hence we may with propriety talk of a servant's getting some water, or a person getting a book off a shelf or getting meat from the butcher, with number- 
less similar cases in which the other terms could not be employed without losing their dignity. Moreover, get is promiscuously used for whatever comes to the hand, whether good or bad, desirable or not desirable, sought for or not; but gain, obtain, and procure always include either the wishes or the instrumentality of the agent, or both together. Thus a person is said to get a cold or a fever, a good or an ill name, without specifying any of the circumstances of the action; but he is said to gain that approbation which is gratifying to his feelings; to obtain a recompense which is the object of his exertions; to procure a situation which is the end of his endeavors.

The word gain is peculiarly applicable to whatever comes to us fortuitously; what we gain constitutes our good fortune; we gain a victory or we gain a cause; the result in both cases may be independent of our exertions. To obtain and procure exclude the idea of chance, and suppose exertions directed to a specific end: but the former may include the exertions of others, the latter is particularly employed for one's own personal exertions. A person obtains a situation through the recommendation of a friend: he procures a situation by applying for it. Obtain is likewise employed only in that which requires particular efforts, that which is not immediately within our reach; procure is applicable to that which is to be got with ease, by the simple exertion of a walk, or of asking for.

GHASTLY. See Hideous.

GHOST. See VIsIoN.

GHOSTLY. See SpIrItuods.

GIBE. See Scoff.

GIDDINESS. See LightNess.

GIFT, Present, Donation. Gift is derived from Anglo-Saxon gifan, to give (the hard $g$ sound being due to Scandinavian influence), in the sense of what is communicated to another gratuitously of one's property. Present is derived from to present, signifying the thing presented to another. Donation, in French donation, from the Latin donare, to present or give, is a species of gift.

The gift is an act of generosity or condescension; it contributes to the benefit of the receiver: the present is an act of kindness, courtesy, or respect; it contributes to the pleasure of the receiver. The gift passes from the rich to the poor, from the high to the low, and creates an obligation; the present passes either between equals or from the inferior to the superior. Whatever we receive from God, through the bounty of His providence, we entitle a gift; whatever we receive from our friends, or whatever princes receive from their subjects, are entitled presents. We are told by all travellers that it is a custom in the East never to approach a great man without a present; the value of a gift is often heightened by being given opportunely. The value of a present often depends upon the esteem we have for the giver; the smallest present from an estecmed friend is of more worth in our eyes than the costliest presents that monarchs receive.

The gift is private, and benefits the individual: the donation is public, and serves some general purpose: what is given to relieve the necessities of any poor person is a gift; what is given to support an institution is a donation. The clergy are indebted to thcir patrons for the livings which are in their gift: it has been the custom of the pious and charitable in all ages to make donations for the support of almshouses, hospitals, infirmaries, and such institutions as serve to diminish the sum of human misery.

Gift, Endowment, Talent.-Gift (see above). Endowment signifies the thing with which one is endowed. Talent (see ABILITY).

Gift and endowment both refer to the act of giving and endowing, and of course include the idea of something given and something received: the word talent conveys no such collateral idea. When we speak of a gift, we refer in our minds to a giver; when we speak of an endowment, we refer in our minds to the receiver; when we speak of a talent, we only think of its intrinsic quality. A gift is either supernatural or natural; an endowment is only natural. The primitive Christians received various gifts through the inspiration of the Holy Spirit, as the 
gift of tongues, the gift of healing, etc. There are some men who have a peculiar gift of utterance; beauty of person and corporeal agility are endowments with which some are peculiarly invested.

The word gift excludes the idea of anything acquired by exertion; it is that which is communicated to us altogether independently of ourselves, and enables us to arrive at that perfection in any art which could not be attained any other way. Speech is denominated a general gift, inasmuch as it is given to the whole human race in distinction from the brutes; but the gift of eloquence is a peculiar gift granted to a few individuals, in distinction from others, and one which may be exerted for the benefit of mankind. Endowments, though inherent in us, are not independent of our exertions; they are qualities which admit of improvement by being used; they are, in fact, the gifts of nature, which serve to adorn and elevate the possessor when employed for a good purpose. Talents are either natural or acquired, or in some measure of a mixed nature; they denote powers without specifying the source from which they proceed; a man may have a talent for music, for drawing, for mimicry, and the like; but this talent may be the fruit of practice and experience as much as of nature. It is clear from the above that an endowment is a gift, but a gift is not always an endowment; and that a talent may also be either a gift or an endowment, but that it is frequently distinct from both. The terms gift and talent are applicable to corporeal as well as spiritual actions; endowment to corporeal or mental qualities. To write a superior hand is a gift, inasmuch as it is supposed to be unattainable by any force of application and instruction; it is a talent, inasmuch as it is a power or property worth our possession, but it is never an endowment. On the other hand, courage, discernment, a strong imagination, and the like are both gifts and endowments; and when the intellectual endowment displays itself in any creative form, as in the case of poetry, music, or any art, so as to produce that which is valued and esteemed, it becomes a talent to the possessor.
GIRDLE. See ZoNE.

GIRL. See VIRGIN.

GIVE, Grant, Bestow. For the derivation of give see GiFT; grant and bestow (see AlLOW).

The idea of communicating to another what is our own or in our power is common to these terms; this is the whole signification of give; but grant and bestow include accessory ideas in their meaning. To grant is to give at one's pleasure; to bestow is to give from a certain degree of necessity. Giving is confined to no object; whatever property we transfer into the hands of another, that we give; we give money, clothes, food, or whatever is transferable: granting is confined to such objects as afford pleasure or convenience; they may consist of transferable property or not; bestowing is applied to such objects only as are necessary to supply wants, which always consist of that which is transferable. We give what is liked or not liked, asked for or unasked for: we grant that only which is wished for and requested. One may give poison or medicine; one grants a sum of money by way of loan: we give what is wanted or not wanted; we bestow that only which is expressly wanted: we give with an idea of a return or otherwise: we grant voluntarily, without any prospect of a return: we give for a permanency or otherwise; we bestow only in particular cases which require immediate notice.

To give has no respect to the circumstances of the action, or the agent; it is applicable to persons of all conditions: to grant bespeaks not only the will, but the power and influence of the grantor: to bestow bespeaks the necessitous condition of the receiver. Children may give to their parents and parents to their children, kings to their subjects or subjects to their kings; but monarchs only grant to their subjects, or parents to their children; and superiors in general bestow upon their dependents that which they cannot provide for themselves.

In an extended application of the terms to moral objects or circumstances they strictly adhere to the same line of distinction. We give our consent; we give our promise; we give our word; we give credit; we give in all cases 
that which may be simply transferred from one to another. Liberties, rights, privileges, favors, indulgences, permissions, and all things are granted which are in the hands of only a few but are acceptable to many. Blessings, care, concern, and the like, are bestowed upon those who are dependent upon others for whatever they have.

Give and bestow are likewise said of things as well as of persons; grant is said only of persons. Give is here equally general and indefinite; bestow conveys the idea of giving under circumstances of necessity and urgency. One gives a preference to a particular situation; one gives a thought to a subject that is proposed; one gives time and labor to any matter that engages one's attention: but one bestows pains on that which demands particular attention; one bestows a moment's thought on one particular subject out of the number which engage attention.

Give, Afford.-Give and afford are allied to each other in the sense of sending forth; but the former denotes an unqualified and unconditional action, as in the preceding article; the latter bears a relation to the circumstances of the agent. A person is said to give money without any regard to the state of his finances: he is said to afford what he gives, when one wishes to define his pecuniary condition. The same idea runs through the application of these terms to all other cases, in which inanimate things are made the agents. When we say a thing gives satisfaction, we simply designate the action; when we say it affords pleasure, we refer to the nature and properties of the thing thus specified - that is to say, its capacity to give satisfaction; the former is employed only to declare the fact, the latter to characterize the object. Hence, in certain cases, we should say this or that posture of the body gives ease to a sick person; but, as a moral sentiment, we should say nothing affords such ease to the mind as a clear conscience. Upon the same grounds the use of these terms is justified in the following cases: to give rise; to give birth; to give occasion; to afford an opportunity; to afford a plea or a pretext; to afford ground, and the like.
Give, Present, Offer, Exhibit.-These terms have a common signification, inasmuch as they designate the manual act of transferring something from one's self to another. The first is, here as elsewhere, the most indefinite and extensive in its meaning; it denotes the complete act: the latter two refer rather to the preliminaries of giving than to the act itself. What is given is actually transferred: what is presented, that is, made a present to any one, or offered, that is, brought in his way, is put in the way of being transferred: we present in giving, and offer in order to give; but we may give without presenting or offering; and, on the other hand, we may present or offer without giving, if the thing presented or offered be not received.

To give is the familiar term which designates the ordinary transfer of property: to present is a term of re spect; it includes in it the formality and ceremony of setting before another that which we wish to give: to offer is an act of humility or solemnity; it bespeaks the movement of the heart, which impels to the making a transfer or gift. We give to our domestics; we present to princes; we offer to God: we give to a person what we wish to be received; we present to a person what we think agreeable; we offer what we think acceptable; what is given is supposed to be ours; what we offer is supposed to be at our command; what we present need not be either our own or at our command: we give a person not only our external property, but our esteem, our confidence, our company, and the like: an ambassador presents his credentials at court; a subject offers his services to his king.

They bear the same relation to each other when applied to words or actions, instead of property: we speak of giving a person an assurance or a contradiction; of presenting an address and offering an apology: of giving a reception, presenting a figure, or offering an insult. They may likewise be extended in their application, not only to personal and individual actions, but also to such as respect the public at large: we give a description in writing, as well as by word of mouth; one pre- 
sents the public with the fruit of one's labors; we offer remarks on such things as attract notice and call for animadversion.

These terms may also be employed to designate the actions of unconscious agents, by which they are characterized: in this sense they come very near to the word exhibit, which, from exhibeo, signifies to hold or put forth. Here the word give is equally indefinite and general, denoting simply to send from one's self, and applies mostly to what proceeds from another, by a natural cause: thus, a thing is said to give pain or to give pleasure. Things are said to present or offer: thus, a town is said to present a fine view, or an idea presents itself to the mind; an opportunity offers, that is, offers itself to our notice. To exhibit is properly applied in this sense of setting forth to view; but expresses, likewise, the idea of attracting notice also: that which is exhibited is more striking than what is presented or offered, thus a poem is said to exhibit marks of genius.

Give Up, Deliver, Surrender, Yield, Cede, Concede.-We give up that which we wish to retain; we deliver that which we wish not to retain. Deliver does not include the idea of a transfer; but give up implies both the giving from and the giving to: we give up our house to the accommodation of our friends; we deliver property into the hands of the owner. To give up is a colloquial substitute for either surrender or yield, as it designates no circumstance of the action; it may be employed in familiar discourse, in almost every case, for the other terms: where the action is compulsory we may either say an officer gives up or surrenders his sword; when the action is discretionary, we may either say he gives up or yields a point of discussion: give up has, however, an extensiveness of application which gives it an office distinct from either surrender or yield. When we speak of familiar and personal subjects, give up is more suitable than surrender, which is confined to matters of public interest or great moment: a man gives $u p$ his place, his right, his claim, and the like; he surrenders a fortress, a vessel, or his property to his creditors. When give up is com- pared with yield, they both respect personal matters; but the former expresses a much stronger action than the latter: a man gives up his whole judgment to another; he yields to the opinion of another in particular cases: he gives himself up to sensual indulgences; he yields to the force of temptation.

Cede, from the Latin cedere, to come to, to yield, to give, is properly to surrender by virtue of a treaty: we may surrender a town as an act of necessity; but the cession of a country is purely a political transaction: thus, generals frequently surrender such towns as they are not able to defend; and governments cede such countries as they find it not convenient to retain. To concede, which is but a variation of cede, is a mode of yielding which may be either an act of discretion or courtesy; as when a government concedes to the demands of the people certain privileges, or when an individual concedes any point in dispute for the sake of peace.

Give Up, Abandon, Resign, Forego.These terms differ from the preceding ones, inasmuch as they designate actions entirely free from foreign influence. A man gives up, abandons, and resigns from the dictates of his own mind, independently of all control from others. To give up and abandon both denote a positive decision of the mind; but the former may be the act of the understanding or the will; the latter is more commonly the act of the will and the passions: to give up is applied to familiar cases; abandon to matters of importance: one gives up an idea, an intention, a plan, and the like; one abandons a project, a scheme, a measure of government.

To give up and resign are applied either to outward actions or merely to inward movements; but the former is active and determinately fixes the conduct; the latter seems to be rather passive-it is the leaning of the mind to the circumstances: a man gives up his situation by a positive act of his choice; he resigns his office when he feels it inconvenient to hold it; so, likewise, we give up expectations and resign hopes. In this sense, forego, which signifies to let go, is comparable 
with resign, inasmuch as it expresses a passive action; but we resign that which we have, and .we forego that which we might have: thus, we resign the claims which we have already made; we forego the claims which we might make: the former may be a matter of prudence; the latter is always an act of virtue and forbearance.

When applied to the state of a person's mind, or the actions flowing from that state, to give up is used either in a good, bad, or indifferent sense; abandon always in a bad sense; resign always in a good sense: a man may give himself $u p$ either to studious pursuits, to idle vagaries, or vicious indulgences; he abandons himself to gross vices; he resigns himself to the will of Providence, or to the circumstances of his condition: a man is said to be given up to his lusts who is without any principle to control him in their gratification; he is said to be abandoned when his outrageous conduct bespeaks an entire insensibility to every honest principle; he is said to be resigned when he discovers composure and tranquillity in the hour of affliction; so one is said to resign a thing to another when one is contented with what one has.

Glad, Pleased, Joyfol, CheerFoL. Glad comes from Anglo-Saxon gloed, smooth, bright, allied to German glatt, smooth, polished. Pleased, from to please, marks the state of being pleased. Joyful bespeaks its own meaning either as full of joy or productive of great joy, from Latin gaudium, joy. Cheerful (see CheErful).

Glad denotes either a partial state or a permanent and habitual sentiment: in the former sense it is most nearly allied to pleased; in the latter sense, to joyful and merry. Glad and pleased are both applied to the ordinary occurrences of the day; but the former denotes rather a lively and momentary sentiment, the latter a gentle but rather more lasting feeling: we are glad to see a friend who has been long absent; we are glad to have good intelligence from our friends and relatives; we are glad to get rid of a troublesome companion; we are pleased to have the approbation of those we esteem: we are pleased to hear our friends well spoken of; we are pleased with the company of an intelligent and communicative person.

Glad, joyful, and cheerful all express more or less lively sentiments; but glad is less vivid than joyful, and more so than cheerful. Gladness seems to arise as much from physical as mental causes; wine is said to make the heart glad: joy has its source in the mind, as it is influenced by external circumstances; instances of good fortune, for either ourselves, our friends, or our country, excite joy: cheerfulness is an even tenor of the mind, which it may preserve of itself independently of all external circumstances; religious contemplation produces habitual cheerfulness. Glad is seldom employed as an epithet to qualify things, except in the scriptural or solemn style, as glad tidings of great joy: joyfui is seldomer used to qualify persons than things; hence we speak of joyful news, a joyful occurrence, joyful faces, joyful sounds, and the like: cheerful is employed either to designate the state of the mind or the property of the thing; we either speak of a cheerful disposition, a cheerful person, a cheerful society, or a cheerful face, a cheerful sound, a cheerful aspect, and the like.

When used to qualify one's actions they all bespeak the temper of the mind; gladly denotes a high degree of willingness as opposed to aversion: one who is suffering under excruciating pains gladly submits to anything which promises relief: joyfully denotes unqualified pleasure, unmixed with any alloy or restrictive consideration; a convert to Christianity joyfully goes through all the initiatory ceremonies which entitle him to all its privileges, spiritual and temporal; cheerful denotes the absence of unwillingness, it is opposed to reluctantly; the zealous Christian cheerfully submits to every hardship to which he is exposed in the course of his religious profession.

See also JoY.

GLANCE AT, Allude To. Glance is a nasalized form of Old French glacier, to slip, slide; it indicated a sliding beam of light. Allude (see Allude).

These terms are nearly allied in the sense of indirectly referring to any object, either in written or verbal discourse: but glance expresses a cursory 
and latent action; allude, simply an indirect but undisguised action: illnatured satirists are perpetually glancing at the follies and infirmities of individuals; the Scriptures are full of allusions to the manners and customs of the Easterns: he who attempts to write an epitome of universal history must take but a hasty glance at the most important events.

See also GLimpSe; Look.

GLARE. See Flame; Shine.

GLARING, BAREFACED. Glaring is here used in the figurative sense, drawn from its natural signification of broad light, which strikes powerfully upon the senses. Barefaced signifies literally having a bare or uncovered face, which denotes the absence of all disguise or all shame.

Glaring designates the thing; barefaced characterizes the person: a glaring falsehood is that which strikes the observer in an instant to be falsehood; a barefaced lie or falsehood betrays the effrontery of him who utters it. A glaring absurdity will be seen instantly without the aid of reflection; a barefaced piece of impudence characterizes the agent as more than ordinarily lost to all sense of decorum.

GLEaM, Glimmer, Ray, Beam. Gleam comes from Anglo-Saxon glom, from a root signifying brightness, whence glimmer, a frequentative, is also derived. Ray comes from Latin radius, a ray - a beam of light issuing from a centre of light. Beam, Anglo-Saxon beam, from Teutonic root cognate with Greek фav̄oıs, a light, which appears in phosphorus.

Certain portions of light are designated by all these terms, but gleam and glimmer are indefinite; ray and beam are definite. A gleam is properly the commencement of light, or that portion of opening light which interrupts the darkness: a glimmer is an unsteady gleam: ray and beam are portions of light which emanate from some luminous body; the former from all luminous bodies in general, the latter more particularly from the sun: the former is, as its derivation denotes, a row of light issuing in a greater or less degree from any body; the latter is a great row of light, like a pole issuing from a body. There may be a gleam of light visible on the wall of a dark room, or a glimmer if it be movable; there may be rays of light visible at night on the back of a glow-worm, or rays of light may break through the shutters of a closed room; the sun in the height of its splendor sends forth its beams.

GLEAMING. See LAMBENT.

GLEe, Gayety, Joviality, Merriment, Mirth. Glee, Anglo-Saxon gleo, joy, mirth, and music, signifies in ordinary language an expression of joy, gladness, happiness, gratification over some pleasing occurrence. Gayety implies the state of being exuberant or having a superabundance of good-humor, liveliness, cheerfulness, blitheness; joviality, the state of being jolly, convivial, festive, joyous; merriment, the state of being full of fun and goodhumor, sportive, frolicsome, loudly cheerful, gay of heart; and mirth, the state of being playful, festive, vivacious, witty, facetious, fond of merrymaking, and the like.

In another application the term glee implies a musical composition sung in parts as a series of interwoven melodies for three or more voices, each part being limited to one voice; may be composed in any style and rendered with or without instrumentation.

GLIB. See Voluble.

GLIDE. See SLIP.

GLIMMER. See Gleam.

GLIMPSE, Glance. A glimpse is the action of the object appearing to the eye; a glance is the action of the eye seeking the object: one catches a glimpse of an object; one casts a glance at an object: the latter, therefore, is properly the means for obtaining the former, which is the end: we get a glimpse by means of a glance. The glimpse is the hasty, imperfect, and sudden view which we get of an object; the glance is the hasty and imperfect view which we take of an object: the former may depend upon a variety of circumstances; the latter depends upon the will of the agent. We can seldom do more than get a glimpse of objects in a carriage that is going with rapidity: when we do not wish to be observed to look, we take but a glance at an object. GLITTER. See SHINe.

GLOAMING, EvENING, Twilight. Of these three terms evening is the term 
which simply denotes the time of daythe beginning of night. The other two terms add to the denotation of time certain special connotations. Gloaming is a poetic word found in the AngloSaxon compound afen-glommung, literally evening-glow, from Anglo-Saxon glowan, to glow. It indicates the time just after sunset, when there is still a glow of light in the western sky, but when the gloom of night is fast falling. The word gloaming has this double suggestion of both gloom and glow. Twilight signifies literally the time of half light, the space between day and night when light has not entirely given way to darkness. Compare Middle Dutch tweelicht.

GLOBE, Ball. Globe comes from Latin globus, ball. Ball, Teutonic ball, is doubtless connected with the words bowl, boil, and the like, signifying that which is turned or rounded.

Globe is to ball as the species to the genus; a globe is a ball, but every ball is not a globe. The globe does not in its strict sense require to be of an equal rotundity in all its parts; it is properly an irregularly round body: a ball, on the other hand, is generally any round body, but particularly one that is entirely, regularly round; the earth itself is therefore properly denominated a globe from its unequal rotundity: and for the same reason the mechanical body, which is made to represent the earth, is also denominated a globe: but in the higher style of writing the earth is frequently denominated a ball, and in familiar discourse every solid body which assumes a circular form is entitled a ball.

See also Circle.

GLOOM, Heaviness. Gloom has its source internally, and is often independent of outward circumstances; heaviness is a weight upon the spirits produced by a foreign cause: the former belongs to the constitution; the latter is occasional. People of a melancholy habit have a particular gloom hang over their minds which pervades all their thoughts; those who suffer under severe disappointments for the present, and have gloomy prospects for the future, may be expected to be heavy at heart; we may sometimes dispel the gloom of the mind by the force of reflec- tion, particularly by the force of religious contemplation: heaviness of spirits is itself a temporary thing, and may be succeeded by vivacity or lightness of mind when the pressure of the moment has subsided.

Gloomy, Sullen, Morose, Splenetic.All these terms denote a temper of mind the reverse of easy or happy: gloomy lies either in the general constitution or in the particular frame of the mind; sullen lies in the temper: a man of a gloomy disposition is an involuntary agent; it is his misfortune, and renders him in some measure pitiable: the sullen man yields to his evil humors; sullenness is his fault, and renders him offensive. The gloomy man distresses himself most; his pains are all his own: the sullen man has a great share of discontent in his composition; he charges his sufferings upon others, and makes them suffer in common with himself. A man may be rendered gloomy for a time by the influence of particular circumstances; but sullenness creates pains for itself when all external circumstances of a painful nature are wanting.

Sullenness and moroseness are both the inherent properties of the temper; but the former discovers itself in those who have to submit, and the latter in those who have to command: sullenness therefore betrays itself mostly in early life; moroseness is the peculiar characteristic of age. The sullen person has many fancied hardships to endure from the control of others; the morose person causes others to endure many real hardships by keeping them under too severe a control. Sullenness shows itself mostly by an unscemly reserve: moroseness shows itself by the hardness of the speech and the roughness of the voicc. Sullenness is altogether a sluggish principle that leads more or less to inaction; moroseness is a harsh feeling, that is, not contented with exacting obedience unless it inflicts pain.

Moroseness is a defect of the temper; but spleen is a defect in the heart: the one betrays itself in behavior, the other more in conduct. A morose man is an unpleasant companion; a splenetic man is a bad member of society; the former is ill-natured to those about him, the 
latter is ill-humored with all the world. Moroseness vents itself in temporary expressions; spleen indulges itself in perpetual bitterness of expression.

See also Dull; HYPochondriacal; Pessimistic.

GLORY, HoNor. Glory is something dazzling and widely diffused, from Latin gloria. That the moral idea of glory is best represented by light is evident from the glory which is painted round the head of our Saviour. Honor is something less splendid, but more solid. It is derived from Latin honorem (accusative), honor, reputation.

Glory impels to extraordinary efforts and to great undertakings. Honor induces to a discharge of one's duty. Excellence in the attainment and success in the exploit bring glory; a faithful exercise of one's talents reflects honor. Glory is connected with everything which has a peculiar public interest; honor is more properly obtained within a private circle. Glory is not confined to the nation or life of the individual by whom it is sought; it spreads over all the earth and descends to the latest posterity: honor is limited to those who are connected with the subject of it and eye-witnesses to his actions. Glory is attainable but by few, and may be an object of indifference to any one; honor is more or less within the reach of all and must be disregarded by no one. A general at the head of an army goes in pursuit of glory; the humble citizen who acts his part in society so as to obtain the approbation of his fellow-citizens is in the road for honor. A nation acquires glory by the splendor of its victories and its superiority in arts as well as arms; it obtains honor by its strict adherence to equity and good faith in all its dealings with other nations.

Glory is a sentiment selfish in its nature, but salutary or pernicious in its effect, according as it is directed; honor is a principle disinterested in its nature and beneficial in its operations. A thirst for glory is seldom indulged but at the expense of others, as it is not attainable in the plain path of duty; there are but few opportunities of acquiring it by elevated acts of goodness, and still fewer who have the virtue to embrace the opportunities that offer: a love of honor can never be indulged but to the advantage of others; it is restricted by fixed laws; it requires a sacrifice of every selfish consideration and a due regard to the rights of others; it is associated with nothing but virtue.

Glory, Boast, Vaunt.-To glory is to hold as one's glory. To boast is to set forth to one's advantage. To vaunt is to set one's self up before others. The first two terms denote the value which the individual sets upon that which belongs to himself; the last term may be employed in respect to others.

To glory is more particularly the act of the mind, the indulgence of the internal sentiment: to boast denotes rather the expression of the sentiment. To glory is applied only to matters of moment; boast is rather suitable to trifling points: the former is seldom used in a bad sense, the latter still seldomer in a good one. A Christian martyr glories in the cross of Christ; a soldier boasts of his courage and his feats in battle. To vaunt is properly to proclaim praises aloud, and is taken either in an indifferent or bad sense.

GLOSS, Varnish, Palliate. Gloss and varnish are figurative terms, which borrow their signification from the act of making the outer surface of any physical object shine. To gloss comes from a Scandinavian word signifying lustre, from a root meaning to glow; it means to give a glow or brightness to anything by means of friction, as in the case of japan or mahogany: to varnish is to give an artificial gloss by means of applying a foreign substance. Hence, in the figurative use of the terms, to gloss is to put the best face upon anything by various artifices; but to varnish is to do the same thing by means of direct falsehood; to palliate, which likewise signifies to give the best possible outside to a thing (see Extenuate), requires still less artifice than either. One glosses over that which is bad by giving it a soft name, as when a man's vices are glossed over with the name of indiscretion or a man's mistress is termed his friend: one varnishes a bad character by ascribing good motives to his bad actions, by withholding many facts that are to his discredit, and fabricating other cir- 
cumstances in his favor; an unvarnished tale contains nothing but the simple truth; the varnished tale, on the other hand, contains a great mixture of falsehood: to palliate is to diminish the magnitude of an offence by making an excuse in favor of the offender, as when an act of theft is palliated by considering the starving condition of the thief.

GLOSSARY. See DictionaRY.

GLOW. See FIRE.

GLUT. See Satisfy.

Go, Advance, Depart, Proceed, Travel. Go is a widely distributed Teutonic word. It is the generic term - signifying to move in any direction. The other terms indicate particular kinds of going. Advance and proceed mean to go forward (see ADVANCE). Depart, from Latin de, from, and pars, part, a separation, means to go away. Travel means to go about for the sake of pleasure or sightseeing.

GODLIKE, DiviNe,

Heavenly. Godlike bespeaks its own meaning, as like God, or after the manner of God, from the Teutonic word corresponding in meaning to Latin Deus, possibly signifying the being worshipped from a root meaning to worship. Divine, in Latin divinus, from divus or Deus, signifies appertaining to God. Heavenly, or heaven-like, signifies like or appertaining to heaven, Anglo-Saxon heofon.

Godlike is a more expressive but less common term than divine: the former is used only as an epithet of peculiar praise for an individual; divine is generally employed for that which appertains to a superior being, in distinction from that which is human. Benevolence is a godlike property: the Divine image is stamped on the features of man, whence the face is called by Milton "the human face divine." As divine is opposed to human, so is heavenly to earthly; the term Divine Being distinguishes the Creator from all other beings; but a heavenly being denotes the agents or inhabitants of heaven, in distinetion from earthly beings, or the inhabitants of earth. A divine influence is to be sought for only by prayer to the Giver of all good things; but a heavenly temper may be acquired by a steady contemplation of heavenly things and an abstraction from those which are earthly: the Divine will is the foundation of all moral law and obligation; heavenly joys are the fruit of all our labors in this earthly course. These terms are applied to other objects with similar distinetion.

Godly, Righteous.-Godly is a contraction of godlike. Righteous signifies conformable to right or truth.

These epithets are both used in a spiritual sense, and eannot, without an indecorous affectation of religion, be introduced into any other discourse than that which is properly spiritual. Godliness, in the strict sense, is that outward deportment which characterizes a heavenly temper; prayer, reading of the Scriptures, public worship, and every religious act enters into the signification of godliness, which at the same time supposes a temper of mind, not only to delight in, but to profit by such exercises: righteousness, on the other hand, comprehends Christian morality, in distinction from that of the heathen or unbeliever; a righteous man does right, not only because it is right, but because it is agreeable to the will of his Maker and the example of his Redeemer; righteousness is therefore to godliness as the effect to the cause. The godly man goes to the sanctuary and by converse with his Maker assimilates all his affections to the character of that Being whom he worships; when he leaves the sanctuary he proves the efficacy of his godliness by his righteous converse with his fellow-creatures. It is easy, however, for men to mistake the means for the end and to rest content with godliness without righteousness, as too many are apt to do who seem to make their whole duty to consist in an attention to religious observances and in the indulgence of extravagant feelings.

GOLD, Golden. These terms aro both employed as epithets, but gold is the substantive used in composition, and golden, the adjective, in ordinary use. The former is strictly applied to the metal of which the thing is made, as a gold cup or a gold coin; but the latter to whatever appertains to gold, whether properly or figuratively, as the golden lion, the golden crown, the golden age, or a golden harvest.

GOOD, Goopvess. Good is a word 
which, under different forms, runs through all the Northern languages.

Good and goodness are abstract terms, drawn from the same word; the former to denote the thing that is good, the latter the inherent good property of persons or things. All good comes from God, whose goodness toward His creatures is unbounded. The good we do is determined by the tendency of the action; but our goodness in doing it is determined by the motive of our actions. Good is of a twofold nature, physical and moral, and is opposed to evil; goodness is applicable either to the disposition of moral agents or to the qualities of inanimate objects; it is opposed to badness. By the order of Providence the most horrible convulsions are made to bring about good; the goodness or badness of any fruit depends upon its fitness to be enjoyed.

See also Virtuous.

Good, Benefit, Advantage.-Good is an abstract universal term which, in its unlimited sense, comprehends everything that can be conceived of as suited in all its parts to the end proposed. In this sense benefit and advantage are modifications of good; but the term good has likewise a limited application, which brings it to a just point of comparison with the other terms here chosen: the common idea which allies these words to one another is that of good as it respects a particular object. Good is here employed indefinitely; benefit and advantage are specified by some collateral circumstances. Good is done without regard to the person who does it, or him to whom it is done; but benefit has always respect to the relative condition of the giver and receiver, who must be both specified. Hence we say of a charitable man that he does much good, or that he bestows benefits upon this or that individual. In like manner, when speaking of particular communities or society at large, we may say that it is for the good of society or for the good of mankind that every one submits to the sacrifice of some portion of his natural liberty; but it is for the benefit of the poorer orders that the charitably disposed employ their money in charity.

Good is limited to no mode or manner, no condition of the person or the thing; it is applied indiscriminately: benefit is more particularly applicable to the external circumstances of a person, as to his health, his improvement, his pecuniary condition, and the like; it is also confined in its application to persons only: we may counsel another for his good, although we do not counsel him for his benefit; but we labor for the benefit of another when we set apart for him the fruits of our labor: exercise is always attended with some good to all persons; it is of particular benefit to those who are of a lethargic habit: an indiscreet zeal does more harm than good to the cause of religion; a patient cannot expect to derive benefit from a medicine when he counteracts its effects.

A benefit is a positive and direct good, an advantage is an adventitious and indirect good: the benefit serves to supply some want, to remove some evil and afford some sort of relief: an advantage serves to promote some ulterior object. An advantage, therefore, will not be a benefit unless it be turned to a good use. Education may be a benefit to a person if it enable him to procure a competence; a polite education is of advantage to one who associates with the great.

GOOD - NATURE, GOOD - HUMOR. Good-nature and good-humor both imply the disposition to please and be pleased; but the former is hahitual and permanent, the latter is temporary and partial: the former lies in the nature and frame of the mind, the latter in the state of the humors or spirits. A good-natured man recommends himself at all times for his good-nature; a good-humored man recommends himself particularly as a companion: good-nature displays itself by a readiness in doing kind offices; goodhumor is confined mostly to the ease and cheerfulness of one's outward deportment in social converse: goodnature is apt to be guilty of weak compliances; good-humor is apt to be succeeded by fits of peevishness and depression. Good-nature is applicable only to the character of the individual; good-humor may be said of a whole company: it is a mark of good-nature in a man not to disturb the good-humor of the company he is in by resenting 
the affront that is offered him by another.

GOODNESS. See GooD.

GOOD OFFICE. See BENEFTT.

GoOdS, Furviture, Chattels, Movables, Effects. All these terms are applied to such things as belong to an individual: the first term is the most general, both in sense and application; all the rest are species.

Furniture comprehends all household goods; wherefore in regard to an individual, supposing the house to contain all he has, the general is put for the specific term, as when one speaks of a person's moving his goods for his furniture: but in the strict sense goods comprehends more than furniture, including not only that which is adapted for the domestic purposes of a family, but also everything which is of value to a person: the chairs and tables are a part of furniture; papers, books, and money are included among his goods: it is obvious, therefore, that goods, even in its most limited sense, is of wider import than furniture.

Chattels, Old French chatel, comes from Late Latin capitale, capital, meaning property, and is a technical term in law, and therefore not so frequent in ordinary use, but still sufficiently employed to deserve notice. It comprehends that species of goods which is in a special manner separated from one's person and house; a man's cattle, his implements of husbandry, the partial rights which he has in land or buildings, are all comprehended under chattels: hence the propriety of the expression to seize a man's goods and chattels, as denoting the disposable property which he has about his person or at a distance. Movables comprehends all the other terms in the limited application to property, as far as it admits of being removed from one place to the other; it is opposed either to fixtures, when speaking of furniture, or to land as contrasted with goods and chattels.

Effects is a term of nearly as extensive a signification as goods, but not so extensive in its application: whatever a man has that is of any supposed value, or convertible into money, is entitled his goods; whatever a man has that can effect, produce, or bring forth money by sale is entitled his effects; goods, therefore, is applied only to that which a man has at his own disposal; effects more properly to that which is left at the disposal of others. A man makes a sale of his goods on his removal from any place; his ereditors or executors take care of his effects either on his bankruptcy or decease; goods, in this case, is seldom employed but in the limited sense of what is removable, but effects includes everything real as well as personal.

Goods, Possessions, Property. - All these terms are applicable to such things as are the means of enjoyment; but the former term respects the direct quality of producing enjoyment, the latter two have regard to the subject of the enjoyment; we consider goods as they are real or imaginary, adapted or not adapted for the producing of real happiness; those who abound in the goods of this world are not always the happiest; possessions must be regarded as they are lasting or temporary; he who is anxious for earthly possessions forgets that they are but transitory and dependent upon a thousand contingencies: property is to be considered as it is legal or illegal, just or unjust; those who are anxious for great property are not always scrupulous about the means by which it is to be obtained. The purity of a man's Christian character is in danger from an overweening attachment to earthly goods; no wise man will boast the multitude of his possessions when he reflects that if they do not leave him the time is not far distant when he must leave them; the validity of one's claim to property which comes by inheritance is better founded than any other.

GORGEOUS, Brilliant, Dazzling. Gorgeous has a curious derivation. It comes from the Old French gorge, throat (compare the slang phrase "Get my gorge"), and originally meant proud. with reference to the swelling of the throat in pride. Gorge itself comes from Latin gurges, a whirlpool, whence in Late Latin it came to signify the gullet, into which everything disappears as if into a whirlpool. Gorgeous now signifies brightly colored with special reference to splendor and richness 
of effect. Brilliant (for derivation see BrightNess) also means very bright, but it suggests light primarily rather than color, or color in so far as it also has the qualities of light. Dazzling indicates brightness of color or especially of light with special reference to the psychological effect upon the spectator. Dazzle refers to the sudden blurring of the rays of light to the eye when it faces something very bright. A dazzling light is something this side of a blinding light.

GOVERN, Rule, Regulate. Govern is in French gouverner, Latin gu-

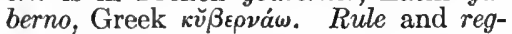
ulate signify to bring under a rule or make by rule.

The exercise of authority enters more or less into the signification of these terms; but to govern implies the exercise likewise of judgment and knowledge. To rule implies rather the unqualified exercise of power, the making the will the rule: a king governs his people by means of wise laws and an upright administration: a despot rules over a nation according to his arbitrary decision; if he have no principle, his rule becomes an oppressive tyranny. These terms are applied either to persons or to things: persons govern or rule others; or they govern, rule or regulate things.

In regard to persons govern is always in a good sense, but rule is sometimes taken in a bad sense; it is frequently associated with an abuse of power: to govern is so perfectly discretionary that we speak of governing ourselves; but we speak only of ruling others: nothing can be more lamentable than to be ruled by one who does not know how to govern himself: it is the business of a man to rule his house by keeping all its members in due subjection to his authority: it is the duty of a person to rule those who are under him in all matters wherein they are incompetent to govern themselves.

In application to things, govern and mule admit of a similar distinction: a minister governs the state and a pilot governs the vessel: the movements of the machine are in both cases directed by the exercise of the judgment; a person rules the times, seasons, fashions, and the like; it is an act of the individual will. Regulate is a species of governing simply by judgment; the word is applicable to things of minor moment, where the force of authority is not so requisite: one governs the affairs of a nation or a large body where great interests are involved; we regulate the concerns of an individual, or we regulate.in cases where good ordes or convenience only is consulted: so likewise in regard to ourselves, we govern our passions, but we regulate our affections.

These terms are all properly used to denote the acts of conscious agents, but by a figure of personification they may be applied to inanimate or moral objects: the price of one market governs the price of another, or governs the seller in his demand; fashion and caprice rule the majority, or particular fashions rule them: the time of one clock regulates that of many others.

Government, Administration. - Both these terms may be employed either to designate the act of governing and administering or the persons governing and administering. In both cases government has a more extensive meaning than administration: the former includes every exercise of authority, while administration implies only that exercise of authority which consists in putting the laws or will of another in force.

When we speak of the government as it respects the persons, it implies the whole body of constituted authorities; and the administration, only that part which puts in execution the intentions of the whole: the government of a country, therefore, may remain unaltered, while the administration undergoes many changes: it is the business of the government to make treaties of peace and war; and without a government it is impossible for any people to negotiate: it is the business of the administration to administer justice, to regulate the finances, and to direct all the complicated concerns of a nation; without an administration all public business would be at a stand.

Government, Constitution. - Government is here, as in the former article, the general term; constitution the specific. Government implies generally the act of governing, or exercising authority under any form whatever; constitution 
implies any constituted or fixed form of government: we may have a government without a constitution; we cannot have a constitution without a government. In the first formation of society, government was placed in the hands of individuals who exercised authority according to discretion rather than any positive rule or law; here then was go'ernment without a constitution: as time and expcrience proved the necessity of some established form, and the wisdom of enlightened men discovered the advantages and disadvantages of different forms, government in every country assumed a more definite shape and became the constitution of the country; hence then the union of government and constitution. Governments are divided by political writers into three classes, monarchical, aristocratic, and republican; but these three general forms have been adopted with such variations and modifications as to impart to the constitution of every country something peculiar. The term constitution is now particularly applied to any popular form of government, or any government formed at the pleasure of the people, and in a still more restricted sense to the government of England.

See also EMPIRE.

GRACE, FAvor. Grace, in French grace, Latin gratia, comes from gratus, kind, because a grace results from pure kindness, independently of the merit of the rcceiver; but favor is that which is granted voluntarily and without hope of recompense, independently of all obligation.

Grace is never used but in regard to those who have offended and made themselves liable to punishment; favor is employed for actual good. An act of grace, in the spiritual sense, is that merciful influence which God exerts over His most unworthy creatures from the infinite goodness of His Divine nature; it is to His special grace that we attribute every good feeling by which we are prevented from committing sin: the term favor is employed indiscriminately with regard to man or his Maker; those who are in power have the greatest opportunity of conferring favors; but all we receive at the hands of our Maker must be acknowledged as a favor.
Grace, Charm.-Grace is altogether corporeal; charm is either corporeal or mental: the grace qualifies the action of the body; the charm is an inherent quality in the body itself. A lady moves, dances, and walks with grace; the charms of her person are equal to those of her mind.

Graceful, Comely, Elegant.-A graceful figure is rendered so by the deportment of the body. A comely figure has that in itself which pleases the eye. Gracefulness results from nature improved by art; comeliness is mostly the work of nature. It is possible to acquire gracefulness by the aid of the dancing-master, but for a comely form we are indebted to nature aided by circumstances. Grace is a quality pleasing to the eye; but elegance, from the Latin $e$, out, and legere, to choose, meaning worthy of being chosen out, is a quality of a higher nature, that inspires admiration; elegant is applicable, like graceful, to the motion of the body, or like comely to the person, and is extended in its meaning also to language, and even to dress. A person's step is graceful; his air or his movements are elegant; the grace of an action lies chiefly in its adaptation to the occasion.

Sec also Becoming.

Gracious, Merciful, Kind.-Gracious, when compared with merciful, is used only in the spiritual sense; the latter is applicable to the conduct of man as well as of the Deity. Grace is exerted in doing good to an object that has merited the contrary; mercy is exerted in withholding the evil which has been merited. God is gracious to His creatures in affording them not only an opportunity to address Him, but every encouragement to lay open their wants to Him; their unworthiness and sinfulness are not made impediments of access to Him. God is merciful to the vilest of sinners, and lends an ear to the smallest breath of repentance; in the moment of cxecuting vengeance $\mathrm{He}$ stops His arm at the voice of supplication: He expects the same mercy to be extended by man toward his offending brother. An act of grace in the largest sense, as not only independent of, but opposite to, the merits of the person, is properly ascribable to 
God alone, but by analogy it has also been considered as the prerogative of earthly princes: thus we speak of acts of grace, by which insolvent debtors are released: in like manner, the grace of the sovereign may be exerted in various ways.

Gracious, when compared with kind, differs principally as to the station of the persons to whom it is applied. Gracious is altogether confined to superiors; kind is indiscriminately employed for superiors and equals: a king gives a gracious reception to the nobles who are presented to him; one friend gives a kind reception to another by whom he is visited. Gracious is a term in peculiar use at court and among princes. Kindness is a domestic virtue; it is found mostly among those who have not so much ceremonial to dispense with.

GRAND. See Great; Noble; SUPERB.

GRANDEUR, MAGNIFICENCE. Grandeur comes from grand, in French grand, great, Latin grandis, great. Magnificence, in Latin magnificentia, from magnus, great, and facere, to make, signifies making or acting on a large scale.

An extensive assemblage of striking qualities in the exterior constitutes the common signification of these terms, of which grandeur is the genus and magnificence the species. Magnificence cannot exist without grandeur, but grandeur exists without magnificence: the former is distinguished from the latter both in degree and in application. When applied to the same objects, they differ in degree, magnificence being the highest degree of grandeur. As it respects the style of living, grandeur is within the reach of subjects; magnificence is mostly confined to princes.

GRANT. See Admit; Allow; Give. GRASP. See NAB.

GRASPING. See GreEdy.

GRATEFUL. See AcCEPTABle.

GRATIFICATION. See ENJOYMENT.

GRATIFY, INDULGE, HuMOR. To gratify, make grateful or pleasant (see ACCEPTABLE), is a positive act of the choice. To indulge (for derivation see Foster) is a negative act of the will, a yielding of the mind to circumstances. One gratifies his desires or appetites and indulges his humors, or indulges in pleasures: by the former, one seeks to get the pleasure which the desire promises; by the latter, one yields to the influences which the humor or passion exercises. Gratifying as a habit becomes a vice, and indulging as a habit is a weakness. In this sense of the words, gratification is mostly applied to mental objects, as to gratify one's curiosity; indulgence, to matters of sense or partial feeling, as to indulge one's palate. A person who is in search of pleasure gratifies his desires as they rise; he lives for the gratification, and depends upon it for his happiness. He who has higher objects in view than the momentary gratification will be careful not to indulge himself too much in such things as will wean him from his purpose.

As occasional acts, gratify and indulge may be both innocent.

We gratify and indulge others as well as ourselves, and mostly in the good sense: to gratify is for the most part in return for services; it is an act of generosity: to indulge is to yield to the wishes or be lenient to the infirmities of others; it is an act of kindness or good-nature. To humor is mostly taken in a bad sense.

See also SATISFY.

GRATITUDE. See ThankfulNESS.

GRATUITOUS, VolUntaRY. Gratuitous is opposed to that which is obligatory. Voluntary is opposed to that which is compulsory or involuntary. A gift is gratuitous when it flows entirely from the free will of the giver, independently of right: an offer is voluntary which flows from the free will independently of all external constraint. Gratuitous is therefore to voluntary as a species to the genus. What is gratuitous is voluntary, although what is voluntary is not always gratuitous. The gratuitous is properly the voluntary in regard to the disposal of one's property; and the voluntary is applicable to all other actions.

Gratuity, Recompense.-The distinction between these terms is very similar to the above. They both imply a gift, and a gift by way of return for some 
supposed service; but the gratuity is independent of all expectation as well as right: the recompense is founded upon some admissible claim. Those who wish to confer a favor in a delicate manner will sometimes do it under the shape of a gratuity: those who overrate their services will in all probability be disappointed in the recompense they receive.

GRAVE, Serious, Solemn. Grave, in Latin gravis, heavy, denotes the weight which keeps the mind or person down and prevents buoyaney; it is opposed to the light. Serious, Latin serius, possibly allied to German schwer, heavy, marks the quality of slowness or considerateness, either in the mind or that which oceupies the mind: it is opposed to the jocose.

Grave expresses more than serious; it does not merely bespeak the absence of mirth, but that heaviness of mind which is displayed in all the movements of the body; seriousness, on the other hand, bespeaks no depression, but simply steadiness of action and a refrainment from all that is jocular. A man may be grave in his walk, in his tone, in his gesture, in his looks, and all his exterior; he is serious only in his general air, his countenance, and demeanor. Gravity is produced by some external eireumstance, seriousness springs from the operation of the mind itself or from eircumstances. Misfortunes or age will produce gravity: seriousness is the fruit of reflection. Gravity is, in the proper sense, confined to the person, as a characteristic of his temper; serious, on the other hand, is a eharacteristie either of persons or of things: hence we should speak of a grave assembly, not a serious assembly, of old men; grave senators, not serious senators; of a grave speaker, not a serious speaker: but a serious, not a grave sermon; a serious, not a grave writer; but grave is sometimes extended to things in the sense of weight, as when we speak of grave matters of deliberation, a grave objection, sentiment. Gravity is peeuliarly ascribed to a judge, from the double cause that much depends upon his deportment, in which there ought to be gravity, and that the weighty coneerns which press on his mind are most apt to produce gravity: on the other hand, both gravity and seriousness may be applied to the preacher; the former only as it respects the manner of delivery; the latter as it respects especially the matter of his diseourse: the person may be grave or serious; the diseourse only is serious.

Solemn expresses more than either grave or serious, from the Latin solennis, yearly; as applied to the stated religious festivals of the Romans, it has acquired the collateral meaning of religious gravity: like serious, it is employed not so much to characterize either the person or the thing: a judge pronounces the solemn sentence of condemnation in a solemn manner; a preacher delivers many solemn warnings to his hearers. Gravity may be the effect of eorporeal habit, and seriousness of mental habit; but solemnity is something oecasional and extraordinary. Some children exhibit a remarkable gravity as soon as they begin to observe; a regular attention to religious worship will induce a habit of seriousness; the admonitions of a parent on his death-bed will have peculiar solemnity.

See also SoBEr.

Grave, Tomb, Sepulchre.-All these terms denote the place where bodies are deposited. Grave, in this sense, comes from Anglo-Saxon grafan, to cut or dig, and signifies something cut or dug out, espeeially the hollow made in the earth. Tomb, Latin tumba, Greek rí $\mu \beta a$, is allied to tumulus, a mound, and tumere, to swell, and has reference to the rising above a grave. Sepulchre, from sepelio, bury, has a reference to the use for which it is employed. From this explanation it is evident that these terms have a certain propriety of application: "To sink into the grave" is an expression that earries the thoughts where the body must rest in death, eonsequently to death itself: "To inseribe on the tomb, or to encirele the tomb with flowers," carries our thoughts to the external of that place in which the body is interred. To inter in a sepulchre, or to visit or enter a sepulchre, reminds us of a place in which bodies are deposited, or, by a figure, where anything may be buried.

GRAVEYARD. See Necropolis. 
GRAVITY. See WeIght.

GREAT, LARGE, BIG. Great, in Anglo-Saxon great, is applied to all kinds of dimensions in which things can grow or increase. Large, in Latin largus, wide, is properly applied to space, extent, and quantity. Big, Middle English big, is probably of Scandinavian origin; it denotes great as to expansion or capacity. A house, a room, a heap, a pile, an army, etc., are great or large; an animal or a mountain is great or big: a road, a city, a street, and the like, are termed rather great than large.

Great is used generally in the improper sense; large and big are used only occasionally: a noise, a distance, a multitude, a number, a power, and the like, are termed great, but not large: we may, however, speak of a large portion, a large share, a large quantity; or of a mind big with conception, or of an event big with the fate of nations.

Great, Grand, Sublime.-These terms are synonymous only in their moral applications. Great simply designates extent; grand includes likewise the idea of excellence and superiority. A great undertaking characterizes only the extent of the undertaking; a grand undertaking bespeaks its superior excellence: great objects are seen with facility; grand objects are viewed with admiration. It is a great point to make a person sensible of his faults; it should be the grand aim of all to aspire after moral and religious improvement.

Grand and sublime are both superior to great; but the former marks the dimensions of greatness; the latter, from the Latin sublimis, designates that of height. A scene may be either grand or sublime: it is grand as it fills the imagination with its immensity; it is sublime as it elevates the imagination beyond the surrounding and less important objects. There is something grand in the sight of a vast army moving forward, as it were, by one impulse; there is something peculiarly sublime in the sight of huge mountains and craggy cliffs of ice shaped into various fantastic forms. Grand may be said of the works of either art or nature; sublime is peculiarly applicable to the works of nature. The Egyptian pyra- mids and the ocean are both grand objects; a tempestuous ocean is a sublime object. Grand is sometimes applied to the mind; sublime is applied both to the thoughts and to the expressions.

GREATEST. See Supreme.

GREATNESS. See Size.

GREEDINESS. See AVIDITY.

GREEDY, Avaricious, Grasping, Rapacious, Selfish: Greedy, in AngloSaxon grodig, from a Teutonic root meaning to be hungry, signifies the state of a person or animal that has a keen appetite for food or drink or an eagerness for anything earnestly desired. The latter implication is the most common one in the relation of the term to persons, and, with the possible exception of being greedy or intensely anxious to obtain useful knowledge, the term greedy indicates a wholly reprehensible quality, though it is to be admitted that many persons are born into that quality or state and in later life fail to escape from it. Such may be more pardonable than those of maturity who knowingly enter that state.

The avaricious person is one who is possessed, nay, controlled, by an inordinate or insatiable desire for gain, without any consideration of the element of need. He wants something because he has none of it now, because his neighbor has it, because he wants to increase the quantity of it that he already possesses, and for all manner of reasons, but decidedly because he wants it.

The grasping person is not only avaricious, that quality giving him a motive, but he is covetous of the possessions of others, desirous of obtaining them, jealous of the possessor because of his possessions, and very apt to reach out, stretch forth, commit some underhand act, or take a mean advantage of another to accomplish his desire. The rapacious person is more of an extremist, for he is addicted to plunderings, forcible seizures, severe exactions, heartless extortions, and preposterous demands for whatever he desires.

The selfish person lives only for one person-himself; is attentive only to his own interests; is influenced in his 
actions by motives of personal advantage only; and, to use a familiar colloquialism, "Wants the whole earth and everything in it." $\mathrm{He}$, too, is jealous of others who have more of this world's goods than himself, covets whatever others have, and is the only person on earth to be considered under all circumstances-in his own estimation.

GREEN, Verdant. Green, in AngloSaxon grene, is allied to grow, and signifies the color of growing things - of grass and herbage. Verdant, Old French verd, green, Latin viridus, green, is the Latin corresponding to Anglo-Saxon green. Green denotes simply the color green. Verdant suggests lusty and flourishing vegetable life. Green makes a clearer impression upon the sensuous imagination; verdant suggests more to the mind. It is a less definite word, but richer in associations. Both terms are applied figuratively to some one who is ignorant or young-green with a definite implied comparison with unripe fruits or vegetable growth; verdant as a humorous substitute for green.

GREET. See Accost.

GREETING. See Salute.

GRIEF. See AFFliction.

GRIEVANCE, HARDSHIP. Grievance, from the Latin gravis, heavy or burdensome, implies that which lies heavy at heart. Hardship, from the adjective hard, denotes that which presses or bears violently on the person.

Grievance is in general taken for that which is done by another to grieve or distress: hardship is a particular kind of grievance that presses upon individuals. There are national grievances, though not national hardships. An infraction of one's rights, an act of violence or oppression, are grievances to those who are exposed to them, whether as individuals or bodies of men: an unequal distribution of labor, a partial indulgence of one to the detriment of another, constitute the hardship. A weight of taxes, levied in order to support an unjust war, will be esteemed a grievance: the partiality and caprice of the collector in making it fall with unequal weight upon particular persons will be regarded as a peculiar hardship. Men seek a redress of their gricvances from some higher power than that by which they are inflicted: they endure their hardships until an opportunity offers of getting them removed.

Grieve, Mourn, Lament.-To grieve (see AFFLICTION) is the general term; mourn, like murmur, being an imitation of the sound produced by pain, is a particular term. To grieve, in its limited sense, is an inward act; to mourn is an outward act: the grief lies altogether in the mind; the mourning displays itself by some outward mark. A man grieves for his sins; he mourns for the loss of his friends. One grieves for that which immediately concerns one's self, or that which concerns others; one mourns for that which concerns others; one grieves over the loss of property; one mourns the fate of a deceased relative.

Grieve, from Old French grever, Latin gravis, is the act of an individual; mourn may be the common act of many: a nation mourns, though it does not grieve, for a public calamity. To grieve is applicable to domestic troubles; mourn may refer to public or private ills. The distractions of a state will cause many to grieve for their own losses and mourn the misfortunes of their country.

Grieve and mourn are permanent sentiments; lament (see BEWAIL) is a transitory feeling: the former are produced by substantial causes, which come home to the feelings; the latter respects things of a more partial, oftentimes of a more remote and indifferent, nature. A real widow mourns all the remainder of her days for the loss of her husband; we lament a thing to-day which we may forget to-morrow. Mourn and lament are both expressed by some outward sign; but the former is composed and free from all noise; the latter displays itself either in cries or simple words. In the moment of trouble, when the distress of the mind is at its height, it may break out into loud lamentation, but commonly grieving and mourning commence when lamentation ceases.

As epithets, grievous, mournful, and lamentable have a similar distinction. What presses hard or unjustly on persons, their property, connections, and circumstances, is gricrous; what touches 
the tender feelings, and tears asunder the ties of kindred and friendship, is mournful; whatever excites a painful sensation in our mind is tamentable. Famine is a grievous calamity for a nation; the violent separation of friends by death is a mournful event at all times, but particularly so for those who are in the prime of life and the fulness of expectation; the ignorance which some persons discover even in the pressent cultivated state of society is truly lamentable.

See also WAIL.

GRIEVED. See SorRY.

GRIM. See Hideous.

GRIPE. Sce Press.

GRISLY. See Hideous.

GROAN, MoAn. Groan, in AngloSaxon granian, may be allied to grin. Groan and moan, however, both have the effect of onomatopoetic words. Groan is a deep sound produced by hard breathing: moan is a plaintive, long-drawn sound produced by the organs of utterance. 'The groan proceeds involuntarily as an expression of severe pain, either of body or of mind: the moan proceeds often from the desire of awakening attention or exciting compassion. Dying groans are uttered in the agonies of death: the moans of a wounded sufferer are sometimes the only resource he has left to make his destitute case known.

GROSS, ConRse. Gross comes from Latin grossus, thick, fat. Coarse (see Conrse).

These terms are synonymous in the moral application. Grossness of habit is opposed to delicacy; coarseness to softness and refinement. A person becomes gross by an unrestrained indulgence of his sensual appetites, particularly in eating and drinking; he is coarse from the want of polish as to either his mind or his manners. A gross sensualist approximates very nearly to the brute; he sets aside all moral considerations; he indulges himself in the open face of day in defiance of all decency: a coarse person approaches nearest to the savage, whose roughness of humor and inclination has not been refined down by habits of restraining his own will and complying with the will of another. A gross expression conveys the idea of that which should be kept from the view of the mind which shocks the moral feeling; a coarse expression conveys the idea of an unseemly sentiment in the mind of the speaker. The representations of the Deity by any sensible image is gross, because it gives us a low and grovelling idea of a superior being; the doing a kindness, and making the receiver at the same time sensible of your superiority and his dependence, indicates great coarseness in the character of the favorer.

Gross, Total.-From the idea of size which enters into the original meaning of gross is derived that of quantity. Total, from the Latin totus, signifies literally the whole: the gross implies that from which nothing has been taken: the total signifies that to which nothing need be added: the gross sum includes everything without regard to what it may be; the total includes everything which one wishes to include; we may, therefore, deduct from the gross that which does not immediately belong to it; but the total is that which admits of no deduction. The gross weight in trade is applicable to any article the whole of which, good or bad, pure or dross, is included in opposition to the net weight; the total amount supposes all to be included which ought to form a part, in opposition to any smaller amount or subdivisions; when employed in the improper sense, they preserve the sam 3 distinction: things are said to be taken or considered in the gross, that is, in the large and comprehensive way, ons with another; things are said to undergo a total change.

GROUND. See Found.

GROUP. See Asszmbly.

GROW. See BE; INCrease.

GRUDGE. See Malice.

Guarantee, Be Security, Be Responsible, Warrant. Guarantee and warrant are both derived from Old High German werent, present participle of weren, to certify to, to warrant; security, from secure (see CerTaIN), has the same original meaning; responsible (see AMENABLE).

To guarantee and be security have respect to what is done for others; to 
be responsible respects what is done by one's self or others; to warrant, what is done by one's self only. To guarantee is applied to matters of public or private interest; to be security, to private matters only. The larger governments frequently guarantee for the performance of stipulations entered into by minor powers; one man becomes security to another for the payment of a sum of money by a third person. Guarantee may be taken for the person or thing that guarantees.

One is security for another in pecuniary concerns, but he is responsible for his own conduct or that of others; he becomes a security by virtue of his contract, as one tradesman becomes security for another-he is responsible by virtue of his relative office or situation; masters are responsible for the conduct of their servants; a jailer is responsible for the safe custody of the prisoner; every man is responsible for that which is placed under his eharge. To warrant is applied to commercial transactions: one warrants the goodness of any commodity that is sold.

The warrant serves to indemnify against loss, or, in a moral sense, to protect against censure, to give a sanction to.

GUARD, Defend, Watch. Guard comes from Anglo-Saxon weardian, to wateh, the $g u$ being due to French influence. Defend (see Apologize and DEFEND). Watch and wake come from Anglo-Saxon wacan, to wake.

To guard, in its largest sense, comprehends both watching and defending, that is, both the preventing the attack and the resisting it when it is made. In the restrieted sense, to guard is properly to keep off an enemy; to defend is to drive him away when he makes the attack. The soldier guards the palace of the king in time of peace, and defends his country in time of war.

Watch, like guard, consists in looking to the danger, but it does not necessarily imply the use of any means to prevent the danger: he who watches may only give an alarm.

In the improper applieation they have a similar sense: modesty guards female honor; clothing defends against the inclemency of the weather: a per- son who wants to escape watches his opportunity to slip out unobserved.

See also FENCE.

Guard, Sentinel.-These terms are used to designate those who are employed for the protection of either persons or things. Guard has been explained above. Sentinel, in French sentinelle, Italian sentinella, a wateh, possibly from Latin sentire, to perceive, signifies a military guard in the time of a campaign; any one may be set as guard over property, who is empowered to keep off every intruder by force; but the sentinel acts in the army as the watch in the police, rather to observe the motions of the enemy than to repel any force.

They are figuratively applied to other objects; the guard in this ease acts on ordinary oceasions, the sentinel in the moments of danger.

Guard, Guardian.-These words are derived from the verb guard; but they have acquired a distinet office. Guard is used either in the literal or figurative sense; guardian only in the improper sense. Guard is applied either to persons or to things; guardian only to persons. In applieation to persons, the guard is temporary; the guardian is fixed and permanent: the guard only guards against external evils; the guardian takes upon him the office of parent, counsellor, and director: when a house is in danger of being attacked, a person may sit up as a guard; when a parent is dead, a guardian supplies his place: we expect from a guard nothing but human assistance; but from our guardian angel we may expect supernatural assistance.

Guard Against, Take Heed. - Both these terms imply express care on the part of the agent; but the former is used with regard to external or internal evils, the latter only with regard to internal or mental evils: in an enemy's country it is essential to be particularly on one's guard, for fear of a surprise; in difficult matters, where we are liable to err, it is of importance to take heed lest we run from one extreme to another: young men, on their entrance into life, cannot be too much on their guard against associating with those who would lead them into expensive pleasures; in slippery paths, 
whether physically or morally understood, it is necessary to take heed how we go.

\section{GUARDIAN. See GUARD.}

GUESS, CONJECTURE, Guess is a Scandinavian word. Conjecture (see that word). Divine, from the Latin divinus and deus, a god, signifies to think and know as a god.

We guess that a thing actually is; we conjecture that which may be; we guess that it is a certain hour; we conjecture as to the meaning of a person's actions. Guessing is opposed to the certain knowledge of a thing; conjecturing is opposed to the full conviction of a thing: a-child guesses at that portion of his lesson which he has not properly learned; a fanciful person employs conjecture where he cannot draw any positive conclusion.

To guess and conjecture are natural acts of the mind: to divine, in its proper sense, is a supernatural act; in this sense the heathens affected to divine that which was known only to an Omniscient Being; and impostors in our time presume to divine in matters that are set above the reach of human comprehension. The term is, however, employed to denote a species of guessing in different matters, as to divine the meaning of a mystery.

GUEST, Visitor, Visitant. Guest is a Seandinavian word from the same root as Latin hostes, signifying a stranger or an enemy; visitor or visitant is the one who pays the visit. The guest is to the visitor as the species to the genus: every guest is a visitor, but every visitor is not a guest; the visitor simply comes to see the person and enjoy social intereourse; but the guest also partakes of hospitality: we are visitors at the tea-table, at the card-table, and round the fire; we are guests at the festive board.

GUIDE, RULE. Guide is to rule as the genus to the speeies: every rule is a guide to a certain extent; but the guide is often that which exeeeds the rule. The guide, in the moral sense, as in the proper sense, goes with us and points out the exact path; it does not permit us to err either to the right or left: the rule marks out a line beyond which we may not go; but it leaves us to trace the line. and eonse- quently to fail either on the one side or on the other. The Bible is our best guid ? for moral practice; its doctrines, as interpreted in the articles of the Christian Church, are the best rule of faith.

See also Chaperon; LeAD; Syluabus.

GUILE. See Deceit.

GUILTLESS, INNOCENT, HARMLESS. Guiltless, without guilt, is more than innocent: innocence, from nocere, to hurt, extends no further than the quality of not hurting by any direct act; guiltless comprehends the quality of not intending to hurt: it is possible, therefore, to be innocent without being guiltless, though not vice versâ; he who wishes for the death of another is not guiltless, though he may be innocent of the crime of murder. Guiltless seems to regard a man's general condition, innocent his particular condition: no man is guiltless in the sight of God, for no man is exempt from the guilt of sin; but he may be innocent in the sight of men, or innocent of all such intentional offences as render him obnoxious to his fellow-creatures. Guiltlessness was that happy state of perfection which men lost at the fall; innocence is that relative or comparative state of perfection which is attainable here on earth: the highest state of innocence is an ignorance of evil.

Guiltless is in the proper sense applicable only to the condition of man, and, when applied to things, it still has a reference to the person: innocent is equally applicable to persons or things; a person is innocent who has not committed any injury or has not any direct purpose to commit any injury; or a conversation is innocent which is free from what is hurtful. Innocent and harmless both recommend themselves as qualities negatively good; they designate a freedom either in the person or in the thing from injuring, and differ only in regard to the nature of the injury: innocence respects moral injury, and harmless physical injury: a person is innocent who is free from moral impurity and wicked purposes; he is harmless if he have not the power or disposition to commit any violence; a diversion is innocent which has nothing in it likely to corrupt the morals; a 
game is harmless which is not likely to inflict any wound or endanger the health.

\section{GUILTY. See Criminal.}

GUISE, HaBIT. Guise is the Freneh form of English wise, both from a Teutonic root, and both signifying the manner. Habit, from the Latin habitus, a habit, fashion, or form, is taken for a settled or permanent mode of dress.

The guise is that which is unusual and often only occasional; the habit is that which is usual among particular classes: a person sometimes assumes the guise of a peasant, in order the better to eonceal himself; he who devotes himself to the clerical profession puts on the habit of a clergyman.

GULF, ABYss. Gulf, French golfe, Italian golfo, comes from Greek kó $\pi_{\pi o s}$, hollow, and is applied literally in the sense of a deep concave receptacle for water, as the gulf of Venice, gulf of

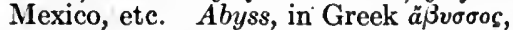
compounded of $\dot{a}$ - and $\beta v \sigma \sigma o s$, a bottom, signifies literally a bottomless pit.

One is overwhelmed in a gulf; it earries with it the idea of liquidity and profundity, into which one inevitably sinks never to rise: one is lost in an abyss; it carries with it the idea of immense profundity, into which he who is cast never reaches a bottom, nor is able to return to the top; an insatiable voracity is the eharacteristic idea in the signification of this term.

A gulf is a capacious bosom, which holds within itself and buries all objects that suffer themselves to sink into it, without allowing them the possibility of escape; hell is represented as a fiery gulf, into which evil spirits are plunged, and remain perpetually overwhelmed: a guilty mind may be said, figuratively, to be plunged into a gulf of woe or despair when filled with the horrid sense of its enormities. An abyss presents nothing but an in- terminable space whieh has neither beginning nor end; he does wisely who dows not venture in, or who retreats before he has plinged too deep to retraee his footsteps; as the ocean, in the natural sense, is a great abyss, so are metaphysics an immense abyss into which the human mind precipitates itself only to be bewildered.

GUMPTION, Acuteness, Cleverness, Discernment, Shrewdness. Gumption is a Scandinavian word. The term is one of colloquial usage, implying, as a substantive, a quickness of perception, the possession of much eommon sense, and, in painting, the art of preparing colors. We say that a person is possessed of gumption who exhibits a quick-acting intellectuality, who pereeives the drift, heart, spirit, of things speedily, whose mental activities evidence sharpness, keenness, acuteness.

Cleverness expresses more than acuteness, for it is that state or quality which enables its possessor to exercise a special skill or ability on certain lines, to be dexterous, expert, handy, adroit, to act expeditiously and efficiently with mind and body, and in intercourse with his fellow-men to be good-natured and obliging. Shrewdness, in a proper sense, implies sagacity, ingenuity, intelligenee, "mother-wit,", and cleverness in practical matters; in an improper sense, craftiness, cunning, slyness, depravity, and iniquity.

Discernment is an act of pereeption, an acuteness or sharpness in judgment, a penetrative ability, and, speeifically, the quality of discrimination, the mental condition of being able to weigh, analyze, segregate, and classify objects so that each may be eonsidered by itself, and the relation of a part to the whole may be elearly determined.

GUSH. See Flow.

GUSTO. See ZEST.

GYROPLANE. See Aircraft. 
Habit. See Custom; Gutse.

haBITATION. See Domicile. HACKNEYED. See Trite.

HAGGARD, GAUNT. These words signify a wasted appearance. Haggard originally was applied to a hawk "that preyed for herself long before she was taken," and meant wild. It was applied to a person with special reference to a wild look in the eyes, but its meaning has been distinctly influenced by the resemblance in form to hag, so that it came to signify hag-like. It differs from gaunt, an East Anglian word meaning lean, in referring primarily to the wasted appearance of the face, especially the hollows under the eyes caused by illness or weariness. Gaunt refers both to the whole face and the whole figure. It means thin, angular, bony, with hollows where rounded flesh would naturally be. Haggard is always an abnormal condition caused by illness or some physical or emotional strain. Gaunt may apply under the same conditions, but it may also indicate the usual or normal appearance of an individual.

HAIL. See Accost.

HALE. See Draw.

Hallow. See Dedicate; SancTIFY.

hallucination, Aberration, Delusion. Hallucination, in French the same form, from the Latin hallucinatio, that from hallucinor, to wander in the mind, signifies, in common language, a perception without a real object to be perceived, an erroneous or insane belief in the reality of things which have no existence. Specifically, the term implies a morbid condition of the mind in which a perception of something occurs where no impression has been made upon the external organs of the special senses, yet where the object is believed to be real and existent. but delusion differs from hallucination in that it originates at the other extremity of the chain of consciousness in the mind itself, and consists of erroneous interpretations of real sensations. Thus we recognize in another an aberration, a departure.from a customary course, a wandering from fact to fancy; a fallacy in a deseptive or false appearance, in an unsound method of reasoning; a phantasm, a vision of something that does not exist, a spectre that appears visible to the victim only. A victim of hallucination imagines that which is wholly erroneous, non-existent, but believes implicitly that it is real.

An aberration, from Latin $a b$, away, and errare, to wander, means a wandering out of the accustomed or normal course, with reference both to thought and to conduct. As applied to the activity of the mind, it differs from hallucination and delusion in emphasizing not the false vision or interpretation, but the abnormal action of the mind itself.

HANDLE. See Wield.

hANDSOME. See Beautiful.

HANKER. See DESIRE.

HAPLESS, ILI-FATED, LUCKLESS. Hapless is a negative of hap, a Scandinavian word signifying good luck, whence happy, happen, etc., are derived. Hapless, accordingly, implies the condition that is contrary to the hap events-hence, misfortune and its attendant vicissitudes.

We say that a person is ill-fated who seems destined to misfortune. This is the strongest of the above group of terms, for it implies the recognition of a condition in which a person may have been born or one into which he has fallen, and from which apparently he cannot extricate himself - a condition to which he was doomed at birth and in which he remains through Luckless, on the contrary, im- 
plies a condition that may be similar to ill-fated, but in the most common usage it suggests not a permanent, but a temporary misfortune, as a venture may be luckless that is without an anticipated advantage; some proceedings out of many may be unfortunate in their results, while the others may turn out according to our desires.

HAPPEN, ChaNce. To happen, that is, to fall out by a hap, is to chance as the genus to the species; whatever chances happens, but not vice versâ. Happen respects all events, without including any collateral idea; chance comprehends likewise the idea of the cause and order of events: whatever comes to pass happens, whether regularly in the course of things or particularly and out of the order; whatever chances happens, altogether without concert, intention, and often without relation to any other thing. Accidents happen daily which no human foresight could prevent; the newspapers contain an account of all that happens in the course of the day or week: listeners and busybodies are ready to catch every word that chances to fall in their hearing.

HAPPINess, Felicity, BlessedNess, Beatitude, Bliss. Happiness signifies the state of being happy. $\mathrm{Fe}$ licity comes from Latin felicitas, happiness. Bliss is in Anglo-Saxon bliths, happiness, literally blitheness, from Anglo-Saxon blithe, English blithe. The original sense of blessedness may have been to consecrate with blood, either by sacrifice or the sprinkling of blood, as the word can be clearly traced back to blood; hence it may have meant to be consecrated, holy; then simply happiness. It retains a religious suggestion still. Beatitude, from the Latin beatus, signifies the property of being happy in a superior degree.

Happiness comprehends that aggregate of pleasurable sensations which we derive from external objects. It is the ordinary term which is employed alike in the colloquial or the philosophical style: felicity is a higher expression, comprehending inward enjoyment, or an aggregate of inward pleasure, without regard to the source whence either is derived: bliss is a still higher term, expressing more than either happiness or felicity, both as to the degree and nature of the enjoyment. Happiness is the thing adapted to our present condition and to the nature of our being, as a compound of body and soul; it is impure in its nature and variable in degree; it is sought for by various means and with great eagerness; but it of ten lies much more within our reach than we are apt to imagine: it is not to be found in the possession of great wealth, of great power, of great dominions, of great splendor, or the unbounded indulgences of any one appetite or desire; but in moderate possessions with a heart tempered by religion and virtue for the enjoyment of that which God has bestowed upon us: it is, therefore, not so unequally distributed as some have been led to conclude.

Happiness admits of degrees, sinee every individual is placed in different eireumstances, either of body or of mind, which fit him to be more or less happy. Felicity is not regarded in the same light; it is that which is positive and independent of all eircumstances: domestic felicity and conjugal felicity are regarded as moral enjoyments, abstracted from everything which ean serve as an alloy. Bliss is that which is purely spiritual; it has its source in the imagination and rises above the ordinary level of human enjoyments: of earthly bliss little is known but in poetry; of heavenly bliss we form but an imperfect conception from the utmost stretch of our powers. Blessedness is a term of spiritual import, which refers to the happy condition of those who enjoy the Divine favor, and are permitted to have a forctaste of heavenly bliss by the exaltation of their minds above earthly happiness. Beatitude denotes the quality of happiness only which is most exalted, namely, heavenly happiness.

See also WeLLmEING.

Happy, Fortunale.-Happy and fortunate are both applied to the external circumstances of a man; but the former conveys the idea of that which is abstractly good, the latter implies rather what is agreeable to one's wishes. A man is happy in his marriage, in his children, in his conneetions, and the like: he is fortunate in his trading con- 
cerns. Happy excludes the idea of chance; forlunate excludes the idea of personal effort: a man is happy in the possession of what he gets; he is fortunate in getting it.

In another sense, they bear a similar analogy. A happy thought, a happy expression, a happy turn, a happy event, and the like, denote a degree of positive excellence; a fortunate idea, a fortunate circumstance, a fortunate cvent, are all rolatively considered with regard to the wishes and views of the individual.

HARANGUE. See AdDrEss.

HARASS. See Distress; Weary; WORRY.

HARBINGER. See ForerunNer.

HARBOR, Haven, Port. The idea of a resting-place for vessels is common to these terms, of which harbor is general and the two others specific in their significance. Harbor is Scandinavian, from Icelandic herbergi, a shelter for an army, compounded of heri, army, German heer, and bergen, to hide; it carries with it little more than the common idea of affording a resting or anchoring place. Haven is also a Scandinavian word possibly allied to Anglo-Saxon heaf, sea. Port, from the Latin porlus, a harbor, allied to porta, a gate, and to English ford, conveys the idea of an enclosurc. A haven is a natural harbor; a port is an artificial harbor. We characterize a harbor as commodious, a haven as snug and secure; a port as safe and easy of access. A commercial country profits by the excellence and number of its harbors; it values itself on the security of its havens, and increases the number of its ports accordingly. A vessel goes into a harbor only for a season; it remains in a haven for a permanency; it seeks a port as the destination of its voyage. Merchantmen are perpetually going in and out of a harbor; a distressed vessel, at a distance from home, seeks some haven in which it may winter; the weary mariner looks to the port, not as the termination of his labor, but as the commencement of all his enjoyments.

Harbor, Shelter, Lodge.-The idea of giving a resting-place is common to these terms; but harbor (see FosTer) is used mostly in a bad sense, shelter (see AsYuUM) in an indefinite sense: lodge, Old French loge, Italian loggia, comes from Old High German loube, an arbor, from loub, a leaf-an arbor being a leafy shelter. Lobby is a doublet of lodge. One harbors that which ought not to find room anywhere; one shelters that which cannot find security elsewhere; one lodges that which wants a resting-place. Thieves, traitors, conspirators, are harbored by those who have an interest in securing them from detection: either the wicked or the unfortunate may be sheltered from the evil with which they are thrcatened: travellers are lodged as occasion may require.

As the word harbor does not, in its original sense, mean anything more than affording a temporary entertainment, it may be taken in a good sense for an act of hospitality.

Harbor and shelter are said of things in the sense of giving a harbor or shelter; lodge in the sense of being a resting-place: furniture harbors vermin, trees shelter from the rain, a ball lodges in the breast; so in the moral sense a man harbors resentment, ill-will, evil thoughts, and the like; he shelters himself from a charge by retorting it upon his adversary; or a particular passion may be lodged in the breast or ideas lodged in the mind.

HARD, FIRM, Solid. The close adherence of the component parts of a body constitutes hardness. The close adherence of different bodies to one another constitutes firmness (see FIXED). That is hard which will not yield to a closer compression; that is firm which will not yield so as to produce a separation. Ice is hard, as far as it respects itself, when it resists every pressure; it is firm, with regard to the water which it covers, when it is so closely bound as to resist every weight without breaking.

Hard and solid respect the internal constitution of bodies and the adherence of the component parts; but hard denotes a much closer degree of adherence than solid: the hard is opposed to the soft; the solid to the fluid; every hard body is by nature solid; although every solid body is not hard. Wood is always a solid body, but it is sometimes hard and sometimes soft; water, when congealed, is a solid body, and admits of different degrees of hardness. 
In another application, hardness is allied to insensibility; firmness to fixedness; solidity to substantiality; a hard man is not to be acted upon by any tender motives; a firm man is not to be turned from his purpose; a solid man holds no purposes that are not well-founded. A man is hardened in that which is bad by being made insensible to that which is good; a man is confirmed in anything good or bad by being rendered less disposed to lay it aside; his mind is consolidated by acquiring fresh motives for action.

Hard, Callous, Hardened, Obdurate.Hard is here, as in the former case, the general term, and the rest particular: hard, in its most extensive physical sense, denotes the property of resisting the action of external force, so as not to undergo any change in its form or separation in its parts: callous is that species of the hard, in application to the skin, which arises from its dryness and the absence of all nervous susceptibility. Hard and callous, from Latin callosus, thick-skinned, are likewise applied in the moral sense: but hard denotes the absence of tender feeling, or the property of resisting any impression which tender objects are apt to produce; callous denotes the property of not yielding to the force of motives to action. A hard heart cannot be moved by the sight of misery, let it be presented in ever so affecting a form: a callous mind is not to be touched by any persuasions, however powerful. Hard does not designate any circumstance of its existence or origin: we may be hard from a variety of causes; but callousness arises from the indulgence of vices, passions, and the pursuit of vicious practices. When we speak of a person as hard, it simply determines what he is: if we speak of him as callous, it refers also to what he was, and from what he is become so.

Callous, hardened, and obdurate are all employed to designate a morally depraved character; but callousness belongs properly to the heart and conscience; hardened, to both the heart and the understanding; obdurate, more particularly to the will. Callousness is the first stage of hardness in moral depravity; it may exist in the infant mind, on its first tasting the poisonous pleasures of vice, without being acquainted with its remote consequences. A hardened state is the work of time; it arises from a continued course of vice, which becomes, as it were, habitual, and wholly unfits a person for admitting any other impressions; $a b$ duracy is the last stage of moral hardness, which supposes the whole mind to be obstinately bent on vice. A child discovers himself to be callous when the entreaties, threats, or punishments of a parent cannot awaken in him a single sentiment of contrition; a youth discovers himself to be hardened when he begins to take a pride and a pleasure in a vicious career; a man shows himself to be obdurate when he betrays a settled and confirmed purpose to pursue his abandoned course without regard to consequences.

Hard, Hardy, Insensible, Unfeeling. - Hard may be applied to either that which makes resistance to external impressions or that which presses with a force upon other objects. Hardy, which is only a variation of hard, is applicable only in the first case: thus, a person's skin may be hard which is not easily acted upon; but the person is said to be hardy who can withstand the elements: on the other hand, hard, when employed as an active principle, is only applied to the moral character; hence the difference between a hardy man who endures everything and a hard man who makes others endure.

Insensible and unfeeling are but modes of the hard; that is, they designate the negative quality of hardness, or its incapacity to receive impression: hard, therefore, is always the strongest term of the three; and of the two others unfeeling is stronger than insensible. Hard and insensible are applied physically and morally; unfeeling is employed only as a moral characteristic. A horse's mouth is hard when it is insensible to the action of the bit; a man's heart is hard which is insensible to the miseries of others; a man is unfeeling who does not regard the feelings of others. The heart may be hard by nature, or rendered so by the influence of some passion; but a person is commonly unfeeling from circumstances. Shylock is depicted by Shakespeare as hard, from his strong 
antipathy to the Christians: people who enjoy an uninterrupted state of good health are often unfeeling in cases of sickness. As that which is hard mostly hurts or pains when it comes in contact with the soft, the term hard is peculiarly applicable to superiors or such as have power to inflict pain: a creditor may be hard toward a debtor. As insensible signifies a want of sense, it may be sometimes necessary: a surgeon, when performing an operation, must be insensible to the present pain which he inflicts. As unfeeling signifies a want of feeling, it is always taken for a want of good feeling: where the removal of pain is required, the surgeon shows himself to be unfeeling who does not do everything in his power to lessen the pain of the sufferer.

Hard, Difficult, Arduous.-Hard is here taken in the sense of causing trouble and requiring pains, in which sense it is a much stronger term than difficult, which, from the Latin difficilis, compounded of the privative dis and facilis, signifies merely not easy. Hard is therefore positive, and difficult negative. A difficult task cannot be got through with without exertion, but a hard task requires great exertion. Difficult is applicable to all trivial matters which call for a more than usual portion either of labor or thought; hard is applicable to those which are of the highest importance and accompanied with circumstances that call for the utmost stretch of every power. It is a difficull matter to get admittance into some circles of society that are select: it is difficult to decide between two fine paintings which is the finer; it is a hard matter to come to any conclusion on metaphysical subjects. A child mostly finds it difficult to learn his letters; there are many passages in classical writers which are hard to be understood by the learned.

Arduous, from the Latin arduus, lofty, signifying set at a distance or out of reach, expresses more than either hard or difficult. What is difflcult may be conquered by labor and perseverance without any particular degree of talent; but what is arduous cannot be effected without great mental powers and accomplishments. What is difficult is so in various degrees, according to circumstances; that which is difficult to one person may be less so to another; but that which is arduous is difficult in a high degree, and positively difficult under every circumstance.

See also Hercolean.

Hard-hearted, Cruel, Unmerciful, Merciless.-Hard-hearted signifies having a hard heart, or a heart not to be moved by the pains of others. Cruel, in Latin crudelis, allied to crudus, raw flesh, and cruor, blood, that is, delighting in blood like beasts of prey, signifies ready to inflict pain: as a temper of mind, therefore, cruel expresses much more than hard-hearted; the latter denotes the want of that scnsibility toward others which ought to be the property of every human heart; the former, the positive inclination to inflict pain and the pleasure from so doing. Hard-hearted is employed as an epithet of the person; cruel, as an epithet to things as well as persons; as a cruel man, a cruel action. Hard-hearted respec.s solely the moral affections; cruelty, in its proper sense, respects the infliction of corporeal pains, but is extended in its application to whatever creates moral pains: a person may be cruel, too, in his treatment of children or brutes by beating or starving them; or he may be cruel toward those who look up to him for kindness.

The unmerciful and merciless are both modes of characteristics of the hardhearted. An unmerciful man is hardhearted, inasmuch as he is unwilling to extend his compassion or mercy to one who is in his power; a merciless man, which is more than an unmerciful man, is hard-hearted, inasmuch as he is restrained by no compunctious feelings from inflicting pain on those who are in his power. Avarice makes a man hardhearted even to twose who are bound to him by the closest ties; it makes him unmerciful to those who are in his debt. There are many merciless tyrants in domestic life, who show their dispositions by their merciless treatment of their poor brutes.

Hardly, Scarcely. - What is hard is not common, and in that respect scarce: hence the idea of unfrequency assimi- 
lates those terms both in signification and application. In many cases they may be used indifferently; but where the idea of practicability predominates hardly seems most proper; and where the idea of frequency predominates scarcely seems preferable. One can hardly judge of a person's features by a single and partial glance; we scarcely ever see men lay aside their vices from a thorough conviction of their enormity: but it may with equal propriety be said in general sentences, hardly one in a thousand, or scarcely one in a thousand, would form such a conclusion.

HARDIHOOD. See AUDACITY.

HARDINESS. See AUDACITY.

HARDSHIP. See GRIEVANCE.

HARLEQUIN. See ZANY.

HARM. See Evil; InJURY; Scathe.

HARMLESS. See GUIltLess.

HARMONIOUS. See EUPHONIOUS.

HARMONY. See CoNCORD; MEL ODY:

HARSH, Rodgh, Severe, Rigorous. Harsh (see Acrimony) and rough (see ABRUPT) borrow their moral signification from the physical properties of the bodies to which they belong. The harsh and the rough both act painfully upon the taste, but the former with much more violence than the latter. An excess of the sour mingled with other unpleasant properties constitutes harshness: an excess of astringency constitutes roughness. Cheese is said to be harsh when it is dry and biting: roughness is the peculiar quality of the damascene. From this physical distinction between these terms we discover the ground of their moral application. Harshness in a person's conduct acts upon the feelings and does violence to the affections: roughness acts only externally on the senses: we may be rough in the tone of the voice, in the mode of address, or in the manner of handling or touching an object; but we are harsh in the sentiment we convey and according to the persons to whom it is conveyed: a stranger may be rough when he has it in his power to be so: only a friend or one in the tenderest relation can be harsh.

Severe (see AUstere). Rigorous, from the Latin rigor and rigere, to stiffen, designates unbending, inflexible. These terms mark different modes of treating those that are in one's power, all of which are the reverse of the kind. Harsh and rough are epithets of that which is unamiable: they indicate the harshness and roughness of the humor: severity and rigor are not always to be condemned; they spring from principle, and are often resorted to by necessity. Harshness is always mingled with anger and personal feeling: severity and rigor characterize things more than the temper of persons. A harsh master renders every burden which he imposes doubly severe by the grating manner in which he communicates his will: a severe master simply imposes the burden in a manner to enforce obedience. The one seems to indulge himself in inflicting pain: the other seems to act from a motive that is independent of the pain inflicted. A harsh man is therefore always severe, but with injustice: a severe man, however, is not always harsh. Rigor is a high degree of severity. One is severe in the punishment of offences: one is rigorous in exacting compliance and obedience. Severity is always more or less necessary in the army, or in a school, for the preservation of good order: rigor is essential in dealing with the stubborn will and unruly passions of men.

\section{HARSHNESS. See ACRIMONY.}

HASTEN, ACCElerate, SPEed, ExPEDITE, DFspatch. Hasten comes from Anglo-Saxon hast, Modern English haste, meaning originally violence. Old French haste is from the same Teutonic root. Accelerate, from celer, quick, signifies literally to quicken for a specific purpose. Speed, from AngloSaxon spowan, to succeed, meant originally to increase, to become prosperous -whence the phrase, speed the parting guest. Expedite (see Diligent). Despatch comes from Spanish despachar, from Latin dis, away, and a root found in the past participle pactus, from pangere, to fix.

Quickness in movement and action is the common idea of all these terms, which vary in the nature of the movement and the action. To hasten expresses little more than the general idea of quickness in moving toward a 
point; thus, he hastens who runs to get to the end of his journey: accelerate expresses, moreover, the idea of bringing something to a point; thus, every mechanical business is accelerated by the order and distribution of its several parts. It may be employed, like the word hasten, for corporeal and familiar actions: a tailor accelerates any particular work that he has in hand by putting on additional hands; or a compositor accelerates the printing of a work by doing his part with correctness. The word speed includes not only quick, but forward movement. He who goes with speed goes effectually forward, and comes to his journey's end the sooner. This idea is excluded from the term haste, which may often be a planless, unsuitable quickness. Hence the proverb, "The more haste the worse speed."

Expedite and despatch are terms of higher import, in application to the most serious concerns in life; but to expedite expresses a process, a bringing forward toward an end: despatch implies a putting an end to, a making a clearance. We do everything in our power to expedite a business: we despatch a great deal of business within a given time. Expedition is requisite for one who executes; despatch is most important for one who determines and directs. An inferior officer must proceed with expedition to fulfil the orders or execute the purposes of his commander; a general or minister of state despatches the concerns of planning, directing, and instructing. Hence it is we speak only of expediting a thing; but we may speak of despatching a person as well as a thing.

Hasten, Hurry.-Hasten (see above). Hurry is a word of imitative origin, indicating the sound of swift movement.

To hasten and hurry both imply to move forward with quickness in any matter; but the former may proceed with some design and good order, but the latter always supposes perturbation and irregularity. We hasten in the communication of good news when we make efforts to convey it in the shortest time possible; we hurry to get to an end when we impatiently and inconsiderately press forward without making choice of our means. To hasten is opposed to delay, or a dilatory mode of proceeding; it is frequently indispensable to hasten in the affairs of human life: to hurry is opposed to deliberate and cautious proceeding: it must always be prejudicial, and unwise to hurry; men may hasten; children hurry.

As epithets, hasty and hurried are both employed in another sense; but hasty implies merely an overquickness of motion which outstrips consideration; hurried implies a disorderly motion which springs from a distempered state of mind. Irritable people use hasty expressions; they speak before they think: deranged people walk with hurried steps; they follow the blind impulse of undirected feeling.

HASTINESS. Sce RASHNESS.

HASTY. See ANgrY; Cursory; SUDDEN.

HATE, DETEST. The alliance between these terms in signification is sufficiently illustrated in the articles referred to. Their difference consists more in sense than application. To hate (see ANTIPATHY) is a personal feeling directed toward the object independently of its qualities; to detest (see ABHOR) is a feeling independent of the person, and altogether dependent upon the nature of the thing. What one hates one hates commonly on one's own account; what one detests one detests on account of the object: hence it is that one hates, but not detests, the person who has done an injury to one's self; and that one detests, rather than hates, the person who has done injuries to others. Joseph's brethren hated him because he was more beloved than they; we detest a traitor to his country because of the enormity of his offence.

In this connection to hate is always a bad passion: to detest always laudable; but, when both are applied to inanimate objects, to hate is bad or good, according to circumstances; to detest always retains its good meaning. When men hate things because they interfere with their indulgences, as the wicked hate the light, it is a bad personal feeling, as in the former case, but when good men are said to hate that which is bad it is a laudable feeling, justified by the nature of the object. As this feeling is, however, so 
closely allied to detest, it is necessary further to observe that hate, whether rightly or wrongly applied, seeks the injury or destruction of the object: but detest is confined simply to the shunning of the object, or thinking of it with very great pain. God hates sin, and on that account punishes sinners; conscientious men detest all fraud, and therefore cautiously avoid being concerned in it.

Hateful, Odious.-Hateful signifies, literally, full of that which is apt to excite hatred. Odious, from the Latin odi, I hate, has the same sense originully.

These epithets are employed in regard to such objects as produce strong aversion in the mind; but when em'ployed, as they commonly are, upon familiar subjects, they indicate an unbecoming vehemence in the speaker. Hateful is properly applied to whatever violates general principles of morality; lying and swearing are hateful vices; odious is more commonly applied to such things as affect the interests of others and bring odium upon the individual; a tax that bears particularly hard and unequally is termed odious, or a measure of government that is oppressive is denominated odious.

Hatred, Enmity, Ill-will, Rancor.These terms agree in this particular, that those who are under the influence of such feelings derive a pleasure from the misfortune of others; but hatred (see Aversion) expresses more than enmity (sce ENEMY), and this more than ill-will, which signifies either an evil will or a willing of evil. Hatred is not contented with merely wishing ill to others, but derives its whole happiness from their misery or destruction; enmity, on the contrary, is limited in its operations to particular circumstances: hatred, on the other hand, is frequently confined to the feeling of the individual; but enmity consists as much in the action as in the feeling. He who is possessed with hatred is happy when the object of his passion is miserable, and is miserable when he is happy; but the hater is not always instrumental in causing his misery or destroying his happiness: he who is inflamed with enmity is more active in disturbing the peace of his enemy, but oftener displays his temper in trifling than in important matters. IIl-will, as the word denotes, lies only in the mind, and is so indefinite in its signification that it admits of every conceivable degree. When the will is evilly directed toward another in ever so small a degree it constitutes ill-icill. Rancor comes from Latin rancius, evil smelling.

HAUGHTINESS, Disdain, ArroGaNce. Haughtiness denotes the abstract quality of haughty, which comes from Old French haut, originally halt, from altus, high. It meant originally "high and mighty." Disdain (see Contemin). Arrogance (see that word).

Haughtiness is founded on the high opinion we entertain of ourselves; disdain, on the low opinion we have of others; arrogance is the result of both, but, if anything, more of the former than the latter. Haughtiness and disdain are properly sentiments of the mind, and arrogance a mode of acting resulting from a state of mind: there may therefore be haughtiness and disdain which have not betrayed themselves by any visible action; but arrogance is always accompanied with its corresponding action: the haughty man is known by the air of superiority which he assumes; the disdainful man, by the contempt which he shows to others; the arrogant man, by his lofty pretensions. Haughtiness and arrogance are both vicious; they are built upon a false idea of ourselves; but disdain may be justifiable when provoked by what is infamous: a lady must treat with disdain the person who insults her honor.

See also Pride.

Haughty, High, High-minded.Haughty and high, derived from the same source as haughty, characterize both the external behavior and the internal sentiment; high-minded marks the sentiment only, or the state of the mind. With regard to the outward behavior, haughty is a stronger term than high; a haughty carriage bespeaks not only a high opinion of one's self, but a strong mixture of contempt for others: a high carriage denotes simply a high opinion of one's self: haughtiness is therefore always offensive, as it is burdensome to others; 
but height may sometimes be laudable, inasmuch as it is justice to one's self: one can never give a command in a haughty tone without making others feel their inferiority in a painful degree; we may sometimes assume a high tone in order to shelter ourselves from insult.

With regard to the sentiment of the mind, haughty, whether it shows itself in the outward behavior or rests in the mind, is always bad; height as an habitual temper, and still more high-mindedness, which more strongly marks the personal quality, are expressly inconsistent with Christian humility; but a man may with reason be too high or too high-minded to condescend to a mean action.

HAUL. See Draw.

HAUNT. See Frequent.

HAVE, Possess. Have comes from Anglo-Saxon habban, a widely distributed Teutonic word. Possess, in Latin possessus, participle of possideo, compounded of Latin pot, as in potes, able, and sedere, to sit, means to remain master, to be able to keep.

Have is the general, possess is the particular term: have designates no circumstance of the action; possess expresses a particular species of having. To have is sometimes to have in one's hand or within one's reach; but to possess is to have as one's own; a clerk has the money which he has fetched for his employer; the latter possesses the money, which he has the power of turning to his use. To have is sometimes to have the right to, to belong; to possess is to have by one and at one's command: a debtor has the property which he has surrendered to his creditor; but he cannot be said to possess it, because he has it not within his reach and at his disposal: we are not necessarily masters of that which we have; although we always are of that which we possess: to have is sometimes only temporary; to possess is mostly permanent: we have money which we are perpetually disposing of: we possess lands which we keep for a permanency: a person has the good graces of those whom he pleases; he possesses the confidence of those who put everything in his power.

HAZARD, Risk, Venture, Jeop-
ARD. All these terms denote actions performed under an uncertainty of the event: but hazard (see CHANCE) bespeaks a want of design and choice on the part of the agent; to risk (see DANGER) implies a choice of alternatives; to venture, which is the same as adventure (see EVENT), signifies a calculation and balance of probabilities: one hazards and risks under the fear of an evil; one ventures with the hope of a good. He who hazards an opinion or an assertion does it from presumptuous feelings and upon slight grounds; chances are rather against him than for him that it may prove erroneous: he who risks a battle does it often from necessity; he chooses the least of two evils; although the event is dubious, yet he fears less from a failure than from inaction: he who ventures on a mercantile speculation does it from a love of gain; he flatters himself with a favorable event, and acquires boldness from the prospect. $\mathrm{He}$ who jeopards a cause (from Old French jeu, Latin iocus, a game, and partitus, parted, meaning a divided game, one in which the outcome is dubious) threatens its downfall or disaster. Jeopard means to hazard, with a presumption, however, in favor of an unfortunate outcome. There are but very few circumstances to justify us in hazarding; there may be several occasions which render it necessary to risk, and very many cases in which it may be advantageous to venture.

\section{HEAD. See Chief; Topic.}

headstrong. See Obstinate.

HEADY. See Obstinate.

HEAL. See CURE.

HEALING. See Sanitary.

HeALTHY, Wholesome, Salubrious, Salutary. Healthy signifies not only having health, but also causing health. Wholcsome, like the German heilsarn, signifies making whole, keeping whole or sound. Salubrious and salutary, from the Latin salus, safety or health, signify likewise contributive to health or good in general.

These epithets are all applicable to such objects as have a kindly influence on the bodily constitution: healthy is the most general and indefinite; it is applied to exercise, to air, situation, 
climate, and most other things but food, for which wholesome is commonly substituted: the life of a farmer is reckoned the most healthy; and the simplest diet is the most wholesome. Healthy and wholesome are rather negative in their sense; salubrious and salutary are positive, that is, healthy and wholesome which does no injury to the health; that is salubrious which serves to improve the health; and that is salutary which serves to remove a disorder: climates are healthy or unhealthy, according to the constitution of the person; water is a wholesome beverage for those who are not dropsical; bread is a wholesome diet for man; the air and climate of southern France have been long famed for their salubrity, and have induced many invalids to repair thither for the benefit of their health; the effects have not bcen equally salutary in all cases

Wholesome and salutary have likewise an extended and moral application; healthy and salubrious are employed only in the proper sense: wholesome in this case seems to convey the idea of making whole again what has been unsound; but salutary retains the idea of improving the condition of those who stand in need of improvement: correction is wholesome which serves the purpose of amendment without doing any injury to the body; instruction or admonition is salutary when it serves the purpose of strengthening good principles and awakening a sense of guilt or impropriety: laws and punishments are wholesome to the body politic, as dict is to the physical body; restrictions are salutary in checking irregularities.

See also Sound.

heap, Pile, Accumulate, Amass. To heap signifies to form into a heap, from Anglo-Saxon heap, a crowd, a pile. To pile is to form into a pile, from Latin pila, originally a pillar, a pier of stone. To accumulate, from the Latin cumulus, a, heap, signifies to put heap upon heap. Amass comes from French $\grave{a}$ masse, Latin ad massa, literally in a mass, meaning to gather to one's self in a mass.

To heap is an indefinite action; it may be performed with or without order: to pile is a definite action done with design and order; thus we heap stones, or pile wood: to heap may be to make into large or small heaps: to pile is always to make something considerable in height: children may heap sticks together; men pile loads of wood together.

To pile is used always, to heap mostly, in t's: physical, accumulate and amass in the physical or moral acceptation. To accumulate is properly to bring or add heap to heap, which is a gradual and unfinished act; to amass is to form into a mass, which is a single complete act; a man may accumulate guineas or anything else in small quantities, but he properly amasses wealth, and in a figurative sense he amasses knowledge. To accumulate and to amass are not always the acts of conscious agents: things may accumulate or amass; water or snow accumulates by the continual accession of fresh quantities; ice amasses in rivers until they are frozen over: so in the moral acceptation, evils, abuses, and the like, accumulate: corruption amasses.

HEaR, Hearken, Overhear. To hear is properly the act of the ear; it is sometimes totally abstracted from the mind, when we hear and do not understand: to hearken is an act of the ear and the mind in conjunction; it implies an effort to hear, a tendency of the ear: to overhear is to hear clandestinely, or unknown to the person who is heard, whether designedly or not. We hear sounds: we hearken for the sense; we overhear the words: a quick ear hears the smallest sound; a willing mind hearkens to what is said; a prying curiosity leads to overhearing. HEARSAY. See FAME.

hEARTEN, Animate, Cheer, Comfort, Encourage. Hearten is a compound of the English heart and the suffix en. Heart, in Anglo-Saxon heorte, allied to Latin wr, implies the vital, inner, or chief part of anything, in persons the seat of the faculties. To hearten another is to bestow upon him an influence directly from the heart; figuratively a spoken word or a voluntary act, when the person is disheartened, that is, timcly, sincere, and thoroughly meant.

To animate either a person, animal, or drooping plant is to impart new 
life to the subject by an infusion that goes directly to the heart; to inspire a person with energy, courage, ardor, to stimulate: to cheer, to comfort, console, invigorate, brace up, produce a joyous, hopeful state of mind: to comfort, to give consolation in time of affliction, sickness, or trouble, support, assistance, relief in time of misfortune or danger: and to encourage, to incite to renewed effort, to urge forward, to give confidence to another, also to promote, help forward, advance.

While there is an apparent similarity in the import of all these terms, there are variant shades of meaning connected with each, which are critically considered in the articles on ANIMATE, Cheer, and Encourage.

HEARTINESS. See ZeAL. ILESS, UNFEeLiNG. Heartless (for derivation see HEARTEN) means literally without heart, and is applied to a variety of conditions that exhibit the worst features of human life, with nothing in extenuation. Of the terms here mentioned brutal and pitiless are the severest. Brutal is associated with the actions of a savage, an irresponsible, conscienceless creature, scarcely a whit better than a wild animal, whose attacks are liable to occur at any moment and to be repeated indefinitely, if death does not ensue from the first.

A person who is naturally brutal or who becomes so by evil influences is capable of deeds of violence and inhumanity with and without provocation. The cruel person may in his conduct reach the state of brutality, for he is disposed to injure or take pleasure in the injury of others, but his acts are generally studied ones, thought out in advance, showing a disposition or a growing gratification to injure others, while the brutal one is more apt to act on a momentary impulse.

Pitiless, however, implies a combination of whatever is brutal and cruel, for those whom these terms designate are destitute of compassion, are merciless, insistent in inflicting injury upon others, deaf to appeals for consideration, pity, and even life itself, unmoved by any sentiment or sympathy, and absolutely unfeeling toward their victims.
A further discussion of the general conditions which the above terms imply will be found in the article on Cruel.

HEARTY, Warm, Sincere, CorDIAL. Hearty, $i$. e., having the heart in a thing, and warm (see FIRE) express a stronger feeling than sincere (see CANDID); cordial, from cor, the heart, $i$. e., according to the heart, is a mixture of the warm and sincere. There are cases in which it may be peculiarly proper to be hearty, as when we are supporting the cause of religion and virtue; there are other cases in which it is peculiarly proper to be warm, as when our affections ought to be roused in favor of our friends; in all cases we ought to be sincere when we express either a sentiment or a feeling; it is peculiarly happy to be on terms of cordial regard with those who stand in any close relation to us. The man himself should be hearty; his heart should be warm; professions should be sincere; a reception cordial.

HEAT. See Fire.

HEATHEN. See Gentile.

HEAVE, Swell. Heave is used either transitively or intransitively, as a reflective or a neuter verb; swell is used only as a neuter verb. Heave implies raising, and swell implies distension: they differ, therefore, very widely in sense, but they sometimes agree in application. The bosom is said both to heave and to swell, because it happens that the bosom swells by heaving; the waves are likewise said to heave themselves or to swell, in which there is a similar correspondence between the actions: otherwise most things which heave do not swell, and those which swell do not heave.

HEAVEnly. See Celestial; GodLIKE.

HEAVINESS. See Gloom; Weight. HEAVY, Dulu, Drowsy. Heavy is allied to both dull and drowsy, but the latter have no close connection with each other.

Heavy and dull are employed as epithets both for persons and for things; heavy characterizes the corporeal state of a person; dull qualifies the spirits or the understanding of the subject. A person has a heavy look whose temperament seems composed of gross and 
weighty materials which weigh him down and impede his movements; he has a dull countenance in whom the ordinary brightness and vivacity of the mind is wanting.

Heavy and drowsy are both employed in the sense of sleepy; but the former is only a particular state, the latter particular or general; all persons may be occasionally heavy or drowsy; some are habitually drowsy from disease: they likewise differ in degree, the latter being much the greater of the two; and occasionally they are applied to such things as produce sleepiness.

Heavy, Burdensome, Weighty, Ponderous.-Heavy, from heave, signifies the causing to heave, or requiring to be lifted up with force; burdensome signifies having a burden; weighty, having a weight; and ponderous, from the Latin pondus, a weight, has the same original meaning.

Heavy is the natural property of some bodies; burdensome is incidental to some. In the vulgar sense things are termed heavy which are found difficult to lift, in distinction from those which are light or easy to be lifted; but those things are burdensome which are too troublesome to be carried or borne: many things, therefore, are actually heavy that are never burdensome; and others are occasionally burdensome that are never heavy: that which is heavy is so whether lifted or not; but that which is burdensome must be burdensome to some one carrying it: hard substances are mostly heavy; but to a weak person the softest substance may sometimes be burdensome if he is obliged to bear it; things are heavy according to the difficulty with which they are lifted; but they are weighty according as they weigh other things down. The heavy is therefore indefinite; but the weighty is definite and something positively great: what is heavy to one may be light to another; but that which is weighty exceeds the ordinary weight of other things: ponderous expresses even more than weighty, for it includes also the idea of bulk; the ponderous, therefore, is that which is so weighty and large that it cannot easily be moved.

HECTOR, BOLLY. These words have a similar meaning. Hector comes

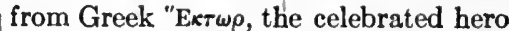
of Troy and a mighty warrior. To hector was to treat others as Hector treated his foes in battle. Hector now differs from bully in suggesting a repeated exercise of argument and force -something irritating and harassing, and less definitely indicating the display of superior brute force. Bully comes from Old Low German. The oldest sense in English is "dear one," a lover. It now signifies a person who gets his own will by a display of force, especially against those whom he knows to be much weaker than himself; it carries the suggestion of a perfectly safe threat of force. The bully generally knows that he will not be called upon to live up to his fierce protestations; that the mere display will make his vietim yield. Hector does not suggest this element in the verb to bully. One may hector one's equal or supcrior; one bullies one's inferiors.

HEed, Care, Attention. Heed (see ATTEND) applies to matters of importance to one's moral conduct; care (see CARE) to matters of minor import: a man is required to take heed; a child is required to take care: the former exereises his understanding in taking heed; the latter exereises his thoughts and his senses in taking care: the former looks to the remote and probable consequences of his actions, and endeavors to prevent the evil that may happen; the latter sees prineipally to the thing that is immediately before him. When a young man enters the world he must take heed lest he be not ensnared by his companions into vicious practices; in a slippery path we must take care that we do not fall.

Heed has, moreover, the sense of thinking on what is proposed to our notice, in which it agrees with attention (see ATTEND); hence we speak of giving heed and paying attention: but the former is applied only to that which is conveyed to us by another, in the shape of a direction, a caution, or an instruction; but the latter is said of everything which we are said to perform. A good child gives heed to his parents when they caution him against any dangerous or false step; he pays attention to the lesson which is sct 
him to learn. He who gives no heed to the counsels of others is made to repent his folly by bitter experience; he who fails in paying attention cannot learn.

\section{HEEDless. See Negligent.}

heighteN, Raise, Aggravate. To heighten is to make higher (see Hadghty). To raise is to cause to rise (see ArISE). To aggravate (see that word) is to make heavy. Heighten refers more to the result of the action of making higher; raise to the mode; we heighten a house by raising the roof, where raising conveys the idea of setting up aloft, which is not included in the word heighten. On the same ground a head-dress may be said to be heightened which is made higher than it was before; and a chair or a table is raised that is set upon something else: but in speaking of a wall we may say that it is either heightened or raised, because the operation and result must in both cases be the same. In the improper sense of these terms they preserve a similar distinction: we heighten the value of a thing; we raise its price: we heighten the grandeur of an object; we raise a family.

Heighten and aggravate have connection with each other only in application to offences: the enormity of an offence is heightened, the guilt of the offender is aggravated, by particular circumstances. The horrors of a murder are heightened by being committed in the dead of the night: the guilt of the perpetrator is aggravated by the addition of ingratitude to murder.

heinous, Flagrant, Flagitious, ATrocrous. Heinous comes from Old French haïnos, from haïr, to hate, from the Teutonic root also found in English hate. Flagrant, in Latin flagrans, burning, is a figurative expression denoting excessive and violent in its nature. Flagitious, in Latin flagitiosus, from flagitium, signifies peculiarly infamous. Atrocious, in Latin atrox, cruel, signifies exceedingly black in guilt.

These cpithets, which are applied to crimes, seem to rise in degree. A crime is heinous which seriously offends against the laws of men; a sin is heinous which seriously offends against the will of God; an offence is flagrant which is in direct defiance of established opinions and practice: it is flagitious if a gross violation of the moral law or coupled with any grossness; a crime is atrocious which is attended with any aggravating circumstances. Lying is a heinous sin; gaming and drunkenness are flagrant breaches of the Divine law; the murder of a whole family is in the fullest sense atrocious.

HELICOPTER. See AIrCRAfT.

HELP, Assist, AID, SUCCOR, RELIEVE. Help is in Anglo-Saxon helpan, German helfen. Assist, in Latin assisto, or ad and sisto, signifies to place one's self by another so as to give him our strength. Aid, in Latin adjutare, a frequentative of $a d$ and juvare, to help, signifies to profit toward a specific end. Succor, in Latin succurrere, to run to the help of any one. Relieve (see Alleviate).

The idea of communicating to the advantage of another in case of need is common to all these terms. Help is the generic term; the rest specific: help may be substituted for the others, and in many cases where they would not be applicable. The first three are employed either to produce a positive good or to remove an evil; the latter two only remove an evil. We.help a person to prosecute his work, or help him out of a difficulty; we assist in order to forward a scheme, or we assist a person in the time of his embarrassment; we aid a good cause, or we aid a person to make his escape; we succor a person who is in danger; we relieve him in time of distress. To help and assist respect personal service, the former by corporeal, the latter by corporeal or mental labor: one servant helps another by taking a part in his employment; one author assists another in the composition of his work. We help up a person's load; we assist him to rise when he has fallen; we speak of a helper or a helpmate in mechanical employments, of an assistant to a professional man.

To assist and aid are used for services directly or indirectly performed: but the former is said only of individuals; the latter may be said of bodies as well as individuals. One friend assists 
another with his purse, with his counsel, his interest, and the like: one person aids another in carrying on a scheme; or one king, or nation, aids another with armies and subsidies. We come to the assistance of a person when he has met with an accident; we come to his aid when contending against numbers. Assistance is given, aid is sent.

To succor is a species of immediate assistance, which is given on the spur of the occasion; the Good Samaritan went to the succor of the man who had fallen among thieves; so in like manner we may succor one who calls us by his cries; or we may succor the poor whom we find in circumstances of distress. So likewise one may succor a nation.

The word relieve has nothing in common with succor, except that they both express the removal of pain; but the latter does not necessarily imply any mode by which this is done, and therefore excludes the idea of personal interference. To help is commonly an act of good-nature or discretion; to relieve, an act of humanity or generosity.

All these terms, except succor, may be applied to things as wel! as persons; we may walk by the help of a stick, read with the assistance of glasses, learn a task quickly by the aid of a good memory, and obtain relief from medicine.

\section{HELPER. See ACCoMmodator.}

HELPING. See AUXILIARY.

HERCUleaN, Brawny, Powerful, Strong, Vigorous. Herculean, an adjective derived from Hercules (in

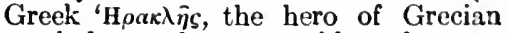
mythology who was said to be possessed of superhuman strength, implies, both as to persons and objects, the quality of extraordinary strength. Applied to persons, brawny designates a tough, muscular condition, and relates particularly to the arms, calves of the legs, the breast, back, and such other parts as are employed in strenuous actions. Powerful, in this sense means might, force, both in an unusually high development; strong, having the power or ability to exert great bodily force, the mental or physical capability to bear or endure great burdens, sorrow, suffering; and vigorous, the condition resulting from sound health, the possession of mental or physical energy, derived from the Latin vigere, to be lively.

Herculean, Difficult, Hard, Perilous, Toilsome. - This application of the term implies actions that require the power, strength, or courage of Hercules to perform or encounter that which is exceedingly great in magnitude and difficult or dangerous in the performance. Difficult implies that which is arduous, not easily managed or comprehended, more or less perplexing, that which requires much labor and skill to overcome or accomplish; hard, that which is compact and solid, not easily pierced or broken, unyielding, and, hence, necessitating continuous application and labor and involving mental or physical fatigue; perilous, that which is beset with danger to the performer, which exposes him to injury or hazard, to the extent of his life; and toilsome, that which requires much time, labor, and ingenuity, the exertion of bodily strength, with efforts of some continuance or duration, producing weariness, exhaustion, fatigue, and other results of over-labor.

HERESY. Sec Heterodoxy.

HERETIC, Schismatic, Sectarian or Sectary, Dissenter, NoN-coNFormIst. A heretic is the maintainer of heresy (see Heterodoxy); the schismatic is the author or promoter of schism; the sectarian or sectary is the member of a sect; the dissenter is one who dissents from an established religion; and the non-conformist one who does not conform to an establishment. A man is a herctic only for matters of faith and doctrine, but he is a schismatic in matters of discipline and practice. The heretic, therefore, is not always a schismatic, nor the schismatic a heretic. Whocver holds the doctrines that are common to the Roman Catholic and reformed churches is not a heretic in the Protestant sense of the word, although he may in many outward formalities be a schismatic. Calvinists are not heretics, but many among them are schismatics; on the other hand, there are many members of the establishment who hold, though they do not avow, heretical notions.

The heretic is considered as such with 
regard to the Catholic Church or the whole body of Christians, holding the same fundamental principles; but the schismatic and sectarian are considered as such with regard to particular bodies of Christians. Schism, from the Greek $\sigma \chi_{i \zeta \varepsilon t \nu}$, to split, denotes an action, and the schismatic is an agent who splits for himself in his own individual capacity: the sectarian does not expressly perform a part, he merely holds a relation; he does not divide anything himself, but belongs to that which is already cut or divided. The schismatic, therefore, takes upon himself the whole moral responsibility of the schism; but the sectarian does not necessarily take an active part in the measures of his sect; whatever guilt attaches to schism attaches to the schismatic; he is a voluntary agent, acting from an erroneous principle, if not an unchristian temper: the sectarian is often an involuntary agent; he follows that to which he has been incidentally attached. It is possible, therefore, to be a schismatic and not a sectarian; as also to be a sectarian and not a schismatic. Those professed members of the establishment who affect the title of evangelical and wish to palm upon the Church the peculiarities of the Calvinistic doctrine, and to ingraft their own modes and forms into its discipline, are schismatics, but not scctarians; on the other hand, those who by birth and education are attached to a sect are sectarians, but not always schismatics. Consequently, schismatic is a term of much greater reproach than sectarian.

The schismatic and sectarian have a reference to any established body of Christians of any country; but dissenter is a term applicable only to the inhabitants of Great Britain, and bearing relation only to the established Church of England: it includes not only those who have individually and personally renounced the doctrines of the Church, but those who are in a state of dissent or difference from it. Dissenters are not necessarily either schismatics or sectarians, for British Roman Catholics are all dissenters, although they are the reverse of what is understood by schismatic and sectarian: it is equally clear that all schis- matics and sectarians are not dissenters, because every established community of Christians, all over the world, have had individuals, or smaller bodies of individuals, setting themselves up against them: the term dissenter being in a great measure technical, it may be applied individually or generally without conveying any idea of reproach; the same may be said of nonconformist, which is a more special term, including only such as do not conform to some established or national religion: consequently, all members of the Romish Church, or of the Kirk of Scotland, are excluded from the number of non-conformists; while on the other hand, all British-born subjects not adhering to these two forms, and at the same time renouncing the established form of their country, are of this number, among whom may be reckoned Independents, Presbyterians, Baptists, Quakers, Methodists, and all other such sects as have been formed since the Reformation.

HESITATE, Falter, Stammer, Stutrer. Hesitate (see Demur). Falter or faulter seems to signify to commit a fault or blunder. Stammer comes from a root found in stand; it meant to stand fixed, amazed, and is related to German stumm, dumb. It now signifies the confusion and hesitation of speech incident to extreme amazement. Stutter is a frequentative of stut, once common in the sense of stutter. "I stutte; I can not speake my wordes redyly," writes Palgrave. The original root of stutter meant to strike against, hence to trip in the speech.

A defect in utterance is the idea which is common in the signification of all these terms: they differ either as to the cause or the mode of the action. With regard to the cause, a hesitation results from the state of the mind and an interruption in the train of thoughts; falter arises from a perturbed state of feeling; stammer and stutter arise either from an incidental circumstance or more commonly from a physical defect in the organs of utterance. A person who is not in the habit of public speaking, or of collecting his thoughts into a set form, will be apt to hesitate even in familiar conversation; he who first addresses a public assembly will be apt 
to falter. Children who first begin to read will stammer at hard words: and one who has an impediment in his speech will stutter when he attempts to speak in a hurry.

With regard to the mode or degree of the action, hesitate expresses less than falter; stammer less than stutter. The slightest difficulty in uttering words constitutes a hesitation; a pause or the repetition of a word may be termed hesitating: but to falter supposes a failure in the voice as well as the lips when they refuse to do their office. Stammering and stuttering are confined principally to the useless moving of the mouth; he who stammers brings forth sounds, but not the right sounds, without trials and efforts; he who stutters remains for some time in a state of agitation without uttering a sound.

\section{See also Scrople.}

HETERODOXY, HeresY. Heterodoxy, from the Greek "̈trepos and dó $\xi a$, signifies another or a different doctrine. Heresy, through French and Latin from the Greek aip opinion adopted by individual choice.

To be of a different persuasion is heterodoxy; to have a faith of one's own is heresy, the heterodoxy characterizes the opinions formed; the heresy characterizes the individual forming the opinion: the heterodoxy exists independently and for itself; the heresy sets itself up against others. As all division supposes error either on one side or on both, the words heterodoxy and heresy are applied only to human opinions, and strictly in the sense of a false opinion, formed in distinction from that which is better founded; but the former implies any opinions, important or otherwise; the latter refers only to matters of importance: the heresy is therefore a fundamental schism. There has been much heterodoxy in the Christian world at all times, and among these have been heresies denying the most serious doctrines which have been acknowledged by the great body of Christians since the Apostles.

HETEROGENEOUS, from Greek ét Tepos, other, and $\gamma^{\prime}$ ' $\gamma$ os, kind, meant literally of a different kind. It signifies that which is made up of different kinds of elements, and is opposed to homogeneous. It has no real synonymes except the more general words listed under different, which see.

HIDDEN. See Secret.

HIDE. See Conceal; Cover; SkIN.

HIDEOUS, Ghastly, Grim, Grisly. Hideous comes from Old French hidos, which is probably derived from Latin hispidosus, rough, shaggy. Ghastly comes from Anglo-Saxon goestan, to terrify, allied to aghast. Grim is derived from Anglo-Saxon grim, fierce. Grisly, Anglo-Saxon grislic, is formed with the suffix lic from grisan, to shudder.

An unseemly exterior is characterized by these terms; but the hideous refers to natural objects, and the ghastly more properly that which is supernatural, or what resembles it. A mask with monstrous grinning features looks hideous; a human form with a visage of death-like paleness is ghastly. The grim is applicable only to the countenance; dogs or wild beasts may look very grim: grisly refers to the whole form, but particularly to the color; as blackness or darkness has always something terrifying in it, a grisly figure having a monstrous assemblage of dark color is particularly calculated to strike terror. Hideous is applicable to objects of hearing also, as a hideous roar; but the rest to objects of sight only.

HIGH, Tall, LofTy. High is allied to German hoch. Tall comes from Middle English tal, seemly, obedient, valiant, which was a general word of approval. Lofty comes from Scandinavian loft, an upper room, allied to AngloSaxon lyft, air, sky, meaning high in the air.

High is the term in most general use, which seems likewise in the most unqualified manner to express the idea of extension upward, which is common to them all. Whatever is tall and lofty is high, but everything is not tall or lofty which is high. Tall and lofty both designate a more than ordinary degree of height; but tall is peculiarly applicable to what shoots up or stands up in a perpendicular direction, while lofty is said of that which is extended in breadth as well as in height, that which 
is lifted up or raised by an accretion of matter or an expansion in the air. By this rule we say that a house is high, a chimney tall, a room lofty. With the high is associated no idea of what is striking; but the tall is coupled with the aspiring, or that which strives to outtop: the lofty is always coupled with the grand and that which commands admiration.

High and lofty have a moral acceptation, but tall is taken in the natural sense only: high and lofty are applied to persons or what is personal, with the same difference in degree as before: a lofty title or lofty pretension conveys more than a high title or a high pretension. Men of high rank should have high ideas of virtue and personal dignity, and keep themselves clear from everything low and mean: a lofty ambition of ten soars too high to serve the purpose of its possessor, whose fall is the greater when he finds himself compelled to descend.

See also Hadghtr.

HIGHEST. See SUPREME.

HIGH-FLOWN, Bombastic, SwolLEN. High-flown is a compound of the English high and flown; high, in Anglo-Saxon heah, implies that which is elevated; flown, from $f y$, in AngloSaxon fleógan, implies to move or pass through the air. High-flown, in most common usage, is applied to the various terms of language as employed in speech and writing that are extravagant, inflated, above the customary quality, in a pretentious flowery or affected style.

Bombastic is from bombast, originally a soft, loose stuff used to swell out garments, and is applied to high-sounding words, big and puffing, without much meaning or relation to a subject under discussion.

Swollen and bombastic are terms more closely allied, each implying language that is puffed up; hence used to make one appear consequential, as possessing greater intelligence than others.

Swollen is a general word which may under certain conditions have the meaning of bombastic or high-flown. Bombastic and high-flown, on the other hand, are specific words applied to language and manncr.
HIGH-MINDED. See HadGhty. HIGH-SOUNDING. See Loud. HILARITY. See MrRTH. HIND. See CounTrYMan.

HINDER, Prevent, Impede, OBSTRUCT. Hinder comes from AngloSaxon hindrian, to keep back or behind. Prevent, from proe and venire, to come before, signifies to hinder by coming before, or to cross another by the anticipation of his purpose. Impede, from in and pedes, signifies to come between a person's feet and entangle him in his progress. Obstruct, from $a b$, in the way of, and struere, to heap together, signifies to set up something in his way, to block the passage.

Hinder is the most general of these terms, as it conveys little more than the idea which is common to them all, namely, that of keeping one from his purpose. To hinder is commonly said of that which is rendered impracticable only for the time being, or merely delayed; prevent is said of that which is rendered altogether impracticable. A person is hindered by the weather and his various engagements from reaching a place at the time he intended; he is prevented but not hindered by ill health from going there at all. If a friend calls, he hinders me from finishing the letter which I was writing; if I wish to prevent my son from reading any book I keep it out of his way. To hinder is an act of the moment, it supposes no design; prevent is a premeditated act, deliberated upon, and adopted for general purposes: the former is applied only to the movements of any particular individual, the latter to events and circumstances. I hinder a person who is running, if I lay hold of his arm and make him walk: it is the object of every good government to prevent offences rather than to punish offenders. In ordinary discourse these words come very close in sense when the circumstances of the case do not sufficiently define whether the action in hand be altogether suspended or suspended only for a time; but the above explanation must make it very clear that to hinder, in its proper sense and application, is but to stop in the progress, and prevent to stop at the outset. 
To impede and obstruct are a species of hindering which is said rather of things than of persons: hinder is said of both; but hinder is commonly employed in regard to trifling matters, or such as retard a person's proceedings in the smallest degree; impede and obstruct are acts of greater importance, or produce a still greater degree of delay. A person is hindered in his work, although neither impeded nor obstructed; but the quantity of artillery and baggage which is attached to an army will greatly impede it in its march; and the trees which are thrown across the roads will obstruct its march. Hindrances always suppose the agency of a person, either of the one who hinders or the one who is hindered: but impediments and obstructions may be employed with regard to the operations of nature on inanimate objects. Cold impedes the growth of plants; a dam obstructs the course of water.

\section{See also RETard.}

Hinder, Stop.-Hinder refers solely to the prosecution of an object: stop, signifying to make to stand, refers simply to the cessation of motion; we may be hindered, therefore, by being stopped; but we may also be hindered without being expressly stopped, and we may be stopped without being hindered. If the stoppage does not interfere with any other object in view, it is a stoppage, but not a hindrance; as when we are stopped by a friend while walking for pleasure: but if stopped by an idler in the midst of urgent business, so as not to be able to proceed according to our business, this is both a stoppage and a hindrance: on the other hand, if we are interrupted in the regular course of our proceeding, but not compelled to stand still or give up our business for any time, this may be a hindrance, but not a stoppage: in this manner, the conversation of others in the midst of our business may considerably retard its progress, and so far hinder, but not expressly put a stop to, the whole concern.

HINT, Suggest, Intimate, InsinuATE. Hint and suggest (see Allude). To intimate is to make one intimate, or specially acquainted with, to communicate one's most inward thoughts.
Insinuate, from the Latin sinus, a bend, is to introduce by a winding course into the mind of another.

All these terms denote indirect expressions of what passes in one's own mind. We hint at a thing from fear and uncertainty; we suggest a thing from prudence and modesty; we intimate a thing from indecision; a thing is insinuated from artifice. A person who wants to get at the certain knowledge of any circumstance hints at it frequently in the presence of those who can give him the information; a man who will not offend others by an assumption of superior wisdom suggests his ideas on a subject, instead of setting them forth with confidence; when a person's mind is not made up on any future action, he only intimates what may be done; he who has anything offensive to communicate to another will choose to insinuate it rather than declare it in express terms. Hints are thrown out; they are frequently characterized as broken: suggestions are offered; they are frequently termed idle or ill-grounded: intimations are given, and are either slight or broad: insinuations are thrown out, they are commonly designated as slanderous, malignant, and the like.

To hint is taken either in a bad or an indifferent sense; it is commonly resorted to by tale-bearers, mischiefmakers, and all who want to talk of more than they know. To suggest is of tener used in the good than the bad sense: as to suggest doubts, queries, difficulties, or improvements in matters of opinion is truly laudable, particularly for young persons; but to suggest anything to the disadvantage of another is even worse than to speak ill of him openly, for it bespeaks cow ardice as well as ill-nature. To intimate is taken either in a good or an indifferent scnse; it commonly passes between relatives or persons closely connected in the communication of their half-formed intentions or of doubtful intelligence; but to insinuate is always taken in a bad sense; it is the resource of an artful and malig. nant enemy to wound the reputation of another, whom he does not dare openly to accuse. A person is said to take a hint, to follow a suggestion, 
to receive an intimation, to disregard an insinuation.

See also KEY.

HIRE. See Allowance.

HIRELING, Mercenary. Hireling, from hire, and mercenary from mercenarius, based on merx, pay, are applied to any one who follows a sordid employment; but hireling may sometimes be taken in its proper and less reproachful sense, for one who is hired as a servant to perform an allotted work: but in general they are both reproacnful epithets, the former having particular reference to the meanness of the employment, and the latter to the sordid character of the person. Hireling papers are those which are in the pay of a party; a mercenary principle will sometimes actuate men in the highest station.

HIT. See BEat; Strike.

HOARD. See Garner; Treasure. HODGE-PODGE. See OLIO.

HOIST. See LIFT.

HOLD, Keep, Detain, RetanN. Hold comes from Anglo-Saxon healdan, to hold; keep from Anglo-Saxon cepan, to observe, notice, attend to. 'Detain and retain both come from the Latin tenere, to hold. The first signifies, by virtue of the particle de, meaning from, to hold from another; the second, by virtue of the particle re, to hold back for one's self.

To hold is a physical act; it requires a degree of bodily strength or at least the use of the limbs; to keep is simply to have by one at one's pleasure. The having in one's power so that it shall not go is the leading idea in the signification of hold; the durability of having is the leading idea in the word keep: we may hold a thing only for a moment; but what we keep we keep for a time. On the other hand, we may keep a thing by holding, although we may keep it by various other means: we may, therefore, hold without keeping, and we may keep without holding. A servant holds a thing in his hand for it to be seen, but he does not keep it; he gives it to his master, who puts it into his pocket, and consequently keeps, but does not hold it. A thing may be held in the hand, or kept in the hand; in the former case the pressure of the hand is an essential part of the action, but in the latter case it is simply a contingent part of the action: the hand holds, but the person keeps it. What is held is fixed in position, but what is kept is left loose, or otherwise, at the will of the individual. Things are held by men in their hands, by beasts in their claws or mouths, by birds in their beaks; things are kept by people either about their persons or in their houses, according to convenience.

Detain and retain are modes of keeping; the former signifies keeping back what belongs to another; the latter signifies keeping a long time for one's own purpose. A person may be either held, kept, detained, or retained: when he is held he is held contrary to his will by the hand of another; as suspected persons are held by the officers of justice, that they may not make their escape: he is kept, if he stops in any place, by the desire of another; as a man is kept in prison until his innocence is proved, or a child is kept at school until he has finished his education: he is detained if he be kept away from any place to which he is going or from any person to whom he belongs; as the servant of another is detained to take back a letter, or one is detained by business, so as to be prevented from attending to an appointment: a person is retained who is kept for a continuance in the service of another; as some servants are said to be retained, while others are dismissed.

Things are held in the improper sense: they are kept, detained, and retained in the proper sense. A money-lender holds the property of others in pledge; the idea of a temporary and partial action is here expressed by hold, in distinction from keep, which is used to express something definite and permanent: the money-lender keeps the property as his own if the borrower forfeits it by breach of contract. When a person purchases anything he is expected to keep it or pay the value of the thing ordered, if the tradesman fulfil his part of the engagement. What is detained is kept either contrary to the will, or without the consent, of the possessor: when things are suspected to be stolen, the officers have the right of detaining them until inquiry be instituted. What is retained 
is continued to be kept; it supposes, however, some alteration in the terms or circumstances under which it is kept: a person retains his seat in a train, notwithstanding that be finds it disagreeable: or a lady retains some of the articles of millinery which are sent for her choice, but she returns the rest.

All are used in a moral application except detain; in this case they are marked by a similar distinction. A person is said to hold an office, by which simple possession is implied: he may hold it for a long or a short time, at the will of others, or by his own will, which is not marked: he keeps a situation or he keeps his post, by which his continuance in the situation or at the post is denoted: but to say he retains his office signifies that he might have given it up, or lost it, had he not been led to continue in it. In like manner, with regard to one's sentiments or feelings, a man is said to hold certain opinions, which are ascribed to him as a part of his creed; he keeps the opinions which no one can induce him to give up; he retains his old attachments, notwithstanding the lapse of years and change of circumstances which have intervened and were naturally calculated to wean him from them.

See also Contarn.

Hold, Occupy, Possess.-Hold (see above). Occupy, in Latin occupo, or $o b$ and capere, to hold or keep near, so that it cannot be held by others, or fill a space so that it cannot be filled by any other object. Possess, from Latin possessus, past! participle of possideo, or potis and sedeo, signifies to sit as master of.

We hold a thing for a long or a short time; we occupy it for a permanence: we hold it for ourselves or others; we occupy it only for ourselves: we hold it for various purposes; we occupy only for the purpose of converting it to our private use. Thus a person may hold an estate, or, which is the same thing, the title-deeds to an estate, pro tempore, for another person's benefit; but he occupies an estate if he enjoys the fruit of it. On the other hand, to occupy is only to hold under a certain compact; but to possess is to hald as one's own. The tenant occupies the farm when he holds it by a certain lease and cultivates it for his subsistence: but the landlord possesses the farm, possessing the right to let it and to receive the rent. We may hold by force, or fraud, or right; we occupy either by force or right; we possess only by right.

Hence we say, figuratively, to hold a person in esteem or contempt, to occupy a person's attention or a place, or to possess one's affection.

Hold, Support, Maintain.-Hold is here, as in the former article, a term of very general import. Support (see Countenance) and maintain (see AssIST) include the idea of holding with other cointeral ideas in their signifcation.

Hold and support are employed in the proper sense, maintain in the improper sense. To hold is a term unqualified by any circumstance; we may hold a thing in any direction, hold it up or down, in a straight or oblique direction: support is a species of holding up; to hold up, however, is a personal act or a direct effort of the individual; to support may be an indirect and a passive act; he who holds anything up keeps it in an upright posture by the exertion of his strength; he who supports a thing only bears its weight or suffers it to rest upon himself: persons or voluntary agents can hold up; inanimate objects may support: a servant holds up a child that it may see; a pillar supports a building.

In the figurative application a person is said to hold power for himsclf, but to support the authority of another, or to have one's own mind supported by circumstances or reflections. To maintain is to hold firmly or with vigor.

These terms are all applied to the opinions with a similar distinction. Opinions are held and maintained as one's own; they are supported when they are another's. We hold and maintain whatever we believe. We support the belief or doctrine of another or what we ourselves have asserted and maintained at a former time. What is held is held by the act of the mind within itself and as regards itself, without ref rence to others; but what is maintained and supported is openly declared to be held; it is maintained with 
others or against others; it is supported in an especial manner against others; it may be maintained by simple declaration or assertions; it is supported by argument.

What is held may be held by means of the affections, as to hold a person dear, or hold a thing in esteem; to maintain and support are applied only to speculative matters with which the understanding is engaged, as to maintain or support truth or error, to maintain or support a cause.

HOLIDAY. See FEAst.

HOLINESS, SANCTIYY. Holiness, from Anglo-Saxon halig, allied to hal, whole, and health, has altogether acquired a Christian signification; it respects the life and temper of a Christian. Sanctity, based on the Latin sanctus, holy, has merely a moral signification, which it derives from the sanction of human authority.

Holiness is to the mind of a man what sanctity is to his exterior, with this difference, that holiness to a certain degree ought to belong to every man professing Christianity; but sanctity, as it lies in the manners, the outward garb, and deportment, is becoming only to certain persons and at certain times. Holiness is a thing not to be affected; but sanctity, consisting in externals, is from its very nature exposed to falsehood. It becomes those who fill a sacred office, but no others.

HOLLOW, EMPTx. Hollow, from hole, signifying like a hole, concerns the body itself; the absence of its own materials produces hollowness. Empty concerns foreign bodies; their absence in another body constitutes emptiness. Hollowness is therefore a preparative to emptiness, and may exist independently of it; but emptiness presupposes the existence of hollowness: what is empty must be hollow; but what is hollow need not be empty. Hollowness is often the natural property of a body; emptiness is a contingent property: that which is hollow is destined by nature to contain; but that which is empty is deprived of its contents by a casualty: a nut is hollow for the purpose of receiving the fruit; it is empty if it contain no fruit.

They are both employed in a moral acceptation and in a bad sense; the hollow, in this case, is applied to what ought to be solid or sound, and empty to what ought to be filled; a person is hollow whose goodness lies only at the surface, whose fair words are without meaning; a truce is hollow which is only an external cessation from hostilities: a person is empty who is void of understanding and knowledge; an excuse is empty which is unsupported by fact and reason; a pleasure is empty which cannot afford satisfaction.

HOLY, Pious, Devout, Religious. Holy (see Holiness). Pious, in Latin pius, signifies having a regard for the gods. Devout, in Latin devotus, from devovere, to engage by a vow, signifies devoted or consecrated. Religious, in Latin religiosus, comes from religio, meaning attention to the worship of the gods.

A strong regard for the Supreme $\mathrm{Be}$ ing is expressed by all these epithets; but holy conveys the most comprehensive idea; pious and devout designate most fervor of mind; religious is the most general and abstract in its signification. A holy man is in all respects heavenly-minded; he is more fit for heaven than earth: holiness, to whatever degree it is possessed, abstracts the thoughts from sublunary objects and fixes them on things that are above. Our Saviour was a perfect pattern of holiness; his apostles after him, and innumerable saints and good men, both in and out of the ministry, have striven to imitate his example by the holiness of their life and conversation.

Pious is a term more restricted in its signification, and consequently more extended in application than holy: $p i$ ety is not a virtue peculiar to Christians; it is common to all believers in a Supreme Being; it is the homage of the heart and the affections to a superior Being: from a similarity in the relationship between a heavenly and an earthly parent, devotedness of the mind has in both cases been denominated piety. Piety toward God naturally produces piety toward parents; for the obedience of the heart, which gives rise to the virtue in the one case, seems instantly to dictate the exercise of it in the other. The difference between holiness and piety is obvious from this, 
that our Saviour and his apostles are characterized as holy, but not pious, because piety is swallowed up in holiness. On the other hand, Jew and Gentile, Christian and heathen, are alike termed pious when they cannot be called holy, because piety is not only a more practicable virtue, but because it is more universally applicable to the dependent condition of man.

Devotion is a species of piety peculiar to the worshipper; it bespeaks that devotedness of mind which displays itself in the temple when the individual seems by his outward services solemnly to devote himself, soul and body, to the service of his Maker. Piety, therefore, lies in the heart and need not appear externally; but devotion requires to be marked by some external observance: a man piously resigns himself to the will of God in the midst of his afflictions; he prays devoutly in the bosom of his family.

Religious is a term of less import than either of the other terms; it denotes little more than the simple existence of religion, or a sense of religion, in the mind: the religious man is so more in his principles than in his affections; he is religious in his sentiments, inasmuch as he directs all his views according to the will of his Maker; and he is religious in his conduct, inasmuch as he observes the outward formalities of homage that are due to his Maker.

When applied to things, these terms preserve a similar distinction: we speak of the holy sacrament; of a pious discourse, a pious ejaculation; of a devout exercise, a devout air; a religious sentiment, a religious life, a religious education, and the like.

Holy, Sacred, Divine.-Holy is here, as in the former article, a term of higher import than either sacred, which is in Latin sacer, or divine (see GopLIKE). Whatever is most intimately connected with religion and religious worship, in its purest state, is holy, unhallowed by a mixture of inferior objects, and elevated in the greatest possible degree, so as to suit the nature of an infinitely perfect and exalted Being. Among the Jews, the holy of holies was that place which was intended to approach the nearest to the heavenly abode, consequently was pre- served as much as possible from all contamination with that which is earthly: among the Christians, that religion or form of religion is termed holy which is esteemed purest in its doctrine, discipline, and ceremonies.

Sacred is less than holy; the sacred derives its sanction from human institutions and is connected rather with our moral than our religious duties; what is holy is altogether spiritual, and abstracted from the earthly. The laws are sacred, but not holy; a man's word should be sacred, though not holy: for neither of these things is to be reverenced, but both are to be kept free from injury or external violence. The holy is not so much opposed to, as it is set above, everything else; the sacred is opposed to the profane: the Scriptures are properly denominated holy, because they are the word of God, and the fruit of His Holy Spirit; but other writings may be termed sacred which appertain to religion, in distinction from the profane, which appertain only to worldly matters.

Divine is a term of even less import than sacred; it signifies either belonging to a deity or being like a deity; but from the looseness of its application it has lost in some respects the dignity of its meaning. The divine is of ten contrasted with the human: but there are many human things which are denominated divine: Milton's poem is entitled a divine poem, not merely on account of the subject, but from the exalted manner in which the poet has treated his subject: what is divine, therefore, may be so superlatively excellent as to be conceived of as having the stamp of inspiration from the Deity, which, of course, as it applies to human performances, is but a hyperbolical mode of speech.

homage, Fealty, Court. Homage, in Old French homage, from Latin homo, a man, signifies a man's, that is an inferior's, act of acknowledging superiority. Homage, in the technical sense, was an oath taken, or a service performed, by the tenant to his lord, on being admitted to his land; or by inferior princes to a sovereign, whereby they acknowledged his sovereignty and promised fidelity: in its extended and figurative sense it comprehends any 
solemn mark of deference, by which the superiority of another is acknowledged. F ealty, through Old French fealte, from Latin fidelatem, based on fidelis, loyal, trusty, is a lower species of homage, consisting only of an oath; it was made formerly by tenants, who were bound thereby to personal service under the feudal system. Court, which derives its meaning from the verb to court, woo, and seek favor, is a species of homage, complaisance, or deference, which is assumed for a specific purpose; it is not only voluntary, but depends upon the humor and convenience of the courtier.

Homage is paid or done to superior endowments; court is paid to the contingent, not the real, superiority of the individual. Fealty is figuratively employed in the sense of fidelity to one's sovereign. Homage consists in any form of respect which is admitted in civil society; the Romans did homage to the talents of Virgil by always rising when he entered the theatre; men do homage to the wisdom of another when they do not venture to contradict his assertions or call in question his opinions. Court is everything or nothing, as circumstances require; he who pays his court consults the will and humor of him to whom it is paid, while he is consulting his own interest.

HOME. See Domicile.

HONEST. See FaIr; Sincere.

HONESTY, PROBITY, UPRIGHTNESS, INTEGRITY. Honesty is the most familiar and universal term; it is applied alike to actions and principles, to a mode of conduct or a temper of mind: a person may be honest, a principle honest, or an action honest; the other terms are applied to the person, as a person of probity, uprightness, and integrity: a man is said to be honest who in his dealings with others does not violate the laws; a servant is honest who does not take any of the property of his master or suffer it to be taken; a tradesman is honest who does not sell bad articles; and people in general are denominated honest who pay what they owe and do not adopt any methods of defrauding others.

Honesty is a negative virtue; all the other terms denote positive virtues and higher characteristics. Probity, from probus, good, and probo, to prove, signifying tried virtue or solid goodness, is applied not merely to the commercial dealings of men, but to all the concerns of life where truth and goodness are called into exercise. Probity refers to the rights of men, giving to every one his due, whether as regards his property, reputation, honor, or any other thing on which a value is set. Honesty is opposed to direct fraud, probity to any species of insincerity.

Uprightness, from upright or up and right, signifies bcaring up in a straight and undeviating course in opposition to every temptation which may offer. Uprightness, therefore, supposes an independent and positive principle which forms the rule of life. Any person may be said to be upright in all situations where confidence and intelligence are required, but more particularly a judge who scrupulously adheres to the dictates of an unbiassed conscience.

Integrity, from integer, whole or sound, signifying soundness of principle, (as in Horace, "integer vitoe, scelerisque purus") is applied, like uprightness, to cases where a particular trust is reposed; but integrity is taken absolutely, that is, without any reference to the outward circumstances which might tend to produce the contrary characteristic. He who faithfully discharges his trust and consults the interests of others rather than his own is justly styled a man of integrity. This virtue is to be looked for especially in those who fill any office.

Honesty, Honor.-These terms both regard the principle which actuates men in the adjustment of their rights with one another. The words are both derived from the same source, namely, the Hebrew hon, substance or wealth, which, being the primitive source of esteem among men, became at length put for the measure or standard of esteem, namely, what is good. Hence honesty and honor are both founded upon what is estimable, with this difference, that honesty is confined to the first principles or laws upon which civil society is founded, and honor is an independent principle that extends to everything which by usage has been admitted as estimable or entitled to 
esteem. An honest action, therefore, can never reflect so much credit on the agent as an honorable action, since in the performance of the one he may be guided by motives comparatively low, whereas in the other case he is actuated solely by a fair regard for the honor or the esteem of others. To a breach of honesty is attached punishment and personal inconvenience in various forms; but a breach of honor is only followed $h r$ disgrace or the ill opinion of others. Un the other hand, honesty is founded on the very first principles of human society, and honor on the incidental principles which have been attached to them in the progress of time and culture; the former is positive and definite, and he who is actuated by this principle can never err; but the latter is indefinite and variable, and, as it depends upon opinion, it will easily mislead. We cannot have a false honesty, but we may have false honor. Honesty always keeps a man within the line of his duty; but a mistaken notion of what is honorable may carry a man very far from what is right, and may even lead him to run counter to common honesty.

See also GLory.

HONOR, Reverence, Respect. These terms agree in expressing the act of an inferior toward his superior; but honor (see GLORY) expresses less than reverence (see'ADORE), and more than respect (see EsTEEM).

To honor is only an outward act; to reverence is either an act of the mind or the outward expression of a sentiment; to respect is mostly an act of the mind, though it may admit of being expressed by some outward act. We honor God by adoration and worship, as well as by the performance of His will; we honor our parents by obeying them and giving them our personal service: we reverence our Maker by cherishing in our minds a dread of offending $\mathrm{Him}$ and making a profane use of His holy name and word: we reverence our parents by holding a similar sentiment in a less degree.

To honor, when applied to things, is taken in the sense of holding in honor; and respect, to have respect for, with the same distinction between them.
Honor, Dignity. - Honor may be taken either for that which intrinsically belongs to a person or for that which is conferred on him. Dignity, based on the Latin dignus, worthy, signifying worthiness, may be equally applied to what is extrinsic or intrinsic in a man.

In the first case honor has a reference to what is esteemed by others; dignity to that which is esteemed by ourselves: a sense of honor impels a man to do that which is esteemed honorable among men; a sense of dignity to do that which is consistent with the worth and greatness of his nature: the former impels a man to elevate himself as an individual; the latter to raise himself to the standard of his species: the former may lead a person astray, but the latter is an unerring guide. It is honor which makes a man draw his sword upon his friend: it is dignity .which makes him despise every paltry affront from others, and apologize for every apparent affront on his own part. This distinction between the terms is kept up in their application to what is extraneous of a man: honor is that which is conferred on him by others; but dignity is the worth or value which is added to his condition: hence we always speak of honors as conferred or received; but dignities as possessed or maintained. Honors may sometimes be casual; but dignities are always permanent: an act of condescension from the sovereign is an honor; but the dignity is that which exalts the man. Hence it is that honors are mostly civil or political; dignities may also be ecclesiastical.

hOPE, Expectation, Trust, ConFIDENCE. Anticipation of futurity is the common idea expressed by all these words. Hope is in Anglo-Saxon hopa. Hope is that which is welcome; expectation (see AWAIT) is either welcome or unwelcome: we hope only for that which is good; we expect the bad as well as the good. In bad weather we hope it will soon be better; but in a bad season we expect a bad harvest, and in a good season a good harvest. Hope is simply a presentiment; it may vary in degree, more according to the temper of the mind than the nature of the circumstances; some hope where there is no ground for hope, 
and others despair where they might hope: expectation is a conviction that excludes doubt; we expect in proportion as that conviction is positive: we hope that which may be or can possibly be; we expect that which must be or which ought to be. The young man hopes to live many years; the old man expects to die in a few years.

Hope and expectation consist in looking for some good, trust (see BELIEF) and confidence (see CONFIDE) in a dependence on a person or thing to bring about the good. We may, therefore, have either hope or expectation grounded on trust or confidence, or we may have them where there is no room for either trust or confidence; a person may hope that something good may turn up because the future is uncertain; we may expect that it will rain to-day; a person may trust to the skill of another, or confide in his promises. Trust and confidence denote the same sentiment, but trust is applied to objects generally, confidence to particular objects; we may trust partially, but we confide entirely; we may trust strangers, we confide in friends or those we are partial to.

Trust and confidence may both be applied to a man's self, or that which belongs to him, with a similar distinction.

Hopeful. See Sanguine.

HOPELESS. See Desperate.

HORRIBLE. See Fearful.

HORRID. See Fearful.

HOST. See Army.

HOSTILE. See Adverse.

HOSTILITY. See ENMiTY.

hot, Fiery, Burning, Ardent. These terms characterize either the presence of heat or the cause of heat. Hot, Anglo-Saxon hat, is the general term which marks simply the presence of heat; fiery, $i$. e., having fire, goes further, it denotes the presence of fire, which is the cause of heat; burning, $i . e$, in a state of burning, denotes the action of fire, and consequently is more expressive than the two; ardent (see FErvor), which is literally the same in signification, is employed either in poetry or in application to moral objects: a room is hot; a furnace or the tail of a comet fiery; a coal burning; the sun ardent.
In the figurative application, a temper is said to be hot or fiery; rage is burning; the mind is ardent in pursuit of an object. Zeal may be hot, fiery, burning, and ardent, but in the first three cases it denotes the intemperance of the mind when heated by religion or politics; the last is admissible so long as it is confined to a good object.

See also Fire.

HOUSE, See FAMILY.

HOWEVER, YeT, NeverTHeless, NotwithstandiNG. These conjunctions are in grammar termed adversative, because they join sentences together that stand more or less in opposition to each other. However is the most general and indefinite; it serves as a conclusive deduction drawn from the whole. "The truth is, however, not yet all come out"; by this is understood that much of the truth has been told, and much yet remains to be told: so likewise in similar sentences, "I am not, however, of that opinion"; where it is implied either that many hold the opinion or much may be said of it, but, be that as it may, I am not of that opinion: "however, you may rely on my assistance to that amount"; that is, at all events, let whatever happen, you may rely on so much of my assistance: however, as is obvious from the above examples, connects not only one single proposition, but many propositions either expressed or understood. Yet, nevertheless, and notwithstanding are mostly employed to set two specific propositions either in contrast or direct opposition to each other; the latter two are but specias of the former, pointing out the opposition in a more specific manner.

There are cases in which yet is pcculiarly proper, others in which nevertheless, and others in which notwithstanding are preferable. Yet bespeaks a simple contrast; "Addison was not a good spcaker, yet he was an admirable writer; Johnson was a man of uncouth manners, yet he had a good heart and a sound head"; nevertheless and notwithstanding could not in these cascs have been substituted. Nevertheless and notwithstanding are mostly used to imply effects or consequences opposite to what might naturally be expected to result. "He has acted an unworthy 
part, nevertheless I will be a friend to him as far as I can"; that is, although he has acted an unworthy part, I will be no less his friend as far as lies in my power. "Notwithstanding all I have said, he still persists in his own imprudent conduct"; that is, all I have said nolwithstanding or not restraining him from it, he still persists. " $\mathrm{He}$ is still rich, notwithstanding his loss"; that is, his loss notwithstanding, or not standing in the way of it, he is still rich. From this resolution of the terms, more than from any specific rule, we may judge of their distinct applications, and clearly perceive that in such cases as those above cited the conjunctions nevertheless and notwithstanding could not be substituted for each other, nor yet for either: in other cases, however, where the objects are less definitely pointed out, they may be used indifferently. "The Iesuits piqued themselves always upon their strict morality, and yet [notwithstanding or nevertheless] they admitted of many things not altogether consonant with moral principle. You know that these are but tales, yet [notwithstanding, nevertheless] you believe them."

HUDDLE. See JUMBLE.

HUE: See Color.

HUG. See Clasp.

HUGE. See ENORMOUS.

HUMAN, HUMANE. Though both derived from homo, a man, they are thus far distinguished that human is said of the genus and humane of the species. The human race or human beings are opposed to the irrational part of the creation; a humane race or a humane individual is opposed to one that is cruel and fond of inflicting pain. He who is not human is divested of the first and distinguishing characteristics of his kind; he who is not humane, of the most important and elevated characteristic that belongs to his nature.

HUMANITY. See Benevolence.

HUMBLE, LowLy, Low. Humble is here compared with the other terms as it respects both persons and things. A person is said to be humble on account of the state of his mind: he is said to be lowly and low either on account of his mind or his outward circumstances. A humble person is so in his principles and in his conduct; a lowly person is so in the tone of his feelings, or in his station and walk of life; a low person is so either in his sentiments, in his actions, or in his rank and condition; but persons may sometimes be low from particular circumstances who are not low in condition. Humility should form a part of the character, as it is opposed to arrogance and assumption; it is most consistent with the fallibility of our nature. Lowliness, in the Christian belief, should form a part of our temper, as it is opposed to an aspiring and lofty mind; it is most consistent with the temper of our Saviour, who was meek and lowly of mind.

The humble and lowly are always taken in a good sense; but the low either in a bad or an indifferent sense. A lowly man, whether as it regards his mind or his condition, is so without. any moral debasement; but a man who is low in his condition is likewise conceived to be low in his habits and his sentiments, which is being nearly akin to the vicious. The same distinction is preserved in applying these terms to inanimate or spiritual objects. A humble roof, a humble office, a humble station are associated with the highest moral worth; while a low office, a low situation, a low birth, seem to exclude the idea of worth.

See also ABASE.

Humble, Modest, Submissive.-These terms designate a temper of mind the reverse of self-conceit or pride. The humble, in Latin humilis, low, from humus, the ground, signifying the lowest position, is so with regard to ourselves or others. Modesty (see MODEsT) is that which regards ourselves only: submissiveness, from submissus, signifying putting under, is that which regards others. A man is humble from a sense of his comparative inferiority to others in point of station and outward circumstances; or he is humble from a sense of his imperfections and a consciousness of not being what he ought to be: he is modest, inasmuch as he sets but little value on his qualifications, acquirements, and endowments. Humility is a painful sentiment; for when it concerns others it is coupled with fear; when it concerns our own unworthiness it is coupled with sorrow: modesty is a peaceful sentiment; it 
serves to keep the whole mind in due bounds. When humility and modesty show themselves in the outward conduct, the former bows itself down, the latter shrinks: a humble man gives freely to others from a sense of their deserving; a modest man demands nothing for himself, from an unconsciousness of deserving in himself.

Between humble and submissive there is this prominent feature of distinction, that the former marks a temper of mind, the latter a mode of action: the former is, therefore, often the cause of the latter, but not so always; we may be submissive because we are humble; but we may likewise be submissive from fear, from interested motives, from necessity, from duty, and the like; and on the other hand, we may be humble without being submissive, when we are not brought into connection with others. A man is humble when in solitude he takes a review of his sinfulness; he is submissive to a master whose displeasure he dreads.

Humble, Humiliate, Degrade.-Humble and humiliate are both drawn from the same source (see above). Degrade (see above).

Humble is commonly used as the act either of persons or things: a person may humble himself or he may be humbled: humiliate is employed to characterize things; a thing is humiliating or a humiliation. No man humbles himself by the acknowledgment of a fault; but it is a great humiliation for a person to be dependent on another for a living when he has it in his power to obtain it for himself.

To humble is to bring down to the ground; it supposes a certain eminence, either created by the mind or really existing in the outward circumstances; to degrade is to set down low or; it supposes steps for descending. He who is most elevated in his own esteem may be most humbled; misfortunes may humble the proudest conqueror: he who is most elevated in the esteem of others may be the most degraded; envy is ever on the alert to degrade. A lesson in the school of adversity is humbling to one who has known nothing but prosperity: terms of peace are humiliating: low vices are peculiarly degrading to a man of rank.
HUMIDITY. See Moisture.

HUMILIATE. See HuMbLE.

HUMOR, TEMPER, MOOD. Humor literally signifies moisture or fluid, in which sense it is used for the fluids of the human body; and as far as these humors or their particular state is connected with, or has its influence on, the animal spirits and the moral feelings, so far is humor applicable to moral agents. Temper (see Disposition) is less specific in its signification; it may, with equal propriety, under the changed form of temperament, be applicable to the general state of the body or the mind. Mood, which is but a change from mode or manner, has an original signification not less indefinite than the former; it is applied, however, only to the mind. As the humors of the body are the most variable parts of the animal frame, humor in regard to the mind denotes but a partial and transitory state when compared with the temper, which is a general and habitual state. The humor is so fluctuating that it varies in the same mind perpetually; but the temper is so far confined that it always shows itself to be the same whenever it shows itself at all: the humor makes a man different from himself; the temper makes him different from others. Hence we speak of the humor of the moment; of the temper of youth or of old age: so likewise we say, to accommodate one's self to the humor of a person; to manage his temper: to put one into a certain humor; to correct or sour the temper. Humor is not less partial in its nature than in its duration; it fixes itself of ten on only one object, or regards only one particular direction of feelings: temper extends to all the actions and opinions as well as feelings of a man: it gives a coloring to all he says, does, thinks, and feels. We may be in a humor for writing or reading; for what is gay or what is serious; for what is noisy or what is quiet; but our temper is discoverable in our.daily conduct; we may be in a good or ill humor in company, but in domestic life and in our closest relations we show whether we are good or ill tempered. A man shows his hu mor in different or trifling actions; he shows his temper in the most important actions: it may be a man's humor to 
sit while others stand, or to go unshaven while others shave; but he shows his temper as a Christian or otherwise in forgiving injuries or not harboring resentments; in living peaceably, not indulging himself in contentions.

When applied to bodies of men humor, as denoting a temporary or fluctuating feeling, is more commonly used than temper.

Humor and mood agree in denoting a particular and temporary state of feeling; but they differ in the cause, the former being attributable rather to the physical state of the body, and the latter to the moral frame of the mind; the former, therefore, is independent of all external circumstances, or at all events of any that are reducible to system; the latter is guided entirely by events, or the view which the mind takes of events.' Humor is, therefore, generally taken in a bad sense unless actually qualified by some epithet to the contrary: mood is always taken in an inc'ifferent sense. There is no calculating on the humor of a man; it depends upon his mood whether he performs ill or well: it is necessary to suppress humor in a ehild; we discover by the melancholy mood of a man that something distressing has happened to him.

See also Gratify; Qualify; Wit.

Humor, Caprice.-Humor is general, caprice (see FANCIFUL) is particular: humor may be good or bad; caprice is always taken in a bad sense. Humor is always independent of fixed principle; it is the fecling or impulse of the moment: caprice is always opposed to fixed principle or rational motives of acting; it is the feeling of the individual setting at naught all rule and defying all reason. The feeling only is perverted when the humor predominates; the judgment and will are perverted by caprice; a child shows its humor in fretfulness and impatience; a man betrays his caprice in his intercourse with others, in the management of his concerns, or in the choice of his amusements.

Indulgence, according to a mode of speech now practically obsolete, renders children and subordinate persons humorsome; prosperity or unlimited power is apt to render a man capricious: a humorsome person commonly objects to be pleased or is easily displeased; a capricious person likes and dislikes, approves and disapproves the same thing in quick succession.

Humorsome, Humorous, Capricious -Humor, when applied to things, has the sense of wit, whence the distinetion between humorsome and humorous, the former implying the existence of humor or perverted feeling in the person; the atter implying the existence of humor or wit in the person or thing. Caprice is improperly applied to things to designate their total irregularity and planlessness of proceeding, as, in speaking of fashion, we notice its caprice when that which has been laid aside is again taken into use; diseases are termed capricious which act in direct opposition to all established rule.

HUNT, Chase. The leading idea in the word hunt from Anglo-Saxon huntian, to capture, is that of searching after; the leading idea in the word chase is that of driving away or before one. In a strict sense, hunt denotes a search for objeets not within sight; chase is a pursuit after such objects only as are within sight: we may hunt, therefore, without chasing: we may chase without hunting: a person hunts after, but does not chase that which is lost: a boy chases, but does not hunt, a butterfly. When applied to field sports, the hunt eommences as soon as the huntsman begins to look for the game; the chase eommences as soon as it is found: on this ground, perhaps, it is that hunt is used, in familiar discourse, to designate the speeific aet of taking this amusement; and chase is used only in particular cases where the peculiar idea is to be expressed: a foxhunt, or a stag-hunt, is said to take place on a particular day; or that there has been no hunting this season, or that the hunt has been very bad: but we speak, on the other hand, of the pleasures of the chase, or that the chase lasted very long; the animal gave a long chase.

HURL. See CAST.

HURRY. See Hasten.

HURT. See Disadvantage; INJURY; SORRY. 
HURTful, Pernicious, Noxious, Norsome. Between hurtful, signifying full of hurt, and pernicious there is the same distinction as between hurting and destroying: that which is hurtful may hurt in various ways; but that which is pernicious necessarily tends to destruction: confinement is hurtful to the health: bad company is pernicious to the morals, or the doctrines of free-thinkers are said to be pernicious to the well-being of society. Noxious and noisome, from nocere, to hurt, are species of the hurtful: things may be hurtful both to body and mind; noxious and noisome only to the body: that which is noxious inflicts a direct injury; that which is noisome inflicts it indirectly: noxious insects are such as wound; noisome vapors are such as tend to create disorders.

HUSBAND, CoNserve, Economize. Husband, from the Icelandic husbondi, that contracted from husbuandi, compound of hus, a house, and buandi, a dwelling, all imply the male head of a household. In the present application the term signifies to manage one's affairs with frugality, to use one's resources so as to produce the best results.

Conserve, from Latin conservare, means primarily to save. We conserve our health and property by adopting such methods as will save them from depreciation, injury, loss, or destruction. We economize our health, time, and property by managing each with care, prudence, and a proper regard for their value. Economize has an original meaning similar to that of husband, being derived from the Greek word for house, and indicating the management of the household. Husband, however, means primarily prudence in saving, in gathering together, and conserving resources; economize signifies prudencein spending. See EconomicaL.

HUSBANDMAN. See FARMER.

HUSBANDRY. See Cultivation. HYDROPLANE. See AIRCRAFT.

HYPNOTISM, MESMERISM, ANImal Magnetism. The difference between these three words is not a difference in meaning, but a difference in the theory implied in them, and in fashionable and professional usage. Hypnotism replaced mesmerism, and mesmerism animal magnetism in professional usage as names for the same phenomenon. This phenomenon is a peculiar condition of the nervous system induced by a fixed, abstracted attention of the mental and visual eye on one object not of an exciting nature. It was called animal magnetism by F. A. Mesmer, because he believed in a magnetic force in animals, peculiar to living beings, by which one acts on another just as the magnet acts on steel; to this the inducing of the hypnotic state was due. The phenomenon was by others called mesmerism, after Mesmer (about 1766), because it was made known to the public everywhere chiefly through his somewhat spectacular methods of producing it. Mesmerism refers, then, primarily to the manner of inducing a hypnotic condition. The term hypnotism, from vँ $\pi \nu$ s, sleep, and $\nu \varepsilon \bar{v} \rho \circ \nu$, nerve, was coined in 1842 by James Braid, who was the first to investigate the subject in a physiological way. This name was intended to imply that the phenomenon was due not to any occult magnetic force, inherent in organic life everywhere, but to a peculiar condition of the nerves. His name replaced mesmerism in popular usage.

HYPOCHONDRIACAL, MELANcholic, Splenetic. These words all refer to an abnormal psychological condition supposed $\supset$ be produced or accompanied by a disorder of the spleen; but they indicate slightly different psychological states.

Hypochondriacal (from Greek i $\pi \dot{o}$ and

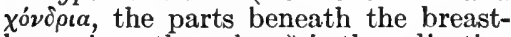
bone, $i . e_{.}$, the spleen) is the adjective corresponding to hypochondria, a gloomy and irritable state of mind in which the subject believes that his health is in a very serious condition and that he is threatened with death. Melancholic (Greek $\mu \varepsilon \lambda a \gamma \chi 0 \lambda i \alpha$, black bile, referring to secretions of the spleen) refers simply to a state of morbid gloom. Splenetic, from Latin splen, Greek $\sigma \pi \lambda \dot{\eta} \nu$, spleen, refers to a state of morbid gloom especially characterized by irritableness of temper, a disposition to take offence at everything.

HYPOCRITE, Dissembler. Hyp-

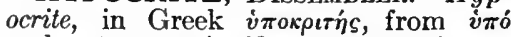

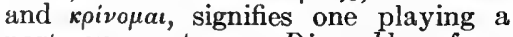
part on a stage. Dissembler, from dissemble, in Latin dissimulo or dis and 
similis, signifies one who makes him- hypocrite is a dissembler; but every disself appear unlike what he really is.

The hypocrite feigns to be what he is not; the dissembler conceals what he is: the former takes to himself the credit of virtues which he has not; the latter conceals the vices that he has; every sembler is not a hypocrite: the hypocrite makes truth serve the purpose of falsehood; the dissembler is content with making falsehood serve his own particular purpose.

- HYPOTHETICAL. See Empirical. 
IDEA, Thо UGнT, Imagnation. Idea, in Latin idea, in Greek ióca, from the root found in Latin videre, to see, signifies the thing seen in the mind. Thought comes from AngloSaxon thencan, modern English think. Imagination signifies the thing imagined, from Latin imago, from the root $i m$, found in imitare, English imitate.

The idea is the simple representation of an object; the thought is the reflection; and the imagination is the combination of ideas: we have ideas of the sun, the moon, and all material objects; we have thoughts on moral subjects; we have imaginations drawn from the ideas already existing in the mind. Ideas are formed; they are the rude materials with which the thinking faculty exerts itself: thoughts arise in the mind by means of association and combination, or recur in the mind by the power of the memory; they are the materials with which the thinking faculty employs itself : imaginations are ereated by the mind's reaction on itself; they are the materials with which the understanding seeks to enrich itself. The term ideas is used in all cases for the mental representation, abstractedly from the agent that represents them: hence ideas are attached to words; ideas are analyzed, confounded, and the like; in which cases the word thought could not be substituted. Thought belongs only to thinking and rational beings: the animals may be said to have ideas, but not thoughts: hence thoughts are either mean, fine, grovelling, or sublime, according to the nature of the mind in which they exist: hence we say with more propriety, to indulge a thought than to indulge an idea; to express one's thoughts, rather than one's ideas, on any subject: although the latter term idea, on account of its comprehensive use, may, without violation of any express rule, be indifferently employed in general discourse for thought; but the former term does not on this account lose its characteristic meaning. Imagination is not only the fruit of thought, but of peculiar thought: the thought may be another's: the imagination is one's own: the thought occurs and recurs; it comes and it goes; it is retained or rejected at the pleasure of the thinking being: the imagination is framed by the power which we term imagination; it is cherished with the partiality of a parent for its offspring. Thoughts are busied with the surrounding objects; imaginations are employed on distant and strange objects: hence thoughts are denominated sober, chaste, and the like; imaginations, wild and extravagant.

See also Perception.

Ideal, Imaginary.-Ideal does not strictly adhere to the sense of its primitive, idea: the idea is the representation of a real object in the mind; but ideal signifies belonging to the idea independently of the reality or the external object. Imaginary preserves the signification of its primitive, imagination (see $F_{A N C Y}$ ) denotes what is created by the mind itself. The ideal is not directly opposed to, but abstracted from the real; the imaginary, on the other hand, is d rectly opposed to the real; it is the unreal thing formed by the imagination. Ideal happiness is the happiness which is formed in the mind without having any direct and actual prototype in nature; but it may, nevertheless, be something possible to be realized; it may be above nature, but not in direct contradiction to it: the imaginary is that which is opposite to some positive existing reality; the pleasure which a lunatic derives from the conceit of being a $\mathrm{king}$ is altogether imaginary.

See also UTOPIAN.

IDIOM. See LANGUAgE.

IDIOT. See Foor.

IDLE, LAzY, InDoLenT. Idle comes from Anglo-Saxon idel, vain, empty. Lazy comes from Low German lasich, allied to loose, signifying languid, idle. 
Indolent, in Latin indolens, from in, not, and dolens, from dolere, to grieve, signifies not grieving, lacking in feeling; hence, lacking in life and energy.

A propensity to inaction is the cormon idea by which these words are connected; they differ in the cause and degree of the quality: idle expresses less than lazy. and lazy less than indolent: one is termed idle who will do nothing useful; one is lazy who will do nothing at all without great reluctance; one is indolent who does not eare to do anything or set about anything. There is no direct inaction in the idler; for a child is idle who will not learn his lesson, but he is aetive enough in that which pleases himself: there is an aversion to eorporeal action in a lazy man, but not always to mental action; he is lazy at work, lazy in walking, or lazy in sitting; but he may not object to any employment, such as reading or thinking, which leaves his body entirely at rest: an indolent man, on the contrary, fails in activity from a defect both in the mind and the body; he will not only not move, but he will not even think, if it give him trouble; and trifling exertions of any kind are sufficient, even in prospect, to deter him from attempting to move.

Lazy is figuratively applied to other objects.

Idle is also applied to things in the sense of leisure and vanity, for which see the next analysis.

Idle, Leisure, Vacant.-Idle is opposed here to busy; leisure comes from Anglo-French leisir, originally the infinitive mood, signifying to be permitted, from Latin licere. $\mathrm{He}$, therefore, who is idle, instead of being busy, commits a fault; which is not always the case with him who is at leisure or free from his employment. Idle is always taken in a sense more or less unfavorable; leisure in a sense perfectly indifferent: if a man says of himself that he has spent an idle hour in this or that place, in amusement, company, and the like, he means to signify he would have spent it better if anything had offered; on the other hand, he would say that he spends his leisure moments in a suitable relaxation: he who values his time will take care to have as few idle hours as possible; but since no one can always be employed in severe labor, he will occupy his leisure hours in that which best suits his taste.

Idle and leisure are said in particular reference to the time that is employed; vacant (see FILL) is a more general term that simply qualifies the thing: an idle hour is one without any proper employment; a vacant hour is in gencral one free from the employments with which it might be filled; a person has leisure time according to his wishes; but he may have vacant time from necessity; that is, when he is in want of employment.

Idle, Vain.-These epithets are both opposed to the solid or substantial; but idle has a more particular reference to what ought or ought not to engage the time or attention; vain, in Latin vanus, signifying empty, seems to qualify the thing without any such reference. A pursuit may be termed either idle or vain: in the former ease, it reflects immediately on the agent for not employing his time on something more serious; but in the latter case it simply charaeterizes the pursuit as one that will be attended with no good consequences: when we consider ourselves as beings who have but a short time to live, and that every moment of that time ought to be thoroughly well spent, we should be careful to avoid all idle concerns; when we consider ourselves as rational beings, who are responsible for the use of those powers with which we have been invested by God we shall be eareful to reject all vain concerns: an idle effort is made by one who does not eare to exert himself for any useful purpose, who works only to please himself; a vain effort may be made by one who is in a state of desperation.

IGNOMINY. See INFAMY.

IGNORANT, ILLITERATE, UNLEARNED, UNLETTERED. Ignorant, in Latin ignorans, from the privative in, and the root gno, signifying to know, signifies not knowing things in general, or not knowing any particular eircumstance. Unlearned, illiterate, and unlettercd are compared with ignorant in the general sense.

Ignorant is a eomprehensive term: 
it includes any degree from the highest to the lowest, and consequently includes the other terms, illiterate, unlearned, and unlettered, which express different forms of ignorance. Ignorance is not always to one's disgrace, since it is not always one's fault; the term is not, therefore, directly reproachful: the poor, ignorant savage is an object of pity rather than condemnation; but when ignorance is coupled with self-conceit and presumption, it is a real deformity: hence the word $i l$ literate, which is mostly used in such cases, has become a term of reproach: an ignorant man who sets up to teach others is termed an illiterate preacher; and quacks, whether in religion or medicine, from the very nature of their calling, are altogether an illiterate race of men. The term illiterate is in all cases taken for one who is without education or even the knowledge of his letters; the words unlearned and unlettered are disengaged from any unfavorable associations. A modest man, who makes no pretensions to learning, may suitably apologize for his supposed deficiencies by saying he is an unlearned or unlettered man; the former is, however, a term of more familiar use than the latter. A man may be described either as generally unlearned or as unlearned in particular sciences or arts; as unlearned in history; unlearned in philosophy; unlearned in the ways of the world: a rustic poet's muse may be described as unlettered.

ILL. See BADLY; EviL.

ILL-FATED. See Hapless.

ILLITERATE. See IgNORANT.

ILLNESS. See SickNESS.

ILLUMINATE, ILLUMINE, ENLIGHTEN. Illuminate, in Latin illuminatus, participle of illumino (from Latin in, and lumen, light), and enlighten, coined with the French en, from the verb lighten, both denote the communication of light; the former in the natural, the latter in the moral sense. We $i l$ luminate by means of artificial lights; or, as in the case of medirval manuscripts (though, in this sense, the term is now obsolete) by color: the sun illuminates the world by its own light: preaching and instruction enlighten the minds of men. Illumine is but a poetic variation of illuminate; as, the Sun of
Righteousness illumined the benighted world; illuminations are employed as public demonstrations of joy; no nation is now termed enlightened but such as has received the light of the Gospel.

Illusion. See Delusion; FalLACY.

ILlUSTRATE. See Explain.

ILlUSTRIOUS. S e D ISTIN GUISHED; FAMOUS.

ILL-WILl. See HATrED.

IMAGE. See LikeNESS.

IMAGINARY. See IDEAL.

IMAGINATION. See FANCY; Idea.

IMAGINE. See APPREHEND; THINK.

IMBECILITY. See Debility.

IMBIBE. See ABSORB.

imitate, Copy, Counterfeit. The idea of taking a likeness of some object is common to all these terms; but imitate (see Follow) is the generic: copy (see that word) and counterfeit, through French contrefait, from the Latin contra, against, and facere, to make, signif ying to make in opposition to the reality, are the specific terms: to imitate is to take a general likeness; to copy, to take an exact likeness; to counterfeit, to take a false likeness: to imitate is, therefore, almost always used in a good or an indifferent sense; to copy mostly, and to counterfeit still of tener, in a bad sense: to imitate an author's style is at all times allowable for one who cannot form a style for himself; but to copy an author's style would be a too slavish adherence even for the dullest writer.

To imitate is applicable to every object, for every external object is susceptible of imitation; and in man the imitative faculty displays itself alike in the highest and the lowest matters, in works of art and moral conduct: to copy is applicable only to certain objects which will admit of a minute likeness being taken; thus, an artist may be said to copy from nature.

To counterfeit is applicable to but few objects: we may counterfeit coin, which is an unlawful act, or we may counterfeit the person, the character, the voice, or the handwriting of any one for whom we would wish to pass, which is also an unlawful act except on the stage.

Imitate, Mimic, Ape, Mock. - To 
imitate is here the general term: to mimic, from the Greek $\mu i \mu \rho s$, an actor or mimic, and to ape, signifying to imitate like an ape (Anglo-Saxon apa, German affe), are both species of vicious imitation. One imitates that which is deserving of imitation, or the contrary: one mimics either that which is not an authorized subject of imitation or which is imitated imperfectly or so as to excite laughter. A person wishes to make that his own which he imitates, but he mimics for the entertainment of others.

To ape is a serious, though an absurd, act of imitation. To mock, Old French mocquer, a Picard form for moucher, to wipe the nose, Latin muccare, to blow the nose (from Latin mucus, English mucus), indicating a vulgar gesture of contempt, signifies to laugh at, and is an ill-natured and vulgar act of imitation. The ape imitates to please himself; the mocker mocks to insult others.

IMMATERIAL. See I N C O R P OREAL; UNIMPORTANT.

IMMEDIATELY. See Directly; Now.

IMMENSE. See ENormous.

IMMINENT, IMPENDING, THREATENING. Imminent, in Latin imminens, from minere, to project, signifies resting or coming upon. Impending, from the Latin pendere, to hang, signifies hanging upon or over. Threat, AngloSaxon threotan, to afflict, vex, urge, is allied to Latin trudere (found in intrude and obtrude), signifying to push, work, urge.

All these terms are used in regard to some evil that is exceedingly near: imminent conveys no idea of duration; impending excludes the idea of what is momentary. A person may be in imminent danger of losing his life in one instant, and the danger may be over the next instant: but an impending danger is that which has bcen long in existence and gradually approaching; we can seldom escape imminent danger by any efforts of our own: but we may be successfully warned to escape from an impending danger. Imminent and impending are said of dangers that are not discoverable; but a threatening evil gives intimations of its own approach; we perceive the threatening tempest in the blackness of the sky; we hear the threatening sounds of the enemy's clashing sword.

IMMODERATE. SEe EXCEssIve. IMMODEST, IMPODENT, SHaMeLEss. Immodest signifies the want of modesty: impudent and shameless signify without shame. Immodest is less than either impudent or shameless: an immodest girl lays aside the ornament of her sex and puts on another garb that is less becoming; but her heart need not be corrupt until she becomes impudent: she lacks a good quality when she is immodest; she is possessed of a positively bad quality when she is impudent. There is always hope that an immodest woman may be conscious of her error, and amend; but of an impudent woman there is no such chance - she is radically corrupt. Impudent may characterize the person or the thing: shameless, from AngloSaxon sceamu, shame, and negative suffix, characterizes the person. A person's air, look, and words are impudent when contrary to all modesty: the person himself is shameless who is devoid of all sense of shame.

See also IMPERTINent; Indecent.

imMunity. See Privilege.

IMPAIR, INJURE. Impair comes through Old French empeirer, from Late Latin impeiorare, compounded of the Latin in and peior, worse, signifying to make worse. Injure, from in, against, and iur, the stem of ius, right, signifies to make otherwise than it ought to be.

Impair seems to be in regard to injury as the species to the genus; what is impaired is injured, but what is injurcd is not necessarily impaired. To impair is a progressive mode of injuring: an injury may take place either by degrees or by an instantaneous act: straining of the eyes impairs the sight, but a blow injures rather than impairs the eye. A man's health may be impaired or injured by his vices, but his limbs are injured rather than impaired by a fall. A person's circumstances are impaired by a succession of misfortunes; they are injured by a sudden turn of fortune.

IMPART. See Communicate.

IMPARTIAL. See NEUTRAL.

IMPASSABLE. See IMPERVIOUS. 
IMPEACH. See ACCUSE.

IMPEDE. See HINDER.

IMPEL. See ACtuate; Compel;

ENCOURAGE.

IMPENDING. See IMMINENT.

IMPERFECTION, DEFECT, FAULT, VICE. These terms are applied either to persons or to things. Imperfection, denoting either the abstract quality of imperfect or the thing which constitutes it imperfect, in a person arises from his want of perfection and the infirmity of his nature; there is no one without some point of imperfection which is obvious to others, if not to himself; he may strive to diminish it, although he cannot expect to get altogether rid of it: a defect (see BLEMISH) is a deviation from the general constitution of man; it is what may be natural to the man as an individual, but not natural to man as a species; in this manner we may speak of a defect in the speech, or a defect in temper. The fault and vice rise in degree and character above either of the former terms; they both reflect disgrace more or less on the person possessing them; but the fault always characterizes the agent, and is said in relation to an individual; the vice, from Latin vitium, a vice or fault, characterizes the action and may be considered abstractedly: hence we speak of a man's faults as the things we may condemn in him; but we may speak of the vices of drunkenness, lying, and the like, without any immediate reference to any one who practices these vices. When they are both employed for an individual their distinction is obvious: the fault may lessen the amiability or excellence of the character; the vice is a stain; a single act destroys its purity; a habitual practice is a pollution.

In regard to things, the distinction depends upon the preceding explanation in a great measure, for we can scarcely use these words without thinking on man as a moral agent, who was made the most perfect of all creatures, and became the most imperfect; and from our imperfection has arisen, also, a general imperfection throughout all the works of creation. The word imperfection is therefore the most unqualified term of all: there may be imperfection in regard to our Maker, or there may be imperfection in regard to what we conceive of perfection; and in this case the term simply and generally implies whatever falls short in any degree or manner of perfection. Defect is a positive degree of imperfection; it is contrary both to our ideas of perfection and to our particular intention: thus, there may be a defect in the materials of which a thing is made; or a defect in the mode of making it: the term defect, however, whether said of persons or things, characterizes rather the object than the agent. Fault, on the other hand, when said of things, always refers to the agent: thus we may say there is a defect in the glass, or a defect in the spring; but there is a fault in the workmanship, or a fault in the putting together, and the like. Vice, with regard to things, is properly a serious or radical defect; the former lies in the constitution of the whole, the latter may lie in the parts; the former lies in essentials, the latter lies in the accidents: there may be a defect in the shape or make of a horse; but the vice is said in regard to his soundness or unsoundness, his docility or indocility.

Imperfection, Weakness, Frailty, Failing, Foible.-Imperfection has already been considered as that which in the most extended sense diminishes the moral perfection of man; the rest are but modes of imperfection varying in degree and circumstances. Weakness is a positive and strong degree of $\mathrm{im}$ perfection which is opposed to strength; it is what we do not so necessarily look for, and therefore distinguishes the individual who is liable to it. Frailty is another strong mode of imperfection which characterizes the fragility of man, but not of all men in the same degree; it differs from weakness in respect to the object. A weakness lies more in the judgment or in the sentiment; frailty lies more in the moral features of an action. It is weakness in a man to yield to the persuasions of any one against his better judgment; it is frailty to yield to intemperance or illicit indulgences. Failings and foibles (from Old French foible, English feeble, Latin flebilis, doleful, from flere, to weep) are the smallest degrees of imperfection to 
which the human character is liable: we all have our failings in temper, and our foibles in our habits and our prepossessions; and he, as Horace observes, is the best who has the fewest.

IMPERIOUS, LORDLY, DOMINEERING, Overbearing. All these epithets imply an unseemly exercise or affeetation of power or superiority. Imperious, from imperare, to command, characterizes either the disposition to command without adequate authority or to convey one's commands in an offensive manner: lordly (from AngloSaxon hlaford, lord, from hlaf, breadEnglish loaf-and weard, guard, English ward, signifying the guardian of the loaf) characterizes the manner of acting the lord: and domineering, from dominus, a lord, denotes the manner of ruling like a lord, or rather of attempting to rule; hence a person's temper or his tone is denominated imperious; his air or deportment is lordly; his tone is domineering. A woman of an imperious temper commands in order to be obeyed; she commands with an imperious tone in order to enforce obedience. A person assumes a lordly air in order to display his own importance; he gives orders in a domineering tone in order to make others feel their inferiority. There is always something offensive in imperiousness; there is frequently something ludicrous in that which is lordly; and a mixture of the ludicrous and offensive in that which is domineering.

These terms are employed for such as are invested with some sort of power, or endowed with some sort of superiority, however trifling; but overbearing is employed for men in the general relations of society, whether superiors or equals. A man of an imperious temper and some talent will frequently be so overbearing in the assemblies of his equals as to awe the rest into silence and carry every measure of his own without contradiction.

See also Commandina.

IMPERTINEN'T, RUDE, SAUCY, IMPUDENT, INSOLENT. Impertinent, in Latin in, a privative prefix, and pertinens, belonging, signifies being or wanting to do what it does not belong to one to be or do. Rude, in Latin rudis, rude, signifies literally unpol- ished, and, in an extended sense, wanting all culture. Saucy comes from sauce, in Latin sals, a, feminine of salsus, salt, signifying literally full of sauce, pungent, and, in an extended sense, stinging like salt. Impudent (see Assurance). Insolent, from the Latin insolens, is a word of doubtful origin, possibly compounded of in, against, and solens, from a root signifying to swellreferring here to the swelling of pride.

Impertinent is allied to rude, as regards one's general relations in soeicty, without regard to station; it is allied to saucy, impudent, and insolent as regards the conduct of inferiors. He who does not respect the laws of eivil society in his intercourse with individuals, and wants to assume to himself what belongs to another, is impertinent: if he carry this impertinence so far as to commit any violent breach of decorum in his behavior, he is rude. Impertinence seems to spring from a too high regard of one's self: rudeness from an ignorance of what is due to others. Impertinent, in comparison with the other terms, saucy, impudent, and insolent, is the most general and indefinite: whatever one does or says that is not compatible with one's station is imperinent; saucy is a sharp kind of impertinence: impudent an unblushing kind of impertinence; insolence is an outrageous kind of impertinence, it runs eounter to all established order: thus, the terms seem to rise in sense. A person may be $i m$ pertinent in words or actions: he is saucy in words or looks: he is impudent or insolent in words, tones, gesture, looks, and every species of action.

IMPERVIOUS, IMPASSABLE, INACCEssible. Impervious, from the Latin in, per, and via, signifies not having a way through; impassable, not to be passed through; inaccessible, not to be approached. A wood is impervious when the trees, branches, and leaves are entangled to such a degree as to admit of no passage at all: a river is impassable that is so deep that it cannot be forded: a roek or a mountain is inaccessible the summit of which is not to be reached by any path whatever. What is impervious is so for a permanency; what is impassable is commonly so only for a time: roads 
are frequently impassable in the winter that are passable in the summer, while a thicket is impervious during the whole of the year: impassable is likewise said only of that which is to be passed by living creatures, but impervious may be extended to inanimate objects; a wood may be impervious to the rays of the sun.

\section{IMPETUOUS. See VIOLENT.}

IMPIOUS. See IrReligious; SaCRILEGIOUS.

IMPLACABLE, UNRELENTING, RELENTLESS, INEXORABLE. Implacable, from Latin in, privative, and placere, to please, signifies not to be softened or pleased. Unrelenting, from the Latin lentus, slow, slack, soft, signifies not rendered soft. Inexorable, from oro, pray, signifies not to be turned by prayers.

Inflexibility is the idea expressed in common by these terms, but they differ in the causes and circumstances with which it is attended. Animosities are implacable when no misery which we occasion can diminish their force, and no concessions on the part of the offender can lessen the spirit of revenge: the mind or character of a man is unrelenting when it is not to be turned from its purpose by a view of the pain which it inflicts: a man is inexorable who turns a deaf ear to every solicitation or entreaty that is made to induce him to lessen the rigor of his sentence. A man's angry passions render him implacable; it is not the magnitude of the offence, but the temper of the offended that is here in question; by implacability he is rendered insensible to the misery he occasions and to every satisfaction which the offender may offer him: fixedness of purpose renders a man unrelenting or relentless; an unrelenting temper is not less callous to the misery produced than an implacable temper; but it is not grounded always on resentment for personal injuries, but sometimes on a certain principle of right and a sense of necessity: the inexorable man adheres to this rule, as the unrelenting man does to his purpose; the former is insensible to any workings of his heart which might shake his purpose, the latter turns a deaf ear to all the solicitations of others which would go to alter his decrees: savages are mostly implacable in their animosities; Titus
Manlius Torquatus displayed an instance of unrelenting severity toward his son; Minos, Eacus, and Rhadamanthus were the inexorable judges of hell.

Implacable and unrelenting are said only of animate beings in whom is wanting an ordinary portion of the tender affections: inexorable may be improperly applied to inanimate objects; justice and death are both represented as inexorable.

IMPLANT, INGRAFT, INCULCATE, INSTIL, INFUSE. To plant is properly to fix plants in the ground; to implant is, in the improper sense, to fix principles in the mind. To ingraft, from graft, to make one plant grow on the stock of another, is to make particular principles flourish in the mind and form a part of the character. Inculcate, from Latin in and culcare, for calcare, or tread into, means to stamp into the mind. To instil, from French instiller, derived from Latin in and stillare, to drop into, is, in the improper sense, to make sentiments, as it were, drop into the mind. To infuse, from in and fusus, past participle of fundere, to pour, is, in the improper sense, to pour principles or feelings into the mind.

To implant, ingraft, and inculcate are said of abstract opinions or rules of right and wrong; instil and infuse of such principles as influence the heart, the affections, and the passions. It is the business of the parent in early life to implant sentiments of virtue in his child; it is the business of the teacher to ingraft them. Instil is a corresponding act with implant; we implant belief; we instil the feeling which is connected with this belief. It is not enough to have an abstract belief of a God implanted into the mind: we must likewise have a love, and a fear of $\mathrm{Him}$, and reverence for His holy name and Word instilled into the mind. To instil is a gradual process which is the natural work of education; to infuse is a more arbitrary and immediate act. Sentiments are instilled into the mind, not altogether by the personal efforts of any individual, but likewise by collateral endeavors; they are, however, infused at the express will and with the express endeavor of some person. Instil is applicable only to permanent sentiments; infuse may be said of any 
partial feeling: hence we speak of infusing poison into the mind by means of insidious and mischievous publications; or infusing jealousy by means of crafty insinuations, or infusing ardor into the minds of soldiers by means of spirited addresses coupled with military successes.

IMPLICATE, INvolve. Implicate, from plicare, to fold, denotes to fold into a thing; and involve, from volvere, to roll, signifies to roll into a thing: by which explanation we perceive that to implicate marks something less entangled than to involve: for that which is folded may be folded only once, but that which is rolled is turned many times. In application, therefore, to human affairs, people are said to be implicated who have taken ever so small a share in a transaction; but they are involved only when they are deeply concerned: the former is likewise especially applied to criminal transactions, the latter to those things which are in themselves troublesome: thus a man is implicated in the guilt of robbery who should stand by and see it done, without interfering for its prevention; he who is in debt in every direction is strictly said to be involved in debt.

IMPLORE. See BEG.

IMPLY. See SigNIFY.

IMPORT. See Signification.

IMPORTANCE, CoNSEqueNCE, Weight, MoMent. Importance, from in and portare, to carry, signifies the carrying or bearing with or in itself. Consequence, from the present participial stem of consequi, to follow, or result, signifies that which follows or results from a thing. Weight, AngloSaxon gewiht, from wegan, to carry, or lift (compare the phrase weigh anchor), hence to weigh, signifies the quantity that a thing weighs. Moment, from momentum, Latin movere, to move, signifies the force that puts in motion.

Importance is what things have in themselves; they may be of more or less importance, according to the value which is set upon them: this may be real or unreal; it may be estimated by the experience of their past utility or from the presumption of their utility for the future: the idea of importance, therefore, enters into the meaning of the other terms more or less. Consequence is the importance of a thing from its consequences. This term, therefore, is peculiarly applicable to such things the consequences of which may be more immediately discerned either from the neglect or the attention: it is of consequence for a letter to go off on a certain day, for the affairs of an individual may be more or less affected by it; an hour's delay sometimes in the departure of a military expedition may be of such consequence as to determine the fate of a battle. The term weight implies a positively great degree of $\mathrm{im}$ portance: it is that importance which a thing has intrinsically in itself, and which makes it weigh in the mind: it is applied, therefore, to such things as offer themselves to deliberation; hence the counsels of a nation are always weighty, because they involve the interests of so many. Moment is that importance which a thing has from the power in itself to produce effects or to determine interests: it is applicable, therefore, only to such things as are connected with our prosperity or happiness: when used without any adjunct, it implies a great degree of importance, but may be modified in various ways, as a thing of no moment, or small moment, or great moment; but we cannot say with the same propriety, a thing of small weight, and still less a thing of great weight: it is a matter of no small moment for every one to choose that course of conduct which will stand the test of a death-bed reflection.

IMPORTANT. See Critical.

IMPORTUNATE. See Pressing.

IMPORTUNITY. See SolicITA-

TION.

IMPOSE. See DeceIve.

IMPOST. Sec TAX.

IMPRECATION. See MALEDICTION.

IMPRINT, IMpress, Engrave. Print and press are both derived from Latin primere, the former from the infinitive, the latter from pressus, the past participle, signifying in the literal sense to press or to make a mark by pressing: to impress and imprint are figuratively employed in the samo sense. Things are impressed on tho mind so as to produce a conviction: they are imprinted on it so as to pro- 
duce recollection. If the truths of Christianity be impressed on the mind, they will show themselves in a corresponding conduct: whatever is imprinted on the mind in early life or by any particular circumstance is not readily forgotten. Engrave, from French $e n$ and grave, imitating Old French $e n$ graver, from Latin in and Old High German graban, to cut, or dig, cognate with English grave, to dig, expresses more in the proper sense than either, imprint, or impress and the same in its moral application; for we may truly say that if the truths of Christianity be engraven in the minds of youth, they can never be eradicated.

IMPRISONMENT. See CoNFrneMENT.

IMPROMPTU. See UNPREMEDITATED.

IMPROVE. See AMEND.

IMPROVEMENT. See Progress. IMPRUDENCE. See Assurance.

IMPUDENT. See IMMODEST; IMPERTINENT.

IMPUGN, Atrack. These terms are employed synonymously only in regard to doctrines or opinions; in which case, to impugn, from in, against, and pugnare, to fight, signifies to call in question, or bring arguments against; to attack is to oppose with warmth. Sceptics impugn every opinion, however self-evident or well-grounded they may be: infidels make attacks upon the Bible and all that is held sacred by the rest of the world. He who impugns may sometimes proceed insidiously and circuitously to undermine the faith of others: he who attacks always proceeds with more or less violence. To impugn is not necessarily taken in a bad sense; we may sometimes impugn absurd doctrines by a fair train of reasoning: to attack (see ATTACK) is sometimes objectionable, either in the mode of the action or its object, or in both; it is a mode of proceeding which may be employed either in the cause of falsehood or of truth: when there are no arguments where-with to impugn a doctrine, it is easy to attack it with ridicule and scurrility: it is one's duty to attack an absurd or an erroneous, or a criminal doctrine, in the interest of truth and progress.

IMPUTE. See AscribE.
INABILITY, DisABILITY. Inability denotes the absence of ability (see ABILITY) in the most general and abstract sense. Disability implies the absence of ability only in particular cases: the inabiliiy lies in the nature of the thing, and is irremediable; the disability lies in the circumstances, and may sometimes be removed: weakness, whether physical or mental, will occasion an inability to perform a task; there is a total inability in an infant to walk and act like an adult: a want of knowledge or of the requisite qualifications may be a disability; in this manner minority of age or an objection to take certain oaths may be a disability for filling a public office.

INACCESSIBLE. See IMrPerviods.

INACTIVE, INERT, Lazy, SlothFUL, SLUGgish. A reluctance to bodily exertion is common to all these terms. Inactive (see Active) is the most general and unqualified term of all; it expresses simply the want of a stimulus to exertion. Inert is something more positive, from the Latin in, privative, and ars, art, without skill or mind; it denotes a specific deficiency either in body or in mind. Lazy (see IDLE). Slothful comes from sloth, which is formed from the adjective slow, originally slowth, and signifies full of slowness; and sluggish, from slug (a Scandinavian word signifying to droop, and hence, to be inactive, drowsy, heavy), denote an expressly defective temperament of the body which directly impedes action.

To be inactive is to be indisposed to action, that is, to the performance of any office, to doing any specific business: to be inert is somewhat more; it is to be indisposed to movement; to be lazy is to move with pain to one's self: to be slothful is never to move otherwise than slowly: to be sluggish is to move in a sleepy and heavy manner. A person may be inactive from a variety of incidental causes, as timidity, ignorance, modesty, and the like, which combine to make him averse to enter upon any business or take any serious step; a person may be inert from temporary indisposition; but laziness, slothfulness, and sluggishness are inherent physical defects: laziness is, however, not altogether independent of the 
mind or the will; but slothfulness and sluggishness are purely the offspring of nature, or, which is the same thing, habit superinduced upon nature. A man of a mild eharacter is frequently inactive.

Some diseases, particularly of the melancholy kind, are accompanied with a strong degree of inertness, since they seem to deprive the frame of its ordinary powers to action, and to produce a certain degree of torpor; hence the term is properly applied to matter to express the highest degree of inactivity, which will not move without an external impulse.

Lazy people move as if their bodies were a burden to themselves; they are fond of rest and particularly averse to be put in action; but they will sometimes move quickly, and perform much when once impelled to move.

Slothful people never vary their pace; they have a physical impediment in themselves to quick motion: sluggish people are with difficulty brought into action; it is their nature to be in a state of stupor.

INADEQUATE. See INCAPABLE.

INADVERTENCY, INATTENTION, Oversight. Inadvertency, from advert, to turn the mind to, is allied to inattention (see ATtentive) when the act of the mind is signified in general terms; and to oversight when any particular instance of inadvertency occurs. Inadvertency never designates a habit, but inattention does; the former term, therefore, is unqualified by the reproachful sense which attaches to the latter: any one may be guilty of inadvertencies, since the mind that is occupied with many subjects equally sèrious may not be turned so steadily toward some others that may escape notice; but inatlention, which designates a direet want of altention, is always a fault, and belongs only to the young, or such as are thoughtless by nature: since inadvertency is an oeeasional act, it must not be too of ten repeated, or it becomes inattention. An oversight is properly a species of inadvertency, which arises from looking over, or passing by, a thing: we pardon an inadvertency in another, since the consequences are never serious; we must be guarded against oversights in business, as their consequences may be serious.
INANIMATE. See LifELESS. INANITY. See VACANCY.

INAPPRECIABLE. See ATOMIC.

INATTENTION. See INADVERTENCY.

INATTENTIVE. See Negligent. INBORN. See INHERENT.

INBRED. See INHERENT.

INCAPABLE, INSUFFICIENT, INCOMPETENT, INADEQUATE. Incapable, that is, nol having capacity (see ABILITY); insufficient, or not sufficient, or not having what is sufficient; incompetent, or not competent (see CoMPETENT), are employed either for persons or for things: the first in a general, the last two in a speeific sense: inadequate, or not adequate or equalled, is applied most generally to things.

When a man is said to be incapable it characterizes his whole mind; if he be said to have insufficiency and incompetency, it regards the particular objects to which the power is applied: he may be insufficient or incompetent for certain things; but he may have a capacity for other things: the term incapacity, therefore, implies a direct charge upon the understanding which is not implied by insufficiency and incompetency.

Incapable is applied sometimes, in colloquial discourse, to signify the absence of that which is bad; insufficient and incompetent always convey the idea of a defieiency in that which is at least desirable: it is an honor to a person to be incapable of falsehood, or incapable of doing an ungenerous action; but to be insufficient and incompetent are, at all events, qualities not to be boasted of, although they may not be expressly disgraceful. These terms are likewise applieable to things, in which they preserve a similar distinetion: infidelity is incapable of affording a man any comfort: when the means are insufficient for obtaining the ends, it is madness to expect suecess; it is a sad condition of humanity when a man's resources are incompetent to supply him with the first necessaries of life.

Inadequate is relative in its signification, like insufficient and incompetent; but the relation is different. A thing is insufficient which does not suffice either for the wishes, the purposes, or 
the necessities of any one in particular or in general cases: thus, a quantity of materials may be insufficient for a particular building: incompetency is an insufficiency for general purposes in things of the first necessity; thus, a person may be incompetent to support a family: inadequacy is still more particular, for it denotes any deficiency which is measured by comparison with the object to which it referred; thus, the strength of an animal may be inadequate to the labor which is required, or a reward may be inadequate to the service.

INCESSANTLY, UNCEASINGLY, UNINTERRUPTEDLY, WITHOUT INTERMISSION. Incessantly and unceasingly are but variations of the same word, Latin cessare, to cease, a frequentative of cedere, to yield; in and un are both negative prefixes. Uninterruptedly (see DisturB). Intermission (see SuBside). Continuity, but not duration, is denoted by these terms: incessantly is the most general and indefinite of all; it signifies without ceasing, but may be applied to things which admit of certain intervals: unceasingly is definite, and signifies never ceasing; it cannot, therefore, be applied to what has any cessation. In familiar discourse, incessantly is an extravagant mode of speech, by which one means to denote the absence of those ordinary intervals which are to be expected; as when one says a person is incessantly talking, by which is understood that he does not allow himself the ordinary intervals of rest from talking: unceasingly, on the other hand, is more literally employed for a positive want of cessation; a noise is said to be unceasing which literally never ceases; or complaints are unceasing which are made without any pauses or intervals. Incessantly and unceasingly are said of things which act of themselves; uninterruptedly is said of that which depends upon other things: it rains incessantly marks a continued operation of nature, independent of everything; but to be uninterruptedly happy marks one's freedom from every foreign influence which is unfriendly to one's happiness. Incessantly and the other two words are employed either for persons or things; without intermission is, however, mostly employed for persons; things act and react incessantly upon one another; a man of a persevering temper goes on laboring without intermission until he has effected his purpose.

incident. See Circumstance; Event.

INCIDENTAL. See Accidental. INCINERATION. See Cremation. INCIPIENT. See EleMENTARY.

INCITE. See Encourage; Excite. InClination, Tendency, ProPensity, Proneness. All these terms are employed to designate the state of the will toward an object: inclination (see ATtachment) denotes its first movement toward an object: tendency, through French from tendere, to stretch, is a continued inclination: propensity, from propensus, past participle of the Latin pro, forward, and pendere, to hang, denotes a still stronger leaning of the will; and prone. from the Latin pronum, accusative of pronus, inclined toward, characterizes a habitual and fixed state of the will toward an object. The inclination expresses the leaning, but not the direction of that leaning; it may be to the right or to the left, upward or downward;' consequently we may have an inclination to that which is good or bad, high or low; tendency does not specify any particular direction; but it is frequently applied to those things which degenerate or lead to what is bad; excessive strictness in the treatment of children has a tendency to damp their spirit: propensity and proneness both designate a downward direction, and consequently refer only to that which is bad and low; a person has a propensity to drinking, and a proneness to lying.

Inclination is always at the command of the understanding; it is our duty, therefore, to suppress the first risings of any inclination to extravagance, intemperance, or any irregularity: as tendency refers to the thing rather than the person, it is our business to avoid that which has a tendency to evil: the propensity will soon get the mastery of the best principles and the firmest resolution; it is our duty, therefore, to seek all the aids which religion affords to subdue every propensity: proneness to evil is inher- 
ent in our nature, which we derive from our animal nature; it is the grace of God alone which can lift us up above this grovelling part of ourselves.

See also BeNT; Disposition.

inCline. See lean; Merge.

INCLOSE, INCLUDE. From the Latin includo (from in, in, and claudere, to shut) are derived inclose and include, inclose being derived through Old French inclore, past participle inclos. The former expresses the proper, and the latter the improper signification: a yard is inclosed by a wall; particular goods are included in a reckoning: the kernel of a nut is inclosed in a shell; morality, as well as faith, is included in Christian perfection.

See also Circumscribe.

INCOHERENT. See INCONSISTENT.

INCOMPETENT. See INCAPABLE.

INCONGRUOUS. See INCONSISTENT.

INCONSIDERABLE. See UNIMPORTANT.

INCONSISTENT, INCONGRUOUS, INCOHERENT. Inconsistent, from in, privative, and consistent (Latin con, together, and sistens, participle of sistere, to eause to stand), marks the unfitness of being placed together. Incongruous, from in, privative, and congruere, to suit, a Latin word of uncertain origin, marks the unsuitableness of one thing to another. Incoherent, from in, privative, con, together, and horere, to stick, marks the incapacity of two things to coalesce or be united to each other.

Inconsistency attaches either to the actions or sentiments of men; incongruity attaches to the modes and qualities of things; incoherency, to words or thoughts; things are made inconsistent by an act of the will; a man acts or thinks inconsistently, according to his own pleasure: incongruity depends upon the nature of the things; there is something very incongruous in blending the solemn service of the church with the extravagant rant of some self-styled religious leaders: incoherence marks the want of eoherence in that which ought to follow sequently; extemporary effusions from the pulpit are often distinguished most by their incoherence.

inconstant. See Changeable.
INCONTROVERTIBLE. See INDUBITABLE.

INCONVENIENCE, ANNOY, MoLEST. To inconvenience is to make not convenient (see Convenient). To annoy eomes from the Old French anoi, Modern French ennui, derived from the Latin phrase in odio, signifying in hatred, or dislike. To molest, from the Latin moles, a mass, or weight, signifies to press with a weight.

We inconvenience in small matters, or by omitting such things as might be convenient; we annoy or molest by doing that which is positively painful: we are inconvenienced by a person's absence; we are annoyed by his presence if he renders himself offensive: we are inconvenienced by what is temporary; we are annoyed by that which is either temporary or durable; we are molested by that which is weighty and oppressive; we are inconvenienced simply in regard to our circumstances; we are annoyed mostly in regard to our corporeal feelings; we are molestcd mostly in regard to our minds: the removal of a seat or a book may inconvenience one who is engaged in business; the buzzing of a fly or the stinging of a gnat may annoy; the impertinent freedom or the rude insults of ill-disposed persons may molest.

INCORPOREAL, UNBODIED, IMMaterial, SpIRITUAL. Incorporeal (sec Corporeal for derivation) marks the quality of not belonging to the body or having any properties in common with it; unbodied (for derivation see Corporeal) denotes the state of being without the body or not inclosed in a body: a thing may therefore be incorporeal without being unbodicd; but not vice versa : the soul of nian is incorporeal, but not unbodied, during his natural life.

Incorporeal is always used in regard to living things, particularly by way of comparison with corporcal or human beings: hence we speak of incorporcal agency, or incorporeal agents, in reference to such beings as are supposed to aet in this world without the help of the body; but immaterial is applied to inanimate objeets; men are corporeal as men, spirits are incorporeal; the body is the material part of man, the soul his immaterial part: what- 
ever external object acts upon the senses is material; but the action of the mind on itself, and its results, are all immaterial: the earth, sun, moon, etc., are termed material; but the impressions which they make on the mind. that is, our ideas of them, are immaterial.

The incorporeal and immaterial have always a relative sense; the spiritual is that which is positive: God is a spiritual, not properly an incorporeal nor immaterial Being: the angcls are likewise designated, in general, as the spiritual inhabitants of heaven; although, when spoken of in regard to men, they may be denominated incorporeal.

See also Corporeal.

INCREASE, GRow. Increase, from the Latin in, in, and crescere, to grow (whence crescent is derived), signifies to grow larger and stronger.

Anglo-Saxon growan, signified to put forth green shoots; it is allied to the word green.

The idea of becoming larger is common to both these terms, but the former expresses the idea in an unqualified manner, and the latter annexes to this gencral idea also that of the mode or process by which this is effected. To increase is either a gradual or an instantaneous act; to grow is a gradual process: a stream increases by the addition of other waters; it may come suddenly or in course of time, by means of gentle showers or the rushing in of other streams; but if we say that the river or stream grows, it is supposed to grow by some regular and continual process of receiving fresh water, as from the running in of different rivulets or smaller streams. To increase is either a natural or an artificial process; to grow is always natural: money increases by artificial means; corn may either increase or grow: in the former case we speak of it in the sense of becoming larger or increasing in bulk; in the latter case we consider the mode of its increasing, namely, by the natural process of vegetation. On this ground we say that a child grows when we wish to denote the natural process by which his body arrives at its proper size; but we may speak of his increasing in stature, in size, and the like. For this reason likewise increase is used in a transitive as well as intransitive sense; but grow always in an intransitive sense: we can increase a thing, though not properly grow a thing, because we can make it larger by whatever means we please; but when it grows it makes itself larger.

In their improper acceptation these words preserve the same distinction: "trade increases" bespeaks the simple fact of its becoming larger; but "trade grows" implies that gradual increase which flows from the natural concurrence of circumstances. The affections which are awakened in infancy grow with one's growth; a natural and moral process is here combined. The fear of death sometimes increases as one grows old; the courage of a truly brave man increases with the sight of danger: a moral process is here indicated which is both gradual and immediate, but in both cases produced by some foreign cause.

See also Enlarge.

Increase, Addition, Accession, Augmentation. - Increase is here, as in the former article, the generic term: there will always be increase where there is augmentation, addition, and accession, though not vice versâ.

Addition is to increase as the means to the end: the addition is the artificial mode of making two things into one; the increase is the result: when the value of one figure is added to another, the sum is increased; hence a man's treasures expericnce an increase by the addition of other parts to the main stock. Addition is an intentional mode of increasing; accession is an accidental mode: one thing is added to another and thereby increased; but an accession takes place of itself; it is the coming or joining of one thing to another so as to increase the whole. A merchant increases his property by adding his gains in trade every year to the mass; but he receives an accession of property either by inheritance or by any other contingency. In the same manner a monarch increases his dominions by adding one territory to another, or by various accessions of territory which fall to his lot. When we speak of an increase we think of the whole and its relative magnitude at different times; when we speak of 
an addition we think only of the part and the agency by which this part is joined; when we speak of an accession we think only of the circumstance by which one thing becomes thus joined to another. Increase of happiness does not depend upon increase of wealth; the miser makes daily additions to the latter without making any to the former: sudden accessions of wealth are seldom attended with any good consequences, as they turn the thoughts too violently out of their sober channel and bend them too strongly on present possessions and good-fortune.

Augmentation is a mode of increasing not merely in quantity or number, but also in value or in the essential ingredient of a thing; it is therefore applied for the most part to the increase of a man's estate, possessions, family, income, or whatever is desirable.

It may also be applied to moral objects, as hopes, fears, joys, etc., with a like distinction.

INCREDULITY. Sce UNBELIEF.

INCULCATE. See IMPLANT.

INCURSION. See INVASION.

INDEBTED, OBLIGED. Indebted is more binding and positive than obliged: we are indebted to whoever confers an essential service: we are obliged to him who does us any service. A man is indebted to another for the preservation of his life; he is obliged to him for an ordinary act of civility: a debt, whether of legal or moral right, must in justice be paid; an obligation which is only moral ought in reason to be returned. We may be indebted to things; we are obliged to persons only: we are indebted to Christianity, not only for a superior faith, but also for a superior system of morality; we ought to be obliged to our friends who admonish us of our faults in friendly wisc. A nation may be indebted to an individual, but men are obliged to one another only as individuals: the English nation is indebted to Alfred for the groundwork of its constitution; the little courtesies which pass between friends in their social intercourse with one another lay them under obligations which it is equally agreeable to receive and to pay.

INDECENT, IMMODEST, INDELI-
CATE. Indecent is the contrary of decent (see Becoming), immodest the contrary of modest (see MoDEST), indelicate the contrary of delicate (see FINE).

Indecency and immodesty violate the fundamental principles of morality: the former, however, in external matters, as dress, words, and looks; the latter in conduct and disposition. A person may be indecent for want of either knowing or thinking better. Indecency may be a partial, immodesty is a positive and entire breach of the moral law. Indecency belongs to both sexes; immodesty is peculiarly applicable to the misconduct of women.

Indecency is less than immodesty, but more than indelicacy: they both regard the outward behavior. It is a great indecency for a man to marry again very quickly after the death of his wife; but a still greater indecency for a woman to put such an affront on her deceased husband: it is a great indelicacy in any one to break in upon the retrement of such as are in sorrow and mourning.

INDEED. See Aye.

INDELICATE. See INDECENT.

INDEMNIFY, COMPENSATE, REIMBURSE. These terms all mean to make good that which has been lost, but they differ somewhat in the extent of their application. Compensate, from Latin con, against, and pensare, to weigh, means, literally, to weigh one thing with another; it is the most general of these three terms. It signifies to give back an equivalent for something lost, taken, or injured. Indemnify and reimburse have a similar meaning, but a more special application. Indemnify is derived from Latin in, privative, damnum, loss, and French fier, English $f y$, from Latin facere, to make. Hence it literally means to make free from loss. It signifies to make a payment to compensate for the loss of life or property. Reimburse is adapted from French rembourser iy substituting Latin re, again, and in, in, for rem. Bourser comes from Latin bursa, a purse, Greek $\beta \dot{v} \rho \sigma \eta$, a hide (purses being usually made of leather), which appears in English as purse. Hence it signifies literally to make in plisse again, and refers to the payment of money in return for money paid out. 
We compensate another for the trouble that he has taken for us by an act of generosity or favor; the United States sought to indemnify itself for the loss of life and property through the attacks of German submarines on trading vessels; we reimburse a friend who has lent us money or paid our debts by returning a sum equivalent to that which he spent. To indemnify and to reimburse are forms of compensation.

INDICATE. See SHow.

INDICATION. See MARK.

INDIFFERENCE, INSENSIBILITY, AрATHY. Indifference signifies no difference, that is, having no difference of feeling for one thing more than another. Insensibility, from Latin in, privative, and sentire, to know through the senses, to feel, signifies incapability of feeling, Apathy, from Greek $\dot{a} \pi \dot{a} \theta \varepsilon \iota \alpha$, from $\dot{a}$, not, and $\pi a \theta_{\varepsilon i \nu}$, to suffer (found in pathetic, pathos, sympathy, etc.), signifies incapability to suffer or to feel.

Indifference is a partial state of the mind; insensibility and apathy are general states of the mind; he who has indifference is not to be awakened to feeling by some objects, though he may by others; but he who has not sensibility is incapable of feeling; and he who has apathy is without any feeling. Indifference is mostly a temporary state; insensibility is either a temporary or a permanent state; apathy is always a permanent state: indifference is either acquired or accidental; insensibility is either produced or natural; apathy is natural. A person may be in a state of indifference about a thing of the value of which he is not aware, or acquire an indifference for that which he knows to be of comparatively little value: he may be in a state of insensibility from some lethargic torpor which has seized his mind; or he may have a habitual insensibility arising from the physical bluntness of his understanding or the deadness of his passions; his apathy is born with him, and forms a prominent feature in the constitution of his mind.

Indifferent, Unconcerned, Regardless. -Indifferent marks the want of inclination: unconcerned, that is, having no concern (see CARE), and regardless, that is, without regard, mark the want of serious consideration. Indifferent regards only the will; unconcerned, either the will or the understanding; regardless, the understanding only: we are indifferent about matters of minor consideration; we are unconcerned or regardless about serious matters that have remote consequences: an author will seldom be indifferent about the success of his work; he ought not to be unconcerned about the influence which his writings may have on the public, or rcgardless of the estimation in which his own character as a man may be held. To be indifferent is sometimes an act of wisdom or virtue; to be unconcerned or regardless is mostly an act of folly or a breach of duty.

See also Neutral.

INDIGENCE. See Poverty.

INDIGENOUS. See NATAL.

INDIGNATION. See ANGER.

INDIGNITY, INSULT. Indignity, from the Latin dignus, worthy, signifying unworthy treatment, regards the feeling and condition of the person offended; insult (see AFFroNT) regards the temper of the offending party. We measure the indignity in our own mind; it depends upon the consciousness we have of our own worth: we measure the insult by the disposition which is discovered in another to degrade us. Persons in high stations are peculiarly exposed to indignities: persons in every station may be exposed to insults. Indignities may, however, be offered to persons of all ranks; but in this case it always consists of more violence than a simple insult; it would be an indignity to a person of any rank to be compelled to do any office which belongs only to a beast of burden.

INDISCRETION. See LAPSE.

INDISPOSITION. See SICKNESS.

INDISPUTABLE. See INDUBITABLE.

INDISTINCT, CONFUSED. Indistinct is negative; it marks simply the want of distinctness: confused is positive; it marks a positive degree of indistinctness. A thing may be indistinct without being confused; but it cannot be confused without being indistinct: two things may be indistinct or not easily distinguished from each other; but many things, or parts of the same things, are confused: two 
letters in a word may be indistinct, but the whole of a writing or many words are confused: sounds are indistinct which reach our ears only in part, but they are confused if they come in great numbers and out of all order. We see objects indistinctly when we cannot see all the features by which they would be distinguished from other objects: we see them confusedly when every part is so blended with the other that no one feature can be distinguished; by means of great distance objects become indistinci; from a defect in sight objects become more confused.

individual. See Particular.

INDOLENT, SUPINE, LISTLESS, Careless. For indolent (in, not, and dolens, suffering, or freedom from pain, hence ease, idlencss). See IdLE. Supine, in Latin supinus, from super, above, signifies lying on one's back or with one's face upward, which, as it is the action of a lazy or idle person, has been made to represent the qualities themselves. Listless, without list, in German lust, desire, signifies without desire. Careless signifies without care or concern.

These terms represent a diseased or unnatural state of the mind when its desires, which are the springs of action, are in a relaxed and torpid state, so as to prevent the necessary degree of exertion. Indolence has a more comprehensive meaning than supineness, and this signifies more than listlessness or carelessness: indolence is a general indisposition of a person to exert either his mind or his body; supineness is a similar indisposition that shows itself on particular occasions: there is a corporeal as well as a mental cause for indolence; but supineness lies principally in the mind: corpulent and largemade people are apt to be indolent; but timid and gentle dispositions are apt to be supine.

The indolent and supine are not, however, like the listless, expressly without desire: an indolent or supine man has desire enough to enjoy what is within his reach, although not always sufficient desire to surmount the aversion to labor in trying to obtain it; the listless man, on the contrary, is altogether without the desire, and is, in fact, in a state of moral torpor, which is, however, but a temporary or partial state arising from particular circumstances; after the mind has been wrought up to the highest pitch, it will sometimes sink into a state of relaxation in which it ceases to have apparently any active principle within itself.

Carelessness expresses less than any of the above; for, though a man who is indolent, supine, and listless is naturally careless, yet carelessness is properly applicable to such as have no such positive disease of mind or body. Carelessness is rather an error of the understanding, or of the conduct, than the will; since the careless man would care, be concerned for, or interested about things if he could be brought to reflect on their importance or if he did not for a time forget himself.

INDUBITABLE, UNQUESTIONABLE, INDISPUTABLE, UNDENIABLE, INCONTROVERTIBLE, IrREFragable. Indubitable signifies admitting of no doubt; unquestionable, admitting of no question (for both see DounT); indisputable, admitting of no dispute (see CoNTrovert); undeniable, not to be denied (see DeNY); incontrovertible, not to be controverted; irrefragable comes from in, against, and a root frag, meaning noise, found also, perhaps, in suffrage, and signifies not to be changed by a popular outery. These terms are all opposed to uncertainty; but they do not imply absolute certainty, for they all express the strong persuasion of a person's mind rather than the absolute nature of the thing: when a fact is supported by such evidence as admits of no kind of doubt it is termed indubitable; when the truth of an assertion rests on the authority of a man whose charaeter for integrity stands unimpeached it is termed unquestionable authority; when a thing is believed to exist on the evidence of every man's senses it is termed undeniable; when a sentiment has always been held as either true or false, without dispute, it is termed indisputable; when arguments have never been controverted they are termed incontrovertible; and when they have never been satisfactorily answered they are termed irrefragable.

INDUCE. See ACTUATE.

indULGE. See Foster; Gratify. 
INDULGENT, FoND. Indulgence (see Gratify) lies more in forbearing from the exercise of authority; fondness (see Amorous) in the outward behavior and endearments: they may both arise from an excess of kindness or love, but the former is of a less objectionable character than the latter. Indulgence may be sometimes wrong, but fondness is seldom right: an indulgent parent is seldom a prudent parent, but a fond parent does not rise above a fool: all who have the care of young people should occasionally relax from the strictness of the disciplinarian and show an indulgence where a suitable opportunity offers; a fond mother takes away from the value of indulgence by an invariable compliance with the humors of her children. However, when applied generally or abstractedly the words are both taken in a good sense.

INDUSTRIOUS. See ACTIVE.

INEFFABLE. See Unspeakable.

INEFFECTUAL. See VAIN.

INELEGANT. See UNGracefUl.

INEQUALITY. See DISPARITY.

INERT. See INACTIVE.

INEXORABLE. See IMPLACABLE.

INEXPRESSIBLE. See UNSPEAKABLE.

infallible, Certain, Positive, SURE, Unerring. Infallible, a compound of in, not, and fallible, failing, erring, from the Latin fallere, to deceive, in French infaillible, signifies the quality of being free from the liability of error. Certain (from Latin certus, sure, and the suffix -anus, allied to cernere, to discriminate) implies that which is fixed, stated, beyond a doubt, anything that is undeniable, indisputable, incontrovertible. Positive concerns that which is real, actual, substantial, existing in fact, and is applicable both to persons and to objects. When, however, the term is related to persons, as a belief or statement, while it may be advanced as absolutely positive, the premises or basic knowledge may be erroneous, and the conclusion, therefore, will not be infallible, though the person may believe it to be so.

Sure implies conditions similar to those that are positive, and, literally, those that are absolutely fixed, established beyond question, and unerring; yet in mortal mind the term at times appears to belie itself, to be fluctuating, as something that to-day has every evidence of being sure may tomorrow prove a delusion, but this is a mere mental misconstruction of the term. Unerring is a term that in common usage is frequently misapplied. God alone is unerring, incapable of mistakes or failure. We speak of a marksman taking an unerring aim, but his action is not completed till his shot has struck its object, and in the meantime a chance change of wind may alter its direction, and though the aim was direct the result is not an unerring shot.

Associated with infallible is the substantive infallibility, implying the state or quality of being exempt from error. At the CEcumenical Council of the Roman Catholic Church, held in Rome in 1870, a dogma was decreed to the effect that when the Roman Pontiff, speaking ex cathedra, or in the discharge of his office, "defines a doctrine regarding faith or morals to be held by the Universal Church, (he) is possessed of that infallibility with which the Divine Redeemer willed that his Church should be endowed," and "that therefore such definitions of the Roman Pontiff are irreformable."

See also OmNiscient.

INFAMOUS, Scandalous. Infamous, like infamy (see INFAMY), is applied to both persons and things; scandalous, only to things: a character is infamous, or a transaction is infamous; but a transaction only is scandalous. Infamous and scandalous are both said of that which is calculated to excite great displeasure in the minds of all who hear it, and to degrade the offenders in the general estimation; but the infamous seems to be that which produces greater publicity and more general reprehension than the scandalous; consequently is that which is more serious in its nature and a greater violation of good morals. Some men of daring character render themselves infamous by their violence, their rapine, and their murders; the trick which was played upon the subscrib- 
ers to the South Sea Company was a scandalous fraud.

Infamy, Ignominy, Opprobrium.Infamy is the opposite to good fame; it consists in an evil report. Ignominy, from the privative in and Latin gnomir for gnomen, old form of nomen, name, signifies an ill name, a stained name. Opprobrium, a Latin word, compounded of $o b$, on, and probrum, disgrace, signifies the highest degree of reproach or stain.

The idea of discredit or disgrace in the highest possible degree is common to all these terms: but infamy is that which attaches either to the person or to the thing; ignominy is thrown upon the person; and opprobrium is thrown upon the agent rather than the action. Infamy causes either the person or the thing to be ill spoken of by all; abhorrence of both is expressed by every mouth, and the ill report spreads from mouth to mouth: ignominy causes the name and the person to be held in contempt; it becomes debased in the eyes of others; opprobrium causes the person to be spoken of in severe terms of reproach, and to be shunned as something polluted. The infamy of a treacherous proceeding is increased by the addition of ingratitude; the ignominy of a public punishment is increased by the wickedness of the offender; opprobrium sometimes falls upon the innocent, when cireumstances seem to convict them of guilt.

INFANTINE. See Childish.

INFECTION. See Contagion.

INFERENCE. See CoNClusion.

INFERIOR. See Second; SUbJect. INFIDELITY. See UNBEliEF.

INFINITE. See Boundless.

INFIRM. See WEAK.

INFLUENCE, AUTHORITY, AscenDENCY or AsCENDENT, SwaY. Influence (see Credit). Authority, in Latin auctoritas, from auctor, the author or prime mover of a thing (originally the increaser or grower, from augere, to increase), signifies that power which is vested in the prime mover of any business. Ascendency, from ascend (see ARISE), signifies having the upper hand. Sway comes from Middle English sweiyen, sway, a word with many Teutonic parallels, allied to swagger.
These terms imply power, under different circumstances: influence is altogether unconnected with any right to direct; authority includes the idea of right necessarily; superiority of rank, talent, or property, personal attachment, and a variety of circumstances give influence; it commonly acts by persuasion, and employs engaging manners, so as to determine in favor of what is proposed: superior wisdom, age, office, and relation give authority; it determines of itself, it requires no collateral aid: ascendency and sway are modes of influence, differing only in degree; they both imply an excessive and improper degree of influence over the mind, independent of reason: the former is, however, more gradual in its process, and consequently more confirmed in its nature; the latter may be only temporary, but may be more violent. A person employs many arts, and for a length of time, to gain the ascendency; but he exerts a sway by a violent stretch of power. It is of great importance for those who have influence to conduct themselves consistently with their rank and station: men are apt to regard the warnings and admonitions of a true friend as an odious assumption of authority, while they voluntarily give themselves up to the ascendency which a valet or a mistress has gained over them, who exert the most unwarrantable sway to serve their own interested and vicious purposes.

Influence and ascendency are said likewise of things as well as persons: true religion will have an influence not only on the outward conduct of a man, but on the inward affections of his heart; and that man is truly happy in whose mind it has the ascendency over every other principle.

INFORM, MAKE KNOWN, ACQUAINT, APPRISE. The idea of bringing to the knowledge of one or more persons is common to all these terms. Inform, from the Latin informare, to shape within, signifies the creative power of knowledge working within the soul; it is therefore the generic term, and the rest specific: to inform is to communicate what has lately happened, or the contrary; but to make known is to bring to light what 
has long been known and purposely concealed: to inform is to communicate directly or indirectly to one or many; to make known is mostly to communicate indirectly to many: one informs the public of one's intentions, by means of an advertisement in one's own name; one makes known a fact through a circuitous channel and without any name.

To inform may be done either personally or otherwise; to acquaint and apprise are immediate and personal communications. One informs the government, or any public body, or one informs one's friends; one acquaints (for derivation see ACQUAINTANCE) or apprises (from Old French aprise, instruction, compounded of Latin $a d$, and the past participle of prehendere, to seize, to take, signifying to take information to another) only one's friends or particular individuals: one is informed of that which concerns either the informant or the person informed; one acquaints a person with, or apprises him of, such things as peculiarly concern himself, but the latter in more specific circumstances than the former: one informs a correspondent by letter of the day on which he may expect to receive his order, or of one's own! wishes with regard to an order; one acquaints a father with all the circumstances that concern his son's conduct: one apprises a friend of a bequest that has been made to him; one informs the magistrate of any irregularity that occurs; one acquaints the master of a family with the misconduct of his servants: one apprises a person of the time when he will be obliged to appear.

Inform may be applied figuratively to things; the other terms to persons only in the proper sense.

Inform, Instruct, Teach.-The communication of knowledge in general is the common idea by which these words are connected with one another. Inform is here, as in the preceding article, the general term; the other two are specific terms. To inform is the act of persons in all conditions; to instruct and teach are the acts of superiors, either on one ground or another: one informs by virtue of an accidental superiority or priority of knowledge; one instructs by virtue of superior knowledge or supe- rior station; one teaches (Anglo-Saxon trecan, to show how to do, from the root found in English token) by virtue of superior knowledge rather than of station: diplomatic agents inform their governments of the political transactions in which they have been concerned; government instructs (Latin in and structus, past participle of struere, to build up) its different functionaries and officers in regard to their mode of proceeding; professors and preceptors teach those who attend public schools to learn. To inform is applicable to matters of general interest: we may inform ourselves or others on anything which is a subject of inquiry or curiosity, and the information serves either to amuse or to improve the mind: to instruct is applicable to matters of serious concern, or to that which is practically useful; a parent instructs his child in the course of conduct he should pursue: to teach regards matters of art and science; the learner depends upon the teacher for the formation of his mind and the establishment of his principles.

To inform and to teach are employed for things as well as persons; to instruct only for persons: books and reading inform the mind; history or experience teaches mankind.

Informant, Informer. - These two epithets, from the verb to inform, have acquired by their application an important distinction, the informant being he who informs for the benefit of others, and the informer to the injury of others. What the informant communicates is for the benefit of the individu$\mathrm{al}$, and what the informer communicates is for the benefit of the whole. The informant is thanked for his civility in making the communication; the informer undergoes a great deal of odium, but is thanked by no one, not even by those who employ him. We may all be informants in our turn, if we know of anything of which another may be informed; but none are informers who do not inform against the transgressors of any law.

See also Atrache.

Information, Intelligence, Notice, Advice.-Information signifies the thing of which one is informed: intelligence, from the Latin intellegere (from inter, between, and legere, to choose, signifying to choose between, hence to dis- 
cern or understand), indicates that by which one is made to understand: notice, from the Latin notitia, is that which brings a circumstance to our knowledge: advice (see ADMONITION) signifies that which is made known. These terms come very near to each other in signification, but differ in application: information is the most general and indefinite of all; the three others are but modes of information. Whatever is communicated to us is information, be it public or private, open or concealed: notice, intelligence, and advice are mostly public, but particularly the former. Information and notice may be communicated by word of mouth or by writing; intelligence is mostly communicated by writing or printing; advices are mostly sent by letter: information is mostly an informal mode of communication; notice, intelligence, and advice are mostly formal communications. A servant gives his master information, or one friend sends another information from the country; magistrates or officers give notice of such things as it coneerns the public to know and to observe; spies give intelligence of all that passes under their notice; or intelligence is given in the public prints of all that passes worthy of notice: a military commander sends advice to his government of the operations which are going forward under his direction; or one merchant gives advice to another of the state of the market. Intelligence, as the first intimation of an interesting event, ought to be early; advices, as entering into details, ought to be clear and particular; official advices often arrive to contradict non-official intelligence.

Information and intelligence, when applied as characteristics of men, have a further distinction: the man of information is so denominated only on account of his knowledge; but a man of intelligence is so denominated on account of his understanding as well as experience and information. It is not possible to be intelligent without information; but we may be well informed without being remarkable for intelligence: a man of information may be an agreeable companion, and fitted to maintain conversation; but an intelli- gent man will be an instructive companion, and most fitted for conducting business.

INFRACTION. See INFringe.

INFRINGE, Violate, Transgress. Infringe, from Latin infringere, frangere, to break, signifies to break into. Violate, from a hypothetical adjective based on the Latin vis, force, signifies to break with force. Transgress, from trans, across, and gredi (past participle gressus), to step, signifies to go beyond, or farther than we ought.

Civil and moral laws and rights are infringed by those who aet in opposition to them: treaties and engagements are violated by those who do not hold them sacred: the bounds which are prescribed by the moral law are transgressed by those who are guilty of any excess. It is the business of government to see that the rights and privileges of individuals or particular bodies be not infringed; policy but too frequently runs counter to equity; where the particular interests of states are more regarded than the dictates of conscience, treaties and compacts are violated: the passions, when not kept under proper control, will ever hurry on men to transgress the limits of right reason.

See also Excroach.

Infringement, Infraction.-Infringement and infraction, which are both derived from the Latin verb infringo or frango, are employed according to the different senses of the verb infringe, the former being applied to the rights of individuals, either in their domestic or public capacity, and the latter rather to national transactions. Politeness, which teaches us what is due to every man in the smallest concerns, considers any unaskerl-for interference in the private affairs of another as an infringement. Equity, which enjoins on nations as well as individuals an attentive consideration to the interests of the whole, forbids the infraction of a treaty in any case.

INFUSE. See IMPLANT.

INGENUITY, WiT. Ingenuity (see Ingendous). Wit, from the AngloSaxon witt, knowledge, German wissen, to know, signifies knowledge or understanding.

Both these terms imply acuteness of 
understanding, and differ mostly in its mode of displaying itself. Ingenuity comprehends invention; wit is the fruit of the imagination, which forms new and sudden conceptions of things. One is ingenious in matters either of art or science; one is witty only in matters of sentiment: things may, therefore, be ingenious, but not witty; or witty, but not ingenious; or both witty and ingenious. A mechanical invention, or any ordinary contrivance, is ingenious, but not witty: we say, an ingenious, not a witty solution of a difficulty; a flash of wit, not a flash of ingenuity: a witty humor, a witty conversation, not an ingenious humor or conversation: on the other hand, a thought is ingenious, as it displays acuteness of intellect and aptness to the subject; it is witty, inasmuch as it contains point and strikes on the understanding of others. Ingenuity is expressed by means of words or shows itself in the act; mechanical contrivances display ingenuity: wit can be only expressed by words; some men are happy in the display of their wit in conversation.

Sometimes the word wit is applied to the operations of the intellect generally, which brings it still nearer in sense to ingenuity, but in this case it always impiies a quick and sharp intellect as compared with ingenuity, which may be the result of long thought or be employed on graver matters.

INGENUOUS, I N GE $\mathrm{N} I O \mathrm{O} \mathrm{s}$. It would not have been necessary to point out the distinction between these two words if they had not been confounded in writing as well as in speaking. Ingenuous, in Latin ingenuus, and ingenious, in Latin ingeniosus, are, either immediately or remotely, both derived from ingignere, to be inborn; but the former regards the freedom of the station and consequent nobility of the character which is inborn: the latter regards the genius or mental powers which are inborn. Truth is coupled with freedom or nobility of birth; the ingenuous, therefore, bespeaks the inborn freedom, by asserting the noblest right, and following the noblest impulse, of human nature, namely, that of speaking the truth; genius is altogether a natural endowment, that is, born with us, indepen- dent of external circumstances; the ingenious man, therefore, displays his powers as occasion may offer. We love the ingenuous character on account of the qualities of his heart; we admire the ingenious man on account of the endowments of his mind. One is ingenuous as a man or ingenious as an author: a man confesses an action ingenuously; he defends it ingeniously.

See also Frank; Naïve.

INGRAFT. See IMPLANT.

INGRATIATE. See Insindate.

INGULF. See ABSORB.

INHABIT. See ABIDE.

INHERENT, INBRED, INBORN, INNATE. The inherent, from hoereo, to stick, denotes a permanent quality or property, as opposed to that which is adventitious and transitory. Inbred denotes that which is derived principally from habit or by a gradual process, as opposed to what is acquired by actual efforts. Inborn denotes that which is purely natural, in opposition to the artificial. Inherent is the most general in its sense; for what is inbred and inborn is naturally inherent; but all is not inbred and inborn which is inherent. Inanimate objects have inherent properties; but the inbred and inborn exist only in that which receives life; solidity is an inherent, but not an inbred or inborn, property of matter: a love of truth is an innate property of the human mind; it is consequently inherent, inasmuch as nothing can totally destroy it. That which is inbred is bred or nurtured in us from our birth; that which is inborn is simply born in us: a property may be inborn, but not inbred; it cannot, however, be inbred and not inborn. Habits, which are ingrafted into the natural disposition, are properly inbred. Propensities, on the other hand, which are totally independent of education or external circumstances, are properly inborn, as an inborn love of freedom; hence, likewise, the properties of animals are inbred in them, inasmuch as they are derived through the medium of the breed of which the parent partakes.

Inborn and innate, from the Latin natus, born, are precisely the same in meaning, yet they differ somewhat in application. Poetry and the grave style have adopted inborn; philosophy 
has adopted innate: genius is inborn in some men; nobility is inborn in others: there is an inborn talent in some men to command, and an inborn fitness in others to obey. Mr. Locke and his followers are pleased to say there is no such thing as innate ideas: and if they mean only that there are no sensible impressions on the soul until it is acted upon by external objects they may be right: but if they mean to say that there are no inborn characters or powers in the soul which predispose it for the reception of certain impressions, they contradict the experience of the learned and the unlearned in all ages, who believe, and that from close observation of themselves and others, that man has, from his birth, not only the general character which belongs to him in common with his species, but also those peculiar characteristics which distinguish individuals from their earliest infancy: all these characters or characteristics are, therefore, not supposed to be produced, but elicited, by circumstances; and ideas, which are but the sensible forms that the soul assumes in its connection with the body, are, on that account, in vulgar language termed innate.

INHUMAN. See Cruel.

INIMICAL. See ADVERSE.

INIQUITOUS. See WICKED.

INJUNCTION. See Command.

INJURE. See IMPAIR.

INJURY, Damage, Hurt, Harm, Mischief. All these terms are employed to denote what is done to the disadvantage of any person or thing.

The term injury (sce DisadvantaGe) sometimes includes the idea of violence, or of an act done contrary to law or right, as to inflict or receive an injury, to redress injuries, etc.

Injury is often taken in the general sense of what makes a thing otherwise than it ought to be: the other terms are taken in that sense only, and denote modes of injury. Damage, from damnum, loss, and a suffix, is that injury to a thing which occasions loss to a person or a diminution of value to a thing. Hurt comes from Old French hurter, to strike or dash against, hence to injure. Its ultimate origin is unknown; it significs the injury which destroys the soundness or integrity of things: the harm (see Evin) is the smallest kind of injury, which may simply produce inconvenience or trouble: the mischief is a great injury, which mcre or less disturbs the order and consistency of things. Injury is applicable to all bodies indiscriminately, physical and moral; damage to physical bodies only; hurt to physical bodies properly, and to moral objects figuratively. Trade may suffer an injury, or a building may suffer an injury, from time or a variety of other causes: a building, merchandise, and other things may suffer a damage if they are exposed to violence.

Hurt is applied to the animal body; a sprain, a cut, or bruise are little hurts. It may be figuratively applied to other bodies which may suffer in a similar manner, as a hurt to one's good name.

Harm and mischief are as general in their application as injury, and comprehend what is physically as well as morally bad, but they are more particularly applicable to what is done intentionally by the person: whence ready to do harm or mischief is a characteristic of the individual.

As applied to things, harm and mischief are that which naturally results from the object; when a thing is said to do harm or mischief, that implies that it is its property.

See also Injustice; Scathe.

INJUSTICE, INJURY, WroNG. Injustice (see Justice), injury (see DisadVANTAGE), and wrong, from Late AngloSaxon wrang, cognate with wring, meaning a hurt resulting from crushing or wringing, are all opposed to the right; but the injustice lies in the principle, the injury in the action that injurcs. There may, therefore, be injustice where there is no specific injury; and, on the other hand, there may be injury where there is no injustice. When we think worse of a person than we ought to think, we do him an act of injustice; but we do not, in the strict sense of the word, do him an injury: on the other hand, if we say anything to the discredit of another, it will be an injury to his reputation if it be believed; but it may not be an injustice, if it be strictly conformable to truth, and that which one is compelled to say.

The violation of justice, or a breach of the rule of right, constitutes the in- 
justice; but the quantum of ill which falls on the person constitutes the injury. Sometimes a person is dispossessed of his property by fraud or violence; this is an act of injustice; but it is not an injury if, in consequence of this act, he obtains friends who make it good to him beyond what he has lost: on the other hand, a person suffers very much through another's inadvertency, which to him is a serious injury, although the offender has not been guilty of injustice.

A wrong partakes both of injustice and injury; it is, in fact, an injury done by one person to another in express violation of justice. The man who seduces a woman from the path of virtue does her the greatest of all wrongs. One repents of injustice, repairs injuries, and redresses wrongs.

INNATE. See INHERENT.

INNER. See INWARD.

INNOCENT. See Guiltless; UnOFFENDING.

INOFFENSIVE. See UNOFFENDING.

INORDINATE. See Irregular.

INQUIRE. See AsK.

INROAD. See INVASION.

INSANITY. See DERANGEMENT.

INSCRUTABLE. See UNSEARCHABLE.

INSIDE, INTERIOR. The term inside may be applied to bodies of any magnitude, small or large; interior is peculiarly appropriate to bodies of great magnitude. We may speak of the inside of a nutshell, but not of its interior: on the other hand, we speak of the interior of St. Paul's or the interior of a palace. This difference of application is not altogether arbitrary: for inside literally signifies the side that is inward; but interior signifies the space which is more inward than the rest, which is enclosed in an enclosure, consequently cannot be applied to anything but a large space that is enclosed.

INSIDIOUS, Treacherous. Insidious, in Latin insidiosus, from insidio, stratagem or ambush (from insidere, to lie in wait or ambush, from in, in, and sedere, to sit), signifies as much as lying in wait. Treacherous is derived through Old French trecherie from Late Latin triccare, based on Latin trice, wiles, difficulties, by which the English trick may also be influenced, and signifies the disposition to deceive, to overcome by wiles.

The insidious man is not so active as the treacherous man; the former only lies in wait to insnare us when we are off our guard; the latter throws us off our guard by lulling us into a state of security, to get us more effectually into his power: an enemy may be denominated insidious, but a friend is treacherous. He who is afraid of avowing his real sentiments on religion makes insidious attacks either on its ministers, its doctrines, or its ceremonies: he who is most in the confidence of another is capable of being the most treacherous toward him.

See also Treacherous.

INSIGHT, INSPECTION. The insight into a thing is what we receive: the inspection is what we give: one gets a view into a thing by an insight; one takes a view over a thing by an inspection. An insight serves to increase our own knowledge; inspection enables us to instruct or direct others. An inquisitive traveller tries to get an insight into the manners, customs, laws, and government of the countries which he visits; by inspection a master discovers the errors which are committed by his scholars, and sets them right.

INSIGNIFICANT. See UNIMPORTANT.

INSINUATE, IngRatiate. Insinuate (see HiNT) and ingratiate, from gratus, grateful or acceptable, are employed to express an endeavor to gain favor; but they differ in the circumstances of the action. A person who insinuates adopts every art to steal into the good-will of another; but he who ingratiates adopts unartificial means to conciliate good-will. A person of insinuating manners wins upon another imperceptibly, even so as to convert dislike into attachment; a person with ingratiating manners procures good-will by manifest efforts. Insinuate and ingratiate may differ in the motive, as well as the mode, of the action: the motive is, in both cases, self-interest; but the former is unlawful, and the latter allowable. In proportion as the object to be attained by another's favor is base, so is it 
necessary to have recourse to insinuation; when the object to be attained is that which may be avowed, ingratiating will serve the purpose. Low persons insinuate themselves into the favor of their superiors, in order to obtain an influence over them: it is commendable in a young person to wish to ingratiate himself with those who are entitled to his esteem and respect. In modern use, however, ingratiate clearly has begun to assume somewhat the same unfavorable connotation of insinuate.

Insinuate may be used in the improper sense for unconscious agents; ingratiate is always the act of a conscious agent. Water will insinuate itself into every body that is in the smallest degree porous; there are few persons of so much apathy that it may not be possible, one way or another, to ingratiate one's self into their favor.

Insinuation, Reflection.-These both imply personal remarks, or such remarks as are directed toward an individual; but the former is less direct and more covert than the latter. An insinuation always deals in half-words; a reflection is commonly open. They are both levelled at the individual with no good intent; but the insinuation is general, and may be employed to convey any unfavorable sentiment; the reflection is particular, and commonly passes between intimates and persons in close connection. The insinuation concerns the honor, the moral character, or the intellectual endowments of the person: the reflection respects his particular conduct or feelings toward another. Envious people throw out insinuations to the disparagement of those whose merits they dare not openly question; when friends quarrel they deal largely in reflections on the past.

1.VSIPID, Dull, Flat. Insipid, in Latin insipidus, from in, privative, and sapere, to taste, signifies without savor. Dull (see Dull). Flat (sce Flat).

A want of spirit in the moral sense is designated by these epithets, which borrow their figurative meaning from different properties in nature: the taste is referred to in the word insipid; the properties of colors are considered un- der the word dull; the property of surface is referred to by the word flat. As the want of flavor in any meat makes it insipid and renders it worthless, so does the want of mind or character in a man render him equally insipid and devoid of the distinguishing characteristic of his nature: as the beauty and perfection of colors consist in their brightness, the absence of this essential property, which constitutes dulness, renders them uninteresting objects to the eye; so the want of spirit in a moral composition, which constitutes its dulness, deprives it at the same time of that ingredient which should awaken attention: as in the natural world objects are either elevated or flat, so in the moral world the spirits are either raised or depressed, and such moral representations as are calculated to raise the spirits are termed spirited, while those which fail in this object are termed flat. An insipid writer is without sentiment of any kind or degree; a dull writer fails in vivacity and vigor of sentiment; a flat performance is wanting in the property of provoking mirth, which should be its peculiar ingredient.

INSIST, PERsist. Both these terms being derived from the Latin sisto, to stand, express the idea of resting or keeping to a thing; but insist signifies to rest on a point, and persist, from per, through or by, and sisto (sce CoNTINUE), signifies to keep on with a thing, to carry it through. We insist on a matter by maintaining it; we persist in a thing by continuing to do it: we insist by the force of authority or argument; we persist by the mere act of the will. A person insists on that which he conceives to be his right: or he insists on that which he conceives to be right: but he persists in that which he has no will to give up. To insist is, therefore, an act of discretion; to persist is mostly an act of folly or caprice: the former is always taken in a good or indifferent sense; the latter mostly in a bad sense. A parent ought to insist on all matters that are of essential importance to his children; a spoiled child persists in its follies from perversity of humor.

INSNARE, ENTrap, ENTaNGLe, INvEIGLE. The idea of getting any ob- 
ject artfully into one's power is common to all these terms: to insnare is to take in, or by means of, a snare, from Anglo-Saxon sneare, a cord, string, or noose; to entrap is to take in a trap, from Anglo-Saxon treppe, a step, a trap being a contrivance into which an animal steps-allied to tramp; to entangle is to take in a tangle, which is a Scandinavian word, a frequentative of tang, sea-weed, and means to twist around and around like sea-weed; to inveigle, or to take by means of making blind, is avitiation of the French aveugle, blind, from Latin $a b$, without, and oculum, eye.

Insnare and entangle are used either in the natural or moral sense; entrap mostly in the natural, sometimes in the figurative, inveigle only in the moral sense. In the natural sense birds are insnared by means of bird-lime, nooses, or whatever else may deprive them of their liberty: men and beasts are entrapped in whatever serves as a trap or an enclosure; they may be entrapped by being lured into a house or any place of confinement; all creatures are entangled by nets, or that which confines the limbs and prevents them from moving forward.

In the moral sense, men are said to be insnared by their own passions and the allurements of pleasure into a course of vice which deprives them of the use of their faculties and makes them virtually captives; they are entangled by their errors and imprudences in difficulties which interfere with their moral freedom and prevent them from acting. They are inveigled by the artifices of others when the consequences of their own actions are shut out from their view, and they are made to walk like blind men.

INSOLENT. See IMPERTINENT.

INSOLVENCY, FAILURE, BANKRUPTCY. Insolvency, from Latin in, not, and solvere, to loose, to discharge one's obligations, hence to pay, signifies the state of not being able to pay. Failure (see that word). Bankruptcy, modified etymologically from French banqueroute by knowledge of the second element, from the two words banka and rupta, signifies literally a broken bank.

All these terms are in particular use in the mercantile world, but are not excluded also from general application.
Insolvency is a state; failure, an act consequent upon that state; and bankruptcy is an effect of that act. Insolvency is a condition of not being able to pay one's debts; failure is a cessation of business, from the want of means to carry it on; and bankruptcy is a legal surrender of all one's remaining goods into the hands of one's creditors, in consequence of a real or supposed insolvency. These terms are seldom confined to one person or description of persons. As an incapacity to pay debts is very frequent among others besides men of business, insolvency is said of any such persons; a gentleman may die in a state of insolvency who does not leave effects sufficient to cover all demands. Although failure is here specifically taken for a failure in business, yet there may be a failure in one particular undertaking without any direct insolvency: a failure may likewise imply only a temporary failure in payment, or it may imply an entire failure of the concern. As a bankruptcy is a legal transaction, which entirely dissolves the firm under which any business is conducted, it necessarily implies a failure to the full extent of the term; yet it does not necessarily imply an insolvency; for some men may, in consequence of a temporary failure, be led to commit an act of bankruptcy who are afterward enabled to give a full dividend to all their creditors.

INSPECTION, SUPERINTENDENCY, Oversight. The office of looking into the conduct of others is expressed by the first two terms, but inspection comprehends little more than the preservation of good order; superintendence includes the arrangement of the whole. The monitor of a school has the inspection of the conduct of his school-fellows, but the master has the superintendence of the school. The officers of an army inspect the men, to see that they observe all the rules that have been laid down for them; a general or superior officer has the superintendence of any military operation. Fidelity is peculiarly wanted in an inspector, judgment and experience in a superintendent. Inspection is said of things as well as persons; oversight only of persons; one has the inspection of books in order to ascertain their ac- 
curaey; one has the oversight of persons to prevent irregularity: there is an inspector of the customs and an overseer of the poor.

See also Insight.

INSPECTOR. See Censor.

INSPIRE. See Aximate; Thrill.

INSPIRING. See ElectrIC.

INSTANCE. See ExAMple.

INSTANT, MoMENT. Instant, from instare, to stand over, signifies the point of time that stands over us, or, as it were, over our heads. Moment, from the Latin momentum, from movere, to move, signifies properly movement, but is here taken for the small particle of time in which any movement is made.

Instant is always taken for the time present; moment is taken generally for either past, present, or future. A dutiful child comes the instant he is called; a prudent person embraces the favorable moment. When they are both taken for the present time, instant expresses a much shorter space than moment; when we desire a person to do a thing this instant, it requires haste: if we desire him to do it this moment, it only admits of no delay. Instantaneous relief is necessary on some occasions to preserve life; a moment's thought will furnish a ready wit with a suitable reply.

Instant, Jiffy.-Jiffy is a colloquial word of uncertain origin, differing in its meaning from moment, much as instant differs, but indicating a still briefer moment of time than instant. It cannot, however, be employed in serious writing.

INSTIGATE. See Encodrage.

INSTIL. See IMPLANT.

INSTITUTE, Establish, Found, ERECT. To institute in Latin institutus, participle of instituo, from in and statuerc, to place or appoint, signifying to dispose or fix for a specific end, is to form according to a certain plan; to establish (see FIX) is to fix in a certain position what has been formed; to found (see Found) is to lay the foundation of anything; to erect (see BuILD) is to make erect. Laws, communities, and particular orders are instituted; schools, colleges, and various societies are established: in the former case something new is supposed to be framed; in the latter case it is supposed only to have a certain situation assigned to it. The order of the Jesuits was instituted by Ignatius de Loyola; schools were established by Alfred the Great in various parts of his dominions. The act of instituting comprehends design and "method; that of establishing includes the idea of authority. The Inquisition was instituted in the time of Ferdinand; the Church of England is established by authority. To institute is always the immediate act of some agent; to establish is sometimes the effect of circumstances. Men of public spirit institute that which is for the public good; a communication or trade between certain places becomes established in course of time. An institution is properly of a public nature, but establishments are as often private: there are charitable and literary institutions, but domestic establishments.

To found is a species of instituting which borrows its figurative meaning from the nature of buildings and is applicable to that which is formed after the manner of a building; a public school is founded when its pecuniary resources are formed into a fund or foundation. To erect is a species of founding, for it expresses, in fact, a leading particular in the act of founding: nothing can be founded without being erected; although some things may be erecled without being expressly founded in the natural sense; a house is both founded and erected; a monument is erected, but not founded; so in the figurative sense, a college is founded and consequently erected: but a tribunal is erected, not forended.

INSTRUCT. See INForM.

INSTRUCTION. See ADVICE; EDUCATION.

INSTRUCTIVE. See Didactic.

INSTRUMENT, TOOL. Instrument, in Latin instrumenlum, from instruo, signifies the thing by which an effect is produced. Tool comes from AngloSaxon tol, an implement for working, signifying the thing with which one toils. These terms are both employed to express the means of producing an end. An instrument is a tool of delicate or elaborate mechanism. Applied figuratively to persons, instrument is used mostly in a good sense, tool only in a 
bad sense. Individuals in high stations are of ten the instruments in bringing about great changes in nations; spies and informers are the tools of government.

INSUFFICIENT. See INCAPABLE; UNSATISFACTORY.

INSULT. See AFFront; Indignity. INSUPERABLE. See INVINCIBLE. INSURRECTION, SEDITION, REBELLION, RevolT. Insurrection, from insurrectus, participle of surgere (English surge), to rise up, signifies rising up against any power that is. Sedition, in Latin seditio, compounded of sed, for se and itio, signifies a going apart, that is, the people going apart from the government. Rebellion, from Latin re, against, and bellum, war, signifies turning upon or against, in a hostile manner, that to which one has been before bound. Revolt, in French révolter, is most probably compounded of re and volter, from volvere, to roll, signifying to roll or turn back from, to turn against that to which one has been bound.

The term insurrection is general; it is used in a good or bad sense, according to the nature of the power against which one rises up: sedition and rebellion are more specific; they are always taken in the bad sense of unallowed opposition to lawful authority. There may be an insurrection against usurped power, which is always justifiable; but sedition and rebellion are levelled against power universally acknowledged to be legitimate. Insurrection is always open; it is a rising up of many in a mass; but it does not imply any concerted or any specifically active measure: a united spirit of opposition, as the moving cause, is all that is comprehended in the meaning of the term: sedition is either secret or open, according to circumstances; in popular governments it will be open and determined; in monarchical governments it is secretly organized: rebellion is the consummation of sedition; the scheme of opposition which has been digested in secrecy breaks out into open hostilities and becomes $r e$ bellion. Insurrections may be made by nations against a foreign dominion, or by subjects against their government: sedition and rebellion are carried on by subjects only against their government.

Revolt, like rebellion, signifies originally a warring or turning against the power to which one has been subject; but revolt is mostly taken either in an indifferent or a good sense for resisting a foreign dominion which has been imposed by force of arms.

Rebel and revolt may be figuratively applied to the powers of the mind when opposed to each other: the will rebels against the reason.
INTEGRAL. See WHOLE.
INTEGRITY. See HoNESTY.
INTELlect, Genius, Talent. Intellect, in Latin intellectus, from inter, between, and the past participle of $l c$ gere, to choose, meaning that which chooses between or judges, signifies the gift of understanding, as opposed to mere instinct or impulse. Genius, in Latin genius, from gignere, to be born, signifies that which is peculiarly born with us. Talent (see FAcUlTy).

Intellect is here the generic term, and includes in its meaning that of the two other terms; there cannot be genius and talent without intellect, but there may be intellect without any express genius $0^{\cdot}$ talent. Intellect is the intellectual power improved and exalted by cultivation and exercise; in this sense we speak of a man of intellect, or a work that displays great intellect; genius is the particular bent of the intellect which is born with a man, as a genius for poetry, painting, music, etc.; talent is a particular mode of intellect which qualifies its possessor to do some things better than others, as a talent for learning languages, a talent for the stage, etc.

See also Understanding.

INTELlECTUAL. See Mental.

INTELLIGENCE. See INFORMATION.

INTEMPERATE. See Excessive. INTEND. See DESIGN.

INTENT, INTENSE. Intent and intense are both derived from the verb to intend, Latin intendere, signifying to stretch toward a point or to a great degree: the former is said only of the person or mind; the latter qualifies things in general: a person is intent when his mind is on the stretch toward I an object; his application is intense 
when his mind is for a continuance closely fixed on certain objects; cold is intense when it seems to have reached its highest pitch. -

See also TeNor.

INTERCEDE, INTERPOSE, MEDIATE, INTERFERE, INTERMEDDLE. Intercede: from inter, between, and cedere, to go, signifies literally going between; interpose, through French from Latin inter, between, and Late Latin pausare, to place, means placing one's self between; mediate, from Latin mediatus, past participle of mediare, based on medius, middle, means coming in the middle; interfere, through French from inter, between, and Latin ferire, to strike, means striking between; and intermeddle, through French from Latin inter, between, and misculare (the intercalated $d$ being an Ang!o-French development, which was brought over into Middle English) (Late Latin), Latin miscere, to mix, signifies meddling or mixing among.

One intercedes between parties that are unequal; one interposes between parties that are equal; one intercedes in favor of that party which is threatened with punishment; one interposes between parties that threaten each other with evil: we intercede with the parent in favor of the child who has offended, in order to obtain pardon for him; one interposes between two friends who are disputing to prevent them from going to extremities. One intercedes by means of persuasion; it is an act of courtesy or kindness in the person between whom and him on whose behalf the intercession is made to comply; one interposes by an exercise of authority; it is a matter of propriety or necessity in the parties to conform. The favorite of a monarch intercedes in behalf of some criminal, that his punishment may be mitigated; the magistrates interpose with their authority to prevent the broils of the disorderly from coming to serious acts of violence.

To intercede and interpose are employed on the highest and lowest occasions; to mediatc is never employed but in matters of the greatest moment. As earthly offenders, we require the intercession of a fellow-mortal; as offenders against the God of heaven, we require the intercession of a Divine Being: without the timely intorposition of a superior, trifling disputes may grow into bloody quarrels; without the interposition of Divine Providence, we cannot conceive of anything important as taking place: to settle the affairs of nations, mediators may afford a salutary assistance; to bring about the redemption of a lost world, the Son of God condescended to be Mediator.

All these acts are performed for the good of others; but interfere and intermeddle are of a different description: one may interfere for the good of others or to gratify one's self; one never intermeddles but for selfish purposes: the first three terms are, therefore, always used in a good sense; the fourth in a good or bad sense, according to circumstances; the last always in a bad sense.

INTERCHANGE, Exchange, RECIPROCITY. Interchange is a frequent and mutual exchange (see CHANGe); exchange consists of one act only; an interchange consists of many aets: an interchange is used only in the moral sense; exchange is used mostly in the proper sense: an interchange of eivilities keeps alive good-will; an exchange of commodities is a convenient mode of trade.

Interchange is an act; reciprocity is an abstract property: by an interchange of sentiment, friendships are engendered; the reciprocity of good services is what renders them doubly acceptable to those who do them and to those who receive them.

INTERCOURSE, CoMmUNiCATION, Connection, Commence. Intercourse, through French, from Latin intercursus, signifies, literally, a running between. Communication (see ComnuNICATE). Connection (see ConNect). Commerce, from cum, and merces, merchandise, signifies, literally, an exchange of merchandise, and generally an interchange.

Intercourse and commerce subsist only between persons; communicalion and connection between persons and things. An intercoursc with persons may be earried on in various forms; either by an interchange of civilities, which is a friendly intercourse; an exchange of 
commodities, which is a commercial intercourse; or an exchange of words, which is a verbal and partial intercourse: a communication, in this sense, is a species of intercourse, namely, that which consists in the communication of one's thoughts to another, which may subsist between man and man or between man and his Maker.

A connection consists of a permanent intercourse; since one who has a regular intercourse for purposes of trade with another is said to have a connection with him, or to stand in connection with him. There may, therefore, be a partial intercourse or communication where there is no connection, nothing to bind or link the parties to each other: but there cannot be a connection which is not kept up by continued intercourse.

The commerce is a species of general but close intercourse; it may consist either of frequent meeting and regular co-operation or in cohabitation: in this sense we speak of the commerce of men one with another, or the commerce of man and wife, of parents and children, and the like.

As it regards things, communication is said of places in the proper sense; connection is used for things in the proper or improper sense: there is said to be a communication between two rooms when there is a passage open from one to the other; one house has a connection with another when there is a common passage or thoroughfare to them: a communication is kept up between two countries by means of regular or irregular conveyances; a connection subsists between two towns when the inhabitants trade with one another, intermarry, and the like.

INTERDICT. See ForbID.

INTEREST, CoNCERN. The interest (from the Latin interesse, to be among, or have a part or a share in a thing) is more comprehensive than concern (see AfFaIR). We have an interest in whatever touches or comes near to our feelings or our external circumstances; we have a concern in that which demands our attention. Interest is that which is agreeable; it consists of either profit, advantage, gain, or amusement; it binds us to an object and makes us think of it: concern, on the other hand, is something involuntary or painful; we have a concern in that which we are obliged to look to, which we are bound to from the fear of losing or of suffering. It is the interest of every man to cultivate a philosophical temper: it is the concern of all to be on their guard against temptation. INTERFERE. See INTERCEDE.

INTERIOR. See INSIDE; INWARD. INTERLOPER. See INTRUDER.

INTERMEDDLE. See INTERCEDE. INTERMEDIATE, INTERVENING. Intermediate signifies being in the midst, between two objects; intervening signifies coming between: the former is applicable to space and time; the latter either to time or circumstances. The intermediate time between the commencement and the termination of a truce is occupied with preparations for the renewal of hostilities; intervening circumstances sometimes change the views of the belligerent parties, and dispose their minds to peace.

\section{INTERMENT. See BURTAL}

INTERMIT. See SUBSIDE.

INTERN, CONFINE, INTERNE. Intern, in French interne, from Latin internus, inward, from inter, within, between, and suffix -nus, Italian and Spanish interno. Intern, as a substantive, signifies a student residing at a school, a boarder; in the more common form, interne, a physician or surgeon living at a hospital or similar institution, in distinction from a visiting or consulting physician or surgeon; also, in war-times, to a person or a vessel detained at an appointed place, without permission to leave. Intern, as a verb, signifies to send and confine in the interior of a country. Prisoners of war are interned at places more or less remote from the field of action, and captured war-ships and some other vessels are interned also at a distance from home ports. The former are usually held till exchanged, the latter till the close of the war. In the summer of 1915 there were about seventy Teutonic vessels of all kinds interned in the ports of the United States, because of the European war.

INTERPOSE. See INTERCEDE.

INTERPRET. See EXPLAIN.

INTERROGATE. See AsK.

INTERVAL, RESPITE. Interval, in Latin intervallum, signifies, literally, the space between the stakes which formed 
a Roman intrenchment; and, by an extended application, it signifies any space. Respite, Old French respit, comes from Latin respectum. It referred originally to the "respect had to a suit on the part of a judge," and so meant a delay, a reprieve.

Every respite requires an interval; but there are many intervals where there is no respite. The term interval concerns time only; respite includes the idea of ceasing from action for a time; intervals of ease are a respite to one who is oppressed with labor; the interval which is sometimes granted to a criminal before his execution is in the most proper sense a respite.

INTERVENTION, INTERPOSITION. The intervention, from inter, between, and the past participle of venio, to come, is said of inanimate objects; the interposition, from inter, between, and positus, past participle of pono, to place, is said only of rational agents. The light of the moon is obstrueted by the intervention of the elouds; the life of an individual is preserved by the interposition of a superior: human life is so full of contingencies that when we have formed our projects we can never say what may intervene to prevent their execution; when a man is engaged in an unequal combat, he has no chance of escaping but by the timely interposition of one who is able to rescue him.

INTIMACY. See Acqualntance. INTIMATE. See HiNT.

INTIMIDATE. See Frighten; OVERAWE.

INTOXICATION, Drunkenness, INFATUATION. Intoxication, from the Latin toxicum (Greek ro for arrows, from tó $\xi \alpha$, arrows), signifies the state of being imbued with a poison. Drunkenness signifies the state of having drunk overmuch. Infatuation, from faluus, foolish, signifies making foolish. or the state of being made foolish.

Intoxication and drunkenness used either in the proper or the improper sense; infatuation in the improper sense only; intoxication is a general state; drunkenness a particular state; intoxication may be produced by various eauses; drunkenness is produced only by an immoderate indul- gence in some intoxicating liquor: a person may be intoxicated by the smell of strong liquors, or by vapors which produce a similar effeet; he becomes drunken by the drinking of wine or other spirits. In another sense, a deprivation of one's reasoning faculties is the common idea in the signification of all these terms: inloxication and drunkenness spring from the intemperate state of the feelings; infatuation springs from the ascendency of the passions over the reasoning powers: a person is intoxicated with success, drunk with joy, infatuated by an excess of vanity, an impetuosity of eharacter, or a passion for one of the opposite sex.

INTRANSIGENT, COMMUNIST, Ninilist, Socialist. Intransigent, in French intransigeant and Spanish intransigente, is a compound of the Latin in, not, and transigo, to agree or settle, and implies a person who is dissatisfied with present conditions, especially of a social character, and who refuses. to come to an agreement with others on questions of publie interest. These terms form a part of a considerable number of designations having a common import, yet conveying different impressions aceording to eonditions in the countries where they are most in voguc.

An intransigent, intransigeant, and intransigente, applied to persons in France, Italy, and Spain, respectively, or an irreconcilable, representing at first a member of the Extreme Left in the Spanish Cortes and subsequently a member of the extreme Republican party in Spain, is one who opposes existing policies in a political, economical, and social sense.

The communist believes in the doetrine that all property should be held equally by all members of a eommunity. The nihilist of Russia believed in destroying existing institutions and governmental forms and policies, and in founding a new order of things generally. The socialist of Germany, the United States, and other countries believes that soeiety should be reconstructed on the basis of co-operation of labor and the community of property, so that there would be neither the really rich nor the really poor.

The prineiples underlying these various doct rines have had carnest and emi- 
nent advocates for many years, and, as in innumerable attempts to harmonize and improve social conditions, many of the propagandists, through overzeal, have been guilty of criminal excesses, especially in France, Italy, and Russia.

A further exposition of movements for social betterment will be found in the article on Socrausm.

INTRENCH. See ENCROACH; TRENCH.

INTREPID. See BoLD.

INTRICACY. See COMPLEXITY.

INTRICATE. See KNOTTY.

INTRIGUING. See Scheming.

INTRINSIC, Real, Genuine, NaTIVE. Intrinsic, in Latin intrinsecus, from intra, within, and sequi, to follow, signified literally following inward, that is, lying in the thing itself. Real, through French réel, or directly from Late Latin realis, from the Latin res, signifies belonging to the very thing. Genuine, in Latin genuinus, from gignere, to bring forth, signifies actually brought forth, or springing out of a thing. Native, in Latin nativus, and natus, born, signifies actually born, or arising from a thing.

The value of a thing is either intrinsic or real: but the intrinsic value is said in regard to its extrinsic value; the real value in regard to the artificial: the intrinsic value of a book is that which it will fetch when sold in a regular way, in opposition to the extrinsic value, as being the gift of a friend, a particular edition, or a particular type: the real value of a book, in the proper sense, lies in the fineness of the paper and the costliness of its binding, and, in the improper sense, it lies in the excellence of its contents, in opposition to the artificial value which it acquires in the minds of bibliophiles from being a scarce edition.

The worth of a man is either genuine or native: the genuine worth of a man lies in the excellence of his moral character, as opposed to his adventitious worth, which he acquires from the possession of wealth, power, and dignity: his native worth is that which is inborn in him, and natural, in opposition to the meretricious and borrowed worth which he may derive from his situation, his talent, or his efforts to please.
INTRODUCE, Present. To introduce, from the Latin intro, into, and ducere, to lead, signifies literally to bring within or into any place; to present (see Give) signifies to bring into the presence of. As they concern persons, the former passes between equals, the latter only among persons of rank and power: one literary man is introduced to another by means of a common friend; he is presented at court by means of a nobleman.

As these terms concern things, we say that subjects are introduced in the course of conversation; men's particular views upon certain subjects are presented to the notice of others through the medium of publication.

INTRUDE, OBTRUDE. To intrude is to thrust one's self into a place; to obtrude, a use now practically obsolete, is to thrust one's self in the way-both from trudere, to thrust. Intrude, therefore, literally corresponds to the slang phrase butt in. It is intrusion to go into any society unasked and uidesired; it is obtruding to put one's self in the way of another by joining the company and taking a part in the conversation without invitation or consent.

An intruder is unwelcome because his company is not at all desired, but an obtruder may be no further unwelcome than as he occasions an interruption or disturbance.

In the moral application they preserve the same distinction. Thoughts which we wish to banish intrude sometimes on the mind; unpleasant thoughts obtrude themselves to the exclusion or interruption of those we wish to retain. See also Excroach.

Intruder, Interloper. - An intruder thrusts himself in: an interloper (coined from inter, Latin, meaning within, and Dutch looper, English leap) runs in between and takes his station. The intruder, therefore, intrudes only for a short space of time, and in an unimportant degree; but the interloper deprives another of his essential rights and for a permanency. A man is an intruder who is an unbidden guest at the table of another; he is an interloper when he joins any society in such manner as to obtain jts privileges without sharing its burdens. Intruders are always 
offensive in the domestic circle: interlopers in trade are always regarded with an evil eye.

INTRUST. See Consign.

INUNDATE. See OvERFLOW.

INVADE. See Excroach.

INVALID, Patient. Invalid, in Latin invalidus, signifies, literally, one not strong or in good health; patient, from the Latin patiens, suffering, signifies one suffering under disease. Invalid is a general, and patient a particular, term; a person may be an invalid without being a patient: he may be a patient without being an invalid. An invalid is so denominated from his wanting the ordinary share of health and strength; but the patient is one who is laboring under some bodily suffering. Old soldiers are called invalids who are no longer able to bear the fatigues of warfare: but they are not necessarily patients. He who is under the surgeon's hands for any wound is a patient, but not necessarily an invalid.

INVASION, INCURSION, IRRUPTION, INROAD. The idea of making a forcible entrance into a foreign territory is common to all these terms. Invasion, from in, into, and vado, to go, expresses merely this general idea, without any particular qualification: incursion, from in and cursus, past participle of curro, to run, signifies a hasty and sudden invasion: irruption, from in, and ruptus, past participle of rumpo, to break, signifies a particularly violent invasion; in road, from in and road, signifying the making a road or way for one's self, implies the going farther into a country and making a longer stay than by an incursion. Invasion is said of that which passes in distant lancls; Alexander invaded India; Hannibal crossed the Alps and made an invasion into Italy: incursion is said of neighboring states; the borderers on each side the Tweed used to make frequent incursions into England or Scotland.

Invasion is the aet of a regular army; it is a systematic military movement: irruption and inroad are the irregular movements of bodies of men; the former is applied particularly to uneultivated nations, and the latter, like incursion, to neighboring states: the Goths and Vandals made irruptions into Europe; the Seotch and English used to make inroads upon each other.

These words preserve the same distinetion in their figurative application. Invade signifies a hostile attack, and may be applied to physical objeets or to spiritual objects; as to invade one's peace of mind, privileges, etc.

Inroad denotes the progress into any body of what is bad; as the inroads of disease into the constitution, into the mind.

INVECTIVE. See ABUse.

INVEIGH. See Declarm.

INVEIGLE. See INSNARE.

INVENT, Feign, Frane, FabriCATE, Forge. All these terms are employed to express the production of something out of the mind, by means of its own efforts. To invent (see CoNTRIVE) is the general term; the other terms imply modes of invention under different eircumstances. To invent, as distinguished from the rest, is busied in creating new forms either by means of the imagination or the reflective powers; it forms combinations either purely spiritual or those which are mechanical and physieal: the poet invents imagery; the philosopher invents mathematical problems or mechanical instruments.

Invent is used for the production of new forms to real objeets, or for the creation of unreal objects; to feign is used for the creation of unreal objects or such as have no existence but in the mind: a play or a story is invented from what passes in the world: Mohammed's religion consists of nothing but inventions: the heathen poets feigned all the tales and fables which constitute the mythology or history of their deities. To frame, that is, to make according to a frame, is a species of invention which consists in the disposition as well as the combination of objects. Thespis was the inventor of tragedy: Psalmanazar framed an entirely new language, which he pretended to be spoken on the island of Formosa; Solon framed a new set of laws for the eity of Athens.

To invent, frame, and feign are all oceasionally employed in the ordinary coneerns of life, and in a bad sense; fabricate is seldom, and forge never, used any otherwise. Invent is employed 
for that which is the fruit of one's own mind and mostly contrary to the truth; to feign is employed for that which is unreal; to frame is employed for that which requires deliberation and arrangement; to fabricate and forge are employed for that which is absolutely false and requiring more or less exercise of the inventive power. A person invents a lie, and feigns sorrow; invents an excuse, and feigns an attachment. A story is invented, inasmuch as it is new and not before conceived by others or occasioned by the suggestions of others; it is framed, inasmuch as it requires to be duly disposed in all its parts, so as to be consistent; it is fabricated, inasmuch as it runs in direct opposition to actual circumstances and therefore has required the skill and labor of a workman; it is forged (from Old French forge, a work-shop, Latin fabrica), inasmuch as it seems by its utter falsehood and extravagance to have caused as much severe action in the brain as what is produced by the fire in a furnace or forge.

See also Contrive; Find.

INVERT. See OVERTURN.

INVEST, ENDUE or ENDOw. To invest, from vestire, to clothe, whence English vestments is derived, signifies to clothe in anything. Endue or endow, from the Latin induo, signifies to put on anything. One is invested with that which is external: one is endued with that which is internal. We invest a person with an office or a dignity: a person is endued with good qualities. To invest is a real external action; but to endue may be merely fictitious or mental. The king is invested with supreme authority; a lover endues his mistress with every earthly perfection. Endow is but a variation of endue, and yet it seems to have acquired a distinct office: we may say that a person is endued or endowed with a good understanding; but as an act of the imagination endow is not to be substituted for endue: for we do not say that it endows, but endues things with properties.

See also BESIEGE.

INVIDIOUS, ENvious. Invidious, in Latin invidiosus, from invidia, or in, not, and videre, to see, signifies look- ing at with an evil eye: envious is literally only a variation of invidious. Invidious, in its common acceptation, signifies causing ill-will; envious signifies having ill-will. A task is invidious that puts one in the way of giving offence; a look is envious that is full of envy. Invidious qualifies the thing; envious qualifies the temper of the mind. It is invidious for one author to be judge against another who has written on the same subject: a man is envious when the prospect of another's happiness gives him pain.

INVIGORATE. See Strengthen. INVINCIBLE, UNCONQUERABLE, INSUPERABLE, INSURMOUNTABLE. Invincible signifies not to be vanquished (see CoNQUER): unconquerable, not to be conquered: insuperable, not to be overcome: insurmountable, not to be surmounted. Persons or things which can withstand all force are in the strict sense invincible; but as in this sense nothing created can be termed invincible, the term is employed to express strongly whatever can withstand human force in general: on this ground the Spaniards termed their Armada invincible. The qualities of the mind are termed unconquerable when they are not to be won over or brought under the control of one's own reason or the judgment of another: hence obstinacy is with propriety dencminated unconquerable which will yield to no foreign influence. The particular disposition of the mind or turn of thinking is termed insuperable, inasmuch as it baffles our resolution or wishes to have it altered; an aversion is insuperable which no reasoning or endeavor on our own part can overcome. Things are denominated insurmountable, inasmuch as they baffle one's skill or efforts to get over them or put them out of one's way: an obstacle is insurmountable which in the nature of things is irremovable. Some people have an insuperable antipathy to certain animals; some persons are of so modest and timid a character that the necessity of addressing strangers is with them an insuperable objection to using any endeavors for their own advancement; the difficulties which Columbus had to encounter in his discovery of the New World would have 
appeared insurmountable to any mind less determined and persevering.

INVITE. See AtTract; Call.

INVOLVE. See IMPLICATE.

INWARD, INTERNAL, INNER, INTEnIOR. Inward signifies toward the inside, that is, not absolutely within: internal signifies positively within: inner, as the comparative of inward, signifies more inward; and interior, as the comparative of internal, signifies more internal. Inward is employed more frequently to express a state than to qualify an object; internal to qualify the objects: a thing is said to be turned inward which forms a part of the inside: it is said to be internal as one of its characteristics; inward, as denoting the position, is indefinite; anything that is in in the smallest degree is inward; thus what we take in the mouth is inward in distinction from that which may be applied to the lips; but that is properly internal which lies in the very frame and system of the body; inner, which rises in degree on inward, is applicable to such bodies as admit of specific degrees of enclosure: thus the inner shell of a nut is that which is enclosed in the inward: so likewise interior is applicable to that which is capacious and has many involutions, as the interior coat of the intestines.

IRE. See ANGER.

IRIDESCENT. See NaCreous.

IRONY. Sce RIDICULE; WIT.

IRRATIONAL, Foolish, ABSURd, Prepostenous. Irrational, compounded of in, not, ratio, reason, and a suffix, signifies contrary to reason, and is employed to express the want of the faculty itself, or a defieiency in the exercise of this faculty. Foolish (see Folly) signifies the perversion of this faculty. $A b$ surd, from $a b$, and surdus, deaf, signifies that to which one would turn a deaf ear. Preposterous, from pro, before, and posterus, behind, signifies, literally, that side foremost which ought to be behind, which is unnatural and contrary to common sense.

Irrational is not so strong a term as foolish: it is applicable more frequently to the thing than to the person, to the principle than to the practice; foolish, on the contrary, is commonly applicabie to the person as well as the thing; to the practice rather than the principle. Scepticism, to those who have faith, is the most irrational thing that exists; the human mind, from this viewpoint, is formed to believe, but not to doubt: he is, of all men, considered most foolish who stakes his eternal salvation on his own fancied superiority of intelligence and illumination. Foolish, absurd, and preposterous rise in degree: a violation of common sense is implied by them all, but they vary according to the degree of violence which is done to the understanding: foolish is applied to anything, however trivial, which in the smallest degree offends our understanding: the conduct of children is therefore often foolish, but not absurd and preposterous, which are said only of serious things that are opposed to our judgment: it is absurd for a man to persuade another to do that which he in like circumstances would object to do himself; it is preposterous for a man to expose himself to the ridicule of others and then be angry with those who will not treat him respectfully.

IRRECONCILABLE. See INTrANSIGENT.

IRREFRAGABLE. See INDUBITABLE.

IRREGULAR, DisORDERLY, INORDINATE, INTEMPERATE. Irregular, that is, literally, not regular, marks merely the absence of a good quality; disorderly, that is, liternlly, out of order marks the presence of a positively bad quality. What is irregular may be so from the nature of the thing; what is disorderly is rendered so by some external circumstance. Things are planted irregularly for want of design: the best troops are apt to be disorderly in a long march. Irregular and disorderly are taken in a moral as well as a natural sense: inordinate, which signifies also put out of order, is employed only in the moral sense. What is irregular is, or ought to be, contrary to the rule that is established; what is disorderly is contrary to the order that has existed; what is inordinale is contrary to the order that is preseribed; what is intemperate is contrary to the temper or spirit that ought to be encouraged. Our habits will be irregular which are not conformable to the 
laws of social society; our practices will be disorderly when we follow the blind impulse of passion; our desires will be inordinate when they are not under the control of reason guided by religion; our indulgences will be intemperate when we consult nothing but our appetites. Young people are apt to contract irregular habits if not placed under the care of discreet and sober people and made to conform to the regulations of domestic life: children are naturally prone to become disorderly if not perpetually under the eye of a master: it is the lot of human beings of all ages and stations to have inordinate desires, which require a constant check so as to prevent intemperate conduct of any kind.

IRRELIGIOUS, Profane, Impious. As epithets to designate the character of the person they seem to rise in degree: irreligious is negative; profane and impious are positive, the latter being much stronger than the former. All men who are not positively actuated by principles of religion are $i r$ religious; profanity and impiety are, however, of a still more heinous nature; they consist not in the mere absence of regard for religion, but in a positive contempt of it and open outrage against its laws; the profane man treats what is sacred as if it were profane; what a belicver holds in reverence and utters with awe is pronounced with an air of indifference or levity, and as a matter of common discourse, by a profane man; he knows no difference between sacred and profane, but as the former may be converted into a source of scandal toward others; the impious man is directly opposed to the pious man; the former is filled with defiance and rebellion against his Maker, as the latter is with love and reverence.

When applied to things, the term irreligious seems to be somewhat more positively opposed to religion; an irreligious book is not merely one in which there is no religion, but that also which is detrimental to religion, such as sceptical or licentious writings: the epithet profane in this case is not always a term of reproach, but is employed to distinguish what is temporal from that which is expressly spiritual in its nature; the history of nations is profane as distinguished from the sacred history contained in the Bible: the writings of the heathens are altogether profane as distinguished from the moral writings of Christians or the believers in Divine Revelation. On the other hand, when we speak of a profane sentiment or a profane joke, profane lips, and the like, the sense is personal and reproachful; impious is never applied but to what is personal, and in the very worst sense; an impious thought, an impious wish, or an impious vow, is the fruit of an impious mind.

IRREPROACHABLE. See BlaMeLESS.

IRREVERENT. See SACRILEgIoUs. IRRITATE. See Aggravate;

WORRY.

IRRUPTION. See INVASION.

ISOlATE. See Segregate.

ISSUE. See ARISE; Consequence; Event; Offspring; Rise; Sally. 
JABBER, Gabble, Mumble. These are all imitative words signifying methods of vocal expression. Between $j a b-$ ber and gabble there is little difference except that suggested by the sound of the words; they are both derived from $g a b$, to talk, itself an imitative word which has an interesting history. They signify the utterance of rapid, inarticulate sounds. Jabber is more frequently used to indicate that which is inarticulate, and suggests a greater rapidity and sharpness of utterance. Parrots and monkeys are said to jabber; ducks and geese, to gabble. Jabber is used especially of the sound of a foreign language; we speak of jabbering French, jabbering Italian, etc. Gabble is contemptuously applied to the sound of any talk. Mumble suggests a different type of utterance. It is a frequentative of Middle English mum, which signifies the least sound made with elosed lips; it means, literally, to keep saying "mum, mum."

See also BABBLE.

JADE. Sce Weary.

JAGGed, Cleft, Denticulated, Serrated, Uneven. Jagged is the adjective form of the substantive jag, a Seandinavian word signifying notch or tooth, and means notehed or toothlike, signifying an uneven edge. An objeet that has been cleft or split usually exhibits irregular or rough edges or surfaces, as a rock that has been blasted; one that has become denticulated (from the Latin denticulus, a small tooth) displays projecting points; one that is serrated (from the Latin serro, to saw) shows protuberances or an irregular edge, as the cutting edge of a fine saw; and whatever is uneven is more or less rough or ragged on its surface or edge.

The Sierra Madre Mountains in Mexico and the Sierra Nevada range in California are so ealled because they have serrated or saw-tooth ridges, and a leaf and other botanical growths that have sharp, straight-edged teeth, pointing to the apex, are termed serrated.
$J a g$ also has the significance of a small load, and from this is derived two American slang terms: a person who is thoroughly intoxicated is said to have a load on or to be carrying a load; another who is but partially intoxicated is said to have a jag on.

JAM. See PACK.

JANGLE, Jar, Wrangle. A verbal contention is expressed by all these terms, but with various modifications: jangle is an imitative word of Scandinavian origin; it conveys by its own discordant sound an idea of the discordance which accompanies this kind of war of words. Jar is also an imitative word, which has parallels in the various Teutonic tongues; it means to utter a harsh sound, and comes from Middle English garren, to chide, AngloSaxon ceorian, to murmur, etc. Wrangle is a frequentative of uring; its original sense was to keep twisting on or urging; hence to argue vehemently. There is in jangling more of cross-questions and perverse replies than direet differenees of opinion; those jangle who are out of humor with one another; there is more of discordant feeling and opposition of opinion in jarring: those who have no good-will to each other will be sure to jar when they come into collision; and those who indulge themselves in jarring will soon convert affection into ill-will. Married people may destroy the good-humor of the company by jangling, but they destroy their domestic peace and felieity by jarring. To wrangle is technically what to jangle is morally: those who dispute by a verbal opposition only are said to wrangle; and the disputers who engage in this scholastic exercise are termed uranglers; most disputations amount to little more than urangling.

JAR. See JANGLE.

JAUNT. See Excursion.

JEALOUSY, ENVY, SUspicion. Jealousy comes from Late Latin zclosus, full of zeal, from Greek $\zeta \bar{\eta} \lambda$ os, zeal, and signifies zcalous for that which 
is one's own, and hence fearful lest some one should take it away. Envy, in French envie, Latin invidia, from invideo, compounded of in, privative, and videre, to sec, signifies not looking at, or looking at in a contrary direction.

We are jealous of what is our own; we are envious of what is another's. Jealousy fears to lose what it has; envy is pained at seeing another have that which it wants for itself. Princes are jealous of their authority; subjects are jealous of their rights; courtiers are envious of those in favor; women are envious of superior beauty.

The jealous man has an object of desire, something to get and something to retain; he does not look beyond the object that interferes with his enjoyment; a jealous husband may therefore be appeased by the declaration of his wife's animosity against the object of his jealousy. The envious man sickens at the sight of enjoyment; he is easy only in the misery of others: all endeavors, therefore, to satisfy an envious man are fruitless. Jealousy is a noble or an ignoble passion, according to the object; in the former case it is emulation sharpened by fear; in the latter case it is greediness stimulated by fear; envy is always a base passion, drawing the worst passions in its train.

Jealous is applicable to bodies of men as well as individuals; envious, to the individuals only. Nations are jealous of any interference on the part of any other power in their commerce, government, or territory; individuals are envious of the rank, wealth, and honors of one another.

Suspicion, from Latin suspicere, sub, under, and specere, to look, i.e., to look from under one's eyelids out of fear of being seen to look, denotes an apprehension of injury, and, like jealousy, implies a fear of another's intentions; but suspicion has more of distrust in it than jealousy: the jealous man doubts neither the integrity nor the sincerity of his opponent; the suspicious man is altogether fearful of the intentions of another: the jealous man is jealous only of him who he thinks wishes for the same thing as he does, and may rob him of it: the suspicious man is suspicious or fearful that he may suffer something from another. Jealousy properly exists between equals or those who have a common object of desire; but suspicion is directed toward any one who has the power as well as the will to hurt; rival lovers are jealous of each other, but one person is suspicious of another's honesty, or parties entering into a treaty may be suspicious of each other's good faith. Jealousy cannot subsist between a king and his people in any other than in the anomalous and unhappy case of power being the object sought for on both sides; a king may then be jealous of his prerogative when he fears that it will be infringed by his people; and the people will be jealous of their rights when they fear that they will be invaded by the crown. According to this distinction, jealousy is erroneously substituted in the place of suspicion.

Jealousy is concerned only in not losing what one wishes for; suspicion is afraid of incurring some positive evil. JEER. See SCOFF.

JEOPARD. See HAZARD.

JEST, Joke, Make Game, Sport. Jest meant originally a story, a merry tale, from Old French geste, an exploit, from Latin gesta, past participle of gerrere, to wage war-a geste being a tale of warlike deeds. Joke is derived from Latin iocus, a game. To make game signifies here to make the subject of game or play (see PlaY). To sport signifies here to sport with or convert into a subject of amusement.

One jests in order to make others laugh; one jokes in order to please one's self. The jest is directed at the object; the joke is practiced with the person or on the person. One attempts to make a thing laughable or ridiculous by jesting about it, or treating it in a jesting manner; one attempts to excite good-humor in others, or indulge it in one's self, by joking with them. Jests are therefore seldom harmless: jokes are frequently allowable. The most serious subject may be degraded by being turned into a jest; but melancholy or dejection of the mind may be conveniently dispelled by a joke. Court fools and buffoons used formerly to turn their jests upon every subject by which they thought to entertain their employers: those who know how to joke with good-nature and discretion may contribute to the mirth of the 
company: to make game of is applicable only to persons: to make a sport of or sport with is applied to objects in general, whether persons or things; both are employed, like jest, in the bad sense of treating $a$ thing more lightly than it deserves.

JIFFY. See Instant.

JILT. See Coqdet.

JITNEY. See AUtomobile.

JOCOSE. See Facetious; Jocular. JOCUND. See LIVELY.

JOIN. See Add.

JOKE. See Jest.

JOLLITY. See Mirth.

JOURNEY, Travel, VoYage. Journey, through the French journée, a day's work, from Latin diurnata, the feminine past participle of Late Latin diurnare, to sojourn, based on diurnus, daily, signifies the course that is taken in the space of a day, or in general any comparatively short passage from one place to another. Travel is the same word as travail, to labor; it may be derived from Late Latin trepalium, a kind of rack for torturing martyrs made of three beams-tres pali. Voyage is derived through French from Latin viaticum, provisions for a journey, based on via, a way, and originally signified any course or passage to a distance, but is now confined to passages by sea.

We take journeys in different counties in England; we make a voyage to the Indies, and travel over the eontinent. Journeys are taken for domestic business; travels are made for amusement or information: voyages are made by captains or merehants for purposes of commerce. We estimate journeys by the day, as one or two days' journey; we estimate travels and voyages by the months and years that are employed. The Israelites are said to have jour-neyed in the wilderness forty years, because they went but short distances at a time. It is a part of polite education for young men of fortune to travel into those countries of Europe which comprehend the grand tour, as it is termed. A voyage round the world, which was at first a formidable undertaking, has now become familiar to the mind by its frequency.

JOViality. See Glee; Mirth.

JOY, Gladness, Mirth. The happy condition of the soul is designated by all these terms; but joy, from the Latin gaudia, joys, and gladness (see GLAD) lie more internally; mirth (see FestivITY) is the more immediate result of external circumstances. What creates joy and gladness is of a permanent nature; that which creates mirth is temporary: joy is the most vivid sensation in the soul; gladness is the same in quality, but inferior in degree: joy is awakened in the mind by the most important events in life; gladness springs up in the mind on ordinary occasions: the return of the prodigal son awakened joy in the heart of his father; a man feels gladness at being relieved from some distress or trouble: publie events of a gratifying nature produce universal joy; relief from either sickness or want brings gladness to an oppressed heart; he who is absorbed in his private distresses is ill prepared to partake of the mirth with which he is surrounder! at the festive board. Joy is depieted on the countenance or expresses itself by various demonstrations: gladness is a more tranquil feeling, which is enjoyed in secret and seeks no outward expression: mirth displays itself in laughter, singing, and noise.

See also Pleasure.

JOYFUL.' See Glad.

JUDGE, Umpire, Arbiter, ArbITrator. Judge, through French juge, from Latin judico and judex, from jus, right, and dicare, to point out, signifies one pronouncing the law or determining right. Umpire is derived through Otd French nomper, from Latin non, not, and par, equal, signifying a third man ealled into decide between two equals. Arbiter and arbitrator, from arbitrari, to think, signify one who deeides.

$J u d g e$ is the generic term, the others are only species of the judge. The judge determines in all matters disputed or undisputed; he pronounces what is law now as well as what will be law for the future; the umpire and arbiter are judges only in particular cases that admit of dispute; there may be judges in literature, in arts, and civil matters; umpires and arbiters are judges only in private matters. The judge pronounces, in matter of dispute, according to a written law or a preseribed rule; the umpire decides in all matters 
of contest; and the arbiter or arbitrator in all matters of litigation, according to his own judgment. The judge acts under the appointment of government; the umpire and arbitrator are appointed by individuals: the former is chosen for his skill; he adjudges the palm to the victor according to the merits of the case: the latter is chosen for his impartiality; he consults the interests of both by equalizing their claims. The office of judge is one of the most honorable; an umpire is of use in deciding contested merits, as the umpire at the games of the Greeks; in poetry and the grave style the term may be applied to higher objects.

The office of an arbiter, although not so elevated as a judge in its literal sense, has often the important duty of a Christian peace-maker; and as the determinations of an arbiter are controlled by no external circumstances, the term is applied to monarchs, and even to the Creator as the sovereign Arbiter of the world.

Judgment, Discretion, Prudence.These terms are all employed to express the various modes of practical wisdom," which serve to regulate the conduct of men in ordinary life. Judgment is that faculty which enables a person to distinguish right and wrong in general: discretion and prudence serve the same purpose in particular cases. Judgment is conclusive; it decides by positive inference; it enables a person to discover the truth: discretion is intuitive (see DiscerNmenT); it discerns or perceives what is in all probability right. Judgment acts by a fixed rule; it admits of no question or variation; discretion acts according to circumstances and is its own rule. Judgment determines in the choice of what is good: discretion sometimes only guards against error or direct mistakes; it chooses what is nearest to the truth. Judgment requires knowledge and actual experience; discretion requires reflection and consideration; a general exercises his judgment in the disposition of his army and in the mode of attack; while he is following the rules of military art he exercises his discretion in the choice of officers for different posts, in the treatment of his men, in his negotiations with the enemy, and various other measures: which depend upon contingencies.

Discretion looks to the present; prudence, from Latin providens, foreseeing, calculates on the future: discretion takes a wide survey of the case that offers: it looks to the moral fitness of things, as well as the consequences which may follow from them; it determines according to the real propriety of anything, as well as the ultimate advantages which it may produce: prudence looks only to the good or evil which may result from things; it is, therefore, but a mode or accompaniment of discretion; we must have prudence when we have discretion, but we may have prudence where there is no occasion for discretion. Those who have the conduct or direction of others require discretion; those who have the management of their own concerns require prudence. For want of discretion the master of a school or the general of an army may lose his authority: for want of prudence the merchant may involve himself in ruin, or the man of fortune may be brought to beggary.

As epithets, judicious is applied to things of tener than to persons; discreet is applied to persons rather than to things; prudent is applied to both: a remark or a military movement is judicious; it displays the judgment of the individual from whom they emanate; a matron is discreet who, by dint of years, experience, and long reflection, is enabled to determine on what is befitting a given case; a person is prudent who does not inconsiderately expose himself to danger; a measure is prudent that guards against the chances of evil. Counsels will be injudicious which are given by those who are ignorant of the subject: it is dangerous to intrust a secret to one who is indiscreet: the impetuosity of youth naturally impels them to be imprudent; an imprudent marriage is seldom followed by prudent conduct in the parties who have involved themselves in it.

See also Decision; Sense.

JUDGMENT - SEAT. S e e TRIBUNAL.

JUGGLE, CoNJuRE. Juggle, based on Old French jugleor, juggler, Modern French jongleur, a story-teller or conjuror, and joculari, to jest, from joculus, 
a little jest, signifies, as a substantive, an imposition, deception, trick, and as a transitive, to deceive by artifice, to play tricks or amuse by feats of legerdemain. Conjure, from Latin con, together, and jurare, to swear, signifies to produce an apparently magical effect by the pronouncing of mysterious words which scem to have a supernatural power. Juggle and conjure produce similar effects by different means. To juggle implies almost supernatural skill of hand or mind; to conjure implies the help of supernatural powers. The magic is within the juggler himself; it is external to the conjuror, but under his control.

\section{See also Cheat.}

JUICE. See Liquid.

JUMBLE, HUDDLE. Jumble and huddle both imply a state of confusion and disorder. Jumble is a Scandinavian word-a frequentative of jump, and signifies to keep making things jump together so that they interfere with each other, and become inextricably confused. Huddle is a frequentative allied to Middle English huden, to hide, and partly influenced by the Dutch hoetelen, to do a thing clumsily; it suggests a number of things carelessly crowded together under a cover or in a hiding-place. Jumble suggests a morc positive state of confusion than huddle. Things huddled are crowded close together without an attempt at adjustment, but without necessarily interfering with' each other or losing their separate identities. Things jumbled together are so crowded that the parts of one are mixed with the parts of others, and the result is disorganizing confusion.

JUNTO. See Combination.

JUST. See RIght.

JUSTICE, EQUITY. Justice, based on ius, right, is founded on the laws of society: equity, from aquitas, fairness, rightness, and equality, is founded on the laws of nature. . Justice is a written or prescribed law, to which one is bound to conform and make it the rule of one's decisions: equity is a law in our hearts; it conforms to no rule, but to circumstances, and decides by the consciousness of right and wrong. The proper object of justice is to secure property; the proper object of equity is to secure the rights of humanity. $J$ ustice is exclusive; it assigns to every one his own; it preserves the existing inequality between men: equity is communicative; it seeks to equalize the condition of men by a fair distribution. Justice forbids us doing wrong to any one, and requires us to repair the wrongs we have done to others: equity forbids us doing to others what we would not have them do to us; it requires us to do to others what in similar circumstances we would expect from them.

JUSTIFY. See Apologize.

JUSTNESS, CorrectNess. Justness, from jus, law, is the conformity to established principle: correctness, from rectus, right or straight (see ConRECT), is the conformity to a certain mark or line: the former is used in the moral or improper sense only; the latter is used in the proper or improper sense. We estimate the value of remarks by their justness, that is, their accordance to certain admitted principles. Correctness of outline is of the first importance in drawing; correctness of dates enhances the value of a history. It has been justly observed by the moralists of antiquity that money is the root of all evil; partisans seldom state correctly what they sec and hear.

JUTTING. Sec Salient.

JUVENILE. Sec Youturul. 
KEEN. See Actte; Sharp; Trenchant.

KeEP, Preserve, Save. The idea of having in one's possession is common to all these terms; it is, however, the simple meaning of keep (see HoLD): to preserve, from proe, beforehand, and servare, to keep, that is, to keep for future use, signifies to keep with care and free from all injury; to save, allied to safe, is to keep laid up in a safe place and free from destruction. Things are kept at all times and under all circumstances; they are preserved in circumstances of peculiar difficulty and danger; they are saved in the moment in which they are threatened with destruction: things are kept at pleasure; they are preserved by an exertion of power; they are saved by the use of extraordinary means: the shepherd keeps his flock by simply watching over them; children are sometimes wonderfully preserved in the midst of the greatest dangers; things are frequently saved, in the midst of fire, by the exertions of those present.

Keep, Observe, Fulfil.-These terms are synonymous in the moral sense of abiding by and carrying into execution what is prescribed or set before one for his rule of conduct; to keep is simply to have by one in such manner that it shall not depart; to observe, in Latin observo, compounded of $o b$, near, and servare, to keep, signifying to keep in one's view, to fix one's attention, is to keep with a steady attention: to fulfil (see Accomplish) is to keep to the end or to the full intent. A day is either kept or observed: yet the former is not only a more familiar term, but it likewise implies a much less solemn act than the latter; one must add, therefore, the mode in which it is kept, by saying that it is kept holy, kept sacred, or kept as a day of pleasure; the term observe, lowever, implies always that it is kept religiously: we may keep, but we do not observe a birthday; we keep or observe the Sabbath.
To keep marks simply a perseverance or continuance in a thing; a man keeps his word if he does not depart from it: to observe marks fidelity and consideration; we observe a rule when we are careful to be guided by it; to fulfil marks the perfection and consummation of that which one has kept; we fulfil a promise by acting in strict conformity to it.

Keeping, Custody.-Keeping is, as before, the general term. Custody is in Latin custodia, from custos, a guardian, literally a "hider," related to Greek $\kappa \varepsilon \dot{\theta} \theta \varepsilon \nu$, to hide. The first of these terms is, as before, the most general in its signification; the latter is more frequent in its use. The keeping amounts to little more than having purposely in one's possession; but custody is a particular kind of keeping, for the purpose of preventing an escape: inanimate objects may be in one's keeping; but a prisoner, or that which is in danger of getting away, is placed in custody: a person has in his keeping that which he values as the property of an absent friend: the officers of justice get into their custody those who have offended against the laws, or such property as has been stolen.

KEY, Clue, Hint. These words represent the same idea under different metaphors. A key, a clue, and a hint are all means of discovery. Key, from Anglo-Saxon coeg, is that which unlocks. Clue signified originally a ball of thread, from Anglo-Saxon cliwen; hence a single thread by which the ball may be unrolled or a web untangled. Hint comes from Middle English henten, to seize; it is that upon which one seizes as a possible aid to discovery. A clue is less certain than a key; and a hint less certain than a clue. If a detective has found the key to a mystery, he is certain that he has succeeded in his case; if he has found a clue, he is hopeful, but not certain. If he has a hint to work upon, he may find a definite clue, but he has no reason for great optimism as yet. 
KILl, Murder, Assassinate, Slay or Slaughter. Kill, from AngloSaxon cwelan, to die, means to cause to die, and is related to the verb quell. Murder, in Anglo-Saxon morth, German mord, etc., is eonnected with the Latin mors, death. Assassinate, from Arabie hashashin, signifies to kill after the manner of an assassin, which word probably comes from the Levant, where, in the thirteenth century, there lived a prince who was called the "Old Man of the Mountains." He lived in a eastle between Antioch and Damascus, and brought up young men, whom he fed on the intoxieating drug hashish (whence assassin) and trained to lie in wait and kill passengers. Slay comes from AngloSaxon slean, to smite.

To kill is the general and indefinite term, signifying simply to take away life; to murder is to kill with open violence and injustice; to assassinate is to murder by surprise or by means of lying in wait; to slay is to kill in battle: to kill is applieable to men, animals, and also vegetables; to murder and assassinate to men only; to slay mostly to men, but sometimes to animals; to slaughter only to animals in the proper sense, but it may be applied to men in the improper sense, when they are killed like brutes, either as to the numbers or to the manner of killing them.

KIND, Species, Sort. Kind comes from Anglo-Saxon cynd, race, indieating those united by ties of blood. Species, in Latin species, from specere, to behold, signifies literally the form or appearance, and in an extended sense that which comes under a partieular form. Sort, in Latin sors, a lot, signifies that which constitutes a particular lot or pareel.

Kind and species are both employed in their proper sense; sort has been diverted from its original meaning by colloquial use: kind is properly employed for animate objects, particularly for mankind, and improperly for moral objects; species is a term used by philosophers, classing things according to their external or internal properties. Kind, as a term in vulgar use, has a less definite meaning than species, which serves to form the groundwork of science: we discriminate things in a loose or general manner by saying that they are of the animal or vegetable kind; of the canine or feline kind; but we discriminate them precisely if we say that they are a species of the arbutus, of the pomegranate, of the dog, the horse, and the like. By the same rule we may speak of a species of madness, a species of fever, and the like; beeause diseases have been brought under a systematic arrangement: but on the other hand, we should speak of a kind of language, a kind of feeling, a kind of influence; and in similar eases where a general resemblance is to be expressed.

Sort may be used for either kind or species; it does not necessarily imply any affinity or common property in the objects, but simple assemblage, produced, as it were, by sors, ehanee: hence we speak of sueh sort of folks or people; sueh sort of practiees; different sorts of grain; the various sorts of merchandise: and in similar eases where things are sorted or brought together, rather at the option of the person than according to the nature of the thing.

Kindred, Relationship, Affinity, Consanguinity.-The idea of a state in which persons are placed with regard to each other is common to all these terms, whieh differ prineipally in the nature of this state. Kindred signifies that of being of the same kin or kind. Relationship signifies that of holding a nearer relation than others (see CoNNECT). Affinity, from Latin ad, to, and finis, border, signifies that of coming elose to each other's boundaries. Consanguinity, from sanguis, the blood, signifies that of having the same blood.

The kindred is the most general state here expressed: it may embrace all mankind or refer to particular families or communities; it depends upon possessing the common property of humanity: the philanthropist claims kindred with all who are unfortunate, when it is in his power to relieve them. $R e-$ lationship is a state less general than kindred, but more extended than either affinity or consanguinity; it applies to particular families only, but it applies to all of the same family, whether remotely or distantly related. Affinity denotes a close relationship, whether of an artificial or a natural kind: there is an affinity between the husband and 
the wife in consequence of the marriage tie; and there is an affinity between those who descend from the same parents or relations in a direct line. Consanguinity is, strictly speaking, this latter species of descent; and the term is mostly employed in all questions of law respecting descent and inheritance.

See also Affectionate; Gracious; RELATION.

KINDNESS. See Benefit; BenevOLENCE.

KINETIC. ACtive, Movable. These three terms signify "pertaining to motion," but they differ in their application. Kinetic, from Greek $\kappa \iota v \dot{\varepsilon} \omega$, I move, means "resulting from motion," or "associated with motion," and is a scientific term. Kinetic energy, for instance, is energy resulting from motion. Active, from Latin actus, past participle of agere, to do or drive, and a suffix, signifies a state of motion, and further suggests motion emanating from within, not the result of force applied from without. Movable means a capacity for being put in motion-suggesting that the motion is a result of an external impetus. Hence none of these terms can be substituted for the other-closely allied in their meaning as they seem to be.

KINGDOM. See EMPIRE.

KINGLY. See RoYal.

KINSMAN. See RELation.

KISS, Osculation. The difference between these two terms is not one of meaning, but of cutomary usage. Kiss, from Anglo-Saxon coss, is the familiar and homely word. It is employed in simple, sincere, emotional, or poetical expression. Osculation, from Latin asculum, a little mouth, is a self-conscious and humorous periphrasis. It may be employed in scientific writing, as when the physiologist writes that "promiscuous osculation is a contributory factor in this disease"; or it may be employed by the smart journalist as a humorous substitute for the familiar Anglo-Saxon term. In this case, as in many others, the Latin furnishes the dignified and impersonal word, whose dignity, however, may be made to look like pomposity; the Anglo-Saxon furnishes the familiar and natural term.

KLEPTOMANIA, Thievery. Here again the difference in meaning corre- sponds to a difference in derivation. Kleptomania is a scientific term, from Greek $\kappa \lambda \dot{\varepsilon} \pi \tau \omega$, I steal, and Latin mania, madness. Thievery comes from AngloSaxon theof, and indicates the act of taking another's property. Thievery is the general and popular word and carries with it the suggestion of moral condemnation. Kleptomania is a specialized scientific word, suggesting an abnormal psychological condition. Kleptomania is an irresistible tendency to theft actuating people who are not tempted to it by necessitous circumstances or any obvious and natural motive, and is regarded as a form of insanity. The thief steals because he wants or needs the object, or intends to exchange it for something that he wants or needs. The kleptomaniac takes objects with which he may be already well provided and makes no apparent use of the stolen goods. Often he steals only a particular kind of article-an article perhaps valueless in itself or useless to him.

KNACK, Adroitness, Dexter1TY. Knack is an imitative word. It meant originally (1) a snap; (2) a snap with the finger-nail; (3) a jester's trick, a piece of dexterity. Knack is usually employed now to indicate a kind of skill or dexterity which does not result from practice and training, but is an accidental gift or acquirement, or the result of some unexplained trick. There is always something inexplicable about a knack; it cannot be imitated or reduced to rules of procedure. Dexterity, on the contrary, from dexter, the right hand, signifies ease and skill in using the hand; hence, by extension, any ease and skill in making or doing something; it may be the result of inborn gifts or of training and practice. Dexterity is uniform and reliable; a knack is casual and may be uncertain. Adroitness, from French à droit, Latin ad directum, or, in a right manner, is practically synonymous with dexterous; it indicates special quickness and cleverness of action. For a further distinction between adroit and dexterous see CLEVER. KNAVISH. See Dishonest.

KNELL, Toln. There is little difference between these two words. Both indicate the slow ringing of a bell to announce death or disaster. Toll sug- 
gests by its sound a more solemn and a slower ringing. Knell is also used as a substantive to indicate figuratively the death or end of anything.

KNOCK. See RAP.

KNOTTy, Intricate, Perplexing. These words all indicate the quality of being difficult under the image of entangled threads, but they differ from each other in the character of the image and the concreteness and vividness with which it is suggested to the mind. A knot is the interweaving of two threads at one point in such a fashion as to tie them tightly together; knotty means full of knots, difficult to unfasten. Intricate, from Latin in and tricoe, wiles or hindrances, did not originally suggest the image of interwoven threads so clearly as perplexing, from Latin per, through, and plexus, past participle of plectere, to weave, which meant woven through and through. Now intricate, which first meant full of hindrances, clearly suggests the physical image of interwoven threads, and perplexing, which first suggested the physical image, is given the more general application. Intricate is an objective word; perplexing, a subjective word. Intricate describes the external object; perplexing indicates the state of mind induced by it. An intricate question becomes perplexing the minute some individual mind tries to solve it. Knotty is also an objective word, but more obviously metaphorical than intricate, and suggesting a somewhat different image.

KNOW, BE Acquarnted With. To know is a general term; to be acquainted with is particular. We may know things or persons in various ways; we may know them by name only, or we may know their internal properties or characters; or we may simply know their figure; we may know them by report, or we may know them by direct intereourse: one is acquainted with either a person or a thing only in a direct manner and by an immediate intercourse in one's own person. We know a man to be good or bad, virtuous or vicious, by being a witness to his actions; we become acquainted with him by frequently being in his company.

Knowledge, Science, Learning, Erudition.-Knowlcdge signifies the thing known, from Anglo-Saxon cnawan, allied to Latin noscere, to know. Science, in Latin scientia, from scire, to know, has the same original meaning. Learning, from learn, signifies the thing learned. Erudition, in Latin eruditio, comes from Latin $\bar{e}$ for $e x$, out, and rudis, rudc, and signifies to bring out of a statc of rudeness or ignorance, that is, the bringing into a state of perfection.

Knowledge is a general term which simply implies the thing known: science, learning, and erudition are modes of knowledge qualified by some collateral idea: science is a systematic species of knowledge which consists of rule and order; lcarning is that species of knowledge which one derives from schools or through the medium of personal instruction; erudition is scholastic knowledge obtained by profound research: knowledge admits of every possible degree, and is expressly opposed to ignorance; science, learning, and crudition are positively high degrees of knowledge.

The attainment of knowledge is of itself a pleasurc independent 0 . the many extrinsic advantages which it brings to every individual, according to the station of life in which he is placed; the pursuits of science have a peculiar interest for men of a peculiar turn. Learning is less dependent on the genius than on the will of the individual; men of moderate talents have overcome the deficiencies of nature by labor and perseverance, and have acquired such stores of learning as have raised them to a respectable station in the republic of letters. Profound erudition is obtained by but few; a retentive memory, a patient industry, and deep penetration are requisites for one who aspires to the title of an erudite man. Knowledge, in the unqualified and universal sense, is not always a good; we may have a knowledge of evil as well as good: science is good as far as it is founded upon experienee; learning is more generally and practically useful to the morals of men than science: erudition is always good, as is a profound knowledge of what is worth knowing.

KNOWN. See Public.

KNUCKLE. Sce QuaIL. 
Labor, Take Panns or Trouble, Use ENDEAvor. Labor, in Latin labor, toil. To take pains is to expose one's self to pains (see PAIN); and to take the trouble is to impose trouble on one's self (see AFFliction). Endeavor (see that word).

The first three terms suppose the necessity for a painful exertion; but to labor expresses more than to take pains, and this more than to trouble: to use endeavor excludes every idea of pain or inconvenience: great difficulties to be conquered; great perfection or correctness require pains; a concern to please will give trouble; but we use endeavors wherever any object is to be obtained or any duty to be performed. To labor is either a corporeal or a mental action; to take pains is principally an effort of the mind or the attention: to take trouble is an effort of either the body or mind: a faithful minister of the Gospel labors to instil Christian principles into the minds of his audience, and to heal all the breaches which the angry passions make between them: when a child is properly sensible of the value of improvement, he will take the utmost pains to profit by the instruction of the master: he who is too indolent to take the trouble to make his wishes known to those who would comply with them cannot expect others to trouble themselves with inquiring into his necessities: a good name is of such value to every man that he ought to use his best endeavors to preserve it unblemished.

See also Work.

\section{LABORIOUS. See ActIVE.}

LABYRINTH, MAZE. Intricacy is common to both the objects expressed by these terms; but the term labyrinth has it to a much greater extent than maze: the labyrinth, from the Greek $\lambda \alpha \beta \dot{v} \rho \iota \nu \theta o s$, of Egyptian origin, was a work of antiquity which surpassed the maze in the same proportion as the ancients surpassed the moderns in all other works of art; it was constructed on so prodigious a scale, and with so many windings, that when a person had once entered he could not find his way out without the assistance of a clue or thread. Maze is a word of doubtful origin; it was at first used to signify dreamy thought, dreamy perplexity, and then a structure of interweaving paths which induced such a state of mind. It is a modern term for a structure similar to a labyrinth, on a smaller scale, which is frequently made by way of ornament in large gardens. From the proper meaning of the two words we may easily see the ground of their metaphorical application: political and polemical discussions are compared to a labyrinth; because the mind that is once entangled in them is unable to extricate itself by any efforts of its own: on the other hand, that perplexity and confusion into which the mind is thrown by unexpected or inexplicable events is termed a maze, because, for the time, the brain is bereft of its power to pursue its ordinary functions of recollection and combination.

LACHRYMOSE. See Tearful.

LACK. See WANT.

LACONiC, Brief, Concise, Pithy. All of these terms indicate speech which contains no unnecessary words, but they differ from each other in the idea that they suggest in addition to that common to them all. Brief, from Latin brevis, means simply short; the opposite of long-containing few words. Concise, from Latin cidere, con, intensive, and caedere, to cut, means cut short-made shorter than it might naturally be-and suggests therefore a deliberate concentration in a small space. Pithy adds to this idea-it means full of pith. It does not necessarily mean short; but is usually connected with that idea-suggesting the concentration of much substance in a little space. $L a-$ conic comes from $\Lambda a \kappa \omega \nu t \kappa o ́ s$, from $\Lambda$ ák $\omega \nu$, a Laconian or inhabitant of Laconia- 
Laconians or Spartans being noted for their brevity of speech. It suggests not only the character of the speechbrief, to the point-but the manner of utterance.

LADING. See Freight.

LAG. See LiNGER.

LAMBENT, Flickering, GleamING, Twinkling. Lambent, from the Latin lambo, to lick, signifies licking or playing about like flames, hence, touching lightly, or gliding over. The term is most generally applied to light from any source as affected by exterior influences. Thus, we say that a light is fickering when it is moving with an unsteady and quick motion, swaying because of a sudden commotion in the air, and fiekering out, especially the light from a candle or a lamp, when the wick or the oil is nearly consumed: gleaming, when it emits shooting or darting rays or exhibits unusual brightness; and twinkling, when it is burning unsteadily, shining with a tremulous, quivering effect, or exhibiting quick, spasmodic spurts, as the twinkling of the stars. The term is often used in poetry to imply that which touches lightly or glides over.

LAMENT. See Bewail; Conplain; Deplore; Grieve; Wail.

LAND, Country. Land, AngloSaxon land, signifies an open, even space, and refers strictly to the earth. Country, through Old French contree, from Late Latin contrala, the region lying opposite, comes from contra, opposite. Compare German gegend, from gegen, opposite. The term land, therefore, in its proper sense, excludes the idea of habitation; the term country excludes that of the earth, or the parts of which it is composed: hence we speak of the land as rich or poor, according to what it yields: of a country, as rich or poor, according to what its inhabitants possess: so, in like manner, we say, the land is ploughed for receiving the grain; or a man's land, for the ground which he possesses or occupies: but the country is cultivated; the country is under a good government; or a man's country is dear to him.

In an extended application, however, these words may be put for one another: the word land may sometimes be put for any portion of land that is under a government, as the land of liberty; and country may be put for any spot of earth or line of country, together with that which is upon it; as a rich country.

LANDSCAPE. See VIEw.

LANGUAGE, ToNgUe, SPEech, Idiom, Dialect. Language, through Middle French language, based on langue, from the Latin lingua, a tongue, and a suffix, signifies, like the word tongue, that which is spoken by the tongue, Anglo-Saxon tunge. Speech is the act of speaking, or the word spoken. Idiom, in Latin idioma, Greek iówua, from ioıs, proprius, proper, or peculiar, signifies a peculiar mode of speaking. Dialect, through French from Latin

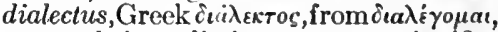
to speak in a dist inct manner, signifies a distinct mode of speech.

All these terms mark the manner of expressing our thoughts, but under different circumstances. Language is the most general term in its meaning and application; it conveys the general idea without any modification, and is applied to other modes of expression besides that of words, and to other objects besides persons; the language of the eyes frequently supplies the place of that of the tongue; the deaf and clumb use the language of signs; birds and beasts are supposed to have their peculiar language: tongue, speech, and the other terms are applicable only to human beings. Language is either written or spoken; but a tongue is coneeived of mostly as something to be spoken: whence we speak of one's mother tongue.

Speech is an abstract term, implying either the power of uttering articulate sounds, as when we speak of the gift of speech, which is denied to those who are dumb; or the words themselves which are spoken, as when we speak of the parts of speech; or the particular mode of expressing one's self, as that a man is known by his speech. Idiom and dialect are not properly a language, but the properties of language: idiom is the peculiar construetion and turn of a language, which distinguishes it altogether from others; it is that which enters into the composition of the language, and cannot be separated from it. A dialect is that which is engrafted 
on a language by the inhabitants of particular parts of a country, and admitted by its writers and learned men to form an incidental part of the language; as the dialects which originated with the Ionians, the Athenians, the Eolians, and were afterward amalgamated into the Greek tongue. Whence the word dialect may be extended in its application to denote any peculiar manner of speech adopted by any community.

I.ANGUID. See FAINT.

LANGUISH. See Flag.

LAPSE. See SLIP.

LARGE, Wide, Broad. Large (see Great) is applied in a general way to express every dimension; it implies not only abundance in solid matter, but also freedom in the space, or extent of a plane superficies. Wide, in AngloSaxon wid, signifies an open space unencumbered by any obstructions. Broad, in Anglo-Saxon brad, has a similar meaning. Many things are large, but not wide; as a large town, a large circle, a large ball, a large nut: other things are both large and wide; as a large field, or a wide field: a large house, or a wide house: but the field is said to be large from the quantity of ground it contains; it is said to be wide both from its figure and the extent of its space in the cross directions; in like manner, a house is large from its extent in all directions; it is said to be wide from the extent which it runs in front: some things are said to be wide which are not denominated large, that is, either such things as have less bulk and quantity than extent of plane surface; as ell-wide cloth, a wide opening, a wide entrance, and the like; or such as have an extent of space only one way; as a wide road, a wide path, a wide passage, and the like. What is broad is in sense, and mostly in application, wide, but not vice versâ: a ribbon is broad; a ledge broad; a ditch is broad; a plank is broad; the brim of a hat is broad; or the border of anything is broad; on the other hand, a mouth is wide, but not broad; apertures in general are wide, but not broad. Large is opposed to small; wide to close; broad to narrow. In the moral application, we speak of largeness in regard to liberal- ity; wide and broad only in the figurative sense of space or size: as a wide difference; or a broad line of distinction. Largely, Copiously, Fully.-Largely is here taken in the moral sense, and, if the derivation given of it be true, in the most proper sense. Copiously comes from the Latin copia, plenty, signifying in a plentiful degree. Fully signifies in a full degree; to the full extent, as far as it can reach.

Quantity is the idea expressed in common by all these terms; but largely has always a reference to the freedom of the will in the agent; copiously qualifies actions that are done by inanimate objects; fully qualifies the actions of a rational agent, but it denotes a degree or extent which cannot be surpassed. A person deals largely in things, or he drinks large draughts; rivers are copiously supplied in rainy seasons; a person is fully satisfied or fully prepared. A bountiful Providence has distributed His gifts largely among His creatures: blood flows copiously from a deep wound when it is first made: when a man is not fully convinced of his own insufficiency he is not prepared to listen to the counsel of others.

LASH. See WhIP.

LASS. See VIRGIN.

LASSITUDE. See Fatigue.

LAST, Latest, Final, Ultimate. Last and latest are both from latst, the superlative of Anglo-Saxon lat, slow-Modern English late-allied to Latin lassus, which is found in English words like lassitude. Final (see that word). Ultimate comes from Latin ultimatus, participle of ultimare, based on ultimus, the last.

Last and ultimate concern the order of succession: latest, the order of time; final, the completion of an object. What is last or ultimate is succeeded by nothing else: what is latest is succeeded at no great interval of time; what is final requires to be succeeded by nothing else. The last is opposed to the first; the ultimate is distinguished from that which immediately precedes it; the latest is opposed to the earliest; the final is opposed to the introductory or beginning. A person's last words are those by which one is guided; his ultimate object is sometimes remote or concealed from the view; a conscientious 
man remains firm to his principles to his latest breath; the final determination of difficult matters requires caution. Jealous people strive not to be the last in anything; the latest intelligence which a man gets of his country is acceptable to one who is in distant quarters of the globe; it requires resolution to take a final leave of those whom one holds near and dear.

See also UTTERMOST.

Lastly, At Last, At Length.-Lastly, like last, implies the order of succession: at last or at length refers to what has preceded. When a sermon is divided into many heads, the term lastly comprehends the last division. When an affair is settled after much difficulty, it is said to be at last settled; and if it be settled after a protracted continuance, it is said to be settled at length.

LAST-TERMS. See UlmimatuM.

LATENT. Sce Secret.

LATEST. See LAST.

laUdable, Praiseworthy, ComMENDABLE. Laudable, from the Latin laudare, to praise, is in sense literally praiseworthy, that is, worthy of praise or to be praised (see Praise). Commendable signifies entitled to commendation, from Latin con, together, and mandare, to place in the hands of - that is to say, worthy of trust, hence worthy of praise.

Laudable is used in a general application; praiseworthy and commendable are applied to individuals: things are laudable in themselves; they are praiseworlhy or commendable in this or that person. That which is laudable is entitled to encouragement and general approbation; an honest endeavor to be useful to one's family or one's self is at all times laudable, and will insure the support of all good people. What is praiseworthy obtains the respect of all men: as all have temptations to do that which is wrong, the performance of one's duty is in all cases praiseworthy, but particularly so in those cases where it opposes one's interests and interferes with one's pleasures. What is commendable is not equally as important as the former two; it entitles a person only to a temporary or partial expression of good-will and approbation; the performance of those minor and particular duties which belong to children and subordinate persons is in the proper sense commendable.

LAUGH, RIDICULE. Laugh is the Anglo-Saxon word, from hlihan, an imitative word; ridicule, from ridiculus, is the Latin term, from ridere, to smile or laugh.

Both these verbs are used here in the sense for laughter, blended with more or less of contempt: but the former displays itself by the natural expression of laughter: the latter shows itself by' a verbal expression: the former is produced by a feeling of mirth on observing the real or supposed weakness of another; the latter is produced by a strong sense of the absurd or irrational in another: the former is more immediately directed to the person who has excited the feeling; the latter is more commonly produced by things than by persons. We laugh at a person to his face; but we ridicule his notions by writing or in the course of conversation: we laugh at the individual; we ridicule that which is maintained by him.

Laughable, Ludicrous, Ridiculous, Comical, Comic, Droll.-Laughable signifies exciting, or fit to excite, laughter. Ludicrous, in Latin ludicrus, from lu$d u s$, a game, signifies belonging to a game or sport. Ridiculous, exciting, or fit to excite, ridicule.

Either the direct action of laughter or a corresponding sentiment is included in the signification of all these terms: they differ principally in the cause which produces the feeling; the laughable consists of objects in general, whether personal or otherwise; the ludicrous and ridiculous have reference more or less to that which is personal. What is laughable may excite simple merriment independently of all personal reference, unless we admit what Mr. Hobbes, and after him Addison, have maintained of all laughter, that it springs from pride. But without entering into this nice question, I am inclined to distinguish between the laughable which arises from the reflection of what is to our own advantage or pleasure, and that which arises from reflecting on what is to the disadvantage of another. The tricks of a monkey or the humorous stories of 
wit are laughable from the nature of the things themselves, without any apparent allusion, however remote, to any individual but the one whose senses or mind is gratified. The ludicrous and ridiculous are, however, species of the laughable which arise altogether from reflecting on that which is to the disadvantage of another; but the ludicrous has in it less to the disadvantage of another than the ridiculous. It is possible, therefore, for a person to be in a ludicrous situation without any kind of moral demerit, or the slightest depreciation of his moral character; since that which renders his situation ludicrous is altogether independent of himself; or it becomes ludierous only in the eyes of incompetent judges. "Let an ambassador," says Mr. Pope, "speak the best sense in the world, and deport himself in the most graceful manner before a prince, yet if the tail of his shirt happen, as I have known it happen to a very wise man, to hang out behind, more people will laugh at that than attend to the other." This is the ludicrous. The same can seldom be said of the ridiculous; for as this springs from positive moral causes, it reflects on the person to whom it attaches in a less questionable shape and produces positive disgrace. Persons very rarely appear ridiculous without being really so; and he who is really ridiculous justly excites contempt.

Droll and comical are in the proper sense applied to things which cause laughter, as when we speak of a droll story, or a comical incident, or a comic song. They may be applied to the person; but not so as to reflect disadvantageously on the individual, as in the former terms.

LAVISH. See Extravagant.

LaW. See Maxim; Ordinance.

LAWFUL, LEgal, Legitimate, Licit. Lawful is the adjective corresponding to law, a Scandinavian word from the root found in lie, a law being that which is laid down, which is fixed or established. Legal comes from Latin legalis, from lex, from the root found in legere, to collect-law being the collection of the customs and judgments of the people in one standard cade of action. Legitimate has the same derivation. They differ, therefore, according to the sense of the word law; lawf ul signifies the law in general, defined or undefined; legal, only the law of the land which is defined; legitimate, the laws or rules of science as well as civil matters in general. Licit, from the Latin licet, it is allowed, is used only to characterize the moral quality of actions; the lawful properly implies conformable to or enjoined by law; the legal what is in the form or after the manner of law, or binding by law: it is not lawful to coin money with the king's stamp; a marriage was formerly not legal in England which was not solemnized according to the rites of the Established Church: men's passions impel them to do many things which are unlawful or illicit; their ignorance leads them into many things which are illegal or illegitimate. As a good citizen and a true Christian, every man will be anxious to avoid everything which is unlawful: it is the business of the lawyer to define what is legal or illegal: it is the business of the critic to define what is legitimate verse in poetry; it is the business of the linguist to define the legitimate use of words: it is the business of the moralist to point out what is illicit.

LAX. See Loose.

Lay, Take Hold Of, Catch, Seize, Snatch, Grasp, Gripe. To lay or take hold of is here the generic expression; it denotes simply getting into one's possession, which is the common idea in the signification of all these terms, which differ in regard to the motion in which the action is performed. To catch is to lay hold of with an effort. To seize is to lay hold of with violence. To snatch is to lay hold of by a sudden effort. One is said to lay hold of that on which one places his hand; he takes hold of that which he secures in his hand. We lay hold of anything when we see it falling; we take hold of anything when we wish to lift it up; we catch what attempts to escape; we seize it when it makes resistance; we snatch that which we are particularly afraid of not getting otherwise. A person who is fainting lays hold of the first thing which comes in his way; a sick person or one that wants support takes hold of another's arm in walking; various artifices are employed to catch ani- 
mals; the wild beasts of the forest seize their prey the moment they come within their reach; it is the rude sport of a sehool-boy to snatch out of the hand of another that which he is not willing to let go.

To lay hold of is to get in the possession. To grasp and to gripe signify to have or keep in the possession; an eagerness to keep or not to let go is expressed by that of grasping; a fearful anxiety of losing and an earnest desire of keeping are expressed by the act of gripping. When a famished man lays hold of food he grasps it, from a convulsive kind of fear lest it should leave him: when a miser lays hold of money he gripes it from the love he bears to it, and the fear he has that it will be taken from him.

See also Lie; Put.

LAZY. See IdLe; Ixactive.

LEAD, Conduct, Guide. Lead is the Anglo-Saxon word, originally ladan, corresponding to Latin ducere, found here in conduct, from cum, with, and ducere, to lead. For the origin of guide see Chaperon.

All these terms are employed to denote the influence which a person has over the movements or actions of some person. To lead is an unqualified aetion: one leads by helping a person onward in any manner, as to lead a ehild by the hand, or to lead a person through a wood by going before him. To conduct and guide are different modes of leading, the former by virtue of one's office or authority, the latter by one's knowledge or power; as to conduct an army, or to conduct a person into the presence of another; to guide a traveller in an unknown country. These words may therefore be applied to the same objects: a general leads an army, inasmuch as he goes before it into the field; he conducts an army, inasmuch as he directs its operations; the stable-boy leads the horses to water; the coachman guides the horses in a carriage.

Conduct and guide may also be applied in this sense to inanimate objects; as the pilot conducts the vessel into the port, the steersman guides a vessel by the help of the rudder.

In the moral application of these terms, persons may lead or guide other persons, but they conduct things; as to lead a person into a course of life; to guide him in a course of reading or study; to conduct a lawsuit, or any particular business. To lead, being a matter of purely personal influence, may be either for the benefit or injury of the person led.

To conduct, supposing judgment and management, and to guide, supposing superior intelligence, are always taken in the good sense, unless otherwise qualified.

Things as well as persons may lead, conduct, and guide, with a similar distinetion. Whatever serves as a motive of action, or as a course and passage to a place or an object, leads.

Whatever influences our conduet rightly conducts.

Whatever serves as a rule or guide guides.

As persons may sometimes be false guides, so things may furnish a false rule.

LEADER. See CHIEF.

LEADING. See Cardinal; SePREME.

LEAGUE. See Alliance.

LEAN, MeAGRe. Lean is the AngloSaxon word, from hlone, originally bending or stooping, hence inclined to bend, or thin; meagre is probably a Latin word from macer, thin, Greek maxoós, long, though it early appears in Anglo-Saxon as meger, probably borrowed from the Continent.

Lean denotes want of fat; meagre want of flesh: what is lean is not always meagre; but nothing can be meagre without being lean. Brutes as well as men are lean, but men only are said to be meagre: leanness is frequently connected with the temperament; meagreness is the consequence of starvation and disease. There are some animals by nature inelined to be lean; a meagre, pale visage is to be seen perpetually in the haunts of vice and poverty.

Lean, Incline, Bend.-Lean, in AngloSaxon hlonan (see above), is derived from the root found in incline, from the Latin, Greek kiivw, I bend. Bend (see that word).

In the proper sense, lean and incline are both said of the position of bodies; bend is said of the shape of bodies: that which leans rests on one side, or 
in a sideward direction; that which inclines leans or turns only in a slight degree: that which bends forms a curvature; it does not all lean the same way: a house leans when the foundation gives way: a tree may grow so as to incline to the right or the left, or a road may incline this or that way; a tree or a road bends when it turns out of the straight course. In another sense, the judgment leans, the will inclines, the will or conduct bends, in consequence of some outward action. A person leans to this or that side of a question which he favors; he inclines, or is inclined, to this or that mode of conduct; he bends to the will of another. It is the duty of a judge to lean to the side of mercy as far as is consistent with justice: whoever inclines too readily to listen to the tales of distress which are continually told to excite compassion will find himself in general deceived; an unbending temper is the bane of domestic felicity.

LEARNED. See ACADEMIC.

LEARNING. See KNOWLEDGE; LETTERS.

LEAVE, QUit, Relinquish. Leave is derived from Anglo-Saxon lofan, to leave, corresponding to the Latin linquere, found in relinquish. Quit, in French quitter, from the Latin quietus, rest, signifies to rest or remain, to give up the hold of. Relinquish (see ABANDON).

We leave that to which we may intend to return; we quit that to which we return no more: we may leave a place voluntarily or otherwise; but we relinquish it unwillingly. We leave persons or things; we quii and relinquish things only. I leave one person in order to speak to another; I leave my house for a short time; I quit it not to return to it.

Leave and quit may be used in the improper as well as the proper sense. It is the privilege of the true Christian to be able to leave all the enjoyments of this life, not only with composure, but with satisfaction; dogs have sometimes evinced their fidelity, even to the remains of their masters, by not quitting the spot where they are laid; prejudices, particularly in matters of religion, acquire so deep a root in the mind that they cannot be made to relinquish their hold by the most persuasive eloquence and forcible reasoning.

See also Cease; Desist.

Leave, Take Leave, Bid Farewell or Adieu.-Leave is here general as before; it expresses simply the idea of separating one's self from an object, whether for a time or otherwise; to take leave and bid farewell imply a separation for a perpetuity. Farewell is a native English expression meaning "May you fare well"; adieu is French, from the phrase à Dieu, Latin ad Deum, meaning "I commit you to God's keeping.'

To leave is an unqualified action; it is applied to objects of indifference, or otherwise, but supposes in general no exercise of one's feelings. We leave persons as convenience requires; we leave them on the road, in the field, in the house, or wherever circumstances direct; we leave them with or without speaking; but to take leave is a parting ceremony between friends, on their parting for a considerable time; to bid farewell, or adieu, is a still more solemn ceremony, when the parting is expected to be final. When applied to things, we leave such as we do not wish to meddle with; we take leave of those things which were agreeable to us, but which we find it prudent to give up; and we bid farewell to those for which we still retain a great attachment. It is better to leave a question undecided than to attempt to decide it by altercation or violence; it is greater virtue in a man to take leave of his vices than to let them take leave of him; when a man engages in schemes of ambition, he must bid adieu to all the enjoyments of domestic life.

Leave, Liberty, Permission, License. -Leave as here used is a word of different origin, from Anglo-Saxon leof, dear, found in English lief-meaning here pleasure, hence freedom of will, literally permission "to do as you please." Liberty is also taken for liberty granted, from Latin liber, free. Permission signifies the act of permitting (see Allow) or the thing permitted. License, in Latin licentia, from licet, it is lawful, signifies the state of being permitted by law or authority.

Leave and liberty may sometimes be taken as well as given; permission and license are never to be taken, but must 
always be granted, and that in an especial manner-the former by express words, the latter by some acknowledged and mostly legal form. Leave is employed only on familiar occasions; liberty is given in more important matters: the master gives leave to his servant to go out for his pleasure; a gentleman gives his friends the liberty of shooting on his grounds: leave is taken in indifferent matters, particularly as it respects leave of absence; liberty is taken by a greater, and in general an unauthorized, stretch of one's powers, and is, therefore, an infringement on the rights of another. What is done without the leave may be done without the knowledge, though not contrary to the will of another; but liberties which are taken without ofiering an apology are always calculated to give offence. Leave respects only particular and private matters; liberty respects general or particular matters, public or private; as liberty of speech, liberty of the press, and the like.

Leave and permission are both the acts of private individuals in special cases. The perinission is a more formal and less familiar act than leave; the permission is often an act of courtesy passing between equals and friends; the leave is properly said of what passes from superiors to inferiors: a person obtains leave of absence. The license is always general, or resting on some general authority; as the licenses given by government, and poetic $l i$ censes. Whenever applied to individuals it carries with it the idea of a special authority; as a license given by a landlord to the tenant to assign his lease.

Leavings, Remains. - Leavings are the consequences of a voluntary act: they signify what is left: remains are what follow in the course of things; they are what remains; the former is therefore taken in the sense to signify what has been left as worthless; the latter is never taken in this sense. When many persons of good taste have the liberty of choosing, it is fair to expect that the leavings will be worth ittle or nothing, after all have made their choice. By the remains of beauty which are discoverable in the face of a female we may be enabled to estimate what her personal gifts were.

\section{LEGAL. See LAwFuL.}

LEGENDARY, Fabulous, Mrthical, Traditional. These are all adjectives signifying the quality of old stories handed down from generation to generation either in oral or written form. Legendary comes from the gerundive of Latin legere, to collect or read; it signifies worthy of being collected and read, or characteristic of old collections of tales. Fabulous, from Latin fabula, a story, signifies storylike, with an emphasis upon the difference between the story which is the product of the untrammelled imagination and the plain reality. Mythical comes from Greek $\mu \hat{v} \theta 0 \varsigma$, a fable. Tradition comes from Latin tradere, to hand down-signifying that which is handed down by word of mouth. Legendary and traditional differ from each other in the indication of the means of communication; the one is written, the other is generally oral, though these distinctions are not strictly observed. We speak of "written tradition" and denominate as legends stories that have never been written. Traditional has more of truth and seriousness than legendary. A tradition is preserved as a record of some fact, and the changes that it undergoes are usually due to natural mistakes and failures of memory; a legend is usually handed down because it is interesting-it makes a good story worthy of being read, and hence it may be improved by the imaginations of successive generations. Mythical suggests less of faet and veracity. A mythical hero, a mythical land are those which exist only in the imagination of those who tell about them. Mythical sometimes refers especially to the myths or old stories of the divinities and heroes preserved by various nations. It therefore suggests stories of the supernatural, and has some of the dignity of a tradition or legend. Fabulous has none of this traditional credibility and seriousness; something fabulous is a deliberate creation of the imagination transcending all bounds of reality. However, there are several curious modifications of these words. Fabulous, while suggesting the wildly extravagant, the appar- 
ently impossible, etc., does not arouse the same degree of incredulity that is aroused by mythical. Mythical wealth is wealth which is said to exist but does not; fabulous wealth is wealth transcending all bounds of probability, with the implication that it does really exist. Mythical indicates that which is believed but does not exist; fabulous that which is not believed but does exist. There is always a distinct difference in the significance of these four words; they are interchangeable only within some definite limits. The traditional splendor of a noble family, for instance, means splendor enduring from generation to generation both in memory and in reality; legendary splendor means splendor described in old stories, existent long ago, but not now; mythical splendor means that which is said to be but is not; fabulous splendor, splendor now existent but so great as to seem impossible.

LEGITIMATE. See Lawful.

LEISURE. See IDLE.

LENITY. See Clemency.

LESSEN. See Abate.

LET, Leave, Suffer. The removal of hindrance or constraint on the actions of others is implied by all these terms; but let, like the German lassen, to leave, is a less formal action than leave, and this than suffer, from the Latin suffero, to bear with, signifying not to put a stop to. I let a person pass in the road by getting out of his way: I leave a person to decide on a matter according to his own discretion, by declining to interfere; I suffer a person over whom I am expected to exercise a control to go his own way. It is in general most prudent to let things take their own course: in the education of youth, the greatest art lies in leaving them to follow the natural bent of their minds and turn of the disposition, and at the same time not suffering them to do anything prejudicial to their character or future interests.

LETHARGIC. See Sleepy.

LETTER, EPISTLE. According to the origin of these words, letter, in Latin literce, signifies any document composed of written letters; and epistle, in Greek $\dot{\varepsilon} \pi \iota \sigma \tau 0 \lambda \dot{\eta}$, from $\dot{\varepsilon} \pi \iota \sigma \tau \dot{\varepsilon} \lambda \lambda \omega$, to send, signifies a letter sent or addressed to any one; consequently the former is the generic, the latter the specific term. Letter is a term altogether familiar; it may be used for whatever is written by one friend to another in domestic life, or for the public documents of this description which have emanated from the pen of writers, as the letters of Madame de Sévigné, the letters of Pope or of Swift; and even those which were written by the ancients, as the leiters of Cicero, Pliny, and Seneca; but in strict propriety those are entitled epistles, as a term most adapted to whatever has received the sanction of ages, and by the same rule, likewise, whatever is peculiarly solemn in its contents has acquired the same epithet, as the epistles of St. Paul, St. Peter, St. John, St. Jude; and by an analogous rule, whatever poetry is written in the epistolary form is denominated an epistle rather than a letter, whether of ancient or modern date, as the epistles of Horace, or the epistles of Boileau; and, finally, whatever is addressed by way of dedication is denominated a dedicatory epistle. Ease and a friendly familiarity should characterize the letter: sentiment and instruction are always conveyed by an epistle.

\section{See also Character.}

Letters, Literature, Learning.-Letters and literature signify knowledge, derived through the medium of written letters or books, that is, information: learning (see KNOWLEDGE) is confined to that which is communicated, that is, scholastic knowledge. The term men of letters or the republic of letters comprehends all who devote themselves to the cultivation of their minds: literary societies have for their object the diffusion of general information:learned societies propose to themselves the higher object of extending the bounds of science and increasing the sum of human knowledge. Men of letters have a passport for admittance into the highest circles; literary men can always find resources for themselves in their own society: learned men, or men of learning, are more the objects of respect and admiration than of imitation.

LEVEl. See Aim; Even; Flat.

LEVITY. See LightNess.

LEXICON. See Dictionary. 
LIABLE. See Subject.

LIBERAL. See Beneficent; Free. LIBERATE. See EMancipate; Free.

LIBERTy. See Freedom; Leave. LICENSE. See LEAVE.

LICENTIOUS. See Loose.

LICIT. See Lawful.

LIE, LAY. By a vulgar error these verbs have been so confounded as to deserve some notice. To lie is neuter, and designates a state: to lay is active, and denotes an action on an object; it is properly to cause to lie; a thing lies on the table; some one lays it on the table; he lies with his fathers; they laid him with his fathers. In the same manner, when used idiomatically, we say a thing lies by us untl we bring it into use; we lay it by for some future purpose: we lie down in order to repose ourselves; we lay money down by way of deposit: the disorder lies in the constitution; we lay a burden upon our friends.

\section{See also UNTrUTH.}

LIFE. See Animation.

LIFELESS, DEAD, INANIMATE. Lifeless and dead suppose the absence of life where it has once been; inanimate supposes its absence where it has never been; a person from whom life has departed is said to be lifeless or dead; the material world consists of objects which are by nature inanimate. Lifeless is negative: it signifies simply without life or the vital spark: dead is positive; it denotes an actual and complete change in the object. We may speak of a lifeless corpse when speaking of a body which sinks from a state of animalion into that of inanimalion; we speak of dead bodies to designate such as have undergone an entire change. A person, therefore, in whom animation is suspended is, for the time being, in appearance at least, lifeless, although we should not say dead.

In the moral acceptation, lifeless and inanimate denote the want of that life or animation which is requisite or proper; dead implies the total want of moral feeling which ought to exist.

See also Abiogenic.

LIfT, Heave, Hoist. These are all Teutonic words that have come into modern English through different Teutonic languages. Lift, Middle English liften, is a Scandinavian word associated with German luft, air, meaning to raise in the air. Heave is an AngloSaxon word from the root found also in Latin capere, to take. Hoist is a Dutch word, from Middle Dutch hyssen, to lift up.

The idea of making high is common to all these words, but they differ in the objects and the circumstances of the action; we lift with or without an effort: we heave and hoist always with an effort; we lift a child up to let him see anything more distinctly; workmen heave the stones or beams which are used in a building; sailors hoist the long-boat into the water. To lift and hoist are transitive verbs; they require an agent and an object: heave is intransitive; it may have an inanimate object for an agent: a person lifts his hand to his head; when whales are killed, they are hoisted into vessels; the bosom heaves when it is oppressed with sorrow; the waves of the sea heave when they are agitated by the wind.

Lift, Raise, Erect, Elevate, Exalt.The idea of making a thing higher than it was before is common to these verbs. To lift (see LiFr) is to take up from a given spot by a direct aplication of force. To raise, a Scandinavian word, meaning to eause to rise, to erecl, from the Latin erectum, supine of erigo; to elevate, from elevatus, participle of elevare, based on $e$, out, and levare, to raise, signify to make higher by a variety of means, but not necessarily by moving the object from the spot where it rests. We lift a stool with our hands, we raise a stool by giving it longer legs; we ereet a monument by heaping one stone upon another; a mountain is elevaled so many feet above the surface of the sea. Whatever is to be carried is lifted; whatever is to be situated higher is to be raised; whatever is to be constructed above other objects is to be erected; and when the perpendicular height is to be described, it is said to be elevated. A ladder is lifted upon the shoulders: a standard ladder is raised against a wall; a scaffolding is erected; a pillar is elevated above the houses.

Lift and raise may sometimes be applied to the same objects: a stone may 
either be lifted or raised, but lift is the more ordinary term; so when raise and erect are applied to the same objects, raise is the more familiar expression. Elevate is most usual in scientific language. All these terms, except erect, have likewise a moral application; exalt, from altus, high, has no other. In this case lift is seldom used in a good sense; to raise is used in a good or an indifferent sense; to elevate is mostly, and exalt always, used in the best sense. A person is seldom lifted up for any good purpose, or from any merit in himself; it is commonly to suit the ends of party that people are lifted into notice or lifted into office; a person may be raised for his merits, or raise himself by his industry, in both of which cases he is entitled to esteem; so likewise one may be lifted up by pride, or raised in one's mind or estimation; one is elevated by circumstances, but still more so by one's character and moral qualities; one is rarely exalted but by means of superior endowments.

In modern building construction the term elevator is synonymous with lift.

LIGHTNESS, LEVITY, FLIGHTINESS, Volatility, GIDDINEss. Lightness, from Anglo-Saxon leoht, light, signifies an abstract quality. Levity, in Latin levitas, from levis, light, signifies the same. Volatility, in Latin volatilitas, from volare, to fy, signifies flitting, or ready to fly swiftly on. Flightiness, from fighty and $f l y$, signifies a readiness to fly. Giddiness is from Anglo-Saxon gidig, insane, possibly from AngloSaxon god, God, meaning possessed by a god, in which case it has the same origin as enthusiasm, from Greek है $\gamma \theta$ єos, a god within.

Lightness and giddiness are taken either in the natural or metaphorical sense; the rest only in the moral sense; lightness is said of the outward carriage or the inward temper; levity is said only of the outward carriage: a lightminded man treats everything lightly, be it ever so serious; the lightness of his mind is evident by the lightness of his motions. Lightness is common to both sexes; levity is peculiarly striking in women; and in respect to them, they are both exceptional qualities in the highest degree: when a woman has lightness of mind, she may easily tend toward vice; when there is levity in her conduct, she exposes herself to public criticism. Volatility, flightiness, and giddiness are degrees of lightness which rise in signification on one another; volatility being more than lightness, and the others more than volatility: lightness and volatility are defects as they relate to age; those only who ought to be serious or grave are said to be light or volatile. When we treat that as light which is weighty, when we suffer nothing to sink into the mind, or make any impression, this is a defective lightness of character; when the spirits are of a buoyant nature, and the thoughts fly from one object to another, without resting on any for a moment, this lightness becomes volatility: a light-minded person sets care at a distance; a volatile person catches pleasure from every passing object. Flightiness and giddiness are the defects of youth; they bespeak that entire want of command over the feelings and animal spirits which is inseparable from a state of childhood; a flighty child, however, fails only from a want of attention; but a giddy child, like one whose head is in the natural sense giddy, is unable to collect itself so as to have any consciousness of what passes: a fighty person makes mistakes; a giddy person commits extravagances.

See also EAsE.

LIKE. See EQUAL.

LIKENESS, RESEMBlaNCE, SMILARITY, Similitude. Likeness denotes the quality of being alike (see EQUAL). Resemblance, from resemble, compounded of re and semble, in French sembler, Latin simulo, from similis, like, signifies putting on the form of another thing. Similarity, from a hypothetical Latin similaritas, extended from simil$i s$, and allied to English same, denotes the abstract property of likeness.

Likeness is the most general, and at the same time the most familiar, term of the three; it implies either external or internal properties: resemblance implies only the external properties: similarity the circumstances or properties: we speak of a likeness between two persons; of a resemblance in the cast of the eye; of a resemblance in the form or figure; of a similarity in age and disposition. Likeness is said 
only of that which is actual; resemblance may be said of that which is apparent: a likeness consists of something specific; a resemblance may be only partial and contingent. A thing is said to be, but not to appear, like another; it may, however, have the shadow. of a resemblance: whatever things are alike are alike in their essential properties; but they may resemble one another in a partial degree or in certain particulars, but are otherwise essentially different. We are most like the Divine Being in the act of doing good; there is nothing existing in nature which has not certain points of resemblance with something else.

Similarity or similitude, which is a higher term, is in the moral application, in regard to likeness, what resemblance is in the physical sense: what is alike has the same nature; what is similar has certain features of similarity: in this sense feelings are alike, sentiments are alike, persons are alike; but cases are similar, circumstances are similar, conditions are similar. Likeness excludes the idea of difference; similarity includes only the idea of casual likeness.

Likeness, Picture, Image, Effigy.-In the former article likeness is considered as an abstract term, but in connection with the words picture and image it signifies the representation of likeness. Picture, in Latin pictura, from pingere, to paint, signifies the thing painted. Imacye, in Latin imago, from the root im, found also in imitari, English imitate, signifies an imitation. Effigy, in Latin effigics, from $e x$, from, and fingere, to fashion, signifies that which is fashioned from or after the image of another thing.

Likeness and picture, as terms of art, are both applied to painting; but the term likencss refers us to the object of the art, namely, to get the likeness; and the picture to the mode of the art, namely, by painting; whenee in familiar language an artist is said to take likenesses who takes or paints the portraits of persons; or in general terms an artist may be said to be happy in taking a likeness who can represent on paper the likeness of any object, but particularly that of persons. In other connections the word picture is most usually employed in regard to works of art, as to sketch a picture, to finish a picture, and the like.

As a likeness may be given by other means besides that of painting, it may be taken for any likeness conveyed; as parents may be said to stamp or impress a likeness on their children. Picture may be figuratively taken for whatever serves as a picture, as a picture of happiness. Image, as appears from its derivation, signifies nothing more than likeness, but has been usually applied to such likenesses as are taken, or intended to represent spiritual objects, whether on paper or in wood or stone, such as the graven images which were the objects of idolatrous worship: it has, however, been extended in its application to any likeness of one object represented by another; as children are sometimes the image of their parents.

A likeness and a picture contain actual likenesses of the things which they are intended to represent; but an effigy may be only an arbitrary likeness, as where a human figure is made to stand for the figure of any particular man without any likeness of the individual. This term is applied to the rude or fictitious pictures of persons in books, and also to the figures of persons on tombstones or on coins, which contain but few traces of likeness. Or to the still ruder representations of individuals who are held up to public odium by the populace.

LIKEWISE. Sce ALSO.

LIMB. SeC MEMBER.

LIMIT, ExTENT. Limit is a more specific and definite term than extent: by the former we are directed to the point where anything ends; by the latter we are led to no particular point, but to the whole space included: limits are in their nature something finite; extent is either finite or infinite: we therefore speak of that which execeds limits or comes within the limits; and of that which comprehends the extent or is according to the extent: a plenipotentiary or minister must not exceed the limits of his instruction; when we think of the immense extent of this globe, and that it is among the smallest of an infinite number of worlds, the mind is lost in admiration and amaze- 
ment: it does not fall within the limits of a periodical work to enter into historical details; a complete history of any country is a work of great extent.

See also Bound; Fix; Term.

LIMITED. See FINITE.

LINEAGE. See FAMILY.

LINGER, TARRY, LOITER, LAG, SAUNTER. Linger is a frequentative of Middle English lengen, from AngloSaxon lang, Modern English long, meaning to keep lengthening the time it takes to do something. Tarry comes from Middle English tarien, to irritate, worry, or vex; hence to hinder or delay. Loiter comes from Middle Dutch leuteren, to trifle. Lag is a Celtic word meaning late or sluggish. Saunter is a word of uncertain origin, perhaps connected with adventure, indicating idle, planless going.

Suspension of action or slow movement enters into the meaning of all these terms: to linger is to stop altogether, or to move but slowly forward; to tarry is properly to suspend one's movement: the former proceeds from reluctance to leave the spot on which we stand; the latter from motives of discretion: one will naturally linger who is going to leave the place of his nativity for an indefinite period; those who have much business to transact will be led to tarry long in a place: to loiter is to move slowly and reluctantly; but, from a bad cause, a child loiters who is unwilling to go to school: to $\operatorname{lag}$ is to move slower than others, to stop while they are going on; this is seldom done for a good purpose; those who lag have generally some sinister and private end to answer: to saunter is altogether the act of an idler; those who have no object in moving either backward or forward will saunter if they move at all.

LIQUID, LIQUOR, JJICE. Liquid (see FLOID) is the generic term: liquor, which is but a variation from the same Latin verb, liquere, to be moist, whence liquid is derived, is a liquid which is made to be drunk: juice, in French jus, Latin ius, broth, soup, is a liquid that issues from bodies. All natural bodies consist of liquids or solids, or a combination of both: liquor serves to quench the thirst as food satisfies the hunger; the juices of bodies are fre- quently their richest parts; water is the simplest of all liquids; wine is the most inviting of all liquors; the orange produces the most agreeable juice.

LIQUIDATE. See FluID.

LIQUOR. See LIQUID.

List, Roll, Catalogue, Register. List is derived through French liste, from Old High German lista, a border, hence a strip, a long strip on which names were written. Roll, from Latin rotula, a little wheel, signifies in general anything rolled up, particularly paper with its written contents. Catalogue, in Latin catalogus, Greek karáloyos, from $\kappa a \tau a \lambda \dot{\varepsilon} \gamma \omega$, to write down, signifies a written enumeration. Register, from re, back, gerere (past participle gestum), to bring, signifies something brought back, a record returned by a messenger or official.

A collection of objects brought into some kind of order is the common idea included in the signification of these terms. The contents and disposition of a list is the most simple; it consists of little more than names arranged under one another in a long, narrow line, as a list of words, a list of plants and flowers, a list of voters, a list of visits, a list of deaths, of births, of marriages: roll, which is figuratively put for the contents of a roll, is a list rolled up for convenience, as a long roll of saints: catalogue involves more details than a simple list; it specifies not only names, but dates, qualities, and circumstances. A list of books contains their titles; a catalogue of books contains an enumeration of their size, price, number of volumes, edition, etc.; a roll of saints simply specifies their names; a catalogue of saints enters into particulars of their ages, deaths, etc.: a register contains more than either, for it contains events, with dates, actors, etc., in all matters of public interest.

See also Enroll.

LISTEN. See Atrend.

LISTLESS. See INDOLENT.

LITERATURE. See LETTERS.

LiTTLE, Smali, Diminutive. Little comes from Anglo-Saxon lytel, from a Teutonic base meaning to stoop. For small see Aтомгc. Diminutive comes from Latin minus, and signifies made less. What is little is so in the 
ordinary sense in respect to size; it is properly opposed to great: the small is that which is less than others in point of bulk; it is opposed to the large: the diminutive is that which is less than it ought to be; as a person is said to be diminutive in stature who is below the ordinary stature.

In the moral application, little is frequently used in a bad sense, small and diminutive may be extended to other than physical objects without any change in their signification.

LIVE. See Abide; Be; Exist.

LIVELIHOOD, LIVING, SUBSISTence, Maintenance, Support, SusTENANCE. The means of living or supporting life is the idea common to all these terms, which vary according to the circumstances of the individual and the nature of the object which constitutes the means. Livelihood was originally livelode, litcrally life-leadingfrom Anglo-Saxon lif, life, and lad, a way, literally a leading. Subsistence comes from Latin sub, under, and sistere, to cause to stand-meaning that which bears one up. Support, from sub and portare, to bear, and sustenance, from $s u b$ and tenere, to hold, have similar origins. Maintenance comes from manus, hand, and tenere, to hold, and signifies to hold in hand, to control and support. A livelihood is that which is sought after by the day; a laborer earns a livelihood by the sweat of his brow: a subsistence is obtained by irregular efforts of various descriptions; beggars meet with so much that they obtain something better than a precarious and scanty subsistence: living is obtained by more respectable and less severe efforts than the former two; tradesmen obtain a good living by keeping shops; artists procure a living by the exercise of their talents; maintenance, support, and sustenance differ from the other three, inasmuch as they do not comprehend what one gains by one's own efforts, but by the efforts of others: maintenance is that which is permanent: it supplies the place of living: support may be casual and vary in degree: the object of most public charities is to afford a maintenance to such as cannot obtain a livelihood or living for themselves; it is the business of the parish to give support, in time of sickness and distress, to all who are legal parishioners. Maintenance and support are always granted; but sustenance is that which is taken or received: the former comprehend the means of obtaining food; sustenance comprehends that which sustains the body and supplies the place of food.

LiVEly, Sprightly, Vivaciods, Sportive, Merry, Jocund. The activity of the heart when it beats high with a sentiment of gayety is strongly depieted by all these terms: the lively is the most general and literal in its signification; life, as a moving or active principle, is supposed to be inherent in spiritual as well as material bodies; the feeling, as well as the body which has a power of moving arbitrarily of itself, is said to have life; and in whatever object this is wanting, this object is said to be dead: in like manner, according to the degree or eircumstanees under which this moving principle displays itself, the objeet is denominated lively, that is, having life. Sprightly, originally spritely, from Latin spiritus, spirit, signifies full of spirit or the active breath of life; and vivacious, in Latin vivax, from vivere, to live, is the same as lively. Liveliness is the property of childhood, youth, or even maturer age; sprightliness is the peculiar property of youth; vivacity is a quality compatible with the sobriety of years: an infant shows itself to be lively or otherwise in a few months after its birth; a girl, particularly in her early years, affords often a pleasing pieture of sprightliness; a vivacious companion recommends himself wherever he goes. Sportiveness, that is, fondness of or readiness for sport, is an aecompaniment of liveliness or sprightliness; a sprightly child will show its sprightliness by its sportive humor; mirth, i. e., merriness (see CHEERFUL), and jocundity, from jocundus or jucundus, and juio, to delight or please, signifying the state of being delighted, are the forms of liveliness which display themselves in social life; the former is a familiar quality, more frequently to be diseovered in vulgar than in polished society: jocundity is a form of liveliness which poets have aseribed to nymphs and goddesses and other aerial ereatures of the imagination. 
The terms preserve the same sense when applied to the characteristics or actions of persons as when applied to the persons themselves: imagination, wit, conception, representation, and the like are lively; a person's air, manner, look, tone, dance, are sprightly; a conversation, a turn of mind, a society, is vivacious; the muse, the pen, the imagination, are sportive; the meeting, the laugh, the song, the conceit, are merry; the train, the dance, are jocund.

LIVING, BENEFICE. Living signifies, literally, the pecuniary resource by which one lives. Benefice, from Late Latin beneficium, based on classical benefacio, signifies whatever one obtains as a benefit: the former is applicable to any situation of life, but particularly to that resource which a parish affords to the clergyman; the latter is applicable to no other object: we speak of a living as a resource immediately derived from the parish, in distinction from a curacy, which is derived from an individual; we speak of a benefice in respect to the terms by which it is held, according to the ecclesiastical law: there are many livings which are not benefices, although not vice versâ.

See also LiveliHood.

loAd. See Clog; Freight; WEIGHT.

LOATH. See Averse.

LOATHE. See ABHOR.

LOATHING. See Disgust.

LOCAlizE. See Segregate.

LOCKOUT. See Close.

LODGE. See Harbor.

LODGINGS, APARTMENTS. For the derivation of lodging see HARBor. A lodging, or a place to lodge or dwell in, comprehends single rooms, or many rooms, or in fact any place which can be made to serve the purpose; apartments only suites of rooms: apartments, therefore, are, in the strict sense, lodgings; but all lodgings are not apartments: on the other hand, the word lodgings is mostly used for rooms that are let out to hire or that serve a temporary purpose; but the word apartments may be applied to the suites of rooms in any large house: hence the word lodging becomes on one ground restricted in its use, and apartments on the other: all apartments to let out for hire are lodgings, but apartments not to let out for hire are not lodgings.

LOFTINESS. See PrIDE.

LOFTY. See High.

LOITER. See LiNGER.

LONELY. See ALONE.

LONG. See Desire.

LONGING. See Yearn.

LOOK, GLANCE. Look (see AIR) is the generic, and glance (see GLANCE) the specific term; that is to say, a casual or momentary look: a look may be characterized as severe or mild, fierce or gentle, angry or kind: a glance as hasty or sudden, imperfect or slight; so likewise we speak of taking a look or catching a glance.

Look, See, Behold, View, Eye.-Look, from Anglo-Saxon locian, signified originally to peep through a hole. See is in Anglo-Saxon seon, to perceive by the eye. Behold, compounded of the intensive be and hold, signifies to hold or fix the eye on an object. View, from Middle French veuë, participle of veoir, based on the Latin video, signifies simply what is seen. To eye, from the noun eye, Anglo-Saxon eage, allied to Latin oculus, eye, naturally signifies to examine with the eye.

We look voluntarily; we see involuntarily: the eye sees; the person looks: absent-minded people often see things before they are fully conscious that they are at hand: we may look without seeing, and we may see without looking: nearsighted people often look at that which is too distant to strike the visual organ. To behold is to look at for a continuance; to view is to look at in all directions; to eye is to look at earnestly and by side glances; that which is seen may disappear in an instant; it may strike the eye and be gone; but what is looked at must make some stay; consequently lightning, and things equally fugitive and rapid in their flight, may be seen, but cannot be looked at. To look at is the familiar as well as the general term, in regard to the others; we look at things in general which we wish to see, that is, to see clearly, fully, and in all their parts; but we behold that which excites a moral or intellectual interest; we view that which demands intellectual attention; we eye that which gratifies any particular passion: 
an inquisitive child looks at things which are new to it, but does not behold them; we look at plants or finery or whatever gratifies the senses, but we do not behold them: on the other hand, we behold any spectacle which excites our admiration, our astonishment, our pity, or our love: we look at objects in order to observe their external properties; but we view them in order to find out their component parts, their internal properties, their powers of motion and action, etc.: we look at things to gratify the curiosity of the moment or for mere amusement; but the jealous man eyes his rival in order to mark his movements, his designs, and his successes; the envious man eyes him who is in prosperity, with a - malignant desire to see him humbled.

Look, Appear.-Look is here taken in the neuter sense: in the preceding article it denotes the action of persons striving to see; in the present case it denotes the action of things figuratively striving to be seen. Appear, from the Latin ad, to, and parere, to come in sight, signifies to be present or at hand, within sight.

The look of a thing implies the impressions which it makes on the senses, that is, the manner in which it looks; its appearance implies the simple act of its coming into sight; the look of anything is therefore characterized as good or bad, mean or handsome, ugly or beautiful; the appearance is characterized as early or late, sudden or unexpected: there is something very unseemly in the look of a clergyman affecting the airs of a fine gentleman; the appearance of the stars in an evening presents an interesting view even to the ordinary beholder. As what $a p$ pears must appear in some form, the signification of the term has been extended to the manner of the appearance, and brought still nearer to look in its application: in this case the term look is rather more familiar than that of appearance: we may speak either of regarding the look or the appearance of a thing, as far as it may impress others; but the latter is less colloquial than the former: a man's conduct is said to look rather than to appear bad; but on the other hand, we say a thing assumes an appearance, or has a certain appearance.
Look is always employed for what is real; what a thing looks is that which it really is: appear, however, sometimes refers not only to what is external, but to what is superficial. If we say a person looks ill, it supposes some positive and unequivocal evidence of illness: if we say he appears to be ill, it is a less positive assertion than the former; it leaves room for doubt and allows the possibility of a mistake. We are at liberty to judge of things by their, looks, without being accused of want of judgment; but as appearances are said to be deceitful, it becomes necessary to admit them with caution as the rule of our judgment. Look is employed mostly in regard to objects of sense; appearance concerns natural and moral objects indifferently: the sky looks dark; an object $a p$ pears through a microscope greater than it really is; a person's conduct appears in a more culpable light when interpreted by an enemy.

Looker-on, Spectator, Bcholder, Observer.-The looker-on and the spectator are both opposed to the agents or actors in any scene; but the former is still more abstracted from the objects he sees than the latter.

A looker-on is careless; he has no part, and takes no part, in what he sces; he looks on because the thing is before him and he has nothing else to do: a spectator may likewise be unconcerned, but in general he derives amuscment, if nothing else, from what he sees. A clown may be a looker-on who with open mouth gapes at all that is before him, without understanding any part of it, but he who looks on to draw a moral lesson from the whole is in the moral sense not an uninterested spectator. The beholder has a nearer interest than the spectalor; and the observer has an interest not less near than that of the bcholder, but scmewhat different: the bcholder has his feelings roused by what he sees; the observer has his understanding employed in that which passes before him: the beholder indulges himself in contemplation; the observer is busy in making it subservient to some proposed object: every beholder of our Saviour's sufferings and patience was struck with the conviction of His divine character, 
not excepting even some of those who were His most prejudiced adversaries; every calm observer of our Saviour's words and actions was convinced of His divine mission.

LOOSE, VaGue, Lax, Dissolute, Licentious. Loose is a Scandinavian word. Vague, in Latin vagus, signifies wandering. Lax, in Latin laxus, is allied to lack. Dissolute, in Latin dissolutus, participle of dissolvere, signifies dissolved or set free. Licentious signifies having the license or power to do as one pleases (see LEAvE).

Loose is the generic, the rest are specific terms; they are all opposed to that which is bound or adheres closely: loose is employed either for physical, moral, or intellectual objects; vague only for intellectual objects; lax sometimes for what is intellectual, but oftener for the moral; dissolute and licentious only for moral matters: whatever wants a proper connection, or linking together of the parts, is loose; whatever is scattered and remotely separated is vague: a style is loose where the words and sentences are not made to coalesce so as to form a regularly connected series; assertions are vague which have but a remote connection with the subject referred to: by the same rule, loose hints thrown out at random may give rise to speculation and conjecture, but cannot serve as the ground of any conclusion; ignorant people are apt to credit every vague rumor and to communicate it as a certainty. Opinions are loose, either inasmuch as they want logical precision or as they fail in moral strictness; suggestions and surmises are induced by the wanderings of the imagination; opinions are lax, inasmuch as they have a tendency to lessen the moral obligation or to loosen moralities. A loose man injures himself, but a lax man injures society at large. Dissoluteness is the excess of looseness; licentiousness is the consequence of laxity or the freedom from external constraint. Looseness of character, if indulged, soon sinks into dissoluteness of morals; and laxity of discipline is quickly followed by licentiousness of manners.

See also SLack.

LOQUACIOUS. See Talkative; Voluble.

\section{LORDLY. Sce IMPERIOUS.}

LORD'S DAY. See SABBATH.

LORD'S - SUPPER, EUCHARIST, Communion, Sacranent. The Lord'sSupper is a term of familiar and general use among Christians, as designating in literal terms the supper of our Lord, that is, either the last solemn supper which $\mathrm{He}$ took with His disciples previous to His crucifixion or the commemoration of that event which conformably to His commands has been observed by the professors of Christianity. Eucharist is a term of peculiar use among the Roman Catholics, from

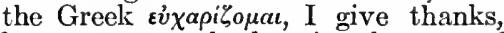
because personal adoration, by way of returning thanks, constitutes in their estimation the chief part of the ceremony. As the social sentiments are kept alive mostly by the common participation of meals, so is brotherly love, the essence of Christian fellowship, cherished and warmed in the highest degree by the common participation in this holy festival: hence, by distinction, it has been denominated the communion. As the vows which are made at the altar of our Lord are the most solemn which a Christian can make, comprehending in them the entire devotion of himself to Christ, the general term sacrament, signifying an oath, has been employed by way of distinction for this ordinance. The Roman Catholics have employed the same term for six other ordinances; but the Protestants, who attach a similar degree of sacredness to no other than baptism, apply this appellation only to these two.

LOSE, Miss. Lose is in Middle English lesen. Miss comes from AngloSaxon missan, to fail to hit, from a base meaning to escape, avoid, etc., allied to Latin mittere, to send. To miss, probably from the participle mis, wrong, signifies to put wrong.

What is lost is supposed to be entirely and irrevocably gone; but what is missed may be only out of sight or not at hand at the time when it is wanted; health or property may be lost; one misses a coach, or one misses what has been mislaid. Things may be lost in a variety of ways independent of the person losing; but missing is mostly by the instrumentality of the 
person who misses. We lose an opportunity which it is not in our power to use; we miss an opportunity when we suffer it to pass without using.

LOSS, Damage, Detriment. Loss signifies the act of losing or the thing lost, from Anglo-Saxon los, destruction. Damage, in French dommage, Latin damnum, loss, signifies the thing taken away. Detriment (see DisadvantaGEOUS).

Loss is here the generic term; damage and detriment are species or modes of loss. The person sustains the loss, the thing suffers the damage or detriment. Whatever is gone from us which we wish to retain is a loss; hence we may sustain a loss in our property, in our reputation, in our influence, in our intellect, and every other object of possession: whatever renders an object less serviceable or valuable, by any external violence, is a damage; as a vessel suffers a damage in a storm: whatever is calculated to cross a man's purpose is a detriment; the bare want of a good name may be a detriment to a young tradesman; the want of prudence is always a great detriment to the prosperity of a family.

LOT. See Destiny.

LOUD, NoISY, HIGH - soUNdING, Clamorous. Loud comes from AngloSaxon hlud, heard from afar. Noisy, from noise, is derived from Old French noise, a debate or quarrel (something that gives rise to noise in our sense), perhaps from nausea. High-sounding signifies the same as pitched upon an elevated key, so as to make a great noise, to be heard at a distance. Clamorous, from the Latin clamare, to cry, signifies crying with a loud voice.

Loud is here the generic term, since it signifies a great sound, which is the idea common to them all. As an epithet for persons, loud is mostly taken in an indifferent sense; all the others are taken for being loud beyond measure; noisy is to be lawlessly and unseasonably loud; high-sounding is to be loud only from the bigness of one's words; clamorous is to be disagreeably and painfully loud. We must speak loudly to a deaf person in order to make ourselves heard: children will be noisy at all times if not kept under control: flatterers are always high- sounding in their eulogiums of princes: children will be clamorous for what they want if they expect to get it by dint of noise; they will be turbulent in case of refusal if not under proper discipline. In the improper application loud is taken in as bad a sense as the rest; the loudest praises are the least to be regarded: the applause of a mob is alway's noisy; high-sounding titles serve only to excite contempt where there is not some corresponding quality: it is the business of a party to be clamorous, as that serves the purpose of exciting the ignorant.

LOVE, Friendship. Love (see AfFECTION) is a term of very extensive import; it may be taken either in the most general sense for every strong and passionate attachment or only for such as exist between the sexes, in either of which cases it has features by which it is easily distinguished from friendship-from Anglo-Saxon freond, modern English friend, from the verb freogan, to love.

Love exists between members of the same family; it springs out of their natural relationship, and is kept alive by their elose intercourse and constant interchange of kindnesses: friendship excludes the idea of any tender and natural relationship; nor is it, like love, to be found in children, but is confined to maturer years; it is formed by time, by circumstances, by congruity of character and mutual sympathy. Love always operates with ardor; friendship is remarkable for firmness and constancy. Love is peculiar to no station; it is to be found equally among the high and the low, the learned and the unlearned: friendship is of nobler growth; it finds admittance only into minds of a loftier make: it cannot be felt by men of an ordinary stamp. Both love and friendship are gratified by seeking the good of the object; but love is more selfish in its nature than friendship; in indulging another it seeks its own gratification, and when this is not to be obtained it will change into the contrary passion of hatred; friendship, on the other hand, is altogether disinterested, it makes sacrifices of every description, and knows no limits to its sacrifice. 
Lover, Suitor, Wooer.-Lover signifies literally one who loves, and is applicable to any object; there are lovers of money and lovers of wine, lovers of things individually and things collectively, that is, lovers of particular women in the good sense, or lovers of women in the bad sense. The suitor (from French suite, based ultimately on Latin sequi, to follow) is one who sues and strives after a thing; the word is equally undefined as to the object, but may be employed for such as sue for favors from their superiors, or sue for the affections and person of a woman. The wooer (from Anglo-Saxon wogian, to court, of obscure origin) is only a species of lover, who woos or solicits the kind regards of a female. When applied to the same object, namely, the female sex, the term lover is employed for persons of all ranks, who are equally alive to the tender passion of love: suitor is a title adapted to that class of life where all the genuine affections of human nature are adulterated by a false refinement or entirely lost in other passions of a guilty nature. Wooer is a tender and passionate title, which is adapted to that class of beings that live only in poetry and romance. There is most sincerity in the lover, he simply proffers his love; there is most ceremony in the suitor, he proffers his suit; there is most ardor in the wooer, he makes his vows.

LOVELY. See Amable.

LOVING. See Amorous.

LOW, Mean, AbJect. Low (see Humble). Mean comes from AngloSaxon gemane, German gemein, common. Abject, in French abject, Latin abjectus, from $a b$, down, and jacere, to cast, signifies, literally, cast down or brought very low.

Low is a much stronger term than mean; for what is low stands more directly opposed to what is high, but what is mean is intermediate: the low is applied only to a certain number or description; but mean, like common, is applicable to the great bulk of mankind. A man of low extraction falls below the ordinary level; he is opposed to a noble man: a man of mean birth does not rise above the ordinary level; he is upon a level with the majority. Abject expresses more than either of the others, for it denotes the lowest depression in a person's outward condition or position, as abject poverty.

When employed to designate character, they preserve the same distinction; the low is that which is positively sunk in itself; but the mean is that which is comparatively low, in regard to the outward circumstances and relative condition of the individual. Swearing and drunkenness are low vices; boxing and cudgelling are low games; a misplaced economy in people of property is mean; a condescension for our own petty advantages to those who are beneath us is meanness. A man is commonly low by birth, education, or habits; but meanness is a/defect of nature which debases a person in spite of every external advantage. Abject, as a characteristic, is applied particularly to the spirit. Slavery is most apt to produce an abject spirit by depriving a man of the use of those faculties which elevate him above the brutes; poverty, fear, or any base passion may have the same effect.

LOWER. See Reduce; Strike.

LOWLY. See Humble.

LUCID. See Clear.

LUCKLESS. See HAPLESS.

LUCKY. See Fortunate.

LUCRE. See GaIN.

LUDICROUS. See LaUghable.

LULL. See Quell.

LUNACY. See Derangement.

LUSTRE. See BrightNess.

LUSTY. See CoRPUlent.

LUXURIANT. See EXUBERANT. 


\section{M}

MADNESS, Frenzy, RAGe, FURY. Madness (see Derangement). Frenzy,

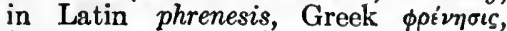
from $\phi \rho \dot{\eta} \nu$, the midriff, heart, senses, signifies a disordered psychology. Rage is in French rage, Latin rabies, madness. Fury comes from Latin furia, madness.

Madness and frenzy are used in the physical and moral sense; rage and fury only in the moral sense: in the first case, madness is a confirmed derangement in the organ of thought; frenzy is only a temporary derangement from the violence of any disease or other cause: the former lies in the system, and is, in general, incurable; the latter is only occasional, and yields to the power of medicine. In the moral sense of these terms the cause is put for the effect, that is, madness and frenzy are put for that exccssive violence of passion by which they are caused; and as rage and fury are species of this passion, namely, the passion of anger; they are, therefore, to madness and frenzy sometimes as the cause is to the effect: the former, however, are much more violent than the latter, as they altogether destroy the reasoning faculty, which is not expressly implied in the signification of the latter terms. Moral madness differs both in degree and duration from frenzy: if it spring from the extravagance of rage, it bursts out into every conccivable extravagance, but is only transitory; if it spring from disappointed love, or any other disappointed passion, it is as permanent as direct physical madness; frenzy is always temporary, but even more impetuous than madness; in the frenzy of despair men commit acts of suicide, in the frenzy of distress and grief people are hurried into many actions fatal to themsclves or others.

Rage refers more immediately to the agitation that exists within the mind; fury refers to that which shows itsclf outwardly: a person contains or stifles his rage; but his fury breaks out into some external mark of violence: rage will subside of itself; fury spends itself; a person may be choked with rage, but his fury finds a vent: an enraged man may be pacified; a furious one is deaf to every remonstrance. Rage, when applied to persons, commonly signifies highly inflamed anger; but it may be employed for inflamed passion toward any object which is specified; as a rage for music, a rage for theatrieal performances, a fashionable rage for any whim of the day. Fury, though commonly signifying rage bursting out, yet may be any impetuous fceling displaying itself in extravagant action; as the divine fury supposed to be produced in the priestess of Apollo by the inspiration of the god, and the bacehanalian fury, which expression depicts the influence of wine upon the body and mind. In the improper application, to inanimate objcets, the words rage and fury preserve a similar distinction: the rage of the heat denotes the excessive height to which it is risen; the fury of the winds indicates their violent commotion and turbulenee; so in like manner the raging of the tempest characterizes figuratively its burning anger; and the fury of the flames marks their impetuous movements, their wild and rapid spread.

See also Deraxgement.

MAGISTERIAL, Majestic, StateLy, Pompous, August, Dignified. Magisterial, from magister, a master, and majestic, from majestas, are both derived from magis, more, or major, greater, that is, more or greater than others; but they differ in this respect, that the magisterial is somcthing assumed, and is therefore often false; the majestic is natural, and consequently always real: an upstart, or an intruder into any high station or office, may put on a magisterial air in order to impose on the multitude; but it will not be in his power to be majestic, which never shows itself in a borrowed shape; none but those who have a supcriority of charaeter, of birth, or outward station can be majestic.

Stately and pompous (sce MAGNif- 
CENCE) are most nearly allied to magisterial; august (from Augustus, the title of the Roman Cæsars) and dignified to majestic: the former being merely extrinsic and assumed, the latter intrinsic and inherent. Magisterial implies the authority which is assumed; stately regards splendor and rank; pompous regards personal importance, with all the appendage of greatness and power: a person is magisterial in the exercise of his office and the distribution of his commands; he is stately in his ordinary intercourse with his inferiors and equals; he is pompous on particular occasions of appearing in public: a person demands silence in a magisterial tone; he marches forward with a stately air; he comes forward in a pompous manner, so as to strike others with a sense of his importance.

Majestic is an epithet that characterizes the exterior of an object; august is that which marks an essential characteristic in the object; dignified serves to characterize a person's action as tending to give dignity: a woman's form is termed majestic when it has something imposing in it suited to the condition of majesty or the most elevated station in society; a monarch is entitled august in order to describe the extent of his empire; a public assembly is denominated august to bespeak its high character and its weighty influence in the scale of society; a reply is termed dignified when it upholds the individual and personal character of a man as well as his relative character in the community to which he belongs: the former two of these terms are associated only with grandeur of outward circumstances; the last is applicable to men of all stations who have each in his sphere a dignity to maintain which belongs to man as an independent moral agent.

MAGNETIC. See Electric.

MAGNIFICENCE, SPLE N OR, PoMp. Magnificence, from magnus, great, and a weak form of facere, to do, signifies doing largely or on a large scale. Splendor, in Latin splendor, from splendere, to shine, signifies brightness of exterior. Pomp, in Latin pompa, Greek $\pi \circ \mu \pi \dot{\eta}$, a procession, from $\pi \dot{\varepsilon} \mu \pi \varepsilon \iota \nu$, to send, signified a sending, an escort- ing, which, of course, was usually splendid and gorgeous, because men honored with an escort were usually deemed worthy also of a certain splendor and ceremony in the accoutrements of the escort.

Magnificence lies not only in the number and extent of the objects presented, but in their degree of richness as to their coloring and quality; splendor is but a characteristic of magnificence, attached to such objects as dazzle the eye by the quantity of light or the beauty and strength of coloring; the entertainments of the Eastern monarchs and princes are remarkable for their magnificence, from the immense number of their attendants, the crowd of equipages, the size of their palaces, the multitude of costly utensils, and the profusion of viands which constitute the arrangements for the banquet; the entertainments of Europeans present much splendor, from the richness, the variety, and the brilliancy of dress, of furniture, and all the apparatus of a feast, which the refinements of art have brought to perfection. Magnificence is seldomer unaccompanied with splendor than splendor with magnificence, since quantity, as well as quality, is essential to the one; but quality more than quantity is an essential to the other: a large army drawn up in battle array is a magnificent spectacle, from the immensity of their numbers and the order of their disposition; it will in all probability be a splendid scene if there be much richness in the dresses; the pomp will here consist in such large bodies of men acting by one impulse and directed by one will, hence military pomp; it is the appendage of power when displayed to public view: on particular occasions a monarch seated on his throne, surrounded by his courtiers and attended by his guards, is said to appear with pomp.

See also Grandeur.

MAGNIFICENT. See Superb.

MAGNITUDE. See Size.

MAIDEN. See Virgin.

MAIM. See Mutilate.

MAIN. See Cardinal; Chief.

MAINTAIN. See Assert; Hold; SUSTAIN; UPHOLD.

MAINTENANCE. See Livel- 
MAJEstic. See Magisterial.

make, Form, Produce, Create. The idea of giving birth to a thing is common to all these terms, which vary in the circumstances of the action: to make (see AcT) is the most general and unqualified term; to form (see ForM) signifies to give a form to a thing, that is, to make it after a given form; to produce (see AFFORD) is to bring forth into the light, to call into existence; to create (see CAUSE) is to bring into existence by an absolute exercise of power; to make is the simplest action of all, and comprehends a simple combination by the smallest efforts; to form requires care and attention and greater efforts; to produce requires time and also labor: whatever is put together so as to become another thing is rade; a chair or a table is made: whatever is put into any distinct form is formed; the potter forms the clay into an earthen vessel: whatever emanates from a thing so as to become a distinct object is produced; fire is often produced by the violent friction of two pieces of wood with each other. The process of making is always performed by some conscious agent, who employs either mechanical means or the simple exercise of power: a bird makes its nest; man makes various things by the exercise of his understanding and his limbs; the Almighty has made everything by His word. The process of forming does not always require a conscious agent; things are formed of themselves or they are formed by the active operations of other bodies; melted lead, when thrown into water, will form itself into various little bodies; hard substances are formed in the human body, which give rise to the disease termed the gravel. What is produced is oftener produced by the process of nature than by any express design; the earth produces all kinds of vegetables from seed; animals, by a similar process, produce their young. Create, in this natural sense of the term, is employed as the act of an intelligent being and that of the Supreme Being only; it is the act of making by a simple effort of power, without the use of materials and without any process. Hence it has been extended in its ap- plication to the making of anything by an immediate exercise of power. The creative power of the human mind is a faint image of that Power which brought everything into existence out of nothing.

They are all employed in the moral sense and with a similar distinction: make is indefinite; we may make a thing that is difficult or easy, simple or complex; we may make a letter or make a poem; we may make a word or make a sentence. To form is the work either of intelligence or of circumstances: education has much to do in forming the habits, but nature has more to do in forming the disposition and the mind altogether; sentiments are frequently formed by young people before they have sufficient maturity of thought and knowledge to justify them in coming to any decision. To produce is the effect of great mental exertion, or it is the natural operation of things: no industry could ever produce a poem or a work of the imagination, but a history or a work of science may be produced by the force of mere labor. All things, both in the moral and intellectual world, are linked together upon the same principle of cause and effect by which onc thing is the producer and the other the thing produced: quarrels produce hatred, and kindness produces love, as heat produces inflammation and fever, or disease produces death. What is created is not made by any natural process, but is called into existence by the creating power; small matters create jcalousies in jealous minds.

MALADY. See Disorder.

MALEDICTION, CURSE, IMPRECAtion, Execration, ANathena. Malediction, from Latin male, ill, and diccre, to say, signifies a saying ill, that is, declaring an evil wish against a person. Curse, Anglo-Saxon cursian, is the nat tive English term corresponding to malcdiction. Imprecation, from Latin in, in, and precari, to pray, signifies a praying down evil upon a person. Execration, from the Latin execror, that is, e sacris excludere, signifies the sanic as to excommunicate, with every form of solemn imprecation. Anathema, in Greek $a^{2} \nu a \dot{\theta} \theta \varepsilon a$, signifies a setting up, hence a devotion, a curse, and thus 
a putting out of a religious community as a penance.

The malediction is the most indefinite and general term, signifying simply the declaration of evil; curse is a solemn denunciation of evil: the former is employed mostly by men; the latter by some superior being as well as by men: the rest are species of the curse pronounced only by men. The malediction is caused by simple anger; the curse is occasioned by some grievous offence: men, in the heat of their passions, will utter maledictions against any object that offends them; God pronounced a curse upon Adam and all his posterity, after the fall.

The term curse differs in the degree of evil pronounced or wished; imprecation and exccration always imply some positive great evil, and, in fact, as much evil as can be conceived by man in his anger; the anathema concerns the evil which is pronounced according to the canon law, by which a man is not only put out of the Church, but held up as an object of offence. The malediction is altogether an unallowed expression of private resentment; the curse was admitted, in some cases, according to the Mosaic law; and that, as well as the anathema, at one time formed a part of the ecclesiastical discipline of the Christian Church; the imprecation formed a part of the heathen ceremony of religion; but the execration is always the informal expression of the most violent personal anger.

MALEFACTOR. See CRIMINal.

MALEVOLENT, MAIICIOUS, Malignant. These words have all their derivation from malus, bad, that is, malevolent, wishing ill; malicious (see Malice), having malice; and malignant, from malus and gignere, to be born, having an inborn disposition that is bad.

Malevolence has a deep root in the heart and is a settled part of the character; we denominate the person malevolent to designate the ruling temper of his mind: maliciousness may be applied as an epithet to particular parts of a man's character or conduct; one may have a malicious joy or pleasure in seeing the distresses of another: malignity is not so often employed to characterize the person as the thing; the malignity of a design is estimated by the degree of mischief which was intended to be done.

Malice, Rancor, Spite, Grudge, Pique. - Malice, in Latin malitia, from malus, bad, signifies the very essence of badness lying in the heart; rancor (see Hatred) is only continued hatred; the former requires no external cause to provoke it, it is inherent in the mind; the latter must be caused by some personal offence. Malice is properly the love of evil for evil's sake, and is, therefore, confined to no number or quality of objects, and limited by no circumstance; rancor depends upon external objects for its existence, and is confined to such objects only as are liable to cause displeasure or anger; malıce will impel a man to do mischief to those who have not injured him and are perhaps strangers to him; rancor can subsist only between those who have had sufficient connection to be at variance.

Spite, from Old French despit, from Latin de, down, and a weakened form of specere, to look-to look down on, to despise-denotes a petty kind of malice, or disposition to offend another in trifling matters; it may be in the temper of the person, or it may have its source in some external provocation: children often show their spite to one another.

Grudge, from Old French groucher, to murmur, from an imitative base gru; and pique, from pike, denoting the prick of a pointed instrument, are employed for that particular state of rancorous or spiteful feeling which is occasioned by personal offences: the grudge is that which has long existed; the pique is that which is of recent date; a person is said to owe another a grudge for having done him an injury; or he is said to show pique to another who has made him an affront.

malicious. See Malevolent; Satanic.

MALIGNANT. See Malevolent; VIRULENT.

MANAGE. See Concert; CoNDUCT; WIELD.

MANAGEMENT. See CARE; ECONOMY.

MANGLE. See Mutilate.

maNIA. See Derangement. 
MANLy, Manfol. Manly, or like a man, is opposed to juvenile, and of course applied properly to youths; but manful, or full of manhood, is opposed to effeminate and is applicable more properly to grown persons: a premature manliness in young persons is hardly less unseemly than a want of manfulness in one who is called upon to display his courage.

MANNER. See AIr; Custom; WAY.

MANNERS, MoRALS. Manners concern the minor forms of acting with others and toward others; morals include the important duties of life: manners have therefore been denominated minor morals. By attention to good manners we render ourselves good companions; by an observance of good morals we become good members of society: in the former instance we gain the good-will of others, in the latter their esteem. The manners of a child are of more or less importance, according to his station in life; his morals cannot be attended to too early, let his station be what it may.

See also ETIQUETTE.

MANEUVRING. See TACTICS.

MARGIN. See Border.

MARINE. See MARITIME.

MARINER. Sce SEAMAN.

MARITIME, MARINE, MARITIME, MARINE, NAVAL,
NAUTICAL. Maritime and marine, from the Latin mare, sca, cognate with English mere, signifies belonging to the sea; naval, from navis, a ship, signifies belonging to a ship; and nautical, from nauta, a sailor, signifies belonging to a sailor or to navigation. Countries and places are denominated maritime from their proximity to the sea or their great intercourse by sea; hence England is called the most maritime nation in Europe. Marine is a technical term, employed by persons in office, to denote that which is offieially transacted with regard to the sea in distinction from what passes on land; hence we speak of the marines as a species of soldiers acting by sea, as contrasted with the maritime society: or of marine stores. Naval is another term of art as opposed to military, and used in regard to the arrangements of government or commerce: hence we speak of naval affairs, naval officers, naval tactics, and the like. Nautical is a scientific term connected with the science of navigation or the management of vessels: hence we talk of nautical instruction, of nautical calculations. The maritime laws of England are essential for the preservation of the naval power which it has so justly acquired. The marine of England is one of its glories. The naval administration is one of the most important branches of our government in the time of war. Nautical tables and a nautical almanae have been expressly formed for the benefit of all who apply themselves to nautical subjects.

MARK, Print, Impression, Stamp. Mark comes from Anglo-Saxon mearc, possibly allied to mearc, signifying a boundary or limit, though this seems to be a different word. Print and impression, both from the Latin premere, to press, signify the visible effect produced by printing or pressing. Stamp signifies the effect produced by stamping, from Anglo-Saxon stcmpan, to stamp on with the feet.

The word mark is the most general in sense: whatever alters the external face of an object is a mark; a print is some specific mark, or a figure drawn upon the surface of an object; an impression is the mark pressed either upon or into a body; a stamp is the mark that is stamped in or upon the body. The mark is confined to no size, shape, or form; the print is a mark that represents an object: the mark may consist of a spot, a line, a stain, or a smear; but a print deseribes a given object, as a house, a man, etc. A mark is either a protuberance or a depression; an impression is always a sinking in of the object: a hillock or a hole are both marks; but the latter is properly the impression: the stamp is an impression made in a specific manner and for a specific object, as the stamp of a seal on wax. The mark is-occasioned by every sort of action, gentle or violent, artificial or natural; by the voluntary act of a person, or the unconscious act of inanimate bodies, by means of compression or friction, by a touch or a blow, and the like: all the others are oceasioned by one or more of these modes. The print 
is occasioned by artificial means of compression, as when the print of letters or pictures is made on paper; or by accidental and natural compression, as when the print of the hand is made on the wall, or the print of the foot is made on the ground. The impression is made by means more or less violent, as when an impression is made upon wood by the axe or hammer; or by gradual and natural means, as by the dripping of water on stone. The stamp is made by means of direct pressure with an artificial instrument.

Mark is of such universal application that it is confined to no objects whatever, either in the natural or moral world; print is mostly applied to material objects, the face of which undergoes a lasting change, as the printing made on paper or wood; impression is more commonly applied to such natural objects as are particularly solid; stamp is generally applied to paper or still softer and more yielding bodies. Impression and stamp have both a moral application: events or speeches make an impression on the mind; things bear a certain stamp which bespeaks their origin. Where the passions have obtained an ascendency, the occasional good impressions which are produced by religious observances but too frequently die away; the Christian religion carries with itself the stamp of truth.

Mark, Sign, Note, Symptom, Token, Indication.-Mark (see above). Sign, in Latin signum, signifies the thing that points out. Symptom, in Latin symptoma, Greek $\sigma i \mu \pi \tau \omega \mu \alpha$, from $\pi i \pi \tau \varepsilon \iota \nu$, to fall out in accordance, signifies what presents itself to confirm one's opinion. Token (see BETOKEN). Indication, in Latin indicatio, from indicare, to point out, signifies the thing which points out.

The idea of an external object which serves to direct the observer is common to all these terms; the difference consists in the objects that are employed. Anything may serve as a mark, a stroke, a dot, a stick set up, and the like; it serves simply to guide the senses; the sign is something more complex; it consists of a figure or representation of some object, as the twelve signs of the zodiac, or the signs which are affixed to houses of enter- tertainment, or to shops. Marks are arbitrary; every one chooses his mark at pleasure: signs have commonly a connection with the object that is to be observed: a house, a tree, a letter, or any external object may be chosen as a mark: but a tobacconist chooses the sign of a redman; the innkeeper chooses the head of the reigning prince. Marks serve in general simply to aid the memory in distinguishing the situation of objects or the particular circumstances of persons or things, as the marks which are set up in a garden to distinguish the ground that is occupied; they may, therefore, be private and known only to the individual that makes them, as the private marks by which a tradesman distinguishes his prices: they may likewise be changeable and fluctuating, according to the humor and convenience of the maker, as the private marks which are employed by the military on guard. Signs, on the contrary, serve to direct the understanding; they have either a natural or an artificial resemblance to the object to be represented; they are consequently chosen, not by the will of one, but by the universal consent of a body; they are not chosen for the moment, but for a permanency, as in the case of language, either oral or written, in the case of the zodiacal signs, or the signs of the cross, the algebraical signs, and the like. It is clear, therefore, that many objects may be both a mark and a sign, according to the above illustration: the cross which is employed in books, by way of reference to notes, is a mark only, because it serves merely to guide the eye or assist the memory; but the figure of the cross, when employed in reference to the cross of our Saviour, is a sign, inasmuch as it conveys a distinct idea of something else to the mind; so likewise little strokes over letters, or even letters themselves, may merely be marks, while they point out only a difference between this or that letter, this or that object; but this same stroke becomes a sign if, as in the first declension of Latin nouns, it is a sign of the ablative case; and a single letter affixed to different parcels is merely a mark so long as it simply serves this purpose; but the same letter, or suppose 
it were a word, is a sign when it is used as a sign. A mark may be something aceidental, and mean nothing; but a sign is that to which a meaning is always given: there may be marks on a wall occasioned by the elements or otherwise, but a sign is always the sign of something: a mark, if it consist of a sensible object, is only visible, but signs may be the object of hearing, smell, or any other sense: many things, therefore, may be signs which are not marks; when words are spoken and not written they are signs and not marks; and in like manner, the cross made on the forehead of a child in baptism is a sign, but not a mark.

When mark and sign are both taken to denote something by which one forms a judgment, the former serves either to denote that which has been or which is, the latter to designate that which is or will be, as persons bear the marks of age, or the marks of violence; or we may judge by the marks of a person's foot that some one has been walking in a particular place; hoarseness is a sign that a person has a cold; when mariners meet with certain birds at sea, they consider them as a sign that land is near at hand.

So likewise in applieation to moral objects or matters of a purely intellectual nature; as a mark of honor, or a mark of distinetion; an outward and visible sign of an inward and spiritual grace.

So likewise in application to objeets which serve as eharaeteristies of the person, the mark illustrates the spring of the action; the sign shows the state of the mind or sentiments; it is a mark of folly or weakness in a man to yield himself implicitly to the guidance of an interested friend; tears are not always a sign of repentanee.

Note is rather a sign than a mark; but it is properly the sign which consists of marks, as a note of admiration (!); or, in the moral sense, the sign by 'which the objeet is known; as persons of note, that is, which have a note upon them, or that by which they are known.

Symptom is rather a mark than a sign; it explains the cause or origin of complaints by the appearances they assume, and is employed as a technical term only in the science of medicine: as a foaming at the mouth and an abhorrence of drink are symptoms of canine madness; motion and respiration are signs of life; but it may likewise be used figuratively in, application to moral objects.

Token is a species of mark in the moral sense, indication a species of sign: a mark shows what is, a token serves to keep in mind what has been: a gift to a friend is a mark of one's affeetion and esteem: if it be permanent in its nature it becomes a token; friends who are in close intercourse have perpetual opportunities of showing each other marks of their regard by reeiprocal acts of courtesy and kindness; when they separate for any length of time they commonly leave some token of their tender sentiments in each other's hands, as a pledge of what shall be as well as an evidence of what has been.

Sign, as it respects indication, is said in abstraet and general propositions: indication itself is employed only for the sign given by any individual; it bespeaks the aet of the persons: but the sign is only the face or appearance of the thing. When a man does not live consistently with the profession which he holds, it is a sign that his religion is built on a wrong foundation; parents are gratified when they observe the slightest indications of genius or goodness in their ehildren.

Mark, Trace, Vestige, Footstep, Track. - The word mark has already been considered at large in the preceding article, but it will admit of further illustration when taken in the sense of that which is visible, and serves to show the existing state of things; mark is here, as before, the most general and unqualified term; the other terms varying in the cireumstances or manner of the mark. Trace, Middle French tracer, to follow, eomes ultimately from Latin trahere, to drag. Vestige, in Latin vestigium, signifies, literally, a print of the foot. Footstep is taken for the place in which the foot has stepped, or the mark made by that step. Track, French trac, a beaten way, comes from a Teutonic verb meaning to scrape or shove.

The mark is said of a fresh and un- 
interrupted line: the trace is said of that which is broken by time: a carriage in driving along the sand leaves marks of the wheels, but in a short time all traces of its having been there will be lost; a mark is produced by the action of bodies on one another in every possible form; the spilling of a liquid may leave a mark on the floor; the blow of a stick leaves a mark on the body; but the trace is a mark produced only by bodies making a progress or proceeding in a continued course: the ship that cuts the waves and the bird that cuts the air leave no trace of their course behind; so men pass their lives, and after death leave no traces that they ever were. The vestige is a species of mark or trace caused by the feet of men, or, which is the same thing, by the works of active industry; as the vestige of buildings: there are traces of the Roman roads still visible in England; there are many vestiges of Roman temples in Italy.

In an extended and moral application they are similarly distinguished. The mark serves to denote as well that which is as that which has been; as marks of desolation, or marks of antiquity: trace and vestige show the remains of something that has been; the former in reference to matters of intellectual research generally, the latter in reference to that which has been built up or pulled down, as there are traces of a universal affinity in all known languages; there are vestiges of ancient customs in different parts of England.

Footstep is employed only for the steps of an individual: the track is made by the steps of many; it is the line which has been beaten out or made by stamping: the footstep is now commonly and properly employed only for men and brutes; but the track is applied to inanimate objects, as the wheel of a carriage. When Cacus took away the oxen of Hercules, he dragged them backward that they might not be traced by their footsteps: a track of blood from the body of a murdered man may sometimes lead to the detection of the murderer.

In the metaphorical application they do not signify a mark, but a course of conduct; the former implies one's moral feelings or mode of dealing; the latter one's mechanical and habitual manner of acting: the former is the consequence of having the same principles; the latter proceeds from imitation or constant repetition. A good son will walk in the footsteps of a good father. In the management of business, it is rarely wise in a young man to leave the track which has been marked out for him by his superiors in age and experience.

Mark, Badge, Stigma.-Mark is still the general and the two others specific terms; they are employed for whatever serves to characterize persons externally, or betoken any part either of their character or circumstances: mark is employed either in a good, bad, or indifferent sense; badge in an indifferent one; stigma in a bad sense: a thing may either be a mark of honor, of disgrace, or of simple distinction; a badge is a mark simply of distinction; the stigma is a mark of disgrace. The mark is that which is conferred upon a person for his merits, as medals, stars, and ribbons are bestowed by princes upon meritorious officers and soldiers; or the mark attaches to a person, or is affixed to him, in consequence of his demerits; as a low situation in his class is a mark of disgrace to a scholar; or a fool's cap is a mark of ignominy affixed to idlers and dunces; or a brand in the forehead is a mark of ignominy for criminals: the badge is that which is voluntarily assumed by one's self according to established custom; it consists of dress by which the office, station, and even religion of a particular community is distinguished: as the gown and wig are the badge of the legal profession; the gown and surplice that of clerical men: the uniform of charity children is the badge of their condition; the peculiar habit of the Quakers, or the Friends, is the badge of their religion: the stigma consists not so much of what is openly imposed upon a person as what falls upon him in the judgment of others; it is the black mark which is set upon a person by the public, and is consequently the strongest of all marks, and one which every one most dreads and every good man seeks least to deserve. Mark, Butt.-The word mark has this additional meaning in common with 
the word butt, that it implies an object aimed at: the mark is literally a mark that is said to be shot at by the marksman with a gun or a bow.

It is also metaphorically employed for the man who by his peculiar characteristics makes himself the object of notice; he is the mark at which every one's looks and thoughts are directed: the butt, derived through French from an Old Low German word meaning to beat, allied to English beat, is a species of mark in this metaphorical sense; but the former calls forth only general observation, the latter provokes the laughter and jokes of every one. Whoever renders himself conspicuous by his eccentricities, either in his opinions or his actions, must not complain if he become a mark for the derision of the public: it is a man's misfortune rather than his fault if he become the butt of a company who are rude and unfeeling enough to draw their pleasures from another's pain.

Mark, Note, Notice.-Mark is here taken in the intellectual sense, fixing as it were a mark upon a thing so as to keep it in mind, which is in fact to fix one's attention upon it in such a manner as to be able to distinguish it by its characteristic qualities: to mark is therefore altogether an intellectual act: to note has the same end as that of marking, namely, to aid the memory, but one notes a thing by making a written note of it; this is therefore a mechanical act: to notice, on the other hand, from notitia, knowledge, is a conscious operation, signifying to bring to one's knowledge, perception, or understanding by the use of our senses. We mark and note that which particularly interests us: the former is that which serves a present purpose; notice that which may be of use in future. 'The impatient lover marks the hours until the time arrives for meeting his mistress: travellers note whatever strikes them of importance to be remembered when they return home: notice, which is a species of noting in small matters, may serve either for the present or the future; we may notice things merely by way of amusement, as a child will notice the actions of animals; or we may notice a thing for the sake of bearing it in mind, as a person notices a particular road when he wishes to return by the same way. See also Show.

MARKSMAN. See SHARPSHOOTER. MARRIAGE, WEDDING, NUPTIAIS. Marriage, from to marry, denotes the act of marrying; wedding and nuptials denote the ceremony of being married. To marry is based on Latin maritus, from a root found also in masculine, signifying a man, and means to be joined to a male; hence marriage comprehends the act of choosing and being legally bound to a man or a woman; wedding, from $w e d$, and the AngloSaxon weddian, to promise or betroth, implies the ceremony of marrying, inasmuch as it is binding upon the parties. Nuptials comes ultimately from nupta, participle of the Latin nubere, to veil, beeause the Roman ladies were veiled at the time of marriage: hence it has been put for the whole ceremony itself. Marriage is an institution which, by those who have been blessed with the light of Divine Revelation, has always been considered as sacred: with some persons, particularly among the lower orders of society, the day of their wedding is converted into a day of riot and intemperance: among the Roman Catholics in England it has been the practice to have their nuptials solemnized by a priest of their own persuasion as well as by the Protestant clergyman.

It is customary among many Italians in the United States to have a civil marriage first and a religious one later, the couple living apart in the interval.

Marriage, Matrimony, Wedlock.Marriage is oftener an act than a state: matrimony and wedlock both describe states.

Marriage is taken in the sense of an act when we speak of the laws of marriage, the day of one's marriage, the congratulations upon one's marriage, a happy or unhappy marriage, the fruits of one's marriage, and the like; it is taken in the sense of a state when we speak of the pleasures or pains of marriage; but in this latter case matrimony, which signifies a married life abstractedly from all agents or acting persons, is preferable; so likewise, to think of matrimony, and to enter into the holy state of malrimony, 
are expressions founded upon the signification of the term. As matrimony is derived from mater, a mother, because married women are in general mothers, it has particular reference to the domestic state of the two parties; broils are but too frequently the fruits of matrimony, yet there are few cases in which they might not be obviated by the good sense of those who are engaged in them. Hasty marriages cannot be expected to produce happiness; young people who are eager for matrimony before they are fully aware of its consequences will purchase their experience at the expense of their peace. Wedlock is the Old English word for matrimony, and is in consequence admitted in law, when one speaks of children born in wedlock; conformably to its derivation, it has a reference to the bond of union which follows the marriage: hence one speaks of living happily in a state of wedlock, of being joined in holy wedlock.

MARTIAL, WARFARE, WARLIKE, Military, Soldier-LIKe. Martial, from Mars, the god of war, is the Latin term for belonging to war: warlike signifies, literally, like war (Old French werre, Modern French guerre, from Old High German werra, broil, confusion, allied to English worse). In sense these terms approach so near to each other that they may be easily admitted to supply each other's place; but custom, the lawgiver of language, has assigned an office to each that makes it not altogether indifferent how they are used. Warfare, from war and the AngloSaxon verb faran, modern fare, to go, means an expedition of war; hence is the carrying on of war, either by land or sea or both. It is also improperly applied to strife between political and other factions. Martial is both a technical and a more comprehensive term than warlike; on the other hand, warlike designates the temper of the individual more than martial: we speak of martial array, martial preparations, martial law, a court martial; but of a warlike nation, meaning a nation which is fond of war; a warlike spirit or temper, also a warlike appearance, inasmuch as the temper is visible in the air and carriage of a man. Military, from miles, signifies belonging to a soldier, and soldier-like, like a soldier (soldier being derived from Late Latin soldum, pay, from solidus, originally an adjective meaning hard; then "hard cash" or money, and signifying originally one who fights for money). Military, in comparison with martial, is a term of particular import, martial having always a reference to war in general: and military to the proceedings consequent upon that: hence we speak of military in distinction from naval, as military expeditions, military movements, and the like; but in characterizing the men we should say that they had a martial appearance; but of a particular place that it had a military appearance, if there were many soldiers. Military, compared with soldier-like, is used for the body, and the latter for the individual. The whole army is termed the military: the conduct of an individual is soldier-like or otherwise.

MARVEL. See WONDER.

MASK. See CloAK.

MASSACRE. See CarNage.

MASSAGE. See Press.

MASSIVE. See Bulky.

MASTER. See Possessor.

MATCH. See TALLY.

MATERIAL. See Corporal; TANGIBLE.

MATRIMONY. See Marriage.

MATTER, Materials, SubJect. Matter and materials are both derived from the same source, namely, the Latin materia, stuff for building. Subject, in Latin subjectum, participle of subicere, to lie under, signifies the thing lying under and forming the foundation.

Matter, in the physical application, is taken for all that composes the sensible world, in distinction from that which is spiritual or discernible only by the thinking faculty; hence matter is always opposed to mind. In regard to materials, it is taken in an indivisible as well as a general sense; the whole universe is said to be composed of matter, though not of materials: on the other hand, materials consist of those particular parts of matter which serve for the artificial production of objects; and matter is said of those things which are the natural parts of the universe: a house, a table, and a chair consist 
of materials, because they are works of art; but a plant, a tree, an animal body, consist of matter, because they are the productions of nature.

The distinction of these terms in their moral application is very similar; the matter which composes a moral discourse is what emanates from the author; but the materials are those with which one is furnished by others. The style of some writers is so indifferent that it disgraces the matter by the manner; periodical writers are furnished with materials for their productions by the daily occurrences in the political and moral world. Writers of dietionaries endeavor to compress as much matter as possible into a small space; they draw their materials from every other writer.

Matter seems to bear the same relation to subject as the whole does to any particular part: the subject is the groundwork of the matter; the matter is that which derives from the subject: the matter is that which we get by the force of invention; the subject is that which offers itself to notice: many persons may, therefore, have a subject who have no matter, that is, nothing in their own minds which they can offer by way of illustrating this subject: but it is not possible to have matter without a subject; hence the word matter is taken for the substance and for that which is substantial; the subject is taken for that which engages the attention: we speak of a subject of conversation and matter for deliberation; a subject of inquiry, a malter of curiosity. Nations in a barbarous state afford but little matter worthy to be recorded in history; people who live a seeluded life and in a contracted sphere have but few subjects to occupy their attention.

MATURE. See RIPE.

MAXIM, PRECEPT, RULe, LAw. Maxim (see Axiom) is a moral truth that carries its own weight with itself. Precept (see Command), rule (see GUIDE), and law (see LAWFUL), signifying the thing laid down, all borrow their weight from some external circumstance: the precept derives its authority from the individual delivering it; in this manner the precepts of our Saviour have a weight which gives them a decided superiority over everything else: the rule acquires a worth from its fitness for guiding us in our proceeding: the law, which is a species of rule; derives its weight from the sanction of power. Maxims are often precepts, inasmuch as they are communicated to us by our parents; they are rules, inasmuch as they serve as a rule for our conduct; they are laws, inasmuch as they have the sanction of conscience. We respect the maxims of antiquity as containing the essence of human wisdom; we reverence the precepts of religion as the foundation of all happiness; we regard the rules of prudence as preserving us from errors and misfortunes; we respect the laws as they are the support of eivil soeiety.

MAY. See CAN.

MAZE. See LabYrinth.

MEAGRE. See LEAN.

MEAN, Pitiful, Sordid. For the derivation of these words see Low, for mean; PITY for pitiful; and BARE for sordid. The moral application of these terms to the characters of men, in their transactions with one another, is what constitutes their common signification. Whatever a man does in common with those below him is mean; it evinces a temper that is prone to sink rather than to rise in the scale of societ y: whatever makes him an object of pity, and consequently of contempt for his degraded character, makes him pitiful: whatever makes him grovel and crawl, intent on low, vile aims, is sordid, from the Latin sordes, dirty. Meanness is in many eases only relatively bad as it respects the disposal of our property: for instance, what is meanness in one might be generosity or prudenee in another: the due estimate of eireumstances is allowable in all, but it is meanness for any one to attempt to save, at the expense of others, that which he can conveniently afford either to give or pay: hence an undue spirit of seeking gain or advantage for one's self to the detriment of others is denominated a mean temper: it is mean for a gentleman to do that for himself which according to his circumstances he might get another to do for him. Pitifulness goes farther than meanness: it is not merely that which degrades, but unmans the person; it is 
that which is weak as well as low: when the fear of evil or the love of gain prompts a man to sacrifice his character and forfeit his veracity he becomes truly pitiful; Blifil in Tom Jones is the character whom all pronounce to be pitiful. Sordidness is peculiarly applicable to one's love of gain; although of a more corrupt, yet it is not of so degrading a nature as the former two: the sordid man does not deal in trifles like the mean man; and has nothing so low and weak in him as the pitiful man. A continual habit of getting money will engender a sordid love of it in the human mind; but nothing short of a degraded character leads a man to be pitiful. We dislike a mean man: we hold a pitiful man in profound contempt: we hate a sordid man. Meanness descends to that which is insignificant and worthless: pitifulness sinks into that which is despicable: sordidness contaminates the mind with what is foul. Low.

See also Base; Common; Design;

MEAN, MEDIUM. Mean, as here used, is but a contraction of medium, which signifies in Latin the middle path. The term mean is used abstractedly in all speculative matters: there is a mean in opinions between the two extremes: this mean is doubtless the point nearest to truth. Medium is employed in practical matters; computations are often erroneous from being too high or too low; the medium is in this case the one most to be preferred. The moralist will always recommend the mean in all opinions that widely differ from each other: our passions always recommend to us some extravagant conduct either of insolent resistance or mean compliance; but discretion recommends the medium or middle course in such matters.

MEANING. See Signification.

MEANS. See Way.

MECHANIC. See ARTIST.

MEDDLE. See INTERMEddLe, under INTERCEDE.

MEdDlesome. See PragmatiCAL.

MEdiate. See Arbitrate; INTERCEDE.

MEDIOCRITY. See Moderation. MEDITATE. See Contemplate.
MEDIUM. See MEan.

MEDLEY. See Difference; MixtURE.

MEEK. See SoFT.

MEET. See FIT.

MEETING, INTERVIEw. Meeting, from to meet, is the act of meeting or coming into the company of any one: interview, compounded of inter, between, and view, to view, is a personal view of each other. A meeting is an ordinary concern, and its purpose familiar; meetings are daily taking place between friends: an interview is extraordinary and formal; its object is commonly business; an interview sometimes takes place between princes or commanders of armies.

See also Assembiy.

MELANCHOLIC. See HYPOCHONDRIACAL.

MELANCHOLY. See DeJection; Splenetic.

MELODY, HaRMonX, AcCoRdance. Melody, from Greek $\mu \varepsilon \lambda \omega \delta$ ía, from Greek $\mu \dot{\varepsilon} \lambda o s$, a song, and $\varphi \dot{\delta} \dot{\eta}$, a song, signifies something intended to be sung. Harmony, in Latin harmonia, Greek

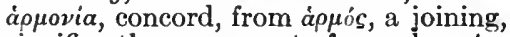
signifies the agreement of sounds. $A c$ cordance denotes the act or state of according (see AGREE).

Melody signifies any measured or modulated sounds measured after the manner of verse into distinct members or parts; harmony signifies the suiting or adapting different modulated sounds to one another; melody is therefore to harmony as a part to the whole: we must first produce melody by the rules of art; the harmony which follows must be regulated by the ear: there may be melody without harmony, but there cannot be harmony without melody: we speak of simple melody where the modes of music are not very much diversified; but we cannot speak of harmony unless there be a variety of notes to fall in with one another. A voice is melodious, inasmuch as it is capable of producing a regularly modulated note; it is harmonious, inasmuch as it strikes agreeably on the ear and produces no discordant sounds. The song of a bird is melodious or has melody in it, inasmuch as there is a combination of sounds in it which are admitted to be regular, and consequently agree- 
able to the musical ear; there is harmony in a concert of voices and instruments. Accordance is, strictly speaking, the property on which both melody and harmony are founded; for the whole of music depends on an accordance of sounds. The same distinction marks accordance and harmony in the moral application. There may be oceasional accordance of opinion or fecling; but harmony is an entire accordance in every point.

MEMBER, LIMB. Member is the Latin term, from membrum, and limb the corresponding native English term from a root signifying a joint.

Member is a general term applied either to the animal body or to other bodies, as a member of a family, or a member of a community: limb is applicable to animal bodies; limb is therefore a species of member; for every limb is a member, but every member is not a limb. The members of the body comprehend every part which is eapable of performing a distinct office; but the limbs are those jointed members that are distinguished from the head and the body: the nose and the eyes are members, but not limbs; the arms and legs are properly denominated limbs.

MEMOIRS. See ANECDOTES.

MEMORABLE. See SigNaL.

MEMORIAL. See MoNUMENT.

MEMORY, REMEMBRANCE, RECOLLection, Reminiscence. The same root, in Latin memor, mindful, memini, I remember, etc., is found in three of these words-memory, remember, and reminiscence. $R c$, in remember and reminiscence, signifies again - to call to mind again being the meaning of the words. Recollection, from $r e$ and collect (Latin con and legere, to bring together), signifies to bring together in the mind again.

Memory is the power of recalling images once made on the mind; remembrance, recollection, and reminiscence are operations or exertions of this power which vary in their mode. The memory is a power which exerts itself either independently of the will or in conformity with the will; but all the other terms express the acts of conscious agents, and consequently are more or less connected with the will. In dreams the memory exerts it- self, but we do not say that we have any remembrance or recollection of objects. Remembrance is the exercise of memory in a conscious agent; it may be the effect of repetition or habit, as in the case of a child who remembers his lesson after having learned it several times; or of a horse who remembers the road which he has been eontinually passing; or it may be the effect of association and circumstances, by which images are casually brought back to the mind, as happens to intelligent beings continually as they exereise their thinking faculties. In these cases remembrance is an involuntary act; for things return to the mind before one is aware of it, as in the case of one who hears a particular name and remembers that he has to call on a person of the same name; or of one who, on seeing a particular tree, remembers all the circumstances of his youth which were connected with a similar tree. Remembrance is, however, likewise a voluntary act, and the consequence of a direct determination, as in the ease of a child who strives to remember what it has been told by its parent, or of a friend who remembers the hour of mecting another friend in consequence of the interest which it has exeited in his mind: experience teaches us, indeed, that scarcely anything in ordinary cases is more under the subservience of the will than the memory; for it is now become almost a maxim to say that one may remember whatever one wishes.

The power of memory, and the simple exereise of that power in the act of remembering, are possessed in common, though in different degrees, by man and animal; but recollection and reminiscence are exereises of the memory that are connected with the higher faculties of man, his judgment and understanding. To remember is to call to mind that which has once been presented to the mind; but to recollect is to remember afresh, to remember what has been remembered before, to recall with an effort what may have been forgotten. Rcmembrance busies itself with objeets that are at hand; recollection carries us baek to distant periods: simple remembrance is engaged in things that have but just left the mind, 
which are more or less easily recalled, and more or less faithfully represented; but recollection tries to retrace the faint images of things that have been so long unthought of as to be almost obliterated from the memory. In this manner we are said to remember in one half-hour what was told us in the preceding half-hour, or to remember what passes from one day to another; but we recollect the incidents of childhood; we recollect what happened in our native place after many years' absence from it. Remembrance is that homely, every-day exercise of the memory which renders it of essential service in the acquirement of knowledge or in the performance of one's duties; recollection is that exalted exercise of the memory which affords us the purest of enjoyments and serves the noblest of purposes; the recollection of all the minute incidents of childhood is a more sincere pleasure than any which the present moment can afford.

Reminiscence is altogether an abstract exercise of the memory, which is employed on purely intellectual idcas in distinction from those which are awakened by sensible objects: the mathematician makes use of reminiscence in deducing unknown truths from those which he already knows. Reminiscence among the disciples of Socrates was the remembrance of things purcly intellectual, or of that natural knowledge which the souls had had before their union with the body; while the memory was exercised upon sensible things, or that knowielge which was acquired through the medium of the senses. Reminiscence, in its familiar application, signifies any event or circumstance long past, which is brought or comes to the mind, and which is usually of a pleasurable nature.

The Latins said that reminiscence belonged exclusively to man because it was purely intellectual, but that memory was common to all animals because it was merely the terminal point of the senses. That divine, though pagan philosopher, the high-winged Plato, fancied that our souls were at the first infusion abrase tabula, and that all our future knowledge was but a reminiscence.
MENACE. See Threat.

MEND. See AMEND.

MENIAL. See Servant.

MENTAL, INTELLECTUAL, INTELLIGENT. There is the same difference between mental and intellectual as between mind and intellect: the mind comprehends the thinking faculty in general, with all its operations; the intellect includes only that part of it which consists of understanding and judgment: mental is therefore opposed to corporeal; intellectual is opposed to sensual or physical: mental exertions are not to be expected from all; intellectual enjoyments fall to the lot of comparatively few. Objects, pleasures, pains, operations, gifts, etc., are denominated mental; subjects, conversation, pursuits, and the like are entitled intellectual. It is not always easy to distinguish our mental pleasures from those corporeal pleasures which we enjoy in common with animals; the latter are, however, greatly heightened by the former in whatever degree they are blended: in a society of wellinformed persons, the conversation will turn principally on intellectual subjects.

Intelligent, from intelligens, understanding or knowing, is a characteristic of the person: an intelligent bcing or an intelligence denotes a being purely spiritual or abstracted from matter.

When applied to individuals, it denotes having a quick understanding of things, as an intelligent child.

MENTION, Notice. Mention, from mens, mind, signifies here to bring to mind. Notice (see MARK). These terms are synonymous only inasmuch as they imply the act of calling things to another person's mind. We mention a thing in direct terms: we notice it indirectly or in a casual manner; we mention that which may serve as information; we notice that which may be merely of a personal or incidental nature. One friend mentions to another what has passed at a particular meeting: in the course of conversation he notices or calls to the notice of his companion the badness of the road, the wideness of the street, or the like.

MERCANTILE, COMME R I AL. Both mercantile and commercial come from Latin merx, pay, salable goods. 
Mercantile, from the same source, signifies the actual transaction of business, or a transfer of merchandise by sale or purchase; commercial comprehends the theory and practice of commerce: hence we speak in a peculiar manner of a mercantile house, a mercantile town, a mercantile situation, and the like; but of a commercial education, a commercial people, commercial speculations, and the like.

MERCENARY. See Hireling; VENAL.

MERCIFUL. See Gracious.

MERCX. See Clemency; Pity.

MERGE, CoMbINe, INCLUde, UNITE. These words all signify the union of two or more things, but they differ in the closeness of the union and the character of the image under which it is suggested. Merge, from Latin mergere, to sink into water, to dip, signifies the closest union - the absolute swallowing up of one thing by another. Include suggests a similar idea-from Latin in, in, and claudere, to closesignifying to enclose. Merge, however, suggests more clearly the loss of identity of the thing merged or swallowed up, and is a stronger word. Unite, from Latin unire, based on unus, one, signifies to make one; it differs in the relation implied between the two or more objects. The lesser can only be included or merged in the greater. Two equal things may be united. Combine (see Association and ConNect) signifies a relation that is not so close as that indicated in unite - as is explained in the article or CoNNECT.

MERRIMENT. See GleE.

MERRY. See LIVELY.

MERRY-ANDREW. Sec ZANY.

MESSAGE, ERRAND. Message, from the Latin missus, participle of mittere, to send, and a suffix, signifies the thing sent. Errand comes from Anglo-Saxon cerende, a message.

The message is properly any communication which is conveyed; the errand on which one person sends another is that which causes one to go: scrvants are the bearers of messages, and are sent on various errands. A message may be either verbal or written; an errand is limited to no form and to no circumstance: one delivers the message, and goes the errand. Sometimes the mes- sage may be the errand, and the errand may include the message: when that which is sent consists of a notice or intimation to another, it is a message; and if that causes any one to go to a place, it is an errand: thus it is that the greater part of errands consists of sending messages from one person to another.

METAMORPHOSE. See TransFIGURE.

METAPHOR. Sce FigURE.

METhOD. See Order; Srstem; WAY.

MILITARISM, Militancy, MiliTary, Militant. Mililarism and militancy both come from Latin miles, a soldier, but they differ in their application. Militarism, and its corresponding adjective, signify the state of being under arms and prepared to engage in war. It refers to formal and governmental preparation for war. Militancy, and its adjective militant, signify merely the general disposition to fight for a cause, and may have nothing to do with the actual science of warfare. A militant individual is one who is ready to fight, either physically or with the pen or the tongue, for his cause; a military man is a man who is or has been a part of a regularly constituted army.

See also Preparervess.

MIMIC. See IMII ITE.

MINARET. Sce T'URRET.

MiND. See AtTEND; Soul.

MINDFUl, Regardful, ObservANT. Mindful signifies that which we wish from others; regardful that which in itself demands regard or serious thought, particularly what regards the interests and feelings of others; observant implies both that which is communieated by others and that which carries its own obligations with itself: a child should always be mindful of its parents' instruetions; they should never be forgotten: every one should be regardful of his several duties and obligations; they ought never to be neglected: one ought to be observant of the religious duties which one's profession enjoins upon him; they cannot with propriety be passed over. By being mindful of what one hears from the wise and good, one learns to be wise and good; by being 
regardful of what is due to one's self and to society at large, one learns to pass through the world with satisfaction to one's own mind and esteem from others; by being observant of all rule and order, we afford to others a salutary example for their imitation.

MINGLE. See Mrx.

MINISTER, AGENT. Minister comes from minus, less, as magister comes from magis, more, the one being less, and the other more, than others: the minister, therefore, is literally one who acts in a subordinate capacity; and the agent (from ago, to act) is the one who takes the acting part: they both perform the will of another, but the minister performs a higher part than the agent: the minister gives his counsel and exerts his intellectual powers in the service of another, but the agent executes the orders or commissions given him: a minister is employed by government in political affairs; an agent is employed by individuals in commercial and pecuniary affairs, or by government in subordinate matters: a minister is received at court and serves as a representative for his government; an agent generally acts under the directions of the minister or some office of government: ambassadors or plenipotentiaries or the first officers of the state are ministers; but those who regulate the affairs respecting prisoners, the police, and the like are termed agents. A minister always holds a public character and is in the service of the state; the agent may be acting only for another individual, as a commercial agent.

See also Clergyman.

Minister, Administer, Contribute.To minister, from the noun minister, in the sense of a servant, signifies to act in subservience to another, and may be taken either in a good, bad, or indifferent sense, as to minister to the spiritual wants or to minister to another's caprices and indulgences when we encourage them unnecessarily. Administer, that is, to minister for a specific purpose, is taken in the good sense of serving another to his advantage: thus the Good Samaritan administered to the comfort of the man who had fallen among thieves. Contribute (see CONDUCE) is taken in either a good or bad sense; we may contribute to the relief of the indigent or we may contribute to the follies and vices of others. Princes are sometimes placed in the unfortunate situation that those who should direct them in early life only minister to their vices by every means in their power: it is the part of the Christian to administer comfort to those who are in want, consolation to the afflicted, advice to those who are feeble, and support to those who cannot uphold themselves: it is the part of all who are in high stations to contribute to the dissemination of religion and morality among their dependents; but there are, on the contrary, many who contribute to the spread of immorality and a contempt of all sacred things by the most pernicious example of irreligion in themselves.

MINUTE. See Atomic; CrrcomSTANTIAL.

MIRACLE. See Wonder.

MIRTH, MERRIMENT, JoVIALITY, Jollity, Hilarity. These terms all express that species of gayety or joy which belongs to company, or to men in their social intercourse. Mirth refers to the feeling displayed in the outward conduct: merriment and the other terms refer rather to the external expressions of the feeling, or the causes of the feeling, than to the feeling itself: mirth shows itself in laughter, in dancing, singing, and noise; merriment consists of such things as are apt to excite mirth: the more we are disposed to laugh the greater is our mirth; the more there is to create laughter the greater is the merriment: the tricks of Punch and his wife and the jokes of a clown cause much mirth among the gaping crowd of rustics; the amusements with the swing or the merrygo-round afford much merriment to the visitants of a fair. Mirth is confined to no age or station; but merriment belongs more particularly to young people or those of the lower station; mirth may be provoked wherever any number of persons is assembled; merriment cannot go forward anywhere so properly as at fairs or public places. Joviality or jollity, and hilarity, are species of merriment which belong to the convivial board: joviality or jollity 
may accompany the pleasures of the table or any social entertainments; hilarity is the same thing qualified by the cultivation and good sense of the company; we may expect to find much joviality and jollity at a public dinner of plain people; we may expect to find hilarity at a public dinner of gentlemen: eating, drinking, and noise constitute the joviality; the conversation, the-songs, the toasts, and the public spirit of the company contribute to hilarity.

See also Festivity; Glee; Joy.

MISANTHROPICAL, CYNICAI. Misanthropical and cynical both indicate a hostile attitude to mankind in general. Misanthropical, from Greek $\mu \iota \sigma \widehat{\varepsilon} \nu$, to hate, and $\tilde{a} \nu \theta \rho \omega \pi \circ \mathrm{s}$, man, means hating mankind. Cynical comes from Greek kvvıkós, which originally meant doglike, currish, snappish, and was the designation of a sect of Greek philosophers who affected to disbelieve in human goodness. Misanthropical implies a morbid psychological condition-often a nervous horror or fear of others, which has some definite external cause. Cynical indicates an intellectual attitude - a disbelief in the goodness of others, and a consequent tendency to sneer. The misanthrope makes himself miserable; the cynic makes others miserable.

The misanthropical man separates himself from the rest of human society; the cynical man moves among men sneering. Cynicism is often a characteristic of men of the world who have seen much of the shams and selfishness of society. The misanthropical man is often one who has suffered from some great shock to his belief in human nature.

MISCARRIAGE. See FaILURE. MISCELlaNY. See Mixture.

MISCHANCE. See Calamity.

MISCHIEF. See Evil; INJURY; Scathe.

MISCONSTRUE, MISINTERPRET. Misconstrue and misinterpret signify to explain in a wrong way; but the former connotes the sense of one's words or the application of one's actions: those who indulge themselves in a light mode of speech toward children are liable to be misconstrued; a too great tenderness to the eriminal may be easily misinter- preted in favor of the crime. These words may likewise be employed in speaking of language in general; but the former implies the literal transmission of foreign ideas into our native language; the latter the general sense which one affixes to any set of words, either in a native or foreign language: the learners of a language will unavoidably misconstrue it at times; in all languages there are ambiguous expressions which are liable to misinterpretations. Misconstruing is the consequence of ignorance; misinterpretations of particular words are oftener the consequence of prejudice and voluntary blindness, particularly in the explanation of the law or of the Scriptures.

MISDEED. See OfFence.

MISDEMEANOR. See CrIME; OF FENCE.

MISERABLE. See UNHAPPY.

MISERLY. See Avaricious.

MISFORTUNE. See Cainamitr; EVIL.

MISHAP. See Calamity.

MISINTERPRET. See MISconSTRUE.

MISMANAGE. See Bungle.

MISS. See Lose.

MISTAKE. See Error.

MISUSE. See ABUSE.

MITIGATE. See Aluay.

mix, Mingle, Blend, Confound. Mix is in Anglo-Saxon miscian, from Latin miscere, to intermingle. Mingle comes from Anglo-Saxon mengan, to mix, allied to among. Blend is a Scandinavian word meaning to mix together.

Mix is here a general and indefinite term, signif ying simply to put together: but we may mix two or several things; we mingle several objects: things are mixed so as to lose all distinction, but they may be mingled and yet retain a distinction: liquids mix so as to become one, and individuals mix in a crowd so as to be lost; things of different sizes are mingled together if they lie in the same spot, but they still may be distinguished. To blend is only partially to mix, as colors blend which fall into each other: to confound is to mix in a wrong way, as objects of sight are confounded when they are erroneously taken to be joined. To 
mix and mingle are mostly applied to material objects, except in poetry; to blend and confound are mental operations, and principally employed on spiritual subjects: thus, events and circumstances are blended together in a narrative; the ideas of the ignorant are confounded in most cases, but particularly when they attempt to think for themselves.

Mixture, Medley, Miscellany.-Mixture is the thing mixed. Medley comes from Old French medler, to mix or confuse. Miscellany, in Latin miscellaneus, from miscere, to mix, signifies also a mixture.

The term mixture is general; whatever ohjects can be mixed will form a mixture: a medley is a mixture of things not fit to be mixed; and a miscellany is a mixture of many different things. Flour, water, and eggs may form a mixture in the proper sense, but if to these were added all sorts of spices it would form a medley. Miscellany is a species applicable only to intellectual subjects: the miscellaneous is opposed to that which is systematically arranged; essays are miscellaneous in distinction from works on one particular subject.

MOAN. See Groan; WaIL.

MOB. See People.

MOBILITY. See People.

MOCK. See Deride; Imitate.

MODE. See WAY.

MODEL. See CoPY.

MODERATION, MEDIOCRITY. Moderation (see MODESTY) is the characteristic of persons; mediocrity (that is, the mean or medium) characterizes their condition: moderation is a virtue of no small importance for beings who find excess in everything to be an evil; mediocrity in external circumstances is exempt from all the evils which attend either poverty or riches.

MODERN. See New.

MODEST, BashFul, Diffident. Modest, in Latin modestus, from modus, a measure, signifies setting measure to one's estimate of one's self. Bashful signifies ready to be abashed (see Abash). Diffident (see Distrustrul).

Modesty is a habit or principle of the mind; bashfulness is a state of feeling: modesty is at all times becoming; bashfulness is observed only in young girls or other young persons in the presence of their superiors: modesty discovers itself in the absence of everything assuming, whether in look, word, or action; bashfulness betrays itself by a downcast look and a timid air: a modest deportment is always commendable; a bashful temper is not desirable.

Modesty is a proper distrust of ourselves; diffidence is a culpable distrust. Modesty, though opposed to assurance, is not incompatible with a confidence in ourselves; diffidence altogether unmans a person and disqualifies him for his duty: a person is generally modest in the display of his talents to others; but a diffident man cannot turn his talents to his own use.

See also Humble.

Modesty, Moderation, Temperance, Sobriety.-Modesty, in French modestie, Latin modestia, and moderation, in Latin moderatio, both come from modus, a measure, limit, or boundary, that is, forming a measure or rule. Temperance, in Latin temperantia, from tempus, time, signifies the observance of proper times and seasons-propriety, selfcontrol. Sobriety (see ABstinent).

Modesty lies in the mind and in the quality of feeling; moderation in the desires: modesty is a principle that acts discretionally; moderation is a rule or line that acts as a restraint on the views and the outward conduct: he who thinks modestly of his own acquirements, his own performances, and his own merits will be moderate in his expectations of praise, reward, and recompense; he, on the other hand, who overrates his own abilities and qualifications will equally overrate the use he makes of them, and consequently be immoderate in the price which he sets upon his services: in such cases, therefore, modesty and moderation are to each other as cause and effect; but there may be modesty without moderation, and moderation without modesty. Modesty is a sentiment confined to one's self as the object, and consisting solely of one's judgment of what one is and what one does; but moderation, as is evident from the above, extends to objects that are external of ourselves: modesty, rather than moderation, belongs to an author; moderation, rather than modesty, belongs to a tradesman 
or a man who has gains to make and purposes to answer.

Modesty shields a man from mortifications and disappointments, which assail the self-conceited man in every direction: a modest man conciliates the esteem even of an enemy and a rival. Moderation protects a man equally from injustice, on the one hand, and imposition, on the other: be who is moderate himself makes others so.

Moderation is the measure of one's desires, one's habits, one's actions, and one's words; temperance is the adaptation of the time or season for particular feelings, actions, or words: a man is said to be moderate in his principles who adopts the medium or middle course of thinking; it rather qualifies the thing than the person: he is said to be temperate in his anger, if he does not suffer it to break out into any excesses; temperance characterizes the person rather than the thing. A moderate man in politics endeavors to steer clear of all party spirit, and is consequently so temperate in his language as to provoke no animosity. Moderation in the enjoyment of everything is essential in order to obtain the purest pleasure: temperance in one's indulgences is always attended with the happiest effects to the constitution; as, on the contrary, any deviation from temperance, even in a single instance, is always punished with bodily pain and sickness.

Temperance and sobriety have already been considered in their proper applieation (see ABSTINENT), which will serve to illustrate their improper application. Temperance is an action; it is the tempering of our words and actions to the circumstances: sobricty is a state in which one is exempt from every stimulus to deviate from the right course; as a man who is intoxicated with wine runs into excesses and loses that power of guiding himself which he has when he is sober or free from all intoxication, so is he who is affected by any passion, in like manner, hurried away into irregularities which a man in his right senses will not be guilty of: sobriety is, therefore, the state of being in one's right or sober senses; and sobriety is, with regard to temperance, as a cause to the effect; sobriety of mind will not only produce moderation and temperance, but extend its influence to the whole conduct of a man in every relation and circumstance, to his internal sentiments and his external behavior: hence we speak of sobriety in one's mien or deportment, sobriety in one's dress and manners, sobriety in one's religious opinions and observances. Sober may also be applied figuratively.

MOISTURE, HUMIDITY, DAMPNESS. Moisture is a word of disputed origin. Humid comes from Latin humidus, from the verb humere, to be moist. Dainpness comes from the same root as the German $\operatorname{dampf}$, a vapor.

Moisture is used in general to express any small degree of infusion of a liquid into a body; humidity is employed scientifically to describe the state of having any portion of such liquid: henee we speak of the moisture of a table, the moisture of paper, or the moisture of a floor that has been wet; but of the humidity of the air or of a wall that has contracted moisture of itself. Dampness is that species of moisture that arises from the gradual contraction of a liquid in bodies capable of retaining it; in this manner a cellar is damp, or linen that has lain long may become damp.

MOLEST. See InCoNVENIENCE; Trovble.

MOLlify, Appease, Pacify, SoOTHE. These words all mean to change from a state of wrath or disturbed emotion to one of peace. Mollify comes from Latin mollis, soft, tender, and a weak form of facere, to make. It signifies to make soft or mild. A ppease comes from Old French a pais, Latin ad pacem, at peace, or rather to a state of peace. Mollify, pacify (from Latin pax, peace, and a weak form of facere, to make), and appease differ from each other in the degree of emotion suggested and the extent of the peace produced. To mollify is not so strong a word as to pacify, and to pacify does not suggest such dangerous wrath as appease. Appease is used especially with reference to persons or powers greater than ourselves. Men offered sacrifices in olden times to appease the gods; in the old fairy-tales beautiful maidens were offered as vie- 
tims to appease the voracity of dragons and sea-monsters, etc. Pacify suggests a less dangerous anger or emation. We appease the wrath that is dangerous to us; we pacify that which is merely annoying or vexatious - as when we pacify a crying child. Mollify and soothe are more general expressions. To mollify is to make gentle that which was violent. To soothe, from AngloSaxon sooth, truth, meant to "say sooth" - to agree with or say "yes" to. Soothe is more suggestive of physical action than mollify. We may soothe a wound by the application of healing salves, for instance, as well as soothe a ruffled temper with gentle words. Mollify has only the moral application. Mollify implies emotional excitement hostile to others which should be allayed; soothe merely implies any kind of disturbance. We mollify others for our own sakes; we soothe them for their own.

MOMENT. See Importance; INSTANT.

MONAD. See UNIT.

MONARCH. See Prince.

MONASTERY. See Cloister.

MONEY, CASH. Money comes from the Latin moneta, a surname of Juno, in whose temple at Rome money was coined. Cash, from the French casse, a chest, signifies that which is put in a chest.

Money is applied to everything which serves as a circulating medium; cash is, in a strict sense, put for coin only: bank-notes are money; guineas and shillings are cash; all cash is therefore money, but all money is not cash. The only money the Chinese have are square bits of metal with a hole through the center by which they are strung upon a string: travellers on the Continent must always be provided with letters of credit, which may be turned into cash, as convenience requires.

MONOPLANE. See AIrcraft.

MONOPOLIZE, ABSORB, APPROpriate, ENGross. These words all mean to take complete or exclusive possession of something. Appropriate is the least emphatic. It comes from Latin ad, to, and proprius, one's own, and means to make completely one's own. Absorb (for derivation see $\mathrm{AB}-$
SORB) goes further. It means not only to make one's own, but to swallow up entirely, so that the identity of the thing absorbed is lost. Engross and monopolize have similar meanings expressed under commercial figures. Engross is from the French en gros, in the gross, and means to buy up by the wholesale. Monopolize has a similar meaning. It comes from Greek $\mu$ óvos and $\pi \omega \lambda \bar{\varepsilon} \nu$, to sell, and means to obtain the exclusive right of selling. In ordinary usage there is little difference between monopolize and engross. Monopolize perhaps carries more of the suggestion of exclusiveness; engross more of absorption.

\section{MONSTER. See WONDER.}

MONSTROUS. See ENoRMOUS.

MONUMENT, MEMorial. Monument, in Latin monumentum or monimentum, from moneo, to advise or remind, and a suffix, signifies that which puts us in mind of something. Memorial, from memory, signifies the thing that helps the memory.

From the above it is clear that these terms have, in their original derivation, precisely the same signification, but differ in their collateral acceptations: monument is applied to that which is purposely set up to keep a thing in mind; memorials are any objects which are calculated to call a thing to mind: a monument is used to preserve a public object of notice from being forgotten; a memorial serves to keep an individual in mind: the monument is commonly understood to be a species of building, as a tomb which preserves the memory of the dead, or a pillar which preserves the memory of some public event: the memorial always consists of something which was the property, or in the possession, of another, as his picture, his handwriting, his hair, and the like. The Monument at London was built to commemorate the dreadful fire of the city in the year 1666: friends who are at a distance are happy to have some token of each other's regard, which they likewise keep as a memorial of their former intercourse.

The monument, in its proper sense, is always made of wood or stone for some specific purpose; but in the improper sense anything may be termed a 
monument when it serves the purpose of reminding the public of any circumstance: thus, the pyramids are mounments of antiquity; the actions of a good prince are more lasting monuments than either brass or marble. Memorials are mostly of a private nature, and at the same time such as remind us naturally of the object to which they have belonged; this object is generally some person.

But it may likewise refer to some thing, if it be of a personal nature, or that by which persons are individually affected: our Saviour instituted the Sacrament of the Lord's-Supper as a memorial of His death.

MOOD. See Humor.

MORAL. See VirTuous."

MORALLY. See ETHICAL.

MORALS. See MANNERS. /

MORATORIUM. See DELAT.

MORBID.' See Sick.

MOREOVER. See Besides.

MORTAL. See DEADLY.

MORTIFICATION. See VexaTION.

MORTIFY. Sce Abash; Snub.

MORTUARY. See NEcropolis.

MOTION, Movement. These are both abstract terms to denote the act of moving, but motion is taken generally and abstractedly from the thing that moves; movemenl, on the other hand, is taken in connection with the agent or thing that moves: hence we speak of a state of motion as opposed to a state of rest, of perpetual motion, the laws of motion, and the like; on the other hand, we say, to make a movement, when speaking of an army, a general movement when speaking of an assembly.

When motion is qualified by the thing that moves it denotes continued motion; but movement implies only a particular motion: hence we say, the motion of the heavenly bodics; the motion of the earth; a person is in continual motion, or an army is in motion; but a person who rises or sits down or goes from one chair to another makes a movement; the different movements of the springs and wheels of any instrument.

MOTION PICTURE. See Moving Picture.

motive. See Cause; Principle.
MOTOR. See AutomobiLe.

MOULD. See ForM.

MOUNT. See Arise.

MOURN. See GRIEve.

MOURNFUL, SAD. Mournful (from Anglo-Saxon mcornan, to grieve, Modern English mourn) signifies full of what causes mourning; sad (see DuLL) signifies either a painful sentiment or what causes this painful sentiment. The difference in the sentiment is what constitutes the difference between these epithets: the mournful awakens tender and sympathetic feelings: the sad oppresses the spirits and makes one heavy at heart; a mournsul tale contains an account of others' distress; a sad story contains an account of one's own distress; a mourriful event befalls our friends and relatives; a sad misfortune befalls ourselves. Selfish people find nothing mournful, but many things sad: tender-hearted people are always affected by what is mournful, and are less troubled about what is sad.

MOVABLE. See Kinetic.

MOVABLES. See Goops.

MOVE. See Go; Stir; Thrill. MOVEMENT. See Motion.

MOVIES. See Moving Picture.

MOVING, Affecting, Pathetic. The moving is in general whatever moves the affections or the passions; the affecting and pathetic are what move the affections in different degrees. The good or bad feelings may be moved; the tender feelings only are affected. A field of battle is a moving spectacle: the death of a friend is an affecting spectacle. The affecting acts by means of the scenes as well as the understanding; the pathelic applies only to what is addressed to the heart: hence, a sight or a description is affecting; but an address is pathetic.

MOVING PICTURE, Motion PICTure, Cinematograph, Photoplay, Movie. As is the case with most names of recent inventions, these terms differ not in meaning, but in application and usage. They all indicate the invention whereby figures in motion are photographed, so that the movement is reproduced when the picture is thrown on a screen. Moving picture was the name first used for this invention, but motion picture has also come into general usage and has been 
adopted by many of the corporations producing these pictures. Moving picture seems to a purist a more desirable term, because moving is an adjective form, whereas in the case of motion picture a substantive is made to do duty as an adjective. But some people contend that motion picture is a more accurate word, since the pictures themselves do not move; they are merely photographs of motion. The two terms, however, are used interchangeably. Movie is a popular abbreviation of moving picture, and one which, perhaps, deserves to receive general recognition as a new word, inasmuch as it is a spontaneous popular coinage to indicate a new invention, rather than a scientific name laboriously patched together out of Greek and Latin. Cinematograph is the technical term corresponding to

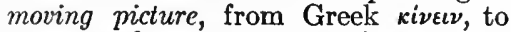
move, and $\gamma \rho \alpha \dot{\phi} \phi \varepsilon \imath \nu$, to mark or write. This is frequently shortened to cinema, which is also becoming a popular term for the moving picture, and is used among educated people sometimes as a more elegant substitute for movie. Photoplay differs somewhat from the other terms in its application. It is applied to a particular moving-picture drama, a play in pictures. The other words are rather indiscriminately used to indicate individual moving-picture plays, moving-picture houses, or the representations of the moving picture.

MULCT. See Fine.

MULTIPLANE. See Aircraft.

MULTITUDE, Crowd, ThroNG, Swarm. The idea of many is common to all these terms, and peculiar to that of multitude, from the Latin multus; crowd comes from Anglo-Saxon crudan, to push; and throng from Anglo-Saxon thringan, to press; and swarm, like the German schwärmen, to fly about, signifies running together in numbers. These terms vary, either in regard to the object or the circumstance: multitude is applicable to any object; crowd, throng, and swarm are in the proper sense applicable only to animate objects: the first two in regard to persons; the last to animals. A multitude may be either in a stagnant or a moving state; all the rest denote a multitude in a moving state: a crowd is always pressing, generally eager and tumultuous; a throng may be busy and active, but not always pressing or incommodious: it is always inconvenient, sometimes dangerous, to go into a crowd; it is amusing to see the throng that is perpetually passing in the streets of the city: the swarm is more active than either of the two others; it is commonly applied to bees which fly together in numbers, but sometimes to human beings, to denote their very great numbers when scattered about; thus the children of the poor in low neighborhoods swarm in the streets.

MUMBLE. See JABBER.

MUNIFICENT. See Beneficent. MUNITIONS. See AMMUnition. MURDER. See KILl.

MURMUR. See Complaint.

MUSE. See Contemplate; Think. MUSTER. See Assemble.

MUTABle. See Changeable. MUTE. See Silent.

MUTilate, MaIm, MaNgle. $M u$ tilate, in Latin mutilatus, from mutilus, Greek $\mu$ vítıos, curtailed, docked, signifies to take off any necessary part. Maim, in Anglo-French mahaym, is a word of unknown origin. Mangle, in Anglo-French mahangler, is a frequentative of it.

Mutilate has the most extended meaning; it implies the total or partial loss of any limb: mangle is applied to irregular wounds in any part of the body: maim is confined to wounds in the limbs, particularly the hands. Men are exposed to the danger of mutilation by means of cannon-balls; they run the risk of being mangled when attacked with the sword; they frequently get maimed when boarding vessels or storming places.

Mutilate and mangle are applicable to moral objects; maim is employed in the natural or figurative sense. In this case mangle is a much stronger term than mutilate; the latter signifies to lop off an essential part; to mangle is to mutilate a thing to such degree as to render it useless or worthless. Every sect of Christians is fond of mutilating the Bible by setting aside such parts as do not favor its own scheme; and among them all the sacred Scriptures become literally mangled and stripped of all their most important doctrines. 
MUtinous. See Tomutroods.

MUTUAL, Reciprocal. Mutual, in Latin mutuus, from muto, to change, signifies exchanged so as to be equal, or the same, on both sides. Reciprocal, in Latin reciprocus, meant, literally, back and forth, from reco, back, and proco, forward. Mutual supposes a sameness in condition at the same time: reciprocal supposes an alternation or succession of returns. Exchange is free and voluntary; we give in exchange, and this action is mutual: return is made either according to law or equity; it is obligatory, and when equally obligatory on each in turn it is reciprocal. Voluntary disinterested services rendered by one person to another are mutual: imposed or merited services, returned from one to the other, are reciprocal: friends render one another mutual services; the services between servants and masters are reciprocal. The husband and wife pledge their faith to each other mutually; they are reciprocally bound to keep their vow of fidelity. The sentiment is mutual, the tie is reciprocal.

Mutual applies mostly to matters of will and opinion: a mutual affection, a mutual inclination to oblige, a mutual interest for each other's comfort, a mutual concern to avoid that which will displease the other-these are the sentiments which render the marriage state happy: reciprocal ties, reciprocal bonds, reciprocal rights, reciprocal duties-these are what every one ought to bear in mind as a member of society, that he may expect of no man more than what in equity he is disposed to return.

Mutual applies to nothing but what is personal; reciprocal is applied to things remote from the idea of personality, as reciprocal verbs, reciprocal terms, reciprocal relations, and the like.

MYSTERIOUS, Mystic. Mysterious and mystic are but variations of the same original, Greek $\mu v_{\sigma \tau} \eta \boldsymbol{s}_{\text {, }}$ one who is initiated into a secret religious order; the former, however, is more commonly applied to that which is supernatural or veiled in an impenetrable obscurity; the latter to that which is natural, but concealed by an artificial or fantastical veil; hence we speak of the mysterious plans of Providence: mystic schemes of theology or mystic principles.

Sce also Secret.

MYTHICAL. See Legendary. 


\section{$\mathrm{N}$}

NAB, APPROPRIATE, Clutch, Grasp, Seize. $N a b$ is a Scandinavian word signifying to snatch at. Although the term has a wide range of usage and has long been recognized in polite language, in itself it is very near slang. A person by cunning, deceit, sharp practice may nab or appropriate from another credit for an achievement, some property, or other possession-conquering nations appropriate, seize, take possession of territory belonging to a defeated opponent as a spoil of war, and this has heretofore been considered right and proper.

To appropriate may be a slow action, one resulting from a more or less prolonged parley or negotiation, but to seize implies the real meaning of to nab. To clutch also implies a swift action, as a drowning person will clutch at anything likely to save his life, a falling person will clutch, seize, lay hold of any near-by object that will save a complete fall. To grasp implies actions both good and indefensible. It is a delight to grasp the hand of a friend; it is a great accomplishment to possess the intellectual capacity to grasp the spirit, truth, intent of a subject readily; but it is not justifiable to grasp, lay hold of greedily, take sudden possession of that which belongs to another without warrant or justification.

NACREOUS, IRIDEscent, Opalescent, Pearly, Polychromatic. These words all signify characterized by an interplay of colors, and derive their names and their respective differences from various substances. Nacreous, from nacre, mother-of-pearl (probably an Oriental word), takes its name from the inner covering of an oyster-shell and of certain other shells. It indicates a shining substance of the silvery gray color of the pearl, but shimmering with iridescent colors that appear and vanish as the light strikes it. Iridescent, from Latin iris, Greek ipıs, the rainbow, signifies, literally, having all the colors of the rainbow. Polyckromatic, from Greek $\pi o \lambda \dot{v}$, much, and $\chi \rho \tilde{\omega} \mu a$, color, has a similar literal meaning less metaphorically expressed. But iridescent suggests both changefulness and light as well as color-an interplay of colors like light. Polychromatic is a more prosaic word; it merely means having many colors. Opalescent (from Latin opalus, English opal, the name of a precious stone) means resembling an opal-that is, having an interplay of soft milky-hued colors shot with flashes and gleams of fiery light. Pearly, from pearl (French perle, a word of unknown origin), means resembling the lustrous silvery white or silvery gray of the'pearl which is sometimes touched with the faintest glow of color. .

NAÏVE, Ingenuous, Artless. These words all refer to an absence of pretence and sophistication, and are used, in a good sense, to describe naturalness and simplicity. Of these three words naïve is the most inclusive and the most difficult to define. It is an imperfectly naturalized French word (from Latin nativus, native, inborn) which is almost always used in English with a feeling that it expresses something that cannot be described in blunt English terms.

Ingenuous (from Latin root gen, indicating birth) meant originally the simplicity and frankness of a well-born youth, and indicates a quality of character.

Artless means without art, and indicates primarily a mental characteristic. We say that a child is artless, that a young girl is artless, but that a youth is ingenuous. Artless conveys the impression of a certain innocence and ignorance of the world; ingenuous, the impression of an inborn disposition. Naive expresses the idea involyed in artless with a certain subtlety. It really differs from artless mainly in indicating a difference in the perceiver, rather than the quality perceived. It 
is faintly suggestive of that slight shade of tender-hearted amusement - of that complete sympathy of the heart, combined with a certain intellectual superiority and detachment - with which the educated or experienced man views an expression of artlessness. There are only a few words in English whose effectiveness depends so entirely upon an atmosphere undefinable and untranslatable; the other words of this character are also French.

NAKED. See BARE.

NAMBY-PAMBY. See Simple.

NAME, CALL. Name comes from Anglo-Saxon nama. a name, allied to Latin nomen, a name. Call is a Scandinavian word. To call signifies properly to address one loudly, consequently we may name without calling, when we only mention a name in conversation; and we may call without naming.

The terms may, however, be employed in the sense of assigning a name. In this case a person is named by his name, whether by the proper patronymic or by some habitual variant; he is called according to the characteristics by which he is distinguished. The Emperor Tiberius was named Tiberius; he was called a monster. William the First of England is named William; he is called the Conqueror.

Name, Appellation, Title, Denomination.-Name (see above). Appellation, in French appellation, Latin appellatio, comes from Latin ad, to, and a stem meaning to speak, allied to AngloSaxon and Modern English spell. Title, in French titre, comes from Latin titulus, a superscription on a tomb. Denomination signifies that which denominates or distinguishes.

Name is a generic term, the rest are specific. Whatever word is employed to distinguish one thing from another is a name; therefore, an appellation and a title are a name, but not vice versa. A name is either common or proper; an appellation is generally a common name given for some specific purpose as characteristic. Several kings of France had the names of Charles, Louis, Philip; but one was distinguished by the $a p-$ pellation of Stammerer, another by that of the Simple, and a third by that of the Hardy, arising from particular characters or circumstances. is a species of appellation, not drawn from anything personal, but conferred as a ground of political distinction. An appellation may be often a term of reproach; but a title is alway's a mark of honor. An appellation is given to all objects, animate or inanimate; a title is given mostly to persons, sometimes to things. A particular house may have the appellation of "the Cottage," or "the Hall," as a particular person may have the title of Duke, Lord, or Marquis.

Denomination is to particular bodies what appellation is to an individual, namely, a term of distinction, drawn from their peculiar characters and circumstances. The Christian world is split into a number of different bodies or communities, under the denominations of Catholics, Protestants, Calvinists, Presbyterians, etc., which have their origin in the peculiar form of faith and discipline adopted by these bodies.

Name, Denominate, Style, Entitle, Designate, Characterize.-To name signifies simply to give a name to, or to address or specify by the given name; to denominate (from Latin nomen, name) is to give a specific name upon specific ground, to distinguish by the name; to style, from the noun style or manner (see Dicriov), signifies to address by a specific name; to entitle is to give the specific or appropriate title. Adam named everything; we denominate the man who drinks excessively "a drunkard"; subjects style their monarch "His Majesty"; books are entitled according to the judgment of the author.

To name, denominate, style, and entitle are the acts of conscious agents only. To designate, signifying to mark out, and characterize, signifying to form a characteristic, are usually said only of things, and agree with the former only inasmuch as words may either designate or characterize: thus the word "capacity" is said to designale the power of holding; and "finesse" characterizes the people by whom it was adopted.

See also Nominate.

Name, Reputation, Repute, Credit.Name is here taken in another sense for a name acquired in public by any 
peculiarity or quality in an object. Reputation and repute, from /reputo, or re, back, and putare, to think, signifies the thinking of or the state of being thought of, or esteemed by, by the public. Credit signifies the state of being believed or trusted in general, from Latin credere, to believe or trust.

Name implies something more specific than reputation; and reputation something more substantial than name; a name may be acquired by some casualty or by some quality that has more show than worth; reputation is acquired only by time and built only on merit: a name may be arbitrarily given, simply by way of distinction; reputation is not given, but acquired, or follows as a consequence of one's honorable exertions. A physician sometimes gets a name by a single instance of professional skill, which by a combination of favorable circumstances he may convert to his own advantage in forming an extensive practice; but unless he have a commensurate degree of talent, this name will never ripen into a solid reputation.

Name and reputation are of a more extended nature than repute and credit. The name and reputation are given by the public at large; the repute and credit are acquired within a narrow circle. Strangers, or it may be distant countries, hear of the name and the reputation of anything; but only neighbors and those who have the means of personal observation can know its repute and credit. It is possible, therefore, to have a name and reputation without having repute and credit, and vice vers $\hat{a}$, for the objects which constitute the former are sometimes different from those which produce the latter. A manufacturer has a name for the excellence of a particular article of his own manufacture a book has a name among would-be connoisseurs and pretenders to literature: a good writer, however, seeks to establish his reputation for genius, learning, industry, or some praiseworthy characteristic: a preacher is in high repute among those who attend him: a master gains great credit from the good performances of his scholars. There is also this distinction between reputation and repute, that reputation signifies the act of reputing or the state of being reputed, repute signifies only the state of being reputed.

Name and repute are taken either in a good or bad sense; reputation mostly, and credit always, are taken in the good sense only: a person or thing may get a good or an ill name; a person or thing may be in good or ill repute; reputation may rise to different degrees of height, or it may sink again into nothing; credit may likewise be high or low, but both reputation and credit, absolutely taken, imply that which is good.

NAP. See SleEP.

NARRATION. See RELATION.

NARRATIVE. See ACCOUNT; RELATION.

NARROW. See CoNTRACTED.

NATAL, NATive, I N D g E N O US. Natal, in Latin natalis, from natus, born, signifies belonging to one's birth, or the act of one's being born; but native, in Latin nativus, likewise from natus, signifies having an origin or beginning. Indigenous, in Latin indigenus, from indu, Old Latin, within, and genitus, born, signifies born in a given place.

The epithet natal is applied only to the circumstances of a man's birth, as his natal day; his natal hour; a natal song; a natal star. Native has a more extensive meaning, as it comprehends the idea of one's relationship by origin to an object; as one's native country, one's native soil, native village, or native place, native language, and the like.

Indigenous is a particular term used to denote the country where races of men are supposed to have first existed. It is also applied to plants in the same sense.

Native, Natural.-Native is to natural as a species to the genus: everything native is, according to its strict signification, natural; but many things are natural which are not native. Of a person we may say that his worth is native, to designate that it is some valuable property which is born with him, not foreign to him, or ingrafted upon his character; but we may say of his disposition that it is natural, as opposed to that which is acquired or otherwise. The former is mostly employed in a good sense, in opposition 
to what is artful, assumed, and unreal; the other is used $m$ an indifferent sense, as opposed to whatever is the effect of habit or circumstances. When children display themselves with all their native simplicity, they are interesting objects of notice: when they display their natural turn of mind, it is not always that which tends to raise human nature in our esteem.

See also InTrinsic.

Naturally, In Course, Consequently, Of Course.-The connection between events, actions, and things is expressed by all these terms. Naturally signifies according to the nature of things, and applies, therefore, to the connection which exists between events according to the original constitution or inherent properties of things: in course signifies in the course of things, that is, in the regular order that things ought to follow: consequently signifies by a consequence, that is, by a necessary law of dependence, which makes one thing follow another: of course signifies on account of the course which things most commonly or even necessarily take. Whatever happens naturally happens as it should do; whatever happens in course, or in due course, happens as we establish it: whatever follows consequently follows as we judge it logical; whatever follows of course follows as we expect it. Children naturally imitate their parents: people naturally fall into the habits of those they associate with: both these circumstances result from the nature of things: whoever is made a peer of the realm takes his seat in the upper house in course; he requires no other qualifications to entitle him to this privilege, he goes thither according to the established course of things; consequently, as a peer, he is admitted without question; this is a decision of the judgment by which the question is at once determined: of course none are admitted who are not peers; this results necessarily from the constituted law of the land.

NATion. See People.

NATIONAL. See Public.

NATURALIZE, A C CLI M A T E, Orient. These words all mean to become at home in a new country. But naturalize, from the very beginning when it was coined as French natura:- iser, has meant to acquire the standing of a natural-born citizen, to be placed on the same footing before law as a native of the country. It is sometimes used with an extended application to refer to the adaptation of plants, etc., to a new country. Acclimate means to become accustomed to the climale of a new country. It may also be used figuratively in an extended sense to mean simply to become accustomed to. Orient is used as a verb to mean to adjust to new conditionsfrom French [ $\left.s^{\prime}\right]$ orienter. It referred originally to the placing of churches so that the altar was at the east (Latin oriens, the place of the rising sun); hence it came to mean to place with reference to the points of the compass; to get one's bearings.

NAUGHT. See ZERo.

NAUSEA. See Disgest.

NAUTICAL. See Maritine.

NAVAL. See Maritime.

NEAR. See Close.

NEAT. See TIDY.

NECESSARIES. See Necessities.

NECESSARY, EXPEDIENT, ESSENTIAL, ReQuisite. For necessary see Necessity. Expedient comes from Latin ex, out, and pedem (accusative), foot, and signified originally taking the foot out, hence aiding movement and action. Essential means containing that essence or property which cannot be omitted, from Latin essentia, being, derived from a supposititious stem from esse, the infinitive of the verb to be. Requisite signifies literally required (see Demaxd).

Necessary is a general and indefinite term; things may be nccessary in the course of nature; it is necessary for all men once to die; or things may be necessary according to the circumstances of the case, or our views of necessity; in this manner we conceive it necessary to call upon another. Expedient, essential, and requisite are modes of relative necessity: the expediency of a thing is a matter of discretion and calculation, and therefore not so self-evidently necessary as many things which we so denominate: it may be expedient for a person to consult another, or it may not, according as circumstances may present themselves. The requisite and the essential 
are more obviously necessary than the expedient; but the former is less so than the latter: what is requisite may be requisite only in part or entirely; it may be requisite to complete a thing when begun, but not to begin it; the essential, on the contrary, is that which constitutes the essence, and without which a thing cannot exist. It is requisite for one who would have a good library to select only the best authors; exercise is essential for the preservation of good health. In all matters of dispute it is expedient to be guided by some impartial judge; it is requisite for every member of the community to contribute his share to the public expenditure as far as he is able: it is essential to a teacher to know more than those he teaches.

Necessities, Necessaries. - Necessity, in Latin necessitas, and necessary, in Latin necessarius, from necesse, signify that which is indispensable. Necessity is the mode or state of circumstances or the thing which circumstances render necessary; the necessary is that which is absolutely and unconditionally necessary. Art has ever been busy in inventing things to supply the various necessities of our nature, and yet there are always numbers who want even the first necessaries of life. Habit and desire create necessities; nature only requires necessaries: a voluptuary has necessities which are unknown to a temperate man; the poor have in general little more than necessaries.

Necessity, Need. - Necessity (see Necessary). Need is in Anglo-Saxon nied, and is the native English word corresponding to the Latin word necessitas.

Necessity implies the thing wanted; need the condition of the person wanting. There would be no necessity for punishments if there were not evildoers; he is peculiarly fortunate who finds a friend in time of need. Necessity is more pressing than need: the former places one in a positive state of compulsion to act; it is said to have no law, it prescribes the law for itsclf; the latter yields to circumstances and leaves in a state of deprivation." We are frequently under the necessity of going without that of which we stand móst in need.
From these two nouns arise two epithets for each, which are worthy of observation, namely, necessary and needful, necessitous and needy. Necessary and needful are both applicable to the thing wanted; necessitous and needy to the person wanting: necessary is applied to every object indiscriminately; needful only to such objects as supply temporary or partial wants. Exercise is necessary to preserve the health of the body; restraint is necessary to preserve that of the mind; assistance is needful for one who has not sufficient resources in himself: it is necessary to go by water to the Continent: money is needful for one who is travelling. The dissemination of knowledge is necessary to dispel the ignorance which would otherwise prevail in the world; it is needful for a young person to attend to the instructions of his teacher, if he wishes to improve.

Necessitous and needy are both ap. plied to persons in want of something important; but necessitous may be employed to denote an occasional want, as to be in a necessitous condition in a foreign country for want of remittances from home; needy denotes a permanent state of want, as to be needy either from extravagance or misfortune.

NECESSITATE. See CoMpel.

NECROPOLIS, BURIAL - GROUND, Cemetery, Graveyard, Mortuary. These words all indicate places where the dead are laid away. Burial-ground and graveyard are the native English terms; of these two graveyard is the more familiar word. It has more intimate and solemn associations than the analogous term burial-ground. We speak of the burial-ground of the Indians, for instance, in indicating an object of merely archæological interest. We speak of an English graveyard with some sympathetic realization of what it has meant to a community of people like ourselves. Cemetery, from

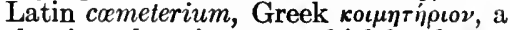
sleeping-place, is aterm which has largely replaced the older term graveyard in ordinary speech now. Being a more modern and sophisticated term, it naturally has somewhat different connotations. We should speak of an old burialground in a little town as a graveyard; of 
the park-like burial-grounds in or near our eities as cemeteries. But this distinction is not always observed. $\mathrm{Ne}$ cropolis, from Greek vexpós, dead, and $\pi$ ódıs, a city, means literally a city of the dead. It is a term applied to large and elaborate cemeteries near cities, or to burial-places of special dignity. Mortuary, from Latin mortuus, dead, is the term applied to a building or a room where dead bodies are kept for a time.

NEFARIOUS. See Wicked.

NEGLECT, OMIT. Neglect (see DisREGARD). Omit, in Latin omitto, or $o b$ and mitto, signifies to put aside.

The idea of letting pass or slip, or of not using, is comprehended in the signification of both these terms; the former is, however, a culpable, the latter an indifferent action. What we neglect ought not to be neglected: but what we omit may be omitted or otherwise, as convenience requires.

These terms differ likewise in the objects to which they are applied; that is neglected which is practicable or serves for action; that is omitted which serves for intellectual purposes: we neglect an opportunity, we neglect the means, the time, the use, and the like; we omit a word, a sentenee, a figure, a stroke, a eireumstance, and the like.

Negligent, Remiss, Careless, Thoughtless, Heedless, Inattentive.-Negligence (see DisRegard) and remissness concern the outward action: careless, heedless, thoughtless, and inatlentive the state of mind.

Negligence and remissness consist in not doing what ought to be done; carelessness and the other mental defects may show themselves in doing wrong, as well as in not doing at all; negligence and remissness are, therefore, to carelessness and the others as the effeet to the cause; for no one is so apt to be negligent and remiss as he who is careless, although negligence and remissness arise from other causes, and carelessness, thoughtlessness, etc., produce likewise other effects. Negligent is a stronger term than remiss: one is negligent in neglecting the thing that is expressly before one's eyes; one is remiss in forgetting that which was enjoined some time previously: the want of will renders a person negligent; the want of interest renders a person remiss: one is negligent in regard to business, and the performance of bodily labor; one is remiss in duty, or in such things as require mental exertion. Servants are commonly negligent in what coneerns their master's interest; teachers are remiss in not correeting the faults of their pupils. Negligence, therefore, is the fault of persons of all deseriptions, but particularly those in low condition; remissness is a fault peculiar to those in a more elevated station: a clerk in an office is negligent in not making proper memorandums; a magistrate, or the head of an institution, is remiss in the exercise of his suthority to cheek irregularities.

Careless denotes the want of eare in the manner of doing things; thoughtless denotes the want of thought or reflection about things; heedless denotes the want of heeding or regarding things; inattentive denotes the want of attention to things. One is careless only in trivial matters of behavior; one is thoughtless in matters of greater moment, in what concerns the eonduet. Carelessness leads ehildren to make mistakes in their mechanical exercises, in whatever they commit to memory or to paper; thoughtlessness leads many who are not children into serious errors of conduct, when they do not think of, or bear in mind, the consequences of their actions. Thoughtless is applied to things past, present, or to come; careless to things present or to conne.

Careless is applied to such things as require permanent care; thoughtless to such as require permanent thought; heedless and inattentive are applied to passing objects that engage the senses or the thoughts of the moment. One is careless in business, thoughlless in conduet, heedless in walking or running, inattentive in listening: hecdless children are unfit to go by themselves; inaltentive ehildren are unfit to be led by others.

Negotiate, Treat, Transact. The idea of conducting business with others is ineluded in the signification of all these terms; but they differ in the mode of conducting it and the nature of the business to be condueted. Negotiate, from Latin negotium (from negfor ne-not, and otium, leisure, signify- 
ing that which one does when one is not at leisure-i.e., business), is applied in the original mostly to merchandise or traffic, but it is more commonly employed in the complicated concerns of governments and nations. Treat, from the Latin tractare, frequentative of trahere, to draw, signifies to turn over and over or set forth in all ways: these two verbs, therefore, suppose deliberation; but transact, from transactus, participle of transago, to carry forward or bring to an end, supposes more direct agency than consultation or deliberation; this latter is therefore adapted to the more ordinary and less entangled concerns of commerce. A congress carries on negotiations for the establishment of good order among different states; individual states treat with each other to settle their particular differences. To negotiate mostly applies to political concerns, except in the case of negotiating bills: to treat, as well as transact, is said of domestic and private concerns: we treat with a person about the purchase of a house, and transact our business with him by making good the purchase and paying down the money.

As nouns, negotiation expresses rather the act of deliberating than the thing deliberated: treaty includes the ideas of the terms proposed and the arrangement of those terms: transaction expresses the idea of something actually done and finished. Negotiations are sometimes very long pending before the preliminary terms are even proposed or any basis is defined; treatics of commerce are entered into by all civilized countries, in order to obviate misunderstandings and enable them to preserve an amicable intercourse; the transactions which daily pass in a great metropolis like that of London are of so multifarious a nature, and so infinitely numerous, that the bare contemplation of them fills the mind with astonishment. Negotiations are long or short; treaties are advantageous or the contrary; transactions are honorable or dishonorable.

\section{See also Treat.}

NEIGHBORHOOD, VICINITY . Neighborhood, from neighbor (AngloSaxon neah, nigh, near, and gebur or bur, a husbandman, the same word as
Dutch Boer, English boor), signified originally the place near by where other farmers live. Vicinity, from vicus, a village, signifies the place which does not exceed in distance the extent of a village.

Neighborhood, which is of Saxon origin, is employed in reference to the inhabitants, or in regard to inhabited places, to denote nearness of persons to each other or to objects in general: but vicinity, which in Latin bears the same acceptation as neighborhood, is employed in English to denote nearness of one object to another, whether person or thing; hence the propriety of saying a populous neighborhood, a quiet neighborhood, a respectable neighborhood, a pleasant neighborhood, and to be in the neighborhood, either as it signifies the people or the country; but to live in the vicinity of a manufactory, to be in the vicinity of the metropolis or of the sea.

\section{NEOPHYTE. See TrRo.}

NEUTRAL, IMPARTIAL, INDIFFERENT. These words all indicate a disposition not to take sides in a quarrel, but they differ in the amount of sympathy for the combatants implied in them. Indifferent signified originally not making a distinction or difference between things-implying such a lack of sympathy or interest that one thing seems much like another. Here it indicates a lack of interest in either combatant. Neutral, from Latin ne, not, . and uter, which of two, means not asking which is right. It implies complete intellectual detachment, but not necessarily lack of sympathy for one or both of the parties. It is the term applied to the non-combatant nations in time of war. Impartial means not taking the part of either side. By derivation it has the same meaning as the other words, but it implies distinct sympathy with one or both combatants, which is not allowed to influence judgment.

NEVERTHELESS. See However. NEW, Novel, Modern, Fresh, ReCENT. New, from Anglo-Saxon neowe, is the native English word corresponding to Latin novus, whence novel is derived, Modern signifies belonging to the present mode, from Latin modus, manner. Fresh is derived from a 
Teutonic root which appears in AngloSaxon fersc, fresh; but its form is due to the feminine form of this same word in Old French-freis, masculine, fresche, feminine.

All these epithets are applied to what has not long existed; new expresses this idea simply without any qualification; novel is something strange or unexpected; the modern is the thing of today as distinguished from that which existed in former time; the fresh is that which is so new as not to be the worse for use, or that which has not been before used or employed; the recent is that which is so new as to appear as if it were just made or done. According to this distinction, new is most aptly applied to such things as may be permanent or durable, as new houses, new buildings, new clothes, and the like; in such cases it is properly opposed to the old; the term may, however, be applied/generally to whatever arises or comes first into existence or notice, as new scenes, new sights, new sounds.

Novel may be applied to whatever is either never or but rarely seen; the freezing of the river Thames is a novelty; but the frost in every winter is something new when it first comes.

Modern is applied to that which is new, or springs up in the day or age in which we live; as modern books, modern writers, modern science; a book is new which is just formed into a book and has not been used; it is modern at the time when it is first published; so likewise principles are new which have never been broached before; they are modern if they have been published lately or within a given period: the modern is opposed to the ancient.

Fresh is said of that which may lose its color, vigor, or other perfection; as a fresh flower, the freshness of youth, ete.

So pleasures or passions are fresh which have not lost their power by satiety; they are new if they have but just sprung into activity.

Recent is applied to those events or circumstances which have just happened, as a recent transaction, or an occurrence of recent date.

News, Tidings.-News implies anything new that is related or circulated; tidings, in its Anglo-Saxon form, meant simply anything that happened; but it aequired the Scandinavian sense of news, especially news that arrived in due time and season, that is timely. News is unexpected; it serves to gratify idle curiosity: tidings are expected; they serve to allay anxiety. In time of war the public are eager for news; and they who have relatives in the army are anxious to have tidings of them.

NICE. See Exact; Fine.

NIGGARDLY. See AVARICIOUS; ECONOMICAL.

NIGH. See Crose.

NIGHTLY, Nocturnal. Nightly, immediately from the word night, and nocturnal, from nox, night, signify belonging to the night, or the night season; the former is therefore more familiar than the latter: we speak of nightly depredations to express what passes every night, or nightly disturbances, nocturnal dreams, nocturnal visits.

NIHILIST. See Intransigent.

NIMBLE. See Active.

NINNY, NincoMPOOP. These are slang or colloquial terms meaning a simpleton, and are not clearly distinguished from one another. Ninny comes probably from Italian ninna, a lullaby to put a child to sleep, based on ninno, child. The origin of nincompoop is supposed to be due to a vitiation of the Latin phrase non compos mentis. These words have been in the English language for centuries, but are so little differentiated from one another that it would be pedantry to make a distinction. Possibly ninny suggests more of silliness; nincompoop more of obtuseness, dulness.

NIP, Bite, Pincil. A nip is something between a bile and a pinch. In biting the substance taken between the teeth is eut; in pinching, which usually refers to a pressure upon a substance eaught between two fingers or an instrument acting like the two fingers, it is simply bruised. To nip is to give a sharp, quick pinch.

NOBLE, GraNd. Noble, in Latin nobilis, from nosco, to know, signifying knowable, or worth knowing, is a term of general import; it simply implies the quality by which a thing is distinguished for excellence above other 
things: the grand (see Grandeur) is, properly speaking, one of those qualities by which an object acquires the name of noble; but there are many noble objects which are not denominated grand. A building may be denominated noble for its beauty as well as its size; but a grand building is rather so called for the expense which is displayed upon it in the style of building. A family may be either noble or grand; but it is noble by birth; it is grand by wealth and an expensive style of living. Nobleness of acting or thinking comprehends all moral excellence that rises to a high pitch; but grandeur of mind is peculiarly applicable to such actions or traits as denote an elevation of character, rising above all that is common.

NOCTURNAL. See NightLY.

NOISE, CRY, OUTCRY, Clamor. Noise is any loud sound; cry, outcry, and clamor are particular kinds of noises, differing either in the cause or the nature of the sounds. A noise proceeds either from animate or inanimate objects; the cry proceeds only from animate objects. The report of a cannon and the loud sounds occasioned by a high wind are noises, but not cries; cries issue from birds, beasts, and men. A noise is produced often by accident; a cry is always occasioned by some particular circumstance: when many horses and carriages are going together they make a great noise; hunger and pain cause cries to proceed both from animals and human beings. Noise, when compared with cry, is sometimes only an audible sound; the cry is a very loud noise; whatever disturbs silence, as the proverbial falling of a pin in a perfectly still assembly, is denominated a noise; but a cry is that which may often drown other noises, as the cries of people selling things about the streets.

A cry is in general a definite sound, but outcry and clamor are irregular sounds; the former may proceed from one or many, the latter from many in conjunction. A cry after a thief becomes an outcry when set up by many at a time; it becomes a clamor if accompanied with shouting, bawling, and noises of a mixed and tumultuous nature.
These terms may all be taken in an improper as well as a proper sense. Whatever is obtruded upon the public notice, so as to become the universal subject of conversation and writing, is said colloquially to make a noise; in this manner a new and good performer at the theatre makes a noise on his first appearance.

A noise may be either for or against; but a cry, outcry, and clamor are always against the object, varying in the degree and manner in which they display themselves: cry implies less than outcry, and this less than clamor. When the public voice is raised in an audible manner against any particular matter it is a cry; if it be mingled with intemperate language it is an outcry; if it be vehement and exceedingly noisy it is a clamor: partisans raise a cry in order to form a body in their favor; the discontented are ever ready to set up an outcry against men in power; a clamor for peace in time of war is easily raised by those who wish to thwart the government.

NOISOME. See HuRTFul.

NOISY. See IJOUD.

NOMENCLATURE. See DictionARY.

NOMINATE, Name. Nominate comes from Latin nomen, name; name (see NAME). To nominate and to name are both to mention by name; but the former is to mention for a specific purpose; the latter is to mention for a general purpose: persons only are nominated; things as well as persons are named: one nominates a person in order to propose him, or appoint him, to an office; but one names a person casually, in the course of conversation, or one names him in order to make some inquiry respecting him. To be nominated is a public act; to be named is generally private: one is nominated before an assembly; one is named in any place: to be nominated is always an honor; to be named is either honorable or the contrary, according to the circumstances under which it is mentioned: a person is nominated for an office; he is named whenever he is spoken of.

NON-CONFORMIST. See HerETIC.

NON-PUTREFYING. See ASEPTIr 
NONSENSE. See Twaddle.

NORMAL, TYPICAL. Normal and typical are both words which are commonly misused. They are taken to mean average, ordinary, whereas they really mean the reverse. The normal person is one that conforms to the norm, Latin norma, a carpenter's rule; that is to say, to the standard of humanity in any or all respects. This standard, however, is not obtained by taking the average of all people. As is shown by the medical standard in accordance with which the candidates for the army are tested, only one in four or five men corresponds sufficiently to the standard. Normal indicates what people would be if their development were not in any way hindered. Typical, from Greek rúmos, a mark, blow, stamp, has the same meaning as normal, with a slight difference of connotation in ordinary usage. A typical man is one who represents the standard to which others approximate more or less. The typical American is not the average or ordinary American. $\mathrm{He}$ is the one who represents the distinctive characteristics of Americans in their most characteristic form. Normal is generally used with reference to a particular standard-a standard of health, for instance. Typical is used with reference to distinguishing characteristics. A normal physique, for instance, is one that corresponds to the general standard, one that every one ought to have. A typical soldier's physique is one that represents the characteristics of the soldier unmodified by other influcnces.

NOTE. See MArk.

NOTED. Notorious. Noted (see Distinguished) may be employed either in a good or a bad sense; notorious is never used but in a bad sense: men may be noted for their talents or their eccentricities; they are notorious for their vices: noted characters excite many and divers remarks from their friends and their enemies; notorious characters are universally shunned.

NOTHING. See Zero.

NOTICE, Remark, Observe. To notice (see ATTEND) is either to take or to give notice: to remark, compounded of $r e$ and mark (see MARK), signifies to reflect or bring back any mark to our own mind, or communicate the same to another; to mark is to mark a thing once, but to remark is to mark it again. Observe (see LoOKER-ON) signifies either to keep a thing present before one's own view or to communicate one's view to another.

In the first sense of these words, as the action concerns ourselves, to notice and remark require simple attention, to observe requires examination. To notice is a more cursory action than to remark: we may notice a thing by a single glance, or on merely turning our head; but to remark supposes a reaction of the mind on an object; we notice a person passing at any time; but we remark that he goes past every day at the same hour: we notice that the sun sets this evening under a cloud, and we remark that it has done so for several evenings successively: we notice the state of a person's health or his manners in company; we remark his habits and peculiarities in domestic life. What is noticed and remarked strikes on the senses and awakens the mind; what is observed is looked after and sought for: the former are often involuntary acts; we see, hear, and think because the objects obtrude themselves uncalled for; but the latter is intentional as well as voluntary; we see, hear, and think of that which we have watched. We remark things as matters of fact; we observe them in order to judge of them or draw conclusions from them: wc remark that the wind lies for a long time in a certain quarter; we observe that whenever it lies in a certain quarter it brings rain with it. People who have no particular curiosity may be sometimes attracted to notice the stars or planets when they are particularly bright; those who look frequently will remark that the same star does not rise exactly in the same place for two successive nights; but the astronomer goes further and observes all the motions of the heavenly bodies, in order to discover the scheme of the universe.

In the latter sense of these words, as concerns the communications to others of what passes in our own minds, to notice is to make known our sentiments by various ways; to remark and observe are to make them known only by means of words: to notice is a personal act 
toward an individual, in which we direct our attention to him, as may happen either by a bow, a nod, a word, or even a look; but to remark and observe are said only of the thoughts which pass in our own minds and are expressed to others: friends notice each other when they meet; they remark to others the impression which passing objects make upon their minds: the observations which intelligent people make are always entitled to notice from young persons.

See also Information; Mention.

NOTION. See Conception; OpINion; Perception.

NOTORIOUS. See Noted; Public.

NOTWITHSTANDING. See HowEVER.

NOURISH, Nurture, Cherish. To nourish and nurture are but variations from the same verb nutrio. Cherish (see Foster). Things nourish, persons nurture and cherish: to nourish is to build up bodily strength to supply the physical necessities of the body; to nurture is to extend one's care to the supply of all its physical necessities, to preserve life, occasion growth, and increase vigor: the breast of the mother nourishes; the fostering care and attention of the mother nurtures. To nurture is a physical act; to cherish is a mental as well as a physical act: a mother nurtures her infant while it is entirely dependent upon her; she cherishes her child in her bosom and protects it from every misfortune, or affords consolation in the midst of all its troubles when it is no longer an infant.

NOVEL. See Fable; New.

NOVICE. See Tyro.

NOW, ImMEdiately, Straightway.
Now is the general term, meaning at this present moment. Immediately suggests more of emphasis and action. It means in the moment following a given moment. Now is static; immediately suggests action, movement. Straightway has the same meaning as immediately, but a slightly different connotation. It is a somewhat archaic word associated with Biblical phraseology, and suggestive of poetry or a distinctly literary style.

NOXIOUS. See HuRTrul.

NUMB, BenUMBed, TorPID. Numb and benumbed come from the past participle of Anglo-Saxon niman, Middle English nomen, to take, and signify overtaken, hence overpowered, unable to move. There are but few things numb by nature, but there may be many things which may be benumbed. Torpid, in Latin torpidus, from torpere, to languish, is most commonly employed to express the permanent state of being benumbed, as in the case of some animals, which lie in a torpid state all the winter; or, in the moral sense, to depict the benumbed state of the thinking faculty; in this manner we speak of the torpor of persons who are benumbed by any strong affection or by any strong external action.

NUMBER. See RECKON.

NUMERAL, NUMERICAL. Numeral, or belonging to number, is applied to a class of words in grammar, as a numeral adjective or a numeral noun: numerical, or containing number, is applied to whatever may concern number; as a numerical difference, where the difference consists between any two numbers or is expressed by numbers.

NUPTIALS. See Marriage. NURTURE. See NoURISH. 


\section{0}

OBEDIENT, SUbMissive, ObseQuIOUS. Obedient (see Dutiful). Submissive denotes the disposition to submit (see YIELD). Obsequious, in Latin obsequius, from obsequor, or the intensive of $o b$, near, and sequi, to follow, signifies following diligently and with a fixed intention to please.

One is obedient to command, submissive to power or the will, obsequious to persons. Obedience is always taken in a good sense; one ought always to be obedient where obedience is due: submission is relatively good; it may, however, be indifferent or bad: one may be submissive from interested motives or meanness of spirit, which is a base kind of submission; but to be submissive for conscience' sake, is the bounden duty of a Christian: obsequiousness is never good; it is an excessive concern about the will of another which has always interest for its end. Obedience is a course of conduct conformable either to some specific rule or the express will of another; submission is often a personal act immediately directed to the individual. We show our obedience to the law by avoiding the breach of it; we show our obedience to the will of God, or of our parent, by making that will the rule of our life: on the other hand, we show submission to the person of the magistrate; we adopt a submissive deportment by a downcast look and a bent body. Obedience is founded upon principle and cannot be feigned; submission is a partial bending to another, which is easily affected in our outward behavior: the understanding and the heart produce obedience; but force or the necessity of circumstances gives rise to submission.

Obedience and submission suppose a restraint on one's own will, in order to bring it into accordance with that of another; but obsequiousness is the consulting the will or pleasure of another: we are obedient from a sense of right; we are submissive from a sense of necessity; we are obsequious from a desire of gaining favor: a love of God is followed by obedience to His will; they are coincident sentiments that reciprocally act on each other so as to serve the cause of virtuc: a sub missive conduct is at the worst an involuntary sacrifice of our independence to our fears or necessities, the evil of which is confined principally to the individual who makes the sacrifice; obsequiousness is a voluntary sacrifice of ourselves to others for interested purposes.

OBJECT, Subject. Object, in Latin objectus, participle of obicere, to lie in the way, signifies the thing that lies in onc's way. Subject, in Latin subjectus, participle of subicere, to lie under, signifies the thing forming the groundwork.

The object puts itself forward; the subject is in the background: we notice the object; we observe or reflect on the subject: objects are sensible; the subject is altogether intellectual: the eye, the ear, and all the senses are occupied with the surrounding objects; the memory, the judgment, and the imagination are supplied with subjects suitable to the nature of the operations.

When object is taken for that which is intellectual, it retains a similar signification; it is the thing that presents itself to the mind; it is seen by the mind's eye: the subject, on the contrary, is that which must be sought for, and when found it engages the mental powers: hence we say an objeet of consideration, an object of delight, an object of concern; a subject of reflection, a subject of mature deliberation, the subject of a poem, the subject of grief, of lamentation, and the like. When the mind becomes distracted by too great a multiplicity of objects, it can fix itself on no one individual object with sufficient steadiness to take a survey of it; in like manner, if a child have too many objects set before it for the exercise of its powers, it will acquire a familiarity with none: such things are not fit subjects of discussion. See also Aim; Find Fault. 
Object, Oppose.-To object is to cast in the way, to oppose, from French opposer (Latin ob, against, and Late Latin pausare, to place, formed on Greck $\pi \alpha$ á the way; there is, therefore, very little original difference, except that casting is a more momentary and sudden proceeding, placing is a more premeditated action; which distinction, at the same time, corresponds with the use of the terms in ordinary life: to object to a thing is to propose or start something against it; but to oppose it is to set one's self steadily against it: one $o b$ jects to ordinary matters that require no reflection; one opposes matters that call for deliberation and afford serious reasons for and against: a parent $o b$ jects to his child's learning the classics or to his running about the streets; he opposes his marriage when he thinks the connection or the circumstances not desirable.

Objection, Difficulty, Exception.-Objection (see DEMur) is here a general term; it comprehends both the difficulty and the exception, which are but species of the objection: an objection and a difficulty are started; an exception is made: the objection to a thing is in general that which renders it less desirable; but the difficulty is that which renders it less practicable; there is an objection against every scheme which incurs a serious risk: the want of means to begin or resources to carry on a scheme is a serious difficulty.

Objection and exception both concern the nature, the moral tendency, or moral conser uerce of a thing; but an objection miy be frivolous or serious; an exception is something serious: the objection is positive; the exception is relatively considered, that is, the thing excepted from other things, as not good, and consequently objected to. Objections are made sometimes to proposals for the mere sake of getting rid of an engagement: those who do not wish to give themselves trouble find an easy method of disengaging themselves, by making objections to every proposition. We take exception at the conduct of others when we think it not sufficiently respectful.

OBJECTIVE, ACTUAL. Objective signifies outside of consciousness, be- longing to that which is presented to consciousness, as opposed to consciousness itself. Actual, based on actus, past participle of Latin agere, to do or act, signifies really existing as distinguished from an idea in the mind-that which is as compared with what we should like to have it. According to these definitions, the two terms seem to have the same meaning, but objective is much more limited in its application than actual. That which is objective is simply outside of ourselves; that which is actual is that which really exists. Though, in one sense, actual implies that contrast between the thing beheld and the mind beholding indicated in objective, that which is within the mind may also be thought of as actual. We speak of "my actual thought," "my actual feeling" -implying a contrast between reality and unreality within the mind itself. Again that which is objective is not necessarily actual or really existent-as a whole school of philosophers have pointed out. In common speech actual is a word of frequent and various uses; objective is a rather special and scientific term.

OBLATION. . See Offering.

OBLIGATION. See DUTY.

OBLIGE. See Bind; Compel.

OBLIGED. See INDEBTED.

OBLIGING. See Civil.

OBLITERATE. See BLot.

OBLIVION. See ForgetFulness.

OBLONG, Oval. Oblong, in Latin oblongus, from the intensive syllable $o b$, across, or over, signifies very long, longer than it is broad. Oval, from the Latin ovum, an egg, signifies eggshaped. The oval is a species of the oblong: what is oval is oblong; but what is oblong is not always oval. $O b-$ long is peculiarly applied to figures formed by right lines, that is, all rectangular parallelograms, except squares, are oblong; but the oval is applied to curvilinear oblong figures, as ellipses, which are distinguished from the circle: tables are oftener oblong than oval; garden beds are as frequently oval as they are oblong.

OBLOQUY. See REPRoACH.

OBNOXIOUS, OFFENSIVE. Obmoxious, from $o b$, against, or in the way of, and noxious, signifies either being in the way of what is noxious or being 
very noxious or hateful. Offensive, from $o b$, against, and a stem fend, meaning to dash, signifies apt to give offerce or displeasure. The obnoxious conveys more than the offensive, implying (though this use is now obsolete) to receive as well as to give offence; a man may be obnoxious to evils as well as obnoxious to persons.

In the sense of giving offence, obnoxious implies as much as hateful. offensive little more than displeasing: a man is obnoxious to a party to whose interests or principles he is opposed; he may be offensive to an individual merely on account of his manners or any particular actions. Men are $o b$ noxious only to their fellow-creatures, but they may be offensive, though not obnoxious, to their Maker.

Persons only are obnoxious to others, things as well as persons are offensive; dust is offensive to the eye; sounds are offensive to the ear; advice, or even one's own thoughts, may be offensive to the mind.

See also Subject.

OBSCURE. See DARK; EcliPse.

OBSEQUIES. See Funeral.

OBSEQUIOUS. See OBEDIENT.

OBSERVANCE. See Form; Ob-

SERVATION.

OBSERVANT. See MindFul.

OBSERVATION, OBSERVANCE. These terms derive their use from the different significations of the verb: $a b-$ servation is the act of observing objects with the view to examine them (see Notice): observance is the act of observing in the sense of keeping or holding sacred (see KeEp). From a minute observation of the human body, anatomists have discovered the circulation of the blood and the source of all the humors; by a strict observance of truth and justice a man acquires the title of an upright man.

See also Remark.

Observe, Watch. - Observe Goard). Watch (see Notice).

These terms agree in expressing the act of looking at an object; but to observe is not to look after so strictly as is implied by to watch; a general observes the motions of an enemy when they are in no particular state of activity; he watches the motions of an cnemy when they are in a state of commotion; we observe a thing in order to draw an inference from it: we watch anything in order to discover what may happen: we observe with coolness; we watch with eagerness: we observe carefully; we watch narrowly: the eonduct of mankind in general is observed; the conduct of suspicious individuals is watched.

See also Keep; Notice; See.

OBSERVER. See LOOKER-ON.

OBSOLETE. See OLD.

OBSTACLE. See DifFicultr.

OBSTINATE, Contumacious, STUBborn, Headstrong, Heady. Obstinate, in Latin obstinatus, participle of $o b s t i n o$, from $o b$ and the stem found in stare, to stand, signifies standing in the way of another. Contumacious (see Contumacy). Stubborn, Middle English stoburn, comes from Anglo-Saxon stybb, Modern English stub, and signified originally like a stick or stub remaining in the ground; hence not easily moved. Headstrong signifies strong in the head or the mind; and heady, inclined, so to speak, to follow one's own head.

Obstinacy is a habit of the mind; contumacy is either a particular state of feeling or a mode of action; $a b-$ stinacy consists in an attachment to one's own mode of acting; contumacy consists in contempt of others: the obstinate man adheres tenaciously to his own ways, and opposes reason to reason; the contumacious man disputes the right of another to control his actions, and opposes force to force. Obstinacy interferes with a man's private conduct and makes him blind to reason; contumacy is an offence against lawful authority; the contumacious man sets himself against his superiors: when young people are obstinate they are recalcitrant to education; when grown people are contumacious they are troublesome subjects to the king.

The stubborn and the headstrong are species of the obstinate: the former lies altogether in the perversion of the will; the latter in the perversion of the judgment: the stubborn person wills what he wills; the headstrong person thinks what he thinks. Stubbornness is mostly inherent in a person's nature; a headstrong temper is commonly associated with violence and impetuosity 
of character. Obstinacy discovers itself in persons of all ages and stations; a stubborn and headstrong disposition betrays itself mostly in those who are expected to conform to the will of another. Heady may be said of any who are full of conceit and bent upon following their own desires.

OBSTRUCT. See HINDER.

OBTAIN. See Acquire; Get.

OBTRUDE. See INTRUDE.

OBTUSE, Blunt, Dull. All these words have the same original meaning; they are all opposed to sharp. Obtuse is the opposite of the sharp point of an angle of less than forty-five degrees; blunt (of unknown origin) is the opposite of a sharp point; dull is the opposite of a sharp edge, such as the blade of a knife. Dull and obtuse are also given a mental application (see DULL), obtuse referring to particular cases of dulness, not to the general character indicated by dull. Blunt has a moral application, referring to the manners and disposition of one who is not finely responsive or adaptable to the feelings and conditions of those around him, who offends by rude telling of unsavory truth, etc.

obviate. See Prevent.

OBVIOUS. See ApParent; TANGIBLE.

OCCASION, OpPoRTUNITY. Occasion, in Latin occasio, from obcasio, from $o b$, in the way of, and cadere, to fall, signifies that which falls in the way so as to produce some change. $O p$ portunity, in Latin opportunitas, from opportunus (ob, near, and portus, harbor), signifies near the harbor or in accordance with the desires or needs.

These terms are applied to the events of life; but the occasion is that which determines our conduct and leaves us no choice; it amounts to a degree of necessity: the opportunity is that which invites to action; it tempts us to embrace the moment for taking the step. We do things, therefore, as the occasion requires, or as the opportunity offers. There are many occasions on which a man is called upon to uphold his opinions. There are but few opportunities for men in general to distinguish themselves.

Occasion, Necessity. - Occasion includes, necessity excludes, the idea of choice or alternative. We are regulated by the occasion, and can exercise our own discretion; we yield or submit to the necessity, without even the exercise of the will. On the death of a relative we have occasion to go into mourning if we do not wish to offer an affront to the family; but there is no express necessity: in case of an attack on our persons there is a necessity of self-defence for the preservation of life.

Occasional, Casual.-These are both opposed to what is fixed or stated; but occasional carries with it more the idea of infrequency, and casual that of unfixedness, or the absence of all design. A minister is termed an occasional preacher who preaches only on certain occasions; his preaching at a particular place or on a certain day may be casual. Our acts of charity may be occasional, but they ought not to be casual.

\section{OCCULT. See Secret.}

OCCUPANCY, OCcUPATION. These words derive their meaning from the different acceptations of the primitive verb occupy, the former being used to express the state of holding or possessing any object, the latter to express the act of taking possession of, or the state of being in possession. He who has the occupancy of land enjoys the fruits of it: the occupation of a country by force of arms is of little avail unless one has an adequate force to maintain one's ground. Both words are employed in regard to houses and lands, but when the term occupation is taken in the sense of a business it is sufficiently distinguished to need no illustration.

See also Business.

OCCUPY. See Houd.

OCCUR. See Transpire.

OCCURRENCE. See Event.

ODD, Uneven. Odd, in Swedish $u d d a$, connected with the Dutch oed, and German oede, empty, deserted, signifying something wanted to match, scems to be a mode of the uneven; both are opposed to the even, but odd is said only of that which has no fellow; the uneven is said of that which does not square or come to an even point: of numbers we say that they are either odd or uneven; but of gloves, shoes, 
and everything which is made to correspond we say that they are odd when they are single; but that they are uneven when they are both different: in like manner, a plank is uneven which has an unequal surface or disproportionate dimensions; but a piece of wood is odd which will not match or suit with any other piece.

See also Particular.

ODIOUS. See Hateful.

ODOR. Sce SMELl.

OFFENCE, Trespass, Transgression, Mrsdemeanor, Misdeed, AfFRONT. Offence is here the general term, signifying merely the act that offends (see DrSPLEASE) or runs counter to something else.

Offence is properly indefinite; it merely implies an object without the least suggestion of the nature of the object; trespass and transgression have a positive reference to an object trespassed upon or transgressed; trespass is contracted from trans and pass (from Latin passus, step), that is, a stepping beyond; and transgress, from trans and gressus (participle of gredi), a going beyond. The offence, therefore, which constitutes a trespass arises out of the laws of property; a passing over or treading upon the property of another is a trespass: the offence which constitutes a transgression derives from the laws of society in general, which fix the boundaries of right and wrong: whoever, therefore, goes beyond or breaks through these bounds is guilty of a transgression. The trespass is a species of offence which peculiarly applies to the land or premises of individuals; transgression is a species of moral as well as political evil. Hunters are apt to commit trespass in the eagerness of their pursuit; the passions of men are perpetually misleading them and causing them to commit various transgressions; the term trespass is sometimes employed improperly as regards time and other objects; transgression is always used in one uniform sense as regards rule and law; we trespass upon the time or patience of another; we transgress the moral or civil law.

An offence is either public or private; a misdemeanor, the negative of demeanor, is a coined word from French $d e$, Latin $d e$, intensive, and French mener, to conduct-ultimately from Late Latin minare, to drive cattle, from minari, to threaten-so that the word meant successively to drive with threats, to lead or conduct, to conduct one's self, and hence came to refer to manners and action. Misdemeanor is properly a private offence, although improperly applied for an offence against public law, for it signifies a wrong demeanor or an offence in one's demeanor against propriety; a misdeed is always private, it signifies a wrong deed, or a deed which offends against one's duty. Riolous and disorderly behavior in company are serious misdemeanors; cvery act of drunkenness, lying, fraud, or immorality of every kind, is a misdeed.

An offence is that which affects persons or principles, communities or individuals, and is committed cither directly or indirectly against the person; an affront (from ad, to, and frontem, brow) is altogether personal, and is made directly in the presence of the person affronted; it is an offence against another to speak disrespeetfully of him in his absence; it is an affront to push past him with violence and rudeness. In this sense, whatever offence is committed against our Maker is properly an affront; and whatever offends Him indirectly may also be denominated an affront, as far as His will is opposed and His laws violater.

Offender, Delinquent.-The offender is he who offends in anything, either by commission or omission; the delinquent (from delinquere, to fail) signifies properly he who fails by omission, but it is extended to signify failing by the violation of a law. Those who go into a wrong place are offenders; those who stay away when they ought to go are delinquents: there are many offenders against the Sabbath who commit violent and open brenches of decorum; there are still more delinquents who never attend a public place of worship.

Offending, Offensive.-Offending signifies either actually offending or calculated to offend; offensive signifies ealculated to offend at all times; a person may be offending in his manners to a particular individual, or use an offending expression on a particular occasion 
without any imputation on his character; but if his manners are offensive, it reflects both on his temper and education.

See also ObNoxious; Umbrage.

OFFER, BID, Tender, Propose. Offer (see Give) is employed for that which is literally transferable, or for that which is indirectly communicable: bid (see Ask) and tender, like the word tend, from tendere, to stretch, signifying to stretch forth by way of offering, belong to offer in the first sense. Propose, from French proposer, Latin pro, before, and French poser, to place (from Late Latin pausare, Greek $\pi a \bar{v} \sigma \iota s, n o t$ from Latin ponere), to place or set before, likewise characterizes a mode of offering, and belongs to offer in the latter sense. To offer is a voluntary and discretionary act; an offer may be accepted or rejected at pleasure; to bid and tender are specific modes of offering which depend on circumstances: one bids with the hope that one's offer will be accepted; one tenders from a prudential motive and in order to serve specific purposes. We offer money to a poor person as an act of charity or good-nature; we bid a price for the purchase of a house, as a commercial dealing subject to the rules of commerce; we tender a sum of money by way of payment, as a matter of discretion in order to fulfil an obligation. By the same rule one offers a person the use of one's horse; one bids a sum at an auction; one tenders one's services to the government.

To offer and propose are both employed in matters of practice or speculation; but the former is a less definite and decisive act than the latter; we offer an opinion by way of promoting a discussion; we propose a plan for the deliberation of others. Sentiments which differ widely from the major part of those present ought to be offered with modesty and caution; we should not propose to another what we would be unwilling to do ourselves. We commonly offer by way of obliging; we commonly propose by way of arranging or accommodating. It is an act of puerility to offer to do more than one is enabled to perform; it does not evince a sincere disposition for peace to propose such terms as we know cannot be accepted.
Offering, Oblation. - Offering, from offer, and oblation, from oblatio and oblatus, come both from offero, the one from the infinitive, the other from the past participle. The former is, however, a term of much more general and familiar use than the latter. Offerings are both moral and religious; oblation is religious only; the money which is put into the sacramental plate is an offering; the consecrated bread and wine at the sacrament are an oblation. The offering in a religious sense is whatever one offers as a gift by way of reverence to a superior; the oblation is the offering which is accompanied with some particular ceremony. The wise men made an offering to our Saviour, but not properly an oblation; the Jewish sacrifices, as in general all religious sacrifices, were in the proper sense oblations.

OFF-HAND. See UNPREMEdITATED.

office, Place, Charge, FuncTION. Office, in Latin, officium, from officio, signifies either the duty performed or the situation in which the duty is performed. Place comprehends no idea of duty, for there may be sinecure places which are only nominal offices and designate merely a relationship with the government: every office, therefore, of a public nature is in reality a place, yet every place is not an office. The place of secretary of state is likewise an office, but that of ranger of a park is a place only, and not always an office. An office is held; a place is filled: the office is given or intrusted to a person; the place is granted or conferred: the office reposes a confidence and imposes a responsibility; the place gives credit and influence: the office is bestowed on a man from his qualification; the place is granted to him by favor or as a reward for past services; the office is more or less honorable; the place is more or less profitable.

In an extended application of the terms office and place, the latter has a much lower signification than that of the former, since the office is always connected with the state or is something responsible; but the place may be a place for menial labor: the offices are multiplied in time of war; the places for domestic service are more 
numerous in a state of peace and prosperity. The office is frequently taken not with any reference to the place occupied, but simply to the thing done; this brings it nearer in signification to the term charge (see CARE). An office imposes a task or some performance: a charge imposes a responsibility; we have always something to do in an office, always something to look after in a charge; the office is either public or private, the charge is always of a private and personal nature: a person performs the office of a magistrate or of a minister; he undertakes the charge of instructing youth or of being a guardian, or of conveying a person's property from one place to another.

The office is that which is assigned by another; function is properly the act of discharging or completing an office or business, from functus, participle of fungor, viz., finem and ago, to put an end to or bring to a conclusion; it is extended in its acceptation to the office itself or the thing done. In its strict sense, therefore, the office is performed only by conscious or intelligent agents who act according to their instructions; the function, on the other hand, is an operation either of unconscious or of conscious agents acting according to a given rule. The office of a herald is to proclaim public events or to communicate circumstances from one public body to another: a minister performs his functions, or the body performs its functions.

The word office is sometimes employed in the same application by the personification of nature, which assigns an office to the ear, to the tongue, to the eye, and the like. In this case the word office is applied to what is occasional or partial; function to that which is habitual and essential. When the frame becomes overpowered by a sudden shock, the tongue will frequently refuse to perform its office; when the animal functions are impeded for a length of time, the vital power ceases to exist.

See also Business.

OFFICIOUS. See Active.

OFFSPRING, ProgenY, Issue. Offspring is that which springs from; progeny, that which is brought forth or out of; issue, that which issues or proceeds from; all used in relation to the family or generation of the human species. Offspring is a familiar term applicable to one or many children; progeny is employed only as a collective noun for a number; issue is used in an indefinite manner without particular regard to number. When we speak of the children themselves we denominate them the offspring; when we speak of the parents, we denominate the children their progeny. A child is said to be the only offspring of his parents, or he is said to be the offspring of low parents; a man is said to have a numerous or a healthy progeny, or to leave his progeny in cireumstances of honor and prosperity. The issue is said only in regard to a man that is deceased: he dies with male or female issue, with or without issue; his property descends to his male issue in a direct line.

OFTEN, FREQUENTLY. Often, or its contracted form oft, is an English word of unknown origin. Frequently, from Latin frequens, crowded or numerous. signifies a plurality or number of objects.

An ignorant man oflen uses a word without knowing what it means; ignorant people frequenlly mistake the meaning of the words they hear. A person goes out very often in the course of a week; he has frequently six or seven persons to visit him in the course of that time. By doing a thing often it becomes habitual: we frequently meet the same persons in the route which we often take.

OLD, ANcient, ANtique, ANTIQUATED, OLD-FASIIONED, OBSOLETE. Old, in Anglo-Saxon eald, is perhaps from a root signifying to nourish, found in the word alma, fostering, in our phrase alma mater. Ancient, in French ancien, Late Latin antianus and antique, antiquated, all come from the Latin ante, before, signifying in general before our time. Old-fashioned signifies after an old fashion. Obsolete comes from the Latin verb obsolescere, to decay.

Old signifies what has long existed and still exists; ancient, what existed at a distant period, but does not necessarily exist at present; antique, that which has been long ancient, and of 
which there remain but faint traces; antiquated, old-fashioned, and obsolete, that which has ceased to be any longer used or esteemed. A fashion is old when it has been long in use; a custom is ancient when its use has long been past; a bust or statue is antique when the model of it only remains; a person looks antiquated whose dress and appearance are out of date; manners which have gone quite out of fashion are old-fashioned; a word or custom is obsolete which has grown out of use.

The old is opposed to the new; some things are the worse for being old, other things are the better. Ancient and antique are opposed to modern: all things are valued the more for being ancient or antique; hence we' esteem the writings of the ancients above those of the moderns. The antiquated is opposed to the customary and established; it is that which we cannot like, because we cannot esteem it: the old-fashioned is opposed to the fashionable: there is much in the old-fashioned to like and esteem; there is much that is ridiculous in the fashion: the obsolete is opposed to the current; the obsolete may be good; the current may be vulgar and mean.

See also ELDERLY.

OLDER. See Senior.

OLD TIMES. See Formerly.

Olio, Farrago, Hodge - PODGe. These are terms borrowed from various languages signifying a mixed food of some sort, and hence, figuratively, any jumble or mixture. They differ from each other in the exact character of the mixed dish indicated and in the frequency and extent of their use as figurative terms. Olio, a mistaken form for olia, is intended to represent Spanish olla, Latin olla, a round earthen pot or dish, and hence that which is frequently served in the dish-i.e., a mixture of different kinds of meat and vegetables. Farrago is a mixed food served to cattle. Hodge-podge is a corruption of hotch-pot, from French hocher, to shake, and pot (Anglo-Saxon pott). The Scotch form of hodge-podge, besides implying a mixture of various ingredients, means a thick broth of meat and vegetables. Of these three terms hodge-podge is the only one which has come into gencral colloquial use.
OMen, Prognostic, Presage. All these terms express some token or sign of what is to come. Omen, in Latin omen, prognostic, in Greek $\pi \rho \circ \gamma \nu \omega \sigma \tau<x^{\prime}$, from $\pi \rho o^{\prime}$, before, and

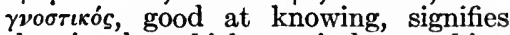
the sign by which one judges a thing beforehand, because a prognostic is rather a deduction by the use of the understanding. Presage (see Augur).

The omen and prognostic are both drawn from external objects; the presage is drawn from one's own feelings. The omen is drawn from objects that have no necessary connection with the thing they are made to represent; it is the fruit of the imagination and rests on superstition: the prognostic, on the contrary, is a sign which partakes in some degree of the quality of the thing denoted. Omens were drawn by the heathens from the flight of birds or the entrails of beasts-" Aves dant omina dira," Tibullus - and often from different incidents; thus Ulysses, when landed on his native island, prayed to Jupiter that he would give him a double sign by which he might know that he should be permitted to slay the suitors of his wife; and when he heard the thunder and saw a maiden supplicating the gods in the temple he took these for omens that he should immediately proceed to put in execution his designs. Prognostics are discovered only by an acquaintance with the objects in which they exist, as the prognostics of a mortal disease are known to none so well as the physician; the prognostics of a storm or tempest are best known to the mariner.

In an extended sense, the word omen is also applied to objects which serve as a sign, so as to enable a person to draw a rational inference, which brings it nearer in sense to the prognostic and presage; but the omen may be said of that which is either good or bad; the prognostic and presage, when it expresses a sentiment, mostly of that which is unfavorable. It is an omen of our success if we find those of whom we have to ask a favor in a good humor; the spirit of discontent which pervades the countenances and discoursc of a people is a prognostic of some popular commotion. The imagination is often filled with strange presages. 
When presage is taken for the outward sign, it is understood favorably, or in an indifferent sense.

OMIT. See NEGLECT.

OMNIPRESENT. See UbIQUITOUS. OMNISCIENT, ALL - KNOWING, All-seeing, All-wise, Infallible. Omniscient, a Latin eompound of omnis, all, and sciens, knowing, from scio, to know, in French omniscient, Spanish omnisciente, is the adjective form of omniscience, one of three attributes of God, the others being omnipresence, everywhere, and omnipotence, infinite power: it signifies universal, unbounded, infinite knowledge and infinite wisdom. In the application of the terms to God, the only proper one, all-wise, implies the quality we accord Him of possessing all the wisdom that has ever existed or ever can exist; all-knowing, the quality of possession of the fullest possible knowledge of all things; all-seeing, literally, the quality of seeing every person and thing; as a substantive, the Being who alone can see all persons and things-God; and infallible, the quality of being supremely perfect, incapable of erring or failing in anything, of being at all times and under all conditions certain, sure, and indisputable.

See also INFALlible.

ON, UPon. There is now little difference between these two words; euphony and rhythm generally determine the ehoice between them on the part of a good writer. Upon is preferred when motion into position is indicated, as in the sentence "Place the book upon the table"; on is preferred when merely rest or support is to be indieated, as in the sentence, "The book is on the table."

ONCE, Erst, Formerly. Once, from Anglo-Saxon an, one, means literally at one time, referring to a particular time in the past. Erst is the superlative corresponding to the preposition and conjunetion ere, AngloSaxon $a r$, before, and also means at a time before this. It is now used only in poetry or in poetic prose. Formerly is from the comparative form answering to erst. It means before this time. It differs from once in emphasizing not the one time in the past, but the relation of that time to the present.
ONE, Single, ONly. Unity is the common idea of all these terms; and at the same time the whole signification of one, which is opposed to none; single, in Latin singulus, each or one by itself, probably contraeted from sine angulo, without an angle, because what is entirely by itself cannot form an angle, signifies that one which is abstracted from others, and is particularly opposed to two, or a double which may form a pair; only, contracted from Anglo-Saxon an-lic, literally onclike, signifying in the form of unity, is employed for that of which there is no more. A person has one child is a positive expression that bespeaks its own meaning: a person has a single child conveys the idea that there ought to be or might be more, that more were expected, or that once there were more: a person has an only child implies that he never had more.

See also Solitary.

ONSET. See ATTACK.

ONWARD, Forward, Progressive. Onward is taken in the literal sense of going nearer to an object: forward is taken in the sense of going from an object, or going farther in the line before one: progressive, from pro, forward, and gressus, past participle of grede, itself from gradus, a step, has the sense of going gradually, or step by step, before one. A person goes onward who does not stand still; he goes forward who does not reeede; he goes progressively who goes forward at certain intervals. Onward is taken only in the proper aeceptation of travelling; the traveller who has lost his way feels it necessary to go onward with the hope of arriving at some point; forward is employed in the improper as well as the proper application; a traveller goes forvard in order to reach his point of destination as quickly as possible; a learner uses his utmost endeavors in order to get forward in his learning: progressively is employed only in the improper applieation to what requires time and labor in order to bring it to a conclusion; every man goes on progressively in his art, until he arrives at the point of perfection attainable by him.

opalescent. See Nacreous.

OPAQUE, DArK. Opaque, in Latin 
opacus, corresponds in meaning to the native English dark (Anglo-Saxon deorc); the word opaque is to dark as the species to the genus, for it expresses that species of darkness which is inherent in solid bodies, in distinction from those which emit light from themselves or admit of light into themselves; it is therefore employed scientifically for the more vulgar and familiar term dark. On this ground the earth is termed an opaque body in distinction from the sun, moon, and other luminous bodies: any solid substance, as a tree or a stone, is an opaque body, in distinction from glass, which is a clear or transparent body.

OPEN. See Candid; Frank; PubLiC; TANGIBle.

OPENING, APERTURe, Cavity. Opening signifies in general any place left open without defining any circumstances; the aperture is generally a specific kind of opening which is considered scientifically: there are openings in a wood when the trees are partly cut away; openings in streets by the removal of houses; or openings in a fence that has been broken down; but anatomists speak of apertures in the skull or in the heart, and the naturalist describes the apertures in the nests of bees, ants, beavers, and the like; the opening or aperture is the commencement of an enclosure; the cavity is the whole enclosure: hence they are frequently as a part to the whole: many animals make a cavity in the earth for their nests, with only a small aperture for their egress and ingress.

OPERATE. See ACT.

OPINIONATED, Opinionative, Conceited, Egotistical. A fondness for one's opinion bespeaks the opinionated man: a fond conceit of one's self bespeaks the conceited man: a fond attachment to himself bespeaks the egotistical man: a liking for one's self or one's own is evidently the common idea that runs through these terms; they differ in the mode and in the object.

Ad opinionated pew is not only fond of hits own opinion, but full of its own opinion; be has an opinion on everything. which is the best possible opinion, and is therefore delivered freely to every one, that they may profit in forming their own opinions. A conceited man has a conceit or a fond opinion of his own talent; it is not only high in comparison with others, but it is so high as to be set above others. The conceited man does not want to follow the ordinary means of acquiring knowledge: his conceit suggests to him that his talent will supply labor, application, reading, and study, and every other contrivance which men have commonly employed for their improvement; he sees by intuition what another learns by experience and observation; he knows in a day what others want years to acquire; he learns of himself what others are contented to get by means of instruction. The egotistical man makes himself the darling theme of his own contemplation; he admires and loves himself to that degree that he can talk and think of nothing else; his children, his house, his garden, his rooms, and the like, are the incessant theme of his conversation, and become invaluable from the mere circumstance of belonging to him. An opinionated man is the most unfit for conversation, which affords pleasure only by an alternate and equable communication of sentiment. A conceited pî́n is the most unfit for co-operation, where a junction of talent and effort is essential to bring things to a conclusion; an egotistical is the most unfit to be a companion or friend, for 4oes not know how tefvalue or like anything out of himself. U, own suy,

Opinion, Sentiment, Notion.-Opinion, in Latin from opinor, think or judge, is the work of the head. Sentiment, from sentio, feel, is the work of the heart. Notion, in Latin notio, from nosco, to know, is a simple operation of the thinking faculty.

We form opinions, we have sentiments: we get notions. Opinions are formed on speculative matters; they are the result of reading, experience, and reflection: sentiments are entertained on matters of practice; they are the consequence of habits and circumstances: notions are gathered from sensible objects and arise out of the casualties of hearing and seeing. One forms opinions on religion as respects its doctrines; one has sentiments on 
religion as respects its practice and its precepts. The heathens formed opinions respecting the immortality of the soul, but they amounted to nothing more than opinions. Christians entertain sentiments of reverence toward God as their creator, and of dependence upon Him as their preserver.

Opinions are more liable to error than sentiments. The opinion of ten springs from the imagination, and in all cases is but an inference or deduction which falls short of certain knowledge: opinions, therefore, as individual opinions, may be false; sentiments, on the other hand, depend upon the moral constitution or habits; they may, therefore, be good or bad, according to the character or temper of the person. Notions are still more liable to error than either; they are the immatured decisions of the uninformed mind on the appearances of things. The difference of opinion among men on the most important questions of human life is a sufficient evidence that the mind of man is very easily led astray in matters of opinion: whatever difference of opinion there may be among Christians, there is but one sentiment of love and good-will among those who follow the example of Christ rather than their own passions: the notions of a Deity are so imperfect among savages in general that they secm to amount to little more than an indistinct idea of some superior invisible agent.

OPPONENT. See ENEMY.

OPPORTUNE, AUSPICIOUS, FAVORable, Seasonable, Timely. Opportune, the adjective form of opportunity, from the Latin opportunus, signifies that which is fit or convenient, either as to a time, place, or occasion. $A u$ spicious is a term applied only to things, and such as are casual or only indicative of good, those having promise of success or happiness, that are propitious, the term being derived from auspicium, an augury from birds, from avis, a bird, and specere, to inspect, hence, omens of success.

Favorable implies a condition that is propitious, advantageous, friendly, one that is wholly acceptable, as a favorable reply, a favorable day or time; seasonable (from Late Latin satio, a sowing, from satus, past participle of serere, to sow, signifying the right time for sowing the seed), that which occurs or is done in a good or proper time, and so is specially welcome, that which belongs to a particular period of time, a benefit received in the time of need, in the nick of time; and timely, that which comes to pass at the right time, when most needed, when expected or promised. Differences between the terms seasonable and timely are critically considered in the article on TIMELY.

OPPORTUNITY. See Occasion.

OPPOSE, RESIST, WithSTAND, Thwart. The action of setting one thing up against another is obviously expressed by all these terms, but they differ in the manner and the circumstances. To oppose (see Contradict) is the most general and unqualified term; it simply denotes the relative position of two objects, and when applied to persons it does not necessarily imply any personal characteristic: we may oppose reason or force to force; or things may be opposed to each other which are in an opposite direction, as a house to a church. Resist, signifying, literally, to stand back, away' from, or against, is always an act of more or less force when applied to persons; it is mostly a culpable action, as when men resist lawful authority; resistance is, in fact, always bad, unless in case of actual self-defence. Opposition may be made in any form, as when we oppose a person's admittance into a house by our personal efforts: or oppose his admission into a socicty by a declaration of our opinions. Resistance is always a direct action, as when we resist an invading army by the sword, or resist the evidence of our senses by denying our assent; or, in relation to things, when wood or any hard substance resists the violent efforts of steel or iron to make an impression.

With in withstand has the force of against, $r e$ in resist the force of back, but stand corresponds to sist, from Latin sistere, to stand. Thwart is a Scandinavian word originally an adverb (compare athwart, meaning across), signifying across, in the contrary direction, and thence developing into a verb meaning to cross, to work against. These words are modes of resistance ap- 
plicable only to conscious agents. To withstand is negative; it implies not to yield to any foreign agency: thus, a person withstands the entreaties of another to comply with a request. To thwart is positive; it is actively to cross the will of another: thus humorsome people are perpetually thwarting the wishes of those with whom they are in connection. It is a happy thing when a young man can withstand the allurements of pleasure. It is a part of a Christian's duty to bear with patience the untoward events of life that thwart his purposes.

See also Combat; Овject.

OPPOSITE. See ADVERSE.

OPPROBRIUM. See INFAMT.

OPPUGN. See CoNfUTE.

OPTIMISTIC, CheERFU, SANGUINE. All these terms mean in general hopeful, inclined to look on the bright side of things, but they differ in the suggested source of the hopefulness. Optimistic expresses an intellectual attitude, cheerful a moral attitude, and sanguine a quality of temper having a physical basis. Optimistic comes from Latin optimus, best, and means seeing the best in everything. For cheerful see Cheer. Sanguine, from Latin sanguis, blood, meant originally full blooded, and describes the attitude to life of the full-blooded people, of abounding animal spirits, who find easy what is hard for others, and are self-confident and bold, being conscious of their own capacity to face life and make the best of a situation. Sanguine, being founded on a physical condition, indicates a hopefulness that is really less enduring and stable than that indicated in optimistic or cheerful.

OPTION, CHOICE. Option is immediately of Latin derivation (from optare, to wish), and is consequently a term of less frequent use than the word choice, for the derivation of which see Choose. The former term implies an uncontrolled act of the mind; the latter a simple leaning of the will. We speak of option only as regards one's freedom from external constraint in the act of choosing: one speaks of choice only as the simple act itself. The option or the power of choosing is given; the choice itself is made: hence we say a thing is at a person's option, or it is his own option, or the option is left to him, in order to designate his freedom of choice more strongly than is expressed by the word choice itself. OPULENCE. See Riches.

ORACULAR, AUTHORITATIVE, Dogmatical, Prophetic. Oracular, in Latin oracularis, from oraculum, an oracle, and that from oro, to speak, implied in its ancient sense that which related to an announcement from the gods in answer to some inquiry, a prophetic declaration, also to the places where such announcements were made, and to the deities making them. Such responses were closely allied to augury, but with this difference, that auguries could be taken anywhere, while the oracular places were defined and limited. From the common belief that the responses or answers were given by or through the influence of a certain divine afflatus, the people came to look upon them as authoritative, as proceeding from a source that could not be questioned, and, consequently, placed implicit confidence in them.

Now, in ordinary language, that is authoritative which proceeds from a source that has the power to act, command, determine, and this source may be beneficial to all under its jurisdiction. Authoritative, therefore, has in general a good significance. Dogmatical, from Greek jóy $\mu \alpha$ (English dogma), an opinion, indicates an attempt to be authoritative - to express opinions with a show and assumption of authority not recognized by others; it has in general a somewhat derogatory implication. These words are allied to oracular through the common idea of expressing a judgment with a show of authority.

Prophetic implies an occurrence foretold, predicted, or presaged, and here again we revert to the ancient oracles, as their chief announcements were declarations of what was about to happen and what the inquirers should and should not do. The prophets of Holy Writ were men divinely inspired, who frequently uttered predictions of coming events, both as warnings and encouragement to the people.

ORAL. See Verbal.

ORATION. See ADDRESS.

ORATORY. See ELOCUTION. 
ORB. See Circle.

ORDAIN. See APPoINT.

ORDER, Method, RULe. Order (see Dispose) is applied in general to everything that is disposed; method, in French méthode, Latin methodus, Greek $\mu \dot{\varepsilon} \theta 0 \delta \delta \delta$, from $\mu \varepsilon \tau \dot{\alpha}$ and $\dot{\delta} \delta o ́ s$, or a way after, signifying the ready or right way to do a thing; and rule, from Latin regula, a rule, and regere, to govern, direct, or make straight (the former expressing the act of making a thing straight or that by which it is made so, the latter the abstract quality of being so), are applied only to that which is done; the order lies in consulting the time, the place, and the object, so as to make them accord; the method consists in the right choice of means to an end; the rule consists in that which will keep us in the right way. Where there are a number of objects there must be order in the disposition of them; where there is work to carry on, or any object to obtain, or any art to follow, there must be method in the pursuit; a tradesman or merchant must have method in keeping his accounts; a teacher must have a method for the communication of instruction: the rule is the part of the method; it is that on which the method rests; there cannot be method without rule, but there may be rule without method; the method varies with the thing that is to be done; the rule is that which is permanent and serves as a guide under all circumstances. We adopt the method and follow the rule. A painter adopts a certain method of preparing his colors according to the rules laid down by his art.

Order is said of every complicated machine, either of a physical or a moral kind: the order of the universe, by which every part is made to harmonize with the other part, and all individually with the whole collectively is that which constitutes its principal beauty: as rational beings, we aim at introducing the same order into the moral scheme of society: order is, there fore, that which is founded upon the nature of things, and seems in its extensive sense to comprehend all the rest. Method is the work of the understanding, mostly as it is employed in the mechanical process; sometimes, however, as respects intellectual objects. Rule is said either of mechanical and physical actions or moral conduct. The term rule is, however, as before observed, employed distinetly from either order or method, for it applies to the moral conduct of the individual. The Christian religion contains rules for the guidance of our conduct in all the relations of human society.

As epithets, orderly, methodical, and regular are applied to persons and even to things according to the above distinction of the nouns: an orderly man, or an orderly society, is one who adheres to the established order of things; the former in his domestic habits, the latter in their public capacity, their social meetings, and their social measures. A methodical man is one who adopts method in all he sets about; such a one may sometimes run into the extreme of formality, by being precise where precision is not necessary: we cannot speak of a methodical society, for method is altogether a personal quality. A man is regular, inasmuch as he follows a certain rule in his moral actions, and thereby preserves a uniformity of conduct: a regular society is one founded by a certain preseribed rule. So we say, an orderly procecding, or an orderly course, for what is done in due order: a regular proceeding, or a regular course, which goes on according to a prescribed rule: a methodical grammar, a methodical delineation, and the like, for what is done according to a given method.

See also Appontr; Class; Conmand; Direction; Dispose; Place; Scccession.

ORDINANCE, DECREE, EDICT, LAw, Rule. Ordinance, in Old French ordenance, from the Latin ordo, erder, signifies a rule of action, an observance commanded, a religious rite or ceremony, a canon of the church, an enactment by a legislative body. Speeifically, the term means an orderly disposition or arrangement, hence, a rule, custom, rite, ceremony, or observance established by an authority having jurisdiction over whatever may be affected by its action. Sovereigns, high political bodies, and courts issue decrces, which are simply orders to produce specified results. 
The term edict (from Latin $e$ for $e x$, out, and dictum, participle of dicere, to speak, signifying a formal "speaking out," to be heard by many people) is also applied to rules and laws promulgated in the same manner as a decree, but with this difference: a decree (from Latin de, from, and cretum, past participle of cernere, to separate, meaning to separate truth from falsehood, good from bad, hence to judge) may be the award of an umpire, an arbitration, or a special authority designated to determine a question in controversy, and may be the subject of review by a higher authority, while an edict is the proclamation of that which takes on the form and force of a law, a mandate, a command.

A law emanates from a regularly constituted authority, and has a power behind it to insure its respect and observance, as a law or act of the United States Congress can be sustained, if necessary, by the entire army and navy of the country. The relation of the term law to other synonymous terms is discussed in the articles on LAwFuL and Maxim. A rule differs from the preceding terms in that it is a direction, a standard or guide; in law, an order by a court on a motion affecting parties to a suit, to regulate the practice of a court, or to establish a principle by a decision. This term is also further discussed in the article on ORDER.

ORDINARY. See CoMmoN.

ORGIES. See SATURNALIA.

ORIENT, EASTERN. Orient is the Latin term; eastern, the Anglo-Saxon word. The former comes from the present participle of the verb oriri, to rise, signifying the quarter where the sun rises. Eastern also signifies the quarter where the sun rises; it may be allied to the stem of the Iatin aurora, signifying the dawn. Orient differs from eastern in the poetic and imaginative connotations that it has acquired. Eastern is the literal term, signifying from the east as a quarter of the heavens or of the earth. Orient signifies characteristic of the eastsuggesting either the light and splendor of the sunrise or the rich lands of the east, whence came pearls and gold and spice and gorgeous fabrics in the old days.
ORIFICE, Perforation. Orifice, in Latin orificium or orifacium, from $o s$, mouth, and facere, to make, signifies a made mouth, that is, an opening made, as it were. Perforation, in Latin perforatio, from per, through, and forare, cognate with English bore, to pierce, signifies a piercing through.

These terms are both scientifically employed to designate certain cavities in the human body; but the former signifies that which is natural, the latter that which is artificial: all the vessels of the human body have their orifices, which are so constructed as to open or close of themselves. Surgeons are frequently obliged to make perforations into the bones: sometimes perforation may describe what comes from a natural process, but it denotes a cavity made through a solid substance; but the orifice is particularly applicable to such openings as most resemble the mouth in form and use. In this manner the words may be extended in their application to other bodies besides animal substances, and applied to other sciences besides anatomy: hence we speak of the orifice of a tube, the orifice of any flower, and the like; or the perforation of a tree by means of a cannon-ball or an iron instrument.

ORIGIN, ORIgINAL, Beginning, RISE, Source. Origin and original are both derived from the Latin oriri, to rise, the former designating the abstract property of rising, the latter the thing that is risen; the first of its kind from which others rise. Origin refers us to the cause as well as the period of beginning; original is said of those things which give an origin to another: the origin serves to date the existence of a thing; the term original serves to show the author of a thing, and is opposed to the copy. The origin of the world is described in the first chapter of Genesis; Adam was the original from whom all the human race has sprung.

Origin has regard to the cause, beginning simply to the period, of existence: everything owes its existence to the origin; it dates its existence from the beginning; there cannot be an origin without a beginning; but there may be a beginning where we do not 
speak of an origin. We look to the origin of a thing in order to learn its nature: we look to the beginning in order to learn its duration. When we have discovered the origin of a quarrel, we are in a fair way of becoming acquainted with the aggressors; when we trace a quarrel to the beginning, we may easily ascertain how long it has lasted.

Origin and rise are both employed for the primary state of existence, but the latter is a much more familiar term than the former: we speak of the origin of an empire, the origin of a family, the origin of a dispute, and the like; but we say that a river takes its rise from a certain mountain, that certain disorders take their rise from particular circumstances which happen in early life: it is, moreover, observable that the term origin is confined solely to the first commencement of a thing's existence; but rise comprehends its gradual progress in the first stages of its existence; the origin of the noblest families is in the first instance sometimes ignoble; the largest rivers take their rise in small streams. We look to the origin as to the cause of existence: we look to the rise as to the situation in which the thing commences to exist, or the process by which it grows up into existence.

The origin and rise are said of only one object; the source is said of that which produces a succession of objects: the origin of evil in general has given rise to much idle speculation; the love of pleasure is the source of incalculable mischief to individuals, as well as to society at large: the origin exists but once; the source is lasting: the origin of every family is to be traced to our first parent, Adam; we have a neverfailing source of consolation in religion.

See also First; Germ; Primary.

ORNATE, Adorned, Decorated, EMBEllished. For the distinction between adorned, decorated, and embellished see the article on ADORN where the verbs of which these are participles are critically discuss:d. Ornate differs from these words in intensity, and in not so distinctly suggesting the application of something external in order to beautify. That which is ornate is very much adorned, decorated, or em- bellished; ornate is, as it were in mean. ing, if not in form, the superlative of these words. Moreover, ornate sug. gests gorgeousness and elaborateness inherent in the very design or material, not simply applied from without.

ORNITHOPTER. See AIRCRAFT. ORTHODOX. See Evangelical. OSCILlate. See Wag.

OSCULATION. See Kiss.

OSTENSIBLE. See Colorable.

OSTENTATION. See Show.

OSTRACIZE. See Proscribe.

OUT, ABroAd, BEYOND. All of these terms signify external to something. Out, Anglo-Saxon $u t$, signifies external to something enclosed. We speak of being out of the house, out of the city; of taking valuables out of a chest, etc. Beyond, from Anglo-Saxon geond, modern English yond, compounded with the prefix be, means external to some line or limit-on the other side of. Abroad, from AngloSaxon $a$ (on) and brad, broad, means in the whole breadth of the land. It means out in the open, and suggests not the definite bounds, but the freedom and space beyond the bounds.

OUTCRY. See NoIsE.

OUTDO. See EXCEED.

OUTLINe. See Syllabus.

OUTLINES. See Sketch.

OUTLIVE, Survive. To oullive is literally to live out the life of another, to live longer: to survive, in French survive, Latin super, beyond, and vivere, to live, is to live beyond any given period; the former is employed to express the comparison between two lives; the latter to denote a protracted existence beyond any given term: one person is said properly to outlive another who enjoys a longer life; but we speak of surviving persons or things, in an indefinite or unqualified manner: it is not an unqualified blessing to oullive all our nearest relatives and friends; no man can be happy in surviving his honor.

OUTRAGE. See Afrront.

OUTSIDE. See SHow.

OUTWARD, External, Exterior. Outward, or inclined to the out, after the manner of the out, indefinitely describes the situation; external, from the Latin externus and extra, is more definite in its sense, since it is em- 
ployed only in regard to such objects as are conceived to be independent of man as a thinking being: hence, we may speak of the outward part of a building, of a board, of a table, a box, and the like; but of external objects acting on the mind, or of an external agency. Exterior is still more definite than either, as it expresses a higher degree of the outward or external, the former being in the comparative and the latter two in the positive degree: when we speak of anything which has two coats, it is usual to designate the outermost by the name of the exterior; when we speak simply of the surface, without reference to anything behind, it is denominated external: as the exterior coat of a walnut, or the external surface of things. In the moral application, the external or outward is that which comes simply to the view; but the exterior is that which is prominent and which consequently may conceal something: a man may sometimes neglect the outside who is altogether mindful of the inward: a man with a pleasing exterior will sometimes gain more friends than he who has more solid merit.

\section{OVAl. See Oblong.}

OVER. See Above; Yonder.

OVERAWE, Daunt, Frighten, InTIMIDATE. Overawe, a compound of the English over and the verb awe (see AwE), signifies, as a transitive, to restrain by fear or by superior influence. $A w e$, as a substantive, implies a fear that is reverential, or a feeling of emotion inspired by the contemplation of something sublime, and, as a transitive, to strike, inspire, or impress with feelings of reverential respect, or to hold one back or restrain him from some improper act by fear or respect. Overawe, in contradistinction, implies not only the usual quality of awe, but it assumes also the quality of a threat, an action that produces apprehension of something serious to come if something else is or is not done previously.

To daunt (see Dismay) a person is to check him in some proceeding by alarming him, to thwart, deter, or prevent him in a purpose, and, in an extreme sense, to appall, dismay, cow, and subdue him; to frighten one is to affright, terrify, shock with sudden fear, and scare him; to intimidate (from Latin timeo, I fear, timidus, fearful) one is to put him into a state of fear, and this term applies not only to an act that frightens a person, but to a series of actions that may affect him in his business and social relations, and on its application serves to restrain or check him in his regular course.

The last term has had a very frequent application of late to certain workmen who have been intimidated from pursuing their regular occupation by others striving to force them to join in a labor strike or some disturbing labor proceeding, the importunities to do so usually being backed up by various threats in case of a refusal. Thus operators in an industrial plant may be restrained from continuing at work by intimidations, threats, insinuations, and other acts that cause a fear of consequences, and by these acts are overawed into doing what is demanded of them.

OVERBALANCE, OUtweigh, PrePoNDERATE. To overbalance is to throw the balance over on one side. To out weigh is to exceed in weight. To preponderate, from pro, before, and pondus, a weight, signifies also to exceed in weight. Although these terms approach so near to each other in their original meaning, yet they have now a different application: in the proper sense, a person overbalances himself who loses his balance and goes on one side; a heavy body outweighs one that is light when they are put into the same pair of scales. Overbalance and outweigh are likewise used in the improper application; preponderate is never used otherwise: things are said to overbalance which are supposed to turn the scale to one side or the other; they are said to outweigh when they are to be weighed against each other; they are said to preponderate when one weighs down everything else: the evils which arise from innovations in society commonly overbalance the good; the will of a parent should outweigh every personal consideration in the mind, which will always be the case where the power of religion preponderates.

OVERBEAR, Bear Down, Overpower, Overwhelm, Subdue. To overbear is to bear one's self over another, that is, to make another bear 
one's weight; to bear down is literally to bring down by bearing upon; to overpower is to get the power c ver an object; to overwhelm, from whelm, a Scandinavian word signifying to overturn, to cover with water, meant literally to drown, to submerge entirely; to subdue (see CoNQUER) is, literally, to lead underneath, in the elliptical sense of leading beneath a yoke. A man overbears by carrying himself higher than others, and putting to silence those who might claim an equality with him; an overbearing demeanor is most conspicuous in narrow circles, where an individual, from certain casual advantages, affects a superiority over the members of the same community. To bear down is an act of greater violence: one bears down opposition; it is properly the opposing force to force until one side yields, as when one party bears another down. Overpower, as the term implies, belongs to the exercise of power which may be either physical or moral: one may be overpowered by another who in a struggle gets one into his power, or one may be overpowered in an argument when the argument of one's antagonist is such as to bring one to silence. One is overborne or borne down by the excrtion of individuals; overpowered by the active efforts of individuals, or by the force of circumstances; overwhelmed by eircumstances or things only: overborne by another of superior influence; borne down by the force of his attack; orerpowered by numbers, by entreaties, by looks, and the like; and overwhelmed by the torrent of words or the impetuosity of the attack.

Overpower and overwhelm denote a partial superiority; subdue denotes that which is permanent and positive: we may overpower or overwhelm for a time or to a certain degree; but to subdue is to get an entire and lasting superiority. Overpower and overwhelm are said of what passes between persons nearly on an equality; but subdue is said of those who are, or may be, reduced to a low state of inferiority: individuals or armies are overpowered or overwhelmed; individuals or nations are subdued.

In the moral or extended application, overbear and bear down both imply force or violence, but the latter even more than the former: one passion may be said to overbear another, or to overbear reason. Whatever bears down carries all before it.

To overbear, overwhelm, and subdue are likewise applied to the moral feelings, as well as to the external relations of things; but the former two are the effects of external circumstances; the latter follows from the exereise of the reasoning powers: the tender feelings are overpowered; the mind is overwhelmed with painful feelings; the unruly passions are subdued by the force of religious contemplation: a person may be so overpowered on seeing a dying friend as to be unable to speak; a person may be so overwhelmed with grief, upon the death of a near and dear relative, as to be unable to attend to his customary duties; the passion of anger has been so completely subdued by the influence of religion on the heart that instances have been known of the most irascible tempers being converted into the most mild and forbearing.

See also IMPERIous.

OVERCOME. See CoNQUER ; QUELL.

OVERFLOW, InUNdate, Deluge. What overflows simply flows over; what inundates (from in and unda, a wave) flows into; what deluges (through French from de, for dis, apart, away, and luere, to wash) washes away.

The term overflow bespeaks abundance; whatever exceeds the measure of contents must flow over, because it is more than can be held: to inundale bespeaks not only abundance, but vehemence; when it inundates it flows in faster than is desired, it fills to an inconvenient height: to deluge bespeaks impetuosity; a deluge irresistibly carries away all before it. This explan:1tion of these terms in their proper sense will illustrate their improper application: the heart is said to oterfow with joy, with gricf, with bitterness, and the like, in order to denote the superabundance of the thing; a country is said to be inundaled by swarms of inhabitants when speaking of numbers who intrude themselves to the annoyanee of the natives; the town is said to be deluged with publications of different kinds when they appear in such 
profusion and in such quick succession as to supersede others of more value.

OVERHEAR. See HEAR.

OVERPOWER. See BEAT; OVERBEAR.

OVERRULE, SUPersede. To overrule is, literally, to get the superiority of rule; and to supersede (from super and sedere), is to get the upper or superior seat; but the former is employed only as the act of persons; the latter is applied to things as the agents: a man may be overruled in his domestic government, or he may be overruled in a public assembly, or he may be overruled in the cabinet; large works in general supersede the necessity of smaller ones, by containing that which is superior both in quantity and qualit $\dot{y}$.

OVERRULING. See Prevailing. OVERRUN. See OVERSPREAD.

OVERSIGHT. See INADVERTENCY; INSPECTION.

OVERSPREAD, OVERRUN, RAVAGE. To overspread signifies simply to cover the whole surface of a body; but to overrun is a mode of spreading, namely, by running; things in general, therefore, are said to overspread which admit of extension; nothing can be said to overrun but what literally or figuratively runs: the face is overspread with spots; the ground is overrun with weeds. To overrun and to ravage (based on French ravir, Late Latin rapire, for rapere) are both employed to imply the active and extended destruction of an enemy; but the former expresses more than the latter: a small body may ravage in particular parts; but immense numbers are said to overrun, as they run into every part; the Barbarians overran all Europe and settled in different countries; detachments are sent out to ravage the country or neighborhood.

OVERTHROW. See BEAT; OvERTURN.

OVERTURN, Overthrow, SubVERT, INVERT, REverse. To overturn is simply to turn over, an act which may be more or less gradual; but to overthrow is to throw over, which will be more or less violent. To overturn is to turn a thing either with its side or its bottom upward; but to subvert is to turn that under which should be upward: to reverse is to turn that before which should be behind; and to invert is to place that on its head which should rest on its feet. These terms differ accordingly in their application and circumstances: things are overturned by contrivance and gradual means; infidels attempt to overturn Christianity by means of ridicule and falsehood: governments are overthrown by violence. To overturn is said of small matters; to subvert only of national or large concerns: domestic economy may be overturned; religious or political establishments may be subverted: that may be overturned which is simply set up; that is subverted which has been established: an assertion may be overturned; the best sanctioned principles may by artifice be subverted.

To overturn, overthrow, and subvert generally involve the destruction of the thing so overturned, overthrown, or subverted, or at least render it for the time useless, and are, therefore, mostly unallowed acts; but reverse and invert, which have a more particular application, have a less specific character of propriety: we may reverse a proposition by taking the negative instead of the affirmative; a decree may be reversed so as to render it nugatory; but both of these acts may be right or wrong, according to circumstances: likewise, the order of particular things may be inverted to suit the convenience of parties; but the order of society cannot be inverted without subverting all the principles on which civil society is built.

See also BEAT.

OVERWHELM, CRush. To overwhelm (see also under OverBeAR) is to cover with a heavy body, so that one should sink under it: to crush (see BREAK) is to destroy the consistency of a thing by violent pressure: a thing may be crushed by being overwhelmed, but it may be overwhelmed without being crushed; and it may be crushed without being overwhelmed: the girl Tarpeia, who betrayed the Capitoline Hill to the Sabines, is said to have been overwhelmed with their arms, by which she was crushed to death: when many persons fall on one he may be overwhelmed, but not necessarily crushed: when a wagon goes over a body, it may be crushed, but not overwhelmed.

OWN. See AckNowledge.

OWNER. See Possessor. 
PACE, Step. Pace, derived from Latin passus, step, is the Latin term corresponding to the native English step (from Anglo-Saxon sicppan), signifying a stretch of the legs.

As regards the act, the pace expresses the general manner of passing on or moving the body; the step implies the manner of setting or extending the foot: the pace is distinguished by being either a walk or a run, and in regard to horses a trot or a gallop: the step is distinguished by being long or short, to the right or left, forward or backward. 'The same pace may be modified so as to be more or less easy, more or less quick; the step may vary as it is light or heavy, graceful or ungraceful, long or-short: we may go a slow pace with long steps, or we may go a quick pace with short steps: a slow pace is best suited to the solemnity of a funeral; a long step must be taken by soldiers in a slow march.

As regards the space passed or stepped over, the pace is a measured distance, formed by a long siep; the $s t e p$, on the other hand, is indefinitely employed for any space stepped over, but particularly that ordinary space which one steps over without an effort: a thousand paces was the Roman measurement for a mile; a step or two designates almost the shortest possible distance.

PACIFIST, Conscientious OBJECTOR, Slacker. These are words which the European war brought into special prominence in England and America. Pacifist and conscientious objector signify one who does not believe in war, but pacifist puts the attitude in positive terms, conscientious objector in negative terms. A pacifist is one who believes in the establishment of world peace with some provision for an international court of arbitration, a league of nations to support the decrees of such a court, etc. Conscientious objector was coined to describe those persons who, without having any theory concerning the establishment of a pa- cific world, believe that war is morally wrong for them and refuse to fight. It referred primarily to members of such religious sects as the Quakers. The two terms are practically interchangeable. Conscientious objector, being the more inclusive term, now seems to be gaining ground. Slacker is a slang term describing a man who refuses to do his share of the fighting, who is slack in his duty. It is a term of contempt often applied by others to those who would call themselves conscientious objectors or pacifists.

PACIFY. See Appease; Mollify; QUELL.

PAGAN. See Gentile.

PaIn, Pang, Agony, Anguish. Pain is connected with the Latin porna, a penalty. Pang is a word of uncertain origin. Agony comes from the Greek á $\gamma \omega \nu i a$, a contest, signifying the labor or pain of a struggle. Anguish, from the Latin angere, to choke (whence anger and anxiety are also derived), signifies the pain arising from choking.

Pain, which expresses the feeling that is most repugnant to the nature of all sensible beings, is here the generic, and the rest specific, terms: pain and agony are applied indiscriminately to what is physical and mental; pang and anguish mostly signify that which is mental: pain signifies either an individual feeling or a permanent state; pang is only a particular feeling: agony is sometimes employed for the individual feeling, but more commonly for the state; anguish is always employed for the state. -Pain is indefinite with regard to the degree; it may rise to the highest or sink to the lowest possible degree; the rest are positively high degrees of pain: the pang is a sharp pain; the agony is a severe and permanent pain; the anguish is an overwhelming pain.

PAINT, DEPICT. Paint and depict both come from the Latin pingere, to represent forms and figures: as a verb, to paint is employed either literally to 
represent figures on paper or to represent circumstances and events by means of words; to depict is used only in this latter sense, but the former word expresses a greater exercise of the imagination than the latter: it is the art of the poet to paint nature in lively colors; it is the art of the historian or narrator to depict a real scene of misery in strong colors.

As nouns, painting describes rather the action or operation, and picture the result. When we speak of a good painting, we think particularly of its execution as to drapery, disposition of colors, and the like; but when we speak of a fine picture, we refer immediatcly to the object represented, and the impression which it is capable of producing on the beholder: paintings are confined either to oil-paintings or paintings in colors: but every drawing, whether in pencil, in crayon, or in India ink, may produce a picture; and we have likewise pictures in embroidery, pictures in tapestry, and pictures in mosaic.

Painting is employed only in the proper sense; picture is often used figuratively: old paintings derive a value from the master by whom they were executed; a well-regulated family, bound together by the ties of affection, presents the truest picture of human happiness.

PAIR. See Both; Couple.

PALATE, TAste. Palate, in Latin Taste, palatum, signifies the roof of the mouth. Middle English tasten, Old French taster, from a Late Latin taxitare (ultimately from Latin tangere, to touch), meant originally to touch, especially to touch lightly, then to touch lightly with the tongue.

Palate is, in an improper sense, employed for taste, because it shares with the tongue the sense of taste, but taste is never employed for palate: a person is said to have a nice palate when he is nice in what he eats or drinks; but his taste extends to all matters of sense, as well as those which are intellectual. A man of taste, or of a nice taste, conveys much more as a characteristic than a man of a nice palate: the former is said only in a good sense, but the latter is particularly applicable to the epicure.
Pale, Pallid, WaN. Pale, in French pâle, and pallid, in Latin palli. dus, both come from pallere, to turn pale. Wan is in Anglo-Saxon wann, signifying dark, black, colorless.

Pallid rises upon pale, and wan upon pallid: the absence of color in any degree, where color is a requisite quality, constitutes paleness; but pallidness is an excess of paleness, and wan is an unusual degree of pallidness: paleness in the countenance may be temporary; but pallidness and wanness are permanent; fear or any sudden emotion may produce paleness; but protracted sickness, hunger, and fatigue bring on pallidness; and when these calamities are combined and heightened by every aggravation, they may produce that which is specifically termed wanness.

PALliate. See Extendate; GLoss.

\section{PALLID. See Pale.}

PALPITATE, Flutter, Pant, Gasp. Palpitate is a frequentative of Latin palpare, to move quickly and frequently. Flutter, from Anglo-Saxon floterian, to float about, meant to drift back and forth, but it now signifies to fly backward and forward in an agitated manner. Pant comes through Old French pantaisier, to breathe with difficulty, from popular Latin phantasiare, to be oppressed with the nightmare, from

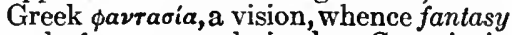
and fancy are derived. Gasp is in Middle English gaspen, but its further origin is not clear.

These terms agree in a particular manner, as they signify the irregular action of the heart or lungs: the former two are said of the heart, and the latter two of the lungs or breath; to palpitate expresses that which is strong; it is a strong beating of the blood against the vessels of the heart: to flutter expresses that which is rapid; it is a violent and alternate motion of the blood backward and forward: fear and suspense produce commonly palpitation, but joy and hope produce a fluttering; panting is, with regard to the breath, what palpitating is with regard to the heart; panting is occasioned by the inflated state of the respiratory organs, which renders this palpitating necessary: gasping differs from the former, 
inasmuch as it denotes a direct stoppage of the breath, a cessation of action in the respiratory organs.

PANEGYRIC. See ENCOMIUM.

PANG. See Pain.

Pant. See Palpitate.

PARABLE, Allegory. Both these terms imply a veiled mode of speech, which serves more or less to conceal the main object of the discourse by presenting it under the appearance of something else, which accords with it in most of the particulars: the parable,

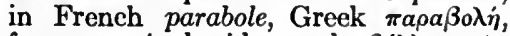
from $\pi \alpha \rho a ́$, beside, and $\beta a ́ l \lambda_{\varepsilon \iota \nu}$, to cast, signifying a placing beside or a comparison of something with something else; the allegory (see FIgUre) in describing historical events. The parable substitutes some other subject or agent, who is represented under a character that is suitable to the one referred to. In the allegory are introduced strange and arbitrary persons in the place of the real personages, or imaginary characteristics and circumstances are ascribed to real persons. The parable is principally employed in the sacred writings; the allegory forms a grand feature in the productions of the eastern nations.

PARADE. See SHow.

PARAMOUNT. See SUPREME.

parasite. See Flatterer.

PARASOL. See Umbrella.

PARDON. See Excuse; Forarve.

PARDONABLE. See Venial.

PARE. See PEel.

PARK. See Forest.

PARLIAMENT. 'See Assembly.

PARODY. See CARICATURE; Travesty.

PARSIMONIOUS. See AvarIcious.

PARSIMONY. See ECONOMY.

PARSON. See Clergyman.

PART, Division, Portion, Share. Part, in Latin pars, a division, is a term not only of more general use, but of more comprehensive meaning than division (see Divide); it is always employed for the thing divided, but division may be employed either for the act of dividing or the thing that is divided: but in all cases the word division has always a reference to some action and the agent by whom it has been performed; whereas part, which is perfectly abstract, has altogether lost this idea. We always speak of the part as opposed to the whole, but of the division as it has been made of the whole. A part is formed of itself by accident or made by design; a division is always the effect of design: a part is indefinite as to its quantity or nature; -it may be large or small, round or square, of any dimension, form, size, or character; but a division is always regulated by some certain principles; it depends upon the circumstances of the divider and the thing to be divided. A pag: a line, or a word is a part of any book; but the books, chapters, sections, and paragraphs are the divisions of the book. Stones, wood, water, air, and the like are parts of the world; fire, air, earth, and water are physical divisions of the globe; continents, seas, rivers, mountains, and the like are geographical divisions, under which are likewise included its political divisions into countries, kingdoms, etc.

A part may be detached from the whole; a division is always conceived of in connection with the whole; portion, from Latin portio, connected with pars, a part, and share (from Anglo-Saxon scearu, a fragment, based on sceran, German scheren, to sheer, allied with Old Irish scaraim, I separate) are particular species of divisions which are said of such matters as are assignable to individuals; portion refers to individuals without any distinction; share to individuals specially referred to. The portion of happiness which falls to every man's lot is more equal than is generally supposed; the share which partners have in the profits of any undertaking depends upon the sum which each has contributed toward its completion. The portion is that which simply comes to any one; but the share is that which belongs to one by a certain right. According to the ancient customs of Normandy, the daughters could have no more than a third part of the property for their share, which was divided into equal portions between them.

See also Segregate.

Part, Piece, Patch.-Part in its strict sense is taken in connection with the whole; piece, in French pièce, may be 
ultimately of Celtic origin. Patch, Middle English pacche, of uncertain origin, is that piece which is distinguished from others.

Things may be divided into parts without any express separation; but when divided into pieces they are actually cut asunder. Hence we may speak of a loaf as divided into twelve parts when it is only conceived to be so; and divided into twelve pieces when it is really so. On this ground we talk of the parts of a country, but not of the pieces; and of a piece of land, not a part of land; so, likewise, letters are said to be the component parts of a word, but the half or the quarter of any given letter is called a piece. The chapters, the pages, the lines, etc., are the various parts of a book; certain passages or quantities drawn from the book are called pieces: the parts of matter may be infinitely decomposed; various bodies may be formed out of so ductile a piece of matter as clay. The piece is that which may sometimes serve as a whole; but the patch is that which is always broken and disjointed, a something imperfect: many things may be formed out of a piece; but the patch serves only to fill up a chasm.

Partake, Participate, Share.-Partake and participate, the one English, the other from Latin purticipare, based on an extended form of pars, and capere, or, to take a part, signify, literally, to take a part in a thing, and may be applied either in the sense of having a part in more than one object at the same time or having a part with others in the same object. In the first sense partake is the more familiar and ordinary expression, as a body may be said to partake of the essence of a salt and an acid. Participate is also used in the same sense, sometimes in poetry.

In the sense of having a part with others in the same object, to partake is a selfish action, to participate is either a selfish or benevolent action; we partake of that which pleases ourselves, we participate in that which pleases others, or in their pleasures.

To partake is the act of taking or getting a thing to one's self; to share is the act of having a title to a share, or being in the habit of receiving a share: we may, therefore, partake of a thing without sharing it, and share it without partaking. We partake of things mostly through the medium of the senses: whatever, therefore, we take a part in, whether gratuitously or casually, of that we may be said to partake; in this manner we partake of an entertainment without sharing it: on the other hand, we share things that promise to be of advantage or profit, and what we share is what we claim; in this manner we share a sum of money which has been left to us in common with others.

PARTICUlaR, Singular, Odd, Eccentric, Strange. Particular, in French particulier, Latin particularis, from particula, a particle, signifies belonging to a particle or a very small part. Singular, in French singulier, Latin singularis, from singulus, every one, signifies, literally, unmatched (see ODD). Eccentric, through Late Latin

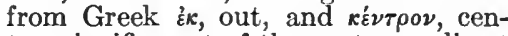
tre, signifies out of the centre or direct line. Strange, in Old French estrange, Latin extraneus, from Greek $\dot{\xi} \xi$, out of, and a suffix, signifies out of some other part, or not belonging to this part.

All these terms are employed either as characteristics of persons or things. What is particular belongs to some small particle or point to which it is confined; what is singular is single, or the only one of its kind; what is odd is without an equal or anything with which it is fit to pair; what is eccentric is not to be brought within any rule or estimate, it deviates to the right and the left; what is strange is different from that which one is accustomed to see, it does not admit of comparison or assimilation. A person is particular as regards himself; he is singular as regards others; he is particular in his habits or modes of action; he is singular in that which is about him; we may be particular or singular in our dress; in the former case we study the minute points of our dress to please ourselves; in the latter case we adopt a mode of dress that distinguishes us from all others.

One is odd, eccentric, and strange, more as it regards established modes, forms, and rules, than individual cir- 
cumstances: a person is odd when his actions or his words bear no resemblance to those of others; he is eccentric if he irregularly departs from the eustomary modes of proceeding; he is strange when that which he does makes him new or unknown to those who are about him. Particularity and singularity are not always taken in a bad sense; oddness, eccentricity, and strangeness are never taken in a good one. A person ought to be particular in the choice of his society, his amusements, his books, and the like; he ought to be singular in virtue, when vice is unfortunately prevalent: but particularity becomes ridiculous when it concerns trifles; and singularity becomes eulpable when it is not warranted by the most imperious necessity. As oddness, eccentricity, and strangeness consist in the violation of good order, of the decencies of human life, or the more important points of moral duty, they can never be justifiable and are often unpardonable. An odd man with whom no one can associate, and who likes to associate with no one, is an outcast by nature. An eccentric eharaeter, who distinguishes himself by the frequent breach of established rule, is a being who is bound to incur the hostility of the world. A strange person, who makes himself a stranger among those to whom he is bound by the closest ties, is a being as unfortunate as he is misunderstood.

When applied to characterize inanimate objeets, these words are mostly used in an indifferent, but sometimes in a bad, sense: the term particular serves to define or specify, it is opposed to the general or indefinite; a particular day or hour, a particular case, a particular person, are expressions which confine one's attention to one precise objeet in distinction from the rest; singular, like the word particular, marks but one objeet, and that which is clearly pointed out in distinction from the rest; but this term differs from the former, inasmuch as the particular is said only of that which one has arbitrarily made particular; but the singular is so from its own properties: thus a place is particular when we fix upon it and mark it out in any manner so that it may be known from others; a place is singular if it have anything in itself which distinguishes it from others. Odd, in an indifferent sense, is opposed to even, and applied to objects in general; an odd number, an odd person, an odd book, and the like: but it is also employed in a bad sense to mark objects which are totally dissimilar to others; thus an odd idea, an odd conceit, an odd whim, an odd way, an odd place. Eccentric is applied in its proper sense to mathematical lines or circles which have not the same centre, and is never employed in an improper sense: strange, in its proper sense, marks that which is unknown or unusual, as a strange face, a strange figure, a strange place; but in the moral application it i- like the word odd, and conveys the unfavorable idea of that which is uncommon and not worth knowing; a strange noise designates not only that which has not been heard before, but that which it is not desirable to hear; a strange place may signify not only that which we have been unaccustomed to see, but that which has also much in it that is objectionable.

Particular, Individual. - Particular (see Peculiar). Individual, in French individuel, Latin individuus, with a suffix, signifies that which eannot be divided.

Both these terms are employed to express one object; but particular is much more specific than individual; the particular confines us to one object only of many; but individual may be said of any one object among many. A particular object cannot be misunderstood for any other while it remains particular; but the individual object can never be known from other individual objects while it remains only individual. Particular is a term used in regard to individuals, and is opposed to the general: individual is a term used in regard to collectives, and is opposed to the whole or that which is divisible into parts.

See also Circumstantial; Exact; SPECIAL.

PARTICULARLY. See EspecialLYY.

PARTISAN. See Follower.

PARTNER. See Collfatue.

PARTNERSHIP. See Association. 
PARTY. See FAction.

PASS, PASSPORT, SAFE-CONDDCT, SAFEgUARd. Pass, in French passer, from Late Latin passare, from passus, a step, Spanish pasar, Italian passare, all virtually mean to step, to go; permission to go or come, evidenced by a ticket or other document issued by a competent authority.

A passport is a warrant of protection issued by a government to one of its citizens to enable the bearer to visit or travel in another country without molestation. An emergency passport may be issued to a citizen of the United States happening to be in a foreign country, under specific circumstances, by certain representatives of the United States in that country.

A safe-conduct may be an official warrant issued as above, or a convoy or guard to protect the bearer in or passing through a hostile or a foreign country. To safeguard a person, a ship, or an important interest is to provide the subject with ample protection in any of the above forms.

In the second year of the European war (1915) it was discovered that many passports issued by the United States government had been forged and had got into the hands of spies of the Teutonic powers. This led the government to adopt more rigorous regulations for the issue of such documents.

PASSAGE. See Course.

PASSING OVER. See Death

PASSIONATE. See ANGRY.

PASSIVE. See Patient.

PASSWORD. See SHIBboleth.

PAST. See Bygone.

PASTIME. See Amusement.

PATCH. See Part.

PATHETIC. See Moving.

PATIENCE, Endurance, ResignaTION. Patience applies to any troubles or pains whatever, small or great; resignation is employed only for those of great moment, in which our dearest interests are concerned: patience, when compared with resignation, is somewhat negative; it consists in the abstaining from all complaint or indication of what one suffers: but resignation consists in a positive sentiment of conformity to the existing circumstances, be they what they may. There are perpetual occurrences which are apt to harass the temper, unless one regards them with patience; the misfortunes of some men are of so calamitous a nature that if they have not acquired resignation they must inevitably sink under them. Patience applies only to the evils that actually hang over us; but there is a resignation connected with a firm trust in Providence which extends its views to futurity and prepares us for the worst that may happen.

As patience lies in the manner and temper of suffering, and endurance in the act, we may have endurance and not patience: for we may have much to endure, and consequently endurance: but if we do not endure it i with an easy mind and without the disturbance of our looks and words, we have not patience: on the other hand, we may have patience, but not endurance: for our patience may be exercised by momentary trifles which are not sufficiently great or lasting to constitute endurance.

Patient, Passive, Submissive.-Patient, from the Latin patiens, signifies, literally, suffering, and is applied to things in general, but especially to what is painful. Passive, from the Latin passivus and passus, signifying, literally, suffered or acted upon, applies to those matters in which persons have to act; he is patient who bears what he has to suffer without any expressions of complaint; he is passive who abstains altogether from acting when he might act.

Patience is a virtue springing from principle; passiveness is always involuntary, and may be supposed to arise from want of spirit.

Patience is therefore applicable to conscious agents only; passiveness is applicable to inanimate objects which do not act at all, or at least not adversely.

Passive and submissive both refer to the will of others; but passive signifies simply not resisting; submissive signifies positively conforming to the will of another.

See also Invalid.

PATTERN. See Copy; Example. PAUSE. See DeMUR.

PAY. See Allow ance.

PEACE, Quiet, Calm, TranquirLITY. Peace is derived through French 
from Latin pax. Quiet (see EASY). Calm (see Abate; Calm). Tranquillity is in Latin tranquillitas, from tranquillus, at rest.

Peace is a term of more general application and more comprehensive meaning than the others; it applies either to communities or individuals; but quiet applies only to individuals or small communities. Nations are said to have peace, but not quiet; persons or families may have both peace and quiet. Peace implies an exemption from public or private broils; quiet implies a freedom from noise or interruption. Every well-disposed family strives to be at peace with its neighbors, and every affectionate family will naturally act in such a manner as to promote peace among all its members: the quiet of a neighborhood is one of its first recommendations as a place of residence.

Peace and quiet, in regard to individuals, have likewise a reference to the internal state of the mind; but the former expresses the permanent condition of the mind, the latter its transitory condition. Serious matters only can disturb our peace; trivial matters may disturb our quiet: a good man enjoys the peace of a good conscience; but he may have unavoidable cares and anxieties which disturb his quiet. There can be no peace where a man's passions are perpetually engaged in a conflict with one another; there can be no quiet where a man is embarrassed in his pecuniary affairs.

Calm is a species of quiet, which affects objects in the natural or the moral world; it indicates the absence of violent motion as well as violent noise; it is that state which more immediately succeeds a state of agitation. As storms at sea are frequently preceded as well as succeeded by a dead calm, so political storms have likewise their ealms, which are their attendants, if not their precursors. Tranquillity, on the other hand, is taken more absolutely: it expresses the situation as it exists at the present moment, independently of what goes before or after; it is sometimes applicable to society, sometimes to natural objects, and sometimes to the mind. The tranquillity of the state cannot be pre- served unless the authority of the magistrates be upheld; the tranquillity of the air and of all the surrounding objects is one thing which gives the country its peculiar charms; the tranquillity of the mind in the season of devotion contributes essentially to produce a suitable degree of religious fervor.

As epithets, these terms bear tho same rclation to each other: people are peaceable as they are disposed to promote peace in society at large, or in their private relations; they are quiet inasmuch as they abstain from every loud expression, or are exempt from any commotion in themselves; they are calm, inasmuch as they are exempt from the commotion which at any given moment rages around them; they aro tranquil, inasmuch as they enjoy an entire exemption from everything which can disecmpose. A town is peaceable as respects the disposition of the inhabitants; it is quiet as respects its external cireumstances of freedom from bustle and. noise: an evening is calm when the air is lulled into a particular stillness which is not interrupted by any loud sounds: a scene is tranquil which combines everything calculated to soothe the spirits to rest. Peaceable, Peaceful, Pacific.-Pcaceable is used in the proper sense of the word peace, as it expresses an exemption from strife or contest; but peaceful is used in its improper sense, as it expresses an exemption from agitation or commotion. Persons or things are peaceable; things, particularly in the higher style, are peaceful: a family is designated as peaceable in regard to its inhabitants; a house is designated as a peaceful abode as it is remote from the bustle and hurry of a multitude. Pacifie signifies either making peace or disposed to make peace, and is applied mostly to what we do to others. We are peaceable when we do not engage in quarrels of our own; we are pacific if we wish to keep peace or make peace between others. Hence the term peaceable is mostly employed for individual or private concerns, and pacific most properly for national concerns: subjects ought to be peaccable, and monarehs parific.

See also Pacifist; UnRuffled. 
PEARLY. See Nacreous.

PEASANT. See Countryman.

PECUliar, Appropriate, ParticULAR. 'Peculiar, in Latin peculiaris, from peculium, private property, pecunia, money, and pecus, cattle, in which property consisted, is said of that which belongs to persons or things; appropriate, signifying belonging, fitting (see Ascribe), is said of that which belongs to things only: the faculty of speech is peculiar to man, in distinction from all other animals; an address may be appropriate to the circumstances of the individual. Peculiar and particular (see PARTICULAR) are both employed to distinguish objects; but the former distinguishes the object by showing its connection with others; particular distinguishes it by a reference to some acknowledged circumstance; hence we may say that a person enjoys peculiar privileges or particular privileges: in this case peculiar signifies such as are confined to him and enjoyed by none else; particular signifies such as are distinguished in degree and quality from others of the kind.

See also UNIQUE.

PEDAGOGIC. See Didactic.

PEEL, PARE. Peel, from the French peler, derived from Latin pellis, a skin, is the same as to skin or to take off the skin: to pare, from the Latin parare, to trim or make in order, signifies to smooth. The former of these terms denotes a natural, the latter an artificial, process: the former excludes the idea of a forcible separation; the latter includes the idea of separation by means of a knife or sharp instrument: potatoes and apples are peeled after they are boiled; they are pared before they are boiled; an orange and a walnut are always peeled but not pared; a cucumber must be pared and not peeled: in like manner, the skin may sometimes be peeled from the flesh, and the nails are pared.

See also Skin.

PEeVish. See Captious: SplenETIC.

PEllucíd, Transparent. Pellucid, in Latin pellucidus, is compounded of per, through, and lucidus, shining. Transparent, in Latin transparens, from trans, through or beyond, and parere, to appear, signifies that which admits light through it. Pellucid is said of that which is pervious to the light or of that into which the eye can penetrate; transparent is said of that which is throughout bright: a stream is pellucid; it admits of the light so as to reflect objects, but it is not transparent for the eye.

See also Diaphanous.

PENALTY. See FIne.

PENetrate, Pierce, Perforate, Bore. To penetrate (see DiscernMENT) is simply to make an entrance into any substance; to pierce is commonly assumed to come through Old French pertuisier, from Latin per, through, and tundere, to beat. Perforate comes from the Latin per, through, and forare, to pierce, which is the same word as the native English bore. To penetrate is a natural and gradual process; in this manner rust penetrates iron, water penetrates wood; to pierce is a violent, and commonly artificial, process; thus an arrow or a bullet pierces through wood. The instrument by which the act of penetration is performed is in no case defined; but that of piercing commonly proceeds by some pointed instrument: we may penetrate the earth by means of a spade, a plough, a knife, or various other instruments; but one pierces the flesh by means of a needle, or one pierces the ground or a wall by means of a pickaxe.

To perforate and bore are modes of piercing that vary in the circumstances of the action and the objects acted upon; to pierce, in its peculiar use, is a sudden action by which a hollow is produced in any substance; but to perforate and bore are commonly the effect of mechanical art. The body of an animal is pierced by a dart; but cannon is made by perforating or boring the iron: channels are formed underground by perforating the earth; holes are made in the ear by perforation; holes are made in the leather, or in the wood, by boring; these last two words do not differ in sense, but in application, the latter being a term of vulgar use, though sometimes used in poetry.

To penetrate and pierce are likewise employed in an improper sense; to 
perforate and bore are employed only in the proper sense. The first two bear the same relation to each other as in the former case: penetrate is, however, employed only as the act of persons; pierce is used in regard to things. There is a power in the mind to penetrate the looks and actions, so as justly to interpret their meaning; the eye of the Almighty is said to pierce the thickest veil of darkness. Affairs are sometimes involved in such mystery that the most enlightened is unable to penetrate either the end or the beginning; the shrieks of distress are sometimes so loud as to seem to pierce the ear.

\section{See also Thrill.}

Penetration, Acuteness, Sagacity.As characteristics of mind, these terms have much more in them in which they differ than in what they agree: penetration is a necessary property of mind; it exists to a greater or less degree in every rational being that has the due exercise of its rational powers; acuteness is an accidental property that belongs to the mind only, under certain circumstances. As penetration (see Discernment) denotes the process of entering into substances physically or morally, so acuteness, which is the same as sharpness, from acútus, sharp, denotes the fitness of the thing that performs this process: and as the mind is in both cases the thing that is spoken of, the terms penetration and acuteness are in this particular closely allied. It is clear, however, that the mind may have penetration without having aculeness, although one cannot have acuteness without penetration. If by penetration we are commonly enabled to get at the truth which lies concealed, by aculeness we succeed in piercing the veil that hides it from our view; the former is, therefore, an ordinary, and the latter an extraordinary, gift.

Sagacity is in Latin sagacitas, from sagire, to perceive by the senses. The term has been applied to animals which discover an intuitive wisdom, and also to children, or uneducated persons, in whom there is more penetration than may be expected from the narrow compass of their knowledge; hence, properly speaking, sagacity is natural or uncultivated acuteness.

PEnItence. See Repentance.
PENMAN. See Writer.

PENURIOUS. See EcoNoMICAL.

PENURY. Sce PoVERTY.

PEOPle, Nation. People is derived through French from the Latin populus. The simple idea of numbers is expressed by the word people: but the term nation, from natio and natus, born, marks the connection of numbers by birth; people is, therefore, the generic, and nation the specific, term. A nation is a people connected by birth; there cannot, therefore, strictly speaking, be a nation without a people: but there may be a people where there is not a nation. The Jews, when considered as an assemblage, under the special direction of the Almighty, are termed the people of God, but when considered in regard to their common origin, they are denominated the Jewish nation. The Americans, when spoken of in relation to the British, are a distinct people, because they have a distinct government; but they are not a distinct nation, because they have a common descent. On this ground the Romans are not called the Roman nation, because their origin was so various, but the Roman people, that is, an assemblage living under one form of government.

In a still eloser application, people is taken for a part of the state, namely, that part of a state which consists of a multitude, in distinction from its government; whence arises a distinetion in the use of the terms; for we may speak of the British people, the French or the Dutch people, when we wish merely to talk of the mass, but we speak of the British nation, the Freneh nation, and the Dutch nation, when public measures are in question, which emanate from the government or the whole people. The English prople have ever been remarkable for their attachment to liberty: the abolition of the slave-trade is one of the most glorious aets of public justice which were ever performed by the British nation. Upon the same ground republican states are distinguished by the name of people: but kingdoms are commonly spoken of in history as nations. Hence we say the Spartan people, the Athenian people, the people of Genos, the prople of Venice, but the nations of Europe, the 
African nations, the English, French, German, and Italian nations.

People, Populace, Mob.-People and populace are evidently changes of the same word to express a number. The signification of these terms is that of a number gathered together. People is said of any body supposed to be assembled, as well as really assembled: populace is said of a body only when actually assembled. The voice of the people is sometimes too loud to be disregarded; the populace in England are fond of dragging their favorites in carriages.

$M o b$ and mobility are from the Latin mobilis, signifying movableness, which is the characteristic of the multitude: hence Virgil's mobile vulgus. (The word mobile was used in this sense in England at the end of the seventeenth century.) The term mob, therefore, designates not only what is low, but tumultuous. A $m o b$ is at all times an object of terror that mostly goes from bad to worse. Mobility, as an adjective, is used in its etymological sense to-day.

People, Persons, Folks. - The term people has already been considered in two acceptations under the general idea of an assembly; but in the present case it is employed to express a small number of individuals: the word people, however, is always considered as one undivided body, and the word person may be distinctly used either in the singular or in the plural; as we cannot say one, two, three, or four people: but we may say one, two, three, or four persons: yet, on the other hand, we may indifferently say, such people or persons; many people or persons; some people or persons, and the like.

With regard to the use of these terms, which is altogether colloquial, people is employed in general propositions, and persons in those which are specific or referring directly to some particular individuals: people are generally of that opinion; some people think so; some people attended: there were but few persons present at the entertainment; the whole company consisted of six persons.

As the term people is employed to designate the promiscuous multitude, it has acquired a certain meanness of acceptation which makes it less suit- able than the word persons, when people of respectability are referred to: were I to say of any individuals I do not know who the people are, it would not be so respectful as to say, I do not know who those persons are: in like manner one says, from people of that stamp one can expect nothing better; persons of their appearance do not frequent such places.

Folks, Anglo-Saxon folc, is a homely and familiar word; it is not unusual to say good people or good folks; and in speaking jocularly to one's friends the latter term is likewise admissible: but in the serious style it is never employed except in a disrespectful manner: such folks (speaking of gamesters) are often put to sorry shifts.

See also Punlic.

PERCEIVE, Discern, DistinGUISH. To perceive, in Latin percipio, or per, an intensive prefix, through, or thoroughly, and a weak form of capere, signifying to take hold of, is a positive, to discern (see Discernment) a relative, action: we perceive things by themselves; we discern them amidst many others: we perceive that which is obvious; we discern that which is remote or which requires much attention to get an idea of it. We perceive by a person's looks and words what he intends; we discern the drift of his actions. We may perceive sensible or spiritual objects; we commonly discern only that which is spiritual: we perceive light, darkness, colors, or the truth or falsehood of anything; we discern characters, motives, the tendency and consequences of actions, etc. It is the act of a child to perceive according to the quickness of its senses; it is the act of a man to discern according to the measure of his knowledge and understanding.

To discern and distinguish (see DiFFERENCE) approach the nearest in sense to each other; but the former signifies to see only one thing, the latter to see two or more in quick succession so as to compare them. We discern what lies in things: we distinguish things according to their cutward marks; we discern things in order to understand their essences; we distinguish in order not to confound them. Experienced and discreet people may discern the signs 
of the times; it is just to distinguish between an action done from inadvertence and that which is done from design. The conduct of people is sometimes so veiled by art that it is not easy to discern their object: it is necessary to distinguish between practice and profession.

See also Ser\%.

Perception, Idea, Conception, Notion. -Perception expresses either the act of perceiving or the impression produced by that act; in this latter sense it is analogous to an idea (see IDEA). The impression of an object that is present to us is termed a perception; the revival of that impression, when the object is removed, is an idea. A combination of ideas by which any image is presented to the mind is a conception (see CoMPreHeND); the association of two or more ideas so as to constitute a decision is a notion (see OpINion). Perceptions are clear or confused, according to the state of the sensible organs and the perceptive faculty; ideas are faint or vivid, vague or distinct; according to the nature of the perception; conceptions are gross or refined according to number and extent of one's ideas; notions are true or false, correct or incorrect, according to the extent of one's knowledge. The perception which we have of remote objects is sometimes so indistinct as to leave hardly any traces of the image on the mind; we have in that case a perception, but not an idea: if we read the description of any object we may have an idea of it; but we need not have any immediate perception: the idea in this case being complex, and formed of many images of which we have already had a perception.

If we present objects to our minds, according to different images which have already been impressed, we are said to have a conception of them: in this case, however, it is not necessary for the objects really to exist; they may be the product of the mind's operation within itself: but with regard to notions it is different, for they are formed respecting objects that do really exist, although perhaps the properties or circumstances which we assign to them are not real. If I look at the moon, I have a perception of it; if it disappear from my sight, and the impression remains, I have an idea of it; if an object, differing in shape and color from anything else which I may have seen, presents itself to my mind, it is a conception; if of this moon I conceive that it is no bigger than what it appears to my eye, this is a notion which, in the present instance, assigns an unreal property to a real object.

See also Sentiment.

PERCEPTIBLE. See TaNgible.

PEREMPTORY. See PosItIVE.

PERFECT. See ACCOMPLISHED; COMPLETE.

PERFECTLY. See QUITE.

PERFIDIOUS. See Faituless.

PERFORATE. See Pexetrate;

THRILI.

PERFORATION. See OrIFICE.

PERFORM. See EFFECT; ExeCUTE.

PERFORMER. See ACTOR.

PERIL. See DANGER.

PERILOUS. See Herculean.

PERIOD. See Sentence; Time.

PERISCOPE. AltisCOPE, TElescope. Periscope, a compound of the Greek $\pi \varepsilon \rho i$, around, and oxo $\pi \varepsilon i \nu$, look, signifies, literally, a general view or a view on all sides, and, specifically, spectacles with concavo-convex glasses constructed to increase the distinctness of objects when vicwed obliquely. As a substantive the term has a distinctive application to a form of telescope by which an observer is enabled to see over a parapet, wall, and other parts of a fortification, known as an altiscope, from the Latin altus, high, and $\sigma \times \sigma \pi \varepsilon \nu$, to see. It consists of a telescopic tube with a right angle at the top and a reverse right angle at the bottorn, with mirrors arranged at these points.

A periscope, with which term the world became more familiar during the great European war, is an improved form of the altiscope, having at the top a lenticular total-reflection prism instead of a mirror, and turning upon a vertical axis, so that it is capable of sweeping the entire horizon. It is the slender instrument that rises above the surface from the body of a submarine when sufficiently submerged to be out of sight, with which 
the navigator scans the horizon and directs the craft for attacking another vessel.

PERISH, Die, Decay. To perish, in French périr, in Latin pereo, compounded of per and $e o$, signifying to go thoroughly away, expresses more than to die (see DIE), and is applicable to many objects; for the latter is properly applied only to express the extinction of animal life, and figuratively to express the extinction of life or spirit in vegetables or other bodies; but the former is applied to express the dissolution of substances, so that they lose their existence as aggregate bodies. What perishes, therefore, does not always die, although whatever dies by that very act perishes to a certain extent. Hence we say that wood perishes, although it does not die; people are said either to perish or die: but as the term perish expresses even more than dying, it is possible for the same thing to die and not perish; thus a plant may be said to die when it loses its vegetative power; but it is said to perish if its substance crumbles into dust.

To perish expresses the end; to decay the process by which this end is brought about: a thing may be long in decaying, but when it perishes it ceases at once to act or to exist: things may, therefore, perish without decaying; they may likewise decay without perishing. Things which are altogether new, and have experienced no kind of decay, may perish by means of water, fire, lightning, and the like: on the other hand, wood, iron, and other substances may begin to decay, but may be saved from immediately perishing by the application of preventives.

PERJURE. See Forswear.

PERMANENT. See DURABle.

PERMISSION. See Leave.

PERMIT. See ADMit; Consent.

PERNICIOUS. See Destructive; HuRTFul.

PERPETRATE, Commit. The idea of doing something wrong is common to these terms; but perpetrate, from the Latin per, intensive, and patrare, signifying thoroughly to compass or bring about, is a much more determined proceeding than that of committing. One may commit offences of various degrees and magnitude; but one perpetrates crimes only, and those of the more heinous kind. Lawless banditti, who spend their lives in the perpetration of the most monstrous crimes, are not to be restrained by the ordinary course of justice; he who commits any offence against the good order of society exposes himself to the censure of others who, in certain respects, may be his inferiors.

PERPETUAL. See Continual.

PERPLEX. See Distress; EMBARRASS.

PERPLEXING. See KNotTy.

PERPLEXITY. See QUANDARY; WORRY.

PERSEVERE. See Continde.

PERSIST. See Continue; Insist. PERSONS. See People.

PERSPICUITY. See Clearness.

PERSUADE, ENtice, Prevail Upon. Persuade (see Conviction) and entice (see ALLURE) are employed to express different means to the same end, namely, that of drawing any one to a thing: one persuades a person by means of words; one entices him either by words or actions; one may persuade either to a good or bad thing; but one entices commonly to that which is bad; one uses arguments to persuade, and arts to entice.

Persuade and entice comprehend either the means or the end, or both; prevail upon comprehends no more than the end: we may persilade without prevailing upon, and we may prevail upon without persuading. Many will turn a deaf ear to all our persuasions, and will not be prevailed upon, although persuaded: on the other hand, we may be prevailed upon by the force of remonstrance, authority, and the like; and in this case we are prevailed upon without being persuaded. We should never persuade another to do that which we are not willing to do ourselves; credulous or good-natured people are easily prevailed upon to do things which tend to their own injury.

See ExhorT.

PERTINACIOUS. See Tenacious. PERVERSE. See AWKWARD.

PESSIMISTIC, DE S P ONDING, Gloomy. Pessimistic is a term derived from the Iatin pessimus, the worst. Desponding comes from Latin de, away, 
and spondere, to promise, and means literally promising away, yielding up wholly, hence despairing.

Gloomy comes from Middle English gloumen, to lower. These three words are used to describe a disposition which is inclined to "look on the dark side of things," to give up hope. Pessimistic describes an intellectual attitude; desponding, an emotional state. The pessimistic man believes that things are worse than they are; the desponding man, holding such a belief, yields up all hope. Desponding indicates an abnormal psychological condition, and is a much stronger word than pessimistic. We may feel pessimistic about all sorts of trivial matters; we become desponding when something vital to happiness has been taken away, thereby, as it were, destroying the emotional balance. Gloomy is a word descriptive of manner, mood, and temperament rather than of a distinet and positive emotional condition such as that indieated in desponding. The gloomy man resembles a lowering sky; the light and sunshine seem to have been obliterated. But the word means little more than a general absence of eheerfulness, and suggests rather a diffused sadness, of tentimes without eause or object, than an intense and absolute hopelessness.

See also Optimistic.

PEST. See Bane.

PEStilential. See Contagious.

PETition. See Prayer.

PETTY. See Trifling.

PETUlant. See Captiods.

PHANTASM. See Hallucination. PHANTOM. See Vision.

PHOTOPLAY. See Moving PictURE.

PHRASE. See Diction; Sentence. PICK. See CHoose.

Picture, Print, Engraving. Picture (see PAINT) is any likeness taken by the hand of the artist: the print is the copy of the painting in a printed state; and the engraving is that which is produced by an engraver: every engraving is a print; but every print is not an engraving; for the picture, as in the case of woodeuts, may be printed from something besides an engraving. The term picture is sometimes used for any representation of a likeness, without regard to the process by which it is formed: in this case it is employed mostly for the representations of the common kind that are found in books; but print and engrat. ing are said of the higher specimens of the art. On certain occasions the word engraving is most appropriate, as to take an engraving of a particular object; on the other occasions the word print, as a bandsome print, or a large print.

See also Radiograph.

PIECE. Sec Part.

PIERCE. See Penetrate; Thrill. PILE. See Heap.

PIllage. See Rapine; Sack; SPOLIATION.

PILlaR, Column. Pillar comes from Latin pila, a pier of stone. Column is in Latin columna, allied to collis, hill, and culmen, a summit (whence our word culminate), indieating a shaft which reaches upward. Both words are applied to the same object, namely, to whatever is artificially set up in wood, stone, or other hard material; but the word pillar, having come first into use, is the most general in its application to any structure, whether rude or otherwise; the term column, on the other hand, is applied to whatever is ornamental, as the Grecian order of columns.

So in poetry, where simply a support is spoken of, the term pillar may be used.

But where grandeur or embellish. ment is to be expressed, the term column.

Both terms are applied to other objects having a similarity either of form or of use. Whatever is set up in the form of a pillar is so denominated; as, stone pillars in crossways, or over graves, and the like.

Whatever is drawn out in the form of a column, be the material of which it is composed what it may, it is denominated a column; as a column of water, smoke, ete.; a column of men, a column of a page.

Pillar is frequently employed in a moral application, and in that case it always implies a support.

PINCH. See Nip; Press.

PINE. See FlaG.

PINNAClE. See TURret.

PIOUS. See HoLY. 
PIQUE. See Malice; Umbrage.

PITEOUS, Doleful, Woful, RueFUL. Piteous signifies moving pity (see PITY.). Doleful, or full of dole, in Latin dolor, pain, signifies indicative of much pain. Woful, or full of woe, signifies likewise indicative of woe (see WOE). Rueful, or full of rue, comes from AngloSaxon hreowan, to be sorry, and signifies indicative of much sorrow.

The close alliance in sense of these words one to another is obvious from the above explanation; piteous is applicable to one's external expression of bodily or mental pain; a child makes piteous lamentations when it suffers from hunger or has lost its way; doleful applies to those sounds which convey the idea of pain; there is something doleful in the tolling of a funeral bell or in the sound of a muffled drum: woful applies to the circumstances and situations of men; a scene is woful in which we witness a large family of young children suffering from sickness and want; rueful applies to the outward indications of inward sorrow depicted in the looks or countenance. The term is commonly applied to the sorrows which spring from a gloomy or distorted imagination, and has therefore acquired a somewhat ludicrous acceptation; hence we find Cervantes's characterization of Don Quixote rendered in English as the knight of the rueful countenance.

Pitiable, Piteous, Pitiful. - These three epithets drawn from the same word have shades of difference in sense and application. Pitiable signifies deserving of pity; piteous, moving pity; pitiful, full of that which awakens pity; a condition is pitiable which is so distressing as to call forth pity; a cry is piteous which indicates such distress as can excite pity; a conduct is pitiful which marks a character entitled to pity. The first of these terms is taken in the best sense of the term pity; the last two in its unfavorable sense: what is pitiable in a person is independent of anything in himself; circumstances have rendered him pitiable; what is piteous and pitiful in a man arises from the helplessness and imbecility or worthlessness of his character; the former connotes that which is weak; the latter that which is worth- less in him: when a poor creature makes piteous moans, it indicates his incapacity to help himself, as he ought to do, out of his troubles; when a man of rank has recourse to pitiful shifts to gain his ends, he betrays the innate meanness of his soul.

See also Contemptible; Mean.

Pity, Compassion. - Pity is contracted from Latin pietas, English piety, from pius, which signified attentive to all natural duties, and implied especially a religious devotion to the gods and to parents and family. Compassion, in Latin compassio, from con, with, and passus, past participle of pati, to suffer, signifies to suffer in conjunction with another.

The pain which one feels at the distress of another is the idea that is common to the signification of both these terms, but they differ in the object that causes the distress: the former is excited principally by the weakness or degraded condition of the subject; the latter by his uncontrollable and inevitable misfortunes. We pity a man of weak understanding who exposes his weakness: we compassionate the man who is reduced to a state of beggary and want. Pity is kindly extended by those in higher condition to such as are humble in their outward circumstances; the poor are at all times deserving of pity, even when their poverty is the positive fruit of vice: compassion is a sentiment which extends to persons in all conditions; the Good Samaritan had compassion on the traveller who fell among thieves. Pity, though a tender sentiment, is so closely allied to contempt that an understanding person is always loath to be the subject of it, since it can never be awakened but by some circumstance of inferiority; it hurts the honest pride of a man to reflect that he can excite no interest but by provoking a comparison to his own disadvantage: on the other hand, such is the general infirmity of our natures, and such our exposure to the casualties of human life, that compassion is a pure and delightful sentiment that is reciprocally bestowed and acknowledged by all with equal satisfaction.

Pity, Mercy.-The feelings one indulges, and the conduct one adopts, 
toward others who suffer through their own fault, are the common ideas which render these terms synonymous; but pity lays hold of those circumstances which do not affect the moral character or which diminish the culpability of the individual: mercy lays hold of those external circumstances which may diminish punishment. Pity is often a sentiment unaccompanied with action; mercy is of ten a mode of action unaccompanied with sentiment: we have or take pity upon a person, but we show mercy to a person. Pity is bestowed by men in their domestic and private capacity; mercy is shown in the exercise of power: a master has pity upon his offending servant by passing over his offences and affording him the opportunity of amendment; the magistrate shows mercy to a criminal by diminishing his punishment. Pity lies in the breast of an individual and may be bestowed at his discretion: mercy is restricted by the rules of civil society; it must not interfere with the administration of justice. Young of fenders call for great pity, as their offences are often the fruit of inexperience and bad example rather than of depravity: mercy is an imperative duty in those who have the power of inflicting punishment, particularly in cases where life and death are concerned.

Pity and mercy are likewise applied to the animal creation with a similar distinction: pity shows itself in relieving real misery and in lightening burdens; mercy is displayed in the measure of pain which one inflicts. One takes pity on a poor animal to whom one gives food to relieve hunger; one shows it mercy by abstaining from beating it.

These terms are, moreover, applicable to the Deity, in regard to His creatures, particularly man. God takes pity on us as entire dependents upon Him: he extends His mercy toward us as offenders against Him: He shows His pity by relieving our wants; He shows His mercy by forgiving our sins.

PITHY. See Laconic.

PItiless. See Heartless.

Place, Station, Situation, PosiTION, Post. Place, from Latin platea, Greek $\pi \lambda a r \varepsilon i a$, a broad way, is the abstract or general term that compre- hends the idea of any given space that may be occupied: station (see CoNDITION) is the place where one stands or is fixed: situation, in Latin situs, a place, and position, from positus, the past participle of ponere, to place, signify the object as well as the place; that is, they signify how the object is put, as well as where it is put. A place or station may be either vacant or otherwise; a situation and a position necessarily suppose some occupied place. A place is either assigned or not as signed, known or unknown, real or supposed: a station is a specifically assigned place. We choose a place according to our convenience, and we leave it again at pleasure; but we take up our station and hold it for a given period. One inquires for a place which is known only by name; the station is appointed for us, and is, therefore, easily found. Travellers wander from place to place; soldiers have always some station.

The terms place and situation are said of objects animate or inanimate; station only of animate objects, or those which are figuratively considered as such; position properly of inanimate objects, or those which are considered as such: a person chooses a place; a thing occupies a place, or has a place set apart for it: a station or stated place must always be assigned to each person who has to act in concert with others; a siluation or position is chosen for a thing to suit the convenience of an individual: the former is said of things as they stand with regard to others; the latter of things as they stand with regard to themselves. The situation of a house comprehends the nature of the place, whether on ligh or low ground, and also its relation to other objects, that is, whether higher or lower, nearer or more distant: the position of a window in a house is considered as to whether it is straight or erooked; the position of a book is considered as to whether it stands leaning or upright, with its face or back forward. Situation is, moreover, said of things that come there of themselves; position only of those things which have been put there at will. The siluation of some tree or rock, on some elevated place, is agreeable to be looked 
at or to be looked from. The faulty position of a letter in writing sometimes spoils the whole performance.

Situation and position when applied to persons are similarly distinguished; the situation is that in which a man finds himself, either with or without his own choice; the position is that in which he is placed without his own choice.

Place, situation, and station have an extended signification in respect to men in civil society, that is, either to their circumstances or actions; post has no other sense when applied to persons. Place is as indefinite as before; it may be taken for that share which we personally have in society either generally, as when every one is said to fill a place in society, or particularly for a specific share of its business, as to fill a place under government: situation is that kind of place which specifies either our share in its business, but with a higher import than the general term place, or a share in its gains and losses, as the prosperous or adverse situation of a man: a station is that kind of place which denotes a share in its relative consequence, power, and honor, in which sense every man holds a certain station; the post is that kind of place in which he has a specific share in the duties of society; the situation comprehends many duties, but the post includes properly one duty only, the word being figuratively employed from the post or particular spot which a soldier is said to occupy. A clerk in a counting-house fills a place: a clergyman holds a situation by virtue of his office; he is in the station of a gentleman by reason of his education as well as his situation: a faithful minister will always consider his post to be there where good is to be done.

See Office; Put.

Place, Dispose, Order.-To place is to assign a place to a thing; to dispose is to place according to a certain rule; to order is to place in a certain order. To place is an unqualified act both as to the manner and circumstances of the action; to dispose is a qualified act; it is qualified as to the manner; the former is an act of expediency or necessity; the latter is an act of judgment or discretion. Things are often placed from the necessity of being placed in some way or another: they are disposed so as to appear to the best advantage. We may place a single object, but it is necessary that there should be several objects to be disposed. One places a book on a shelf, or disposes a number of books, according to their sizes, on different shelves.

To order and dispose are both taken in the sense of putting several things in some order, but dispose may be simply for the purpose of order and arrangement; ordering, on the other hand, comprehends command as well as regulation. Things are disposed in a shop to the best advantage, or, in the moral application, the thoughts are disposed; a man orders his family, or a commander orders the battle.

Place, Spot, Site.-A particular or given space is the idea common to these terms; but the former is general and indefinite, the latter specific. Place is llimited to no size or quantity; it may be large: but spot implies a very small place, such as, by a figure of speech, is supposed to be no larger than a spot: the term place is employed upon every occasion; the term spot is confined to very particular cases: we may often know in a general way the place where a thing is, but it is not easy after a series of years to find out the exact spot on which some event has happened. The place where our Saviour was buried is to be seen and pointed out, but not the very spot where he lay.

The site is the spot on which anything stands or is situated; it is more commonly applied to a building or any place marked out for a specific purpose; as the site on which a camp had been formed.

PLACID. See Calm.

Plain. See Apparent; Even; Frank; Sincere; Tangible.

PLAN. See Design; Premeditate; Syllabus.

PLANNING. See Scheming.

PlaUsible. See Colorable.

Play, Game, Sport. Play comes from Anglo-Saxon plegian, from plega, a fight, battle, sport. Game comes from Anglo-Saxon gamen, to play. Sport is derived from OId French disport, from 
the phrase se desporter (Latin dis, apart, and portare, to carry), meaning to carry one's self away from work or annoyance.

Play and game both include exercise, corporeal or mental, or both; but play is an unsystematic, game a systematic, exercise: children play when they merely run after each other, but this is no game; on the other hand, when they exercise with the ball according to any rule, this is a game; every game, therefore, is a play, but every play is not a game: trundling a hoop is a play, but not a game: cricket is both a play and a game. One person may have his play by himself, but there must be more than one to have a game. Play is adapted to infants; games to those who are more advanced in years. Play is sometimes taken for the act of amusing one's self with anything intellectual, and game for the act with which any game is played.

Play and sport signify any action or motion for pleasure, whether as it regards inan or animals; but play refers more to the action, and sport to the pleasure produced by the action.

Game and sport both imply an object pursued, but game comprehends an object of contest which is to be obtained by art, as the Olympic and other games of antiquity.

$S$ port comprehends a pleasurable object to be obtained by bodily exercise; as field sports, rustic sports, and the like.

Game may be extended figuratively to any object of pursuit; as the game is lost, the game is over.

Sport is sometimes used for the subject of sport to another.

Playful, Sportive.-Playful, or full of play, and sportive, disposed to sport, are taken in a sense similar to the primitive. Playful is applicable to youth or childhood, when there is the greatest disposition to play. Sportive is applied in a good sense to persons of maturer years. A person may be said to be sportive who indulges in harmless sport.

PLAYER. See Actor.

PLEAD. See APologize.

PLEADER. See Defender.

PLEASANT. See Agreeable; FACETIOUS.

PI,EASE. See Satisfy.
PLEASEd. See Glad.

PLEASING. See Agreenble.

PLEASURE, Joy, Delight, Charm. Pleasure, through French plaisir, from the Latin placere, to please or give content, is the generic term, involving in itself the common idea of the other terms. Joy (see Glad). Delight, from French déliter, Latin delectare, a frequentative of delicere, to allure (whence our adjective delicious is derived), signifies what allures the mind.

Pleasure is a term of most extensive use; it cmbraces one large class of our feelings and sensations, and is opposed to nothing but pain, which embraces the second class or division: joy and delight are but modes or modifications of pleasure, differing as to the degree and as to the objects or sources. Pleasure, in its peculiar acceptation, is smaller in degree than either joy or delight, but in its universal acceptation it defines no degree: the term is indifferently employed for the highest as well as the lowest degree: whereas joy and delight can be employed only to express a positively high degree. Pleasure is produced by any or every object; everything by which we are surrounded acts upon us more or less to produce it; we may have pleasure either from without or from within: pleasure from the gratification of our senses, from the excrcise of our affections, or the exercise of our understandings; pleasures from our own selves or pleasures from others: but joy is derived from the exercise of the affections; and delight either from the emotions or the understanding. In this manner we distinguish the pleasures of the table, social pleasures, or intellectual pleasures; the joy of meeting an old friend; or the delight of pursuing a favorite object.

Pleasures are either transitory or otherwise: joy is in its nature commonly short of duration; it springs from particular events; it is pleasure at high tide, but it may come and go as suddenly as the events which caused it: one's joy may be awakened and destroyed in quick succession. Delight is more fleeting even than joy, and much more intense than simple pleasure; delight arises from a state of outward circumstances which is naturally less 
durable than that of joy; but it is a state seldomer attainable and not so much at one's command as either pleasure or joy.

Pleasure, joy, and delight are likewise employed for the things which give pleasure, joy, or delight. Charm (see AtTraction) is used only in the sense of what charms or gives a high degree of pleasure, but not a degree equal to that of joy or delight, though greate: than of ordinary pleasure; pleasure intoxicates; the joys of heaven are objects of a Christian's pursuit; the delights of matrimony are lasting to those who are susceptible of true affection; the charms of rural scenery never fail of their effect whenever they offer themselves to the eye.

See also Coufort.

PLEDGE. See Deposit; EARNest.

PLENIPOTENTIARY. See AMBASSADOR.

PLENITUde. See Fulness.

Plentiful, Plenteous, Abundant, Copious, Ample. Plentiful and plenteous, signifying the presence of plenty, plenitude, or fulness, differ only in use, the former being mostly employed in the familiar, the latter in the grave, style. Plenty fills; abundance, in Latin abundantia (from abundo, to overflow, compounded of the intensive $a b$ and $u n d a$, a wave, signifying, literally, overflowing), does more, it leaves a superfluity; as that, however, which fills suffices as much as that which flows over, the term abundance is often employed promiscuously with that of plenty; we may say indifferently a plentiful harvest or an abundant harvest. Plentiful is, however, a more familiar term than abundant: we say, therefore, most commonly, plenty of provisions; plenty of food; plenty of corn, wine, and oil: but an abundance of words; an abundance of riches; an abundance of wit or humor. In certain years fruit is plentiful, and at other times grain is plentiful; in all cases we have abundant cause for gratitude to the Giver of all good things.

Copious, in Latin copiosus, from copia, or con, together, and opes, wealth, signifying having a store, and ample, from Latin amplus, spacious, are modes either of plenty or abundance: the former is employed in regard to what is collected or brought into one place; the term ample is employed only in regard to what may be narrowed or expanded; a copious stream of blood, or a copious flow of words, equally designate the quantity which is collected, as an ample provision, an ample store, an ample share, marks that which may at pleasure be increased or diminished.

Pliant. See Flexible.

PLOT. See Combination.

PLUCK. See Draw.

PLUNDER. See RAPINE; SACK; SPOLIATION.

PLUNGE, Dive. Plunge comes from a hypothetical Latin plumbicare, based on plumbum, lead, through French plonger, and means to fall into the water like the lead thrown out to plumb the depth. Dive, from Anglo-Saxon $d y f a n$, to immerse, is allied to dip, deep, etc.

One plunges sometimes in order to dive; but one may plunge without diving, and one may dive without plunging: to plunge is to dart head foremost into the water: to dive is to go to the bottom of the water or toward it; it is a good practice for bathers to plunge into the water when they first go in, although it is not advisable for them to dive; ducks frequently dive into the water without ever plunging. Thus far they differ in their natural sense; but in the figurative application they differ more widely: to plunge, in this case, is an act of rashness: to dive is an act of design: a young man hurried away by his passions will plunge into every extravagance when he comes into possession of his estate: a "nervy" speculator will often make a plunge in the stock or commodities markets for control of an interest.

POINT. See AIM.

POISE, Balance. For the derivations of poise and balance see CounTERPOISE.

To prise is properly to keep the weight from pressing on either side; to balance is to keep the balance even. The idea of bringing into an equilibrium is common to both terms, but a thing is poised as regards itself; it is balanced as regards other things; a person poises a plain stick in his hand when he wants it to lie even; he 
balances the stick if it has a particular weight at each end: a person may poise himself, but he balances others: when not on firm ground it is necessary to poise one's self; when two persons are situated one at each end of a beam they may balance one another. In the moral application they are similarly distinguished.

See also CodNTERPoIsE.

POISON, Venom. Poison, in French poison, Latin potio, a drink, is a general term; in its original meaning it signifies any potion which acts destructively upon the system. Venom, in French venin, Latin venenum, is a species of deadly or malignant poison: a poison may be either slow or quick; a venom is always most active in its nature: a poison must be administered inwardly to have its effect; a venom will act by an external application: the juice of the hellebore is a poison; the tongue of the adder and the tooth of the viper contain venom; many plants are unfit to be eaten on account of the poisonous quality which is in them; the Indians are in the habit of dipping the tips of their arrows in a venomous juice, which renders the slightest wound mortal.

The moral application of these terms is clearly drawn from their proper acceptation: the poison must be infused or injected into the subject; the venom acts upon him externally: bad principles are justly compared to a poison, which some are so unhappy as to suck in with their mother's milk; the shafts of envy are peculiarly venomous when directed against those in elevated stations.

POlite, Polished, Refined. Polite, from Latin polire, to make smooth (sce Civin), denotes a quality; polished, of a similar derivation, a state: he who is polite is so according to the rules of politeness; he who is polished is polished by the force of art: a polite man is, in regard to his behavior, a finished gentleman; but a rude person may be more or less polished and yet not free from rudeness. Refined rises in sense, both in regard to polite and polished: a man is indebted to nature, rather than to art, for his refinement; but his politeness or his polish is entirely the fruit of education. Politeness and polish do not ex- tend to anything but externals; refinement applies as much to the mind as the body: rules of conduct and good society will make a man polite; lessons in dancing will serve to give a polish; refined manners or principles will naturally arise out of refinement of men.

As polish extends only to the exterior, it is less liable to excess than refinement: when the language, the walk, and deportment of a man are polished, he is divested of all that can make him offensive in social intercourse; but if his temper be refined beyond a certain boundary, he loses the energy of character which is essential for maintaining his dignity against the rude shocks of human life.

See also Genteel; Well-bred.

POLITICAL, Politic. Political has the proper meaning of the word polity, which, from the Greek modireia and $\pi$ ì $ı$, a city, signifies the government either of a city or a country. Politic, like the word policy, has the improper meaning of the word polity, namely, that of elever management, because the affairs of states are sometimes managed with considerable art and finesse: hence we speak of political government as opposed to that which is ecclesiastic; and of politic conduct as opposed to that which is unwise and without foresight: in political questions, it is not politic for individuals to set themselves up in opposition to those who are in power; the study of politics, as a science, may make a man a clever statesman, but it may not always enable him to be truly politic in his private concerns.

pollute. See Contaninate;

DEBAUCi.

POLYCHROMATIC. See NACrEous.

POMP. See Magnificence.

POMPOUS. See Magisterial; THEATRICAL.

PONDER. See TIINK.

PONDEROUS. See HeavY.

POOR, PAUPER. Poor and pauper are both derived from the Latin pauper, Old French porre, poor. Poor is a term of general use; pauper is a term of particular use: a pauper is a poor man who lives upon alms or the relief of the parish: the former is, therefore, 
indefinite in its meaning; the latter conveys a reproachful idea. The word poor is used as a substantive only in the plural number; pauper is a substantive both in the singular and plural: the poor of the parish are, in general, a heavy burden upon the inhabitants: there are some persons who are not ashamed to live and die as paupers.

POPUlACE. See People.

PORTEND. See AUgur.

PORTION. See Deal; Part.

POSITION, Posture. Position (see also Place) is here the general term, posture the particular term. The position is that in which a body is placed in respect to other bodies: as the standing with one's face or back to an object is a position; but a posture is that position which a body assumes in respect to itself, as a sitting or reclining posture.

\section{See also Tenet.}

POSITIVe, Absolute, PerempTony. Positive, in Latin positivus, from positus, past participle of pono, to put or place, and a suffix, signifies placed or fixed, that is, fixed or established in the mind. Absolute, from Latin $a b$, away, and solutus, participle of solvere, to loosen, signifies uncontrolled by any external circumstances. Peremptory, in Latin peremptorius, from peremptor, a destroyer, per, utterly, and emere, to take, signifying to take away utterly, means removing all further question.

Positive and absolute are employed for either things or persons; peremptory for persons only, or for that which is personal. What is positive has a determinate existence; it is opposed to what is negative, indeterminate, or precarious; as positive good, positive pleasure or pain; what is absolute is without dependence or connection, it is opposed mostly to the relative or conditional, as absolute existence, absolute justice.

In regard to persons or what is personal, positive applies either to the assurance of a man or to the mannc $r$ of his expressing that assurance; a person may be positive in his own mind (see Confident), or he may make a positive assertion; absolute applies either to the mode of acting or the circumstances under which one acts, as to have an absolute possession or command, to make an absolute promise; peremptory is applied to the nature of the action or the manner of performing it; a command may be peremptory, and a tone peremptory. A positive assertion will remove doubt if made by one entitled to credit; an absolute promise will admit of no reservation on the part of the person making it. A peremptory command admits of no demur or remonstrance; a peremptory answer satisfies or puts to silence.

See also Actual; Categorical; Confident; Definite; Infallible.

\section{POSSESS. See Hold.}

POSSESSIONS. See Goods.

POSSESSOR, Proprietor, OWNER, Master. The possessor has the full power, if not the right, of the present disposal over the object of possession; the proprietor and owner have the unlimited right of transfer, but not always the power of immediate disposal. The proprietor and the owner are the same in signification, though not in application, the first term being used principally in regard to matters of importance; the latter on familiar occasions: the proprietor of an estate is a more suitable expression than the owner of an estate: the owner of a book is more becoming than the proprietor. The possessor and the master are commonly the same person when those things are in question which are subject to possession; but the terms are otherwise so different in their original meaning that they can scarcely admit of comparison: the possessor of a house is naturally the master of the house; and, in general, whatever a man possesses that he has in his power and is consequently master of; but we may have, legally, the right of possessing a thing over'which we have actually no power of control: in this case, we are nominally possessor, but virtually not master. A minor, or insane person, may be both possessor and proprietor of that over which he has no control; a man is, therefore, on the other hand, appropriately denominated master, not possessor, of his actions.

POSSIble, Practicable, PracTICAL. Possible, from the Latin posse, to be able, and a suffix, signifies properly able to be done: practicable, 
compounded of Latin practicus, Greek . do, and a suffix, signifies to be able to put in practice: hence the difference between possible and practicable is the same as between doing a thing at all or doing it as a rule. There are many things possible which cannot be called practicable; but what is practicable must, in its nature, be possible. The possible depends solely on the power of the agent; the practicable depends on circumstances: a child cannot say how much it is possible for him to learn until he has tried; schemes have sometimes everything apparently to recommend them to notice, but that which is of the first importance, namely, their practicability.

The practicable is that which may or can be practiced; the practical is that which is intended for practice: the former, therefore, applies to that which men devise to carry into practice: the latter to that which they have to practice: projectors ought to consider what is practicable; divines and moralists have to consider what is practical. The practicable is opposed to the impracticable; the practical to the theoretical or speculative.

POST. See Place.

POSTPONE. See Delay.

POSTURE. See Action; Position.

POTENT. See Powerful.

POTentate. See Prince.

POUND. See Break.

POUR, SpILl, Shed. Pour meant originally to purify or clarify by pressure, or pouring out, from Late Latin purare, Latin purus, pure. Spill is a Scandinavian word meaning to destroy or shed. Shed comes from AngloSaxon sceadan.

We pour with design; we spill by accident: we pour water over a plant or a bed; we spill it on the ground. To pour is an act of convenience; to spill and shed are acts more or less hurtful; the former is to cause to run in small quantities, the latter in large quantities: we pour wine out of a bottle into a glass; but the blood of a person is said to be spilled or shed when his life is violently taken away: what is poured is commonly no part of the body whence it is poured; but what is shed is no other than a component part; hence trees are said to shed their leaves, animals their hair, or human beings to shed tears. Hence the distinction between these words in their moral application.

POVERTy, Want, Pendry, InDIGENCE, NEED. Poverty, through French from Latin paupertatem, based on pauper, poor, which marks the condition of being poor, is a general state of fortune opposed to that of riches.

Poverty admits of different states or degrees which are expressed by the other terms. Want, from the verb to want, denotes, when taken absolutely, the want of the first necessaries, which is a permanent state, and a low state of poverty; but it may sometimes denote an occasional want, as a traveller in a desert may be exposed to want; or it may imply the want of particular things, as when we speak of our wants.

Penury, in Latin penuria, allied to Greek $\pi$ eiva, hunger, signifying extreme want, is poverty in its most abject state, which is always supposed to be as permanent as it is wretched, to which those who are already poor are brought, either by misfortune or imprudence.

Indigence, in Latin indigentia, from indigere, from ind, for, and egere, to be in need, to want, signifies the state of wanting such things as one has been habituated to or which are suited to one's station, and is properly applied to persons in the superior walks of life.

Need (see NECEssitr) implies a present want, or the state of wanting such things as the immediate occasion calls for: a temporary state to which persons of all conditions are exposed.

POWER, Strengti, Force, AuThority, Dominion. Power, from Anglo-French poër, which in Middle English developed a $w$; Late Latin potere, to be able, is the generic and universal term, comprehending in it that simple principle of nature which exists in all subjects. Strength, or the abstract quality of strong, and force (see ENERGY) are modes of power. These terms are all used either in a physical or a moral application. Power, in a physical sense, signifies whatever causes motion: strength that species of power that lies in the vital and muscular parts of the body. Strength is there- 
fore internal, and depends on the internal organization of the frame; power on the external circumstances. A man may have strength to move, but not the power, if he be bound with cords. Our strength is proportioned to the health of the body and the firmness of its make: our power may be increased by the help of instruments.

Power may be exerted or otherwise; force is power exerted or active; bodies have a power of resistance while in a state of rest, but they are moved by a certain force from other bodies.

The word power is used technically for the moving force.

In a moral acceptation, power, strength, and force may be applied to the same objects with a similar distinction: thus we may speak of the power of language generally; the strength of a person's expressions to convey the state of his own mind; and the force of terms, as to the extent of their meaning and fitness to convey the ideas of those who use them.

Power is either public or private, which brings it into alliance with authority (see INFLUeNCE). Civil power includes in it all that which enables us to have any influence or control over the actions, persons, property, etc., of others; authority is confined to that species of power which is derived from some legitimate source. Power exists independently of all right; authority is founded only on right. A king has often the power to be cruel, but he has never the authority to be so. Subjects have sometimes the power of overturning the government, but they can in no case have the authority.

Power is indefinite as to degree; one may have little or much power: dominion is a positive degree of power. A monarch's power may be limited by various circumstances; a despot exercises dominion over all his subjects, high and low. One is not said to get power over any object, but to get an object into one's power: on the other hand, we get a dominion over an object; thus some men have a dominion over the conscience of others.

Powerful, Potent, Mighty.-Powerful is full of power; potent, from the Latin potens, the present participle of the verb posse (whence possible is derived), sig- nifies, literally, being able or having power, and mighty signifies having might. Powerful is applicable to strength as well as power: a powerful man is one who by size and build can easily overpower another; and a powerful person is one who has much in his power: potent is used only in this latter sense, in which it expresses a larger extent of power: a potent monarch is much more' than a powerful prince: mighty expresses a still higher degree of power; might is power unlimited by any consideration or circumstance; a giant is called mighty in the physical sense, and genius is said to be mighty which takes everything within its grasp; the Supreme Being is entitled either Omnipotent or Almighty; but the latter term seems to convey the idea of boundless extent more forcibly than the former.

See also Herculean.

PRACTICABLE. See Possible.

PRACTICE. See Custom; ExerCISE.

PRAGMATISM, Practicalism, Humanism. These words all refer to a recent philosophy, "the most recent and (philosophically speaking) fashionable 'ism' that the new century has produced, known by some as Humanism, and by others as Pragmatism" (Academy, August 4, 1906). The philosophy teaches that the whole meaning of a conception expresses itself in practical consequences, either in the shape of conduct to be recommended or of experiences to be expected, if it is true. In short, "if it works, it is true." This was called practicalism by some because the test of truth is its results in practice (ultimately from Greek $\pi \rho a ́$ ' $\tau \varepsilon \iota \nu$, to do; but William James, the American exponent of the philosophy, gave it the name pragmatism, from the same Greek verb $\pi \rho a \dot{\tau} \tau \varepsilon \iota \nu$, which has the same meaning as practicalism but is a trifle more euphonious. Humanism, from Latin humanus, pertaining to man, from homo, man, is applied to the philosophy because it judges truth not; by abstract or theoretical principles, but simply by its practical outcome in human life. But the objection to the title humanism is that the word has already been applied to the work of the 
scholars of the Renaissance who revived the ideal of a perfect "human" life, on the basis of the Greek and Roman art, as contrasted with the spiritual ideal of the mediæval theologians. Hence, when humanism is used for pragmatism, there is confusion. As is the case with most new words, the difference between the synonymes is not one of meaning, but of customary usage.

PRAISE, Commend, ApplaUd, ExToL. Praise, through French preis, is connected with our own word price (Latin pretium), signifying to give a value to a thing. Commend, in Latin commendo, compounded of con, together, and mandare, to put into the hands, signifies to commit to the good opinion of others. Applaud (see APplause). Extol, in Latin $e x$, beyond, and tollere, to lift, signifies to lift up very high.

All these terms denote the act of expressing approbation. To praise is the most general and indefinite; it may rise to a high degrce, but it generally implies a lower degree: we praise a person generally; we commend him particularly: we praise him for his diligence, sobriety, and the like; we commend him for his performanees, or for any particular instance of prudence or good conduct. To applaud is an ardent mode of praising; we applaud a person for his nobility of spirit: to extol is a reverential mode of praising; we extol a man for his heroic exploits. Praise is confined to no station, though with most propriety bestowed by superiors on equals: commendation is the part of a superior; a parent commends his child for an act of charity: applause is the act of many as well as of one; theatrical performances are the frequent subjects of public applause: to extol is the act of inferiors, who declare thus decidedly their sense of a person's superiority.

PRAISEWORTHY. See LAUDABLE.

PRANK. See Frolic.

PRATTLE. See BabBle.

PRAYER, PetrTION, REQCest, ENTreaty, Surt. Prayer, from the Old French preier, Latin precari, to pray, is a general term, including the common idea of application to some person for any favor to be granted: petition, based on petere, to seek; request (see AsK); entreaty (see $\mathrm{BEg}$ ); suit, from sue, in Anglo-French suer, Latin sequi, to follow after, denote different modes of prayer, varying in the circumstances of the action and the object acted upon.

The prayer is made more commonly to the Supreme Being; the petition is made more generally to one's fellowcreatures; we may, however, pray our fellow-creatures, and petition our Creator: the prayer is made for everything which is of the first importance to us as living beings; the petition is made for that which may satisfy our desires: hence our prayers to the Almighty concern all our circumstances as moral and responsible agents; our petitions the temporary circumstances of our present existence.

When the term prayer is applied to men, it carries with it the idea of earnestness and submission; the petition is a public act, in which many express their wishes to the Supreme Authority; the request and entreaty are individual acts between men in their private relations: the people petition the king or the parliament; a child makes a request to its parent; one friend makes a request to another. The request marks an equality, but the entreaty defines no condition; it differs, however, from the former in the nature of the object and the mode of preferring; the request is but a simple expression; the entreaty is urgent: the request may be made in trivial matters; the entreaty is made in matters that deeply interest the feelings: we request a friend to lend us a book; we use every entreaty in order to divert a person from those purposes which we think detrimental: one complies with a request; one yields to entreaties. It was the dying request of Socrates that they would sacrifice a cock to Esculapius; Regulus was deaf to every entreaty of his friends, who wished him not to return to Carthage.

The suit is a higher kind of prayer, varying both in the nature of the subject and the character of the agent. A gentleman pays his suit to a lady; a courtier makes his suit to the prince: suit in legal nomenclature meant originally a petition or a prayer.

PREARRANGE. See

PremediTATE. 
PRECARIOUS. See DoubTFul. PRECEDENCE. See PRIORITY. PRECEDENT. See EXaMple. PRECEDING. See ANTECEDENT. PRECEPT. See Command; DocTRINE; MAXIM.

PRECEPTIVE. See Didactic.

PRECINCT. See Border.

PRECIOUS. See Valuable.

PRECIPITATE. See SUdDEN.

PRECISE. See ACcurate.

PREClUde. See Prevent.

PRECONTRIVE. See Premedi-

TATE.

PRECURSOR. See ForerdNNER.

PREDETERMINE. See PremediTATE.

PREDICAMENT. See Situation. PREDICT. See ForETELL.

PREDOMINAN'T. See PREVaIL ING; SUPREME.

PRE-EMINENCE. See Priority. PRE-EMINENT. See SUPREME.

PREFACE. See Prelude.

PREFer. See Choose; Encourage. PREFERABLE. See Eligible. PREFERENCE. See PrIoRITY. PREJUDICE. See BIAS; DISADVANTAGE.

PRELIMINARY. See Previous.

PRElUde, Preface. Prelude, from the Latin pre, before, and ludere, to play; signifies the game that precedes another; preface, from the Latin fari, to speak, signifies the speech that precedes. The idea of a preparatory introduction is included in both these terms; but the former consists of actions, the latter of words: the throwing of stones and breaking of windows is the prelude on the part of a mob to a general riot, and apology for one's ill behavior is sometimes the preface to soliciting a remission of punishment. The prelude is frequently, though not always, preparatory to that which is in itself actually bad: the preface is either to guard against something objectionable or to secure something desirable. Intemperance in liquor is the prelude to every other extravagance; when one wishes to insure compliance with a request that may possibly be unreasonable, it is necessary to pave the way by some suitable preface.

In the extended application they are both taken in an indifferent sense.
PREMEditate, Plan, Prearrange, Precontrive, Predeterine, Propose. Premeditate, from Latin proe, before, and meditari, to think, means to think over something beforehand. Plan, from Latin planum, a flat surface, means properly a drawing on a flat surface-hence an outline of what is to be done. It has, therefore, more specific reference to action than premeditate. Precontrive means to contrive beforehand. (For derivation and meaning see CoNTrive.) It suggests a working out of petty details and ad. justment of the relations of the parts of a plan, and is applied to comparatively small projects, whereas plan may be applied to anything. Prearrange (see Class) also suggests the adjust. ment beforehand, but not the petty ingenuity of precontrive. Predetermine is to determine beforehand (see DETERMINE), and propose, from Latin pro, before, and French poser, to place, has a similar meaning. But propose means merely to place the possibility of a future course before the mind; predetermine suggests also an action of the will.

PRemise, Presume. Premise, from pro and missum, the past participle of mittere, signifies to set down beforehand; presume, from pro and sumere, to take, or take up, signifies to take up or accept beforehand. Both these terms are employed in regard to our previous assertions or admissions of any circumstance; the former is used for what is theoretical or belongs to opinions; the latter is used for what is practical or belongs to facts: we premise that the existence of a Deity is unquestionable when we ar. gue respecting His attributes; we pre sume that a person has a firm belief in Divine revelation when we exhort him to follow the precepts of the Gospel. No argument can be pursued until we have premised those points upon which both parties are to agree; we must be careful not to presume upon more than what we are fully authorized to take for certain.

PREPARATORY. See Previods.

PREPARE. See FIT.

PREPAREDNESS, PREPARATION. Preparedness is a substantive developed recently in the United States 
from the past participle of the verb prepare, and means prepared for war. It has in itself no other meaning than is implied in the substantive corresponding to prepare, already in existence -i.e., preparation; but it derives its special significance and vogue from the agitation for increased armaments. It cannot be substituted for preparation in other connections. Preparation is the normal substantive corresponding to prepare.

Thus we plan things ahead of the time when wanted or to be done; we prearrange family matters before our death; we precontrive or experiment with transactions before results are needed; we predetermine or settle a problem or future action in our minds before it is necessary to accomplish it; and we propose something that may become a settled matter in the future.

PREPONDERATE. See OverbalANCE.

PREPOSSESSION. See BENT; Bras.

PREPOSTEROUS. See IRRATIONAL.

PRerogative. See Privilege.

PRESAGE. See AUgUR; OMEN.

PRESCRIBE. See APPOINT; DICTATE.

PRESCRIPTION. See UsAge.

PRESENT. See GIFT; INTRODUCE. PRESERVATION. See Salvation. PRESERVE. See KeEP; SAVE.

PRESS, SQueeze, Pinch, Gripe. Press, in Latin pressus, participle of premere, to press. Squeeze comes from Anglo-Saxon cwiesan, to crush, with the addition of $e s$, from the Old French prefix es (Latin ex) which has a privative force. Pinch is a nasalized form of Italian picciare or pizzare, North French pincher, meaning to prick with a sharp-pointed instrument-a pick or pike; it is not now applied to a pricking, however. Gripe, a word now scldom used in this spelling, and generally substituted by the analogous grip, is in Anglo-Saxon gripan.

The forcible action of one body on another is included in all these terms. In the word press this is the only idea; the rest differ in the circumstances. We may press with the foot, the hand, the whole body, or any particular limb; one squeezes commonly with the hand; one pinches either with the fingers or an instrument constructed in a similar form; one gripes with teeth, claws, or any instrument that can gain a hold upon the object. Inanimate as well as animate objects press or pinch; but to squeeze and gripe are more properly the actions of animate objects; the former is always said of persons, the latter of animals; stones press that on which they rest their weight; a door which shuts of itself may pinch the fingers; one squeezes the hand of a friend; lobsters and many other shell-fish gripe whatever comes within their claws.

In the figurative application they have a similar distinction; we press a person, by importunity, to some coercive measure; an extortioner squeezes in order to get that which is given with reluctance or difficulty; a miser pinches himself if he contracts his subsistence; he gripes (in modern parlance, grips) all that comes within his possession.

Press, Massage. - Massage, from French massage, signifying kneading, ultimately from massa, dough, is a certain kind of pressing, technically defined as "motion with pressure" used in the treatment of certain forms of physical illness and weakness. It is thercfore a special and somewhat technical word corresponding to the general word press.

Pressing, Urgent, Importunate.Pressing and urgent, from to press and urge, are applied as qualifying terms either to persons or things; importunate, from the verb to importune (based on Late Latin importunatus, past participle of importunari, compounded of in, privative, and portus, port, no port, $i$. e., difficult of access), is applied only to persons. In regard to pressing, it is said either of one's demands, one's requests, or one's exhortations; urgent is said of one's solicitations or entreaties; importunate is said oi one's begging or applying for a thing. The pressing has more of violence in it; it is supported by force and authority; it is employed in matters of right: the urgent makes an appeal to onc's feelings; it is more persuasive, and is employed in matters of favor: the importunate has some of the force, but none of the authority 
or obligation, of the pressing; it is employed in matters of personal gratification. When applied to things, pressing is as much more forcible than urgent as in the former case; we speak of a pressing necessity, an urgent case. A creditor will be pressing for his money when he fears to lose it; one friend is urgent with another to intercede in his behalf; beggars are commonly importunate with the hope of teasing others out of their money.

PRESUME. See Premise.

PRESUMPTION. See ArRogance; ASSUMPTION.

PRESUMPTIVE, Presumptuous, Presuming. Presumptive comes from presume, in the sense of supposing or taking for granted; presumptuous, presuming (see AssUMPTION), comes from the same verb in the sense of taking upon one's self, or taking to one's self, any importance: the former is therefore employed in an indifferent, the latter in a bad, acceptation: a presumptive heir is one presumed or expected to be heir; presumptive evidence is evidence founded on some presumption or supposition; so likewise presumptive reasoning; but a presumptuous man, a presumptuous thought, or presumptuous behavior, all indicate an unauthorized presumption in one's own favor. Presumptuous is a stronger term than presuming, because it has a more definite use; the former, from the termination ous, signifies full of presumption; the latter the inclination to presume: a man is presumptuous when his conduct partakes of the nature of presumption; he is presuming, inasmuch as he shows himself disposed to presume: hence we speak of presumptwous language, not presuming language: a presuming temper, not a presumptuous temper. In like manner, when one says it is presumptuous in a man to do anything, this expresses the idea of presumption much more forcibly than to say it is presuming in him to do it. It would be presumptuous in a man to address a monarch in a language of familiarity and disrespect; it is presuming in a common person to address any one who is superior in station with familiarity and disrespect.

PRETENCE,
TEXT, Excuse. Pretence comes from pretend (see FeigN) in the sense of setting forth anything independent of ourselves. Pretension comes from the same verb in the sense of setting forth anything that depends upon ourselves. The pretence is commonly a misrepresentation; the pretension is frequently a miscalculation: the pretence is set forth to conceal what is bad in one's self; the pretension is set forth to display what is good: the former betrays one's falsehood, the latter one's conceit or self-importance; the former can never be employed in a good sense, the latter may sometimes be employed in an indifferent sense: a man of bad character may make a pretence of religion by adopting an outward profession; men of the least merit often disp'ay the highest pretensions.

The pretence and pretext alike consist of what is unreal; but the former is not so great a violation of truth as the latter: the pretence may consist of truth and falsehood blended; the pretext consists altogether of falsehood: the pretence may sometimes serve only to conceal or palliate a fault; the pretext serves to hide something seriously culpable or wicked: a child may make indisposition a pretence for idleness; a thief makes his acquaintance with the servants a pretext for getting admittance into a house.

The pretence and excuse are both set forth to justify one's conduct in the eyes of others; but the pretence always conceals something more or less culpable, and by a greater or less violation of truth; the excuse may sometimes justify that which is justifiable, and with strict regard to truth. To oblige one's self under the pretence of obliging another is a contemptible trick; illness is an allowable excuse to justify any omission in business. And even where the excuse may be frivolous it does not imply direct falsehood.

Pretension, Claim. - Pretension and claim (see Ask) both signify an assertion of rights, but they differ in the nature of the rights. The first refers only to the rights which are considered as such by the individual; the latter to those which exist independently of his supposition: there cannot, therefore, be a pretension without some one 
to "pretend, but there may be a claim without any immediate claimant: thus we say a person rests his pretension to the crown upon the ground of being descended from the former king; in hereditary monarchies there is no one who has any claim to the crown except the next heir in succession.

The pretension is commonly built upon personal merits; the claim rests upon the laws of civil society: a person makes high pretensions who estimates his merits and consequent deserts at a high rate; he judges of his claims according as they are supported by the laws of his country or the circumstances of the case: the pretension when denied can never be proved; the claim, when proved, can be enforced.

PRETEXT. See Pretence.

PRETTY. See BEAUTIFUL.

PREVAIling, Prevalent, Ruling, Overruling, Predominant. Prevailing and prevalent both come from the Latin pravalere, to be strong above others. Ruling, overruling, and predominant (from dominari, itself derived from dominus, lord) signify ruling or bearing greater sway than others.

Prevailing expresses the actual state or quality of a particular object: prevalent marks the quality of prevailing, as it affects objects in general. The same distinction exists between overruling and predominant. A person has a prevailing sense of religion; religious feeling is prevalent in a country or in a community. There is always some prevailing fashion which some persons are ever ready to follow. The idea has of late years become prevalent.

Prevailing and prevalent mark simply the existing state of superiority: ruling and predominant express this state in relation to some other which it has superseded or reduced to a state of inferiority. An opinion is said to be prevailing as respects the number of persons by whom it is maintained: a principle is said to be ruling as respects the superior influence which it has over the conduct of men more than any other. Particular disorders are prevalent at certain seasons of the year, when they affect the generality of persons: a particular taste or fashion is predominant which supersedes all other tastes or fashions.
PREVAIL UPON. See Persuade. PREVAlent. See Prevailing. PREVARICATE. See EVADE.

PREVENT, ANTICIPATE. To prevent is literally to come beforehand, from Latin pra, before, and venire, to come; and anticipate to take beforehand, from Latin ante, before, and a weakened form of the verb capere, to take. The former is employed for actual occurrences; the latter as much for calculations as for actions: to prevent is the act of a person toward other persons or things; to anticipate is the act of a being either toward himself or another. In this original and now obsolete sense God is said to prevent man with His favor by interposing so as to direct his purposes to the right object.

So also a man may prevent what is to happen by causing it to happen before the time.

We anticipate the happiness which we are to enjoy in future; we anticipate what a person is going to say by saying the same thing before him.

Prevent, in its modern use, is always taken in the sense of causing a thing not to be done: anticipate may also be so used, but with this distinction, that to prevent is to cause a thing not to be done or happen at all, and anticipate is to prevent another from doing it by doing it one's self.

Prevent, Obviate, Preclude.-All these terms imply the causing something not to take place or exist. To prevent (see HINDER) is to cause something to happen before, so as to render another thing impractieable. To obviate, from ob, beforc, opposite, and via, way, significs coming in the way so as to render the thing unnecessary or of no value. Prevent applies to events or circumstances in life; obviate to mental acts or objects: bad weather prevents a person setting out according to a certain arrangement; a change of plan obviates every difficulty.

To preclude, from Latin proe and cludere, based on claudere, to shut, and signifying to shut out a possibility by the intervention of something else, is, like obviate, applied to mental objects.

To present and preclude are rather the act of the thing than of the person; to obviate is rather the act of the person than of the thing. Circumstances 
may prevent or preclude anything from happening: a person obviates a diffculty or objection; so, according to this distinction, we may say either to obviate a necessity or to preclude a necessity for anything, according as this is effected by any person or by any circumstance.

PREVIOUS, Preliminary, PreparATORY, INTRODUCTORY. Previous, in Latin provius, compounded of pro, before, and via, way, signifies leading the way or going before. Preliminary, from proe and limen, a threshold, signifies belonging to the threshold or entrance. Preparatory and introductory signify belonging to a preparation or introduction.

Previous denotes simply the order of succession: the other terms, in addition to this, convey the idea of connection between the objects which succeed each other. Previous applies to actions and proceedings in general; as a previous question, a previous inquiry, a previous determination: preliminary is employed only for matters of contract: a preliminary article, a preliminary condition, are what precede the final settlement of any question: preparatory is employed for matters of arrangement; the disposing of men in battle is preparatory to an engagement; the making of marriage deeds and contracts is preparatory to the final solemnization of the marriage: introductory is employed for matters of science or discussion; as remarks are introductory to the main subject in question: compendiums of grammar, geography, and the like, as introductory to larger works, are useful to young people. Prudent people are careful to make every previous inquiry before they seriously enter into engagements with strangers: it is impolitic to enter into details until all preliminary matters are fully adjusted: one ought never to undertake any important matter without first adopting every preparatory measure that can facilitate its prosecution: in complicated matters it is necessary to have something introductory by way of explanation.

See also ANTECEDENT.

PREY. See BOOTY.

PRICE. See Cost; Valde.
PRIDE, VANity, Conceit. Pride comes from Anglo-Saxon pryte, from prut, proud, valiant, notable, which seems to be of French origin. It meant valiant, notable; hence a consciousness of being valiant and notable. Vanity, Latin vanitas, comes from vanus, empty, signifying a pride that has no basis in reality. Conceit (see that word).

The valuing of one's self for the possession of any property is the idea common to these terms, but they differ either in regard to the object or the manner of the action. Pride is the term of most extensive import and application, and comprehends in its signification not only that of the other two terms, but likewise ideas peculiar to itself. Pride is applicable to every object, good or bad, high or low, small or great; vanity is applicable only to small objects: pride is therefore good or bad: vanity is always bad, it is always emptiness or nothingness. A man is proud who values himself for his possession of literary or scientific talent, for his wealth, his rank, his power, his acquirements, or his superiority over his competitors; he is vain of his person, his dress, his walk, or anything that is frivolous. Pride is the inherent quality in man; and, while it rests on noble objects, it is his noblest characteristic; vanity is the distortion of one's nature resulting from inherent tendency or an injudicious education: pride shows itself variously, according to the nature of the object on which it is fixed; a noble pride seeks to display itself in all that can command the respect or admiration of mankind; the pride of wealth, of power, or of other adventitious properties, commonly displays itself in unseemly deportment toward others; vanity shows itself in false pretensions.

Pride, in the limited and bad sense, is always associated with strength and produces more or less violence; vanity is coupled with weakness.

Conceit is that species of self-valuation that respects one's talents only; in so far, therefore, it is closely allied to pride; a man is said to be proud of that which he really has, but to be conceited of that which he really has not: a man may be proud to an excess 
of merits which he actually possesses; but when he is conceited, his merits are all in his own conceit; the latter is therefore obviously founded on falsehood altogether. As self-conceit is the offspring of ignorance and vanity, it is most frequently found in youth, but as it is the greatest obstacle to improvement, it may grow up with a person and go on with him through life.

Pride, Haughtiness, Loftiness, Dignity.-Pride is employed principally as respects the temper of the mind: haughtiness (see Haughtr) and loftiness (see HigH) concerns either the temper of mind or the external behavior. Dignity (see HoNOR) only the external behavior. Pride is, as before, the general term; the others are modes of pride. Pride, inasmuch as it consists purely of self-esteem, is a positive sentiment which one may entertain independently of other persons: it lies in the inmost recesses of the human heart, and mingles itself insensibly with our affections and passions. Haughtiness is that mode of pride which springs out of comparison of one's self with others; the haughty man dwells on the inferiority of others; the proud man, in the strict sense, dwells on his own perfections. Loftiness is a mode of pride which raises the spirit above objects supposed to be inferior; it does not set man so much above others as above himself, or that which concerns himself.

As respects the exterior, pride in the behavior is always bad. But it is taken in an indifferent sense in application to animals or unconscious agents.

Haughtiness in one's earriage, and loftiness in one's tone or air, are mostly unbecoming and seldom warranted.

Dignity, which arises from a proper consciousness of what is due to one's self, is always taken in a good sense. It is natural to some men, and shows itself at all times; on other occasions it requires to be assumed.

PRIMARY, Primitive, Pristine, Original. Primary, from primus and the suffix arius, signifies belonging to or like the first. Primitive, from the same ordinal, signifies being the first. Pristine, in Latin pristinus, from prius, signifies in former times. Original signifies containing the origin, from the verb oriri, to rise or begin.
The primary denotes simply the order of succession, and is therefore the generic term; primitive, pristine, and original include also the idea of some other relation to the thing that succeeds, and are therefore modes of the primary. The primary has nothing to come before it; in this manner we speak of the primary cause as the cause which precedes secondary causes: the primitive is that after which other things are formed; in this manner a primitive word is that after which, or from which, the derivatives are formed: the pristine is that which follows the primitive, so as to become customary; there are but few specimens of the pristine purity of life among the professors of Christianity: the original is that which either gives birth to the thing or belongs to that which gives birth to the thing; the original meaning of a word is that which was given to it by the makers of the word.

\section{See also First.}

PRINCE, Monarce, Sovereign, Potentate. Prince, in French prince, Latin princeps, from primus and capere, to take, signifies the man who takes the first place. Monarch, from Latin mon-

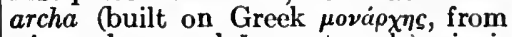

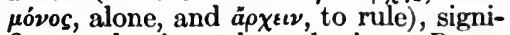
fies one having sole authority. Potentate, from potens, powerful, signifies one having supreme power. Sovereign is derived from Latin superanus.

Prince is the generic term, the rest are specific terms; every monarch, sotereign, and potentate is a prince, but not vice versâ. The term prince is indefinite as to the degree of power: a prince may have a limited or despotic power; but in its restricted sense it denotes a smaller degree of power than any of the other terms: the term monarch does not define the extent of the power, but simply that it is undivided, as opposed to that species of power which is lodged in the hands of many: sovereign and potentate indicate the highest degree of power; but the former is employed only as respects the nation that is governed, the latter in respect to other nations: a sovereign is supreme over his subjects; a potentate is powerful by means of his subjects. Every man having independent power is a prince; let his territory be ever so in- 
considerable: Germany was divided into a number of small states, governed by their petty princes. Every one reigning by himself in a state of some considerable magnitude, and having independent authority over his subjects, is a monarch; kings and emperors, therefore, are all monarchs. Every monarch is a sovereign whose extent of dominion and number of subjects rises above the ordinary level; he is a potentate if his influence either in the cabinet or in the field extends very considerably over the affairs of other nations.

PRINCIPAL. See Chinf; SuPREME.

PRINCIPALLY. See Espectally.

PRINCIPLE, Motive. The principle (see Doctrine) may sometimes be the motive; but often there is a principle where there is no motive, and there is a motive where there is no principle. The principle lies in conscious and unconscious agents; the motive only in conscious agents; all nature is guided by certain principles; its movements go forward upon certain principles: man is put into action by certain motives; the principle is the prime moving cause of everything that is set in motion; the motive is the prime moving cause that sets the human machine into action. The principle in its restricted sense comes still nearer to the motive, when it refers to the opinions which we form: the principle in this case is that idea which we form of things so as to regulate our conduct; the motive is that idea which simply impels to action: the former is therefore something permanent, and grounded upon the exercise of our reasoning powers; the latter is momentary and arises simply from our capacity of willing and thinking: bad principles lead a man into a bad course of life; but a man may be led by bad motives to do what is good as well as what is bad.

See also CHIEF.

PRINT. See Mark; Picture.

PRIOR. See ANTECEDENT.

PRIORITY, Precedence, Pre-EMInence, Preference. Priority denotes the abstract quality of being before others: precedence, from pro, before, and cedere, to go, signifies the act of going before: pre-eminence signifies be- ing more eminent or elevated than others: preference signifies being put before others. Priority implies simply the order of succession, and is applied to objects either in a state of motion or rest; precedence signifies priority in going, and depends upon a right or privilege; pre-eminence signifies priority in being, and depends upon merit; preference signifies priority in placing, and depends upon favor. The priority is applicable rather to the thing than the person; it is not that which is sought for, but that which is to be had: age frequently gives priority where every other claim is wanting. The immoderate desire for precedence is often nothing but a childish vanity; it is a distinction that results from rank and power; a nobleman claims a precedence on all occasions of ceremony. The love of pre-eminence is laudable inasmuch as it requires a degree of moral worth which exceeds that of others; a general aims at pre-eminence in his profession. Those who are anxious to obtain the best for themselves are eager to have the preference: we seek for the preference in matters of choice.

PRISTINE. See Primary.

PRIVACy, Retirenent, Seclusion. Privacy literally denotes the abstract quality of private (from the Latin adjective privatus, based on privare); but when taken by itself it signifies the state of being private: retircment literally signifies the abstract act of retiring: and seclusion that of secluding one's self: but retirement by itself frequently denotes a state of being retired or a place of retirement; seclusion, a state of being secluded: hence we say a person lives in privacy, in retirement, in seclusion: privacy is opposed to publicity; he who lives in privacy, therefore, is one who follows no public line, who lives so as to be little known: retirement is opposed to openness or freedom of access; he, therefore, who lives in retirement withdraws from the society of others, he lives by himself: seclusion is the excess of retirement; he who lives in seclusion bars all access to himself; he shuts himself from the world. Privacy is most suitable for such as are in circumstances of humiliation, whether from their misfortune or their fault; retirement is peculiarly agreeable 
to those who are of a reflective turn, but seclusion is chosen only by those who labor under some strong affection of the mind, whether of a religious or a physical nature.

PRIVATE-CARRIER. See CoMMON-CARRIER.

PRIVATE MEETING. See CAUcus.

PRIVilege, Prerogative, ExEMPTION, IMMUNity. Privilege, in Latin privilegium, compounded of privus and lex, signifies a law made for any individual or set of individuals. Prerogative, from Latin prorogativa (sc., tribus or centuria), based on pra, before, and rogare, to ask, was applied to the tribe or century to whom it fell by lot to vote first in the Comitia, which was asked first whom it would have for consul: hence applied in our language to the right of determining or choosing first in many particulars. Exemption, from the verb to exempt, and immunity, from the Latin immunis, free of public service, from in, not, and munis, not ready to serve, based on munus, a public office, are both employed for the object from which one is exempt or free.

Privilege and prerogative consist of positive advantages; exemption and immunity of those which are negative: by the former we obtain an actual good, by the latter the removal of an evil. Privilege, in its most extended sensc, comprehends all the rest: for prerogative, exemption, and immunity are privileges, inasmuch as they rest upon certain laws or customs which are made for the benefit of certain individuals. In the restrieted sense, the privilege may be enjoyed by many; the prerogative, which is a peculiar and distinguished privilege, can be enjoyed only by a few. As they concern the public, privileges belong to the subject or are granted to him; prerogatives belong to the crown. It is the privilege of a member of Parliament to escape arrest for debt; it is the prerogative of the crown to be irresponsible for the conduct of its ministers; as respeets private cases, it is the privilege of women to have the best places assigned to them; it is the prerogative of the man to address the woman.

Privileges are applied to every object which it is desirable to have; prerogative is confined to the case of making one's election or exercising any special power; exemption is applicable to cases in which one is exempted from any tribute or payment; immunity, because of its derivation above explained, is peculiarly applicable to cases in which one is freed from a service: all chartered towns or corporations have privileges, exemptions, and immunities: it is the privilege of the city of London to shut its gates against the king.

See also Righr.

PRIZE. See Capture; Value.

PROBABILITY. See ChaNce.

PROBITY. See HoNESTY.

PROCEED. See Advance; ArISE; Go.

PROCEEDing, Process, ProGREss. The first two of these words are based on Latin pro, forward, and the verb cedere, in the sense of go; the last on progredior, to advance. The manner of performing actions for the attainment of a given end is the common idea comprehended in these terms. Proceeding is the most general, as it simply expresses the general idea of the manner of going on; the rest are specific terms, denoting some particularity in the action, object, or circumstance. Proceeding is said commonly of such things as happen in the ordinary way of doing business; process is said of such things as are done by rule: the former is considered from a moral point of view; the latter from a scientific or technical standpoint: Freemasons have bound themselves by a law of secrecy not to reveal any part of their proceedings; the process by which paper is made has undergone considerable improvements sinee its first invention.

Proceeding and progress both refer to the moral actions of men; but the proceeding simply denotes the act of going on or doing something; the progress denotes an approximation to the end: the proceding may be only a partial action comprekending both the beginning and the end; but the progress is applied to that which re quires time and a regular succession of action to bring it to completion: that is a proceeding in which every man is tried in a court of law; that is a progress which one makes in learning, 
by the addition to one's knowledge: hence we do not talk of the proceeding of life, but of the progress of life.

Proceeding, Transaction.-Proceeding signifies, literally, the thing that proceeds; and transaction the thing transacted: the former, therefore, is used of something that is going forward; the latter of something that is already done: we are witnesses to the whole proceeding; we inquire into the whole transaction. The term proceeding is said of every event or circumstance which goes forward through the agency of men; transaction comprehends only those matters which have been deliberately transacted or brought to a conclusion: in this sense we use the word proceeding in application to a disturbance in the street; and the word transaction to some commercial negotiation that has been carried on between certain persons. The term proceeding marks the manner of proceeding; "as when we speak of the proceedings in a court of law: transaction marks the business transacted; as the transactions on the Exchange. A proceeding may be characterized as disgraceful; a transaction as iniquitous.

Procession, Train, Retinue-Procession, from the verb proceed, signifies the act of going forward or before, that is, in the present instance, of going before others, or one before another. Train, from Old French traïn, Low Latin trahinare, a derivative of classical trahere, to draw, signifies the thing drawn after another, as in the modern train, a succession of cars; and in the present instance the persons who are led after, or follow, any object. Retinue, from French retenue, past participle of retenir (from Latin $r e$ and tenere, to hold back, retain), signifies those who are retained as attendants.

All these terms are said of any number of persons who follow in a certain order; but this, which is the leading idea in the word procession, is but collateral in the terms train and retinue: on the other hand, the procession may consist of persons of all ranks and stations; but train and retinue apply only to such as follow some person or thing in a subordinate capacity: the former in regard to such as make up the concluding part of some procession, the latter only in regard to the servants or attendants on the great. At funerals there is frequently a long train of coaches belonging to the friends of the deceased, which close the procession; princes and nobles never go out on state or public occasions without a numerous retinue: the beauty of every procession consists in the order with which every one keeps his place and the regularity with which the whole goes forward; the length of a train is what renders it most worthy of notice; the number of a retinue in eastern nations is one criterion by which the wealth of the individual is estimated. PROCESS. See ProceEdING.

PROClAIM. See ANNoUnce; DeCLARE.

PROClaMATION. See Decree. PROCRASTINATE. See Delay. PROCURE. See GeT; Provide. PRODIGAL. See Extravagant. PRODIGIOUS. See ENormous. PRODIGY. See WONDER.

PRODUCTION, Produce, ProdठCT. The term production expresses either the act of producing or the thing produced; product and produce express only the thing produced: the production of a tree from a seed is one of the wonders of nature; the product will not be considerable. In the sense of the thing produced, production is applied to every individual thing that is produced, whether by nature or art, as a tree is a production or a painting is a production of art or skill: produce and product are properly applicable to those productions of nature which are made to turn to account; the former in a collective sense, and in reference to some particular object, the latter in an abstract and general sense: the aggregate quantity of grain drawn from a field is termed the produce of the field; but corn, hay, vegetables, and fruits in general are termed products of the earth: the naturalist examines all the productions of nature; the husbandman looks to the produce of his lands; the topographer and traveller inquire about the products of different countries.

There is the same distinction between these terms in their improper as in their proper acceptation; the production is whatever results from 
an effort, physical or mental, as a production of genius, a production of art, and the like; the produce is the aggregate result from physical or mental labor: thus, whatever the husbandman reaps from the cultivation of his land is termed the produce of his labor; whatever results from any public subscription or collection is, in like manner, the produce: the product is employed properly in regard to the mental operation of figures, as the product from multiplication, but may be extended to anything which is the fruit of the brain.

Production, Performance, Work.When we speak of anything as resulting from any specified operation, we term it a production: as the production of an author, signifying what he has produced by the effort of his mind: Homer's Iliad is esteemed as one of the finest productions of the imagination. When we speak of anything as executed or performed by some person, we term it a performance, as a drawing or a painting is denominated the performance of a particular artist. The term production cannot be employed without specifying or referring to the source from which it is produced or the means by which it is produced; as the production of art, the production of the inventive faculty, the production of the mind, etc.: but a performance may be spoken of without referring to the individual by whom it has been performed; hence we speak of this or that person's performance; but we may also say, a good performance. When we wish to specify anything that results from work or labor, it is termed a work: in this manner we speak either of the work of one's hands or of a work of the imagination, a work of time, a work of magnitude.

See also Afrord; EFFect; Make.

PROFANE. See Irreligious; SaCRILEGIOUS.

PROFESS, Declare. Profess, in Latin professus, participle of profiteor, compounded of pro and fateri, to speak, signifies to set forth or present to public view. Declare (see that word).

An exposition of one's thoughts or opinions is the common idea in the signification of these terms; but they differ in the manner of the action, as well as in the object: one professes by words or by actions; one declares by words only: a man professes to believe that on which he acts; but he declares his belief in it either with his lips or in his writings. A profession may be general and partial; it may amount to little more than an intimation: a declaration is positive and explicit; it leaves no one in doubt: a profession may, therefore, sometimes be hypocritical; he who professes may wish to imply that which is untrue: a declaration must be either directly true or false; he who declares expressly commits himself upon his veracity. One professes either as respects single actions or a regular course of conduct; one declares either passing thoughts or settled principles. A person professes to have walked to a certain distance, to have taken a certain route, and the like: a Christian professes to follow the doctrine and precepts of Christianity; a person declares that a thing is true or false, or he declares his firm belief in a thing.

To profess is employed only for what concerns one's self; to declare is also employed for what concerns others: one professes the motives and principles by which one is guided: one declares facts and circumstances with which one is acquainted: one professes nothing but what one thinks may be creditable and fit to be known; but one declares whatever may have fallen under one's notice or passed through one's mind, as the case requires; there is always a particular and private motive for profession; there are frequently public grounds for making a declaration.

See also Business.

PROFESSION. See Business; VoCATION.

PROFICIENCY. See Progress.

PROFIt. Sce Advantage; Gain.

PROFLIGATE, ABandoned, ReproBate. These words have all a close connection. Profligate, in Latin profligatus, participle of proftigo, compounded of the prefix pro, forward, down, and fligare, to dash, signifies properly one dashed down and destroyed; hence, by extension, wretched and then vile, used as a term of extreme reproach: so Cicero called Catiline "most profligate 
and abandoned of all mortals." Abandoned (see ABANDON). Reprobate (see REPROVE) signifies one thoroughly hardened to reproof.

A profligate man is one completely overcome and ruined by his vices: an abandoned man is one abandoned to his passions: the reprobate man is one who has been reproved until he becomes insensible to reproof and cannot be diverted from following his evil course.

PROFUNDITY. See DEPTH.

PROFUSE. See Extravagant.

PROFUSION, Profuseness. Profusion, from the Latin profundo, to pour forth, is taken in relation to unconscious objects, which pour forth in great plenty; profuseness is taken from the same, in relation to conscious agents, who likewise pour forth in great plenty: the term profusion, therefore, is put for plenty itself, and the term profuseness as a characteristic of persons in the sense of extravagance. At the hospitable board of the rich there will naturally be a profusion of everything which can gratify the appetite; when men see an unusual degree of profusion, they are apt to indulge themselves in profuseness.

PROGENITORS. See ForefathERS.

PROGENY. See OFFsPRING.

PROGNOSTIC. See OMEN.

PROGNOSTICATE. See ForeTELL.

PROGRESS, Progression, ADVANCEMENT. A forward motion is designated by these terms: but progress and progression simply imply this sort of motion; advance and advancement also imply an approximation to some object: we may make progress in that which has no specific termination, as progress in learning, which may cease only with life; but the advance is made only to some limited point or object in view; as an advance in wealth or honor, which may find a termination within the lifetime. Progress and advance are said of that which has been attained; but progression and advancement may be said of that which one is attaining: the progress or the advance has been made, or the person is in the act of progression or advancement: a child makes progress in learning by daily attention; the progression from one stage of learning to another is not always perceptible; it is not always possible to overtake one who is in advance; sometimes a person's advancement is retarded by circumstances thai are altogether contingent: the first step in any destructive course prepares for the second, and the second for the third, after which there is no stop, but the progress is infinite.

See also Procending.

Progress, Proficiency, Improvement.Progress is a generic term, the rest are specific; proficiency, from the Latin proficio, compounded of pro, forward, and a weakened form of facere, to do, signifies a state of progression-that is to say, a progress already made; and improvement, from the verb improve (see AMEND), signifies an improved condition-that is, progress in that which improves. The term progress here, as in the former paragraph, marks the step, or motion onward, and the two others the point already reached: but progress is applied either in the proper or improper sense: that is, either to those travelling forward or to those going on stepwise in any work; proficiency is applied, in the improper sense, to the ground gained in an art, and improvement to what is gained in knowledge, or understanding, or abilities; when idle people set about any work it is difficult to perceive that they make any progress in it from time to time; those who have a thorough taste for either music or drawing will show a proficiency in it which is astonishing to those who are unacquainted with the circumstances; the improvement of the mind can never be so effectually and easily obtained as in the period of childhood.

Progress and proficiency are applied to the acts of persons, but improvement denotes also the act or state of things; one must make progress or show proficiency, but things admit of improvement.

PROGRESSIVE. See ONWARD.

PROHIBIT. See BAN.

PROHIBITION. See Embargo.

PROJECT. See Design.

PROJECTING. See SAlitent.

PROLETARIAT, The MAsses, HoI Pollor. Proletariat, from Latin proletarius, one who helped the state by 
his children only (from proles, offspring), is a word which has come into general usage as a result of the popular interest in political economy during the later nineteenth century. It refers to the lowest class in an organized society, the laborers who have no capital and are dependent on the work of their hands from day to day for subsistence. The term the masses (from mass, a lump of unorganized, unmolded matter, from Greek $\mu a ́ \sigma \sigma \varepsilon \iota \nu$, to knead-that which may be or should be kneaded) is also a comparatively recent phrase. It has the same meaning as proletarial, but a slightly different meaning, emphasizing not the existence of the lower order, as a distinct order, but as a great multitude outside of the distinct classes. Having been used somewhat contemptuously, it has been adopted as a name of honor by some of the leaders among "the masses," as the title of one of their organs in America, The Masses, shows. Hoi polloi is the Greek phrase oi $\pi 0 \lambda \lambda$ oi, transliterated with Roman letters. It means, literally, "the many," and among the Greeks was opposed to "the few," as "the masses" were opposed by Gladstone to "the classes." It has much the same connotations as the masses, but is generally used in a somewhat flippant and frivolous tone, whereas the phrase the masses is becoming a word to conjure with, to be uttered in all seriousness.

See also Massage under Press.

PROLIFIC. See Fertile.

PROLIX. See Diffuse.

PROLONG. See Delay.

PROMINENT, CoNSPICUOUS. Prominent signifies hanging over; conspicuous (see Distinguished) signifies easy to be beheld: the former is, therefore, to the latter, in some measure, as the species to the genus; what is prominent is, in general, on that very account conspicuous; but many things may be conspicuous which are not expressly prominent: nothing is prominent but what projects beyond a certain line; everything is conspicuous which may be seen by many: the nose on a man's face is a prominent feature, owing to its projecting situation; and it is sometimes conspicuous, according to the position of the person: a figure in a painting is said to be prominent if it appears to stand forward or before the others; but it is not properly conspicuous unless there be something in it which attracts the general notice and distinguishes it from all other things; on the contrary, it is conspicuous, but not expressly prominent, when the colors are vivid.

PROMISCUOUS, INDISCRIMINATE. Promiscuous, in Latin promiscuus, compounded of the prefix pro and miscere, to mingle, signifies thoroughly mingled. Indiscriminate, from the Latin in, privative, and discrimen, a difference, signifies without any difference.

Promiscuous is applied to any number of different objects mingled together; indiscriminate is applied only to the action in which one does not discriminate different objects: a multitude is termed promiscuous, as characterizing the thing; the use of different things for the same purpose, or of the same things for different purposes, is termed indiscriminate, as characterizing the person: things bccome promiscuous by the want of design in any one; they are indiscriminate by the express intention of some one: plants of all descriptions are to be found promiscuously situated in the beds of a garden: it is folly to level any charge indiscriminately against all the members of any community or profession.

PROMISE, ENGageMENT, WolzD. Promise, in Latin promissus, from promitto, compounded of pro, before, and the past participle of miltere, to send; that is, in this application, to pledge be forehand, is specific, and consequently more binding than the engagement (see Business): we promise a thing in a set form of words that are clearly and strictly understood; we engage in general terms that may admit of alteration: a promise is mostly unconditional; an engagement is frequently conditional. In promises the faith of an individual is accepted upon his word and relied upon as if it were a deed: in engagements the intentions of an individual for the future are all that are either implied or understood: on the fulfilment of promises often depend the most important interests of individuals; an attention to engagements is a matter of mutual conven- 
ience in the ordinary concerns of life: a man makes a promise of payment, and upon his promise it may happen that many others depend for the fulfilment of their promises: when engagements are made to visit or meet others, the failure to observe such engagements causes great trouble.

As a promise and engagement can be made only by words, the word is of ten put for either, or for both, as the case requires: he who breaks his word in small matters cannot be trusted when he gives his word in matters of consequence.

PROMOTE. See Encourage.

PROMPT. See Diligent; Ready.

PROMUlgate. See Publish.

PRONENESS. See InClination.

PRONOUNCE. See UTTER.

PROOF, Evidence, Testimony. The proof (see ARGUMeNT) is that which simply proves; the evidence is that which makes evident (see CLEAR); the testimony, from testis, a witness, is a species of evidence by means of witnesses. In the legal acceptation of the terms proofs are commonly denominated evidence, because nothing can be admitted as proof which does not tend to make evident; but as what is proved is made more certain or indubitable than what is made evident, proof is more than evidence. Proof is likewise taken for the act of proving as well as for the thing that proves, which distinguishes it still further from evidence.

Evidence comprehends whatever is employed to make evident, be it words or deeds, be it writing or discourse; testimony is properly evidence by words spoken, and more strictly understood by the person giving the evidence.

In an extended application of these terms they are employed with a similar distinction: the proof is the mark or sign which proves: the evidence is the mark or sign which makes evident: the testimony is that which is offered or given by things personified in proof of anything.

The proof is employed for facts or physical objects: the evidence is applied to that which is moral; testimony regards that which is personal. All that our Saviour did and said were evidences of his divine character, which might have produced faith in the minds of many, even if they had not had such numerous and miraculous proofs of his power. One friend makes a present to another in testimony of his regard: the proof and the testimony are something external, or some outward mark or indication; the evidence may be internal or lie in the thing itself, as the internal evidences of Christianity.

See also EXPERIENCE.

PROP. See Staff.

PROPAGANDA. See Spread.

PROPENSITY. See INCLINATION.

PROPER. See RIGHT.

PROPERTY. See Estate; Goods; QUALITY.

PROPHESY. See Foretell.

PROPHETIC. See Oracular.

PROPITIOUS. See Auspicious; FAVORABLE.

PROPORTION. See RATE; SyMMETRY.

PROPORTIONATE, CoMmENSURate, Adequate. Proportion, from the Latin proportio, compounded of pro, suitable to, in ratio with, and portio, a share, signifies having a portion, suitable to, or in agreement with, some other object. Commensurate, from the Latin prefix com, based on cum, with, and mensuratus, the past participle of the post-classical mensurare, to measure, I measure, signifies measuring in accordance with some other thing, being suitable in measure to something else. Adequate, in Latin adoquatus, participle of adoquare, from $a d$, to, and aquus, equal, signifies made level with some other body.

Proportionate is here a term of general use; the others are particular terms, employed in a similar sense, in regard to particular objects: that is proportionate which rises as a thing rises and falls as a thing falls; that is commensurate which is made to rise to the same measure or degree; that is adequate which is made to come up to the height of another thing. Proportionate is employed either in the proper or improper sense; in recipes and prescriptions of every kind proportionate quantities must always be taken; when the task increases in difficulty and complication, a proportionate degree of labor and talent must be employed upon it. Commensurate and adequate are employed only in the moral sense, 
the former to denote suitability of things in point of measure, the latter to denote the equalizing of powers: a person's recompense should in some measure be commensurate with his labor and deserts: a person's resources should be adequate to the work he is engaged in.

PROPOSAL, Proposition. Proposal comes from propose, based on Latin pro and ponere, meaning to put forward, in the sense of offer: proposition comes from propose, in the sense of setting down in a distinet form of words. We make a proposal to a person to enter into a partnership with him; we make a proposition to one who is at variance with us to settle the difference by arbitration.

PROPOSE. See Offer; PremediTATE; PURPose.

\section{- PROPOSITION. See Proposal; SENTENCE.}

PROPRIETOR. See Possessor.

PROROGUE, ADJoUr. Prorogue, from the Latin prorogare, from pro, publicly, and rogare, to ask, means to propose an extension of office, to defer. Adjourn, from ad, to or until, and the French journée, the day, signifies only to put off for a day, or some short period: the former is applied to national assemblies only, the latter is applied to any meeting.

PROSCRIBE, BANISH, CoNDEMN, Denounce, Exile, Expel, Ostracize, Reject. Proscribe, in Iatin proscribere, from pro, before, openly, and scribere, to write, is virtually to put beyond the protection of the law by a written order. Banish, expel, and exile are closely allied applications signifying the act of driving or forcing a person from his country as a punishment by authority. Condemn is to censure, blame, declare to be forfeited, pronounce or judge guilty. Denounce is to threaten or accuse publicly; in diplomacy it is the act of abrogating a treaty. Ostracize meant originally to banish by a vote written on a potsherd, from Greek borpaxiלtuv, to banish

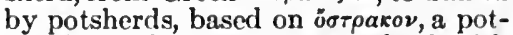
sherd, a tablet for voting, allied with oyster, which originally signified a shell. Ostracize differs from proscribe, banish, etc., in indicating a cutting off of the victim from social intercourse by a general, but often informal, withdrawing of favor on the part of a whole group or community. Reject is to discard, cast aside, all of which is applicable alike to persons and things.

In old Roman history, to proscribe a person was to publish his name as one doomed to death and forfeiture of property; in ancient Athens to banish a citizen was to throw a shell, inscribed with the name of the person, into an urn.

PROSECUTE. See Continue.

PROSELYTE. See CoNvert.

PROSPECT. See VIEW.

PROSPER. See FloURISH.

PROSPERITY. See WELL-BEING.

PROSPEROUS. See Fortunate.

PROTECT. See Defend; Save.

PROTEST, EXPOSTUlate, REMONSTRATE. These words all indicate the statement of an objection on the part of some one to the acts or statements of another. Protest, from Latin pro, publicly, and testor, I bear witness, is a more solemn and formal act than expostulate and remonstrate. In business, for instance, a protest is a formal declaration by the holder of a bill of exehange of its non-payment or nonacceptance. Remonstrate, from Latin $r e$, agninst, and monstrare, to show, is a mild form of protest in which the protesting party brings up arguments against a proposed course. To expostulate is a friendly form of remonstrating.

See also Ultimatom.

PROTRACT. See Delay.

PROUD. See Hign-Flows.

PROVE, Demonstrate, Evince, Manifest. Prove, in Latin probure, signifies to make good, $i$. e., to make good by proofs, which is here the general term; the other terms inply different modes of proving: we prove in different ways and in different degrees. To demonstrate, from monstrare, to show, and the intensive syllable de, signifies to prove in a specific manner, that is, in a clear and undeniable manner; we may prove facts, innocence, guilt, and the like; we demonstrate the truth or falsity of a thing.

Prove and demonstrate may also be applied to that which a person may show of himself; cvince (which is of less frequent use) and manifest are 
used only in this application. To prove in this case is to give a proof, as to prove one's valor; to demonstrate is to give a clear or ocular proof, as to demonstrate an attachment to a thing; to evince is to show by convincing proof, as to evince one's integrity by the whole course of one's dealings; to manifest is to make manifest, as to manifest one's displeasure or satisfaction.

In regard to things, to prove is to serve as a proof; to evince is to serve as a particular proof; to manifest is to serve as a public proof. The beauty and order in the Creation prove the wisdom of the Creator; a persistence in a particular course of conduct may evince either great virtue or great folly; the miracles wrought in Egypt manifested the Divine power.

PROVERB. See AXIOM.

PROVIDE, Procure, Furnish, SuPPLX. Provide, in Latin providere, $i$. e., to foresee, signifies, literally, to see before, but, figuratively, to get in readiness for some future purpose. Procure (see GET). Furnish is in French fournir, from Old High German frumjan, to provide. Supply, in French suppléer, from Latin sub, up, and plere, to fill, signifies to fill up a deficiency or make up what is wanting.

Provide and procure are both actions that have a special reference to the future; furnish and supply are employed for that which is of immediate concern: one provides a dinner in the expectation that some persons are coming to partake of it; one procures help in the expectation that it may be wanted; we furnish a room as we find it necessary for the present purpose; one supplies a family with any article of domestic use. Calculation is necessary in providing; one does not wish to provide too much or too little: labor and management are requisite in procuring; when a thing is not always at hand, or not easily obtained, one must exercise one's time, strength, or ingenuity to procure it: judgment is requisite in furnishing; what one furnishes ought to be selected with reference to the circumstances of the individual who furnishes; care and attention are required in supplying; we must be careful to know what a person really wants in order to supply him to his satisfaction. One provides against all contingencies; one procures all necessaries; one furnishes all comforts; one supplies all deficiencies.

Provide and procure are the acts of persons only; furnish and supply are the acts of unconscious agents: one's garden and orchard may be said to furnish one with delicacies; the earth supplies us with food. So in the improper application: the daily occurrences of a great city furnish materials for a newspaper; a newspaper, to many people, supplies almost every other want.

Providence, Prudence. - Providence and prudence are both derived from the verb to provide; but the former expresses the particular act of providing, the latter the habit of providing. The former is applied both to animals and men; the latter is employed only as a characteristic of men. We may admire the providence of the ant in laying up a store for the winter; the prudence of a parent is displayed in his concern for the future settlement of his child. It is provident in a person to adopt measures of escape for himself in certain situations of peculiar danger; it is prudent to be always prepared for all contingencies.

Prudent, Prudential. - Prudent (see JUDGMENT) characterizes the person or the thing; prudential characterizes only the thing. Prudent signifies having prudence; prudential, that which accords with rules of prudence or as respects prudence. The prudent is opposed to the imprudent and inconsiderate; the prudential is opposed to the voluntary: the course is prudent which accords with the principles of prudence; the reason or motive is prudential as flowing out of circumstances of prudence or necessity. Every one is called upon at certain times to adopt prudent measures; those who are obliged to consult their means in the management of their expenses must act upon prudential motives.

See also Wispom.

PROVIDENT. See Careful.

PROVISION. See FARE.

PROVISIONAL, CoNDITIONAL, Contingent, Hypothetical. The adjective provisional is derived from the Latin provisio, foresight, and implies the act of providing beforehand, 
previous preparation, temporary arrangement. Conditional signifies within certain limits, preseribed. Contingent, as an adjective, signifies accidental, also partial, as a lawyer's contingent fee; as a substantive, a possibility, a quota of troops. Hypotheical implies tbat which is a supposition or conjecture, something assumed in an argument.

See also EMPI IICAL.

PROVOKE. See A g G A VATE; Awaken; EXCITE.

PRY, Scrutinize, Delve Into. Pry is in all probability changed from provs, in the sense of try. Scrutinize comes from the Latin scruta, broken pieees, and signifies to seareh carcfully as if among rubbish or broken pieces.

Pry is taken in the bad sense of looking more narrowly into things than one ought: scrutinize and delve into are employed in the good sense of searching things to the bottom. A person who pries looks into that which does not belong to him, and too narrowly also into that which may belong to him; it is the consequence of a too eager curiosity or a busy, meddling temper: a person who scrutinizes looks into that which is intentionally concealed from him; it is an aet of duty flowing out of his office: a person who delves penetrates into that which lies hidden very deep; he is impelled to this action by the thirst of knowledge and a laudable curiosity.

A love of prying into the private affairs of families makes a person a troublesome neighbor; it is the business of the magistrate to scrutinize all matters which affect the good order of society: there are some minds so imbued with a love of science that they delight to delve into the serrets of nature.

PUBlic, Community, People, SoCIETY, World. In these applications the term public is usually preceded by the artiele the, and implies personality. The community is a body of citizens embraced in a region of any size. People are persons generally, inhabitants, race, kindred, family. Society is a collection or union of people having a common interest, often applied to the more cultivated portion of a community in its social relations. The world ineludes all people on earth, in the universe; sometimes applied to a personal environment, as the world about us, or to special bordies of people, as the world of finance.

PUBlish, Promulgate, Divolge, Reveal, Disclose. Publish (see ADverTise). Promulgate, from Latin promulgare, to make known, is a word of unknown origin. Divulge, in Latin divulgare, from di, for dis, apart, and vulgare, based on vulgus, people, significs to make known among the people. Reveal, in Latin revelare, from vcli, veil, signifies to take off the veil or cover. Disclose signifies to make the reverse of closed.

To publish is the most general of these terms, conveying in its extended sense the idea of making known; but it is in many respects indefinite: we may publish to many or few; but to promulgate is always to make known to many. We may publish that which is a domestic or a national coneern; we promulgate properly only that which is of general interest: the affairs of a family or of a nation are published in the newspapers; doctrines, principles, precepts, and the like are promulgated.

We may publish things to be known, or things not to be known; we divulge things mostly not to be known: we may publish our own shame or the shame of another, and we may publish that which is advantageous to another; but we commonly divulge the seerets or the crimes of another.

To publish is said of that which was never before known or never before existed; to reveal and disclose are said of that which has been only coneealed or lain hidden: we publish the events of the day; we reveal the secret or the mystery of a transaction; we disclose from beginning to end a whole affair which has never been properly known or accounted for.

See also Axwounce; Dechare.

PUERILE. See YouTHFUl.

PULl. See Draw.

PUNCTUAL. See Exact.

PURCHASE. Sce BUY.

PURE. See Clean; Virtuous.

PURIFY. See SANCTIFY.

PURPORT. See TENOR.

PURPOSE, Propose. We purpose (sec Design) that which is near at 
hand or immediately to be set about; we propose that which is more distant: the former requires the setting before one's mind, the latter requires deliberation and plan. We purpose many things which we never think worth while doing; but we ought not to propose anything to ourselves which is not of too much importance to be lightly adopted or rejected. We purpose to go to town on a certain day; we pro ose to spend our time in a particular study.

PURSUE. See Continet Follow.

PUSH, Shove, Thrust, Ram. All these words denote the giving an impulse to a body with more or less force, but differ as to the situation in which the impulse is given. Push (ultimately from Latin pulsare, to beat, a frequentative of pellere, to drive), and shove, Anglo-Saxon scufan, require the bodies which give and receive the impulse to be in contact: one person cannot push or shove another without coming in direct personal contact with him; as when a person touches another in passing, it may be a push more or less violent: to shove is a continued action, which causes the body to move forward; as to shove a load along the ground. A body may be both pushed and shoved along, but in the former case this is effected by repeated pushes, and in the latter case by a continuation of the same act. To thrust, like push, is a single act; but thrusting is commonly performed by some instrument, as a pole, a stick, a hand, or some part of a body. It is a Scandinavian word allied to threat and to Latin trudere, found in intrude.
A body may likewise, in a similar manner, thrust itself, but it always pushes or shoves some other body.

Ram (a word which may be allied to ram, a male sheep, signifying to butt or strike as the sheep strikes with his horns) means also to thrust into, but it implies a more sharp and energetic action than thrust. Push and shove do not imply injury to the object; ram does. The word is applied as a substantive to a solid beak or point projecting from the bows of a war-vessel and enabling it to ram or batter its opponent.

PUT, Place, Lay, Set. Put comes from Anglo-Saxon potian, to thrust, Middle English putten. Place (see that word). Lay is in Anglo-Saxon licgan, to cause to lie, Middle English leggen. Put is the most general of all these terms; place, lay, and set are but modes of putting; one puts things generally, but the way of putting is not defined; one may put a thing into one's room, one's desk, onè's pocket, and the like; but to place is to put in a specific manner and for a specific purpose; one places a book on a shelf as a fixed place for it, and in a position most suitable to it. To lay and set are still more specific than place, the former being applied only to such things as can be made to lie; and set only to such as can be made to stand: a book may be said to be laid on the table when placcd in a downward position, and set on a shelf when placed on one end: we lay ourselves down on the ground; we set a trunk upon the ground.

PUTREFY. See RoT. 


\section{$\mathbf{Q}$}

QUAIl, Cower, Cringe, Knuckle. Quail is from a Teutonic base, kwal; cf. Modern German qual, anguish or distress. Cower, represented in Middle English by couren, is Scandinavian; it meant originally to lie quiet, to sit hunched up. Cringe, Anglo-Saxon cringan, meant to fall before the foe in battle. Knuckle, in Middle English kno$k i l$, a diminutive form allied to Middle Dutch knoke, a bone or knuckle, meant to place one's knuckles on the ground in shooting or casting marbles; it developed the meaning of to acknowledge one's self beaten in a game, to yield. All these words indicate a movement of fear or submission before an attack. Quail is the strongest word. It implies an absolute sinking of heart, a loss of courage before an attack or a misfortune. Cringe has a similar meaning, but is a milder word; it refers to a temporary physical shrinking before a blow. Cower means to huddle together and shudder with fear. There is more of physical fear in cower; more of mental and moral abasement accompanying fear in cringe. Fnuckle means to yield to another under pressure; it does not necessarily imply physical fear, however.

QUAKE. See ShaKe.

QUALIFICATION, ACCOMPLISIMENT. The qualification (sce ComPETENT) serves the purpose of utility; the accomplishment serves to adorn: by the first we are enabled to make ourselves uscful; by the second we are cnabled to make ourselves agreeable. The qualifications of a man who has an office to perform must be considered: of a man who has only pleasure to pursue, the accomplishmen!s are to be considered. A readiness with one's pen and a facility at accounts are necessary qualificalions either for a sehool or a counting-house; drawing is one of the most agreeable and suitable accomplishments that can be given to a young person.

Qualify, Temper, Humor. - Qualify (sec Competent). Temper, from Latin temperare, is to regulate the temperament. Humor, from Latin humor, is to suit the humor. See Humor.
Things are qualified according to circumstances: what is too harsh must be qualified by something that is soft and lenitive; things are tempered by nature or by Providence, so that things perfectly discordant should not be combined; things are humored by contrivance: what is subject to many changes requires to be humored; a polite person will qualify a refusal by some expression of kindness; Providence has tempered the scasons so as to mix something that is pleasant in them all. Nature itself is sometimes to be humored when art is employed: but the tempers of man require still more to be humored.

See also Fit.

QUAlity, Property, AtTribute. Quality, in Latin qualilas, from qualis, how constituted, signifies such as a thing really is. Property, from proprius, proper or onc's own, signifies belonging to a thing as an essential ingredient. Attribute, in Latin attributus, participle of attribuere, to bestow upon, signifies the things bestowed upon or assigned to another.

The quality is that which is inherent in the thing and coexistent; the properly is that which belongs to it for the time being; the attribule is the quality which is assigned to any object. We cannot alter the quality of a thing without altering the whole thing; but we may give or take away properties from bodies at pleasure, without entirely destroying their identity; and we may ascribe altributes at discretion.

See also Fashron.

QUANDARY, DILEMMA. These words both indicate a statc of embarrassment in which the victim does not "know which way to turn." Quandary is a word of uncertain origin, possibly derived from scholastic Latin. Dilem$m a$, Latin dilemma, Greek $\delta i \lambda \eta \mu \mu a$, is a double proposition or argument in which one is caught between two difficulties. It differs from quandary in distinctly suggesting two difficulties and the impossibility of deciding between them. Quandary simply sug- 
gests a general state of confusion and doubt. Quandary is generally used in the phrase "in a quandary."

QUANTITY. See DEAL.

QUARREL, BROIL, FEUD. Quarrel, from Latin querela, a complaint (see Difference), is the general and ordinary term; broil is in Old French brouiller, to jumble or confuse, allied to Italian broglio, whence the English imbroglio is derived. Feud, Old French feide, is also allied to Anglo-Saxon faehd, enmity, and fáh, hostile, modern English foe. The idea of a variance between two or more parties is common to these terms; but the first signifies the complaints and charges which are reciprocally made; broil the confusion and entanglement which arise from a contention and collision of interests; feud the hostilities which arise out of the variance. There are quarrels where there are no broils, and there are both where there are no feuds; but there are no broils and feuds without quarrels. The quarrel is not always openly conducted between the parties; it may sometimes be secret and sometimes manifest itself only in a coolness of behavior: the broil is a noisy kind of quarrel, it always breaks out in loud and most reproachful language: feud is a deadly kind of quarrel which is heightened by mutual aggravations and insults. Quarrels are very lamentable when they take place between members of the same family; broils are very frequent among profligate and restless people who live together: feuds were very general in former times between different families of the nobility.

Quarrel, Affray, Fray.-A quarrel is indefinite, both as to the cause and the manner in which it is conducted; an affray or fray, from frico, to rub, signifies the conflict of the passions and is a particular kind of quarrel: a quarrel may arise between two persons from a private difference; an affray always takes place between many upon some public occasion: a quarrel may be carried on merely by words; an affray is commonly conducted by acts of violence: many angry words pass in a quarrel between too hasty people; many are wounded, if not killed, in affrays when opposite parties meet.

See also Bicker.
QUARRELSOME. See QUERULOUS. QUARTER. See DISTRICT.

QUARTERS, Abode, Cantonment, Post, Station. In these applications the term assumes the plural form and applies to both domestic and military concerns. Abode and duelling imply any kind of habitation, lodging, or temporary residence. Cantonment, post, and station are specifically military terms, implying, respectively, a part of a town allotted to a body of troops for temporary or permanent occupation; a permanent military establishment, as an important fortress, and a region assigned for the permanent location of a naval squadron, as the Atlantic station. The term headquarters designates the station or building where a crmmanderin-chief and his staff are losested.

QUELL, QUASH. Quell is derived from Anglo-Saxón cuellan, to kill. It means to overcome completely, to reduce to quietness and peace. Quash comes from Latin quassare, to shatter. In some connections it means to annul completely; in this sense it is used in legal procedure. It is also used to refer to the complete suppression of an idea or a proposal. The police quell a riot; the opposition on a board of directors may quash a plan that does not seem feasible. Quell implies an active disturbance; quash only an incipient disturbance.

QUERULOUS, Petulant. Both of these words apply to a fretful and dissatisfied temper, but they differ somewhat in their indication of the way in which the dissatisfaction shows itself. Querulous comes from querulus, full cf complaints, and like quarrel (see above) derived ultimately from Latin queri, to complain. It means weakly and futilely complaining. A querulous person does not rise to the height of a really energetic protest. He merely continues to object in an ineffectual and self-pitying tone. Petulant comes from Latin petulare, a diminutive of petere, to attack in a small way. It refers to small outbursts in which there are more of wilfulness and "temper" than of the feeble misery implied in querulous. A cheerful person may be petulant; he cannot be querulous. Petulance is characteristic of healthy 
but undisciplined youth; querulousness of feeble age.

See also Difference; QunRrei.

QUESTION, QUERY. Question (see Ask). Query is but a variation of quare (seek!), from the verb quarere, the Latin imperative to seek or inquire.

Questions and queries are both put for the sake of obtaining an answer; but the former may be for a reasonable or unreasonable cause; a query is mostly a rational question: idlers may put questions from mere curiosity; learned men put queries for the sake of information.

QUICK. See SUdden.

QUICKNESS, SwIFTNESS, FLeETness, Celerity, Rapidity, Velocity. These terms are all applied to the motion of bodies, of which quickness, from quick, denotes the general and simple idea which characterizes all the rest. Quickness is nearly akin to life (from Anglo-Saxon cwic, alive, lively - the older meaning of which is found in the phrase the "quick and the dead" in the Apostles' Creed) and is directly opposed to slowness. Swiftness comes from Anglo-Saxon swifan, to move quickly; and fleetness is allied to Anglo-Saxon fleotan, to float. Swiftness and fleetness express higher degrees of quickness. Celerity, from Latin celer, Greek $\boldsymbol{x}^{\prime} \hat{\varepsilon} \lambda \boldsymbol{s}$, a racer; velocity, ultimately from volo, to fly; and rapidily, from rapere, to seize or hurry along, differ more in application than in degree. Quick and swift are applicable to any objects; men are quick in moving, swift in running: dogs hear quickly, and run swifly; a mill goes quickly or swiftly round, according to the force of the wind: fleetness is the peculiar characteristic of winds or horses; a horse is fleet in the race, and is sometimes described to be as fleet as the winds: that which we wish to characterize as particularly quick in our ordinary operations we say is done with celerity; in this manner our thoughts pass with celerity from one object to another: those things are said to move with rapidity which seem to hurry everything away with them; a river or stream moves with rapidity; time goes on with rapid flight: velocity signifies the swiftness of flight, which is a motion that exceeds all others in swiftness: hence, we speak of the velocity of a ball shot from a cannon, or of a celestial body moving in its orbit; sometimes these words, rapidity and velocity, are applied in the improper sense by way of emphasis to the very swift movements of other bodies: in this manner the wheel of a carriage is said to move rapidly; and the flight of an animal, or the progress of a vessel before the wind, is compared to the flight of a bird in point of velocity.

QUIET. See Appease; Ease; Peace. QUIT. See Leave; Strike.

QUITE, CoMpletely, ENTIREly, Perfectly, Totally, Wholly. These terms are so similar and so interchangeable in all respects that there is no necessity for a discrimination between them. The original significance and derivation can be found under the corresponding adjective forms. Quite, of the same origin (Middle English quite as quit, and connoting a similar fnality), is, strictly speaking, synonymous with the words here given rather than with rather or very, with which it is often interchanged, as when we say quite good, meaning not entirely good, but rather good.

QUIVER. See SHAKe.

QUIXOTIC, Fantastic, Visionary. Properly speaking, Quixotic has no synonymes because it signifies acts akin in nature to those of Don Quixote, the hero of Cervantes's romance of that name, champion of all persons in distress and observer of all the magnanimities of knighthood. Don Quixote being a character absolutely unique in literature, there is no adjective that corresponds to Quixotic; but fanlastic

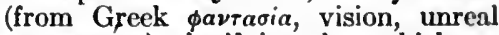
appearance), signifying that which resembles the strange world of dreams, and visionary (Latin visio), which has the same original meaning, but suggests not the oddness and waywardness of the dream world, but its unreality and its wistful appeal-these two words partly correspond to the quality of action and thought indicated in Quixotic, while suggest ing none of the humor and pathos, the contrast between the noble intention and the awkward and ridiculous action, also implied in that word.

QUOTE. See Cite. 
RaCe, Generation, Breed. Race (see Family). Generation, in Latin generatio, from generare, signifies the thing begotten. Breed signifies that which is bred (see BresD). These terms are all employed in regard to a number of animate objects which have the same origin; the first two are said only of human beings, the latter only of animals: the term race is employed in regard to the dead as well as the living; generation is employed mostly in regard to the living: hence we speak of the race of the Heraclidx, the race of the Bourbons, the race of the Stuarts, and the like; but the present generation, the whole generation, a worthless generation, and the like (yet we also speak of past generations): breed is said of those animals which ari brought forth and brought up in the same manner. Hence, we denominate some domestic animals as of a good breed, where particular heed is given to the animals from which they come, and special care is taken of those which are brought forth.

See also Course; Family.

RACK. See Break.

RADIANCE, BRILliancy. Both these terms express the circumstance of a great light in a body; but radiance, from radius, a ray, denotes the emission of rays, and is, therefore, peculiarly applicable to bodies naturally luminous, like the heavenly bodies; and brilliancy (see BRIGHT) denotes the whole body of light emitted, and may, therefore, be applied equally to natural and artificial light. The radiancy of the sun, moon, and stars constitutes a part of their beauty; the brilliancy of a diamond is frequently compared with that of a star.

Brilliancy is applied to objects which shine or glitter like a diamond. It is also applied figuratively to moral objects.

RADIATE. See SHINe.

RADIOGRAPH, Picture, RepreSENTATION. A radiograph, from the Latin radio, a ray, and the Greek $\gamma \rho \alpha \dot{\phi} \phi \omega$, to write, is a picture or representation of an object in shadowy form by the action of Röntgen or X-rays on certain sensitive salts. It is a modern aid of great value in surgical science.

RAGE. See Anger; Madness.

RAISE. See Heighten; LIFT.

RALLY. See Deride.

RAM. See PUSH.

RAMBLE. See Excursion; WaiDER.

RANCOR. See Hatred; Malice. RANGE. See WANDER.

RANK. See Class; Fulsome.

RANSACK. See Rummage.

RANSOM. See REDEEM.

RAP. See KNock.

RAPACIOUS, Ravenous, VoracIous. Rapacious, in Latin rapax, from rapere, to seize, signifies seizing or grasping anything with an eager desire to possess. Ravenous, from the Latin rapina, from rapere, to seize, signifies the same as rapacious. Voracious, from vorax, based on vorare, to devour, signifies an eagerness to devour.

The idea of greediness, which forms the leading feature in the signification of all these terms, is varied in the subject and the object: rapacions is the quality peculiar to beasts of prey or what is like beasts of prey: ravenous and voracious are common to all animals when impelled by hunger. The beasts of the forest are rapacious at all times; all animals are more or less ravenous or voracious, as circumstances may make them: the term rapacious applies to the seizing of anything that is eagerly wanted; ravenous applies to the seizing of anything which one takes for one's food: a lion is rapacious when it seizes on its prey: it is ravenous in the act of consuming it. The word ravenous implies the haste with which one eats; the word voracious the quantity which one consumes: a ravenous person is loath to wait for the dressing or cooking of his food; he consumes it without any preparation: a voracious person not only eats in haste, but he consumes great quantities and con- 
tinues to do so for a long time. Abstinence from food for an unusual length of time will make any healthy creature ravenous; habitual intemperance in eating or an abnormal appetite will produce voracity.

In an extended sense, rapacity is applied as a characteristic of persons to denote their eagerness to seize anything which falls in their way.

Ravenous denotes an excess of rapac$i t y$, and voracious is applied figuratively to moral objects.

See also GreEdy.

RAPIDITY. See QUICKNESS.

Rapine, Plunder, Pillage. The idea of property taken from another contrary to his consent is included in all these terms: but the term rapine, from Latin rapina (see above), implies most violence; plunder (from a Germanic word signifying trash, baggage, plunder), meaning to strip a house even of its least valuable contents, includes removal or carrying away; pillage, derived from Latin pilare, to pull out hair, to strip entirely, means wholesale booty which is searched for and taken away. A soldier who makes a sudden incursion into an enemy's country and carries away whatever comes within his reach is guilty of rapine: he goes into a house full of property, and carries away much plunder; he enters with the rest of the army into a town, and, stripping it of everything that was to be found, goes away loaded with pillage; mischief and bloodshed attend rapine: loss attends plunder; distress and ruin follow wherever there has been pillage.

RAPTURE. See ECSTASY.

RARE, Scarce, Singular. Rare, in Latin rarus. Scarce comes from Low Latin scarpsus, a shortened form of $e x$ carpsus, for classical excerptus, to select, meaning picked out.' Singular (see Pafticular).

Rare and scarce both imply number or quantity, which admit of expansion or diminution: rare is a thinned number; scarce is a quantity cut short. Rare is applied to matters of convenience or luxury; scarce to matters of utility or necessity: that which is rare becomes valuable and fetches a high price; that which is scarce becomes precious, and the loss of it is seriously felt. The best of everything is in its nature rare; there will never be a superfluity of such things; there are, however, some things, as particularly curious plants or particular animals, which, owing to circumstances, are always rare: that which is most in use will, in certain cases, be scarce; when the supply of an article fails, and the demand for it continues, it naturally becomes scarce. An aloe in blossom is a rarity, for nature has prescribed such limits to its growth as to give but very few of such flowers: the paintings of Raphael and the distinguished painters of former days are daily becoming more scarce, because time will diminish their quantity, although not their value.

What is rare will of ten be singular and what is singular will of ten, on that account, be rare: but these terms are not necessarily applied to the same object: fewness is the idea common to both; but rare is said of that of which there might be more; while singular is applied to that which is single or nearly single in its kind. The rare is that which is always sought for; the singular is not always that which one esteems: a thing is rare which is difficult to obtain; a thing is singular for its peculiar qualities, good or bad. Indian plants are many of them rare in England, because the elimate will not agree with them: the sensitive plant is singular, as its quality of yielding to the touch distinguishes it from all others.

See also UNique.

RASH. Sce Foolhardy; SUdden.

RASHNESS, TEMERITY, Hastiness, Precipitancy. Rashness denotes the quality of being rash. Cf. Anglo-Saxon rascan, to flash, to move quickly and abruptly; Modern German rasch, quick. Temerity comes from Latin temere, from a root meaning gloom, darkness; and signifies the tendency to act "in the dark"; without sufficient information or foresight. Hastiness (see ANGRY and Cursory). Precipitancy, from the Latin procipiti, a crude form of proceps, headlong, based on pra, before, and caput, head, means, literally, the quality of being headlong, and signifies the quality or disposition of taking things before they ought to be taken.

Rashness and temerity have a close 
alliance with each other in sense; but they have a slight difference which is entitled to notice: rashness is a general and indefinite term, in the signification of which an unreasoned and impulsive swiftness of action is the leading idea: this may arise either from a vehemence of character or a temporary ardor of the mind: in the signification of temerity, the leading idea is want of consideration, springing mostly from an overweening confidence or a presumptuous character. Rashness is therefore applied to corporeal actions, as the jumping into a river without being able to swim, or the leaping over a hedge without being an expert horseman; temerity is applied to our moral actions, particularly such as require deliberation and a calculation of consequences. Hastiness and precipitancy are but modes or characteristics of rashness, and consequently employed only in particular cases, as hastiness in regard to our movements, and precipitancy in regard to our measures.

RATE, Proportion, Ratio. Rate (see Estimate) and ratio, which has the same origin and original meaning as rate, are in sense species of proportion (see Proportion): that is, they are supposed or estimated proportions, in distinction from proportions that lie in the nature of things. The first term, rate, is employed in ordinary affairs; a person receives a certain sum weekly at the rate of a certain sum yearly: ratio is applied only to numbers and calculations; as two is to four, so is four to eight, and eight to sixteen; the ratio in this case being double: proportion is employed in matters of science, and in all cases where the two more specific terms are not admissible; the beauty of an edifice depends upon observing the doctrine of proportions; in the disposing of soldiers a certain regard must be had to proportion in the height and size of the men.

See also TAX; Value.

RATIFY, APPROVE, Bind, CONfirm, Corroborate, Settle, SubSTANTIATE. Ratify, from French ratifier, from Latin ratus, fixed, and ficare, a crude form of facere, to make, in its broadest sense implies the settlement or establishment of something. We approve something that has been considered without previous action or already done for us by another; we bind ourselves to a specific action, as in a contract; we confirm an agreement reached in consultation; we corroborate something that has been said or done before; we settle a proposal, controversy, business affair; and we substantiate or prove a prior assertion, declaration. All of these actions are or may be confirmed in writings signed by the parties in interest.

A ratification is the act or evidence of ratifying. As an act it is that by which a competent authority confirms or accepts something done by another. In the case of a person who has reached his or her majority, it is an approval of something done during the period of minority which gives validity to what was done.

RATIONAL. See Reasonable.

Ravage, Desolation, DevastaTION. Ravage takes its root from the Latin rapere, signifying a seizing or tearing away. Desolation, from solus, alone, signifies made solitary or reduced to solitude. Devastation, in Latin devastatio, from devastare, to lay waste, based on vastus, waste, signifies reducing to a waste or desert.

Ravage expresses less than either desolation or devastation: a breaking, tearing, or destroying is implied in the word ravage; but desolation signifies the entire unpeopling of a land, and devastation the entire clearing away of every vestige of cultivation. Torrents, flames, and tempests ravage; war, plague, and famine desolate; armies of barbarians, who overrun a country, carry devastation with them wherever they go.

Ravage is employed likewise in the moral application; desolation and devastation only in the proper application to countries. Disease makes its ravages on beauty; death makes its ravages among men in a more terrible degree at one time than at another.

See also Overspread; Sack.

RAVENOUS. See RAPACIOUS.

RAY, Beam. Ray (see Gleam) is indefinite in its meaning; it may be said either of a large or small quantity of light: beam, from Anglo-Saxon beam, 
is something positive; it can be said only of that which is considerable. We may speak of rays either of the sun or the stars or any other luminous body; but we speak of the beams of the sun or the moon. The rays of the sun break through the clouds; its beams are scorching at noonday. A room can scarcely be so shut up that a single ray of light shall not penetrate through the crevices; the sea, in a calm moonlight night, presents a beautiful spectacle, with the moon's beams playing on its waves.

RAZE. See Demolish.

REACH. See EXTEND.

READY, APT, Prompt. Ready (see EASY) is in general applied to that which has been intentionally prepared for a given purpose; prompt (see ExPEDITIOUs) is applied to that which is at hand so as to answer the immediate purpose; apt, from aptus, fit, is applied to that which is fit or from its nature has a tendency to produce effects.

When applied as personal characteristics, ready connotes the will or understanding, which is prepared for anything; as ready to serve a person, a ready wit; prompt denotes the vigor or zeal which impels to action without delay, or at the moment when wanted; and $a p t$, a fitness to do anything from the habit or temper of the mind.

See also Preparedness.

REAL. See Actual; Intrinsic; Tangible.

REALIZE. See Fulfil.

REALM. See STATE.

REASON. See Account; ARgoment; Cause; Consideration.

REASONABLE, Rational. Reasonable, or according to reason, and rational, having reason, are both derived from the same Latin word ratio, reason, which, from ratus, itself from reor, to think, signifies the thinking faculty. They differ principally according to the different meanings of the word reason. Reasonable is sometimes applied to persons in the general sense of having the faculty of reason. But more frequently the word rational is used in this abstract sense of reason.

In application to things reasonable and rational both signify according to reason; but the former is used in reference to the business of life, as a reason- able proposal, wish, ete.; rational to abstract matters, as rational motives, grounds, questions, etc. See also FAIR.

REBATE. See Abate.

REBEllion. Se e Contumacy; INSURRECTION.

REBOUND, REVERBERATE, RECOIL. To rebound is to bound or spring back: a ball rebounds. To reverberate (from Latin verber, a scourge) is to beat back: a sound reverberates when it echoes. To recoil is to coil (from Latin culus, hinder part) or whirl back: a snake recoils. The two former are used in an improper application, although rarely; but we may say of recoil that a man's schemes will recoil on his own head.

REBUFF. See Refuse.

REBUKE. See CHECK.

RECALL. See AbJure.

RECANT. See ABJURE.

RECAPITULATE. See REPEAT.

RECEDE, Retreat, Retire, WithDRAW, SECEDE. To recede is to go back; to retreat is to draw back; the former is a simple action, suited to one's convenience: the latter is a particular action, dictated by nccessity: we recede by a direct backward movement; we retreat by an indirect backward movement; we recede a few stcps in order to observe an object more distinctly; we retreat from the position we have taken in order to escape danger; whoever can advance can recede; but in general only those retreat whose advance is not freo: receding is the act of every one; retreating is peculiarly the act of soldiers or those who make hostile movements.

To retire and wilhdraw signify fundamentally the same as retreat, that is, to draw back or off; but they agree in application mostly with recede, to denote leisurely and voluntary acts: to recede is to go back from a given spot; but to retire and withdraw have implication of the place or the presence of the persons: we may recede on an open plain, but we retire or withdraw from a room or from some company. In this application withdraw is the more familiar term: retire may likewise be used for an army; but it denotes a much more leisurely action than retreat: a general retreats, by compulsion, before an enemy, but he may retire from an enemy's country when there is no enemy present. 
Recede, retreat, retire, and withdraw are also used in a moral application; secede is used only in this sense: a person recedes from his engagement or his pretentions; he retires from business or withdraws from a society. To secede is a public act; men secede from a religious or political body; withdraw is a private act; they withdraw themselves as individual members from any society.

RECEIPT, RECEPTION . Receipt comes from receive, in its application to inanimate objects, which are taken into possession. Reception comes from the same verb, in the sense of treatment of persons at their first arrival: in the commercial intercourse of men, the receipt of goods or money must be acknowledged in writing; in the friendly intercourse of men, their reception of each other will be polite or cold, according to the sentiments entertained toward the individual.

RECEIVE. See Admit; Take.

RECENT. See NEW.

RECIPROCAL. See Mutual.

RECITAL. See Relation.

RECITE. See REPEAT.

RECKON, Count, ACCount, NUMBER. The idea of estimating is common to these terms, which differ less in meaning than in application: reckon (see Calculate) is the most familiar; account and number, i.e., to put in the number, are employed only in the grave style: we reckon it a happiness to enjoy the company of a particular friend; we ought to account it a privilege to be enabled to address our Maker by prayer; we must all expect to be one day numbered with the dead.

RECLAIM, REFORM. Reclaim, from the Latin prefix re, again, and clamare, to call, signifies to call back to its right place that which has gone astray. Reform signifies to form anew that which has changed its form: they are allied only in their application to the moral character. A man is reclaimed from his vicious actions by the force of advice or exhortation; he may be reformed by various means, external or internal. A parent endeavors to reclaim a child, but too often in vain; the offender is in general not reformed.

RECLINE, REPOSE. to lean back; to repose is to place one's self back and usually to rest: he who reclines, reposes: but we may recline without reposing: when we recline we put ourselves into a particular position; but when we repose we put ourselves into that position which will be most easy and enable us to rest.

RECOGNIZE, ACK N OWLEDGE. Recognize, in Latin recognoscere, is to take cognizance of that which comes again before our notice; to acknowledge (see ACKNowLEDGE) is to admit to one's knowledge whatever comes freshly to our notice: we recognize a person whom we have known before; we recognize him either in his former character or in some newly assumed character; we acknowledge either former favors or those which have been just received: princes recognize certain principles which have been admitted by previous consent; they acknowledge the justice of claims which are preferred before them.

RECOIL. See Rebound.

RECOLLECTION. See MeMory. RECOMPENSE. See CoMPENSATion; Gratuity.

\section{RECONCILE. See Conciliate.}

RECORD, REgISTER, ARCHIVe. Record is taken for the thing recorded, or the collection in which a thing is recorded; register, either for the thing registered or the place in which it is registered; archive, mostly for the place, and sometimes for the thing: records are either historical details or short notices, which serve to preserve the memory of things; registers are but short notices of particular and local circumstances; archives are always connected with the state: every place of antiquity has its records of the different circumstances which have been connected with its rise and progress and the various changes which it has experienced; in public registers we find accounts of families and of their various connections and fluctuations; in a, chives we find all legal deeds and instruments which involve the interests of the nation, both in its internal and external economy. In an extended application of these terms, records contain whatever is to be remembered at ever so distant a period; registers, that which is to serve present purposes; 
archives, that in which any things are stored.

See also Enroll.

RECOUNT. See RELATE.

RECOVER, RETRIEVE, REPAIR, RECRUIT. Recover comes from Latin recuperare (whence English recuperate is derived), compounded of re, again, and cipere, a weakened form of capere, to take, eontaminated with sabine; cuprus, good, signifying to recover and make good again. Retrieve, from the occasional form of the Old French retreuver, Modern retrouver, is to find again. Repair, in French réparer, Latin reparo, from re and parare, to make ready or right again, signifies to make a thing as good as it was before. Recruit is an ill-formed word from French recroître, Latin recrescere, to grow again.

Recover is the most general term, and applies to objects in general; retrieve, repair, and the others are only partial applications: we recover things either by our own means or by chance; we retrieve and repair by our own efforts only: we recover that which has been taken or that which has been lost; we retrieve that which has not finally been impaired or consumed; we repair that which has been injured; we recruit that which has been diminished: we recover property from those who wish to deprive us of it; we retrieve our misfortunes or our lost reputation; we repair the damage done to our property; we recruit the strength which has been exhausted: we do not seek after that which we think irrecoverable; we give that up which is irretrievable; we do not labor on that which is irreparable; our power of recruiting depends upon circumstances; he who makes a moderate use of his resources may in general easily recruit himself when they are gone.

Recovery, Restoration. - Recovery is the regaining of any object which has been lost or missing; restoration is the getting back of what has been taken away or that of which one has been deprived. What is recovered may be recovered with or without the use of means; the restoration is effected by others' agency; that which is lost by accident may be recovered by accident; the restoration of a prince to his throne is mostly effected by his subjects.
In respect to health or other things, recovery signifies, as before, the regaining something; and restoration, the bringing back to its former state.

See also Recruit.

RECREANT, APostate, ReneGADE. These words all signify one who repudiates a faith or a cause to which he has given his allegiance. Recreant, from Low Latin recredere, from Latin re, again, and.credere, to believe, meaning to believe again, carries most condemnation. A recrcant is thought of as cowardly and dastardly, and the word is applied not merely to one who repudiates a particular faith, but to one who is generally faithless and unreliable. Renegade, from Latin re, again, and negare, to deny, also signifies one who abandons a faith or a cause; but it does not carry so strong a suggestion of something cowardly and despicable. A postate has a more limited significance. It is derived from Late Latin apostata, from

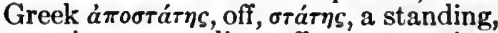
meaning a standing off, a separation, and it refers specifically to one who repudiates a religious belief. Julian, the A postate, was so called because he reverted from Christianity to paganism.

RECREATION. See Amusement. RECTIFY. Sec CORRECT.

RECTITUDE, UPRIGHTNESS. Rectitude, based on Latin rectus, straight, is properly rightness, which is expressed in a stronger manner by uprightness: we speak of the rectitude of conduct or of judgment; of uprightness of mind or of moral character, which must be something more than straight, for it must be elevated above everything mean or devious.

REDEEM, Ransom. Redeem, in Latin redimere, is compounded of red and emere, to buy off, or back to one's self. Ransom comes from the substantive redemptio, redemption, corresponding to redimere.

Redeem is a term of general application; ransom is employed only on particular occasions: we redeem persons as well as things; we ransom persons only: we may redeem by labor or by anything which supplies an equivalent for money; we ransom persons with money only: we redeem a watch or 
whatever has been given in pawn; we ransom a captive: redeem is employed in the improper application; ransom only in the proper sense: we may redeem our character, redeem our life, or redeem our honor; and in this sense our Saviour redeems repentant sinners; but those who are ransomed recover only their bodily liberty.

REDEMPTION. See Salvation.

REDRESS, RELIEF. Redress, like address (see Accost), in all probability from the Low Latin drectus, for directus, straight, right, and hence signifying to make straight or right, is said only with regard to matters of right and justice; relief (see HELP) to those of kindness and humanity: by power we obtain redress; by active interference we obtain relief: an injured person looks for redress to the government; an unfortunate person looks for relief to the compassionate and kind: what we suffer through the oppression or wickedness of others can be redressed only by those who have the power of dispensing justice; whenever we suffer, in the order of Providence, we may meet with some relief from those who are more favored. Redress applies to public as well as private grievances; relief applies only to private distresses: under a pretence of seeking redress of grievances, mobs are frequently assembled to the disturbance of the better disposed; under a pretence of soliciting charitable relief, thieves gain admittance into families.

REDUCE, Lower. Reduce is to bring back or to a given point, $i$. $e$., in an extended sense, to bring down; lower is to make low or lower, which proves the close connection of these words in their original meaning; it is, however, only in their improper application that they have any further connection. Reduce is used in the sense of lessen when applied to number, quantity, price, etc.; lower is used in the same sense when applied to price, demands, terms, etc.: the former, however, occurs in cases where circumstances as well as persons are concerned; the latter only in cases where persons act: the price of corn is reduced by means of importation; a person lowers his price or his demand when he finds it too high.
In the moral application, reduce expresses more than lower; a man is said to be reduced to an abject condition, but to be lowered in the estimation of others; to be reduced to a state of slavery, to be lowered in his own eyes.

REDUNDANCY. See ExcEss.

REEL. See StAGger.

REFER, RELATe, Respect, REGARD. Refer, from the Latin re and ferre, signifies, literally, to bring back; and relate, from the participle latus, of the same verb, signifies brought back: the former is, therefore, transitive, and the latter intransitive. Refer is commonly said of circumstances that carry the memory to events or circumstances; relate is said of things that have a natural connection: the religious festivals and ceremonies of the Roman Catholics have all a reference to some events that happened in the early periods of Christianity; the notes and observations at the end of a book relate to what has been inserted in the text.

Refer and relate carry us back to that which may be very distant; but respect and regard (see EsTEEM) turn our views to that which is near. Whatever respects or regards a thing has a moral influence over it; it is the duty of the magistrates to take into consideration whatever respects the good order of the community; laws respect the general welfare of the community; the due administration of the laws regards the happiness of the individual. Neither of these verbs, as such, are in common use to-day, except in such fixed formulas as in respect or in regard to, as respects or as regards a given object or idea.

See also Allude.

REFINED. Se e Polite; WellBRED.

REFINEMENT. Se CUltivaTION.

REFlect. See Consider; Think. REFLECTION. See Insinuation. REFORM, REFormation. Reform has a general application; reformation a particular application: whatever undergoes such a change as to give a new form to an object occasions a reform; when such a change is produced, or claimed to be produced, in the moral character either of persons or institu- 
tions, it is termed a reformation: the concerns of a state require occasional reform; those of an individual require reformation; the Reformation was the work of Martin Luther. When reform and reformation are applied to the moral character, the former has a more extensive signification than the latter; the term reform conveying the idea of a complete amendment; reformation implying only the process of amending or improving. A reform in one's life and conversation will always be accompanied by a corresponding increase of happiness to the individual; when we observe any approaches to reformation, we may cease to despair of the individual who shows such tendency.

See also ReCLatM.

REFRACTORY. See UNRULY.

REFRAIN. See ABSTAIN.

REFRESH. See Revive.

REFUGE. See AsYluM.

REFUSE, Decline, Reject, RePEL, Rebuff. Refuse (see DeNY), from Latin refundere, signifies simply to pour back - that is, to send back - which is the common idea of all these terms. Decline, in Latin declinare, signifies, literally, to turn aside; reject, from jactare, to throw, to cast back; repel, from pellere, to drive, to drive back. Rebuff comes from Latin re, back, and buffare, a word of onomatopœic or imitative origin, like English puff.

Refuse is an unqualified action: it is accompanied by no expression of opinion; decline is a gentle and indirect mode of refusal; reject is a direct mode, and conveys a positive sentiment of disapprobation: we refuse what is asked of us for want of inclination to comply; we decline what is proposed from motives of discretion; we reject what is offered to us because it does not fall in with our views: we refuse to listen to the suggestions of our friends; we decline an offer of service; we reject the insinuations of the interested and evil-minded.

To refuse is said only of that which passes between individuals; to reject is said of that which comes from any quarter: requests and petitions are refused by those who are solicited; opinions, propositions, and counsels are rejected by particular communities: the king refuses to give his assent to a bill; the Parliament rejects it.

To repel is to reject with violence; to rebuff is to refuse with contempt or what may be considered as such. We refuse and reject that which is either offered or simply presents itself for acceptance: the act may be negative or not outwardly expressed; we repel and rebuff that which forces itself into our presence contrary to our inclination: it is in both cases a direct act of force; we repel the attack of an enemy, or we repel the advances of one who is not agreeable; we rebuff those who put that in our way which is offensive. Importunate persons must necessarily expect to meet with rebuffs, and are in general less susceptible to them than others; sensitive minds feel a refusal as a rebuff.

See also Dregs; Garnish.

REFUTE. See CoNFUTE.

REGAL. See Royal.

REGARD. See ATtend; Care; Consider; Esteem.

REGARDFUL. See MINDFUL.

REGARDLESS. See INDIFFERENT.

REGIMEN. See Food.

REGION. See DisTrict.

REGISTER. See ENROLL; LIST; RECORD.

REGRET. See CoMplain.

REGUlATE. See Direct; GorERN.

REHEARSE. See REPEAT.

REIGN. See EMPIRE.

REIMBURSE. See INDEMNIFY.

REJECT. See Proscribe; Refuse. REJOINDER. See ANSWER.

RELATE (see REFER), RECOUNT, Describe. Relate, in Latin relatus, participle of referre, signifies to bring that to the notice of others which has before been brought to our own notice. Recount is properly to count again or count over again. Describe, from the Latin scribere, to write, is literally to write down.

The idea of giving an account of events or circumstances is common to all these terms, which differ in the object and circumstances of the action. Relate is said generally of all events, both of those which concern others as well as ourselves; recount is said particularly of those things in which the recounter has a special interest: those 
who relate all they hear of ten relate that which never happened; it is a gratification to an old soldier to recount all the events in which he had a part during the military career of his early youth. We relate events that have happened at any period of time immediate or remote; we recount mostly those things which have been long past: in recounting, the memory reverts to past scenes and counts over all that has deeply interested the mind. Travellers are pleased to relate to their friends the noteworthy or remarkable things they have seen in other countries; the recounting of our adventures in distant regions of the globe has a peculiar interest for all who hear them. We may relate either by writing or by word of mouth; we recount mostly by word of mouth. Relate is said properly of events or that which passes: describe is said of that which exists: we relate the particulars of our journey, and we describe the country we pass through. Personal adventure is always the subject of a relation; the quality and condition of things are the subject of the description. We relate what happened on meeting a friend; we describe the dress of the parties or the ceremonies which are usual on particular occasions.

Relation, Recital, Narration, Narrative.-Relation, from the verb relate, denotes the act of relating or the thing related. Recital, from recite (Latin re, again, and citare, to quote), denotes the act of reciting or the thing recited. Narration, from narrate (from Latin narus, gnarus, knowing), denotes either the act of narrating or the thing narrated. Narrative, from the same verb, denotes the thing narrated. Relation is here, as in the former paragraphs, the general, and the others the particular terms. Relation applies to every object which is related, whether of a public or private, a national or an individual nature, history is the relation of national events; biography is the relation of particular lives; recital is the relation or repetition of actual or existing circumstances; we listen to the recital of misfortunes, distresses, and the like. The relation may concern matters of indifference: the recital is always of something that affects the interests of some individual: the pages of the journalist are filled with the relation of daily occurrences which simply amuse in the reading: but the recital of another's woes often draws tears from the audience to whom it is made. Relation and recital are seldom employed without connection with the object related or recited; narrative is mostly used by itself: hence we say the relation of any particular circumstance; the recital of any one's calamities; but an affecting narrative, or a simple narrative.

See also Connection.

Relation, Relative, Kinsman, Kindred.-Relation is here taken to express the person related; it is, as in the former paragraph, the general term both in sense and application; relative is employed only as respects the particular individual to whom one is related; kinsman designates the particular kind of relation, and kindred is a collective term comprehending all one's relations or those who are one's kin. In abstract propositions the word relations is used in a more extended and universal sense: a man who is without relations feels himself an outcast from society; in designating one's close and intimate connection with persons we use the term relative; our near and dear relatives are the first objects of our regard: in designating one's relalionship and connection with persons, kinsman is preferable; when a man has no children, he frequently adopts one of his kinsmen as his heir: when the ties of relationship are to be specified in the persons of any particular family, they are denominated kindred; a man cannot abstract himself from his kindred while he retains any spark of human feeling.

RELATIONSHIP. See AFFINITY; KINDRED.

RELAX, ReMit. The general idea of lessening is that which allies these words to each other; but they differ very widely in their original meaning and somewhat in their ordinary application; relax, from re, again, and laxare, to loosen, signifies to make loose, and in its moral use to lessen anything in its degree of tightness or rigor; to remit, from re, again, and mittere, to send, signifies to take off in part or 
entirely that which has been imposed, that is, to lessen in quantity. In regard to our own attempts to act, we may speak of relaxing in our endeavors and remitting our labors or exertions, though the latter in this sense is now very rare ly used: in regard to our dcalings with others, we may speak of relaxing in discipline, relaxing in the severity or strictness of our conduct, of remilting a punishment or remilting a sentence. The discretionary power of showing mercy when placed in the hands of the sovereign serves to relax the rigor of the law; when the punishment seems to be disproportionate to the magnitude of the offence, it is but equitable to remit it.

RELENTLESS. See IMPLACABLE.

RELIANCE. See Dependence.

RELICS. Sec REMAINS.

RELIEF. See REDRESS.

RElieve. See Ali.eviate; Help. RELIGIOUS. See Holy.

RELINQUISH. See A вANDON; LLAVE; WAIVE.

RELISH. See TASTE.

RELUCTANT. See Averse.

REMAIN. See CoNTINUE.

REMAINDER. See REST.

REMAINS, RELICs. Remains signifies, literally, what remains: relics, from relictus, the past participle of the Latin relinquere, to leave, signifies what is left. The former is a term of general and familiar application; the latter is specific. What remains after the use or consumption of anything is termed the remains; what is left of anything after a lapse of years is the relic or relics. There are remains of buildings mostly after a conflagration; there are relics of antiquity in most monasteries and old churches. Remains are of valuc, or not, according to the circumstances of the case; relics always derive a value from the person to whom they were supposed originally to belong. The remains of a person-that is, what corporeally remains of a person after the extinction of life-will be respected by his friend; a bit of a garment that belonged, or was supposed to belong, to some saint will be a precious relic in the eyes of many devout Roman Catholics. All nations have agreed to respect the remains of the dead; religion, under most forms, has given a sacredness to relics in the eyes of its most zealous votaries; the veneration of genius, or the devotedness of friendship, has in like manner transferred itself from the individual himself to some object which has been his property or in his possession, and thus acquired relics equally precious.

Sometimes the term relics is used to denote what remains after the decay or loss of the rest, which further distinguishes it from the word remains, which simply signifies what is left.

See also Leavings.

REMARK, OBSERvation, CoMment, Note, ANNotation, Commentary. Remark (sce Notice), observation, and comment, in Latin commentum, past participle of comminisce (from Lat in com, a prefix based on cum, intensive, and the root found in Latin memini, memoria, English memory, signifying to remember), are either spoken or written: note, annotation (sce NoTE), commentary, a variation of comment, are always written. Remark and observation, admitting of the same distinction in both cases, have been sufficiently explainerl in the articles referred to: comment is a species of remark which often loses in good-nature what it gains in seriousness; it is mostly applied to particular persons or cases, and more commonly employed as a mode of censure than of commendation; public speakers and public performers are exposed to all the comments which the vanity, the envy, and ill-nature of sclf-constituted crities can suggest; but when not $\mathrm{cm}$ ployed in personal cases, it serves for explanation: the other terms are used in this sense only; but with certain modifications; the note is most general, and serves to call the attention to particular passages in the text and to illustrate them: annotations and commentaries are more minute; the former being that which is added by way of appendage; the latter being employed in a general form; as the annotations of the Greek scholiasts, and the commenturies on the sacred writirgs.

REMARKABLE. See ExTrAORDINARY.

REMEDY. See CURE.

REMEMBRANCE. See MEMORY.

REMEMBRANCER. SE MONUMENT. 
REMINISCENCE. See MEMORY. REMISS. See Negligent. REMISSNESS. See LAXNess. REMIT. See Abate; Forgive; Relax; Waive.

REMNANT. See Rest.

REMONSTRATE. See ExpostuLATE.

REMORSE. See Repentance.

REMOTE. See Distant.

REMOVE. See Transfer; UNVEIL.

REMUNERATION. See CoMpenSATION.

REND. See Break.

RENEGADE. See Recreant.

RENEW. See REVIVE.

RENOUNCE. See ABANDon.

RENOVATE. See REvive.

RENOWN. See FAME.

REPAIR. Sec RECOVER.

REPARATION. See REstoration. REPARTEE. See RETORT.

REPAY. See Restore.

REPEAL. See ABolish.

REPEAT, Recite, Rehearse, ReCapitulate. The idea of going over any words or actions is common to all these terms. Repeat, from the Latin re, again, and petere, to seek, or go over again, is the general term, including only the common idea. To recite, rehearse, and recapitulate are modes of repetition, conveying each some accessory idea. To recite is to repeat in a formal manner; to rehearse (from Latin re, again, and Old French hercer, to harrow, from herce, derived from Latin hirpex, a harrow) is to repeat or recite by way of preparation; to recapitulate, from capitulum, a chapter, is to repeat the chapters or principal heads of any discourse. We repeat both actions and words; we recite only words: we repeat single words or even sounds; we recite always a form of words: we repeat our own words or the words of another; we recite only the words of another; we repeat a name; we recite an ode or a set of verses.

We repeat for purposes of general convenience; we recite for the convenience or amusement of others; we rehearse for some specific purpose, either for the amusement or instruction of others: we recapitulate for the instruction of others. We repeat that which we wish to be heard; we recite a piece of poetry before a company; we rehearse the piece in private which we are going to recite in public; we recapitulate the general heads of that which we have already spoken in detail. A master must always repeat to his scholars the instruction which he wishes them to remember; Homer is said to have recited his verses in different parts; players rehearse their different parts before they perform in public; ministers recapitulate the leading points in their discourse. To repeat is commonly to use the same words; to recite, to rehearse, and to rccapitulate do not necessarily require any verbal sameness. We repeat literally what we hear spoken by another; but we recite and rehearse events, and we recapitulate in a concise manner what has been uttered in a particular manner. An echo repeats with the greatest possible precision; Homer recites the names of all the Grecian and Trojan leaders, together with the names and account of their countries and the number of the forces which they commanded; Virgil makes Eneas rehearse before Dido and her courtiers the story of the capture of Troy and his own adventures; a judge recapitulates evidence to a jury.

REPEL. See REFuse.

Repentance, Penitence, Contrition, Componction, Remorse. Repentance, from re, back, and ponitere, to be sorry, allied to Greek $\pi \varepsilon \hat{\varepsilon} \nu a$, hunger, signifies thinking one's self wrong for something past: penitence, from the same source, signifies simply sorrow for what is amiss. Contrition, from the past participle of conterere, to rub together, is to bruise, as it were, with sorrow; compunction, from compungere, to prick thoroughly; and remorse, from remorsus, the past participle of remordere, to have a gnawing pain; and hence to vex, to torment. All express modes of penitence differing in degree and circumstance. Repentance refers more to the change of one's mind with regard to an object, and is properly confined to the time when this change takes place; we, therefore, strictly speaking, repent of a thing but once; we may, however, have penitence for the same thing all our lives. Repentance supposes a change of conduct, at least as long as the sorrow lasts; 
but the term penitence is confined to the sorrow which the sense of guilt occasions to the offender.

Repentance is a term of more general application than penitence, being employed in respect to offences against men as well as against God; penitence, on the other hand, is applicable only to spiritual guilt. Repentance has applieation to our interests here, penilence to our interests hereafter.

Peritence is a general sentiment which belongs to all men as offending creatures; but contrition, compunction, and remorse are awakened by reflecting on particular offences: contrition is a continued and severe sorrow, appropriate to one who has been in a continued state of peculiar sinfulness: compunction is rather an occasional but sharp sorrow, provoked by a single offence or a moment's reflection; remorse may be temporary, but it is a still sharper pain awakened by some particular offence of peculiar magnitude and atrocity. The prodigal son was a contrite sinner; the brethren of Joseph felt great compunction when they were carried back with their sacks to Egypt; David was struck with remorse for the murder of Uriah.

REPETITION, TAUTOLOGY. Repetition is to tautology as the genus to the species, the latter being a species of repetition. There may be frequent repetition which is warranted by necessity or convenience; but tautology is that which nowise adds to either the sense or the sound. A repetition may or may not consist of literally the same words; but lautology, from the Greek

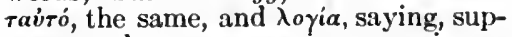
poses such a sameness in expression as renders the signification the same. In the liturgy of the Church of England there are some repetitions which add to the solemnity of the worship; in most extemporary prayers there is much tautology that destroys the religious effect of the whole.

REPINE. Sec CoMplain.

REPLY. See ANSwER.

REPORT. See FAME.

REPOSE. See Ease; Recline.

REPREHENSION, REPROOF. Personal blame or censure is implied by both these terms, but the former is much milder than the latter, and is of less frequent use. By reprehension the personal independence is not so sensibly affected as in the ease of reproof: people of all ages and stations, whose conduct is exposed to the investigation of others, are liable to reprehension; but children only, or such as are in a subordinate capacity, are exposed to reproof. Reprehension amounts to little more than passing an unfavorable sentence upon the conduct of another: reproof adds to this words more or less severe. The master of a school may be exposed to the reprehension of the parents for any supposed impropriety: his scholars are subject to his reproof.

See also Reproach; Blane.

REPRESENTATION. See RADIOGRAPH; SHOW.

REPRESS, REstrain, Suppress. To repress is to press back or down: to restrain is to strain back or down: the former is the general, the latter the specific, term: we always repress when we restrain, but not vice versa. Repress is used mostly for pressing down, so as to keep that inward which wants to make its appearance: restraint is an habitual repression by which a thing is kept in a state of lowness: a person is said to repress his feelings when he does not give them vent either by his words or actions; he is said to restrain his feelings when he never lets them rise beyond a certain pitch: good morals as well as good manners call upon us to repress every unscemly expression of joy in the company of those who are not in a condition to partake of our joy; it is prudence as well as virtue to restrain our appetites by a systematic inhibition, that they may not gain the ascendency.

To restrain is the act of the individual toward himself; repress may be an act directed to others, as to repress the ardor and impetuosity of youth; to suppress, which is to keep under, or keep from appearing or being perceptible, is also said in respect to ourselves or others: as to repress one's feelings; to suppress laughter, sighs, etc.

So likewise when applied to external objects, as to repress the impetuosity of the combatants, to suppress a rebellion, information, etc.

REPRIEVE, RESPITE. Reprieve is a doublet of reprove, from reprobare, 
to try a case a second time, with the implication of rejection, and hence to disallow a sentence. Respite comes through French from Latin respectum, English respect, and refers to the respect had to a suit.

The idea of a release from any pressure or burden is common to these terms; but the reprieve is that which is granted; the respite sometimes comes to us in the course of things: we gain a reprieve from any punishment or trouble which threatens us; we gain a respite from any labor or weight that presses upon us. A criminal gains a reprieve when the punishment of death is commuted for that of imprisonment for life; a debtor may be said to obtain a reprieve when, with a prison before his eyes, he gets such indulgence from his creditors as sets him free: there is frequently no respite for persons in a subordinate station, when they fall into the hands of a hard taskmaster; Sisyphus is feigned by the poets to have been condemned to the toil of perpetually rolling a stone up a hill as fast as it rolled back, from which toil he had no respite.

REPRIMAND. See CHECK.

REPRISAL. See RETaliation.

REPROACH, CoNTUMEly, OBloQUY. The idea of contemptuous or angry treatment of others is common to all these terms; but reproach is the general, contumely and obloquy are the particular, terms: the last two terms are of infrequent use to-day. Reproach (see BLAME) is either deserved or undeserved; the name of Puritan is applied as a term of reproach to such as affect greater purity than others; the name of Christian is a name of reproach in Turkey: contumely, of uncertain origin, but probably connected with contumacious, from Latin contumax (proud, stubborn, perverse, offensive), self-supposedly from contemnere, to despise, condemn, is always undeserved; it is the insolent and contemptuous rejection by a worthless person of merit in distress; our Saviour was exposed to the contumely of the Jews: obloquy, from $o b$, against, and loqui, to speak, signifying to speak against or to the disparagement of any one, is always supposed to be deserved or otherwise; it is applicable to those whose conduct has ren- dered them objects of general censure, and whose name, therefore, has almost become a reproach. A man who uses his power only to oppress those who are connected with him will naturally and deservedly bring upon himself much obloquy.

See also Discredit.

Reproachful, Abusive, Scurrilous.Reproachful, or full of reproach, when applied to persons, signifies full of reproaches; when to things, deserving of reproach: abusive, or full of abuse, is applied only to the person, signifying using abuse: scurrilous, in Latin scurrilis, from scurra, signifying a buffoon or saucy jester, is employed as an epithet either for persons or things in the sense of using scurrility. The conduct of a person is reproachful inasmuch as it provokes or is entitled to the reproaches of others; the language of a person is reproachful when it abounds in reproaches or partakes of the nature of a reproach: a person is abusive who indulges himself in abuse or abusive language: and he is scurrilous who adopts scurrility or scurrilous language. When applied to the same object, whether to the person or to the thing, they rise in sense; the reproachful is less than the abusive, and this less than the scurrilous; the reproachful is sometimes warranted by the provocation; but the abusive and scurrilous are always unwarrantable; reproachful language may be, and generally is, consistent with decency and propriety of speech: abusive and scurrilous language is an outrage against the laws of good-breeding, if not of morality. A parent may sometimes find it necessary to address an unruly son in reproachful terms; or one friend may adopt a reproachful tone to another; none, however, but the lowest orders of men, and those only when their anger is awakened, will descend to abusive or scurrilous language.

REPROBATE, CoNDEMN. To reprobate is much stronger than to condemn, but of less frequent application: we always condemn when we reprobate, but not vice versâ: to reprobate is to condemn in strong and reproachful language. We reprobate all measures which tend to sow discord in society and to loosen the ties by which men are bound to each other; we condemn 
all disrespectful language toward superiors. We reprobate only the thing; we condemn the person also: any act of disobedience in a child cannot be too strongly reprobaled; a person must expect to be condemned when he involves himself in embarrassments through his own imprudence.

See also Profligate.

REPROOF. See REPREHENSION:

REPROVE. See Blame; Check.

REPUBLIC. See EMPIRE.

REPUGNANCE. Sce Aversion.

REPUTATION. See Character; Fame; Name.

ReQuest. See Ask; Phayer.

REQUIRE. See DeMaNd.

REQUISITE. See Necessary.

REQUITAL. See Compensation; RETRIBUTION.

RESCUE. See Salvation.

RESEARCH. See Examination.

RESEMBLANCE. See LiKENESS.

RESENTMENT. Se A AGER; UMBRAGE.

RESERVE, Resenvation. Reserve and reservation, from servare, to keep, and re, back, both signify a keeping back, but differ as to the object and the circumstances of the action. Reserve is applied in a good sense to anything natural or moral which is kept back to be employed for a better purpose on a future oceasion; reservation is an artful keeping back for selfish purposes: there is a prudent reserve which every man ought to keep in his discourse with a stranger; equivocators deal altogether in mental reservation.

Reserve, Retain. - Reserve, from the Latin prefix re and servare, to keep, signifies to keep back. Retain, from tenere, to hold, signifies to hold back: they in some measure, therefore, have the same distinction as keep and hold.

To reserve is an act of more specific design; we reserve that which is the particular object of our choice: to retain is a simple exertion of our power; we retain that which has once come in our possession. To reserve is employed only for that which is allowable; we reserve a thing, that is, keep it back with care for some future purpose: to relain is often an unlawful act; a debtor frequently retains in his hands the money which he has borrowed.

To reserve, whether in the proper or improper application, is employed only as the aet of a conseious agent; to retain is often the act of an unconscious agent: we reserve what we have to say on a subject until a more suitable opportunity offers; the mind retains the impressions of external objects by its peculiar faculty, the memory; certain substances are said to retain the color with which they have been dyed.

RESIDE. See ABIDE.

RESIDENCE. See Domille.

RESIGN. See Abandon; Give UP. REsignation. See Patience. RESIST. See OpPose.

RESOlUTE. See Decided; StalWART; UNSWERVING.

RESOlUtion. See Courage.

RESOlVE. See Determine; Solve.

RESORT. See Frequent.

RESOURCE. See EXPEDIENT.

RESPECT. See EsteeM; Hovor; REFER.

RESPECTFUL. See Dutiful.

RESPITE. See INTERVAL; REPRIEVE.

RESPONSE. See ANswer.

RESPONSIBLE. See ANSWerable; Guaran'tee.

Rest, Pemainder, R e m N A T , REsidue. Rest is the substantive based on the Latin restare, compounded of $r e$ and stare, to stand behind, in this case, though not in the former (sce EASE), signifying what stands or remains back. Remainder literally signifies what remains after the first part is gone. Remnant is but a variation of remainder; it comes from the present participle of remancre, whence remainder is derived. Residue, from the neuter of the Latin adjective residuus, based on $r e$, back, and sedere, to sit, signifies likewise what remains back.

All these terms express that part which is separated from the other and left distinct: rest is the most general, both in sense and application; the others have a more specifie meaning and use: the rest may be either that which is left behind by itself or that which is set apart as a distinet portion: the remainder, remnant, and residue are the quantities which remain when the other parts are gone. The rest is said of any part, large or small; but the remainder commonly regards the smaller part which has been left after the 
greater part has been taken. A person may be said to sell some and give away the rest: when a number of hearty persons sit down to a meal, the remainder of the provisions, after all have been satisfied, will not be considerable. Rest is applied either to persons or things; remainder only to things: some were of that opinion, but the rest did not agree to it: the remainder of the paper was not worth preserving.

Remnant, from the Latin participle stem remanent, remaining, is a species of remainder after the greater part has been consumed or wasted: it is, therefore, properly a small remainder, as a remnant of cloth; and metaphorically applied to persons, as a remnant of Israel. A residue is another species of remainder, which resides or keeps back after a distribution or division of anything has taken place; as the residue of a person's property, that which remains undisposed of.

See also Cessation; Stand.

RESTITUTION. Se RestoraTION.

RESTORATION, RESTITUTION, Reparatión, Amends. Restoration is employed in the ordinary application of the verb restore: restitution, from the Latin verb restituere, is employed simply in the sense of making good that which has been unjustly taken or which ought to be restored. Restoration of property may be made by any one, whether it be the person taking it or not: restitution is supposed to be made by him who has been guilty of the injustice." The dethronement of a king may be the work of one set of men and his restoration that of another; it is the moral duty of every individual who has committed any sort of injustice to another to make restitution to the utmost of his power.

Restitution and reparation are both employed in the sense of undoing that which has been done to the injury of another; but the former connotes only injuries that affect the property, and reparation those which affect a person in various ways. He who is guilty of theft or fraud must make restitution by either restoring the stolen article or its full value: he who robs another of his good name, or does any injury to his person, has it not in his power so easily to make reparation.

Reparation and amends (see СомPENSATION) are both employed in cases where some mischief or loss is sustained; but the term reparation comprehends the idea of the act of repairing, as well as the thing by which we repair; amends is employed only for the thing that will amend or make better: hence we speak of the reparation of an injury; but of the amends by itself. The term reparation comprehends all kinds of injuries, particularly those of a serious nature; the amends is applied only to matters of inferior importance. It is impossible to make reparation for taking away the life of another. It is easy to make amends to any one for the loss of a day's pleasure.

See also RECOVERY.

Restore, Return, Repay. - Restore comes from Latin restaurare, to set up again. Return comes from Latin re, again, and Low Latin tornare, to turn a lathe. For repay see PaY.

The common idea of all these terms is that of giving back. What we restore to another may or may not be the same as what we have taken; justice requires that it should be an equivalent in value, so as to prevent the individual from being in any degree a sufferer; what we return and repay ought to be precisely the same as we have received: the former in application to general objects, the latter in application only to pecuniary matters. We restore upon a principle of equity: we return upon a principle of justice and honor; we repay upon a principle of undeniable right. We cannot always claim that which ought to be restored; but we cannot only claim, but enforce the claim in regard to what is to be returned or repaid: an honest man will be scrupulous not to take anything from another without restoring to him its full value. Whatever we have borrowed we ought to return; and when it is money which we have obtained, we ought to repay it with punctuality. We restore to many as well as to one, to communities as well as to individuals; a king is restored to his crown; or one nation restores a territory to another; we return and repay not only individually, but personally and par- 
ticularly: we return a book to its owner; we repay a sum of money to him from whom it was borrowed.

Restore and return may be employed in their improper applications as respects the moral state of persons and things; as a king restores a courtier to his favor, or a physieian restores his patient to health: we return a favor; we return an answer or a compliment. Repay may be figuratively employed in regard to moral objects, as an ungrateful person repays kindnesses with reproaches.

RESTRAIN, RESTRICT. Restrain (see CoERce) and restrict are but variations of the same Latin verb restringere: the first from the infinitive, the second from its past participle, restrictus; but they have acquired a distinet aeceptation: the former applies to the desires as well as the outward eonduct: the latter only to the outward conduct. A person restrains his inordinate appetite; or he is restrained by others from doing mischief: he is restricted in the use of his money. To restrain is an act of power; but to restrict is an act of authority or law: the will or the aetions of a ehild are restrained by the parent, but a patient is restricted in his diet by a physician, or any body of people may be restricted by laws.

\section{See also RePress.}

RESTRAINT. See Constrain; EMBARGO.

RESTRICT. See BOUND; RESTRAIN.

REsult. See Consequence.

RETAIN. See Hold; Reserve.

RETALIATION, REPRISAl. Retaliation, from retaliate, in Latin retaliatum, participle of retaliare, compounded of $r e$ and taliare, to requite in kind (the etymology of talis is far from certain), signifies so mueh again, or like for like. Reprisal, a word much used in connection with the European war, is a verbal substantive based on repris, past participle of the French verb reprendre, in Latin reprehendere, to take again, signifies to take in return for what has been taken. The idea of making another suffer in return for the suffering he has occasioned is common to these terms; but the former is employed in ordinary cases; the latter mostly in regard to a state of warfare or to aetive hostilities. A trick praeticed upon another in return for a trick is a retaliation; but a reprisal always extends to the capture of something from another, in return for what has been taken. Retaliation is very frequently employed in the good sense for what passes innocently between friends: reprisal has always an unfavorable sense. Goldsmith's poem, entitled "Retaliation," was written for the purpose of retaliating on his friends the joke that they had played upon him; when the quarrels of individuals break through the restraints of the law and lead to acts of violence to each other's property, reprisals are made alternately by both parties.

RETARD, HINDER. To retard, from the Latin tardus, slow, signifying to make slow, is applied to the movements of any object forward, as in the Latin "Impetum inimici tardare": to hinder (see that word) is applied to the person moving or acting: we retard or make slow the progress of any scheme toward completion; we hinder or keep back the person who is completing the scheme: we retard a thing, therefore, often by hindering the person; but we frequently hinder a person without expressly retarding, and, on the contrary, the thing is retarded without the person being hindered. The publication of a work is sometimes retarded by the hindrances which an author meets with in bringing it to a conelusion; but a work may be retarded through the idleness of printers, and a variety of other eauses which are independent of any hindrance. So in like manner a person may be hindered in going to his place of destination; but we do not say that he is retarded, beeause it is only the exeeution of an object and not the simple movements of the person which are retarded.

To retard stops the completion of an object only for a time, but to hinder is to stop it altogether.

See also Delay.

RetinUe. See Procession.

RETIRE. See RECEdE.

Retirement. See Privacy.

RETORT, REPARTEE. Retort, from $r e$, back, and torquere, to turn, signify- 
ing to twist or turn back, is an illnatured reply: repartee, a misspelling of repartie, feminine of the past participle of the French repartir, from Latin re, again, and partire, to divide, hence to lunge, is to answer thrust with thrust, cut with cut. The retort is always in answer to a censure, for which one returns a like censure; the repartee is commoniy in answer to the wit of another, where one returns wit for wit. In the acrimony of disputes it is common to hear retort upon retort to an endless extent ; the liveliness of discourse is sometimes greatly increased by the quick repartee of those who take part in it.

\section{RETRACT. See AbJore.}

RETREAT. See Asylum; ReCEde. RETRIBUTION, REQUTTAL. Retribution, from retribuere, to bestow, signifying a bestowing back or giving in return, is a particular term; requital (see REWARD) is general: the retribution comes from Providence; requital is the act of man: retribution is by way of punishment; requital is mostly by way of reward: retribution is not always dealt out to every man according to his deeds; it is a poor requital for one who has done a kindness to be abused.

RETRIEVE. See RECOVER.

RETROSPECT, REVIEW, StTRVEY. A retrospect, which signifies, literally, looking back, from retro, behind, and spicere, to behold or cast an eye upon, is always taken of that which is past and distant; review, which is a view repeated, may be taken of that which is present and before us; every retrospect is a species of review, but every review is not a retrospect. We take a retrospect of our past life in order to draw salutary reflections from all that we have done and suffered; we take a review or a second view of any particular circumstance which is passing before us, in order to regulate our present conduct. The retrospect goes farther by virtue of the mind's power to reflect on itself and to recall all past images to itself; the review may go forward by the exercise of the senses on external objects. The historian takes a retrospect of all the events which have happened within a given period; the journalist takes a review of all the events that are pass- ing within the time in which he is living.

The review may be said of the past as well as the present; it is a view not only of what is, but what has been: the survey, which is a looking over at once, from the French sur, upon, and Old French veër, for voir, to see, is entirely confined to the present; it is a view only of that which is, and is taken for some particular purpose. We take a review of what we have already viewed, in order to get a more correct insight into it; we take a survey of a thing in all its parts, in order to get a comprehensive view of it, in order to examine it in all its bearings. A general occasionally takes a review of all his army; he takes a survey of the fortress which he is going to besiege or attack.

RETURN, REverT. Return is the English, and revert the Latin: return is therefore used in ordinary cases to denote the coming back to any point of time or place; as to return home, or to return at a certain hour, or to apply one's self again to the same business or employment; as to return to one's writing: to revert is to throw back with one's mind to any object; we may, therefore, say, to return or revert to any intellectual object, with this distinction, that to return is to go back to the point here one left off treating of any subject; to revert is simply to carry one's mind back to the same object. As an act of an unconscious agent, return is used as before.

Revert signifies either to fall back into the same state or to return by reflection to the same object; all things revert to their primitive order and regularity.

See also Restore.

Reveal. See Publish; Unveil. REVELS. See Saturnalia.

REVENGE. See AvENGE.

REVERBERATE. See REBound.

REVERE. See ADORE.

REVERENCE. See ADore; Awe; HoNon.

REVERSE. See Overturn.

REVERT. See RETURN.

REVERY. See DrEaM.

REVIEW. See Retrospect; REVISAL.

REVILE, VILIFY. Revile, from the Latin prefix re and old French aviler, 
to make vile, built on the Latin vilis, cheap, worthless, signifies to reflect upon a person, or retort upon him that which is vile: to vilify signifies to makc a thing vile, that is, to set it forth as vile. To revile is a personal act; it is addressed directly to the object of offence, and is addressed for the purpose of making the person vile in his own eyes: to vilify is an indireet attack whieh serves to make the object appear vile in the eyes of others. Revile is said only of persons, for persons only are reviled; but to vilify is said of persons as well as things. "To revile is uncharitable : to vilify is seldom justifiable, for we eannot vilify without using improper language; it is seldom resorted to except as a manifestation of ill-nature.

REVISAL, Reviston, Review. Reitsal, revision, and review all come from the Latin videre, to see, and signify looking back upon a thing or looking at it again: the terms revised and revision are, however, mostly employed in regard to what is written; review is used for things in general. The revisal of a book is the work of the author, or of a reviser, for the purposes of correction: the review of a book is the work of the critic, for the purpose of estimating its value. Revisal and revision differ neither in sense nor application, that except the former is more frequently employed abstractedly from the objeet revised and revision mostly in conjunction: whoever wishes his work to be correct will not spare a revisal; the revision of classical books ought to be intrusted only to men of profound crudition.

See also Retrospect.

REVIVE, Refresh, Renovate, ReNEw. Revive, from the Iatin vivere, to live, signifies to bring to life again; to refresh, to make fresh again; to renew and renovate, to make new again. The restoration of things to their primitive state is the common idea included in these terms; the difference consists in their application. Revive, refresh, and renovate are applied to animal bodies; revive expressing the return of motion and spirits to one who was for the time lifcless; refresh expressing the return of vigor to one in whom it has been diminished; the air revives one who is faint; a cool breeze refreshes one who is affeeted by the heat. Revive and refresh connote only the temporary state of a body; renovale the permanent state, that is, the health or powers of a body; one is revived and refreshed after partial exhaustion; one's health is renovated after having been considerably impaired.

Revive is applied likewise in the moral sense; refresh and renovate mostly in the proper sense; renew only in the applied sense. A discussion is said to be revived or a report to be revived; a elamor is said to be renewed or entreaties to be renewed: customs are revived which have long lain dormant and, as it were, dead; practices are renewed that have ceased for a time.

REVOKE. See Abjure; Abolish.

REVOLT. See Defection; InsurRECTION.

REWARD. Sce Compensation.

RHETORIC. Sec FlocUtioN.

Riches, Wealth, Opulence, AfFLUENCE. Riches comes from Old French richesse, wealth, from Middle High German riche, which is the same word as Anglo-Saxon ric. Wealth, Middle English welthe, extended from weal, prosperity, which is allied to well. Opulence, from the stem of the Latin opcs, riches, denotes the state of having riches. Afluence, from the Latin ad, to, and fluere, to flow, denotes either the act of riches flowing in to a person or the state of having things flowing in.

Riches is a general term denoting any considerable share of property, but without immediate reference to a possessor; whatever serves to make one rich is denominated riches, inasmuch as it supplies us with the means of getting what is really good; weallh and the other terms refer to outward possessions.

Riches is a condition opposed to poverty; the whole world is divided into rich and poor, and riches are distributed in different degrees; but wealth, opulence, and affluence all denote a considerable share of riches: wealth is a positive and substantial share of this world's goods, but particularly of money or the precious commodities; it may be taken in the abstract or in application to individuals: opulence consists of any large share in possessions or property generally, as 
houses, lands, goods, and chattels, and is applicable to the present and actual condition of the individual. Affluence is a term peculiarly applicable to the fluctuating condition of things which flow in in great quantities to a person. We speak of riches as to their effects upon men's minds and manners; it is not every one who knows how to use them: we speak of wealth as it raises a man in the scale of society and contributes to his weal or wellbeing: we speak of opulence as the present actually flourishing state of the individuals; and of affuence as the temporary condition. Wealth and opulence are applied to communities as well as individuals.

RIDICULE, SATIRe, Irony, SarCASM. Ridicule (see DERIDE) has simple laughter in it; satire comes from satura lanx, a full dish, a dish of mixed ingredients, indicating a poem full of topical and personal hits: the former is employed in matters of a trifling nature; 'but satire is employed either in personal or grave matters. Irony,

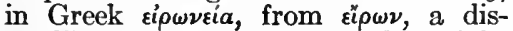
sembler who says less than he thinks or means, is disguised satire; an ironist seems to praise that which he really means to condemn. Sarcasm, from the

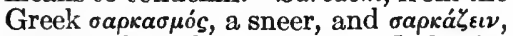
to sneer, both based on $\sigma a ́ \rho \xi$, flesh, signifying biting or nipping satire, so, as it were, to tear the flesh, is bitter and personal satire; all the others may be successfully and properly employed to expose folly and vice; but sarcasm, which is the indulgence only of personal resentment, is never justifiable.

See also Ladgh.

RIGHT, Just, Fit, Proper. Right, from Anglo-Saxon riht, signifying upright, not leaning to one side or the other, standing as it ought, is here the general term: the others express modes of right. The right and wrong are defined by the written will of God, or are written in our hearts according to the original disposition of our nature: the just, in Latin justus, from jus, law, signifying according to a rule of right, and the unjust, are determined by the written laws of men; the fit and proper, in Latin proprius, signifying belonging to a given specific rule, are determined by the established principles of society.
Between the right and the wrong there are no gradations: a thing cannot be more right or more wrong; whatever is right is not wrong, and whatever is wrong is not right: the just and unjust, proper and improper, fit and unfit, on the contrary, have various shades and degrees that are not so easily definable by any forms of speech or written rules.

The right and wrong depend upon no circumstances; what is once right or wrong is always right or wrong, but the just or unjust, proper or improper, are relatively so according to the circumstances of the case: it is a just rule for every man to have that which is his own; but what is just to the individual may be unjust to society. It is proper for every man to take charge of his own concerns; but it would be improper for a man in an unsound state of mind to undertake such a charge. Right is applicable to all matters, important or otherwise; just is employed mostly in matters of essential interest; proper is rather applicable to the minor concerns of life. Everything that is done may be characterized as right or wrong: everything done to others may be measured by the rule of just or unjust: in our social intercourse, as well as in our private transactions, fitness and propriety must always be consulted. As Christians, we desire to do that which is right in the sight of God and man; as members of society, we wish to be just in our dealings; as rational and intelligent beings, we wish to do what is fit and proper in every action, however trivial.

See also Straight.

Right, Claim, Privilege.-Right signifies in this sense what it is right for one to possess, which is, in fact, a word of large meaning: for since the right and the wrong depend upon indeterminable questions, the right of having is equally indeterminable in some cases with every other species of right. A claim (see Ask) is a species of right to have that which is in the hands of another; the right to ask another for it. The privilege is a species of right peculiar to particular individuals or bodies.

Right, in its full sense, is altogether 
an abstract thing which is independent of human laws and regulations; claims and privileges are altogether connected with the laws of society. Liberty, in the general sense, is an inalienable right which belongs to man as a rational and responsible agent; it is not a claim, for it is set above all question and all condition: nor is it a privilege, for it cannot be exclusively granted to one being nor unconditionally be taken away from another.

Between right and power there is often as wide a distinction as between truth and falsehood; we have of ten a right to do that which we have no power to do; and the power to do that which we have no right to do: slaves have a right to the freedom which is enjoyed by creatures of the same species as themselves, but they have not the power to use this freedom as others do. In England men have the power of thinking for themselves as they please; but by the abuse which they make of this power we see that in many cases they have not the right, unless we admit the contradiction that men have a right to do what is wrong; they have the power, therefore, of exercising this right only because no other person has the power of controlling them. We have often a claim to a thing which is not in our power to substantiate; and, on the other hand, claims are set up in cases which are totally unfounded on any right. Privileges are rights granted to individuals, depending either upon the will of the grantor, or the circumstances of the receiver, or both; privileges are therefore partial rights transferable at the discretion of persons individually or collectively.

RIGHTEOUS. See GodLY.

RIGID. See Ascetic; Austere.

RIGOROUS. See Austere; Harsh.

RIM. See Border.

RIND. See SKIN.

RIPE, Mature. Ripe is the English (from Anglo-Saxon ripe, fit for reaping), mature the Latin word: the former has a universal application both proper and improper; the latter has mostly an improper application. The idea of completion in growth is simply designated by the former term; the idea of moral perfection, as far, at least, as it is attainable, is marked by the latter: fruit is ripe when it requires no more sustenance from the parent stock; a judgment is mature which requires no more time and knowledge to render it perfect or fitted for exercise: in the same manner a project may be said to be ripe for execution or a people ripe for revolt; and, on the contrary, reflection may be said to be mature to which suffieiency of time has been given, and age may be said to be mature which has attained the highest pitch of perfection. Ripeness is, however, not always a good quality; but maturity is alway's a perfection: the ripeness of some fruit diminishes the excellence of its flavor: there are some fruits which have, no flavor until they come to maturity.

RISE, Issue, Everge. To rise (see ARISE) may either refer to open or enclosed spaces; issue and emerge (see EMERGENCY) have both a reference to some confined body: a thing may either rise in a body, without a body, or out of a body; but it issues and emerges out of a body. A thing may either rise in a plain or a wood; it issues out of a wood: it may either rise in water or out of the water; it emerges from the water; that which rises out of a thing comes into view by becoming higher: in this manner an air balloon might rise out of a wood; that which issues comes from the very depths of a thing, and, as it wcre, comes out as a part of it; but that which emerges proceeds from the thing in which it has been, as it were, concealed. Hence, in the moral application, a person is said to rise in life without a reference to his former condition; but he emerges from obscurity: color rises in the face; but words issue from the mouth.

See also Origin.

RISK. See Hazard.

RITE. See ForM.

ROAD. See Route.

ROAM. See WANDER.

ROBbERY. See Depredation.

ROBUST. See Strong.

ROLL. See List.

ROMANCE. See Fable.

ROOM. See SPACE.

ROT, Putrefy, Conrupt. The dissolution of bodies by an internal process is implied by all these terms: but 
the first two are applied to natural bodies only; the last to all bodies, natural and moral. Rot is the strongest of all these terms; it denotes the last stage in the progress of dissolution: putrefy (the modern variant of putrefy, based on putrid) expresses the progress toward rottenness; and corruption the commencement. After fruit has arrived at its maturity or proper state of ripeness it rots: meat which is kept too long putrefies: there is a tendency in all bodies to corruption; iron and wood corrupt with time; whatever is made, or done, or wished by men is equally liable to be corrupt or to grow corrupt.

ROUGH. See Abrupt; Harsh.

ROUND. See Circuit.

ROUNDNESS, ROTUNDITY. Roundness and rotundity both come from the Latin rotundus and rota, a wheel, which is a perfectly round body: the former term is. however, applied to all objects in general; the latter only to solid bodies which are round in all directions: one speaks of the roundness of a circle, the roundness of the moon, the roundness of a tree; but the rotundity of a man's body which projects in a round form in all directions, and the rotundity of a full cheek or the rotundity of a turnip.

ROUSE. See AWAKEN.

ROUSING. See Electric.

ROUT. See BEAT.

ROUTE, ROAD, Course. Route comes through the French from the adjective of the Latin phrase, via rupta, or "broken road." Road comes from the Anglo-Saxon ridan, to ride, signifying the place where one rides, as course, from the Latin cursus (see Course), signifies the place where one walks or runs.

Route is to road as the species to the genus: a route is a circular kind of road; it is chosen as the circuitous direction toward a certain point, and may consist of more than one road successively: the road may be either in a direct or indirect line; the route is always indirect: the route is chosen only by horsemen or those who go to a considerable distance, as those who choose the "route to India"; the road may be chosen for the shortest distance; the route and road are pursued in their beaten and frequented track; the course is often chosen in the un- beaten track: an army or a company go a certain route, foot-passengers are seen to take a certain course over fields: course often implies circular completion, as, the sun runs its course.

ROVE. See W ANDER.

ROYAL, Regal, K1NGLY. Royal and regal, both from the adjective regalis, based on Latin rex, a king, though of foreign origin, have obtained more general application than the corresponding English term kingly. Royal signifies belonging to a king, in its most general sense; regal signifies appertaining to a king, in its particular application; kingly signifies properly like a king. A royal carriage, a royal residence, a royal couple, a royal salute, royal authority, all designate the general and ordinary appurtenances to a king: regal government, regal state, regal power, regal dignity, denote the peculiar properties of a king: kingly always implies what is becoming a king, or after the manner of a king; a kingly crown is such as a king ought to wear; a kingly mien that which is after the manner of a king.

RUB, Chafe, Fret, Gaj.l. Rub, Middle English rubben, is of Celtic origin; it is nct allied to German reiben, from which rive is taken; it is the generic term, expressing simply the act of bodies moving in contact with and against others; to chafe (from! Old French chaufer, from Low Latin calef'care, a late form of the classical calfacere, to make hot) signifies to $r u b$ a thing until it is heated: to fret comes from Anglo-Saxon frétan, compounded of for, intensive prefix, and etan, meaning to eat away; to gall is a different word from the noun gall, and corresponds probably to Latin galla, a gall-nut, oak-apple-hence a tumor, a skin affection; hence to rub or itch. Things are rubbed sometimes for purposes of convenience; but they are chafed, fretted, and galled injuriously: the skin is liable to chafe from any violence; leather will fret from the motion of a carriage; when the skin is once broken animals will become galled by a continuance of the friction. These terms are likewise used in the moral sense, to denote the actions of things on the mind, where the distinction is clearly kept up: we meet with rubs from the 
opposing sentiments of others; the similarly derived from frangere, to angry humors are chafed; the mind is break, denote different kinds of breakfretted and made sore by the frequent repetition of small troubles and vexations; pride is galled by humiliations and severe degradations:

RUDE. See IMPERTINENT.

RUDIMENTARY. See ElementARY.

RUEFUL. See Piteous.

RUGGED. See ABRUPT.

RUIN. See Bane; Destrection; FaLl.

RUlle. See Govern; Guide; MAXIM; ORder.

RULing. See Prevaining.

RUMMAGE, RANSACK. These two words both signify to look for something. Rummage, compounded of French suffix age and Dutch ruim, a ship's hold, allied to room. It meant to stow away and then to search among things stowed away. Ransack comes from Scandinavian rann, a house, and $s a k$, a root allied to seek, signifying to search a house thoroughly and carry away. Ransack signifies a thorough rummaging. The difference between the two words is mainly one of degree.

RUMOR. See FAMr.

RUPTURE, Fracture, Fraction. Rupture, from ruptura, the feminine of the future participle of rumpere, to break or burst, and fracture or fraction, ing, according to the objects to which the action is applied. Soft substances may sufier a rupture; as the rupture of a blood-vessel; hard substances a fracture, as the fracture of a bone.

Fraction is used only in respect to broken numbers; as the fraction of a unit.

Rupture is also used in an improper application; as the rupture of a treaty. RURAL, RUSTIC. Although both these terms, from the Latin rus, country, signify belonging to the country, yet the former, from the genitive stem ruris, is used in a good, and the latter in a bad or an indifferent, sense. Rural applies to all country objects except man; it is, therefore, always connected with the charms of nature: rustic applies only to persons or what is personal, in the country, and is, therefore, always associated with the want of culture. Rural scenery is always interesting; but the rustic manners of the peasants have frequently too much that is uncultivated and rude in them to be agreeable; a rural habitation may be fitted for persons in a higher station; but a rustic cottage is adapted only for the poorer inhabitants of the country. See also Countryman. 
SABBATH, Sunday. The term Sabbath, from the Hebrew shabbáth, to rest, through French sabbat, implies a sacred day of rest from customary occupations, the institution of which, under the name of the seventh day, is first mentioned in Genesis 11:2-3. Always in the Gospels and as a rule in the other books, Sabbath means the seventh day of the week.

Distinctions between the Sabbath and Sunday were at one time very sharply drawn, the Sabbath being considered a purely Jewish term, and Sunday, otherwise called the Lord's Day, a Christian one; but most of the old contentions were long ago abandoned. The elder Disraeli is authority for the statement that the term Sabbath meant Saturday in the Middle Ages, and that it was first used in England for Sunday in 1554.

Both Jews and Christians observe the seventh day of the week, but from a different start, the former recognizing Saturday as their Sabbath and the latter the following day as their Sunday.

SACK, Despoil, Devastate. Sack, in French sac, waste or ruin, may be derived from Latin saccus, a bag or sack for carrying away things. Despoil comes from Latin spoliare, based on spolium, a skin stripped off, referring to the dress of a dead warrior. Devastate, from devastare, based on Latin vastus, signifying large, empty space, means to lay waste. Sack is a stronger word than despoil. It means to go through a conquered territory and carry off everything of value. Despoil means to strip off something valuable, but it does not imply such thorough and wholesale destruction. Devastate means literally to lay waste, and refers not merelv to the carrying away of valuables, but to the utter destruction of everything. We may speak of a city devastated by fire, or a country devastated by storm-so that the word has a wider application than sack and does not refer merely to warfare. Despoil may refer to the action of individuals. An unscrupulous lawyer may despoil a widow of the property left to her, etc. But sack is applied specifically to the treatment of captured territory in warfare. See also RAPINE; RaVAGE.

SACRAMENT. See LoRD'S-SUPPER.

\section{SACRED. See Holy.}

SACRILEGIOUS, IRREVERENT, Desecrating. Sacrilegious, from Latin sacrilegium (based on the crude stem sacri and legere, to gather up and steal sacred things), the robbing of a temple, is a much more positive word than irreverent, which simply means not reverent (for the derivation see ADORE): but it is a less positive word than desecrating, from Latin de, not, and sacer, sacred, which means depriving of sacredness, and has a more extended application. Sacrilegious means positively irreverent, implying an irreverence that reveals itself in a distinct speech or act which shows a lack of regard for things held holy. Desecrating means not merely a positive expression of the disregard for things sacred, but an expression of such violence that it destroys the sacred character. Irreverent applies to an attitude of mind, sacrilegious to manner and speech, desecrating to action, though these distinctions are not clearly observed. (Sacrilegious is of ten mispronounced, even by educated persons, as sacrilegious.) See also IRRELIGIOUS.

SAD. See Dull; Mournfol.

SAFE, SECuRE. Safe, in Latin salvus, to be tranquil, implies exemption from harm or the danger of harm; secure (see Certain) the exemption from danger: a person may be safe or saved in the midst of a fire, if he be untouched by the fire; but he is, in such a case, the reverse of secure. In the sense of exemption from danger, safety expresses much less than security: we may be safe without using any particular measures; but none can reckon on any degree of security without great 
precaution: a person may be very safe on the top of a coach in the daytime; but if he wishes to secure himself, at night, from falling off, he must be fastened.

SAFE-CONDUCT. See PASS.

SAFEGUARD. See PASS.

SAGACIOUS. See SAGE.

SAGACITY. See Penetration.

SAGE, Sagacious, Sapient. Sage and sagacious come from different Latin words, despite their similarity of form and meaning, sage being derived ultimately from Latin sapere, to be wise; sagacious from sagax, connected with sagire, to perceive by the senses. Sapient is derived from the present participle of sapere.

The first of these terms has a good sense, in application to men, to denote the faculty of discerning immediately, which is the fruit of experience, and very similar to that sagacity in animals which instinctively perceives a thing without the deductions of reason; $s a-$ pient is now employed only in regard to animals which are trained to particular arts; its use, therefore, in respect to human beings, is mostly in the lofty or burlesque style.

SAILOR. See SEaman.

SAINTLY. See HoLY.

SAINT-SIMONIANISM. See SoCIALISM.

SAKe, Account, Reason, Purpose, END. These terms are all employed adverbially, to modify or connect propositions; hence one says, for his sake, on his account, for this reason, for this purpose, and to this end. Sake, from Anglo-Saxon sacu, strife, a side in a strife, hence a cause, is mostly said of persons; what is done for a person's sake is the same as in behalf of his cause; one may, however, say in regard to things, for the sake of good order, implying what good order requires: account is indifferently employed for persons or things; what is done on a person's account is done in his behalf and for his interest; what is done on account of indisposition is done in consequence of it, the indisposition being the cause: purpose is properly personal and refers to that which a person purposes to himself; if we ask, therefore, for what purpose a thing is done, it may be to know something of some other person's character and principles: reason and end are applied to things only: we speak of the reason as the thing that justifies: we explain why we do a thing when we say we do it for this or that reason; we speak of the end by way of explaining the nature of the thing: the propriety of a measure cannot be known unless we know what end it will answer.

SALARY. See Allowance.

SALIENT, OUTSTaNdiNG. Both of these words indicate that which is a noticeable or prominent feature of something. Outstanding is really just an English translation of salient, from Latin salire, to leap, hence to stand out; and the difference between them is mainly the difference usually found between words of English and Latin derivation. Outstanding suggests the picture more clearly. The outstanding feature of an occurrence is that which strikes the attention most vividly, which stands out from the rest. Salient does not so clearly suggest the image, but it is a somewhat more polished word.

SALLY, Issue. Sally, from Latin salire, to leap, is a particular kind of issuing. (For issue see ArISE.) It referred to the going forth of a detachment of soldiers from a besieged place to attack the besiegers. Issue means, in general, to go forth. Sally means to go forth with a certain spirit and gallantry, with an attitude of adventurousness. Sally is applied figuratively to a humorous thrust, a witticism or jest; in this sense it is used mainly as a noun. Here, too, it keeps its fundamental implication of a spirited and unexpected attack.

SALUBRIOUS. See Healthy.

SALUTARY. See Healthy.

Salute, Salutation, Greeting. Salute (see Accost) concerns the thing; and salutation, which is a variation of salute, the person giving the salule: a salute may consist either of a word or an action; salutations pass from one friend to another: the salute may be either direct or indirect; the saluitation is always direct and personal; guns are fired by way of a salute: bows are given as a salulation.

The salutation is a familiar and ordinary form of courtesy between individ- 
uals; greeting is frequently a particular mode of salutation adopted on extraordinary occasions, indicative of great joy or satisfaction in those who greet.

Salvation, Deliverance, Preservation, Saving, Redemption, ResCUE. Salvation, in French salvation, from Latin salvationem, from salvus, whole, has both a physical and a moral application. In the physical application we seek or receive deliverance from impending or present peril from some power beyond our own. We gain preservation from something destructive by some act of our own or of others, and we may be the subject or object of a rescue from danger, restraint, or violence.

In the moral application we are taught that salvation is the spiritual deliverance from sin and death, through the saving mercy of Jesus Christ, who offered himself as a ransom for mankind, his death being the final act of man's redemption; or the releasing and setting free of all living in sin.

SANATIVE. See SANITARY.

SANATORY. See SaNitary.

SANCTIFy, Cleanse, Consecrate, Devote, Hallow, Purify. Sanctify, in Frencl sanctifier, from Latin sanctificere, compound of sanctus, holy, and a weakened form of facere, to make, signifies literally to make holy or sacred, and applies both to persons and objects of a religious character.

In the personal application, to sancti$f y$ is to make holy, to have one's heart and life made to conform to the will of God. Prior to this act comes that to cleanse or purify from sin, to convert from a former state, to regenerate or make anew.

To consecrate is to set a person or object apart from that which is ordinary for some sacred purpose. This is done by others, as the consecration of a religious edifice or some part thereof, and the consecration of a person to the calling of the ministry.

To devote one's self to a sacred purpose is the act of the individual, to devote an object is for one or others to give or apply it. To hallow a place or object is to consecrate or set it apart for a sacred purpose.

SANCTION. See Countenance; UPHOLD.
SANCTITY. See Hounness.

SANE. See Sound.

SANGUINARY, BLOODY, BLOODTHIRSTY. Sanguinary, from sanguis, is employed both in the sense of bloody, or having blood, and bloodythirsty, or thirsting after blood; sanguinary, in the first case, relates only to blood shed, as a sanguinary engagement or a sanguinary conflict; bloody is used in the familiar application, to denote the simple presence of blood, as a bloody coat or a bloody sword.

In the second case, sanguinary is employed to characterize the tempers of persons only; bloodthirsty to characterize the tempers of persons to any other beings: revolutionists will be frequently sanguinary. because they are abandoned to their passions and follow a lawless course of violence: tigers are by nature the most bloodthirsty of all creatures.

SANGUINE, ARDENT, BUOYANT, Chemrful, Confident, Elated, Enthusiastic, Hopeful, Warm. Sanguine, from the Latin sanguis, meaning blood. One who abounds in blood is said to have a sanguine temperament, and that gives birth to the conditions indicated by the other terms.

The ardent person is warm, glowing, passionate, eager, and zealous; the buoyant one is in a state of mental uplift and is seldom depressed; the cheerful one is abounding in good spirits, is happy himself, and strives to make others happy; the confident one feels assured of his own power and future; the elated one is exultant, apt to be excitable, and is easily raised in spirits.

Enthusiastic persons are generally ardent, frequently visionary, scmetimes fanatical, and always zealous in their undertakings. Hopeful ones always look on the bright side of things, see the silver lining of clouds, and are full of anticipation, expectation, and trust; warm ones are full of zeal, ardor, affection, and welcome, and are apt to be easily irritated.

See also Optimistic.

SANITARY, SaNatory. Sanitary, in French sanitaire, a coined word from Latin sanitas, sanity, and sanatory, extended from sanator, a healer (hence sanatorium), are terms commonly used indiscriminately, but having different 
applications. Sanitary specifically signifies something pertaining to health, sanatory something conducive to health.

Whatever is conducive to health, such as curing or healing applications or treatment, is sanatory; whatever pertains to or is connected with the preservation of health is sanitary. Allied to these terms are sanitation, or the system of promoting healthful reforms, and sanitarium or sanatorium, a resort for hygienic, restful, or curative treatment.

SAP, UNDERMINE. Sap, AngloSaxon $s a p$, signifies the juice which springs from the root of a tree; but sap, in the sense of undermine, is probably derived from Latin sappa, a spade or mattock; hence signifies to come at the root of anything by digging: to undermine signifies to form a mine under the ground or under whatever is upon the ground: we may sap, therefore, without undermining; and undermine without sapping: we may sap the foundation of a house without making any mine underneath; and in fortifications we may undermine either a mound, a ditch, or a wall without striking immediately at the foundation: hence, in the moral application, to $s a p$ is a more direct and decisive mode of destruction; to undermine is a gradual, and may be a partial, action. Infidelity saps the morals of a nation; courtiers undermine one another's interests at court.

SAPIENT. See SAge.

SARCASM. See Ridicule.

SARCASTIC. See Trenchant.

SATANIC. See Drabolic.

SATIATE. See Satisfy.

SATIRE. See Ridicule; Wit.

SATISFACTION. Sce CoMpensaTION; ConTENTMENT.

Satisfy, Please, Gratify. To satisfy (see Contentment) is rather to produce pleasure indirectly; to please (see Agrefander) is to produce it directly: the former is negative, the latter positive, pleasure: as every desire is accompanied by more or less pain, satisfaction, which is the removal of desire, is itself to a certain extent pleasure; but what satisfies is not alwav's calculated to please; nor is that which pleases that which will always satisfy: plain food satisfies a hungry person, but does not please him when he is not hungry; social enjoyments please, but they are very far from satisfying those who do not restrict their indulgences. To gratify is to please in a high degree, to produce keen pleasure: we may be pleased with trifles, but we are commonly gratified with such things as act strongly either on the senses or the affections: an epicure is gratified with those delicacies which suit his taste; an amateur in music will be gratified by hearing a piece of Handel's composition finely performed.

See also Compensation.

Satisfy, Satiate, Glut, Cloy.-To satisfy is to make enough: satiate is a frcquentative, formed similarly from satis, enough, but signifying to have more than enough. Glut, in Latin glutire, allied to gula, the throat, signifies to take down the throat. Satisfaction brings pleasure; it is what nature demands; and nature, therefore, makes a suitable return: satiety, meaning that which exceeds the desire, is attended with disgust; glutting is an act of intemperance; it is what the inordinate appetite demands; it greatly exceeds the former in degree both of the cause and the consequence: cloying is the consequence of glutting. Every healthy person satisfies himself with a regular portion of food; children, if unrestrained, seek to satiate their appetitcs, and cloy themselves by their excesses; brutes, or men sunk to the level of brutes, glut themselves with that which is agreeable to their appetites. So, in the moral application, we satisfy desires in general or any particular desire; we satiate the appetite for pleasure; one gluts the eyes or the ears by anything that is horrible or painful or cloys the mind.

Saturnalia, Carntyas, Orgies. These words all indicate particular festivals, and henee, by extension, unrestrained licensc and riotous selfindulgenee. Saturnalia, in Latin the neuter plural of saturnalis, pertaining to Saturn, was an ancient Roman festival in honor of the gorl Saturn, in which all elasses. including slaves, took part. It was celebrated in December and was regarded as a period of unrestrained license.

Carnival (not, as commonly misun- 
derstood, from Italian carne, vale! or "Farewell, oh flesh! nor, as Lord Byron tried to explain it, 'Farewell to flesh" ") is derived from Latin carnis, flesh, and Latin levare, to lift, remove, take away, and is the festival immediately preceding Lent in Italy, celebrating the beginning of fleshless and fasting days by a riot of self-indulgence. Orgy, Latin orgia, from Greek ő $\rho$ yıa, secret rites, refers to the secret festivals in honor of Bacchus, the god of wine, celebrated by extravagant revels; the word is usually employed in the plural-orgies. In the figurative application of these words there is little difference. All indicate unrestrained riot; but there is more of harmless gayety in carnival, perhaps, and more of extravagance, violence, and shamelessness in orgies.

SAUCY. See IMPERTINENT.

SAUNTER. See LINGER.

SAVAGe. See Cruel; Ferociods.

SaVe, Spare, Preserve, Protect. To save is to keep or make safe. Spare comes from Anglo-Saxon spær. Preserve, compounded of pre, before, and servare, keep (cf. German hüten... vor.), signifies to keep away from. Protect (see DefEND).

The idea of keeping free from evil is the common idea of all these terms, and the peculiar signification of the term save; they differ either in the nature of the evil kept off or the circumstances of the agent: we may be saved from every kind of evil; but we are spared only from those which it is in the power of another to inflict: we may be saved from falling or saved from an illness; a criminal is spared from punishment, or we may be spared by Divine Providence in the midst of some calamity.

We may be saved and spared from any evils, great or small; we are preserved and protected only from evils of magnitude: we may be saved either from the inclemency of the weather or the fatal vicissitudes of life: we may be spared the pain of a disagreeable meeting or we may be spared our lives; we are preserved from ruin or protected from oppression. To save and spare apply to evils that are actual and temporary; preserve and protect to those which are possible or permanent: we may be saved from drowning; a person may be preserved from infection or protected from an attack. To save may be the effect of accident or design; to spare is always the effect of intentional forbearance; to preserve and protect are the effect of a special exertion of power, the latter in a still higher degree than the former: we may be preserved, by ordinary means, from the evils of human life; but we are protected by the government or by Divine Providence from the active attacks of those who aim to do us harm.

To spare and protect refer mostly to personal injuries; save and preserve are said of whatever one keeps from injury on account of its value; as to save one's good name, to preserve one's honor.

See also Deliver; Keep.

SAVING. See Economical; SalVATION.

SAVOR. See TAste.

SAW. See Axiom.

SAY. See Speak.

SAYING. See Axiom.

SCALE. See ARISE.

SCANDAL. Sce Discredit.

SCANDALOUS. See InfaMots.

SCANTY. See BARE.

SCARCE. See RARE.

SCARCELY. See HARdLY.

SCARCITY, DEARTH. Scarcity (see RARE) is a generic term to denote the circumstance of a thing being scarce. Dearth, which is the same as dearness (Middle English derthe, formed from the adjective as warmth, health, wealth are formed), is a mode of scarcity applied in the literal sense to provisions mostly, as provisions are mostly dear when they are scarce; the word dearth, therefore, denotes scarcity in a high degree: whenever men want something and find it difficult to procure, they complain of its scarcity: when a country has the misfortune to be visited with a famine, it experiences the frightfulest of all dearths.

Dearth is figuratively applied to moral objects; as a dearth of intelligence, of talent, and the like.

SCATHE, DAMAge, HARM, INJURY, Mischief. Scathe is from a Teutonic root meaning to harm. These terms apply both to the body and material objects and to the individual mind.

SCATTER. See Spread. 
SCEPTICISM, AgNosticism, ATHEISM. These words are al! used to indicate a disbelief in the articles of a religion, especially of the Christian religion, but they differ considerably in the degree and kind of unbelief that they indicate. Scepticism, from

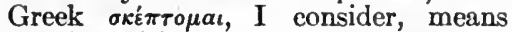
the disposition to doubt all things, to come to no intellectual conclusion, because of an insufficiency of evidence. It has a wider application than the other two words and refers to a general intellectual attitude in respect to all things and not merely to an attitude to religious questions. Agnosticism has a similar meaning. It was a word coined by Huxley in a heated controversy between the theologians of the old school and the evolutionary scientists of the new to express his own attitude - that of simple open-mindedness on the subject of all questions concerning which he had no scientific evidence, especially concerning articles of religious faith. The doctrines of the Church could not be proved, he said. They cannot therefore be declared a true gnosis-a matter of intellectual knowledge. Agnosic he coined by prefixing the privative $a$ to the Greek gnosis to signify one who refused to consider statements not based, like the facts of natural science, on the evidence of the senses as matters of scientific fact. He wished to proclaim himself open to correction, however, ready to examine all evidence. Agnostivism has therefore the same fundamental meaning as scepticism. The agnostic, ilke the sceptic, says, "I will consider," but, practically and historically, the words have had a different meaning. The sceptic doubts all evidence; the agnostic admits the validity of a certain kind of evidence - the evidence of the senses. Sceplicism, as applied to religion, has generally indicated positive disbelief; agnosticism, the position of the open-minded inquirer. Atheism, while often confuser with the other terms, has an entirely different meaning. It signifies a disbelief in the existence oi a God, or at least of a personal God. The consistent agnostic cannot be an atheist, berause, if he cannot prove the existence of a God, he is equally unable to prove $\mathrm{His}$ non-existence.
SCHEMING, Artful, Contriving, Designing, Intriguing, Planning. Scheming, in Latin schema, Greek $\sigma \chi \hat{\eta} \mu a$, form, from $\sigma \chi \dot{\eta} \sigma \omega$, future of,

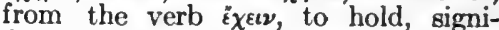
fies holding in one's hands or one's mind the plan and means of future action. As acts of contriving, designing, and planning, the term may be used both in a proper or praiseworthy sense and in an improper and reprehensible one.

These terms in the proper sense imply acts intended to result in benefits to ourselves or others on material lines, in which we devise, invent, project, outline, or sketch that which is necessary to the accomplishment of the purpose in mind. In the improper sense these operations may be to the disadvantage or injury of others.

In being artful and in intriguing we become cunning, erafty, engaged in secret and underhand plots. We may be artful solely, or all by ourselves, but when we are intriguing we usually need confederates, as the plot or scheme in mind is generally of a more or less complicated nature, and, as more than one person is involved, the intriguer cannot hold all the strings in his hands.

See also Design.

SCHISMATIC. See HERETIC.

SCHOLAR, Disciple. Scholar (see Scroor, below) and disciple are both applied to such as learn from others: but the former is said only of those who learn the rudiments of knowledge; the latter of one who acquires any art or science from the instruetion of another: the scholar is opposed to the teacher; the disciple to the master: children are always scholars; adult persons may be disciples. Scholars chiefly employ themselves in the study of words; disciples, as the disciples of our Saviour, in the study of things: we are the scholars of any one under whoso care we are placed or from whom we learn anything, good or bad; we are the disciples only of those who are distinguished, and for the most part in the good sense, though not always so: children are sometimes too apt scholars in learning evil from one another. Philosophers of old had their disciples, and nowadays there are many who have been exalted 
into that character who have their disciples and followers.

SCHOlASTIC. See Academic.

SCHOOL, ACADEMY. The Latin term schola signified a loitering-place, a place for desultory conversation or instruction, from the Greek $\sigma \chi^{\circ} \lambda_{\eta}$, leisure; hence it has been extended to any place where instruction is given, particularly that which is communicated to youth. Academy derives its name from the Greek ákadín $\mu \varepsilon \iota$, the name of a gymnasium near Athens (so named for the hero Academus), where the philosopher Plato first gave his lectures, and which afterward became a place of resort for learned men; hence societies of learned men have since been termed academies. The leading idea in the word school is that of instruction given and doctrine received; in the word academy is that of association among those who have already learned: hence we speak in the literal sense of the school where young persons meet to be taught, $\mathrm{cr}$ in the extended and moral sense of the old and new school, the Pythagorean school, the philosophical school, and the like; but the academy of arts or sciences, the French Academy, being members of any academy, and the like.

SCIENCE. See KNowledge.

SCOFF, Gibe, Jeer, SNeer. Scoff is from an Old Low German word which may have meant originally a playful shove. Gibe (also spelled jibe) is from the Scandinavian. Jeer is a word of doubtful origin. Sneer, Middle English sneren, is allied to snarl.

Scoffing is a general term for expressing contempt; we may scoff either by gibes, jeers, or sneers; or we may scoff by opprobrious language and contemptuous looks, with gibing, jeering, or sneering: to gibe, jeer, and sneer are personal acts; the gibe and jeer consist of words addressed to an individual: the former has most of ill-nature and reproach in it; the latter has more of ridicule or satire in it; they are both, however, applied to the actions of vulgar or unseemly people who practice their coarse jokes on others.

Scoff and sneer are directed either to persons or things as the object; gibe and jeer only toward persons; scoff is taken only in the proper sense; sneer derives its meaning from the literal act of sneering: the scoffer speaks lightly of that which deserves serious attention: the sneerer speaks either actually with a sneer or as it were by implication with a sneer: the scoffers at religion set at naught all thoughts of decorum, they openly avow the little estimation in which they hold it; the sneerers at religion are more sly; but not less malignant; they wish to treat religion with contempt, but not to bring themselves into the contempt they deserve.

SCOPE. See TENDENCY.

SCORN. See Contemn.

SCORNFUL. See Contemptuous.

SCOUT. See SPY.

SCREAM. See CrY.

SCREEN. See Cover.

SCRIBE. See WrITER.

SCRUPle, Hesitate, Waver. To scruple (see Conscientious) simply keeps us from deciding; the terms hesitate (see DeMur) and waver, from Anglo-Saxon wafre, restless, wandering, bespeak a fluctuating or variable state of the mind. We scruple simply from motives of doubt as to the propriety of a thing; we hesitate and waver from various motives, particularly such as affect our interests. Conscience produces scruples, fear produces hesitation, irresolution produces wavering: a person scruples to do an action which may hurt his neighbor or offend his Maker; he hesitates to do a thing which he fears may not prove advantageous to him; he wavers in his mind between going or staying, according as his inclinations impel him to the one or the other: a man who does not scruple to say or do as he pleases will be an offensive companion, if not a dangerous member of society: he who hesitales only when the doing of good is proposed shows himself a worthless member of society; he who wavers between his duty and his inclination will seldom maintain a long or doubtful contest.

SCRUTINIZE. See Pry.

SCRUTINY. See Examination.

SCUM. See Dregs.

SCURRILOUS. See REPROACHFUL.

SEAL, Stamp. Seal is a specific, stamp a general, term: there cannot be a seal without a stamp; but there may be many stamps where there is no seal. The seal, in Latin sigillum, the diminu- 
tive of signum, signifies a signet or little sign, consisting of any one's coat of arms or any device; the stamp is, in general, any impression whatever which has been made by stamping (from $\operatorname{stamp}$, meaning to step heavily, Greek $\sigma \tau^{\prime} \mu \beta \varepsilon \iota \nu$, to stamp), that is, any impression which is not easily to be effaced. In the improper sense, the seal is the authority; thus, to set one's seal is the same as to authorize, and the seal of truth is any outward mark which characterizes it: but the stamp is the impression by which we distinguish the thing; thus a thing is said to bear the stamp of truth, of sincerity, of veracity, and the like.

SEAMAN, Waterman, SaILOR, MARINER. All these words denote persons occupied in navigation; the seaman, as the word implies, follows his business on the sea; the waterman is one who gets his livelihood on fresh water: the sailor and the mariner are both specific terms to designate the seaman: every sailor and mariner is a seaman; although every seaman is not a sailor or mariner; the former is one who is employed about the laborious part of the vessel; the latter is one who traverses the ocean to and fro, who is attached to the water and passes his life upon it. Men of all ranks are denominated seamen, whether officers or men, whether in a merchantman or a king's ship: sailor is used only for the common men, or, in the sea phrase, for those before the mast, particularly in vessels of war; hence our sailors and soldiers are spoken of as the defenders of our country; a mariner is an independent kind of seaman who manages his own vessel and goes on an expedition on his own account; fishermen and those who trade along the coast are in a particular manner distinguished by the name of mariners.

SEARCH. See Examine; RumMAGE; SEEK.

SEASON. See Time.

SEASONABLE. See Opportune;

TIMELY.

SECEDE. See Recede.

SEClUSion. See Privacy.

SECOND, SuPPORT. To second is to give the assistance of a second person; to support is to bear up on one's own shoulders. To second does not express so much as to support: we second only by our presence or our word; but we support by our influence and all the means that are in our power: we second a motion by a simple declaration of our assent to it; we support a motion by the force of persuasions: so likewise we are said always to second a person's views when we give him openly our countenance by declaring our approbation of his measures; and we are said to support him when we give the assistance of our purse, our influence, or any other thing essential for the attainment of an end.

Second, Secondary, Inferior.-Second and secondary both come from the Latin secundus, changed from sequun$d u s$ and sequi, to follow, signifying the order of succession: the former simply expresses this order; but the latter includes the accessory idea of comparative demerit: a person stands second in a list, or a letter is second which immediately succeeds the first; but a consideration is secondary, or of secondary importance, which is opposed to that which holds the first rank. Secondary and inferior both designate some lower degree of a quality: but secondary is applied only to the importance or value of things; inferior is applied generally to all qualities: a man of business reckons everything as secondary which does not forward the object he has in view; men of inferior abilities are disqualified by nature for high and important stations, although they may be more fitted for lower stations than those of greater abilities.

SECRECy. See Concealment.

SECRET, Hidden, LATENT, OCcult, Mrsterious. What is secret (see Clandestine) is so far removed as to be out of observation; what is hidden (sce CoNcenL) is so covered over as to be altogether concealed: as a corner may be secret; a hole underground is hidden.

What is secret is known to some one; what is hidden may be known to no one: it rests in the breast of an individual to keep a thing secret; it depends on the course of things if anything remains hidden: every man has more or less of that which he wishes to keep secret; the talent of many lies hidden for 
want of opportunity to bring it into exercise, as many treasures lie hidden in the earth for want of being discovered and brought to light. A secret may concern only the individual or individuals who hold it, and those from whom it is kept; but that which is hidden may concern all the world: sometimes the success of a transaction depends upon its being kept secret; the stores of knowledge which yet remain hidden may be much greater than those which have been laid open. The latent, from the stem of Latin latens, lying hid, is the secret or concealed in cases where it ought to be open: a latent motive is that which a person intentionally, though not justifiably, keeps to himself; the latent cause for any proceeding is that which is not revealed.

Occult, in Latin occultus, participle of occulere, compounded of $o b$, over, and the stem found in celare, to hide, signifying that which is covered over; and mysterious (see DARK) are species of the hidden: the former connotes that which has a veil naturally thrown over it; the latter that mostly which is covered with a supernatural veil: an occult science is one that is hidden from the view of persons in general, which is attainable but by few; occult causes or qualities are those which lie too remote to be discovered by the inquirer: the operations of Providence are said to be mysterious, as they are altogether past our finding out; many points of doctrine in our religion are equally mysterious, as connected with and dependent upon the attributes of the Deity.

SECRET AGENT. See SPY.

SECRETE. See Conceal.

SECTARIAN. See HERETIC.

SECULAR, TeMporal, WorldLy. Secular, in Latin sacularis, from saculum, an age or division of time, signifies belonging to time or this life. Temporal, in Latin temporalis, from tempus, time, signifies lasting only for a time. Worldly signifies after the manner of the world (from Anglo-Saxon weoruld, which is compounded of wer, a man, and eld, an age, signifying the age of a man, a man's life, the scene of a man's life).

Secular is opposed to ecclesiastical; temporal and worldly are opposed to spiritual or eternal. The idea of the world or the outward objects and pursuits of the world, in distinction from that which is set above the world, is implied in common by all the terms; but secular is an indifferent term, applicable to the legitimate pursuits and concerns of men; temporal is used either in an indifferent or a bad sense; and worldly mostly in a bad sense, as contrasted with things of more value. The office of a clergyman is ecclesiastical, but that of a school-master is secular, which is frequently vested in the same hands; the Upper House of Parliament consists of lords spiritual and temporal; worldly interest has a more powerful sway over the minds of the great bulk of mankind than their spiritual interests.

Secure. See Certain; PreparEDNESS; SAFE.

SECURITY. See Deposit; Fence; Guarantee.

SEDATE. See Composed.

SEDIMENT. See Dregs.

SEDITION. See InsURRECTION.

SEDITIOUS. See Factiods; TUMULTUOUS.

SEDUCE. See Allore.

SEDULOUS, Diligent, Assiduous. The idea of application is expressed by these epithets; but sedulous, from the Latin sedulus, probably from sedere, to sit (the etymology se, apart, and dolus, guile, free from guile, working honestly, is an error), is a particular, diligent (see Active) is a general, term: one is sedulous by habit; one is diligent either habitually or occasionally: a sedulous scholar pursues his studies with regular and close application; a scholar may be diligent at a certain period, though not invariably so. One is sedulous from a conviction of the importance of the thing; one may be diligent by fits and starts, according to the humor of the moment.

Assiduous (Latin ad, near, and sedere, to sit) and sedulous both express the quality of sitting or sticking close to a thing, but the former may, like diligent, be employed on a partial occasion; the latter is always permanent: we may be assiduous in our attentions to a person; but we are sedulous in the important concerns of life. Sedulous peculiarly concerns the quiet employ- 
ments of life, but may be applied to any pursuit requiring persevering attention; a teacher may be entitled sedulous: diligent implies the active employments; one is diligent at work: assiduity holds a middle rank; it may be employed equally for that which requires active exertion or otherwise: we may be assiduous in the pursuits of literature, or we may be assiduous in our attendance upon a person or the performance of any office.

See, Perceive, Observe. See, Anglo-Saxon seón, may be either a voluntary or involuntary action: perceive, through French from the Latin percipere, based on per, thoroughly, and a weakened form of capere, to take into the mind, is always a voluntary action; and observe (see NoTICE) is an intentional action. The cye sees when the mind is absent; the mind and the eye or other senses perceive in conjunction: hence, we may say that a person sees, but does not perceive: we observe not merely by a simple act of the mind, but by its positive and fixed exertion. We see a thing without knowing what it is; we perceive a thing, and know what it is, but the impression passes away; we observe a thing, and afterward retrace the image of it in our mind. We see a star when the eye is directed toward it; we perceive it move if we look at it attentively; we observe its position in different parts of the heavens. The blind cannot see, the absent cannot perceive, the dull cannot observe. Seeing, as a corporeal action, is the act only of the eye; perceiving and observing are actions in which all the senses are concerned. We see colors, we perceive the state of the atmosphere and observe its changes.

Seeing sometimes extends further in its application to the mind's operations, in which it has an indefinite sense; but perceive and observe have both a definite sense; we may see a thing distinctly and clearly or otherwise; we perceive it always with a certain degree of distinctness, and observe it with a positive degree of minuteness: we see the truth of a remark; we perceive the force of an objection; we observe the reluctance of a person. It is further to be remarked, however, that, when see expresses a mental operation, it expresses what is purely mental; perceive and observe are applied to such objects as are seen by the senses as well as the mind. We see the light with our eyes, or we see the truth of a proposition with our mind's eyes; but we perceive the difference of climate, or we perceive the difference in the comfort of our situation; we observe the motions of - the heavenly bodies.

See also Look.

SEED. See GERM.

SEEK, SeARCH. To seek and search (see Examine) are both employed in the sense of looking after something that is not in sight: seek applies to that which is near at hand and easily found; search, to that which is remote, hidden, or not to be found without difficulty: to search, therefore, is properly to seck laboriously; we seek a person by simply going to the place where he is supposed to be; search is made from place to place when it is not known where he is: a school-boy seeks birds' nests; the botanist searches for plants.

These terms may also be applied to moral objects with the same distinction: as to seek peace, knowledge; to search the thoughts, to search into mysteries.

SEEM, APPEAR. The idea of coming to the view is expressed by both these terms; but the word seem rises upon that of appear. Seem, from Anglo-Saxon séman, to satisfy, conciliate, signifies literally to appear like, and is thercfore a species of appearance; appear, from the Latin ad, to, and parere, to come in sight, signifies to be present or before the eye. Every object may appear; but nothing seems, except that which the mind admits to appear in any given form. To seem requires some reflection and comparison of objects in the mind one with another; it is, therefore, peculiarly applicable to matters that may be different from what they appear, or of an indeterminate kind: that the sun seems to move is a conclusion which we draw from the exercise of our senses and comparing this case with others of a similar nature; it is only by a further research into the operation of nature that we discover this to be no conclusive proof of its motion. To appear, on the
contrary, is the express act of things 
themselves on us; it is, therefore, peculiarly applicable to such objects as make an impression on us: to appear is the same as to present itself: the stars appear in the firmament, but we do not say that they seem; the sun appears dark through the clouds.

They are equally applicable to moral as well as natural objects with the above-mentioned distinction. Seem is said of that which is dubious, contingent, or future; appear, of that which is actual, positive, and past. A thing seems strange which we are led to conclude as strange from what we see of it: a thing appears clear when we have a clear conception of it: a plan seems practicable or impracticable; an author appears to inderstand his subject or the contrary. It seems as if all efforts to reform the bulk of mankind will be found inefficient; it $a p$ pears, from the long catalogue of vices which are still very prevalent, that little progress has hitherto been made in the work of reformation.

SEEMLY. See Becoming.

SEGREGATE, SEParate. Segregate and separate both mean to divide from something, to set apart. But segregate, from Latin se, meaning apart, away, and gregare, from gregem, accusative, meaning flock, herd, signifies to set apart in a group by itself. It means not merely to separate (see SeParate) but, after separation, to keep in a separate group. It is therefore a word of more specific meaning and narrower application.

SEIZE. See NAB.

SEIZURE. See CAPTURE.

SELECT. See SEgregate.

SELF-CONCEIT. See SElF-will.

SELFISH. See Greedy.

SELF-WILl, SELF-CONCEIT, SelfSUFFICIENCY. Self-will signifies the will in one's self: self-conceit, conceit of one's self: self-sufficiency, sufficiency in one's self. As characteristics they come very near to each other, but that disposition of the will which refuses to submit to every control either within or without is born with a person, and is among the earliest indications of character; in some it is less predominant than in others, but, if not early checked, it is that defect in our natures which will always prevail; self-conceit is a vicious habit of the mind which is superinduced on the original character; it is that which determines in matters of judgment: a self-willed person thinks nothing of right or wrong; whatever the impulse of the moment suggests is the motive to action: the self-conceited person is always much concerned about right and wrong, but it is only that which he conceives to be right and wrong; self-sufficiency is a species of self-conceit applied to action: as a self-conceited person thinks of no opinion but his own; a self-sufficient person refuses the assistance of every one in whatever he is called upon to do.

SEMBLANCE. See Show.

SENIOR, ELDER, OldER. These are all comparatives expressive of the same quality, and differ, therefore, less in sense than in application. Senior is employed not only in regard to the extent of age, but also to duration either in office or any given situation: elder is employed only in regard to age: an officer in the army is a senior by virtue of having served longer than another; a boy is a senior in a school either by virtue of his age, his standing in the school, or his situation in the class; when, therefore, age alone is to be expressed, elder is more suitable than senior; the elder children or the elder branches of a family are clearly understood to include those who have priority of age.

Senior and elder are both employed as substantives, older only as an adjective: hence we speak of the seniors in a school, or the elders in an assembly; but an older inhabitant, an older family. Elder has only a partial use; older is employed in general cases: in speaking of children in the same family we may say the elder son is heir to the estate; he is older than his brother by ten years.

SEnsation. See Feelixa; SenTIMENT.

SENSE, Judament. Sense (see Fenuing) signifies in general the faculty of feeling corporeally or perceiving mentally; in the latter case it is synonymous with judgment, which is a special operation of the mind. The sense is that primitive portion of the understanding which renders an 
account of things; and the judgment that portion of the reason which selects or rejects from this account. The sense is, so to speak, the reporter which collects the details and exposes the facts; the judgment is the judge that passes sentence upon them. According to the strict import of the terms, the judgment depends upon the sense, and varies with it in degree. He who has no sense has no judgment; and he who loses sense loses judgment: since sense supplies the knowledge of things, and judgment pronounces upon them, it is evident that there must be sense before there can be judgment.

On the other hand, sense may be so distinguished from judgment that there may be sense without judgment, and judgment without sense: sense is the faculty of perceiving in general; it is applied to abstract science as well as general knowledge: judgment is the faculty of determining, that is, of determining mostly in matters of practice. By sense the mind perceives by an immediate act, by the judgment it arrives at conclusions by a process. It is the lot of many, therefore, to have sense in matters of theory who have no judgment in matters of practice; while others, on the contrary, who have nothing above common sense will have a soundness of judgment that is not to be surpassed. Nay, further, it is possible for a man to have good sense and yet not solid judgment: as they are both natural faculties, men are gifted with them as variously as with every other faculty. By good sense a man is enabled to discern, as it were, intuitively, that which requires another of less sense to ponder over and study; by solid judgment a man is enabled to avoid those errors in conduct which one of weak judgment is always falling into. There is, however, this distinction between sense and judgment, that the deficiencies of the former may be supplied by diligence and attention; but a defect in the latter is not so easily to be supplied by efforts of one's own. A man may improve his sense in proportion as he has the means of information; but the judgment once matured rarely makes any advances toward improvement afterward.
The words sense and judgment are frequently employed without any epithets to denote a positively large share of these faculties.

As epithets, sensible and judicious both denote the possession of these faculties in a high degree, but in their application they are distinguished as above. A writer or a speaker is said to be sensible; a friend, or an adviser, to be judicious. Sense displays itself in the conversation or the communication of one's ideas; judgment in the propriety of one's actions. A sensible man may be an entertaining companion, but a judicious man in any post of command is an inestimable treasure. Sensible remarks are always calculated to please and interest sensible people; judicious measures have a sterling value in themselves that is appreciated according to the importance of the object. Hence it is obvious that to be sensible is a desirable thing, but to be judicious is an indispensable requisite in those who have to act a part.

Sce also Signification.

Sensible, Sensitive, Sentient. - All these epithets, which are derived from the same source, have obviously a great sameness of meaning, though not of application. Sensible and sensitive both denote the capacity of being moved to feeling: sentient implies the very act of feeling. Sensible expresses either a habit of the body and mind or only a particular state referring to some particular object: a person may be sensible of things in general, or sensible of cold, sensible of injuries, sensible of the kindnesses which he has received from an individual. Sensitive signifies always an habitual or permanent quality; it is the characteristic of objects: a sensitive creature implies one whose sense is quickly to be acted upon; a sensitive plant is a peculiar species of plants, marked for the property of having sense or being sensible of the touch.

Sensible and sensitive have always a reference to external objects; but sentient expresses simply the possession of feeling or the power of feeling, and excludes the idea of the cause. Hence, the terms sensible and sensitive are applied only to persons or corporeal objects: but sentient, which conveys the 
most abstract meaning, is applicable to men and spirits; sentient beings, taken absolutely, may include angels as well as men; it is restricted in its meaning by the context only.

Sensible, Perceptible.-These epithets are here applied not to the persons capable of being impressed, but to the objects capable of impressing: in this case sensible (see FEEL) applies to that which acts on the senses merely; perceptible (see SEE), to that which acts on the senses in conjunction with the mind. All corporeal objects are naturally termed sensible, inasmuch as they are sensible to the eye, the ear, the nose, the touch, and the taste; particular things are perceptible, inasmuch as they are to be perceived or recognized by the mind. Sometimes sensible signifies discernible by means of the senses, as when we speak of a sensible difference in the atmosphere, and in this case it comes nearer to the meaning of perceptible; but the latter always refers more to the operation of the mind than the former: the difference between colors is said to be scarcely perceptible when they approach very near to each other, so likewise the growth of a body is said not to be perceptible when it cannot be marked from one time to another by the difference of state.

SENSIBILITY. See FEELING.

SENSITIVE. See Sensible.

SENSUALIST, VolUPTUARY, EpICURE. The sensualist lives for the indulgence of his senses: the voluptuary (from voluptas, pleasure) is devoted to his pleasures, and as far as these pleasures are the pleasures of sense the voluptuary is a sensualist: the epicure, from Epicurus, is one who makes the pleasures of sense his god, and in this sense he is a sensualist and a voluptuary. In the application of these terms, however, the sensualist is one who is a slave to the grossest appetites; the voluptuary is one who studies his pleasures so as to make them the most valuable to himself; the epicure is a species of voluptuary who practices more than ordinary refinement in the choice of his pleasures.

Sentence, Proposition, Period, Phrase. Sentence, in Latin sententia, is but a variation of sentiment (see
Opinion). Proposition (see PropoSAL). Period, in Latin periodus, Greek $\pi \varepsilon \rho i o \delta o s$, from $\pi \varepsilon \rho i$, about, and ódós, way, signifies the circuit or round of words which renders the sense complete. Phrase, from the Greek $\phi \rho \alpha^{\prime} \xi \varepsilon \iota \nu$, to speak, signifies the words uttered.

The sentence consists of any words which convey sentiment: the proposition consists of the thing set before the mind, that is, either our own minds or the minds of others; hence the term sentence has more special regard to the form of words, and the proposition to the matter contained: they are both used technically or otherwise, the former in grammar and rhetoric, the latter in logic. The sentence is simple and complex; the proposition is universal or particular. Period and phrase, like sentence, are forms of words, but they are solely so, whereas the sentence depends on the connection of ideas by which it is formed: we speak of sentences either as to their structure or their sentiment; hence the sentence is either grammatical or moral: but the period regards only the structure; it is either well or ill turned: the term phrase denotes the character of the words; hence it is either vulgar or polite, idiomatic or general: the sentence must consist of at least two words to make sense; the phrase may be a single word or otherwise.

See also Decision.

Sentence, Doom, Condemn.-To sentence, or pass sentence, is to give a final opinion or decision which is to influence the fate of an object. Condemn, from con for cum, wholly, and aamnare, to harm or punish, is to pass such a sentence as shall be to the hurt of an object. Doom comes from Anglo-Saxon dom, a thing set or decided on, from the verb don, to do, Modern English do.

When these terms are taken in the judicial sense, to sentence is indefinite as to the quantum of punishment, which may be great or small; a criminal may be sentenced to a mild or severe punishment: to condem $n$ and doom are always employed to denote a severe punishment, and the latter still severer than the former. A person is condemned to the galleys, to transportation for life, or to death; he is doomed to eternal misery. 
To sentence is always the act of some conscious agent; but to condemn and doom may be the effect of circumstances or brought about by the nature of things. A person is always sentenced by some one to suffer in consequence of his conduct; he is condemned or doomed, either by his misfortune or his fault, to suffer whatever circumstances impose upon him; immoral writers are justly condemned to oblivion or infamy; or persons may be condemned by their hard lot to struggle through life for a bare living; and some are doomed by a still harder lot to penury and wretchedness.

To sentence is to pass sentence in the judicial sense only; but the noun sentence is taken in the sense of a judgment, and has likewise a moral as well as a judicial application, in which latter case it admits of a further comparison with condemn or condemnation. The sentence is a formal and the condemnation an informal judgment: the sentence may be favorable or unfavorable: the condemnation is always unfavorable: critics pronounce their sentence on the merits or demerits of a work; the public may condemn a measure in any manner by which they make their sentiments known. To doom, which signifies only to determine the fate of a person, is not allied to the other terms in their moral application.

Sententious, Sentimental. - Sententious signifies having or abounding in sentences or judgments; sentimental, having sentiment (see OPINION). Books and authors are termed sententious; but travellers, society, intercourse, correspondence, and the like are characterized as sentimental. Moralists, whose works and conversation abound in moral sentences, like Dr. Johnson's, are termed sententious; novelists and romance-writers, like Mrs. Radcliffe, are properly sentimental. Sententious books always serve for improvement; sentimental works, unless they are of a superior order, are in general hurtful.

SENTIENT. See SENSIBLE.

Sentiment, Sensation, PercepTION. Sentiment and sensation are obviously derived from the same source (see FEel). Perception, from perceive (sec SeE), expresses the act of perceiving or the impressions produced by perceiving.
The impressions which objects make upon the person are designated by all these terms; but the sentiment has its seat in the heart, the sensation is confined to the senses, and the perception rests in the understanding. Sentiments are lively, sensations are grateful, perceptions are clear. Gratitude is a sentiment most pleasing to the human mind: the sensation produced by the action of electricity on the frame is generally unpleasant; a nice perception of objects is one of the first requisites for perfection in any art.

The sentiment extends to manners and renders us alive to the happiness or misery of others as well as our own; it is that by which men are most nearly allied to each other: the sensation is purely physical, and the effect of external objects upon either the body or the mind: perceptions carry us into the district of science; they give us an interest in all the surrounding objects as intellectual observers. A man of spirit or courage receives marks of honor, or affronts, with very different sentiments from the poltroon; he who bounds his happiness by the present fleeting existence must be careful to remove every painful sensation: we judge of objects as complex or simple according to the number of perceptions which they produce in us.

\section{See also OPINION.}

\section{SENTINEL. See Guard.}

SEPARATE, Sever, Disjorn, DeTACH. To separate (see ABstract) is the general term: whatever is united or joined in any way may be separated, be the junction natural or artificial; but to sever, which is but a variation of separate, is a mode of separaling natural bodies or bodies naturally joined: we may separate in part or entirely; we sever entirely: we separate with or without violence; we sever with violence only: we may separate papers which have been pasted together or fruits which have grown together; but the head is severed from the body or a branch from the trunk.

To scparate may be said of things which are only remotely connected; disjoin, signifying to destroy a junction, is said of that which is intimately connected so as to be joined: we separate as convenience requires; we may 
separate in a right or a wrong manner; we mostly disjoin things which ought to remain joined: we separate syllables in order to distinguish them; but they are sometimes disjoined in writing by an accidental erasure. To detach, from Latin de, from, and French tacher, perhaps from a German word akin to the English tack or nail, signifying to take from a nail, has an intermediate sense between separate and disjoin, applying to bodies which are neither so loosely connected as the former nor so closely as the latter: we separate things that directly meet in no point; we disjoin those which may meet in many points; we detach those things which meet in one point only.

Separate, sever, and detach may be applied to mental as well as corporeal objects; persons may be separated from each other by diversity of interests or opinions; they may be severed from each other when their affections are estranged toward each other; they may be detached from each other by circumstances after having been attached by any tie.

See also Different; Divide; SegREGATE.

SEPARATION. See DIVorce.

SEPULCHRE. See Grave.

SEPULTURE. See BURIAL.

SEQUEL, Close. Sequel is a species of close; it is that which follows by way of termination; but the close is simply that which closes, or puts an end to anything. There cannot be a sequel without a close, but there may be a close without a sequel. A story may have either a sequel or a close; when the end is detached from the beginning so as to follow, it is a sequel; if the beginning and end are uninterrupted, it is simply a close. When a work is published in distinct parts, those which follow at the end may be termed the sequel; if it appears all at once, the concluding pages are the close.

SERENE. See CALM.

SERIES, Course. A series, in Latin series, from serere, to bind or connect, is applied to things which are connected with each other simply in order of time or number. Course, in Latin cursus, from currere, to run, signifying the line formed or the direction taken in running, applies to things which are so connected as to form, as it were, a line; a series of events are such as follow in order of time; a series of numbers of any work are such as follow in numerical order; a course of events is such as tends to the same end; a course of lectures, such as is delivered on the same subject.

See also SuccEssion.

SERIOUS. See EAger; Grave.

SERRATED. See JAGgED.

SERVANT, Domestic, Menial, DRUdGe. In the term servant is included the idea of the service performed: in the term domestic, ultimately from domus, a house, is included the idea of one belonging to the house or family: in the word menial, from Old French meisnee (from Low Latin mansionata), a household (compare the title of Ruskin's book Love's Meinie), there is a similar suggestion; drudge comes from an Anglo-Saxon root signifying to endure, and is allied to drudgery, meaning hard and unpleasant work. We hire a servant at a certain rate and for a particular service; we are attached to our domestics according to their assiduity and attention to our wishes; we employ as a menial one who is unfit for a higher employment; and a drudge in any labor, however hard and disagreeable.

SERVICE. See BenEFIT; UTILITY.

SERVITUdE, Slavery, Bondage. Servitude expresses less than slavery, and this less than bondage.

Servitude, based on servire, conveys simply the idea of performing a service without specifying the principle upon which it is performed. Among the Romans, servus signified a slave, because all who served were literally slaves, the power over the person being almost unlimited. The mild influence of Christianity has corrected men's notions with regard to their rights as well as their duties, and established servitude on the just principle of a mutual compact, without any infraction of that most precious of all human gifts, personal liberty. Slavery, which marks a condition incompatible with the existence of this invaluable endowment, is a term odious to the modern ear: it had its origin in the grossest state of society, the word being derived from the Late Latin sclavus, 
from Sclavi or Slavi (cf. the Russian slava, glory), a fierce and intrepid people who made a long stand against the Germans, and, being at last defeated, were made slaves. Slavery, therefore, includes not only servilude, but also the odious circumstances of the entire subjection of one individual to another. Bondage came through Anglo-French from the Scandinavian bondi, a tiller of the soil (compare husband), but it has been associated in the popular mind with the verb bind; it signifies slavery in its most aggravated form, in which, to the loss of personal liberty, is added cruel treatment; the term is seldom applied in its proper sense to any persons but the Israelites in Egypt. In a figurative sense we speak of being a slave to our passions, and under the bondage of sin, in which cases the terms preserve precisely the same distinction.

The same distinction exists between the epithets servile and slavish, which are employed only in the moral application. He who is servile has the mean character of a servant, but he is still a free agent; but he who is slavish is bound and fettered in every possible form.

SET. See PUT.

SETtle. See Arbitrate; Com-OSE; FIX; RATIFY.

SEVENTH DAY. See Sabbath.

SEVER. See Separate.

SEVERAL. See Different.

SEVERE. See AUstere; Harsh; STRICT.

SEX. See Gender.

SHACKLE. See Chain.

SHADE, SHaDOw. Shade and shadow both come from Anglo-Saxon scoed, sceadu, a shadow. Both these terms express that darkness which is occasioned by the sun's rays being intercepted by any body; but shade simply expresses the absence of the light, and shadow signifies also the figure of the body which thus intercepts the light. Trees naturally produce a shade, by means of their branches and leaves: and wherever the image of the tree is reflected on the earth that forms its shadow. It is agreeable in the heat of summer to sit in the shade; the constancy with which the shadow follows the man has been proverbially adopted as a simile for one who clings close to another.

In the moral application they are more widely distinguished in their signification. As a shade implies darkness, so to be in the shade is the same as to be in obscurity; as the shadow is but a reflection or appearance, so, in the moral sense, the shadow of a thing is that which is opposed to the substance.

ShaKe, Tremble, Shodder, QuivER, QUAKE. Shake is in Anglo-Saxon sceacan; and shudder is a frequentative verb based on Old Low German expressing a similar idea. Quake is derived from Anglo-Saxon cwacian, having the same meaning. Quiver comes from Anglo-Saxon cuifer in the adverb cuifer-lice, eagerly. Tremble comes from Low Latin tremulare, from classical Latin tremulus, trembling.

To shake is a generic term, the rest are but modes of shaking: to tremble is to shake from an inward cause or what appears to be so: in this manner a person trembles from fear, from cold, or weakness; and a leaf which is imperceptibly agitated by the air is also said to tremble: to shudder is to tremble violently: to quiver and to quake are both to tremble quickly; but the former denotes rather a vibratory motion, as the point of $a$ spear when thrown against wood: the latter a quick motion of the whole body, as in the case of bodies that have not sufficient consistency in themselves to remain still.

Shake, Agitate, Toss. - Shake (see above). Agitate, in Latin agitare, is a frequentative of ago, to drive, that is, to drive different ways. Toss is probably contracted from torsi, perfect of torqueo, to whirl.

A motion more or less violent is signified by all these terms, which differ both in the manner and the calse of the motion. Shake is indefinite, it may differ in degree as to the violence; to agitate and toss rise in sense upon the word shake: a breeze shakes a leaf, a storm agitates the sea, and the waves toss a vessel to and fro: large and small bodies may be shaken; large bodies are agitated: a handkerchief may be shaken; the earth is agitated by an earthquake. What is shaken and agitated is not removed from its place; 
but what is tossed is thrown from place to place. A house may frequently be shaken, while the foundation remains good; the waters are most agitated while they remain within their bounds; but a ball is tossed from hand to hand.

To shake and toss are the acts either of persons or things; to agitate is the act of things when taken in the active sense. A person shakes the hand of another, or the motion of a carriage shakes persons in general and agitates those who are weak in frame: a child tosses his food about; or the violent motion of a vessel tosses everything about which is in it. To shake arises from external or internal causes; .we may be shaken by others, or shake ourselves from cold: to agitate and toss arise from some external action, direct or indirect; the body may be agitated by violent concussion from without, or from the action of perturbed feelings; the body may be tossed by various circumstances, and the mind may be tossed to and fro by the violent action of the passions. Hence the propriety of using the terms in the moral application. The resolution is shaken, as the tree is by the wind; the mind is agitated like troubled waters; a person is tossed to and fro in the ocean of life, as the vessel is tossed by the waves.

SHALlOW. See Superficial.

ShaMe. See Abash; Dishonor.

SHAMELESS. See IMMODEST.

SHAPE. See ForM.

SHARE. See Divide; Part; ParTAKE.

SHARP, ACUTE, KeEN. The general property expressed by these epithets is that of sharpness, or an ability to cut. The term sharp, in Anglo-Saxon scearp, to cut, is generic and indefinite; the two others are modes of sharpness differing in the circumstance or the degree: the acute is not only more than sharp in the common sense, but signifies also sharppointed: a knife may be sharp, but a needle is properly acute. Things are sharp that have either a long or a pointed edge; but the keen is applicable only to the long edge, and that in the highest degree of sharpmess: a common knife may be sharp; but a razor or a lancet is properly said to be keen. These terms preserve the same dis- tinction in their figurative use. Every pain is sharp which may resemble that which is produced by cutting; it is acute when it resembles that produced by piercing deep: words are said to be sharp which have any power in them to wound; they are keen when they cut deep and wide.

See also Acute; Trenchant.

SHARP-SHOOTER, MARKSMAN, SNIPER. Sharp-shooter is a compound of sharp, in Anglo-Saxon scearp, and English shooter. A sharp-shooter, as a marksman, is one skilled in shooting with a revolver or rifle at a target or other object. In warfare a sharpshooter is an expert marksman selected to pick off an enemy at long range or under unusual conditions, and his employment is considered legitimate.

A sniper, on the contrary, is a sneaking soldier or other person, skilled in the use of a rifle, who fires from the roof or upper windows of a building on persons passing in the street below. On the occupation of Vera Cruz, Mexico, by United States forces in 1914, much annoyance was caused soldiers passing on the streets by shots from concealed snipers.

\section{SHED. See Pour.}

SHELTER. See Asylum; Cover; HARBOR.

Shibboleth, Criterion, PasswORD, TEst. Shibboleth, in Hebrew shibbóleth, meaning an ear of corn, also a river, from shábal, to grow, to flow, signifies, specifically, the testword or password used by the Gileadites, under Jephthah, after their victory over the Ephraimites, as recorded in Judges xii, 6 . The latter were unable to pronounce the $s h$, and, in attempting to escape, gave the word as sibbóleth, by which they betrayed themselves, and were slaughtered mercilessly.

Figuratively, the term is now used as a watchword, password, testword, or countersign of a political party, sect, or other organization, and, as such, it implies a criterion, a standard, law, principle, or fact by which the quality of anything may be estimated, or, as applied to persons, that by which they may be identified or have their accounts of themselves established. A watchword, password, or testword, in 
military, naval, politieal, and society usage, is a word or phrase given to persons entitled thereto by which they can prove themselves when questioned.

For a critical comparison of criterion and standard see the article on the former term.

SHIFT. See Evasion.

SHINe, Glitter, Glare, Sparkle, Radiate. Shine is in Anglo-Saxon scinan. Glitter comes from AngloSaxon glitinian, to shine. Glare is derived from Anglo-Saxon gloer, a pellucid substance, amber, where the $r$ stands for an older $s$; hence glare is elosely allied to glass. To sparkle signifies to produce sparks; and spark is in AngloSaxon spearca, and refers to the crackling sound of the firebrand. To radiate is to produce rays, from the Latin radius, a ray.

The emission of light is the common idea conveyed by these terms. To shine expresses simply this general idea: glitter and the other verbs include some collateral idea in their signification. To shine is a steady emission of light; to glitter is an unsteady emission of light, occasioned by the reflection on transparent or bright bodies: the sun and moon shine whenever they make their appearance; but a set of diamonds glitters by the irregular reflection of the light on them; or the brazen spire of a steeple glitters when the sun in the morning shines upon it. This is the same in the improper as the proper application.

Shine specifies no degree of light; it may be barely sufficient to render itself visible, or it may be a very strong degrce of light: glare, on the contrary, denotes the highest possible degree of light: the sun frequently glarcs when it shines only at intervals; and the eye also glares.

To shine is to emit light in a full stream; but to sparkle is to emit it in small portions, and to radiate is to emit it in long lines. The fire sparkles in the burning of wood; or the light of the sun sparkles when it strikes on knobs or small points; or the eye sparkles: the sun radiates when it seems to emit its light in rays.

SHIPPER. See COMMON-CARRIER.

SHOCK, Concussion. Shock de- notes a violent jolt or agitation; concussion, a shaking together. The shock is often instantaneous, but does not necessarily extend beyond the act of the moment; the concussion is permanent in its consequences, it tends to derange the system. Hence the different application of the terms: the shock may affeet either the body or the mind; the concussion affects properly only the body or corporeal objeets: a violent and sudden blow produces a shock at the moment it is given, but it does not always produce a concussion: the violence of a fall will, however, sometimes produce a concussion in the brain, which in future affeets the intelleet.

As shock conveys no idea of separation, only of impression, it is equally applicable to the mind and the body. Sudden news of an exceedingly painful nature will of ten produce a shock on the mind; but time mostly serves to wear away the effect which has been produced.

SHOCKING. See Formidable.

SHOOT, DART. To shoot and dart, in the proper sense, are elearly distinguished from each other, as expressing different modes of sending bodies to a distance from a given point. From the eircumstances of the actions arise their different application to other objects in the improper sense; as that which proceeds by shooting goes forth from a body unexpectedly and with great rapidity: so, in the figurative sense, a plant shoots up, or a star is said to shoot in the sky which seems to move in a shooting manner from one place to another.

SHORT, Brief, Concise, Succinct, Summary. Short, Anglo-Saxon sceort, comes from a root meaning to eut; it is the generic, the rest are specific terms: everything which admits of dimensions may be short, as opposed to the long, that is, either naturally or artificially; the rest are species of artifieial shortness, or that which is the work of art: hence it comes that material, as well as spiritual, objects may be termed short: but brief, in Latin brevis, in Greek Boaxús, concise, from Latin concisus, signifying cut into a small body, succinct, in Latin succinctus, participle of sub, up, and cingere, to girdle, meaning to 
draw up the skirts under the girdle, and fasten that tightly, signifying therefore brought within a small compass, and summary (see ABRIDGMENT) are intellectual or spiritual only. We may term a stick, a letter, or a discourse short; but we speak of brevity only in regard to the mode of speech; conciseness and succinctness as to the matter of speech; summary as to the mode either of speaking or acting: the brief is opposed to the lengthy or prolix; the concise and succinct to the diffuse; the summary to the circumstantial or ceremonious. It is a matter of comparatively little importance whether a man's life be long or short; but it deeply concerns him that every moment be well spent: brevity of expression ought to be consulted by speakers, even more than by writers; conciseness is of peculiar advantage in the formation of rules for young persons; and succinctness is a requisite in every writer who has extensive materials to digest; a summary mode of proceeding may have the advantage of saving time, but it has the disadvantage of incorrectness and often of injustice.

SHOVE. See Push.

SHOW, POINT OUT, MARK, INDIcate. Show, Anglo-Saxon scéawian, to see, then to make to see, is here the general term, and the others specific: the common idea included in the signification of them all is that of making a thing visible to another. To show is an indefinite term; one shows by simply setting a thing before the eyes of another: to point out, to fix a point upon a thing, is specific; it is to show some particular point by a direct and immediate application to it: we show a person a book when we put it into his hands; but we point out the beauties of its contents by making a point upon them or accompanying the action with some particular movement which shall direct the attention of the observer in a specific manner. Many things, therefore, may be shown which cannot be pointed out: a person shows himself, but he does not point himself out; towns, houses, gardens, and the like are shown; but single things of any description are pointed out.

To show and point out are direct personal acts; to mark, $i$. e., to put a mark on, is an indirect means of making a thing visible or observable: a tradesman marks the prices of the articles which he sets forth in his shop.

Show and mark denote the acts of conscious or unconscious agents; point out, that of conscious agents only: indicate (see MARK) that of unconscious agents only; in this case, what shows serves as an evidence or proof; what marks serves to direct or guide; what indicates serves as an index to point out. That shows the fallacy of forming schemes for the future; it marks the progress of time; it indicates decay.

In an extended moral application they preserve the same distinction; to show is to prove in a general way that a thing is or will be; to indicate is to show or point out in a particular manner that a thing is.

Show, Exhibit, Display.-To show is here, as before, the generic term; to exhibit (see Grve) and display, from Old French despleier, derived from Latin dis, apart, and plicare, to fold, signifying to unfold or set forth to view, are specific: they may all designate the acts either of persons or things: the first, however, does this either in the proper or the improper sense; the latter two rather in the improper sense. To show is an indefinite action applied to every object: things are shown for purposes of convenience; as one shows a book to a friend: exhibit is applied to matters that are extraordinary or unusual; things are exhibited to attract notice, as to exhibit flowers or animals: we show to one or many; we exhibit or display in as public a manner, and to as great numbers, as possible; as to show the marks to the by-standers; to exhibit a figure upon a pole; to display one's finery.

They admit of the same distinction when applied to moral objects: we may show courage, dislike, or any other emotion: exhibit skill, prowess, etc., in the field of battle; display heroism, and whatever may shine forth.

When said of things, they differ principally in the manner or degree of clearness with which the thing appears to present itself to view: to show is, as before, altogether indefinite, and implies simply to bring to view; exhibit 
implies to bring inherent properties to light, that is, apparently by a process; to display is to set forth so as to strike the eye: the windows on a frosty morning will show the state of the weather; experiments with the airpump exhibit the many wonderful and interesting properties of air; the beauties of the creation are peculiarly displayed in the spring season.

See also UNveIL.

Show, Exhibition, Representation, Sight, Spectacle. - Show signifies the thing shown; exhibition signifies the thing exhibited; representation, the thing represented; sight, the thing to be seen; and spectacle, from the Latin spectaculum, based on spectare, stands for the thing to be beheld.

Show is here, as in the former article, the most general term. Everything set forth to view is shown; and, if set forth for the amusement of others, it is a show. This is the common idea included in the terms exhibition and representation: but show is a term of vulgar meaning and application; the others have a higher use and signification. The show consists of that which merely pleases the eye; it is not a matter either of taste or art, but merely of curiosity: an exhibition, on the contrary, presents some effort of talent or some work of genius; and a representation sets forth the image or imitation of something by the power of art: hence we speak of a show of wild beasts, an exhibition of paintings, and a theatrical represcntation. The conjurer makes a show of his tricks at a fair, to the wonder of the gazing multitude; the artist makes an exhibition of his works; representations of men and manners are given on the stage.

Shows, exhibitions, and representations are presented by some one to the view of others; sights and spectacles present themselves to view. Sight, like show, is a vulgar term, and spectacle the nobler term. Whatever is to be seen to excite notice is a sight, in which general sense it would comprehend every show, but in its particular sense it includes only that which casually offers itself to view; a spretacle, on the contrary, is that species of sight which has something in it to interest either the heart or the head of the observer: processions, reviews, sports, and the like are sights; but battles, bull-fights, or public games of any description are spectacles, which interest and stimulate the feelings.

Show, Outside, Appearance, Semblance. - Where there is show there must be outside and appearance; but there may be the last without the former. The term show always denotes an action, and refers to some person or thing as agent; but the outside may be merely the passive quality of something. We speak, therefore, of a thing as mere show, to signify that what is shown is all that exists; and in this sense it may be termed mere outside, as consisting only of what is on the outside. In describing a house, however, we speak of its outside, and not of its show; as also of the outside of a book, and not of the show. Appearance denotes an action as well as show; but the former is the act of an unconscious agent, the latter of one that is conscious and voluntary: the appearance presents itself to the view; the show is purposely presented to view. A person makes a show so as to be seen by others; his appearance is that which shows itself in him. To look only to show, or to be concerned for show only, signifies to be concerned for that only which will attract notice; to look only to the outside signifies to be concerned only for that which may be seen in a thing, to the disregard of that which is not seen: to look only to appearances signifies the same as the former, except that outside is said in the proper sense of that which literally strikes the eye; but appearances extend to a man's conduct and whatever may affect his reputation.

Semblance, from Old French semblance, formed with suffix ance from Latin -antia, on Old French sembl-er, from Latin simulare, to make like, always conveys the idea of an unreal appearance, or at least is contrasted with that which is real; he who wears only the semblance of friendship would be ill deserving the confidence of a friend.

Show, Parade, Ostentation. - These terms are synonymous when they imply abstract actions: show is here, as in the preceding article, taken in the 
vulgar sense; ostentation and parade include the idea of something particular. Show consists simply in letting that be seen which a person might, if he pleased, keep out of view; parade is a studious effort to show, which serves to attract notice: in this manner a person may make a show of his equipage or furniture who sets it out to be seen; he makes a parade of his wealth if he sets it forth with any artifice or formality so as to make it more striking. Ostentation is, like parade, a studied show, but it refers rather to the intention of the person than to the method by which the show is made. Show and parade may, therefore, according to the circumstances, serve the purpose of ostentation. A person makes a show of his liberality, or a parade of his gifts, and thus he gratifies his ostertation.

When taken in zeference to things, the show is opposed to the reality; it is that which shows itself: the parade and ostentation is that which is ceremonious and artificial: the former in respect to what strikes the eye, and the latter in respect to what strikes the mind.

Showy, Gaudy, Gay.-Showy, having or being full of show, is mostly an epithet of dispraise; that which is showy has seldom anything to deserve notice beyond that which catches the eye: gaudy, from Latin gaudere, to rejoice, signifies literally full of joy, and is applied figuratively to the exterior of objects, but with the annexed bad idea of being striking to an excess: gay, Old French gai, Old High German $w a ̀ h i$, fine, beautiful, is used in the same sense as an epithet of praise: it is in this sense that the gay science of the Provençal troubadours was taken. Some things may be showy, and in their nature properly so; thus the tail of a peacock is showy: artificial objects may likewise be showy, but they will not be preferred by persons of taste: that which is gaudy is always artificial, and is always chosen by the vain, the vulgar, and the ignorant; a maid-servant will bedizen herself with gaudy-colored ribbons. That which is gay is either nature itself or nature imitated in the best manner: spring is a gay season, and flowers are its gayest accompaniments.

See also Theatrical.
SHREWD. See ACUTE.

SHRIEK. See CRY.

SHRINK. See QUAIL; SPrIng.

SHUDDER. See SHAKE.

SHUT. See Blockade; Close.

SICK, Sickly, Diseased, Morbid. Sick denotes a partial state, sickly a permanent state, of the body, a proneness to be sick: he who is sick may be made well; but he who is sickly is seldom really well: all persons are liable to be sick, though few have the misfortune to be sickly: a person may be sick from the effects of cold, violent exercise, and the like; but he is sickly only from constitution.

Sickly expresses a permanent state of indisposition unless otherwise qualified; but diseased expresses a violent state of derangement without specifying its duration; it may be for a time only or for a permanency: the person or his constitution is sickly; the person or his frame, or particular parts, as his lungs, his stomach, his brain, and the like, may be diseased.

Sick, sickly, and diseased may all be used in a moral application; morbid is used in no other except in a technical sense. Sick denotes a partial state, as before, namely, a state of disgust, and is always associated with the object of the sickness; we are sick of turbulent enjoyments, and seek for tranquillity: sickly and morbid are applied to the habitual state of the feelings or character; a sickly sentimentality, a morbid sensibility: diseased is applied in general to individuals or communities, to persons or to things; a person's mind is in a diseased state when it is under the influence of corrupt passions or principles; society is in a diseased state when it is overgrown with wealth and luxury.

Sickness, Illness, Indisposition.Sickness denotes the state of being sick; illness that of being ill (see EvIL): indisposition that of being physically not well disposed. Sickness denotes the state generally or particularly; illness denotes it particularly: we speak of sickness as opposed to good health; in sickness or in health; but of the illness of a particular person: when sickness is said of the individual, it designates a protracted state: a person may be said to have much sickness in his 
family. Illness denotes only a particular or partial sickness: a person is said to have had an illness at this or that time, in this or that place, for this or that period. Indisposition is a slight illness, such a one as is capable of disturbing him either in his enjoyments or in his business; colds are the ordinary causes of indisposition.

SIGHT. See Show.

SIGN, Signal. Sign and signal are both derived from the same source (see MARK), and the latter is but a species of the former. The sign enables us to recognize an object; it is, therefore, sometimes natural: signal serves to give warning; it is always arbitrary. The changes which are visible in the countenance are commonly the signs of what passes in the heart; the beat of the drum is the signal for soldiers to repair to their post. We converse with those who are present by signs; we make ourselves understood by those who are at a distance by means of signals.

See also WAFT.

Signal, Memorable.-Signal signifies serving as a sign, memorable signifies worthy to be remembered. They both express the idea of extraordinary, or being distinguished from every other thing: whatever is signal deserves to be stamped on the mind and to serve as a sign of some property or characteristic; whatever is memorable impresses upon the memory and refuses to be forgotten: the former applies to the moral character, the latter to events and times: the Scriptures furnish us with many signal instances of God's vengeance against impenitent sinners, as also of His favor toward those who obcy His will; the Reformation is a memorable event in the annals of ecclesiastical history.

Signalize, Distinguish.-To signalize, or make one's self a sign of anything, is a much stronger term than simply to distinguish; it is in the power of many to do the latter, but few only have the power of accomplishing the former: the English have always signalized themselves for their unconquerable valor in battle; there is no nation that has not $d$ istinguished itself, at some period or another, in war.

Significant, Expressive.-The signifi- cant is that which serves as a sign; the expressive is that which speaks out or declares; the latter is, therefore, a stronger term than the former: a look is significant when it is made to express an idea that passes in the mind; but it is expressive when it is made to express a feeling of the whole mind or heart: looks are but occasionally significant, but the countenance may be habitually expressive. Significant is applied in an indifferent sense, according to the nature of the thing signified; but expressive is always applied to that which is good: a significant look may convey a very bad idea, but an expressive countenance always expresses good feeling.

The distinction between these words is the same when applied to things as to persons: a word is significant of whatever it is made to signify, but a word is expressive according to the force with which it conveys an idea. The term significant, in this case, simply explains the nature, but the epithet expressive characterizes it as something good: technical terms are significant only of the precise ideas which belong to the art; most languages have some terms which are peculiarly expressive, and consequently adapted for poetry.

Signification, Meaning, Import, Sense.-The signification (see Express) is that which is signified to another; the meaning is that which the person means to express: this latter word, therefore, is properly used in connection with the person meaning.

The signification of a word is that which it is made to signify, and the meaning is that which it is meant to express: in this sense, therefore, we may indifferently say the proper, improper, metaphorical, or general signification or meaning of words; but, in reference to individuals, meaning is more proper than signification, as to convey a meaning, to attach a meaning to a word, and not to convey or attach a signification.

On the other hand, it is more appropriate to say a literal signification than a literal meaning. There is also this further distinction between signify and mean that the latter is applied in its proper sense to things as well as words. 
Import, from in and portare, to carry, signifying that which is carried or conveyed to the understanding, is most allied to signification, inasmuch as it is applied to single words. The signification may include the whole or any part of what is understood by a word; the import is the whole that is comprehended under a word. The signification of words may be learned by definition, but their full import can be collected only from examples.

Sense (see Feeling), signifying that which is perceived by the senses, is most nearly allied to the word meaning, inasmuch as they both refer to the mind of the individual; but the sense being that which is rational and consistent with sense, is that which is taken or admitted abstractedly.

Signify, Imply. - Signify (see ExPREss). Imply, a coined word ultimately from the Latin implicare, to fold in, signifies to fold or involve an idea in any object.

These terms may be employed either as respects actions or words. In the first case signify is the act of the person making known by means of a sign, as we signify our approbation by a look; imply marks the value or force of the action; our assent is implied in our silence. When applied to words or marks, signify denotes the positive and established act of the thing; imply is its relative act: a word signifies whatever it is made literally to stand for; it implies that which it stands for figuratively or morally. The term house signifies that which is constructed for a dwelling; the term residence implies something superior to a house. A cross, thus + , signifies addition in arithmetic or algebra; a long stroke, thus with a break in the text of a work, $i m$ plies that the whole sentence is not completed. It frequently happens that words which signify nothing particular in themselves may be made to imply a great deal by the tone, the manner, and the connection.

Signify, Avail.—Signify is here employed with regard to events of life and their relative importance. Avail (see Avalu) is never used otherwise. That which a thing signifies is what it contains; if it signifies nothing, it contains nothing and is worth noth- ing; if it signifies much, it contains much or is worth much. That which avails produces; if it avails nothing, it produces nothing, is of no use; if it avails much, it produces or is worth much. We consider the end as to its signification and the means as to their avail. Although it is of little or no signification to a man what becomes of his remains, yet no one can be reconciled to the idea of leaving them to be exposed to contempt; words are but too of ten of little avail to curb the unruly wills of children.

See also Declare; Denote.

SILENCE, TACITURNity. The Latins have the two verbs silere and tacere: the former of which is interpreted by some as signif ying to cease to speak, and the latter not to begin to speak; others maintain the direct contrary. According to the present use of the words, silence expresses less than taciturnity: the silent man seldom speaks, the taciturn man will not speak at all. The Latins designated the most profound silence by the epithet of taciturna silentia.

Taciturnity is always of some duration, arising either from necessity or from a particular frame of mind.

Silence always supposes something occasional that is adopted to suit the convenience of the party.

Silent, Tacit. - Silent characterizes either the person or the thing: a person is silent as opposed to one that talks; a place is silent as opposed to one that is noisy. Tacit characterizes only the act of the person; a person gives a tacit consent, or there was a tacit agreement between the parties.

Silent, Dumb, Mute, Speechless.Not speaking is the common idea included in the signification of these terms, which differ either in the cause or the circumstance: silent is altogether an indefinite and general term, expressing little more than the common idea. We may be silent because we will not speak or we may be silent because we cannot speak; but in distinction from the other terms it is always employed in the former case. Dumb, Anglo-Saxon dumb, Old High German tump, stupid or idiotic, denotes a physical incapacity to speak: hence persons are said to be born $d u m b$; they 
may likewise be $d u m b$ from temporary physical causes, as from grief, shame, and the like; a person may be struck dumb. It is in the Old High German sense, which is that of the Modern German dumm, that the so-called Pennsylvania Dutch employ incorrectly the English dumb. Mute, in Latin mutus, dumb, signifies a temporary disability to speak from arbitrary and incidental causes: hence the office of mutes, or of persons who engage not to speak for a certain time; and, in like manner, persons are said to be mute who dare not give utterance to their thoughts.

Speechless, or void of speech, denotes a physical incapacity to speak from incidental causes; as when a person falls down speechless in an apoplectic fit or in consequence of a violent concussion.

The terms silent, mute, and $d u m b$ are also applied to things as well as persons, the former two in the sense of not sending forth a sound; as the silent grove, a mute tongue, or a mute letter: dumb, in the sense of being without words, as dumb show.

SILLY. See Smple.

SIMILARITY. See LIKeness.

Simile, Similitude, Comparison. Simile and similitude are both drawn from the Latin similis, like, the former signifying the thing that is like, the latter either the thing that is like or the quality of being like: in the former sense only it is to be compared with simile, when employed as a figure of speech or thought; everything is a simile which associates objects on account of any real or supposed likeness between them; but a similitude signifies a prolonged or continued simile. The latter may be expressed in a few words, as when we say the godlike Achilles; but the former enters into minute circumstances of comparison, as when Homer compares any of his heroes fighting and defending themselves against multitudes to lions who are attacked by dogs and men. Every simile is more or less a comparison, but every comparison is not a simile: the latter compares things only as far as they are alike, but the former extends to those things which are different: in this manner, there may be a comparison between large things and small, although there can be no good simile.

See also Likeness.

Simple, Single, Singular. Simple, in Latin simplex, from a root sim, meaning the same one (appearing in singuli, single, etc.), and plicare, to fold, signifying composed of one and the same fold, is opposed to the complex, which has many folds, or to the compound, which has several parts involved or connected with each other. Single and singular (see $\mathrm{ONE}_{\mathrm{N}}$ ) are opposed, one to double and the other to multifarious: but the latter is generally used in the sense of odd, unusual, or eccentric. We may speak of a simple circumstance as independent of anything; of a single instance or circumstance as unaccompanied . by any other; and a singular instance as one that rarely has its like. In the moral application to the person, simplicity, as far as it is opposed to duplicity in the heart, can never be excessive: but when it lies in the head it is a mental defect. Singleness of heart and intention is that species of simplicity which is altogether to be admired: singularity may be either good or bad, according to circumstances; to be singular in virtue is to be truly good; but to be singular in manner is affectation, which is at variance with genuine simplicity, if not directly opposed to it.

Simple, Silly, Foolish.-The simple, when applied to the understanding, implies such a contracted power as is incapable of combination; silly, which originally meant "timely," hence lucky, blessed, innocent, and finally simple or foolish, and foolish, i. e, like a fool, rise in sense upon the former, signifying either the perversion or the total deficiency of understanding; the behavior of a person may be silly who from any excess of feeling loses his sense of propriety; the conduct of a person will be foolish who has not judgment to direct himself. Country people may be simple, owing to their want of knowledge; children will be silly in company if they have too much liberty given to them; there are some persons who never acquire wisdom enough to prevent them from committing foolish errors.

See also Naive. 
SIMULATION, Dissim dLation. Simulation, ultimately from similis, is the making onc's self like what one is not; and dissimulation, from dissimilis, unlike, is the raking one's self appear unlike what one really is. The hypocrite affects the simulation of virtue to recommend himself to the virtuous; the dissembler resorts to dissimulation to conceal his vices when he wants to gain the simple or ignorant to his side.

SIMULTANEOUS. See SrncrroNous.

SIN. See Crime.

Sincere, Honest, True, Platn. Sincere (see CANDID) is here the most comprehensive term: honest (see HoNESTY), true, and plain (see EvEN) are but modes of sincerity.

Sincerity is a fundamental characteristic of the person; honesty is but a part of sincerity; it denotes simply the absence of intentional or fraudulent concealment; we look for a sincere friend to tell us everything; we look for an honest companion who will speak without disguise; truth is a characteristic of sincerity, for a sincere friend is a true friend; but sincerity is, properly speaking, only a mode of truth. Sincere and honest are personal characteristics; true is a characteristic of the thing, as a sincere man, an honest confession, a true statement.

A sincere man must needs be plain, because plainness consists in an unvarnished style; and the sincere man will always adopt that mode of speech which expresses his sentiments most truly; but a person may be occasionally plain in his speech who is not so from sincerity. The plain, whether it respects the language or the conduct, is that which is divested of everything extraneous or artificial, and so far plainness is an auxiliary to truth by enabling the truth to be better seen.

See also Hearty.

SINGLE. See One; StMple; SoliTARY.

SINGULAR. See Particular; Rare; Simple.

SINK. See Fall.

Site. See Place.

Situation, Condition, State,
Predicament, Flight, Case. Situation (see PlaCE) is said generally of objects as they concern others; condi. tion, as they are concerned themselves: our situation consists of those external circumstances in respect of property, honor, liberty, and the like which affect our standing in society generally. Whatever affects our person immediately is our condition: a person who is unable to pay a sum of money to save himself from a prison is in a bad situation: a traveller who is left in a ditch robbed and wounded is in a bad condition.

Situation and condition are said of that which is contingent and changeable, the latter still more so than the former; state, from the past participle of stare, to stand, signifying that position in which one stands, is said of that which is comparatively stable or established. A tradesman is in a good siluation who is in the way of carrying on a good trade: his affairs are in a good state if he is enabled to answer every demand and to keep up his credit. Hence it is that we speak of the state of health and the state of the mind, not the situation or condition, because the body and mind are considered as to their general frame, and not as to any relative or particular circumstances, as the passing condition of one's health or transient disposition of one's mentality, so likewise a state of infancy, a state of guilt, a state of innocence.

When speaking of bodies, there is the same distinction in the terms as in regard to individuals. An army may be either in a situation, a condition, or a state. An army that is on service may be in a critical situation with re spect to the enemy and its own com. parative weakness; it may be in a deplorable condition if it stand in need of provisions and necessaries: an army that is at home will be in a good or bad state according to the regulations of the commander-in-chief. Of a prince who is threatened with invasion from foreign enemies and with rebellion from his subjects we should not say that his condition, but his situation, was critical. Of a prince, however, who like Alfred was obliged to fly and to seek safety in disguise and 
poverty, we should speak of his hard condition: the state of a prince cannot be spoken of, but the stale of his affairs and government may: hence, likewise, state may with most propriety be said of a nation: but situation seldom, unless in respect to other nations, and condition never. . On the other hand, when speaking of the poor, we seldom employ the term situation, because they are seldom considered as a body in relation to other bodies: we mostly speak of their condition as better or worse, according as they have more or less of the comforts of life; and of their state as regards their moral habits.

These terms may likewise be applied to inanimate objects; and, upon the same grounds, a house is in a good situation as respects the surrounding objects; it is in a good or bad condition as respects the painting and exterior altogether; it is in a bad state as respects the beams, plaster, roof, and interior structure altogether. The hand of a watch is in a different situation every hour; the watch itself may be in a bad condition if the wheels are clogged with dirt, but in a good state if the works are altogether sound and fit for service.

Situation and condition are either permanent or temporary. The predicament, originally a term in logic signifying one of the most general classes into which things can be divided, from Latin prodicare, to assert or declare, signifies that which is predicated or asserted; a class or kind described by definite marks, originally it had no unfavorable connotation, but in modern parlance, when applied to circumstances, it expresses a temporary embarrassed situation conceivably but not necessarily occasioned by an act of one's own: hence we speak of being in or bringing ourselves into a predicament. Plight, in the sense of peril, is derived from Anglo-Saxon pliht, risk, danger, hence also a promise involving risk or peril: it has no connection with the English plight in the sense of fold, which is derived from the Latin plicatus, participle of plicare, to fold. It signifies any circumstance in which one is disagreeably entangled. Case signifies anything which may befall us or into which we fall, from casus, past participle of cadere, to fall, mostly, though not necessarily, contrary to our inclination. Those latter two terms, therefore, denote a species of temporary condition, for they both express that which happens to the object itself, without reference to any other. A person is in an unpleasant siluation who is shut up in a railway compartment with disagreeable company. $\mathrm{He}$ is in an awkward predicament when, in attempting to please one friend, he displeases another. He may be in a wretched plight if he is overturned in a car at night and at a distance from any habitation. He will be in evil case if he is compelled to put up with a spare and poor diet.

See also Circomstance.

SIZE, Magnitude, Greatness, BuLK. Size is short for assize, from assise, the feminine past participle of the French verb asseoir, to sit: from its meaning of the sitting of judges came the tax by them established, hence a fixed amount, and thence it developed the meaning of quantity or size in general; it is a general term including all manner of dimension or measurement; magnitude, from the Latin magnitudo, from magnus, great, answering, literally, to the English word greatness, is cmployed in science or in an abstract sense to denote some specific measurement; greatness is an unscientific term applied in the same sense to objects in general: size is indefinite, it never characterizes anything either as large or small; but magnitude and grealness always suppose something greal; and bulk denotes a considerable degree of grealness: things which are diminutive in size will of ten have an extraordinary degree of beauty or some other adventitious perfection to compensate the deficiency; astronomers have classed the stars according to their different magnitudes; greatnȩss has been considered as one source of the sublime: bulk is that species of grealness which destroys the symmetry, and consequently the beauty, of objects.

SKETCH, OUTLINES. A sketch may form a whole; oullines are but a part: the skelch may comprehend the oullines and some of the particulars; oullines, as the term bespeaks, comprehend only the line on the exterior: the skelch, in drawing, may serve as a 
landscape, as it presents some of the features of a country; but the outlines serve only as bounding lines, within which the sketch may be formed. So in the moral application, we speak of the slietches of countries, characters, manners, and the like, which serve as a description; but of the outlines of a plan, of a work, a project, and the like which serve as a basis on which the subordinate parts are to be formed: barbarous nations present us with rude skeiches of nature; an abridgment is little more than the outlines of a larger work.

\section{See also Delineate.}

\section{SKILFUL. See Clever.}

SKILFULNESS. See KNACK.

SKIN, Hide, Peel, Rind. Skin, a Scandinavian word, is the term in most general use; it is applicable both to human creatures and to animals: hide, Anglo-Saxon hýd, allied to Latin cutis, skin (whence cuticle), is used only for the skins of large animals: we speak of the skins of birds or insects, but of the hides of oxen or horses and other animals, which are to be separated from the body and converted into leather. Skin is equally applied to the inanimate and the animate world, but peel, Latin pellis, a skin, and rind, Anglo-Saxon rinde, the bark of a tree, possibly allied to rim, signifying that which goes round and envelops, belong only to inanimate objects: the skin is generally said of that which is interior, in distinction from the exterior, which is the peel: an orange has both its peel and its thin skin underneath; an apple, a pear, and the like has a peel. The peel is a soft substance on the outside; the rind is generally interior and of a harder substance: in regard to a stick, we speak of its peel and its inner skin; in regard to a tree, we speak of its bark and its rind: hence, likewise, the term rind is applied to cheese and other incrusted substances that envelop bodies.

SLACK, Lo os E. Slack, AngloSaxon sleac, meant originally fluid. Loose is a Scandinavian word allied to the verb lose. These two words differ more in application than in sense: they are both opposed to that which is close bound; but slack is said only of that which is tied or that with which anything is tied; while loose is said of any substances the parts of which do not adhere closely: a rope is slack in contrast with the tight rope, which is stretched to its full extent; and in general cords or strings are said to be slack which fail in the requisite degree of tightness; but they are said to be loose in an indefinite manner, without conveying any collateral idea: thus the string of an instrument is denominated slack rather than loose; on the other hand, loose is said of many bodies to which the word slack cannot be applied: a garment is loose, but not slack; the leg of a table is loose, but not slack.

In the moral application, that which admits of additional activity is denominated slack, and that which fails in consistency and close adherence is loose: trade is slack, or a person's zeal, etc., becomes slack (hence the term of reproach slacker, which arose during the European war to denote persons unwilling to work to help the allied countries to victory); but an engagement is loose and principles are loose.

SLANDER. See Asperse.

SLANT, Slope. Slant is a Scandinavian word, meaning to slope or glide, and slope, from the root found in the verb slip, are both expressive of a sideward movement or direction: they are the same in sense, but different in application: slant is said of small bodies only; slope is said indifferently of all bodies, large and small: a book may be made to slant by lying in part on another book on a desk or a table, but a piece of ground is said to slope.

SLAUGHTER. See Carnage; Kill. SLAVERY. See SERVITUdE ; Thralldom.

SLAY. See KILL.

Sleep, Slumber, Doze, Drowse, NAP. Sleep is in Anglo-Saxon slöpan. Slumber comes through Middle English slumeren, from a Teutonic root meaning to be silent. Doze is a Scandinavian word allied to dizzy and to daze. Drowse comes from the AngloSaxon druisian, to be sluggish. $N a p$ is in Anglo-Saxon hnoppian, to doze.

Sleep is the general term, which designates in an indefinite manner that state of the body to which all animated beings are subject at certain seasons in the course of nature; to 
slumber is to sleep lightly and softly; to doze is to incline to sleep or to begin sleeping; to nap is to sleep for a time: every one who is not indisposed sleeps during the night; those who are accustomed to wake at a certain hour of the morning commonly slumber only after that time; there are many who, though they cannot sleep in a carriage, will yet be obliged to doze if they travel in the night; in hot elimates the middle of the day is commonly chosen for a uap.

Sleepy, Drowsy, Lethargic. - Sleepy expresses either a temporary or a permanent state. Drowsy expresses mostly a temporary state; lethargic, from lethargy, in Latin lethargia, Greek $\lambda_{\eta} \theta a \rho \gamma^{\prime} \alpha$, compounded of $\lambda i \eta \eta \eta$, forgetfulness, signifying a proneness to forgetfulness or sleep, describes a permanent or habitual state.

Sleepy, as a temporary state, expresses also what is natural or seasonable; drowsiness expresses an inclination to seep at unseasonable hours; it is natural to be sleepy at the hour when we are accustomed to retire to rest; it is common to be drowsy when sitting still after dinner. Sleepiness, as a permanent state, is an infirmity to which some persons are subject constitutionally; lethargy is a disease with which people otherwise the most wakeful may be occasionally attacked.

SLENDER. See THin.

SLIDE. See SlIP.

SLIGHT. See Cursory ; DisRegard; SNub; Thin.

SLIM. See Thin.

SLIP, Slide, Glide. Slip, from slipan, and slide, from slidan, and glide, from glidan, are all Anglo-Saxon words.

To slip is an involuntary, and slide a voluntary, motion: those who go on the ice in fear will slip; boys slide on the ice by way of amusement. To slip and slide are lateral movements of the feet, but to glide is the movement of the whole body and just that easy motion which is made by slipping, sliding, flying, or swimming: a person glides along the surface of the ice when he slides; a vessel glides through the water.

In the moral and figurative application, a person slips who commits unin- tentional errors; he who wittingly, and yet without difficulty, falls into the practice and habits which are recommended slides into a certain course of life: he glides through life if he pursues his course smoothly and without interruption.

See also LAPSE.

SLOPE. See Slant.

SLOTHFUL. See INACTIVE.

SlOW, Dilatony, Tardy, Tedious. Slow, in Anglo-Saxon sláw, may be allied to laves, in Latin signifying the left hand, the left hand being slow of movement. Dilatory, of the same derivation as the English dilate, comes from Latin di-dis, apart, and lalus, carried, the past participle of ferre, i.e., an action which is put off and brought over from the time of its conception or requirement. It means lengthening out the time required for any performance. Tardy, from the Latin tardus, signifies, literally, slow. Tedious, from the Latin tadium, weariness, signifies causing weariness.

Slnw is a general and unqualified term applieable to the motion of any object or to the motions and actions of persons in particular, and to their dispositions also; dilatory relates to the disposition only of persons: we are slow in what we are about; we are dilatory in setting about a thing. Slow is applied to corporeal or mental actions; a person may be slow in walking or slow in eonceiving: tardy is applicable to mental actions; we are tardy in our proceedings or our progress; we are tardy in making up accounts or in eoncluding a treaty. We may be slow with propriety or not, to our own inconvenience or that of others; when we are tedious we are always so improperly: "To be slow and sure" is a vulgar proverb, but a great truth; by this we do ourselves good and inconvenience no one; but he who is tedious is slow to the annoyance of others: a prolix writer must always be tedious, for he keeps the reader long in suspense before he comes to the conelusion of a period.

SLUGGISH. See InActive.

SLUMBER. See SLEEP.

SLY. See Cunnina.

SMALL. See Atomic; LitTre.

SMEAR, DAUB. Smear is allied to 
Anglo-Saxon smerien, a weak verb from the substantive smeru fat or grease, and originally signified to cover with fat or grease. Daub comes from Old French dauber, to plaster, from Latin de, down, and albare, to whiten.

To smear in the literal sense is appiied to such substances as may be rubbed like grease over a body; if said of grease itself, it may be proper; as coachmen smear the coach-wheels with tar or grease; but if said of anything else, it is an improper action, and tends to disfigure, as children smear their hands with ink or smear their clothes with dirt. To smear and daub are both actions which tend to disfigure; but we smear by means of rubbing over; we daub by rubbing, throwing, or any way covering over: thus a child smears the window with his finger or he daubs the wall with dirt.

By a figurative application smear is applied to bad writing or whatever is soiled or contaminated, and daub to bad painting or to whatever is executed coarsely or clumsily: indifferent writers who wish to excel are fond of retouching their letters until they make their performance a sad smear; bad artists, who are injudicious in the use of their brush, load their paintings with color and convert them into daubs.

SMell, Scent, Odor, Perfume, Fragrance. Smell, Middle English smel, is allied to smoulder. Scent, changed from sent, comes from the Iatin sentire, to perceive or feel. Odor, in Latin odor, allied with Greek oै ${ }^{\prime} \varepsilon t \nu$, to smell. Perfume, ccmpounded of per and fumis, a smoke or vapor, that is, the vapor that issues forth. Fragrance, in Latin fragrantia, comes from fragrare, to emit an odor; hence, in Latin, fragum, a strawberry.

Smell and scent are said either of that which receives or that which gives the smell; the odor, the perfume, and? fragrance, of that which communicates the smell. In the first case, smell is said generally of all living things without distinction; scent is said only of such animals as have this peculiar faculty of tracing objects by their smell: some persons have a much quicker smell than others, and some have an acuter smell of particular ob- jects than they have of things in general: dogs are remarkable for their quickness of srent, by which they can trace their masters and other objects at an immense distance; other animals are gifted with this faculty to a surprising degree, which serves them as a means of defence against their enemies.

In the second case, smell and scent are compared with odor, perfume, and fragrance either as respects the objects communicating the smell or the nature of the smell which is communicated. Smell is indefinite in its sense and universal in its application; scent, odor, perfume, and fragrance are species of smell: every object is said to smell which acts on the olfactory nerves; flowers, fruits, woods, earth, water, and the like have a smell; scent is most commonly applied to the smell which proceeds from animal bodies; the odor is said of that which is artificial or extraneous; the perfume and fragrance of that which is natural: the burning of things produces an odor; the perfume and fragrance arises from flowers or sweet-smelling herbs, spices, and the like. The terms smell and odor do not specify the exact nature of that which issues from bodies; they may both be either pleasant or unpleasant; but smell, if taken in certain connections, signifies a bad smell, and odor signifies that which is sweet: meat which is kept too long will have a smell, that is, of course, a bad smell; the odors from a sacrifice are acceptable, that is, the sweet odors ascend to heaven. Perfume is properly a widespreading smell, and when taken without any epithet never signifies anything but what is good; it is the sweetest and most powerful perfume: the perfume from flowers and shrubs is as grateful to one sense as their colors and conformation are to the other; the fragrance from groves of myrtle and orange trees surpasses the beauty of their fruit or foliage.

SMITE. See STRIKE.

SMOOTH. See Even; UnRUFFled.

SMOTHER. See STIFle; SufFoCATE.

SNEER. See SCOFF.

SNIPER. See SHARP-SHooter.

SNUB, Cut, Slight. These words 
all signify to treat another with contempt. Slight means to treat as if of slight importance. We may slight a friend indirectly by failing to invite him to a social entertainment or to consult his wishes in some matter in which he feels that he has a right to an opinion. Snub, the original meaning of which is to cut off, something short, indicates a more crude and direct action. We snub another by obviously disregarding him or treating him with eontempt. To cut is to cut a friend or aequaintance out of the circle of our interests entirely. We may slight an acquaintance by treating him with less consideration than he expects. We snub him by treating him with a positive lack of respect or consideration. We cul him by disregarding him altogether, by failing to recognize his existence at all.

See also ABAsh.

SOAK, Drench, Steep. Soak, from Anglo-Saxon socian, is related to suck. Steep is a Seandinavian word meaning to make to stoop, to overturn, hence to pour water over grain by turning the reeeptacle upside down. Drench is a variation of drink; it means, literally, to cause to drink.

The idea of eommunicating or recciving a liquid is eommon to these terms. $\Lambda$ person's elothes are soaked in rain when the water has penetrated every thread; he himself is drenched in the rain when it has penetrated, as it were, his very body; drench, therefore, in this ease only expresses the idea of soak in a stronger manner. To steep is a species of soaking employed as an artificial process; to soak is, however, a permanent action by which hard things are rendered soft; to steep is a temporary action by which sof $t$ bodies become penetrated with a liquid: thus salt meat requires to be soaked; fruits are steeped in brandy.

SOBER, GRAve. Sober (see ABSTINENT) expresses the absence of all exhilaration of spirits: grave (see that word) expresses a weight in the intellectual operations whieh makes them proceed slowly. Sobriety is therefore a more natural and ordinary state for the human mind than gravily: it behooves every man to be sober in all situations; but those who fill the most important stations of life must be grave. Even in our pleasures we may observe sobriety, which keeps us from any exeessive ebullition of mirth; but on partieular oecasions, where the importance of the subject ought to weigh on the mind, it beeomes us to be grave. At a feast we have neer of sobricty; at a funeral we have need of gravity.

Sobriety extends to many more objeets than gravity; we must be sober in our thoughts and opinions, as well as in our outward conduct and behavior; but we ean be grave, properly speaking, only in our looks and our outward deportment.

See also Modesty.

SOBRIETY. See Modestr.

SOCIABLE. See CrCle; Social.

SOCIAL, Sociable. Sorial, from socius, a companion, signifies belonging or allied to a companion, having the disposition of a companion; soriable, from the same, signifies able or fit to be a companion; the former is an active, the latter a passive, quality: social people seek others; sociable people are sought for by others. It is possible for a man to be social and not sociable; to be sociable and not social: he who draws his pleasures from soeiety without communicating his share to the common stock of entertainments is social, but not sociable; men of a taciturn disposition are often in this ease; they reeeive more than they give: he, on the contrary, who has talents to please company, but not the inelination to go into company, may be soriable, but is seldom social; of this description are humorists who go into company to gratify their pride and stay away to indulge their humor.

Sncial and sociable are likewise applieable to things, with a similar distinction; social intercourse is that intercourse which men have together for the purposes of soeiety; social pleasures are what they enjoy by associating together: a family is sociable; fellow-travellers are sociable: a church gives a sociable.

See also Convivial.

SOCIALISM, CoMMUNISM. Both of these words indicate a theory of government which holds that neecssities of life should not the wholly in the eontrol 
of the individuals strong enough to take possession of them, but should be equitably distributed by some central authority acting in aceordance with the will of the whole eommunity. But communism, from Latin communis, eommon, holds that all goods should be held in common, that the possessions w yor earnings of each individual should go into a eonimon fund to be redistributed in accordance with the needs of all the members composing the community. This system has been earried out in some special social groupsin the monasteries, for example -and, to some extent, in the organization of the Russian Zemstva, and it obtains today in many families, especially those of the working classes. But it has never been successfully extended to the large and various community composing a state. Sociatism, on the other hand, simply provides that all that is necessary to support life $-i$. e., landsand the machinery of production shall be un der the control of the community as a whole, so that no individual shall have it in his power to buy up any of the crops, like wheat, which are necessary to support life, and to eontrol the selling price, or to keep in his possession large tracts of land not under cultivation, etc. Socialists differ in their ideas eoncerning the character and extent of the communal control; and socialism is often associated with doetrines of pacifism, etc., which bring it into disrepute. But, as a matter of fact, in moments of erisis, when national existence is threatened, the socialistic principle of the control of that which is neeessary for the welfare of the whole community by the whole community, is promptly applied =as in the food-control regulations in the warring countries during the European war, and the regulation of eonscription in the United States.

-SOCIALIST. See InTransigent.

SOCIETY, CoMpany. Society and company (for both see Association) here express either the persons associating, the act of assoeiating, or the state of being associated. In either case society is a general and company a particular term; as respects persons associating, society comprehends either all the associated part of mankind, as when we speak of the laws of society, the well-being of society; or it is said only of a partieular number of individuals assoeiated, in which latter ease it comes nearest to company, and differs from it only as to the purpose of the association. A society is always formed for some solid purpose, as the Humane Society; and a company is always brought together for pleasure or profit, as has already been observed. Good sense teaches us the necessity of eonforming to the rules of the society to which we belong: good-breeding prescribes to us to render ourselves agreeable to the company of which we form a part.

When expressing the abstract action of assoeiating, the term society is even more general and indefinite than before; it expresses that which is eommon to mankind, and company that which is peculiar to individuals. The love of society is inherent in our nature; it is weakened or destroyed only by the defeet of our disposition or by some mentäl or psychological derangement: every one naturally likes the company of his own friends and connections in preference to that of strangers. Society is a permanent and habitual aet; company is only a particular act suited to the oceasion: it behooves us to shun the society of those from whom we can learn no good, although we may sometimes be obliged to be in their coinpany. The society of intelligent men is desirable for those who are entering life; the company of facetious men is agreeable in travelling.

See also Community; Fellowship; Public.

SOF', Mild, Gentle, Meek. Soft and mild have the same form and application in Anglo-Saxon as in Modern English. Gentle (see that word). Meek is a Scandinavian word.

All these terms denote the absence of an unpleasant action, sometimes also a positively pleasant aetion, and sometimes a positive readiness to yield to the action of other bodies. Soft is taken in these different senses, as a soft pressure or tread which is not easily felt or heard, and a soft substance that yields readily to the touch or pressure. Mild and genile are mostly taken in the sense of not act- 
ing with an unpleasant force; as mild cheese, or mild fruits, gentle motion. Meek is taken in the passive sense of not resisting force by force. The first three terms have a physical and moral application; the last only a moral application. Soft is applied to such objects as act pleasantly in point of strength on the ear or the eye, as a soft voice, a soft light; or pleasantly, in point of smoothness, on the feeling, as a soft cushion, a soft skin. Mild and gentle are applied to objects that act not unpleasantly on the senses; as mild beer, not too strong either for the palate or the body; mild air, that is, not unpleasantly cold; gentle exercise, gentle motion, not violent or excessive in degree: so a gentle stream and a gentle rain. These terms are, agreeably to this distinction, applied to the same objeets; a soft voice, soft music, as that which is positively pleasant; a gentle voice is one not loud.

A soft air or elimate is positively pleasant; a mild air or elimate is simply without any undue eold; a gentle wind is opposed to one that is boisterous.

Soft is sometimes applied to motion in the purely negative sense; as a soft step, $i$. $e$., one made without great pressure of the foot; a gentle motion is one that is made slowly, not quick. It is necessary to tread softly when no noise is to be made, and to move gently when one is ill.

So likewise when these terms are applied to objects that act on the moral feelings, they admit of a similar distinction. Words are either soft, mild, or gentle; soft words are calculated to soften or diminish the angry feeling of others. The proverb says, "A soft answer turneth away wrath." A reproof is mild, inasmuch as it does not wound the feelings; a censure, or admonition, or reproach, is gentle, inasmuch as it is free from asperity. So likewise punishments are mild that inflict little pain; means of coercion are gentle that are not violent. Manners are soft, mild, and gentle, but sofiness in this ease is not always commendable. Too much softness in the manners of a man is inconsistent with manly firmness. Mildness and gentleness are more generally commendable. Mild manners are peculiarly becoming in superiors or those who have the power of controlling others, provided they do not interfere with good order. Gentle manners are becoming in all persons who take a part in social life. Softness of manner may likewise be assumed, but mildness and gentleness are always genuine, the former arising from the temper, the latter either from the temper or from good-breeding, of which it is the greatest mark.

When these terms are employed as characteristies of the person or his disposition, they are comparable with meek, which is used only in this sense. Soft, as far as it denotes a susceptibility of soft or tender emotions, may and ought to exist in both sexes; but it ought to be the peculiar charaeteristic of the female sex; mildness, as a natural gift, may disqualify a man for command, unless it be tempered by firmness and discretion. Gentleness, as a part of the eharacter, is not so much to be recommended as gentleness from habit.

Meekness denotes the forbearance to use force, even in cases of peculiar provocation: in those who are called upon to direet or command it may be carried to an excess.

Gentle, mild, and meek are likewise applied to animals, the former to designate that easy flow of spirits which fits them for being guided in their movements, and the latter to mark that passive temper that submits to every kind of treatment, however harsh, without an indication even of displeasure. A horse is gentle, as opposed to one that is spirited; the former is devoid of that impetus in himself to move which renders the other ungovernable: the lamb is a pattern of meekness, and yields to the knife of the butcher without a struggle or a groan.

SoIl. See Stain.

SOJOURN. SeC ABIDE.

SOlACE. See Console.

SOLDIER-LIKE. See MARTIAL.

SOLE. See Solitary; Unique.

SolemN. See Grave.

solicit. See Beg; Bespeak.

SOLICITATION, IMPORTUNITY. Solicitation is general; importunity is partieular: it is importunate or trouble- 
some solicitation. Solicitation itself is that which gives trouble to a certain extent, but it is not always unreasonable: there may be cases in which we may yield to the solicitations of friends, to do that which we have no objection to be obliged to do; but importunity is that solicitation which never ceases to apply for that which it is not agreeable to give. We may sometimes be urgent in our solicitations of a friend to accept some proffered honor; the solicitation, however, in this case, although it may even be troublesome, yet is sweetened by the motive of the action: the importunity of beggars is often a deliberate means of extorting money from the traveller.

SOLICITOR. See DrUmMer.

SOLICITUDE. See Care.

SOLID. See Firm; Hard; SUbSTANTIAL.

SOlitary, Sole, Only, Single. All these terms are more or less opposed to several or many. Solitary and sole, both derived from solus, alone or whole, signify a thing left by itself; the former mostly in application to particular sensible objects, the latter in regard mostly to moral objects: a solitary shrub expresses not only one shrub, but one that has been left to itself: the sole cause or reason signifies that reason or cause which stands unsupported by anything else. Only, that is, onely, signifying the quality of unity, does not include the idea of desertion or deprivation, but it comprehends that of want or deficiency: he who has only one shilling in his pocket means to imply that he wants more or ought to have more. Single, which is an abbreviation of singular (sce SrMple), signifies simply one or more detached from others, without conveying any -other collateral idea: a single sheet of paper may be sometimes more convenient than a double one; a single shilling may be all that is necessary for the present purpose: there may be single ones, as well as a single one; but the other terms exclude the idea of there being anything else. A solitary act of generosity is not sufficient to characterize a man as generous: with most criminals the sole ground of their defence rests upon their not having learned to know and do better: harsh language and severe looks are not the only means of correcting the faults of others: single instances of extraordinary talents now and then present themselves in the course of an age.

In the adverbial form, solely, only, and singly are employed with a similar distinction. The disasters which attend an unsuccessful military enterprise are seldom to be attributed solely to the incapacity of the general: there are many circumstances both in the natural and moral world which are to be accounted for only by admitting a Providence as presented to us in Divine revelation: there are many things which men could not effect singly that might be effected by them conjointly.

See also ONE.

Solitary, Desert, Desolate. - Solitary (see above). Desert is the same as deserted, from Latin desertus, de, privative, and the past participle of serere, to join, meaning disjoined, abandoned, forsaken. Desolate, in Latin desolatus, signifies made solitary.

All these epithets are applied to places, but with different modifications of the common idea of solitude which belongs to them. Solitary simply denotes the absence of all beings of the same kind: thus a place is solitary to a man where there is no human being but himself; and it is solitary to a brute when there are no brutes with which it can hold society. Desert conveys the idea of a place made solitary by being shunned, from its unfitness as a place of residence. All deserts are places of such wildness as seem to frighten away almost all inhabitants. Desolate conveys the idea of a place made solitary, or bare of inhabitants, and all traces of habitation, by violent means: desolation is solitude coupled with wretchedness; every country may become desolate which is exposed to the inroads of a ravaging army, and a person may be desolate who feels himself unable to associate with others.

SOLVE, Resolve. Solve and resolve both come from the Latin solvere, to loosen.

Between solve and resolve there is no considerable difference either in sense or application: the former seems merely to speak of unfolding in a general 
manner that which is wrapped up in obseurity; to resolve is rather to unfold it by the particular method of carrying one back (re-) to first principles; we solve a problem and resolve a difficulty.

SOME, ANY. Some, Anglo-Saxon sum, allied to same, is altogether restrictive in its sense: any, AngloSaxon anig (an, one, with suffix $i g$ ), signifying $a$ one, is altogether universal and indefinite. Some applies to one particular part in distinetion from the rest: any to every individual part without distinction. Some think this and others that: any person might believe if he would; any one can conquer his passions if he uses his will-power. In consequence of this distinction in sense, some can be used only in partieular affirmative propositions; but any, which is equivalent to all, may be either in negative, interrogative, or hypothetical propositions: some say so: does any one believe it? He will not give to any.

SOON, Early, Betimes. All these words are expressive of time; but soon respects some future period in general; early, or ere, before, and betimes, or by the time, before a given time, respect some particular period at no great distance. A person may come soon or early; in the former case he may not be long in eoming from the time that the words are spoken; in the latter case he comes before the time appointed. He who rises soon does nothing extraordinary; but he who rises early or betimes exceeds the usual hour considerably. Soon is said mostly of particular acts, and is always dated from the time of the person speaking, if not otherwise expressed; come soon signifies after the present moment: early and betimes, if not otherwise expressed, have always respect to some specific time appointed; come early will signify a visit, a meeting, and the like; do it betimes will signify before the thing to be done is wanted: in this manner, both are employed for the actions of youth. An early attention to duties will render them habitual and pleasing; we must begin betimes to bring the stubborn will into subjection.

SOOTHE. See Allay; Mollify.
SOPHISTRY, FALLACY. Sophistry comes from Greek ropinting, a teacher of arts and seiences for money; a pretended lover of wisdom. It derives its name from the so-called sophists, the teachers of rhetorie, who travelled from eity to eity imparting the seerets of plausible and convincing speech, making "the worse appear the better cause." Sophistry applies to an argument or reason which has a deceptive appearance of rationality and truth; fallacy, from Latin fallax, deceitful, to a general statement which seems to be true partly beeause it has been generally accepted without question. Sophisiry is often founded on a fallacy, that is, it is a chain of argument that is deceptive, beginning with a general statement, a fallacy, which seems to be true, but is not.

SORDID. See MEAN.

SORROW. See AFFliction.

SORRY, Grieved, HURT.

and grieved are epithets somewhat differing from their primitives sorrow and grief (see AfFliction), inasmueh as they are applied to ordinary subjects. We speak of being sorry for anything, however trivial, which concerns ourselves; but we are commonly grieved for that which concerns others. I am sorry that I was not at home when a person ealled upon me; I am grieved that it is not in my power to serve a friend who stands in need. Both these terms connote only that which we do ourselves: hurt (see Displesase and INJURY) that which is done to us, denoting painful feeling from hurt or wounded feelings; we are hurt at being treated with disrespect.

SORT. See KIND.

SOUL, MiND. These terrals, or the equivalents to them, have been employed by all eivilized nations to designate that part of human nature which is presumed to be distinet from matter. The soul, however, from Anglo-Saxon sáwel, is probably from a Sanskrit root meaning light. Like the anima of the Latin, which comes from the Greek

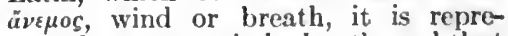
sented to our minds by the subtlest or most ethereal of sensible objects, namely, breath or spirit, and denotes properly the quiekening or vital prineiple. Mind, on the contrary, from 
Anglo-Saxon gemynd, is that sort of power which is closely allied to, and in a great measure dependent upon, corporeal organization: the former is, therefore, the immortal, and the latter the mortal, part of us; the former connects us with spirits, the latter with brutes; in the former we distinguish consciousness and will, which is possessed by no other created being that we know of; in the latter we distinguish nothing but the power of receiving impressions from external objects, which we call ideas, and which we have in common with the brutes. Poets and philosophers speak of the soul in the same strain, as the active and living principle.

The ancients, though unaided by the light of Divine revelation, yet represented the soul as a distinct principle. The Psyche of the Greeks, which was the name they gave to the human soul, was feigned to be one of their incorporeal or celestial beings. The anima of the Latins was taken precisely in the modern sense of the soul, by which it was distinguished from the animus or mind. Thus the Emperor Hadrian is said on his dying bed to have addressed his soul in words which clearly denote what he thought of its independent existence.

The mind, being considered as an attribute to the soul, is taken sometimes for one faculty and sometimes for another; as for the understanding, when we say a person is not in his right mind: sometimes for the intellectual power; or for the intellectual capacity; or for the imagination or conception.

Sometimes the word mind is employed to denote the operations of the thinking faculty, the thoughts or opinions; or the will, choice, determination, as in the colloquial phrase, to have a mind to do a thing.

Sometimes it stands for the memory, as in the familiar expressions to call to mind, put in mind, etc.

Lastly, the mind is considered as the seat of all the faculties, and also of the passions or affections.

The soul, being the better part of a man, is taken for the man's self; as Horace says, in allusion to his friend Virgil, "et serves animæ dimidium mex"; hence the term is figuratively extended, in its application, to denote a human being, or the individual in general. Also, what is excellent, the essential or principal part of a thing, the spirit.

SOUND, Sane, Healthy. Sound is the Anglo-Saxon word, sund, corresponding to Latin sanus, whence sane is derived. Healthy (see that word).

Sound is extended in its application to all things that are in the state in which they ought to be, so as to preserve their vitality; thus animals and vegetables are said to be sound when in the former there is nothing amiss in their breath, and in the latter in their root. By a figurative application, wood and other things may be said to be sound when they are entirely free from any symptom of decay; sane is applicable to human beings, in the same sense, but with reference to the mind; a sane person is opposed to one that is insane. The mind is also said to be sound when it is in a perfect state to form right opinions.

Healthy expresses more than either sound or sane; we are healthy in every part, but we are sound in that which is essential for life; he who is sound may live, but he who is healthy enjoys life. Sound, in the sense of noise, comes from Latin sonus, a sound; tone, from Latin tonum, Greek róvos, a thing stretched, the string of a musical instrument, the sound made by the vibrating of the string.

Sound is that which issues from any body, so as to become audible; tone is a species of sound which is produced from particular bodies: a sound may be accidental; we may hear the sounds of waters or leaves, of animals or men: tones are those particular sounds or modulations of sound which are made either to express a particular feeling or to produce harmony; a sheep will cry for its lost young in a tone of distress; an organ is so formed as to send forth the most solemn tones.

SOURCE. See Germ; Origin; SPRING.

SOURCELESS. See AbIogenic. SOVEREIGN. See Prince.

SPACE, ROom. For the derivation of space see spacious under AMPLE. Room, Anglo-Saxon rúm, meant originally a wide space, and is allied to Latin 
rus (whence rural, etc.), meaning wide open country.

These are both abstract terms, expressive of that portion of the universe which is supposed not to be occupied by any solid body: space is a general term which includes within itself that which infinitely surpasses our comprehension; room is a limited term which comprehends those portions of space which are artificially formed: space is either extended or bounded; room is always a bounded space: the space between two objects is either natural, incidental, or designedly formed; the room is that which is the fruit of design, to suit the convenience of persons: there is a sufficient space between the heavenly bodies to admit of their moving without confusion; the value of a house essentially depends upon the quantity of room which it affords: in a row of trees there must always be vacant spaces between each tree; in a car there will be room only for a given number of persons.

Space is taken only in the natural sense; room is also employed in the moral application; in every person there is ample room for amendment or improvement.

SPACIOUS. See Ample.

SPARE. See AFFord; Save.

SPARING. See EcoNomical.

SPARK. See G.:LLANT.

SPARKLE. See ShINe.

SPEAK, SAY, Tell. Jpeak and say are Anglo-Saxon words whose meaning has not altered from the beginningspeak being derived from later AngloSaxon specan, and say from secgan; compare German sprechen and sagen. Tell, Anglo-Saxon tellan, is allied to Anglo-Saxon talu, a number, a narrative-modern English tale.

To speak may simply consist in uttering an articulate sound; but to say is to communicate some idea by means of words: a child begins to speak the moment it opens its lips to utter any acknowledged sound; but it will be some time before it can say anything: a person is said to speak high or low, distinctly or indistinctly; but he says that which is true or false, right or wrong: a dumb man cannot speak; a fool cannot say anything that is worth hearing: we speak languages, we speak sense or nonsense, we speak intelligibly or unintelligibly; but we say what we think at the time.

In an extended sense, speak may refer as much to sense as to sound, but then it applies only to general cases, and say to particular and passing circumstances of life: it is a great abuse of the gift of speech not to speak the truth; it is very culpable in a person to say that he will do a thing and not to do it.

To say and tell are both the ordinary actions of men in their daily intercourse; but say is very partial, it may comprehend single unconnected sentences or even single words: we may say yes or no, but we tell that which is connected and which forms more or less of a narrative. To say is to communicate that which passes in our own minds, to express our ideas and feelings as they rise; to tell is to communicate events or circumstances respecting ourselves or others: it is not good to let children say foolish things for the sake of talking: it is still worse for them to be encouraged in telling everything they hear: when every one is allowed to say what he likes and what he thinks, there will commonly be more speakers than hearers; those who accustom themselves to tell long stories impose a burden upon others which is not repaid by the pleasure of their company.

See also UTTER.

Speak, Talk, Converse, Discourse.The idea of communicating with, or communicating to, another, by means of signs, is common in the signification of all these terms: to speak is an indefinite term specifying no circumstance of the action; we may speak only one word or many; but talk, which is but a variation of tell, is a mode of speaking, namely, for a continuance: we may speak from various motives; we talk for pleasure; we converse for improvement or intellectual gratification: we spcak with or to a person: we talk commonly to others; we converse with others. Spcaking a language is quite distinct from writing it: those who think least talk most: conversation is the rational employment of social beings, who seek by an interchange of ideas to purify 
the feelings and improve the understanding.

Conversation is the act of many together; discourse, in Latin discursus, expressing properly an examining or deliberating upon, like talk, may be the act of one addressing himself to others; parents and teachers discourse with young people on moral duties.

SPECIAL, SPECIFIC, Particular. Special, in Latin specialis, signifies belonging to the species; specific, in Latin specificus, from speci-, for species, a species, and a weakened form of facere, to make, signifies making a species; particular, belonging to a particle or small part. The special is that which comes under the general; the particular is that which comes under the special: hence we speak of a special rule; but a particular case. Particular and specific are both applied to the properties of individuals; but particular is said of the contingent circumstances of things, specific of their inherent properties: every plant has something particular in itself different from others, it is either longer or shorter, weaker or stronger; but its specific property is that which it has in common with its species: particular is, therefore, the term adapted to loose discourse; specific is a scientific term which describes things minutely.

The same may be said of particularize and specify: we particularize for the sake of information; we specify for the sake of instruction: in describing a man's person and dress we particularize if we mention everything singly which can be said about it; in delineating a plan it is necessary to specify time, place, distance, materials, and everything else which may be connected with the carrying it into execution.

SPECIES. See KIND.

SPECIFIC. See Special.

SPECIMEN. See CoPY.

SPECIOUS. See Colorable.

SPECK. See BLEMisH.

SPECTACLE. See SHow.

SPECTATOR. See LOOKER-ON.

SPECTRE. See VISION.

SPECUlation. See Theory.

SPEECH. See Address; Language. SPEECHLESS. See SileNt.

SPEED. See Hasten.
SPELlBOUND, Bewitched. These words have a similar meaning. Both are of Anglo-Saxon origin, and bear their original meaning on their face. as it were. Spellbound means bound by a spell, a spell being originally a narrative myth or fable, hence the absorption of one who listens to such narration; thence by extension an utterance or incantation, by which superhuman spirits were called upon to take the victim under their power. Bewitched means under the influence of a witch. Spellbound and bewitchcd are both used figuratively-spellbound to indicate a state of rapt attention in which all motion is suspended; bewitched to signify under a powerful influence, which seems in some way abnormal. Bewitched often describes absorbing and exclusive admiration of or devotion to a person or an idea.

SPEND, ExhaUst, Drain. Spend comes from Anglo-Sax n spendan, to spend, shortened from Latin dispendere, from dis, out, and pendere, to weigh, meaning to weigh out money. Exhaust, from the Latini ex, out, and haustus, past participle of haurire, to draw water. Drain, in Anglo-Saxon drenian, originally meant to become $d r y$, and is allied to $d r y$.

The idea of taking from the substance of anything is common to these terms; but to spend is to deprive it in a less degree than to exhaust, and that in a less degree than to drain: every one who exerts himself in that degree spends his strength; if the exertions are violent he exhausts himself; a country which is drained of men is supposed to have no more left. To spend may be applied to that which is either external or inherent in a body; exhaust to that which is inherent; drain to that which is external of the body in which it is contained: we may speak of spending our wealth, our resources, our time, and the like; but of exhausting our strength, our vigor, our voice, and the like; of draining, in the proper application, a vessel of its liquid, or in the improper application, draining a treasury of its contents: hence arises this further distinction, that to spend and to exhaust may tend, more or less, to the injury of a body; but to drain may be to its advantage. 
Inasmuch as what is spent or exhausted may be more or less essential to the soundness of a body, it cannot be parted with without diminishing its value or even destroying its existence; as when a fortune is spent it is gone, or when a person's strength is exhausted he is no longer able to move: on the other hand, to drain, though a more complete evacuation, is not always injurious, but sometimes even useful to a body, as when the land is drained of a superabundance of water.

Spend, Expend, Waste, Dissipate, Squander. - Spend and expend both come ultimately from Latin pendere, to weigh - spend indirectly through AngloSaxon, expend directly from Latin ex, out, and pendere, to weigh; but spend implies simply to tarn to some purpose or make use of; to expend earries with it likewise the idea of exhausting; and waste, moreover, comprehends the idea of exhausting to no good purpose: we spend money when we purchase anything with it; we expend it when we lay it out in large quantities so as essentially to diminish its quantity: individuals spend what they have; government expends vast sums in conducting the affairs of a nation; all persons waste their property who have not suffieient diseretion to use it well: we spend our time, or our lives, in any employment; we expend our strength and faculties upon some arduous undertaking; we waste our time and talents in trifles.

Dissipate, in Latin dissipatus, from dissipare, means to disperse, to throw in all directions. Squander meant originally to seatter abroad, and is a nasalized form allied to Lowland Scoteh squatter, to splash about, seatter. Both these terms, therefore, denote modes of wasting; but the former seems peculiarly applicable to that which is wasted in detail upon different objects, and by a distraction of the mind; the latter respects rather the act of wasting in the gross, in large quantities, by planless profusion: young men are apt to dissipate their property in pleasure; the open, generous, and thoughtless are apt to squander their property.

SPHERE. See CirCle.

SPILL. See Pour.
SPIRIT. See Animation; UNCTION.

SPIRITED. See SPIRITUOUs.

SPIRITUAL. See INCORPOREAL; SPIRItUous.

SPIRITUOUS, SPIRITED, SPIRITUAL, Ghostly. Spirituous signifies having spirit as a physical property, after the manner of spirituous liquors: spirited is applicable to the animal spirits of either men or brutes; a person or a horse may be spirited.

What is spiritual is after the manner of a spirit, and what is ghostly is like a ghost: although originally the same in meaning, the former being derived from the Latin spiritus, and the latter from the Anglo-Saxon gast, German geist, and both signifying what is not corporeal, yet they have acquired a difference of application. Spiritual objects are mostly distinguished from those of sense. Hence it is that the spiritual is opposed to the temporal.

Ghostly is more immediately opposed to the carnal or the secular, and is a term, therefore, of more solemn import.

SPITE. See Malice.

SPLASH. See DABble.

SPLENDID. See SUPERB.

SPLENDOR. See Brightness;

MAGNificenCE.

SPLENETIC. See HyPochoNdrIACAL.

SPLENIC FEVER. See ANTHRAX. SPLIT. See BREAK.

SPOIL. See Booty; Buxgle. SPOLIATION. See Rapine; RavAGE; SACK.

SPONTANEOUSLY. Se WILLINGLY.

SPORT. See Amusement; Jest;

PlaY.

SPORTIVE. See Lively; PlayFUL.

SPOT. See Blemish; Place.

SPOTLESS. See Blameless.

SPOUT. See SPURT.

SPRAIN. See Strain.

SPREAD, Scatter, Disperse. Spread applies equally to divisible or indivisible bodies; we spread our money on the table, or we may spread a cloth on the table; but scatter, like shatter, is a frequentative of shake, and is applicable to divisible bodies only; we scatter corn on the ground. To 
spread may be an act of design or otherwise, but mostly the former; as when we spread books or papers before us: scatter is mostly an act without design; a child scatters the papers on the floor. When taken, however, as an act of design, it is done without order; but spread is an act done in order; thus hay is spread out to dry, but corn is scattered over the land.

Things may spread in one direction, or at least without separation; but they disperse (see DisPEL) in many directions, so as to destroy the continuity of bodies: a leaf spreads as it opens in all its parts, and a tree also spreads as its branches increase; but a multitude disperses, an army disperses. Between scatter and disperse there is no other difference than that one is immethodical and of ten involuntary, the other systematic and intentional: flowers are scattered along a path which accidentally fall from the hand; a mob is dispersed by an act of authority: sheep are scattered along the hills; religious tracts are dispersed among the poor: the disciples were scattered as sheep without a shepherd after the delivery of our Saviour into the hands of the Jews; they dispersed themselves, after his ascension, over every part of the world.

To spread is the general, the other two are particular terms. To spread may be said of anything which occupies more space than before, whether by a direct separation of its parts or by an accession to the substance; but to $e x-$ pand, from Latin expandere, is to spread by means of extending or unfolding the parts; a mist spreads over the earth; a flower expands its leaves; a tree spreads by the growth of its branches; the opening bud expands when it feels the genial warmth of the sun. Diffusion is that process of spreading which consists literally in pouring out in different ways.

Spread and expand are used likewise in a moral application; diffuse is seldom used in any other application: spread is here, as before, equally indefinite as to the mode of the action; everything spreads, and it spreads in any way; but expansion is that gradual process by which an object opens or unfolds itself after the manner of a flower. Evils spread, and reports spread; the mind expands, and prospects expand; knowledge diffuses itself, or cheerfulness is diffused throughout a company.

Spread, Circulate, Propagate, Disseminate.-To spread is said of any object material or spiritual; the rest are mostly employed in the moral application. To spread is to extend to an indefinite width; to circulate is to spread within a circle: thus news spreads through a country; but a story circulates in a village or from house to house, or a report is circulated in a neighborhood.

Spread and circulate are the acts of persons or things; propagate and disseminate are the acts of persons only. The thing spreads and circulates, or it is spread and circulated by some one; it is always propagated and disseminated by some one. Propagate, from the Latin propagare, to increase by layers, from propages, a layer, from stem contained in compages (compare English compact), a fastening together, and disseminate, from dis, apart, and semen, a seed, are here figuratively employed as modes of spreading, according to the natural operations of increasing the quantity of anything which is implied in the first two terms. What is propagated is supposed to secure new adherents, as when doctrines, either good or bad, are propagated among the people so as to make them converts: what is disseminated is supposed to be sown in different parts; thus principles are disseminated among youth.

SPRIGHTLY. See CheERUL; LIVELY.

SPRING, Fodntain, S O U R C E. Spring denotes that which springs; the word, therefore, carries us back to the point from which the water issues. Fountain, through French from Low Latin fontana, based on classical fons, a fountain, signifies that from which anything is poured, and comprehends in it a collection or certain quantity of water, both natural and artificial: and source is from Old French sorse, the feminine past participle of the verb sourdre (with intercalated $d$ ), from surgere, to rise, and carries us back to the place whence the water takes its rise. Springs are to be found by digging a sufficient 
depth in all parts of the earth: in mountainous countries, and also in the East, we read of fountains which form themselves, and supply the surrounding parts with refreshing streams: the sources of rivers are mostly to be traced to some mountain.

These terms are all used in a figurative sense: spring is taken for that which is always flowing; fountain for that which contains an abundant supply for a stream, and source for the channel through which from the commencement any event comes to pass.

Spring, Start, Startle, Shrink.-The idea of a sudden motion is expressed by all these terms, but the circumstances and mode differ in all; spring is indefinite in these respects, and is therefore the most general term. To spring and start, Middle English sterten, to move suddenly, may be either voluntary or involuntary movements, but the former is mostly voluntary and the latter involuntary; a person springs out of bed, or one animal springs upon another; a person or animal starts from a certain point to begin running, or starts with fright from one side to the other. To startle, which is a frequentative of start, is always an involuntary action; a horse starts by suddenly flying from the point on which he stands; but if he startles he seems to fly back on himself and stops his course; to spring and start, therefore, always carry a person farther from a given point; but startle and shrink are movements within one's self; startling is a sudden convulsion of the frame which makes a person stand in hesitation whether to proceed or not; shrinking, from Anglo-Saxon scrincan, is allied to shrug, shrimp, etc., and means a contraction of the frame within itself; any sudden and unexpected sound makes a person startle; the approach of any frightful object makes him shrink back; spring and start are mostly employed only in the proper sense of corporeal movements; startle and shrink are employed in regard to the movements of the mind as well as the body.

See also ArIsE.

Sprinkle, Bedew. Sprinkle is from sprenkle, the frequentative form of Middle English sprengen, allied to
Dutch sprenkelen, to sprinkle; it denotes either an act of nature or design: to bedew is to cover with dew, which is an operation of nature. By sprinkling, a liquid falls in visible drops upon the earth; by bedewing, it covers by imperceptible drops: rain besprinkles the earth; dew bedews it.

So likewise, figuratively, things are sprinkled with flour; the cheeks are bedewed with tears.

\section{SPRINGING. See Salient.}

SPROUT, BUD. Sprout is in AngloSaxon sprutan, meaning to germinate, allied to spout. Bud is a word of uncertain but probably Teutonic origin which does not appear in Anglo-Saxon, but is found in Middle English as budden, to bud. Cf. Dutch bot, a bud. To buid is to put forth buds; the noun bud is a variation from button, which it resembles in form. (Cf. the French bouton, which means both bud and button.) To sprout is to come forth from the stem; to bud, to put forth in buds.

\section{SPRUCE. See Finical.}

SPURIOUS, Supposititious, CouNTERFEIT. Spurious comes from Latin spuries, false, of illegitimate birth. Supposititious is derived from Latin suppositicius, from the stem of supponere, suppose or substitute, and signifies to be supposed or conjeetured, something not real but substituted, in distinction from being positively known. Counterfeit (see IMrTate).

All these terms are modes of the false; the former two indirectly, the latter direetly; whatever is uncertain that might be certain, and whatever is conjectured that might be conclusive, are by implication false; that which is made in imitation of another thing, so as to pass for it as the true onc, is positively false. Hence, the distinetion between these terms and the ground of their applications. An illegitimate offspring is said to be spurious in the literal sense of the word, the father in this case being always uncertain; and any offspring which is termed spurious falls necessarily under the imputation of not being the offspring of the person whose name it bears. In the same manner an edition of a work is termed spurious which comes out under a false name or a name different from that on the title- 
page; supposititious expresses more or less of falsehood, according to the nature of the thing. A supposititious parent implies little less than a directly false parent; but in speaking of the origin of any person in remote periods of antiquity, it may be merely supposititious or conjectural from the want of information. Counterfeit respects rather works of art which are exposed to imitation: coin is counterfeit which bears a false stamp, and every invention which comes out under the sanction of the inventor's name is likewise a counterfeit if not made by himself or by his consent.

SPURT, SPouT. To spurt meant originally to germinate and is the same word as sprout; Middle English spruten. Spout. Middle English spouten, to spurt out-the word has probably no relation to the English spit; they bcth express the idea of sending forth liquid in small quantities from a cavity; the former, however, does not always include the idea of the cavity, but simply that of springing up; the latter is, however, confined to the circumstances of issuing forth from some place; dirt may be spurted in the face by means of kicking it up, or blood may be spurted out of a vein when it is opened, water out of the mouth, and the like; but a liquid spouts out from a pipe. To spurt is a sudden action arising from a momentary impetus given to a liquid either intentionally or incidentally; the beer will spurt from a barrel when the vent-peg is removed: to spout is a continued action produced by a perpetual impetus which the liquid receives equally from design or accident; the water spouts out from a pipe which is denominated a spout, or it will spout out from any cavity in the earth, or in a rock which may resemble a spout; a person may likewise spout water in a stream from his mouth.

Hence the figurative application of these terms; any sudden conceit which compels a person to an eccentric action is a spurt, particularly if it springs from ill-humor or caprice; a woman will sometimes take a spurt and treat her intimate friends very coldly, either from a fancied offence or a fancied superiority; to spout, on the other hand, is to send forth a stream of words in imitation of the stream of liquid, and is applied to those who affect to be speakers or who recite in an affected manner.

SPY, Scour. For the derivation of spy see Emissary. Scout is derived from Old French escouter, to listen, Latin auscultare. A spy and a scout are both agents sent out to gain information, but spy suggests secrecy and disguise; scout active and watchful movement. A spy, in times of war, enters directly into the camp of the enemy and gains what information he can by pretending to espouse the enemy's cause. A scout, on the other hand, is a kind of watchman, as it were, sent out to explore a territory and find out what he can without being caught. He depends upon quickness of movement, skill, and observation rather than upon deceit.

SQUALID, DIRTY, Foul. Squalid, dirty, and foul all indicate a condition of uncleanness. Dirty signifies merely that which is not clean, that which is covered with dirt. Foul, AngloSaxon ful, adds to the idea of uncleanness the suggestion of something loathsome, offensive. Squalid, from Latin squalidus, adds to the idea of uncieanness the suggestion of misery and poverty. A palace may be dirty or foul; but it will not be squalid. A peasant's hut may be spoken of as squalid.

SQUANDER. See SPEND.

SQUEAMISH. See FASTIDIOUS.

SQUEEZE. See BreaK; Press.

STABILITY. See Constancy.

STABLE. See FIRM.

STAFF, Stay, Prop, Support. From staff in the literal sense comes staff in the figurative application: anything may be denominated a staff which holds up after the manner of a staff, particularly as it respects persons; bread is said to be the staff of life; one person may serve as a staff to another.

The staff serves in a state of motion; the stay and prop are employed for objects in a state of rest: the stay makes a thing stay for the time being, it keeps it in its place; it is equally applied to persons and things: we may be a stay to a person who is falling by letting his body rest against us; in the same manner buttresses against a wall, and shores against a building, serve the purpose of stays 
while they are repairing. For the same reason that part of a woman's dress which serves as a stay to the body is denominated stays: the prop keeps a thing up as a permanency; every pillar on which a building rests is a prop; whatever, therefore, requires to be raised from the ground and kept in that state may be set upon props. Support (see HoLD) is a general term, and in its most general sense comprehends all the others as species: whatever supports, that is, bears the weight of an object, is a support, whether in a state of motion like a staff or in a state of rest like a stay or prop.

Staff, stay, and prop are applied figuratively in the sense of a support, with a similar distinction between them.

Support is applied in the proper sense to moral as well as tangible objects: hope is the support of the mind under the most trying circumstances; religion, as the foundation of all our hopes, is the best and surest support under affliction.

Staff, Stick, Crutch. - Staff is in Anglo-Saxon stof. Stick is AngloSaxon sticca, something that could stick or pierce into another object. Crutch comes from Anglo-Saxon cricc, developing to crick (cf. cricket), and through critch to crutch, a bent stick, and hence a crutch or staff.

The ruling idea in a staff is that of firmness and fixedness; it is employed for leaning upon; the ruling idea in the stick is that of sharpness with which it can penetrate; it is used for walking and ordinary purposes: the ruling idea in the crutch is its form, which serves the specific purpose of support in case of lameness; a staff can never be small, but a stick may be large; a cruich is in size more of a staff than a common stick.

STAGGER, REel, TotTer. Stagger is a Scandinavian word from a root signifying to push allied to stake. To reel signifies to go around like a reel, a small spindle for winding yarn. Totter is for tolter, a frequentative of tilt.

All these terms designate an involuntary and an unsteady motion; they vary both in the cause and the mode of the action; slaggering and reeling are occasioned either by drunkenness or sickness; tottering is purely the effect of weakness, particularly the weakness of old age: a drunken man always staggers as he walks; one who is giddy reels from one part to another: to stagger is a much less degree of unsteadiness than to reel; for he who staggers is only thrown a little out of the straight path, but he who reels altogether loses his equilibrium; reeling is commonly succeeded by falling. To stagger and reel are said as to the carriage of the whole body; but totter has particular reference to the limbs; the knees and the legs totter, and consequently the footsteps become tottering. In an extended application, the mountains may be said to stagger and to reel in an earthquake: the houses may totter from their very bases. In a figurative application, the faith or the resolution of a person staggers when its hold on the mind is shaken and begins to give way; a nation or a government will totter when it is torn by internal convulsions.

STAGNATE. See STAND.

STAIN, Soll, SUlly, TARnish. Stain (see Blemish). Soil comes through French from Latin suillus, a pig; from sus, a sow, and signifies to wallow as a sow. Sully, Anglo-Saxon sylian, means to bemire, from Teutonic sol, mud, Modern English soil; but its meaning may be influenced by the verb to soil. Tarnish comes through French from Old High German tarnen, to obscure, darken.

All these terms imply the act of diminishing the brightness of an object; but the term stain denotes something grosser than the other terms and is applied to inferior objects: things which are not remarkable for purity or brightness may be stained, as hands when stained with blood or a wall stained with chalk; nothing is sullied or tarnished but what has some intrinsic value; a fine picture or piece of writing may be easily soiled by a touch of the finger; the finest glass is the soonest tarnished: hence, in the moral application, a man's life may be stained by some gross immorality: his honor may be sullicd or his glory tarnished.

See also Atraint; Color.

STALWART, ATHLETIC, BRAWNY. Stalwart comes from Anglo-Saxon sto- 
pol-wyrde, literally, foundation-worthy, capable of being used as a foundation, hence strong, steadfast. Athletic, from Greek $\dot{\alpha} \theta \lambda \eta r^{\prime}{ }^{\prime}$, , one who contends for a prize, means characteristic of one trained for physical contests. Brawny means having brawn, from Old French braon, a slice of flesh, German braton, flesh for roasting, brawn referring especially to the fleshy, muscular portions of the arms or legs. All these words signify "in possession of physical strength." In the case of stalwart the idea of physical endurance and courage is added to that of strength; in the case of athletic the idea of a special training rendering the body flexible and self-controlled as well as strong is added; in the case of brawny the specific suggestion of large muscles and hardened flesh is added to the idea common to all three words.

STAMMER. See Hesitate.

STAMP. See Mark; Seal.

STAND, Stop, Rest, Stagnate. To stand, in Middle English standen, cognate with German stehen, Russian stai' or stoyát', Latin stare, Greek ' $\sigma \tau \eta \mu$, to stand, Hebrew sut, to settle. Stop, in Saxon stoppan, etc., conveys the ideas of pressing, thickening, as in the Low Latin stupare, to stop up with food, from the classical stupa, meaning tow, and the Greek $\sigma \tau \dot{v} \pi \eta$, whence it has been made in English to express immovability. Rest (see EASE). Stagnate, in Latin stagnatus, participle of stagnare, comes from stagnum, a pool, and that either from stare, to stand, because waters stand perpetually in a pool, or

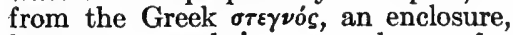
because a pool is an enclosure for waters.

The absence of motion is expressed by all these terms; stand is the most general of all the terms; to stand is simply not to move; to stop is to cease to move: we stand either for want or inclination or power to move; but we stop from a disinclination to go on: to rest is to stop from an express dislike to motion; we may stop for purposes of convenience or because we have no farther to go, but we rest from fatigue.

To stagnate is only a species of standing as respects liquids; water may both stand and stagnate; but the former is a temporary, the latter a permanent, stand: water stands in a puddle, but it stagnates in a pond or in any confined space.

All these terms admit of an extended application; business stands still, or there is a stand to business; a mercantile house stops, or stops payment; an affair rests undecided, or rests in the hands of a person; trade stagnates.

See also Brook.

STANDARD. See Criterion.

STARE. See GAPE.

START. See Spring.

STARTLE. See SPRING.

STATE, Realm, Commonwealth. The state is that consolidated part of a nation in which lie its power and greatness. The realm, from Old French realme, Modern royaume, a kingdom, both based on a hypothetical Low Latin regalimen, is any state whose government is monarchial. The commonwealth is the grand body of a nation, consisting both of the government and people, which forms the commonwealth, welfare, or wealth.

The ruling idea in the sense and application of the word state is that of government in its most abstract sense; affairs of state may either concern the internal regulations of a country or the arrangements of different states with each other. The term realm is employed for the nation at large, but confined to such nations as are monarchial and aristocratical; peers of the realm sit in the English Parliament by their own right. The term commonwealth refers rather to the aggregate body of men and their possessions than to the government of a country: it is the business of the minister to consult the interests of the commonwealth.

Its political components constitute the commonwealth of Australia, and its counties the commonwealth of Massachusetts.

See also Situation.

STATEly. See Magisterial; ORNATE; SUPERB.

Station. See Condition; Place. STAY. See Contindal; Staff.

STEADINESS. See Constancy.

STEAL AWAY. See ABscond.

STEEP. See SOAK.

STEP. See PACE.

STERN. See Ascetic; Austere. 
STICK, Cleave, Adhere. Stick is in Anglo-Saxon stecan, Low German

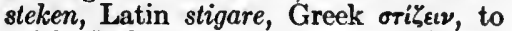
prick, Hebrew stock, to press. Cleave, in Anglo-Saxon cleofian, Low German kliven Danish klaebe, is connected with our words glue and lime, in Latin gluten, Greek кó $\lambda \lambda \alpha$, glue. Adhere (see ATTACH).

These terms all express the being joined to a body so as not to part from it without an effort. Stick, which is the general and familiar expression, denotes a junction more or less close: things may stick very slightly, so as to come off with the smallest touch, or things may be made to stick together so fast that they cannot be separated; wet paper may stick for a time, and by means of glue may stick firmly.

What sticks may stick in any manner, but what adheres, when said of natural bodies, adheres by the sticking on the outer surface: a foot sticks in the mud: wax adheres to the fingers. Adhesion, denoting a property of matter, is a scientific term.

Cleave is seldomer used than either of the other terms, but always implies a close adhesion produced by some particular cause.

Stick and adhere may also be applied figuratively, with the like distinction.

As the act of conscious agents, stick is, as before, the familiar expression, whether applied to material or spiritual objects; a person may stick with his body or his mind to anything: in both cases it is an act of determination or perseverance.

A person cleaves or adheres to an object, in the former case out of feeling, in the latter case from principle: a drowning man will cleave to anything by which he can be saved; a conscientious man adheres to the truth.

See also Adhere; Fix; StafF.

STIFLE, SUPPRESS, SMOTHER. Stifle is a Scandinavian word, allied to Icelandic stifla, to dam up, make stiff, and to English stiff. Suppress (see Repress). Smother comes from Middle English smorther, a suffocating smoke, and means to have the effect of a suffocating smoke.

Stifle and smother in their literal sense will be more properly considered under the article on Suffocate; they are here taken in a moral application. The leading idea in all these terms is that of keeping out of view: stifle is applicable to the feelings only; suppress to the feelings or to outward circumstances; smother to outward circumstances only: we stifle resentment; we suppress anger: the former is an act of some continuance; the latter is the act of the moment: we stifle our resentment by abstaining to take any measures of retaliation; we suppress the rising emotion of anger, so as not to give it utterance or even the expression of a look. It requires time and powerful motives to stifle, but only a single effort to suppress; nothing but a long course of vice can enable a man to stifle the admonitions and reproaches of conscience; a sense of prudence may sometimes lead a man to suppress the joy which an occurrence produces in his mind. In regard to outward circumstances, we say that a book is suppressed by the authority of government; that vice is suppressed by the exertions of those who have power: an affair is smothered so that it shall not become generally known, or the fire is smothered'under the embers.

See also Suffocate.

STIGMA. See MARK.

STILL. See APPEAsF; QUEll.

STIMUlate. See Excourage.

STIPEND. See Allowance.

STIR, Move. Stir is in AngloSaxon styrian, to move. Move (see MOTION).

Stir is here a specific, move a generic, term: we may move in any manner, but to stir is to move so as to disturb the rest and composure either of the body or mind; the term stir is therefore mostly employed in cases where any motion, however small, is a disturbance: a soldier must not stir from the post which he has to defend; atrocious criminals or persons raving mad are bound hand and foot, that they may not stir.

\section{See also THRILL.}

STIR UP. See AWAKEN.

STOCK, STORE. Stock meant originally a stump remaining in the ground -a significance which it still retains; hence it developed the meaning of something fixed. 
The ideas of wealth and stability being naturally allied, it is not surprising that stock, which expresses the latter idea, should also be put for the former, particularly as the abundance here referred to serves as a foundation, in the same manner as stock in the literal sense does to a tree. Store likewise implies a quantity; but it implies an accumulated quantity. Any quantity of materials which is in hand may serve as a stock for a given purpose; thus a few shillings with some persons may be their stock-in-trade: any quantity of materials brought together for a given purpose may serve as a store; thus the industrious ant collects a store of grain for the winter. The stock is that which must increase of itself; it is the source and foundation of industry; the store is that which we must add to occasionally; it is that from which we draw in time of need. By a stock we gain riches; by a store we guard against want.

The same distinction exists between these words in their moral application; he who wishes to speak a foreign language must have a stock of familiar words; stores of learning are frequently lost to the world for want of means and opportunity to bring them forth to public view.

As verbs, to stock and to store both signify to provide; but the former is a provision for the present use and the latter for some future purpose: a tradesman stocks himself with such articles as are most salable; a fortress or a ship is stored: a person stocks himself with patience or stores his memory with knowledge.

Stop. See Cessation; Check; HiNDER; STAND.

STORE. See STOck.

STORY, TALE. The story (see ANECDOTE) is either an actual fact or something feigned; the tale (see FABLE) is always feigned: stories are circulated respecting the accidents and occurrences which happen to persons in the same place; tales of distress are told by many merely to excite compassion. When both are taken for that which is fictitious, the story is either an untruth or falsifying of some fact or it is altogether an invention; the tale is always an invention. As an untruth, the story is commonly told by children; and as a fiction, the story is commonly made for children: the tale is of deeper invention, formed by men of mature understanding, and adapted for persons of mature years.

STOUT. See Corpulent.

STRAIGHT, RIGHT, DIRECT. Straight is the Middle English past participle of the verb which is now stretch, and meant literally stretched. Straight is applied, therefore, in its proper sense, to corporeal objects; a path which is straight is kept within a shorter space than if it were curved. Right and direct, from the rectus, the past participle of Latin regere (to rule, guide), meaning here regulated or made as it ought, are said of that which is made by the force of the understanding, or by an actual effort, what one wishes it to be: hence, the mathematician speaks of a right line, as the line which lies most justly between two points, and has been made the basis of mathematical figures; and the moralist speaks of the right opinion, as that which has been formed by the best rule of the understanding; and, on the same ground, we speak of a direct answer as that which has been framed so as to bring one soonest and easiest to the point desired.

STRAIN, Sprain, Stress, Force. Strain is derived through Old French estraindre, from Latin stringere, to pull tight, related to Anglo-Saxon streccan, to stretch: sprain comes from Old French espreindre, to press or wring, from Latin exprimere, to press out. To strain is to extend beyond its ordinary length by some extraordinary effort; to sprain is to strain so as to put out of its place or extend to an injurious length: the ankle and the wrist are liable to be sprained by a sudden wrenching; the back and other parts of the body may be strained by overexertion.

Strain and stress are kindred terms, as being both variations of stretch and stringere; but they differ now very considerably in their application: figuratively we speak of straining a nerve, or straining a point, to express making great exertions, even beyond our ordinary powers; and morally we speak of laying a stréss upon any particular 
measure or mode of action, signifying to give a thing importance: the slrain (see STress) may be put for the course of sentiment which we express and the manner of expressing it; the stress may be put for the efforts of the voice in uttering a word or syllable: a writer may proceed in a strain of panegyric or invective; a speaker or a reader lays a siress on certain words by way of distinguishing them from others. To strain is properly a species of forcing; we may force in a variety of ways, that is, by the exercise of force upon different bodies and in different directions; but to strain is to exercise force by stretching or prolonging bodies; thus to strain a cord is to pull it to its full extent; but we may speak of forcing any hard substance in, or forcing it out, or forcing it through, or forcing it from a body: a door or a lock may be forced by violently breaking it; but a door or a lock may be strained by putting the hinges or the spring out of their place. So, likewise, a person may be said to force himself to speak when by a violent exertion he gives utterance to his words; but he strains his throat or his voice when he exercises the force on the throat or lungs so as to extend them. Force and stress, as nouns, are in like manner comparable when they are applied to the mode of utteranee; we must use a certain force in the pronunciation of every word; this, therefore, is indefinite and general; but the stress is that particular and strong degree of force which is exerted in the pronunciation of certain words.

STRAIT, NARROw. Strait is derived through French from Latin strictus, participle of stringere, to bind elose, and signifies bound tight, that is, brought into a small compass: narrow, from Anglo-Saxon nearu, closely drawn, expresses a mode of nearness or closeness. Strait is a particular term; narrow is general: straitness is an artificial mode of narrowness; a cont is strait which is made to compress a body within a small compass: narrow is either the artificial or the natural property of a body, as a narrow ribbon or a narrow leaf. That which is strait is so by the means of other bodies, as a piece of water confined close on each side by land is called a strait: whatever is bounded by sides that are near each other is narrow; thus a picee of land whose prölonged sides are at a small distance from each other is narrow. The same distinction applies to these terms in their moral or extended use.

STRANGe. See Particular.

STRANGER, Foreigner, AIIIEN. Stranger, in Old French estrangier, from Latin extraneus, based on the preposition extra, in Greek $\varepsilon \xi$, signifies out of, that is, out of another country: foreigner, from Old French forain, derived from Low Latin foranens, from elassical foras, out of doors, and alien, from alienus, another's, have obviously the same original meaning: they have, however, deviated in their acceptations.

Stranger is a general term and applies to one not known or not an inhabitant, whether of the same or another country; foreigner is applied only to strangers of another country, and alien to one who has no political or natural tie. Ulysses, after his return from the Trojan war, was a stranger in his own house; the French are foreigners in England, and the English in France; neither ean enjoy, as aliens, the same privileges in a foreign country as they do in their own: the laws of hospitality require us to treat strangers with more ceremony than we do members of the same family or very intimate friends: the lower orders of the English are apt to treat foreigners with an undeserved contempt; every alien is obliged, in time of war, to have a license for residing in a foreign country.

Stranger is sometimes taken for one not acquainted with an object or not experienced in its effects: foreigner is used only in the proper sense; but the epithet foreign sometimes signifies not belonging to an object: alien is applied in its natural sense to that which is unconnected by any tic.

STRATAGEM. See ARTifice.

STRATEGY. See Tactics.

STRAY. See Deviate.

STREAM, Current, Tine. A fluid body in a progressive motion is the object described in eommon by these terms: streain is the most general, the other two are but modes of the strcam: stream, in Anglo-Saxon stream, 
in German strom, comes from a root meaning to flow; a current, from currere, to run, is a stream running in a particular direction; and a tide, AngloSaxon tid, time, in German zeit, time, is a periodical stream or current. All rivers are streams, which are more or less gentle according to the nature of the ground through which they pass; the force of the current is very much increased by the confinement of any water, between rocks, or by means of artificial impediments: the tide is high or low, strong or weak, at different hours of the day; when the tide is high, the current is strongest.

From knowing the proper application of these terms, their figurative and moral application becomes obvious: a stream of air or a stream of light is a prolonged moving body of air or light: so a stream of charity, bounty, and the like is that which flows in a stream: a current of air is a particular stream of air passing through or between other bodies, as the current of air in a house; so the current of men's minds or opinions, that is, the running in a particular line: the tide being a temporary stream; fashion, or the ruling propensity of the day, may be denominated a tide: it is sometimes vain to attempt to stem the tide of folly, it is therefore wiser to get out of its reach.

See also Frow.

STRENGTH. See Power.

STRENGTHEN, FoRTIFY, INvigoRATE. Strengthen, from strength, and fortify, from fortis and a weakened form of facere, signify to make strong: invigorate signifies to put in vigor (see ENERGY).

Whatever adds to the strength, be it in ever so small a degree, strengthens; exercise strengthens either body or mind; whatever gives strength for a particular emergency fortifies; religion fortifies the mind against adversity: whatever adds to the strength, so as to give a positive degree of strength, invigorates; morning exercise in fine weather invigorates.

STRENUOUS, BoLD. Strenuous, in Latin strenuus, from the Greek orpqvins, strong, undaunted, untamed, expresses much more than bold; boldness is a prominent idea, but it is only one idea which enters into the signification of strenuousness; this combines likewise fearlessness, activity, and ardor. An advocate in a cause may be strenuous or merely bold: in the former case he omits nothing that can be either said or done in favor of the cause, he is always on the alert, he heeds no difficulties or danger; but in the latter case he displays his spirit only in the undisguised declaration of his sentiments. Strenuous supporters of any opinion are always strongly convinced of the truth of that which they support, and deeply impressed with a sense of its importance; but the bold supporter of an opinion may be impelled rather by the desire of showing his boldness than maintaining his point.

STRESS, Strain, EMphasis, AcCENT. Stress and strain (for both see STRAIN) are general both in sense and application; the former (from Old French estrecir, based on a hypothetical derivative of Latin strictus, tightened) still more than the latter: emphasis, from the Greek $\ddot{\varepsilon} \mu \phi a \sigma \iota s$, composed of $\dot{\varepsilon} \nu$, in, and $\phi \dot{a} \sigma \iota s$, an appearance, signifying making to appear, and accent, in Latin accentus, from ad, to, and cantus, a song, signifying to suit the tune or tone of the voice, are modes of the stress. Stress is applicable to all bodies the powers of which may be tried by exertion, as the stress upon a rope, upon a shaft of a carriage, a wheel or spring in a machine: the strain is an excessive stress, by which a thing is thrown out of its course; there may be a strain in most cases where there is a stress: but stress and strain are to be compared with emphasis and accent, particularly in the exertion of the voice, in which case the stress is a strong and special exertion of the voice on one word, or one part of a word, so as to distinguish it from another; but the strain is the undue exertion of the voice beyond its usual pitch, in the utterance of one or more words: we lay a stress for the convenience of others; but when we strain the voice it is as much to the annoyance of others as it is hurtful to ourselves. The stress may consist in an elevation of voice or a prolonged utterance; the emphasis is that species of stress which is employed to distinguish one 
word or syllable from another: the stress may be accidental; but the emphasis is an intentional stress: ignorant people and children are often led to lay the stress on small and unimportant words in a sentence; speakers sometimes find it convenient to mark particular words, to which they attach a value, by the emphasis with which they utter them. The stress may be casual or regular, on words or syllables; the accent is that kind of regulated stress which is laid on one syllable to distinguish it from another: there are many words in our own language, such as subject, object, present, and the like, where, to distinguish the verb from the noun, the accent falls on the last syllable for the former and on the first syllable for the latter.

In reference to the use of words, these terms may admit of a further distinction; for we may lay a stress or emphasis on a particular point of our reasoning, in the first case, by enlarging upon it longer than on other points; or, in the second case, by the use of stronger expressions or epithets. The strain or accent may be employed to designate the tone or manner in which we express ourselves, that is, the spirit of our discourse: in familiar language, we talk of a person's proceeding in a strain of panegyric or of censure; but, in poetry, persons are said to pour forth their complaints of love in tender accents.

STRETCH. See Extend.

STRICT, SEVERE. Strict, from strictus, bound or confined, characterizes the thing which binds or keeps in control: severe (see Austere) characterizes in the proper scnse the disposition of the person to inflict pain, and in an extended application the thing which inflicts pain. The term strict is, therefore, taken always in the good sense; severe is good or bad, according to circumstances: he who has authority over others must be strict in enforcing obedience, in keeping good order, and in requiring a proper attention to their duties; but it is possible to be very severe in punishing those who are under us and yet very lax in all matters that our duty demands of us.

Strict may with propriety be applied to one's self as well as others: severe is applied to one's self only to denote selfmortification.

STRICTURE. See ANIMAdversion.

STRIFE, Contention. Strife and contention, derived from the verbs strive and contend (see STrive), have this further distinction, that they are both taken in the bad sense for acts of anger or passion; in this case strife is mostly used for verbal strife, where each party strives against the other by the use of contemptuous or provoking expressions; contention is used for an angry striving with others, either in respect to matters of opinion or matters of claim, in which each party seeks to get the better of the other. Strife is the result of a quarrelsome humor; contention, of a restless, selfish, and greedy humor: strife is most commonly to be found in private life; contention but too frequently mingles itself in all the affairs of men.

See also Discond.

STRIKE, Hit, KNOCK, SMITE, RAP, CuFf, Slap. These words all signify to give a blow to something, but they differ in respect to the kind of blow indicated. Strike, from Anglo-Saxon strican, to go, proceed, allied to German streichen, to stroke, means to give a smooth, swift blow in which the length of something hits another thing. Hit, on the other hand, is a Scandinavian word meaning to light on-to touch quickly and sharply with a point of something. The arrow hits the mark; the pcasant strikes his horse with a stick. These distinctions are not generally observed, but they are certainly implied in the use of the two words. To knock, Anglo-Saxon cnucian, is to strike one thing against another so as to make a sound; it implies the use of something hard and knobby. To rap, from Danish rap, is to knock lightly. To smite, from Anglo-Saxon smilan, meant originally to smear or to rub, and was a sarcastic expression for strike. It implies the use of the flat surface of something in delivering the blow. It is a slightly archaic word in English, with a Biblical flavor, and is the strongest and most energetic of these terms. It implies the overcoming of another with blows. To slap, perhaps an onomatopoic word, is to strike with the flat surface of the hand. To cuff, from the Scandinavian, 
is to strike with the doubled fist, or perhaps with the palm of the hand, implying random, sidelong blows. The distinctions here suggested are not absolute distinctions carefully observed. The words are in many circumstances well-nigh interchangeable, and the meaning of one readily merges into another; but the differences mentioned seem to be implied in the general use of the several terms when they are used most carefully.

See also BEAT.

STRIP. See BEREAVE.

STRIVE, Contend, VIe. Strive comes through Old French estriver, from the Scandinavian. For contend see ConTend. Vie is derived from OId French envier, Latin invitare, meaning to invite to a game, hence to contend in a game.

To strive is the act of individuals without regard to others; as when a person strives to get a living or to improve himself; to contend and vie both denote the act of an individual in reference to others; as to contend in a lawsuit, to vie in dress. To strive may sometimes be applied where there is more than one party, as to strive for the mastery; but in this case the efforts of the individual are more distinctly considered than when we speak of contending for a prize; for this reason these words may be applied in precisely the same connection, but still with this distinction.

Striving consists always of some active effort, as when persons strive at the oar; contending may proceed verbally, as when men contend for their opinions; and vying may be indicated by any expression of the wish to put one's self in a state of competition with another; as persons vie with each other in the grandeur of their houses or equipages.

Contend may be used in a moral application, as to contend with difficulties: and vie may be used figuratively, as one flower may be said to vie with another in the beauty of its colors.

See also Endeavor.

STROKE. See Blow.

STROLL. See WANDER.

STRONG, Robust, Sturdy. Strong is in Anglo-Saxon strang, answering to German streng. Robust, in Latin ro- busius, from robur, signifies, literally, having the strength of oak. Sturdy comes through Middle English sturdi, from Old French estourdi, amazed, of unknown origin. It meant rash, hence the physical frame of one capable of an adventurous deed.

Strong is here the generic term; the others are specific, or specify strength under different circumstances; robust is a positive and high degree of strength arising from a peculiar bodily make: a man may be strong from the strength of his constitution, from the power which is inherent in his frame; but a robust man has strength from both the size and texture of his body, in. bone and nerve he is endowed with great power. A little man may be strong, although not robust; a tall, stout man, in full health, may be termed robust. A man may be strong in one part of his body and not in another; he may be stronger at one time, from particular circumstances, than he is at another: but a robust man is strong in his whole body; and, as he is robust by nature, he will cease to be so only from disease.

Sturdiness lies both in the make of the body and the temper of the mind: a sturdy man is capable of making resistance, and ready to make it; he must be naturally strong, and not of slender make, but he need not be robust: a sturdy peasant presents us with a man who, both by nature and habit, is formed for withstanding the inroads of an enemy.

Things as well as persons may be said to be strong, as opposed to the weak; as a strong rope, a strong staff : robust and sturdy are said only of persons or things personal; as a robust make, a robust habit; a sturdy air, a sturdy stroke.

See also Cogent; Herculean.

STRUCTURE. See EDIFICE.

STRUGGLE. See Endeavor.

STUBBORN. See OBstinate.

STUDY. See ATtention.

STUPID, DuLc. Stupid, in Latin stupidus, from stupere, to be amazed or bewildered, expresses an amazement which is equivalent to a deprivation of understanding: dull, Anglo-Saxon dol, foolish, is connected with the German toll, and denotes a simple deficiency. Stupidity in its proper sense is natural to a man, although a par- 
ticular circumstance may have a similar effect upon the understanding; he who is questioned in the presence of others may appear very stupid in that which is otherwise very familiar to him. Dull is an incidental quality, arising principally from the state of the animal spirits: a writer may sometimes be dull in a large circle, while he is very lively in private intercourse.

See also Doll.

STURDY. See Strong.

STUTTER. See Hesitate.

STYLE. See Diction; NaMe.

SUAVITY, URBANITY. Suavity is, literally, sweetness; and urbanity the refinement of the city, in distinction from the country: inasmuch, therefore, as a polite education tends to soften the mind and the manners, it produces suavity; but suavity may sometimes arise from natural temper, and exist, therefore, without urbanity; although there cannot be urbanity without suavily. By the suavity of our manners we gain the love of those around us; by the urbanity of our manners we render ourselves agreeable companions: hence also arises another distinction, that the term suavity may be applied to other things, as the voice or the style; but urbanity to manners only.

SUBDUE. See Conquer; OverBEAR; QUelL; SUbJECT.

SUBJECT, Liable, Likely, ExPosed, Obnoxious. Subject, in Latin subjectus, participle of subicere, to cast under, signifies thrown underneath. Liable is compounded with the suffix able, from Old French lier, to tie, Latin ligare. Exposed is the participle of the verb expose, from Latin $e x$, and French poser, for the derivation of which see Compose. Obnoxious, in Iatin obnoxi$u s$, compounded of $o b$, on account of, and noxius, hurtful, signifies in the way of hurting.

All these terms are applied to those circumstances in human life by which we are affected independently of our own choice. Direct necessity is included in the term subject; whatever we are obliged to suffer, that we are subject to; we may apply remedies to remove the evil, but often in vain: liable conveys more the idea of casualties; and likely that of mere proba- bility; we are likely to encounter good fortune, but are liable to incur disasters: we may suffer that which we are liable to, but we may also escape the evil if we are careful: exposed conveys the idea of a passive state, into which we may be brought either through our own means or through the instrumentality of others; we are exposed to that which we are not in a condition to keep off from ourselves; it is frequently not in our power to guard against the evil: obnoxious signifies properly exposed to the harm of anything; as obnoxious to the multitude, that is, exposed to their resentment: a person may avoid bringing himself into this state, but he cannot avoid the consequences which will ensue from being thus involved. We are subject to disease or subject to death; this is the irrevocable law of our nature: delicate people are liable to catch cold; all persons are liable to make mistakes: a person is exposed to insults who provokes the anger of a low-bred man: a minister sometimes renders himself obnoxious to the people.

Subject, liable, and exposed may be applied to things as well as persons, with a similar distinction: things are subject by nature, as subject to decay; liable by accident, as liable to be broken; exposed by situation, or for want of protection, as exposed to the cutting winds. Obnoxious is said only of persons or that which is personal.

To subject and expose, as verbs, are taken in the same sense: a person subjects himself to impertinent freedom by descending to unseemly familiarities with his inferiors; he exposes himself to the derision of his equals by an affectation of superiority.

Subject, Subordinate, Inferior, Subservient.-Subject (see above). Subordinate, compounded of $s u b$ and ordinem, signifies to be in an order that is under others. Inferior, in Latin inferior, is the comparative of inferus, low, which has no relation to infero, to cast into. Subservient, compounded of sub and servio, signifies serving under something else.

These terms may express either the relation of persons to persons or things or of things to things. Subject in the first ease respects the exercise of power; subordinate is said of the station and 
office; inferior, either of a man's outward circumstances or of his merits and qualifications; subservient, of one's relative services to another, but always in a bad sense. According to the law of nature, a child should be subject to his parents: according to the law of a realm, he must be subject to his prince: the good order of society cannot be rightly maintained unless there be some to act in a subordinate capacity: men of inferior talent have a part to act which, in the aggregate, is of no less importance than that which is sustained by men of the highest endowments: men of no principle or character will be most subservient to the base purposes of those who pay them best. It is the part of the ruler to protect the subject, and of the subject to love and honor the ruler: it is the part of the exalted to treat the subordinate with indulgence, and of the latter to show respect to those under whom they are placed: it is the part of the superior to instruct, assist, and encourage the inferior; it is the part of the latter to be willing to learn, ready to obey, and prompt to execute. It is not necessary for any one to act the degrading part of being subservient to another.

In the second instance subject has the same sense as in the preceding article, when taken in the relation of things to things; subordinate designates the degree of relative importance between things: inferior designates every circumstance which can render things comparatively higher or lower; subservient designates the relative utility of things under certain circumstances, but not always in the bad sense. All things in this world are subject to change: matters of subordinate consideration ought to be entirely eliminated when any great object is to be attained: things of inferior value must necessarily sell for an inferior price: there is nothing so insignificant that it may not be made subservient to some purpose.

Subject, Subjugate, Subdue.-Subject signifies to make subject. Subjugate, from jugum, a yoke, signifies to bring under the yoke. Subdue (see CoNQUER).

Subject is here the generic, the two other specific terms: we may subject either individuals or nations; but we subjugate only nations. We subject ourselves to reproof, to inconvenience, or to the influence of our passions; one nation subjugates another: subjugate and subdue are both employed with regard to nations that are compelled to submit to the conqueror: but subjugate expresses even more than subdue, for it implies to bring into a state of permanent submission; whereas to subdue may be only a nominal and temporary subjection: Cæsar subjugated the Gauls, for he made them subjects of the Roman Empire: but Alexander subdued the Indian nations, who revolted after his departure.

See also MatTER; OBJEct; Topic.

SUBJECTION. See Thraldom.

SUBJOIN. See AFFIx.

SUBJUGATE. See SUbJEct.

SUBLIME. See Gorgeous; GranDeUR; Great; Magnificence; MaJestic; SPlendor; SUPERB; Thrill.

SUBMARINE, S U B M ER S BLE, U-BOAT. These words do not differ in meaning, but there is a slight variation in their usage and application. They all indicate a boat propelled entirely under water. In the hands of the Germans, in the European war, the submarine became an exceedingly dangerous and lawless mode of offence, and the source of an infinite complication of international relations which eventually brought the United States into the war and necessitated a reconsideration of all the laws of honorable warfare and international usage. Submarine is the most general term. It means, literally, "under-sea" craft, from Latin sub, under, and mare, sea. Submersible is a descriptive term sometimes substituted for submarine, especially by newspaper reporters anxiously in search of something to break the monotony of the endless repetition of a term to which the war gave such a general currency. It means a boat that submerges or dips under the water, from Latin $s u b$, under, and mergere, to dip. U-boat, a semi-transcription, semitranslation of the German $U$ or Unterseeboote, was originally applied to German submarines of the type of the U-53 which visited the shores of the United States in the autumn of 1916, and attacked ships of the Allies 
lying just beyond the three-mile line. In popular usage it was soon applied to all German submarines armed to attack the ships of the Allies.

SUBMISSIVE. See CoMPLIANT; Humble; Obedient; Patient.

SUBMIT. See COMPLY.

SUBORDINATE. See SUbJECT.

SUBORN. See Forswear.

SUBSERVIENT. See SUBJECT.

SUBSIDE, ABate, INTERMit. Subside, from the Latin sub and sedeo, signifies to settle to the bottom. Abate (see that word). Intermit, from the Latin inter and mitto, signifies to leave a space or interval between.

A settlement after agitation is the peculiar meaning of subside. That which has been put into commotion subsides: heavy particles subside in a fluid that is at rest, and tumults are said to subside: a diminution of strength characterizes the meaning of abate; that which has been high in action may abate; the rain abates after it has been heavy, and a man's anger abales: alternate action and rest is implied in the word intermit; whatever is in action may sometimes cease from action; labor without intermission is out of the power of man.

SUBSIST. See BE.

SUBSISTENCE. See LIVElithood.

SUBSTANTIAL, Solid. Substantial, based on $s u b$, under and stare, to stand, signifies to be present, to exist, and hence having a substance: solid, from Latin solidus, based on solum, the ground (which meant originally that which is whole, entire), signifies having a firm foundation. The substantial is opposed to that which is thin and has no consistency: the solid is opposed to the liquid or that which is of loose consistency. All objects which admit of being handled are in their nature substantial; those which are of so hard a texture as to require to be cut are solid. Substantial food is that which has a consistency in itself and is capable of giving fulness to the empty stomach: solid food is meat in distinction from drink: so substantial beings are such as consist of flesh and blood, and may be touched, in distinction from those which are airy or spiritual: the earth is solid which is so hardened as not to yield to pressure.
So in the moral application, the substantial is opposed to that which exists in the mind only and which is frequently fictitious; as a substantial benefit, as distinguished from that which gratifies the mind: the solid is that which rests on reason and has the properties of durability and reality, as a solid reputation.

SUBSTANTIATE. See Ratify.

SUBSTITUTE. See Change.

SUBTERFUGE. See Evasion.

SUBTLE. See CunNing.

SUBTRACT. See DEDUCT.

SUBVERT. See OVERTURN.

SUCCEED. See FolLOW.

SUCCESS. See TruUMPH.

SUCCESSFUl. See Fortunate.

SUCCESSION, SERIES, ORDER. Succession, signifying the act or state of succeeding (see Follow), is a matter of necessity or casualty: things succeed each other, or they are taken in succession either arbitrarily or by design: the series (see that word) is a connected succession; the order (see Place), the ordered or arranged succession. We observe the succession of events as a matter of curiosity; wc trace the series of events as a matter of intelligence; we follow the order which the historian has pursued as a matter of judgment; the succession may be slow or quiek; the series may be long or short; the order may be correct or incorrect. The present age has afforded a quick succession of events, and presented us with a series of atrocious attempts to disturb the peace of society under the pretence of self-protection. The historian of these times needs only pursuc the order which the events themselves point out.

Successive, Allernate. -What is successive follows directly; what is allernate follows indirectly. A minister preachessuccessively who preaches every Sunday uninterruptedly at the same hour; but he preaches allernately if he preaches every other Sunday, or on one Sunday in the morning and the other Sunday in the afternoon, at the same place. The successive may be accidental or intentional; the alternale is always intentional; it may rain for three successive days or a fair may be held for thinee successive days: trees are placed sometimes in alternate order 
when every other tree is of the same size and kind.

SUCCINCT. See SHort.

SUCCOR. See Help.

SUDDEN, Abrupt, Precipitate. Sudden, from Old French sodain, Low Latin subitanus (for subitaneus), Latin subitus, is derived ultimately from Latin subire, past participle subitus, meaning to come upon one by stealth, to arrive or go unexpectedly. It denotes that which happens quickly and unexpectedly. Abrupt and precipitate express the same idea under a metaphor. Abrupt (see AвRUPT) means literally "broken off"- something so unrelated to other things that it seems like something suddenly broken off. An abrupt movement is a sudden movement with a certain sharpness and decisiveness in the suddenness. Precipitate, from Latin pro, before, and cipiti, the stem of proceps, based on caput, head, means literally head-foremost. It refers to something that is not merely sudden, but is a little ahead of time.

SUFFER. See ADMIT; BEAR; Leave; Tolerate; , Undergo.

SUFFICIENT. See ENovgh.

SUFFOCATE, Stifle, SMother, CHоке. Suffocate, in Latin suffocatus, participle of suffocare, compounded of $s u b$ and faux, throat, signifies to constrain or tighten the throat. For stifle and smother see STIFLE. Choke, from Middle English choken, is allied to Icelandic koka, to gulp, and kok, the throat.

These terms express the act of stopping the breath, but under various circumstances and by various means; suffocation is produced by every kind of means, external or internal, and is therefore the most general of these terms; stifling proceeds by internal means, that is, by the admission of foreign bodies into the passages which lead to the respiratory organs: we may be suffocated by excluding the air externally, as by gagging, confining closely, or pressing violently: we may be suffocated or stifled by means of vapors, close air, or smoke. To smother is to suffocate by the exclusion of air externally, as by means of any substance with which one is covered or surrounded, as smoke, dust, and the like: to choke is a mode of stifling by means of large bodies, as by a piece of food lodging in the throat.

To choke, in an extended and figurative sense, is to interrupt the action of any body by the intervention of any foreign substance, as a garden is choked with weeds; to stifle is altogether to put a stop or end to a thing by keeping it down, as to stifle resentment, sighs, etc.: to smother is to choke or prevent free action by covering or surrounding, as good resolutions are smothered by unruly desires or appetites.

SUFFOCATION. See Asphyxia.

SUFFRAGETTE. See Vote.

SUGGEST. See Allude; Hint.

SUGGESTION. See Dictate.

SUIT. See Agree; Fit; Prayer; TALLY.

SUITABle. See Becoming; Conformable; Convenient; CorresponDENT.

SUITOR. See LOVER.

SULLY. See Stain.

SUMMARY. See ABRIDGMENT; SHORT.

SUMMON. See Call; Cite.

SUNDAY. Sae Sarbath.

SUNDRY. See DIFFERENT.

SUPERB, August, Stately. These words have in common the idea of pride and dignity and external splendor. Superb, from Latin superbus, proud, is often used simply as a general superlative. It means excellent, with a special emphasis upon that which is externally striking and complete. August is derived from the name of the Roman Cresars, Augustus. It denotes that which is impressive and aweinspiring in the last degree - a union of dignity and power both unlimited. In this sense we speak of the august power of God, etc. Stately means full of state, something full of dignity, with special emphasis upon the idea of stability and endurance. It does not denote the complete and striking impression produced by that which is superb nor the awe inspired by that which is august, but lays a greater emphasis upon the single impression of external and stable dignity.

SUPERFicial, Shallow, Flimsy. The superficial is that which lies only at the surface; it is therefore by implication the same as the shallow, which has nothing underneath. Hence a 
person may be called either superficial or shallow to indicate that he has not a profundity of knowledge; but, otherwise, superficiality is applied to the exercise of the thinking faculty and shallowness to its extent. Men of freely expressed sentiments may be superficial thinkers, although they may not have understandings more shallow than others. Superficial and shallow are applicable to things as well as persons: flimsy is applicable to things only. Flimsy (from Welsh llymsi? ef. the American dialect word limsy; or perhaps connected with $f(m)$ is a modern word. In the proper sense we may speak of giving a superficial covering of paint or color to a body; of a river or piece of water being shallow; of cotton or cloth being flimsy.

In the improper sense, a survey or a glance may be superficial which does not extend beyond the superficies of things; a conversation or a discourse may be shallow which does not contain a basis of sentiment; and a work or performance may be flimsy which has nothing solid in it to engage the attention.

SUPERfICIES. See SURface.

SUPERFLUITY. See ExcEss.

SUPERINTENDENCY. S e INSPECTION.

SUPERIORITY. See ExcELlENCE. SUPERSCRIPTION. See DIRECTION.

SUPERSEDE. See OverRULE.

SUPINE. See INDOLENT.

SUPPLE. Sec FleXIBLE.

SUPPLICATE. Sce BEg.

SUPPLY. See Provide.

SUPPORT. See Bear; CounteNANCE; Espouse; Hold; Livelihood; Second; Staff; Sustain; Uphold.

SUPPOSE. Sec APPREHEND; THINK. SUPPOSITION. See Conjecture. SUPPOSITITIOUS. Sce Spurious. SUPPRESS. See QUELl; RePrEss; STIFLE.

SUPReme, Predominant, PreEMINENT. All these words mean surpassing in power or in importance. Predominant, from Latin pro, above, before, and dominari, to rule, meant ruling over others. Pre-eminent, from Latin pro, and eminere, to project, means projecting beyond others. Preeminent indicates a state of being, pre- dominant one of action. At the same time pre-eminent is a stronger word than predominant. That which is predominant asserts its power over others, that which is pre-eminent stands out so that all see and recognize the superiority. Pre-eminent implies a more lasting superiority than predominant, which implies a state of struggle in which the first place may be yielded to another. Supreme, from Latin supremus, means holding the first place of all, beyond rivalry and comparison, possessing neither a superior nor an equal. It expresses the highest possible degree of pre-eminence.

SURE. See Certain; Infallible. SURFACE, SUPERFICIEs. Surface, compounded of French sur, for super, and face, from faciem, is a variation of the Latin term superficies; and yet they have acquired this distinetion, that the former is the current and the latter the scientific term; of course the former has a more indefinite and general application than the latter. A surface is either even or uneven, smooth or rough; but the mathematician always conceives of a plane superficies on which he founds his operations.

Surface, in its moral application, is extended to whatever presents itself first to the mind of the observer.

Superficies may bc applied in its proper and definite sense to other objects than those which relate to science.

SURGE. See Wave.

SURMISE. Sce CoNJecture.

SURMOUNT. See CoNQUER.

SURPASS. Se EXCEED.

SURPRISE. See SUDDEN; WONDER.

SURRENDER. See GIVE UP.

SURROUND, ENCOMPASS, ENviron, Excircle. Surround, from Old French suronder, meant originally to overflow, from super, over, and unda, a wave. Encompass is compounded of French er, in, and compas, from Low Lat in compassus, a circle or circuit, and meaning a going around in a cirele till the last step ends where the first began. To encompass is to enclose in a circle. Environ comes from Old French $\mathrm{cr}$, in, and virer, to turn, whence veer is derived. Encircle means to enclose within a circle. Blockade is formed, with the suffix ade, from block, derived through old 
French from Dutch. It now means a blocking of the coasts of a hostile country by encompassing it with ships which prevent merchant-vessels from getting through with supplies; but it has been used to signify any blocking up of all exit or entrance by surrounding troops or fortifications.

Surround is the most literal and general of all these terms, which signify to enclose any object either directly or indirectly. We may surround an object by standing at certain distances all round it; in this manner a person may be surrounded by other persons, and a house surrounded with trees, or an object may be surrounded by enclosing it in every direction and at every point; in this manner a garden is surrounded by a wall. To encompass is to surround in the latter sense, and applies to objects of a great or indefinite extent: the earth is encompassed by the air, which we term the atmosphere; towns are encompassed by walls. To surround is to go round an object of any form, whether square or circular, long or short; but to environ and to encircle carry with them the idea of forming a circle round an object; thus a town or valley may be enironed by hills, a basin of water may be encircled by trees, or the head may be encircled by a wreath of flowers.

In an extended or moral sense we are said to be surrounded by objects which are in great numbers and in different directions about us: thus a person living in a particular spot where he has many friends may say he is surrounded by his friends, or environed by objects in such manner that he cannot escape from them; so likewise a particular person may say that he is surrounded by dangers and difficulties: but, in speaking of man in a general sense, we should rather say he is encompassed by dangers, which expresses in a much stronger manner our peculiarly exposed condition.

Blockade may be figuratively applied to any cutting off of supplies.

SURVEY. See RETROSPECT; VIEW.

SURVIVE. See OuthIVE.

SUSCEPTIBILITY. See FeELING.

SUSPENSE. See DoubTs.

SUSPICION. See Distrust; JealOUSY.
SUSTAIN, Support, Maintain. Sustain, from Old French sustenir, compounded of sus or sub and tenere, to hold, signifies to hold or keep up. Support (see Countenance). Maintain (see AssERT).

The idea of keeping up or preventing from falling is common to these terms, which vary either in the mode or object of the action. To sustain and support are frequently passive, maintain is always active. To sustain and support both imply the bearing or receiving the weight of any object, the former in reference to any great weight, the latter to any weight however small.

Sustain and support may also imply an active exercise of power or means which brings them still nearer to maintain; in this case sustain is an act of the highest power, support of any ordinary power.

So in bearing up against any opposing force; but support is here an act for the benefit of others; maintain is an act for one's own benefit, as to sustain a shock, to support one another in battle; to maintain one's self in a contest.

Existence is said to be sustained under circumstances of weakness or pressure; it is supported by natural means, as the milk of the mother supports the babe; or indirectly by what supplies the means, as to support one's family by labor: what is maintained is upheld by pecuniary means, as to maintain a family, a fleet, etc.

In the moral application, what presses on the mind is sustained, or supported, with the like distinction: grievous losses or injuries are sustained; afflictions and disappointments supported.

Things are supported and maintained voluntarily; the former in respect to what is foreign to us, as to support an assumed character, the latter in respect to what belongs to us, as to maintain one's own character.

SUSTENANCE. See LIVELIHOOD.

SWAIN. See Countryman.

SWALLOW. See ABsorb.

SWAY. See INFLUENCE; WILL.

SWEAR, TAKe OATH, Testify. Swear, from Anglo-Saxon swerian, originally meant simply to speak loudly; it is the stem found in answer. 
It now means to affirm by an appeal to the powers recognized as holy, to assert in the name of God. To take oath (from Anglo-Saxon ath) means to swear formally by going through the ceremony of taking an oath or making an appeal to God. To take oath is a somewhat more exact and specific term than swear, but it means the same thing. To testify, from Latin testes, a witness, and a weakened form of facere, to make, means literally to make, or bear witness. It is associated with swear and take oath through the fact that a formal bearing of witness is preceded by an oath.

SWELl. See Heave.

SWERVE. See Deflect; Deviate. SWIFTNESS. See QUICKNESS.

SWING. See WAG.

SWOLlEN. See High-Flown.

SYCOPHANT: See FlatTERER.

SYLLABUS, Srnopsis. A syllabus, from Late Latin syllabus, Late Greek $\sigma \dot{v} \lambda \lambda \alpha \beta o s$, a list, allied to $\sigma v \lambda \lambda \alpha \beta \dot{\eta}$, a syllable, literally "that which holds together," from Greek oviv, together, and the aorist stem of $\lambda \alpha \mu \beta a \dot{\nu \varepsilon t \nu}$, to take, is an outline or summary of the main points of a subject, course, lecture, or treatise. A synopsis, from Greek ov'v, together, ơ $\psi$ เs, sight, is a complete view of the subject in a brief space. The two words have almost the same meaning, but synopsis emphasizes the summing up, the inclusion of everything in a little space, and syllabus emphasizes the outlining of the points to be made. A syllabus of a course of lectures, for example, is the outline distributed beforehand. The synopsis of a lecture may be given in the newspaper afterward. But synopsis is often used interchangeably with syllabus, though syllabus cannot always take the place of synopsis.

SYMBOL. See Figure.

SYMMETRY, Proportion. Symmetry, in Latin symmetria, Greek $\sigma v \mu \mu \varepsilon \tau \rho i a$, from $\sigma \dot{\nu} \nu$ and $\mu \dot{\varepsilon} \tau \rho o \nu$, signifies a measure that accords. Proportion, in Latin proportio, compounded of pro, as regards or in relation to, and portio, a part, signifies every portion or part according with the other or with the whole.

The signification of these terms is obviously the same, namely, a due admeasurement of the parts to each other and to the whole: but symmetry has now acquired but a partiat-application to the human body or to things nicely fitting each other; and proportion is applied to everything which admits of dimensions and an adaptation of the parts: hence we speak of symmetry of feature; but proportion of limbs, the proportion of the head to the body.

SYMPATHY, COMPASSION, COMMiseration, CoNDOLENCE. Sympalhy, from the Greek $\sigma \dot{v} \mu$ for $\sigma \dot{v} \nu$, with, and $\pi \dot{a} \theta \varepsilon t a$, feeling, has the literal meaning of fellow-feeling, that is, a kindred or like feeling or feeling in company with another. Compassion (see PITY); commiseration, from the Latin cum, with, and miserari, to pity; condolence, from the Latin con and dolere, to grieve, signify a like suffering or a suffering in company. Hence it is obvious that, according to the derivation of the words, the sympalhy may be said either of pleasure or pain, the rest only of that which is painful. Sympathy preserves its original meaning in its application, for we laugh or ery by sympathy; this may, however, be a merely physical operation.

Compassion is altogether a moral feeling which makes us enter into the distresses of others: we may, therefore, sympathize with others, without essentially serving them; but if we feel compassion we naturally turn our thoughts toward relieving them

Sympathy, indeed, may sometimes be taken for a secret alliance or kindred feeling between two objects.

Compassion is awakened by various kinds of suffering, but particularly by those which are attributable to our misfortunes; commiseration is awakened by suffering arising from our faults; condolence is awakened by the troubles of life, to which all are equally liable. Poverty and want excite our compassion; we endeavor to relieve them: a poor eriminal suffering the penalty of the law excites our commiseration; we endeavor, if possible, to mitigate his punishment: the loss which a friend sustains produces condolence; we take the best means of testifying it to him.

Compassion is the sentiment of one 
mortal toward another; commiseration is represented as the feeling which our wretchedness excites in the Supreme Being. Compassion may be awakened in persons of any condition; commiseration is awakened toward those who are in an abject state of misery; condolence. supposes an entire equality and is often produced by some common calamity.

SYMPTOM. See MARK.

SYNCHRONOUS, SimULTANEOUS, Contemporaneous. These words all mean occurring at the same time. Simultaneous, from Late Latin simult$\mathrm{im}$, at the same time, contaminated by Latin moment-aneous, means occurring at exactly the same instant. Synchronous, from Greek oúv, together, and крóvos, time, means happening within the same period of time, but not necessarily at exactly the same instant. Synchronous and simultaneous are applied to occurrences; contemporaneous to both events and people. Contemporaneous' comes from Latin con, for cum, together, and tempus, time; it means living or happening within the same period, the period being thought of not merely as a division of time, as in the case of synchronous, but as an age, a generation, a period marked by certain characteristics distinguishing it from other periods.

SYNOD. See AsSEMBLY.

SYNTHETIC, CoNsTRUCTIVE. Synthetic, from Greek ov́v, with, and $\theta \varepsilon \tau \iota \kappa o ́ s$, skilled in putting together, from $\sigma \nu \nu \theta \varepsilon ́ \tau \eta s$, a putter-together, and constructive, from Latin con, together, and structus, the past participle of struere, a heaping up, both mean putting together. Synthetic is opposed to analytic, and constructive to destructive. Synthetic refers merely to an intellect- ual process, constructive to moral attitude and practical building up. Synthetic is more limited in its application, but more exact within its own field. It means putting together the constituent elements of a conception in such a way as to form an intellectual whole, a single idea. Constructive means in general building up. Constructive criticism is that which not merely destroys an old method or standard, but builds up a new one. Constructive social work is that which builds up a new order of society instead of merely destroying what was bad in the old régime. It implies active creation, which is not necessarily purely intellectual, and is often consciously opposed to the idea of destructive.

SYSTEM, MEтноD. System, in Latin systema, Greek $\sigma v \sigma \tau \eta \mu \alpha$, from

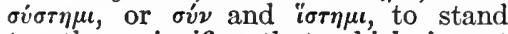
together, signifies that which is put together so as to form a whole. Method, in Latin methodus, is from the Greek $\mu \varepsilon \theta^{\prime}$, for, $\mu \varepsilon \tau \alpha^{\prime}$, after, and $\delta \delta o s$, a way, the literal sense thus being a way after, or a way by which anything is effected.

System expresses more than method, which is but a part of system: system is an arrangement of many single or individual objects according to some given rule, so as to make them coalesce; method is the manner of this arrangement, or the principle upon which this arrangement takes place. The term system, however, applies to a complexity of objects, but arrangement, and consequently method, may be applied to everything that is to be put into execution. All sciences must be reduced to system; and without system there is no science: all business requires method; and without method little can be done to any good purpose. 
TACIT. See Silent.

TACITURNITY. See Silence.

TaCTICS, Generalship, MangevRING, Strategy. Tactics, from Greek rakrıkís, fit for arranging, means the art of handling troops on the field of

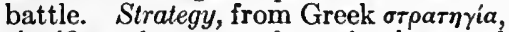
signifies the art of projecting and planning a military movement. Strategy represents an intellectual achievement; tactics, a practical carrying out of that which has been directed by strategy. Manouvring, through French, from Late Latin man( $u$ )opera, a working with the hand (manus, hand, and opera, work), means the making of adroit or artful moves on the field of battle, the control of the troops in such a way as to bring about a desired result. It differs from tactics in emphasizing simply skilful movement.

TACTILE. See TaNGible.

TAINT. See Atraint; ContamiNATE.

TAKE, Recerve, Accept. Take, Middle English taken, is a Scandinavian word signifying to lay hold of. Receive, in Old French recever, Latin recipere, from re, back, and a weakened form of capere, to take, signifies to take back; and accept, from accipere, of a similar derivation ( $a c=\mathrm{ad}$, for), signifies to take for a special purpose.

To take is the general term, receive and accept are modes of taking. To take is an unqualified action; we take whatever comes in the way; we receive only that which is offered or sent: we take a book from a table; we receive a parcel which has been sent; we take either with or without consent; we receive with the consent, or aceording to the wishes, of another: a robber takes money from a traveller; a person receives a letter from a friend.

To receive is frequently a passive act; whatever is offered or done to another is received; but to accept is an act of choice: many things, therefore, may be received which eannot be accepled; as a person receives a blow or an insult: so in an engagement one may be said to receive the enemy, who is ready to receive his attack; on the other hand, we accept apologies.

Some things are both received and accepted, but with the same distinction. What is given as a present may be both received and accepted, but the inferior receives and the superior accepts. What is received comes to a person either by indirect means or, if by direct means, it comes as a matter of right; but what is accepted is a matter of favor either on the part of the giver or receiver. Rent in law may be both received and accepted; it is received when it is due from the tenant after he has broken his contract with his landlord. A challenge may be received contrary to the wishes of the receiver, but it rests with himself whether he will accept it or not.

Animals and things, as well as persons, may take; things may receive; but persons only accept. An animal may take what is offered to it; things take whatever attaches to them, but they receive that which by an express effort is given to them. The chameleon is said to take its hue from the surrounding objects; marble receives its polish from the hands of the workman.

TAKE OATH. See Swear.

TALE. See FABLE; Story.

TALENT. See AbILITY; Girt; INTELLECT.

TALK. See Speak.

TALKative, Loquaciods, GarRulous. Talkative, ready or prone to lalk, from Middle English talken, to talk, from talen, to tell tales, AngloSaxon talian, to reckon or compute. Loquacious, from loquari, to speak or talk, has the same original meaning. Garrulous, in Latin garrulus, from garrire, to blab, signifies prone to tell or make known.

These reproachful epithets differ principally in the degree. To talk is allowable, and consequently it is not altogether so unbecoming to be oc- 
casionally talkative; but loquacity, which implies an immoderate propensity to talk, is always bad, whether springing from affection or an idle temper: and garrulity, which arises from the excessive desire of communicating, is a failing that is pardonable only in the aged, who have generally much to tell.

See Voluble.

TALL. See Hrgh.

TALLY, MATCH. A tally was originally a piece of wood (Low Latin talea, French taille) on which notches were cut to indicate number; it was a way of keeping a reckoning. Match comes from the stem found in AngloSaxon gemoecca, a companion. To tally means to correspond exactly with something that serves as a standard of measurement. To match is to be like another thing, to fit something so that the result is a harmonious whole. It is therefore less specific than tally. Tally indicates an exact correspondence, one that satisfies the desire for accurate knowledge. Match may refer to a correspondence that merely satisfies the taste.

TAME. See Gentre.

TANGIBLE, Obvrous, Real. Tangible means literally touchable, that which can be handled, from Latin tangere, to touch. Obvious, from Latin $o b$, opposite, and via, way, means lying in the way of. A tangible object is not necessarily obvious nor an obvious one tangible, but the two words have in common the idea of easily perceived. In the one case the means of perception is the sense of touch; in the other case it may be any of the senses, but especially the sense of sight. Tangible is used figuratively to denote anything that may be readily grasped by the mind and proved to exist; in this sense we speak of a tangible reason, of tangible evidence, etc. Real, from Low Latin realis, derived from res, thing, and a suffix, is applied to those things which have an actual existence. Where the proof of existence is thought to be demonstrable by the senses, real means having a physical form.

TANTALIZE. See AgGRAVATE; Tease.

TARDY. See Slow.

TARNISH. See StaIN.
TARRY. See LINGER.

TARTNESS. See ACRIMONY.

TASK. See Work.

TASTE, Flavor, Relish, Savor. Taste comes from the Teutonic tasten, to touch lightly, and signifies either the organs which are easily affected or the act of discriminating by a light touch of the organ or the quality of the object which affects the organs; in this latter sense it is closely allied to the other terms. Flavor most probably comes through Old French fleür, flaür, from the Latin flare, to blow, to breathe, signifying the rarefied essence of bodies which affect the organ of taste. Relish was originally an after-taste, from Old French reles, that which is left behind, from relaxare, to loosen, to allow to rest, to leave behind. Savor comes through French from Latin sapor, smell, taste, the $v$ being analogical from savor.

Taste is the most general and indefinite of all these; it is applicable to every object that can be applied to the organs of taste, and to every degree and manner in which the organs can be affected: some things are tasteless, other things have a strong taste, and others a mixed taste. The flavor is the predominating taste and consequently is applied to such objects as may have a different kind or degree of taste; an apple may have not only the general taste of apple, but also a flavor peculiar to itself; the flavor is commonly said of that which is good; as a fine flavor, a delicious flavor; but it may designate that which is not always agreeable; as the flavor of fish, which is unpleasant in things that do not admit of such a taste. The relish is also a particular taste; but it is that which is artificial, in distinction from the flavor, which may be the natural property. We find the flavor such as it is; we give the relish such as it should be or as we wish it to be: milk and butter receive a flavor from the nature of the food with which the cow is supplied: sauces are used in order to give a relish to the food that is dressed with them.

Savor is a term in less frequent use than the others, but, conforming to the Latin derivation, it is employed to designate that which smells as well as tastes, a sweet-smelling savor; so like- 
wise, in the moral application, a man's actions or expressions may be said to savor of vanity.

Taste and relish may be, moreover, compared as the act or power of tasting or relishing: we taste whatever affects our taste, but we relish that only which pleases our taste: we taste fruits in order to determine whether they are good or bad; we relish fruits as a dessert or at certain seasons of the day.

So in the extended or moral application, the words are distinguished in the same manner.

Taste, Genius. - Taste, in another sense, designates the capacity to derive pleasure from an object: genius designates the power we have for accomplishing any object. He who derives particular pleasure from music may be said to have a taste for music; he who makes very great proficiency in the theory and practice of music may be said to have a genius for it. It is obvious, therefore, that we may have a taste without having genius; but it would not be possible to have genius for a thing without having a taste for it: for nothing can so effectually give a taste for any accomplishment as that capacity to learn it and that susceptibility to all its beauties, which are circumstances inseparable from genius.

TAUBE. See Aircraft.

TAUNT. See TEase; Twit.

TAUTOLOGY. See REPETITION.

TAX, DUTy, Custon, TOLL, Impost, Tribute, Contribution. The idea of something given by the people to the government is expressed by all these terms. Tax comes through French from the substantive based on Late Latin taxare (ultimately from tangere), to touch, to handle, also to rate, value, appraise, whence Low Latin taxa, a tax, signifying the handling and appraising of valuables. Custom signifies that which is given under certain circumstances, according to custom, from Old French costume, based on an assumed neuter plural, consuetumina, derived from classical consuetudo, custom. Duty signifies that which is given is a due or debt. Toll, in Anglo-Saxon toll, etc., Low Latin tolonium, classical teloneum, Greek ré̉ ${ }^{\prime}$, a custom, signifies a particular kind of custom or due.

Tax is the most general of these terms, and applies to or implies whatever is paid by the people to the government, according to a certain estimate: the customs are a species of tax which are less specific than other laxes, being regulated by custom rather than any definite law; the customs apply particularly to what was customarily given by merchants for the goods which they imported from abroad: the duty is a species of $\operatorname{tax}$ more positive and binding than the custom, being a specific estimate of what is due upon goods, according to their value; hence it is not only applied to goods that are imported, but also to many other articles inland: toll is that species of tax which serves for the repair of roads and havens, or the liberty to buy or sell at fairs or other places.

The preceding terms refer to that which is levied by authority on the people; but they do not directly express the idea of levying or paying: impost, on the contrary, signifies, literally, that which is imposed; and tribute that which is paid or yielded; the former, therefore, exclude that idea of coercion which is included in the latter. The tax is levied by the consent of many, the impost is imposed by the will of one, and the tribute is paid at the demand of one or a few: the tax serves for the support of the nation; the impost and the tribute serve to enrich a government. Conquerors lay heavy imposts upon the conquered countries; distant provinces pay a tribute to the princes to whom they owe allegiance. Contribution signifies the tribule of many in unison or for the same end; in this general sense it includes all the other terms; for taxes and imposts are paid alike by many for the same purpose; but, as the predominant idea in contribution is that of common consent, it supposes a degree of freedom in the agent which is incompatible with the exercise of authority expressed by the other terms: hence the term is with more propricty applied to those cases in which men voluntarily unite in giving toward any particular object, as charitable contributions, or contributions in support of a war; but it may be taken in the general sense of a forced payment, as in speaking of military contribution. 
These words, tax, tribute, and contribution, have an extended application to other objects besides those which are pecuniary: tax, in the sense of what is laid on without the consent of the person on whom it is imposed; tribute, that which is given to another as his due; and contribution, that which is given by one in common with others for some common object.

Tax, Rate, Assessment.-Tax, according to the above explanation, and rate, from the Latin ratus and reor, to think or estimate, both derive their principal meaning from the valuation or proportion, according to which any sum is demanded from the people; but the tax is imposed directly by the government for public purposes, as the land-tax and the window-tax; and the rate is imposed indirectly for the local purposes of each parish, as the church-rates, and the poor-rates. The tax or rate is a general rule or ratio by which a certain sum is raised upon a given number of persons; the assessment is the application of that rule to the individual.

TEACH. See INFORM.

TEAR. See BREAK.

TEARFUL. See LACHRYMaL.

TEASE, Vex, Taunt, Tantalize, Torment. Tease is developed from Anglo-Saxon toesan, to card wool, to pluck or pull, and hence, in a figurative sense, meaning to vex or tease. Vex (see Displease). Taunt is from the French tenter, Latin tentare, to tempt, to try or test. Tantalize (see Aggravate). Torment, from the Latin tormentum and torquere, to twist, signifies to give pain by twisting or griping.

The idea of acting upon others so as to produce a painful sentiment is common to all these terms; they differ in the mode of action and in the degree of the effect. To tease is applied to that which is most trifling; torment to that which is most serious. We are teased by a jocose friend, or we are vexed by the carelessness and stupidity of our servants; we are taunted by the sarcasms of others; we are tantalized by the fair prospects which present themselves only to disappear again; we are tormented by the importunities of troublesome béggars. It is the repetition of unpleasant trifles which teases; it is the crossness and perversity of persons and things which vex; it is the contemptuous and provoking behavior which taunts; it is the disappointment of awakened expectations which tantalizes; it is the repetition of grievous troubles which torments. We are tormented by that which produces bodily or mental pain; we are teased, vexed, taunted, and tantalized only in the mind. Irritable and nervous people are most easily teased; captious and fretful people are most easily vexed or taunted; sanguine and eager people are most easily tantalized: in all these cases the imagination or the bodily state of the individual serves to increase the pain: but persons are tormented by such things as inflict positive pain.

TEDIOUS. See Slow; WearISOME.

TEGUMENT, Covering. Tegument, in Latin tegumentum, from tegere, to cover, is properly but another word to express the sense of covering, yet it is now employed in cases where the term covering is inadmissible. Covering signifies mostly that which is artificial; but tegument is employed for that which is natural; clothing is the covering for the body; the skin of vegetable substances, as seeds, is called the tegument. The covering is said of that which covers the outer surface: the tegument is said of that which covers the inner surface; the pods of some seeds are lined with a soft tegument.

Telescope. See Periscope.

TELL. See SPEAK.

TEMERITY. See Rashness.

TEMPER. See DISPOSITION; FraIIE; HUMOR; QUALIFY.

TEMPERAMENT, TEMPERATURE. Temperament and temperature are both used to express that state which arises from the tempering of opposite or varying qualities; the temperament is said of animal bodies and the temperature of the atmosphere. Men of a sanguine temperament ought to be cautious in their diet; all bodies are strongly affected by the temperature of the air.

See also Frame.

TEMPERANCE. See Modesty.

TEMPERATE. See Abstinent. 
TEMPLE, Church. These words designate an edifice destined for the exercise of religion, but with collateral ideas which sufficiently distinguish them from each other. The templum of the Latins signified originally an open, elevated spot (the name being derived through Latin temulum, from Greek t'́ $\mu \varepsilon \nu o s$, a sacred enclosure, from ré $\mu \nu \varepsilon \imath \nu$, to cut), marked out by the augurs with their lituus, or sacred wand, whence they could best survey the heavens on all sides: the idea, therefore, of spacious, open, and elevated enters into the meaning of this word. The Greek väós, from vaiw, to inhabit, signifies a dwelling-place, and, by distinction, the dwelling-place of the Almighty; in which sense the Hebrew word is also taken to denote the high and holy place where Jehovah peculiarly dwelleth, otherwise called the holy heavens, Jehovah's dwelling or resting-place; whence St. Paul ealls our bodies the temples of God when the Spirit of God dwelleth in us. The Roman poets used the word templum in a similar sense.

The word temple, therefore, strietly signifies a spacious open place set apart for the peculiar presence and worship of the Divine Being: it is applied with particular propriety to the saered edifices of the Jews, but may be applied to any sacred place without distinction of religion.

Church is an interesting word because it seems to have been a term taken over by the northern barbarians into the Teutonic tongues directly from Greek, some time before they were Christianized. There is nothing corresponding to it in Latin, the usual intermediary between Greek and Eng-

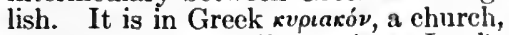
neuter of rvpiaxós (from xípios, Lord), and signifies literally House of the Lord. A church is therefore a building consecrated to the Lord, and from the earliest periods of building churches this was done by some solemn ordinance.

The word church has by a figure of speech been applied to any building consecrated to the service of God.

Church, in the sense of a religious assembly, is altogether a different word, bearing no affinity to the word temple.

\section{TEMPORAL. See SEcUlar.}

TEMPORARY, TrANSIENT, TraNsitory, Fleeting. Temporary, from tempus, time, characterizes that which is intended to last only for a time, in distinction from that which is permanent; offices depending upon a state of war are temporary, in distinction from those which are connected with internal policy: transient, that is, passing, or in the act of passing, characterizes what in its nature exists only for the moment: a glance is transient. Transitory, that is, apt to pass away, characterizes everything in the world which is formed only to exist for a time and then to pass away; thus our pleasures, and our pains, and our very being, are denominated transitory. Fleeting, which is derived from Anglo-Saxon fleotan, to float, is but a stronger term to express the same idea as transitory.

See also Próvisional.

TEMPORIZING. S e e T I M E SERVING.

TEMPT. See Allure; Try.

TENACIOUS, Pertinacious. To be tenacious is to hold a thing close, to let it go with reluctance: to be pertinacious is to hold it out in spite of what can be advanced against it, the prepositive syllable per having an intensive force. A man of a tenacious temper insists on matters which he considers important; one of a pertinacious temper insists on every trifle which is apt to affect his opinions. Tenacily may be a virtue or a viec, depending on circumstances; pertinacity is usually a foible: the former, if reprehensible, is more exeusable than the latter. We may be tenacious of that which is good, as when a man is tenacious of whatever may affect his honor; but we cannot be pertinacious in anything but our opinions, and that, too, in cases when they are least defensible. It commonly happens that people are most tenacious of being thought to possess that in which they are most deficient, and most pertinacious in maintaining that which is most absurd. A liar is tenacious of his reputation for truth: persons of an iconoclastic tendeney are the most pertinacious objectors to whatever is established.

TENDENCY, Drift, Scope, Aim. 
Tendency, from to tend, denotes the property of tending toward a certain point, which is the characteristic of all these words, but this is applied only to things; and drift, from the AngloSaxon drifan, modern English drive, to drive; scope, probably from a Late

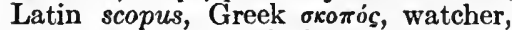
spy, from $\sigma \alpha \dot{\varepsilon} \pi \tau \tau^{\prime} \mu \iota$, look; and aim, from the verb to aim (see that word), all characterize the thoughts of a person looking forward into futurity and directing his actions to a certain point. Hence we speak of the tendency of certain principles or practices as being pernicious; the drift of a person's discourse; the scope which he gives himself either in treating of a subject or in laying down a plan; or a person's aim to excel, or aim to supplant another, and the like. The tendency of many writings in modern times has been to unsettle the opinions of men: where a person wants the services of another, whom he dares not openly solicit, he will reveal his wishes by the drift of his discourse; a man of a comprehensive mind will allow himself full scope in digesting his plans for every alteration which circumstances may require when they come to be developed: our desires will naturally give a cast to all our aims; and, so long as they are but innocent, they are necessary to give a proper stimulus to exertion.

See also InCLINATION.

TENDER. See OFFER.

TENDERFOOT. See UNSOPHISTICATED.

TENDERNESS. Se e BENEVOLENCE.

TENET, Position. The tenet (Latin enet, he holds) is the opinion which we hold in our minds; the position is that which we lay down for others. Our tenets may be hurtful, our positions false. $\mathrm{He}$ who gives up his tenets readily evinces an unstable mind; he who argues on a false position shows more tenacity and subtlety than good sense. The lenets of the different denominations of Christians are scarcely to be known or distinguished, inasmuch as they often rest upon such trivial points: the positions which an author lays down must be very definite and clear when he wishes to build upon them any theory or system. See also Doctrine.

TENOR, Drift, Purport. These words all signify the apparent significance of something, generally of a speech or series of remarks in oral or written form. Purport means the meaning that another is intended to get, the general intent. Tenor and drift express this meaning also under rather obvious metaphors. Tenor comes from Late Latin tenorem, a holding on, and refers to the voice which, in a masculine chorus, carries the air, and hence seems to hold the whole musical composition together. The tenor of a speech is the general theme and meaning, something corresponding to the part of the musical whole which is sustained by the tenor voice. Drift expresses the same idea under a different metaphor. It refers to the movement of a current, which even in moments of deceptive tranquillity, or in a storm which drives the waves before the wind against the current, may be detected by the direction in which floating objects on the surface of the water are drifting or moving. The drift of a speech is the general direction in which its thought seems to be moving, the apparent intention and meaning.

TENTATIVE. See EMPIRICal.

TERM, LIMIT, BoUNdary. Term, in Latin terminus, from the Greek Ti $\rho \mu a$, an end, is the point that ends and that to which we direct our steps: limit, from the stem of the Latin limes, a landmark, is the line which marks. Boundary, from Late Latin bodina, possibly of Celtic origin, is the obstacle which interrupts our progress and prevents us from passing.

We are carried either toward or away from the term; we keep either within limits or we overstep them; we contract or extend a boundary. The term and the limit belong to the thing; by them it is ended: the boundary is that which is made or conceived by the person bounding. The term is the point that terminates; the limit is either a line or point which marks where to stop; the boundary is a line which includes a space and points out the extent beyond which one may not pass. The Straits of Gibraltar was the term of Hercules's voyages: it was 
said, with more eloquence than truth, that the limits of the Roman Empire were those of the world: the sea, the Alps, and the Pyrenees are the natural boundaries of France.

So likewise in application to moral objects. We mostly reach the term of our prosperity when we attempt to pass the limits which Providence has assigned to human efforts: human ambition often finds a boundary set to its gratification by circumstances which were the most unlooked for and apparently the least adapted to bring about such important results. We sec the term of our evils only in the term of our life: our desires have no limits; their gratification only serves to extend our prospects indefinitely: those only are happy whose fortune is the boundary of their desires.

See also Article; Bound; Word. TERMINATE. See END.

TERRIBLE. See Fearful; ForMIDABLE.

TERRIFIC. See Fearful.

TERRITORY, DOMINION. these terms signify a portion of Both try under a particular government; but the word territory brings to our minds the land which is included; dominion conveys to our minds the power which is exercised: the territory speaks of that which is in its nature bounded; dominion may be said of that which is boundless. A petty prince has his territory, the monarch of a great empire has dominions. It is the object of every ruler to guard his territory against the irruptions of an enemy; ambitious monarchs are always aiming to extend their dominions. See also EMPIRE.

TERROR. See Alarm.

TEST. See Assay.

TESTIFY. See Declare; Swear. TESTIMONY. See Proof.

THANKFUlness, Gratitude. Thankfulness, or a fulness of thanks (from Anglo-Saxon thanc, a thought, hence a pleasant thought, a grateful remembrance), is the outward expression of a grateful feeling. Gratitude, from the Latin gratitudo, is the feeling itself. Our thankfulness is measured by the number of our words; our gratitude is measured by the nature of our actions. A person appears very thankful at the time who afterward proves very ungrateful. Thankfulness is the beginning of gratitude: gratitude is the completion of thankfulness.

THEatrical, Dramatic, Stagey, Histrionic. These words all signify belonging to the stage or the art of the stage, but they differ considerably in their meaning. Theatrical, from Latin theatricus, Greek Oearpoxós, a dramatic show, means pertaining to the theatre, that is, exaggerated and artificial in such a way as to create an emotional and sensuous effect. Theatrical is sometimes applied in a derogatory sense to actions or manners which are artificial, but it always adds to the general idea of artificiality that of a deliberate effect, usually an emotional effect. Dramatic comes through Latin from the Greek word $\delta \rho \bar{a} \mu a$, a deed, act, drama, meaning that which is done or acted, from $\delta \rho \dot{\alpha} \omega$, I do, and means pertaining to an action represented on the stage-i.e., a drama. Dramatic docs not suggest artificiality; it merely indicates that which is emotionally striking and exciting - that in which the normal effect of action and fceling is heightened and emphasized without transcending the bounds of reality. Theatrical implies something falsely dramatic, wherein the effeet does not arise naturally, but is created simply by a method of presentation. Stagey is a translation of theatrical into ruder and more downright terms. It means resembling the exaggerations of the stage. Histrionic, from Latin histrio, an actor, has an entirely different meaning. It means pertaining to the art of the actor, and is not used in a derogatory sense.

THEME. See ToPIC.

THEORY, Speculation. Theory, from the Greek $\theta \varepsilon w p i a$, from $\theta \varepsilon \dot{a} о \mu a t$, to bchold, and speculation, from the Latin speculatus, participle of speculari, to behold, based on specula, a watch-tower, are both employed to express what is seen with the mind's cye. Theory is the fruit of reflection, it serves the purposes of seience: practice will be incomplete when the theory is false; speculation belongs more to the inagination; it has, therefore, less to do with realities; it is that which is rarely to be redueed to practice, and can, therefore, seldomer be brought to the test of experience. 
Hence it arises that theory is contrasted sometimes with the practice, to designate its insufficiency to render a man complete; and speculation is put for that which is fanciful and unreal; a general who is so only in theory will acquit himself miserably in the field; a religionist who is so only in speculation will make a wretched Christian.

THERE. See YONDER.

THEREFORE, CoNSEqUENTLY, ACCoRdingly. Therefore, that is, for this reason, marks a deduction; consequently, that is, in consequence, marks a consequence; accordingly, that is, according to some thing, implies an agreement or adaptation. Therefore is employed particularly in abstract reasoning; consequently is employed either in reasoning or in the narrative style; accordingly is used principally in the narrative style. Young persons are perpetually liable to fall into error through inexperience; they ought, therefore, the more willingly to submit themselves to the guidance of those who can direct them: the world is now reduced to a state of little better than moral anarehy; consequently nothing but renewed ideals and good government can bring the people back to the use of their sober senses: every preparation was made, and every precaution was taken; accordingly at the fixed hour they proceeded to the place of destination.

THICK, DENsE. Between thick (Anglo-Saxon thicce) and dense (Latin densus) there is little other difference than that the latter is employed to express that species of thickness which is philosophically considered as the property of the atmosphere in a certain condition: hence we speak of thick in regard to hard or soft bodies, as a thick board or thick cotton; solid or liquid, as a thick cheese or thick milk: but we use the term dense mostly in regard to the air in its various forms, as a dense air, a dense vapor, a dense cloud, and figuratively a dense population.

THIEVERY. See Kleptomania.

THIN, Slender, Slight, Slim. Thin, Anglo-Saxon thine, meant originally stretched out. Slender, Old French esclendre, is allied to Old Low German slender, a trailing gown, and is a nasalized form of the stem found in the verb slide; that which is long, trailing, is associated generally with the idea of slenderness in the modern sense. Slight is an Old Low German word meaning originally even or flat, then plain, smooth, simple; then trivial, of no real weight and importance-thence slight in the sense in which it is here used. Slim comes from Dutch; it meant originally oblique, hence weak, poor, bad, thin, slight. In most of these cases the present physical application develops out of a more general application. Thin is the generic term, the rest are specific: thin may be said of that which is small and short, as well as small and long; slender is always said of that which is small and long at the same time: a board is thin which wants solidity or substance: a poplar is slender, because its tallness is disproportioned to its magnitude or the dimensions of its circumference. Thinness is sometimes a natural property; slight and slim are applied to that which is artificial: the leaves of trees are of a thin texture; a board may be made slight by continually planing; a paper box is very slim. Thinness is a good property sometimes; thin paper is frequently preferred to that which is thick: slightness and slimness, which is a greater degree of slightness, are always defects; that which is marle slight is unfit to bear the stress that will be put upon it: that which is slim is altogether unfit for the purpose proposed: a carriage that is made slight is quickly broken and always out of repair; paper is altogether too slim to serve the purpose of wood.

Thinness is a natural property of many bodies, whether solid or fluid; slender and slight have a moral and figurative application.

ThInK, Reflect, Ponder, Muse. Think is a Teutonic word found in most of the Germanic tongues in some form. Reflect, in Latin reflectere, signifies literally to bend back, that is, to bend the mind back on itself. Ponder, from pondus, a weight, signifies to weigh. For the derivation of muse sce AMUse.

To think is a general and indefinite term; to reflect is a particular mode of thinking; to ponder and muse are dif- 
ferent modes of reflecting, the former on grave matters, the latter on matters that interest either the affections or the imagination: we think whenever we receive or recall an idea to the mind; but we reflect only by recalling, not one only, but many ideas: we think if we only suffer the ideas to revolve in succession in the mind; but in reflecting we compare, combine, and judge of those ideas which thus pass in the mind: we think, therefore, of things past, as they are pleasurable or otherwise; we reflect upon them as they are applicable to our present condition: we may think on things past, present, or to come; we reflect, ponder, and muse mostly on that which is past or present. The man thinks of the days of his childhood and wishes them back; the child thinks of the time when he shall be a man and is impatient until it has come: the man reflects on his past follies and tries to profit by experience; he ponders over any serious concern that affects his destiny, and muses on the happy events of his childhood.

Think, Suppose, Imagine, Believe, Deem.-To think is here, as in the preceding article, the generic term. It expresses, in common with the other terms, the act of having a particular idea in the mind; but it is indefinite as to the mode and the object of the action. To think may be the act of the understanding or merely of the imagination: to suppose and imagine are rather the acts of the imagination than of the understanding. To think, that is, to have any thought or opinion upon a subject, requires reflection; it is the work of time: to suppose and imagine may be the acts of the moment. We think a thing right or wrong; we suppose it to be true or false; we imagine it to be real or unreal. To think is employed promiscuously in regard to all objects, whether actually existing or not, or. if existing, are above our comprehension: to suppose applies to those which are uncertain or precarious; imagine, to those which are unreal. Think and imagine are said of that which affects the senses immediately; suppose is said only of that which occupies the mind. We think that we hear a noise as soon as the sound catches our attention; in 43 certain states of the body or mind we imagine we hear noises which were never made: we think that a person will come to-day, because he has informed us that he intends to do so; we suppose that he will come to-day, at a certain hour, because he came at the same hour yesterday.

In regard to moral points, in which case the word deem may be compared with the others, to think is a conclusion drawn from certain premises. I think that a man has acted wrong: to suppose is to take up an idea arbitrarily or at pleasure; we argue upon a supposed case merely for the sake of argument: to imagine is to take up an idea by accident or without any connection with the truth or reality; we imagine that a person is offended with us, without being able to assign a single reason for the idea; we imagine evils even more numerous than those which are real: to deem is to form a conclusion; things are deemed hurtful or otherwise in consequence of observation.

To think and believe are both opposed to knowing or perceiving; but think is a more partial action than believe: we think as the thing strikes us at the time; we believe from a settled deduction: hence it expresses much less to say that I think a person speaks the truth than that I believe that he speaks the truth. I think from what I can recollect that such and such were the words, is a vague mode of specch, not admissible in a court of law as positive evidence: the natural question which follows upon this is, Do you firmly believe it? an affirmative answer to which, when made with the appearance of sincerity, must be admitted as testimony. Hence it arises that the word think can be employed only in matters that require but little thought in order to come to a conclusion; and believe is applicable to things that must be admitted only on substantial evidence. We are at liberty to say that I think or I believe that the account is made out right; but we must say that I believe, not think, that the Bible is the word of God.

THOUGHT. See IdeA.

THOUGHTFUL, CONSIDERATE, Deliberate. Thoughtful, or full of 
thinking; considerate, or ready to consider (see CoNsiden); and deliberate, ready to deliberate, rise upon one another in their signification: he who is thoughtful does not forget his duty; he who is considerate pauses and considers properly what is his duty; he who deliberates considers deliberately. It is a recommendation to a subordinate person to be thoughtful in doing what is wished of him: it is the recommendation of a confidential person to be considerate, as he has often to judge according to his own discretion; it is the recommendation of a person who is acting for himself in critical matters to be deliberate, from Latin de and librare, to weigh. There is this further distinction in the word deliberate that it may be used in the bad sense to mark a settled intention to do evil: young people may sometimes plead in extenuation of their guilt that their misdeeds do not arise from deliberate malice.

THOUGHTLESS. See Negligent. THRALDOM, VASSALAGE. Thraldom refers to the condition of the northern thrall (Icelandic throll) or slave, who served in the household and on the land; vassalage to the condition of the feudal vassal or dependent who was bound to render his lord certain military and financial services. Thraldom therefore suggests a more absolute state of servitude, an entire subjection to the will of another, with the implication of something irksome and harassing in the state. Vassalage indicates a partial subjection, a subjection of will and more or less personal dependence.

See also Servitude.

THREAT, MENACE. Threat comes from Anglo-Saxon threát, a crowd, a pushing, and signifies a method of exerting force by word of mouth. Menace is of Latin extraction. They do not differ in signification; but, as is frequently the case, the Anglo-Saxon is the familiar term and the Latin word is employed only in the higher style. We may be threatened with either small or great evils; but we are menaced only with great evils. One individual threatens to strike another: a general menaces the enemy with an attack. We are threatened by things as well as persons: we are menaced by persons only (or things personified): a person is threatened with a look: he is menaced with a prosecution by his adversary.

THREATENING. See IMMINENT. THRIFTY. See ECONOMICAL.

THRILL, STIR, VibRate. Thrill, from Anglo-Saxon thyrlian, meant originally to pierce. For the derivations of stir and vibrate see those rords. These three terms all indicate a movement in response to some impulse received from without, and are figuratively applied to a psychological state. But the character of the movement differs. Stir is the most general of the three words. It means simply to be set in motion, and refers to any physical or psychological response to a stimulus. Vibrate refers to a regular motion to and fro, or up and down. Thrill indicates a sudden piercing, poignant movement which quickly spends itself. Figuratively applied to psychological states, to vibrate means simply to respond to a stimulus, to move in harmony with it, as a soundingboard may respond to the soundwaves and vibrate accordingly. To thrill indicates more definite but momentary emotion, an electric current of feeling, as it were, suddenly quivering through the whole nervous system.

THRIVE. See Flodrish.

THRONG. See Multitude.

THROW. See CAST.

THRUST. See PUSH.

THWART. See Oppose.

TIDE. See Stream.

TIDINGS. See News.

See aliso Advice; Information.

TIDY, Neat, Trim. These three words contain the same general idea of a combination of orderliness and cleanness, but they differ in the degree and kind of orderliness indicated. Tidy, from Middle English $t i d$, time, emphasizes the idea of a seasonable, and hence a seemly, order - a tidy room is a room in which everything is picked up and put in its proper place. Neat emphasizes the idea of cleanness added to order. Trim adds to the notion of cleanness and order a suggestion of something more positively pleasing. A trim attire is one in which neatness and tidiness are made positively striking by effective arrangement and emphasis. 
TIE. See Bind.

TIllage. See Cultivation.

TIME, Season. Time is here the generic term; it is taken either for the whole or the part: season is any given portion of time. We speak of time when the simple idea of time only is to be expressed; as the time of the day or the time of the year; the season is spoken of in reference to given circumstances, as the year is divided into four parts, called the seasons, according to the nature of the weather: hence in general time is called the season which is suitable for any particular purpose; youth is the season for improvement. It is a matter of necessity to choose the time; it is an affair of wisdom to choose the season.

Time, Period, Age, Date, Era, Epoch. -Time is, as before, taken either for time in general or time in particular; all the other terms are taken for particular portions of time. In the sense of a particular portion of time, the word time is applied generally and indefinitely.

Time included within any given points is termed a period, from the Greek $\pi$ epiodos, signifying a course, round, or any revolution: thus, the period of day or of night is the space of time comprehended between the rising and setting, or setting and rising, of the sun: the period of a year comprehends the space which, according to astronomers, the earth requires for its annual revolution. So, in an extended and moral application, we have stated periods in our life for particular things: during the period of infancy a child is in a state of total dependence on its parents; a periol of apprenticeship has been appointed for youth to learn different trades.

The period is sometimes taken not only for the space of time included between two points of lime, but sometimes for the terminating point; in this sense, to put a priod to a thing is to terminate its existence, to destroy it.

The age is the period comprehended within the life of one man, or of numbers living at the same time, and consequently refers to what is done by men living within that period: hence we speak of the different ages that have existed since the commencement of the world, and characterize this or that age by the particular degrees of vice or virtue, genius, and the like, for which it is distinguished.

The date is properly the point of time which is marked on a writing, either to show the time when it was written, as the date of a letter, or to show when any contract is to be performed, or thing done, as the date of a bill of exchange. As the date in the first case shows when anything has been done, the word date may be applied generally to the time of any past event, as a thing of late date or early date; so of a thing out of date, which is so long gone by that the date of it is not known.

As the date in the second case shows how long it will be before a thing is to be done, as a bill of short dale shows that it has but a short time to run, so the term date may be applied to the duration of any event.

$E r a$, in Latin ara, probably from cs, brass, signifying a brass counter used in computing; and epoch, from the Greek $\dot{\varepsilon} \pi 0 \chi^{\prime}$, from $\dot{\varepsilon} \pi \dot{\varepsilon} \chi \varepsilon \nu$, to stop, signifying a resting-place; both refer to points of time that are in some manner marked or distinguished; but the former is more commonly employed in the literal sense for points of computation in ehronology, as the Christian era; the latter is indefinitely employed for any period distinguished by remarkable events: the eaptivity of the Jews is an epoch in the history of that nation. The terms may also be figuratively employed in the latter sense, as an eventful era.

Timely, Seasonable.-The same digtinction exists between the epithets timely and scasonable as between time and senson in the precerling article. The former signifies within the time, that is, before the time is past; the latter aceording to the season, or what the season requires. A timely notice prevents that which would otherwise hapmen; a seasonable hint seldom fails of its effeet because it is seasonable. We must not expeet to have a timely notice of death, but must be prepared for it at any time; an admonition to one who is on a sickbed is very seasonable when given by a minister or a friend. The opposites of 
these terms are untimely or ill-timed and unseasonable: untimely is directly opposed to timely, signifying before the time appointed; as an untimely death; but ill-timed is indirectly opposed, signifying in the wrong time; as an ill-timed remark.

Time-serving, Temporizing. - Timeserving and temporizing are both applied to the conduct of one who adapts himself servilely to the time and season; but a time-server is rather active, and a temporizer passive. A time-server avows those opinions which will serve his purpose: the temporizer forbears to avow those which are likely for the time being to hurt him. The former acts from a desire of gain, the latter from a fear of loss. Time-servers are of all parties, as they come in the way: temporizers are of no party, as occasion requires. Sycophant courtiers must always be time-servers: ministers of state are frequently temporizers.

See also OPPORTUNE.

TIMID. See AFraID.

TIMOROUS. See AFraID.

TINGE. See Color.

TINT. See Color.

TIRE. See WEARY.

TIRESOME. See WEARISOME.

TITLE. See NAME.

TOGETHER. See SrNCHRONOUS. TOIL. See Work.

TOILsOME. See HerculeaN.

TOKEN. See MARK.

TOLERATE, ENDURE, SUFFER. Tolerate comes ultimately from Latin tollere, to bear; endure, from Latin durus, firm, lasting; suffer, from Latin $s u b$, up, and ferre, to bear. The words all indicate submission to something unpleasant, but they differ in the kind of submission and the extent of the unpleasantness indicated. Tolerate suggests something annoying borne with some patience; endure, something in the nature of positive suffering borne with courage and fortitude. Suffer may indicate merely the granting of permission, the submission of the will, or it may imply the bearing of positive pain - t at is, it may be either a much stronger word than endure or merely a slightly more emphatic form of tolerate. In this last sense it is used in the Bible and in other somewhat archaic expressions.
TOLL. See TAX.

TOMB. See Grave.

TONE. See Sound.

TONGUE. See LANGUAge.

TOO. See Also.

TOOL. See INSTRUMENT.

TOPSY-TURVY, UPSIDE-DOW N . Topsy-turvy, earlier topsy-tervy, or topside-tervy, where tervy represented a Middle English terven, to roll or overturn. Upside-down bears its meaning on its face. Upside-down is a prosaic and literal way of saying what is more humorously suggested in topsyturvy. Upside-down means merely turned so that the upper part is where the lower part ought to be. Topsyturvy, while implying the same inversion, adds the idea of general confusion. It is a humorous and colloquial word.

TORMENT, ToRTURE. Torment and torture both come from torquere, to twist, and express the agony which arises from a violent twisting or griping of any part; but the latter, which is more immediately derived from the verb, expresses much greater violence and consequent pain than the former. Torture is an excess of torment. We may be tormented by a variety of indirect means; but we are said to be tortured mostly by the direct means of the rack or similar instrument. Torment may be permanent: torture is only for a time or on certain occasions. It is related in history that a person was once tormented to death by a violent and incessant beating of drums in his prison: the Indians practiced every species of torture upon their prisoners: whence the application of these terms to moral objects. A guilty conscience may torment a man all his life: the horrors of an awakened conscience are a torture to one who is on his death-bed.

TORPID. See NUMB.

TORTURE. See ToRMENT.

TOSS. See SHaKe.

TOTAL. See Whole.

TOTALLY. See Quite.

TOTTER. See STAGger.

TOUCH. See Contact; Strike;

THRILL.

TOUR. See Circuit; Excursion. TOWER. See TURrET.

TRACE. See Derive; Mark.

TRACK. See MarK. 
TRACT. See EsSAY.

TRACTABLE. See Docile.

TRADE, CoMMERCE, TrafFic, Dealing. The old Middle English sense of trade was path; the word is allied to tread. It meant the beaten path worn between merehant and customer, hence regular business. Commerce is derived from Latin cum, with, and merx, merchandise. It refers to an exchange of merchandise between two or more people. Traffic comes through French from Italian trafficare, a Low Latin traficum, trafica, based perhaps on trans and a hypothetical verb vicare, vicis, or "change across." To engage in exchange or trade.

The leading idea in trade is that of carrying on business for purposes of gain; the rest are but modes of trade; commerce is a mode of trade by exchange: traffic is a sort of personal trade, a sending from hand to hand; dealing is a bargaining or calculating kind of trade. Trade is either on a large or small seale, commerce is always on a large seale; we may trade retail or wholesale; we always carry on commerce by wholesale: trade is either within or without the country; commerce is always between different countries: there may be a trade between two towns; but there is a commerce between England and America, between France and Italy: hence it arises that the general term trade is of inferior import when compared with commerce. The commerce of a country, in the abstract and general sense, conveys more to our mind, and is a more noble expression, than the trade of the country, as the merchant ranks higher than the tradesman, and a commercial. house than a trading concern. Trade may be altogether domestic and between neighbors; the traffic is that which goes backward and forward between any two or more points: in this manner there may be a great traffic between two towns or eities, as between London and the eapitals of the different counties; we also speak of busy thoroughfares of a city as full of traffic. Trade may consist simply in buying and selling according to a stated valuation; dealings are carried on in matters that admit of a variation: hence we speak of dealers in wool, in corn, seeds, and the like, who buy up portions of these goods, more or less, according to the state of the market.

Trade, however, in its most extended sense, comprehends all the rest.

See also Business; Deal.

TRAditional. See Legendary. TRADUCE. See Disparage.

TRAFFIC. See Trade.

Train. See Procession.

TRAITOROUS. See Treacherous.

TRAMONTANE, UltraMontane.

Tramontane, in French tramontain, northerly, from Italian tramontano, that from Late Latin transmontanus, across or beyond the mountains, is both an adjective and a substantive. As an adjective it implies lying north or being beyond the mountains, that is, the Alps, as the Italians originally applied the term, hence foreign. Subsequently the term was applied by the French to the Italians, as being south, beyond, or on the other side of the mountains. In the latter application the term takes the form of ultramontane, from Latin ultra, beyond, and montanus, a mountain.

As a substantive tramontane, as well as ultramontane, signifies one living or coming across or from beyond or from the other side of the mountains, hencr. a stranger, one of foreign habitation.

Tramontane also implies the north -ind (tramontana) in the Mediterranean, and a peculiar blighting wind, very harmful in the Archipelago: and ultramontane, in church history, the name given in the Vatican Council (1870) to the opinion of the church that the Papal utterances ex cathedra on matters of faith and morals are irrevocable.

TRANQUIL. See UNRUFFLED.

TRANQUILlity. See Peace.

TRANSACT. See Negotiate.

TRANSCEND. See EXCEED.

TRANSCRIBE. See COPY.

TRANSFER, Transmit. These words both signify to remove from one place to another, but there is a slight difference in meaning corresponding to the difference in derivation. Transfor comes from Latin trans, across, and ferre, to carry, and signifies to carry across an intervening space. Transmit comes from Latin trans, across, and mittcre, to send, and signifies to send 
across. We use transfer wherever the idea of actually bearing or carrying is prominent. We speak of transmitting messages by telegraph; of transferring goods by freight.

TRANSFIGURE, TRA N S O R M, Metamorphose. Transfigure is to make to pass over into another figure: transform and metamorphose (from Greek $\mu \varepsilon \tau \dot{\alpha}$ and $\mu o \rho \phi o ́ \omega$, or I change about) are to put into another form, the first being said only of spiritual beings, and particularly in reference to our Saviour; the other two terms being applied to that which has a corporeal form.

Transformation is commonly applied to that which changes its outward form; in this manner a harlequin transforms himself into all kinds of shapes and likenesses. Metamorphosis is applied to the form internal as well as external, that is, to the whole nature; in this manner Ovid describes, among others, the metamorphoses of Narcissus into a flower and Daphne into a laurel: with the same idea we may speak of a rustic being metamorphosed, by the force of art, into a fine gentleman.

TRANSFORM. See TRANSFIGURE. TRANSGRESS. See INFRINGE.

TRANSGRESSION. See OFFENCE. TRANSIENT. See TEMPORARY.

TRANSITORY. See EVANESCENT; TEMPORARY.

TRANSLATE. See Transfer.

TRANSLUCENT. See DIAPHANOUS.

TRANSMIT. See Transfer; WAFT. TRANSPARENT. See PELlUCID.

TRANSPIRE, EXHALE, LEAK OUT. Transpire originally meant to be sent off as vapor, to be breathed out, from Latin trans, through, and spirare, to breathe. It is a synonyme of exhale (from Latin ex, out, and halare, to breathe) when used literally, and a synonyme of leak out, used figuratively. It is not a synonyme of happen or occur, though vulgarly employed as such. We speak of a secret transpiring, meaning that it is breathed out, becomes known. Exhale has the same literal meaning, but not the same figurative application. Leak out has a similar figurative application, but the metaphor is not that of vapor exhaled, but of water, or other liquid, dripping out.
TRANSPORT. See BEAR; EcSTASY.

TRANSPORTER. See COMMONCARRIER.

TRAVEL. See Go.

TRAVESTY, BURlesque, CaricaTuRe, Parody. Travesty, in French travesti, past participle of travestir, to disguise one's self, from the Latin trans, across, over, implying a change, and vestire, to clothe, signifies that which has a changed or unusual attire, disguised in garments so as to present a ridiculous appearance. As a substantive it signifies that which has been changed, transformed, from a lofty, serious style into a ridiculous, ludicrous one.

Burlesque, as an adjective, signifies the exciting to laughter by an extravagant contrast; as a substantive, a ludicrous, grotesque representation; as a verb, to ridicule or make ridiculous by a humorous, fantastic, sarcastic change in an original. Caricature, as a substantive, comes through Italian from Latin carricare, to load a car, hence to overweight, to "lay on thick," to caricature. It signifies a figure or description of a person or thing in which defeets are greatly exaggerated in order to give the subject a ridiculous appearance, a representation in which the salient features of the original are changed to the extent of producing a ludicrous effect, without entirely, or even essentially, destroying the resemblance.

Though travesty and parody have a general relationship they differ in application. Parody changes the subjectmatter in hand and the personalities. and mockingly imitates the style of the original, as Richelieu's parody of Corneille's Cid; travesty leaves the subject matter partially, and the personalities wholly, unaltered, produeing its intended effect by substituting the grotesque in action or speech for the serious, noble, or heroic.

For further critical distinctions between the meaning and derivations of these words see CARICATURE.

TREACHEROUS, TRAITOROUS, TrEasonable. These epithets are all applied to one who betrays his trust, treacherous, from Middle High German trechen, to draw, entice, and traitorous, 
from Latin traditorem, a traitor, based on tradere, to give up; but treacherous (see Faithless) connotes a man's private relations; traitorous, his public relation to his ruler and his country: he is a treacherous friend and a traitorous subject. We may be treacherous to our enemies as well as our friends, for nothing can lessen the obligation to be faithful in keeping a promise; we may be traitorous to our country by abstaining to lend that aid which is in our power. Traitorous and treasonable are both applicable to subjects: but the former is extended to all publie acts; the latter only to those which affect the supreme power: a soldier is traitorous who goes over to the side of the enemy against his eountry; a man is guilty of treasonable practices who meditates taking the life of the king or aims at subverting his government: a man may be a traitor and be guilty of treason under all forms of government.

See also Insidious.

TREASURE, HoARD. The idea of laying up carefully is eommon to these verbs; but to treasure is to lay up for the sake of preserving; to hoard, to lay up for the sake of accumulating; we treasure the gifts of a friend; the miser hoards up his money: we attach a real value to that which we treasure, a fictitious value to that which is hoarded. To treasure is used either in the proper or improper sense; we treasure a book on which we set particular value or we treasure the words or actions of another in our recollection; the miser hoards up whatever he can serape together.

TREAT. See Feast.

TREATISE. See Essay.

TREATMENT, UsAge. Treatment implies the act of treating and usage that of using: treatment may be partial or temporary, but usage is properly employed for that which is permanent or continued: a passer-by may meet with ill-treatment, but ehildren and domesties are liable to meet with illusage. All persons may meet with good or ill trealment from others with whom they casually come in connection, but usage is applied more properly to those who are more or less in the power of others: children may reeeive good or ill usage from those who have the charge of them, servants from their masters or wives from their husbands.

TREATY. See Convention.

TREMBLE. See Quall; Shake.

TREMBLING, TrEMOR, TREPIDATION. The first two of these terms are derived from the same source (see AgITATION), and designate a general state of agitation: trembling is not only the most familiar, but also the most indefinite, term of the three; trepidation (from Latin trepidare) and tremor are species of trembling. Trembling expresses any degree of involuntary shaking of the frame, from the affection either of the body or the mind; cold, nervous affeetions, fear, and the like are the ordinary eauses of trembling: tremor is a slight degree of trembling, which arises mostly from a mental affeetion; when one is agitated one's mind is thrown into a tremor by any trifling ineident: trepidation is more violent than either of the two, and springs from the defective state of the mind; it shows itself in the action, or the different movements, of the body, rather than in the body; those who have not the requisite eomposure of mind to eommand themselves on all oecasions are apt to do what is required of them with trepidation.

Trembling and tremulous are applied as epithets, either to persons or things; a trembling voice evinees trepidation of mind, a tremulous voice evinees a tremor of mind: notes in music are sometimes trembling; the motion of the leaves of trees is tremulous.

TREMENDOUS. See Fearful.

TRENCH, Chinnela, Ditch, Furrow. These words all indieate a passage eut in the ground. Furrow is the passage made by a plough in the field for the receiving of the seed. A trench is a deeper and wider passage cut in the ground and thoroughly excavated; it now refers particularly to the protective fortifications developed underground by both sides in the European war. A ditch is a small trench into which water is drained and earried off. A channel serves the same purpose as a ditch, but usually refers to a natural passageway made by the action of a stream or is figuratively extended to refer to solnething resembling such 
a natural passage, as when we speak of channels of trade, channels of intercourse, etc.

TRENCHANT, SHARP. Trenchant, from French trencher, to cut (Latin truncare), to cut down the trunk of a tree, means sharp, but implies a positive action of the sharp instrument on something. It is now used mainly in the figurative sense, whereas sharp has a literal as well as a figurative significance. A sharp speech is that which hurts or cuts like the blade of a knife; a trenchant criticism is that which suggests a sharp instrument wielded by an energetic hand. There is more action and deliberate purpose in trenchant than in sharp.

TRESPASS. See OFFENCE.

TRIAL. See AtTempt ExperiENCE.

TRIBUNAL, Bar, Bench, CoUrt, JUdGMenT-seat. Tribunal is a substantive, derived from Latin tribunal, based on tribunus. The term implies a place for making decisions, a high or principal resort for litigants, consistently with its Latin prototype, which meant a raised platform on which the seats of the tribunes, or magistrates, were placed.

In ordinary language the bar in a court-room applies to the railing which separates the space for spectators from the part reserved for the judge, jury, lawyers, court officers, and witnesses when testifying. A law student is called to the bar when he is summoned to this railing to be sworn as a practitioner, and after the ceremony he is admitted to the bar and permitted to take a place within the bar.

The bench, or, figuratively, the judgment-seat, is the seat of a judge, singly or with associates, when discharging judicial duties. Collectively judges and lawyers are spoken of as the bench and bar.

The bar, bench, and court, the latter applying to the judge, the judicial department, and the place of adjudication, have varied jurisdictions, according to the special purpose of a court. The bar and bench remain the lawyers and judges in all cases, but the court, as the judicial department of government, is generally divided into several parts, each having authority to deal with specific cases, and all ranging from trial to appeal.

The term tribunal has received a very broad application in recent years by its extension to the adjudication of international disputes, etc., the highest type of which is what is known officially as the Permanent Court of Arbitration of The Hague, and popularly as The Hague Tribunal.

TRIBUTE. SEe TAX.

TRICE, JIFFY. Trice is a Scandinavian word, but the phrase in a trice is imitated from Spanish en un tris, tris, an imitative word meaning here the cracking of glass - the phrase therefore signifying in the time that it takes to smash something. Jiffy is a somewhat colloquial word of unknown origin. There is little difference in the meaning of the two words. Both signify "in the least possible time"; but jiffy is a familiar and half-humorous term. Trice is more suitable in dignified writing.

TRICK. See Artifice; Cheat.

TRIFLE. See DALLY.

TRIFling, Trivial, Petty, Frivolous, Futile. Trifling comes from Old French truffe, signifying a thing of small worth. Trivial is derived from Latin trivium, from tres, three, and via, way, a place where three roads met, signifying that which can be picked up on the most frequented part of the common highway; hence, worthless, of no account. Petty comes from French petit, small-a Celtic word. Frivolous is derived from Latin frivola, broken potsherds, and goes back ultimately to fricare, to rub away. Futile contains the same root as Latin fundere, to pour, and signifies that which is poured out as worthless.

All these epithets characterize an object as of little or no value: trifing and trivial differ only in degree, the latter denoting a still lower degree of value than the former. What is trifling or trivial is that which does not require any consideration and may be easily passed over as forgotten: trifling objections can never weigh against solid reason; trivial remarks only expose the shallowness of the remarkers: what is petty is beneath our consideration, it ought to be disregarded and held cheap; - it would be a petty con- 
sideration for a minister of state to look to the small savings of a private family: what is frivolous and futile is disgraceful for any one to consider; the former in relation to all the objects of our pursuit or attachment, the latter only in regard to matters of reasoning; dress is a frivolous occupation when it forms the chief business of a rational being; the objections of anarchists against orderly government are as futile as they are mischievous.

TRIM. See TIDY.

TRIP. See Excursion.

TRIPLANE. See AIrCRAFT.

TRITE, Banal, HackNeYED. these words signify that which through familiarity has bred contempt. Trite comes from Latin tritus, the past participle of terere, to rub or grind. It refers to something out of which all possible interest or meaning has been rubbed or ground. A trite remark is that which has been made many times. Hackneyed comes through French from an uncertain source; perhaps from Dutch hacken, to chop, and negge, a nag, with the implication of jolting. A hackney was originally a horse used for every-day riding, as opposed to a war-horse; hackney then came to signify a hired equipage (whence hack is derived), and through that something common. Banal is derived from Late Latin bannum, from a Germanic root bannan, to summon. It referred originally to the service demanded of all feudal vassals, and, through the idea of something common to all, developed the meaning of commonplace. Of these three words hackneyed expresses most distinctly the idea of worn out by usage. A hackneyed quotation, for example, may be an excellent quotation in itself, but it has been used so of ten that it has lost its significance. Trite conveys the same meaning, but does it less elearly and distinctly. However, it adds to the suggestion of constant use a general implication that the whole substance of the thing denominated trite is stale and uninteresting. A hackneycd remark is one which has been made before; a trite remark may not have been made before in exactly the same form, but it conveys an idea which has lost its force through familiarity. Banal emphasizes the rdea of staleness, obviousness, still further, and departs more widely from the simple idea of hackneyed. Banal means "what any ordinary person might think of "implying not repetition so much as an utter lack of originality in the first place.

TRIUMPH, Conquest, ExultaTION, Success, Victory. Triumph, ir, old French triumphe, French triomphe, from Latin triumphum, accusative of triumphus, cognate with Greek $\theta$ pin $\mu$ Bos, a hymn to Bacchus, Spanish triunfo, Portuguese triumfo, Italian trionfo, implied originally a grand procession in which a vietorious general entered Rome by the Porta Triumphalis, in a chariot drawn by four horses, wearing an embroidered robe, an undergarment decorated with palm leaves, and a wreath of laurel round his forehead.

As a substantive, in ordinary language, the term signifies a display of pomp of any kind; a public festivity, tournament, pageant, unusual celebration; the expression of joy, great gladness, exultation for some noteworthy success. As a verb, it signifies to win a conquest, prevail over an adversary, achieve a decisive advantage in battle or other encounter, to subdue opposition, to accomplish a victory.

In a reprehensible sense it signifies to boast, brag, chuckle, exult on an advantage gained over another or believed to be gained, to "crow" insolently over the discomfiture of another.

TROOP, COMPANY. In a military sense, a troop is among the horse what a company is among the foot; but this is only a partial acceptation of the terms. Troop, in French troupe, immediately from Low Latin troppus, may be a metathesized form of English thorp; ef. Icelandic thorp, German dorf; it signifies an indiscriminate multitude; company (see Accompasy) is any number joined together and bearing one another company: hence we speak of a troop of hunters, a company of players; a troop of horsenien, a company of travellers.

TROUBle, Disturb, Molest. Whatever uneasiness or painful sentiment is produced in the mind by outward eireumstances is effected either 
by trouble (see AfFuiction), by disturbance (see Commotion), or by molestation (see InCONVENIENCE). Trouble is the most general in its application; we may be troubled by the want of a thing or troubled by that which is unsuitable; we are disturbed and molested only by that which actively troubles. Pecuniary wants are the greatest troubles in life, the perverseness of servants, the indisposition or ill behavior of children, are domestic troubles: but the noise of children is a disturbance, and the prospect of want disturbs the mind. Trouble may be permanent; disturbance and molestation are temporary, and both refer to the peace which is destroyed; a disturbance ruffles or throws out of a tranquil state, a molestation burdens or bears hard either on the body or the mind: noise is always a disturbance to one who wishes to think or to remain in quiet; talking, or any noise, is a molestation to one who is in an irritable frame of body or mind.

Troublesome, Irksome, Vexatious.These epithets are applied to the objects which create trouble or vexation. Troublesome is here, as before, the generic term; irksome and vexatious are species of the troublesome: what is troublesome creates either bodily or mental pain; what is irksome creates a mixture of bodily and mental pain; and what is vexatious creates purely mental pain. What requires great exertion, or a too long-continued exertion or exertions, coupled with difficulties, is troublesome: in this sense the laying in stores for the winter is a troublesome work for the ants, and compiling a dictionary is a troublesome labor to the compiler: what requires any exertion which we are unwilling to make, or interrupts the peace which we particularly long for, is irksome; in this sense giving and receiving of visits is irksome to some persons; travelling is irksome to others: what comes across our particular wishes, or disappoints us in a particular manner, is vexatious; in this sense the loss of a prize which we had hoped to gain may be vexatious.

See also Worry.

TRUANT, Tramp, VAgRant, VagaBOND. Truant means one who wilfully absents himself from his duties or his usual place-a wanderer out of the beaten track, with the suggestion of idleness and irresponsibility. A vagrant (from Old French walcrer, to wander about, Old High German walchan (cf. English walk), probably influenced by French vagant, wandering, based on Latin vagari, to wander) is a wanderer; vagabond comes from the same Latin word, but adds to the idea of wandering that of shiftlessness, uselessness, irresponsibility. A tramp, from the verb tramp, is one that tramps through the country begging from house to house. Ail these words have therefore in common the idea of wandering with the implication of idleness and irresponsibility.

TRUCE, Armistice. Truce comes through Middle English trews, a plural form, from Anglo-Saxon treowa, a compact; cf. Anglo-Saxon treowe, Modern English true. It means a cessation of hostilities on both sides accompanied by a pledge to refrain from attack until further notice. The implication of true comes from this mutual pledge. Armistice is derived from Latin arma, arms, and -stitum, the form assumed in composition by statum, past participle of sistere, a secondary form of stare, to stand. It means a suspension of arms by mutual agreement. In ordinary usage there is really no difference between armistice and truce. Truce indicates perhaps an armistice of some duration. It is the more simple and practical of the two words, and has therefore a wider figurative application.

TRUCK. See Exchange.

TRUE. See SINCERE.

TRUST. See Belief; Confide; HOPE.

TRUSTWORTHY. See FAITHFul. TRUSTY. See FaITHFUL.

TRUTH, VERACITY. Truth belongs to the thing, veracity to the person: the truth of the story is admitted upon the veracity of the narrator.

TRY, TEMPT. To try (see also ATTEMPT) is a particular species of trial: we try either ourselves or others; we tempt others: we try a person only in the path of his duty; but we may tempt him to depart from his duty: it is necessary to try the fidelity of a servant before you place confidence in him; it is wicked to tempt any one to 
do that which we should think wrong to do ourselves; our strength is tried by frequent experiments; we are tempted, by the weakness of our principles, to give way to the violence of our passions.

TUG. See Draw.

TUMBLE. See FALL.

TUMID. See TURGID.

TUMULTUOUS, TUMOLTUARY. Tumultuous signifies having tumult; tumultuary (a word but rarely used today), disposed for tumult: the former is applied to objects in general, the latter to persons only: in tumultuous meetings the voice of reason is the last thing that is heard; it is the natural tendency of large and promiscuous assemblies to become tumultuary.

Tumultuous, Turbulent, Seditious, Mutinous.-Tumultuous (see Bostre) describes the disposition to make a noise; those who attend the playhouses, particularly the lower orders, are frequently tumultuous: turbulent marks a hostile spirit of resistance to authority; when prisoners are dissatisfied they are frequently turbulent: seditious marks a spirit of resistance to government; in republics the people are often disposed to be seditious: mutinous marks a spirit of resistance against officers either in the army or navy; a general will not fail to quell the first risings of a mutinous spirit. Electioneering mobs are always tumultuous; the young and the ignorant are so averse to control that they are easily led by the example of an individual to be turbulent; among the Romans the people were in the habit of holding seditious meetings, and sometimes the soldiery would be mutinous.

TURGID, TUMid, Bombastic. Turgid and tumid both signify swollen (from Latin turgere and tumere, both meaning to swell), but they differ in their application: turgid is most commonly applied to what sweils by a physical process, as a turgid vessel; tumid is said of that which seems to swell in an unnatural or unusual manner, as the tumid waves. They are both applied to words. Bombastic, from bombast, a kind of cotton, signif ying puffed up like cotton, is, figuratively, applicable to words only; but the bombastic includes the sentiments expressed; turgidity is confined mostly to the mode of expression. A writer is turgid who expresses a simple thought in lofty language: a person is bombastic who deals in large words and introduces high sentiments in common discourse.

Tumid is rarely applied to the style.

TURN, BEND, Twist, Distort, WRING, Wrest, Wrench. Turn comes from Latin tornare, to turn a lathe, Greek rópvos, a lathe. Bend (see that word). Twist, Anglo-Saxon twist, signified originally a rope of double thread, from root found in tuice, and hence as a verb it signifies the motion involved in winding one thread about another. Distort, in Latin distortus, participle of distorquere, compounded of dis, apart, and torquere, to turn, signifies to turn violently aside.

To turn signifies in general to put a thing out of its place in an uneven line; to bend, and the rest, are species of turning: we turn a thing by moving it from one point to another; thus we turn the earth over: to bend is simply to ehange its direction; thus a stick is bent or a body may bend its dircetion to a certain point: to tuist is to bend many times, to make many turns: to distort is to turn or bend out of the right course; thus the face is distorted in convulsions. To uring is to turist with violence; thus linen which has been wet is urung: to urest or urench is to separate from a body by means of tuisting; thus a stick may be urested out of the hand or a hinge urenched off the door.

The same distinction holds good in the figurative or moral application: we turn a person from his design; we bend the will of a person; we turst the meaning of words to suit our purposes; we distort them so as to give them an entirely false meaning; we uring a confession from one.

Turn, Bent.-These words are compared here only in the figurative application, as respects the state of a person's inclination: turn is, therefore, as before, indefinite as to the degree; it is the first rising inclination: bent is a positively strong turn, a confirmed inclination; a child may early discover a turn for music or drawing; 
but the real bent of his genius is not until he has made progress in his education and has had an opportunity of trying different things: it may be very well to indulge the turn of mind; it is of great importance to follow the bent of the mind as far as respects arts and sciences.

Turn, Wind, Whirl, Twirl, Writhe.To turn (sce above) is, as before, the generic term; the rest are but modes of turning; wind is to turn a thing round in a regular manner; whirl, to turn it round in a violent manner; twirl, to turn it round in any irregular and unmeaning way; writhe, to turn round in convolution within itself. A worm seldom moves in a straight line; it is, therefore, always turning: sometimes it lies, and sometimes it writhes in agony: a wheel is whirled round by the force of gunpowder: a top is twirled by a child in play.

TURRET, Minaret, Pinnacle, Tower. Turret, in old French tourette, diminutive of French tour, a tower, Latin turris, a tower, implied, in ancient warfare, a movable structure of wood for carrying soldiers, implements, supplies, etc., that could be rolled on its wheels to an advantageous position for attacking a fortified place, a contrivance suggestive of the wooden horse of Troy.

A minaret (Spanish minarete, from Arabian manárat, a candlestick, lamp, lighthouse) is a tall, slender turret or tower attached to a mosque and surrounded with balconies from which the muezzin calls the people to prayer. In Tudor architecture a turret is a small tower attached to another tower or erected at the angles of a church or public building. A pinnacle (Latin pinnaculum, a double diminutive of pinna, a wing) is a small polygonal turret rising above the rest of a building and forming its highest point.

In modern and most common usage the term turret applies to a rotating cylindrical steel tower rising above the deck of a warship and bearing guns that can be trained to discharge in any required direction. The first vessel constructed with such a turret was Captain John Ericsson's Monitor, described by the Confederates as "a cheese-box on a raft," which was hastily built for the Federal navy in the early part of the American Civil War. This had a single turret, mounting two guns. The later development of the warship into the battleship, and then the dreadnaught and the superdreadnaught, has called for twin turrets on some vessels and a second set superimposed on the first or others.

TWADDLE, BALDERDASH. Twaddle and balderdash have practically the same meaning. They differ only in their original derivation and in the general effect created by the form and sound of the word. Twaddle is an imitative word, a variation of tattle, a frequentative signifying to say "Ta, ta, ta." Balderdash is a Scandinavian word which originally signified a jumbled mixture of liquids. Twaddle more distinctly suggests the act of talking; balderdash, the nonsensical character of the talk.

TWAIN. See Both.

TWeedle, Allure, Coax, Decoy, ENTICE. Tweedle is a term of unproved etymology, but is believed to be allied with twaddle (see that word) or twiddle, signifying, in music, to touch lightly, to play, as on a violin, with a tremulous, quivering motion, also to busy one's self with trifles. Tweedle is closely allied with wheedle, both terms as verbs signifying to allure, to tempt by the offer of something good, real, or apparent, to coax or cajole one to do or give something against his first impulse, to flatter in order to gain a point; to decoy, to lead or allure or to practice deception to gain an end, and to entice or attract with soft words with the intent of getting what might otherwise be unattainable, to wheedle out of a person that which one wishes to get or know.

A very familiar use of the term tweedle is in connection with the term tweedledum in the phrase tweedledum and tweedledee, implying a distinction without a difference, an attempt to distinguish things or parts where no difference actually exists. This expression is said to have arisen in the eighteenth century, when a controversy occurred between the admirers of Bononcini and those of Handel concerning the merits of those musicians. The controversy reached such a wide 
and animated state that John Byrom (1691-1763) alluded to it as follows:

"Some say, compared to Bononcini, That Mynheer Handel's but a ninny; Others aver that he to Handel Is scarcely fit to hold a candle. Strange all this difference should be 'Twixt tweedledum and tweedledee."

TWILIGHT. See Gloaming. TWINKLING. See LAMBENT. TWISTED. See WRY.

TWIT, Gibe, TaUnT. Twit comes from Anglo-Saxon atwilan, to point to, to reproach. It means to annoy by reminding of something disereditable or assumed to be disereditable. To gibe, allied to the Swedish dialeetical word gipa, to gape, to talk foolishly or rashly, means to speak in a sneering or sarcastic manner. Taunt (see Tease) is an exaggerated form of twitting - something positively malicious, not merely teasing. Twitting is a particular form of gibing-a more specific word.

TWO. See Both.

TYPE. See Frgdre.

TYRANNICAL. See Absolute. TYRO, AMATEdr, NeOPHYTE, Nov-lante.
ICE. Tyro, properly tiro, in Latin in similar form, Italian tirone, French

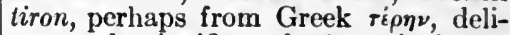
cate, soft, signifies a beginner in learning, a learner of the first rudiments, one having only an imperfect or slight knowledge, a mere smattering of a subject, an apprentice to a trade. A neophyte, through Latin from Greek

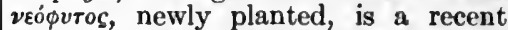
convert, one recently baptized, or one newly admitted to the order of the priesthood, a term sometimes used by Roman Catholic missionaries to designate their converts in non-Christian lands.

A novice, from Latin novilius, a derivative of novus, new, in ordinary language, is one who is new to any business, profession, art, or vocation, one who is as yet unskilled, just at the bottom of the ladder. In ecclesiastical usage the term signifies the title given to men or women who have entered a religious house and desire to embrace its rules, and in this sense it is synonymous with postulant, speeifically one who asks, demands, or requests, a French substantive from Latin postulo, to demand, Spanish and Italian postu- 
UBIQUITOUS, EVERYWHERE, OMNIPRESENT, UNIVERSAL. Ubiquitous, from Latin ubique, everywhere, is simply the Latin corresponding to the native English everywhere, used as an adjective. It differs from everywhere in being distinctly an "educated" word, one found only in the vocabulary of the educated. Omnipresent differs from ubiquitous in meaning not merely everywhere, but present everywhere at the same time. Omnipresence is one of the attributes of God. Universal is a more general word which may be limited to correspond to everywhere; it means everywhere throughout the whole scheme of things.

UGLY, Homelx, Hideous, UNsightLY. Ugly, from Anglo-Saxon oga, fear, from the Teutonic root $a g h$, which also appears in the English word awe (Gothic agis, Icelandic agi), and $l y$, like, signifies that which is hateful, and hence the opposite of beautiful. Homely meant originally homelike, that which belongs to the home. It came to signify that which is contrasted with the splendor and beauty of social life outside of the home-that which is not regarded outside of the circle of the hearth. It indicates the opposite of beautiful, but not a positive degree of unpleasantness. To be homely is to be only mildly ugly or merely not beautiful; it does not suggest the presence of something really disagreeable as does ugly. Unsightly and hideous characterize that which is ugly by the psychological reaction to it. Unsightly means not fit for the sight, something from which we turn away our eyes. Hideous, through French hideux, a development of Old French hisdos, from Latin hispidosus, rough, bristly, meant originally something fearful, revolting - the superlative degree of ugliness characterized by its effect upon the onlooker. It is therefore the strongest of these words, as homely is the mildest.

ULTIMATE. See LAST. ULTIMATUM, FINAL WORD, LAST of many American lives, was more of
Terms. Ultimatum, in Latin the neuter singular of ultimatus, the past participle of ultimare, signifies, literally, to be the last, to come to an end, and, in ordinary language, the last word. The term is used in connection with many actions, but its strongest application is to diplomatic negotiations, in which it has the dual sense of a declaration and a demand. In an international controversy the term implies directly the most favorable terms which a negotiator is prepared or willing to offer, the rejection of which will be considered as putting an end to negotiation and placing upon the second party the responsibility for whatever consequences may follow. In critical cases an ultimatum implies the last terms or conditions that will be offered, the final word, the extreme end in a controversy, and a direct or suggestive threat that if rejected resort will be had to redressive measures, but, apart from these rather lame attempts at periphrasis, it really has no synonymes.

The ultimatum was frequently employed in the great European war. Just prior to the outbreak Austria sent an ultimatum to Serbia regarding the assassination of Archduke Francis Ferdinand and his wife; and later Japan sent one to Germany, Russia one to Bulgaria, and, it was believed that both the Entente and the Central Powers had sent one to Greece for the purpose of winning her active cooperation in the war. The United States had frequent occasion to send messages to the belligerents, but these were known officially as protests, though they contained the essence of an ultimatum, as they pointed out the possibility of a severance of friendly relations if unheeded.

The "note" to Austria-Hungary, under date of December 12, 1915, concerning the sinking of the steamship Ancona by a submarine flying the Austro-Hungarian flag, with the loss
of many American lives, was more of 
the eharacter of an ultimatum, for it demanded that "the Imperial and Royal Government denounee the sinking of the Ancona as an illegal and indefensible act, that the officer who perpetrated the deed be punished, and that reparation by the payment of an indemnity be made for the eitizens of the United States who were killed or injured by the attack on the vessel." The "note" further expressed the expectation that the Austro-Hungarian Government would "accede to its demand promptly."

ULTRAMONTANE. See TraMONTANE.

UMBRAGe, Pique. Umbrage comes from Latin umbra, a shade. Pique comes through French from the Teutonic word found in pick, meaning a prick, the sensation produced by contact with a sharp point. Both words are used now in a figurative sense to indicate a slight and momentary feeling or expression of vexation or jealous annoyance. Umbrage, in the phrase, to take umbrage, indieates the more positive feeling of the two-a shadowing, as it were, of anger and jealousy. $P$ ique indicates a slighter and more frivolous feeling, a temporary pang of jealousy that is not strong enough to become a real and effective emotion. Neither of them indicate serious or permanent states of feeling.

UMBRELla, PARAsol. Umbrella comes from Latin umbra, and is a diminutive form, meaning a little shadow. It indicates a sereen, composed of a kind of canopy held over the head by a handle, to ward off the rain. Parasol, borrowed through French from Portuguese, and compounded of parar, to ward off (English parry), and sol, sun, means a similar sereen of lighter and gayer material earried to protect the bearer from the sun.

UMPIRE. See JUDGE.

UNAFFECTED. See Nalve.

UNBELIEF, INFIDELITY, INCREDULITY. Unbelief (see BELIEF) concerns matters in general; infidelity (see FAITHFUL) is unbelief as respeets Divine revelation; incredulity is unbelief in ordinary matters. Unbelief is taken in an indefinite and negative sense; it is the want of belief in any particular thing that may or may not be believed. The term unbelief does not of itself convey any reproachful meaning; it signifies properly a general disposition not to believe.

We may be unbelievers in indifferent as well as the most important matters, but the term unbeliever taken absolutely means one who disbelieves religious dogmas.

Infidelity is a more active state of mind; it supposes a violent and total rejection of that which is commonly believed: incredulity is also an aetive state of mind, in which we refuse belief in matters that may or may not be rejected. The Jews are unbelievers in the mission of our Saviour; the Turks, from the Christian point of view, are infidels, inasmuch as they do not believe in the Bible: Deists and atheists alike are likewise considered infidels, inasmuch as they set themselves up against the Christian revelation; well-informed people are always incredulous of stories respecting ghosts and apparitions.

See also Disbelief.

UNBLEMISHED. See Brameless.

UNBODIED. See INCORPOREAL.

UNBOUNDED. See BoundLess.

UNCEASINGLY. See INCESSANTLY.

UNCERTAIN. See DoubTFUl.

UNCERTAINTY. See QUANDARY.

UNCLEAN. See Squalid.

UNCONCERNED. See INDIFFERENT.

UNCONQUERABLE. See INVINCIBLE.

UNCOUTH. See UNGaInly.

UNCOVER, Discovel, Disclose. To uncover, like discover, implies to take off the covering; but the former refers mostly to an artificial, material, and oeeasional covering; the latter, of rarer application, to a natural, moral, and habitual eovering: plants are uncovered that they may receive the benefit of the air; they are discovered to aid the researches of the botanist.

To discover and disclose (see PoBLisH) both signify to lay open, but they differ in the object and manner of the action: to discover is to remove the covering which hides a thing from view, whether it be there by aceident or design; to disclose is to open that which has been closed: as many things may be eovered which are not closed, 
such things may, by drawing aside the covering, be discovered: a country is properly discovered, or a plant growing in some heretofore unknown place may be discovered; whatever is disclosed must have been previously closed or enclosed in some other body; as to disclose the treasures which lie buried in the earth.

So, in the figurative or moral application, a plot may be discovered, but a secret which lies deep in the bosom may be disclosed.

See also Bare; Disclose.

UNCTION, UNGUENT. Both of these words come from Latin ungere, to anoint, but unguent has kept its literal significance, and unction, while not wholly losing its original meaning, has developed a figurative application. An unguent is a soothing salve or oil applied to the skin; unction had originally the same meaning, but it is now used figuratively to signify that which is soothing or healing. Moreover, from its original significance of an oil for anointing, it has developed another figurative meaning, and refers to a kind of manner or speech, insincere suavity or exaggerated fervor $\rightarrow$ so that it is a variation of that which is expressed in popular speech by the figurative use of oily, in "an oily manner," an "oily address." In the phrase extreme unction, the word retains its literal significance with the addition of a figurative meaning. It signifies the anointing of the eyes, ears, nostrils, hands, and feet of a person mortally ill to signify the application of the oil of grace to the soul. The phrase means literally the "last anointing."

UNDAUNTED. See BoLD.

UNDENIABLE. See INdUBITABLE.

UNDER, BELOW, BENEATH. Under, like hind in behind, and the German unter, hinter, etc., are all connected with the preposition in, implying the relation of enclosure. Below denotes the state of being low; and beneath, Anglo-Saxon beneothan, allied to German nieder and English nether, has the same original signification. It is evident, therefore, from the above, that the preposition under denotes any situation of retirement or concealment; below, any situation of inferiority or lowness; and beneath, the same, only in a still greater degree. We are covered or sheltered by that which we stand under; we excel or rise above that which is below us; we look down upon that which is beneath us: we live under the protection of government; the sun disappears when it is below the horizon; we are apt to tread upon that which is altogether beneath us.

UNDERGO, BEAR, ENDURE, EXPERIENCE, SUFFer. Undergo, a compound of the prefix under and the English go, signifies, literally, to go, move, or pass under or below something, and has numerous applications. We undertake, or take upon ourselves, an enterprise, duty, obligation; we bear up with or against sorrow, misfortune, pain; we endure or put up with physical suffering, wrongs, conditions that we cannot alter; we suffer from annoyances, ill-health, untoward circumstances, accidents, losses, the enmity or machinations of others; and we experience, pass through, partake of, are subjected to, much that is unpleasant, disastrous, burdensome, heart-breaking.

UNDERMINE. See SAP.

UNDERSTAND. See CoNCEIVE.

UNDERSTANDING, INTELLECT, INTELLIGENCE. Understanding (see Concerve), being the Saxon word, is employed to describe a familiar and easy power or operation of the mind in forming distinct ideas of things. Intellect (see that word) is employed to mark the same operation in regard to higher and more abstruse objects. The understanding applies to the first exercise of the rational powers: it is therefore aptly said of children and savages that they employ their understandings on the simple objects of perception; a child uses his understanding to distinguish the dimensions of objects or to apply the right names to the things that come before his notice.

Intellect, being a matured state of the understanding, is most properly applied to the efforts of those who have their powers in full vigor: we speak of understanding as the characteristic distinction between man and brute; but human beings are distinguished from one another by the measure of their intellect. We' may expect the 
youngest children to employ an understanding according to the opportunities which they have of using their senses; we are gratified when we see great intellect in the youth whom we are instructing.

Intellect and intelligence are derived from the same word; but intellect is applied merely to human power and intelligence to the spiritual power of higher beings, as the intelligence of angels: so, when applied to human beings, it is taken in the most abstract sense for the intellectual power: hence we speak of intelligence as displayed in the countenance of a child whose looks evinee that he has exerted his intellect and thereby proved that it exists.

UNDERTAKING. See ATTEMPT. UNDETERMINED, UNSETTLED, UNSTEADY, WAVERING. Undetermined (see Determine) is a temporary state of the mind; unsettled is commonly more lasting: we are undetermined in the ordinary concerns of life; we are unsettled in matters of opinion: we may be undetermined whether we shall go or stay; we are unsettled in our faith or religious profession.

Undetermined and unsettled are applied to particular objects; unsteady and wavering are habits of the mind: to be unsteady is, in fact, to be habitually unsettled in regard to all objects. An unsettled character is one that has no settled principles: an unsteady character has an unfitness in himself to settle. Undetermined describes one uniform state of mind, namely, the want of determination: wavering describes a changeable state, namely, the state of determining variously at different times. Undetermined is always taken in an indifferent, wavering mostly in a bad, sense: we may frequently be undetermined from the nature of the case, which does not present motives for determining; but a person is mostly wavering, from a defect in his character, in cases where he might determine. A parent may with reason be undetermined as to the line of life which he shall choose for his son: men of soft and timid characters are always wavering in the most trivial, as well as the most important, concerns of life.
UNDIGNIFIED. See UNGRACEFUL.

UNDULATE, Vibrate, Wave. Undulate, in Latin undulatus, from unda, a wave, allied to Greek $v \dot{\omega} \omega \rho$, water, and the English word water (as well as to the Russian root vodá, water, which appears in vodka), refers to the rise and fall of the waves of the sea, and hence to any alternate elevation and depression of a surface. Vibrate, Latin vibrare, means to move to and fro or up and down. It usually signifies a quicker and more regular motion than undulate, with lesser elevations and depressions. Wave, as verb, comes from Anglo-Saxon wafian; the noun wave, derived from the verb, took the place of the Middle English wave, allied to wag: it means to move to and fro in response to an impulse received from without. A flag waves to and fro in the wind; we wave a handkerchief to a friend on the deck of a steamer. Wave does not suggest alternate elevation and depression as do vibrate and undulate. It merely suggests a movement to and fro.

UNEASINESS. See WorRY.

UNEASY. See UNGRACEFUL.

UNERRING. See INFALLIBLE.

UNEVEN. See JAGGED; ODD.

UNEXAMPLED. See UNPRECEDENTED.

UNEXPECTED. See SUDDEN.

UNFAITHFUL. See FAITHLESS.

UNFEELING. See HARD: HearTLESS.

UNFOlD. Unravel, Develop. To unfold is to open that which has been folded; to unravel is to open that which has been ravelled or tangled; to develop is to open that which has been wrapped in an envelope. The application of these terms, therefore, to moral objects is obvious: what has been folded and kept secret is unfolded; in this manner a hidden transaction is unfolded by being related circumstantially: what has been entangled in any mystery or confusion is unravelled: in this manner a mysterious transaction is unravelled if any circumstanee is fully accounted for: what has been wrapped up so as to be entirely shut out from view is developed; in this manner the plot of a play or novel, or the talent of a person, is developed. 
UNFORESEEN. See SUDDEN.

UNFUNDED, FLOATING. Unfund$e d$ is a compound of the prefix $u n$, not, and funded, provided with funds, and signifies a monetary obligation that has not been paid through lack of necessary means. While the term implies a debt, comprising bills, notes, and other evidences, in varying amounts, and due at different dates, it is most commonly employed to designate the part of a debt remaining unpaid and standing against a corporation or government.

A floating debt is that unfunded one which constitutes the real debt, the part of an originally larger one that is still owing, is unpaid. The unfunded debt of a government arises from arrears in its receipts, from obligations on which money has been raised, to be repaid out of future receipts. It is thus distinguished from a funded debt, which is that part of a public debt for the payment of interest for the reduction of which funds are appropriated at necessary intervals.

UNGAINLY, UNCOUTH. Ungainly is compounded of the negative prefix $u n$ and Icelandic gegn, ready, serviceable: cf. Scotch gane, fit, meaning originally not fitting. Uncouth, from Anglo-Saxon uncuth, unknown, hence strange, signifies a lack of conformity to prevailing modes of conduct or style, hence roughness, lack of social grace, etc. (Compare the similar development of outlandish, which originally meant simply from another land.) Ungainly refers mainly to physical awkwardness, uncouth to awkwardness of speech or manner. An ungainly person is one who is so constructed physically that he does not move with ease or grace. Uncouth indicates a lack of education and social advantages.

UNGOVERNABLE. See UNRULY.

UNGRACEFUL, INELEGANT, UNDIGNIFIED, UNEASY. Ungraceful, a compound term, signifies, in its application to a person or object, that which is not pleasing to the eye or appropriate to its particular use. A person is ungraceful who is awkward, clumsy, bungling, unhandy, rough, uncouth in manners, unrefined, unpolished; undignified, uncouth in speech, clownish, gawky, slouchy in action: inelegant, in the choice of language or attire; uneasy, overactive, restless, boorish, unmannerly, excessively nervous, in general bearing.

A material object is ungraceful when it is unbecoming, ill-fitted, inappropriate, lacking in harmonious, pleasing appearance, unsuitable, not conformable to surroundings. An article of attire is ungraceful that does not correspond with other associated articles or does not accord with the wearer's complexion or figure.

UNHAPPY, Miserable, WretchED. Unhappy is literally not to be happy; this is the negative condition of many who might be happy if they pleased. Miserable, from misereri, to pity, is to deserve pity; that is, to be positively and extremely unhappy: this is the lot only of comparatively few: wretched, from our word ureck, Anglo-Saxon wrecca, an outcast (compare the Anglo-Saxon verb wreccan, to persecute, from which our words wreck and the verb wreak, in the phrase wreak vengeance, are derived), signifies cast away or abandoned, that is, particularly miserable, which is the lot of still fewer. As happiness lies properly in the mind, unhappy is taken in the proper sense with regard to the state of the feelings, but is figuratively extended to the outward circumstances which occasion the painful feelings; we lead an unhappy life, or are in an unhappy condition: as that which excites the compassion of others must be external, and the state of abandonment must of itself be an outward state, miserable and wretched are properly applied to the outward circumstances which cause the pain, and improperly to the pain which is occasioned. We may measure the force of these words, that is to say, the degree of unhappiness which they express, only by the circumstances which cause the unhappiness. An unhappy man is indefinite, as we may be unhappy from slight circumstances or from those which are important; a child may be said to be unhappy at the loss of a plaything; a man is unhappy who leads a vicious life: miserable and wretched are more limited in their application; a child may be both miserable and wretched if it has some serious cause, either in its own mind or in its 
circumstances, to make it so: a man is miserable who is tormented by his conscience; a mother will be wretched whose child is taken from her.

UNIFORM. See EQUAL.

UNIMPORTANT, INSIGNIFICANT, IMMATERIAL, INCONSIDERABLE. The want of importance, of consideration, of signification, and of matter or substance, is expressed by these terms. They differ, therefore, principally according to the meaning of the primitives; but they are so closely allied that they may be employed sometimes indifferently. Unimportant regards the consequences of our actions: it is unimportant whether we use this or that word in certain cases: inconsiderable and insignificant respects those things which may attract notice: the former is more adapted to the grave style, to designate the comparative low value of things; the latter is a familiar term which seems to convey a contemptuous meaning: in a description, we may say that the number, the size, the quantity, ete., is inconsiderable; in speaking of persons, we may say they are insignificant in stature, look, talent, station, and the like; or, speaking of things, an insignificant production or an insignificant word: immaterial is a species of the unimportant which is applied only to familiar subjects; it is immaterial whether we go to-day or to-morrow; it is immaterial whether we have a few or many.

UNINTERRUPTEDLY. See INCESSANTLY.

UNION, Confederation, Coalimion, Fusion. These are all words used to signify a governmental or political combination. Union is the most general word. It signifies a making different entities one, from Latin unus, one, and may refer to any combination. Confcderation, coalition, and fusion are different forms of political union. Confederation, from Latin con, together, and foedus, league, means a joining together, a union in which different groups surrender part of their individual rights or powers to a central authority, but without entirely losing their separate identities. In a confederation such as that of the United States, for example, the states delegate certain of their powers to the central government without merging their separate identities in one. Coalition is derived from the past participle of the Latin word coalescere, found in English coalesce, and meaning to grow together. It signifies a temporary union of representatives of political parties for the purpose of carrying through some project in which they are all interested. A coalition cabinet is a eabinet composed of leaders of various political parties united in a common cause. Fusion, from the past participle fusus of Latin fundere, to pour (meaning something poured together, so that separate identities are lost), refers to a union of political parties in support of a single eandidate or platform.

UNIQUE. See UNPRECEDENTEd.

UNITE. See ADD; CoNNECT; MERGE.

UNITED. See Srnthetic.

UNIVERSAL. See Cosmos; Geveral; Public; Úbiquitous.

UNLEARNED. See IgNorant.

UNLESS, EXCEPT. Unless, which is equivalent to in less than, on a less supposition, is employed only for the particular case; but except has always a reference to some general rule, of which an exception is hereby signified: I shall not do it unless he ask me; no one can enter except those who are provided with tiekets.

See also BuT.

UNLETTERED. See IGNORANT.

UNLIKE. See DIFPERENT.

UNLIMITED. See BOUNDLESS.

UNMERCIFUL. Se e H A R D HEARTED.

UNOFFENDING, INOFFENSIVE. Both of these words indieate the negative of offending or offensive, and mean not offending. But inoffensive refers to a general disposition; unoffending, to a particular case. An inoffensive person is in the nature of things unoffending; one who is unoffending in one matter may not always be inoffensive. Inoffensive of ten carries with it the faintest implication of contemptuous condescension on the part of the speaker. It may mean not able to offerd, not having capacity or energy enough to offend. Unoffending does not suggest this ides.

UNPOLLUTED. See VIRsix.

UNPRECEDENTED, EXCEPTION- 
AL, UNEXAMPLED, UNRIVALLED, UNIQUE. Unprecedented, a compound of the English un, not, and precedented, antecedent, previous, former, or prior, signifies that which is so rare that there is nothing to be compounded with it, something that is sui generis, of its own kind, standing alone, wholly by itself. It is a stronger term than exceptional, which implies that which is unusual, and it is more closely allied with unexampled and unrivalled, each implying something without a counterpart or anything parallel with or equal to it. The distinction is seen, for instance, in a formal address. An exceptional address may be one of unusual cleverness, interest, and brilliancy, without being so rare as to reach the acme of intellectual effort, yet it may not be an unexampled one, much less an unrivalled one, as the just application of those terms depends on the varying viewpoints of the hearers. Strictly, unexampled implies that which is without the same likeness in its essentials, and unrivalled, that which is of the best, of the first water; but in common usage the terms are frequently erroneously applied to several objects or degrees of objects when in truth they belong to one only, as only one can be supreme. Unique expresses the same idea in positive rather than negative terms. That which is unique is the only one of its kind (from Latin unus, one). It is the superlative expression of the idea common to all these terms, and should not be compared; a thing is unique; it cannot be more or most unique.

UNPREMEDITATED, EXTEMPORANEOUS, IMPROMPTU, OFF-HAND, UNsTUDiED. Unpremeditated, a compound of the English un, not, and premeditated, from the Latin promeditatus, pro, before, and meditari, to meditate, implying to think of before, in advance of an action. 'This term is a very common one in criminology, signifying the commission of an act on the spur of the moment, on a sudden provocation, without previous cause, plan, or thought, as a felonious attack upon another that may result in a charge of assault and battery or of some degree of homicide, justifiable or otherwise.
Extemporaneous, from the Latin phrase ex tempore, at the moment, and impromptu, from the phrase in promptu, in readiness, from promere, to bring forward, are most generally applied to a spoken address that is called forth by an unexpected invitation, permitting the person called upon no opportunity for preparation. Off-hand is a less dignified term, as it implies a certain degree of carelessness, an indifferent fitting of language to occasion, a feeling that "anything will answer." Unstudied is most akin to unpremeditated, yet it implies a different effort, as an unpremeditated act may be one not previously thought of, while an unstudied act may be one that would ordinarily be studied or planned beforehand, but in its special application was done without any previous preparation.

UNQUESTIONABLE. See INDUBITABLE.

UNRAVEL. See UNFOLD.

UNRELENTING. See IMPLACABLE. UNRIVALLED. See UNPRECEDENTED.

UNRUffled, Calm, Peaceful, Smooth, Tranquil. Unruffled, a compound of the English un, not, and ruffled, parallel with Old Dutch ruyffelen, to wrinkle, and allied to ruff, rumple, etc., is applied both to objects and persons, implying that which is not agitated, not stirred up, not changed from a normal condition. The surface of a stream remains unruffled when it is not forced into ripples by the wind; a person, when under exciting conditions, displays neither agitation, nervousness, apprehension, nor fear. The sea, the atmosphere, a person, are calm when undisturbed by abnormal conditions; they are then said to be serene, placid, imperturbable. Peaceful and peaceable are terms frequently misapplied. The former signifies freedom from agitation or commotion, and thus belongs to the present group, while the latter signifies freedom from strife or contest.

Smooth and even, too, are likewise used erroneously, to imply a level condition; but they really signify more than that. Smooth, as distinguished from even, means that which is free from every degree of roughness, 
however small, while whatever is even may be free only from unusual roughness or irregularities. Smooth, therefore, in its truest application is in full accord with unruffed. Tranquil, however, admits of but one condition, that is, freedom from agitation, physical or mental, from disturbance, roughness of any character or degree, or from anything that would interfere with quietude, repose.

UNRULY, UNGOVERNABLE, REFRACTORY. Unruly marks the want of disposition to be ruled; ungovernable, an absolute incapacity to be governed: the former is a temporary or partial error, the latter is an habitual defect in the temper: a high-spirited child will be occasionally unruly; any child of strong passions will become ungovernable by excessive indulgence: we say that our wills are unruly and our tempers are ungovernable. Refractory, from refractus, past participle of the Latin refrangere, to break open, marks the disposition to break everything down before it: it is the excess of the unruly with regard to children: the unruly is, however, negative; but the refractory is positive: an unruly child objects to be ruled; a refractory child sets up a positive resistance to all rule; an unruly child may be altogether silent and passive; a refractory child always commits himself by some act of insubordination in word or deed: he is unruly if in any degree he gives trouble in the ruling; he is refractory if he actively resists being ruled.

UNSATISFACTORY, DISSATISFYING, INSUFFICIENT. All these terms mean not meeting the wishes or expectations. Unsatisfactory, however, is a less positive term than dissatisfying. That which is unsatisfactory fails to satisfy; that which is dissatisfying produces a positive emotional reaction which is the opposite to satisfaction. One fails to meet the conditions; the other definitely opposes them. Insufficient means literally not enough. It indicates a speeial kind of unsatisfactoriness. That which is insufficient is lacking in quantity; that which is unsatisfactory may be lacking in quality as well. That which is insufficient is unsatisfactory; that which is unsatisfactory may be much more than insufficient.
UNSEARCHABLE, INSCRUTABLE. These terms are both applied to things set above the understanding of man, but not altogether indifferently; for that which is unsearchable is not set at so great a distance from us as that which is inscrutable: for that which is searched is in common concerns easier to be found than that which requires a scrutiny. The ways of God are to us finite creatures more or less unsearchable; but the mysterious plans of Providence, as frequently evinced in the affairs of men, are altogether inscrutable.

UNSETTLED. See UNdeterMINED.

UNSHACKLE. See EMANCIPATE. UNSIGHTLY. See UGLY.

UNSPEAKABLE, INEFFABLE, UNUTTERABLE, INEXPRESSIBLE. Unspeakable and ineffable, from the Latin ineffabilis, based on in, not, and effabilis, utterable, from effari, to speak out, have precisely the same meaning; but the unspeakable is said of objects in general, particularly of that which is above human conception, and surpasses the power of language to describe; as the unspeakable goodness of God: ineffable is said of such objects as cannot be painted in words with adequate force; as the ineffable sweetness of a person's look: unutterable and inexpressible are extended in their signifieation to that which is incommunicable by signs from one being to another; thus grief is unutterable which it is not in the power of the sufferer by any sounds to bring home to the feelings of another; grief is inexpressible which is not to be expressed by looks, or words, or any signs. Unutterable is therefore applied only to the individual who wishes to give utterance; inexpressible may be said of that which is to be expressed concerning others: our own pains are unulterable; the sweetness of a person's countenance is inexpressible.

UNSPOTTED. See Brameless.

UNSTEADY. See UNDETERMINED. UNSTUDIED. See UNPREMEDITATED.

UNSWERVING, Constant, DeTERMINEd, Resolute. In the moral sense, unswerving implies the quality that makes a person steadfast in his 
course of life, in his friendships, in his varied dealings with others, always resolved, faithful, persevering, unhesitating, unwavering, wholly dependable. $\mathrm{He}$ is constant whose course of action is incessant, uninterrupted, regular, who remains true through all contingencies. Determined is a more vigorous term, as it implies a consideration of certain conditions, a decision as to a proper course to follow, and a persistent adherence to that course, despite allurements or seeming advantages to the contrary. A resolute person is one possessing the quality of more than ordinary firmness of purpose, one having a fixed, unalterable purpose, one constant in the pursuit of an aim, one who is unshaken on all occasions, undaunted, inflexible, stout-hearted under trying or adverse circumstances. The terms determined and resolute have various shades of meaning, which are more critically considered under the term DECIDED.

UNTOUCHED. See VIRGIN.

UNTOWARD. See AwKWARD.

UNTRUTH, FALSEHOOD, FALSITY, LIE. Untruth is an untrue saying; falsehood and lie are false sayings: untruth of itself reflects no disgrace on the agent; it may be unintentional or not: a falsehood and a lie are intentional false sayings, differing only in degree as to the guilt of the offender: a falsehood is not always spoken for the express intention of deceiving, but a lie is uttered only for the worst of purposes. Some persons have a habit of telling falsehoods from the mere love of talking: those who are guilty of bad actions endeavor to conceal them by lies. Children are apt to speak untruths for want of understanding the value of words: travellers, from a love of exaggeration, are apt to introduce falsehoods into their narrations: it is the nature of a lie to increase itself to a tenfold degree; one lie must be backed by many more.

Falsehood is also used in the abstract sense for what is false. Falsity is never used but in the abstract sense, for the property of the false. The former is general, the latter particular, in the application: the truth or falsehood of an assertion is not always to be distinctly proved; the falsity of any particular person's assertion may be proved by the evidence of others.

\section{UNUSED. See VIRgIN.}

UNUTTERABLE. See UNSPEAKABLE.

UNVEIL, Disclose, Remove, ReVEAL, SHOW. Unveil, a compound of the English un, not, and veil, a covering, the latter in Old French veile, French voile, from the Latin velum, a sail, from vehere, to carry (i.e., that which carries or moves the boat), and hence any piece of cloth, or a covering, signifies, as a transitive, to remove a covering from something, to make clear something that was previously hidden or but slightly visible; as an intransitive, to come to light or become known. The term has many applications-among them: we unveil a memorial, statue, or painting by removing its temporary covering; we unveil a secret, conspiracy, plot, purpose, by making it known; we unveil a mental burden by confiding it to another.

Disclose, from the Latin discludere, to open, signifies the act of making known or public something that is concealed, to bring to light something not generally known, and reveal, from the Latin revelare, to draw back a cover, in French révéler, signifies to divulge something known to ourselves but not to others, to lay bare a mystery or a secret purpose, in a special sense, to make known something which could not become known without divine or supernatural instruction. Remove signifies to take away, put aside, disassociate, separate, as to displace something that covers or conceals something else; and show implies an exhibition, a display, a presentation to the view, of something that has not been generally seen, by an action that makes it visible.

UNWILliNG. See Averse.

UNWORTHY, WORTHLESS. Unworthy is a term of less reproach than worthless; for the former signifies not to be worthy of praise or honor; the latter signifies to be without any worth, and consequently in the fullest sense bad. It may be a mark of modesty or humility to say that I am an unvorthy recipient of your kindness; but it would be folly and extravagance to 
say that I am a worthless recipient of your kindness. There are many unworthy members in every religious community; but every society that is conducted upon proper principles will take care to exclude worthless members. In regard to one another, we are often unworthy of the distinctions or privileges we enjoy; in regard to our Maker, we are all unworthy of His goodness, though not worthless in His eyes.

UPBRAID. See Blame.

UPHOLD, AID, Maintain, SancTion, Support, Vindicate. Uphold, a compound of the English $u p$ and hold, from a widely distributed Germanic root, hal, signifying to raise, hence to grasp and keep, means to keep raised or elevated. The term is equally applicable to persons and objects. We uphold a person when we agree with him, stand by him, make his attitude our own, on some controversy, proposition, or position he has assumed; we aid him by helping, assisting him to retain the position or attitude he has taken; we maintain his actions or declarations by affirming or defending them, adopting them as consistent with our own judgment; we sanction what he does or says by confirming, assenting to, coinciding with, the act or saying; we support him by favoring, seconding, consenting' to, or vouching for, his position; and we vindicate him when we corroborate, establish the validity, or defend successfully that which he has said or done. In a material sense, uphold and support are applied to one object set beneath another, to bear it up, sustain it, or keep it from falling, as a pillar, base, foundation, or any object on which another object rests, and maintain is applied to the province or duty of the objeet so used.

UPON. See Above; ON.

UPRIGHT. See VIRTUOUS.

UPRIGHTNESS. See HoNESTY; RECTITUDE.

UPROAR. See BUSTLE.

UPSIDE-DOWN. Se e ToPsY TURVY.

URBANITY. See SUAVITY.

URGE. See ENCoURAGE.

URgent. See Pressing.

USAGe, Custom, Prescription. The usage is what one has been long used to do; custom is what one generally does; prescription is what is prescribed by usage to be done. The usage acquires force and sanction by dint of time; the custom acquires sanction by the frequency of its being done or the numbers doing it; the prescription acquires force by the authority which prescribes. Hence it arises that customs vary in every age, but that usage and prescription supply the place of written law.

Sce also Treatament.

USE. See EMPLOY; UtiltTY.

USUALLY. See Commonly.

USURP. See APPROPRIATE.

UTILITY, Use, Service, Avall. Utility and use both come ultimately from utor. Service, from the Latin servire, to employ or make use of. Avail, from $a$ or ad and French valoir, Latin valere, signifies strength for a given purpose or to a given end.

All these terms imply fitness to be employed to advantage (see ADvaxTAGE). Utility is applied in a general sense to what may be usefully employed: use to that which is actually so employed; things are said to be of general utility, or a thing is said to be of a particular use.

The word use refers us to the employment of things generally and the advantage derived from such use; service, the particular state or capacity of a thing to be usefully employed. It is proper, therefore, to say that prayers and entreatics are of use; but in speaking of tools, weapons, and the like, to say they are of service. Prudence forbids us to destroy anything that may be of use; economy enjoins upon us not to throw aside anything as long as it is fit for service.

All the preceding terms are taken absolutely; avail is a term of relative import; it respects the eircumstances under which a thing may be fit or otherwise to be employed with efficacy. When entreaties are found to be of no avail, females sometimes try the foree of tears.

UTOPIAN, Chimerical, Fanciful, IDEAL, Visionary. Utopian was derived from the Greek oí, not, and ró $\pi$ os, a place, literally nowhere, and has the sense of a good or happy place. The term Utopia was coined by Sir Thomas 
More for his famous work, published in 1513, describing an imaginary island, where the most nearly perfect system of laws and institutions existed; hence Utopian, as an adjective, has come to apply to anything founded on or involving ideal perfection, and, as a substantive, to a person enthusiastic in efforts to promote schemes for unalloyed social happiness. The term has had a general acceptance ever since Sir Thomas coined it, as it seemed to apply admirably to a class of political and social propagandists who aimed at impracticable, ideal perfectibility.

The term chimerical, from the Latin

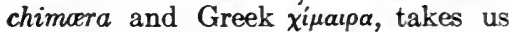
back to the annals of mythology, wherein the chimera is described as a firespouting monster with a lion's head, a serpent's tail, and a goat's body, that was killed by Bellerophon. Hesiod narrates that the monster was the daughter of Typhaon and Echidna. When the term was introduced into common English language, it was used to imply an unreal creature of the imagination, and hence any vain or idle fancy. As fancy (for derivation see Fancirul) signifies a notion, caprice, idea, creative imagination, or that which does not really exist, but is hoped to exist, so fanciful signifies whatever one would like to see, do, or possess, yet is incapable of in any of these respects. So, too, is the ideal a visionary condition impossible of realization, however desirable or beneficial that state might be, because existing only in the imagination, a mental image, a conception of what ought to be. This term is also applied to a person or object regarded as a standard of perfection, as possessing qualities far above the ordinary.
UTTER, Speak, Articulate, ProNoUNCE. Utter, from out, Middle English outen, a verb formed from the adverb out, corresponding to the colloquial expression "out with it," signifies to send forth a sound: this, therefore, is a more general term than speak, which is to utter an intelligible sound. We may utter a groan; we speak words only or that which is intended to serve as words. To speak, therefore, is only a species of utterance; a dumb man has utterance, but not speech. Articulate and pronounce are modes of speaking; to articulate, from articulation, a joint, is to pronounce distinctly the letters or syllables of words; which is the first effort of a child beginning to speak. It is of great importance to make a child articulate every letter when he first begins to speak or read. To pronounce, from the Latin pronunciare, to speak out loud, is a formal mode of speaking. A child must first articulate the letters and the syllables, then he pronounces or sets forth the whole word; this is necessary before he can speak to be understood.

See also Announce; Declare; SPEAK.

UTTERMOST, ExTREME, FARTHEST, LAST. Uttermost, from AngloSaxon utor, signifies the extreme outer edge of anything. It therefore is a more limited application of the idea contained in extreme. The same is true of its relation to farthest and last. Farthest and last have a meaning similar to that of extreme, but they emphasize the utmost limit suggested in extreme from different points of view. Farthest lays the stress on distance; last expresses the idea in terms of numbers, or rather from the standpoint of some one counting. Last is that which comes at the end of a series. 
VACANCY, VACUITY, INANITY. Vacancy and vacuity both denote the space unoccupied, or the abstract quality of being unoccupied. Inanity, from the Latin inanis, denotes the abstract quality of emptiness or of not containing anything: hence the former terms vacancy and vacuity are used in an indifferent sense; inanity always in a bad sense: there may be a vacancy in the mind, or a vacancy in life, which we may or may not fill up as we please; but inanity of charaeter denotes the want of the essentials that constitute a character.

VACANT. See EMPTY; IDLE.

VACILLATE, WAVER. Vacillate, from Latin vacillare, to waver, is the Latin word corresponding to the native English waver, a frequentative of wave. Waver is used with a literal as well as a figurative significance. Vacillate is now used only figuratively to indicate mental indecision, an inability to determine upon a course of action or an opinion and to stick to it. It has a more limited application than waver, but is more specific within its narrower field.

VAGARY, Crotchet, FANCY, Whim. Vagary, in Latin vagari, French vaguer, Italian vagare, as a transitive signifies to roam, stroll, wander; as a substantive, a wandering of the thoughts, a wild freak, a whim, an unsubstantial purpose, an imaginary concept, a eapricious frolic; as a verb, to wander about or wind, as a river.

A vagary, in whatever form it may assume, is an outgrowth of an unsteady mind, in most instances harmless, though of ten annoying to others; in some instances a consequence of imbecility, delirium, or insanity.

A caprice (derived through French from Italian capriccio, from capria, goat, meaning a sudden leap of the mind like the leap of a goat-compare caper), or sudden impulse of the mind, may take the form of an innocent frolic or of a questionable aet; a crotchet, originally a musical term, "tune" or "air," hence a fancy or a whim, is usually a fancy made especially noticeable by the tenaeity with which its possessor clings to and displays it, a thought or idea out of the ordinary, a bit of imagination, groundless but conjured up; and a whim may be a sudden flash of the mind, a more or less ridiculous impression, or the result of a progressive aberration.

VAGRANT. See Truant.

VAGUE. See Loose.

VAIN, INerfectual, Fruttless. These epithets are all applied to our endeavors; bi: the term vain (see IDLE) is the most general and indefinite; the other terms are particular and definite. What we aim at, as well as what we strive for, may be vain; but neff ctual, that is, not effectual (see EFFective), and fruitless, that is, without fruit, signifying not produeing the desired fruit of one's labor, refer only to the termination or value of our labors. When the object aimed at is general in its import it is common to term the endeavor vain when it cannot attain this object: it is vain to attempt to reform a person's character until he is convinced that he stands in need of reformation; when the means employed are inadequate for the attainment of the particular end, it is usual to eall the endeavor ineffectual; cool arguments will be ineffectual in convineing any one inflamed with a particular passion; when labor is speeifieally employed for the attainment of a particular object, it is usual to term it fruitless if it fail: peace-makers will often find themselves in this condition, that their labors will be rendered fruiless by the violent passions of angry opponents.

VALOR. See BRAVERY.

VALUABLE, Preciods, Costhy. Valuable signifies fit to be valued; precious, having a high price; costly, costing much money. Valuable expresses direetly the idea of value; pre-
cious and costly express the same idea 
indirectly: on the other hand, that which is valuable is said only to be fit or deserving of value; but precious and costly denote that which is highly valuable, according to the ordinary measure of valuing objects, that is, by the price they bear; hence, the latter two express the idea much more strongly than the former.

They are similarly distinguished in their moral application: a book is valuable according to its contents, or according to the estimate which men set upon it, either individually or collectively. The Bible is the only precious book in the world that has intrinsic value, that is, set above all price. I There are many costly things, which are valuable only to the individuals who are disposed to expend money upon them.

Value, Worth, Rate, Price.-Value, from the feminine past participle of the French valoir, Latin valere, to be strong, implies those essential qualities which constitute its strength. Worth, in Anglo-Saxon weorth, valuable, a Germanic word from the root war, to guard or keep, found in wary, ward, etc., signifies that which deserves to be kept and guarded, hence the good experienced or felt to exist in a thing. Rate (see Proportion). Price, through Old French from Latin pretium, signifies what a thing is sold for.

Value is a general and indefinite term, applied to whatever is conceived to be good in a thing: the worth is that good only which is conceived or known as such. The value, therefore, of a thing is as variable as the humors and circumstances of men; it may be nothing or something very great in the same object at the same time in the eyes of different men. The worth is, however, that value which is acknowledged; it is therefore something more fixed and permanent: we speak of the value of external objects which are determined by taste; but the worth of things as determined by rule. The value of a book that is out of print is fluctuating and uncertain; but its real worth may not be more than what it would fetch for waste paper. The rate and price are the measures of that value or worth; the former in a general, the latter in a particular, application to mercantile transactions. Whatever we give in exchange for another thing, whether according to a definite or an indefinite estimation, is said to be done at a certain rate; thus we purchase pleasure at a dear rate when it is at the expense of our health: price is the rate of exchange estimated by coin or any othe: medium: hence price is a fixed rate, and may be figuratively applied in that sense to moral objects; as when health is expressly sacrificed to pleasure, it may be termed the price of pleasure.

Value, Prize, Esteem.-To value is in the literal sense to fix a value on a thing. Prizc, signifying to fix a price, and esteem are both modes of valuing.

To value is to sct any value, real or suppcsititious, relative or absolute, on a thing: in this sense men value gold above silver, or an appraiser values goods. To value may be applied to either material or spiritual subjects, to corporeal or mental actions: prize and esteem are taken only as mental actions; the former in reference to sensible or moral objects, the latter only to moral objects: we may value books according to their market price, or we may value them according to their contents; we prize books only for their contents, in which sense prize is a much stronger term than value; we also prize men for their usefulness to society; we esteem their moral characters.

VANISH. See Disappear.

VANity. See Pride.

VANQUISH. See CoNQUER.

VARIABle. See Changeable.

VARIATION, VARIETY. Variation denotes the act of varying (see ChANGE); variety denotes the quality of varying, or the thing varied. The astronomer observes the variations in the heavens; the philosopher observes the variations in the climate from year to year. Variety is pleasing to all persons, but to none so much as the young and the fickle: there is an infinite variety in every species of objects, animate or inanimate.

VARIOUS. See Different.

VARNISH. See GLOSS.

VARY. See Change; Differ.

VASSALAGE. See Thraldom.

VAST. See Enormods.

VAUNT. See Gasconade; Glory. 


\section{Cueturap}

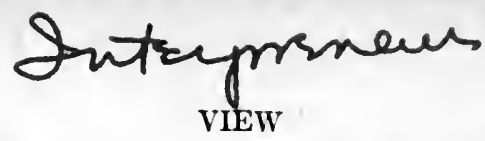

VEHEMENT. See VIOLENT.

VEIL. See Cloak.

VELOCITY. See QUICKNESS.

VENAL, Mercenary. Venal from the Latin venalis, signifies salable or ready to be sold, which anolied as it commonly is to persons, is a much stronger term than mercenary. A venal man gives up all principles for interest; a mercenary man seeks his interest without regard to principle: venal writers are such as write in tavor of the cause that can promote them to riches or honors; a servant is commonly a mercenary whe guves his services according as he is paid: those who are loudest in their professions of political vurity are the best subjects for a minister to make venal: a mercenary spirit is engendered in the minds of those who devote themselves exclusively to trade.

VEINERATE. SEe ADORE.

VENIAL, Pardonable. from the Latin venia, pardon or indulgence, is applied to what may be tolerated without express disparagement to the individual or direct censure; but the pardonable is that which may only escape severe censure, yet cannot be allowed: garrulity is a venial offence in old age; levity in youth is pardonable in single instances.

VENOM. See PoIson.

VENTURE. See HAZARD.

VERACITY. See Truth.

VERBAL, Vocal, Oral. from verbum, a word, signifies after the manner of a spoken word; oral, from the stem of os, a mouth, signifies by word of mouth; and vocal, from the stem of vox, the voice, significs by the voice: the former two of these words are used to distinguish speaking from writing; the latter to distinguish the sounds of the voice from any other sounds, particularly in singing: a verbal message is distinguished from one written on a paper or in a note; oral tradition is distinguished from that which is handed down to posterity by means of books; vocal music is distinguished from instrumental; vocal sounds are more harmonious than those which proceed from any other bodies.

See also Announce; Speak.

VERDANT. See GREEN.

VERGE. Sec BOKDER.
VERSATIle. See Changeable. VERY. See QUITE.

VESTIGE. See Mark.

VEX. See Displeasure; Tease.

VEXation, Montification, ChaGRIN. Vexation (see DispleAsURE) springs from a variety of causes, acting unpleasantly on the inclinations or passions of men; morlification (see HUMBLE) is a strong degree of vexation, which arises from particular circumstances acting on particular passions: the loss of a day's pleasure is a vexation to one who is eager for pleasure; the loss of a prize, or the circumstance of coming into disgrace where we expected honor, is a mortification to an ambitious person. Vexation arises principally from our wishes and views being crossed; mortification, from our pride and self-importance being hurt; chagrin, in French chagrin (compare the title of Balzac's novel, La Pcau de Chagrin), comes originally from shagreen, a word of Oriental origin meaning a rough and granular skin used for polishing, henee by extension anything irritating, or a state of irritation; disappointments are always attended with more or less vexation, according to the circumstances which give pain and trouble; an exposure of our poverty may be more or less of a mortification, according to the value which we set on wealth and grandeur; a refusal of a request will produce more or less chagrin, as it is accompanied with circumstances more or less morlifying to our pride.

See also Trovblesome.

VIBRATE. See Tи RILL; UNDULATE; WAG.

VICE. See Crime; Imperfection. VICINITY. See NeIGIHOHIOOD.

vicissitude. See Change.

VICTOR. See CoNqukror.

VICTORY. See TriUMPH.

VIE. See Strive.

VIEW, Survey, Prospect. lieno (see Look) and survey, compounded of vey or view and sur, over (Coleridge uses the word surview to mean a complete view of a thing as a whole), mark the act of the person, namely, the looking over a thing with more or less attention: prospect, from the Latin prospectus and prospicere, to see before, designates the thing seen. We take 3 
view or survey; the prospect presents itself: the view is of an indefinite extent; the survey is always comprehensive in its nature. Ignorant people take but narrow views of things; men take more or less enlarged views, according to their cultivation: the capacious mind of a genius takes a survey of all nature. The view depends altogether on the train of a person's thoughts; the prospect is set before him, it depends upon the nature of the thing: our views of advancement aro sometimes very fallacious; our prospects are very delusive; both occasion disappointment; the former is the keener, as we have to blame the miscalculation upon ourselves. Sometimes our prospects depend upon our views, at least in matters of religion; he who forms erroneous views of a future state has not foreseen the prospect beyond the grave.

View, Prospect, Landscape. - View and prospect, though applied here to external objects of sense, have a similar distinction as in the preceding article. The view is not only that which may be seen, but that which is actually seen; hence the term view is mostly coupled with the person viewing, although a prospect exists continually, whether seen or not: hence we speak of our view being intercepted, but not our prospect intercepted; a confined or bounded view, but a lively or dreary prospect, or the prospect clears up or extends.

View is an indefinite term; it may be said either of a number of objects or of a single object, of a whole or of a part: prospect is said only of an aggregate number of objects; we may have a view of a town, of a number of scattered houses, of a single house, or of the spire of a steeple; but the prospect comprehends that which comes within the range of the eye. View may be said of that which is seen directly or indirectly; prospect only of that which directly presents itself to the eye: hence a drawing of an object may be termed a view, although not a prospect. View is confined to no particular objects; prospect mostly suggests rural objects; and landscape means only a view on land. Landscape, landskip, or landshape, denote any portion of country which is in a particular form: hence the landscape is a species of prospect. A prospect may be wide, and comprehend an assemblage of objects both of nature and art; but a landscape is narrow, and lies within the compass of the naked eye: hence it is also that landscape may be taken for the drawing of a landscape, and consequently for a species of view: the taking of views or landscapes is the last exercise of the learner in drawing.

See also AIM; J,ook; SPY.

VIGILANT. See WAKEFUL.

VIGOR. See ENERGY.

VIGOROUS. See HerculeaN.

VILE. See Base; Squalid.

VILIFY. See REvile.

VINDICATE. See Assert; Avenge; DEFEND; UPHOLD.

VIOLATE. See INFRINGE.

VIOLENCE. See ForCE.

VIOLENT, Furious, Boisterous, Vehement, IMPETUous. Violent signifies having force (see Force). Furious signifies having fury (see Axger). Boisterous comes possibly from bestir, signifying ready to bestir or come into motion. Vehement, in Latin vehemens, compounded of veho and mens, signifies carried away by the mind or the force of passion. Impetuous signifies having an impetus (from in, on, and petere, to fly, hence to seek, to rush on, to fall upon).

Violent is here the most general term, including the idea of force or violence, which is common to them all; it is as general in its application as in its meaning. When violent and furious are applied to the same objects, the latter expresses a higher degree of the former: a furious whirlwind is violent beyond measure. Violent and boisterous are likewise applied to the same objects; but the boisterous refers only to the violence of the motion or noise: hence we say that a wind is violent inasmuch as it acts with great force upon all bodies; it is boisterous inasmuch as it causes the great motion of bodies: impetuous, like boisterous, is also applied to bodies moving with great violence.

These terms are all applied to persons, or what is personal, with a similar distinction: a man is violent in his opinions, violent in his measures, violent in 
his resentments; he is furious in his anger, or has a furious temper; he is vehement in his affections or passions, vehement in love, vehement in zeal, vehement in pursuing an object, vehement in expression: violence transfers itself to some external object on which it acts with force; but vehemence implies that species of violence which is confined to the person himself: we may dread violence because it is always liable to do mischief; we ought to suppress our vehemence because it is injurious to ourselves: a violent partisan renders himself obnoxious to others; a man who is vehement in any cause puts it out of his own power to be of use. Impetuosity is rather the extreme of violence or vehemence: an impetuous attack is an excessively violent attack; an impetuous character is an excessively vehement character. Boisterous is said of the manner and the behavior rather than the mind.

VIRGIN, Damsel, Girl, Lass, Maid, MaIden. All these words indicate a young unmarried woman. Virgin, Latin virgo, virginis, refers specifcally to a lack of experience of sexual intercourse, and may be used simply as a synonyme of pure, untouched, etc., as when we speak of virgin soil, virgin forests, etc. Damsel comes from the Old French damoisel, a young page or squire, from Late Latin dominicellus, a little lord, the diminutive of dominus, lord. Girl, also, was originally applied to a boy; it meant a child in general. Lass may be of Scandinavian origin. Maid is an abbreviation of maiden, AngloSaxon magden, an unmarried girl. Of these terms girl is the usual word; virgin carries the special emphasis upon chastity. Lass is arehaic or colloquial; maiden is poetic, laying some emphasis upon the idea suggested in virgin; maid is poetic, but is also used colloquially to indicate a female servant. Damsel is also a somewhat poetic and archaic word, sometimes humorously applied to particularly unpoetic persons.

VIRTUOUS, Chaste, Good, MorAL, PURe, UPright. Virtuous, in French vertueux, from Low Latin virtuosus, Latin virtus, indicated the proper character of a man (vir), the sum of all manly virtues. It now signifies the person who is at heart morally good, who abstains from vice, acts in the spirit of the moral law, is brave, valorous, and strong in principles, efficient through the operation of inherent qualities, pure in deed and thought, upright, honest, impartial, prompt in all his dealings, and, when applied to women, one having excellent qualities, specifically being chaste, pure, unspotted. When applied to actions the term signifies that which is done in conformity with the moral or divine law or with duty, that which is beneficial to others, that which creates or promotes goodness, morality, purity, in the community.

VIRULENT, Malignant. Virulent comes from Latin virus, originally slime, but used to signify poison. Malignant comes from Latin malus, bad, and gignere, to be born, to be of a certain nature. (Compare benignant for a similar formation and contrary meaning.) Both words signify actively and violently hostile or evil. In accordance with their derivations, however, virulent indicates that which is poisonous, malignant that which is fatally hostile to life or peace. Virulent spech is speech so permeated by intense and morbid ill-will that it seems to be poisoned. Venomous has a similar meaning, but is not so strong a word as virulent. Malignant speech is that which is also hostile; but the emphasis is placed upon the ill-will itself, not upon its morbid and poisonous character. Malignant is applied more frequently to actions and facial expression, virulent mainly to speech and emotion.

VISAGE. See FACE.

VISIBLE. See APPARENT.

VISION, Apparition, P'haston, Spectike, Gilost. Vision, from the Latin visus, secing or seen, signifies either the act of seeing or thing seen: apparition, from appcar, signifies the thing that appears. As the thing seen is only the improper signification, the term vision is never employed but in regard to some agent: the vision depends upon the state of the visual organ; the vision of a person whose sight is defective will frequently be fallacious, he will see some things double which are single, long which are short, and the like. 
In like manner, if the sight be miraculously impressed; his vision will enable him to see that which is supernatural: hence it is that vision is either true or false, according to the circumstances of the individual; and a vision, signifying a thing seen, is taken for a supernatural exertion of the vision; apparition, on the contrary, refers us to the object seen; this may be true or false, according to the manner in which it presents itself. Joseph was warned by a vision to fly into Egypt with his family; Mary Magdalene was informed of the resurrection of our Saviour by an apparition: feverish people often think they see visions; timid and credulous people sometimes take trees and posts for apparitions.

Phantom, from the Greek фá $\tau \tau \alpha \sigma \mu \alpha$, based on фaivw, to appear, is used for a false apparition or the appearance of a thing otherwise than what it is; thus the ignis fatuus, vulgarly called jack-o'lantern, is a phantom. Spectre, formed from specere, to behold, and ghost, from Anglo-Saxon gast, a spirit, are the apparitions of immaterial substances. The spectre is taken for any spiritual being that appears, but ghost is taken only for the spirits of departed men who appear to their fellow-creatures: a spectre is sometimes made to appear on the stage; ghosts exist mostly in the imagination of the young and the ignorant.

VISIONARY. See ENTHUSIAST; QUIXOTIC; UTOPIAN.

VISITANT. See Guest.

VITAL. See Critical.

VITIATE. See DEBAUch.

VIVACIOUS. See Lively.

VIVACITY. See ANIMATION.

VIVID. See Clear.

VOCABULARY. See DictionaRX. VOCAL. See VERBAL.

VOCATION, Calling, Employment, Occupation, Profession. All these words refer to a man's habitual business. Vocation is the Latin word corresponding to Teutonic calling. It means the business to which the natural talents or tastes lead a man. Employment signifies a more temporary business than occupation. Profession implies a formal intellectual training and is applied to the occupations de- manding such a training - as law, medicine, etc.

VOGUE, FAshion. Vogue, ultimately from a Germanic word allied to wave or wag, and fashion, from Latin factionem, a noun derived from facere, to make, have much the same meaning, but vogue is a somewhat more specific and sophisticated word applied to the fashion that makes a particular appeal to the wealthy and otherwise élite and is temporarily emphasized by them. (See Fashion.)

VOID. See EMPTY.

VOLATILITY. See LightNess.

VOlUble, Fldent, Glib, Loquacious, Talkative. Voluble, a French term taken from the Latin volubilem, that from volvere, signifies that which is easily turned about, rolled, or fickle. Fluent, from Latin fluere, to flow, signifies a ready speech which resembles Tennyson's brook or a brimming river in its continuous movement. Glib, originally slippery, is allied to the verb glide. (Compare Dutch glibbery.) Loquacious is derived ultimately from the Latin loqui, to speak, through loquax, talkative, and corresponds to talkative in its derivation. These words all mean ready of speech, but there are slight shades of difference between them. Fluent simply indicates speech that is uttered easily, without hesitation. It is generally a term of praise, or, at least, merely indifferent, not derogatory. Loquacious may be derogatory. A loquacious person is one who talks a great deal or talks too much. Talkative has a similar significance, but, being of English derivation, it carries its meaning on the face of it more plainly than does loquacious and is a more homely word. Voluble means both fluent and loquacious, inclined to talk freely and uttering the words with great speed and readiness. Glib means ready of speech, with especial reference to plausible and conciliatory language.

VOLUNTARILY. See WILLINGLY.

VOLUNTARY. See Gratuitous.

VOLUPTUARY See Sensualist.

VORACIOUS. See RAPACIOUS.

VOTE, SUfFrage, Voice. Vote comes from votum, the neuter past participle of Latin vovere, to vow, and has therefore the same derivation as English vow; it signified a formal ex- 
pression of opinion. Suffrage comes from Latin suffragium. Voice is here figuratively taken for the voice that is raised in favor of a thing.

The vote is the wish itself, whether expressed or not; a person has a vote, that is, the power of wishing; but the suffrage and the voice are the wish that is expressed; a person gives his suffrage or his voice. The vote is the settled and fixed wish, it is that by which social concerns in life are determined; the suffrage is a vote given only in particular cases; the voice is the declared opinion or wish, expressed either by individuals or the public at large. The vote and voice are given either for or against a person or thing; the suffrage is commonly given in favor of a person: in all public assemblies the majority of votes decide the question; members of most representative political bodies are chosen by the suffrages of the people; in the execution of a will, every executor has a voice in all that is transacted.

VOUCH. See AFFIRM.

VOYAGE. See JoURNeY.

VULGAR. See CoMmon.

VULNERABLE, WEAK, ExPOSED. Vulnerable, from Latin vulnus, wound, means easily wounded. It is therefore a synonyme of weak, but only in a special sense. Vulnerable refers to only one kind of weakness, and, it is therefore much more limited in its application, but more specific within its own range of application. Exposed expresses the idea involved in vulnerable by an indirect reasoning from cause to effect, as it were. That which is $e x$ posed is easily hit by a missile; it is therefore vulnerable. 
WaFt, Bear, Convey, Float, Signal, Transmit. Waft, a variant of Wave (which see), signifies to bear, convey, transport something through a fluid or buoyant medium like the air or sea, to float, as on the water or through the air, to beckon or signal by moving a flag or other object in the air, to transmit (poetical) a message, good wishes, a blessing; also to turn quickly, as "Wafting his eyes to the contrary," Shakespeare's Winter's Tale, to buoy up, as "Their lungs being able to waft up their bodies," Browne's Vulgar Errors, and a breath or current, as of air, as "One wide waft," 'Thomson's Winter.

Wag, Fluctuate, Oscillate, Swing, Vibrate. Wag, from wegan, to bear, carry, move (whence weigh, to raise or lift, hence, in our sense, to weigh, is derived), signified to move back and forth, to keep moving. Fluctuate, from Latin fluctus, signified to move like a flood, like the tides of the sea, for instance. Oscillate is derived from oscillum, literally "a little mouth," applied to an image of Bacchus suspended from a tree, and hence meant to swing like a pendulum. Swing is derived from Anglo-Saxon swingan, to shake. (Compare swinge from the same verb.) Vibrate comes from Latin vibrare, to shake, brandish, etc. Wag is a highly colloquial word meaning to move back and forth, especially applied to the conscious movements of living creatures. A dog wags his tail. Oscillate means to swing between two objects. Fluctuate means to rise and fall irregularly like the waves of the sea; vibrate to move with a regular alternate depression and elevation. Swing means simply to move back and forth as if suspended from something.

See also Undulate.

WAGES. See Allowance.

WAil, Cry, Deplore, Grieve, LaMENT, MoAN, Weep. Wail, from Scandinavian vala, signifies to cry woe, from $v a$, vei, woe, used as an interjection. Compare woe. Cry, Old French cricr,
Italian gridare; Latin quiritare, is a frequentative of Latin queri, to complain or lament, whence the word querulous is derived. Deplore comes from Latin plorare, to weep, to shed tears. For the derivation of grieve see grief; for lament see bewail; for moan see groan. Weep is derived from Anglo-Saxon wepan, to cry aloud, to raise an outcry. All of these terms indicate a different shade of wailing. When we cry we make either a low, partially suppressed noise or one that amounts to a shriek or scream, according to the intensity of the cause or our power of selfcontrol; so, too, when we deplore, grieve, or lament for or over a distressing condition, the expressions may be entirely inaudible, more apparent in manner or a change of countenance, or be indicated by a moan, which is always a low and, generally, prolonged expression of pain or sorrow, or a grief or lamentation may reach the height of hysteria, with its paroxysms of loud laughter or weeping. Then, when we weep we express our grief or anguish by shedding tears, a silent action in itself, but this, too, may be accompanied by an outcry, where the cause is especially intense.

WAIT, WaIt For, AwaIt, LoOK For, EXPECT. Wait, wait for, await, Old French waite, gaite, a guard, allied to Anglo-Saxon wacian, to wateh, whence the verb watch is itself derived, to see or look, and expect, from the Latin ex, out of, and specto, to behold, both signify originally the same thing as look for, that is, to look with concern for a thing.

All these terms express the action of the mind when directed to future matters of personal concern to the agent. Wait, wait for, and await differ less in sense than in application, the former two being in familiar use, and the latter only in the grave style: these words imply the looking simply toward an object in a state of suspense or still regard; as to wait until a person arrives or wait for his arrival; and 
await the hour of one's death, that is, to keep the mind in readiness for it.

Wait and wait for refer to matters that are remote and obscure in the prospect or uncertain in the event; auait may be applied to that which is considered to be near at hand and probable to happen, and in this sense it is clearly allied to look for and expect, the former of which expresses the acts of the eye as well as the mind, the latter, the act of the mind only, in contemplating an object as very probable or even certain. It is our duty patiently to await the severest trials when they threaten us. When children are too much indulged and caressed, they are apt to look for a repetition of caresses at inconvenient seasons; it is in vain to look for or expect happiness from the conjugal state when it is not founded on a cordial and mutual regard.

See also ATTEnd.

WAIVE, Abandon, Forego, ReLINQUish, Remit, ReNounce. Waive, a very common legal term, derived through Norman French from Old Norse, and ultimately from a Germanic root, waibyan, to fluctuate, to swing about, signifies, literally, to give up a claim to something, to abstain from insisting on some right or claim. The term implies a variety of actions. When we abandon a person, object, or purpose, it is to be assumed that we give him or it up permanently, unless a time period is specified; but when we forego an action it is to be supposed that we abandon it temporarily only, either for convenience or expediency, and are privileged to resume it subsequently.

We relinquish something by giving it up, parting with it, and this, too, may be either a permanent or temporary act; but when we remit anything in the sense of waive, we moderate a condition by giving up a part of it, or surrender the condition or object to the other party in interest, as a magistrate may remit or give up a fine he has imposed, for sufficient reason. To renounce a matter, however, admits of but one effect, the total final rejection of it, either by positive repudiation, absolutely disowning it, or by other means of separating ourselves from it.
WAKEFUL, WatchFUl, Vigilant. We may be wakeful without being watchful; but we cannot be watchful without being uakeful. Wakefulness is an affair of the body, and depends upon the temperament; waichfulness is an affair of the will, and depends upon the determination: some persons are more wakeful than they wish to be; few are as watchful as they ought to be. Vigilance, from the Latin vigil, expresses a high degree of watchfulness: a sentinel is watchful who on ordinary occasions keeps good watch: but it is necessary for him, on extraordinary occasions, to be vigilant in order to detect whatever may pass. We are watchful only in the proper sense of watching; but we may be vigilant in detecting moral as well as natural evils.

WALK. See Carriage.

WALK-OUT. See STrikE.

WAN. See PALE.

WANDER, Stroll, Ramble, Rove, Roam, Range. Wander, in German wandern, is a frequentative of wenden, to turn, signifying to turn frequently. To stroll, from a Germanic base found in the word to strike, allied with straggle, struggle, etc., refers to an indefinite finding one's way about-feeling one's way. Ramble is a frequentative of roam. Rove, Dutch roover, a robber, is derived from Anglo-Saxon reafian, to rob, whence $r o b$ itself is derived, as well as the verb bereave. It referred to the movements of pirates, wandering robbers, and hence came to refer rather to the wandering than to the robbing. Range, from Old High German hring, allied to rank, referred to something set in rows, ranged in an orderly fashion; from this meaning the special significance of moving about in a certain fashion arose because the word referred to the movements of armed troops, ranks of men, and, as in the case of rove, came to signify the action rather than the subject acting. The word suggests the scouring of the country by armed men.

The idea of going in an irregular and free manner is common to all these terms. To wander is to go in no fixed path; to stroll is to wander out of a path that we had taken. To uander may be an involuntary action; a person may uxinder to a great distance or 
for an indefinite length of time; in this manner a person wanders who has lost himself in a wood: to stroll is a voluntary action, limited at our discretion; thus when a person takes a walk he sometimes strolls from one path into another as he pleases: to ramble is to wander without any object, and consequently with more than ordinary irregularity; in this manner he who sets out to take a walk, without knowing or thinking where he shall go, rambles as chance directs: to rove is to wander in the same planless manner, but to a wider extent; a fugitive who does not know his road roves about the country in quest of some retreat: to roam is to wander from the impulse of a troubled mind; in this manner a lunatic who has broken loose may roam about the country; so likewise a person who travels about, because he cannot rest in quiet at home, may also be said to roam in quest of peace: to range is the contrary of to roam; as the former indicates a disordered state of mind, the latter indicates composure and fixedness; we range within certain limits, as the hunter ranges the forest, the shepherd ranges the mountains.

See also Deviate.

WANT, NEED, LACK. To be without is the common idea expressed by these terms; but to want (of Scandinavian origin) is to be without that which contributes to our comfort or is an object of our desire; to need (AngloSaxon $n y d$, from a root signifying to force-that which forces us to the last extremity), a Germanic word, is to be without that which is essential for our existence or our purposes; to lack expresses a little more than the general idea of being without, unaccompanied by any collateral idea. From the close connection which subsists between desiring and want, it is usual to consider what we want as artificial and what we need as natural and indispensable: what one man wants is a superfluity to another; but that which is needed by one is in like circumstances needed by all: tender people want a fire when others would be glad not to have it; all persons need warm clothing and a warm house in the winter.

To want and need may extend in- definitely to many or all objects; to lack, or be deficient, is properly said of a single object; we may want or need everything; we lack one thing, we lack this or that; a rich man may lack understanding, virtue, or religion; he who wants nothing is a happy man; he who needs nothing may be happy if he wants no more than he has; for then he lacks that which alone can make him happy, which is contentment.

See also Poverty.

WARM. See Hearty; Sanguine.

WARMTH. See FIRE.

WARN. See GarnisH.

WARNING. See Admonition; CAVEAT.

WARPED. See WRY.

WARRANT. See Guarantee.

WARY. See CaUtious.

WASTE. See DestroY; SACK; SPEND.

WATCh. See Guard; Observe. WATCHFUL. See WaKeFUL.

Wave, Billow, Surge, Breaker. Wave, from the verb to wave, is applied to water in an undulating state; it is, therefore, the generic term, and the rest are specific terms: those waves which swell more than ordinarily are termed billows, which is allied to the words bulge, bag, bowl, bulk, belly, etc., from a root signifying to swell: those waves which rise higher than usual are termed surges, from the Latin surgere, to rise: those waves which dash against the shore or against vessels with more than ordinary force are termed breakers.

See also Undulate.

WAVER. See Fluctuate; ScruPLe; VACILlate.

WAVERING. See UNDETERMINED.

WAY, Manner, Method, Mode, Course, Means. All these words denote the steps which are pursued from the beginning to the completion of any work. The way (Anglo-Saxon weg, allied to Latin via) is both general and indefinite; it is either taken by accident or chosen by design: the manner, from Old French maniere, manner, through a verb manier, to handle, from Latin manus, hand, and method (Latin methodus, from Greek $\mu \dot{\varepsilon} \theta 0 \delta o s$, from $\mu \varepsilon \tau \dot{c}$, after, and ídós, way, meaning after the manner of) are species of the way chosen by de- 
sign. Whoever attempts to do that which is strange to him will at first do it in an awkward way; the manner of conferring a favor is of ten more than the favor itself; experience supplies men in the end with a suitable method of carrying on their business.

The method is said of that which requires contrivance; the mode (from Latin modus, a measure, manner, kind, way, from a root also found in the verb mete), of that which requires practice and habitual attention, the former being applied to matters of art and the latter to mechanical actions: the master has a good method of teaching to write; the scholar has a good or bad mode of holding his pen. The course (Latin cursus, from currere, to run-a way in which one runs) and the means are the way which we pursue in our moral conduct: the course is the course of measures which are adopted to produce a certain result; the means collectively for the course which lead to a certain end: in order to obtain legal redress we must pursue a certain course in law; law is one means of gaining redress, but we do wisely, if we can, to adopt the safer and pleasanter means of persuasion and cool remonstrance.

WAYWARD, WrLFUL. These words both indicate a disposition to follow one's own will, but wayward is a stronger word than wilful. The wilful boy does not easily yield his will to that of another; he wishes to have his own way, but the wish may go no further than a mere expression of it in speech or manner. A wayward boy deliberately goes his own way contrary to the wishes of others. He expresses his wilfulness in action.

WEAK, FEEBLE, INFIRM. Weak, allied to the Middle English verb weken, from Anglo-Saxon wican, to make weak, is itself derived from an adjective, wac, weak, and related to the German weichen, to weaken. Feeble, Old French fleble, is derived from the Latin flebilis, from flere, to weep, and means doleful, a thing to be wept over, hence weak. Infirm (see DeBiLITY).

The Saxon term weak is here, as it usually is, the familiar and universal term; feeble is suited to a more polished style; infirm is only a species of the weak: we may be weak in body or mind; but we are commonly feeble and infirm only in the body: we may be weak from disease or weak by nature; it equally conveys the gross idea of a defect: but the terms feeble and infirm are qualified expressions for weakness: a child is feeble from its infancy; an old man is feeble from age; the latter may likewise be infirm in consequence of sickness. We pity the weak, but their weakness of ten gives us pain; we assist the feeble when they attempt to walk; we support the infirm when they are unable to stand. The same distinction exists between weak and feeble in the moral use of the words: a weak attempt to excuse a person conveys a reproachful meaning; but the feeble efforts which we make to defend another may be praiseworthy, although feeble.

See also VuLnerable.

Weaken, Enfeeble, Debilitate, Enervate, Invalid.-To weaken is to make $w e a k$, and is, as before, the generic term: to enfeeble is to make feeble: to debilitate is to cause debility: to enervate is to unnerve; and to invalidate is to make not valid or strong: all of which are but modes of weakening applicable to different objects. To weaken may be either a temporary or permanent act when applied to persons; enfeeble is permanent, either as to the body or the mind: we may be weakened suddenly by severe pain; we are enfeebled in a gradual manner, either by the slow effects of disease or age. To weaken is either a particular or a complete aet; to enfeeble, to debilitate, and enervate are properly partial acts: what enfeebles deprives of vital or essential power; what debilitales may lessen power in one particular, though not in another; the severe exereise of any power, such as the memory or the attention, may tend to debilitate that faeulty: what enervates acts particularly on the nervous system; it relaxes the frame and unfits the person for action either of body or mind. To weaken is said of things as well as persons; to invalidate is said of things only; we weaken the force of an argument by an injudicious applieation; se invalidate the elaim of another by proving its informality in law. 
WEAKNESS. See IMPERFECTION.

WEAL, Welfare. Both of these words are derived from Anglo-Saxon wela, abundance, allied to Modern English well and wealth. Weal is simply the archaic and poetic term corresponding to welfare in ordinary speech.

\section{WEALTH. See RICHES.}

WEAN, Alienate, Detach, WithDRAW. These terms all suggest the abandonment of some object of affection or desire or something to which one has been accustomed; but they differ in the character of the metaphor under which the idea is suggested and the energy of the action. To alienate (for derivation and meaning see alien) and wean are the strongest of these terms. Wean, in Anglo-Saxon wenian, to accustom, German entwöhnen, to accustom to do without, signifies literally to accustom an infant to do without its mother's milk, and figuratively it suggests the detaching or withdrawing of something to which one is as accustomed as the child is to its daily nourishment. Detach (for derivation see attach) means, literally, to unfasten. Withdraw means to draw away. Both of these terms may be used literally of physical objects or figuratively of the mind, the affections, or the desires.

WEAPONS. See ARMS.

WEARINESS. See Fatigue.

WEARISOME, TIRESOME, Tedious. Wearisome is the general and indefinite term; tiresome and tedious, causing tedium, a specific form of wearisomeness: common things may cause weariness; that which acts painfully is either tiresome or tedious; but in different degrees the repetition of the same sounds will grow tiresome; long waiting in anxious suspense is tedious: there is more of the physical in tiresome and of the mental in tedious.

Weary, Tire, Jade, Harass.-To weary is a frequentative of wear, that is, to wear out the strength. To tire, Anglo-Saxon tirian, to be weary, may be used both as a transitive and an intransitive verb. To jade is derived from the noun jade, a term of contempt applied to a worn-out horse. Harass (see Distress).

Long exertion wearies; a little exertion will tire a child or a weak man; foreed exertions jade; painful exer- tions or exertions coupled with painful circumstances harass: the horse is jaded who is forced on beyond his strength; the soldier is harassed who in his march is pressed by a pursuing enemy. We are wearied with thinking when it causes us effort to think any longer; we are tired of our employment when it ceases to give us pleasure; we are jaded by incessant attention to business; we are harassed by perpetual complaints which we cannot redress.

WEDDING. See Marriage.

WEDLOCK. See Marriage.

WEEP. See CRY; WaIL.

WEEPING. See LACHRYMaL.

WEIGH. See Counterpoise.

WEIGHT, Heaviness, Gravity. Weight, from to weigh, is that which a thing weighs. Heaviness, from heavy and heave, signifies the abstract quality of the heavy, or difficult to heave. Gravity, from the Latin gravis, likewise denotes the same abstract quality.

Weight is indefinite: whatever may be weighed has a weight, whether large or small: heaviness and gravity are the property of bodies having a great weight. Weight is opposed only to that which has or is supposed to have no weight, that is, what is incorporeal or immaterial; for we may speak of the weight of the lightest conceivable bodies, as the weight of a feather: heaviness is opposed to lightness; the heaviness of lead is opposed to the lightness of a feather. Weight lies absolutely in the thing; heaviness is relatively considered with respect to the person: we estimate the weight of things according to a certain measure; we estimate the heaviness of things by our feelings. Gravity is that species of weight which is scientifically considered as inherent in certain bodies; the term is therefore properly scientific.

See also Heavy; Importance.

Weight, Burden, Load.-Weight (for derivation see above). Burden, from bear, signifies the thing borne. Load, Anglo-Saxon lad, a way, journey, or conveyance, signified originally that which was carried on a journey, hence, in our sense, a load. It has been confused with the verb lade, which has a different derivation, and this confusion has influenced the meaning.

The term weight is here considered in 
common with the other terms, in the sense of a positive weight; by which it is allied to the word burden: the weight is said either of persons or things; the burden more commonly respects persons; the load may be said of either: a person may sink under the weight that rests upon him; a platform may break down from the weight upon it: a person sinks under his burden or load; a cart breaks down from the load. The weight is abstractedly taken for what has weight, without reference to the cause of its being there; burden and load have respect to the person or thing by which they are produced; accident produces the weight; a person takes a burden upon himself or has it imposed upon him; the load is always laid on: it is not proper to carry any weight that exceeds our strength; those who bear the burden expect to reap the fruit of their labor; he who carries loads must be contented to take such as are given him.

In the moral applieation these terms mark the pain which is produced by a pressure; but the weight and load rather describe the positive severity of the pressure; the burden respects the temper and inclinations of the sufferer; the load is in this case a very great weight: a minister of state has a weight on his mind at all times, from the heavy responsibility which attaches to his station; one who labors under strong apprehensions or dread of an evil has a load on his mind; any sort of employment is a burden to one who wishes to be idle; and time unemployed is a burden to him who wishes to be always in action.

WELCOME. See Acceptable; Accost.

WELFARE. See Weal.

Well-Being, Welfare, ProsPERITY, HAPpINess. Well-being may be said of one or many, but more of a body; the well-being of society depends upon a due subordination of the different ranks of which it is composed. Welfare, or faring well, respects the good condition of an individual; a parent is naturally anxious for the welfare of his child. Well-being and welfare consist of such things as more immediately affect our existence: prosperity, which comprehends both well- being and welfare, includes likewise all that can add to the enjoyments of man. The prosperity of a state or of an individual, therefore, consists in the increase of wealth, power, honors, and the like; as outward circumstances more or less affect the happiness of man: happiness is, therefore, often substituted for prosperity; but it must never be forgotten that happiness properly lies only in the mind, and that consequently prosperity may exist without happiness; but happiness, at least as far as respects a body of men, cannot exist without some portion of prosperity.

See also Fortunate; Happiness.

WELL-BRED, Courteous, Cultivated, Polished, Refined. Wellbred, a compound of two English terms, well and bred, from breed, meaning to generate, beget, signifies a person or animal born of a good breed, stock, or race, or one well-born. The term has a broad application in the personal sense, as it implies refinement and cultivation in either sex. A courteous person (i.e., one who has courtly manners) is always polite and obliging: a cultivated one exhibits the training or refining of the intellectual and socisl faculties; a polished one possesses elegance and suavity of manners: and a refined one displays an unvarying good taste and an instinctive aversion to anything that is coarse or extreme in thought or expression.

These qualities are not always to be found in one person, for a courteous one may be such from eultivation, not from nature, education, or association; a polished one is not necessarily courteous, for he may be such from study, association, or imitation and still lack many of the qualities of good-breeding; but a cultivated one is apt to exhibit the best and most attractive features of a broad and universal training, a wide knowledge of both books and men, and a high regard for the niceties of polite society.

WHEEDLE. See Coax.

WHIM. See Freak; Vagart.

WHIMSICAL. Sec FaNciful.

WHINING. See QUERULOUS.

WHIP. See LASH.

WHIRL. See TurN.

WHOLE, ENTIRE, Complete, ToTaL, INTEgraL. Whole exeludes subtraction; entire cxcludes division; 
complete excludes deficiency: a whole orange has had.nothing taken from it; an entire orange is not yet cut; and a complete orange is grown to its full size: it is possible, therefore, for a thing to be whole and not entire: and to be both, and yet not complete: an orange cut into parts is whole while all the parts remain together, but it is not entire; it may be whole as distinguished from a part, entire as far as it has no wound or incision in it; but it may not be a complete orange if it is defective in its growth. Whole is applied to everything of which there may be a part actually or in imagination; as the whole line, the whole day, the whole world: entire is applied only to such things as may be damaged or injured, or is already damaged to its fullest extent; as an entire building, or entire ruin: complete is applied to that which does not require anything further to be done to it; as a complete house, a complete circle, and the like.

Total, from Low Latin totalis, extended from totus, the whole, has the same significance, but only a limited application; as a total amount or a total darkness, as distinguished from a partial amount or a partial degree of darkness.

Integral, from integer, literally untouched, from in (not) and the root tag which appears in the Latin tangere, to touch, has the same signification, but is applied now to parts or numbers not broken.

See also Alu.

WHOLESOME. See Healthy.

WHOLLY. See QUITE.

WICKED, INIqUitous, Nefarious. Wicked (see $\mathrm{BAD}$ ) is here the generic term; iniquitous, from iniquus, inxquus, not equal, signifies that species of wickedness which consists in violating the law of right between man and man; nefarious, from the Latin nefas, not according to the law (from fari, to spcak, a law being something spoken, decreed, either by man or a power above man. Compare fatum, fate, the thing spoken). The term wicked, being indefinite, is commonly applied in a milder sense than iniquitous; and iniquitous than nefarious: it is wicked to deprive another of his property unlawfully, under any circumstances; but it is iniquitous if it be done by fraud and circumvention, and nefarious if it involves any breach of trust; any undue influence over another, in the making of his will, to the detriment of the rightful heir, is iniquitous; any underhand dealing of a servant to defraud his master is nefarious.

WIDE. See LARGE.

WIELD, BRANDISH. Wield, from Anglo-Saxon wealdan, to have power, means to exercise with skill and effect. It is used with reference to the skilful handling of a weapon-to wield a sword, to wield an axe-and, figuratively, of the exercising of any power, as when we say "He wields a great influence." Brandish resembles wield in its physical application. It meant, literally, to wield a sword, from old French brand, sword, of Germanic origin. However, it does not imply such a skilful handling as wield; there is more show and flourish in brandish. To brandish a sword is to wave it in the air so that every one may see and fear; to wield a sword is to exercise it skilfully in the work for which it was intended. In its figurative application brandish means to make a great show of power and authority, to flourish threateningly.

WILFUL. See WaYward.

WILL, WIsH. The will is that faculty of the soul which is the most prompt and decisive; it immediately impels to action: the wish is but a gentle motion of the soul toward a thing. We can will nothing but what we can effect; we may wish for many things which lie above our reach. The will must be under the entire control of reason or it will lead a person into every mischief: wishes ought to be under the direction of reason or otherwise they may greatly disturb our happiness.

Willingly, Voluntarily, Spontaneously.-To do a thing willingly is to do it with a good will; to do a thing voluntarily is to do it of one's own accord: the former implies one's willingness to comply with the wishes of another; we do what is asked of us; it is a mark of good-nature: the latter implies our freedom from foreign influence; we do that which we like to do; it is a mark of our sincerity. It is pleasant to see a child do his task 
willingly; it is pleasant to see a man voluntarily engage in any service of public good. Spontaneously (from a lost Latin substantive spons) is but a mode of the voluntary, applied, however, more commonly to inanimate objects than to the will of persons: the ground produces spontaneously when it produces without culture; and words flow spontaneously which require no effort on the part of the speaker to produce them. If, however, applied to the will, it bespeaks in a stronger degree the totally unbiassed state of the agent's mind: the spontaneous effusions of the heart are more than the voluntary services of benevolence. The willing is opposed to the unwilling, the voluntary to the mechanical or involuntary, the spontaneous to the reluctant or the artificial.

WILY. See Cunning.

WIN. See ACQUIRE.

WIND. See TurN.

WISDOM, Prudence. Wisdom, allied to German wissen, to know, is the general term; it embraces the whole of practical knowledge: prudence (see Prudent) is a branch of wisdom. Wisdom directs all matters present or to come. Prudence, which acts by foresight, directs what is to come. Rules of conduct are framed by wisdom, and it is the part of prudence to apply these rules to the business of life.

WISH. See Desire; Will.

WIT, HUMOR, Satire, IroNy, BurLESQUE. Wit, like wisdom, according to its original, from Anglo-Saxon vitan, to know (compare German wissen), signifies knowledge, but it has so extended its meaning as to signify that faculty of the mind by which knowledge or truth is perceived, and in a more limited sense the faculty of discovering the agreements or disagreements of different ideas. Wit, in this latter sense, is properly a spontancous faculty, and is, as it were, a natural gift: labored or forced wit is no wit. Reflection and expericnce supply us with wisdom; study and labor supply us with learning; but wit seizes with an eagle eye that which escapes the notice of the deep thinker and elicits truths which are in vain sought for with any severe effort.

Humor is a species of wit which flows out of the humor of a person. Wit, as distinguished from humor, may consist of a single brilliant thought; but humor runs in a vein; it is not a striking, but an equable and pleasing flow of wit. Of this description of wit $\mathrm{Mr}$. Addison, who knew best how to explain what wit and humor were, and to illustrate it by his practice, has given us the most admirable specimens in his writings.

Humor may likewise display itself in actions as well as words, whereby it is more strikingly distinguished from wit, which displays itself only in the happy expression of happy thoughts. Satire (from satura lanx, a full dish, a dish of mixed ingredients, applied figuratively to a species of poetry full of animadversions on different persons and events) and irony, from the Greek

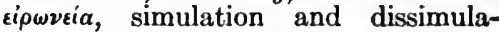
tion, are personal and censorious sorts of wit, the first of which openly points at the object and the second in a covert manner takes its aim.

Burlesque (perhaps from Latin burrula, diminutive of burre, trifles, Italian burlesco, ludicrous) is rather a species of humor than direct wit, which consists in an assemblage of ideas extravagantly discordant. The satire and irony are the most ill-natured kinds of wil; burlesque stands in the lowest rank.

See also INGENUITY.

WithdRaW. See Recede; Wean.

WITHSTAND. See Oppose.

WITNESS. See DEPONENT.

WOFUL. See Piteous.

WONDER, ADMIRE, SURPRISE, AsTonish, AMAzE. Wonder is a Germanic word whose ultimate derivation is unknown. Admire is derived from Latin admirari, to wonder at, and allied to miracle, a thing to be wondered at. Surprise, compounded of French sur, on, and prise, taken, the feminine past participle of prendre, from Latin prehendere, signifies to take on a sudden. Astonish, Old French estoner, Latin $e x$ and tonare, to thunder (compare the word thunderstruck, a forceful and colloquial synonyme of astonished), signifies to strike as it were with the overpowering noise of thunder. Amaze signifies to be in a maze, so as not to be able to collect one's self.

That particular feeling which any- 
thing unusual produces on our minds is expressed by all these terms, but under various modifications. Wonder is the most indefinite in its signification or application, but it is still the least vivid sentiment of all: it amounts to little more than a pausing of the mind, a suspension of the thinking faculty, an incapacity to fix on a discernible point in an object that rouses our curiosity: it is that state which all must experience at times, but none so much as those who are ignorant: they wonder at everything, because they know nothing. Admiration is wonder mixed with esteem or veneration: the admirer suspends his thoughts, not from the vacancy, but the fulness, of his mind: he is riveted to an object which for a time absorbs his faculties: nothing but what is great and good excites admiration, and none but cultivated minds are susceptible of it: an ignorant person cannot admire, because he cannot appreciate the value of anything. Surprise and astonishment both arise from that which happens unexpectedly; they are species of wonder differing in degree, and produced only by the events of life: the surprise, as its derivation implies, takes us unawares; we are surprised if that does not happen which we calculate upon, as the absence of a friend whom we looked for; or we are surprised if that happens which we did not calculate upon; thus we are surprised to see a friend returned whom we supposed was on his journey: astonishment may be awakened by similar events which are more unexpected and more unaccountable: thus we are astonished to find a friend at our house whom we had every reason to suppose was many hundred miles off; or we are astonished to hear that a person has got safely through a road which we conceived to be absolutely impassable.

Surprise may for a moment startle; astonishment may stupefy and cause an entire suspension of the faculties; but amazement has also a mixture of perturbation. We may be surprised and astonished at things in which we have no particular interest: we are mostly amazed at that which immediately concerns us.

Wonder, Miracle, Marvel, Prodigy,
Monster.-Wonder is that which causes worder. Miracle, Latin miraculum, is allied to admire, which see above. Marvel is derived from Latin mirabilia, which has the same root-signifying wonder. Prodigy, from Latin prod for pro, and a supposititious word, agium, a saying, which also appears in adage, means a saying beforehand, hence a sign, token, or portent, something extraordinary. Monster, in Latin monstrum, comes from moneo to warn, because among the Romans any unaccountable appearance was considered as an indication of some future event.

Wonders are natural: miracles are supernatural. The whole universe is full of wonders; the Bible contains an account of the miracles which happened in those days. Wonders are real; marvels are of ten fictitious; prodigies are extravagant and imaginary. Natural history is full of wonders; travels abound in marvels or in marvellous stories, which are the inventions either of the artful or the ignorant and credulous: ancient history contains numberless accounts of prodigies. Wonders are fitting to the laws of nature; they are wonderful only as respects ourselves: monsters are violations of the laws of nature. The production of a tree from a grain of seed is a wonder; but the production of a calf with two heads is a monster.

WOOD-ENGRAVING. See XYLOGRAPHY.

WOOER. See Lover.

WORD, TERM, Expression. Word is here the generic term, the other two are specific. Every term and expression is a word, but every word is not denominated a term or expression. Language consists of words; they are the connected sounds which serve for the communication of thought. Term, from terminus, a boundary, signifies any word that has a specific or limited meaning; expression (see Express) signifies any word which conveys a forcible meaning. Usage determines words; science fixes terms; sentiment provides expressions. The purity of a style depends on the choice of words; the precision of a writer depends upon the choice of his terms; the force of a writer depends upon the aptitude of his expressions. The grammarian treats of 
the nature of words; the philosopher weighs the value of scientific terms; the rhetorician estimates the force of expressions.

See also Promise.

WORK, Labor, ToIl, DrdDgery, TASK. Work, in Saxon weorc, Greek E oyov, is the general term, as including that which calls for the exertion of our strength: labor (for derivation see that term) differs from it in the degree of exertion required; it is hard work: loil, probably connected with till, expresses a still higher degree of painful exertion: drudgery (sce SerVANT) implies a mean and degrading work. Every member of society must work for his support, if he is not in independent circumstances: the poor are obliged to labor for their daily subsistence; some are compelled to toil incessantly for the pittance which they earn: drudgery falls to the lot of those who are the lowest in society. A man wishes to complete his work; he is desirous of resting from his labor; he seeks for a respite from his toil; he submits to drudgery.

Task, from Latin tasca, a tax (tax being another form of the same word), is a work imposed by others, and consequently more or less burdensome. Sometimes taken in the good sense for that which one imposes on one's self.

WORLD. See PUblic.

WORLDLY. See Secular.

WORRY, ANXIETY. Worry comes from Anglo-Saxon wyrgan, to strangle, to harm. It has thus a metaphorical signifieanee similar to that of anxicty, for which see Care. As a substantive worry has almost the same meaning as anxiety, but being an Anglo-Saxon word, whereas anxiety is of Latin origin, it differs in quality and atmosplice. Worry is a more homely and emphatic word than anxiety, and suggests the psychological state more directly.

For a further discussion of the synonymes of anxiety, and hence of worry, see Care.

WORSHIP. See ADORE.

WORTH. Sce Desert; VAlUe.

WORTHLESS. See UNwORTHY.

WRANGLE. See JANGLe.

WRATH. See ANger.

WRENCH. See TURN.

WREST. See TURN.
WRETCHED. See UNHAPPY.

WRING. See TURN.

WRITER, Penman, Scribe. Writer is an indefinite term; every one who writes is called a uriter; but none are penmen but such as are expert at their pen. Many who profess to teach writing are themselves but sorry writers: the best penmen are not always the best teachers of writing. The scribe is one who writes for the purpose of copying; he is, therefore, an official writer.

Writer and penman have an extended application to one who writes his own compositions; the former is now used for an author or composer, as the writer of a letter or the uriter of a book; the latter for one who pens anything worthy of notice for the use of the public.

Scribe may be taken for one who performs, as it were, the office of writing for another.

Writer, Author.-Writer refers us to the act of writing; author (from Latin auctor, an originator, literally one who makes a thing to grow, from augure, to increase) lays cmphasis on the act of inventing. There are, therefore, many urilers who are not authors, but there is no author of books who may not be termed a writer: compilers and contributors to periodical works are properly uriters, though not always entitled to the name of authors. Poets and historians arc properly termed authors rather than uriters.

WRITHE. Sec TURN.

WRONG. See InJUstice.

WRY, Distorted, Twisted, Askew, WARPED. All of these words signify a turning from a normal position. Wry means bent to one side and somewhat twisted in the bending. Distorted, from torquere, to turn, means turned out of a normal state or position, with the implication not simply of bending, but of turning round and round. Tuisted, past participle of turist, meant originally wound round and round, as in the case of two threads wound around and around each other by twisting. Askew is from Old Low German; it means turned aside like a shying horse, and is derived from the root that appears in English shy. Warped means made uneven in outline, referring to a flat surface that has become somewhat arched or otherwise irregular. 


\section{$\mathrm{X}$}

XANTHOUS. See Blonde.

XYLOGRAPHY, WOOD - ENGRAVING. Xylography is the technical term, wood-engraving the common term for the same process. The difference is therefore not one of meaning, but of usage. Xylography, a term compounded of the Greek $\xi \dot{v} \lambda o v$, wood, and ${ }_{\gamma} \rho a \dot{\phi} \phi \varepsilon \iota \nu$, to write or draw, signifies the art of the wood-engraver or the act of cutting designs or figures on wood for printing, an art that in recent years has been largely superseded by various processes for book and periodical illustration. The term is also applied to a mode of printing or graining from the natural surface of the wood, and to a process of decorative painting on wood. 


\section{Y} YEARN, CrA v E, LoN G Yearn,
crave, and long, as verbs, all mean to desire intensely, but the quality of the desire differs. Long means simply to wish intensely. Yearn, from AngloSaxon georn, eager, has a special suggestion of tenderness; crave is used of physical appetite:

YES. See AYE.

YET. See But; However.

YIELD. See AfFord; BeAR; CoMPLY; Give UP.

YIELDING. See Compliant.

YONDER, B E Y O N D, YON. The first two words are derived from the Anglo-Saxon adverb geond; yon is the Saxon adjective geon, signifying a place removed by more or less distance. Yonder means at a distance; it is becoming slightly archaic now. $Y o n$ is a poetic abbreviation for yonder. Beyond differs from yonder in signifying a place on the other side of a given point. We may say in general that the village is yonder, or we may say quite specifically that it is beyond the river.

YOUTHFUL, Juvenile, Puerile. Youthful signifies full of youth, or in the complete state of youth: juvenile, from the Latin juvenis, signifies the same; but puerile, from puer, a boy, signifies, literally, boyish. Hence the first two terms are taken in an indifferent sense, but the latter in a bad sense, or at least always in the sense of what is suitable to $\mathrm{s}$ boy only: thus we speak of youthf: $l$ vigor, youthful employments, juvenile performances, juvenile years, and the like: but puerile objections, puerile conduct, and the like. We expect nothing from a youth but what is juvenile; we are surprised and dissatisfied to see what is puerile in a man. 


\section{Z}

ZANY, HARLEQUIN, MERRX-ANDREw. Zany, a substantive derived from the Old Italian zane, in Modern Italian zanni, the familiar form of Giovanni or John, signifies a sillyJohn, a former appellation of buffoon and clown, a person who amuses others professionally by jests, antics, odd gestures, etc., especially by awkwardly and ineffectually trying to mimic the other actors. A harlequin (a word of uncertain origin, but probably from Old Low German helle Kyn, "kin of hell," goblins, devils; thence by extension clown, buffoon) is the performer in the Italian pantomime who wears party-colored garments and carries a talismanic wand with which he produces unexpected or ludicrous effects while executing his part; he is the lover of Columbine.

Merry-andrew is a term that is now comparatively seldom used in the United States, though at one time it was quite common here and very popular in England. It is said to be derived from Andrew Borde, physician to Henry VIII, "who, in order to instruct the people, used to address them at fairs and other crowded places in an eccentric and amusing manner," but this is doubtful.

ZEAL, ARDor, EARNestNess. of these words indicate energy and intensity of interest. Earnestness indicates a general attitude of mind; ardor is applied to warm emotions; zeal indicates energy applied to the carrying through of a cause or the propagation of an idea.

ZENITH, ACME, APEX. Zenith, a substantive from the Old French cenith, derived from Arabic samt, pronounced semt, signifies the summit or top of the heavens, the part directly over a spectator's head. Figuratively, it is the highest or culminating point of anything seen or referred to. Acme, Greek $a \dot{\alpha} \kappa \dot{\eta}$, has a similar meaning; it means the point or top. A pex, Latin apex, meant the summit or topmost point of something. While the two words had originally the same meaning, acme is now used with a figurative significance, whereas"apex more clearly retains its original literal meaning.

ZEPPELIN. See AIRCRAFT.

ZERO, Cipher, NaUght, NeUtral, Nothing. Zero is the same in form in French and Italian, and is considered a contraction of zefiro or zifro, from the Arabian sifr, meaning a cipher. The Old Latin treatises on arithmetic Latinized the Arabic term as zephyrum, which became zefiro in Italjan, and then zero. Low Latin zifra, Old French cifre, Modern French chiffre, Italian, Spanish, and Portuguese cifra, German ziffer, all meaning nothing, the absence of anything, all come from a parallel Arabic form zifra. Cipher and zero, therefore, are doublets, and each is indicated by the sign 0 . In general these terms mean no thing or nothing, and stand for the neutral point between any ascending and descending scale or series, implying the extreme point of depression.

In the thermometer and similar scales the zero is the point or line from which all the divisions are measured, up or down. In the Centigrade and Réaumur thermometers zero marks the freezing-point of water; in the Fahrenheit scale it is placed at $32^{\circ}$ below that freezing-point. The absolute zero of the temperature is the lowest possible temperature which the nature of heat permits, or $-273^{\circ}$ Centigrade. Zero in arithmetic is called naught, and implies no number; in algebra, no quantity; in mathematics it possesses no value of its own, but when placed after a number it increases the value of that number tenfold.

While zero and cipher are distinctly scientific terms, they, and more commonly the latter, have come to be applied to persons and objects in a depreciative sense, as a person is said to be a mere cipher who possesses no value in character, importance, influence, or otherwise, or who has got 
down to zero, when he has expended all | uancy, or sharpness, tartness, spicilis money, energy, will-power: so an object, proposition, argument, objection, is said not to amount to a cipher when it is unquestionably worthless.

ZEST, Gusto. Zest, in Old French the same, Modern French zeste, from the Latin schistos, that from the Greek $\sigma \chi^{i} \zeta_{\omega}$, meaning to peel, skin, or divide, the Freneh form implying a piece of the skin of a citron or lemon, and the English form something that gives a special relish, an added taste, as the skin or rind of a citron or lemon, commonly used in cookery for flavoring. That is zest, therefore, that imparts to anything an increased taste, flavor, satisfaction, enjoyment, a piq- around the earth. ness. Gusto, from the Latin guslo, taste, meant the taste, the hearty cnjoyment of food, hence any particularly hearty enjoyment. Z est and gusto both mean keenness of enjoyment, but gusto indicates a more pronounced pleasure than zest.

ZONE, GiRDle, Belt. These words differ rather in the dignity of their usage than in their meaning. All signify a band encircling the waist used for support or ornament. Zone is a purely poetic word; girdle is more dignified and less homely than belt. Zone has also been extended to signify a region of the earth-a belt, as it were, 


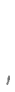



$-$

1. 1. 



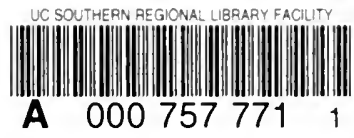


